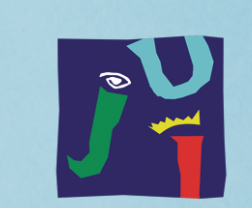

UNIVERSITAT

JAUME•I

\title{
DISEÑO Y PLANIFICACIÓN DE COMPETENCIAS ESPECÍFICAS EN EL CURRÍCULUM DE ENSEÑANZAS PROFESIONALES DE MÚSICA:
}

modalidades composición-dirección en la enseñanza superior

Carlos Eduardo Pascual Pérez

Dirigida por:

Dr. José María Peñalver Vilar

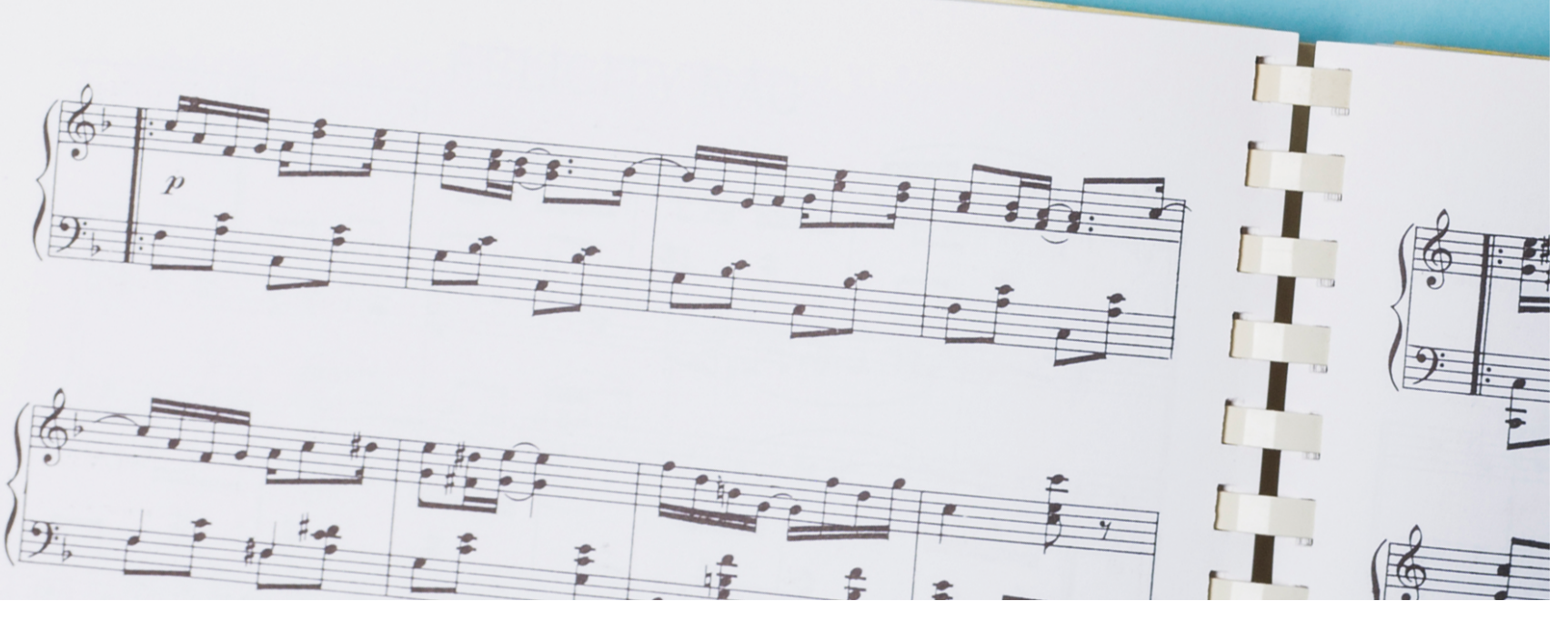




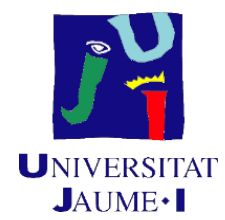

Programa de Doctorado en Educación

Escuela de Doctorado de la Universitat Jaume I

Diseño y planificación de competencias específicas en el currículum de enseñanzas profesionales de música: modalidades composición-dirección en la enseñanza superior.

Memoria presentada por Carlos Eduardo Pascual Pérez para optar al grado de doctor por la Universitat Jaume I

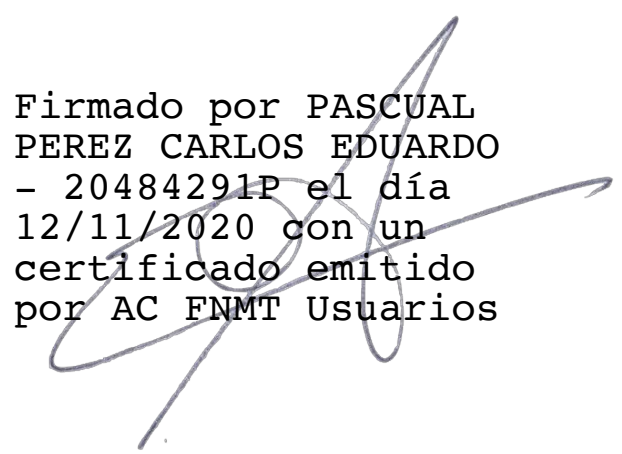

Carlos Eduardo Pascual Pérez

\author{
JOSE MARIA Firmado \\ PEÑALVER digitalmente por \\ PENALVER JOSE MARIA \\ VILAR - PENAALVR VILAR - \\ NIF:1898851 NIF:18988516S \\ 6S $18: 30: 00+01^{\prime} 00^{\prime}$
}

Dr. José María Peñalver Vilar 
Diseño y planificación de competencias específicas en el currículum de enseñanzas profesionales de música: modalidades composición-dirección en la enseñanza superior.

Carlos Eduardo Pascual Pérez 
Diseño y planificación de competencias específicas en el currículum de enseñanzas profesionales de música: modalidades composición-dirección en la enseñanza superior.

Carlos Eduardo Pascual Pérez

A Rosa, maestra de la que nunca dejo de aprender. 
Diseño y planificación de competencias específicas en el currículum de enseñanzas profesionales de música: modalidades composición-dirección en la enseñanza superior.

\section{Agradecimientos}

Al Dr. D. José María Peñalver Vilar, por creer desde un principio en la necesidad y viabilidad de esta tesis doctoral y por su incesante guía en estos cuatro años.

Al Centro Autorizado Profesional de Música San José de Calasanz (Castelló), más conocido como Conservatorio Calasancio, al que considero mi segundo hogar y al que ya pertenece gran parte de mi ser. Por supuesto a sus alumnos - de quienes no dejo nunca de aprender -, y muy especialmente a los participantes en los grupos experimentales de los cursos 2017-18 y 2018-19, sin los que no hubiese sido posible llevar a cabo esta tesis doctoral.

Al Conservatori Professional de Música Mestre Feliu de Benicarló (Castelló) y en particular a su profesor Martí Bellmunt Blasco, por su amistad, por respaldar esta investigación y facilitar su puesta en práctica. Y por supuesto, a todos los alumnos que participaron en ella desinteresadamente y con la máxima voluntad.

Al Conservatori Professional de Música de Mestre Berenguer de Teulada (Alicante), a su directora Fany Bañuls Ascó y en particular a su profesor Alberto Ramírez Martínez, por su 
Diseño y planificación de competencias específicas en el currículum de enseñanzas profesionales de música: modalidades composición-dirección en la enseñanza superior.

Carlos Eduardo Pascual Pérez

amistad, por respaldar esta investigación y facilitar su puesta en práctica. Y por supuesto, a todos los alumnos que participaron en ella desinteresadamente y con la máxima voluntad.

A todos los catedráticos, profesores, directores, compositores e intérpretes que han dado su testimonio sobre la necesidad de esta investigación, cuyas palabras han ido afianzando mis pasos.

A mis estimados maestros - ellos y ellas sabrán -, reconociendo que sin su existir no hubiese alcanzado ni esta ni muchas otras metas en mi vida, tanto personales como profesionales.

A Rosa, por su cariño, paciencia y comprensión ante todos los menesteres de esta larga tarea de investigación y elaboración de tesis doctoral.

A mis padres y hermanos, convencido de que sin su guía y ejemplo nunca hubiese vivido por y para la música y la educación.

Siempre gracias. 
Diseño y planificación de competencias específicas en el currículum de enseñanzas profesionales de música: modalidades composición-dirección en la enseñanza superior.

Carlos Eduardo Pascual Pérez 


\section{Índice}

1. CONTEXTUALIZACIÓN DE LOS OBJETIVOS Y METODOLOGÍA

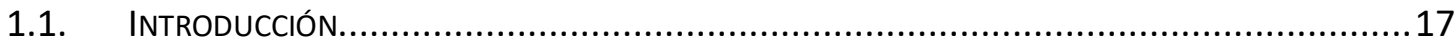

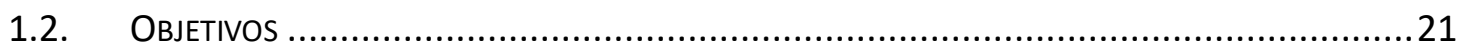

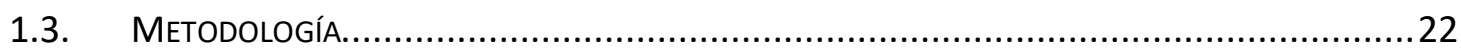

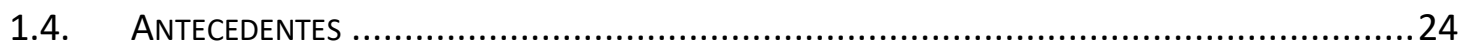

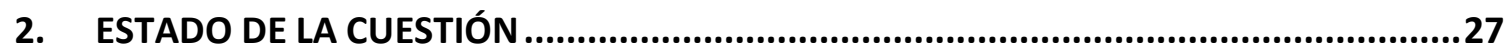

2.1. CONTRASTE DE LA REALIDAD Y NECESIDAD DE LA PROPUESTA. TESTIMONIOS. ........................27

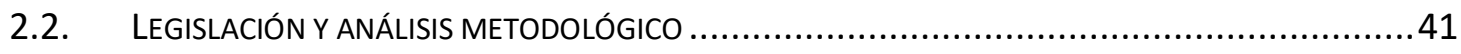

2.3. De LOS ASPECtOS CURRICULARES en LAS ENSEÑANZAS ProfeSIONALES ..............................43

2.4. DE LAS PRUEBAS DE ACCESO A LAS ENSEÑANZAS SUPERIORES .....................................47

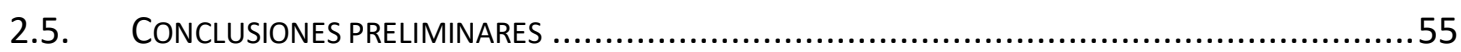

\section{PROPUESTA METODOLÓGICA Y CURRICULAR PARA LAS ESPECIALIDADES DE} COMPOSICIÓN Y DIRECCIÓN EN LA COMUNIDAD VALENCIANA....................................59

3.1. COMPETENCIAS REQUERIDAS PARA EL ACCESO AL GRADO SUPERIOR ..............................59

3.2. EL PLAN DE ESTUDIOS EN LAS ENSEÑANZAS PROFESIONALES DE MÚSICA EN LA COMUNIDAD

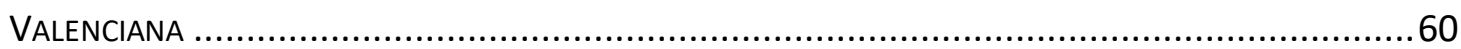

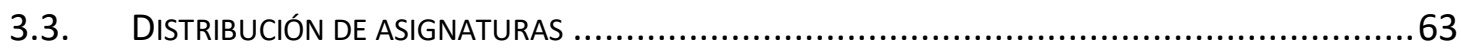

3.4. EL CURRÍCULUM EN LAS ASIGNATURAS DE ARMONÍA Y ANÁLISIS........................................65

3.5. EL CURRÍCULUM EN LA ASIGNATURA FUNDAMENTOS DE COMPOSICIÓN .............................69

3.6. ASOCIACIÓN Y COTEJO DE LAS COMPETENCIAS REQUERIDAS EN LA PRUEBA DE ACCESO Y LOS CONTENIDOS CURRICULARES DE LAS ENSEÑANZAS PROFESIONALES.......................................... 71

3.7. DEFINICIÓN Y DESARROLLO DE LAS COMPETENCIAS TRANSVERSALES AL CURRÍCULUM.................72

3.7.1. Reproducción escrita de fragmentos melódicos y polifónicos de hasta cuatro voces a partir de una escucha orquestal (Competencia V)...................................... 73

3.7.2. Organología, instrumentación y orquestación en el ámbito de la orquesta

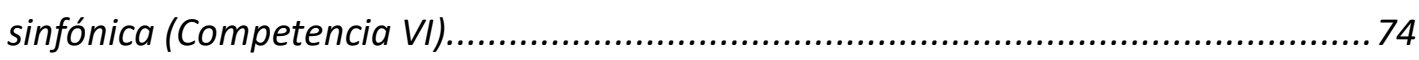

3.7.3. Aspectos básicos de la técnica de dirección (Competencia VII)........................ 75

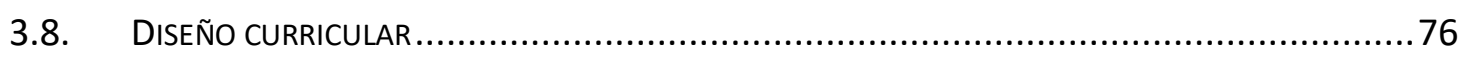

3.8.1. Armonía aplicada a la composición y la dirección ........................................ 77 
Diseño y planificación de competencias específicas en el currículum de enseñanzas profesionales de música: modalidades composición-dirección en la enseñanza superior.

3.8.2. Análisis aplicado a la composición y la dirección..........................................78

3.8.3. Optativa de obligada oferta: Fundamentos de composición ..........................82 82

3.8.4. Optativa de diseño propio: Fundamentos de dirección.................................87

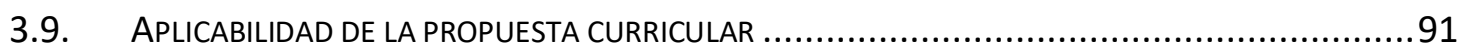

\section{DISEÑO E INTERVENCIÓN EN EL PRIMER CURSO DE LA ASIGNATURA ARMONÍA ....97}

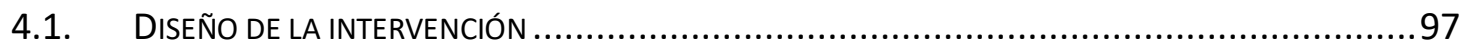

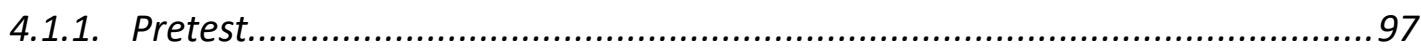

4.1.1.1. Currículum de la asignatura Lenguaje Musical en la Comunidad Valenciana y su contenido vinculante a la elaboración del Pretest........................................................98

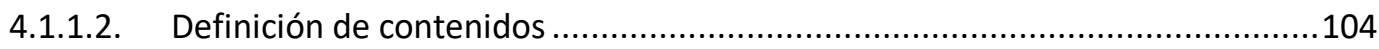

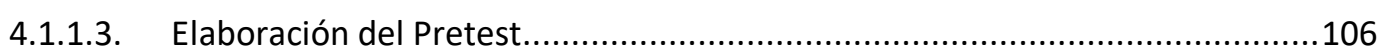

4.1.2. Ejercicios tipo y metodología ............................................................. 111

4.1.3. Diseño de la intervención................................................................... 126

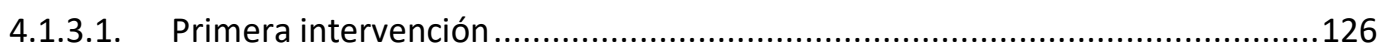

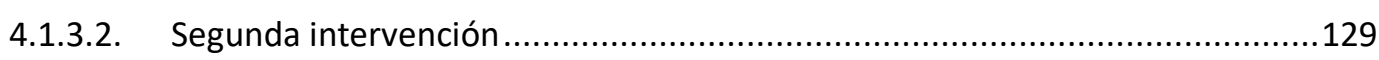

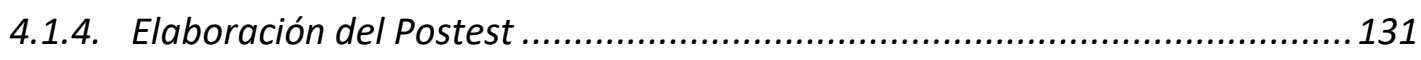

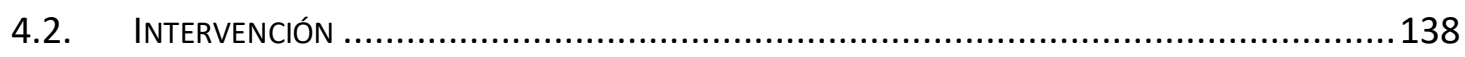

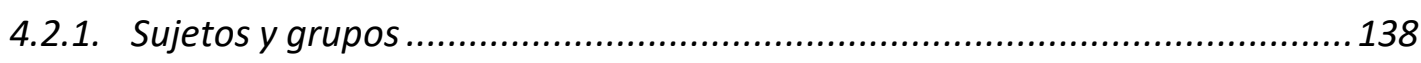

4.2.2. Grupo experimental. Análisis individualizado de casos.............................. 141

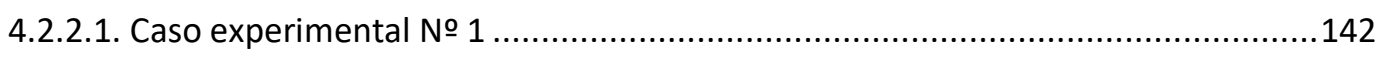

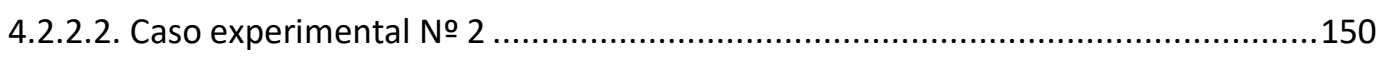

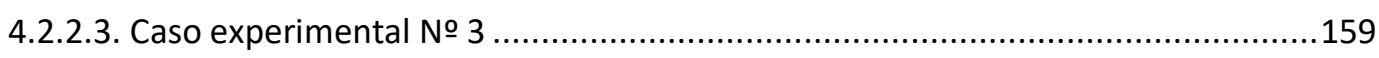

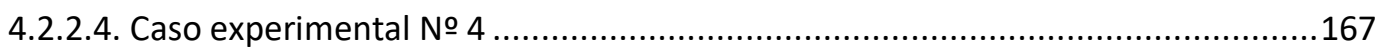

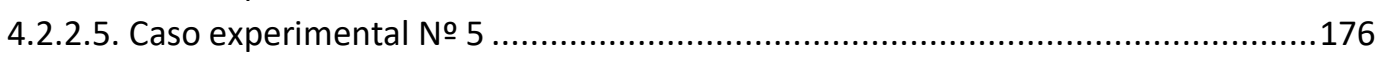

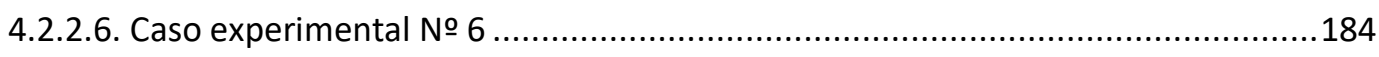

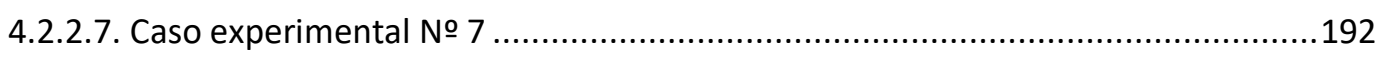

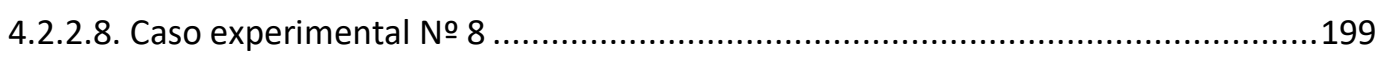

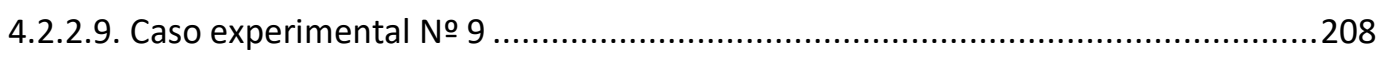

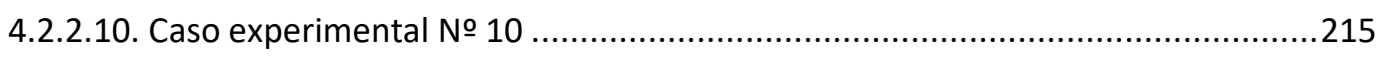

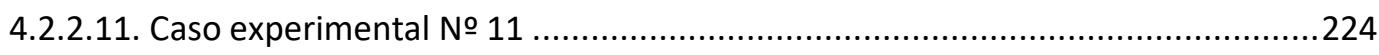

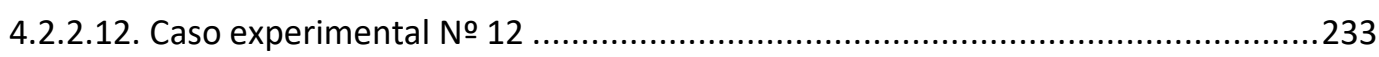

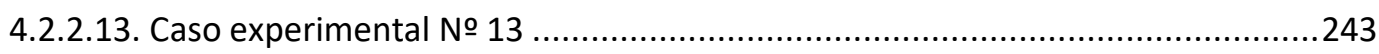

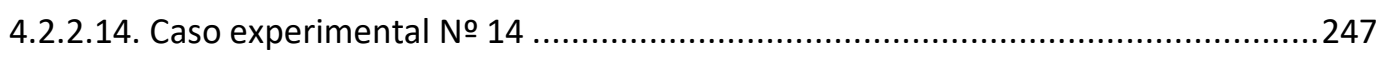

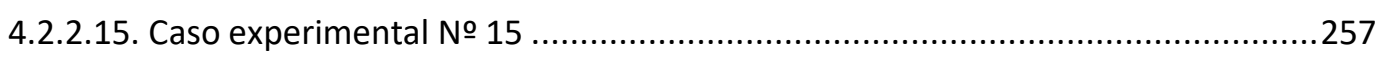

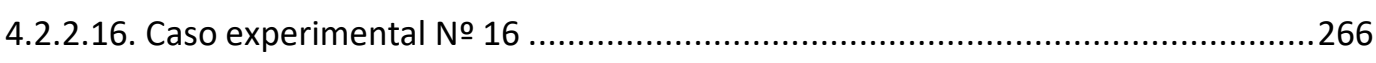

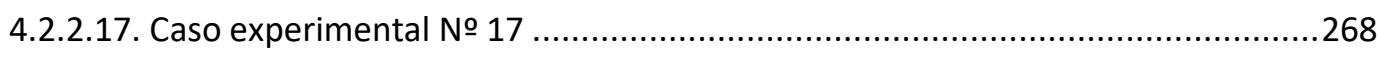

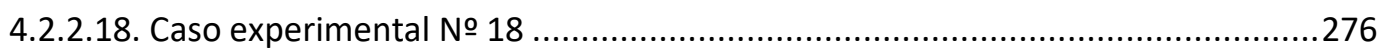


Diseño y planificación de competencias específicas en el currículum de enseñanzas profesionales de música: modalidades composición-dirección en la enseñanza superior.

4.2.3. Grupo control. Análisis individualizado de casos.......................................293

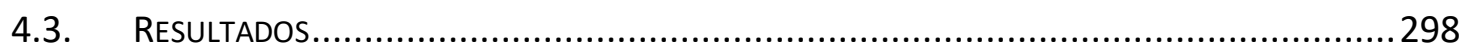

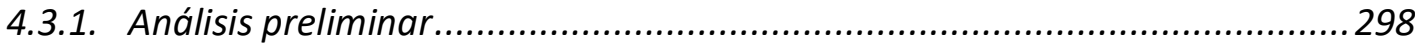

4.3.2. Eficacia y significación de la intervención ................................................... 302

4.3.3. Contraste único entre resultados del grupo experimental y el de control ......304

4.3.4. Contraste grupal entre resultados del grupo experimental y el de control ... 307

5. CONCLUSIONES .309

ANEXOS. 313

\section{Índice de tablas}

Tabla 1. Relación organizativa en las Enseñanzas Profesionales por autonomías

(elaboración propia).

Tabla 2. Relación organizativa de la normativa referente a las pruebas de acceso y de su correspondencia curricular con las Enseñanzas Profesionales por autonomías (elaboración propia)

Tabla 3. Distribución de las competencias específicas en el contenido curricular por materias (elaboración propia).

Tabla 4. Comparativa curricular con su propuesta de modificación (elaboración propia)...76

Tabla 5. Propuesta curricular para la asignatura optativa Fundamentos de dirección (elaboración propia).

Tabla 6. Relación entre los contenidos curriculares y la competencias específicas seleccionadas para el pretest (elaboración propia). 108

Tabla 7. Vinculación curricular para la primera intervención (elaboración propia). 127

Tabla 8. Vinculación curricular para la segunda intervención (elaboración propia). 130

Tabla 9. Relación entre los contenidos curriculares y la competencias específicas seleccionadas para el postest (elaboración propia).

Tabla 10. Resumen puntuaciones de variables, medias y global para el sujeto $\mathrm{N}^{\mathrm{o}} 1$ 150 
Diseño y planificación de competencias específicas en el currículum de enseñanzas profesionales de música: modalidades composición-dirección en la enseñanza superior.

Carlos Eduardo Pascual Pérez

Tabla 11. Resumen puntuaciones de variables, medias y global para el sujeto $\mathrm{N}^{\mathrm{o}} 2$........ 159

Tabla 12. Resumen puntuaciones de variables, medias y global para el sujeto $\mathrm{N}^{\mathrm{o}} 3 \ldots \ldots . .167$

Tabla 13. Resumen puntuaciones de variables, medias y global para el sujeto $\mathrm{N}^{\mathrm{o}} 4 \ldots \ldots \ldots 176$

Tabla 14. Resumen puntuaciones de variables, medias y global para el sujeto $\mathrm{N}^{\circ} 5 \ldots \ldots \ldots 184$

Tabla 15. Resumen puntuaciones de variables, medias y global para el sujeto $\mathrm{N}^{\mathrm{o}} 6 \ldots \ldots . . .192$

Tabla 16. Resumen puntuaciones de variables, medias y global para el sujeto №7 .......... 198

Tabla 17. Resumen puntuaciones de variables, medias y global para el sujeto $\mathrm{N}^{\mathrm{o}}$ 8........208

Tabla 18. Resumen puntuaciones de variables, medias y global para el sujeto $\mathrm{N}^{\circ} 9$..........214

Tabla 19. Resumen puntuaciones de variables, medias y global para el sujeto $\mathrm{N}^{\mathrm{o}} 10 \ldots \ldots .224$

Tabla 20. Resumen puntuaciones de variables, medias y global para el sujeto $\mathrm{N}^{\mathrm{o}} 11 \ldots \ldots .233$

Tabla 21. Resumen puntuaciones de variables, medias y global para el sujeto $\mathrm{N}^{\mathrm{o}} 12 \ldots \ldots .243$

Tabla 22. Resumen puntuaciones de variables, medias y global para el sujeto $\mathrm{N}^{\mathrm{o}} 13 \ldots \ldots .247$

Tabla 23. Resumen puntuaciones de variables, medias y global para el sujeto $\mathrm{N}^{\mathrm{o}} 14 \ldots \ldots .257$

Tabla 24. Resumen puntuaciones de variables, medias y global para el sujeto $\mathrm{N}^{\mathrm{o}} 15 \ldots \ldots .266$

Tabla 25. Resumen puntuaciones de variables, medias y global para el sujeto $\mathrm{N}^{\mathrm{o}} 16 \ldots \ldots .268$

Tabla 26. Resumen puntuaciones de variables, medias y global para el sujeto $\mathrm{N}^{\circ} 17 \ldots \ldots .276$

Tabla 27. Resumen puntuaciones de variables, medias y global para el sujeto $\mathrm{N}^{\circ} 18 \ldots \ldots .283$

Tabla 28. Resumen puntuaciones de variables, medias y global para el sujeto $\mathrm{N}^{\mathrm{o}} 19 \ldots \ldots .292$

Tabla 29. Resultados para las pruebas de normalidad aplicadas a las variables (elaboración

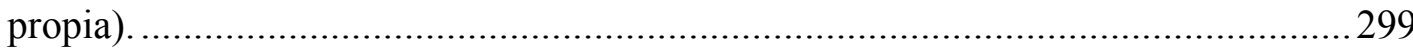

Tabla 30. Resultados para la Prueba T de Wilcoxon (elaboración propia). ........................302

Tabla 31. Resultados paramétricos complementarios mediante Prueba T de Gosset

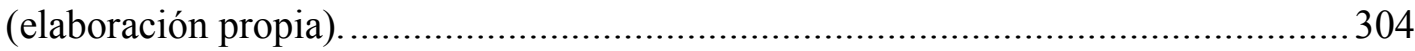

Tabla 32. Resultados para la prueba U de Mann-Withney (elaboración propia).................305

Tabla 33. Resultados para la comparación de medias entre grupos (elaboración propia).. 306

Tabla 34. Resultados para la Prueba T de Gosset (elaboración propia)............................ 306

Tabla 35. Resultados para la Prueba H de Krustal-Wallis (elaboración propia). ............... 307

Tabla 36. Resultados paramétricos complementarios para la Prueba F de análisis de la varianza (elaboración propia) 


\section{Índice de figuras}

Figura 1. Dicotomía comparativa de la legislación estatal y autonómica referida

Figura 2. Comparativa del desarrollo curricular diversificado por autonomías (elaboración propia).

Figura 3. Distribución horaria por materias para una especialidad instrumental (Decreto $158 / 2007$, p. 37071).

Figura 4. Ejemplo analítico sobre el inicio de la Sinfonía No.41 en su versión original para orquesta sinfónica (Mozart, 1957, p.1).

Figura 5. Ejemplo analítico idéntico al propuesto en la Figura 4, en este caso en una reducción de la citada partitura para piano (Hummel, 1825, p.1).

Figura 6. Ejemplo de ejercicio propuesto mediando el criterio de evaluación 2 (elaboración propia).

Figura 7. Realización para piano del ejercicio propuesto en la Figura 6 (elaboración propia).

Figura 8. Realización para orquesta de cámara del ejercicio propuesto en la Figura 6 (elaboración propia) .86

Figura 9. Pretest (elaboración propia). 107

Figura 10. Ejemplo de bajo cifrado para su realización a cuatro voces (Gilabert, 2020)... 112

Figura 11. Ejemplo de realización del bajo cifrado de la Figura 5 (Gilabert, 2020). 112

Figura 12. Ejemplo de características técnicas y organológicas de un instrumento. Extraído de El estudio de la orquestación (p.83) por Samuel Adler, 2006, Barcelona: Idea Books. Todos los derechos reservados; reproducción autorizada con fines académicos según Artículo 32.1 de la Ley de Propiedad Intelectual en España. 113

Figura 13. Ejemplo de plantilla instrumental para su realizaciones armónicas a cuatro partes (elaboración propia). 
Diseño y planificación de competencias específicas en el currículum de enseñanzas profesionales de música: modalidades composición-dirección en la enseñanza superior.

Carlos Eduardo Pascual Pérez

Figura 14. Realización propuesta en la Figura 6 para un conjunto de cuatro instrumentos (elaboración propia).

Figura 15. Ejercicio mixto con bajo cifrado, bajo sin cifrar y soprano dado (Gilabert, 2020).

Figura 16. Esquema armónico propuesto para la composición de un ejercicio a cuatro partes (elaboración propia). 117

Figura 17. Coral $\mathrm{N}^{\mathrm{o}} 1$ en su versión original para coro mixto (Bach, 1875; p.12). 119

Figura 18. Orquestación del Coral $\mathrm{N}^{\mathrm{o}} 1$ de Bach para cuarteto de viento madera (Abeling, 2006; p.1).

Figura 19. Entorno de software Finale para la edición y reproducción de partituras (elaboración propia).

Figura 20. Ejemplo de análisis sobre una partitura instrumental camerística (Mozart, 1881; p.1)

Figura 21. Ejemplo de análisis sobre una partitura orquestal (Tchaikovsky, 1881; p.1)... 123

Figura 22. Ejemplo de análisis temático y formal para una obra camerística (Beethoven, $1864 ;$ p.1).

Figura 23. Realización armónica para cuatro instrumentos con incorrecciones armónicas (elaboración propia).

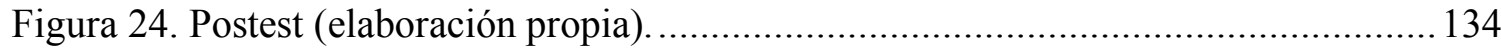

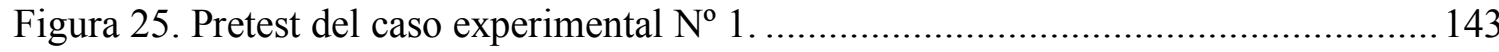

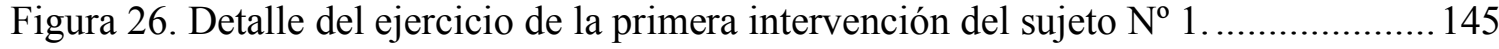

Figura 27. Detalle del ejercicio de la segunda intervención del sujeto $\mathrm{N}^{\mathrm{o}} 1$..................... 146

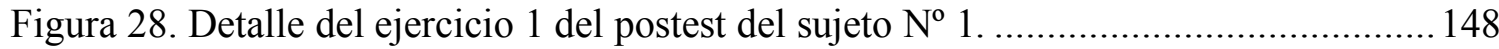

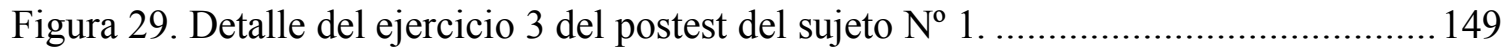

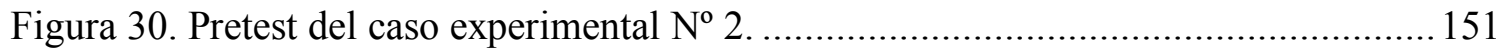

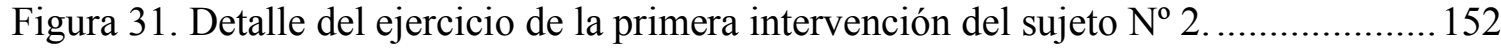

Figura 32. Detalle del ejercicio de la segunda intervención del sujeto $\mathrm{N}^{\mathrm{o}} 2$ 2.................... 154

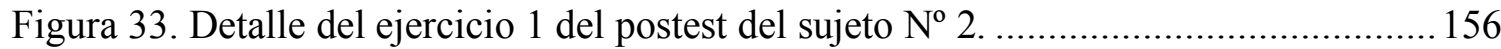

Figura 34. Detalle del ejercicio 2 del postest del sujeto $\mathrm{N}^{\mathrm{o}} 2$...................................... 157 
Figura 35. Detalle del ejercicio 3 del postest del sujeto $\mathrm{N}^{\mathrm{o}} 2$.................................... 158

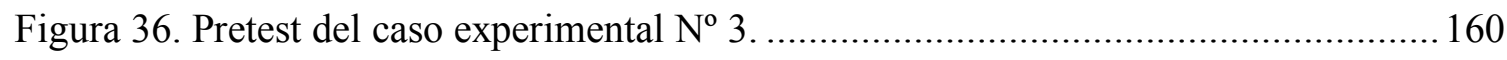

Figura 37. Detalle del ejercicio de la primera intervención del sujeto $\mathrm{N}^{\mathrm{o}} 3 \ldots \ldots \ldots \ldots \ldots \ldots \ldots . . . . . . . .162$

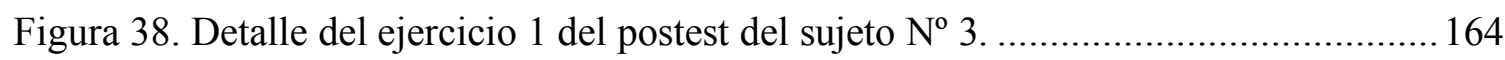

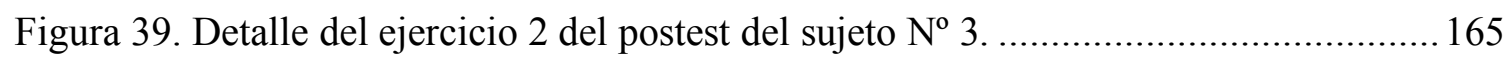

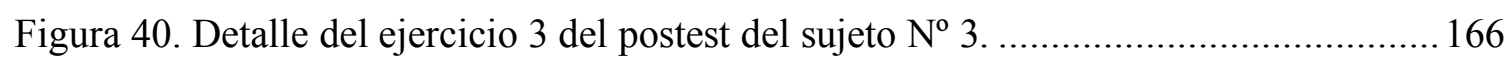

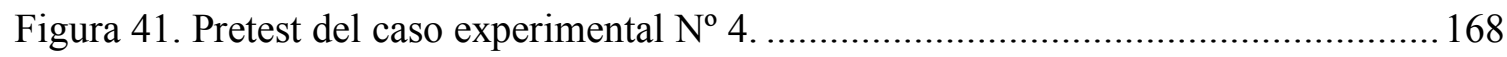

Figura 42. Detalle del ejercicio de la primera intervención del sujeto $\mathrm{N}^{\mathrm{o}} 4$.................... 170

Figura 43. Detalle del ejercicio de la segunda intervención del sujeto $\mathrm{N}^{\mathrm{o}} 4$. ................... 171

Figura 44. Detalle del ejercicio 1 del postest del sujeto $\mathrm{N}^{\mathrm{o}} 4$........................................ 173

Figura 45. Detalle del ejercicio 2 del postest del sujeto $\mathrm{N}^{\mathrm{o}} 4$.................................... 174

Figura 46. Detalle del ejercicio 3 del postest del sujeto $\mathrm{N}^{\mathrm{o}} 4$...................................... 175

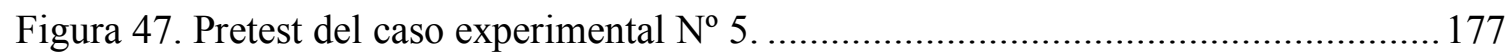

Figura 48. Detalle del ejercicio de la segunda intervención del sujeto $\mathrm{N}^{\mathrm{o}} 5$................... 179

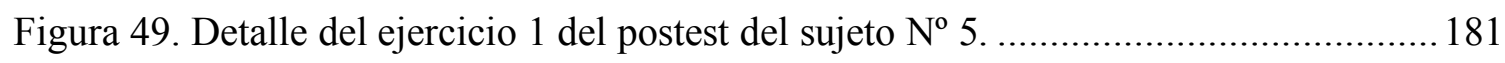

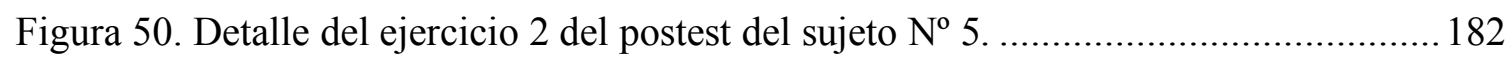

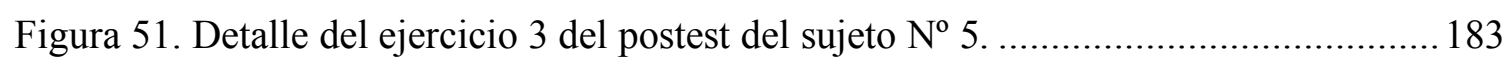

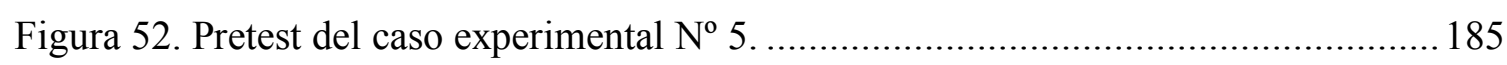

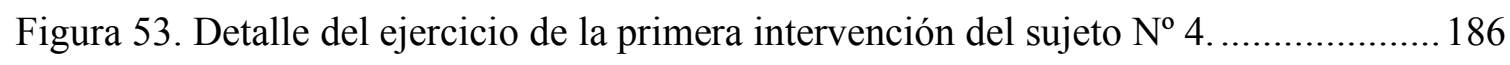

Figura 54. Detalle del ejercicio de la segunda intervención del sujeto $\mathrm{N}^{\mathrm{o}} 5$.................... 187

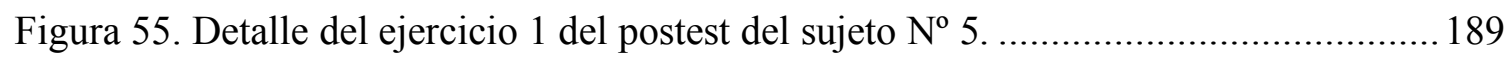

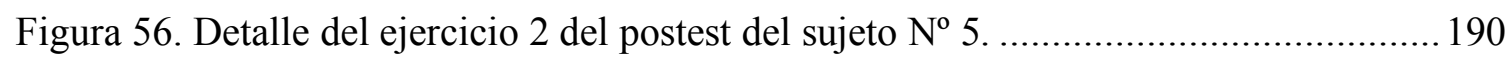

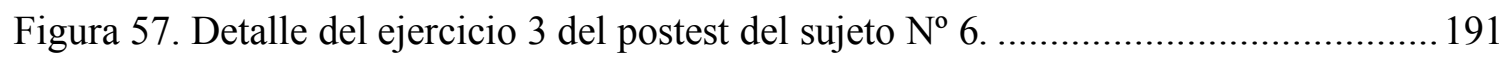

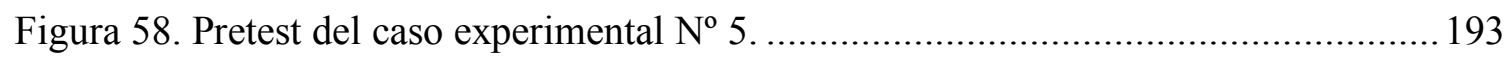

Figura 59. Detalle del ejercicio de la primera intervención del sujeto $\mathrm{N}^{\circ} 4$.................... 195

Figura 60. Detalle del ejercicio de la segunda intervención del sujeto $\mathrm{N}^{\mathrm{o}} 5$..................... 197

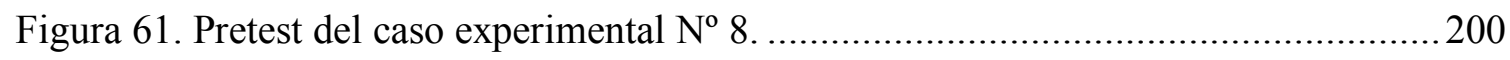

Figura 62. Detalle del ejercicio de la primera intervención del sujeto $\mathrm{N}^{\mathrm{o}} 8$.....................202

Figura 63. Detalle del ejercicio de la segunda intervención del sujeto $\mathrm{N}^{\mathrm{o}} 8$. .................... 204 
Figura 64. Detalle del ejercicio 1 del postest del sujeto $\mathrm{N}^{\mathrm{o}} 8$......................................205

Figura 65. Detalle del ejercicio 2 del postest del sujeto $\mathrm{N}^{\mathrm{o}} 8$.....................................206

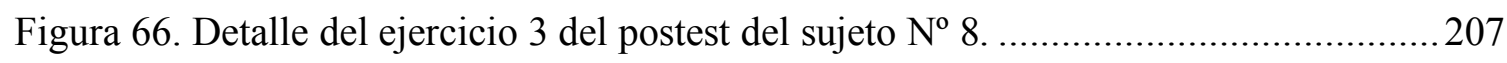

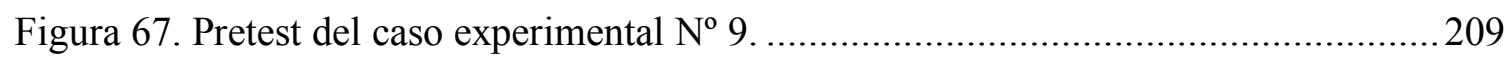

Figura 68. Detalle del ejercicio de la primera intervención del sujeto $\mathrm{N}^{\mathrm{o}} 9$......................211

Figura 69. Detalle del ejercicio de la segunda intervención del sujeto $\mathrm{N}^{\circ}$ 9. ..................2 213

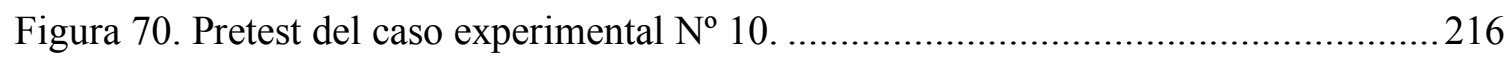

Figura 71. Detalle del ejercicio de la primera intervención del sujeto $\mathrm{N}^{\mathrm{o}} 10$..................218

Figura 72. Detalle del ejercicio de la segunda intervención del sujeto $\mathrm{N}^{\mathrm{o}} 10 \ldots \ldots \ldots \ldots \ldots \ldots . . . . . . .219$

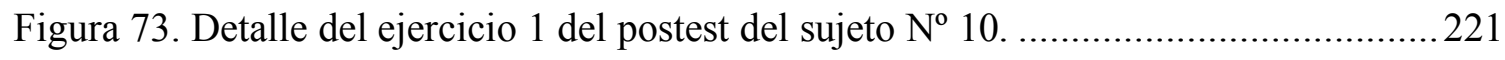

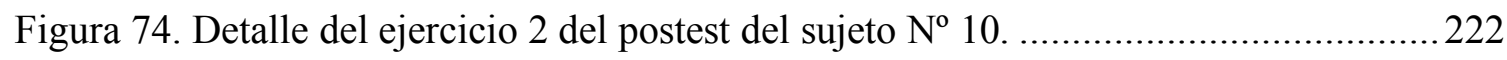

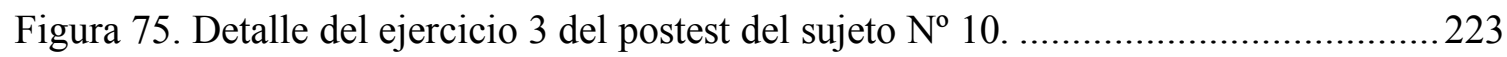

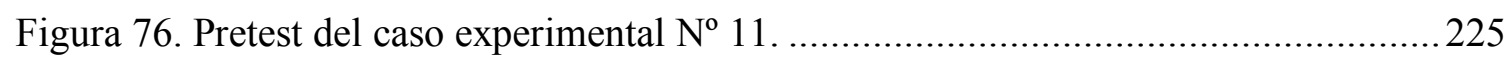

Figura 77. Detalle del ejercicio de la primera intervención del sujeto $\mathrm{N}^{\mathrm{o}} 11 \ldots \ldots \ldots \ldots \ldots \ldots . . .227$

Figura 78. Detalle del ejercicio de la segunda intervención del sujeto $\mathrm{N}^{\mathrm{o}} 11 \ldots \ldots \ldots \ldots \ldots \ldots . . . .229$

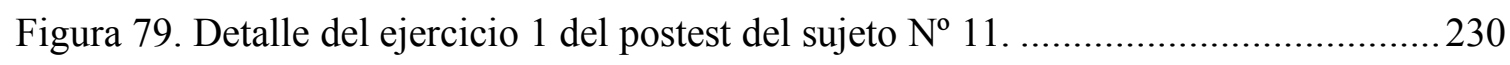

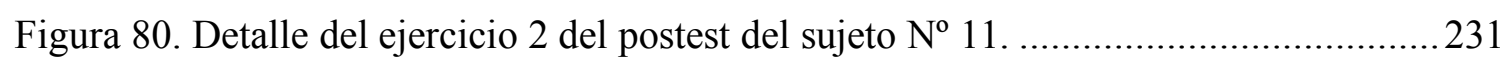

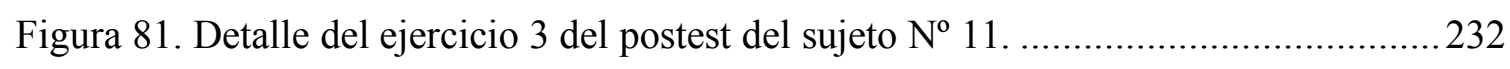

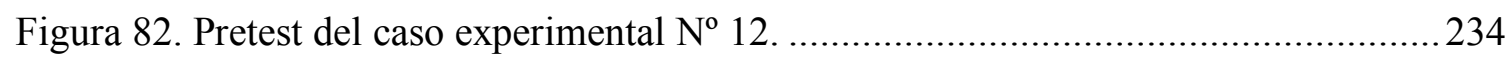

Figura 83. Detalle del ejercicio de la primera intervención del sujeto $\mathrm{N}^{\mathrm{o}} 11 \ldots \ldots \ldots \ldots \ldots \ldots . . .236$

Figura 84. Detalle del ejercicio de la segunda intervención del sujeto $\mathrm{N}^{\mathrm{o}} 12 \ldots \ldots \ldots \ldots \ldots \ldots . . . . . .238$

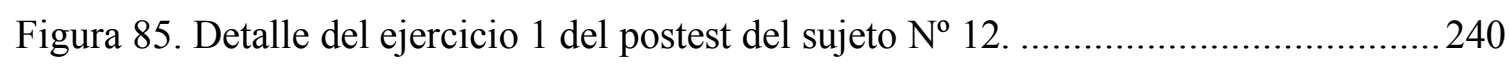

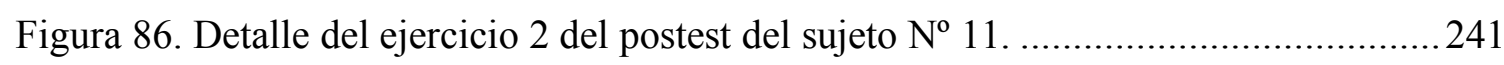

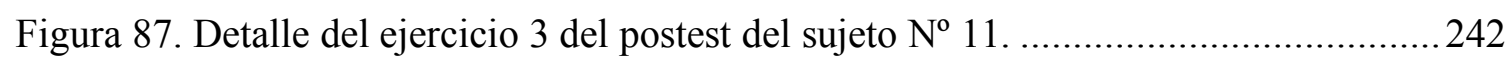

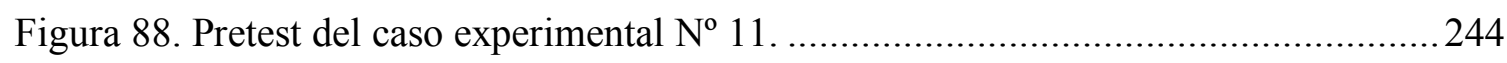

Figura 89. Detalle del ejercicio de la segunda intervención del sujeto $\mathrm{N}^{\mathrm{o}} 13 \ldots \ldots \ldots \ldots \ldots \ldots . . . .246$

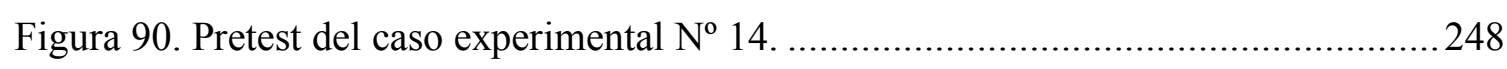

Figura 91. Detalle del ejercicio de la primera intervención del sujeto $\mathrm{N}^{\mathrm{o}} 14 \ldots \ldots \ldots \ldots \ldots \ldots . .250$

Figura 92. Detalle del ejercicio de la segunda intervención del sujeto $\mathrm{N}^{\mathrm{o}} 14 \ldots \ldots \ldots \ldots \ldots \ldots . . .252$ 
Figura 93. Detalle del ejercicio 1 del postest del sujeto $\mathrm{N}^{\mathrm{o}} 14$...................................254

Figura 94. Detalle del ejercicio 2 del postest del sujeto $\mathrm{N}^{\mathrm{o}} 14$...................................255

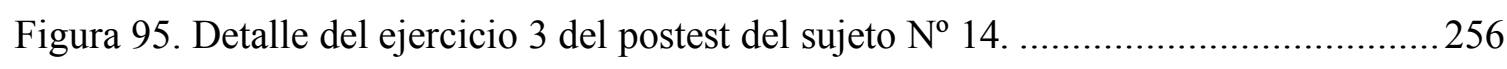

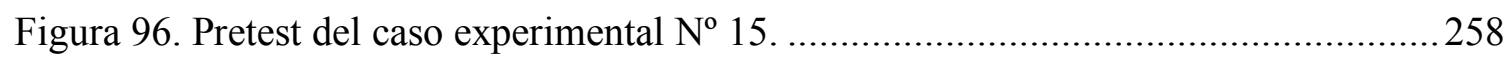

Figura 97. Detalle del ejercicio de la primera intervención del sujeto $\mathrm{N}^{\mathrm{o}} 15 \ldots \ldots \ldots \ldots \ldots \ldots . . . . . . .260$

Figura 98. Detalle del ejercicio de la segunda intervención del sujeto $\mathrm{N}^{\mathrm{o}} 15 \ldots \ldots \ldots \ldots \ldots \ldots . . . . . .262$

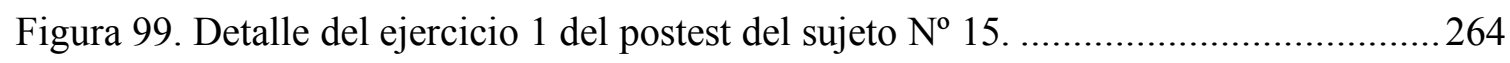

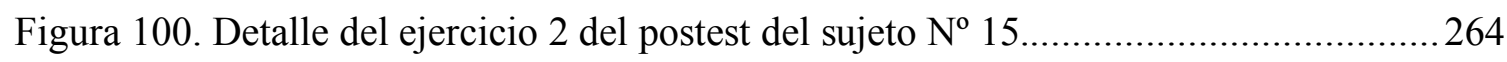

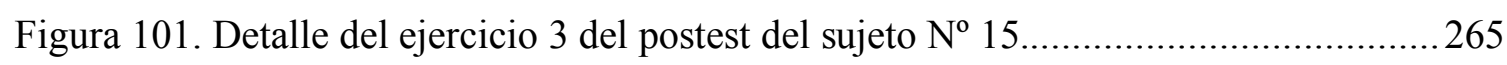

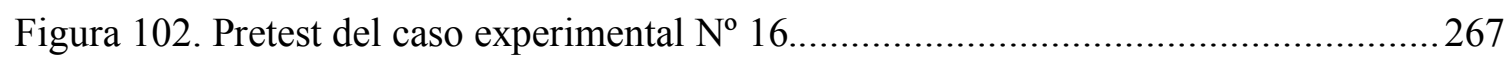

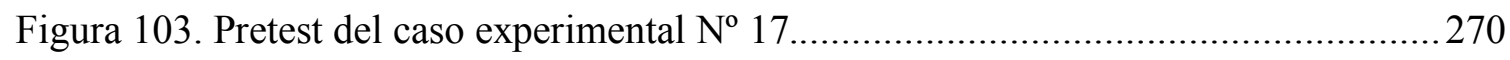

Figura 104. Detalle del ejercicio de la segunda intervención del sujeto $\mathrm{N}^{\mathrm{o}} 17 \ldots \ldots \ldots \ldots \ldots . . .272$

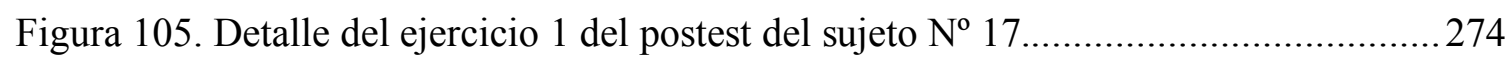

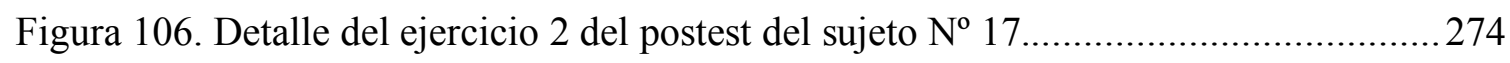

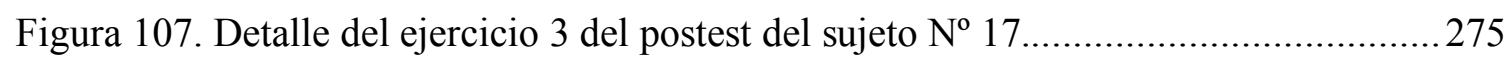

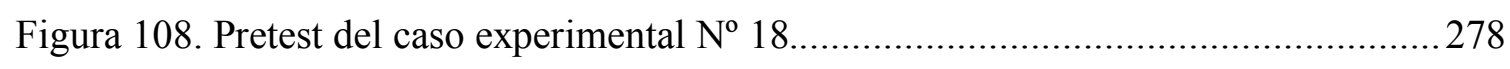

Figura 109. Detalle del ejercicio de la primera intervención del sujeto $\mathrm{N}^{\mathrm{o}} 18$.................280

Figura 110. Detalle del ejercicio de la segunda intervención del sujeto $\mathrm{N}^{\mathrm{o}} 18 \ldots \ldots \ldots \ldots \ldots . . .282$

Figura 111. Detalle del ejercicio de la primera intervención del sujeto $\mathrm{N}^{\mathrm{o}} 19$.................285

Figura 112. Detalle del ejercicio de la segunda intervención del sujeto $\mathrm{N}^{\mathrm{o}} 19 \ldots \ldots \ldots \ldots \ldots . . .287$

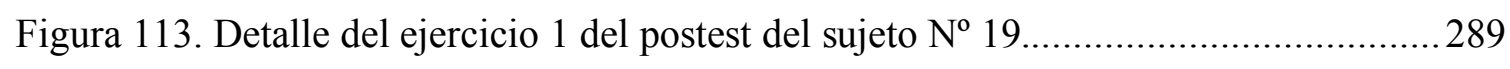

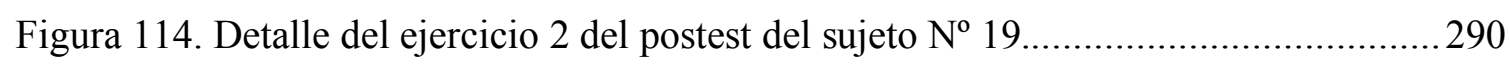

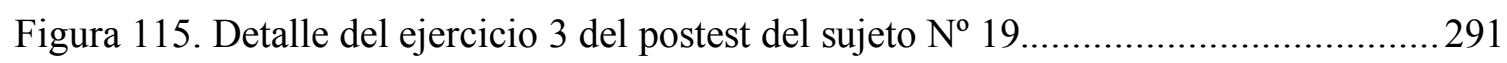

Figura 116. Detalle del ejercicio 2 del postest del sujeto $\mathrm{N}^{\mathrm{o}} 21$, en el que se refleja un acierto en un instrumento coincidente con la especialidad cursada por el sujeto (clarinete).

Figura 117. Detalle del ejercicio 2 del postest del sujeto $\mathrm{N}^{\circ} 53$, en el que se refleja un acierto en un instrumento coincidente con la especialidad cursada por el sujeto (trompa). 
Diseño y planificación de competencias específicas en el currículum de enseñanzas profesionales de música: modalidades composición-dirección en la enseñanza superior.

Carlos Eduardo Pascual Pérez

Figura 118. Detalle del ejercicio 1 del postest del sujeto $\mathrm{N}^{\circ} 50$, en el que se refleja un acierto considerable sin que se condicione el mismo por la especialidad del sujeto (violín).

Figura 119. Detalle del ejercicio 2 del postest del sujeto $N^{\circ} 43$, en el que se refleja un acierto considerable sin que se condicione el mismo por la especialidad del sujeto (violoncello). 


\section{Contextualización de los objetivos y metodología}

\subsection{Introducción}

Desde el Decreto de 15 de junio de 1942 "sobre organización de los Conservatorios de Música y Declamación” hasta la actualidad los Reales Decretos que han establecido en nuestro país los planes de estudios musicales han dispuesto una variedad curricular - así como no organizativa - muy dispar en cada una de las especialidades. Tomamos esta fecha inicial y no otra anterior dado que la publicación de dicho Decreto es la culminación de varios intentos gubernamentales desde 1904 para establecer un marco legislativo nacional, dado que “estas enseñanzas no han tenido en nuestra Patria, a pesar de laudables intentos, un plan orgánico, eficaz y bien determinado" (Decreto de 15 de junio de 1942). No podemos referir en lo organizativo por tanto a las situaciones anteriores de inicio del siglo XX - ni a lo acontecido durante el XIX que se reduce prácticamente a la creación de una Escuela y luego Conservatorio en Madrid y algunas sucursales del mismo "casi limitados a los muros de Madrid" (Eslava, 1856) -, que estuvieron en busca perpetua de un amparo legal nacional, desde la legalización de las escuelas de música municipales, la validación de sus estudios elementales, la creación de un cuerpo nacional de profesores, la autonomía organizativa provincial hasta la creación de una red de Escuelas Nacionales de Música. No obstante, esta trayectoria sigue una constante en el tiempo, evolucionando desde la casi pura práctica instrumental hasta la formación en otros contenidos y materias con mayor cariz teórico o interdisciplinar. De aquí que nuestro sistema actual intente perfilar al músico más allá de ser 
Diseño y planificación de competencias específicas en el currículum de enseñanzas profesionales de música: modalidades composición-dirección en la enseñanza superior.

Carlos Eduardo Pascual Pérez

un mero instrumentista - intérprete de un instrumento en el sentido más literal -, lo cual ha derivado en los distintos Grados Superiores en Música que existen hoy en día.

Pero habría que esperar hasta la formulación del Real Decreto 756/1992 para descubrir a nivel curricular subyace una trayectoria hacia la formación meta instrumental del músico, minorando el tiempo de práctica instrumental e implementando la formación en otros ámbitos teóricos y de conocimiento musical transversal. Pero no obstante se sigue manteniendo (RD 1765/1992, p.29782),

\begin{abstract}
"un planteamiento educativo de los grados elemental y medio se fundamenta en el estudio de una especialidad instrumental que actúa de vertebrador del currículo con la doble finalidad preparatoria de servir de formación básica para acceder a estudios de especialización en el grado superior, dentro de la opción elegida, o servir de fundamento para la apertura hacia otros itinerarios."
\end{abstract}

Es decir, el estudiante sigue recibiendo formación de instrumentista con algo más de carga teórica para su diversificación ya una vez acceda al Grado Superior. 
Carlos Eduardo Pascual Pérez

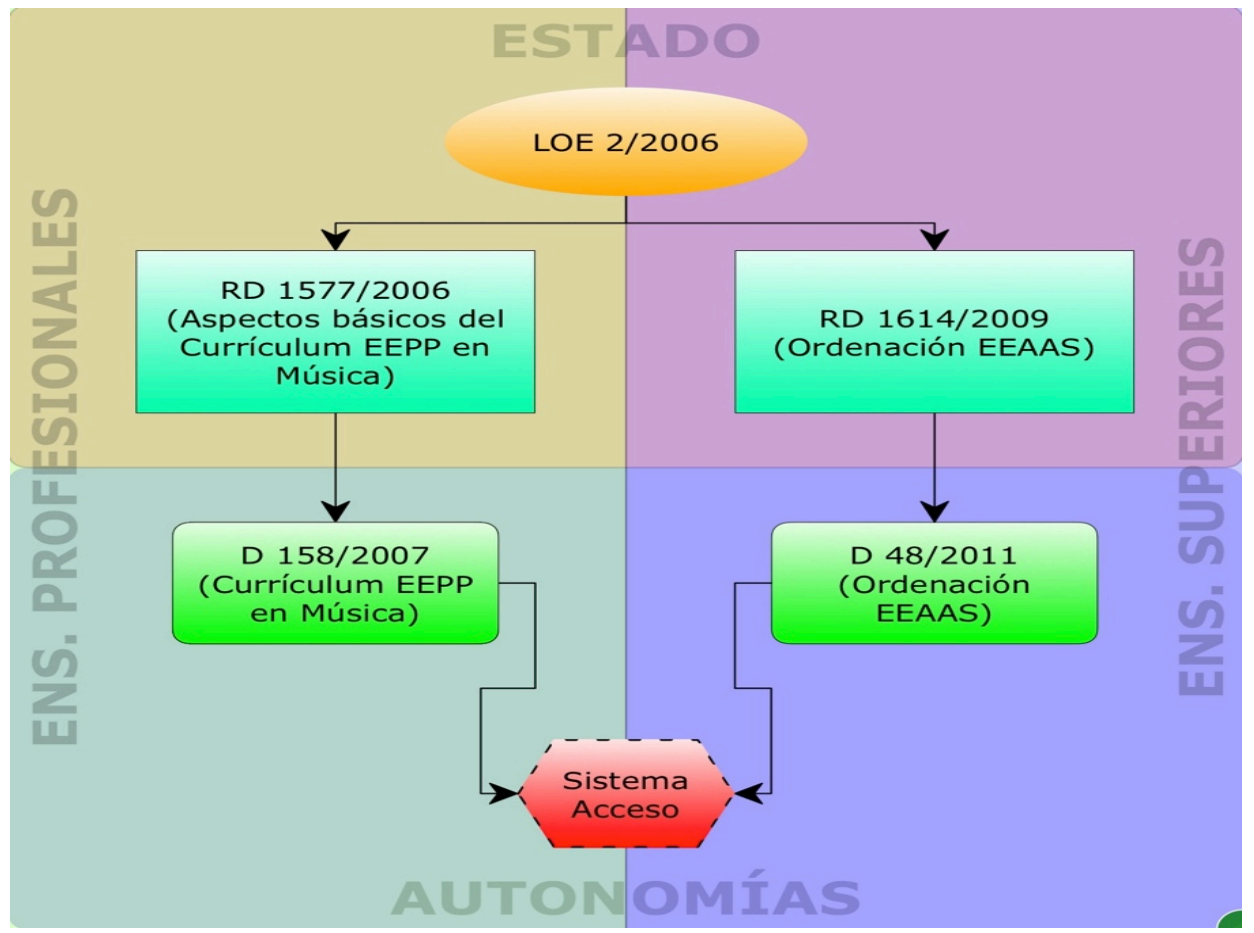

Figura 1. Dicotomía comparativa de la legislación estatal y autonómica referida a las Enseñanzas Profesionales y Superiores (elaboración propia).

Aunque el vigente Real Decreto 1577/2006 retomara la nomenclatura del Plan del 42 nuevamente Enseñanzas Elementales y Profesionales -, continúa en la misma línea que la establecida en la LOGSE de 1992, sin cambios notables a nivel curricular. Sin embargo, las Enseñanzas Superiores se regirán en una disposición diferente, el Real Decreto 1614/2009, cuya escisión - agravada además por su transmisión de competencias a las Autonomías enmarca el origen de la problemática que trata de abordar nuestra investigación. Así pues, el RD 1577/2006 propone una línea única curricular basada en la interpretación instrumental para las Enseñanzas Profesionales, y por contra, el RD 1614/2009 dispone que los Centros Superiores desarrollarán sus pruebas de acceso específicas para cada uno de los Grados, 
Diseño y planificación de competencias específicas en el currículum de enseñanzas profesionales de música: modalidades composición-dirección en la enseñanza superior.

donde generalmente - y con salvedad del Grado en Interpretación o Pedagogía cuya prueba sí que tiene una correspondencia directa con el contenido curricular de la etapa profesional se exige unos conocimientos y habilidades los cuales no pertenecen en su totalidad al citado currículum precedente. Concretamente, las pruebas específicas las encontramos para acceder al resto de los Grados existentes en las Enseñanzas Artísticas Superiores, siendo estos Dirección, Composición, Flamenco, Jazz, Sonología, Producción y Gestión y Musicología. Llegados a este punto, obtenemos un nexo de convección entre los planes de estudio citados que carece de correspondencia curricular, generando así una gran desigualdad geográfica y competencial, la cual ponemos de manifiesto en esta investigación. No obstante, el acceso a dichas pruebas es libre y no requiere de haber cursado la etapa previa para acceder a las mismas - aunque tener el título profesional supone a voluntad del aspirante obtener el 50\% de la nota de acceso convalidado por la nota media de dichas enseñanzas -, por lo que la formación o preparación específica para abordar dichas pruebas en centros privados no oficiales, o incluso la preparación autónoma de las mismas - como por ejemplo un aspirante con una titulación superior ya adquirida - sería siempre una alternativa. La misma no es objeto del presente estudio, puesto que nuestra referencia serán las Enseñanzas Oficiales a nivel nacional, y que están situadas por edad idónea a la etapa anterior a las Enseñanzas Superiores, es decir, entre los 12 y los 18 años.

Asimismo, tras esta introducción en la que reflejamos nuestra motivación, planteamos nuestra hipótesis; es posible incidir significativamente mediante metodologías curriculares y organizativas que logren una diversificación en las Enseñanzas Profesionales, concretamente 
aplicadas a las modalidades de Enseñanzas Superiores en Composición y Dirección, y establecer así un modelo exportable a las demás especialidades.

\subsection{Objetivos}

Podemos definir los objetivos que pretendemos alcanzar mediante la presente investigación en esta relación:

- Evidenciar la falta de relación curricular existente entre las etapas oficiales de Enseñanzas Profesionales y Enseñanzas Superiores de música en España, incidiendo en el requisito de competencias específicas precisadas por el alumnado que pretende acceder a estas últimas.

- Diseñar una propuesta curricular de diversificación concreta que responda a nuestro perfil profesional y docente, y que pueda servir como guía para futuras líneas de investigación sobre otras especialidades.

- Validar o rehusar la hipótesis de nuestra propuesta aplicándola a dos grupos experimentales durante dos cursos académicos, obteniendo resultados de la misma y contrastándolos con otros datos mediante grupos de control. 
Diseño y planificación de competencias específicas en el currículum de enseñanzas profesionales de música: modalidades composición-dirección en la enseñanza superior.

Para alcanzarlos, los acometeremos en el orden indicado, dado que entendemos que desde la motivación que sugiere el primero de ellos se desprenden los consiguientes, y deben por tanto estar resuelto uno antes de intentar resolver el siguiente.

\subsection{Metodología}

Mediante la presente tesis doctoral vertebraremos los tres objetivos que pretendemos en tres bloques de la misma: el estado de la cuestión, la propuesta de diseño curricular aplicado a la composición y la dirección y por último el desarrollo y resultados de su aplicación experimental. En este orden, acometeremos su desarrollo siguiendo una metodología que nace en la motivación del presente estudio y concluirá con el análisis de los resultados de nuestra experimentación.

En primer lugar, podemos admitir que existe una motivación personal y antigua por parte del investigador principal de este texto. El mismo pasó por el sistema de las Enseñanzas Profesionales, concluyéndolas y afrontando varias pruebas de acceso a las Enseñanzas Superiores en las especialidades de Composición y Dirección. Del mismo modo que evidenciamos en nuestro estudio, el entonces aspirante debió buscar formación paralela y complementaria a la que le aportó curricularmente la etapa que recientemente terminaba, pudiendo finalmente acceder tanto a los Grados Superiores de Composición y Dirección. En aquel momento parecía obvio - y estaba generalizada dicha opinión, ya que la misma era aplicable a cualquiera de los compañeros que decidían afrontar unas pruebas de acceso 
Diseño y planificación de competencias específicas en el currículum de enseñanzas profesionales de música: modalidades composición-dirección en la enseñanza superior.

distintas a la de Interpretación - que para afrontar dichas pruebas era necesario complementar la formación competencial de forma externa. Años más tarde, y tras la experiencia propia profesional como docente en las Enseñanzas Superiores, y encontrarse esta vez en el tribunal de dichas pruebas como evaluador, volvió a evidenciarse la misma situación que la vivida años atrás, y que revelaba la persistencia del problema con el paso del tiempo. En ese punto comenzó a forjarse el diseño de la presente tesis.

Fundamentada la motivación, el primer paso será plantear un estado de la cuestión que se fundamente en un estudio en profundidad acerca de la legislación estatal y autonómica que articula todos los planes de estudios en las etapas cuestionadas, y sobre todo en su nexo de unión: las pruebas de acceso. Buscamos evidenciar el desarrollo curricular en las Enseñanzas Profesionales como insuficiente ante las diferentes pruebas de acceso a las Enseñanzas Superiores, concretamente ejemplificadas las especialidades de Composición y Dirección. Y derivado de este estudio, desvelar también la heterogeneidad curricular entre las autonomías y la desigualdad geográfica que esto supone.

En este punto, también aportaremos testimonios de docentes e investigadores relacionados con una o ambas de las enseñanzas cuestionadas, con deseo de que refuercen nuestra perspectiva, avalen nuestra hipótesis y puedan también aportar algún nuevo prisma que haga extensiva nuestra investigación a otras disciplinas o futuras líneas de investigación. 
Diseño y planificación de competencias específicas en el currículum de enseñanzas profesionales de música: modalidades composición-dirección en la enseñanza superior.

Carlos Eduardo Pascual Pérez

Un análisis de lo revelado en el estado de la cuestión sobre los requisitos de las pruebas que no derivan de la conexión curricular con la etapa predecesora nos definirá en forma de competencias específicas las necesidades para implementar en nuestra propuesta. Tomando dichas especialidades de Composición y Dirección, diseñaremos una propuesta curricular de Enseñanzas Profesionales que incluya dichas competencias específicas de forma transversal, y que sea una modalidad enfocada a dichos estudios superiores.

En último término, llevaremos a cabo una experiencia de aplicación de la propuesta curricular, de un modo parcial dado que lo haremos únicamente en el primero de los cursos en los que proponemos la diversificación de modalidad, y lo haremos en nuestro ámbito competencial docente - el Conservatorio en el que ejercemos profesionalmente -, mediante una asignatura con grupos experimentales en dos cursos académicos. Finalizado dicho término procederemos al análisis de resultaos tanto cualitativos como cuantitativos, y para cuyo contraste habremos tomado muestras de otros grupos de control en diversos centros educativos de la Comunidad Valenciana.

\subsection{Antecedentes}

Simplificando el concepto que motiva en gran parte la presente investigación, podemos sintetizarlo en la interrelación entre las Enseñanzas Profesionales y Superiores de Música mediante su sistema de acceso. En este sentido, encontramos una similitud con las pruebas selectivas de acceso a la universidad que relaciona estas con el Bachiller como etapa inmediatamente anterior de forma general. $\mathrm{Y}$ al igual que encontramos dicho paralelismo en 
Diseño y planificación de competencias específicas en el currículum de enseñanzas profesionales de música: modalidades composición-dirección en la enseñanza superior.

Carlos Eduardo Pascual Pérez

el concepto, hallamos también un gran número de diferencias y particularidades según la región o centro en el que se realice dicha prueba y dichos estudios.

Partiendo de este hecho, la búsqueda de otras investigaciones o estudios que analizaran, evaluaran o interpretaran la citada relación entre etapas educativas nos ha reportado un único resultado, una única tesis doctoral (Garres, 2011) con título "La prueba de acceso a grado superior de clarinete como eje vertebrador de la docencia en el último ciclo de Enseñanzas Profesionales: propuesta metodológica ", la cual no tiene entre sus objetivos cuestionar el sistema de acceso, sino proponer una metodología didáctica más concreta en la superación de la propia prueba de interpretación. Esta tesis no debilita nuestra hipótesis, sino que la refuerza, puesto que reafirma la idoneidad curricular de las Enseñanzas Profesionales para la superación de la prueba de acceso a la especialidad de Interpretación, poniendo en entredicho las dificultades con las que se encuentra el alumnado que se enfrenta a las diferentes de pruebas de acceso a Grados que no sean Interpretación o Pedagogía. E incluso de una forma colateral obtenemos de la citada tesis una cita que se desprende de un testimonio que refuerza nuestra hipótesis (Garres, 2011, p.308):

"yo no entiendo porqué preparamos a todos los chavales para interpretación, cuando sólo un cinco por ciento van a ser intérpretes. Entonces, ¿por qué no se mete aquí la opción de prepararlos para Pedagogía, prepararlos para Composición? Es que la normativa... Yo tengo varios alumnos que los voy a presentar ahora para Dirección 
Diseño y planificación de competencias específicas en el currículum de enseñanzas profesionales de música: modalidades composición-dirección en la enseñanza superior.

\section{Carlos Eduardo Pascual Pérez}

porque son muy válidos y los tengo que preparar a parte porque el centro no te permite estudiar el plan pedagógico.”

De este testimonio se evidencia la carencia curricular en los centros de enseñanzas profesionales más allá de las competencias en interpretación, y que a pesar de que como veremos en nuestro análisis estatal no se da por igual en todas las regiones de nuestro país, siendo la tónica generalizada la falta de competencias específicas para abordar una prueba de acceso diferente a la de interpretación. Esta evidencia junto al conocimiento de la situación actual nos remite inequívocamente a una revisión de la legislación curricular y organizativa, tanto a nivel nacional como autonómico, y en la que se incluyen las regulaciones a nivel de centros educativos. 
Diseño y planificación de competencias específicas en el currículum de enseñanzas profesionales de música: modalidades composición-dirección en la enseñanza superior.

\section{Estado de la cuestión}

Revisados los antecedentes y comprobada la ausencia documental al respecto, así como disponiendo la línea de investigación a seguir, necesitamos satisfacer un estado de la cuestión el cual se entrevé difícil de establecer. Por ello, consideramos en primer lugar aportar una visión testimonial de quienes lidian con esta cuestión a diario; los profesionales y docentes de la enseñanza profesional y superior en nuestro territorio. Tras esta verificación analizaremos el marco legislativo español - el que aplica a nivel estatal como autonómico así como también los planes de estudios que versan de los mismos o de los propios documentos de centro en algunos casos. Este análisis que relacionará ambas etapas educativas y situará el foco en nuestra hipótesis nos conducirá a elaborar unas conclusiones preliminares, las cuales afianzarán la continuidad de nuestra investigación.

\subsection{Contraste de la realidad y necesidad de la propuesta. Testimonios.}

Como primer testimonio, el Dr. Vicente Llimerá - exdirector del Instituto Superior de Enseñanzas Artísticas de la Comunidad Valenciana (ISEACV) y Catedrático en el Conservatorio Superior de Música Joaquín Rodrigo de Valencia, verifica la carencia de relación curricular entre las Enseñanzas Profesionales y las Enseñanzas Superiores que motivan nuestra hipótesis, al tiempo que avala nuestra propuesta de diversificación. 
Diseño y planificación de competencias específicas en el currículum de enseñanzas profesionales de música: modalidades composición-dirección en la enseñanza superior.

Carlos Eduardo Pascual Pérez

\section{GENERALITAT} VALENCIANA

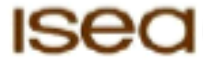

Instituto superior de ensen̂̉anzas artísticas Comunitat Volenciano

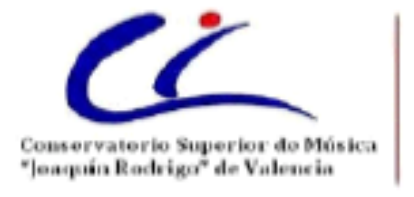

Valencia, 16 de junio de 2020

A quien concierna,

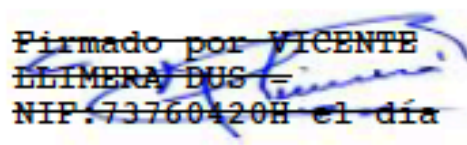

Vicente Llimerá Dus, catedrático de oboe del Conservatorio Superior de Música "Joaquin Rodrigo" de Valencia, tiene la satisfacción de ofrecer su testimonio respecto a la investigación desarrollada por el doctorando Carlos Pascual en la Universitat Jaume I de Castellón.

Esta investigación acomete un estudio sobre la carencia en nuestro pais de una verdadera relación curricular, y de competencias, respecto las enseñanzas profesionales y las enseñanzas superiores de música. Incide el investigador sobre el problema que supone la transferencia autonómica en este tipo de legislación, pues provoca una cierta desigualdad en cada autonomía.

Nuestra legislación plantea un espacio superior artístico con una oferta de titulaciones superiores de Nivel de Grado: Composición, Dirección, Flamenco, Interpretación, Musicología, Pedagogía, Producción y Gestión, y Sonología ${ }^{1}$. E1 alumnado que finaliza estos estudios, obtienen el título Superior de Música en la especialidad correspondiente, que es equivalente a todos los efectos al título universitario de Licenciado o el título de Grado equivalente (Artículo 54.3 de la LOE, texto consolidado tras la publicación de la LOMCE).

Sin embargo, los estudios profesionales de música están enfocados principalmente como una línea única de interpretación. Esto impide la capacitación necesaria para el acceso a ciertas de las titulaciones superiores, como son las de Dirección y Composición.

En esta investigación se plantea una diversificación curricular en los itinerarios de estudios profesionales mediante el uso de metodologias especificas y la adquisición de

Disponible en: htto//wwweaducacionvfipgober/contenidos/estudiantes/ensenanzasantisticas/musica/ensenanzas-superiores/titulo-superior/especialidades.htm] [última consulta 31_05_2020] 
Diseño y planificación de competencias específicas en el currículum de enseñanzas profesionales de música: modalidades composición-dirección en la enseñanza superior.

Carlos Eduardo Pascual Pérez

una serie de competencias especificas que permitan un acceso en condiciones idóneas a las titulaciones citadas. Todo lo cual, respetando el currículum actual de las enseñanzas profesionales.

En consecuencia y por todo lo anteriormente expuesto, recomendamos el desarrollo de esta investigación mediante una tesis doctoral por considerar que es una investigación original y relevante en su campo de investigación.

Vicente Llimerá Dus

Doctor por la Universitat de València. Estudi General.

Catedrático de oboe del Conservatorio Superior de Música "Joaquín Rodrigo" de Valencia.

Ex Director General del Instituto Superior de Enseñanzas Artísticas de la Comunitat Valenciana.

En un segundo testimonio, D. Fernando Ferrer - más conocido por su pseudónimo Ferrer Ferran, compositor y director de gran reconocimiento universal, así como ex-catedrático de Composición en el Conservatorio Superior Salvador Seguí de Castellón -, vuelve a reforzar la idea de la falta de relación entre las etapas mencionadas, así como se aporta credibilidad a nuestra propuesta por enfocarse esta cuestión desde la rigurosidad académica. 
Diseño y planificación de competencias específicas en el currículum de enseñanzas profesionales de música: modalidades composición-dirección en la enseñanza superior.

A quien corresponda,

En mi nombre, Fernando Ferrer Martínez con DNI 25.389.566G, con mi seudónimo Ferrer Ferran, compositor, director, director de "Allegro Centro Musical" y profesor en el Conservatorio Profesional de Valencia y más de veinte años de experiencia como Catedrático de Composición en el Conservatorio Superior de Castelló, entiendo del mismo modo que D. Carlos Pascual la falta de relación que existe entre la etapa profesional y los distintos grados superiores de que disponemos en la actualidad.

El curriculum actual, en mi opinión, no satisface las necesidades de aquellos alumnos que aspiren a realizar otras pruebas distintas a la de interpretación, y veo plasmada en esta investigación multitud de observaciones y comentarios que desde años se han viniendo haciendo al respecto, pero que no se habían abordado desde un prisma académico y riguroso. Por tanto, estoy seguro que sus resultados arrojarán luz en este aspecto y sobretodo planteará alternativas y opciones siempre en pos de la mejora permanente de nuestros ahora estudiantes y en un futuro músicos de nuestra tierra.

Por último, quiero manifestar que conociendo como conozco personal y profesionalmente a Carlos Pascual, no me cabe duda de que su planteamiento de las propuestas curriculares alternativas en el ámbito de la Composición y la Dirección, así como su estudio analítico han sido y serán las más acertadas y veraces. Seguro que esta tesis será una destacable aportación reivindicativa a nuestra comunidad, desde la lógica y la necesidad, tal y como se ha planteado.

Cordialmente,

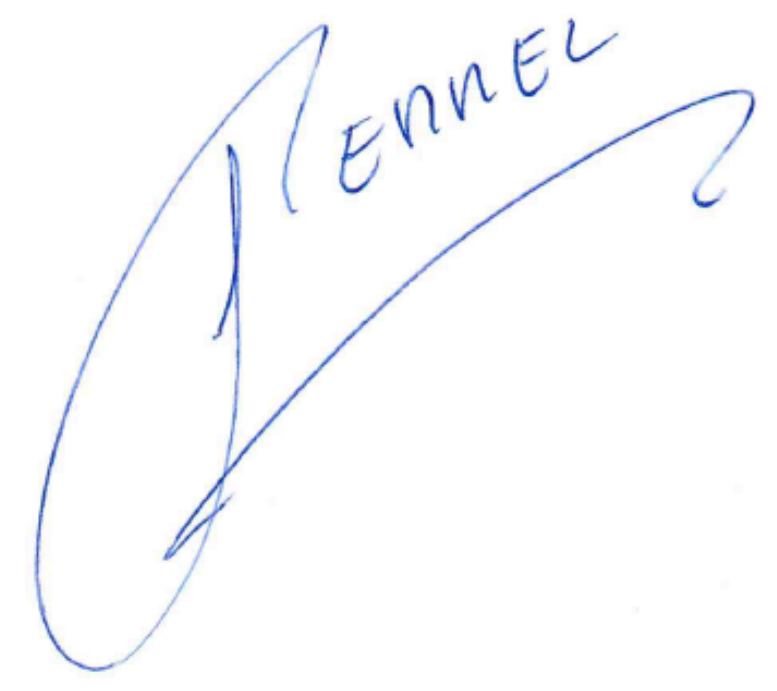


El tercer testimonio, a cargo del Dr. Luis Vallés - profesor de Conservatorio Profesional Francesc Peñarroja de Vall d’Uixó - valora muy positivamente nuestra investigación, así como proporciona un nuevo prisma de enfoque a los resultados que esperamos obtener, donde más allá de mejorar la relación curricular entre etapas aportemos nuevos perfiles profesionales a aquel alumnado que no desee continuar con los estudios superiores.

Un cuarto testimonio de la compositora y Catedrática de Composición en el Conservatorio Superior de Valencia $\mathrm{D}^{\mathrm{a}}$. Claudia Montero, reconoce y avala nuevamente nuestra investigación, así como pone de manifiesto su experiencia en primer término respecto a la situación que se da en las pruebas de acceso a las Enseñanzas Superiores, las cuales suponen un descarte de alumnos injustificado al darse la manifiesta inconexión curricular entre etapas. 
Diseño y planificación de competencias específicas en el currículum de enseñanzas profesionales de música: modalidades composición-dirección en la enseñanza superior.

Carlos Eduardo Pascual Pérez

Sr. Dr. Carlos Eduardo Pascual Pérez

Estimado Sr.,

Valoro muy positivamente su investigación en torno al acceso a las Enseñanzas Superiores de Música en España, tanto por sus aportaciones como por el debate que abre. Considero muy importante que se discuta y reflexione acerca del sistema educativo musical actual, cuestionando la idoneidad de su organización y acceso a las Enseñanzas Superiores, así como plantear una propuesta de mejora atendiendo a las necesidades actuales, realizando un ejercicio de coherencia misma dentro del propio sistema educativo.

No obstante, si bien cabe pensar en la continuidad y conexión entre las Enseñanzas Profesionales y las Superiores, también es cierto que el acceso al Grado Superior no supone la exigencia de haber superado la etapa anterior, puesto que se prevén otras formas de acceso y superación aparte de la superación de las Enseñanzas Profesionales. Por este motivo, también veo acertado un enfoque profesionalizador de la investigación, al sugerir la creación de itinerarios como ya sucede en algunos documentos autonómicos, y así ofrecer formación para diferentes salidas profesionales de los músicos en el estado anterior a las Enseñanzas Superiores. Esta vía profesionalizadora está obteniendo cada vez más interés dentro de la comunidad educativa.

Por ello, considero que tanto como perspectiva profesional como continuación de los estudios, debería haber una adecuada base de conexión entre las diferentes especialidades previstas en la legislación educativa entre las Enseñanzas Superiores de Música y las Profesionales, cuestión que plantea de manera general para otras titulaciones, y de manera particular en la de Composición y/o Dirección.

Le felicito por su iniciativa y trabajo, y, a la vez, le animo a que siga adelante con su investigación y que, gracias a su propuesta, se abra el debate en la comunidad educativa para su discusión y mejora.

Un cordial saludo,

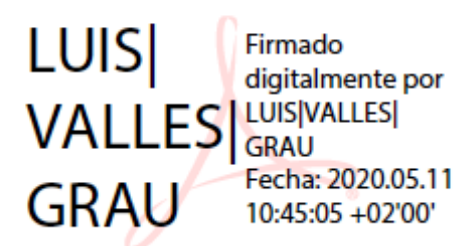




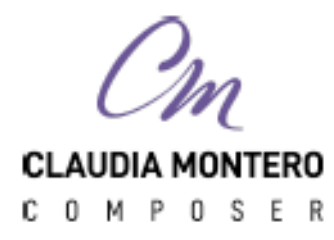

Propuesta de Investigación de Carlos Pascual Perez:

En la actualidad somos muchos docentes de música , que hemos ejercido nuestra función en diferentes niveles nuestras clases.

Para quienes hemos tenido esta experiencia , puedo afirmar en primera persona que hay serias dificultades a la hora de articular las pruebas de ingreso a los Conservatorios Superiores.

En el grado profesional nos encontramos solamente con las especialidades instrumentales, mientras que en el Superior además de las estas especialidades se pueden cursar Composición, Musicología. Dirección de Orquesta y Dirección de Coros, además de las carreras instrumentales y las Pedagogías de las instrumentales

¿Qué nos sucede con estos alumnos ingresantes en las especialidades que no tienen itinerario en el profesional?

Ocurre que las pruebas de acceso puede ser que dejen fuera muchos alumnos que tienen talento, condiciones e ideas pero no han recibido una formación más específica o articulada con estos nuevos itinerarios.

Por esta razón entre otras, veo muy interesante y necesario el trabajo que plantea el Doctorando Carlos Eduardo Pascual Pérez en su tesis doctoral que lleva por título "DISEÑO Y PLANIFICACIÓN DE COMPETENCIAS ESPECÍFICAS EN EL CURRÍCULUM DE ENSEÑANZAS PROFESIONALES DE MÚSICA: MODALIDADES EN LA ENSEÑANZA SUPERIOR", y que está realizando en la Escola de Doctorat de la Universitat Jaume I, en el Departamento de Educación bajo la dirección del Dr. José María Peñalver Vilar y la tutorización de la Dr. María Amparo Porta Navarro. 
Diseño y planificación de competencias específicas en el currículum de enseñanzas profesionales de música: modalidades composición-dirección en la enseñanza superior.

Carlos Eduardo Pascual Pérez

Creo que las aportaciones de su Investigación y Tesis serán de una grandísima utilidad con miras a rediseñar este paso intermedio entre las Enseñanzas Profesionales y Superiores, con clarisimas mejoras tanto para el proceso de evaluación, como para los futuros alumnos de estos niveles y para el profesorado involucrado en la preparación desde las Enseñanzas Profesionales hasta el Profesorado del Conservatorio Superior que recibirá y evaluará a estos alumnos, con el objetivo de formarlos en las Áreas de Composición, Dirección y Musicologia.

Sirva la presente como una carta de apoyo a la propuesta de Carlos Eduardo Pascual Perez-

Claudia Montero

claudiacarmenmonter@gmail.com

tel 630356911

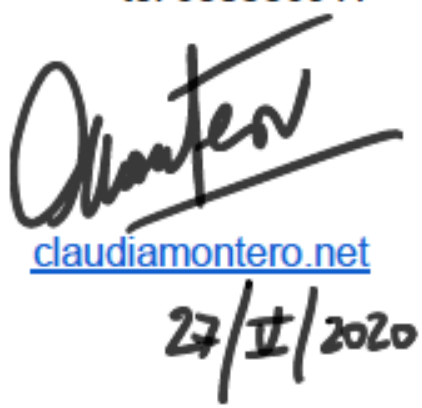

En el quinto testimonio, la Dra. Paloma Mora hace una analogía de nuestra hipótesis con la relación de acceso entre la etapa de bachiller y la prueba de acceso a la universidad, mostrando así cómo debería ser la relación curricular entre etapas. 
Diseño y planificación de competencias específicas en el currículum de enseñanzas profesionales de música: modalidades composición-dirección en la enseñanza superior.

Carlos Eduardo Pascual Pérez

En la actualidad, aquellas personas que deciden dedicarse profesionalmente a la música disponen a nivel de formación y de especialización de muchas más opciones de las que tenían aquellos que les precedieron 50 años atrás, o sin ir más lejos en 1992, cuando el Real Decreto $756 / 1992$ marco el punto de inicio de la transformación de los planes de estudio que ha terminado dando pie al sistema de enseñanzas artísticas, y más concretamente las musicales, que se imparte en estos momentos.

Hoy en día, ese músico que quiere hacerse profesional puede elegir si lo quiere hacer como docente, como director, como intérprete de música clásica o cómo intérprete de música antigua por poner varios ejemplos. Pero cuando le llega la hora de poder tomar esa decisión, la tiene que tomar sin haber tenido la oportunidad de conocer ni mínimamente las diferencias entre sus opciones. ¿Qué curioso verdad? Sería impensable que el alumno que termina $2 \%$ de Bachillerato y quiere estudiar medicina hubiera recibido la misma formación que el que quiere estudiar historia del arte o ingeniería aeroespacial. iQué barbaridad! Estarán pensando. Como van a recibir esos alumnos la misma formación si quieren estudiar cosas tan dispares. Sin embargo, cuando eso mismo está ocurriendo todavía hoy en día en el ámbito de la música, nadie clama al cielo ni se plantea que no tiene nada que ver ser docente en un conservatorio o un intérprete de jazz que se dedica a grabar discos y dar conciertos, por lo que debería de haber alguna diferencia en los itinerarios que ambos músicos siguen antes de comenzar la especialización.

Si bien, más curioso es todavía, que aunque en las Enseñanzas Profesionales solo encontramos una línea de formación, la de interpretación (centrada además por lo general únicamente en la música clásica), las pruebas de acceso a las Enseñanzas Superiores sí que hacen distinción entre las diferentes especialidades. Y este hecho no tiene mucho sentido cuando no has preparado a los alumnos de modo diferente, igual que no tendría sentido que hubiera diferencias en la pruebas de acceso a la universidad, si todos los alumnos hubieran seguido el mismo itinerario durante el Bachillerato.

Por estos motivos, entre otros, veo muy interesante y necesario el trabajo que plantea el Doctorando Carlos Eduardo Pascual Pérez en su tesis doctoral que lleva por título "DISEÑO Y PLANIFICACIÓN DE COMPETENCIAS ESPECÍFICAS EN EL CURRÍCULUM DE ENSEÑANZAS PROFESIONALES DE MÚSICA: MODALIDADES EN LA ENSEÑANZA SUPERIOR", y que está realizando en la Escola de Doctorat de la Universitat Jaume I, en el Departamento de Educación bajo la dirección del Dr. José María Peñalver Vilar y la tutorización de la Dr. María Amparo Porta Navarro.

Y firmo este documento para que así conste en Vila-real, a 6 de mayo de 2020.

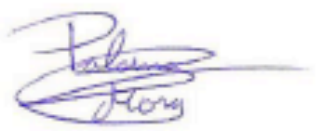

Firmado: Dra. Paloma Mora Goterris

Doctora en Educación por la Universitat Jaume I de Castellón, Máster en Educación Secundaria por la Universitat Jaume I de Castellón, Titulada Superior en Música en la Especialidad de Instrumentos de la Música Tradicional y Popular por la Escola Superior de Música de Catalunya y Diplomada en Arquitectura Técnica por la Universidad Politécnica de Valencia. 
El testimonio del Dr. Emilio Calandín - compositor y Catedrático de Composición en el Conservatorio Superior Salvador Seguí de Castelló - vuelve a avalar nuestra propuesta, así como nuestro perfil y enfoque adecuados, con referencia a los textos académicos que se han desprendido de la presente investigación y nuevamente uniéndose a la necesidad de la misma. 
Diseño y planificación de competencias específicas en el currículum de enseñanzas profesionales de música: modalidades composición-dirección en la enseñanza superior.

Carlos Eduardo Pascual Pérez

EMILIO CALANDIN

Compositor

Catedrático Interino del Conservatorio

Superior de Música de Castellón

Dr. en Música por la Universidad

Politécnica de Valencia

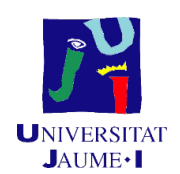

JAUME+ I

\section{A QUIEN CORRESPONDA:}

Carlos Pascual fue durante años alumno mío en el CSMC manteniendo una cercana relación posterior a su graduación en el mismo centro, por lo que he podido seguir de cerca su evolución, la cual ha sido siempre en visible progresión ascendente como preludiaba ya su actitud en las clases. Mostró en todo momento una capacidad de análisis, una implicación en las actividades propuestas muy por encima de lo exigido; atento a las orientaciones que se le daban y con un interés por aprehender fuera de lo habitual.

Ya en su época de estudiante mostraba un claro interés por la adecuación de las pruebas de acceso a los conservatorios superiores a las programaciones docentes desarrolladas en los conservatorios profesionales, mostrando especial interés por las carreras de Composición y Dirección, ambas estudiadas por Carlos Pascual. Este interés ha ido in crescendo con el paso del tiempo como bien queda reflejado tanto en el artículo escrito a la limón con el Dr. José Ma Peñalver Vilar, editado en la revista especializada Epistemus (volumen 7 - número 1 de julio de 2019), como también por el proyecto pedagógico llevado a cabo en el Conservatorio Profesional donde Carlos Pascual desarrolla desde hace años su actividad pedagógica.

Queda muy claro en el citado artículo que actualmente sigue existiendo una real inadecuación entre las pruebas de acceso propuestas por los conservatorios superiores y las enseñanzas recibidas por el alumnado en los conservatorios profesionales. Pensamos que la línea de investigación comenzada por el doctorando, no solo a nivel térico sino, sobre todo, con trabajos de campo que se realizan actualmente, y desde hace unos cursos, en el Conservatorio Calasancio de Música y Danza, deben 
Diseño y planificación de competencias específicas en el currículum de enseñanzas profesionales de música: modalidades composición-dirección en la enseñanza superior.

Carlos Eduardo Pascual Pérez

seguir profundizándose y desarrollándose en nuevas y más exhaustivas investigaciones ya que, sin duda, los resultados aportarán luz y facilitarán, con las modificaciones pertinentes, adecuar tanto las programaciones de los centros profesionales como la preparación a los estudios impartidos en los centros superiores y, por ende, a las pruebas de acceso por estos propuestas; en definitiva una adecuación a una realidad y no a una utopía irreal que en muchos casos provoca la frustración en más de un/a aspirante a los centros superiores, segando así más de una carrera.

En conclusión, consideramos muy oportuna y necesaria la continuación y profundización de la línea de investigación comenzada por el sr. Pascual y que, sin duda, será beneficiosa para la comunidad pedagógica musical y en concreto para una verdadera convivencia entre los centros de nivel profesional y superior de enseñanzas musicales los cuales, en muchos desafortunados casos, viven al margen unos de otros, cuando en realidad deberían ser unos la prolongación natural de los otros, proporcionando así una evolución real y progresiva del alumnado.
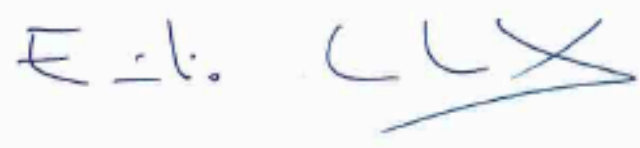

Fdo.: Dr. Emilio Calandín Hernández

Concluiremos la serie testimonial con las referencias del Dr. Vicente Campos, director del Conservatorio Superior de Música Salvador Seguí de Castelló, quien refuerza nuestra 
Diseño y planificación de competencias específicas en el currículum de enseñanzas profesionales de música: modalidades composición-dirección en la enseñanza superior.

Carlos Eduardo Pascual Pérez

propuesta al incidir en la demanda real en perfiles formativos y laborales para las cuales sería favorecedor así como avala además nuestro perfil como compositor y director, y con la del Dr. Oscar Campos, jefe del Departamento de tecla y profesor del Conservatorio Profesional de Música Mestre Tárrega de Castelló, quien sintetiza el objetivo de nuestro estudio como una mejora de calidad en los conservatorios profesionales que facilita la inserción del alumnado en las Enseñanzas Superiores.

El trabajo que plantea el Doctorando Carlos Pascual es muy apropiado en mi opinión porque pone de manifiesto la necesidad de revisar los currículo de Grado Profesional para adaptarlos a la oferta formativa que se ofrece en los Conservatorios Superiores, para que los alumnos que deciden abordar estos estudios tengan la preparación necesaria para superar la prueba de acceso en el itinerario escogido de los muchos que hoy en día se ofrecen.

Sí que es verdad que la tradición que la Comunidad Valenciana tiene con el movimiento bandístico hace que sea muy elevado el numero de alumnos que buscan acceder por el itinerario de Interpretación, pero los mercados cada vez estan demandando nuevas modalidades de trabajo que también obligan a los Conservatorios Superiores a estar al día para ofrecer toda la demanda que nos demandan los mercados. Conozco a Carlos Pascual desde que inicio los estudios de Composición en el Conservatorio Superior de Castellón donde obtuvo el premio extraordinario, también he comprobado personalmente su valía como Director de Orquesta asistiendo a algunas de sus producciones de Opera en el Teatro Principal de Castellón al frente de la Orquesta Lirica.

Castellón a 27 de Agosto de 2020

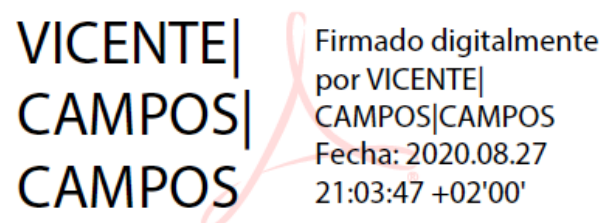

Fdo Vicente Campos

Catedrático de Música y Artes escénicas, Doctor por la Universidad de Valencia d'Estudi General y Director del Conservatorio Superior "Salvador Segui" de Castello. 
Diseño y planificación de competencias específicas en el currículum de enseñanzas profesionales de música: modalidades composición-dirección en la enseñanza superior.

Carlos Eduardo Pascual Pérez

Oscar Campos Micó, doctor por la Universidad Jaume I de Castelló, jefe del Departamento de Tecla y profesor en el Conservatorio Profesional de Música de Castelló, hago constar que,

habiendo leído y analizado la síntesis de la investigación emprendida por el doctorando Carlos Eduardo Pascual Pérez, que lleva por título Diseño y planificación de competencias especificas en el currículum de enseñanzas profesionales de música: modalidades en la enseñanza superior, avalo dicha investigación al considerar que sus resultados muestran un claro interés y trascendencia para la comunidad educativa en el ámbito de los conservatorios del Estado.

Se trata de un estudio que testimonia la carencia de correspondencia curricular y competencial entre los centros profesionales y superiores de música a nivel nacional. Dicha carencia queda demostrada por el doctorando partiendo del análisis de la legislación vigente que regula las pruebas de acceso a las enseñanzas superiores en las diferentes comunidades, y la comparación de los contenidos de dichas pruebas con los contenidos curriculares de las Enseñanzas Profesionales. El resultado, tal como indica en sus conclusiones Carlos Eduardo Pascual, denota una escasa adecuación curricular y adaptativa entre las Enseñanzas Profesionales y Superiores.

La investigación se focaliza en las especialidades de composición y dirección de orquesta, elección que queda justificada al ajustarse al perfil del doctorando. Visto el currículum del Carlos Eduardo Pascual, considero muy apropiada la elección de las mencionadas especialidades para este trabajo. Desde mi punto de vista, los conocimientos adquiridos por el doctorando en el ámbito compositivo, así como su amplia experiencia y destreza en la dirección de orquestas tanto a nivel nacional como internacional, lo convierten en un investigador suficientemente versado en dichos ámbitos para emprender un estudio científico y técnico con garantías de éxito. 
Diseño y planificación de competencias específicas en el currículum de enseñanzas profesionales de música: modalidades composición-dirección en la enseñanza superior.

\section{Carlos Eduardo Pascual Pérez}

Por otra parte, la investigación acometida por Carlos Eduardo Pascual deja abiertas futuras líneas de investigación que podrán ser abordadas y desarrolladas en futuros trabajos. Entiendo que el objetivo principal de este estudio es, por lo tanto, favorecer y mejorar la calidad de las enseñanzas de música en los conservatorios profesionales y facilitar la inserción de sus alumnos a las enseñanzas superiores. Ello queda justificado a través de una propuesta que incluye líneas curriculares diversas, además de la propiamente interpretativa contemplada por la legislación, que tienden puentes a las enseñanzas superiores con el fin de lograr el máximo aprovechamiento de dichas enseñanzas.

Glasgow, a 26 de Junio de 2020.

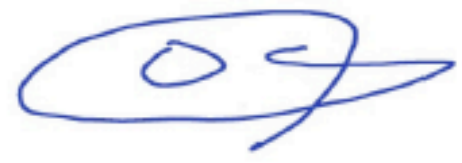

Fdo. Oscar Campos Micó

\subsection{Legislación y análisis metodológico}

Aunque la raíz de nuestro sistema educativo se halla en las Leyes y Reales Decretos, al estar transferidas las competencias curriculares y en materia de ordenación a las administraciones autonómicas, nuestras principales fuentes de datos serán los Decretos y Órdenes. Partimos 
Diseño y planificación de competencias específicas en el currículum de enseñanzas profesionales de música: modalidades composición-dirección en la enseñanza superior.

Carlos Eduardo Pascual Pérez

de una Ley General de Educación (LOE) y de sus derivados Real Decreto 1577/2006, que regula los aspectos básicos del currículum en Enseñanzas Profesionales y el Real Decreto 1614/2009, que rige la ordenación de las Enseñanzas Artísticas Superiores. Por tanto, disponemos fundamentalmente de estos dos continentes de los cuales se desprenderán en el territorio de las Autonomías las concreciones pertinentes. Derivándose de ellos el entramado legislativo autonómico ha alumbrado 18 decretos o resoluciones alusivos a lo curricular de las enseñanzas profesionales y 15 sendos documentos para el sistema de acceso a las enseñanzas superiores, y dado que el análisis documental de dichos documentos nos remite en muchos casos a la autonomía de los propios conservatorios, se genera la obligada inclusión de más documentos a nuestro análisis - los propios de cada conservatorio superior de nuestro país referentes a la normativa y condiciones para el acceso a los mismos -, generando una casuística impredecible en cuanto a la finalización de estudios profesionales en cualquier centro de nuestro país y el acceso a cualquier otro centro también nacional.

Tal y como versa el Real Decreto 1614/2009, las autonomías - mediante las citadas Órdenes y Decretos- confiarán a las comisiones designadas por los Centros Superiores el diseño y publicación de las distintas pruebas de acceso, bien sea unilateralmente para cada Centro o a nivel de Autonomía mediante una Resolución o Instrucción, la cual establecería las mismas características para todos los Centros Superiores de la comunidad autónoma.

Llegados a este punto, nuestra revisión de los citados documentos de todos los Conservatorios Superiores de Música y aquellos que se desprenden de las administraciones 
Diseño y planificación de competencias específicas en el currículum de enseñanzas profesionales de música: modalidades composición-dirección en la enseñanza superior.

autonómicas de las Enseñanzas Superiores de nuestro país pone claramente de manifiesto dos posturas análogas en cuanto a la definición de los criterios de acceso; potestativamente, la adecuación de dichas pruebas a la continuidad de la etapa anterior, o legislativamente, el libre diseño de dichas pruebas. Del mismo modo, incidiendo sobre el perfil profesional del investigador principal del presente texto, analizaremos las propuestas de prueba de acceso para las especialidades de Composición y Dirección, que además están intrínsecamente vinculadas a nivel curricular. Por último, clarificamos que en este análisis obviaremos las pruebas que son comunes a todas las especialidades, siendo estas la interpretación de repertorio en el instrumento del aspirante y el ejercicio de análisis escrito de partitura, puesto que estas sí que tienen correspondencia curricular con las Enseñanzas Profesionales, y por tanto no son susceptibles de incurrir a priori en una discontinuidad.

\subsection{De los aspectos curriculares en las Enseñanzas Profesionales}

En País Vasco, Navarra, Cataluña y Comunidad Valenciana no existe ninguna variación del itinerario o currículum en las enseñanzas profesionales más allá del que dicta como base el Real Decreto 1577/2006, aunque con matices como la existencia de asignaturas optativas que en el caso de la Comunidad Valenciana especifica algunas como de obligada oferta -, entre las que se puede encontrar Fundamentos de composición (Decreto 25/2008, p.8328; Decreto 158/2007, p.37008; Decreto 229/2007, p.5704; Decreto Foral 21/2007, p.4940). 
Diseño y planificación de competencias específicas en el currículum de enseñanzas profesionales de música: modalidades composición-dirección en la enseñanza superior.

Los centros profesionales de Aragón, Extremadura, Castilla y León, Cantabria, Illes Balears, La Rioja, Murcia, Asturias, Ceuta y Melilla, atendiendo a los Decretos y Órdenes que rigen sus enseñanzas, tienen en común un perfil de diversificación, pero que atiende únicamente a escoger entre la asignatura Análisis o Fundamentos de composición en el último curso de las Enseñanzas Profesionales (Orden de 3 de mayo, 2007, p.8741; Decreto 111/2007, p.9586; Decreto 126/2007, p.13264; Decreto 60/2007, p.291; Decreto 53/2011, p.15; Orden ECI/1890/2007 de 19 de junio, p.27816).

Ocurre algo similar para los conservatorios de Castilla-La Mancha (Decreto 76/2007, p.16975), donde se propone tres perfiles para el último curso, uno de los cuales incluye la asignatura de Fundamentos de composición, siendo los otros dos una selección concreta de optativas. No obstante, entendemos este desarrollo como un posibilitador de mejora organizativa de centro que como una oferta curricular competencial.

Con un planteamiento muy distinto, para la Comunidad de Madrid existen perfiles definidos para los últimos dos cursos de las Enseñanzas Profesionales: Instrumento, Jazz, Composición, o Música antigua (Decreto 30/2007, p.11-40). Esta medida de diversificación es en nuestra opinión más adecuada que las alternativas que presentan el resto de autonomías, aunque para poder ser un modelo extrapolable a nivel nacional debería mantener una relación completa con las especializaciones de las Enseñanzas Superiores, ya que deja sin itinerario a futuros aspirantes a los Grados en Dirección o Sonología, entre otros. 
Diseño y planificación de competencias específicas en el currículum de enseñanzas profesionales de música: modalidades composición-dirección en la enseñanza superior.

En Galicia sí que encontramos una especialización más orientada a las especialidades superiores, pero únicamente en el último curso y mediante los itinerarios de Interpretación, Composición, Pedagogía y Musicología. Nuevamente quedan especialidades fuera del enfoque de la diversificación - Dirección, Jazz o Sonología, entre otras -, y además entendemos que reduciéndose la especialización a este único curso podría quedar deficiente la adquisición de las competencias necesarias (Decreto 203/2007, p.17470).

En Canarias disponen unos itinerarios agrupados para el último ciclo (los dos últimos cursos) de las enseñanzas profesionales que desvelan un enfoque profesional/laboral en lugar de una especialización para la continuidad de los estudios. Dichos itinerarios son Interpretación, Composición, musicología y pedagogía, Cívico-social y Tecnológico (Decreto 364/2007, p.23609).

Por último, los centros profesionales en Andalucía proponen cuatro itinerarios para los dos últimos cursos de las enseñanzas, los cuales aglutinan diversas materias para lograr una diversificación, pero no orientados por completo a las enseñanzas superiores, siendo estos Composición, Análisis - enfocado a la interpretación y la pedagogía -, Teoría y un itinerario Mixto (Decreto 241/2007, p.17) "para quienes aun no tengan claras sus opciones futuras". Nuevamente se evidencia la dicotomía que existe a nivel nacional en cuanto a escoger entre las asignaturas Composición y Análisis, elección acompañada en este caso de otras materias no troncales afines, y con una alternativa en el itinerario Teoría, aunque que incluye prácticamente las mismas asignaturas que el itinerario de Composición. 
Diseño y planificación de competencias específicas en el currículum de enseñanzas profesionales de música: modalidades composición-dirección en la enseñanza superior.

Carlos Eduardo Pascual Pérez

\begin{tabular}{|c|c|c|c|c|}
\hline Autonomías & $\begin{array}{l}\text { Sin itinerarios } \\
\text { (selección de } \\
\text { optativas en el } \\
\text { último ciclo) }\end{array}$ & $\begin{array}{l}\text { Selección } \\
\text { entre dos } \\
\text { asignaturas } \\
\text { en último } \\
\text { curso }\end{array}$ & $\begin{array}{c}\text { Cuatro } \\
\text { itinerarios } \\
\text { en último } \\
\text { curso }\end{array}$ & $\begin{array}{c}\text { Cuatro } \\
\text { itinerarios } \\
\text { en último } \\
\text { ciclo }\end{array}$ \\
\hline Andalucía & $\sqrt{ }$ & & & \\
\hline Aragón & & $\sqrt{ }$ & & \\
\hline Principado de Asturias & & $\sqrt{ }$ & & \\
\hline Islas Baleares & & $\sqrt{ }$ & & \\
\hline Canarias & & & & $\sqrt{ }$ \\
\hline Cantabria & & $\sqrt{ }$ & & \\
\hline Castilla-La Mancha & & $\sqrt{ }$ & & \\
\hline Castilla y León & & $\sqrt{ }$ & & \\
\hline Cataluña & $\checkmark$ & & & \\
\hline Comunidad Valenciana & $\sqrt{ }$ & & & \\
\hline Extremadura & & $\checkmark$ & & \\
\hline Galicia & & & $\checkmark$ & \\
\hline La Rioja & & $\sqrt{ }$ & & \\
\hline Comunidad de Madrid & & & & $\sqrt{ }$ \\
\hline Región de Murcia & & $\sqrt{ }$ & & \\
\hline C. Foral de Navarra & $\checkmark$ & & & \\
\hline País Vasco & $\checkmark$ & & & \\
\hline Ceuta & & $\checkmark$ & & \\
\hline Melilla & & $\sqrt{ }$ & & \\
\hline
\end{tabular}

Tabla 1. Relación organizativa en las Enseñanzas Profesionales por autonomías (elaboración propia). 


\subsection{De las pruebas de acceso a las Enseñanzas Superiores}

En los centros superiores de Andalucía, como primer ejemplo, se dispone para el acceso a Composición (Orden de 18 de abril de 2012, p.10) que "la prueba específica de acceso a estos estudios se llevará a cabo para cada especialidad y tendrá como finalidad valorar la madurez, los conocimientos y las aptitudes para cursar con aprovechamiento estas enseñanzas”. La clave de su adecuación está en la cita "con aprovechamiento", la cual trata de otorgar una continuidad con la etapa anterior. Prueba de ello es el ejercicio dispuesto para la prueba de Composición, consistente en la (p.22) "realización de un trabajo armónico-contrapuntístico, de una extensión aproximada de dieciséis compases con bajo/tiple dados, disponiendo la persona aspirante de un tiempo de tres horas para su elaboración", dado que los conocimientos exigidos para dicha realización deben estar adquiridos por los aspirantes en el momento en que superan las enseñanzas profesionales, al ser dichas pruebas en su totalidad correspondientes curricularmente. No obstante, (p.22) la prueba también contará con una parte consistente en la "presentación y defensa oral de obras y trabajos realizados por la persona aspirante", lo cual implica que el aspirante a los estudios superiores de Composición cuente previamente con competencias en dicha materia - la cual analizaremos más adelante - así como con material de autoría propia. Por otro lado, para el acceso a las enseñanzas de Dirección de orquesta, además del ya citado trabajo armónico-contrapuntístico en la prueba de composición, se sustituye la defensa de obras por una prueba de (p.22) "audición comentada de un fragmento orquestal que incluya tímbrica, estilo y la reproducción escrita 
Diseño y planificación de competencias específicas en el currículum de enseñanzas profesionales de música: modalidades composición-dirección en la enseñanza superior.

de algún motivo o frase" donde se evidencia, entre otras, la habilidad necesaria de relacionar la audición y escritura de instrumentos orquestales.

De un modo similar a los centros de Andalucía, para el Real Conservatorio Superior de Música de Madrid (Orden 2369/2011, p.59) se incide en que "el nivel de dificultad exigido para la prueba será el equivalente al alcanzado al final de las asignaturas de "Análisis" y/o "Fundamentos de Composición" de las Enseñanzas Profesionales". Al igual que ocurre para los centros de Extremadura, se establece el marco de correspondencia, pero se declina la decisión final en el centro citándose (Orden de 9 de mayo de 2013, p.11396) que "el nivel técnico y estructural de la prueba teórico práctica será el de $6^{\circ}$ de Enseñanzas Profesionales". Por tanto, para los centros de sendas comunidades no se exige para las pruebas de composición o dirección otros contenidos extracurriculares a los de las Enseñanzas Profesionales.

Por el contrario, en las disposiciones dictadas para el Conservatorio Superior de Música de Aragón, la prueba para acceso a Composición constará (Orden 15 de abril de 2013, p.9125) de un

“ejercicio de composición e instrumentación en el que puede haber instrumentos transpositores, para la evaluación de conocimientos y capacidades del aspirante $[\ldots]$ y una entrevista donde cada aspirante presentará y defenderá ante el tribunal composiciones propias" 
Diseño y planificación de competencias específicas en el currículum de enseñanzas profesionales de música: modalidades composición-dirección en la enseñanza superior.

Carlos Eduardo Pascual Pérez

En este caso, y de igual modo que en la ya citada parte de la prueba en los centros superiores de Andalucía, las capacidades y conocimientos a evaluar no se encuentran en lo estrictamente curricular de las enseñanzas profesionales - con salvedad de si se ha cursado o no una optativa específica en dichas enseñanzas -, ni tampoco la obligatoriedad de disponer de composiciones propias para puntuar en dicha prueba de acceso. Siguiendo esta línea, para la prueba de acceso a Dirección de Orquesta del CSM de Aragón existe una parte específica (Conservatorio Superior de Música de Aragón, 2018, p.1). consistente en una “instrumentación/orquestación para plantilla de orquesta clásica un fragmento de menos de 10 compases perteneciente a una obra de piano clásica. Plantilla: 2,2,2,2-2,2,0,0-timp.cuerdas". La realización de esta prueba exige al aspirante disponer de conocimientos muy avanzados referentes a la instrumentación orquestal, que son completamente ajenos a los contenidos curriculares actuales en las distintas comunidades autónomas, y ni tan siquiera los encontramos en los contenidos de una asignatura optativa tan afín a dicha prueba como lo es Fundamentos de Composición.

Hallamos un caso similar de no correspondencia entre etapas en el acceso al Centro Superior de Música del País Vasco Musikene, en el que (Musikene, 2017, p.2-4) además de una "realización de obra libre instrumental de hasta cuatro instrumentos basada en el material que proponga el tribunal", la prueba consta de una "presentación oral de hasta 30 minutos en la que el aspirante responderá a preguntas planteadas por el tribunal en relación al proceso de composición y análisis de sus obras, así como sus conocimientos, su trayectoria artística y sus intereses artísticos”. Respecto al acceso a Dirección, disponen una 
Diseño y planificación de competencias específicas en el currículum de enseñanzas profesionales de música: modalidades composición-dirección en la enseñanza superior.

Carlos Eduardo Pascual Pérez

"reducción al piano de un fragmento orquestal breve (con una plantilla de cuerda e instrumentos de viento, incluidos transpositores), un dictado polifónico a cuatro voces y una prueba práctica de dirección de dos breves piezas, una instrumental y otra vocal, que se comunicarán a los o las aspirantes en el día del examen.”

También en esta línea de exigencia, la Escola Superior de Música de Catalunya dispone para la prueba de acceso a Composición (Escola Superior de Música de Catalunya, 2018) “escribir un pasaje musical y la instrumentación de dicho ejercicio para un grupo de instrumentos dado (tipo orquesta clásica), entre los cuales puede haber instrumentos transpositores”. Es más, incide también en los criterios de evaluación de dicha prueba siendo críticos en "se valorará el uso correcto de los instrumentos, la idoneidad de las frases y los registros en cada caso, las dinámicas y tipo de ataque y la corrección en las partes transportadas”, o incluso que el aspirante "sepa desarrollar nuevas partes y figuraciones como arpegios, escalas, glisandi, trinos, tremolos, octavaciones y refuerzos", así como "se valorará el sentido del timbre, la adecuación y equilibrio de las combinaciones instrumentales". Además de esta prueba, también se vuelve a exigir la presentación de obras compuestas por el aspirante, valoradas hasta con un $30 \%$ de la calificación final. Para la prueba específica de acceso a dirección de orquesta en dicho centro se incluye, entre otras, "una armonización a cuatro voces y una instrumentación de dicha armonización para una plantilla instrumental dada" (Escola Superior de Música de Catalunya, 2018), poniendo de manifiesto una vez más la necesidad de adquisición de habilidades específicas en los aspirantes las cuales no existen curricularmente en las Enseñanzas Profesionales. 
En el Conservatorio Superior de Música de Castilla-La Mancha se propone como parte del acceso a Composición un "análisis y reconocimiento auditivo de parámetros estructurales, armónicos o instrumentales, a partir de una serie de fragmentos de diferentes autores propuestos por el tribunal", además de "realizar por escrito las partes eliminadas, de hasta un máximo de 10 compases en total, de una composición propuesta por el tribunal, completando estos espacios de una manera libre, pero atendiendo a las cuestiones de coherencia técnica, estilística y motívica propias de cada fragmento" (Conservatorio Superior de Castilla-La Mancha, 2018, p.1) Esta prueba se completará con la “presentación de obras compuestas por el aspirante y su defensa e identificación de varios fragmentos de distintas partituras de las cuales se habrá eliminado el título y el autor. El candidato irá observando y exponiendo sobre la marcha aquellas cuestiones que puedan atribuirse a un estilo o escuela compositiva determinada" (p.2). Para la prueba de acceso a Dirección, además de las partes exigidas para la de Composición se incluye una prueba de gesto, consistente en la "dirección de una breve pieza instrumental o vocal propuesta por el Tribunal. La prueba de gesto se realizará con un piano o con un pequeño conjunto instrumental.” (p.3-4).

En la prueba específica de Composición para el Conservatorio Superior de Castilla y León podemos encontrar un caso similar a la ya descrita anteriormente para varias comunidades autónomas, siendo la "realización de una prueba de escritura de naturaleza armónicocontrapuntística, que constará de uno o más ejercicios propuestos por el tribunal" 
Diseño y planificación de competencias específicas en el currículum de enseñanzas profesionales de música: modalidades composición-dirección en la enseñanza superior.

(Conservatorio Superior de Castilla y León, 2018, p.3), y que de igual modo no especifica sus contenidos ni la posible correlación a nivel curricular con las Enseñanzas Profesionales.

Para el acceso a Composición en Canarias se exige la "presentación de, al menos, dos obras originales. El examinando hará una breve presentación de las obras y responderá a las preguntas del tribunal”, y también la "realización de un trabajo armónico-contrapuntístico en las condiciones que determine el tribunal, a escoger entre un coral a 4 voces sobre melodía dada o un acompañamiento pianístico a una melodía dada". (Resolución, de 25 de mayo de 2011, p.13995-13996).

Asturias ofrece una escueta información para su prueba de acceso a Composición, siendo "la realización de un ejercicio contrapuntístico", pero en otra parte de la prueba exigirá la “presentación y defensa de obras y trabajos” (Resolución de 16 de marzo de 2017, p.10), con la exigencia de tener que interpretarlas, cosa ciertamente incongruente como requisito (salvo en el caso de que las obras presentadas sean para un instrumento dominado por el aspirante). De un modo similar, en Galicia se dispone este mismo criterio para la prueba de Composición (sin la obligatoriedad de interpretarlas), y para la prueba de Dirección los contenidos sí que se vinculan curricularmente con las Enseñanzas Profesionales sin exigir otras capacidades o habilidades en los aspirantes (Orden de 21 de noviembre de 2016, p.53231-53234).

En la región de Murcia, para el acceso a Composición se exige una "realización, a partir de un arranque propuesto por el tribunal, de un pasaje musical con textura armónica o armónico- 
Diseño y planificación de competencias específicas en el currículum de enseñanzas profesionales de música: modalidades composición-dirección en la enseñanza superior.

Carlos Eduardo Pascual Pérez

contrapuntística para coro mixto o para cuarteto de cuerda, con una extensión mínima de 24 compases y máxima de 36", junto a la "presentación de un mínimo de dos obras o trabajos realizados por el aspirante y debate con el tribunal sobre estos trabajos y sobre el efectuado en la realización" (Resolución de 25 de julio de 2013, p.33092).

En los tres Conservatorios Superiores de la Comunidad Valenciana proponen una fórmula mixta en el acceso a Composición, al contener una parte de la prueba el "análisis estructural de uno o varios fragmentos de un conjunto de obras realizadas por el candidato que presente al tribunal" (Resolución de 8 de mayo de 2012, p.13864). Es decir, que cada aspirante no sólo debe presentar composiciones propias, sino que también deberá analizarlas y defenderlas para valorarse hasta con el $40 \%$ de la calificación final. Sin embargo, para el acceso a Dirección los contenidos exigidos podrían ser curricularmente relacionados con las enseñanzas profesionales (siendo una prueba solfística y una prueba auditiva melódica y armónica), aunque al no disponer los detalles de las mismas podrían incurrir en la no correlación.

Por otro lado, observamos que Baleares todavía no dispone de documento público de desarrollo y contenido de dichas pruebas, y se remite únicamente al Decreto y la Orden de ordenación y currículum, los cuales no ofrecen información detallada del sistema de acceso. Y finalizamos así con La Rioja, Ceuta y Melilla y Cantabria, que al no disponer de Conservatorios Superiores de Música y por tanto de legislación inherente, quedan excluidas de esta revisión. 
Diseño y planificación de competencias específicas en el currículum de enseñanzas profesionales de música: modalidades composición-dirección en la enseñanza superior.

Carlos Eduardo Pascual Pérez

\begin{tabular}{|c|c|c|c|c|}
\hline & $\begin{array}{l}\text { Normativa } \\
\text { autonómica }\end{array}$ & $\begin{array}{c}\text { Normativa } \\
\text { transferida } \\
\text { a los } \\
\text { centros }\end{array}$ & $\begin{array}{c}\text { Correspondencia } \\
\text { con las EEPP } \\
\text { (Composición) }\end{array}$ & $\begin{array}{c}\text { Correspondencia } \\
\text { con las EEPP } \\
\text { (Dirección) }\end{array}$ \\
\hline Andalucía & $\sqrt{ }$ & & Parcial & Parcial \\
\hline Aragón & & $\checkmark$ & Ninguna & Ninguna \\
\hline $\begin{array}{r}\text { Principado de } \\
\text { Asturias }\end{array}$ & $\checkmark$ & & Parcial & - \\
\hline Islas Baleares & ¿? & ¿? & ¿? & ¿? \\
\hline Canarias & $\checkmark$ & & Parcial & - \\
\hline Cantabria & \multicolumn{4}{|c|}{ No dispone de ningún conservatorio superior } \\
\hline Castilla-La Mancha & & $\checkmark$ & Parcial & Parcial \\
\hline Castilla y León & & $\sqrt{ }$ & Parcial & Parcial \\
\hline Cataluña & & $\sqrt{ }$ & Ninguna & Ninguna \\
\hline $\begin{array}{l}\text { Comunidad } \\
\text { Valenciana }\end{array}$ & $\sqrt{ }$ & & Parcial & ¿Total? \\
\hline Extremadura & $\sqrt{ }$ & & Total & - \\
\hline Galicia & $\sqrt{ }$ & & Parcial & Total \\
\hline La Rioja & \multicolumn{4}{|c|}{ No dispone de ningún conservatorio superior } \\
\hline $\begin{array}{r}\text { Comunidad de } \\
\text { Madrid }\end{array}$ & $\checkmark$ & & Total & Total \\
\hline Región de Murcia & $\sqrt{ }$ & & Parcial & Parcial \\
\hline C. Foral de Navarra & $\sqrt{ }$ & & Parcial & - \\
\hline País Vasco & & $\sqrt{ }$ & Ninguna & Ninguna \\
\hline Ceuta & \multicolumn{4}{|c|}{ No dispone de ningún conservatorio superior } \\
\hline Melilla & \multicolumn{4}{|c|}{ No dispone de ningún conservatorio superior } \\
\hline
\end{tabular}

Tabla 2. Relación organizativa de la normativa referente a las pruebas de acceso y de su correspondencia curricular con las Enseñanzas Profesionales por autonomías (elaboración propia). 
Carlos Eduardo Pascual Pérez

\subsection{Conclusiones preliminares}

Tras el análisis del estado de la cuestión encontramos un panorama de lo más variado, que oscila desde una prueba de acceso adecuada a los contenidos curriculares de las enseñanzas profesionales hasta la necesidad de aspirantes con el nivel, las capacidades y los conocimientos casi propios de haber cursado parcialmente estudios superiores en dichas materias.

Es cierto que en los aspectos curriculares de las enseñanzas profesionales encontramos una dicotomía generalizada al respecto de la leve diversificación u orientación del último curso - o en el mejor del último ciclo, es decir los últimos dos cursos - que recae esencialmente en la elección de la materia "Análisis" para los aspirantes a un Grado de Interpretación o "Fundamentos de Composición" para el resto de aspirantes a otros Grados (aunque estos también deberán enfrentarse a una prueba específica de análisis, lo cual incurre nuevamente en otra incongruencia). Reforzando esta tendencia, encontramos casi a partes iguales las autonomías que no diversifican el currículum y las que sí lo hacen ofreciendo itinerarios más concretos y en cierto modo orientados a las modalidades superiores.

Sin embargo, desde nuestra perspectiva profesional en el ámbito de la Composición y la Dirección de orquesta, no podemos entender una diversificación que obligue a escoger entre dos materias tan necesarias para este perfil como son el Análisis musical y los Fundamentos de Composición, hecho que hallamos en más de la mitad de las comunidades autónomas de 
Diseño y planificación de competencias específicas en el currículum de enseñanzas profesionales de música: modalidades composición-dirección en la enseñanza superior.

Carlos Eduardo Pascual Pérez

nuestro país. Consideramos ambas materias como imprescindibles para el correcto desarrollo profesional de un músico independientemente de cual sea su perfil (instrumentista, compositor, director, musicólogo, etc...), teniendo mayor importancia si cabe dado que en todas las pruebas de acceso a Enseñanzas Superiores habrá una parte específica de análisis. En cualquier caso, esta elección de itinerario obliga únicamente a los estudiantes a disponerse organizativamente en dos grupos, sin clarificar como se dividen los futuros perfiles profesionales.

\section{Desarrollo curricular por Autonomías}

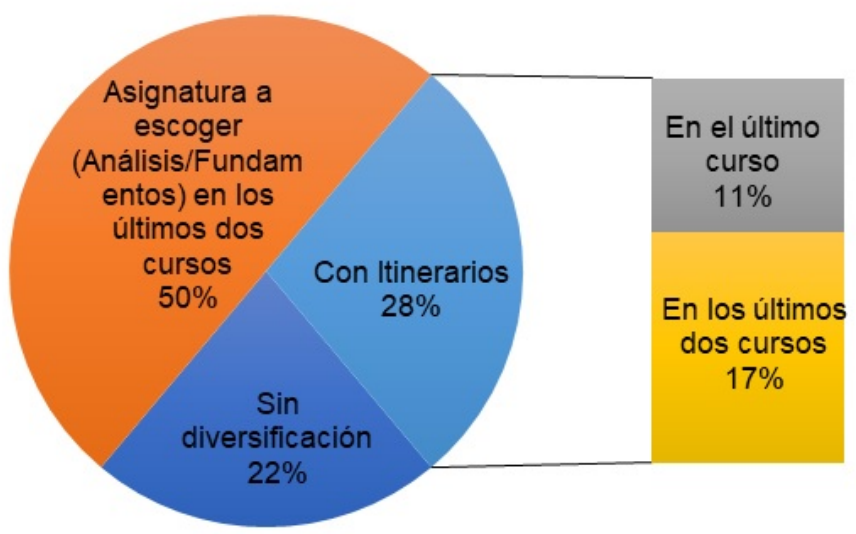

Figura 2. Comparativa del desarrollo curricular diversificado por autonomías (elaboración propia).

Por otro lado, esta revisión pone de manifiesto la práctica no existencia curricular ni adaptativa en las Enseñanzas Profesionales en lo que a al enfoque hacia las especializaciones en Sonología, Producción y Gestión o Jazz se refiere. Al no ser el nuestro un perfil 
Diseño y planificación de competencias específicas en el currículum de enseñanzas profesionales de música: modalidades composición-dirección en la enseñanza superior.

especializado en dichas áreas no debemos realizar un juicio complementario académico, pero sí podemos comprobar colateralmente que revisados los contenidos de las pruebas de acceso a dichas especialidades se exigen habilidades y conocimientos (informática musical, matemáticas o física acústica, entre otras) que no están incluidos en el currículo común de las enseñanzas profesionales ni tampoco en la mayoría de materias optativas o de diversificación propuestas en algunas comunidades autónomas.

Además de confirmarse la hipótesis que planteábamos como motivación de la presente investigación - referida a la no adecuación entre lo curricular al finalizar una etapa y lo exigido para acceder a la siguiente -, se evidencia tras este análisis la inexistencia de un criterio común ni correlativo a nivel nacional. Llegados a este punto debemos presuponer la movilidad geográfica del alumnado a nivel nacional, aquel que quiere acceder a las enseñanzas superiores en un determinado centro (motivado principalmente por no existir en todas las autonomías conservatorios superiores, ni estos disponer de oferta o plazas en todos los grados, al igual que ocurre en el ámbito de las Universidades), pero que se ha formado en el conservatorio que le ha facilitado el área geográfica de su lugar de residencia entre los 12 y 18 años ordinariamente. Dicho alumnado, dada la citada variedad curricular autonómica, habrá tenido mayores o menores oportunidades de enfocar y especializar el acceso a su futuro profesional, y este hecho será condicionante, si no determinante, en el momento de acometer una prueba de acceso a un grado superior. 
Diseño y planificación de competencias específicas en el currículum de enseñanzas profesionales de música: modalidades composición-dirección en la enseñanza superior.

Carlos Eduardo Pascual Pérez

Quedaría en nuestra opinión pendiente, no como una línea de posible futura investigación, sino como una revisión administrativa común nacional del desarrollo curricular de las Enseñanzas Profesionales, la normalización en la diversificación de dichas enseñanzas hacia los vigentes títulos superiores, con objeto de garantizar una equidad de la enseñanza y las correctas competencias específicas del alumnado en sus distintos perfiles académicos y profesionales. 


\section{Propuesta metodológica y curricular para las especialidades}

\section{de Composición y Dirección en la Comunidad Valenciana}

De un modo autónomo y compatible con el cumplimiento del currículum existente para cada región planteamos como una alternativa a lo establecido la diversificación competencial del mismo en las materias comunes de los planes de estudio, bien sea en las asignaturas previas a la diversificación que ya proponen algunas autonomías o en todo el currículum en los casos que no se atiende todavía. No es por tanto una propuesta que sustituye al actual currículo dispuesto en las diferentes Órdenes y Decretos autonómicos, sino que lo articula mediante las competencias específicas que se pueden obtener tras el estudio de la correspondencia entre las etapas profesional y superior -como en nuestro caso hemos completado bajo los perfiles de la Composición y la Dirección-.

\subsection{Competencias requeridas para el acceso al grado superior}

Tras el análisis de los requisitos específicos en las pruebas de acceso a dichas especialidades para los distintos conservatorios superiores de España, podemos concretar una reducción a mínimos comunes con tal de enumerar las Competencias Específicas requeridas en su conjunto.

I. Análisis auditivo estructural, tímbrico y estilístico. 
Diseño y planificación de competencias específicas en el currículum de enseñanzas profesionales de música: modalidades composición-dirección en la enseñanza superior.

II. Instrumentación para voz sola acompañada y coral.

III. Armonización contrapuntística.

IV. Aspectos básicos de la composición.

V. Reproducción escrita de fragmentos melódicos y polifónicos de hasta cuatro voces a partir de una escucha orquestal.

VI. Organología, instrumentación y orquestación en el ámbito de la orquesta sinfónica.

VII. Aspectos básicos de la técnica de dirección.

Llegamos a estos siete ítems sintetizando las características y enunciados de dichas pruebas para agruparlas de forma lógica y sintáctica. De este modo podremos cotejarlas con los contenidos curriculares y concretar cuales quedan ajenas y por tanto deben ser abordadas transversalmente en el diseño de nuestra propuesta curricular.

\subsection{El plan de estudios en las enseñanzas profesionales de música en la Comunidad Valenciana}

El Decreto 158/2007 de 21 de septiembre es el documento legislativo que rige prácticamente todos los aspectos de las Enseñanzas Profesionales de música en la Comunidad Valenciana. Además de este decreto coexisten la Orden 49/2015 de 14 de mayo referente a los aspectos de admisión y ordenación general de todas las enseñanzas artísticas de música y danza y otras 
Diseño y planificación de competencias específicas en el currículum de enseñanzas profesionales de música: modalidades composición-dirección en la enseñanza superior.

Carlos Eduardo Pascual Pérez

órdenes e instrucciones complementarias, que versan sobre aspectos como programas de coordinación horaria con la etapa de Educación Secundaria o recesión de alumnado invitado en la Comunidad Valenciana, entre otros. En ningún caso estos documentos (a excepción del citado Decreto) contienen datos relevantes para nuestro campo de estudio.

Los objetivos específicos de las Enseñanzas Profesionales que versan en el Decreto 158/2007 evidencian el enfoque principal hacia la interpretación instrumental, y que es uno de los elementos motivadores de la presente investigación dado que dejan en un plano secundario las competencias referentes a la continuidad con otros tipos de enseñanzas superiores.

\section{$\underline{\text { Objetivos específicos de las enseñanzas profesionales de música }}$}

a) Superar con domino y capacidad critica los contenidos y objetivos planteados.

b) Conocer los elementos básicos de los lenguajes musicales, sus características, funciones y evoluciones en los diferentes contextos históricos.

c) Utilizar el "oído interno" como base de la afinación, de la audición armónica y de la interpretación musical.

d) Formar una imagen ajustada de las posibilidades y características musicales tanto a nivel individual como en relación con el grupo, con la disposición necesaria para saber integrarse como un miembro más del mismo o como responsable del conjunto.

e) Compartir vivencias musicales de grupo en el aula y fuera de ella que permitan enriquecer la relación afectiva con la música a través del canto y de participación instrumental en grupo. 
Diseño y planificación de competencias específicas en el currículum de enseñanzas profesionales de música: modalidades composición-dirección en la enseñanza superior.

Carlos Eduardo Pascual Pérez

f) Utilizar el cuerpo y la mente para adquirir la técnica necesaria y así, concentrarse en la audición e interpretación musical.

g) Interrelacionar y aplicar los conocimientos adquiridos en todas las asignaturas que componen el currículo junto con las vivencias y experiencias propias para conseguir una interpretación artística de calidad.

h) Adquirir y aplicar las destrezas necesarias para resolver las dificultades que surjan en la interpretación de la música.

i) Practicar la improvisación y la transposición como elementos inherentes a la creatividad musical.

j) Interpretar, individualmente o dentro de la agrupación correspondiente, obras escritas en todos los lenguajes musicales profundizando en el conocimiento de los diferentes estilos y épocas, así como en los recursos interpretativos de cada uno de ellos.

k) Actuar en publico con autocontrol, dominio de la memoria musical y capacidad comunicativa.

1) Adquirir autonomía personal en la interpretación musical.

m) Consolidar hábitos de estudio adecuados y continuados en función de la dificultad de los contenidos de las asignaturas de los diferentes cursos y niveles.

n) Conocer y aplicar las técnicas del instrumento o de la voz de acuerdo con las exigencias de las obras. 
De una forma directa los objetivos c, d, e, f, g, h, i, j, k, ly n atañen a la interpretación, siendo el $80 \%$ de los objetivos descritos, y por ello muy significativo al acercarse a la totalidad de los estos. Los objetivos restantes a, b y m versan sobre aspectos contextuales o colaterales al aprendizaje del proceso de aprendizaje y de la enseñanza artística en particular.

\subsection{Distribución de asignaturas}

En el Anexo II del citado Decreto se establecen los tiempos lectivos y el plan de estudios para las diferentes especialidades. Encontramos ligeras variaciones en las asignaturas de especialidad entre los planes de los instrumentos sinfónicos, canto, instrumentos polifónicos o instrumentos antiguos y tradicionales. Por ejemplificar algunos, los estudiantes de la especialidad Canto son los únicos que tienen asignatura de idiomas aplicados o los estudiantes de Piano no tienen la asignatura Piano Complementario que sí tienen el resto de especialidades. No obstante, todas las especialidades tienen la misma distribución en cuanto a las asignaturas comunes y optativas. 
Diseño y planificación de competencias específicas en el currículum de enseñanzas profesionales de música: modalidades composición-dirección en la enseñanza superior.

Carlos Eduardo Pascual Pérez

Especialitat: Percussió

\begin{tabular}{|c|c|c|c|c|c|c|c|}
\hline Assignatura & \multicolumn{6}{|c|}{$\begin{array}{c}\text { Curs } \\
\text { hores setmanals }\end{array}$} & \multirow[t]{2}{*}{$\begin{array}{l}\text { Total } \\
\text { grau }\end{array}$} \\
\hline A. Pròpies de l'especialitat & 1 & 2 & 3 & 4 & 5 & 6 & \\
\hline Instrument & 1 & 1 & 1 & 1 & 1 & 1 & 180 \\
\hline Piano complementari & & 0,5 & 0,5 & 0,5 & & & 45 \\
\hline Música de cambra & & & 1 & 1 & 1 & 1 & 120 \\
\hline Orquestra / banda / conjunt & 2 & 2 & 2 & 2 & 2 & 2 & 360 \\
\hline \multicolumn{8}{|l|}{ B. Comunes } \\
\hline Llenguatge musical & 2 & 2 & & & & & 120 \\
\hline Harmonia & & & 2 & 2 & & & 120 \\
\hline Anàlisi & & & & & 2 & 2 & 120 \\
\hline Història de la música & & & & & 2 & 2 & 120 \\
\hline \multicolumn{8}{|l|}{ C. Optativitat } \\
\hline Optativa & & & & & 3 & 3 & 180 \\
\hline & & & & & & & \\
\hline Total setmanal & 5 & 5,5 & 6,5 & $6 ' 5$ & 11 & 11 & \\
\hline & & & & & & total & 1365 \\
\hline
\end{tabular}

Figura 3. Distribución horaria por materias para una especialidad instrumental

(Decreto 158/2007, p. 37071).

Las asignaturas propias de la especialidad, así como su carga lectiva son prácticamente idénticas en todas las especialidades. A parte de la especialidad (instrumento) encontramos en piano como instrumento complementario y otras asignaturas de práctica de conjunto, como pueden ser Orquesta, Banda, Conjunto, Coro o Música de Cámara.

Dentro de las asignaturas comunes - a excepción de la asignatura Historia de la Música -, las asignaturas están organizadas manteniendo una continuidad. De este modo se enuncia en el Anexo I del Decreto; “Por ser la Armonía la continuación del Lenguaje Musical, es lógico 
Diseño y planificación de competencias específicas en el currículum de enseñanzas profesionales de música: modalidades composición-dirección en la enseñanza superior.

que sus aspectos teóricos más básicos estén ya incluidos en los estudios de esta materia didáctica" y "La asignatura de análisis está pensada como continuación lógica de la asignatura de armonía” (p.37019-37020).

Del mismo modo, para todas las especialidades están distribuidas una asignatura optativa diferentes para el penúltimo y último curso de estas enseñanzas. El Artículo 8 del Decreto indica la obligada oferta de las asignatarias optativas "Complemento pianístico, Complemento coral, Estética de la música, Fundamentos de composición, Fundamentos de informática musical y edición de partituras, Cultura audiovisual y Creatividad y música.” (p.37008), así como la posibilidad de cada centro de diseñar y ofertar asignaturas optativas propias previa autorización de la conselleria competente.

Bajo la articulación de este sistema, nuestra propuesta se basará en dos premisas: la diversificación a partir del $3^{\circ}$ curso de las Enseñanzas Profesionales y a través de las asignaturas comunes (a excepción de Historia de la Música) y las optativas.

\subsection{El currículum en las asignaturas de Armonía y Análisis}

Según versa el Decreto 158/2007 de 21 de septiembre en su Anexo I, los objetivos, contenidos y criterios de evaluación de la asignatura Armonía para las enseñanzas profesionales son: 
Diseño y planificación de competencias específicas en el currículum de enseñanzas profesionales de música: modalidades composición-dirección en la enseñanza superior.

Carlos Eduardo Pascual Pérez

\section{$\underline{\text { Objetivos }}$}

a) Conocer los elementos básicos de la armonía tonal y sus características, funciones y transformaciones en los distintos contextos históricos.

b) Utilizar en trabajos escritos los elementos y procedimientos básicos de la armonía tonal

c) Desarrollar el oído interno tanto en el análisis como en la realización de ejercicios escritos.

d) Identificar a través de la audición los acordes y procedimientos más comunes de la armonía tonal.

e) Identificar a través del análisis de obras los acordes, los procedimientos más comunes de la armonía tonal y las transformaciones temáticas.

f) Comprender la interrelación de los procesos armónicos con la forma musical.

g) Aprender a valorar la calidad de la música.

\section{Contenidos}

El acorde. Consonancia y disonancia. Estado fundamental e inversiones de los acordes triadas y de séptima sobre todos los grados de la escala y de los acordes de novena dominante. Enlace de acordes. Tonalidad y funciones tonales. Elementos y procedimientos de origen modal presentes en el Sistema Tonal. El ritmo armónico. Cadencias Perfecta, Imperfecta, Plagal, Rota. Procesos carenciales. Modulación: diatónica y cromática, por cambio de función tonal, cambios de tono y modo, etc. Flexiones introtonales. Progresiones unitonales y modulantes. Series de sextas y de séptimas. Utilización de los elementos y procedimientos anteriores en la realización 
Diseño y planificación de competencias específicas en el currículum de enseñanzas profesionales de música: modalidades composición-dirección en la enseñanza superior.

Carlos Eduardo Pascual Pérez

de trabajos escritos. Practica auditiva e instrumental que conduzca a la interiorización de los elementos y procedimientos aprendidos. Análisis de obras para relacionar dichos elementos y procedimientos, así como las transformaciones temáticas de los materiales utilizados con su contexto estilístico y la forma musical.

\section{$\underline{\text { Criterios de evaluación }}$}

1. Realizar ejercicios a partir de un bajo cifrado dado.

2. Realizar ejercicios de armonización a partir de tiples dados.

3. Realizar ejercicios de armonización a partir de bajos sin cifrar dados.

4. Componer ejercicios breves a partir de un esquema armónico dado o propio.

5. Identificar auditivamente los principales elementos morfológicos de la armonía tonal.

6. Identificar auditivamente los principales procedimientos sintácticos de la armonía tonal.

7. Identificar auditivamente estructuras formales concretas.

8. Identificar mediante el análisis de obras los elementos morfológicos de la armonía tonal.

Del mismo modo, siguiendo el Decreto 158/2007 de 21 de septiembre en su Anexo I, los objetivos, contenidos y criterios de evaluación de la asignatura Análisis para las enseñanzas profesionales son: 
Diseño y planificación de competencias específicas en el currículum de enseñanzas profesionales de música: modalidades composición-dirección en la enseñanza superior.

Carlos Eduardo Pascual Pérez

\section{$\underline{\text { Objetivos }}$}

1. Conocer los principales elementos y procedimientos compositivos de las distintas épocas y autores, desde el canto gregoriano hasta la actualidad, profundizando en el periodo tonal bimodal.

2. Avanzar en la comprensión de las obras mediante el análisis de sus elementos constitutivos parciales, para poder relacionarlos con el todo.

3. Comprender la interrelación de los procedimientos compositivos de las distintas épocas, con las estructuras formales que de ellos se derivan.

4. Profundizar en el análisis de las obras mediante la audición.

5. Reproducir los elementos y procedimientos básicos de obras de distintas épocas median- te el uso de instrumentos polifónicos.

\section{$\underline{\text { Contenidos }}$}

Estudio a través del análisis de los diversos componentes del lenguaje musical (forma, melodía, ritmo, transformación temática, enlaces armónicos, modulación, contrapunto, procesos de tensión y relajación, cadencias, etc.), a partir de obras de diferentes épocas y autores, desde el canto gregoriano hasta la actualidad (incluyendo referencias a la música no occidental). Practica auditiva e instrumental de los elementos y procedimientos aprendidos que conduzcan a su interiorización.

\section{Criterios de evaluación}

1. Identificar mediante el análisis de obras los elementos morfológicos y sintácticos de menor a mayor complejidad. 
Diseño y planificación de competencias específicas en el currículum de enseñanzas profesionales de música: modalidades composición-dirección en la enseñanza superior.

Carlos Eduardo Pascual Pérez

2. Identificar auditivamente los elementos y procedimientos que configuran la forma, de menor a mayor complejidad.

\subsection{El currículum en la asignatura Fundamentos de Composición}

De las asignaturas optativas de obligada oferta que se enuncian en el Decreto 158/2007 de

21 de septiembre, pueden asociarse como afines al presente diseño curricular la asignatura Fundamentos de composición. En el Anexo I de dicho Decreto, los objetivos, contenidos y criterios de evaluación de la asignatura Fundamentos de composición para las enseñanzas profesionales son:

\section{$\underline{\text { Objetivos }}$}

1. Conocer los principales elementos y procedimientos compositivos de las distintas épocas y autores desde el canto gregoriano hasta la actualidad.

2. Utilizar los principales elementos y procedimientos compositivos de las épocas barroca, clásica y romántica.

3. Realizar pequeñas obras libres con el fin de desarrollar la espontaneidad creativa.

4. Tocar en un instrumento polifónico de forma esquemática los procedimientos compositivos básicos estudiados.

5. Tocar en un instrumento polifónico los trabajos realizados. 
Diseño y planificación de competencias específicas en el currículum de enseñanzas profesionales de música: modalidades composición-dirección en la enseñanza superior.

Carlos Eduardo Pascual Pérez

\section{Contenidos}

Practica escrita de los elementos y procedimientos compositivos que intervienen en el sistema tonal, tanto de carácter armónico como contrapuntístico. Conocimiento básico de las características y posibilidades de los diferentes instrumentos. Realización de trabajos y composición de pequeñas obras vocales o instrumentales (o fragmentos) en los estilos barroco, clásico o romántico. Realización de pequeñas obras libres.

\section{Criterios de evaluación}

1. Realizar ejercicios a partir de bajos cifrados, bajos sin cifrar y tiples dados.

2. Componer ejercicios breves a partir de un esquema armónico o procedimiento, dado o propio, pensando en un medio instrumental o vocal concreto.

\section{Armonizar corales.}

4. Escribir líneas melódicas en contrapunto a dos, tres y cuatro voces a una voz dada.

5. Dado un fragmento, de carácter predominantemente armónico, completarlo en el mismo estilo, siguiendo un esquema formal predeterminado o libre.

6. Dado un fragmento, de carácter predominantemente contrapuntístico, completarlo en el mismo estilo, siguiendo un esquema formal predeterminado o libre.

7. Realizar ejercicios de contrapunto invertible a distintos intervalos.

8. Realizar cánones por movimiento directo, contrario, retrógrado, aumentación y disminución a dos o más voces. 
Diseño y planificación de competencias específicas en el currículum de enseñanzas profesionales de música: modalidades composición-dirección en la enseñanza superior.

\section{Carlos Eduardo Pascual Pérez}

9. Componer pequeñas obras vocales o instrumentales (o fragmentos) en los estilos barroco, clásico o romántico.

\subsection{Asociación y cotejo de las competencias requeridas en la prueba de}

\section{acceso y los contenidos curriculares de las Enseñanzas Profesionales.}

Una primera comparativa entre los descriptores que hemos obtenido tras el análisis de las pruebas de acceso a enseñanzas superiores - y que hemos catalogado como "Competencias requeridas" al inicio de este capítulo - y los criterios de evaluación de las asignaturas sujetas a la implementación curricular de nuestra propuesta nos reporta la siguiente relación.

\begin{tabular}{|c|c|c|c|}
\hline Competencias & Armonía & Análisis & $\begin{array}{l}\text { Fundamentos de } \\
\text { composición }\end{array}$ \\
\hline $\begin{array}{l}\text { I. Análisis auditivo } \\
\text { estructural, tímbrico } \\
\text { y estilístico. }\end{array}$ & CE5, CE6, CE7 & CE2 & \\
\hline $\begin{array}{l}\text { II. Instrumentación } \\
\text { para voz sola } \\
\text { acompañada y coral. }\end{array}$ & & & CE2, CE4 \\
\hline $\begin{array}{l}\text { III. Armonización } \\
\text { contrapuntística. }\end{array}$ & CE1, CE2, CE3, & & $\begin{array}{l}\text { CE1, CE3, CE5, } \\
\text { CE6, CE7, CE8 }\end{array}$ \\
\hline $\begin{array}{l}\text { IV. Aspectos básicos } \\
\text { de la composición. }\end{array}$ & CE4, & & $\begin{array}{l}\text { CE2, CE5, CE6, } \\
\text { CE7, CE8, CE9, } \\
\text { CE10 }\end{array}$ \\
\hline $\begin{array}{l}\text { V. Reproducción } \\
\text { escrita de } \\
\text { fragmentos } \\
\text { melódicos y } \\
\text { polifónicos de hasta } \\
\text { cuatro voces a partir } \\
\text { de una escucha } \\
\text { orquestal. }\end{array}$ & & & \\
\hline
\end{tabular}


Diseño y planificación de competencias específicas en el currículum de enseñanzas profesionales de música: modalidades composición-dirección en la enseñanza superior.

Carlos Eduardo Pascual Pérez

\section{Organología,} instrumentación y orquestación en el ámbito de la orquesta sinfónica.

VII. Aspectos

básicos de la técnica

de dirección.

Tabla 3. Distribución de las competencias específicas en el contenido curricular por materias (elaboración propia).

Quedan por tanto sin relacionar tres de las competencias requeridas tal y como mostramos en la Tabla 3, lo cual indica que dichas habilidades y contenidos no se verán cubiertos por el actual currículum en las citadas asignaturas comunes y la optativa afín seleccionada. Para clarificar su concepto de ahora en adelante, pasaremos a nombrar estas tres competencias específicas como competencias transversales, ya que serán las que implementaremos metodológicamente al currículum existente.

\subsection{Definición y desarrollo de las competencias transversales al currículum}

A continuación, desarrollamos las citadas competencias requeridas de acceso que no tienen relación alguna con los criterios de evaluación en las Enseñanzas Profesionales (asignaturas de Armonía, Análisis y Fundamentos de composición), convirtiéndolas en competencias 
Diseño y planificación de competencias específicas en el currículum de enseñanzas profesionales de música: modalidades composición-dirección en la enseñanza superior.

transversales aplicables al currículum. Estableceremos por tanto sendos descriptores que aunarán en sí la transversalidad objetivo-contenido-criterio de evaluación, puesto que no pretenden incorporarse curricularmente, sino establecerse como eje transversal formativo, dado que su objetivo se ubica en la futura prueba de acceso, al igual que se desprende de la misma su contenido y su evaluación no puede ser tomada curricularmente, por lo que una vez más se ejecutará en la citada prueba de acceso.

\subsubsection{Reproducción escrita de fragmentos melódicos y polifónicos de hasta cuatro voces a partir de una escucha orquestal (Competencia V)}

Las habilidades que se desprenden de este descriptor se aplican parcialmente en el currículum existente, concretamente en la asignatura de Lenguaje Musical (cursos $1^{\circ}$ y $2^{\circ}$ de las Enseñanzas Profesionales). Las hallamos en sus criterios de evaluación 12 y 14:

12. Reconocer y escribir fragmentos musicales realizados por dos instrumentos diferentes, excluyendo el piano. Con este criterio se pretende comprobar que la capacidad auditiva del alumnado no sufre distorsión cuando recibe el mensaje a través de un vehículo sonoro diferente al piano.

14. Reconocer auditivamente diferentes timbres instrumentales. Se pretende constatar la familiarización del alumnado con los timbres provenientes de otros instrumentos diferentes del que constituye su especialidad.

Podemos presuponer que, tras la superación de dichos cursos, el alumnado habrá tenido la experiencia auditiva a dúo a través de instrumentos orquestales (al excluir el piano podemos englobar prácticamente a la gran mayoría los instrumentos de las especialidades reguladas en el currículum como orquestales), y también habrá implementado la reproducción escrita 
Diseño y planificación de competencias específicas en el currículum de enseñanzas profesionales de música: modalidades composición-dirección en la enseñanza superior.

de dicho discurso. Asimismo, la práctica tímbrica auditiva se habrá desarrollado de forma independiente, pero también asociada a la anterior reproducción instrumental a dos voces. Quedará por tanto seguir implementando este proceso en sus dos vertientes: la melódica aplicada a la tímbrica orquestal - a cada uno de los principales instrumentos de la orquesta sinfónica - y la polifónica en su faceta no desarrollada, es decir, a tres y cuatro voces de forma armónico-contrapuntística.

\subsubsection{Organología, instrumentación y orquestación en el ámbito de la orquesta sinfónica (Competencia VI)}

Hallamos en esta competencia la ausencia directa de contenido en todo el currículum de las Enseñanzas Profesionales que versan según el Decreto 158/2007. Por tanto, requiere de una aportación íntegramente nueva de contenido que genere las destrezas necesarias, y que esta respete a su vez el currículum establecido. Será por tanto una de las competencias fundamentales a implementar en nuestra propuesta metodológica al recaer en ella al menos el $50 \%$ de las habilidades esenciales a incorporar.

Como su título indica, será fundamental la adquisición de conocimientos esenciales acerca de las características técnicas, uso normo-típico y posibilidades en la escritura y ejecución de los instrumentos que se relacionan en el ámbito de la orquesta sinfónica. Dichos instrumentos abarcan prácticamente la totalidad de los comunes, generando así una gran lista a la que aplicar el procedimiento. No obstante, podemos aventurar una lista-resumen que generalice esta limitación en instrumentos de cuerda frotada (violín, viola, violoncello, contrabajo), de 
Diseño y planificación de competencias específicas en el currículum de enseñanzas profesionales de música: modalidades composición-dirección en la enseñanza superior.

viento-madera (flauta, oboe, clarinete, fagot, saxofón), de viento-metal (trompeta, trompa, trombón, tuba), de percusión (timbales, xilófono, lira, bombo, platos, caja, instrumentos de pequeña percusión) e incluyendo el arpa y el piano como instrumentos de posible asociación al ámbito sinfónico.

\subsubsection{Aspectos básicos de la técnica de dirección (Competencia VII)}

Nuevamente encontramos una total ausencia curricular que relacione la citada competencia en ninguna de las asignaturas troncales, propias, comunes u optativas del sistema. Es nada menos que curioso que, estando presente la figura del director en las Enseñanzas Profesionales - ya sea orquestal, coral o de cualquier otro conjunto instrumental que lo precise - no exista ninguna referencia competencial a dicha función. El alumno interesado en sus estudios se encontrará por primera vez con dicho requerimiento competencial en la prueba de acceso al Grado en Dirección. Sin embargo, habrá tenido presente a dicha figura durante todas las etapas anteriores, incluida las Enseñanzas Elemental, mediante las asignaturas de coro, conjunto instrumental, orquesta, banda e incluso música de cámara.

A pesar de carecer de la citada información, desarrollar un descriptor eficiente para nuestra competencia VII es sencillo: adquirir la capacidad de lectura comprensiva ante partituras sencillas y de entre las más habituales agrupaciones instrumentales o vocales (coral a cuatro voces mixtas, de música de cámara, orquesta de cuerda, orquesta de cámara, orquesta sinfónica y banda sinfónica) así como las capacidades gestuales que permitan ejercer la 
Carlos Eduardo Pascual Pérez

dirección de una interpretación satisfactoria (gestualización del tempo, la agógica y la dinámica).

\subsection{Diseño curricular}

Como enunciábamos anteriormente, nuestro diseño parte de la diversificación a partir del $3^{\circ}$ curso de las Enseñanzas Profesionales y a través de las asignaturas de Armonía, Análisis y las optativas.

\begin{tabular}{|c|c|c|}
\hline & Asignaturas vigentes & Propuesta de itinerario \\
\hline \multirow{8}{*}{$\begin{array}{l}\text { Propias de } \\
\text { especialidad }\end{array}$} & Instrumento & Instrumento \\
\hline & Piano complementario & Piano complementario \\
\hline & Música de cámara & Música de cámara \\
\hline & Orquesta / Banda / Conjunto & Orquesta / Banda / Conjunto \\
\hline & Coro & Coro \\
\hline & Acompañamiento & Acompañamiento \\
\hline & Idiomas y otras específicas & Idiomas y otras especificas \\
\hline & Lenguaje Musical & Lenguaje Musical \\
\hline \multirow{3}{*}{ Comunes } & Armonía & $\begin{array}{l}\text { Armonía aplicada a la Composición y } \\
\text { Dirección }\end{array}$ \\
\hline & Análisis & $\begin{array}{l}\text { Análisis aplicado a la Composición y } \\
\text { Dirección }\end{array}$ \\
\hline & Historia de la Música & Historia de la Música \\
\hline Optativa & Según oferta del centro & Optativa afín a la Composición y/o Dirección \\
\hline
\end{tabular}

Tabla 4. Comparativa curricular con su propuesta de modificación (elaboración propia).

Proponemos por tanto la generación de dos variantes en el itinerario actual para las asignaturas de Armonía y Análisis, además de recomendar las optativas afines de obligada oferta como Fundamentos de composición y/o alguna otra específica o afín para la dirección, que deberá ser de diseño propio del centro dada la inexistencia de estas en las designadas curricularmente como optativas de obligada oferta. Este itinerario propuesto responde a la 
Diseño y planificación de competencias específicas en el currículum de enseñanzas profesionales de música: modalidades composición-dirección en la enseñanza superior.

conjunción de todas las realidades que coexisten en el sistema educativo: motivación del alumnado, criterios organizativos de centro y economía de recursos materiales y humanos. Consideramos que este diseño de itinerario puede cumplir las necesidades que hemos desvelado para el alumnado que desee aspirar a un grado en Composición y/o Dirección, al tiempo que respeta la legislación vigente y únicamente supone un criterio de organización grupal en los propios centros. Además, la propuesta de diversificación será en los últimos cuatro cursos, dado que consideramos los dos primeros se establecen las bases comunes a cualquier enseñanza superior que se desee aspirar.

\subsubsection{Armonía aplicada a la composición y la dirección}

Esta asignatura diversificada será la primera del itinerario, y que coincide además con la experiencia que llevaremos a cabo - recogida en el Capítulo 4 - y que es parte fundamental de esta tesis. Recordamos que no se trata de una modificación curricular, sino que partiendo del diseño curricular existente y legislativo, implementaremos sobre este nuestras competencias transversales. Concretamente, las competencias V y VI serán las que aplicaremos en esta asignatura, la cual ocupa dos cursos $-3^{\circ}$ y $4^{\circ}$ de las Enseñanzas Profesionales - con dos horas lectivas semanales. Dicha aplicación y su metodología la describimos detalladamente en el epígrafe 4.1.2 del presente texto, puesto que es el fundamento para nuestra intervención práctica, y que para evitar duplicidades no vamos a reproducir en este punto. 
Diseño y planificación de competencias específicas en el currículum de enseñanzas profesionales de música: modalidades composición-dirección en la enseñanza superior.

Carlos Eduardo Pascual Pérez

\subsubsection{Análisis aplicado a la composición y la dirección}

De un modo similar a como acometemos la asignatura de Armonía, y por ser Análisis la continuación lógica de esta, volveremos a implementar aquí nuestras competencias transversales V y VI. En este caso, la transversalidad de estas tiene una mayor facilidad de aplicación al disponer el currículum únicamente dos criterios de evaluación (Decreto 158/2007, p.37019).

1. Identificar mediante el análisis de obras los elementos morfológicos y sintácticos de menor a mayor complejidad. Con este criterio se pretende valorar el conocimiento del alumno de los diversos componentes del lenguaje musical.

2. Identificar auditivamente los elementos y procedimientos que configuran la forma, de menor a mayor complejidad. Mediante este criterio se pretende evaluar el progreso en la capacidad auditiva del alumno y en la interiorización de los elementos y procedimientos aprendidos.

Podemos observar que no se menciona en estos criterios una necesidad de plantilla instrumental o vocal determinada, lo cual genera una libertad para poder implementar las metodologías que motivan nuestras competencias transversales. Además, llegamos a la misma conclusión observando los contenidos curriculares que versa el mismo Decreto.

Estudio a través del análisis de los diversos componentes del lenguaje musical (forma, melodía, ritmo, transformación temática, enlaces armónicos, modulación, contrapunto, procesos de tensión y relajación, cadencias, etc.), a partir de obras de diferentes épocas y autores, desde el canto gregoriano hasta la actualidad (incluyendo referencias a la 
Diseño y planificación de competencias específicas en el currículum de enseñanzas profesionales de música: modalidades composición-dirección en la enseñanza superior.

\section{Carlos Eduardo Pascual Pérez}

música no occidental). Practica auditiva e instrumental de los elementos y procedimientos aprendidos que conduzcan a su interiorización.

Llegados a este punto, concluimos que una aplicación metodológica de las competencias transversales V y VI dependerá únicamente de la programación didáctica en consecuencia. Obviamente esta asignatura no tendrá el mismo punto de partida según sea un grupo dado de alumnos que haya cursado o no la asignatura Armonía común o nuestra propuesta de Armonía aplicada a la composición y la dirección. Este último grupo de alumnos dispondrán ya de la capacidad para afrontar los contenidos de Análisis aplicados directamente, por ejemplo, a una partitura orquestal.

Veamos a continuación un ejemplo de análisis armónico-formal sobre un mismo fragmento musical, la Sinfonía No.41 de Mozart, en su versión original - plantilla de orquesta sinfónica - y en una reducción a piano. En el caso de la partitura original, consideramos que su análisis puede ser abordado por alumnos que hayan cursado ya la diversificación, y, sin embargo, otros perfiles de alumnado partirían con dificultades añadidas al carecer de lo adquirido transversalmente en los cursos anteriores, concretamente respecto a la competencia transversal VI. Este conjunto debería poder acometer el análisis que proponemos en la versión de reducción a piano, para el cual ni se implementan ni es necesaria dicha competencia. 
Diseño y planificación de competencias específicas en el currículum de enseñanzas profesionales de música: modalidades composición-dirección en la enseñanza superior.

Carlos Eduardo Pascual Pérez

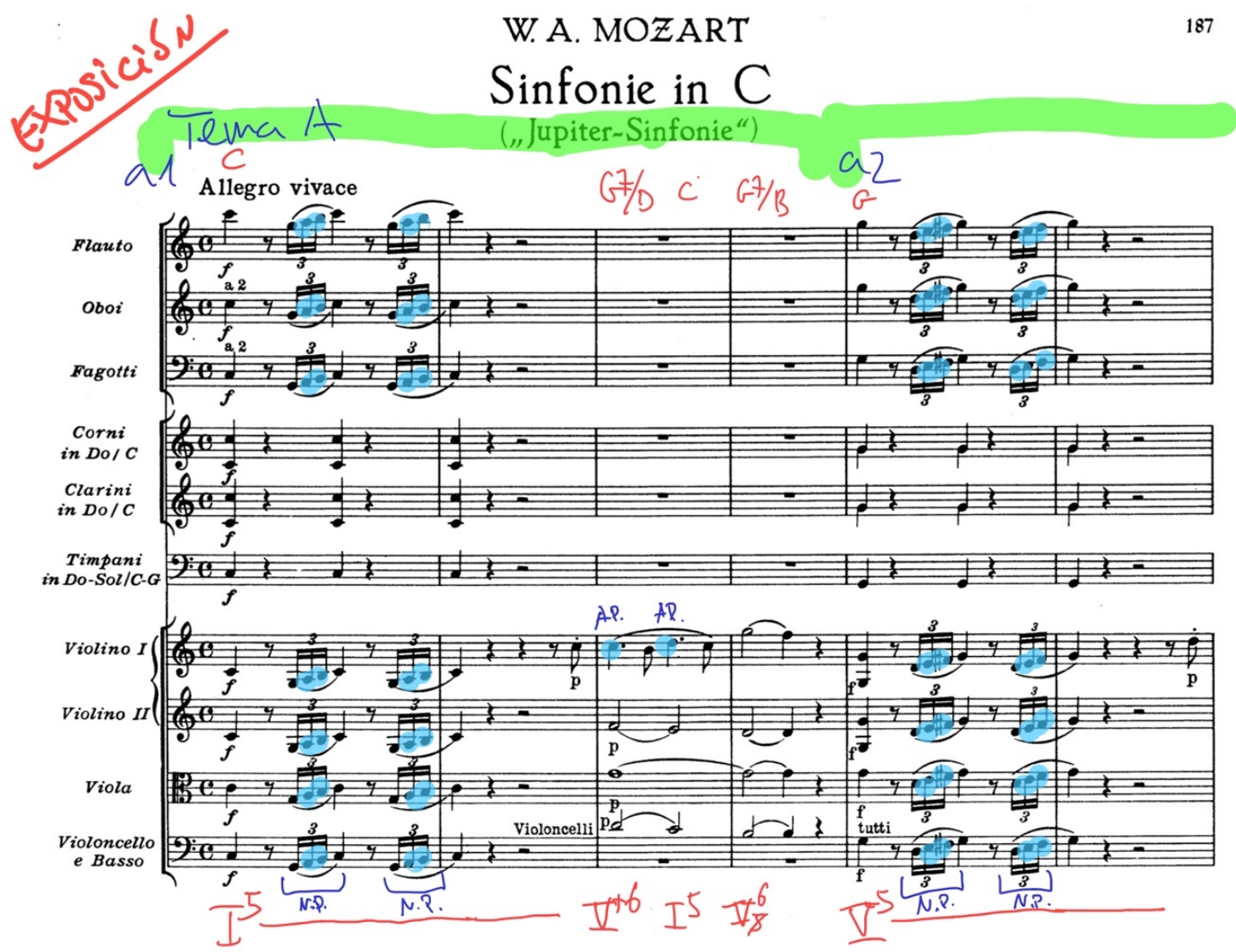

Figura 4. Ejemplo analítico sobre el inicio de la Sinfonía No.41 en su versión original para orquesta sinfónica (Mozart, 1957, p.1).

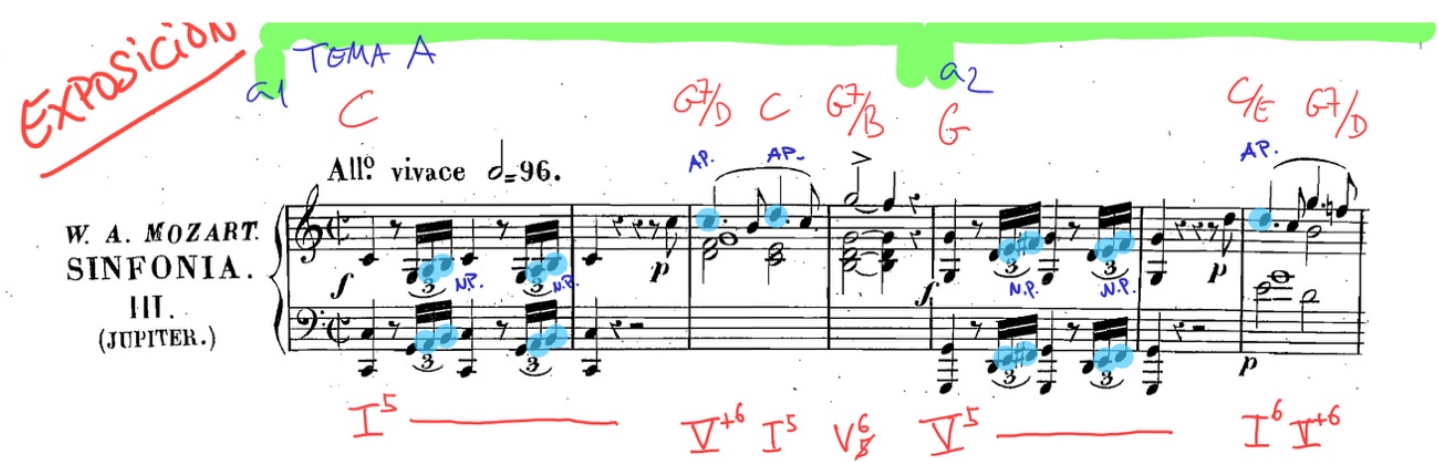

Figura 5. Ejemplo analítico idéntico al propuesto en la Figura 4, en este caso en una reducción de la citada partitura para piano (Hummel, 1825, p.1). 
Diseño y planificación de competencias específicas en el currículum de enseñanzas profesionales de música: modalidades composición-dirección en la enseñanza superior.

Carlos Eduardo Pascual Pérez

En la Figura 5, al tratarse de escritura pianística en dos pentagramas, tal y como viene siendo habitual en la metodología de la asignatura Armonía, es sencillo imaginar cómo el alumnado puede comenzar a abordar curricularmente el análisis mediante dicho formato. Sin embargo, el alumnado que ya hubiese cursado la asignatura de Armonía aplicada, puede partir de otros formatos, con los mismos objetivos y contenidos, pero sin dejar de adquirir la competencia transversal VI, tal y como mostramos en la Figura 4.

Del mismo modo ocurre con la competencia $\mathrm{V}$, la cual afecta directamente a la práctica auditiva, relacionada en los contenidos y en el criterio de evaluación 2 de la asignatura. Nuevamente el perfil de alumnado que viene de un itinerario diversificado dispondrá de las habilidades necesarias para afrontar un análisis auditivo mediante un formato ambicioso, como puede ser la orquesta sinfónica, y ante el cual podrá aportar información relevante sobre la instrumentación, que recordamos no es un contenido curricular, sino que se desprende de la transversalidad de nuestras competencias.

En cualquier caso, no es nuestra intención declarar que un alumnado de la asignatura Análisis que no provenga de una diversificación no podrá con el tiempo llegar a abordar tales prácticas analíticas que impliquen la complejidad de la organología instrumental, sino que el alumnado que ya dispone de dichas habilidades partirá de un punto avanzado y dispondrá de dos cursos para seguir reforzando sus conocimientos y poder adquirir mayores destrezas. No olvidemos que tras finalizar la asignatura de Análisis - que se desarrolla en los cursos $5^{\circ}$ y $6^{\circ}$ de las Enseñanzas Profesionales con una temporalización de dos horas semanales - finalizará la etapa de estas enseñanzas y será el momento de acometer la prueba de acceso a las 
Diseño y planificación de competencias específicas en el currículum de enseñanzas profesionales de música: modalidades composición-dirección en la enseñanza superior.

Carlos Eduardo Pascual Pérez

Enseñanzas Superiores, momento para el cual deberán haberse adquirido en su totalidad las habilidades propuestas para todas las competencias específicas, es decir, aquellas que se desprenden directamente del currículum y las que hemos propuesto transversalmente.

Por último, y dado que dicha propuesta no cuenta con su parte experimental en la presente investigación - recordamos que dicha parte empírica corresponde al primer curso de la asignatura Armonía -, proponemos un ejercicio práctico cuya realización por parte del alumnado podría evaluar la adquisición tanto de los contenidos curriculares como de las competencias transversales aplicadas tras ambos cursos de esta asignatura, de un modo similar al desarrollado para la práctica (Figura 24), que además desempeña el último cuestionario en la metodología pretest-postest empleada para el contraste de datos. Dada su extensión emplazamos dicho ejercicio junto a los respectivos de las demás asignaturas en el Anexo VIII.

\subsubsection{Optativa de obligada oferta: Fundamentos de composición}

Nuevamente - y como sucede con la asignatura de Análisis - disponemos de una asignatura cuyo contenido curricular es abierto y nos permite implementar competencias transversales de una forma metodológica y que no suponga un gran ajuste. El diseño de esta asignatura se dispone en tres horas semanales, pudiendo ser su distribución en sesión única o en dos sesiones de hora y media, sin olvidar que únicamente puede cursarse una vez, en $5^{\circ}$ o $6^{\circ}$ curso de Enseñanzas Profesionales. La motivación propia de esta asignatura es "iniciarse en el estudio de la composición y de avanzar cada vez más en la comprensión de las obras 
Diseño y planificación de competencias específicas en el currículum de enseñanzas profesionales de música: modalidades composición-dirección en la enseñanza superior.

musicales que posibilite su interpretación adecuada", y "ha sido diseñada primordialmente para aquellos alumnos que deseen orientarse hacia la composición, la musicología, la dirección, o la pedagogía, para los cuales es imprescindible la formación de escritura previa a los estudios de grado superior" (Decreto 158/2007, p.37062). No obstante, y como ya hemos demostrado en el análisis de los requisitos para las pruebas de acceso, los contenidos de la asignatura (Decreto 158/2007, p.37063) no son lo suficientemente extensivos.

Practica escrita de los elementos y procedimientos compositivos que intervienen en el sistema tonal, tanto de carácter armónico como contrapuntístico. Conocimiento básico de las características y posibilidades de los diferentes instrumentos. Realización de trabajos y composición de pequeñas obras vocales o instrumentales (o fragmentos) en los estilos barroco, clásico o romántico. Realización de pequeñas obras libres.

No se determina la aplicabilidad de estos contenidos a un conjunto determinado de plantillas instrumentales o vocales, estando muchas de estas necesariamente dentro de nuestra competencia VI. Por tanto, un perfil de alumnado que no disponga de la trayectoria diversificada, en un único curso de duración tendrá muchas dificultades para desarrollar todas las habilidades que presupongan una adquisición completa de dicha competencia. Sin embargo, el alumnado que haya seguido la trayectoria de cuatro cursos de armonía y análisis diversificados, podrá acometer los contenidos de la asignatura aplicándolos con destreza a recursos más avanzados que le permitan terminar de desarrollar completamente las destrezas de la competencia VI. 
Diseño y planificación de competencias específicas en el currículum de enseñanzas profesionales de música: modalidades composición-dirección en la enseñanza superior.

Carlos Eduardo Pascual Pérez

Si nos referimos a los criterios de evaluación (Decreto 158/2007, p.37063), tenemos nuevamente un perfil abierto, el cual nos permite hacer una intervención únicamente metodológica.

1. Realizar ejercicios a partir de bajos cifrados, bajos sin cifrar y tiples dados.

2. Componer ejercicios breves a partir de un esquema armónico o procedimiento, dado o propio, pensando en un medio instrumental o vocal concreto.

\section{Armonizar corales.}

4. Escribir líneas melódicas en contrapunto a dos, tres y cuatro voces a una voz dada.

5. Dado un fragmento, de carácter predominantemente armónico, completarlo en el mismo estilo, siguiendo un esquema formal predeterminado o libre.

6. Dado un fragmento, de carácter predominantemente contrapuntístico, completarlo en el mismo estilo, siguiendo un esquema formal predeterminado o libre.

7. Realizar ejercicios de contrapunto invertible a distintos intervalos.

Todos los criterios de evaluación pueden aplicarse tanto a una escritura pianística en dos pentagramas - la escritura habitual proveniente de la práctica armónica y el análisis sin aplicar competencias transversales - como a una instrumental o vocal que incluya necesariamente los conocimientos adquiridos acerca de la instrumentación y la organología mediante la competencia VI. Utilizando el criterio de evaluación 2, proponemos a modo de ejemplo un ejercicio tipo, el cual aplicaremos en la Figura 7 a un "medio instrumental" pianístico, mientras que en la Figura 8 haremos una realización similar pero aplicada a una 
Diseño y planificación de competencias específicas en el currículum de enseñanzas profesionales de música: modalidades composición-dirección en la enseñanza superior.

Carlos Eduardo Pascual Pérez

plantilla instrumental de orquesta de cámara, siendo necesario para esta última la adquisición de la competencia VI.

Ejercicio: realizar una composición libre de 8 compases a partir de los elementos armónicos y melódicos que a continuación se detallan:

- Instrumentación: libre

- Tempo: Andantino

- Textura: melodía acompañada

- Inicio melódico:

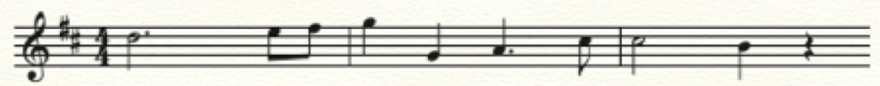

- Inicio armónico:

\begin{tabular}{|ll|ll|ll|ll|l|ll|}
\hline D & D/C\# & G/B & A & Gsus $^{4}$ & G & Em & Em/D & C & Dsus $^{4}$ & D $^{7}$ \\
\hline
\end{tabular}

Figura 6. Ejemplo de ejercicio propuesto mediando el criterio de evaluación 2 (elaboración propia).
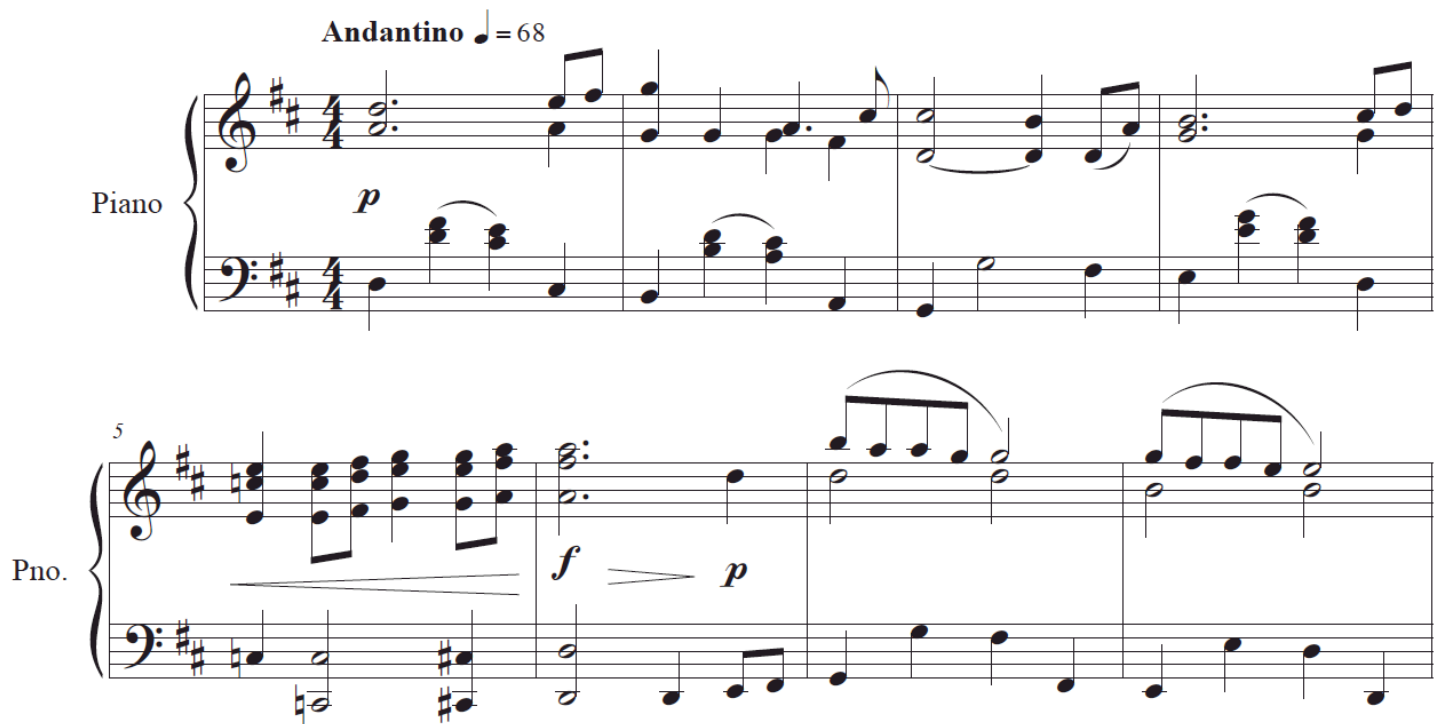

Figura 7. Realización para piano del ejercicio propuesto en la Figura 6 (elaboración propia). 
Diseño y planificación de competencias específicas en el currículum de enseñanzas profesionales de música: modalidades composición-dirección en la enseñanza superior.

Carlos Eduardo Pascual Pérez

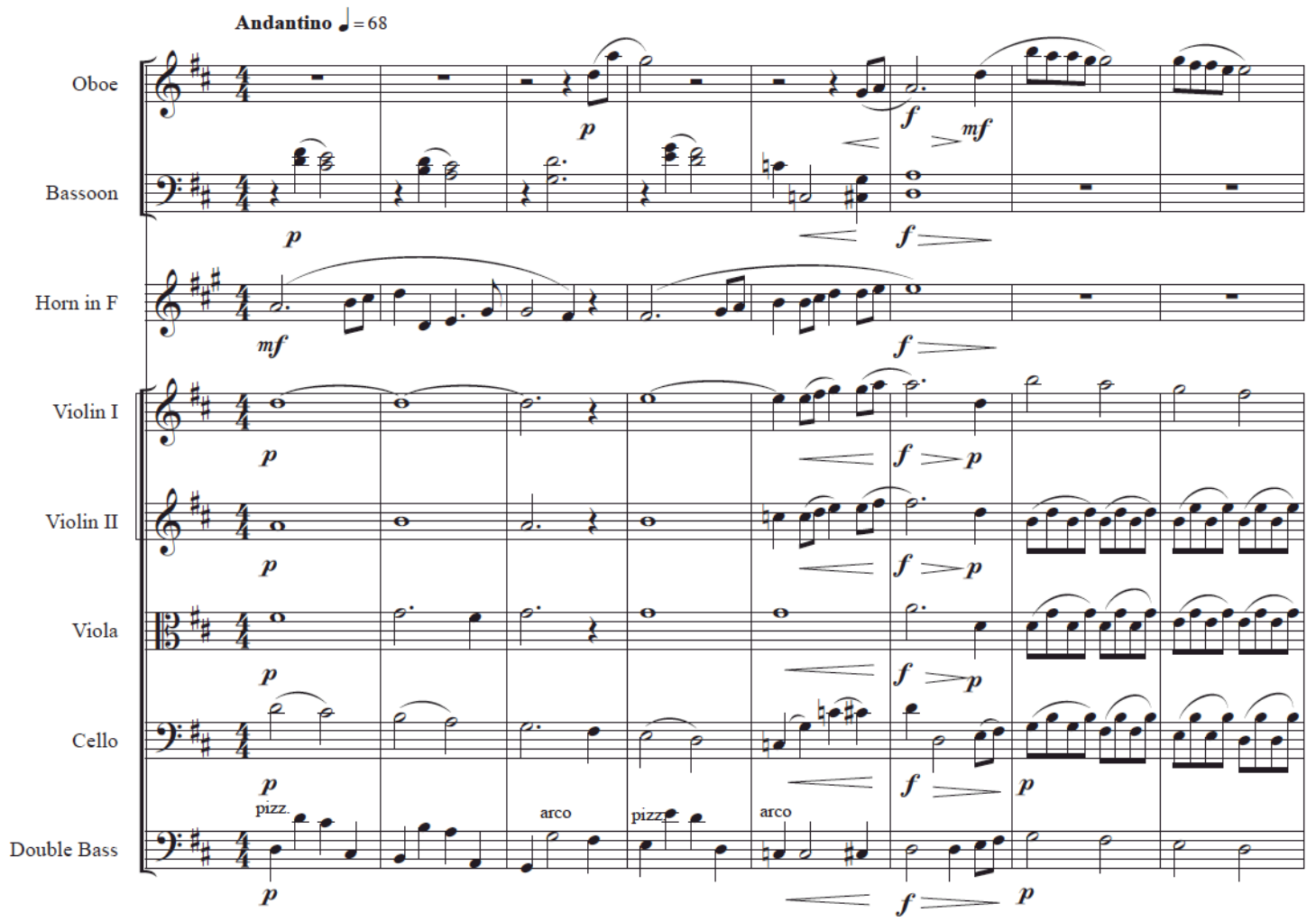

Figura 8. Realización para orquesta de cámara del ejercicio propuesto en la Figura 6

(elaboración propia).

Al finalizar esta asignatura, y con los mencionados cuatro cursos anteriores, las competencias transversales V y VI deberían estar adquiridas prácticamente en su totalidad, pudiendo seguir - aunque en menor medida - desarrollándose en la optativa de Fundamentos de dirección, la cual tendrá como principal desarrollo la competencia VII, pero que necesariamente implica a estas dos competencias para su completa evolución.

Nuevamente, dado que dicha propuesta tampoco cuenta con su parte experimental en la presente investigación, proponemos un ejercicio práctico cuya realización por parte del alumnado podría evaluar la adquisición tanto de los contenidos curriculares como de las 
Diseño y planificación de competencias específicas en el currículum de enseñanzas profesionales de música: modalidades composición-dirección en la enseñanza superior.

competencias transversales aplicadas tras ambos cursos de esta asignatura. Dada su extensión emplazamos dicho ejercicio junto a los respectivos de las demás asignaturas en el Anexo VIII.

\subsubsection{Optativa de diseño propio: Fundamentos de dirección}

Dado que el diseño de asignaturas optativas de diseño propio de un centro está contemplado en el Artículo 43 de la Orden 49/2015 de 14 de mayo de la Conselleria de Educación, Cultura y Deporte, la posibilidad de llevar a cabo un plan de estudios personalizado y perfilado no debería suponer un problema, salvo por deber cada centro realizar el suyo y quedando con efecto únicamente a los dos últimos cursos de las Enseñanzas Profesionales. Además, la citada Orden limita en su Artículo 42 a que "el alumnado curse una asignatura optativa en el quinto curso y otra distinta en el sexto curso", siendo todavía más complejo disponer de una continuidad de asignaturas afines. Este sería el caso nuestra asignatura propuesta para abordar íntegramente la competencia transversal VII; Fundamentos de dirección, que tendría además una continuidad lógica a la selección en el curso anterior de la asignatura Fundamentos de Composición.

Existen ejemplos de centros que han implementado una asignatura optativa relativa a esta iniciación a la dirección; muestra de ello es el Conservatorio Profesional de Música de Valencia (2020), con la optativa de creación propia Fundamentos de dirección. Desgraciadamente, no existe el documento público con la programación de dicha asignatura 
Diseño y planificación de competencias específicas en el currículum de enseñanzas profesionales de música: modalidades composición-dirección en la enseñanza superior.

en el momento de esta búsqueda, motivo por el cual no podemos contrastar el diseño curricular de la misma con el de nuestra propuesta.

Metodológicamente, en un primer nivel será necesario adquirir la capacidad de lectura y comprensión ante una partitura de una formación determinada, instrumental o coral. Más concretamente, deberá procederse desde partituras para agrupaciones más estandarizadas y sobre todo muchas de las que se desprenden de los descriptores de algunas pruebas de acceso al Grado de Dirección, siendo estas de música de cámara, coral a cuatro voces mixtas, orquesta de cuerda, orquesta de cámara, orquesta sinfónica o banda sinfónica - en este punto, la asignatura Análisis, así como el desarrollo de nuestra competencia VI serán fundamentales para agilizar este aprendizaje -. En un segundo nivel consecuente llega la gestualización de la dirección, es decir, la técnica básica propiamente del gesto, como punto de conexión entre todos los intérpretes de un conjunto. Como hemos referido antes, el alumno ya tiene conocimiento de dicha función gestual del director, al haber sido intérprete en varias agrupaciones de las asignaturas precedentes, y debe conocer ya de una manera profunda la práctica gestual en formato de receptor. Este hecho puede ayudar a la adquisición e interiorización de los conceptos básicos de esta iniciación técnica, como es la expresión gestual del tempo, la agógica y la dinámica.

La formación competencial podría continuar en un tercer nivel que acometería la corrección o adecuación de la interpretación, así como la dinámica de ensayo y elaboración del discurso. No obstante, consideramos que este plano no debe ser competencial en este nivel, puesto que 
Diseño y planificación de competencias específicas en el currículum de enseñanzas profesionales de música: modalidades composición-dirección en la enseñanza superior.

\section{Carlos Eduardo Pascual Pérez}

no se requerirá para superar una prueba de acceso, y que además requiere un conocimiento más profundo de muchos aspectos relacionados con la interpretación que el alumno no posee todavía, sin obviar que para dicho trabajo se requiere un grupo instrumental o vocal para poder realizarlo debidamente, y este planteamiento excede las limitaciones organizativas y curriculares del marco legislativo. Por otro lado, y sin profundizar en este tercer plano, existen múltiples posibilidades para que los alumnos puedan aplicar de manera práctica la competencia VII, mediante cualquiera de los grupos instrumentales y vocales de que dispone el centro incluido en el actual sistema de asignaturas ya descrito anteriormente.

Sirviendo los párrafos antecesores como introducción justificativa y metodológica, nos ajustamos a la norma proponiendo por último un modelo curricular basado en la relación de objetivos, contenidos y criterios de evaluación. Para la redacción de este tendremos como referencia el establecido para la asignatura Fundamentos de composición, debido a su máxima afinidad competencial.

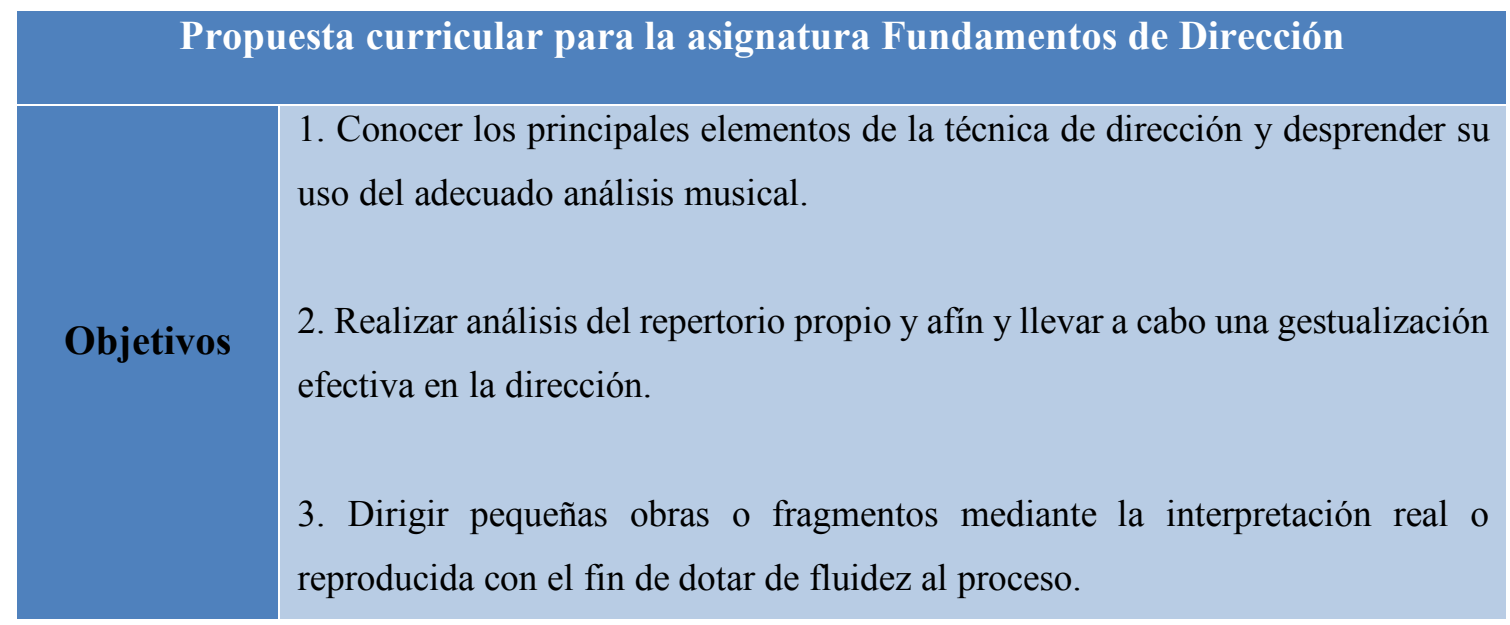


Diseño y planificación de competencias específicas en el currículum de enseñanzas profesionales de música: modalidades composición-dirección en la enseñanza superior.

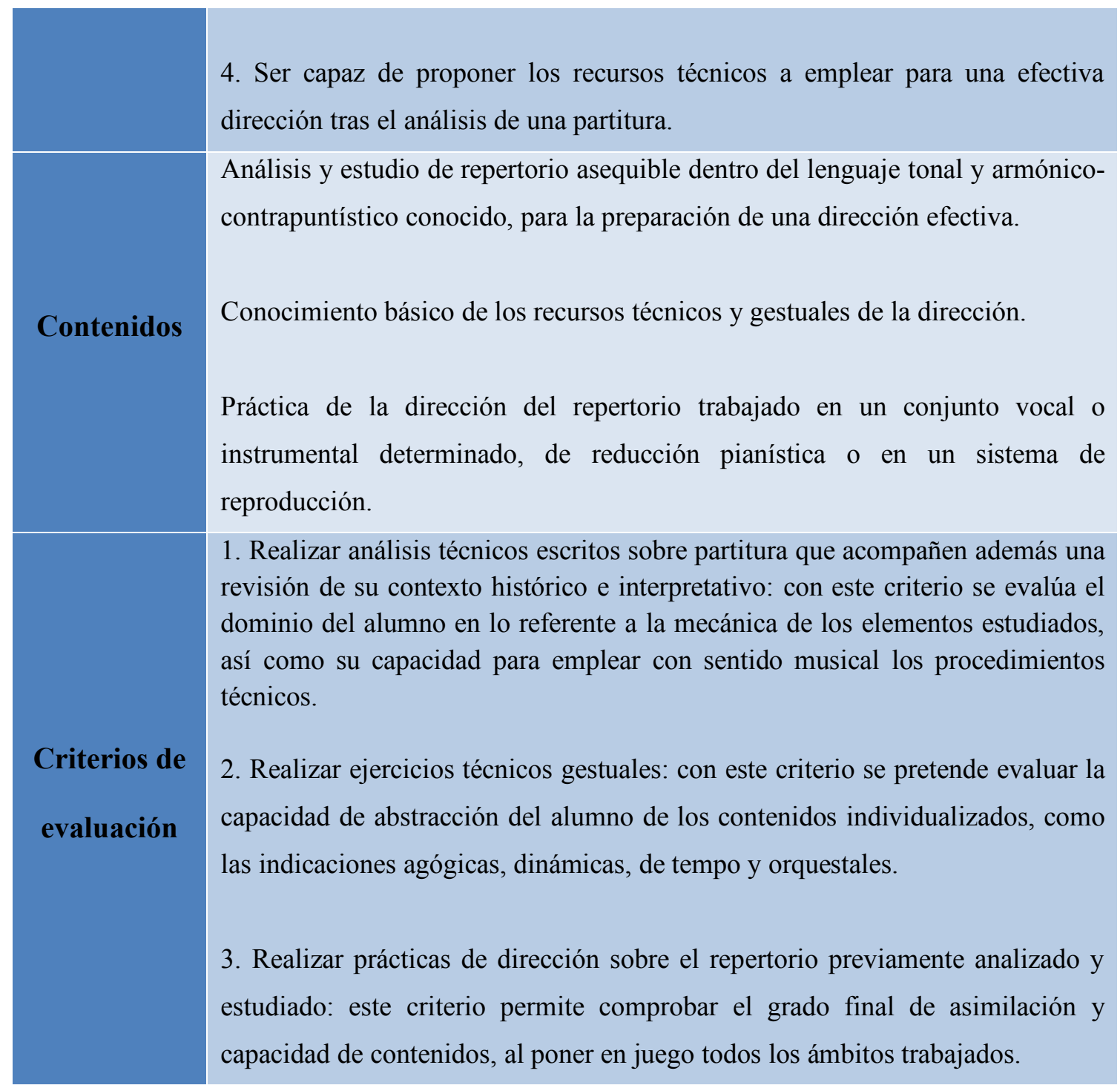

Tabla 5. Propuesta curricular para la asignatura optativa Fundamentos de dirección (elaboración propia).

Por último, dado que dicha propuesta tampoco cuenta con su parte experimental en la presente investigación, proponemos un ejercicio práctico cuya realización por parte del alumnado podría evaluar la adquisición tanto de los contenidos curriculares como de las 
Diseño y planificación de competencias específicas en el currículum de enseñanzas profesionales de música: modalidades composición-dirección en la enseñanza superior.

competencias transversales aplicadas tras ambos cursos de esta asignatura. Dada su extensión emplazamos dicho ejercicio junto a los respectivos de las demás asignaturas en el Anexo VIII.

\subsection{Aplicabilidad de la propuesta curricular}

Las posibilidades reales de aplicación de nuestra propuesta dependerán en gran medida de la predisposición del equipo directivo, departamentos y docentes - ya que de ellos deberá nacer la iniciativa de implementar cualquiera de las propuestas metodológicas -, pero sobre todo de la realidad y contexto del centro.

En primer lugar, debería existir una concienciación sobre la idoneidad de orientación y diversificación hacia los distintos grados superiores, o, aunque no haya un objetivo de continuidad por parte del alumnado, podría orientarse de igual modo hacia las preferencias o intereses del mismo. Dicha orientación debe perfilarse durante los dos primeros cursos de las enseñanzas profesionales (los cuales permanecen sin modificación en nuestra propuesta), y debería darse la situación de poder ofertar una diversificación que aglutinara al resto de grados superiores no referenciados en nuestra propuesta -la cual se desprende de nuestro perfil profesional y docente y sus dos titulaciones superiores afines-. Es decir, en el caso idóneo quedarían por implementar y diseñar las propuestas metodológicas para las especialidades de Jazz, Música antigua, Flamenco, Sonología, Musicología y Producción y gestión. Para ello sería necesaria una revisión en detalle de las pruebas de acceso a las mismas 
Diseño y planificación de competencias específicas en el currículum de enseñanzas profesionales de música: modalidades composición-dirección en la enseñanza superior.

y un desarrollo similar al que hemos realizado en nuestra propuesta concreta de Composición y Dirección. No obstante, las preferencias del alumnado podrían determinar un número limitado de perfiles, e incluso agrupar curricularmente aquellos que puedan tener correspondencia (como Sonología y Producción y gestión). Además, un análisis de la realidad de cada centro que incluya necesariamente sus características geográficas y sociales sería muy recomendable para determinar las posibles diversificaciones a realizar, que incluso podrían ser susceptivas de indicadores obtenidos mediante estadística por parte del alumnado y sus familias.

En segundo lugar, la realidad de centro también será factor determinante para dicha aplicación, puesto que la diversificación no debería suponer un aumento de la capacidad de este, es decir, un aumento de profesores y/o grupos, sino que se puede plantear como una reorganización de los recursos propios del centro. Podemos pensar, por ejemplo, en un centro que tiene cincuenta alumnos por curso, lo cual implica cinco grupos de la asignatura Armonía y otros cinco de Análisis al ser 1:10 la ratio que rige el Decreto 158/2007, en cuyo caso permitiría hasta cinco diversificaciones en un caso de distribución homogénea - las cuales podrían cubrir todos los itinerarios hacia los distintos títulos superiores -, pero en caso de existir otra distribución desigual ya no podría aplicarse toda la oferta, pero sí una selección concreta de la misma. Obviamente, en centros con un número menor de alumnado la posibilidad de ofertar una diversificación completa no será posible, pero esto no imposibilita la aplicación parcial de la propuesta, es decir, de uno o varios de los itinerarios. 
Diseño y planificación de competencias específicas en el currículum de enseñanzas profesionales de música: modalidades composición-dirección en la enseñanza superior.

Carlos Eduardo Pascual Pérez

Otro aspecto determinante para una aplicación de la propuesta es la competencia docente, la cual debería cubrir las necesidades que se desprendan de las competencias transversales. Los profesores que se desenvolviesen en la diversificación deberán poder aplicar las metodologías didácticas específicas, y esto implica que sean intrínsecas a su especialidad, como podrían ser las de nuestra propuesta para Composición, cuyo perfil docente para impartir las asignaturas de Armonía, Análisis y Fundamentos de Composición se desprenden de una titulación afín como es el Título Superior en Composición o el ingreso al cuerpo de profesores mediante una prueba específica o proceso selectivo denominado Fundamentos de Composición. En el caso de las competencias específicas para diversificar curricularmente hacia Jazz o Música antigua, por ejemplo, se requerirá una competencia docente que puede no se desprenda de la titulación afín de que disponga. Sin embargo, la formación permanente de un docente puede aportar dicha competencia, e incluso a partir de los perfiles profesionales del colectivo docente de un centro podrían cubrirse dichas las necesidades.

En el caso ideal, para un centro que contase con una diversificación completa, podrían habilitarse puestos específicos para titulados en estas especialidades, o sustituyéndose por otros perfiles más generalistas o centralistas en la rama interpretativa con objeto de no variar numéricamente los recursos humanos de un centro. En este sentido, encontramos la viabilidad de disponer de un perfil docente muy definido en el Real Decreto 303/2010, de 15 de marzo, por el que se establecen los requisitos mínimos de los centros que impartan enseñanzas artísticas reguladas en la Ley Orgánica 2/2006, de 3 de mayo, de Educación. En su Artículo 15 (p. 32105) autoriza lo siguiente. 
Diseño y planificación de competencias específicas en el currículum de enseñanzas profesionales de música: modalidades composición-dirección en la enseñanza superior.

Carlos Eduardo Pascual Pérez

"Excepcionalmente, para determinadas materias se podrán incorporar como profesores especialistas a profesionales, no necesariamente titulados, que ostenten la necesaria cualificación profesional y desarrollen su actividad en el ámbito laboral, de conformidad con las necesidades del sistema educativo."

Este hecho posibilita la incorporación en régimen laboral o administrativo de recursos humanos destinados a las necesidades causadas por una diversificación de itinerarios o perfiles formativos.

Con la citada voluntad mediante, existen herramientas económicas que pueden reforzar la idea de una diversificación convertida en proyecto de innovación educativa. Al amparo de la Resolución de 30 de abril de 2019, del director general de Política Educativa, existen “subvenciones y asignaciones económicas para desarrollar proyectos de investigación e innovación educativa en centros educativos sostenidos con fondos públicos”, que renovada anualmente hace referencia a la Orden 31/2016, de 4 de julio, de la Conselleria de Educación, Investigación, Cultura y Deporte, la cual estipula "las bases reguladoras de las subvenciones y asignaciones económicas para la realización de proyectos de investigación e innovación educativa en centros educativos no universitarios de la Comunitat Valenciana", dispone una financiación de entorno a los dos millones de euros anuales. Esto supone una cuantía que a modo de reparto podría paliar sobradamente las necesidades que implementar un itinerario diversificado pudiese suponer. Dichos proyectos susceptibles de subvencionarse deben responder a "a una necesidad de cambio o mejora detectada y reflexiona sobre la manera de 
Diseño y planificación de competencias específicas en el currículum de enseñanzas profesionales de música: modalidades composición-dirección en la enseñanza superior.

poner en marcha el proceso de cambio o mejora", contar con "un marco teórico que avala y da apoyo a la mejora", "aplicar metodologías activas que sitúan al alumnado en el centro del proceso", ser "viable económica y técnicamente, y perdurables en el tiempo" pudiendo "ser aplicadas en contextos educativos semejantes", entre otros descriptores. Ante todo lo expuesto, consideramos que nuestra propuesta ya conforma en sí misma un proyecto de innovación educativa que encaja con las características de los que se fomentan desde la administración, y que por tanto supondrían un generador de impulso válido para la implicación de los centros educativos desde su autonomía.

Sin perjuicio de todo lo expuesto, la aplicación de nuestra propuesta centrada en perfilar un itinerario hacia los grados superiores de Composición y/o Dirección (sin tener en cuenta las otras diversificaciones posibles) puede llevarse a cabo de un modo que únicamente afecte a la organización grupal. Como ya hemos indicado, los docentes encargados de la impartición de las asignaturas de Armonía, Análisis y Fundamentos de Composición deben, por su competencia afín, ser capaces de aplicar todas las propuestas metodológicas que se desprenden de las competencias específicas. Además, la figura docente encargada de las asignaturas obligatorias de Orquesta, Banda, Conjunto y/o Coro, contará de igual modo con la competencia docente para impartir una posible asignatura optativa referida a la técnica de la dirección, y que afectaría directamente a la Competencia Transversal VII. 
Diseño y planificación de competencias específicas en el currículum de enseñanzas profesionales de música: modalidades composición-dirección en la enseñanza superior.

Carlos Eduardo Pascual Pérez 


\title{
4. Diseño e intervención en el primer curso de la asignatura
}

\begin{abstract}
Armonía
Partiendo del diseño de competencias transversales al currículum propuesto, llevamos a cabo una experiencia de su aplicación inicial, para una de las asignaturas de nuestro itinerario en su primer curso de diversificación: “Armonía aplicada a la composición y dirección”, en su primer curso ubicado en $3^{\circ}$ de Enseñanzas Profesionales de Música, y que es simbiótica en la asignatura Armonía. Consideramos necesaria la experimentación y por tanto aplicación de la propuesta para obtener resultados que determinen si nuestra elaboración teórica puede ser significativa, y sobre todo desvelar las fisuras que pudiera contener para ejercer una autoevaluación y adecuación de la misma, si así fuese necesario. Dada la magnitud de la propuesta completa - que afectaría a cuatro cursos escolares y tres asignaturas con diversificación para cada uno de ellos -, focalizamos nuestra aplicación a la primera de las asignaturas, con diversos grupos experimentales en conservatorios de la Comunidad Valenciana.
\end{abstract}

\subsection{Diseño de la intervención}

\subsubsection{Pretest}

Para el diseño del test de conocimientos iniciales hemos tomado los contenidos curriculares que previamente al momento del pretest (inicio del $3^{\circ}$ curso de Enseñanzas Profesionales) 
Diseño y planificación de competencias específicas en el currículum de enseñanzas profesionales de música: modalidades composición-dirección en la enseñanza superior.

Carlos Eduardo Pascual Pérez

deberían estar asumidos. Estos se desprenden fundamentalmente de los dos cursos anteriores y que son predecesores naturales en el plan de estudios; la asignatura de Lenguaje Musical.

\subsubsection{Currículum de la asignatura Lenguaje Musical en la Comunidad Valenciana y su contenido vinculante a la elaboración del Pretest}

Tal y como versa el Decreto 158/2007 de 21 de septiembre, los objetivos, contenidos y criterios de evaluación de la asignatura Lenguaje musical para las enseñanzas profesionales son:

\section{$\underline{\text { Objetivos }}$}

a) Compartir vivencias musicales con los demás elementos del grupo que le permita enriquecer su relación afectiva con la música a través del canto y de participación instrumental en grupo.

b) Conocer los elementos del lenguaje musical y su evolución histórica, para relacionarlos con las obras musicales dentro de su tiempo y su circunstancia.

Interpretar correctamente los símbolos gráficos y conocer los que son propios del lenguaje musical contemporáneo.

c) Utilizar la disociación motriz y auditiva necesarias para ejecutar o escuchar con independencia desarrollos rítmicos o melódicos simultáneos.

d) Reconocer y representar gráficamente obras, fragmentos musicales a una o dos voces realizadas con diferentes instrumentos.

e) Reconocer a través de la audición y de la lectura estructuras armónicas básicas. 
Diseño y planificación de competencias específicas en el currículum de enseñanzas profesionales de música: modalidades composición-dirección en la enseñanza superior.

Carlos Eduardo Pascual Pérez

f) Utilizar los conocimientos sobre el lenguaje musical para afianzar y desarrollar hábitos de estudio que propicien una interpretación consciente.

g) Conocer los elementos del lenguaje musical relativos al “jazz” y la música moderna.

\section{$\underline{\text { Contenidos }}$}

Rítmicos: Practica, identificación y conocimiento de compases originados por dos o más pulsos desiguales. Conocimiento y practica de metros irregulares con estructuras fijas o variables. Polirritmias y polimetrías. Reconocimiento y práctica de grupos de valoración especial con duraciones y posiciones métricas varias. Practica de ritmos simultáneos que suponen divisiones distintas de la unidad. Practica de estructuras rítmicas atípicas en compases convencionales. Ritmos "aksak", "cojos" o de valor añadido. Practica de música sin compasear. Reconocimiento y práctica de ritmos que caracterizan la música de "jazz", "pop”, etc. Practica de cambios de compás con unidades iguales o diferentes y aplicación de las equivalencias indicadas. Desarrollo de hábitos interpretativos a partir del conocimiento y análisis de los elementos rítmicos. Improvisación sobre esquemas rítmicos establecidos o libres.

Melódico-armónicos: Practica auditiva y vocal de estructuras tonales enriquecidas en su lenguaje por flexiones o modulaciones, con reconocimiento analítico del proceso. Practica auditiva y vocal de obras modales en sus diversas manifestaciones históricas y folklóricas. Practica de interválica pura (no tonal) y aplicación a obras post-tonales $\mathrm{o}$ atonales. Reconocimiento auditivo y análisis de estructuras tonales y formales no complejas. Improvisación sobre esquemas armónicos y formales establecidos o libres. Aplicación vocal o escrita de bajos armónicos a obras propuestas de dificultad adaptada al nivel. Desarrollo de hábitos interpretativos a partir del conocimiento y análisis de los elementos melódicos-armónicos.

Lecto-escritura: Practica de lectura horizontal de notas con los ritmos escritos e indicaciones metronómicas diversas. Lecturas de agrupaciones verticales de notas. 
Diseño y planificación de competencias específicas en el currículum de enseñanzas profesionales de música: modalidades composición-dirección en la enseñanza superior.

Carlos Eduardo Pascual Pérez

Conocimiento y práctica de las normas de escritura melódica y armónica. Practica de lectura de notas, sin clave, ateniéndose al dibujo interválico. Practica de identificación y escritura de notas en su registro correcto. Conocimiento del ámbito sonoro de las claves. Iniciación a las grafías contemporáneas. Practica de la lectura a primera vista.

Audición: Practica de identificación de elementos rítmicos, melódicos, modulatorios, cadenciales, formales, tímbricos y estilísticos en las obras escuchadas. Identificación de errores o diferencias entre un fragmento escrito y lo escuchado. Practica de la memoria: memorización previa a la escritura de frases o fragmentos progresivamente más amplios. Escritura de temas conocidos y memorización en diferentes alturas, tonalidades. Realización escrita de dictados a una y dos voces. Identificación de acordes. Audición de obras o fragmentos en los que se reconozcan elementos estudiados.

Expresión y ornamentación: Conocimiento y aplicación de signos y términos relativos a dinámica y agógica. Conocimiento y aplicación de los signos que modifican el ataque de los sonidos. Conocimiento de los signos característicos en la escritura de los instrumentos. Conocimiento y aplicación de ornamentos adecuándolos a la época de la obra interpretada.

\section{$\underline{\text { Criterios de evaluación }}$}

1. Mantener el pulso durante períodos de silencio prolongados. Este criterio tiene por objetivo evaluar una correcta interiorización del pulso que permita una ejecución correcta bien individual o en conjunto.

2. Identificar y ejecutar estructuras rítmicas de una obra o fragmento, con o sin cambio de compás, en un tempo establecido.

Con este criterio se trata de evaluar la capacidad del alumnado para encadenar diversas fórmulas rítmicas, la aplicación correcta, en su caso, de cualquier equivalencia si se 
Diseño y planificación de competencias específicas en el currículum de enseñanzas profesionales de música: modalidades composición-dirección en la enseñanza superior.

Carlos Eduardo Pascual Pérez

produce cambio de compás y la interiorización aproximada de diversas velocidades metronómicas.

3. Entonar repentizando una melodía o canción tonal con o sin acompañamiento, aplicándole todas las indicaciones de carácter expresivo.

Este criterio de evaluación tiene por objeto comprobar la capacidad del alumnado para aplicar sus técnicas de entonación y la justeza de afinación a un fragmento melódico tonal con alteraciones accidentales que pueden o no provocar una modulación, haciéndose consciente de las características tonales o modales del fragmento. Si es acompañado instrumentalmente, este acompañamiento no debe reproducir la melodía.

4. Leer internamente, en un tiempo breve y sin verificar su entonación, un texto musical y reproducirlo de memoria.

Se trata de comprobar la capacidad del alumnado para imaginar, reproducir y memorizar imágenes sonoras de carácter melódico a partir de la observación de la partitura.

5. Identificar o entonar todo tipo de intervalo melódico.

Este criterio de evaluación permite detectar el dominio del intervalo por parte del alumnado como elemento de aplicación a estructuras tonales o no tonales.

6. Entonar una obra atonal con o sin acompañamiento, aplicando las indicaciones de carácter expresivo.

Se trata de evaluar la aplicación artística a una obra atonal de los conocimientos melódicos y rítmicos adquiridos. El acompañamiento, en su caso, no reproducirá la melodía.

7. Identificar intervalos armónicos y escribirlos en su registro correcto. 
Diseño y planificación de competencias específicas en el currículum de enseñanzas profesionales de música: modalidades composición-dirección en la enseñanza superior.

\section{Carlos Eduardo Pascual Pérez}

Se busca conocer la capacidad del alumnado para la percepción simultánea de dos sonidos en diferentes relaciones interválicas, así como la identificación de las regiones sonoras en que se producen.

8. Reproducir modelos melódicos, escalísticos o acordales en diferentes alturas.

Se trata de comprobar la destreza del alumnado para reproducir un hecho melódico a partir de diferentes sonidos, haciéndose consciente de las alteraciones necesarias para su exacta reproducción.

9. Improvisación vocal o instrumental de melodías dentro de una tonalidad determinada.

Este criterio pretende comprobar el entendimiento por parte del alumnado de los conceptos tonales básicos al hacer uso libre de los elementos de una tonalidad con lógica tonal y estructural.

10. Identificar y reproducir por escrito fragmentos musicales escuchados.

Con este criterio se evalúa la destreza del alumnado para la utilización correcta de la grafía musical y su capacidad de relacionar el hecho musical con su representación gráfica.

11. Reconocer y escribir fragmentos musicales a dos voces.

Se pretende comprobar la percepción e identificación por parte del alumnado de aspectos musicales polifónicos.

12. Reconocer y escribir fragmentos musicales realizados por dos instrumentos diferentes, excluyendo el piano.

Con este criterio se pretende comprobar que la capacidad auditiva del alumnado no sufre distorsión cuando recibe el mensaje a través de un vehículo sonoro diferente al piano. 
Diseño y planificación de competencias específicas en el currículum de enseñanzas profesionales de música: modalidades composición-dirección en la enseñanza superior.

Carlos Eduardo Pascual Pérez

13. Reconocer auditivamente aspectos cadenciales y formales de un fragmento musical.

Por medio de este criterio se trata de comprobar la capacidad del alumnado para percibir aspectos sintácticos y estructurales de la obra escuchada y denominarlos correctamente.

14. Reconocer auditivamente diferentes timbres instrumentales.

Se pretende constatar la familiarización del alumnado con los timbres provenientes de otros instrumentos diferentes del que constituye su especialidad.

15. Reconocer auditivamente modos de ataque, articulaciones, matices y ornamentos de una obra o fragmento.

Se trata en este caso de comprobar la capacidad de observación del alumnado de aspectos directamente relacionados con la interpretación y expresión musicales.

16. Improvisar vocal o instrumentalmente sobre un esquema armónico dado.

Este criterio de evaluación va ordenado a comprobar, dentro del nivel adecuado, la comprensión por parte del alumnado de la relación entre armonía y voces melódicas.

17. Entonar fragmentos memorizados de obras de repertorio seleccionados entre los propuestos por el alumno o alumna.

Este criterio trata de evaluar el conocimiento de las obras de reper- torio y la capacidad de memorización.

18. Aplicar libremente ritmos percutidos a un fragmento musical escuchado.

Se busca aquí evaluar la capacidad de iniciativa implicando, además, el reconocimiento rápido de aspectos rítmicos y expresivos de la obra en cuestión. 
Diseño y planificación de competencias específicas en el currículum de enseñanzas profesionales de música: modalidades composición-dirección en la enseñanza superior.

\section{Carlos Eduardo Pascual Pérez}

19. Aplicar bajos armónicos sencillos, vocal o gráficamente, a una obra breve previamente escuchada.

Este criterio pretende buscar la asociación melodía-armonía imaginando ésta desde la melodía escuchada.

20. Situar con la mayor aproximación posible la época, el estilo y, en su caso, el autor o la autora de una obra escuchada.

Se trata de una propuesta para fomentar la curiosidad y la atención del alumnado al escuchar música, haciéndose consciente de los caracteres generales que identifican estilos y autores.

21. Analizar una obra de su repertorio instrumental, como situación histórica, autor y características musicales de la misma: Armónicas, formales, tímbricas, etc.

Intenta este criterio potenciar los hábitos del estudio inteligente y riguroso, haciéndose consciente de las circunstancias técnicas y sociales que rodean a la obra artística.

\subsubsection{Definición de contenidos}

Tras analizar el contenido curricular de la asignatura, extraemos aquellos contenidos que son susceptibles de servir como punto inicial para el desarrollo de nuestra intervención, y que basarán la elaboración del pretest:

CPreT1: Desarrollo de hábitos interpretativos a partir del conocimiento y análisis de los elementos melódico-armónicos (contenido melódico-armónico). 
Diseño y planificación de competencias específicas en el currículum de enseñanzas profesionales de música: modalidades composición-dirección en la enseñanza superior.

Carlos Eduardo Pascual Pérez

CPreT2: Lectura de agrupaciones verticales de notas (contenido lecto-escritura).

CPreT3: Conocimiento y práctica de las normas de escritura melódica y armónica (contenido lecto-escritura).

CPreT4: Práctica de identificación y escritura de notas en su registro correcto (contenido lecto-escritura).

CPreT5: Conocimiento del ámbito sonoro de las claves (contenido lecto-escritura).

CPreT6: Conocimiento de los signos característicos en la escritura de los instrumentos (contenido expresión-ornamentación).

Por otro lado, necesitamos analizar también de forma previa si las competencias específicas (referidas a la organología) que pretendemos desarrollar en nuestra futura intervención se desconocen o al menos en qué grado están asumidas, ya sea por haber desarrollado contenidos no curriculares en cursos anteriores o bien por la práctica inherente de una especialidad instrumental. En este caso, tomamos nuestra competencia transversal VI (Organología, instrumentación y orquestación en el ámbito de la orquesta sinfónica) como referencia, ya que será la competencia fundamental en nuestra intervención. 


\subsubsection{Elaboración del Pretest}

El Pretest de conocimientos iniciales constará, según lo atendido en el punto anterior, de dos ejercicios escritos. El primero de ellos consiste en identificar la afinación y octavación (transporte) de una serie de instrumentos orquestales, que comprenderán desde los más comunes hasta los más excepcionales, así como de todas las familias instrumentales, con objeto de tener un amplio espectro de respuestas. Este primer ejercicio abarcará la organología en el ámbito de la orquesta sinfónica, referida a la competencia transversal. El segundo ejercicio consta de la realización escrita de cuatro acordes, partiendo del cifrado armónico (cifrado barroco) y/o del cifrado de acordes (cifrado americano), pero aplicada a una plantilla instrumental en la que hay instrumentos transpositores e instrumentos no transpositores y en distintas claves. En este ejercicio se incluye la instrumentación en el ámbito de la orquesta sinfónica, referida también a la competencia transversal. 
Diseño y planificación de competencias específicas en el currículum de enseñanzas profesionales de música: modalidades composición-dirección en la enseñanza superior.

\section{PRETEST: CONOCIMIENTOS INCIALES}

Alumno:

Fecha:

Firma:

1. Identifica la afinación y octavación de los siguientes instrumentos. Puedes indicar el número de octavas que transportan y su sentido (ascendente o descentente) o también el intervalo resultante de su transporte.

\begin{tabular}{|l|l|l|l|l|l|}
\hline \multicolumn{1}{|c|}{ Instrumento } & Afinación & Octavación & Instrumento & Afinación & Octavación \\
\hline Oboe & & & Clarinete bajo & & \\
\hline Flautín & & & Saxofón alto & & \\
\hline Fagot & & & Saxofón tenor & & \\
\hline Contrabajo & & & Lira & & \\
\hline Trompa & & & Flauta alto & & \\
\hline
\end{tabular}

2. Realiza los siguientes acordes a cuatro voces partiendo de una nota en el bajo con cifrado barroco o a partir de cifrado de acordes (americano). Fijate que cada voz es un instrumento, habiendo transpositores y no transpositores.

$\mathrm{Am} / \mathrm{C}$

C 7

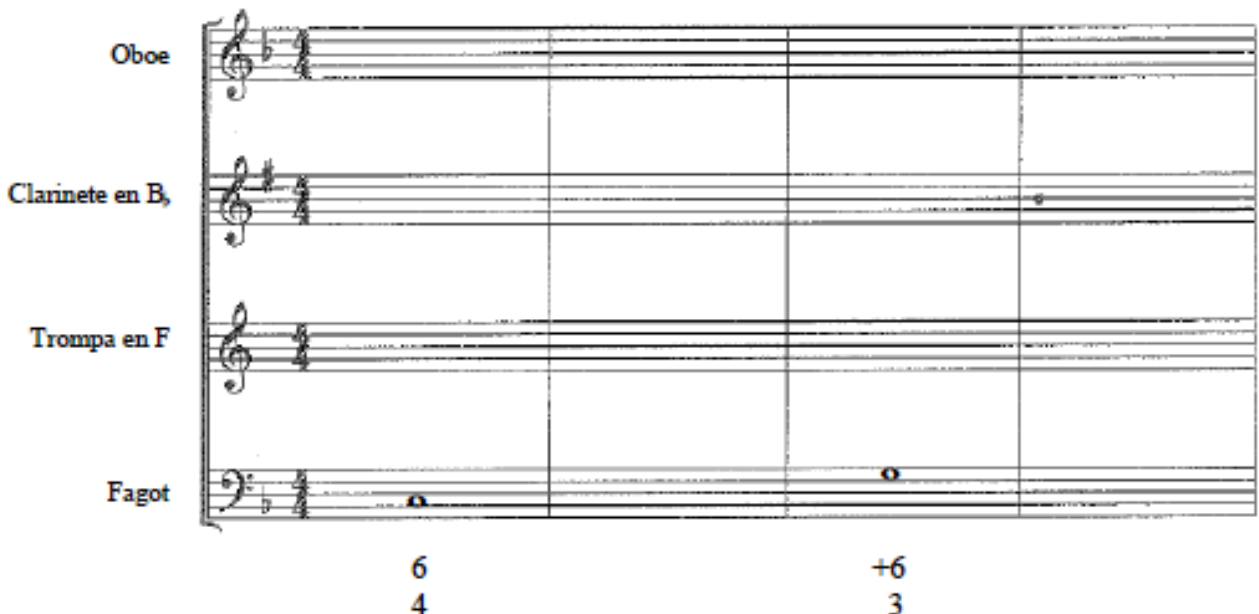

Figura 9. Pretest (elaboración propia). 
La determinación de los contenidos curriculares nos permite aislar en variables la competencia transversal que implementamos en este pretest, y no considerar el grado de adquisición de los contenidos mencionados. En cualquier caso, dichos contenidos están incluidos en los dos cursos precedentes y se plantean de un modo sencillo, por lo que no contemplamos el escenario de que un el alumno no sepa resolver el ejercicio o que le suponga un impedimento para su comprensión.

\begin{tabular}{l|l|l|} 
& $\begin{array}{l}\text { Contenidos curriculares de } \\
\text { asignatura de Lenguaje Musical }\end{array}$ & seleccionadas como base \\
\hline Ejercicio 1 & CPreT4, CPreT6 & VI \\
\hline Ejercicio 2 & CPreT1, CPreT2, CPreT3, CPreT4, & VI \\
& CpreT5, CPreT6 & \\
\hline
\end{tabular}

Tabla 6. Relación entre los contenidos curriculares y la competencias específicas seleccionadas para el pretest (elaboración propia).

Mediante esta separación definimos seis variables y sus descriptores cuyo origen reside únicamente en el descriptor de nuestra competencia transversal, así como el número de ítems asociados a las mismas del pretest. La diferencia entre el número de ítems aplicados a cada variable reside en la complejidad de la respuesta, aplicando un menor número para las asociaciones múltiples y un mayor número para las individuales: 
Diseño y planificación de competencias específicas en el currículum de enseñanzas profesionales de música: modalidades composición-dirección en la enseñanza superior.

Carlos Eduardo Pascual Pérez

- Organología de instrumentos no transpositores: 5 ítems

- Conoce y sabe interpretar las características de ámbito, registro y técnica de los siguientes instrumentos no transpositores pertenecientes a las diferentes familias instrumentales del ámbito orquestal (cordófonos, aerófonos e idiófonos): Oboe, Flautín, Fagot, Contrabajo y Lira.

- Organología de instrumentos transpositores: 5 ítems

- Conoce y sabe interpretar las características de ámbito, registro y técnica de los siguientes instrumentos transpositores (aerófonos) del ámbito orquestal : Clarinete bajo, Trompa en F, Saxofón alto, Saxofón tenor y Flauta alto.

- Lecto-escritura de instrumentos no transpositores: 6 ítems

- Sabe reconocer comportamientos armónicos en dos voces ejecutadas de los siguientes instrumentos no transpositores, ya sean de su misma familia instrumental o combinadas: Oboe y Fagot.

- Lecto-escritura en instrumentos transpositores: 8 ítems

- Sabe reconocer comportamientos armónicos en dos voces ejecutadas de los siguientes instrumentos transpositores, ya sean de su misma familia instrumental o combinadas: Clarinete en $\mathrm{Bb}$ y Trompa en $\mathrm{F}$. 
Diseño y planificación de competencias específicas en el currículum de enseñanzas profesionales de música: modalidades composición-dirección en la enseñanza superior.

- Asociación entre instrumentos transpositores y no transpositores: 4 ítems

- Sabe reconocer comportamientos armónicos entre cuatro voces ejecutadas por los siguientes instrumentos mixtos (dos transpositores junto a dos no transpositores), ya sean de su misma familia instrumental o combinadas: Oboe, Clarinete en Bb, Trompa en F y Fagot.

Decidimos crear una división entre aquellos instrumentos transpositores y aquellos que no lo son debido a que estos últimos coinciden en su base con la práctica en escritura pianística o sin determinación de afinación, siendo esta la práctica habitual en los cursos precedentes. Por tanto, consideramos analizar si existe esta diferencia por asociación de estos instrumentos o no la hay, para en cualquier caso disponer de un conjunto de respuestas válido para el análisis. Además, ajustamos la proporcionalidad en el número de ítems de mayor a menor dificultad de realización. Por último, establecemos unos criterios de calificación homogéneos y estándares, que responderán a una regla de simplicidad en la que los ítems reducidos al mínimo forman una unidad cuantitativa no variable para la cual sólo se admite acierto completo o por el contrario errónea otra respuesta distinta. Además, eliminaremos la penalización ante la carencia de respuesta, puesto que buscamos establecer una evaluación inicial ante contenidos que no podemos presumir como ya asimilados por el alumnado.

- Respuesta válida por cada ítem (cuantitativa): única 
Diseño y planificación de competencias específicas en el currículum de enseñanzas profesionales de música: modalidades composición-dirección en la enseñanza superior.

Carlos Eduardo Pascual Pérez

- Puntuación por cada ítem correcto: 1

- Puntuación por cada ítem incorrecto: 0

- Puntuación por cada ítem carente de respuesta: 0

\subsubsection{Ejercicios tipo y metodología}

Teniendo siempre presente que se debe respetar el currículum establecido (Decreto 158/2007, p.37021), partiremos de los criterios de evaluación estipulados para la asignatura Armonía para implementar en ellos la competencia transversal VI mediante ejemplos técnicos y metodológicos. Podemos agruparlos en tres subconjuntos; los se fundamentan en la creación / elaboración (del $n^{\circ} 1$ al no 4), del análisis auditivo $\left(n^{\circ} 5, n^{\circ} 6, n^{\circ} 7\right.$ y $\left.n^{\circ} 11\right)$ y del análisis visual (no $8, n^{\circ} 9, n^{\circ} 10$ y n 12$)$

El criterio de evaluación $\mathrm{n}^{\circ} 1$, "Realizar ejercicios a partir de un bajo cifrado dado" pretende comprobar el dominio del alumnado en lo referente a la mecánica de encadenamiento de acordes y su aplicación a una realización cuidada e interesante desde el punto de vista musical. Los ejemplos habituales de esta realización a cuatro voces corales en distribución de doble pentagrama los hallamos en todos los manuales y metodologías empleados en la actualidad de forma generalizada, como en Harmony (Piston, 1941), Harmonielehre (de la Motte, 1998), Apuntes de Armonía (Chuliá, 2002), Armonía Tonal (Blanes, 2002) o Armonía práctica (Mateu, 2004) entre otros. 
Diseño y planificación de competencias específicas en el currículum de enseñanzas profesionales de música: modalidades composición-dirección en la enseñanza superior.

Carlos Eduardo Pascual Pérez

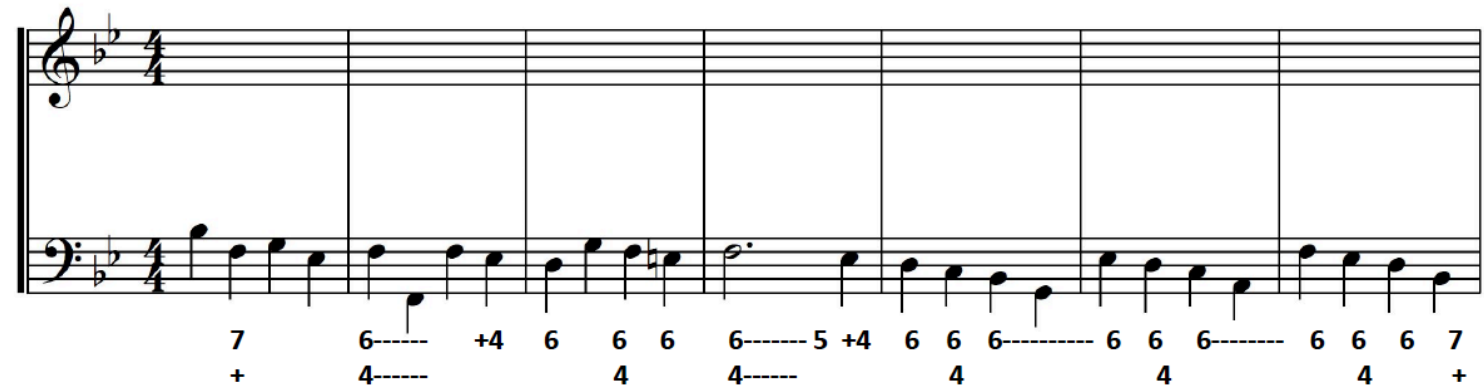

Figura 10. Ejemplo de bajo cifrado para su realización a cuatro voces (Gilabert, 2020).

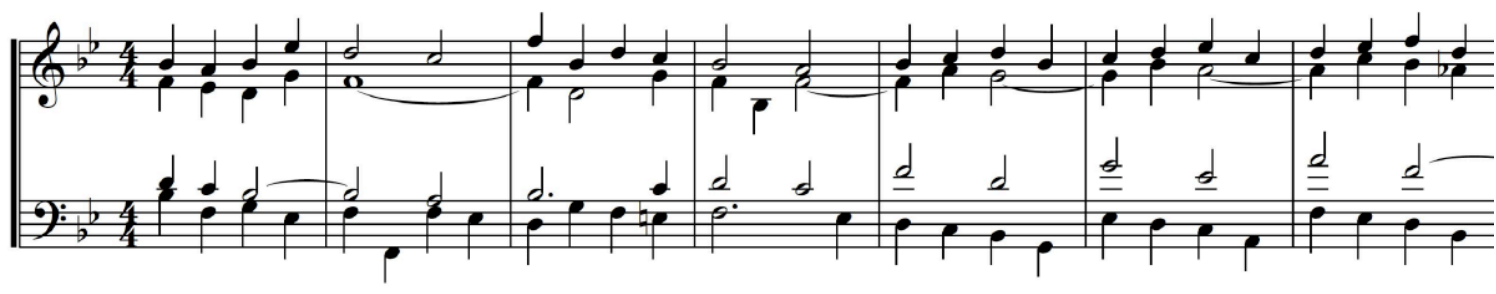

Figura 11. Ejemplo de realización del bajo cifrado de la Figura 10 (Gilabert, 2020).

La metodología empleada para la implementación de nuestra competencia VI mediante la realización de bajos dados se fundamentará en la no realización tradicional a cuatro voces corales en doble pentagrama, sino a cuatro voces instrumentales en pentagramas individuales. Para ello será necesario abordar teóricamente los aspectos técnicos de organología aplicados al conjunto de cuatro instrumentos que se escoja. La determinación del mismo deberá ser adecuada para que se puedan respetar las normas de realización estándar a cuatro partes - fundamentalmente la distancia máxima entre voces y el registro asociado a la práctica coral -, y teniendo siempre presente completar la totalidad de las familias e instrumentos descritos en el desarrollo de la competencia VI al concluir ambos cursos de la asignatura. 
Diseño y planificación de competencias específicas en el currículum de enseñanzas profesionales de música: modalidades composición-dirección en la enseñanza superior.

Carlos Eduardo Pascual Pérez

La ayuda técnica y ejemplos pueden extraerse de los manuales de orquestación, instrumentación y organología de uso generalizado, como El estudio de la orquestación (Adler, 2006), Orchestration (Piston, 1955), Principios de orquestación (Korsakov, 1946) o La técnica de la orquesta contemporánea (Casella, 1950), entre otros. No obstante, deberá limitarse y filtrarse debidamente la información técnica de cada instrumento para que se ajuste a las necesidades propiamente descritas en la competencia.

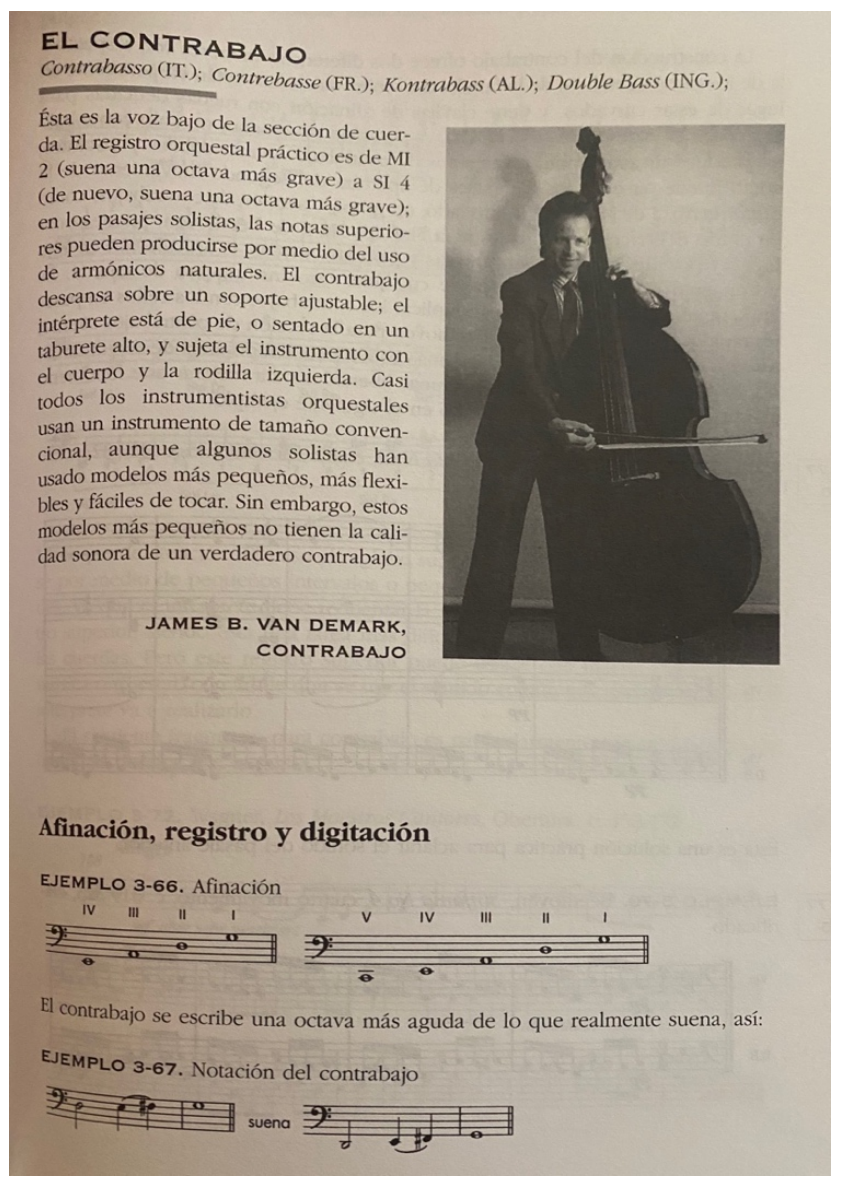

Figura 12. Ejemplo de características técnicas y organológicas de un instrumento. Extraído de $E l$ estudio de la orquestación (p.83) por Samuel Adler, 2006, Barcelona: Idea Books. Todos los derechos reservados; reproducción autorizada con fines académicos según Artículo 32.1 de la Ley de Propiedad Intelectual en España. 
Diseño y planificación de competencias específicas en el currículum de enseñanzas profesionales de música: modalidades composición-dirección en la enseñanza superior.

Establecido el marco instrumental y estudiadas sus características propias, será necesario ejecutar el criterio de evaluación, pero ya aplicado a un conjunto instrumental concreto. Para ello se puede proveer al alumnado de una plantilla similar a la propuesta en la Figura 13, o bien permitir al alumnado crear una similar partiendo desde cero.

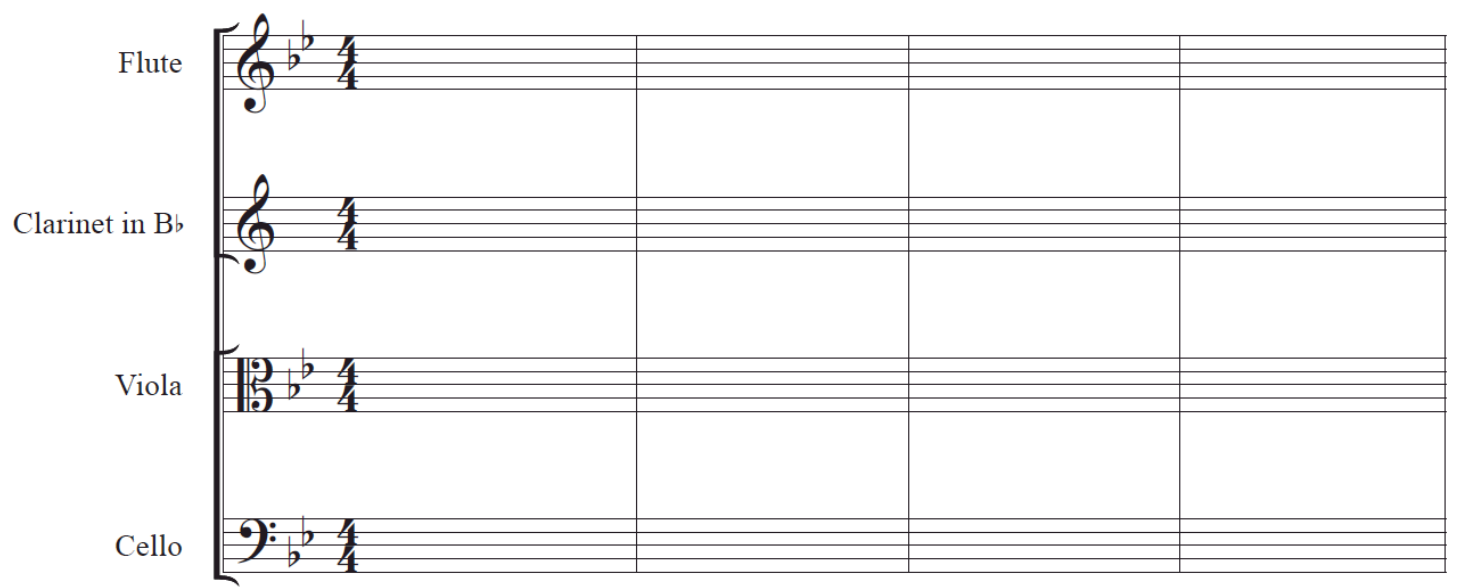

Figura 13. Ejemplo de plantilla instrumental para realizaciones armónicas a cuatro partes (elaboración propia).

Puesto que la realización armónica responde a los contenidos curriculares de la asignatura, su mecanismo para el alumno será idéntico, salvo que deberán tenerse en cuenta el conjunto de características propias de los instrumentos empleados - y que previamente han sido estudiados -, por lo que estará poniendo en práctica la competencia transversal VI. Tomando como ejemplo el bajo propuesto en la Figura 10 y su realización en la Figura 11, obtendríamos la realización instrumental que mostramos a continuación en la Figura 14. 
Diseño y planificación de competencias específicas en el currículum de enseñanzas profesionales de música: modalidades composición-dirección en la enseñanza superior.

Carlos Eduardo Pascual Pérez
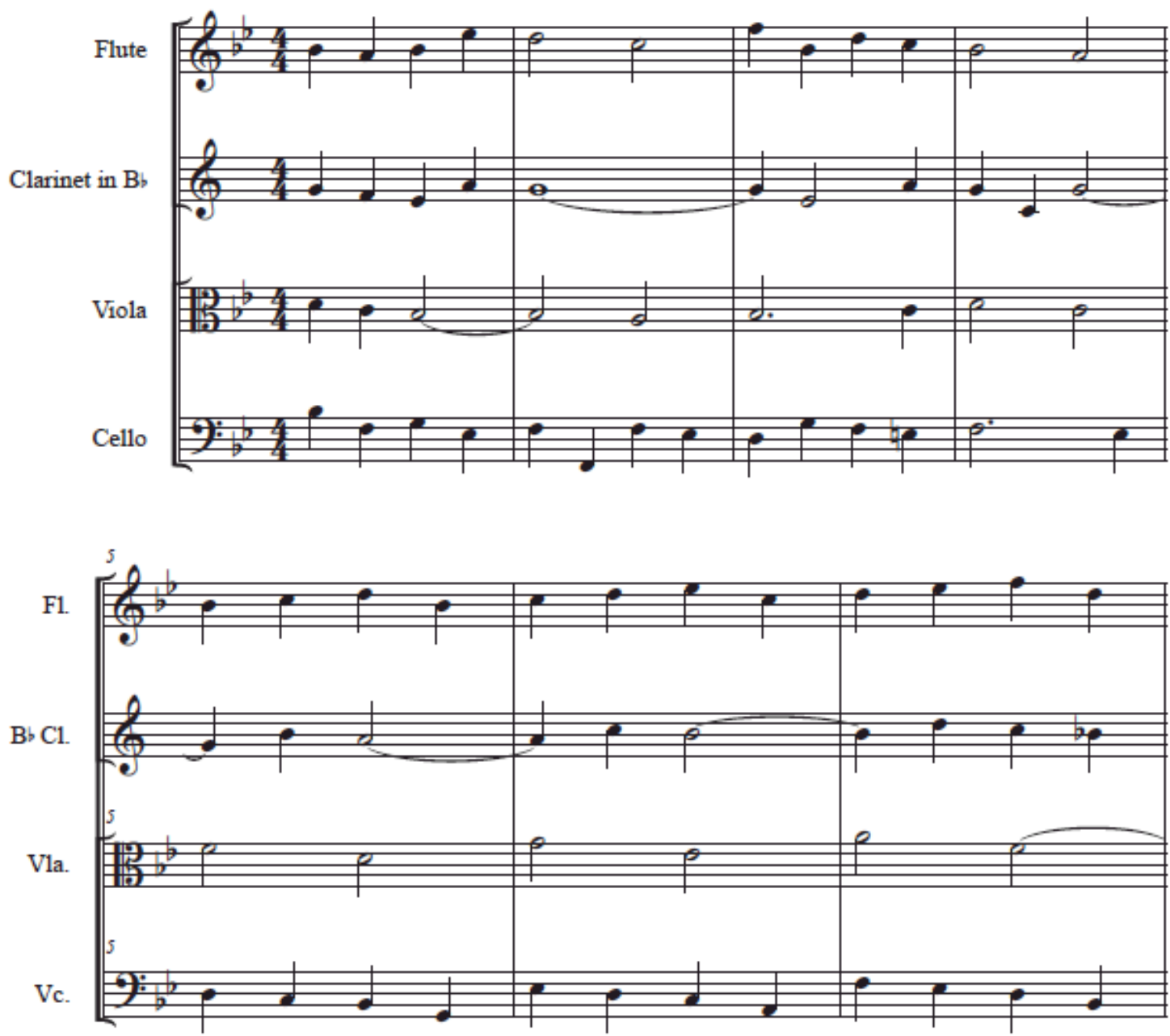

Figura 14. Realización propuesta en la Figura 10 para un conjunto de cuatro instrumentos (elaboración propia).

El resultado esperado de dichas realizaciones será que en el alumno vayan interiorizándose las habilidades que hemos descrito para la competencia transversal VI. A medio plazo, las mismas serán de utilidad para seguir desarrollándose la misma competencia y poder abordar satisfactoriamente la VII, en su ámbito de relación con la lectura instrumental. Por supuesto, 
Diseño y planificación de competencias específicas en el currículum de enseñanzas profesionales de música: modalidades composición-dirección en la enseñanza superior.

el fin último de dicho proceso será haber adquirido en su totalidad las habilidades necesarias que se desprenden de las específicas pruebas de acceso.

Para los criterios de evaluación $\mathrm{n}^{\mathrm{o}} 2, \mathrm{n}^{\mathrm{o}} 3$ y $\mathrm{n}^{\circ} 4$ aplicaremos una metodología similar a la descrita para el $\mathrm{n}^{\circ} 1$. Son, respectivamente, "Realizar ejercicios de armonización a partir de tiples dados", "Realizar ejercicios de armonización a partir de bajos sin cifrar dados" y "Componer ejercicios breves a partir de un esquema armónico dado o propio". Estos tienen como objetivos evaluar la capacidad de síntesis el uso de los procedimientos armónicos ya asimilados, incidiendo en lograr una consecución correcta e interesante desde la musicalidad. Es decir, estos criterios requieren nuevamente de realización a cuatro voces, pero con elementos origen distintos o ausentes, lo cual supone mayor dificultad y necesariamente mayor dominio técnico del alumnado, y sin embargo aplicar a ello nuestra competencia transversal VI no supone un incremento de dificultad, sino que sigue siendo idéntico al procedimiento descrito para el criterio $\mathrm{n}^{\circ} 1$. Sirva de ejemplo la Figura 15 como ejercicio mixto para los criterios de evaluación $\mathrm{n}^{\mathrm{o}} 1, \mathrm{n}^{\mathrm{o}} 2$ y n n⿳亠口冋, así como para el no 4 en la Figura 16, todos ellos realizables para instrumentación a cuatro partes como en la Figura 14. 
Diseño y planificación de competencias específicas en el currículum de enseñanzas profesionales de música: modalidades composición-dirección en la enseñanza superior.

Bajo cifrado

Bajo sin cifrado

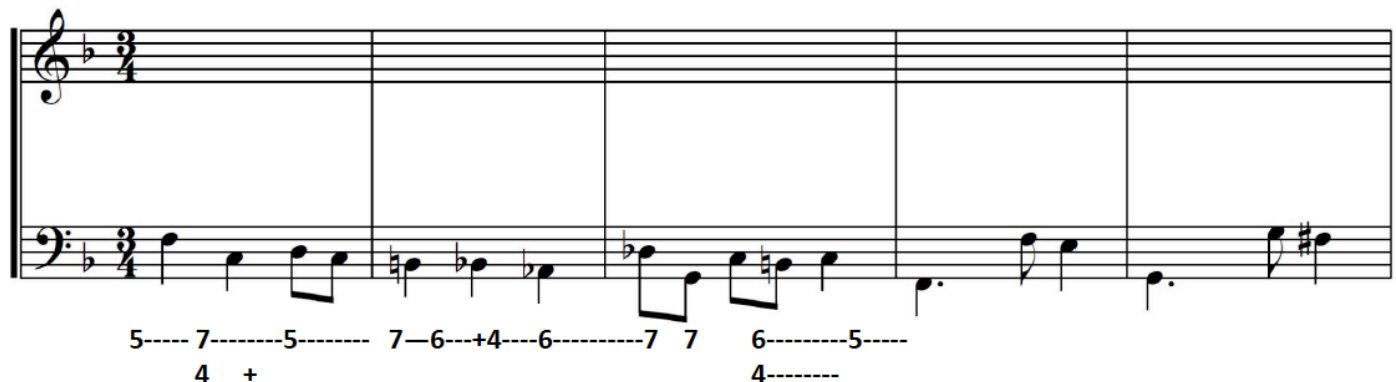

Soprano

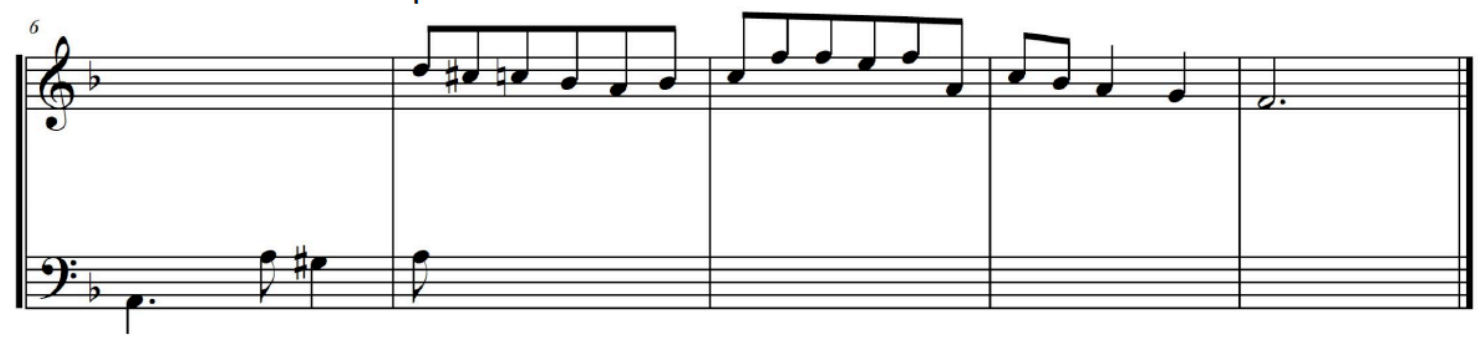

Figura 15. Ejercicio mixto con bajo cifrado, bajo sin cifrar y soprano dado (Gilabert, 2020).

\section{Tonalidad: Mi Mayor}

Compás: ternario

\begin{tabular}{|c|c|c|c|c|c|c|c|}
\hline $1^{5}$ & $\mathrm{IV}^{5}$ & $\mathrm{ii}^{5}$ & $\mathrm{~V}^{5}$ & & $\mathrm{iii}^{5}$ & $v i^{5}$ & \\
\hline $\mathrm{IV}^{6}$ & $\mathrm{~V}^{7}$ & $1^{5}$ & & $1^{6}$ & $\mathrm{IV}^{5}$ & & $\mathrm{~V}^{5} / \mathrm{V}$ \\
\hline$V^{5}$ & $V^{7}$ & $\left.\right|^{5}$ & $\mathrm{IV}_{4}^{6}$ & $1^{5}$ & & & \\
\hline
\end{tabular}

Figura 16. Esquema armónico propuesto para la composición de un ejercicio a cuatro partes (elaboración propia). 
Diseño y planificación de competencias específicas en el currículum de enseñanzas profesionales de música: modalidades composición-dirección en la enseñanza superior.

Los criterios de evaluación $\mathrm{n}^{\circ} 5, \mathrm{n}^{\circ} 6, \mathrm{n}^{\circ} 7$ y $\mathrm{n}^{\mathrm{o}} 11$ implican principalmente a las capacidades auditivas, siendo estos "Identificar auditivamente los principales elementos morfológicos de la armonía tonal”, "Identificar auditivamente los principales procedimientos sintácticos de la armonía tonal", "Identificar auditivamente estructuras formales concretas" e "Identificar auditivamente diversos errores en ejercicios preparados con esta finalidad y proponer soluciones". Los mismos buscan evaluar la habilidad auditiva del alumno en el reconocimiento de acordes, funciones tonales, cadencias, progresiones y forma, así como errores. No se menciona explícitamente - ni tampoco podemos encontrarlo vinculado en los objetivos o contenidos curriculares - el uso de determinados instrumentos, y por nuestra experiencia sabemos que la generalización para estos criterios de evaluación es de reducir el instrumento emisor al piano. En este punto incidiremos en el uso de nuestra competencia transversal V, "Reproducción escrita de fragmentos melódicos y polifónicos de hasta cuatro voces a partir de una escucha orquestal". Usando los instrumentos ya empleados por el alumno para las realizaciones de $\operatorname{los}$ criterios $n^{\circ} 1$ a $n^{\circ} 4$, se procederá a la escucha de fragmentos a cuatro instrumentos para su análisis morfológico y sintáctico, pero también para practicar su reproducción escrita, es decir, a modo de dictado. Para llevarlo a cabo existen en la actualidad sistemas sampler digitales, pero también puede partirse de grabaciones disponibles en el ámbito discográfico - sirva de ejemplo la compilación de 36 corales para coro mixto de Bach en sus distintas orquestaciones a cuatro instrumentos (Abeling, 2006) de las cuales mostramos en la Figura 18 un ejemplo de la orquestación para cuarteto de viento madera del coral Aus meines Herzens Grunde (Figura 17) - e incluso realizadas ex profeso previamente para estos ejercicios por profesores y/o alumnos. 


\section{Aus meines Herzens Grunde BWV 269}

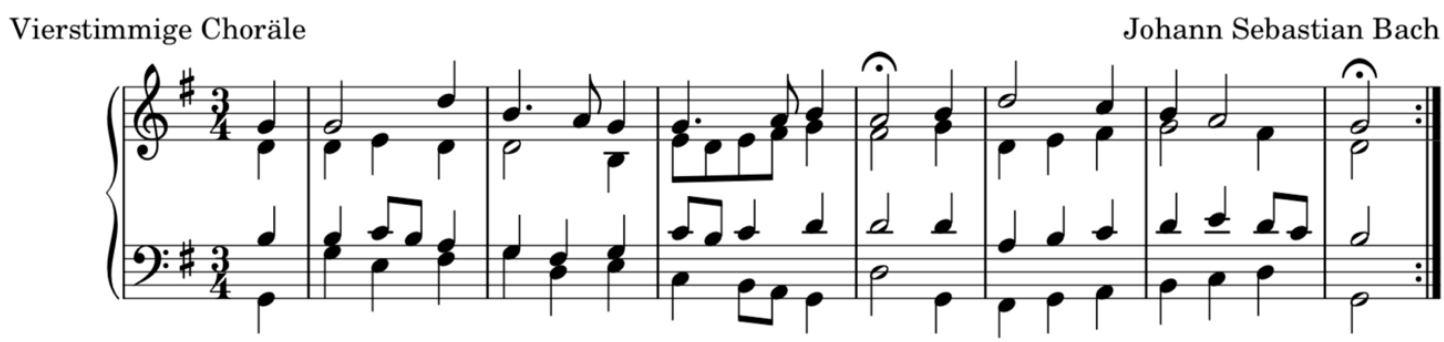

Figura 17. Coral $\mathrm{N}^{\mathrm{o}} 1$ en su versión original para coro mixto (Bach, 1875; p.12).

\section{Bach Chorales}

(for Woodwind Quartet)

1. Aus meines Herzens Grunde

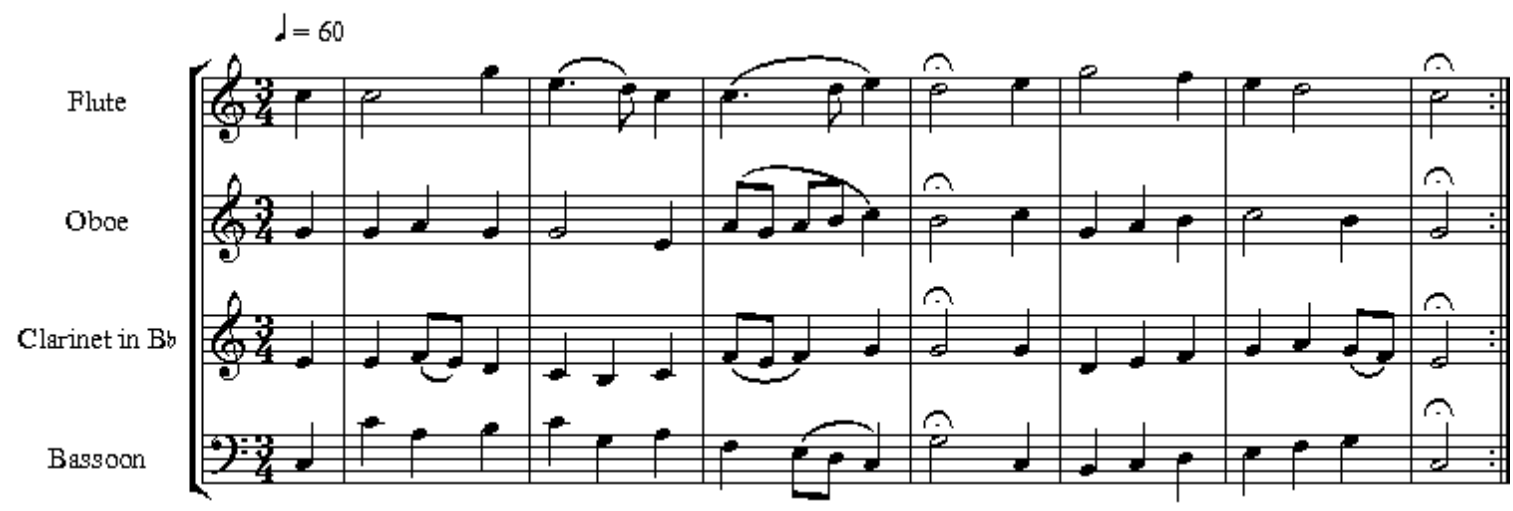

Figura 18. Orquestación del Coral $\mathrm{N}^{\circ} 1$ de Bach para cuarteto de viento madera

(Abeling, 2006; p.1).

Por supuesto, la ejecución en directo por un conjunto de instrumentos sería la mejor opción para la realización de estos ejercicios, pero su disponibilidad real y por tanto aplicabilidad es muy limitada al tener en cuenta el contexto de asignatura. En la Figura 19 mostramos un 
Diseño y planificación de competencias específicas en el currículum de enseñanzas profesionales de música: modalidades composición-dirección en la enseñanza superior.

Carlos Eduardo Pascual Pérez

ejemplo sencillo de un ejercicio a cuatro partes instrumentales en sampler digital para ser reproducido cuando no puede hacerse uso de grabaciones reales o interpretaciones en directo.
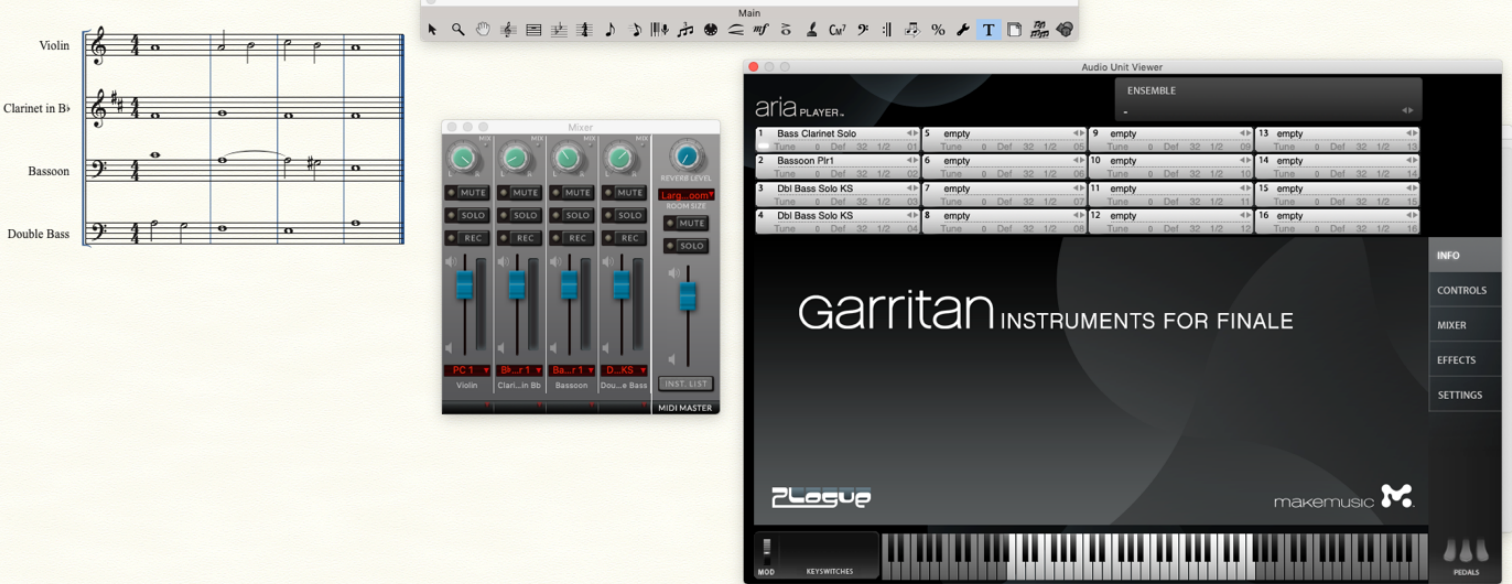

Figura 19. Entorno de software Finale para la edición y reproducción de partituras

(elaboración propia).

Por último, los criterios de evaluación $\mathrm{n}^{\mathrm{o}} 8, \mathrm{n}^{\mathrm{o}} 9, \mathrm{n}^{\mathrm{o}} 10 \mathrm{y} \mathrm{n}^{\mathrm{o}} 12$ focalizan el análisis visual de partitura para reconocer y comprender los elementos sintácticos y morfológicos de la armonía, como son los acordes, las funciones tonales, la forma, el material temático, el contexto estilístico y los errores o incorrecciones. Versan respectivamente como "Identificar mediante el análisis de obras los elementos morfológicos de la armonía tonal", "Identificar mediante el análisis de obras los procedimientos sintácticos y formales de la armonía tonal”, "Identificar mediante el análisis de obras los procedimientos de transformación temática" e 
Diseño y planificación de competencias específicas en el currículum de enseñanzas profesionales de música: modalidades composición-dirección en la enseñanza superior.

Carlos Eduardo Pascual Pérez

"Identificar mediante el análisis diversos errores en ejercicios preparados con esta finalidad y proponer soluciones". Nuevamente ocurre como con los criterios de evaluación de carácter auditivo; no están relacionados explícitamente con la práctica instrumental, y su realización habitual suele ser reducida al pentagrama doble, es decir, la escritura habitual organística o vocal a cuatro partes. Por tanto, mediando nuestra competencia transversal VI podemos llevar a cabo ejercicios y prácticas que cumplan dichos criterios y que además refuercen las habilidades perseguidas. En este sentido, los ejercicios tipo y metodología son relativamente sencillos, ya que se trata básicamente de escoger de entre el vasto repertorio instrumental existente piezas o fragmentos que reúnan las características curriculares a trabajar y que responda nuevamente a una plantilla instrumental que se haya trabajado previamente o pueda retomarse la didáctica de la organología de esta.

Como ejemplo para con los criterios de evaluación $n^{\circ} 8$ y $n^{\circ} 9$ que versan sobre el análisis morfo-sintáctico y formal de la armonía sobre una partitura, proponemos un completo análisis de grados tonales, cifrado de acordes y notas extrañas a la armonía sobre el Cuarteto de Cuerda No.4 en Do Mayor K.157 de Mozart (Figura 20). Para que el alumnado aborde dicho análisis será necesaria la asimilación de nuestra competencia transversal VI en lo que afecte a los respectivos instrumentos de la obra, en este caso el violín, la viola y el violoncello. 
Carlos Eduardo Pascual Pérez

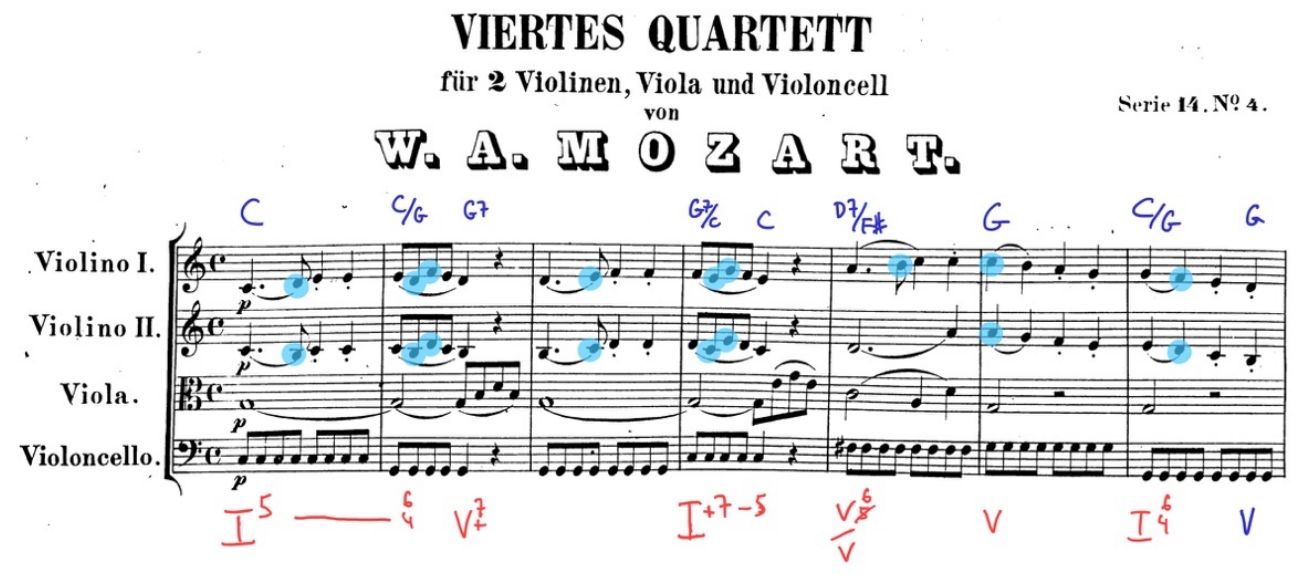

Figura 20. Ejemplo de análisis sobre una partitura instrumental camerística (Mozart, 1881; p.1).

Otro ejemplo de mayor complejidad al incluir instrumentos transpositores sería el propuesto en la Figura 21, un análisis similar aplicado al inicio de Romeo y Julieta (obertura-fantasía) de Tchaikovsky, el cual implica a dos clarinetes y dos fagotes, y para el cual añadimos el análisis de las cadencias. 


\section{A Mr M. BALAKIREW \\ ROMÉO ET JULIETTE \\ OUVERTURE-FAN'TAISIE}

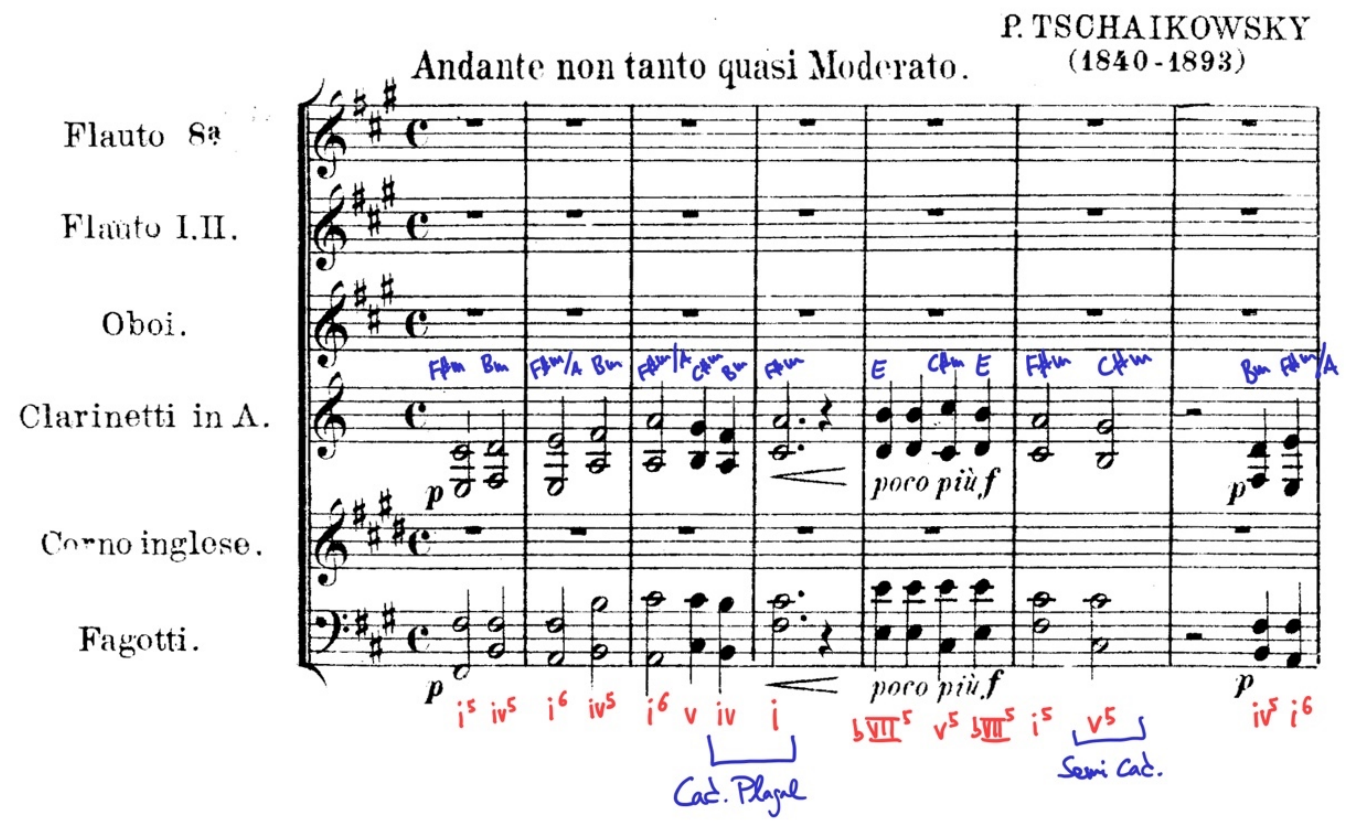

Figura 21. Ejemplo de análisis sobre una partitura orquestal (Tchaikovsky, 1881; p.1).

Para el criterio de evaluación $\mathrm{n}^{\circ} 10$, el cual incide en el análisis de los elementos de transformación temática, es decir, un análisis melódico desde el nivel motívico al fraseológico, propondremos en primer lugar un ejemplo sobre el Trío para instrumentos de viento No.63 de Beethoven. En este forman parte dos oboes y un corno inglés, nuevamente con la dificultad añadida de un instrumento transpositor. En la Figura 22 hemos realizado un análisis del motivo, las imitaciones temáticas y la estructura de frases. 
Diseño y planificación de competencias específicas en el currículum de enseñanzas profesionales de música: modalidades composición-dirección en la enseñanza superior.

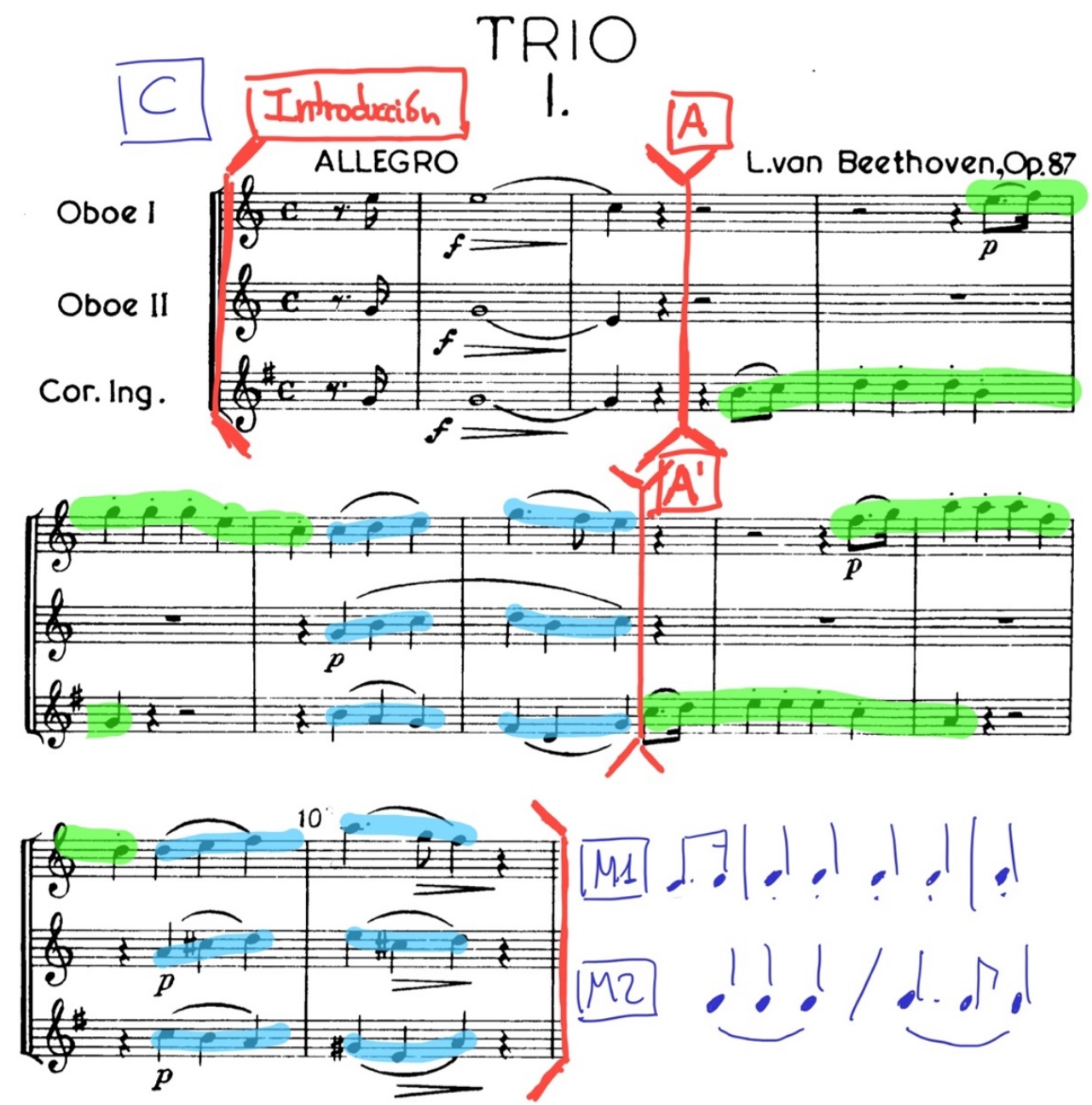

Figura 22. Ejemplo de análisis temático y formal para una obra camerística (Beethoven, 1864; p.1).

Por último, para el criterio de evaluación $\mathrm{n}^{\circ} 12$, que se refiere específicamente a la detección de errores armónicos y sus posibles soluciones, nos vamos a referir directamente a la tipología de ejercicios que proponemos en el epígrafe 4.1.4 de este texto, ya que son los que fundamentan el postest de la metodología experimental que llevaremos a cabo. Dentro de una serie limitada de errores o incorrecciones armónicas referidas a la conducción de voces y sus movimientos asociados no permitidos, así como a la duplicación u omisión de sonidos 
Diseño y planificación de competencias específicas en el currículum de enseñanzas profesionales de música: modalidades composición-dirección en la enseñanza superior.

Carlos Eduardo Pascual Pérez

concretos, deben proponerse partituras para que el alumno proceda a esta detección y si procede proponga una solución. Para ello deberemos proceder a la elaboración de estos, ya que no es habitual hallar en la bibliografía ejemplos de piezas o fragmentos con incorrecciones, y menos frecuente todavía el hecho de hallarlos en una plantilla instrumental que se ajuste al desarrollo de nuestra competencia transversal VI. En la Figura 23 mostramos una realización armónica incorrecta aplicada a una plantilla instrumental de cuarteto, junto con su detección de errores y propuesta de solución.

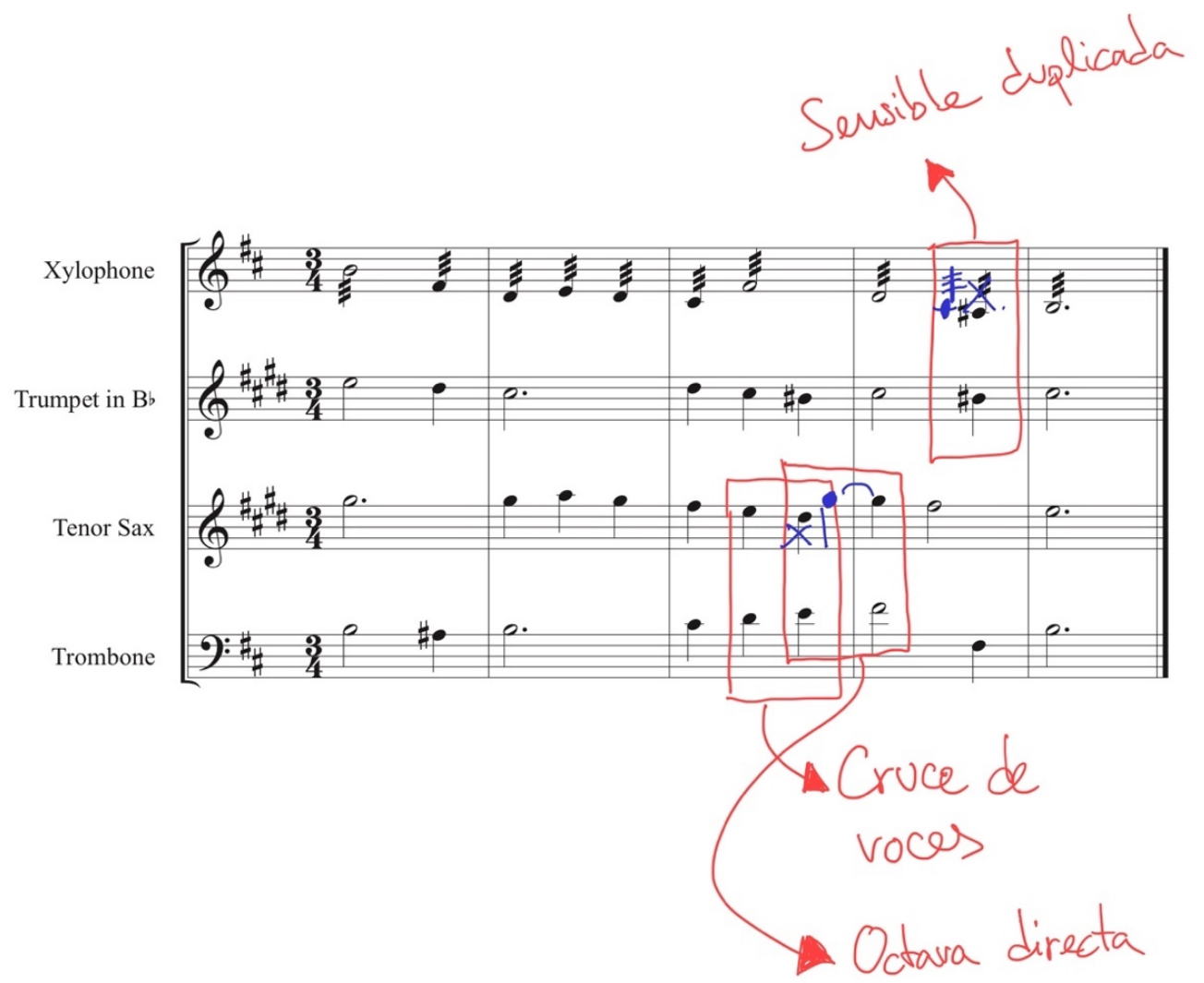

Figura 23. Realización armónica para cuatro instrumentos con incorrecciones armónicas (elaboración propia). 
Diseño y planificación de competencias específicas en el currículum de enseñanzas profesionales de música: modalidades composición-dirección en la enseñanza superior.

Carlos Eduardo Pascual Pérez

En definitiva, hemos mostrado como aplicar todos los criterios de evaluación que rige el currículum actual mediante metodologías y ejercicios tipo que han conllevado la transversalidad de nuestras competencias V y VI. Recordemos que estas suponen dos terceras partes del total de las competencias necesarias a implementar, quedando sin referencia en la asignatura de Armonía la competencia VII, que afecta directamente a los aspectos de la dirección y que será aplicada más adelante en el sistema de estudios. No obstante, recordamos que las competencias V y VI son necesarias como base para la VII y por ello las aplicamos previamente en la cronología académica, como hemos establecido en el epígrafe 3.8 del presente texto.

\subsubsection{Diseño de la intervención}

\subsubsection{Primera intervención}

Descripción: cuando el alumnado está adquiriendo o ya ha adquirido la capacidad de realizar bajos cifrados a cuatro voces (Criterio de Evaluación 1 de la asignatura Armonía, según Decreto 158/2007), dado que el proceso se habrá hecho en sistema de dos pentagramas y aplicado al ámbito coral, se procederá a aplicar la misma mecánica, pero a un cuarteto instrumental con vinculación a la orquesta clásica. Este hecho implicará necesariamente a la competencia transversal VI “Organología, instrumentación y orquestación en el ámbito de la orquesta sinfónica". 
Diseño y planificación de competencias específicas en el currículum de enseñanzas profesionales de música: modalidades composición-dirección en la enseñanza superior.

Competencias transversales desarrolladas: VI “Organología, instrumentación y orquestación en el ámbito de la orquesta sinfónica”

Temporalización: se planteará en tres sesiones ordinarias de 1h, siendo esta la distribución habitual según el currículum vigente. En caso excepcional de una única sesión semanal de 2h, la intervención debería plantearse utilizando la mitad de la sesión durante tres jornadas.

Vinculación curricular:

Objetivos
Contenidos

El acorde.

Estado fundamental e

inversiones de los acordes

triadas y de séptima sobre

todos los grados de la escala y

de los acordes de novena

dominante.

Cadencias Perfecta,

Imperfecta, Plagal, Rota.

Enlace de acordes.

El ritmo armónico.

g) Aprender a valorar la calidad de la música. realización de ejercicios escritos.

la Utilización de los elementos y procedimientos anteriores en
1. Realizar ejercicios a partir de un bajo cifrado dado. la realización de trabajos escritos.

Practica auditiva e instrumental que conduzca a la interiorización de los elementos y procedimientos aprendidos.

Tabla 7. Vinculación curricular para la primera intervención (elaboración propia). 
Contenidos no curriculares: Los instrumentos transpositores, Los instrumentos de vientomadera, Los instrumentos de viento-metal, El transporte.

Metodología: En la primera sesión se planteará al alumnado el ejercicio y se trabajará el ámbito teórico necesario para desarrollarlo (cualidades, ámbito y transposición de los instrumentos). Se trasladarán todas las normas y procedimientos utilizados hasta el momento para la realización de bajos cifrados a cuatro voces corales (soprano, contralto, tenor y bajo) para aplicarlas a la plantilla instrumental dada (oboe, clarinete, trompa y fagot). Se usará la disposición de cuatro pentagramas con las claves y transposiciones propias de cada instrumento. En la segunda sesión se revisarán los ejercicios realizados, donde además de corregir errores propios de la realización armónica a cuatro partes, se resolverán los errores específicos de transposición y ámbito, así como se aprovechará para aplicar mejoras a la escritura instrumental aunque no haya habido necesariamente errores. En la tercera sesión los alumnos entregarán el ejercicio finalizado, y se presentará un ejercicio realizado para que sea tomado como referencia. Se procederá a la escucha activa del mismo mediante un sistema de reproducción sampler o si fuera posible con los instrumentos en vivo (ya fuesen alumnos y/o profesores que pudiesen llevar a cabo la interpretación).

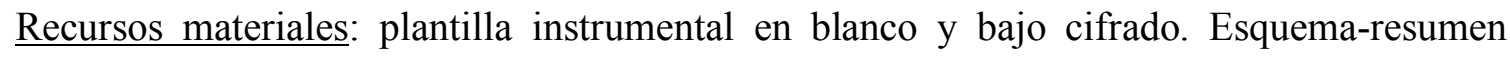
organología. Ejercicio realizado de referencia. Sistema de reproducción sampler. 


\subsubsection{Segunda intervención}

Descripción: tras la experiencia de la primera intervención y pasadas unas sesiones ordinarias, llegado el alumnado está adquiriendo o ya ha adquirido la capacidad de realizar armonizaciones a partir de un tiple (soprano) dado (Criterio de Evaluación 2 de la asignatura Armonía, según Decreto 158/2007), dado que el proceso se habrá hecho en sistema de dos pentagramas y aplicado al ámbito coral, se procederá a aplicar la misma mecánica pero a un cuarteto instrumental con vinculación a la orquesta clásica. Retomaremos por tanto la primera experiencia como punto metodológico de partida e iniciaremos de nuevo el proceso de aprendizaje con nuevas competencias. Nuevamente este hecho implicará necesariamente a la competencia transversal VI “Organología, instrumentación y orquestación en el ámbito de la orquesta sinfónica”.

Competencias transversales desarrolladas: VI “Organología, instrumentación y orquestación en el ámbito de la orquesta sinfónica"

Temporalización: se planteará en tres sesiones ordinarias de 1h, siendo esta la distribución habitual según el currículum vigente. En caso excepcional de una única sesión semanal de 2h, la intervención debería plantearse utilizando la mitad de la sesión durante tres jornadas. 
Diseño y planificación de competencias específicas en el currículum de enseñanzas profesionales de música: modalidades composición-dirección en la enseñanza superior.

Carlos Eduardo Pascual Pérez

Vinculación curricular:

\section{Objetivos}

\section{Contenidos}

El acorde.

a) Conocer los elementos sus características, funciones y transformaciones en los distintos contextos históricos.

c) Desarrollar el oído interno tanto en el análisis como en la realización de ejercicios escritos.

b) Utilizar en trabajos escritos los elementos y procedimientos básicos de la armonía tonal

g) Aprender a valorar la Tonalidad y funciones tonales. calidad de la música.

Estado fundamental e inversiones de los acordes triadas y de séptima sobre todos los grados de la escala y de los acordes de novena dominante.

Cadencias Perfecta, Imperfecta, Plagal, Rota.

Enlace de acordes.

El ritmo armónico.

Utilización de los elementos y procedimientos anteriores en la realización de trabajos escritos.

Practica auditiva e instrumental que conduzca a la interiorización de los elementos y procedimientos aprendidos.

\section{Criterios de evaluación}

2. Realizar ejercicios de armonización a partir de tiples dados. 
Diseño y planificación de competencias específicas en el currículum de enseñanzas profesionales de música: modalidades composición-dirección en la enseñanza superior.

instrumentos). Se trasladarán todas las normas y procedimientos utilizados hasta el momento para la realización de tiples (sopranos) dados a cuatro voces corales (soprano, contralto, tenor y bajo) para aplicarlas a la plantilla instrumental dada (saxofón alto, violín, viola y violoncello). Se usará la disposición de cuatro pentagramas con las claves y transposiciones propias de cada instrumento. En la segunda sesión se revisarán los ejercicios realizados, donde además de corregir errores propios de la realización armónica a cuatro partes, se resolverán los errores específicos de transposición y ámbito, así como se aprovechará para aplicar mejoras a la escritura instrumental aunque no haya habido necesariamente errores. En la tercera sesión los alumnos entregarán el ejercicio finalizado, y se presentará un ejercicio realizado para que sea tomado como referencia. Se procederá a la escucha activa del mismo mediante un sistema de reproducción sampler o si fuera posible con los instrumentos en vivo (ya fuesen alumnos y/o profesores que pudiesen llevar a cabo la interpretación).

Recursos materiales: plantilla instrumental en blanco y soprano dado. Esquema-resumen organología. Ejercicio realizado de referencia. Sistema de reproducción sampler.

\subsubsection{Elaboración del Postest}

El postest diseñado combina los contenidos curriculares propios de la asignatura de Armonía (descrito en el epígrafe 4.3 del Capítulo 3) con su aplicación a las competencias transversales desarrolladas en nuestra intervención, y por este motivo no ubicamos en el presente epígrafe los mismos referidos al contenido curricular ni a la definición de contenidos - tal y como 
hicimos con el pretest -, al estar ya definidos con anterioridad. La resolución del postest se ha diseñado de una forma simplificada al máximo para evitar entrar en un análisis cualitativo (desde el punto de vista de la realización o creación armónica) y poder obtener así unos patrones comparativos desde el punto de vista cuantitativo. Consta de tres ejercicios breves con una misma dinámica: armonizaciones ya realizadas a cuatro voces aplicadas a una plantilla instrumental, en las cuales se deben detectar errores (incorrecciones) armónicomelódicos, los cuales están tipificados al inicio del test. Además, en cada ejercicio hay una opción para indicar la ausencia de errores, para no confundir la no respuesta con este hecho. La identificación de los errores debe hacerse indicando número de compás, número de tiempo, instrumentos implicados y tipo de error. Este tipo de respuesta nos permite aislar cuantitativamente las respuestas, del mismo modo que hicimos con los contenidos del pretest. 
Diseño y planificación de competencias específicas en el currículum de enseñanzas profesionales de música: modalidades composición-dirección en la enseñanza superior.

Carlos Eduardo Pascual Pérez

Carlos Eduardo Pascual Pérez (investigador) - José María Peñalver Vilar (director) - Amparo Porta Navarro (tutora)

\section{TEST FINAL 1ํ Armonía (3ํㅡseñanzas Profesionales)}

Detección de errores armónicos estudiados aplicados a una plantilla instrumental

Instrucciones: Debe analizarse cada fragmento instrumental como si de una realización armónica a cuatro partes se tratase, y localizar (si los hay) errores armónicos de los que figuran en el listado*, para seguidamente enumerarlos en la tabla de respuestas, indicando para cada error su localización (compás y tiempo), parte/s implicada/s (instrumento/s) y tipo de error $(a, b, c, d, \ldots)$. Puede haber más de un error en un mismo tiempo, en ese caso anotarlos por separado. Si se considera, tambien puede anotarse alguna observación.

Además, si no se detectan errores en un ejercicio, debe marcarse la casilla correspondiente. Si se desconoce o no se sabe como responder al ejercicio, dejar en blanco.

*Listado de posibles tipos de error:
a) Octavas seguidas
b) Quintas seguidas
c) Octavas directas
d) Quintas directos
e) Cruzamiento de vaces
f) Superación de la separación máxima entre voces

g) Duplicación de la sensible

h) Resolución incorrecta o irresolución de la sensible

i) Resolución incorrecta o irresolución de la séptima (acordes de $7^{g}$ de dte.)

j) Ausencia de preparación de la séptima (acordes de $7^{9}$ de dte.)

Instrumento/s o especialidad/es que estás cursando o has cursado:

\section{EJERCICIO 1}

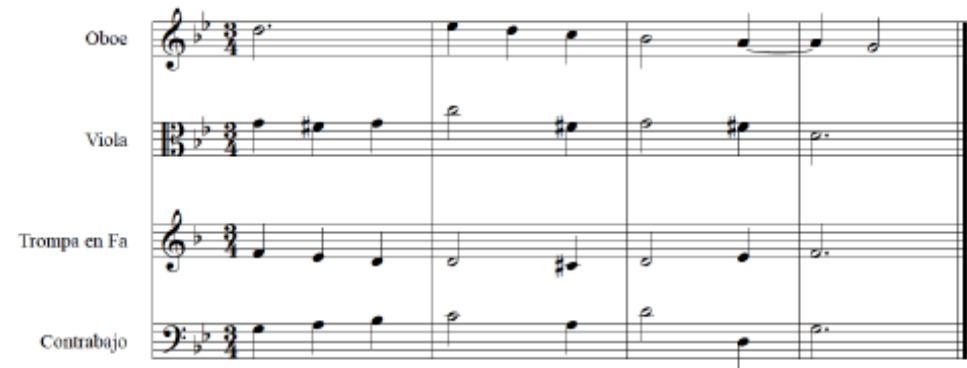

Marcar si no detectas ningún error:

\begin{tabular}{|l|l|l|l|l|}
\hline Compás & Tiempo & Instrumento/s implicado/s & Tipo de error & Observaciones \\
\hline & & & & \\
\hline & & & & \\
\hline & & & & \\
\hline & & & & \\
\hline & & & & \\
\hline & & & & \\
\hline & & & & \\
\hline & & & & \\
\hline
\end{tabular}


Diseño y planificación de competencias específicas en el currículum de enseñanzas profesionales de música: modalidades composición-dirección en la enseñanza superior.

Carlos Eduardo Pascual Pérez

EERCICIO 2

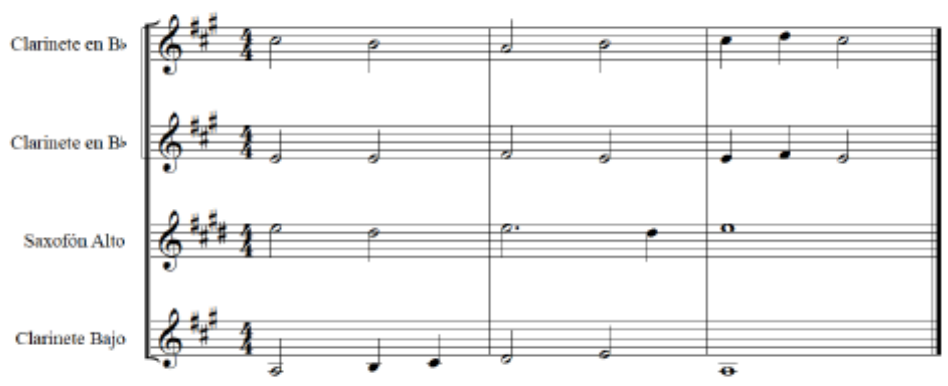

Marcar si no detectas ningún error:

\begin{tabular}{|l|l|l|l|l|}
\hline Compás & Tiempo & Instrumento/s implicado/s & Tipo de error & Observaciones \\
\hline & & & & \\
\hline & & & & \\
\hline & & & & \\
\hline & & & & \\
\hline & & & & \\
\hline & & & & \\
\hline & & & & \\
\hline & & & & \\
\hline
\end{tabular}

\section{EJERCICIO 3}

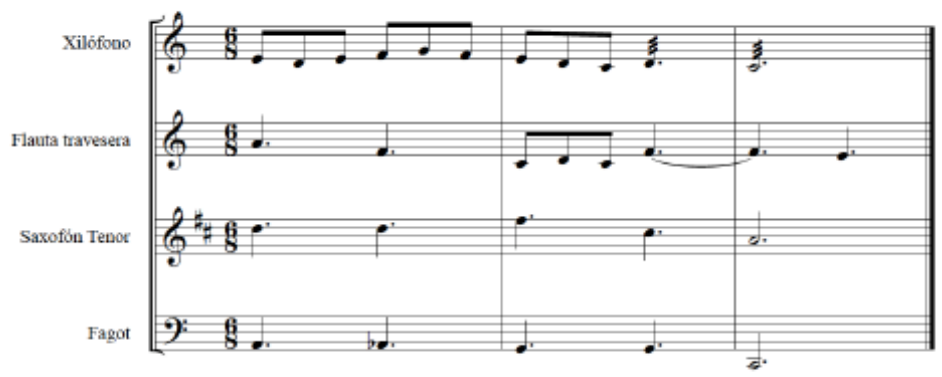

Marcar si no detectas ningún error:

\begin{tabular}{|l|l|l|l|l|}
\hline Compás & Tiempo & Instrumento/s implicado/s & Tipo de error & Observaciones \\
\hline & & & & \\
\hline & & & & \\
\hline & & & & \\
\hline & & & & \\
\hline & & & & \\
\hline & & & & \\
\hline & & & & \\
\hline & & & & \\
\hline
\end{tabular}

Figura 24. Postest (elaboración propia). 
Diseño y planificación de competencias específicas en el currículum de enseñanzas profesionales de música: modalidades composición-dirección en la enseñanza superior.

Carlos Eduardo Pascual Pérez

En esta ocasión tampoco tendremos en consideración el grado de adquisición de los contenidos curriculares, que además al plantearse de un modo sencillo y únicamente analítico no podría ser susceptible de dicho análisis con veracidad. Tampoco contemplamos el escenario de que un el alumno no sepa afrontar el ejercicio desde ese prisma de lo curricular o que le suponga un impedimento para su comprensión, puesto que contamos con el beneplácito del departamento docente y del propio profesor de cada grupo-aula en los que se efectúe el test, validando así la comprensibilidad del mismo.

Contenidos curriculares

de la asignatura de Armonía
Competencias específicas

aplicadas

Objetivos: a), b), c) y e).

Ejercicios

Contenidos: El acorde. Estado fundamental e inversiones de los acordes triadas y de séptima sobre todos los grados de la escala y de los acordes 1,2 y3 de novena dominante. Enlace de acordes. Análisis de obras para relacionar dichos elementos y procedimientos, así como las transformaciones temáticas de los materiales utilizados con su contexto estilístico y la forma musical.

Criterios de evaluación: 1, 2, 3, 8 .

Tabla 9. Relación entre los contenidos curriculares y la competencias específicas seleccionadas para el postest (elaboración propia). 
Carlos Eduardo Pascual Pérez

Del mismo modo a como elaboramos las variables del pretest, y dado que necesitamos usar las mismas para poder comparar metodológicamente, mediante las cinco variables conocidas que tienen origen en el descriptor de nuestra competencia transversal vinculamos un número de ítems mínimos asociados a las mismas del pretest. La diferencia entre el número de ítems aplicados a cada variable reside en la complejidad de la respuesta, aplicando un menor número para las asociaciones múltiples y un mayor número para las individuales:

- Organología de instrumentos no transpositores: 5 ítems

- Conoce y sabe interpretar las características de ámbito, registro y técnica de los siguientes instrumentos no transpositores pertenecientes a las diferentes familias instrumentales del ámbito orquestal (cordófonos, aerófonos e idiófonos): Viola, Contrabajo, Flauta travesera/Oboe, Fagot y Xilófono.

- Organología de instrumentos transpositores: 5 ítems

- Conoce y sabe interpretar las características de ámbito, registro y técnica de los siguientes instrumentos transpositores (aerófonos) del ámbito orquestal : Clarinete en $\mathrm{Bb}$, Clarinete bajo, Trompa en $\mathrm{F}$, Saxofón alto y Saxofón tenor.

- Lecto-escritura entre instrumentos no transpositores: 3 ítems

- Sabe reconocer comportamientos armónicos entre dos voces ejecutadas por los siguientes pares de instrumentos no transpositores, 
Diseño y planificación de competencias específicas en el currículum de enseñanzas profesionales de música: modalidades composición-dirección en la enseñanza superior.

Carlos Eduardo Pascual Pérez

ya sean de su misma familia instrumental o combinadas: Oboe-Viola y Xilófono-Flauta travesera.

- Lecto-escritura entre instrumentos transpositores: 2 ítems

- Sabe reconocer comportamientos armónicos entre dos voces ejecutadas por los siguientes pares de instrumentos transpositores, ya sean de su misma familia instrumental o combinadas: Saxofón altoClarinete bajo y Clarinete en Bb-Clarinete bajo.

- Asociación entre instrumentos transpositores y no transpositores: 3 ítems

- Sabe reconocer comportamientos armónicos entre dos voces ejecutadas por los siguientes pares de instrumentos mixtos (un transpositor con un no transpositor), ya sean de su misma familia instrumental o combinadas: Viola-trompa en F, Flauta traveseraSaxofón tenor y Fagot-Saxofón tenor.

Además, ajustamos la proporcionalidad en el número de ítems de mayor a menor dificultad de realización. Por último, establecemos los mismos criterios de calificación homogéneos y estándares que asignamos a la evaluación del pretest.

- Respuesta válida por ítem (cuantitativa): única

- Puntuación por cada ítem correcto: 1

- Puntuación por cada ítem incorrecto: 0

- Puntuación por cada ítem carente de respuesta: 0 
Para finalizar realizaremos también una puntuación global para poder hacer comparaciones aritméticas estadísticas entre los grupos no relacionados. Para ello tendremos en cuenta la siguiente relación, que busca la imparcialidad e independencia de los resultados, además de la no penalización por la ausencia de respuestas o respuestas erróneas, dado que el objetivo de la comparación entre resultados la hacemos desde una perspectiva positivista que no contabilice el error sino los aciertos como indicadores de mejora o adquisición de competencias:

-Total ítems puntuables: 10

-Respuesta válida por ítem (cuantitativa): única

-Puntuación por cada ítem completo correcto: 1

-Puntuación por cada ítem parcialmente correcto: 0

-Puntuación por cada ítem erróneo: 0

-Puntuación por cada ítem carente de respuesta: 0

\subsection{Intervención}

\subsubsection{Sujetos y grupos}

Parte imprescindible y fundamental en la presente investigación es el convertir toda la teoría desarrollada en un estudio de caso. De este modo, se llevó a cabo en los cursos 2017-18 y 2018-19 una experiencia con alumnos voluntarios del Centro Autorizado Profesional de 
Diseño y planificación de competencias específicas en el currículum de enseñanzas profesionales de música: modalidades composición-dirección en la enseñanza superior.

Carlos Eduardo Pascual Pérez

Música San José de Calasanz [Código de Centro de la Generalitat Valenciana 12007875] centro en el que trabaja el investigador principal del presente estudio y donde imparte además la asignatura de Armonía-. La aceptación por parte del alumnado les suponía invertir 6 sesiones durante el curso académico para realizar los elementos de la intervención (Pretest, Ejercicios 1 y 2 y Postest) dentro de la asignatura de primer curso de Armonía. Dichas sesiones no serían extraordinarias, sino que se incluirían en el desarrollo de la programación de la asignatura.

Tuvimos respuesta afirmativa de seis alumnos en el curso 2017-18 y de trece en el 2018-19, aunque de este último curso sólo completaron la experiencia nueve. Así, con dichos alumnos se formó un grupo de la asignatura para todo el curso escolar, realizándose por completo la intervención en las dos anualidades indicadas.

La aceptación de la misma por parte de la dirección del centro así como de los alumnos fue formalizada mediante las directrices y normativa que rige la Comisión Deontológica de la Universitat Jaume I, así como la derivada solicitud a la misma para realizar la intervención con sujetos.

Por otro lado, la necesidad comparativa del grado de asimilación de las competencias específicas nos llevó a solicitar la realización del Postest de forma altruista y voluntaria en diferentes Conservatorios y Centros Autorizados de la Comunidad Valenciana, dado que todos comparten el currículum autonómico objeto de nuestro estudio, y por ello también en 
Diseño y planificación de competencias específicas en el currículum de enseñanzas profesionales de música: modalidades composición-dirección en la enseñanza superior.

Carlos Eduardo Pascual Pérez

la asignatura de Armonía. Además, para poder realizar el test en centros públicos con titularidad de la Conselleria d'Educació tuvimos que solicitar a dicha Secretaría Autonómica de Educación e Investigación la autorización de nuestro proyecto de investigación, que fue resuelta favorablemente el 4 de mayo de 2018. En dicha autorización se incluye la validación del test propuesto (el postest de nuestra intervención) así como el respaldo en la metodología empleada.

Tras informar y solicitar formalmente a seis Centros la realización del test, tuvimos respuesta afirmativa únicamente de dos; el Conservatorio Profesional de Música Mestre Feliu de Benicarló (Castellón) [Código de Centro de la Generalitat Valenciana 12005386] y el Conservatorio Profesional de Música de Altea (Alicante) [Código de Centro de la Generalitat Valenciana 03012505]. Los centros que tras atendernos consideraron rehusar nuestra petición fueron el Centro Autorizado Profesional de Música Mestre Goterris de Vila-real (Castellón), Centro Autorizado Profesional de Música "Centro de estudios musicales" de Onda (Castellón), Conservatorio Profesional de Música Francesc Peñarroja de Vall d’Uxó (Castellón) y Conservatorio Profesional de Música Mestre Tàrrega de Castelló.

Referente a este último, dado que contábamos con autorización explícita de la Secretaría Autonómica de Educación e Investigación para realizar los test en dicho Centro, y tras ser aceptado por la Dirección de este, así como por su Consejo Escolar, recibimos una misiva del Departamento de Composición e Instrumentación en la que se argumenta en contra de realizar las pruebas. Nosotros rebatimos dicha carta ajustándonos a los contenidos 
Diseño y planificación de competencias específicas en el currículum de enseñanzas profesionales de música: modalidades composición-dirección en la enseñanza superior.

curriculares e incluso a las programaciones didácticas públicas del Centro, las cuales a nuestro entender son consecuentes con los criterios de nuestra investigación. Finalmente, no obtuvimos respuesta a esta última carta y dimos por perdida la intervención en dicho centro.

Desde la propia Secretaría Autonómica de Educación e Investigación, pasado un año desde que nos otorgaran la autorización nos requirieron los resultados o avances de la esta, solicitud a la que tuvimos que responder argumentando la negativa por parte de los centros públicos, la cual había puesto punto y final a la autorización del proyecto en centros públicos con titularidad de la Generalitat Valenciana. En el Anexo I relacionamos todo el intercambio documental de dicho proceso.

Por el contrario, entre mayo y junio de 2019 pudimos llevar a cabo los test en dos centros públicos de titularidad municipal (Conservatorio Profesional de Música Mestre Feliu de Benicarló y el Conservatorio Profesional de Música de Altea). Logramos dedicar una sesión de una hora en cada uno de los grupos de la asignatura de Armonía de $3^{\circ}$ curso de Enseñanzas Profesionales, y tras el planteamiento voluntario de la realización del test y su explicación obtuvimos 37 pruebas individuales.

\subsubsection{Grupo experimental. Análisis individualizado de casos.}

Plantearemos el análisis de cada alumno participante en el proceso experimental como un único ente, para observar las individualidades que se desprendan de la evolución desde el pretest hasta el postest pasando por los dos ejercicios de la intervención. El número de caso 
Diseño y planificación de competencias específicas en el currículum de enseñanzas profesionales de música: modalidades composición-dirección en la enseñanza superior.

referido en este epígrafe coincidirá con al número asignado para el análisis estadístico referido en el Anexo IV, salvaguardando en todo momento el anonimato de los sujetos al eliminar o difuminar las partes en las que aparecen sus datos personales o las referidas a su especialidad. De igual modo no se revela el grupo-aula de la experiencia al que pertenece cada caso. Los documentos en formato completo original se relacionan en el Anexo II, recopilados en orden ascendente todos los pretest, ejercicios 1 y 2 y postest, para poder revisarlos y compararlos de forma completa, puesto que en la descripción mostraremos selecciones de los mismos.

Además, tras el análisis cualitativo de cada caso procederemos a la valoración cuantitativa tanto de las cinco variables definidas para la comparación pretest-postest así como de las puntuaciones absolutas del postest para su contraste con los grupos de control.

\subsubsection{Caso experimental $N^{o} 1$}

La valoración inicial del primer ejercicio del pretest nos sugiere una inexperiencia acerca de la organología de los instrumentos sinfónicos del ámbito orquestal. Los aciertos son aceptados parcialmente, puesto que se refiere a los índices de afinación absoluta como si de tonalidades mayores se tratasen, lo cual es una incorrección. En el caso del clarinete bajo (instrumento transpositor) no se aporta la octavación del mismo. 
Diseño y planificación de competencias específicas en el currículum de enseñanzas profesionales de música: modalidades composición-dirección en la enseñanza superior.

Carlos Eduardo Pascual Pérez

Respecto al segundo ejercicio de lecto-escritura y asociación entre instrumentos transpositores y no transpositores, podemos observar errores en el ámbito del clarinete (instrumento transpositor), así como de la interpretación de uno de los acordes que incurre en un error en el oboe (instrumento no transpositor). También apreciamos un error al cruzarse las voces de estos dos instrumentos mencionados (ejercicio 2, primer acorde).

1. Identifica la afinación y octavación de los siguientes instrumentos:

\begin{tabular}{|l|c|l|l|l|l|}
\hline \multicolumn{1}{|c|}{ Instrumento } & Afinación & Octavación & Instrumento & Afinación & Octavación \\
\hline Oboe & Po M & & Clarinete bajo & Sib & \\
\hline Flautín & & & Saxofón alto & & \\
\hline Fagot & DoM & & Saxofón tenor & & \\
\hline Contrabajo & & & Lira & & \\
\hline Trompa & Fa Mayer & & Flauta alto & & \\
\hline
\end{tabular}

2. Realiza los siguientes acordes:

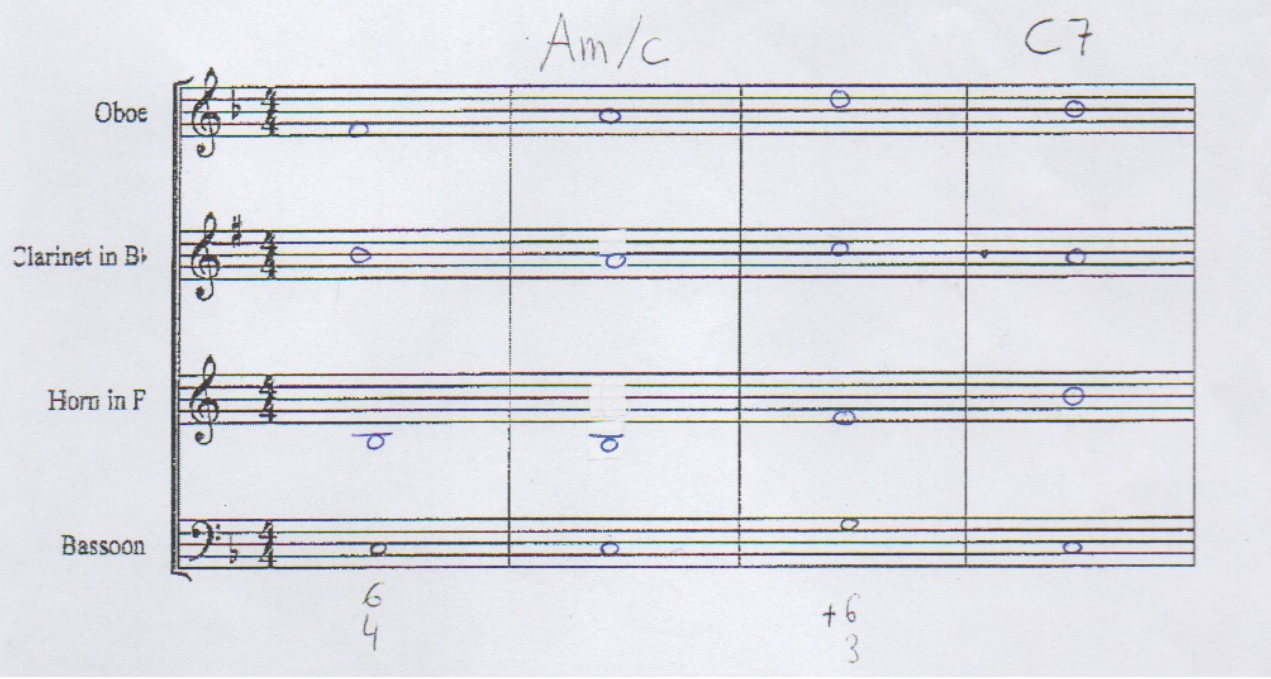

Figura 25. Pretest del caso experimental $\mathrm{N}^{\mathrm{o}} 1$. 


\section{Carlos Eduardo Pascual Pérez}

A la vista de los resultados creemos que sujeto ha podido relacionar o deducir las afinaciones del primer ejercicio a partir de las del segundo, e incluso que este hecho llevara al error de confundir y relacionar la afinación del clarinete con la del clarinete bajo sin tener en cuenta su transposición de octava baja. Por ello deducimos que existe un alto grado de desconocimiento en el ámbito de la organología pero un poco mayor en la capacidad de lectoescritura entre instrumentos transpositores y no transpositores.

Tras la primera intervención y la entrega del primer ejercicio observamos una mejora en el ámbito de la lecto-escritura. Se corrigen los errores de cruce entre voces así como los errores puntuales de transposición. No obstante encontramos una respuesta incompleta en la trompa en $\mathrm{fa}$ - uno de los instrumentos transpositores, compases 2 y 3 -, aunque la respuesta parcial que hay es correcta. También se evidencian errores conceptuales propios en lo curricular de la asignatura de armonía, no siendo estos aplicables al desarrollo de nuestra competencia transversal. 
Diseño y planificación de competencias específicas en el currículum de enseñanzas profesionales de música: modalidades composición-dirección en la enseñanza superior.

Carlos Eduardo Pascual Pérez

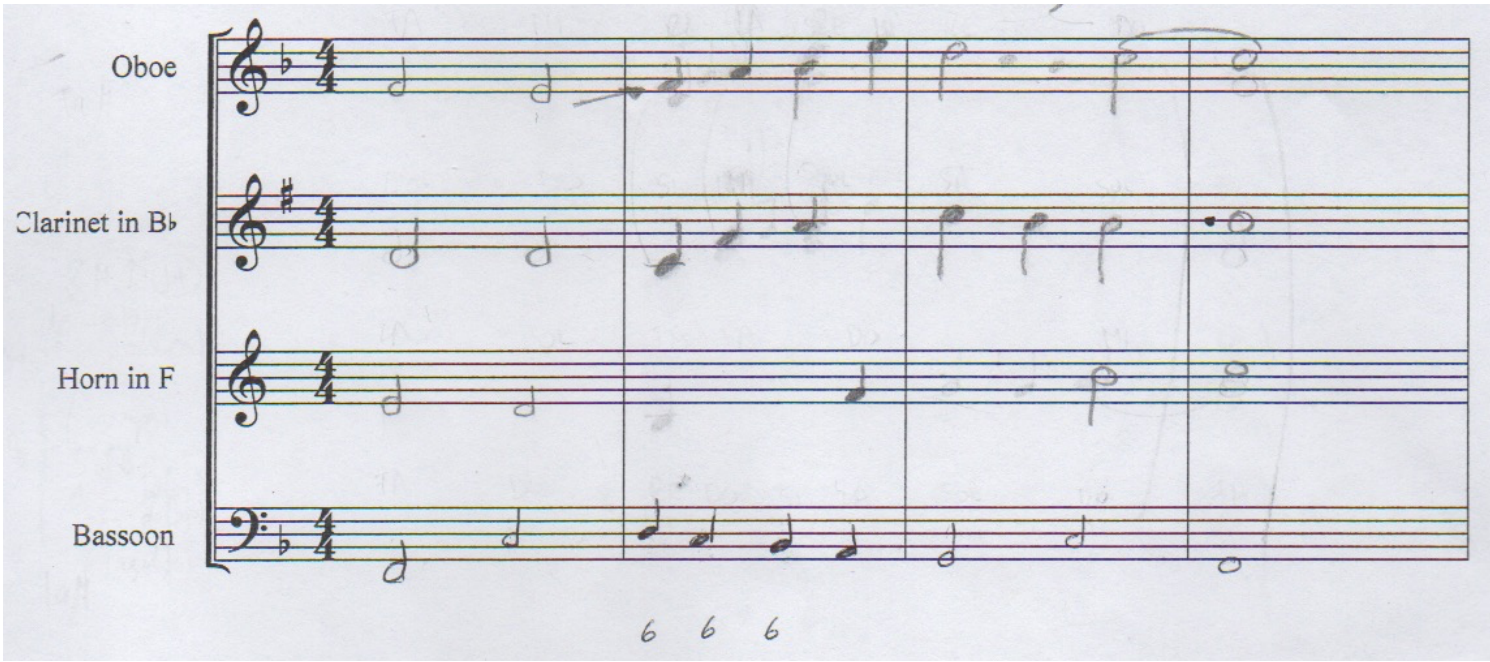

Figura 26. Detalle del ejercicio de la primera intervención del sujeto $\mathrm{N}^{\mathrm{o}} 1$.

En el ejercicio de la segunda intervención nos llama la atención el recurso accesorio de ubicar la nota DO3 como referencia en el violín y en la viola. En este último podemos entenderlo como una medida de ayuda ante la clave de do propia de la viola, y que es poco habitual para el sujeto, sin embargo no tiene demasiado sentido hacer lo mismo en el violín, ya que su escritura coincide con la más habitual de las claves. Respecto a la lectura del saxofón alto único instrumento transpositor del ejercicio - encontramos el recurso de lectura de transposición mediante el cambio de clave, anotado al inicio de su pentagrama. Esta clave de fa escrita confirma que se asocia la lectura correcta de este instrumento, reforzada además por la escritura de la nota real en clave de sol (La3) también al inicio. Todas estas anotaciones son indicios de la comprensión del sistema del ejercicio y su dificultad al combinar diferentes claves y transposiciones. 
Diseño y planificación de competencias específicas en el currículum de enseñanzas profesionales de música: modalidades composición-dirección en la enseñanza superior.

Carlos Eduardo Pascual Pérez

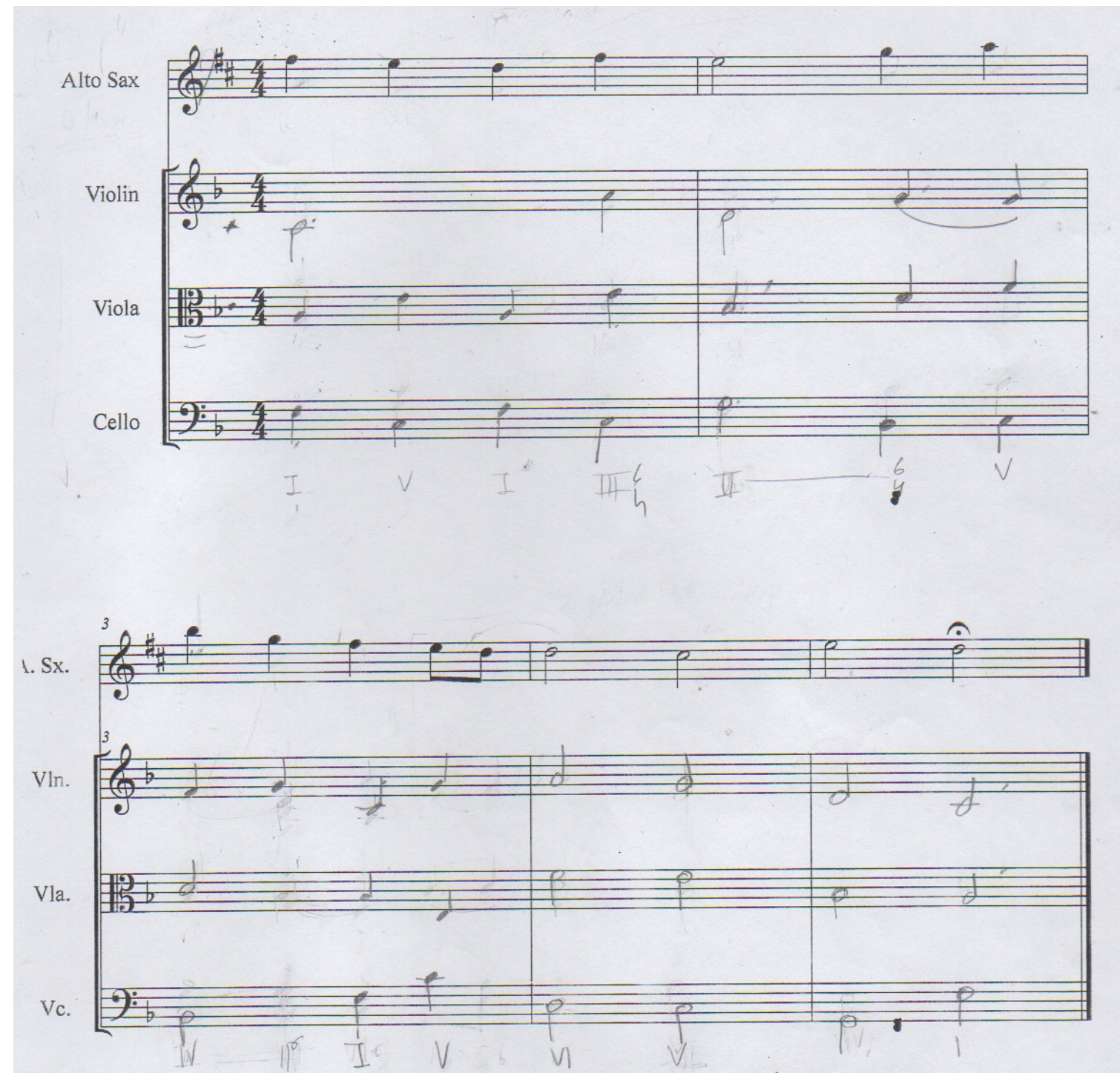

Figura 27. Detalle del ejercicio de la segunda intervención del sujeto $\mathrm{N}^{\circ} 1$.

No obstante, volvemos a detectar errores en la asociación entre voces como sucedió en el pretest, al cruzarse las voces entre el violín y la viola en el compás 1 y 4 , siendo estos dos instrumentos no transpositores. También encontramos otros errores armónicos que si son relacionables con la lecto-escritura de los instrumentos implícitos, como el unísono mal 
Diseño y planificación de competencias específicas en el currículum de enseñanzas profesionales de música: modalidades composición-dirección en la enseñanza superior.

Carlos Eduardo Pascual Pérez

resuelto entre el saxofón alto y el violín en el compás 1 y 3 , las octavas seguidas entre el saxofón alto y el violoncello en el compás 2 o entre el saxofón alto y la viola en el compás 4, e incluso errores individualizados de notas desprendidas del cifrado armónico como en la viola en el compás 3. Nuevamente también observamos errores propios curriculares sin que implique a nuestra competencia transversal, como las quintas seguidas entre el violín y el violoncello - instrumentos no transpositores y con uso de claves comunes en la práctica armónica de la asignatura - el compás 4, o el propio uso de la segunda inversión en los compases 1 y 2 .

En la evaluación final a través del postest observamos un alto grado de acierto a nivel de organología tanto de instrumentos transpositores como no transpositores. Por las anotaciones al margen de cada pentagrama podemos deducir que el alumno conoce las propiedades de la mayoría de los instrumentos, sobre todo de aquellos que conllevan una octavación además de la transposición (como el contrabajo o el saxofón tenor). No obstante, se aprecian errores organológicos en instrumentos como el xiolófono o en todos los que forman parte del segundo de los ejercicios - el cual queda completamente si realizar, y nos sorprende en parte ya que en él aparecen instrumentos que han aparecido recurrentemente en la intervención, como el clarinete o el saxofón alto - . Nuevamente por las anotaciones al margen observamos que el alumno ha acertado las tonalidades correctas de los ejercicios 1 y 3 . 
Diseño y planificación de competencias específicas en el currículum de enseñanzas profesionales de música: modalidades composición-dirección en la enseñanza superior.

Carlos Eduardo Pascual Pérez

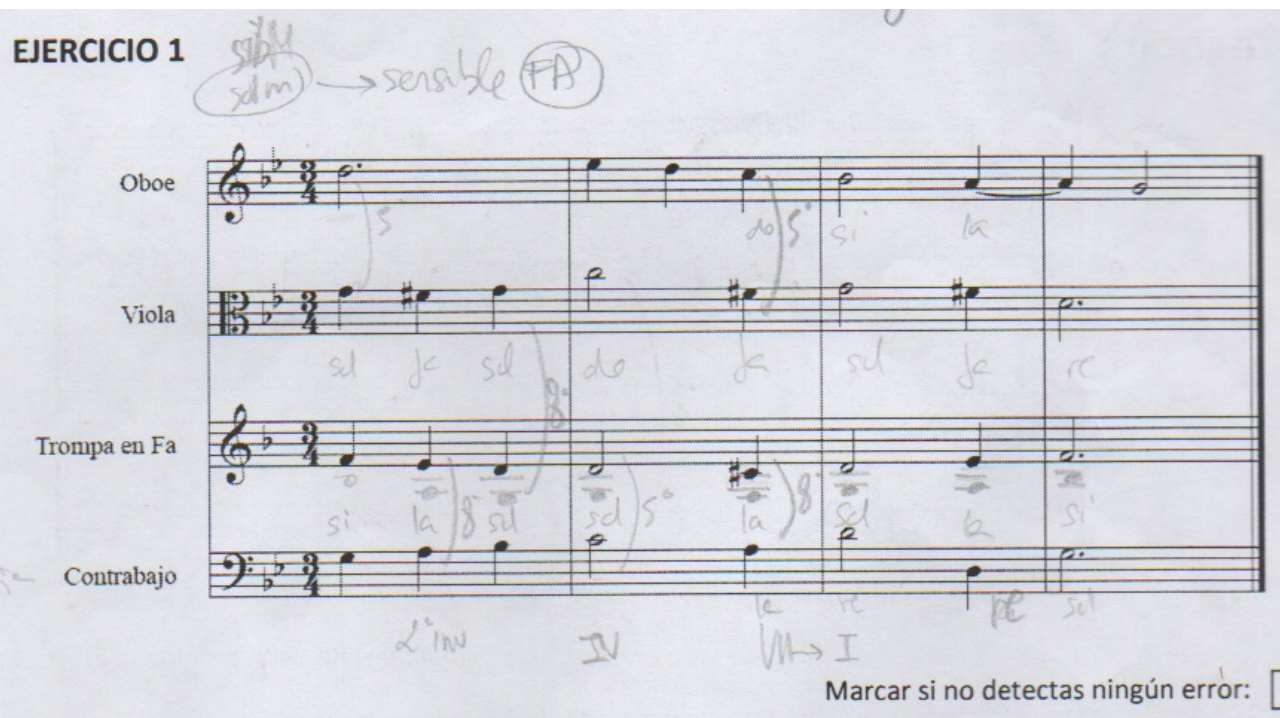

\begin{tabular}{|c|c|l|l|l|}
\hline Compás & Tiempo & Instrumento/s implicado/s & Tipo de error & Observaciones \\
\hline 1 & 3 & Vola & a & \\
\hline 2 & 1 & Trompa n ta & & \\
\hline 2 & 1 & Vola & & \\
\hline 2 & 3 & Oboe & $b$ & \\
\hline & & & & \\
\hline & & & & \\
\hline & & & & \\
\hline & & & & \\
\hline
\end{tabular}

Figura 28. Detalle del ejercicio 1 del postest del sujeto $\mathrm{N}^{\circ} 1$.

Respecto a la resolución del test (detección de errores armónicos) no hallamos ningún acierto para el ejercicio 1, acompañado de cuatro respuestas incorrectas, las cuales se desprenden de incorrecciones propiamente armónicas, es decir, que no implican el uso de la competencia transversal. El ejercicio 2, como ya hemos comentado, aparece completamente en blanco, ausente de respuestas. Por último, en el ejercicio 3 encontramos un $20 \%$ de aciertos, acompañado de otra respuesta incorrecta que se desprende del error organológico de la 
Diseño y planificación de competencias específicas en el currículum de enseñanzas profesionales de música: modalidades composición-dirección en la enseñanza superior.

Carlos Eduardo Pascual Pérez

transposición del xiolófono (no transpositor), dado que al no conocerse su octavación ha llevado a incurrir en un falso error armónico.

\section{EJERCICIO 3}

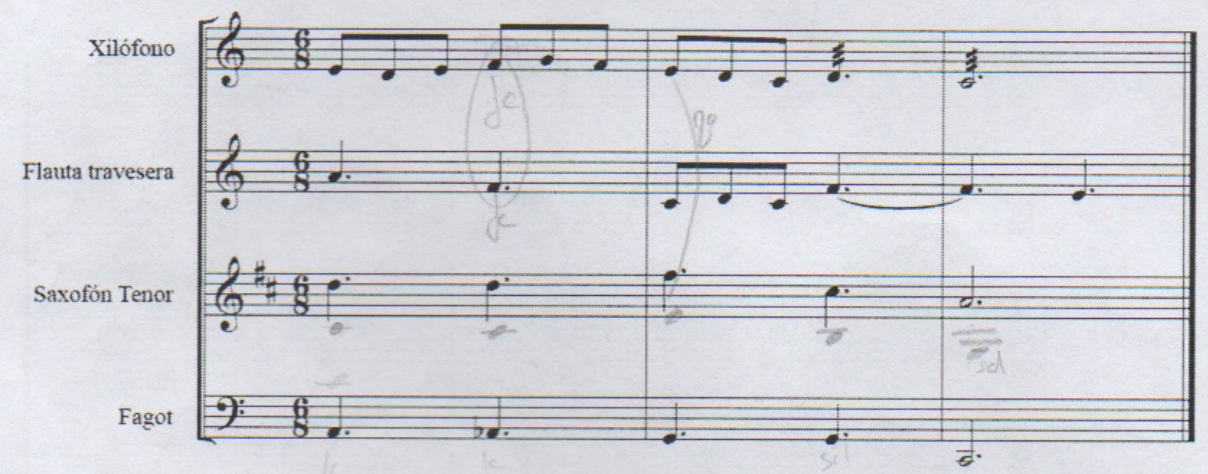

Marcar si no detectas ningún error:

\begin{tabular}{|c|c|c|c|c|}
\hline Compás & Tiempo & Instrumento/s implicado/s & Tipo de error & Observaciones \\
\hline 1 & 2 & Xilojono & n & \\
\hline 2 & 1 & savelen end & $e$ & \\
\hline 2 & 2 & Laula trevoeca & e & \\
\hline & & $y$ & & \\
\hline & & & & \\
\hline & & & & \\
\hline & & & & \\
\hline & & & & \\
\hline
\end{tabular}

Figura 29. Detalle del ejercicio 3 del postest del sujeto $\mathrm{N}^{\circ} 1$.

A la vista de los resultados del postest podemos concluir que la competencia transversal de

“Organología, instrumentación y orquestación en el ámbito de la orquesta sinfónica" está asumida parcialmente. Concretamente denotamos mejoría en las variables referidas a la organología de los instrumentos transpositores y no transpositores, así como a la asociación 
Diseño y planificación de competencias específicas en el currículum de enseñanzas profesionales de música: modalidades composición-dirección en la enseñanza superior.

\section{Carlos Eduardo Pascual Pérez}

de estos. Por último, observamos un alto nivel de error propiamente en lo curricular de la asignatura de armonía que posiblemente haya sido determinante para no poder obtener un mejor resultado en la puntuación global del test, y de la que se desprende un empeoramiento en las variables referidas a la lecto-escritura y que además resulta en un empeoramiento aritmético en la comparativa de medias referidas a las variables en su conjunto.

\begin{tabular}{|c|c|c|c|c|c|c|c|c|c|c|c|c|}
\multicolumn{1}{|c|}{ PRETEST } & \multicolumn{10}{c|}{ POSTEST } \\
\hline ONT & OT & LENT & LET & ANTT & $M V$ & ONT & OT & LENT & LET & ANTT & $M V$ & MG \\
\hline 0,00 & 2,00 & 7,50 & 8,80 & 2,50 & 4,15 & 4,0 & 4,00 & 5,00 & 0,00 & 3,33 & 3,27 & $\mathbf{1 , 0 0}$ \\
\hline
\end{tabular}

Tabla 10. Resumen puntuaciones de variables, medias y global para el sujeto $\mathrm{N}^{\mathrm{o}} 1$.

\subsubsection{Caso experimental $N^{o} 2$}

La valoración inicial del primer ejercicio del pretest nos sugiere un cierto grado de conocimiento acerca de la organología de los instrumentos sinfónicos del ámbito orquestal, aunque con algunos errores. Los aciertos son aceptados parcialmente, puesto que se refiere a los índices de afinación absoluta como si de tonalidades mayores se tratasen, lo cual es una incorrección. En el caso del el contrabajo o el saxofón tenor se acierta su octavación pero no su afinación y/o transposición.

Respecto al segundo ejercicio de lecto-escritura y asociación entre instrumentos transpositores y no transpositores, podemos observar errores en el ámbito del clarinete y de 
Diseño y planificación de competencias específicas en el currículum de enseñanzas profesionales de música: modalidades composición-dirección en la enseñanza superior.

Carlos Eduardo Pascual Pérez

la trompa (instrumentos transpositores, primer y segundo acorde respectivamente), así como de la interpretación del último de los acordes que incurre en un error en el oboe (instrumento no transpositor). También apreciamos un error al cruzarse las voces de estos dos instrumentos mencionados (ejercicio 2, primer acorde).

1. Identifica la afinación y octavación de los siguientes instrumentos:

\begin{tabular}{|c|c|c|c|c|c|}
\hline Instrumento & Afinación & Octavación & Instrumento & Afinación & Octavaciór \\
\hline Oboe & Do $\mathrm{M}$ & octouri noun & Clarinete bajo & Mib M & $8 a v$ \\
\hline Flautín & DO M & $8 a$ alta & Saxofón alto & $\mathrm{Fa} \mathrm{M}$ & $8 a$ \\
\hline Fagot & Do $M$ & $8 a v$ & Saxofón tenor & & $8 a v$ \\
\hline Contrabajo & & $8 a v$ & Lira & Do $M$ & $8 a \uparrow$ \\
\hline Trompa & Fa M & $8 a$ & Flauta alto & & $8 a v$ \\
\hline
\end{tabular}

2. Realiza los siguientes acordes:

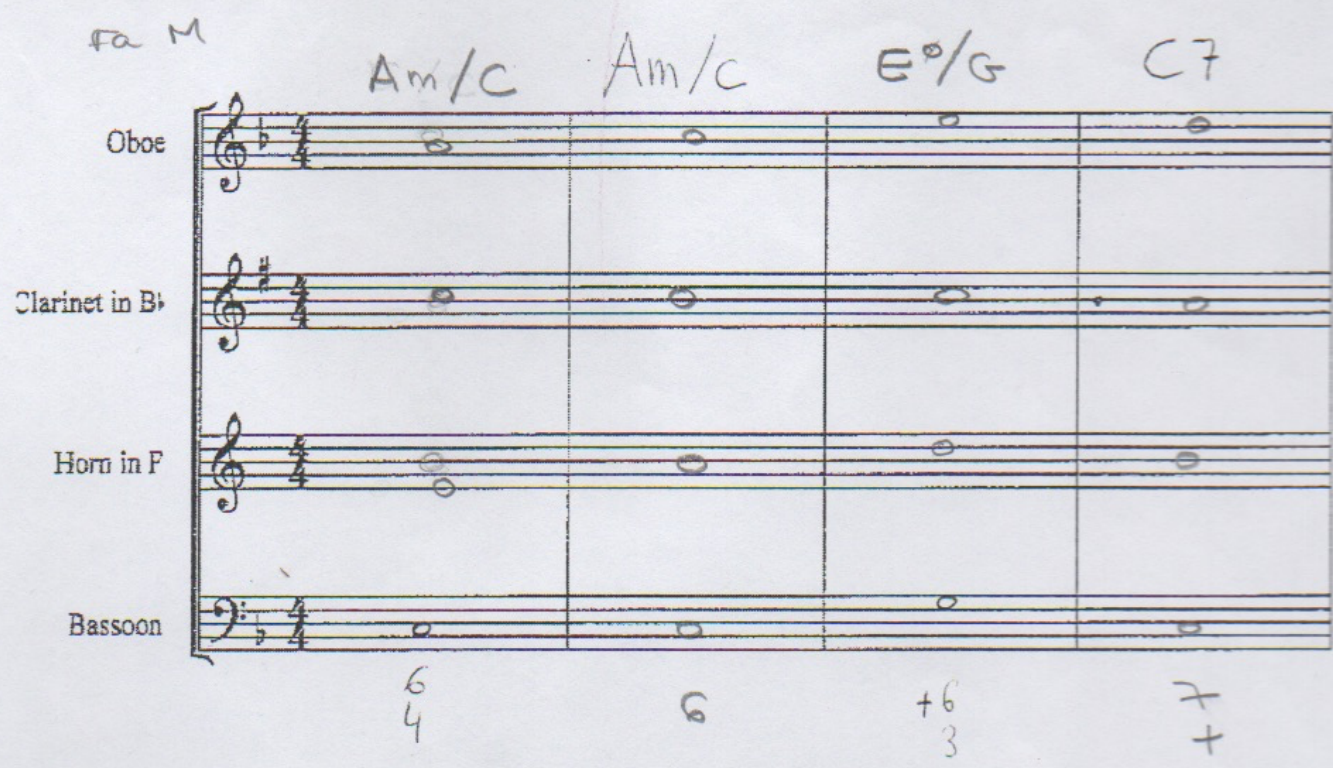

Figura 30. Pretest del caso experimental $\mathrm{N}^{\circ} 2$. 
Diseño y planificación de competencias específicas en el currículum de enseñanzas profesionales de música: modalidades composición-dirección en la enseñanza superior.

Carlos Eduardo Pascual Pérez

A la vista de los resultados creemos que sujeto ha podido relacionar o deducir las afinaciones del primer ejercicio a partir de las del segundo. Por ello deducimos que existe un grado medio de desconocimiento en el ámbito de la organología, pero un poco mayor en la capacidad de lecto-escritura entre instrumentos transpositores y no transpositores.

Tras la primera intervención y la entrega del primer ejercicio no observamos una mejora en el ámbito de la lecto-escritura, dado que continúan los errores de cruce entre voces (oboe y clarinete, compases 1 y 2). Encontramos el error de octavas seguidas entre la trompa y el fagot (compás 2). También se evidencian errores conceptuales propios en lo curricular de la asignatura de armonía, no siendo estos aplicables al desarrollo de nuestra competencia transversal.

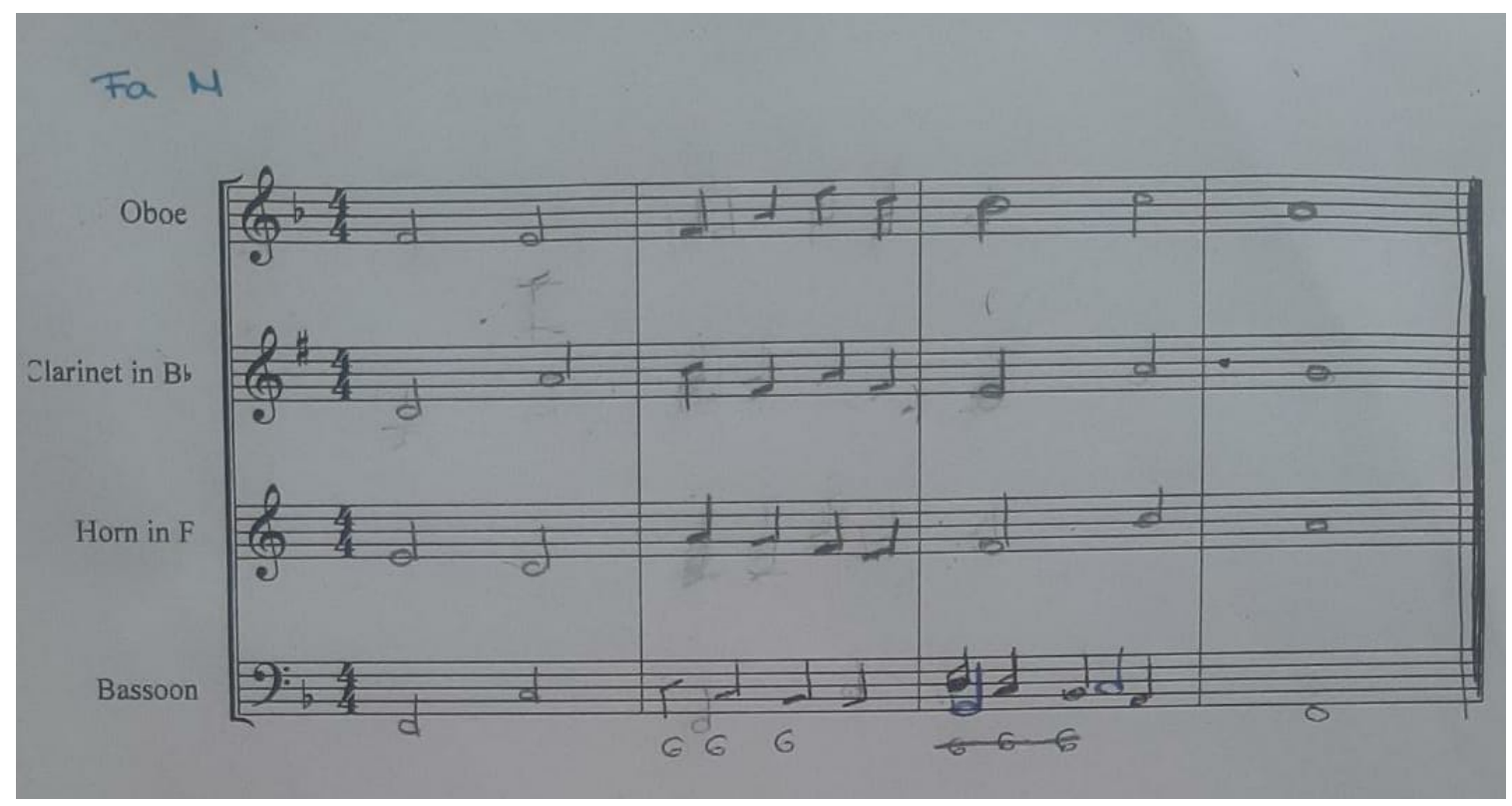

Figura 31. Detalle del ejercicio de la primera intervención del sujeto $\mathrm{N}^{\circ} 2$. 
En el ejercicio de la segunda intervención nos llama la atención el recurso accesorio de ubicar el registro de cada instrumento al inicio del pentagrama. Aunque en algún caso es incorrecto (como en el violín en su registro grave o en violoncello en el agudo), esta medida nos reporta un cierto entendimiento de las posibilidades técnicas de cada instrumento. Respecto a la lectura del saxofón alto - único instrumento transpositor del ejercicio - encontramos el recurso de transporte manual de la nota real anotándolo debajo de cada nota transpuesta, recurso que evidencia el correcto transporte del instrumento. Todas estas anotaciones son indicios de la comprensión del sistema del ejercicio y su dificultad al combinar diferentes claves y transposiciones. 
Diseño y planificación de competencias específicas en el currículum de enseñanzas profesionales de música: modalidades composición-dirección en la enseñanza superior

Carlos Eduardo Pascual Pérez

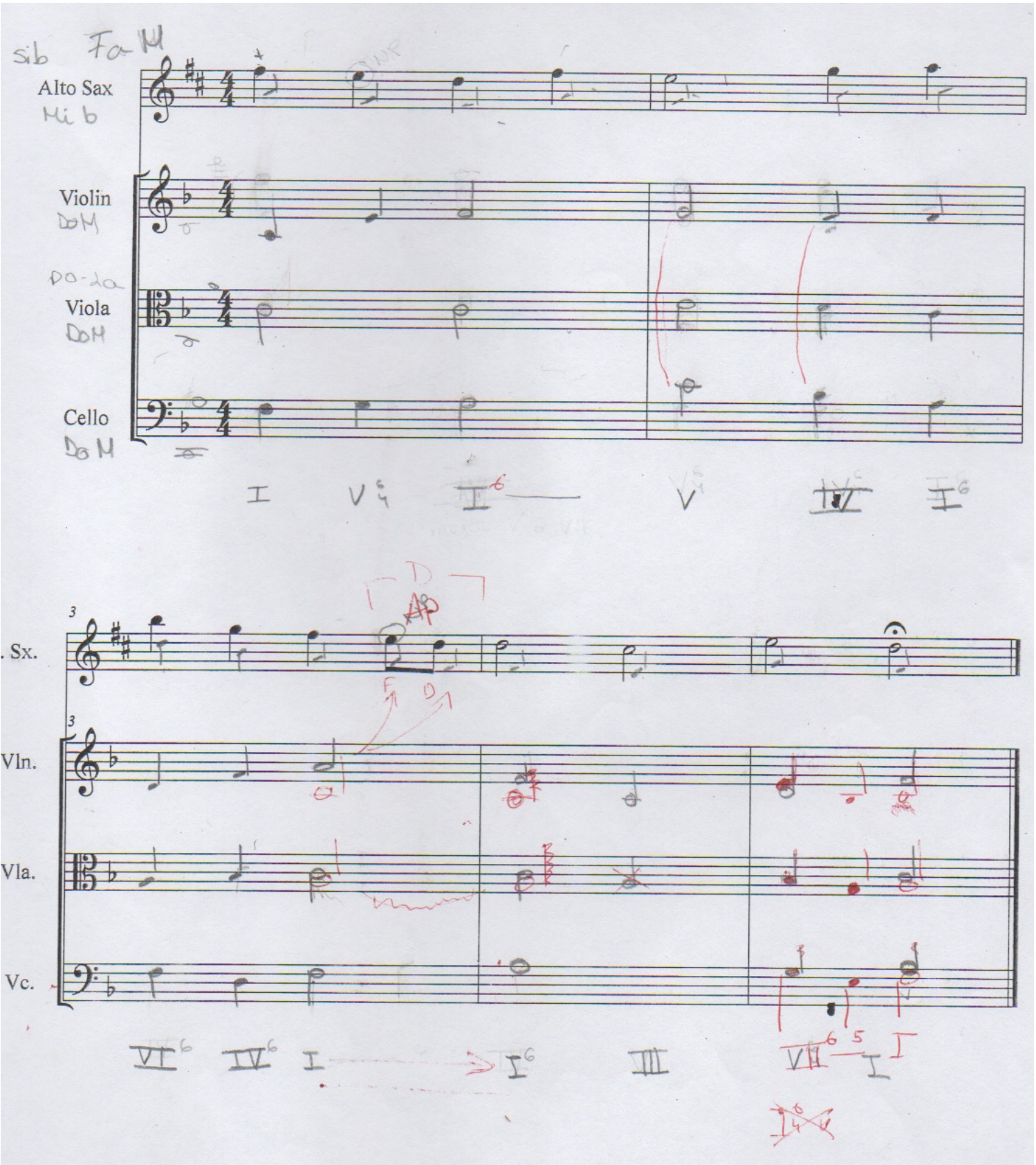

Figura 32. Detalle del ejercicio de la segunda intervención del sujeto $\mathrm{N}^{\mathrm{0}} 2$. 
No obstante, volvemos a detectar errores en la asociación entre voces como sucedió en el pretest, al cruzarse las voces entre el saxofón y el violín en el compás 3. Nuevamente también observamos errores propios curriculares sin que implique a nuestra competencia transversal, como las quinta seguidas entre el violín y el violoncello - instrumentos no transpositores y con uso de claves comunes en la práctica armónica de la asignatura - en el compás 2 o el tritono tonal mal resuelto entre sendos instrumentos en el compás 5.

En la evaluación final a través del postest observamos un alto grado de acierto a nivel de organología tanto de instrumentos transpositores como no transpositores, así como de lectoescritura en instrumentos no transpositores. Por las anotaciones al margen de cada pentagrama podemos deducir que el alumno conoce las propiedades de la totalidad de los instrumentos (incluida la octavación del xilófono y del contrabajo), sobre todo de aquellos que conllevan una octavación además de la transposición (como el contrabajo, el saxofón tenor o el clarinete bajo). Queda patente el alto grado de asimilación de los instrumentos trabajados a nivel práctico en la intervención, así como de los instrumentos únicamente revisados a nivel teórico. 
Carlos Eduardo Pascual Pérez

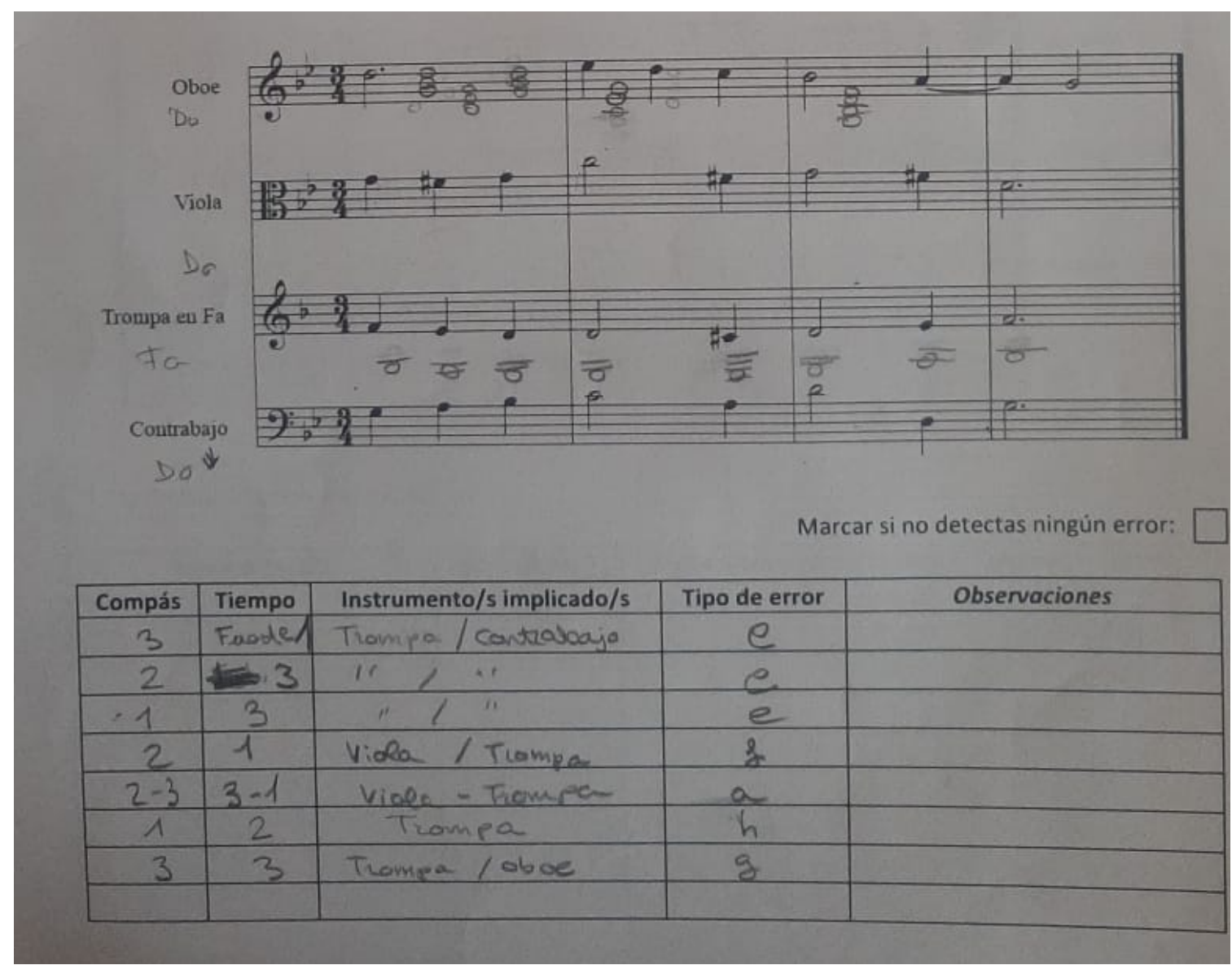

Figura 33. Detalle del ejercicio 1 del postest del sujeto $\mathrm{N}^{\mathrm{o}} 2$.

Respecto a la resolución del test (detección de errores armónicos) hallamos el 100\% de aciertos para el ejercicio 1, acompañado de cinco respuestas incorrectas, las cuales se desprenden tanto de incorrecciones propiamente armónicas - que no implican el uso de la competencia transversal - como de errores de asociación entre instrumentos transpositores y no transpositores. 


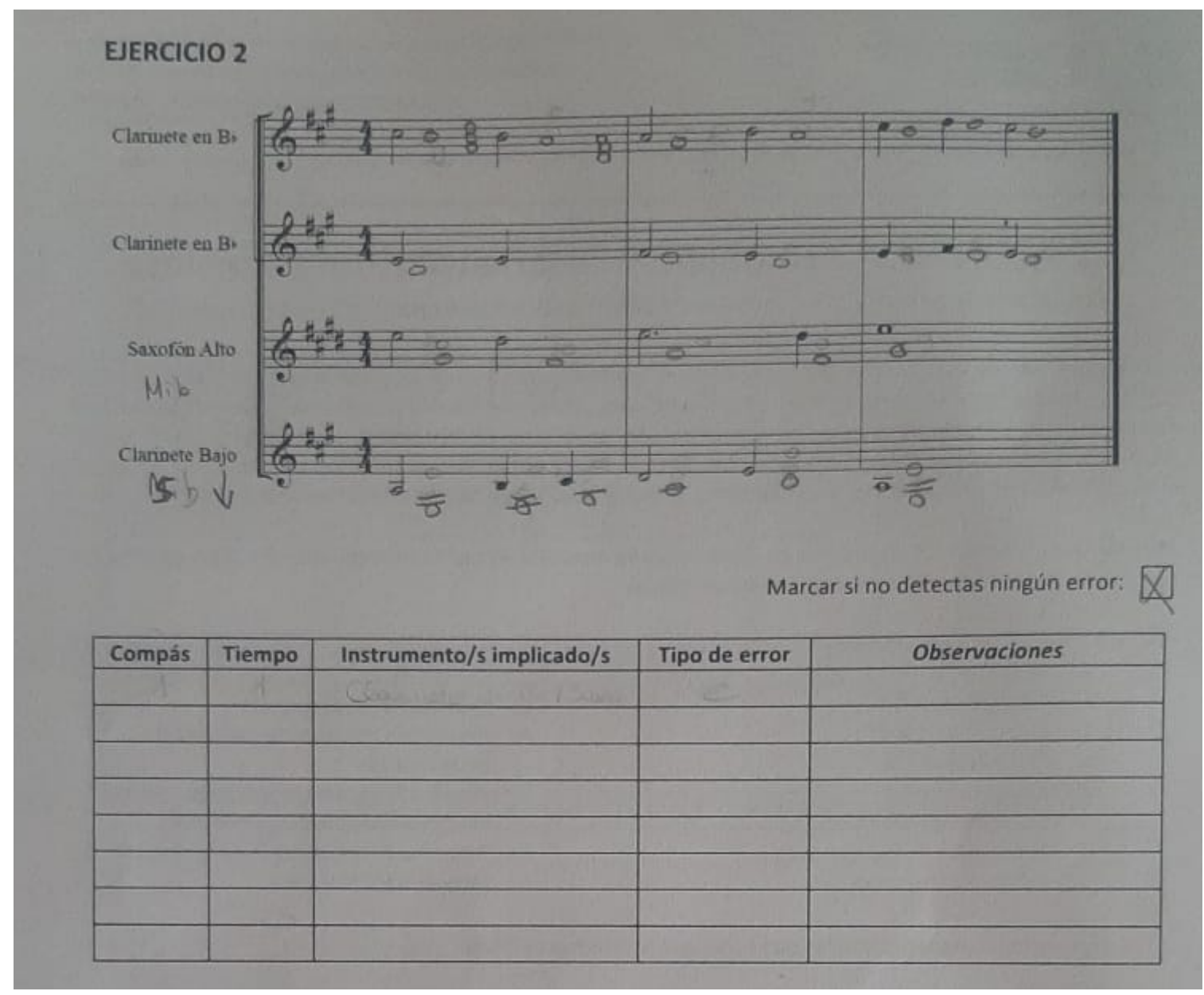

Figura 34. Detalle del ejercicio 2 del postest del sujeto $\mathrm{N}^{\circ} 2$.

El ejercicio 2 aparece indicado como ausencia total de errores, lo cual es erróneo, y esto nos reporta un $0 \%$ de aciertos para dicho ejercicio. No obstante, por las anotaciones al margen podemos saber que se aciertan todas las transposiciones y octavaciones de los instrumentos implicados. También nos sorprende que el error anotado y posteriormente borrado era correcto, por lo que suponemos que se ha incurrido en una malinterpretación del ejercicio. Por último, en el ejercicio 3 encontramos un 20\% de aciertos, acompañado de otra respuesta 
Diseño y planificación de competencias específicas en el currículum de enseñanzas profesionales de música: modalidades composición-dirección en la enseñanza superior.

Carlos Eduardo Pascual Pérez

incorrecta que creemos se desprende de una malinterpretación del error tipo a), dado que sabemos por las anotaciones al margen que el sujeto conoce las transposiciones y octavaciones correctas para los instrumentos relacionados (flauta y saxofón tenor).

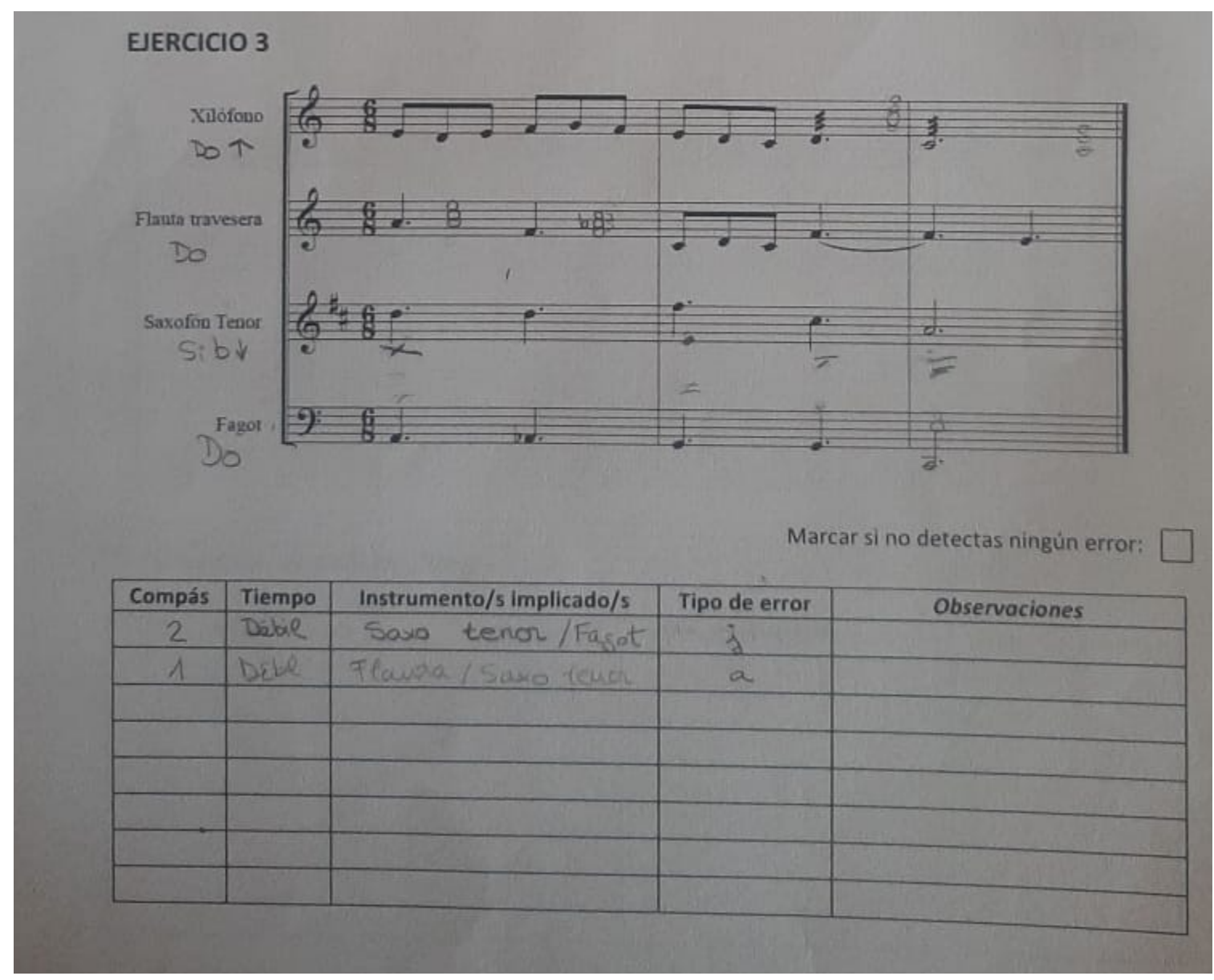

Figura 35. Detalle del ejercicio 3 del postest del sujeto $\mathrm{N}^{\circ} 2$.

A la vista de los resultados del postest podemos concluir que la competencia transversal de “Organología, instrumentación y orquestación en el ámbito de la orquesta sinfónica” está asumida en un alto grado. Concretamente denotamos mejoría notable en las variables 
Diseño y planificación de competencias específicas en el currículum de enseñanzas profesionales de música: modalidades composición-dirección en la enseñanza superior.

referidas a la organología de los instrumentos transpositores y no transpositores, así como a la asociación de estos y su lecto-escritura. Por último, observamos un grado error medio propiamente en lo curricular de la asignatura de armonía que posiblemente haya sido determinante para no poder obtener un mejor resultado en la puntuación global del test, y de la que se desprende un empeoramiento en las variables referidas a la lecto-escritura y que además resulta en un empeoramiento aritmético en la comparativa de medias referidas a las variables en su conjunto.

\begin{tabular}{|c|c|c|c|c|c|c|c|c|c|c|c|c|}
\hline \multicolumn{10}{|c|}{ PRETEST } & \multicolumn{10}{c|}{ POSTEST } \\
\hline ONT & OT & LENT & LET & ANTT & $M V$ & ONT & OT & LENT & LET & ANTT & $M V$ & MG \\
\hline 6,00 & 0,00 & 7,5 & 7,5 & 5,0 & 5,20 & 10,0 & 10,00 & 10,00 & 0,00 & 6,67 & 7,33 & $\mathbf{4 , 0 0}$ \\
\hline
\end{tabular}

Tabla 11. Resumen puntuaciones de variables, medias y global para el sujeto $\mathrm{N}^{\circ} 2$.

\subsubsection{Caso experimental $N^{o} 3$}

La valoración inicial del primer ejercicio del pretest nos sugiere una notable inexperiencia acerca de la organología de los instrumentos sinfónicos del ámbito orquestal. En el caso del clarinete bajo (instrumento transpositor) no se aporta la octavación del mismo. 
Diseño y planificación de competencias específicas en el currículum de enseñanzas profesionales de música: modalidades composición-dirección en la enseñanza superior.

Carlos Eduardo Pascual Pérez

Respecto al segundo ejercicio de lecto-escritura y asociación entre instrumentos transpositores y no transpositores, podemos observar errores en el ámbito del clarinete (ejercicio 2, primer acorde) y también apreciamos un error al cruzarse las voces de estos este y el oboe (ejercicio 2, tercer acorde).

1. Identifica la afinación y octavación de los siguientes instrumentos:

\begin{tabular}{|l|l|l|l|l|l|}
\hline Instrumento & Afinación & Octavación & Instrumento & Afinación & Octavación \\
\hline Oboe & & & Clarinete bajo & $\mathrm{Bb}$ & \\
\hline Flautín & & & Saxofón alto & & \\
\hline Fagot & & & Saxofón tenor & & \\
\hline Contrabajo & & Lira & & \\
\hline Trompa & $\mathrm{Fa}$ & $\mathrm{NO}$ & Flauta alto & & \\
\hline
\end{tabular}

2. Realiza los siguientes acordes:

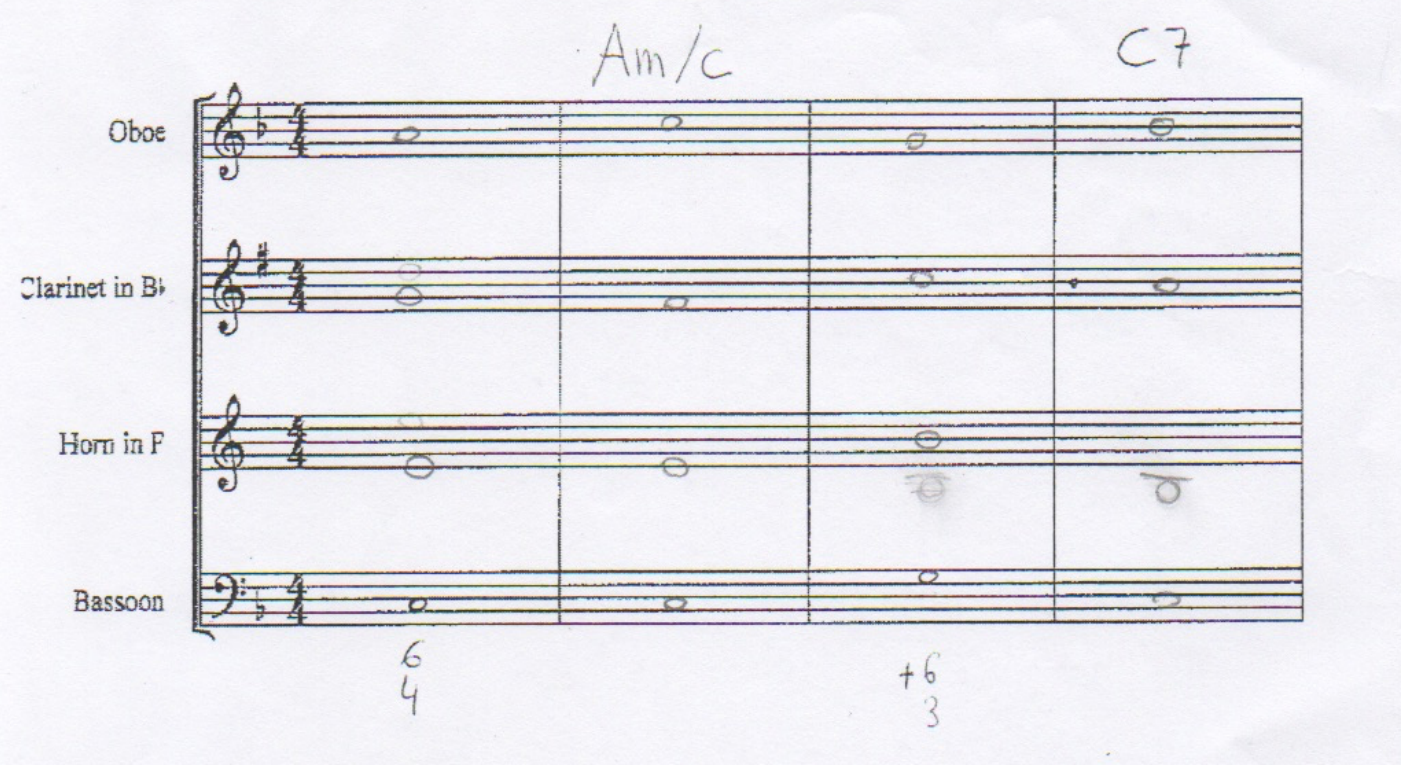

Figura 36. Pretest del caso experimental $\mathrm{N}^{\circ} 3$. 
A la vista de los resultados creemos que sujeto ha podido relacionar o deducir las afinaciones del primer ejercicio a partir de las del segundo. Por ello deducimos que existe un alto grado de desconocimiento en el ámbito de la organología, pero un poco mayor en la capacidad de lecto-escritura entre instrumentos transpositores y no transpositores.

Tras la primera intervención y la entrega del primer ejercicio observamos una mejora en el ámbito de la lecto-escritura, dado que continúan los errores de cruce entre voces (trompa y clarinete, compases 1). Encontramos el error de octavas seguidas entre el oboe y el fagot (compás 3) y de quintas y octavas directas con todos los instrumentos implicados (compases 4 y 5). También se evidencian errores conceptuales propios en lo curricular de la asignatura de armonía, no siendo estos aplicables al desarrollo de nuestra competencia transversal. Es peculiar el uso del primer espacio de compás para indicar a modo de apunte la extensión de cada instrumento, además de las anotaciones de las afinaciones y transposiciones de los instrumentos al principio de cada pentagrama. Aunque en algún caso es no es del todo exacto (como en la trompa en su registro grave), esta medida nos reporta un alto entendimiento de las posibilidades técnicas de cada instrumento. 
Diseño y planificación de competencias específicas en el currículum de enseñanzas profesionales de música: modalidades composición-dirección en la enseñanza superior.

Carlos Eduardo Pascual Pérez
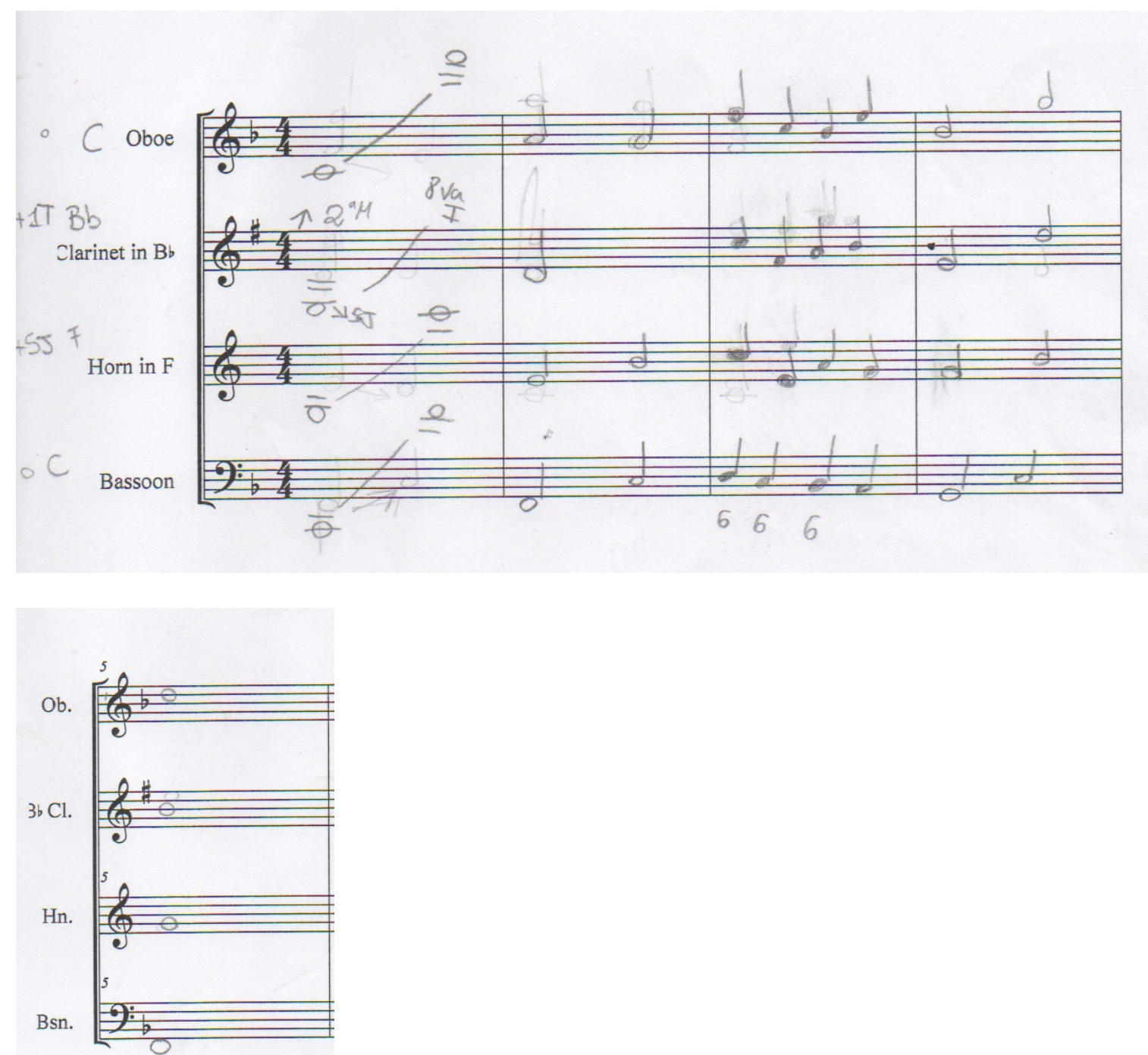

Figura 37. Detalle del ejercicio de la primera intervención del sujeto $\mathrm{N}^{\circ} 3$.

No tenemos respuesta del segundo ejercicio dado que el sujeto no lo presentó por motivos personales. No obstante, asistió a la sesión de la intervención y se le entregó el ejercicio para su realización. Desconocemos si pudo realizar parte del mismo a pesar de no presentarlo. 


\section{Carlos Eduardo Pascual Pérez}

En la evaluación final a través del postest observamos un alto grado de acierto a nivel de organología tanto de instrumentos transpositores como no transpositores, así como de lectoescritura en instrumentos no transpositores. Por las anotaciones al margen de cada pentagrama podemos deducir que el alumno conoce las propiedades de bastantes de los instrumentos, a excepción del xilófono y del contrabajo. También percibimos un error de la anotación del transporte de la trompa a pesar de que luego se ejecute correctamente el mismo. Queda patente el alto grado de asimilación de los instrumentos trabajados a nivel práctico en la intervención, así como de los instrumentos únicamente revisados a nivel teórico. 
Diseño y planificación de competencias específicas en el currículum de enseñanzas profesionales de música: modalidades composición-dirección en la enseñanza superior.

Carlos Eduardo Pascual Pérez

\section{EJERCICIO 1}

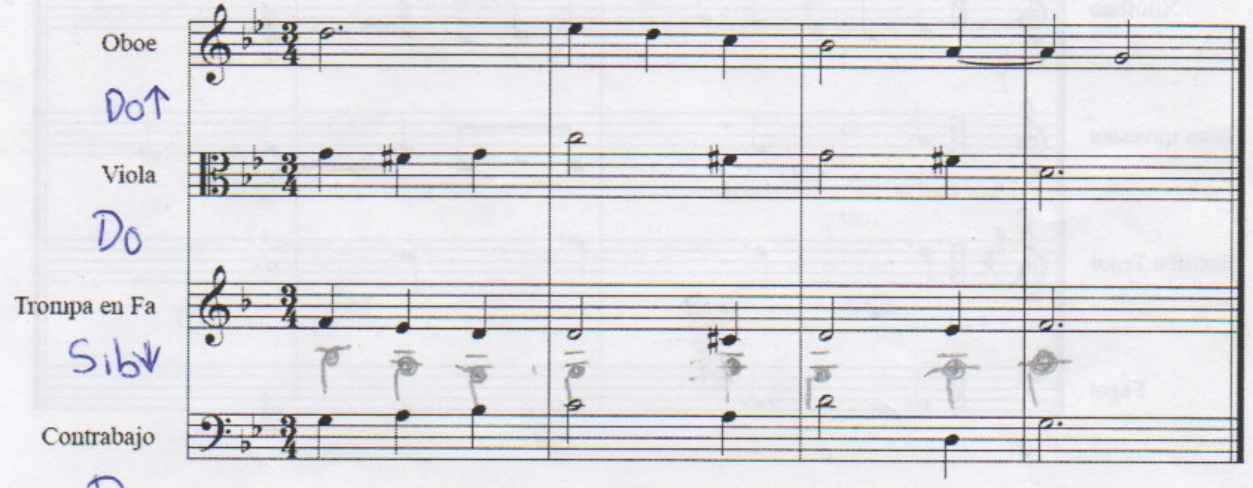

Do

Marcar si no detectas ningún error:

\begin{tabular}{|c|c|c|c|c|}
\hline Compás & Tiempo & Instrumento/s implicado/s & Tipo de error & Observaciones \\
\hline 2 & 1 & Viola Trompa & & \\
\hline 2 & 2 & II & & \\
\hline 3 & 1 & Vida I Iranda & $c$ & \\
\hline 4 & 1 & Viola & $h$ & \\
\hline & & & & \\
\hline & & & & \\
\hline & & & & \\
\hline
\end{tabular}

Figura 38. Detalle del ejercicio 1 del postest del sujeto $\mathrm{N}^{\mathrm{o}} 3$.

Respecto a la resolución del test (detección de errores armónicos) hallamos el 50\% de aciertos para el ejercicio 1, acompañado de tres respuestas incorrectas, las cuales se desprenden tanto de incorrecciones propiamente armónicas - que no implican el uso de la competencia transversal - como de errores de asociación entre instrumentos transpositores y no transpositores. 
Diseño y planificación de competencias específicas en el currículum de enseñanzas profesionales de música: modalidades composición-dirección en la enseñanza superior.

Carlos Eduardo Pascual Pérez

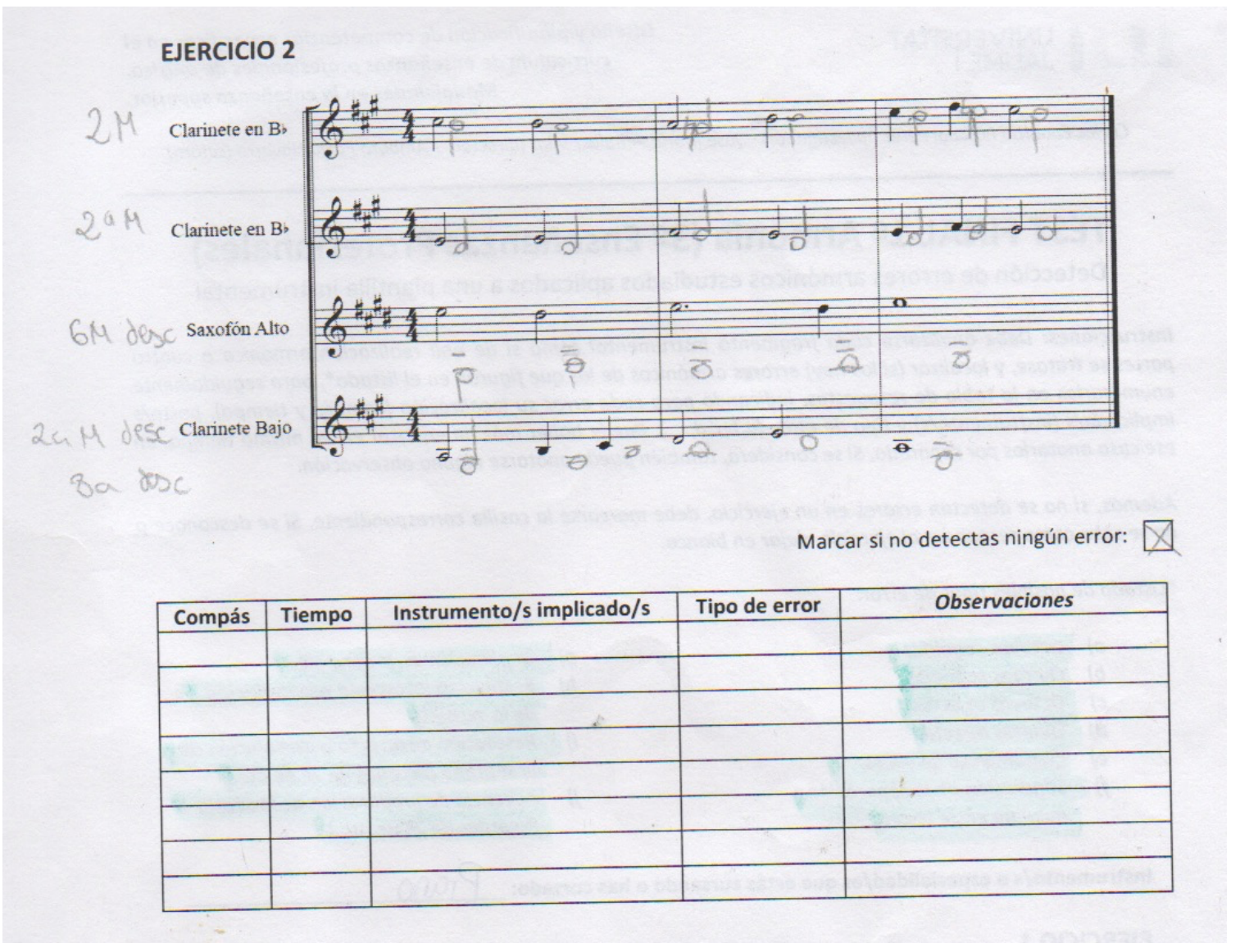

Figura 39. Detalle del ejercicio 2 del postest del sujeto $\mathrm{N}^{\circ} 3$.

El ejercicio 2 aparece indicado como ausencia total de errores, lo cual es erróneo, y esto nos reporta un $0 \%$ de aciertos para dicho ejercicio. No obstante, por las anotaciones al margen y la escritura de altura real en el pentagrama podemos saber que se aciertan todas las transposiciones y octavaciones de los instrumentos implicados, aunque se incurre en el error de escritura del saxofón alto. Por último, en el ejercicio 3 encontramos un $0 \%$ de aciertos, acompañado de otra respuesta incorrecta que creemos se desprende de incorrecciones propiamente armónicas. Nuevamente hallamos una escritura de altura real aplicada 
Diseño y planificación de competencias específicas en el currículum de enseñanzas profesionales de música: modalidades composición-dirección en la enseñanza superior.

Carlos Eduardo Pascual Pérez

correctamente a la transposición del saxofón tenor, pero queda ausente la misma aplicación para el xilófono, supuestamente debido a su desconocimiento.

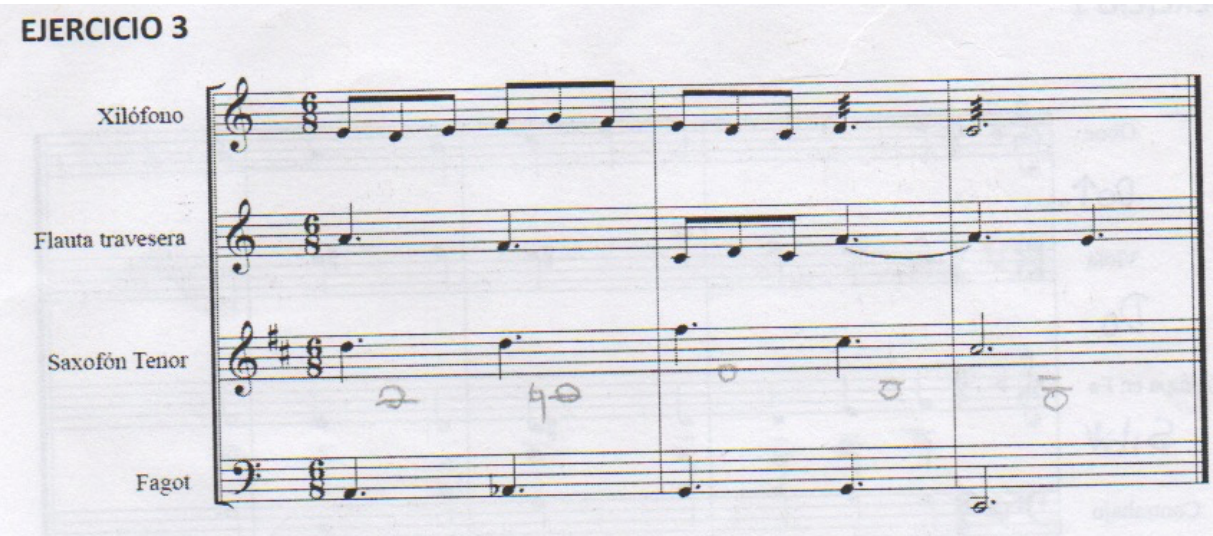

Marcar si no detectas ningún error:

\begin{tabular}{|c|c|c|c|c|}
\hline Compás & Tiempo & Instrumento/s implicado/s & Tipo de error & Observaciones \\
\hline 3 & 1 & Soxo & h & \\
\hline & & & & \\
\hline & & & & \\
\hline & & & & \\
\hline & & & & \\
\hline & & & & \\
\hline
\end{tabular}

Figura 40. Detalle del ejercicio 3 del postest del sujeto $\mathrm{N}^{\mathrm{o}} 3$.

A la vista de los resultados del postest podemos concluir que la competencia transversal de “Organología, instrumentación y orquestación en el ámbito de la orquesta sinfónica" está asumida parcialmente. Concretamente denotamos mejoría muy significativa en las variables referidas a la organología de los instrumentos transpositores y no transpositores. Por último, observamos un alto grado de error propiamente en lo curricular de la asignatura de armonía 
que posiblemente haya sido determinante para no poder obtener un mejor resultado en la puntuación global del test, y de la que se desprende un empeoramiento en las variables referidas a la lecto-escritura y que además resulta en un empeoramiento aritmético en la comparativa de medias referidas a las variables en su conjunto.

\begin{tabular}{|c|c|c|c|c|c|c|c|c|c|c|c|c|}
\multicolumn{10}{c|}{ PRETEST } & \multicolumn{10}{c|}{ POSTEST } \\
\hline ONT & OT & LENT & LET & ANTT & $M V$ & ONT & OT & LENT & LET & ANTT & $M V$ & MG \\
\hline 0,00 & 2,00 & 10,0 & 8,8 & 10,0 & 6,15 & 4,0 & 10,00 & 10,00 & 0,00 & 3,33 & 5,47 & $\mathbf{2 , 0 0}$ \\
\hline
\end{tabular}

Tabla 12. Resumen puntuaciones de variables, medias y global para el sujeto $\mathrm{N}^{\mathrm{O}} 3$.

\subsubsection{Caso experimental $N^{o} 4$}

La valoración inicial del primer ejercicio del pretest nos sugiere una inexperiencia de conocimiento acerca de la organología de los instrumentos sinfónicos del ámbito orquestal, con un único acierto parcial.

Respecto al segundo ejercicio de lecto-escritura y asociación entre instrumentos transpositores y no transpositores, podemos observar error continuo de la transposición durante todo el ejercicio en el ámbito del clarinete, que lleva a producir un error en cada 
Diseño y planificación de competencias específicas en el currículum de enseñanzas profesionales de música: modalidades composición-dirección en la enseñanza superior.

Carlos Eduardo Pascual Pérez

acorde. También apreciamos un error al cruzarse las voces de este instrumento con el oboe

(ejercicio 2, segundo y tercer acorde).

1. Identifica la afinación y octavación de los siguientes instrumentos:

\begin{tabular}{|l|l|l|l|l|l|}
\hline \multicolumn{1}{|c|}{ Instrumento } & Afinación & Octavación & \multicolumn{1}{|c|}{ Instrumento } & Afinación & Octavación \\
\hline Oboe & & & Clarinete bajo & & \\
\hline Flautín & & & Saxofón alto & & \\
\hline Fagot & & & Saxofón tenor & & \\
\hline Contrabajo & & & Lira & & \\
\hline Trompa & F & & Flauta alto & & \\
\hline
\end{tabular}

2. Realiza los siguientes acordes:

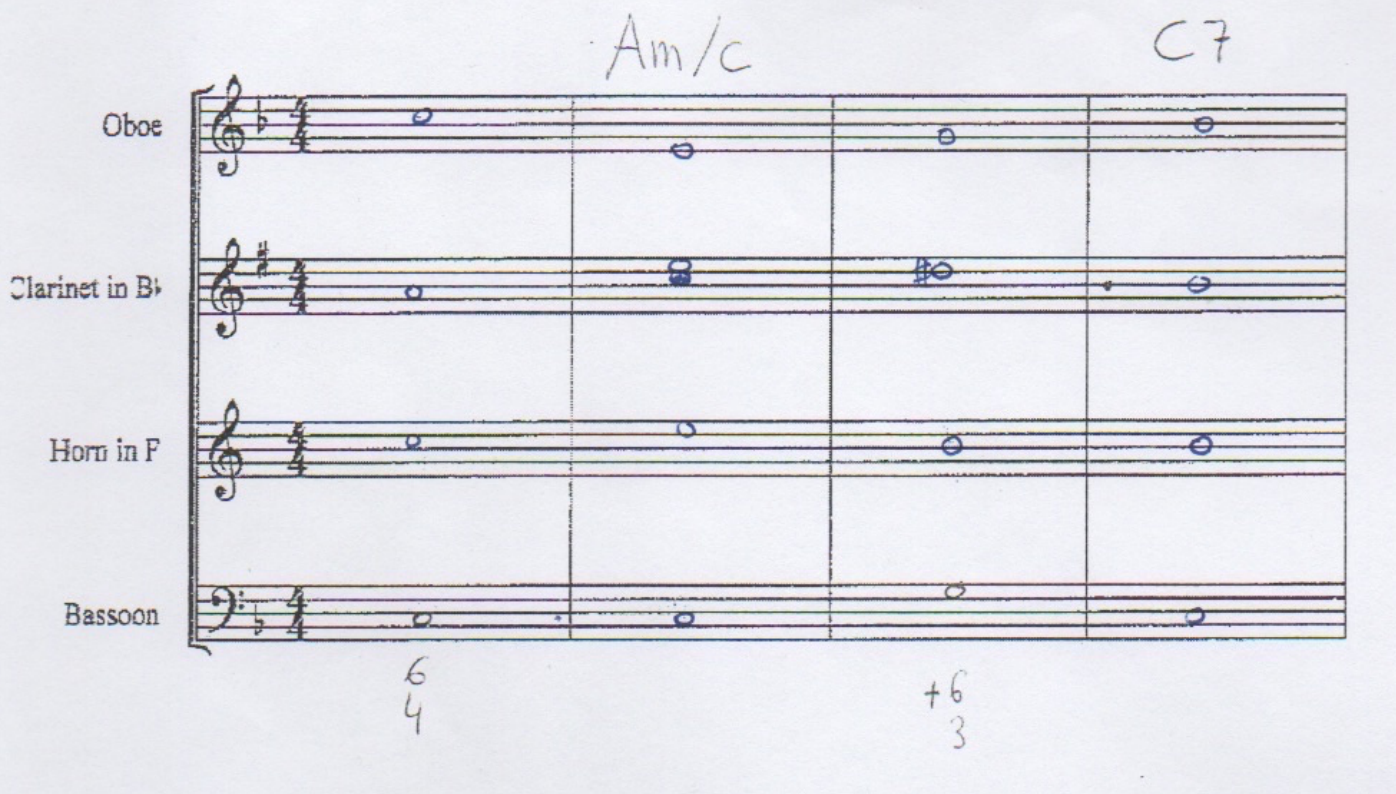

Figura 41. Pretest del caso experimental $\mathrm{N}^{\circ} 4$. 


\section{Carlos Eduardo Pascual Pérez}

A la vista de los resultados creemos que sujeto ha podido relacionar o deducir la afinación de la única respuesta del primer ejercicio a partir de las del segundo. Por ello deducimos que existe un alto grado de desconocimiento en el ámbito de la organología y también en la capacidad de lecto-escritura entre instrumentos transpositores y no transpositores.

Tras la primera intervención y la entrega del primer ejercicio no observamos una mejora en el ámbito de la lecto-escritura, dado que continúan los errores de cruce entre voces (oboe y clarinete, compases 3, 4 y 2). Encontramos el error de quintas seguidas entre la trompa y el fagot (compás 2) y también quintas directas (compás 5). También se evidencian errores conceptuales propios en lo curricular de la asignatura de armonía, no siendo estos aplicables al desarrollo de nuestra competencia transversal. Nuevamente observamos el uso del primer espacio de compás para ubicar el registro de cada instrumento, como ocurre en el caso del sujeto $\mathrm{N}^{\mathrm{o}} 3$. 
Diseño y planificación de competencias específicas en el currículum de enseñanzas profesionales de música: modalidades composición-dirección en la enseñanza superior.

Carlos Eduardo Pascual Pérez

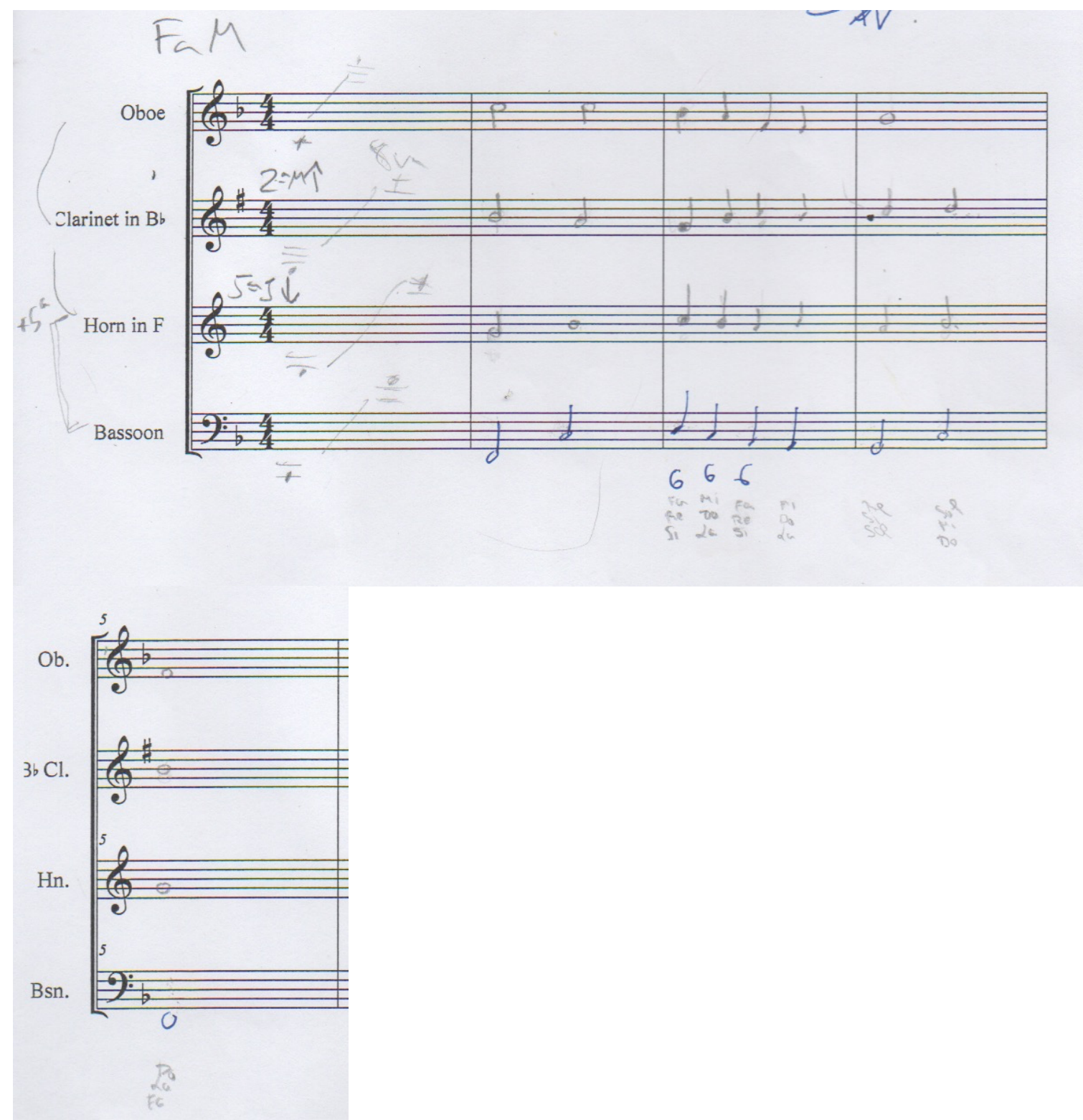

Figura 42. Detalle del ejercicio de la primera intervención del sujeto $\mathrm{N}^{\mathrm{o}} 4$.

En el ejercicio de la segunda intervención hallamos una mejora significativa en cuanto a la organología y la lecto-escritura. Respecto a la lectura del saxofón alto - único instrumento transpositor del ejercicio - encontramos el recurso de transporte manual de la nota real 
Diseño y planificación de competencias específicas en el currículum de enseñanzas profesionales de música: modalidades composición-dirección en la enseñanza superior.

Carlos Eduardo Pascual Pérez

anotándolo debajo de cada nota transpuesta, recurso que evidencia el correcto transporte del instrumento. Además, encontramos una escritura correcta del uso de la clave de Do en la viola.

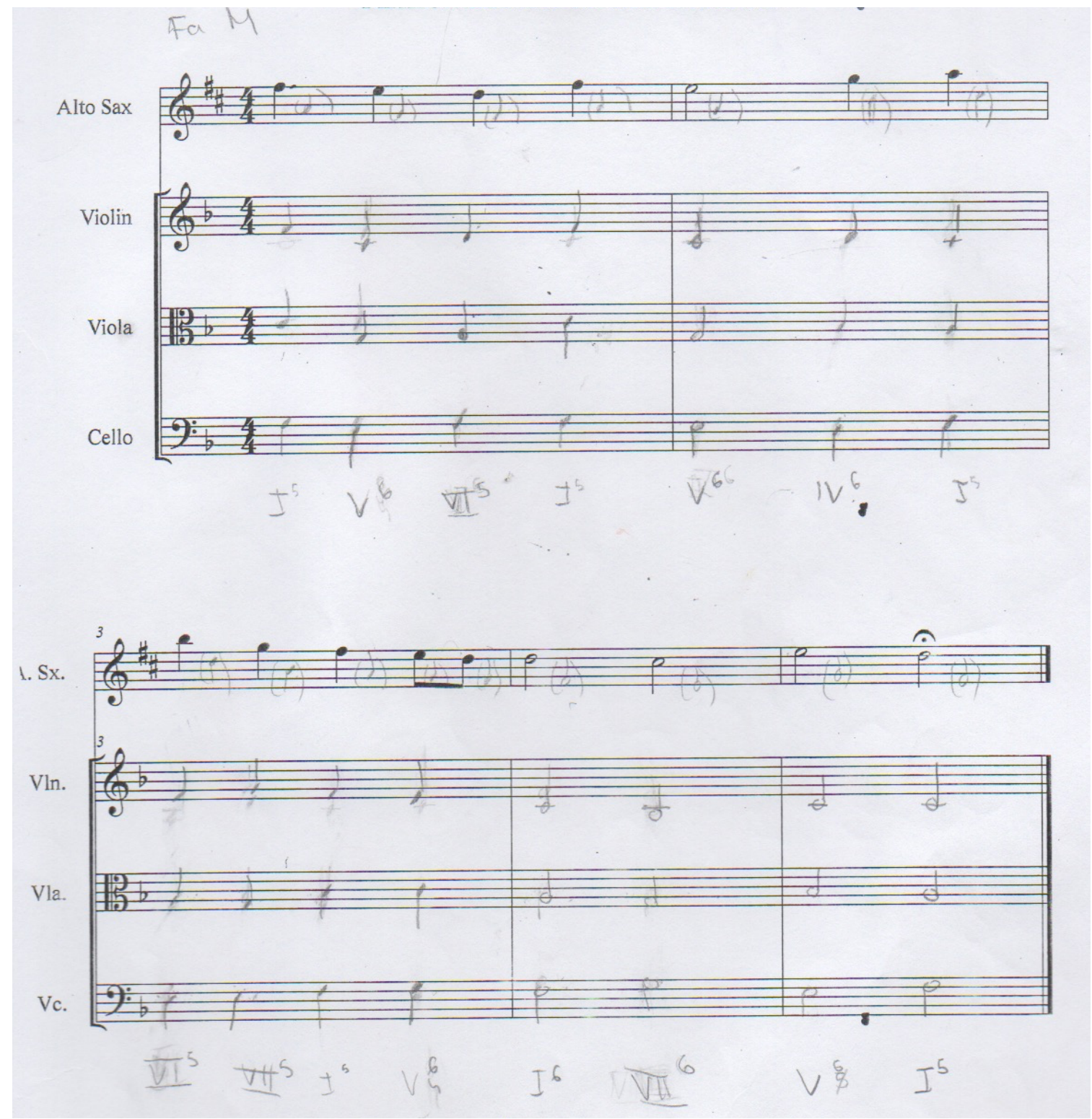

Figura 43. Detalle del ejercicio de la segunda intervención del sujeto $\mathrm{N}^{\circ} 4$. 
No detectamos los errores anteriores en la asociación entre voces como sucedía en el pretest y en el ejercicio de la primera intervención, dado que no hay cruces entre voces. No obstante, observamos errores propios curriculares sin que implique a nuestra competencia transversal, como disonancias entre el saxofón y el violoncello - instrumentos no transpositores y con uso de claves comunes en la práctica armónica de la asignatura - en los compases 3 y 4, o la incorrección en las notas propias del acorde de dominante en el compás 3.

En la evaluación final a través del postest observamos un alto grado de acierto a nivel de organología tanto de instrumentos transpositores como no transpositores, así como de lectoescritura en instrumentos no transpositores. Por las anotaciones al margen de cada pentagrama podemos deducir que el alumno conoce las propiedades de la totalidad de los instrumentos (incluida la octavación del xilófono y del contrabajo), sobre todo de aquellos que conllevan una octavación además de la transposición (como el contrabajo, el saxofón tenor o el clarinete bajo). Queda patente el alto grado de asimilación de los instrumentos trabajados a nivel práctico en la intervención, así como de los instrumentos únicamente revisados a nivel teórico. 
Carlos Eduardo Pascual Pérez

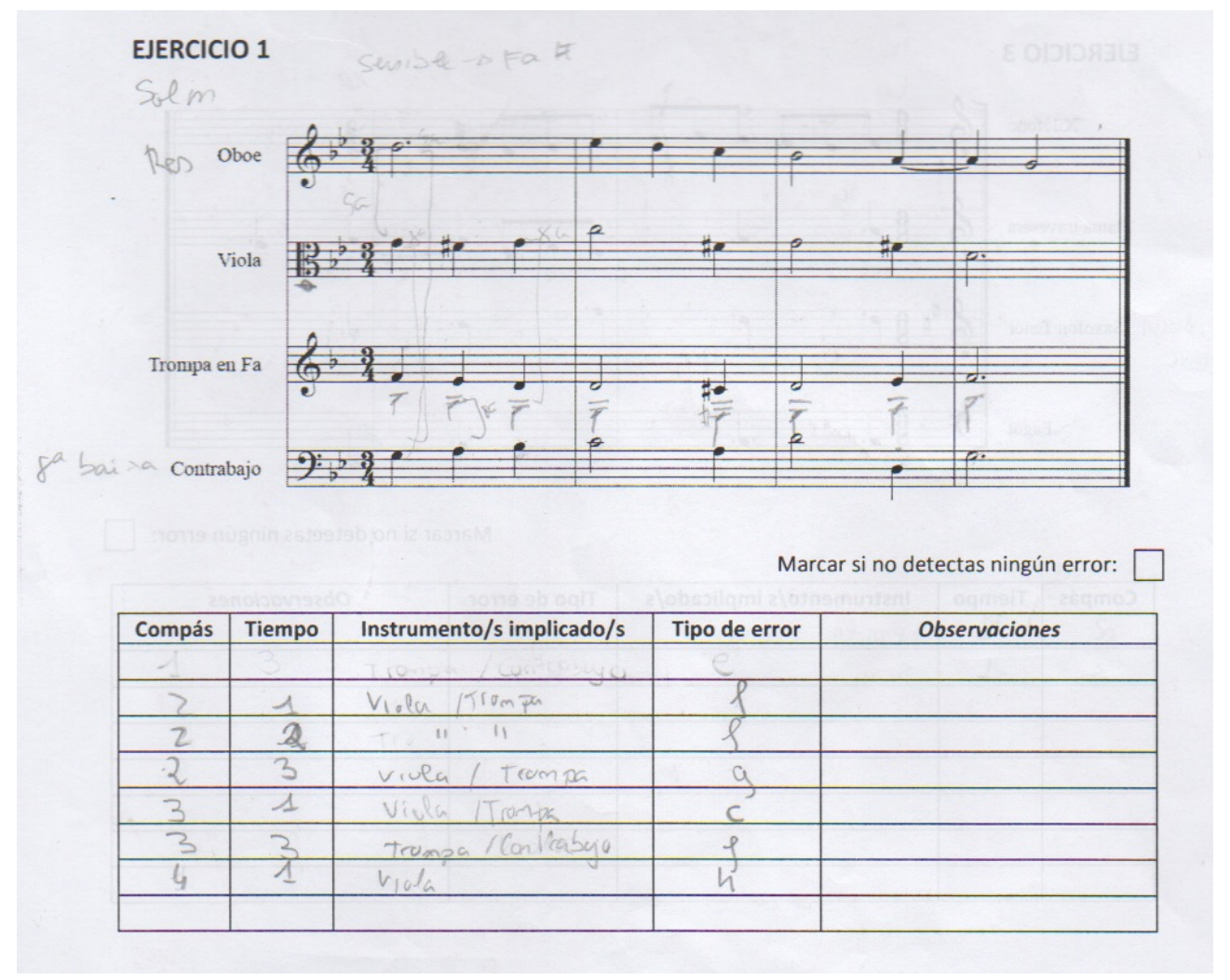

Figura 44. Detalle del ejercicio 1 del postest del sujeto $\mathrm{N}^{\circ} 4$.

Respecto a la resolución del test (detección de errores armónicos) hallamos el 100\% de aciertos para el ejercicio 1, acompañado de tres respuestas incorrectas, las cuales se desprenden tanto de incorrecciones propiamente armónicas - que no implican el uso de la competencia transversal - como de errores de asociación entre instrumentos transpositores y no transpositores. 
Carlos Eduardo Pascual Pérez

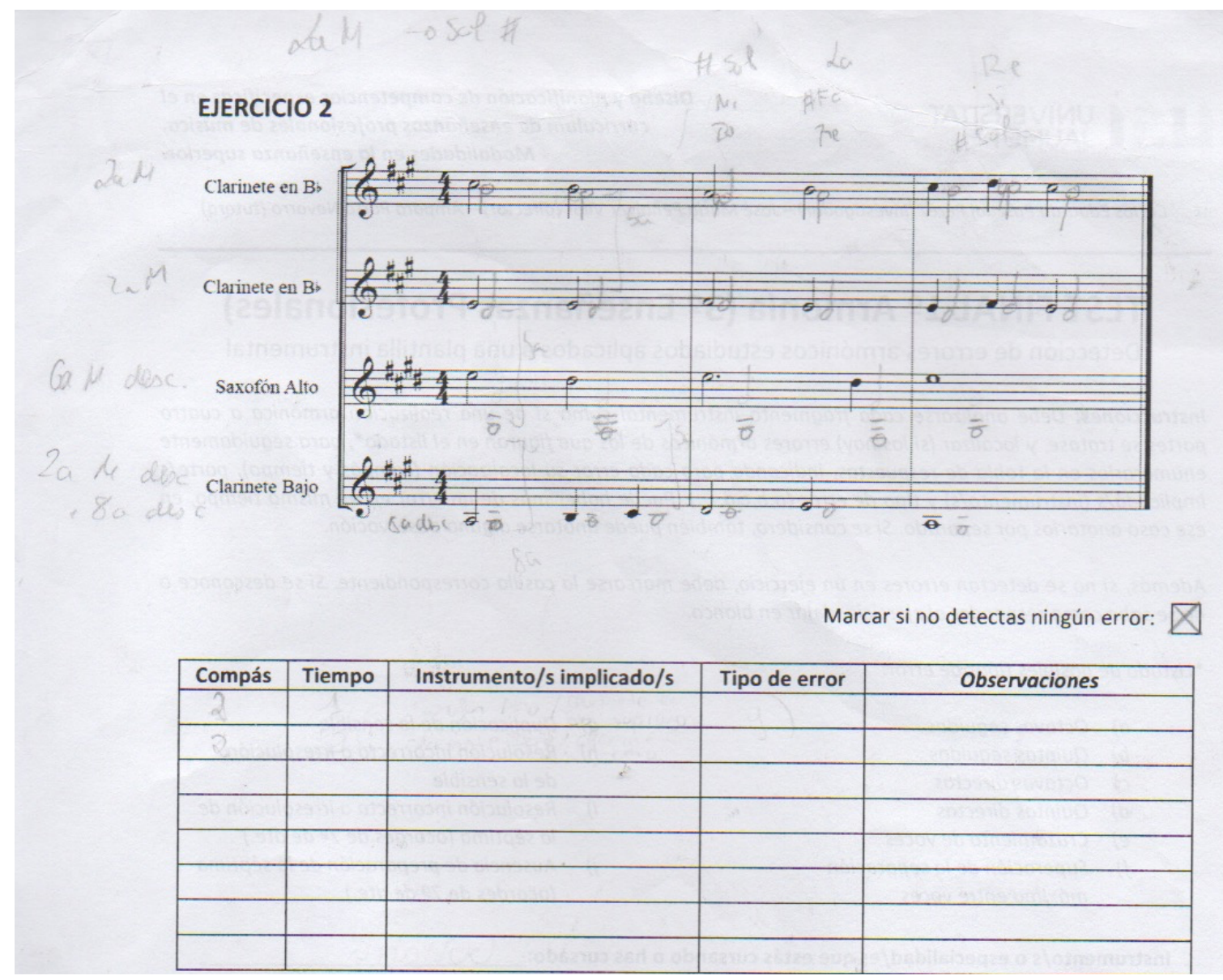

Figura 45. Detalle del ejercicio 2 del postest del sujeto $\mathrm{N}^{\circ} 4$.

El ejercicio 2 aparece indicado como ausencia total de errores, lo cual es erróneo, y esto nos reporta un $0 \%$ de aciertos para dicho ejercicio. No obstante, por las anotaciones al margen y la escritura de altura real en el pentagrama podemos saber que se aciertan todas las transposiciones y octavaciones de los instrumentos implicados, aunque se incurre en el error de escritura del saxofón alto durante todo el ejercicio. Por último, en el ejercicio 3 encontramos un $20 \%$ de aciertos, acompañado de otra respuesta incorrecta propia de lo 
Diseño y planificación de competencias específicas en el currículum de enseñanzas profesionales de música: modalidades composición-dirección en la enseñanza superior.

Carlos Eduardo Pascual Pérez

curricular de la asignatura de armonía, no siendo estos aplicables al desarrollo de nuestra competencia transversal.

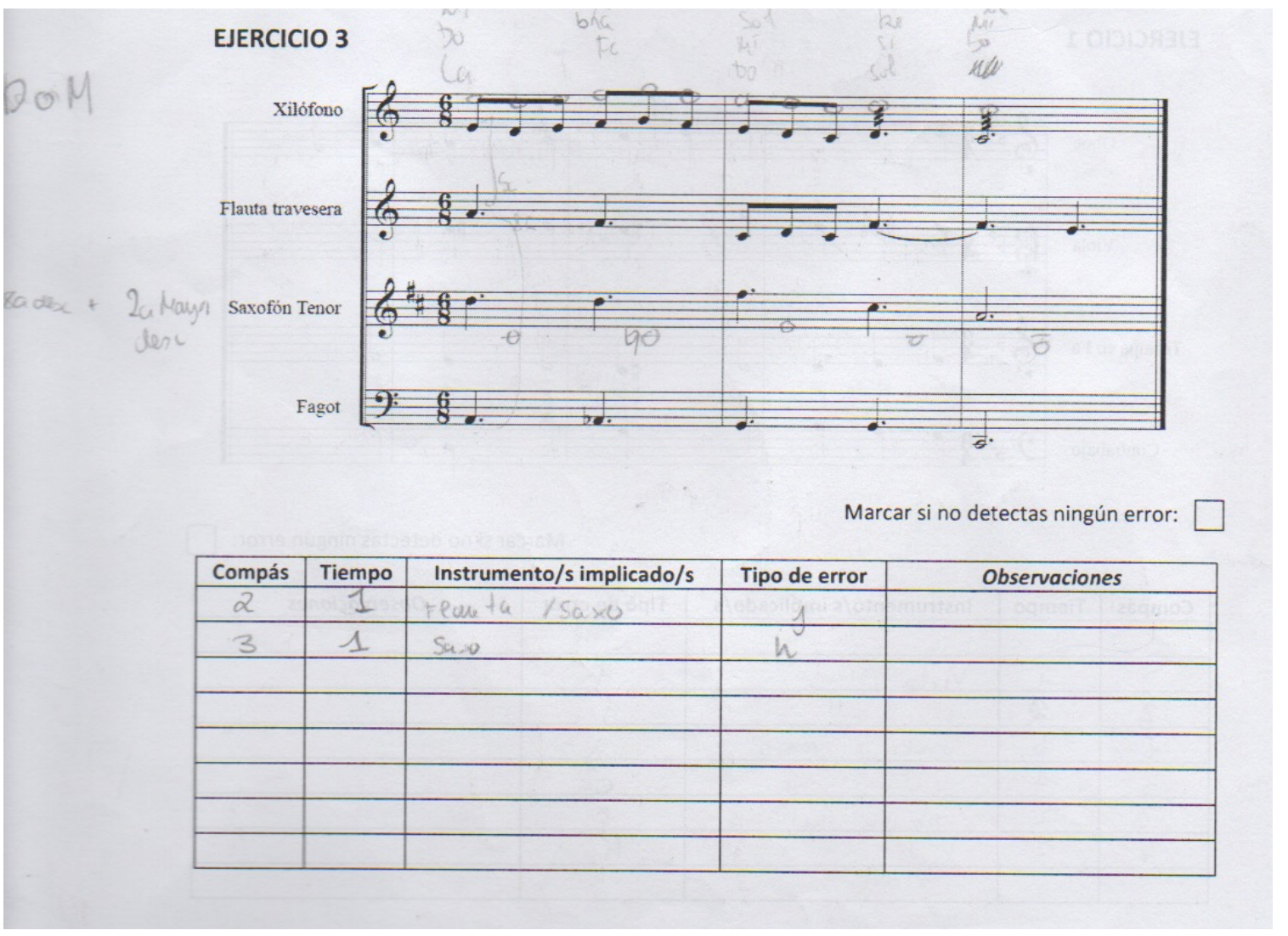

Figura 46. Detalle del ejercicio 3 del postest del sujeto $\mathrm{N}^{\circ} 4$.

A la vista de los resultados del postest podemos concluir que la competencia transversal de “Organología, instrumentación y orquestación en el ámbito de la orquesta sinfónica" está asumida en un alto grado. Concretamente denotamos mejoría notable en todas las variables a excepción de la lecto-escritura entre instrumentos transpositores. Por último, observamos un grado error elevado en lo curricular de la asignatura de armonía que posiblemente haya 
sido determinante para no poder obtener un mejor resultado en la puntuación global del test, y de la que se desprende un empeoramiento en las variables referidas a la lecto-escritura y que además resulta en un empeoramiento aritmético en la comparativa de medias referidas a las variables en su conjunto.

\begin{tabular}{|c|c|c|c|c|c|c|c|c|c|c|c|c|}
\hline \multicolumn{10}{|c|}{ PRETEST } \\
\hline ONT & OT & LENT & LET & ANTT & $M V$ & ONT & OT & LENT & LET & ANTT & $M V$ & MG \\
\hline 0,00 & 0,00 & 7,5 & 5,0 & 0,0 & 3,00 & 6,0 & 6,00 & 10,00 & 0,00 & 6,67 & 5,73 & $\mathbf{3 , 0 0}$ \\
\hline
\end{tabular}

Tabla 13. Resumen puntuaciones de variables, medias y global para el sujeto $\mathrm{N}^{\circ} 4$.

\subsubsection{Caso experimental $N^{o} 5$}

La valoración inicial del primer ejercicio del pretest nos sugiere un alto grado de conocimiento acerca de la organología de los instrumentos sinfónicos del ámbito orquestal, con más del $50 \%$ de aciertos completos.

Respecto al segundo ejercicio de lecto-escritura y asociación entre instrumentos transpositores y no transpositores, podemos observar ciertos errores puntuales en el oboe 
Diseño y planificación de competencias específicas en el currículum de enseñanzas profesionales de música: modalidades composición-dirección en la enseñanza superior.

Carlos Eduardo Pascual Pérez

(ejercicio 2, primer acorde), clarinete (primer acorde) y trompa (cuarto acorde). También apreciamos errores al cruzarse las voces de este oboe y clarinete (segundo acorde).

1. Identifica la afinación y octavación de los siguientes instrumentos:

\begin{tabular}{|l|c|c|l|c|c|}
\hline \multicolumn{1}{|c|}{ Instrumento } & Afinación & Octavación & Instrumento & Afinación & Octavación \\
\hline Oboe & DO & - & Clarinete bajo & & \\
\hline Flautín & DO & $8 a$ a d a & Saxofón alto & Mib & - \\
\hline Fagot & DO & - & Saxofón tenor & & \\
\hline Contrabajo & DO & $8 a$ baja & Lira & & \\
\hline Trompa & FA & - & Flauta alto & DO & - \\
\hline
\end{tabular}

2. Realiza los siguientes acordes:

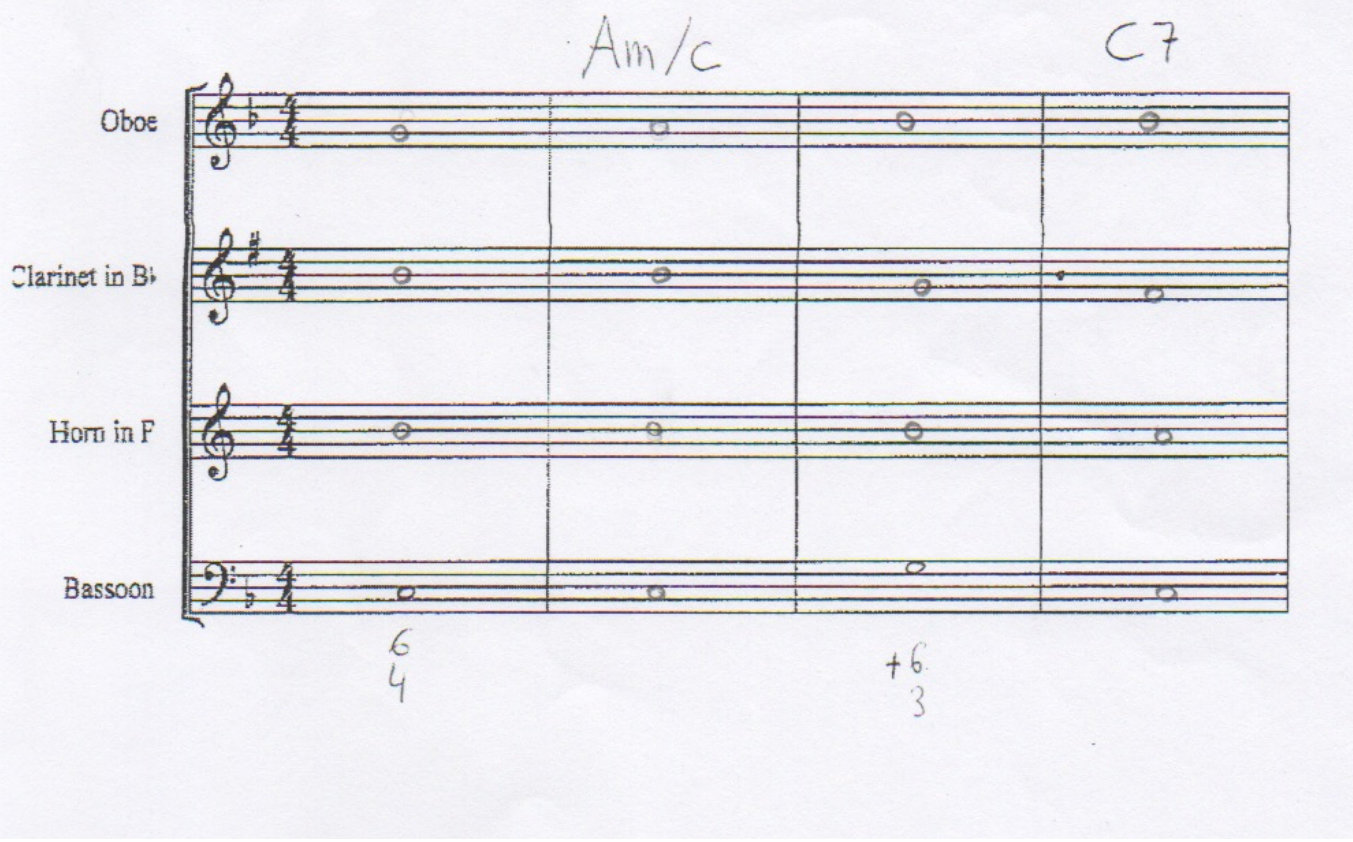

Figura 47. Pretest del caso experimental $\mathrm{N}^{\circ} 5$. 
A la vista de los resultados creemos que existe un cierto grado de experiencia en el ámbito de la organología pero que no se ha visto reflejado en la relación de lecto-escritura y asociación entre instrumentos transpositores y no transpositores.

No tenemos respuesta del primer ejercicio dado que el sujeto no lo presentó por motivos personales. No obstante, asistió a la sesión de la intervención y se le entregó el ejercicio para su realización. Desconocemos si pudo realizar parte del mismo a pesar de no presentarlo.

En el ejercicio de la segunda intervención no hallamos una mejora significativa en cuanto a la organología y la lecto-escritura. Respecto a la lectura del saxofón alto - único instrumento transpositor del ejercicio - encontramos el recurso de transporte manual de la nota real anotándolo debajo de cada nota transpuesta y borrándolo para su entrega, recurso que evidencia el correcto transporte del instrumento. Además, encontramos una escritura correcta del uso de la clave de Do en la viola. 
Diseño y planificación de competencias específicas en el currículum de enseñanzas profesionales de música: modalidades composición-dirección en la enseñanza superior.

Carlos Eduardo Pascual Pérez
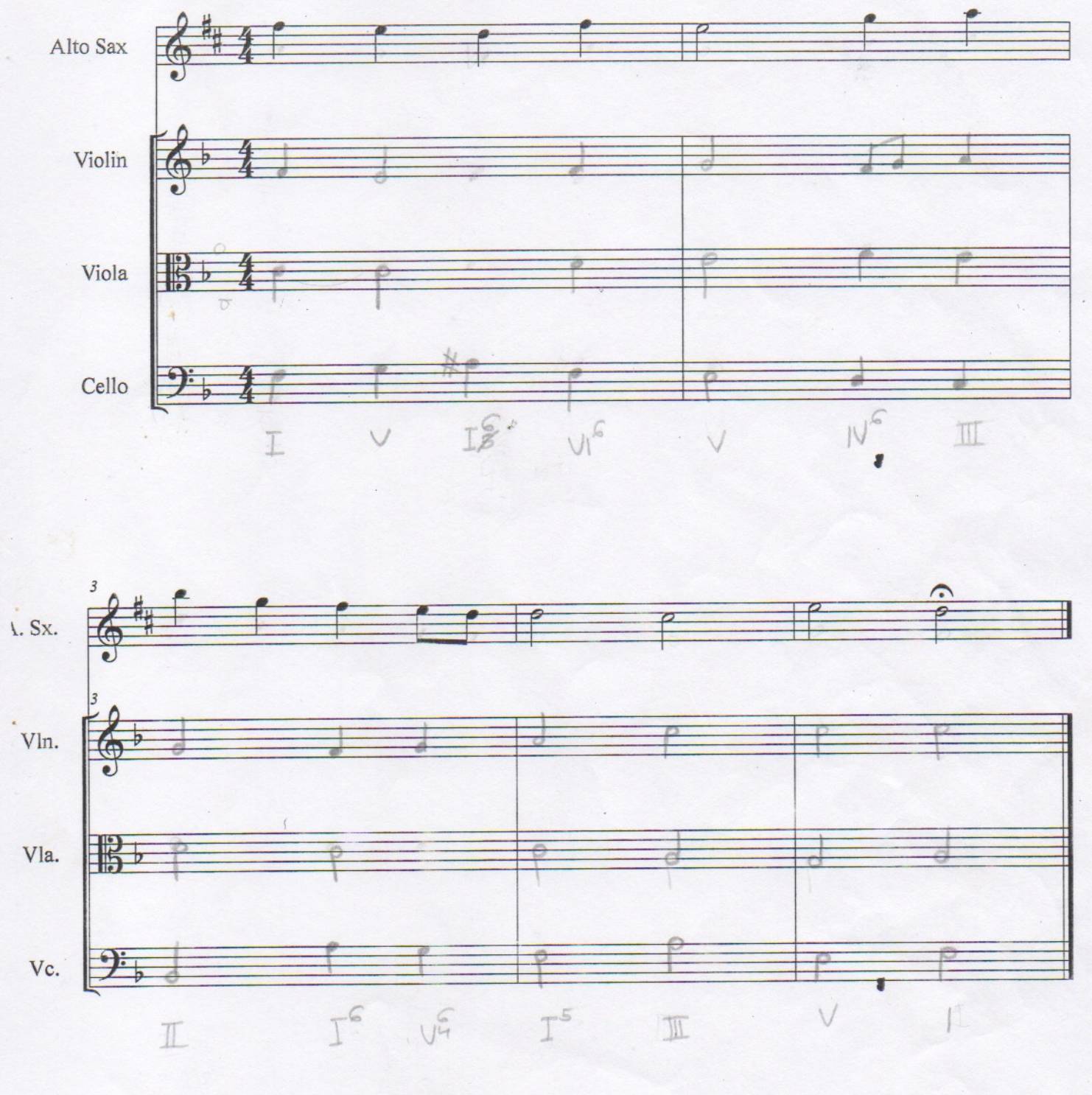

Figura 48. Detalle del ejercicio de la segunda intervención del sujeto $\mathrm{N}^{\circ} 5$.

No obstante, volvemos a detectar errores de cruce de voces entre el saxofón y el violín (compases 4 y 5). También observamos errores melódicos como la resolución de unísonos 
por movimiento directo entre la viola y el violoncello en los compases 4 y 5 , o la errores propiamente curriculares - no significantes en la competencia transversal desarrollada como el uso de acordes en segunda inversión en el compás 3.

En la evaluación final a través del postest observamos un alto grado de acierto a nivel de organología tanto de instrumentos transpositores como no transpositores, así como de lectoescritura en instrumentos no transpositores. No hallamos anotaciones al margen sobre la transposición u octavación de los instrumentos, pero por su resolución entendemos que están interiorizadas. Queda patente el alto grado de asimilación de los instrumentos trabajados a nivel práctico en la intervención, así como de los instrumentos únicamente revisados a nivel teórico. 
Diseño y planificación de competencias específicas en el currículum de enseñanzas profesionales de música: modalidades composición-dirección en la enseñanza superior.

Carlos Eduardo Pascual Pérez

\section{EJERCICIO 1}

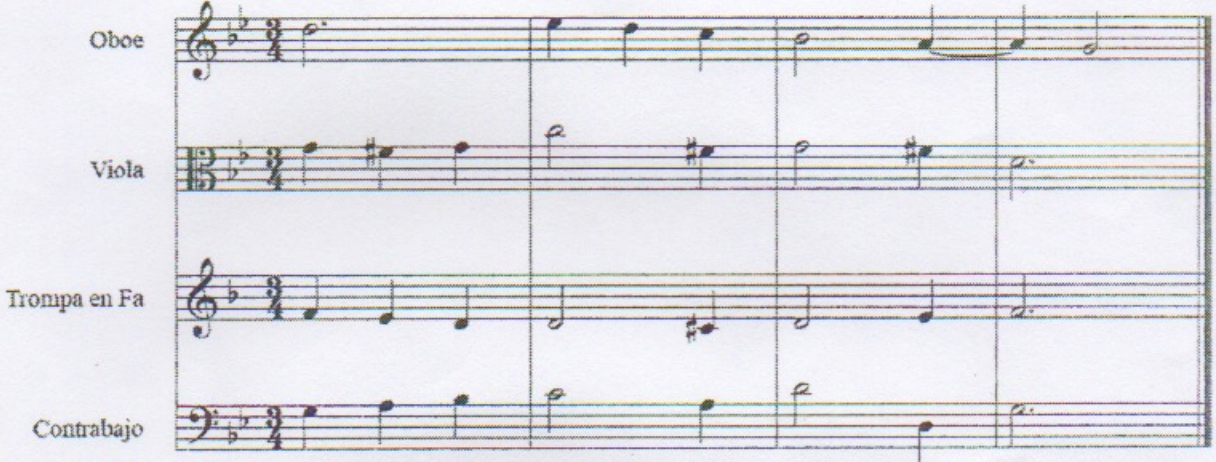

Marcar si no detectas ningún error:

\begin{tabular}{|c|c|c|c|c|}
\hline Compás & Tiempo & Instrumento/s implicado/s & Tipo de error & Observaciones \\
\hline 2 & 1 & Viala y trompa & 8 & \\
\hline 2 & 3 & Viola y trompa & 8 & \\
\hline 2 y 3 & 3 y $\$$ & Viala y trompa & $a$ & \\
\hline 2 y 3 & 3 ys & Viala y trompa & $c$ & \\
\hline 3 & 3 & viola & $h$ & \\
\hline & & & & \\
\hline & & & & \\
\hline & & & & \\
\hline
\end{tabular}

Figura 49. Detalle del ejercicio 1 del postest del sujeto $\mathrm{N}^{\circ} 5$.

Respecto a la resolución del test (detección de errores armónicos) hallamos el 100\% de aciertos para el ejercicio 1, acompañado de dos respuestas incorrectas, las cuales se desprenden tanto de incorrecciones propiamente armónicas - que no implican el uso de la competencia transversal - como de errores de asociación entre instrumentos transpositores y no transpositores. 
Carlos Eduardo Pascual Pérez

\section{EJERCICIO 2}

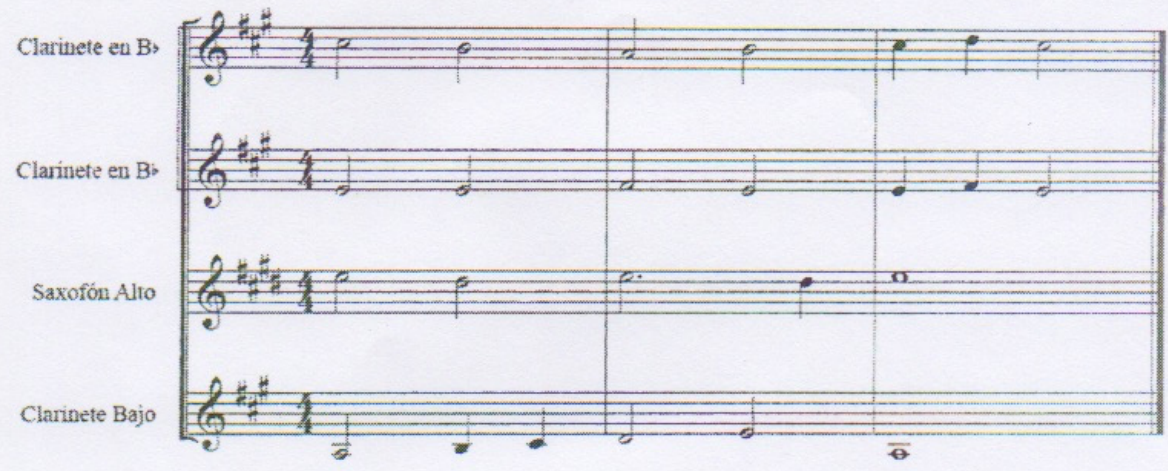

Marcar si no detectas ningún error:

\begin{tabular}{|c|c|c|c|c|}
\hline Compás & Tiempo & Instrumento/s implicado/s & Tipo de error & Observaciones \\
\hline $1 y^{2}$ & $3,4,2$ & Saxafin y Clarinete Baj & b & \\
\hline$s$ \& 2 & $3,4, y 1$ & Saxolón y Clarinete Bap & $d$ & \\
\hline 2 & 2.83 & Clarinete en Bb y. Claninete Bajp & b & \\
\hline 2 & 243 & Carinete as Bb y Caripete Bag & d & \\
\hline & & & & \\
\hline & & & & \\
\hline & & & & \\
\hline & & & & \\
\hline
\end{tabular}

Figura 50. Detalle del ejercicio 2 del postest del sujeto $\mathrm{N}^{\circ} 5$.

El ejercicio 2 hallamos un $66 \%$ de aciertos, acompañado de acompañado de dos respuestas incorrectas que suponemos se desprenden de una mala interpretación del transporte del saxofón tenor durante todo el ejercicio. Por último, en el ejercicio 3 encontramos un $60 \%$ de aciertos, acompañados de otra respuesta derivada de una incorrección armónica de conceptos curriculares ajenos a la competencia transversal. 
Diseño y planificación de competencias específicas en el currículum de enseñanzas profesionales de música: modalidades composición-dirección en la enseñanza superior.

Carlos Eduardo Pascual Pérez

\section{EJERCICIO 3}

Xilófono

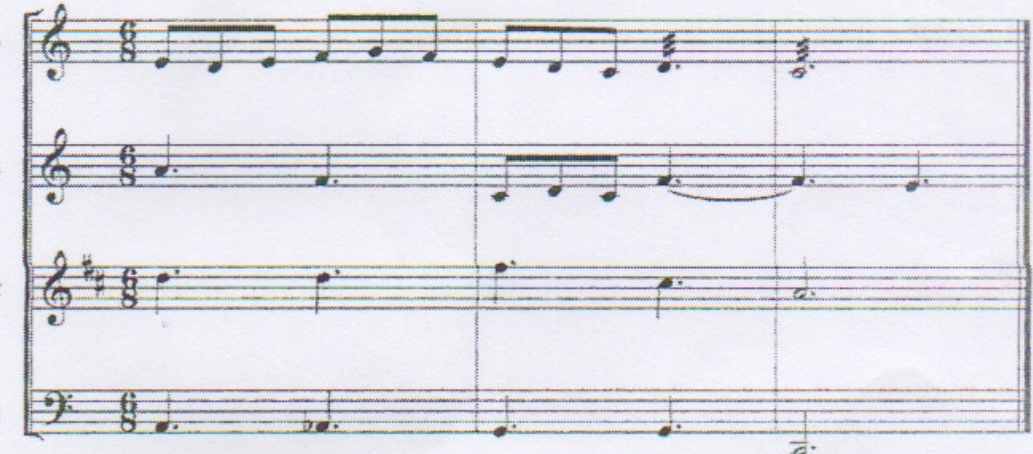

Marcar si no detectas ningún error:

\begin{tabular}{|c|c|c|c|c|}
\hline Compás & Tiempo & Instrumento/s implicado/s & Tipo de error & Observaciones \\
\hline 2 & $\lambda$ & Xilosano y plouta & en & \\
\hline 2 & $b$ & Xigosono y glaute & C & \\
\hline 2 & $\Delta-2$ & Frauta travesera & $i$ & \\
\hline 2 y 3 & $2-1$ & Savión tenor & h & \\
\hline & & & & \\
\hline & & & & \\
\hline & & & & \\
\hline & & & & \\
\hline
\end{tabular}

Figura 51. Detalle del ejercicio 3 del postest del sujeto $\mathrm{N}^{\circ} 5$.

A la vista de los resultados del postest podemos concluir que la competencia transversal de “Organología, instrumentación y orquestación en el ámbito de la orquesta sinfónica” está asumida en un muy alto grado. A pesar de respuesta de la primera intervención, denotamos una mejoría muy notable en todas las variables excepto en la asociación de instrumentos transpositores y no transpositores. Por último, observamos un grado error dentro de la normalidad en lo curricular de la asignatura de armonía, el cual no consideramos determinante para no poder obtener un mejor resultado en la puntuación global del test. 


\begin{tabular}{|c|c|c|c|c|c|c|c|c|c|c|c|c|}
\hline \multicolumn{6}{|c|}{ PRETEST } & \multicolumn{7}{|c|}{ POSTEST } \\
\hline ONT & OT & LENT & LET & ANTT & $M V$ & ONT & OT & LENT & LET & ANTT & $M V$ & MG \\
\hline 8,00 & 4,00 & 8,8 & 8,8 & 5,0 & 6,90 & 8,0 & 10,00 & 10,00 & 10,00 & 3,33 & 8,27 & 7,00 \\
\hline
\end{tabular}

Tabla 14. Resumen puntuaciones de variables, medias y global para el sujeto $\mathrm{N}^{\circ} 5$.

\subsubsection{Caso experimental $N^{o} 6$}

La valoración inicial del primer ejercicio del pretest nos sugiere un alto grado de conocimiento acerca de la organología de los instrumentos sinfónicos del ámbito orquestal, con más del $50 \%$ de aciertos completos.

Respecto al segundo ejercicio de lecto-escritura y asociación entre instrumentos transpositores y no transpositores, podemos observar un error continuado en toda la transposición de la trompa. También apreciamos errores al cruzarse las voces entre el oboe y clarinete (segundo acorde). 
Diseño y planificación de competencias específicas en el currículum de enseñanzas profesionales de música: modalidades composición-dirección en la enseñanza superior.

Carlos Eduardo Pascual Pérez

1. Identifica la afinación y octavación de los siguientes instrumentos:

\begin{tabular}{|c|c|c|c|c|c|}
\hline Instrumento & Afinación & Octavación & Instrumento & Afinación & Octavación \\
\hline Oboe & DO & - & Clarinete bajo & & \\
\hline Flautín & 80 & $8^{n} A C T A$ & Saxofón alto & & \\
\hline Fagot & DO & $5-$ & Saxofón tenor & & \\
\hline Contrabajo & Do & $B^{C} B A O A$ & Lira & Do & $8^{2}$ ACIA \\
\hline Trompa & FA & - & Flauta alto & Po & - \\
\hline
\end{tabular}

2. Realiza los siguientes acordes:

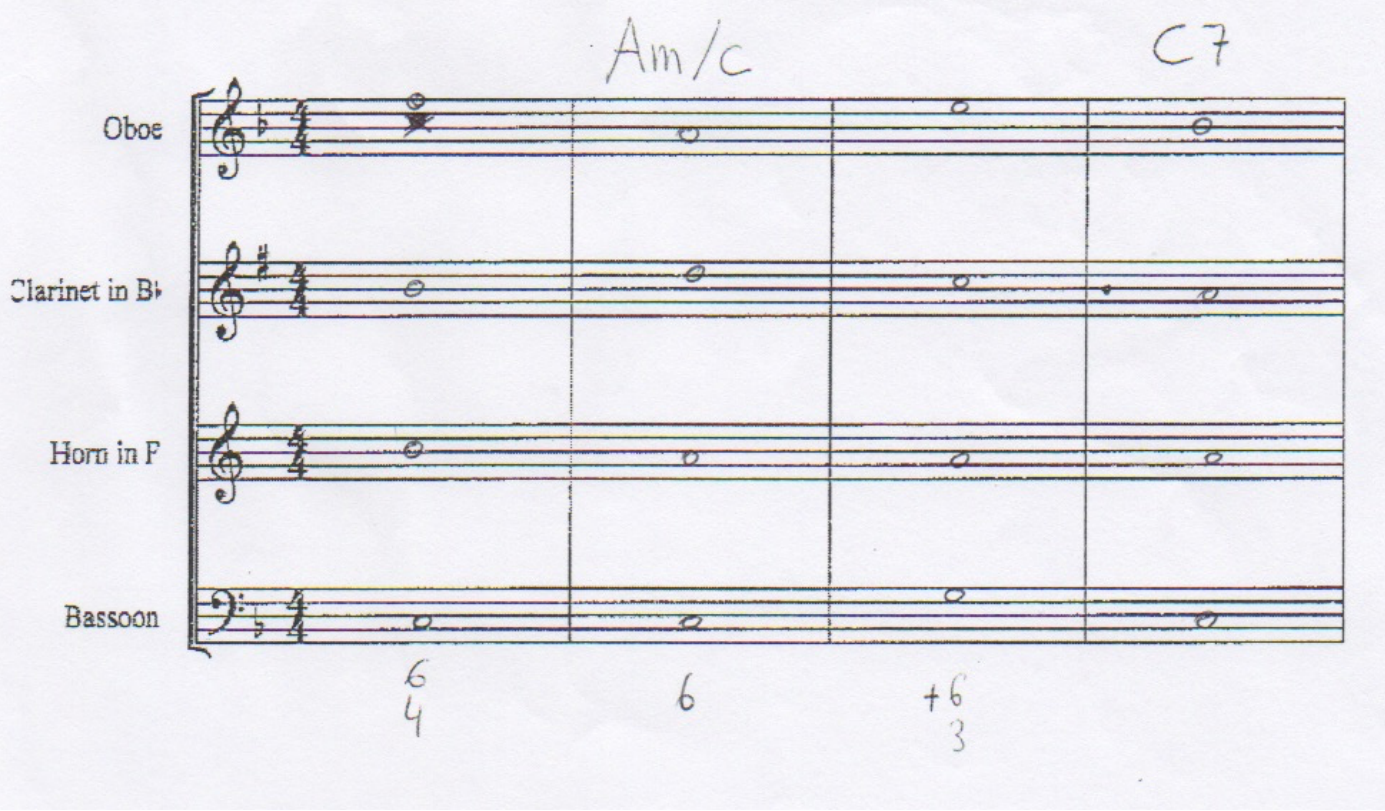

Figura 52. Pretest del caso experimental № 5.

A la vista de los resultados creemos que existe un cierto grado de experiencia en el ámbito de la organología pero que no se ha visto reflejado totalmente en la relación de lecto-escritura 
Diseño y planificación de competencias específicas en el currículum de enseñanzas profesionales de música: modalidades composición-dirección en la enseñanza superior.

Carlos Eduardo Pascual Pérez

y asociación entre instrumentos transpositores y no transpositores debido a una mala interpretación de uno de los transportes.

Tras la primera intervención y la entrega del primer ejercicio observamos una mejora significativa en el ámbito de la lecto-escritura, dado que desaparecen los errores de cruce de voces. También se evidencian errores conceptuales propios en lo curricular de la asignatura de armonía, no siendo estos aplicables al desarrollo de nuestra competencia transversal, como la realización incorrecta de la serie de sextas (compás 2).

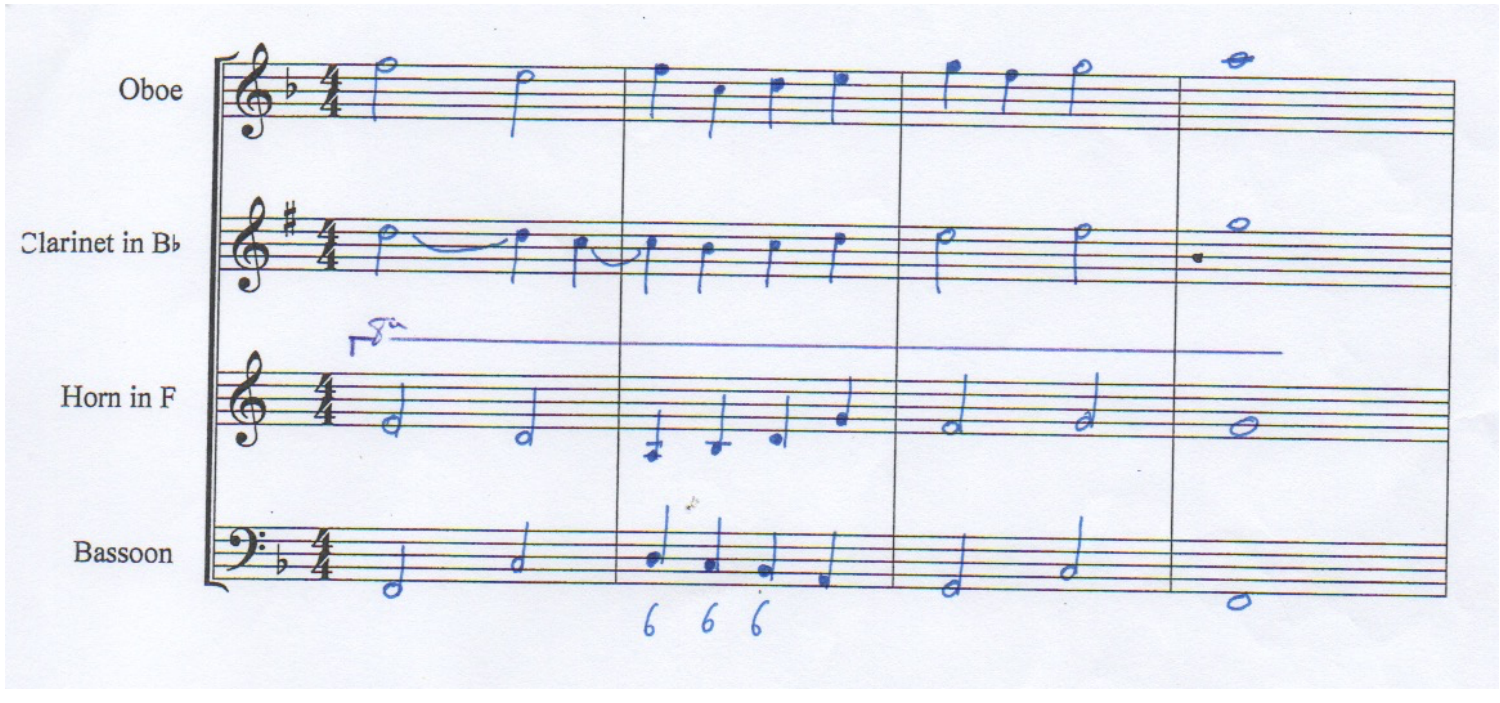

Figura 53. Detalle del ejercicio de la primera intervención del sujeto $\mathrm{N}^{\mathrm{o}} 4$.

En el ejercicio de la segunda intervención hallamos una mejora significativa en cuanto a la organología y la lecto-escritura. Respecto a la lectura del saxofón alto - único instrumento transpositor del ejercicio - encontramos el recurso de transporte manual de la nota real 
Diseño y planificación de competencias específicas en el currículum de enseñanzas profesionales de música: modalidades composición-dirección en la enseñanza superior.

Carlos Eduardo Pascual Pérez

anotándolo debajo de cada nota. Además, encontramos una escritura correcta del uso de la clave de Do en la viola, y una anotación al margen a modo de íncipit que resume la disposición inicial de las cuatro voces en un único pentagrama.

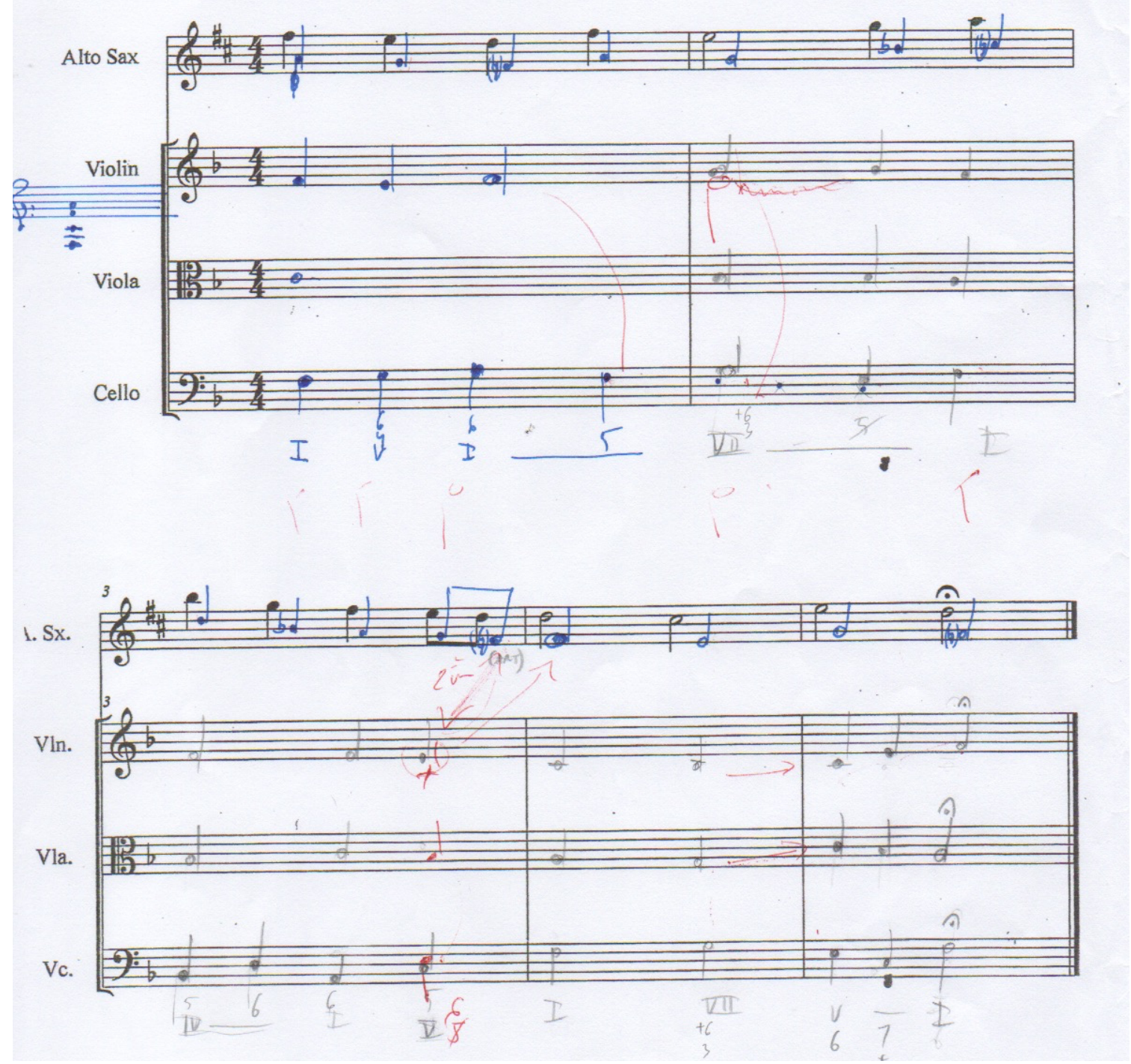

Figura 54. Detalle del ejercicio de la segunda intervención del sujeto $\mathrm{N}^{0} 5$. 
No obstante, detectamos errores melódicos como la resolución de unísonos por movimiento directo entre el violín y el saxofón, o la errores propiamente curriculares - no significantes en la competencia transversal desarrollada - como las octavas seguidas entre violín y violoncello (compás 2).

En la evaluación final a través del postest observamos un alto grado de acierto a nivel de organología tanto de instrumentos transpositores como no transpositores, así como de lectoescritura en instrumentos no transpositores. No hallamos anotaciones al margen sobre la transposición u octavación de los instrumentos, pero por su resolución entendemos que están interiorizadas. Queda patente el alto grado de asimilación de los instrumentos trabajados a nivel práctico en la intervención, así como de los instrumentos únicamente revisados a nivel teórico. 
Diseño y planificación de competencias específicas en el currículum de enseñanzas profesionales de música: modalidades composición-dirección en la enseñanza superior.

Carlos Eduardo Pascual Pérez

\section{EJERCICIO 1}

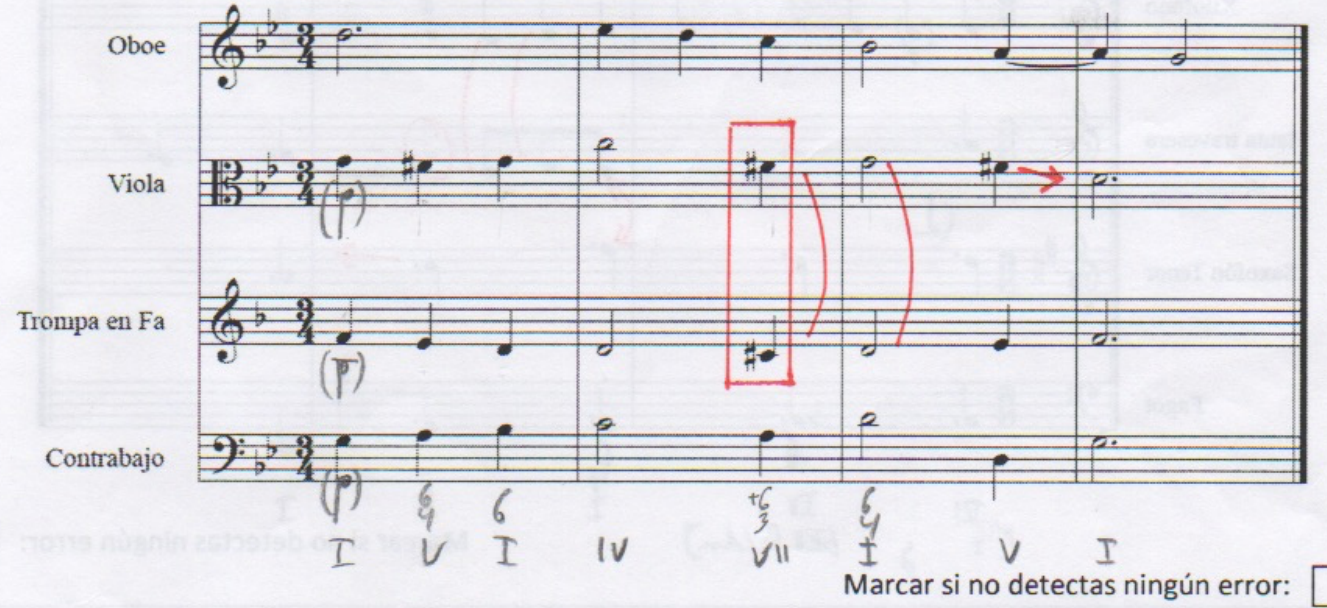

\begin{tabular}{|c|c|l|c|c|}
\hline Compás & Tiempo & Instrumento/s implicado/s & Tipo de error & Observaciones \\
\hline 2 & 3 & VIOLA /TROMPA & G & DUPLTCACION SENSIBCE \\
\hline $2-3$ & $3-1$ & VIOLA /TROMPA & A & OCTAVAS SE GUI DAS \\
\hline $3-4$ & $3-1$ & VIOLA & H & SENST GLE MAC RESUELTA \\
\hline & & & & \\
\hline & & & & \\
\hline & & & & \\
\hline & & & & \\
\hline & & & & \\
\hline
\end{tabular}

Figura 55. Detalle del ejercicio 1 del postest del sujeto $\mathrm{N}^{\circ} 5$.

Respecto a la resolución del test (detección de errores armónicos) hallamos el 100\% de aciertos para el ejercicio 1, acompañado de una respuesta incorrecta, las cuales se desprende de incorrecciones propiamente armónicas - que no implican el uso de la competencia transversal - 
Carlos Eduardo Pascual Pérez

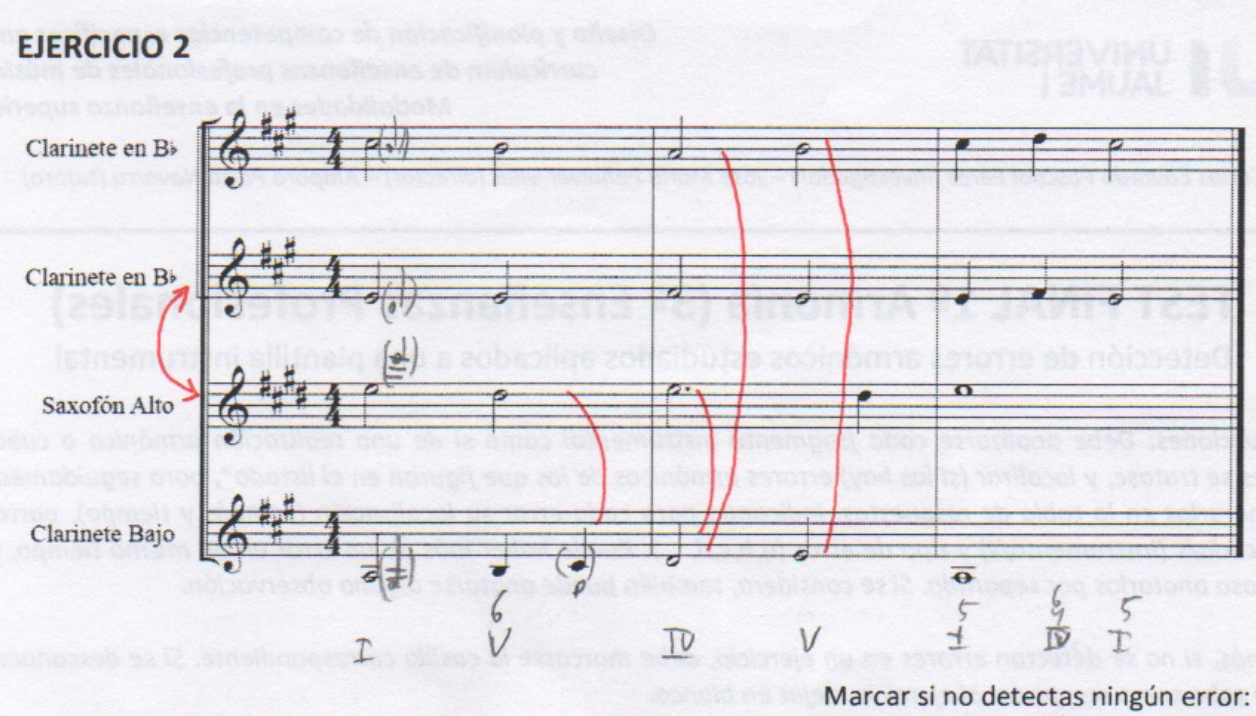

\begin{tabular}{|c|c|c|c|c|}
\hline Compás & Tiempo & Instrumento/s implicado/s & Tipo de error & Observaciones \\
\hline Topos & Togos & CLARINETE 2 / SAXOFOSN & E & 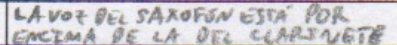 \\
\hline $1-2$ & $4-1$ & SAXOFON / CLARTNETE BASO & $B$ & 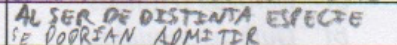 \\
\hline 2 & $1-2$ & CLARINETE $1^{\circ} / \angle L A R Z N E I E B N O$ & $B$ & QLINTAS SEGUIDAS \\
\hline & 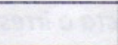 & 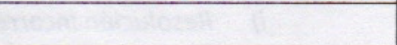 & & \\
\hline & & & & \\
\hline & & & & \\
\hline & & & & \\
\hline & & 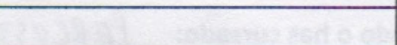 & & $1002 \cos$ \\
\hline
\end{tabular}

Figura 56. Detalle del ejercicio 2 del postest del sujeto $\mathrm{N}^{\circ} 5$.

El ejercicio 2 hallamos nuevamente un $100 \%$ de aciertos, sin respuestas incorrectas añadidas. Observamos también la escritura en notación real de todos los instrumentos transpositores al inicio del pentagrama. Por último, en el ejercicio 3 encontramos un $60 \%$ de aciertos, acompañados de otra respuesta derivada de una incorrección armónica de conceptos curriculares ajenos a la competencia transversal. 
Diseño y planificación de competencias específicas en el currículum de enseñanzas profesionales de música: modalidades composición-dirección en la enseñanza superior.

Carlos Eduardo Pascual Pérez

\section{EJERCICIO 3}

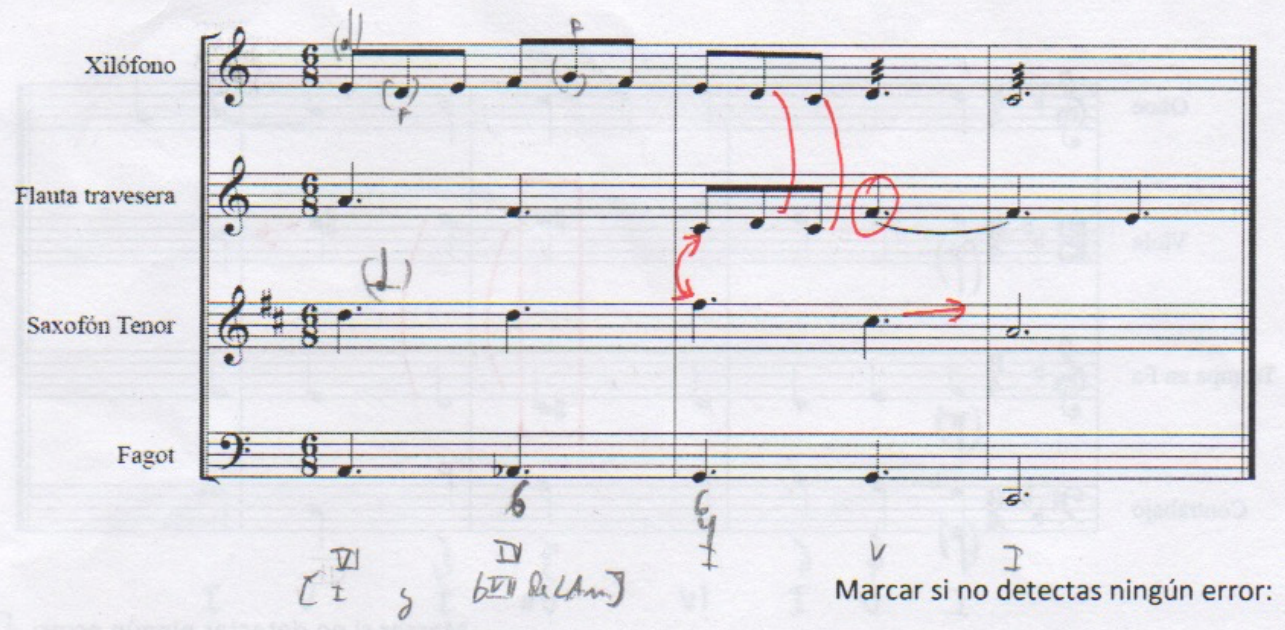

\begin{tabular}{|c|c|c|c|c|}
\hline Compás & Tiempo & Instrumento/s implicado/s & Tipo de error & Observaciones \\
\hline 2 & 1 & FLAUTA / SAXOFO'N & $E$ & 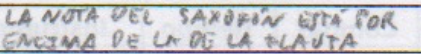 \\
\hline 2 & 1 & XILÓFONO / FLAUTA & $A, C$ & DTAUES SEGUIOAS Y DURECIAS \\
\hline 2 & 2 & FLAUTA & J & $7^{\circ}$ NO PREPARAOA \\
\hline 2 & 2 & SAXOFON & $I$ & SENSIBLE MAL RESVELTA \\
\hline & & & & \\
\hline & & & & \\
\hline & & & & \\
\hline & & & & \\
\hline
\end{tabular}

Figura 57. Detalle del ejercicio 3 del postest del sujeto $\mathrm{N}^{\mathrm{o}} 6$.

A la vista de los resultados del postest podemos concluir que la competencia transversal de “Organología, instrumentación y orquestación en el ámbito de la orquesta sinfónica” está asumida en un muy alto grado. Denotamos una mejoría muy notable en todas las variables sin excepción, así como en la media aritmética de comparativa pretest-postest. Por último, observamos un grado error mínimo en lo curricular de la asignatura de armonía, el cual no 
Carlos Eduardo Pascual Pérez

consideramos determinante para no poder obtener un mejor resultado en la puntuación global del test.

\begin{tabular}{|c|c|c|c|c|c|c|c|c|c|c|c|c|}
\multicolumn{10}{|c|}{ PRETEST } & \multicolumn{10}{c|}{ POSTEST } \\
\hline ONT & OT & LENT & LET & ANTT & $M V$ & ONT & OT & LENT & LET & ANTT & $M V$ & MG \\
\hline 10,00 & 2,00 & 8,00 & 4,00 & 0,00 & 4,80 & 10,00 & 8,00 & 10,00 & 10,00 & 6,67 & 8,93 & $\mathbf{8 , 0 0}$ \\
\hline
\end{tabular}

Tabla 15. Resumen puntuaciones de variables, medias y global para el sujeto $\mathrm{N}^{\mathrm{o}} 6$.

\subsubsection{Caso experimental $N^{o} 7$}

La valoración inicial del primer ejercicio del pretest nos sugiere un cierto grado de conocimiento acerca de la organología de los instrumentos sinfónicos del ámbito orquestal. Los aciertos son aceptados parcialmente, puesto que se refiere a los índices de afinación absoluta como si de tonalidades mayores se tratasen, lo cual es una incorrección. En el caso del clarinete bajo y el saxofón tenor (instrumentos transpositores) no se aporta la octavación del mismo.

Respecto al segundo ejercicio de lecto-escritura y asociación entre instrumentos transpositores y no transpositores, podemos observar un error continuado en toda la 
Diseño y planificación de competencias específicas en el currículum de enseñanzas profesionales de música: modalidades composición-dirección en la enseñanza superior.

Carlos Eduardo Pascual Pérez

transposición de la trompa (tercer y cuarto acorde) y el clarinete (segundo, tercer y cuarto acorde). También apreciamos errores al cruzarse las voces entre el fagot y la trompa (tercer acorde).

1. Identifica la afinación y octavación de los siguientes instrumentos:

\begin{tabular}{|l|c|c|l|c|c|}
\hline \multicolumn{1}{|c|}{ Instrumento } & Afinación & Octavación & \multicolumn{1}{|c|}{ Instrumento } & Afinación & Octavación \\
\hline Oboe & Si $b$ & & Clarinete bajo & Si $b$ & \\
\hline Flautín & B M & & Saxofón alto & Mi $b$ & \\
\hline Fagot & & & Saxofón tenor & Si $b$ & \\
\hline Contrabajo & D M & $18^{a} \downarrow$ & Lira & & $1-8^{-} \uparrow$ \\
\hline Trompa & Fa M & & Flauta alto & Sol M & \\
\hline
\end{tabular}

2. Realiza los siguientes acordes:

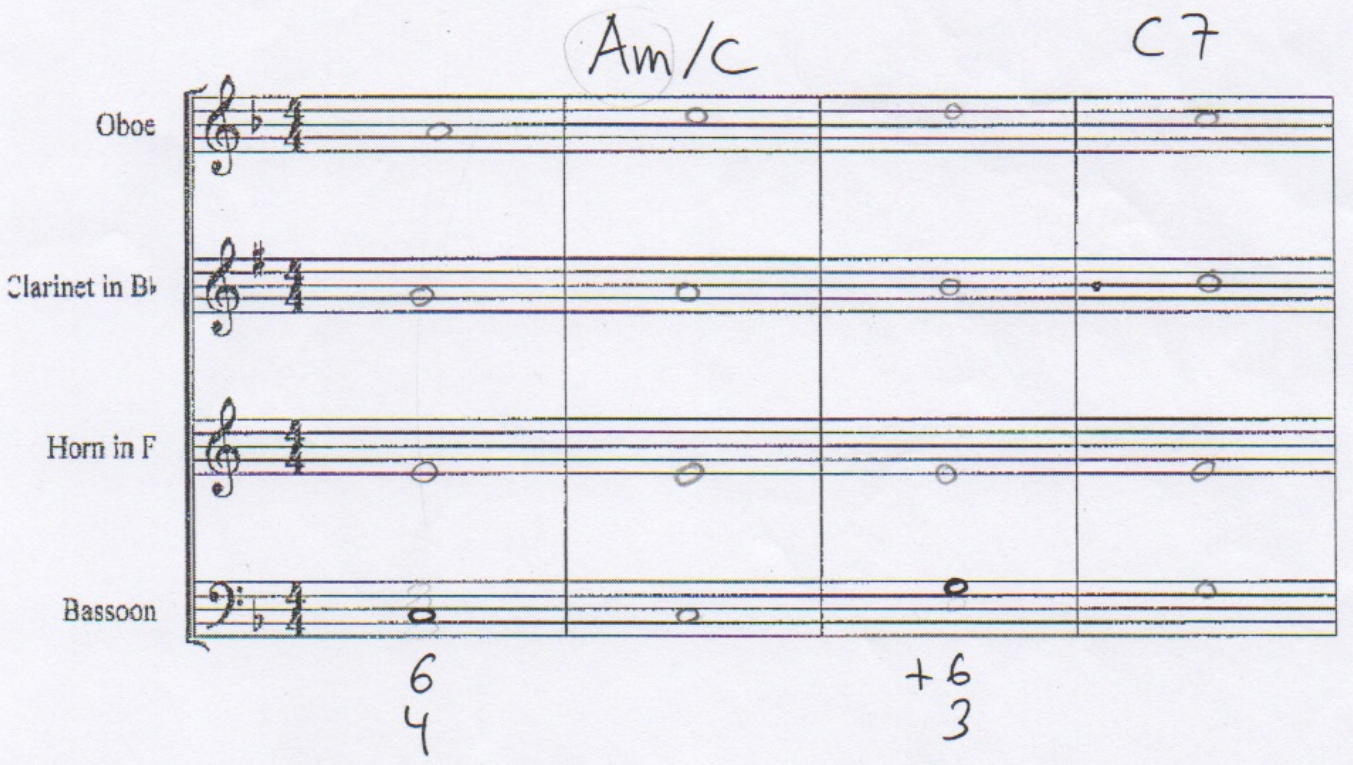

Figura 58. Pretest del caso experimental $\mathrm{N}^{\circ} 5$. 
A la vista de los resultados creemos que existe un cierto grado de experiencia en el ámbito de la organología, aunque con errores u omisiones, y que no se ha visto reflejado totalmente en la relación de lecto-escritura y asociación entre instrumentos transpositores y no transpositores.

Tras la primera intervención y la entrega del primer ejercicio no observamos una mejora en el ámbito de la lecto-escritura, dado que continúan los errores de cruce de voces entre la trompa y el fagot (compás 3) o la superación máxima entre voces entre el saxofón y el violín. También se evidencian errores conceptuales propios en lo curricular de la asignatura de armonía, no siendo estos aplicables al desarrollo de nuestra competencia transversal, como el uso incorrecto de notas alteradas durante todo el ejercicio o la incorrección al realizar acordes. 
Diseño y planificación de competencias específicas en el currículum de enseñanzas profesionales de música: modalidades composición-dirección en la enseñanza superior.

Carlos Eduardo Pascual Pérez

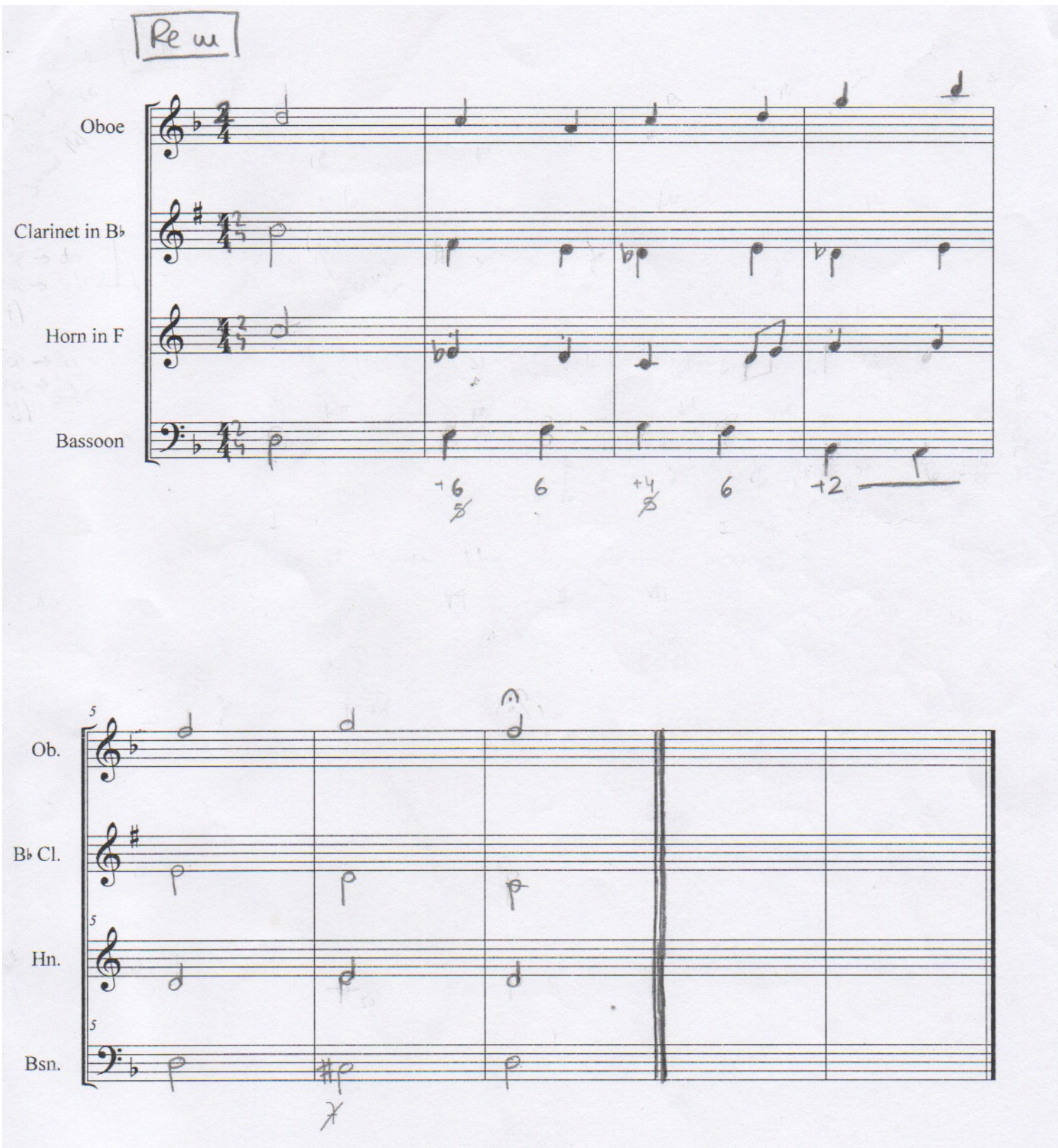

Figura 59. Detalle del ejercicio de la primera intervención del sujeto $\mathrm{N}^{\circ} 4$. 
En el ejercicio de la segunda intervención hallamos una mejora significativa en cuanto a la organología y la lecto-escritura, dado que desaparecen los errores de cruce entre voces y de separación máxima entre ellas. Respecto a la lectura del saxofón alto - único instrumento transpositor del ejercicio - encontramos una anotación al margen muy completa, la cual evidencia la correcta transposición del instrumento. Además, encontramos una escritura correcta del uso de la clave de Do en la viola. 
Diseño y planificación de competencias específicas en el currículum de enseñanzas profesionales de música: modalidades composición-dirección en la enseñanza superior.

Carlos Eduardo Pascual Pérez

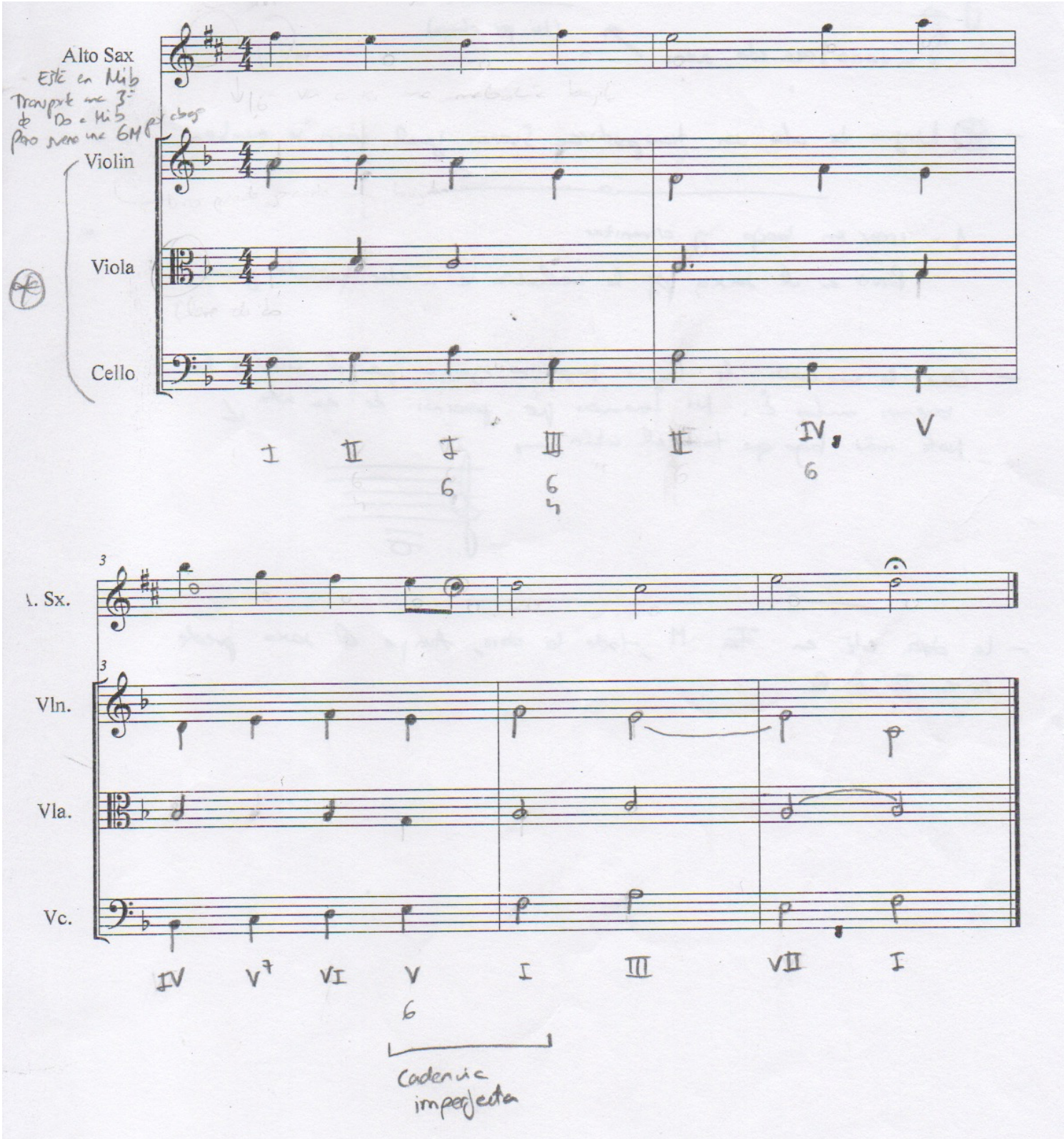

Figura 60. Detalle del ejercicio de la segunda intervención del sujeto $\mathrm{N}^{0} 5$.

No obstante, detectamos errores melódicos como la resolución de unísonos por movimiento directo entre el violín y el saxofón (compás 4), o la errores propiamente curriculares - no 
significantes en la competencia transversal desarrollada - como las octavas seguidas entre violín y violoncello (compás 1).

No disponemos de resultados para el postest, dado que el sujeto abandonó la experiencia tras la segunda intervención y no se presentó a la realización de esta última prueba. No obstante, a la vista de los resultados de la intervención, podemos concluir que la competencia transversal "Organología, instrumentación y orquestación en el ámbito de la orquesta sinfónica" está asumida parcialmente. Aunque no podemos cuantificar los resultados, denotamos una mejoría en la segunda experiencia respecto a la anterior y a su vez respecto al pretest. Por último, observamos un grado error considerable en lo curricular de la asignatura de armonía, el cual no podemos considerar determinante para no poder obtener un mejor resultado en la puntuación global del test al carecer de dichos resultados.

\begin{tabular}{|c|c|c|c|c|c|c|c|c|c|c|c|c|}
\hline \multicolumn{10}{|c|}{ PRETEST } & \multicolumn{10}{c|}{ POSTEST } \\
\hline ONT & OT & LENT & LET & ANTT & $M V$ & ONT & OT & LENT & LET & ANTT & $M V$ & MG \\
\hline 2,00 & 0,00 & 6,30 & 3,80 & 2,50 & 2,90 & - & - & - & - & - & - & - \\
\hline
\end{tabular}

Tabla 16. Resumen puntuaciones de variables, medias y global para el sujeto $\mathrm{N}^{\circ} 7$. 


\subsubsection{Caso experimental $N^{o} 8$}

La valoración inicial del primer ejercicio del pretest nos sugiere un alto grado de conocimiento acerca de la organología de los instrumentos sinfónicos del ámbito orquestal, con más del 70\% de aciertos completos. Entenderemos la anotación "afinación normal” como la estándar en Do, es decir, la de instrumentos no transpositores.

Respecto al segundo ejercicio de lecto-escritura y asociación entre instrumentos transpositores y no transpositores, podemos observar un error continuado en toda la transposición del clarinete. Sin embargo, no hallamos cruce de voces entre los instrumentos. 
Diseño y planificación de competencias específicas en el currículum de enseñanzas profesionales de música: modalidades composición-dirección en la enseñanza superior.

Carlos Eduardo Pascual Pérez

1. Identifica la afinación y octavación de los siguientes instrumentos:

\begin{tabular}{|c|c|c|c|c|c|}
\hline Instrumento & Afinación & Octavación & Instrumento & Afinación & Octavación \\
\hline Oboe & Normal & NDD & Clarinete bajo & Eb & si 8 - frase \\
\hline Flautín & nnel & $\dot{h} \nabla=$ alb & Saxofón alto & El & No \\
\hline Fagot & & si 8 yrare & Saxofón tenor & $B b$ & No \\
\hline Contrabajo & urtural & 8. 8-que & Lira & urapial & Si $8=a l t$ \\
\hline Trompa & & No & Flauta alto & movure & $8 \leq a b l a$ \\
\hline
\end{tabular}

2. Realiza los siguientes acordes:

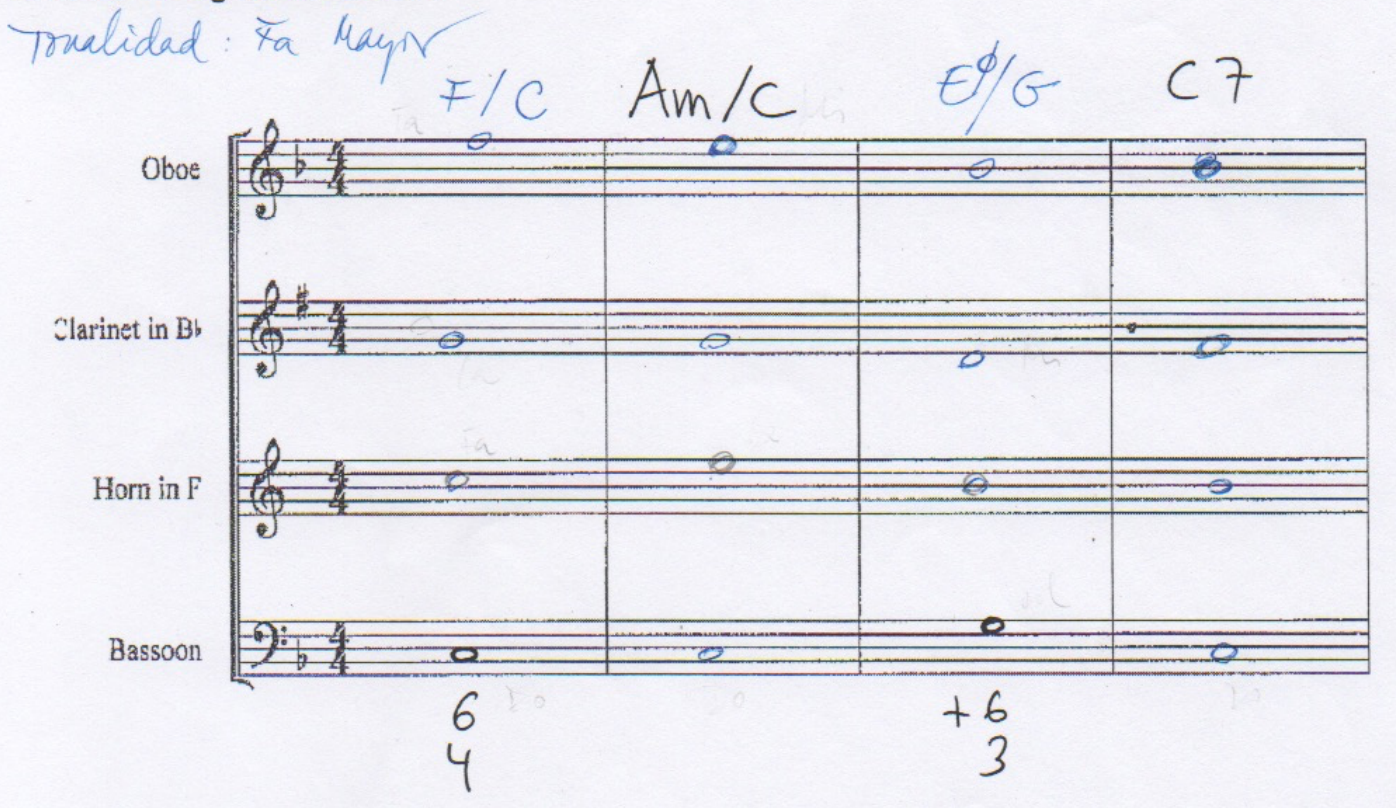

Figura 61. Pretest del caso experimental $\mathrm{N}^{\mathrm{o}} 8$.

A la vista de los resultados creemos que existe un alto grado de experiencia en el ámbito de la organología pero que no se ha visto reflejado totalmente en la relación de lecto-escritura y 
Diseño y planificación de competencias específicas en el currículum de enseñanzas profesionales de música: modalidades composición-dirección en la enseñanza superior.

Carlos Eduardo Pascual Pérez

asociación entre instrumentos transpositores y no transpositores debido a una malinterpretación de uno de los transportes.

Tras la primera intervención y la entrega del primer ejercicio no observamos una mejora significativa en el ámbito de la lecto-escritura, dado que aparecen errores de cruce de voces entre el oboe y el clarinete (compases 3,4 y 5). También se evidencian errores conceptuales propios en lo curricular de la asignatura de armonía, no siendo estos aplicables al desarrollo de nuestra competencia transversal, como el movimiento melódico con intervalo aumentado (clarinete, compás 2). No existe ninguna anotación al margen o apunte que indique la ayuda para la transposición o la lectura en claves poco usuales, pero entendemos que está interiorizado correctamente al no producirse errores en la realización. 
Diseño y planificación de competencias específicas en el currículum de enseñanzas profesionales de música: modalidades composición-dirección en la enseñanza superior.

Carlos Eduardo Pascual Pérez

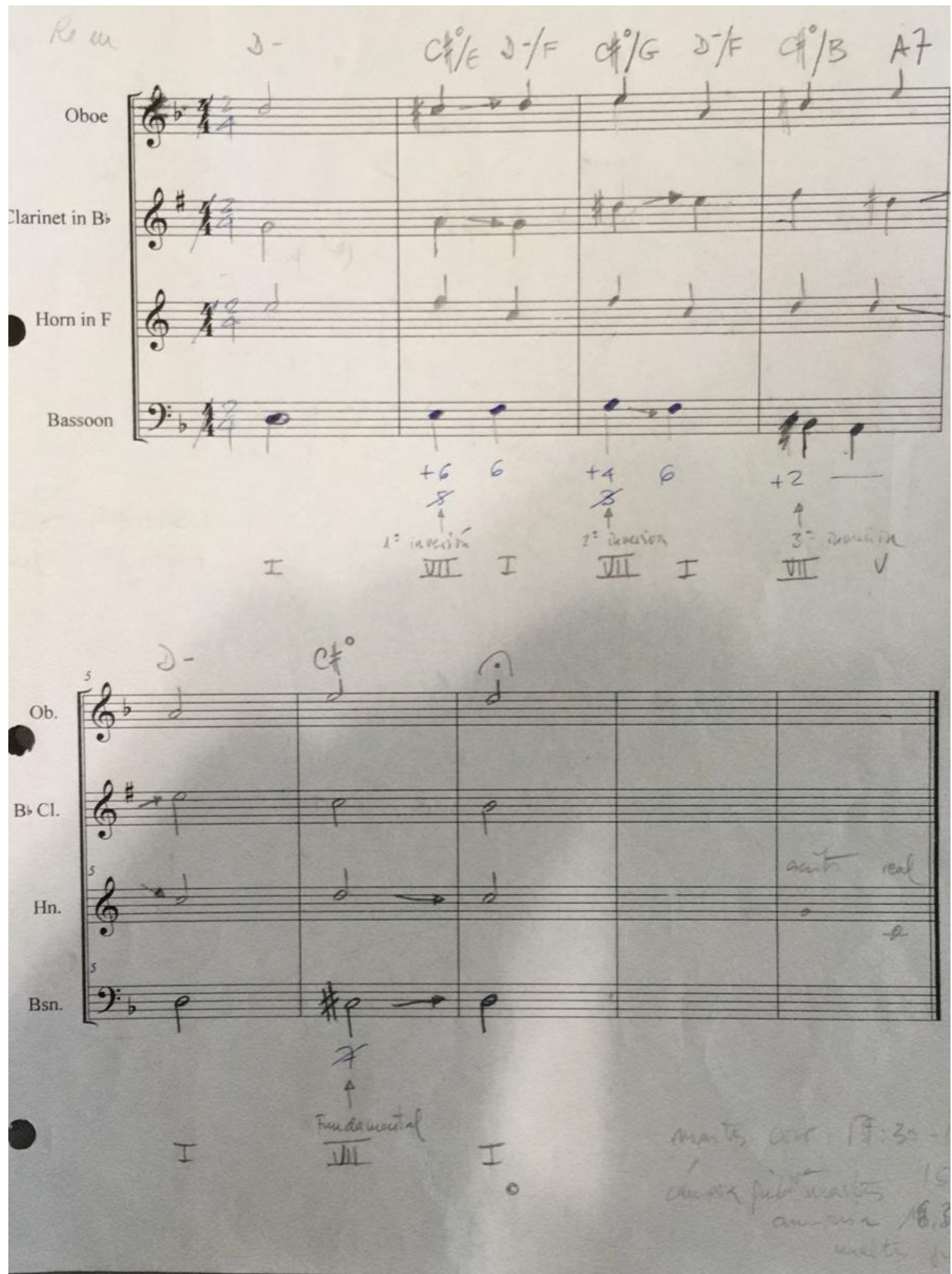

Figura 62. Detalle del ejercicio de la primera intervención del sujeto $\mathrm{N}^{\mathrm{o}} 8$. 
Diseño y planificación de competencias específicas en el currículum de enseñanzas profesionales de música: modalidades composición-dirección en la enseñanza superior.

Carlos Eduardo Pascual Pérez

En el ejercicio de la segunda intervención hallamos una mejora significativa en cuanto a la organología y la lecto-escritura, dado que ya no hallamos cruce entre voces. Nuevamente no hallamos anotaciones al margen o apuntes que indiquen ayudas a la realización, pero la misma es correcta.
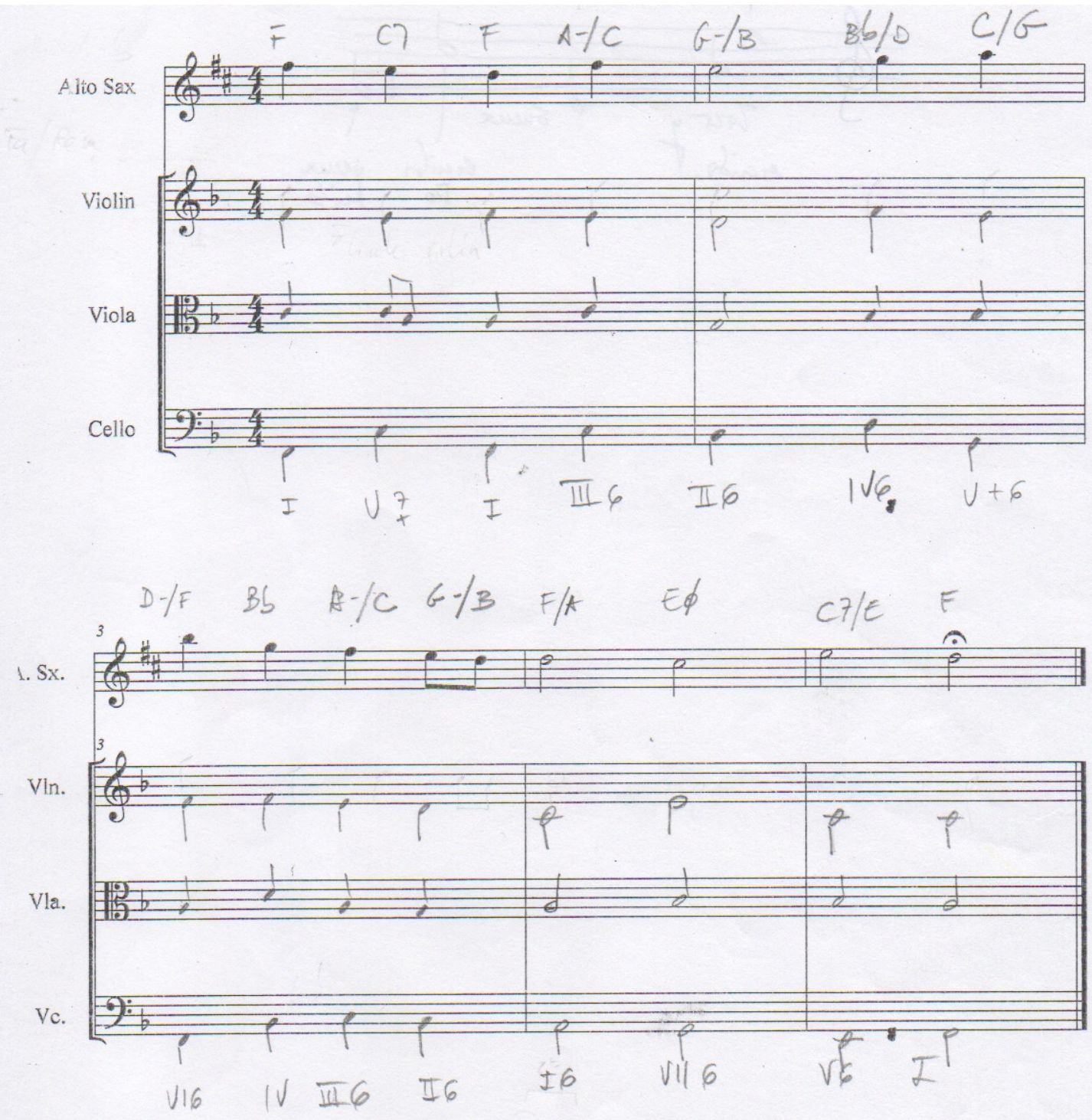
Diseño y planificación de competencias específicas en el currículum de enseñanzas profesionales de música: modalidades composición-dirección en la enseñanza superior.

\section{Carlos Eduardo Pascual Pérez}

Figura 63. Detalle del ejercicio de la segunda intervención del sujeto $\mathrm{N}^{\mathrm{o}} 8$.

No detectamos errores melódicos a excepción de los propiamente curriculares - no significantes en la competencia transversal desarrollada - como las octavas seguidas entre viola y saxofón (compás 2).

En la evaluación final a través del postest observamos un buen grado de acierto a nivel de organología tanto de instrumentos transpositores como no transpositores, así como de lectoescritura en instrumentos no transpositores. No hallamos anotaciones al margen sobre la transposición u octavación de los instrumentos, pero por su resolución entendemos que están interiorizadas. Queda patente el alto grado de asimilación de los instrumentos trabajados a nivel práctico en la intervención, así como de los instrumentos únicamente revisados a nivel teórico. 
Diseño y planificación de competencias específicas en el currículum de enseñanzas profesionales de música: modalidades composición-dirección en la enseñanza superior.

Carlos Eduardo Pascual Pérez

\section{EJERCICIO 1}

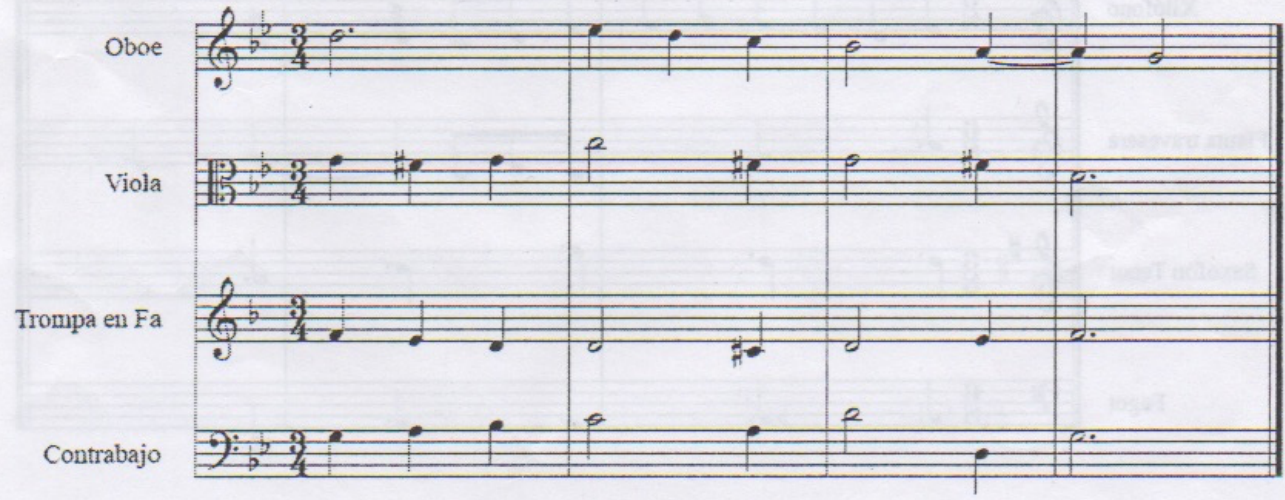

Marcar si no detectas ningún error:

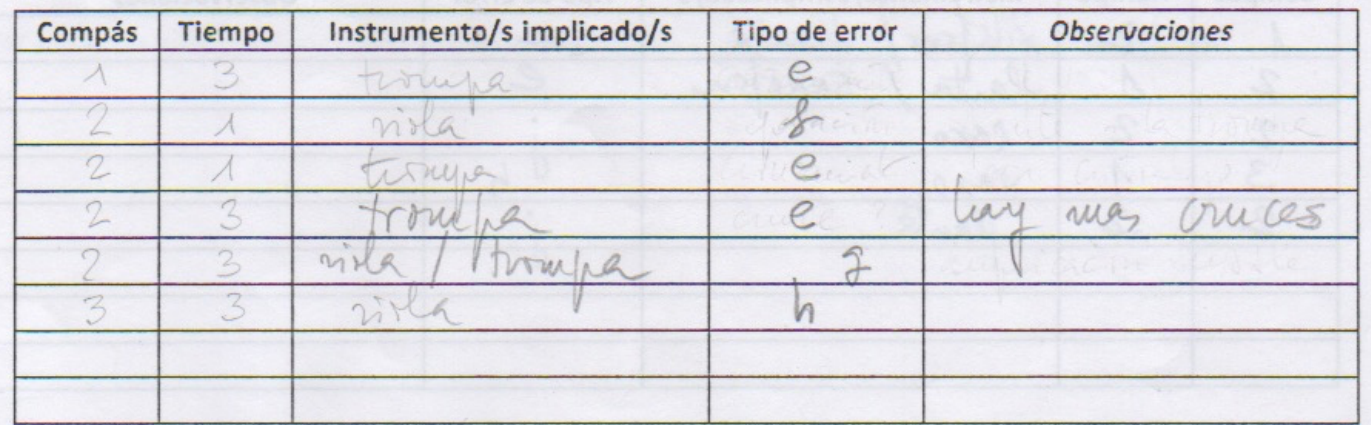

Figura 64. Detalle del ejercicio 1 del postest del sujeto $\mathrm{N}^{\circ} 8$.

Respecto a la resolución del test (detección de errores armónicos) hallamos el 100\% de aciertos para el ejercicio 1, acompañado de cuatro respuestas incorrectas, las cuales se desprende de incorrecciones propiamente que implican el uso de la competencia transversal, como la transposición errónea de la trompa junto a la octavación del contrabajo. 
Diseño y planificación de competencias específicas en el currículum de enseñanzas profesionales de música: modalidades composición-dirección en la enseñanza superior.

Carlos Eduardo Pascual Pérez

\section{EJERCICIO 2}

Clarinete en B

Clarinete en B;

Saxofón Alto

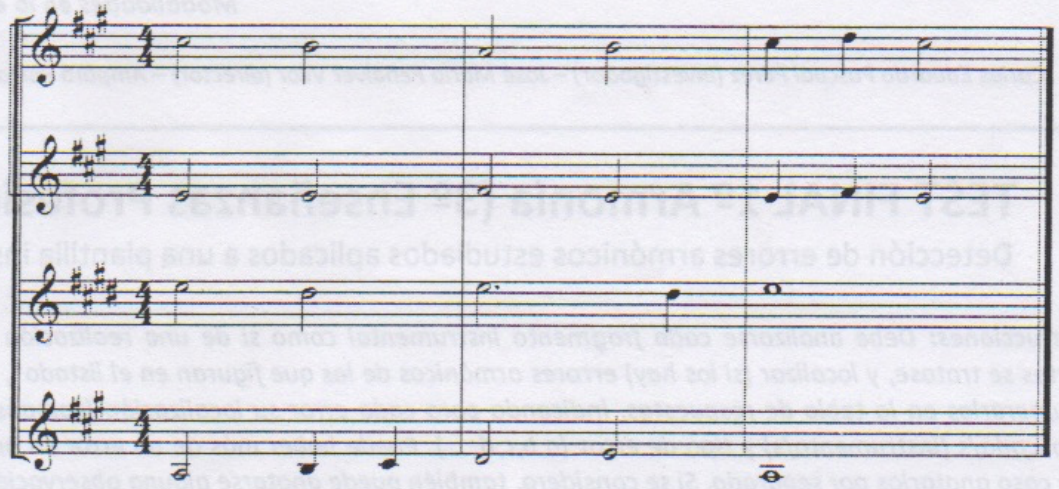

Clarinete Bajo

Marcar si no detectas ningún error:

\begin{tabular}{|c|c|c|c|c|}
\hline Compás & Tiempo & Instrumento/s implicado/s & Tipo de error & Observaciones \\
\hline $1 / 2 / 3$ & & claniete saxo & e & \\
\hline 2 & $1 / 3$ & " en Bb/Clar. bao & $b$ & \\
\hline 1 & 3 & daviel on Bb/ "I & c & $x_{2}$ \\
\hline & & 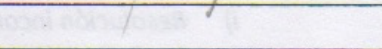 & & 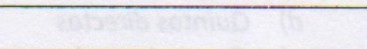 \\
\hline & & & & \\
\hline & & & & \\
\hline & & & & \\
\hline & & 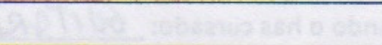 & 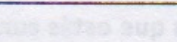 & 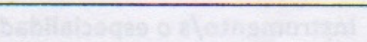 \\
\hline
\end{tabular}

Figura 65. Detalle del ejercicio 2 del postest del sujeto $\mathrm{N}^{\circ} 8$.

El ejercicio 2 hallamos nuevamente un $66 \%$ de aciertos con una respuesta incorrecta.

Nuevamente no hallamos anotaciones al margen respecto a la escritura real de las transposiciones. Por último, en el ejercicio 3 encontramos un $40 \%$ de aciertos, acompañados de tres respuestas derivadas de una incorrección armónica de conceptos curriculares ajenos a la competencia transversal. 
Diseño y planificación de competencias específicas en el currículum de enseñanzas profesionales de música: modalidades composición-dirección en la enseñanza superior.

Carlos Eduardo Pascual Pérez

\section{EJERCICIO 3}

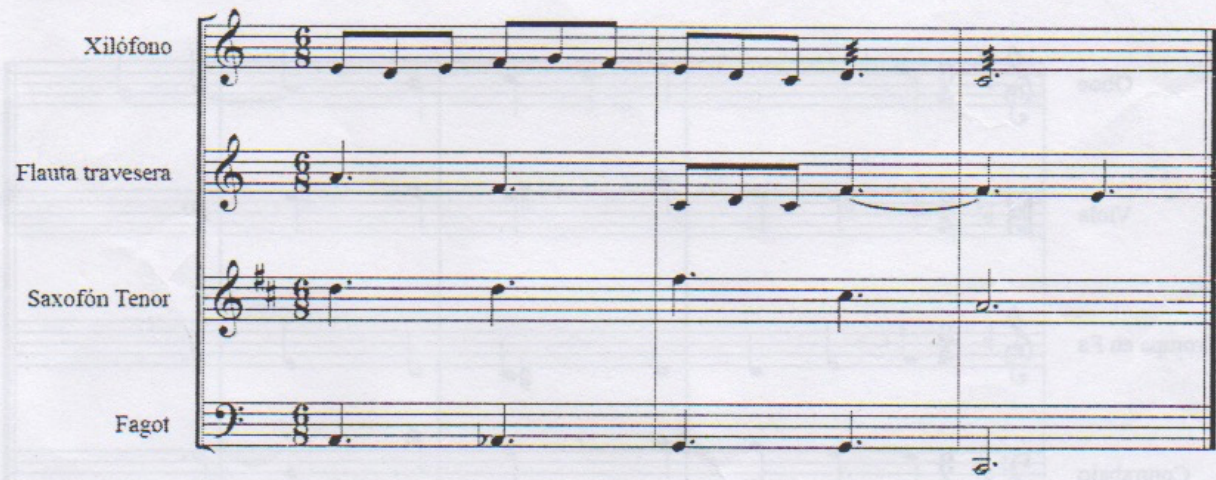

Marcar si no detectas ningún error:

\begin{tabular}{|c|c|c|c|c|}
\hline Compás & Tiempo & Instrumento/s implicado/s & Tipo de error & Observaciones \\
\hline 1 & 2 & xikrus lan' & $c$ & \\
\hline 2 & 1 & lanta / saxitin & $e$ & \\
\hline 2 & 2 & $\operatorname{sax} 0$ & j & \\
\hline 3 & 1 & $5 a \times 0$ & $h$ & \\
\hline 2 & 2 & $\operatorname{lan}{ }^{2}$ & $\because$ & \\
\hline & & 1 & 0 & \\
\hline & & & & \\
\hline & & & & \\
\hline
\end{tabular}

Figura 66. Detalle del ejercicio 3 del postest del sujeto $\mathrm{N}^{\circ} 8$.

A la vista de los resultados del postest podemos concluir que la competencia transversal de

“Organología, instrumentación y orquestación en el ámbito de la orquesta sinfónica” está asumida en un muy alto grado. Denotamos una mejoría muy notable en todas las variables excepto en la lectura entre instrumentos transpositores, así como en la media aritmética de comparativa pretest-postest. Por último, observamos un grado error mínimo en lo curricular 
de la asignatura de armonía, el cual no consideramos determinante para no poder obtener un mejor resultado en la puntuación global del test.

\begin{tabular}{|c|c|c|c|c|c|c|c|c|c|c|c|c|c|}
\hline \multicolumn{10}{|c|}{ PRETEST } & \multicolumn{10}{c|}{ POSTEST } \\
\hline ONT & OT & LENT & LET & ANTT & $M V$ & ONT & OT & LENT & LET & ANTT & $M V$ & MG \\
\hline 8,00 & 0,00 & 10,0 & 7,5 & 5,0 & 6,10 & 8,0 & 8,00 & 10,00 & 5,00 & 6,67 & 7,53 & $\mathbf{6 , 0 0}$ \\
\hline
\end{tabular}

Tabla 17. Resumen puntuaciones de variables, medias y global para el sujeto $\mathrm{N}^{\mathrm{o}} 8$.

\subsubsection{Caso experimental $N^{o} 9$}

La valoración inicial del primer ejercicio del pretest nos sugiere una inexperiencia acerca de la organología de los instrumentos sinfónicos del ámbito orquestal. No hallamos ningún acierto completo, puesto que creemos se confunden los índices de afinación con la nota de referencia usada para afinar en conjunto. Hay también algún acierto parcial, como la octavación del flautín o la afinación de varios instrumentos.

Respecto al segundo ejercicio de lecto-escritura y asociación entre instrumentos transpositores y no transpositores, podemos observar un error continuado en toda la 
Diseño y planificación de competencias específicas en el currículum de enseñanzas profesionales de música: modalidades composición-dirección en la enseñanza superior.

Carlos Eduardo Pascual Pérez

transposición del clarinete en todos los acordes. También apreciamos errores al cruzarse las voces entre el clarinete y el oboe en todos los acordes.

1. Identifica la afinación y octavación de los siguientes instrumentos:

\begin{tabular}{|c|c|c|c|c|c|}
\hline Instrumento & Afinación & Octavación & Instrumento & Afinación & Octavación \\
\hline Oboe & $L_{a}$ & & Clarinete bajo & Si & \\
\hline Flautín & La & $\pi 8^{a}$ & Saxofón alto & mib & \\
\hline Fagot & & 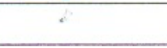 & Saxofón tenor & Le do & \\
\hline Contrabajo & do & & Lira & La & \\
\hline Trompa & Sib & & Flauta alto & La & \\
\hline
\end{tabular}

2. Realiza los siguientes acordes:

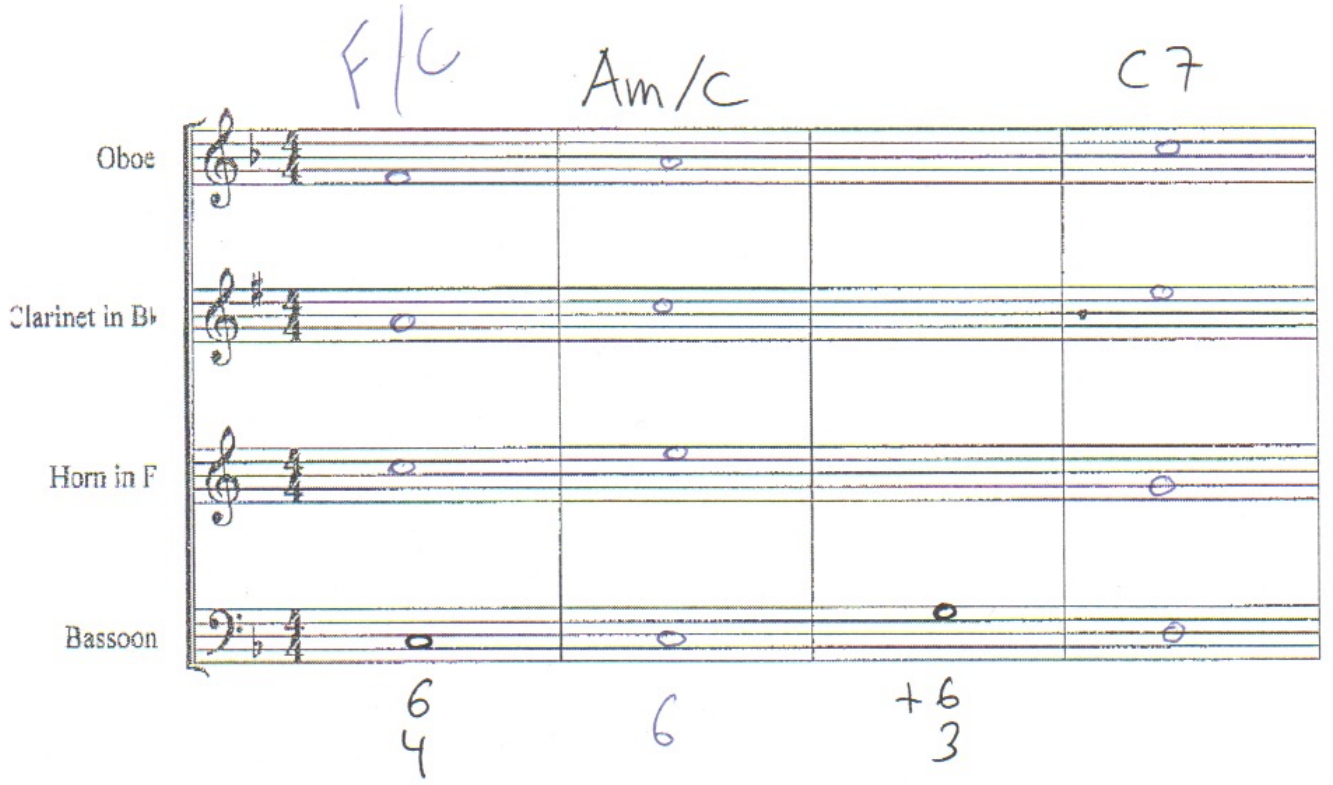

Figura 67. Pretest del caso experimental $\mathrm{N}^{\circ} 9$. 
Diseño y planificación de competencias específicas en el currículum de enseñanzas profesionales de música: modalidades composición-dirección en la enseñanza superior.

Carlos Eduardo Pascual Pérez

A la vista de los resultados creemos que existe un desconocimiento notable en el ámbito de la organología. Además, encontramos la ausencia de respuesta para el tercer acorde, entendiendo que se desprende de un desconocimiento del cifrado propuesto, que en todo caso es curricular de los contenidos de cursos anteriores.

Tras la primera intervención y la entrega del primer ejercicio observamos una mejora notable en el ámbito de la lecto-escritura y la organología, dado que desaparecen los errores de cruce de voces continuos o los errores continuados de transposición. No obstante, hallamos cruce de voces puntuales entre la trompa y el clarinete (compases 4 en adelante). También se evidencian errores conceptuales propios en lo curricular de la asignatura de armonía, no siendo estos aplicables al desarrollo de nuestra competencia transversal, como las quintas seguidas entre oboe y clarinete (compás 3) o el uso de intervalos aumentados en la trompa (compás 3). Hallamos también anotaciones al inicio de cada pentagrama con las indicaciones de registro de cada instrumento, así como una indicación de mejor uso del registro de un instrumento. 
Diseño y planificación de competencias específicas en el currículum de enseñanzas profesionales de música: modalidades composición-dirección en la enseñanza superior.

Carlos Eduardo Pascual Pérez

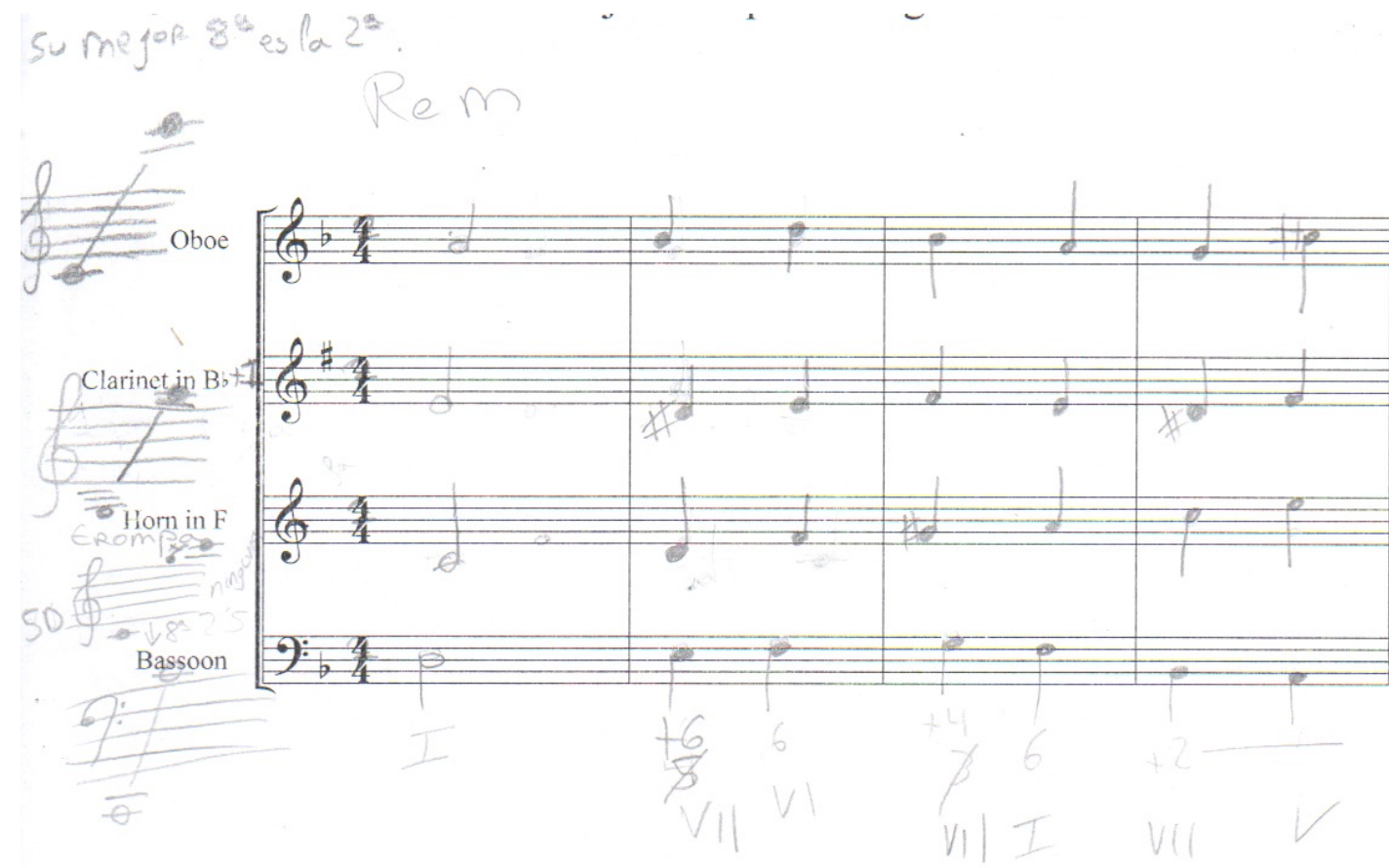

$\mathrm{Ob}$

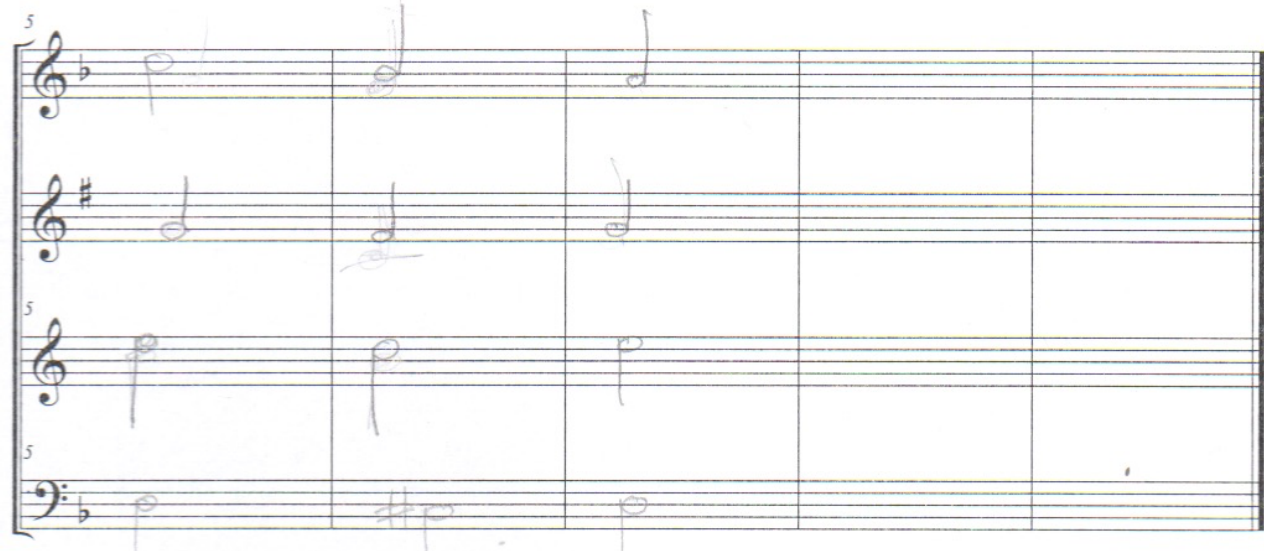

Figura 68. Detalle del ejercicio de la primera intervención del sujeto $\mathrm{N}^{\mathrm{o}} 9$. 
En el ejercicio de la segunda intervención hallamos una mejora significativa en cuanto a la organología y la lecto-escritura, dado que desaparecen los errores de cruce entre voces sistemáticos, aunque hallamos un error en la superación del registro de la viola (compás 2) acompañado de un cruce puntual con el violoncello. Respecto a la lectura del saxofón alto único instrumento transpositor del ejercicio - encontramos una anotación al margen y en la primera nota escrita que evidencia la correcta transposición del instrumento. Además, encontramos una escritura incorrecta del uso de la clave de Do en la viola. 
Diseño y planificación de competencias específicas en el currículum de enseñanzas profesionales de música: modalidades composición-dirección en la enseñanza superior.

Carlos Eduardo Pascual Pérez
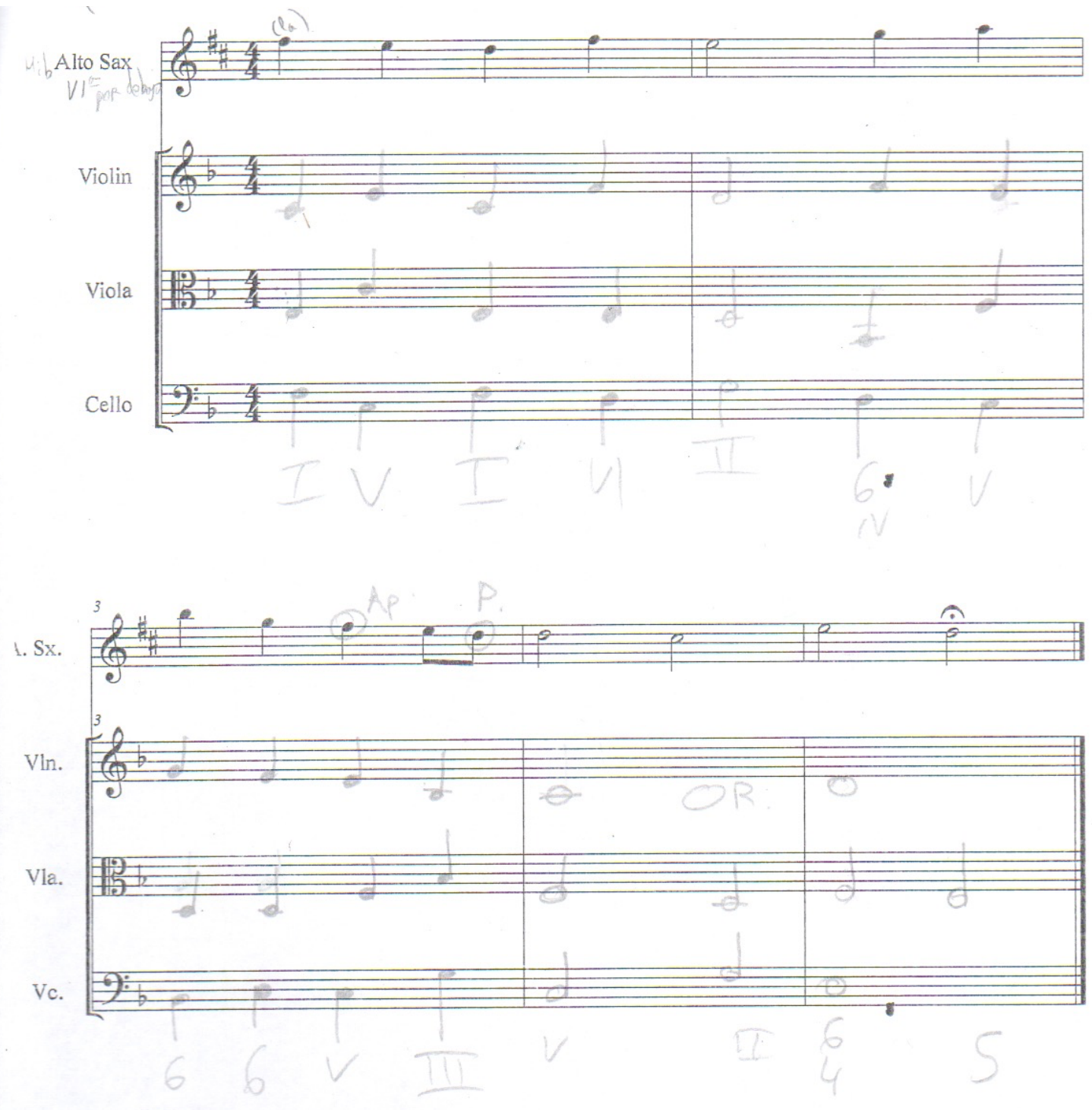

Figura 69. Detalle del ejercicio de la segunda intervención del sujeto $\mathrm{N}^{\circ} 9$. 
No obstante, detectamos errores propiamente curriculares - no significantes en la competencia transversal desarrollada - como el uso incorrecto de las notas extrañas (compás 3).

No disponemos de resultados para el postest, dado que el sujeto abandonó la experiencia tras la segunda intervención y no se presentó a la realización de esta última prueba. No obstante, a la vista de los resultados de la intervención, podemos concluir que la competencia transversal "Organología, instrumentación y orquestación en el ámbito de la orquesta sinfónica” está asumida parcialmente. Aunque no podemos cuantificar los resultados, denotamos una mejoría en la segunda experiencia respecto a la anterior y a su vez - y de forma muy significativa - respecto al pretest. Por último, observamos un grado error medio en lo curricular de la asignatura de armonía, el cual no podemos considerar determinante para no poder obtener un mejor resultado en la puntuación global del test al carecer de dichos resultados.

\begin{tabular}{|c|c|c|c|c|c|c|c|c|c|c|c|c|}
\hline \multicolumn{10}{|c|}{ PRETEST } & \multicolumn{10}{c|}{ POSTEST } \\
\hline ONT & OT & LENT & LET & ANTT & $M V$ & ONT & OT & LENT & LET & ANTT & $M V$ & MG \\
\hline 0,00 & 0,00 & 6,30 & 3,80 & 0,00 & 2,00 & - & - & - & - & - & - & - \\
\hline
\end{tabular}

Tabla 18. Resumen puntuaciones de variables, medias y global para el sujeto $\mathrm{N}^{\circ} 9$. 


\subsubsection{Caso experimental $N^{o} 10$}

La valoración inicial del primer ejercicio del pretest nos sugiere una inexperiencia acerca de la organología de los instrumentos sinfónicos del ámbito orquestal. Aparecen mal relacionados los índices de afinación con su octavación, o en muchos casos no se aporta la misma o se yerra en el propio índice.

Respecto al segundo ejercicio de lecto-escritura y asociación entre instrumentos transpositores y no transpositores, podemos observar un error puntual en la transposición del clarinete (segundo acorde) así como un cruce de voz con el oboe (cuarto acorde). También apreciamos un error de superación máxima de la distancia entre voces de la trompa y el clarinete (cuarto acorde). 
Diseño y planificación de competencias específicas en el currículum de enseñanzas profesionales de música: modalidades composición-dirección en la enseñanza superior.

Carlos Eduardo Pascual Pérez

1. Identifica la afinación y octavación de los siguientes instrumentos:

\begin{tabular}{|l|l|l|l|l|l|}
\hline Instrumento & Afinación & Octavación & Instrumento & Afinación & Octavación \\
\hline Oboe & Sib & & Clarinete bajo & Si $b$ & \\
\hline Flautín & Do & $18^{a} \uparrow$ & Saxofón alto & Mi & \\
\hline Fagot & Do & & Saxofón tenor & Fa & \\
\hline Contrabajo & Sol & 4 Octava $\downarrow$ & Lira & OO & \\
\hline Trompa & fa & & Flauta alto & Do & \\
\hline
\end{tabular}

2. Realiza los siguientes acordes:

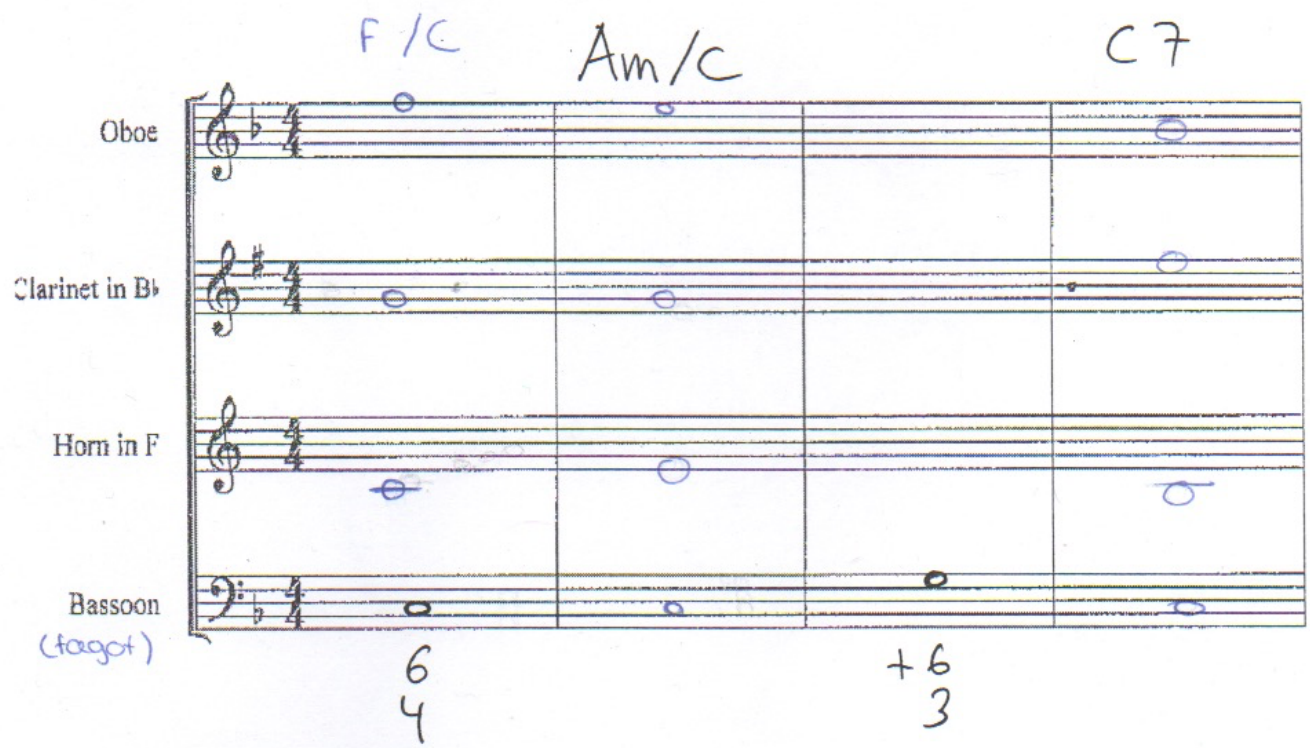

Figura 70. Pretest del caso experimental $\mathrm{N}^{\mathrm{o}} 10$.

A la vista de los resultados creemos que existe un cierto desconocimiento en el ámbito de la organología y la lecto-escritura de los instrumentos. Además, encontramos la ausencia de 
Diseño y planificación de competencias específicas en el currículum de enseñanzas profesionales de música: modalidades composición-dirección en la enseñanza superior.

Carlos Eduardo Pascual Pérez

respuesta para el tercer acorde, entendiendo que se desprende de un desconocimiento del cifrado propuesto, que en todo caso es curricular de los contenidos de cursos anteriores.

Tras la primera intervención y la entrega del primer ejercicio no observamos una mejora en el ámbito de la lecto-escritura, dado que continúan los errores de cruce entre voces (oboe y clarinete, compases 2 y 3). También se evidencian errores conceptuales propios en lo curricular de la asignatura de armonía, no siendo estos aplicables al desarrollo de nuestra competencia transversal, como la irresolución de la sensible (compases 2 y 3). Hallamos anotaciones de la transposición del clarinete y la trompa al inicio de sus pentagramas. 
Diseño y planificación de competencias específicas en el currículum de enseñanzas profesionales de música: modalidades composición-dirección en la enseñanza superior.

Carlos Eduardo Pascual Pérez

Rem
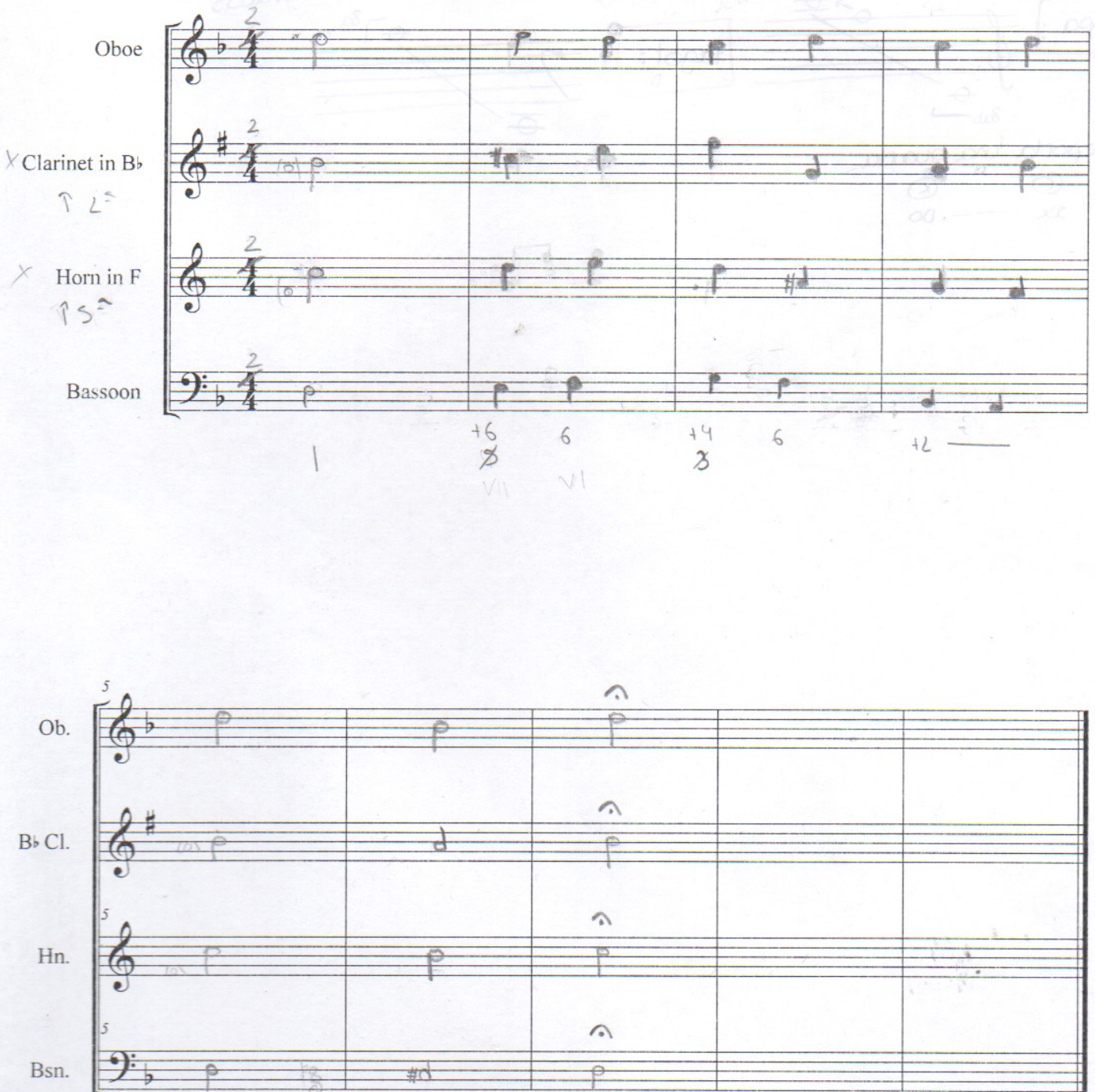

Bsn.

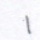

Figura 71. Detalle del ejercicio de la primera intervención del sujeto $\mathrm{N}^{\mathrm{o}} 10$.

En el ejercicio de la segunda intervención no hallamos una mejora significativa en cuanto a

la organología y la lecto-escritura, dado que volvemos a detectar errores de cruce de voces 
Diseño y planificación de competencias específicas en el currículum de enseñanzas profesionales de música: modalidades composición-dirección en la enseñanza superior.

Carlos Eduardo Pascual Pérez

de una forma continuada entre el saxofón y el violín. Hallamos una anotación de la transposición del saxofón alto, así como una referencia a la escritura vocal a cuatro voces al vincular la voz "tenor" correctamente con la viola en este caso concreto.

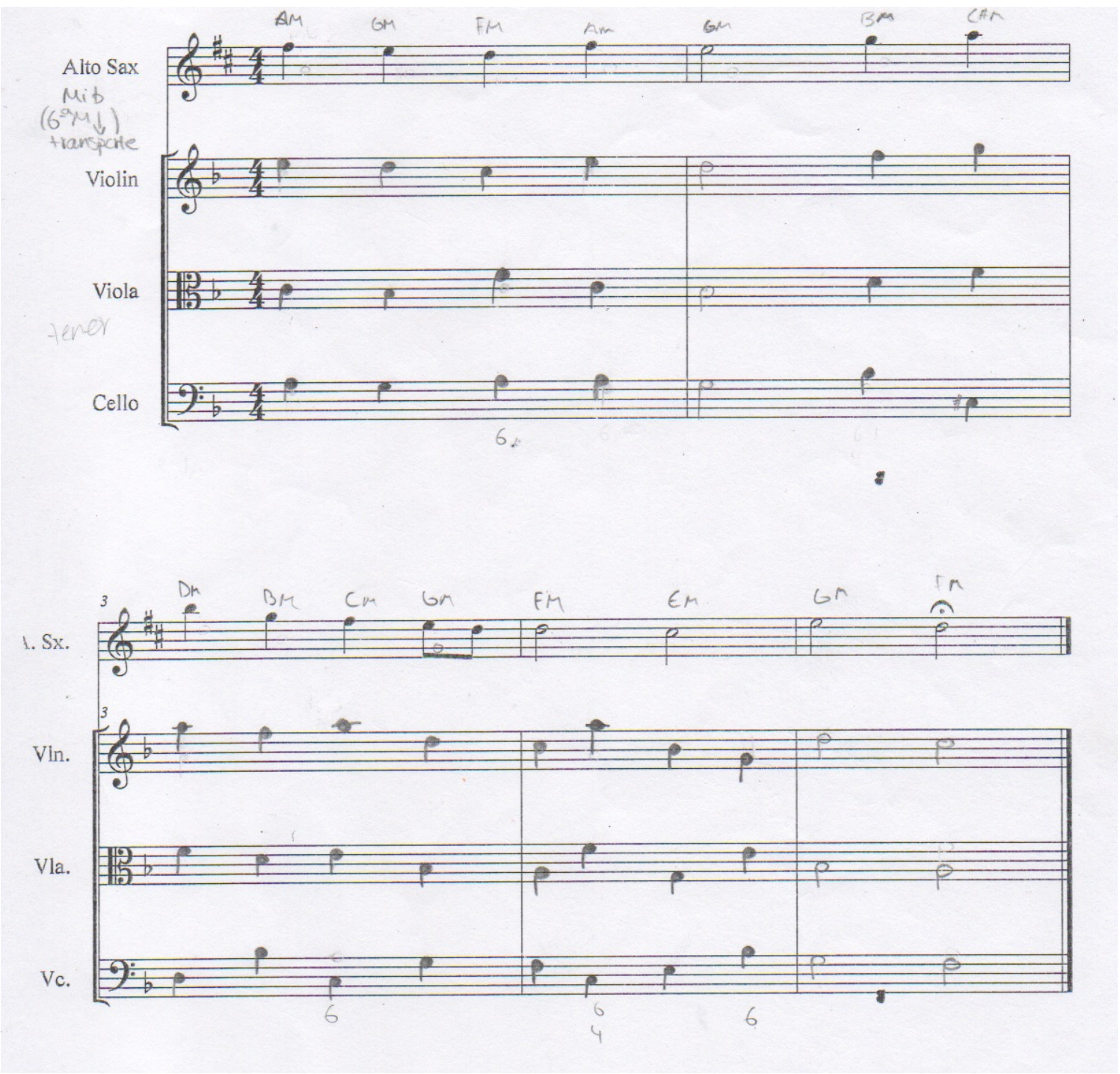

Figura 72. Detalle del ejercicio de la segunda intervención del sujeto $\mathrm{N}^{\circ} 10$. 
Los errores detectados son de importancia, como la superación máxima de la distancia entre voces (compás 4, entre el violoncello y la viola), así como el cruce de voces continuado entre el violín y el saxofón. Además, encontramos errores en lo propiamente curricular de la asignatura, como la incorrección en la realización de acordes en segunda inversión (compás 4) o la interpretación de los grados tonales en todo el ejercicio.

En la evaluación final a través del postest observamos un alto grado de acierto a nivel de organología tanto de instrumentos transpositores como no transpositores, así como de lectoescritura en instrumentos no transpositores. No hay anotaciones al margen ni tampoco de escritura real en las notas, de lo que podemos deducir que el alumno conoce las propiedades de bastantes de los instrumentos (a excepción del xilófono) y que no necesita de dichos apuntes para su entendimiento. Queda patente el alto grado de asimilación de los instrumentos trabajados a nivel práctico en la intervención, así como de los instrumentos únicamente revisados a nivel teórico. 
Diseño y planificación de competencias específicas en el currículum de enseñanzas profesionales de música: modalidades composición-dirección en la enseñanza superior.

Carlos Eduardo Pascual Pérez

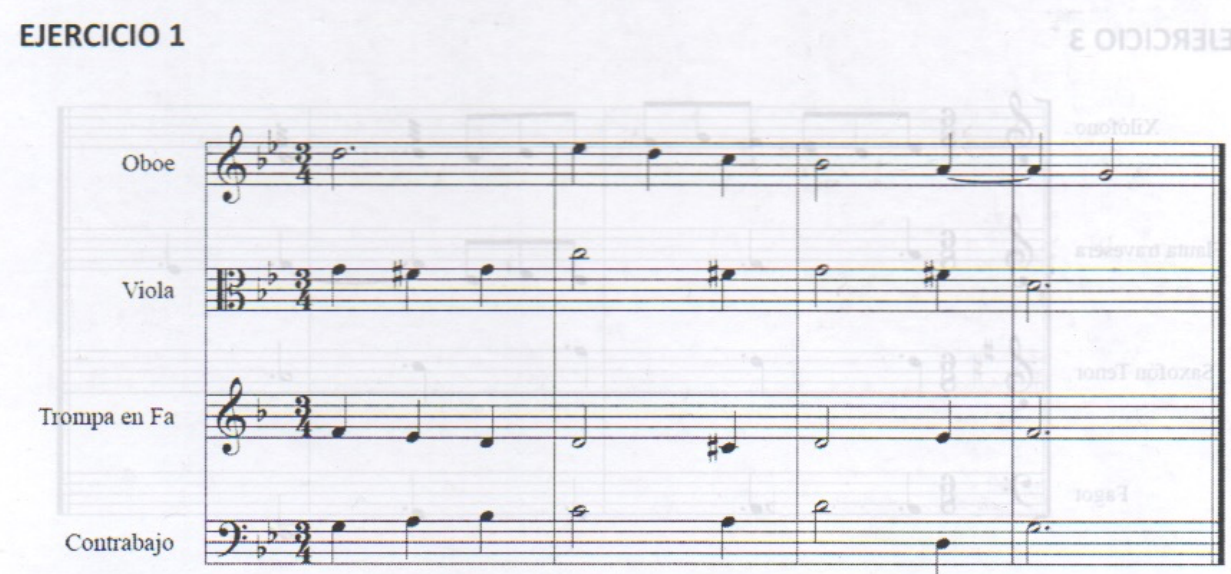

Marcar si no detectas ningún error:

\begin{tabular}{|c|c|c|c|c|}
\hline Compás & Tiempo & Instrumento/s implicado/s & Tipo de error & Observaciones \\
\hline 1 & 3 & trompa & $e$ & \\
\hline 2 & 7 & niola & $\rho$ & \\
\hline 2 & 3 & trompa & $e$ & \\
\hline 2 & 3 & viopa & 9 & \\
\hline 2 & 3 & trompa & 9 & \\
\hline 3 & 3 & co Pa & $h$ & \\
\hline & & & & \\
\hline & & & & \\
\hline
\end{tabular}

Figura 73. Detalle del ejercicio 1 del postest del sujeto $\mathrm{N}^{\circ} 10$.

Respecto a la resolución del test (detección de errores armónicos) hallamos el 100\% de aciertos para el ejercicio 1, acompañado de cuatro respuestas incorrectas, las cuales se desprenden tanto de incorrecciones propiamente armónicas - que no implican el uso de la competencia transversal - como de errores de asociación entre instrumentos transpositores y no transpositores. 
Diseño y planificación de competencias específicas en el currículum de enseñanzas profesionales de música: modalidades composición-dirección en la enseñanza superior.

Carlos Eduardo Pascual Pérez

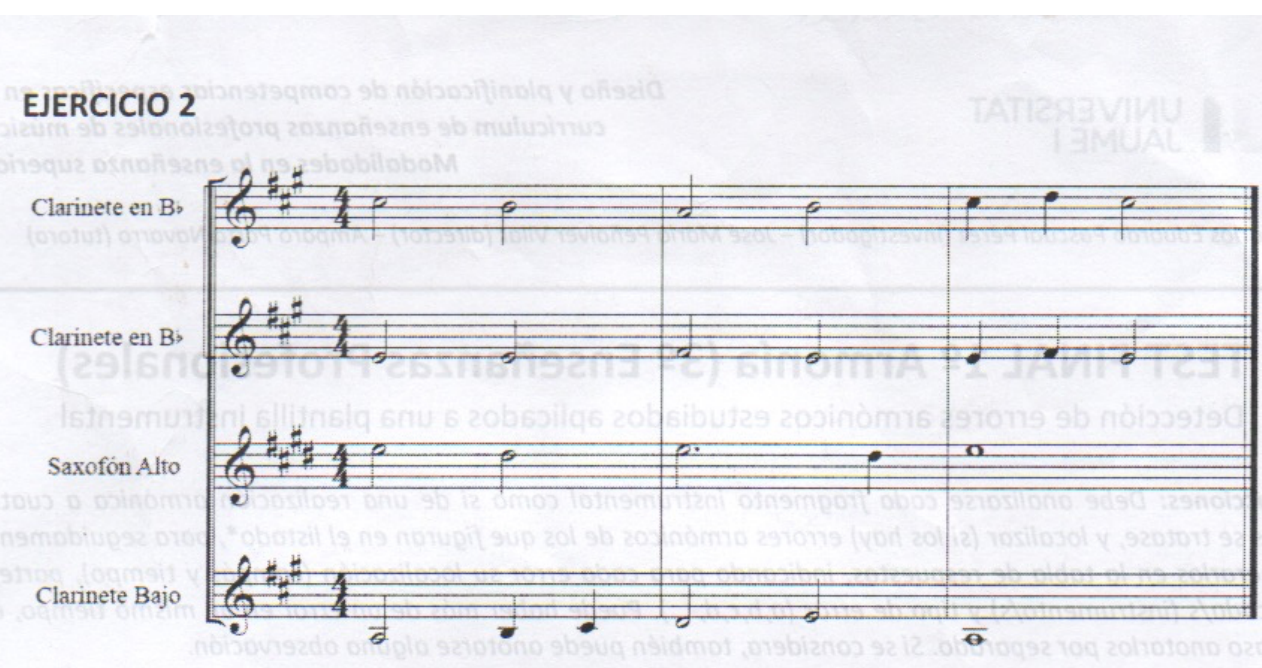

Marcar si no detectas ningún error:

\begin{tabular}{|c|c|c|c|c|}
\hline Compás & Tiempo & Instrumento/s implicado/s & Tipo de error & Observaciones \\
\hline 1 & todo & cearinete & $e$ & \\
\hline 2 & 7 & clarchede is $-/$ Dajo & $b$ & 0 \\
\hline 2 & 3 & carinele ob / paia & D & 20339116 20voto \\
\hline 560 & 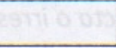 & 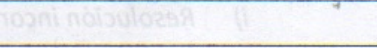 & & 20109316 zosnitup (60) \\
\hline & & 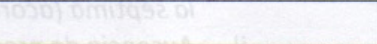 & & 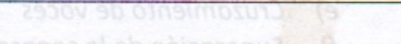 \\
\hline & & & & \\
\hline & & & & \\
\hline & & zobsenua asd o ob & 627450605000 & 9)babilsiagaza o aloingmunian| \\
\hline
\end{tabular}

Figura 74. Detalle del ejercicio 2 del postest del sujeto $\mathrm{N}^{\circ} 10$.

Del ejercicio 2 hallamos el $66 \%$ de aciertos para dicho ejercicio, acompañado de una respuesta incorrecta. Por último, en el ejercicio 3 encontramos un $20 \%$ de aciertos, acompañado de otras tres respuestas incorrectas que creemos se desprenden de incorrecciones propiamente armónicas. 
Diseño y planificación de competencias específicas en el currículum de enseñanzas profesionales de música: modalidades composición-dirección en la enseñanza superior.

Carlos Eduardo Pascual Pérez

\section{EJERCICIO 3}

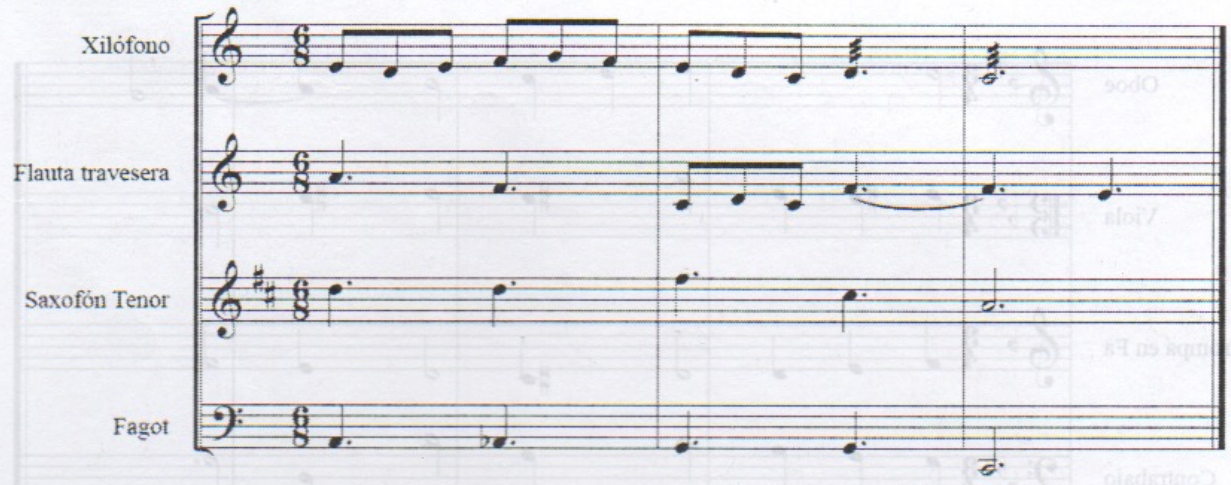

Marcar si no detectas ningún error:

\begin{tabular}{|c|c|c|c|c|}
\hline Compás & Tiempo & Instrumento/s implicado/s & Tipo de error & Observaciones \\
\hline 1 & 2 & xilósono & $c$ & \\
\hline 1 & 2 & jeareta & $c$ & \\
\hline 2 & 1 & Jeauta & $e$ & \\
\hline 2 & 1 & saxo ión & $e$ & \\
\hline 3 & 1 & Saxojón & $h$ & \\
\hline & & & & \\
\hline & & & & \\
\hline & & & & \\
\hline
\end{tabular}

Figura 75. Detalle del ejercicio 3 del postest del sujeto $\mathrm{N}^{\mathrm{o}} 10$.

A la vista de los resultados del postest podemos concluir que la competencia transversal de “Organología, instrumentación y orquestación en el ámbito de la orquesta sinfónica” está asumida en un alto grado. Concretamente denotamos mejoría muy significativa en todas las variables sin excepción. Por último, observamos un bajo grado de error propiamente en lo curricular de la asignatura de armonía que no creemos haya sido determinante para no poder 


\section{Carlos Eduardo Pascual Pérez}

obtener un mejor resultado en la puntuación global del test, y de la que se desprende un empeoramiento en las variables referidas a la lecto-escritura.

\begin{tabular}{|c|c|c|c|c|c|c|c|c|c|c|c|c|}
\multicolumn{10}{|c|}{ PRETEST } & \multicolumn{10}{c|}{ POSTEST } \\
\hline ONT & OT & LENT & LET & ANTT & $M V$ & ONT & OT & LENT & LET & ANTT & $M V$ & MG \\
\hline 2,00 & 0,00 & 7,50 & 5,00 & 5,00 & 3,90 & 6,00 & 8,00 & 10,00 & 5,00 & 6,67 & 7,13 & $\mathbf{5 , 0 0}$ \\
\hline
\end{tabular}

Tabla 19. Resumen puntuaciones de variables, medias y global para el sujeto $\mathrm{N}^{\mathrm{o}} 10$.

\subsubsection{Caso experimental $N^{o} 11$}

La valoración inicial del primer ejercicio del pretest nos sugiere una gran inexperiencia en la organología de los instrumentos sinfónicos del ámbito orquestal, con apenas un $10 \%$ de aciertos completos. Aunque hay algún acierto parcial - como la octavación del contrabajo fallan los índices acústicos de prácticamente todos los instrumentos, que además carecen de octavación.

Respecto al segundo ejercicio de lecto-escritura y asociación entre instrumentos transpositores y no transpositores, podemos observar un error continuado en toda la 
Diseño y planificación de competencias específicas en el currículum de enseñanzas profesionales de música: modalidades composición-dirección en la enseñanza superior.

Carlos Eduardo Pascual Pérez

transposición del clarinete y de la trompa. Además, hallamos cruce de voces entre el oboe y

el clarinete (cuarto acorde).

1. Identifica la afinación y octavación de los siguientes instrumentos:

\begin{tabular}{|c|c|c|c|c|c|}
\hline Instrumento & Afinación & Octavación & Instrumento & Afinación & Octavación \\
\hline Oboe & sib & - & Clarinete bajo & sib & - \\
\hline Flautín & Do & $8 a \pi$ & Saxofón alto & sib & - \\
\hline Fagot & $15=5$ sib & - & Saxofón tenor & Mib & - \\
\hline Contrabajo & Mib & $8 a \downarrow$ & Lira & Mib & $8 a T$ \\
\hline Trompa & De & - & Flauta alto & Sib & SRa- \\
\hline
\end{tabular}

2. Realiza los siguientes acordes:

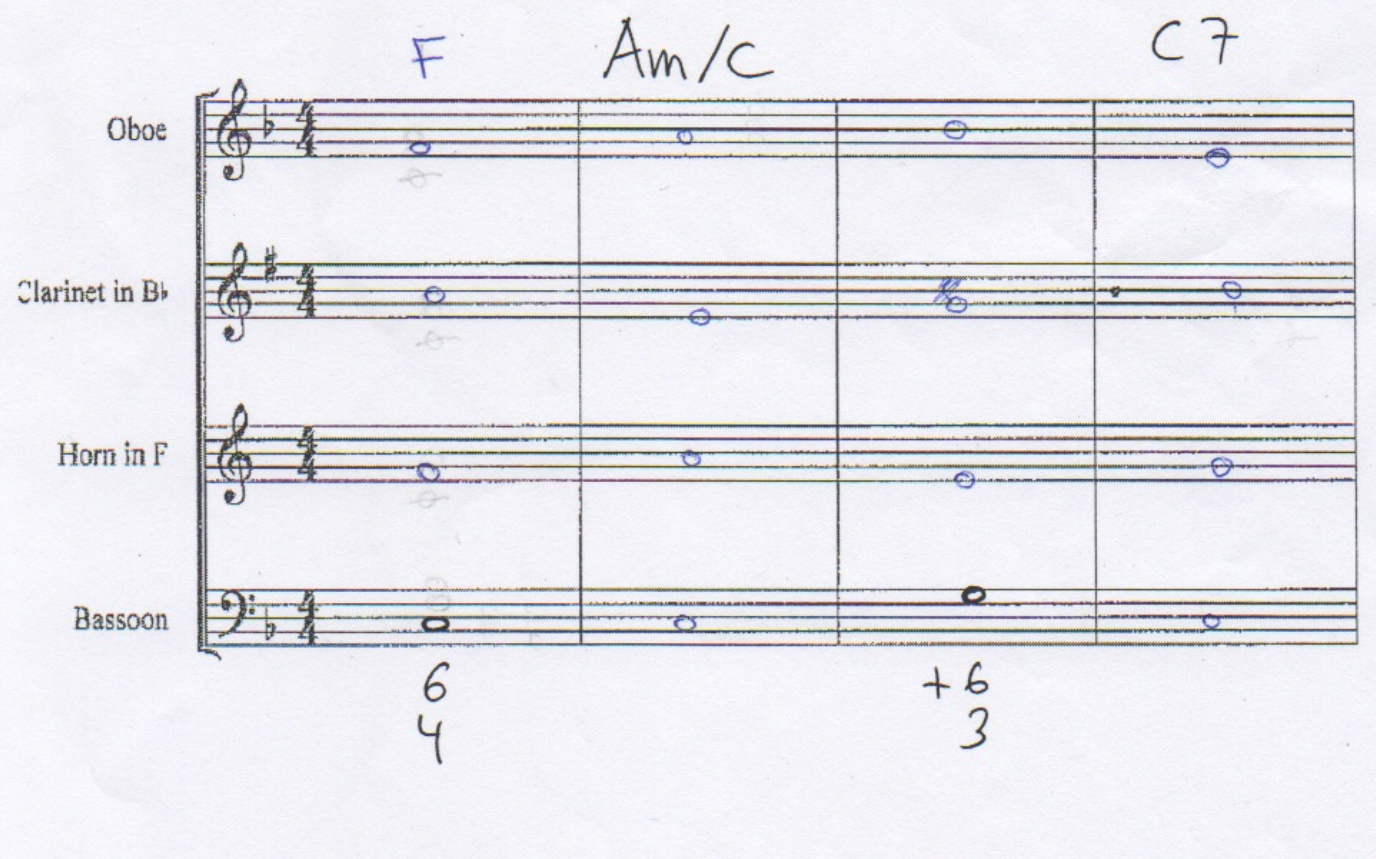

Figura 76. Pretest del caso experimental № 11. 
A la vista de los resultados sugerimos la inexperiencia citada como determinante para la resolución del ejercicio segundo en el ámbito de la lecto-escritura y asociación entre instrumentos transpositores y no transpositores.

Tras la primera intervención y la entrega del primer ejercicio observamos una mejora significativa en el ámbito de la lecto-escritura y la organología, dado que desaparecen los errores en la transposición de los instrumentos. No obstante, seguimos detectando cruce de voces entre el oboe y el clarinete (compases 2, 6 y 7). También se evidencian errores conceptuales propios en lo curricular de la asignatura de armonía, no siendo estos aplicables al desarrollo de nuestra competencia transversal, como la ausencia de alteración de la sensible (compás 2, 3 y 4). No existe ninguna anotación al margen o apunte que indique la ayuda para la transposición o la lectura en claves poco usuales, pero entendemos que está interiorizado correctamente al no producirse errores en la escritura absoluta de notas. 
Diseño y planificación de competencias específicas en el currículum de enseñanzas profesionales de música: modalidades composición-dirección en la enseñanza superior.

Carlos Eduardo Pascual Pérez

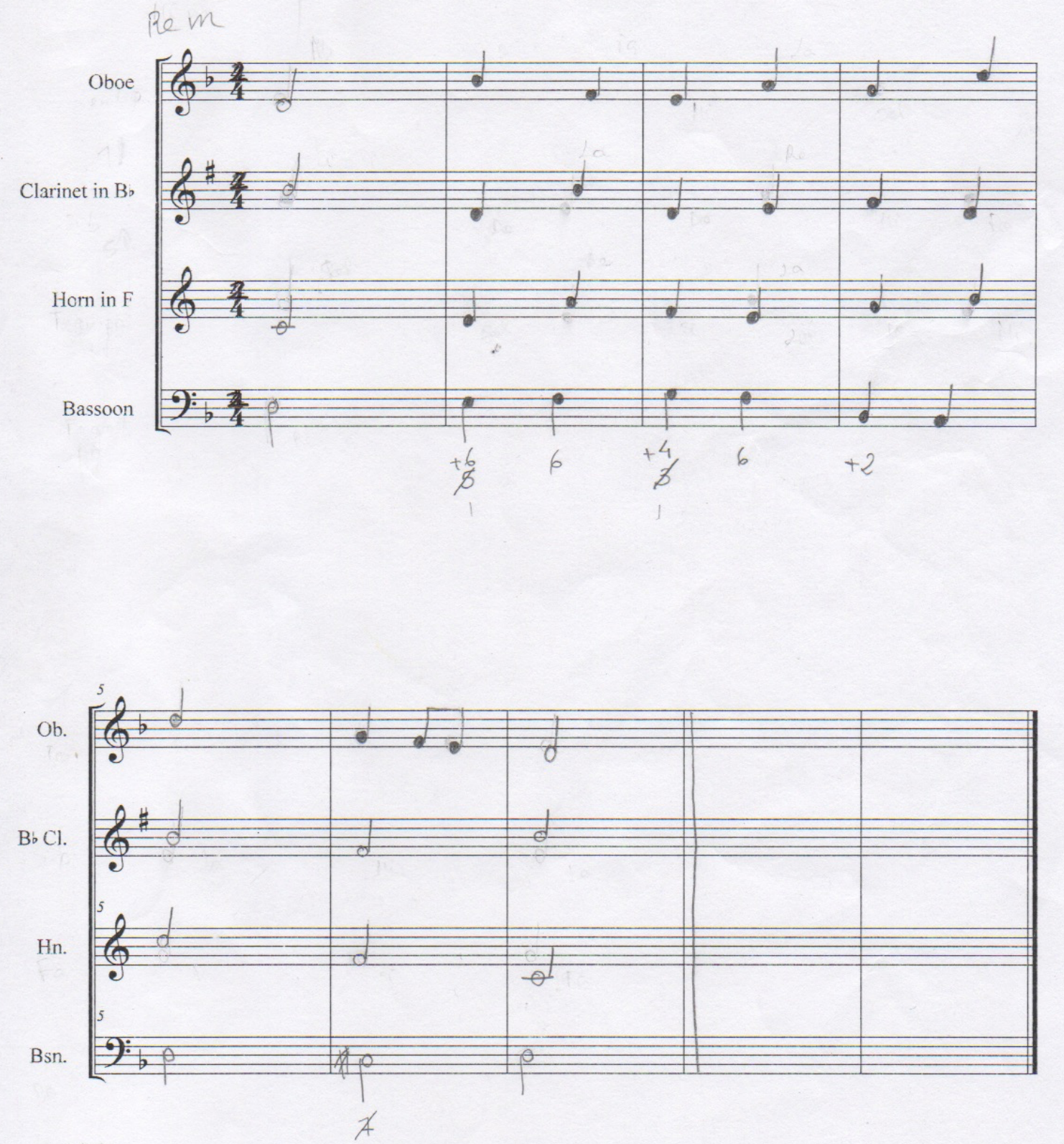

Figura 77. Detalle del ejercicio de la primera intervención del sujeto $\mathrm{N}^{\circ} 11$. 
Diseño y planificación de competencias específicas en el currículum de enseñanzas profesionales de música: modalidades composición-dirección en la enseñanza superior.

Carlos Eduardo Pascual Pérez

En el ejercicio de la segunda intervención no hallamos una mejora significativa en cuanto a la organología y la lecto-escritura, dado que volvemos a detectar errores de cruce de voces, así como una duplicación directa de dos de las mismas. Hallamos una anotación de la transposición del saxofón alto, así como otra acerca de la tonalidad del ejercicio.

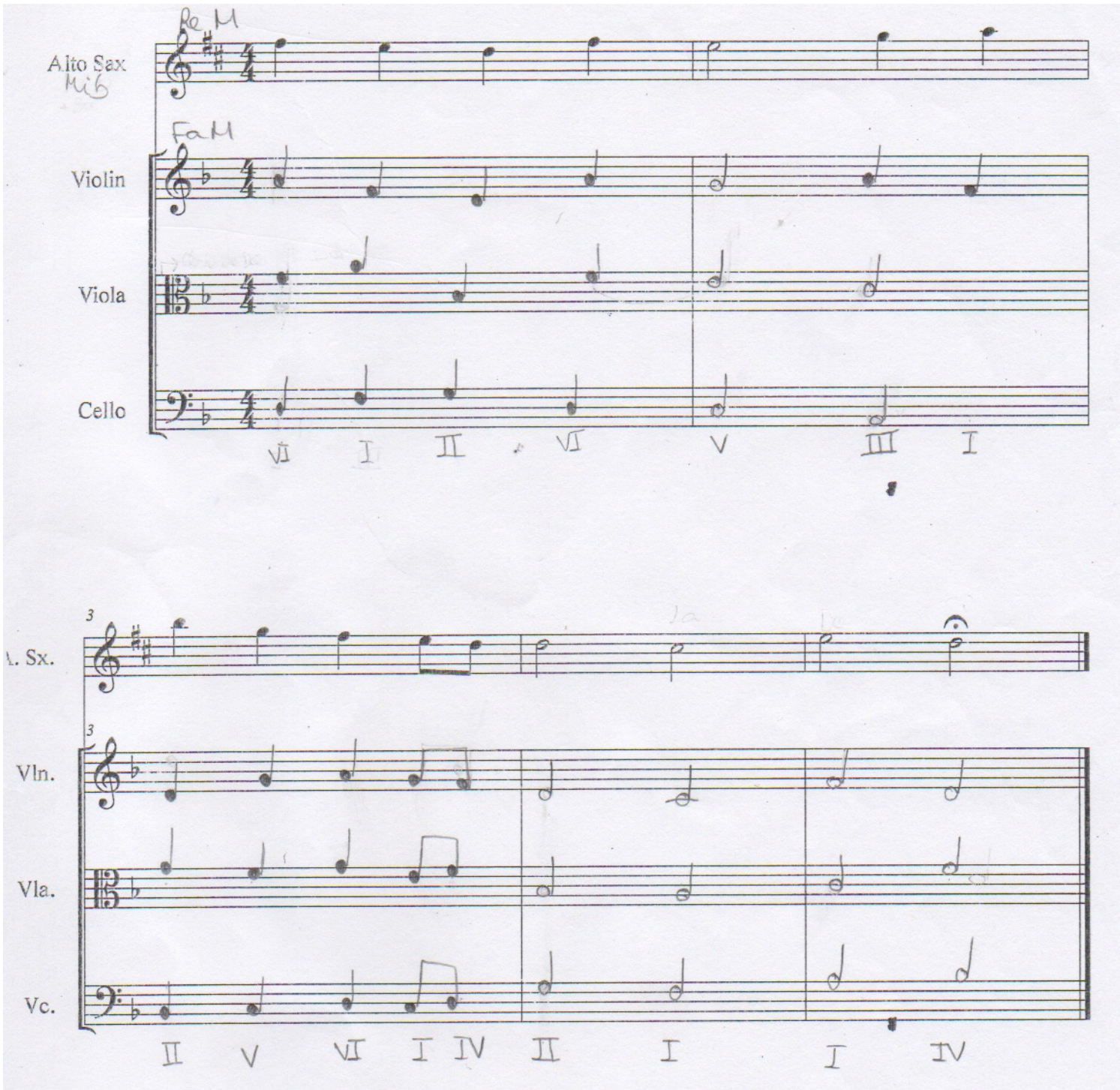


Diseño y planificación de competencias específicas en el currículum de enseñanzas profesionales de música: modalidades composición-dirección en la enseñanza superior.

\section{Carlos Eduardo Pascual Pérez}

Figura 78. Detalle del ejercicio de la segunda intervención del sujeto $\mathrm{N}^{\mathrm{o}} 11$.

Los errores detectados son de importancia, como el unísono en prácticamente todo el ejercicio entre el saxofón alto y el violín, así como el cruce de voces entre el violín y la viola (compases 1, 3 y 5). Además, encontramos errores en lo propiamente curricular de la asignatura, como la interpretación de los grados tonales en todo el ejercicio.

En la evaluación final a través del postest observamos un grado de acierto bajo a nivel de organología tanto de instrumentos transpositores como no transpositores, así como de lectoescritura en instrumentos no transpositores. No hallamos anotaciones al margen sobre la transposición u octavación de los instrumentos, y por su resolución tenemos dudas de si están o no interiorizadas. 
Diseño y planificación de competencias específicas en el currículum de enseñanzas profesionales de música: modalidades composición-dirección en la enseñanza superior.

Carlos Eduardo Pascual Pérez

\section{EJERCICIO 1}

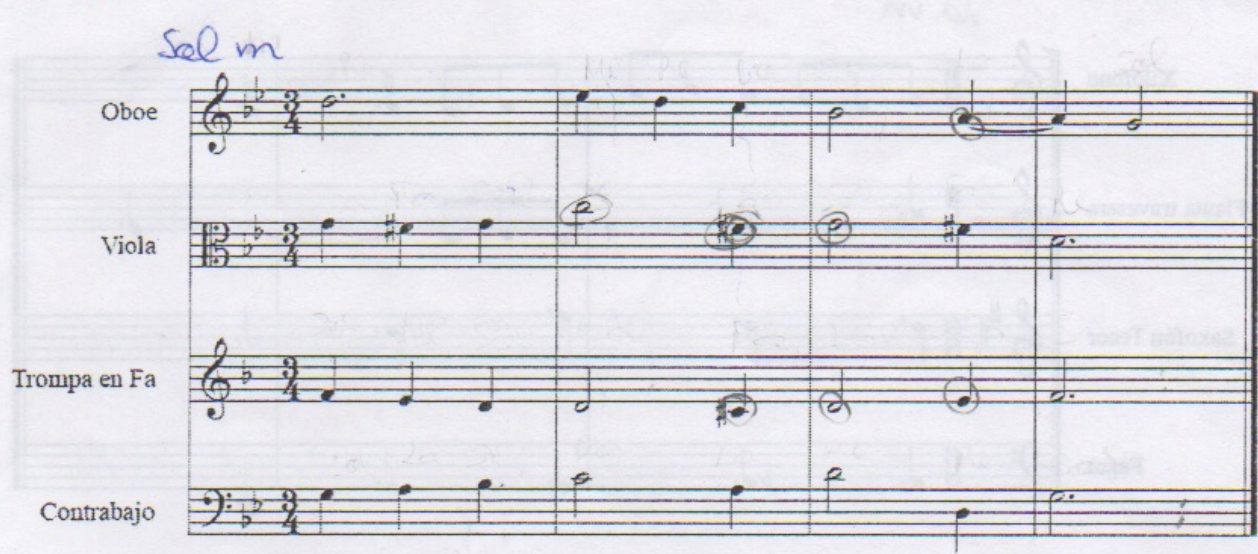

Marcar si no detectas ningún error:

\begin{tabular}{|c|c|c|c|c|}
\hline Compás & Tiempo & Instrumento/s implicado/s & Tipo de error & Observaciones \\
\hline 2 & 3 & Viala y trompa & $\mathrm{g}$ & \\
\hline 3 & 1 & Viola y trompa & a & \\
\hline 3 & 3 & Trompo y obre & $a$ & \\
\hline 2 & 3 & Vicala & $h$ & \\
\hline & & & & \\
\hline & & & & \\
\hline & & & & \\
\hline & & & & \\
\hline
\end{tabular}

Figura 79. Detalle del ejercicio 1 del postest del sujeto $\mathrm{N}^{\mathrm{o}} 11$.

Respecto a la resolución del test (detección de errores armónicos) hallamos el 50\% de aciertos para el ejercicio 1, acompañado de una respuesta incorrecta, la cual se desprende de incorrecciones propiamente que implican el uso de la competencia transversal, como la resolución diferida de la sensible. 
Diseño y planificación de competencias específicas en el currículum de enseñanzas profesionales de música: modalidades composición-dirección en la enseñanza superior.

Carlos Eduardo Pascual Pérez

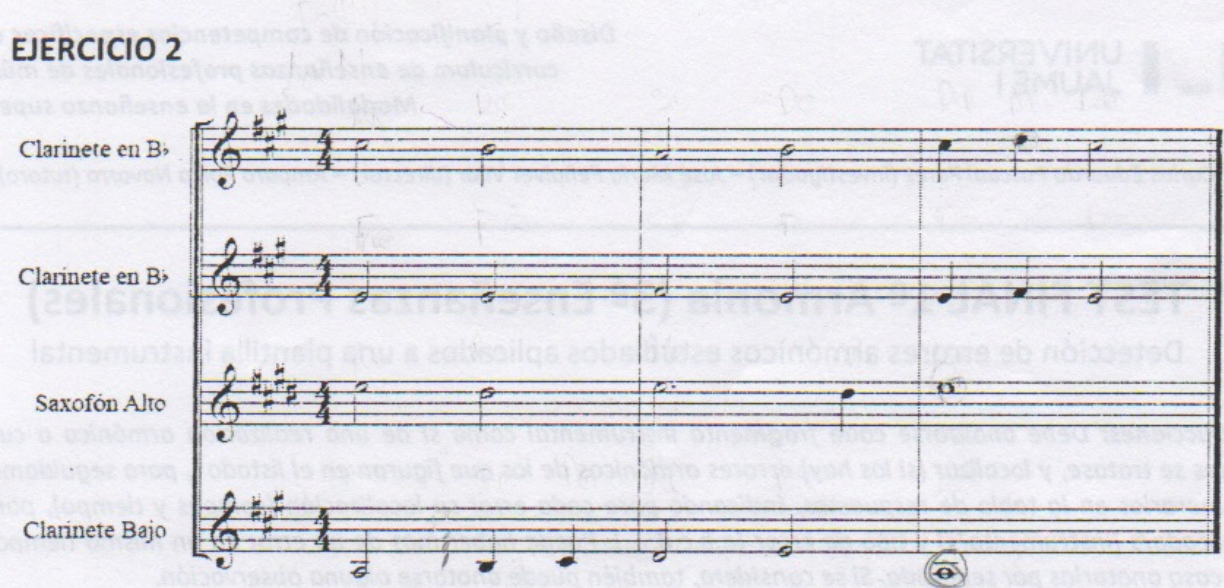

(ब)

Marcar si no detectas ningún error:

\begin{tabular}{|c|c|c|c|c|}
\hline Compás & Tiempo & Instrumento/s implicado/s & Tipo de error & Observaciones \\
\hline 3 & $1 y^{2}$ & Savojón y Carinete & g & \\
\hline 3 & 1 & Savofón y Carinete & $j$ & \\
\hline & & & & \\
\hline & & & & \\
\hline & & & & \\
\hline & & & & \\
\hline & & & & \\
\hline
\end{tabular}

Figura 80. Detalle del ejercicio 2 del postest del sujeto $\mathrm{N}^{\mathrm{o}} 11$.

El ejercicio 2 hallamos nuevamente un $0 \%$ de aciertos con dos respuestas incorrectas.

Nuevamente no hallamos anotaciones al margen respecto a la escritura real de las transposiciones. Por último, en el ejercicio 3 encontramos un $0 \%$ de aciertos, al indicar expresamente la ausencia de errores para todo el ejercicio. 
Diseño y planificación de competencias específicas en el currículum de enseñanzas profesionales de música: modalidades composición-dirección en la enseñanza superior.

Carlos Eduardo Pascual Pérez

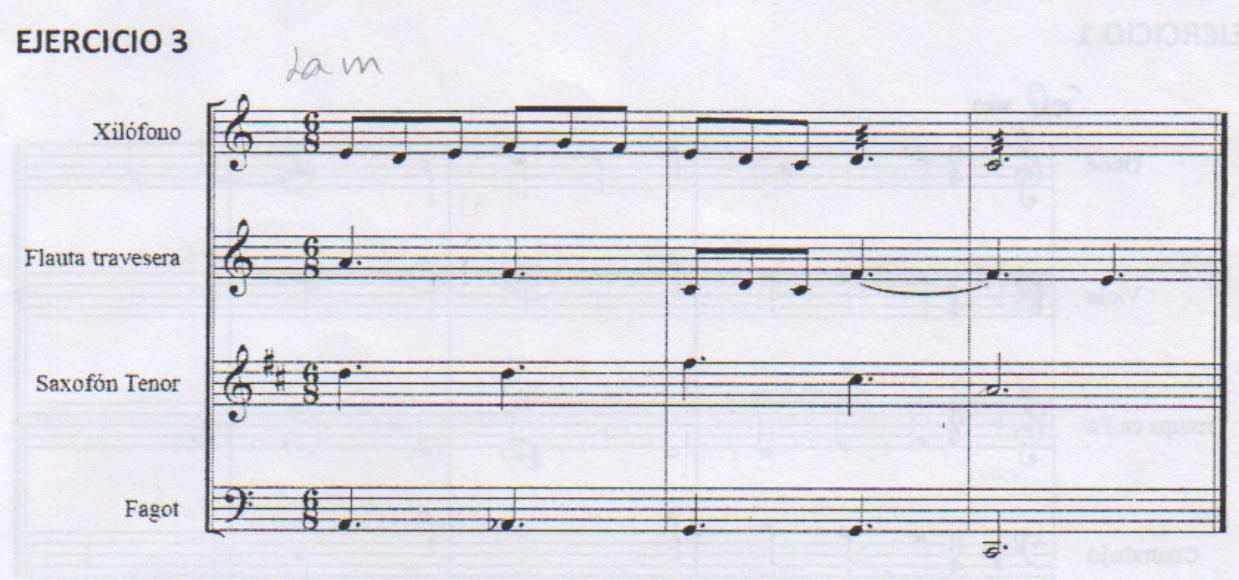

Marcar si no detectas ningún error:

\begin{tabular}{|l|l|l|l|l|}
\hline Compás & Tiempo & Instrumento/s implicado/s & Tipo de error & Observaciones \\
\hline & & & & \\
\hline & & & & \\
\hline & & & & \\
\hline & & & & \\
\hline & & & & \\
\hline & & & & \\
\hline & & & & \\
\hline
\end{tabular}

Figura 81. Detalle del ejercicio 3 del postest del sujeto $\mathrm{N}^{\mathrm{o}} 11$.

A la vista de los resultados del postest podemos concluir que la competencia transversal de “Organología, instrumentación y orquestación en el ámbito de la orquesta sinfónica” está asumida parcialmente, y en un grado ciertamente bajo. No denotamos una mejoría significativa en el resultado de las variables. así como tampoco en la media aritmética de comparativa pretest-postest. Por último, observamos un grado error elevado en lo curricular 


\section{Carlos Eduardo Pascual Pérez}

de la asignatura de armonía, el cual consideramos determinante para no poder obtener un mejor resultado en la puntuación global del test.

\begin{tabular}{|c|c|c|c|c|c|c|c|c|c|c|c|c|}
\multicolumn{10}{|c|}{ PRETEST } & \multicolumn{10}{c|}{ POSTEST } \\
\hline ONT & OT & LENT & LET & ANTT & $M V$ & ONT & OT & LENT & LET & ANTT & $M V$ & MG \\
\hline 2,00 & 0,00 & 10,00 & 0,00 & 0,00 & 2,40 & 6,00 & 2,00 & 10,00 & 0,00 & 3,33 & 4,27 & 1,00 \\
\hline
\end{tabular}

Tabla 20. Resumen puntuaciones de variables, medias y global para el sujeto $\mathrm{N}^{\mathrm{o}} 11$.

\subsubsection{Caso experimental $N^{o} 12$}

La valoración inicial del primer ejercicio del pretest nos sugiere una gran inexperiencia en la organología de los instrumentos sinfónicos del ámbito orquestal, con un $0 \%$ de aciertos completos. Únicamente hallamos un acierto parcial en el índice de afinación del saxofón tenor.

Respecto al segundo ejercicio de lecto-escritura y asociación entre instrumentos transpositores y no transpositores, podemos observar que no está resuelto el ejercicio, con únicamente unas anotaciones a tipo de boceto en el pentagrama del oboe. 
Diseño y planificación de competencias específicas en el currículum de enseñanzas profesionales de música: modalidades composición-dirección en la enseñanza superior.

Carlos Eduardo Pascual Pérez

1. Identifica la afinación y octavación de los siguientes instrumentos:

\begin{tabular}{|l|l|l|l|c|c|}
\hline \multicolumn{1}{|c|}{ Instrumento } & Afinación & Octavación & \multicolumn{1}{|l|}{ Instrumento } & Afinación & Octavación \\
\hline Oboe & & & Clarinete bajo & $M_{i} b M$ & \\
\hline Flautín & & & Saxofón alto & & +2 \\
\hline Fagot & SibM & -2 & Saxofón tenor & SibM & \\
\hline Contrabajo & & & Lira & & \\
\hline Trompa & & & Flauta alto & & \\
\hline
\end{tabular}

2. Realiza los siguientes acordes:

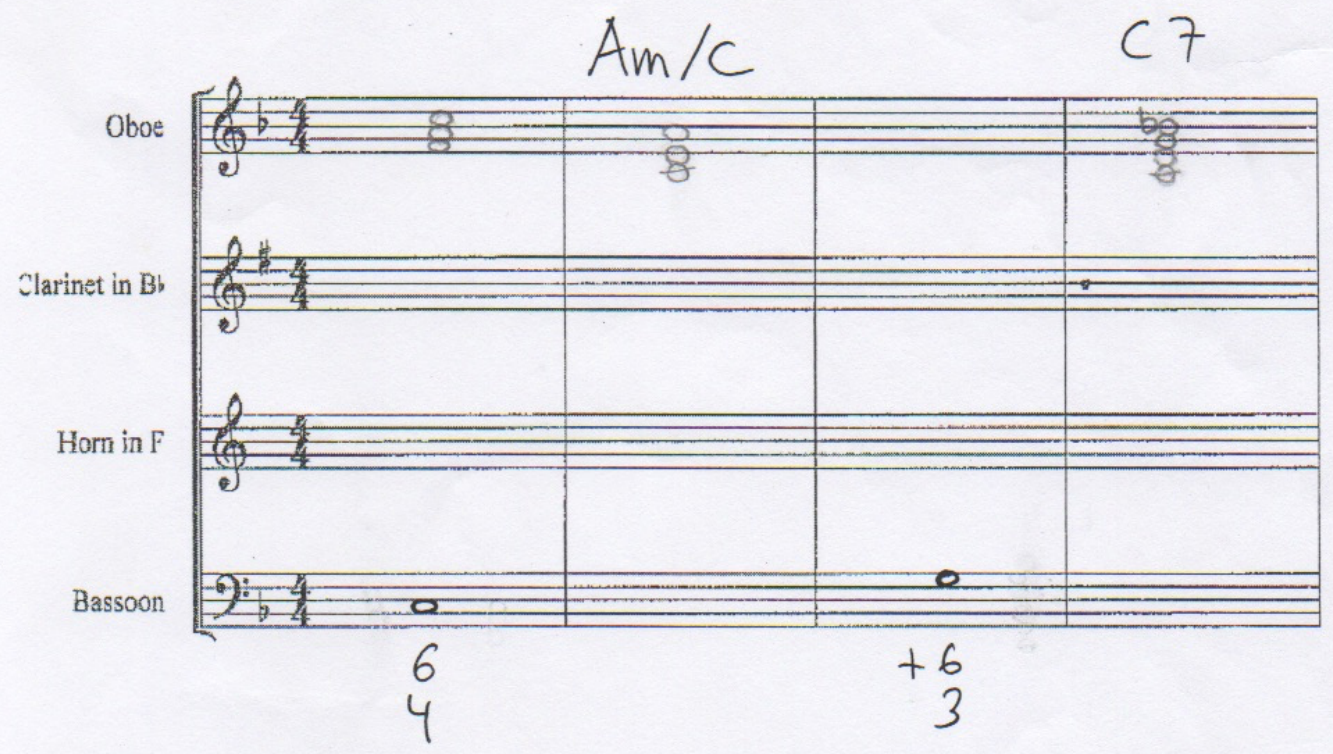

Figura 82. Pretest del caso experimental No 12. 
Diseño y planificación de competencias específicas en el currículum de enseñanzas profesionales de música: modalidades composición-dirección en la enseñanza superior.

Carlos Eduardo Pascual Pérez

A la vista de los resultados sugerimos la inexperiencia citada como determinante para la resolución de ambos ejercicios, estableciendo un nivel cero de conocimientos iniciales.

Tras la primera intervención y la entrega del primer ejercicio observamos una mejora importante en el ámbito de la lecto-escritura y la organología, dado que cualquier mínimo acierto será significativo. No obstante, detectamos cruce de voces entre el oboe y el clarinete (compases 2, 4, 5 y 7) y entre el clarinete y la trompa (compás 3). También se evidencian errores conceptuales propios en lo curricular de la asignatura de armonía, no siendo estos aplicables al desarrollo de nuestra competencia transversal, como la ausencia de alteración de la sensible (compás 2, 3 y 4). Hallamos una anotación al margen con el resumen de los índices de afinación de los instrumentos, pero carente de su transposición, aunque por la realización entendemos que están interiorizados. 
Diseño y planificación de competencias específicas en el currículum de enseñanzas profesionales de música: modalidades composición-dirección en la enseñanza superior.

Carlos Eduardo Pascual Pérez

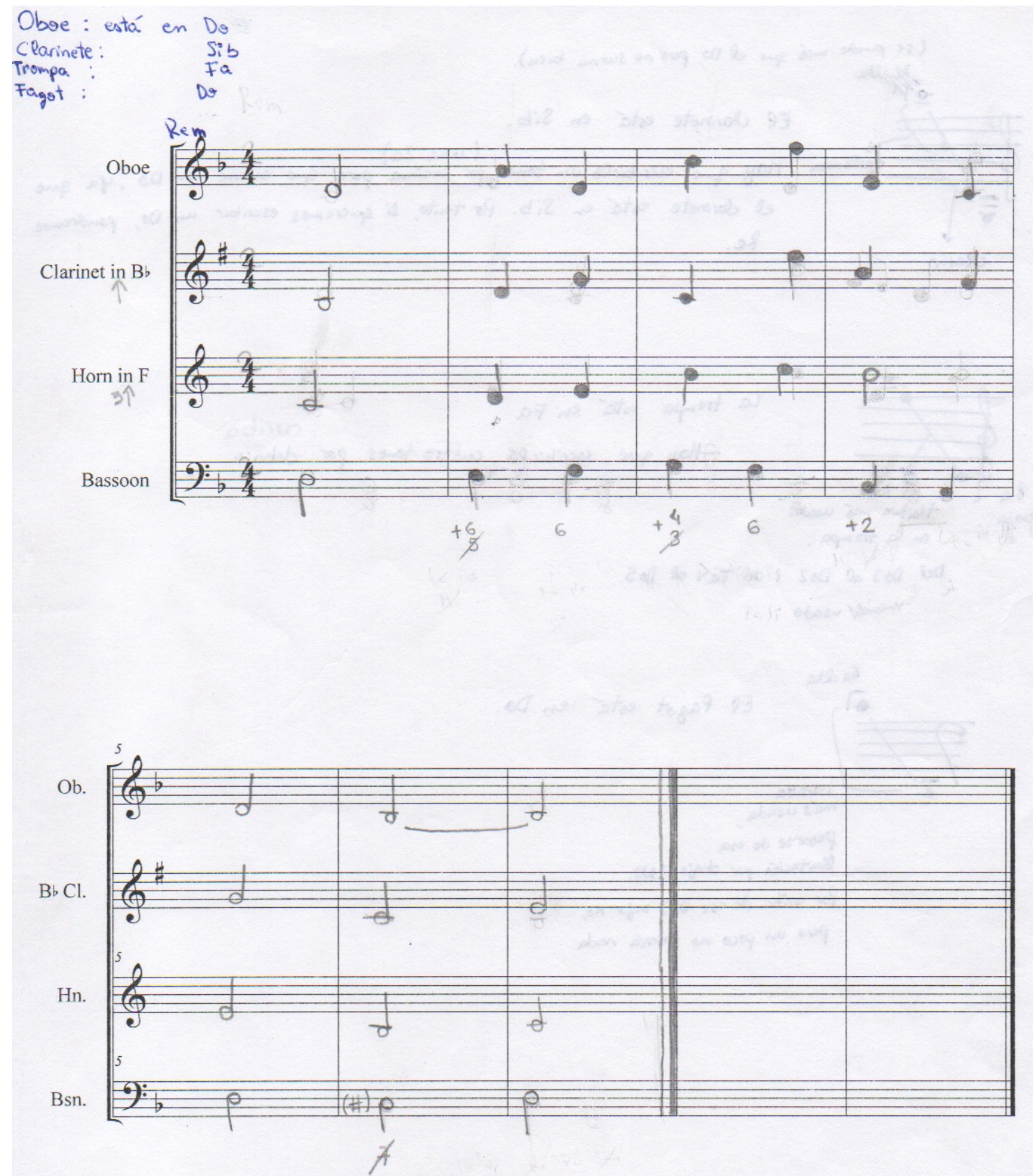

Figura 83. Detalle del ejercicio de la primera intervención del sujeto $\mathrm{N}^{\circ} 11$. 
En el ejercicio de la segunda intervención no hallamos una mejora significativa en cuanto a la organología y la lecto-escritura, dado que volvemos a detectar errores de cruce de voces, así como una duplicación directa de dos de las mismas. Hallamos anotaciones de las tonalidades del ejercicio aplicadas a cada instrumento, pero no de sus transposiciones. Además, encontramos una advertencia sobre el uso de la clave de Do en la viola. 
Diseño y planificación de competencias específicas en el currículum de enseñanzas profesionales de música: modalidades composición-dirección en la enseñanza superior.

Carlos Eduardo Pascual Pérez

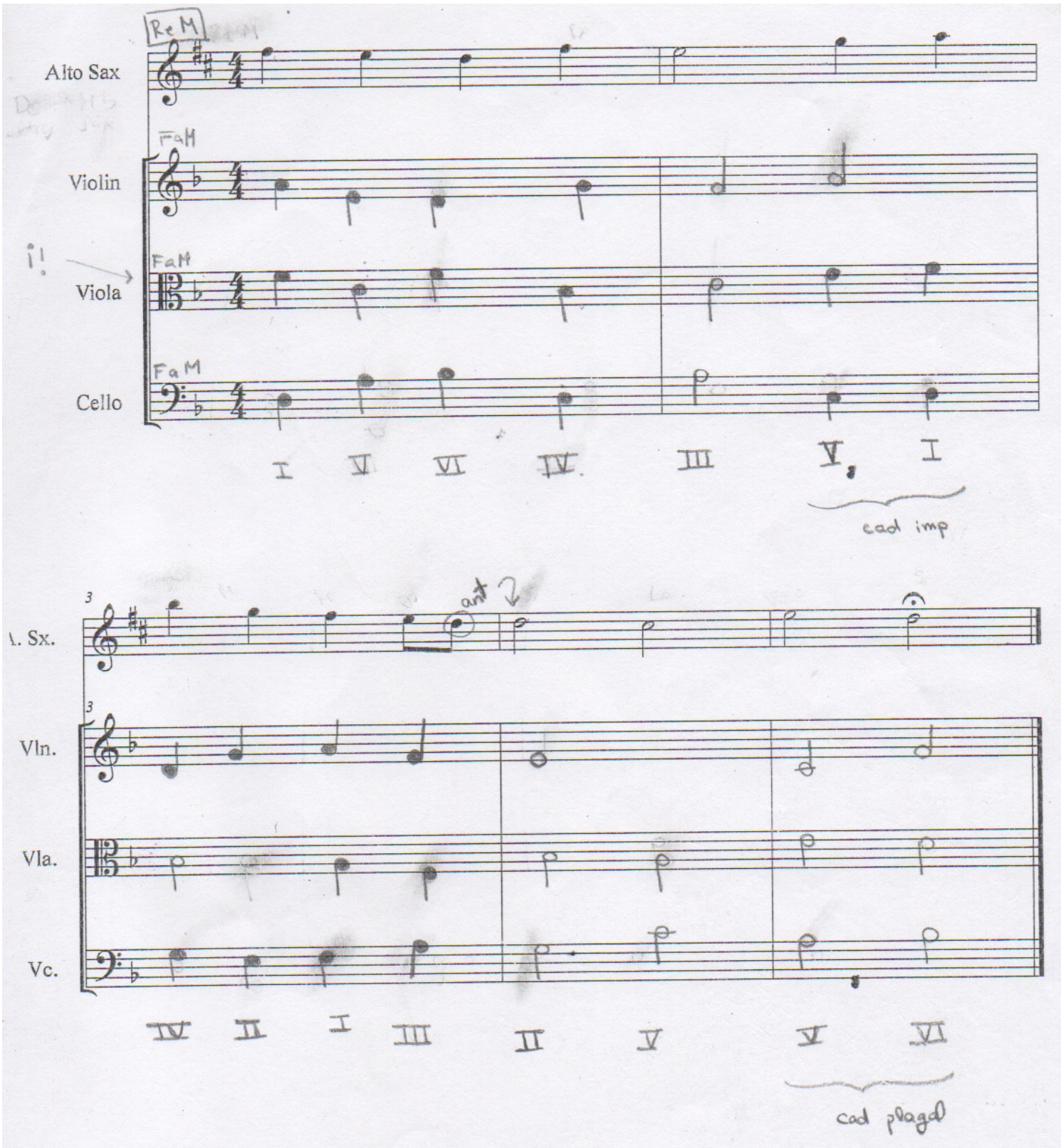

Figura 84. Detalle del ejercicio de la segunda intervención del sujeto $\mathrm{N}^{\mathrm{o}} 12$. 
Diseño y planificación de competencias específicas en el currículum de enseñanzas profesionales de música: modalidades composición-dirección en la enseñanza superior.

Carlos Eduardo Pascual Pérez

Los errores detectados son de importancia, como los unísonos irregulares y mal resueltos en prácticamente todo el ejercicio entre el saxofón alto y el violín, así como el cruce de voces entre el violín y la viola (compases 1 y 6). Además, encontramos errores en lo propiamente curricular de la asignatura, como la interpretación de los grados tonales en todo el ejercicio.

En la evaluación final a través del postest observamos un grado de acierto bajo a nivel de organología tanto de instrumentos transpositores como no transpositores, así como de lectoescritura en instrumentos no transpositores. No hallamos anotaciones al margen sobre la transposición u octavación de los instrumentos, y por su resolución tenemos dudas de si están o no interiorizadas. 
Diseño y planificación de competencias específicas en el currículum de enseñanzas profesionales de música: modalidades composición-dirección en la enseñanza superior.

Carlos Eduardo Pascual Pérez

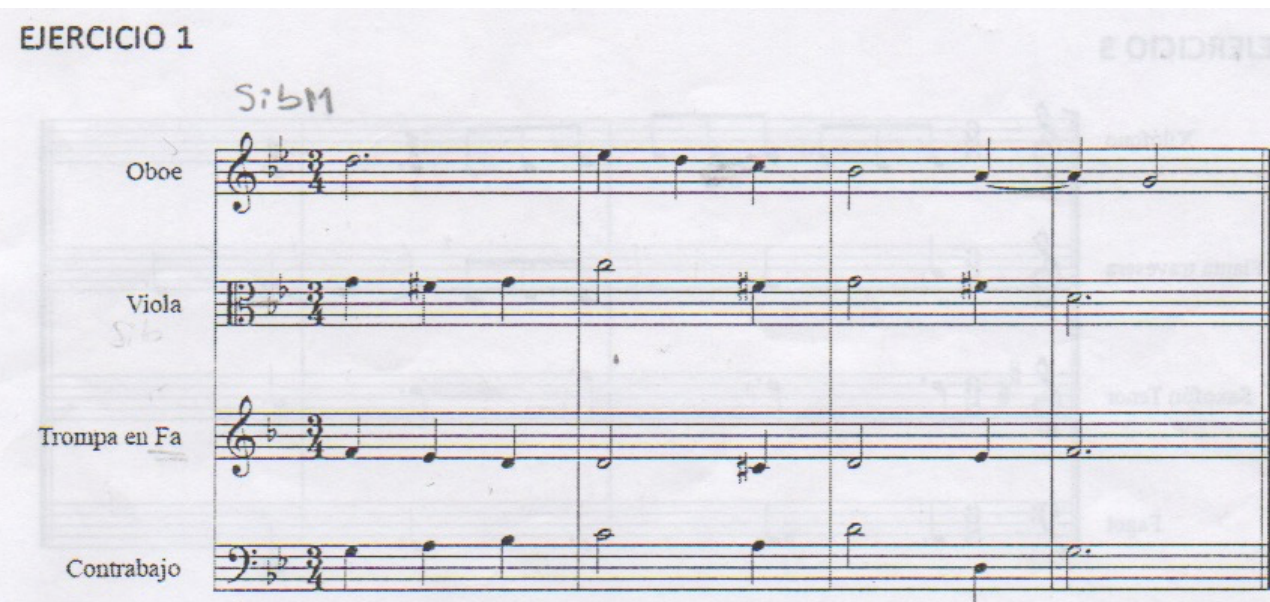

Marcar si no detectas ningún error:

\begin{tabular}{|c|c|c|c|c|}
\hline Compás & Tiempo & Instrumento/s implicado/s & Tipo de error & Observaciones \\
\hline 1 & 1 & & $a$ & \\
\hline 2 & 2 & & $g$ & \\
\hline 4 & 1 & & $f$ & \\
\hline & & & & \\
\hline & & & & \\
\hline & & & & \\
\hline & & & & \\
\hline & & & & \\
\hline
\end{tabular}

Figura 85. Detalle del ejercicio 1 del postest del sujeto $\mathrm{N}^{\mathrm{o}} 12$.

Respecto a la resolución del test (detección de errores armónicos) hallamos un $50 \%$ de aciertos para el ejercicio 1, acompañado de dos respuestas incorrectas, la cuales se desprenden de incorrecciones propiamente que implican el uso de la competencia transversal. 
Diseño y planificación de competencias específicas en el currículum de enseñanzas profesionales de música: modalidades composición-dirección en la enseñanza superior.

Carlos Eduardo Pascual Pérez

\section{EJERCICIO 2}

Clarinete en $B$

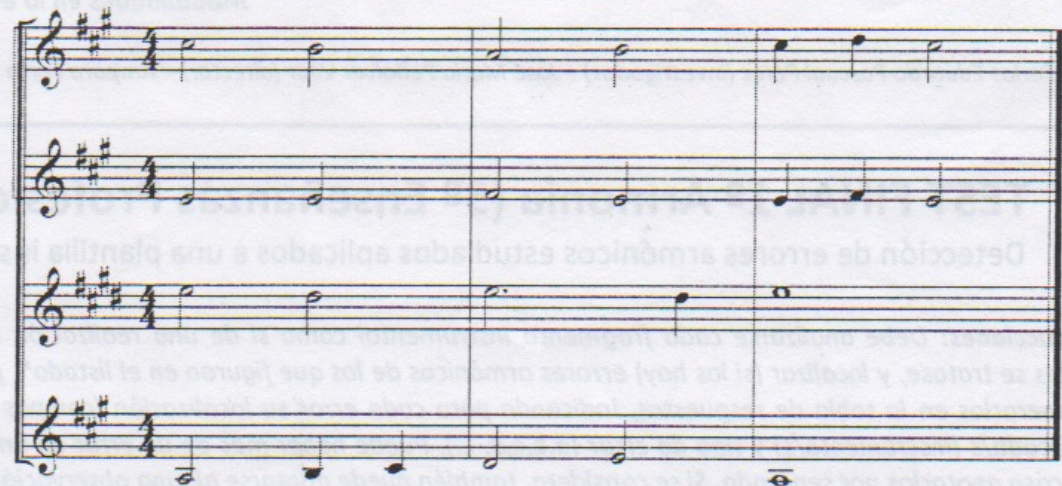

Clarinete Bajo

Clarinete en $\mathrm{B}$

Saxofón Alto

Marcar si no detectas ningún error: $\varnothing$

\begin{tabular}{|l|l|l|l|l|}
\hline Compás & Tiempo & Instrumento/s implicado/s & Tipo de error & Observaciones \\
\hline & & & & \\
\hline & & & & \\
\hline & & & & \\
\hline & & & & \\
\hline & & & & \\
\hline & & & & \\
\hline & & & & \\
\hline
\end{tabular}

Figura 86. Detalle del ejercicio 2 del postest del sujeto $\mathrm{N}^{\mathrm{o}} 11$.

El ejercicio 2 hallamos nuevamente un $0 \%$ de aciertos con dos respuestas incorrectas, al indicarse como ausente de fallos el ejercicio. Nuevamente no hallamos anotaciones al margen respecto a la escritura real de las transposiciones. Por último, en el ejercicio 3 encontramos un $0 \%$ de aciertos. 
Diseño y planificación de competencias específicas en el currículum de enseñanzas profesionales de música: modalidades composición-dirección en la enseñanza superior.

Carlos Eduardo Pascual Pérez

\section{EJERCICIO 3}

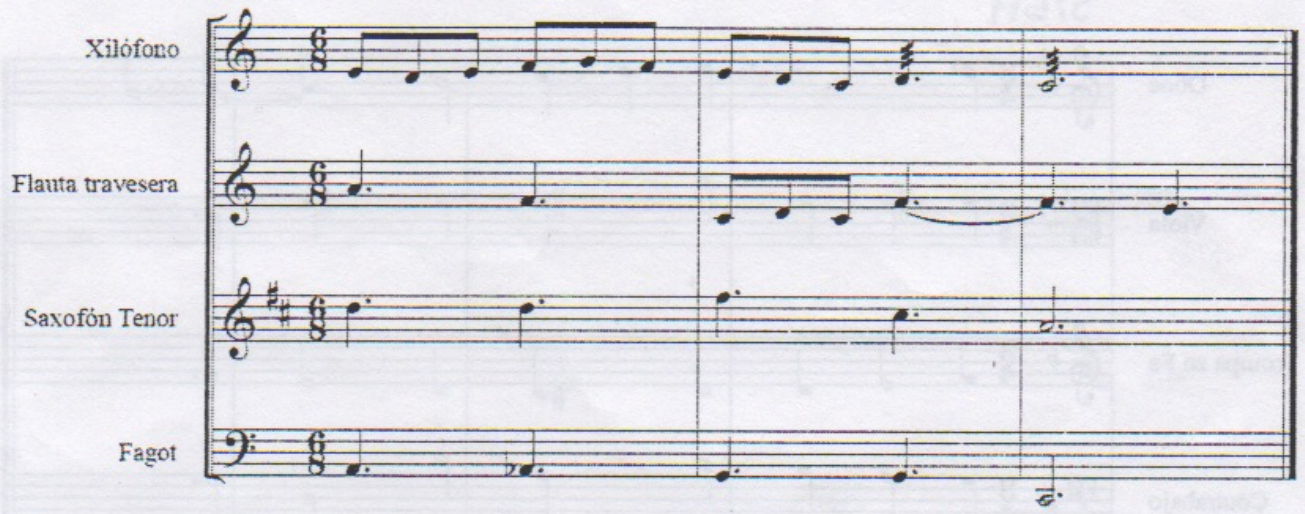

Marcar si no detectas ningún error:

\begin{tabular}{|c|c|c|c|c|}
\hline Compás & Tiempo & Instrumento/s implicado/s & Tipo de error & Observaciones \\
\hline 1 & 2 & & $b$ & \\
\hline 2 & 1 & & $c$ & \\
\hline & & & & \\
\hline & & & & \\
\hline & & & & \\
\hline & & & & \\
\hline & & & & \\
\hline & & & & \\
\hline
\end{tabular}

Figura 87. Detalle del ejercicio 3 del postest del sujeto $\mathrm{N}^{0} 11$.

A la vista de los resultados del postest podemos concluir que la competencia transversal de “Organología, instrumentación y orquestación en el ámbito de la orquesta sinfónica” está asumida parcialmente, y en un grado ciertamente bajo. No denotamos una mejoría significativa en el resultado de las variables. así como tampoco en la media aritmética de comparativa pretest-postest. Por último, observamos un grado error elevado en lo curricular 
Carlos Eduardo Pascual Pérez

de la asignatura de armonía, el cual consideramos determinante para no poder obtener un mejor resultado en la puntuación global del test.

\begin{tabular}{|c|c|c|c|c|c|c|c|c|c|c|c|c|c|}
\hline \multicolumn{10}{|c|}{ PRETEST } & \multicolumn{10}{c|}{ POSTEST } \\
\hline ONT & OT & LENT & LET & ANTT & $M V$ & ONT & OT & LENT & LET & ANTT & $M V$ & MG \\
\hline 0,00 & 0,00 & 3,80 & 0,00 & 0,0 & 0,75 & 2,00 & 0,00 & 5,00 & 0,00 & 0,00 & 1,40 & 1,00 \\
\hline
\end{tabular}

Tabla 21. Resumen puntuaciones de variables, medias y global para el sujeto $\mathrm{N}^{\mathrm{o}} 12$.

\subsubsection{Caso experimental $N^{o} 13$}

La valoración inicial del primer ejercicio del pretest nos sugiere una gran inexperiencia en la organología de los instrumentos sinfónicos del ámbito orquestal, con un $0 \%$ de aciertos completos. Únicamente hallamos un acierto parcial en el índice de afinación del saxofón tenor.

Respecto al segundo ejercicio de lecto-escritura y asociación entre instrumentos transpositores y no transpositores, podemos observar que no está resuelto el ejercicio, con únicamente unas anotaciones a tipo de boceto en el pentagrama de la trompa y del fagot. 
Diseño y planificación de competencias específicas en el currículum de enseñanzas profesionales de música: modalidades composición-dirección en la enseñanza superior.

Carlos Eduardo Pascual Pérez

1. Identifica la afinación y octavación de los siguientes instrumentos:

\begin{tabular}{|l|c|c|l|c|c|}
\hline Instrumento & Afinación & Octavación & Instrumento & Afinación & Octavación \\
\hline Oboe & SibM & +1 & Clarinete bajo & MibM & 0 \\
\hline Flautín & MibM & +2 & Saxofón alto & SibM & +2 \\
\hline Fagot & SibM & - & Saxofón tenor & SibM & +1 \\
\hline Contrabajo & Do M & -2 & Lira & MibM & 0 \\
\hline Trompa & MibM & - & Flauta alto & SibM & +2 \\
\hline
\end{tabular}

2. Realiza los siguientes acordes:

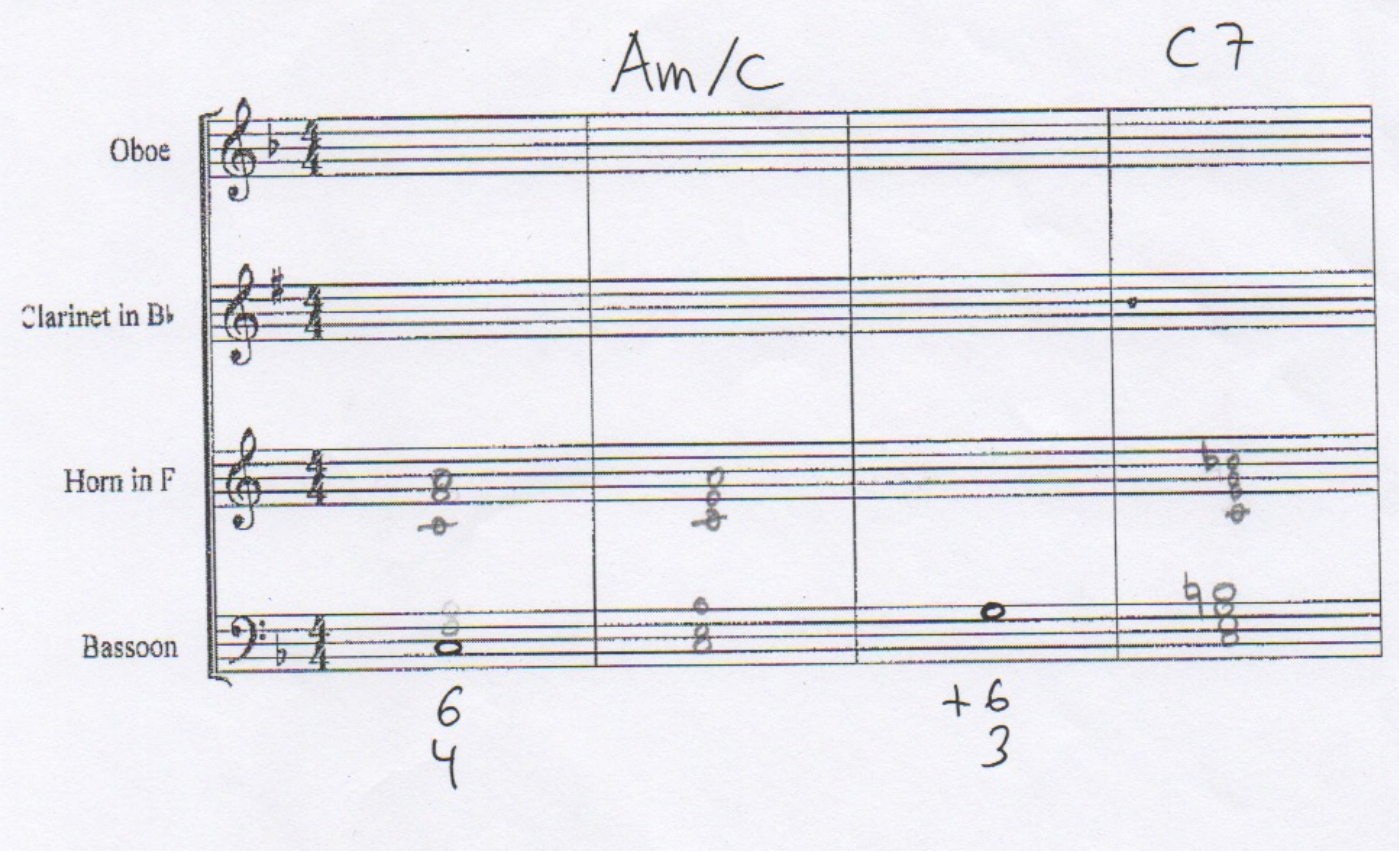

Figura 88. Pretest del caso experimental $\mathrm{N}^{\circ} 11$.

No tenemos respuesta del primer ejercicio dado que el sujeto no lo presentó por motivos personales. No obstante, asistió a la sesión de la intervención y se le entregó el ejercicio para su realización. Desconocemos si pudo realizar parte del mismo a pesar de no presentarlo. 
En el ejercicio de la segunda intervención observamos una mejora importante en el ámbito de la lecto-escritura y la organología, dado que cualquier mínimo acierto será significativo dados los precedentes de que disponemos. No obstante, hallamos cruce de voces entre el violín y la viola (compás 2) y entre el saxofón y el violín (compases 3, 4 y 5). No hallamos ninguna indicación al margen o anotación al respecto de la transposición de los instrumentos, pero podemos observar una correcta realización de la viola en su clave. 
Diseño y planificación de competencias específicas en el currículum de enseñanzas profesionales de música: modalidades composición-dirección en la enseñanza superior.

Carlos Eduardo Pascual Pérez

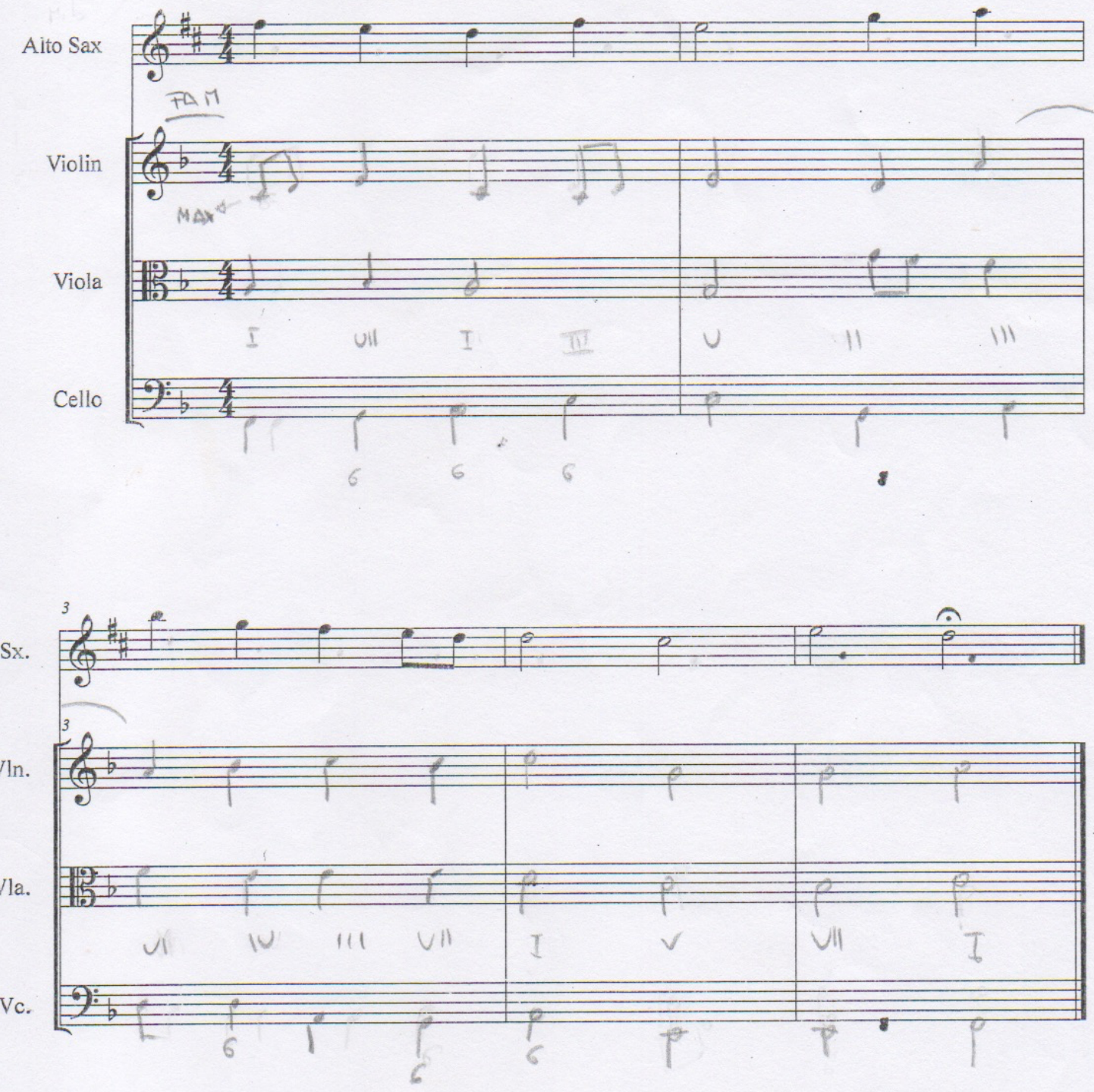

Figura 89. Detalle del ejercicio de la segunda intervención del sujeto $\mathrm{N}^{0} 13$.

No disponemos de resultados para el postest, dado que el sujeto abandonó la experiencia tras la segunda intervención y no se presentó a la realización de esta última prueba. No obstante, a la vista de los resultados de la intervención, podemos concluir que la competencia transversal "Organología, instrumentación y orquestación en el ámbito de la orquesta 
Diseño y planificación de competencias específicas en el currículum de enseñanzas profesionales de música: modalidades composición-dirección en la enseñanza superior.

sinfónica" está asumida parcialmente, pero en un mínimo grado dada la ausencia de respuesta en gran parte de nuestra intervención. Aunque no podemos cuantificar los resultados, denotamos una mejoría en la segunda experiencia respecto a la anterior y a su vez - y de forma muy significativa - respecto al pretest. Por último, observamos un grado error medio en lo curricular de la asignatura de armonía, el cual no podemos considerar determinante para no poder obtener un mejor resultado en la puntuación global del test al carecer de dichos resultados.

\begin{tabular}{|c|c|c|c|c|c|c|c|c|c|c|c|c|}
\multicolumn{10}{|c|}{ PRETEST } & \multicolumn{10}{c|}{ POSTEST } \\
\hline ONT & OT & LENT & LET & ANTT & $M V$ & ONT & OT & LENT & LET & ANTT & $M V$ & MG \\
\hline 0,00 & 0,00 & 2,50 & 0,00 & 0,00 & 0,50 & - & - & - & - & - & - & - \\
\hline
\end{tabular}

Tabla 22. Resumen puntuaciones de variables, medias y global para el sujeto $\mathrm{N}^{\mathrm{o}} 13$.

\subsubsection{Caso experimental $N^{o} 14$}

La valoración inicial del primer ejercicio del pretest nos sugiere una inexperiencia acerca de la organología de los instrumentos sinfónicos del ámbito orquestal, con menos de un $20 \%$ de aciertos completos y pocos aciertos parciales.

Respecto al segundo ejercicio de lecto-escritura y asociación entre instrumentos transpositores y no transpositores, podemos observar un error generalizado en todos los 
Diseño y planificación de competencias específicas en el currículum de enseñanzas profesionales de música: modalidades composición-dirección en la enseñanza superior.

Carlos Eduardo Pascual Pérez

instrumentos implicados referido a las transposiciones. También apreciamos ausencia de respuesta en el tercer acorde, por o que deducimos que no ha sabido interpretarse el cifrado para su realización.

1. Identifica la afinación y octavación de los siguientes instrumentos:

\begin{tabular}{|l|l|l|l|l|c|}
\hline Instrumento & \multicolumn{1}{|c|}{ Afinación } & Octavación & \multicolumn{1}{|c|}{ Instrumento } & Afinación & Octavación \\
\hline Oboe & Sib & & Clarinete bajo & Sib & $\$$ \\
\hline Flautín & Do & $\uparrow$ & Saxofón alto & Mib & \\
\hline Fagot & Mib & & Saxofón tenor & Sih & \\
\hline Contrabajo & Mib & $\downarrow$ & Lira & Fa & $\uparrow$ \\
\hline Trompa & Fa & & Flauta alto & $\uparrow$ & \\
\hline
\end{tabular}

2. Realiza los siguientes acordes:

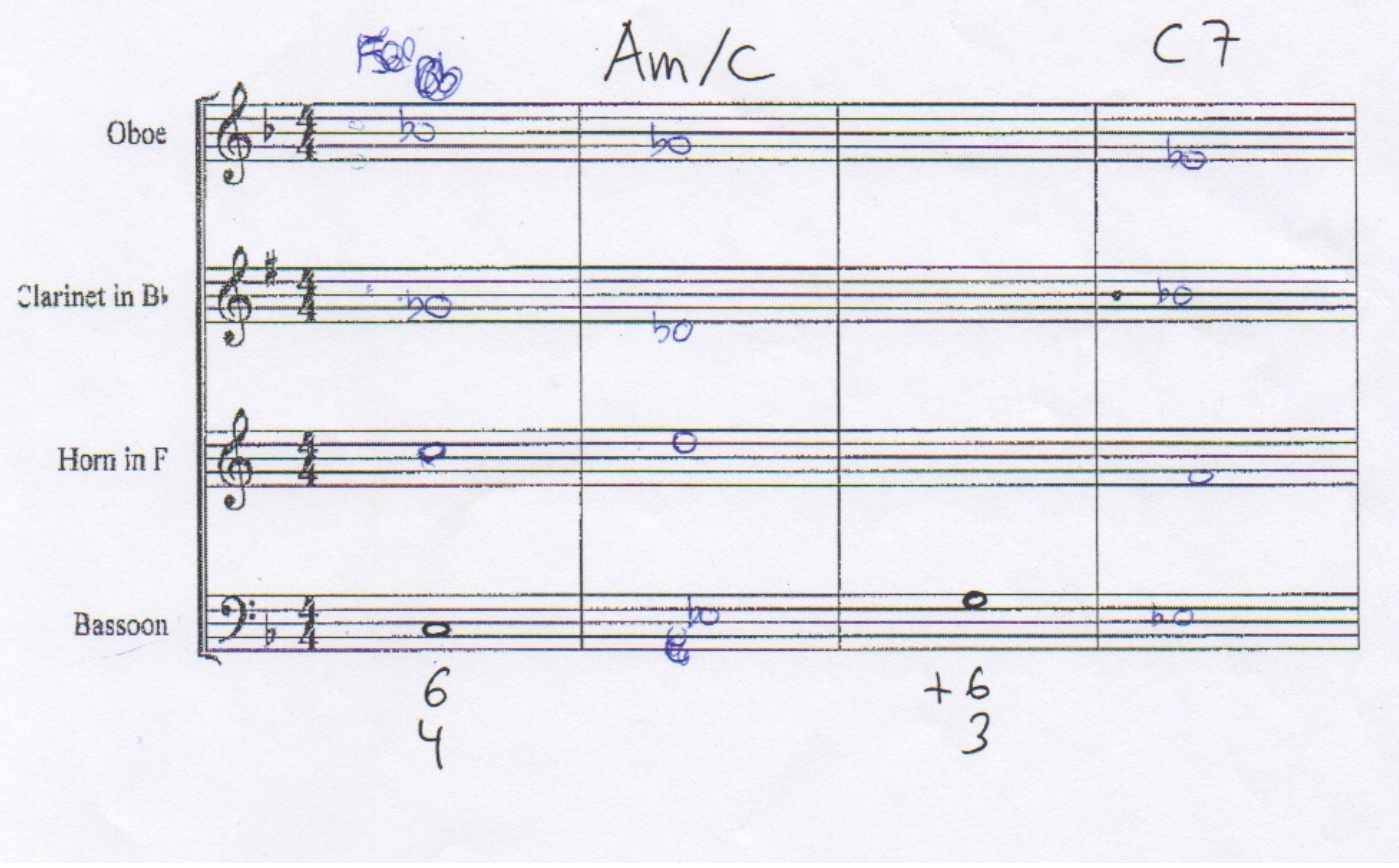

Figura 90. Pretest del caso experimental № 14. 
A la vista de los resultados creemos que existe una gran inexperiencia en todos los ámbitos referidos, tanto la organología como la lecto-escritura de instrumentos transpositores y no transpositores.

Tras la primera intervención y la entrega del primer ejercicio observamos una mejora significativa en el ámbito de la lecto-escritura, dado que desaparecen los errores en las transposiciones, pero encontramos un único error puntual de cruce de voces entre el oboe y el clarinete (compás 7). Tampoco se aprecian errores conceptuales propios en lo curricular de la asignatura de armonía. 
Diseño y planificación de competencias específicas en el currículum de enseñanzas profesionales de música: modalidades composición-dirección en la enseñanza superior.

Carlos Eduardo Pascual Pérez

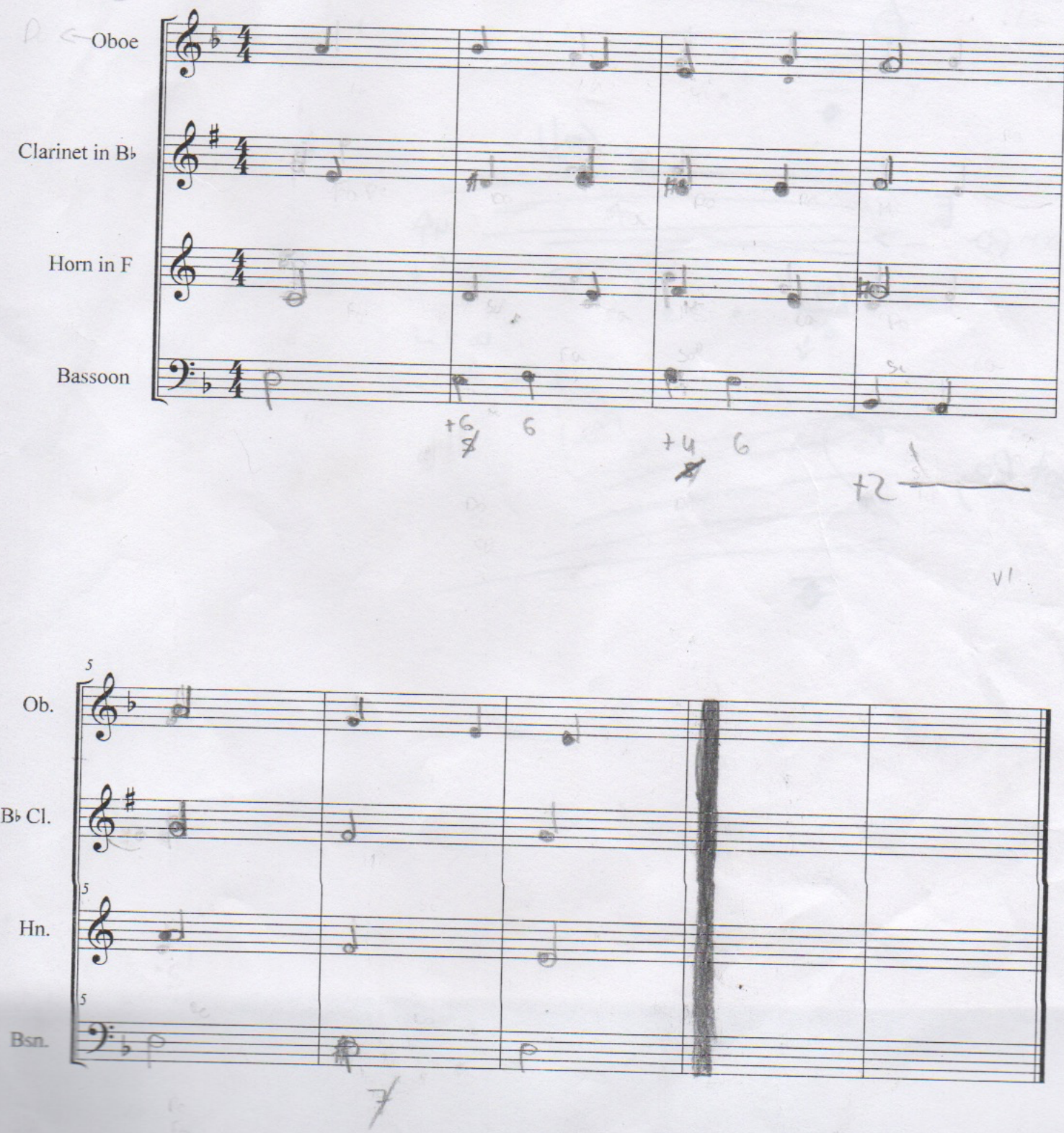

Figura 91. Detalle del ejercicio de la primera intervención del sujeto № 14 . 
En el ejercicio de la segunda intervención hallamos la misma línea de habilidad completa que se obtuvo en el primer ejercicio respecto a la organología y la lecto-escritura. Además, ya no hallamos ningún cruce de voces entre los instrumentos implicados. Encontramos una escritura correcta del uso de la clave de Do en la viola y una anotación leve de la primera nota real escrita en el saxofón alto a modo de ayuda. 
Diseño y planificación de competencias específicas en el currículum de enseñanzas profesionales de música: modalidades composición-dirección en la enseñanza superior.

Carlos Eduardo Pascual Pérez

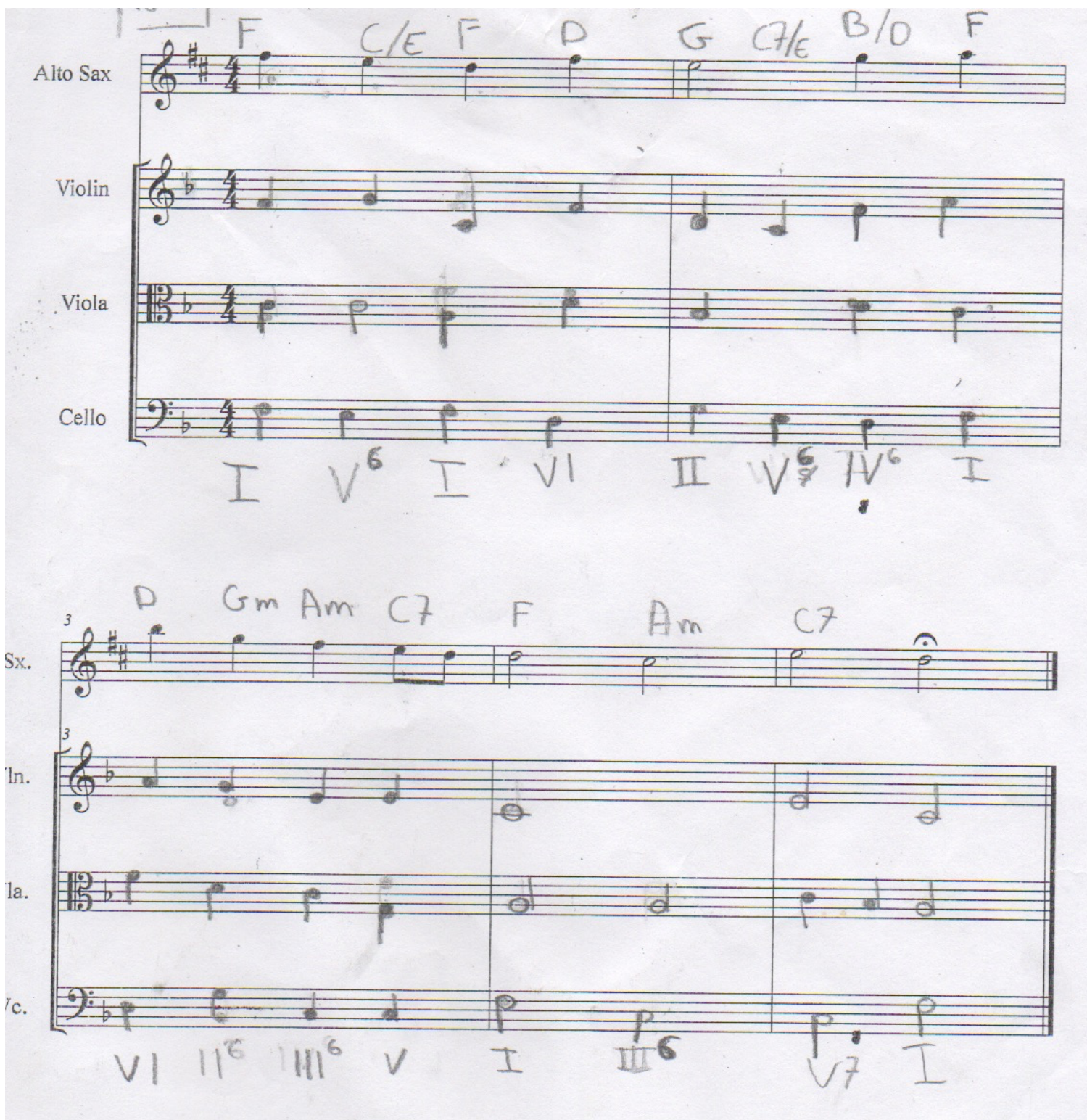

Figura 92. Detalle del ejercicio de la segunda intervención del sujeto $\mathrm{N}^{\mathrm{o}} 14$. 
Diseño y planificación de competencias específicas en el currículum de enseñanzas profesionales de música: modalidades composición-dirección en la enseñanza superior.

Carlos Eduardo Pascual Pérez

No obstante, detectamos errores propiamente curriculares - no significantes en la competencia transversal desarrollada - como la escritura errónea del acorde de $7^{\mathrm{a}}$ de dominante (compás 3).

En la evaluación final a través del postest observamos un alto grado de acierto a nivel de organología tanto de instrumentos transpositores como no transpositores, así como de lectoescritura en instrumentos no transpositores. No hallamos anotaciones al margen sobre la transposición u octavación de los instrumentos, pero por su resolución entendemos que están interiorizadas. Queda patente el alto grado de asimilación de los instrumentos trabajados a nivel práctico en la intervención, así como de los instrumentos únicamente revisados a nivel teórico. 
Diseño y planificación de competencias específicas en el currículum de enseñanzas profesionales de música: modalidades composición-dirección en la enseñanza superior.

Carlos Eduardo Pascual Pérez

\section{EJERCICIO 1}

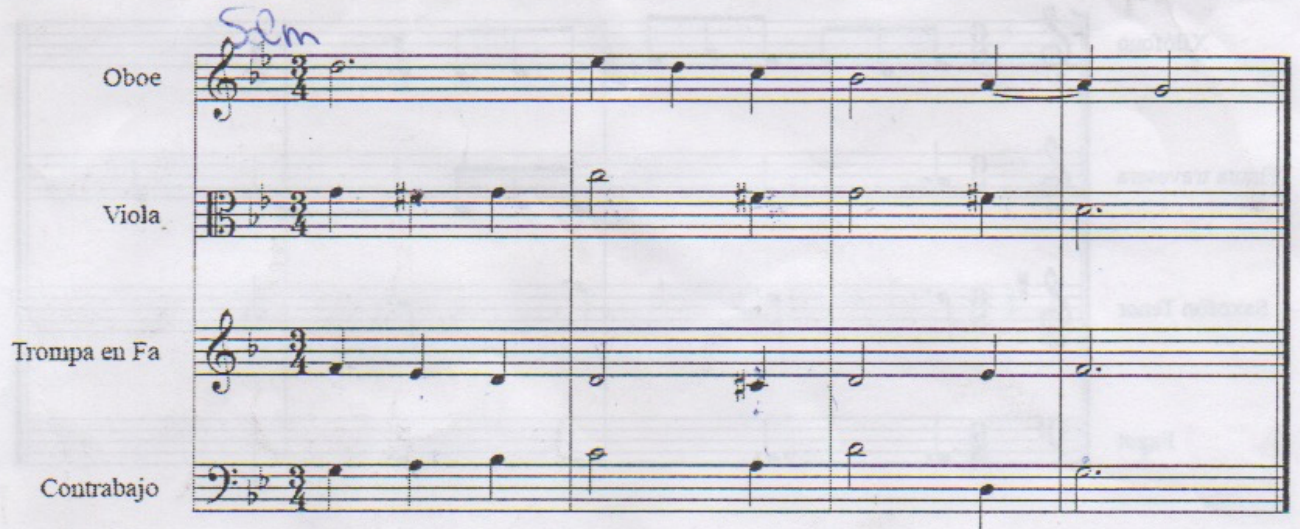

Marcar si no detectas ningún error:

\begin{tabular}{|c|c|c|c|c|}
\hline Compás & Tiempo & Instrumento/s implicado/s & Tipo de error & Observaciones \\
\hline 2 & 1 & Tromna en Fa vich & 7 & \\
\hline & 3 & Arompect & है & \\
\hline 3 & 1 & Trompa, ore & a & \\
\hline 1 & 2 & Voln & i & \\
\hline 42 & 3 & Viola & j & \\
\hline & & & & \\
\hline & & & & \\
\hline & & & & \\
\hline
\end{tabular}

Figura 93. Detalle del ejercicio 1 del postest del sujeto $\mathrm{N}^{\circ} 14$.

Respecto a la resolución del test (detección de errores armónicos) hallamos el 100\% de aciertos para el ejercicio 1, acompañado de dos respuestas incorrectas, las cuales se desprende de incorrecciones propiamente armónicas - que no implican el uso de la competencia transversal - . 
Diseño y planificación de competencias específicas en el currículum de enseñanzas profesionales de música: modalidades composición-dirección en la enseñanza superior.

Carlos Eduardo Pascual Pérez

\section{EJERCICIO 2}

Clarinete en B;

Clarinete en

Clarinete en B

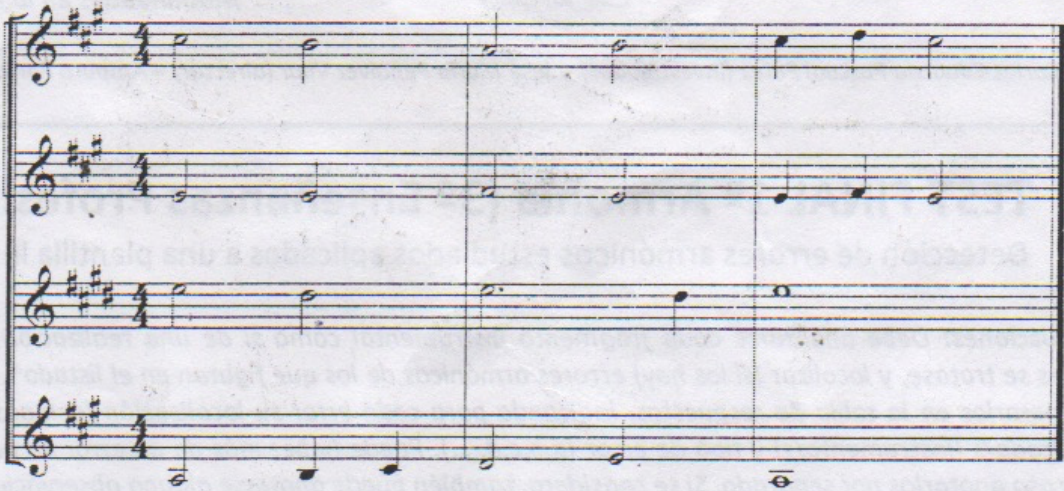

Clarinete Bajo

Marcar si no detectas ningún error:

\begin{tabular}{|c|c|c|c|c|}
\hline Compás & Tiempo & Instrumento/s implicado/s & Tipo de error & Observaciones \\
\hline 1 & 1 & Q Qarinedc/Soxo & $e$ & \\
\hline 2 & 3 & Qarinete/Soxo & $e$ & \\
\hline 1 & 2 & Qarinete bajo & $j$ & \\
\hline & & & & \\
\hline & & & & \\
\hline & & & & \\
\hline & & & & \\
\hline & & & & \\
\hline
\end{tabular}

Figura 94. Detalle del ejercicio 2 del postest del sujeto $\mathrm{N}^{0} 14$.

El ejercicio 2 hallamos nuevamente un 33\% de aciertos, con dos respuestas incorrectas. Por último, en el ejercicio 3 encontramos un $40 \%$ de aciertos sin otras respuestas incorrectas. 
Diseño y planificación de competencias específicas en el currículum de enseñanzas profesionales de música: modalidades composición-dirección en la enseñanza superior.

Carlos Eduardo Pascual Pérez

\section{EJERCICIO 3}

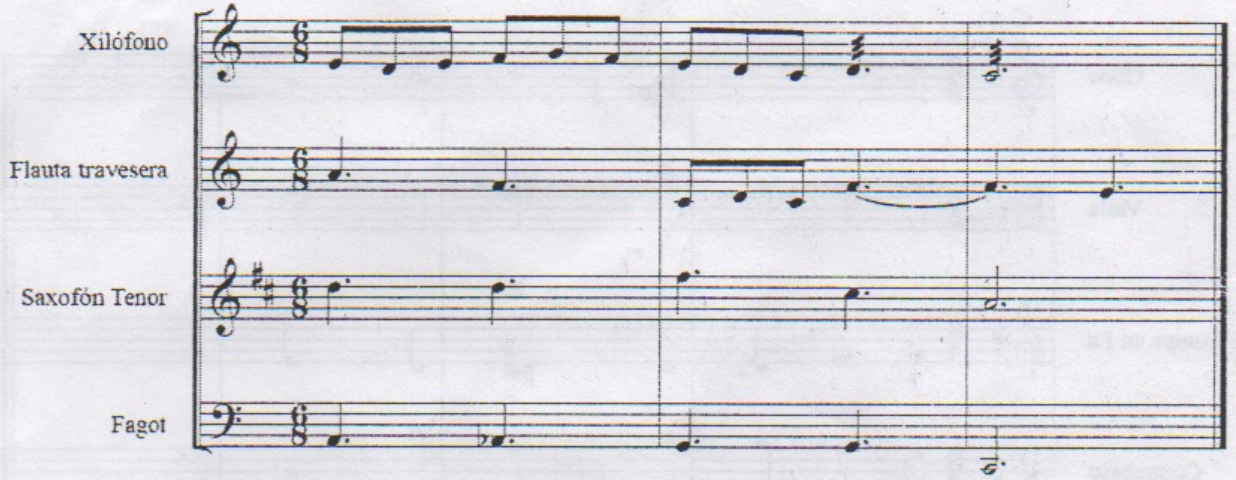

Marcar si no detectas ningún error:

\begin{tabular}{|c|c|c|c|c|}
\hline Compás & Timmo & Instrumento/simplicado/s & Tipo de error & Observociones \\
\cline { 3 - 5 } & 4 & Jlauta, Xildono & 8 & \\
\hline 3 & 1 & Savo, lagot & $a$ & \\
\hline & & & & \\
\hline & & & & \\
\hline & & & & \\
\hline & & & & \\
\hline & & & \\
\hline
\end{tabular}

Figura 95. Detalle del ejercicio 3 del postest del sujeto $\mathrm{N}^{\mathrm{o}} 14$.

A la vista de los resultados del postest podemos concluir que la competencia transversal de "Organología, instrumentación y orquestación en el ámbito de la orquesta sinfónica” está asumida en un muy alto grado. Denotamos una mejoría muy notable en todas las variables sin excepción, así como en la media aritmética de comparativa pretest-postest. Por último, observamos un grado error mínimo en lo curricular de la asignatura de armonía, el cual no 
Carlos Eduardo Pascual Pérez

consideramos determinante para no poder obtener un mejor resultado en la puntuación global del test.

\begin{tabular}{|c|c|c|c|c|c|c|c|c|c|c|c|c|}
\multicolumn{10}{|c|}{ PRETEST } \\
\hline ONT & OT & LENT & LET & ANTT & $M V$ & ONT & OT & LENT & LET & ANTT & $M V$ & MG \\
\hline 2,00 & 2,00 & 0,00 & 0,00 & 0,00 & 0,80 & 6,00 & 4,00 & 5,00 & 5,00 & 6,67 & 5,33 & $\mathbf{5 , 0 0}$ \\
\hline
\end{tabular}

Tabla 23. Resumen puntuaciones de variables, medias y global para el sujeto $\mathrm{N}^{\circ} 14$.

\subsubsection{Caso experimental $N^{o} 15$}

La valoración inicial del primer ejercicio del pretest nos sugiere una cierta experiencia en la organología de los instrumentos sinfónicos del ámbito orquestal, con un 30\% de aciertos completos y algunos aciertos parcialmente aceptados.

Respecto al segundo ejercicio de lecto-escritura y asociación entre instrumentos transpositores y no transpositores, podemos observar que no está resuelto el ejercicio, con únicamente unas anotaciones de las transposiciones al inicio de los pentagramas. 
Diseño y planificación de competencias específicas en el currículum de enseñanzas profesionales de música: modalidades composición-dirección en la enseñanza superior.

Carlos Eduardo Pascual Pérez

1. Identifica la afinación y octavación de los siguientes instrumentos:

\begin{tabular}{|c|c|c|c|c|c|}
\hline Instrumento & Afinación & Octavación & Instrumento & Afinación & Octavación \\
\hline Oboe & Do of & & Clarinete bajo & $M_{i b}$ & unc $8^{\prime}$ nov abije \\
\hline Flautín & Do & Una $8^{\circ}$ arriba & Saxofón alto & Me & I \\
\hline Fagot & Fa & 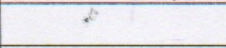 & Saxofón tenor & sib & Wha ga por chay \\
\hline Contrabajo & Do $\quad H$ & $18^{a}$ per abajo & Lira & RuM & Unc $8^{h}$ crriva \\
\hline Trompa & & & Flauta alto & $D_{0} M$ & \\
\hline
\end{tabular}

2. Realiza los siguientes acordes:

$$
\begin{array}{ll}
\mathrm{Lam} / D_{0} & \mathrm{~b}_{0}{ }^{7} \\
\mathrm{Am} / \mathrm{C} & C 7
\end{array}
$$<smiles>C1CCCC1</smiles>

Clarinet in Bb

Sils

Horn in F

Fa

Bassoon

fagot

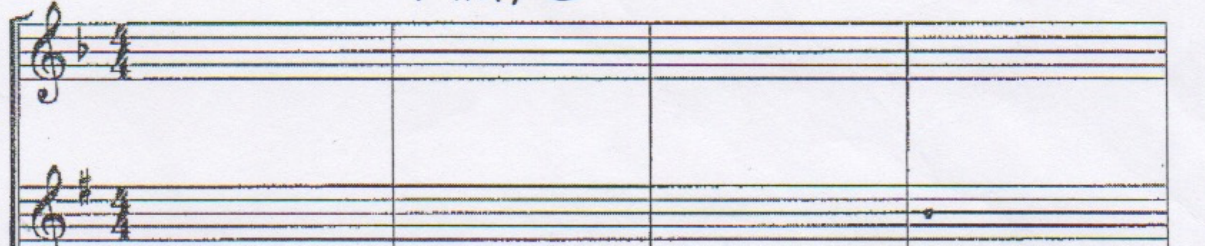

$$
\text { ह }
$$

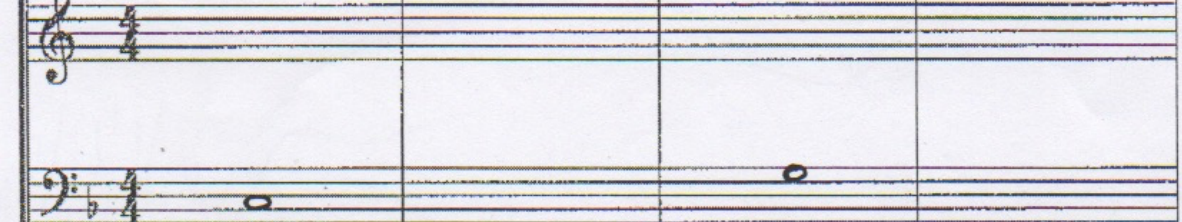

6
4

$+6$

3

Figura 96. Pretest del caso experimental No 15. 
Diseño y planificación de competencias específicas en el currículum de enseñanzas profesionales de música: modalidades composición-dirección en la enseñanza superior.

Carlos Eduardo Pascual Pérez

A la vista de los resultados sugerimos la inexperiencia citada como determinante para la resolución de ambos ejercicios, estableciendo un nivel bajo de conocimientos iniciales.

Tras la primera intervención y la entrega del primer ejercicio observamos una mejora importante en el ámbito de la lecto-escritura y la organología. No detectamos cruces entre voces, dato que sorprende puesto que suele ser un error habitual al relacionar instrumentos transpositores. No obstante, hallamos todo el transporte de la trompa mal efectuado. También se evidencian errores conceptuales propios en lo curricular de la asignatura de armonía, no siendo estos aplicables al desarrollo de nuestra competencia transversal, como alteraciones erróneas (oboe, compás 2). 
Diseño y planificación de competencias específicas en el currículum de enseñanzas profesionales de música: modalidades composición-dirección en la enseñanza superior.

Carlos Eduardo Pascual Pérez

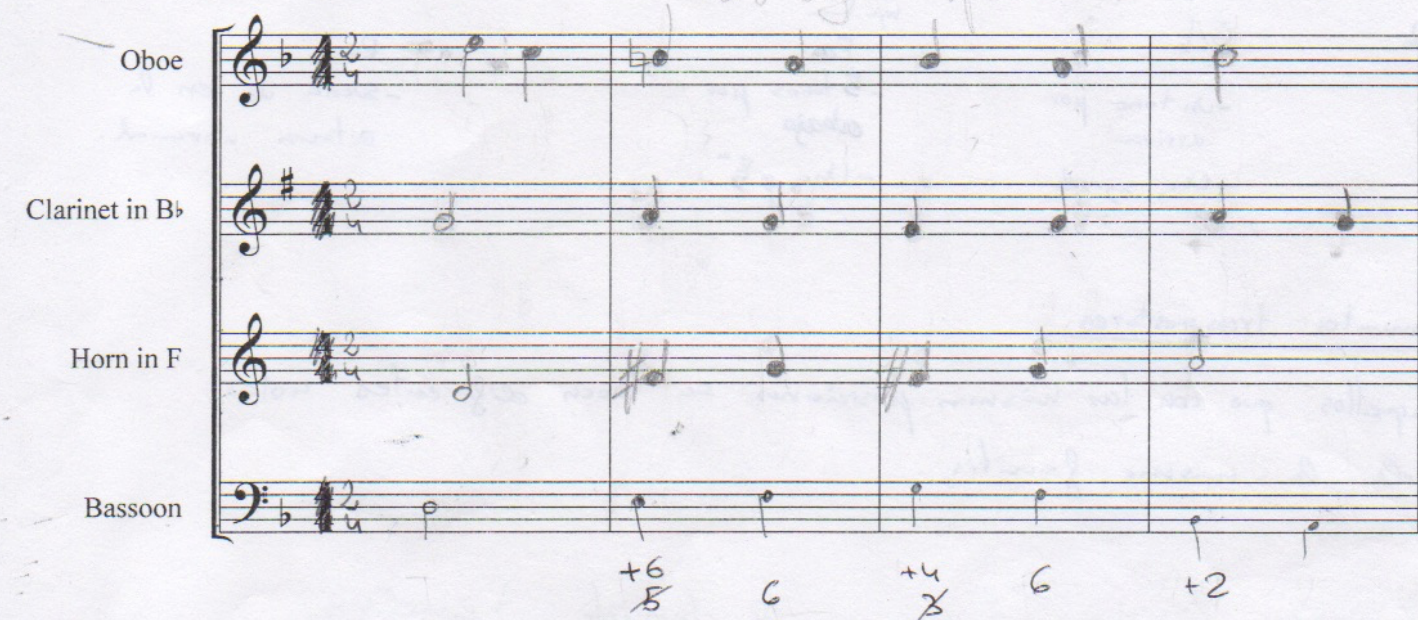

$\mathrm{Ob}$

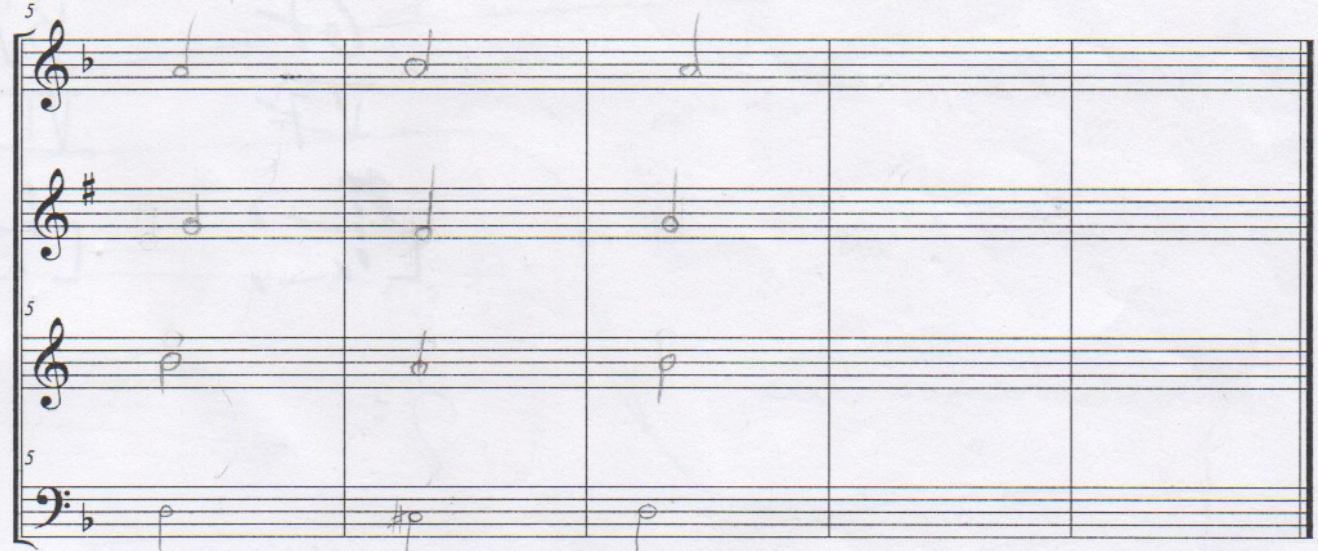

7

Figura 97. Detalle del ejercicio de la primera intervención del sujeto $\mathrm{N}^{\circ} 15$. 


\section{Carlos Eduardo Pascual Pérez}

En el ejercicio de la segunda intervención no hallamos una mejora significativa en cuanto a la organología y la lecto-escritura, dado que detectamos por primera vez errores de cruce de voces (violoncello y viola, compases 3 y 4) o el unísono inicial y mal resuelto del saxofón con el violín (compás 1). No hallamos anotaciones de las tonalidades o transposiciones de los instrumentos, pero sí una referida a la lectura por sustitución de clave del saxofón (instrumento transpositor). 
Diseño y planificación de competencias específicas en el currículum de enseñanzas profesionales de música:

modalidades composición-dirección en la enseñanza superior.

\section{Carlos Eduardo Pascual Pérez}

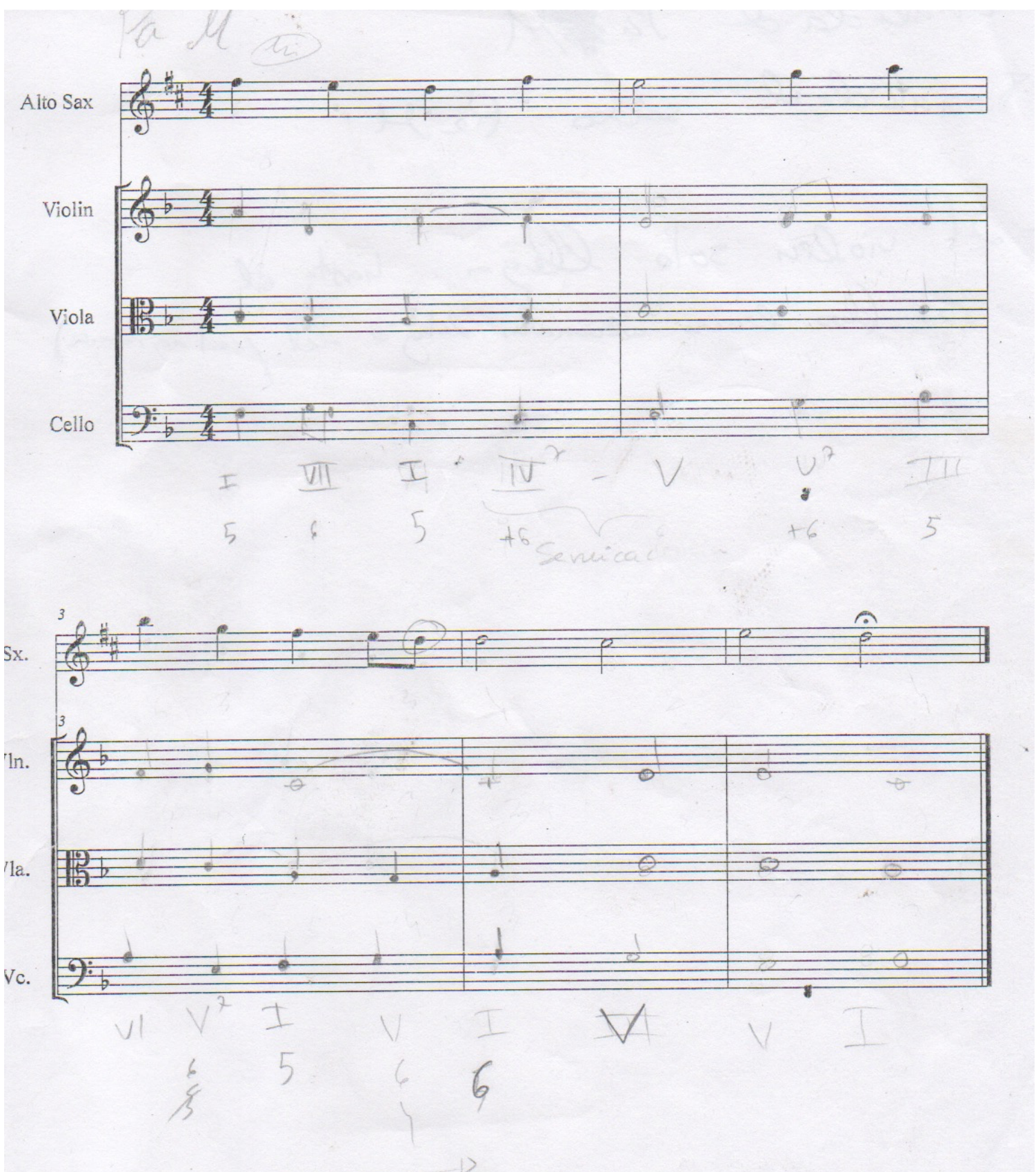

Figura 98. Detalle del ejercicio de la segunda intervención del sujeto $\mathrm{N}^{\circ} 15$. 
Diseño y planificación de competencias específicas en el currículum de enseñanzas profesionales de música: modalidades composición-dirección en la enseñanza superior.

Carlos Eduardo Pascual Pérez

Encontramos también errores en lo propiamente curricular de la asignatura, como la resolución incorrecta del acorde de $7^{\mathrm{a}}$ de dominante o la duplicación de la sensible.

En la evaluación final a través del postest observamos un grado de acierto medio a nivel de organología tanto de instrumentos transpositores como no transpositores, así como de lectoescritura en instrumentos no transpositores. Hallamos anotaciones al margen sobre la transposición u octavación de los instrumentos, y por su resolución entendemos que las mismas están interiorizadas.
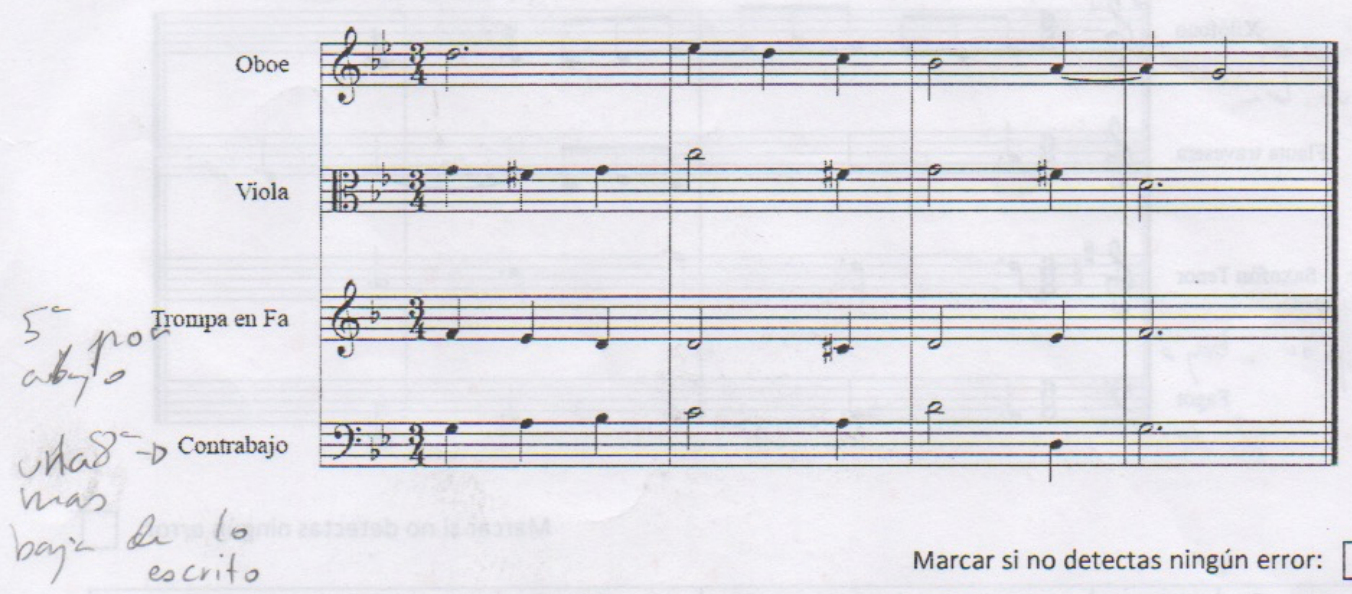

Marcar si no detectas ningún error:

\begin{tabular}{|c|c|c|c|c|}
\hline Compás & Tiempo & Instrumento/s implicado/s & Tipo de error & Observaciones \\
\hline z & 1 & wola & 8 & \\
\hline 2 & 1 & Trompa & 8 & \\
\hline 2 & 3 & Uiok $/$ trompa & 9 & \\
\hline & & & 0 & \\
\hline & & & & \\
\hline & & & & \\
\hline & & & & \\
\hline & & & & \\
\hline
\end{tabular}


Diseño y planificación de competencias específicas en el currículum de enseñanzas profesionales de música: modalidades composición-dirección en la enseñanza superior.

Carlos Eduardo Pascual Pérez

Figura 99. Detalle del ejercicio 1 del postest del sujeto $\mathrm{N}^{\mathrm{o}} 15$.

Respecto a la resolución del test (detección de errores armónicos) hallamos un $100 \%$ de aciertos para el ejercicio 1, acompañado de una respuesta incorrecta, la cual se desprende del uso de la competencia transversal aplicado al cruce de voces.

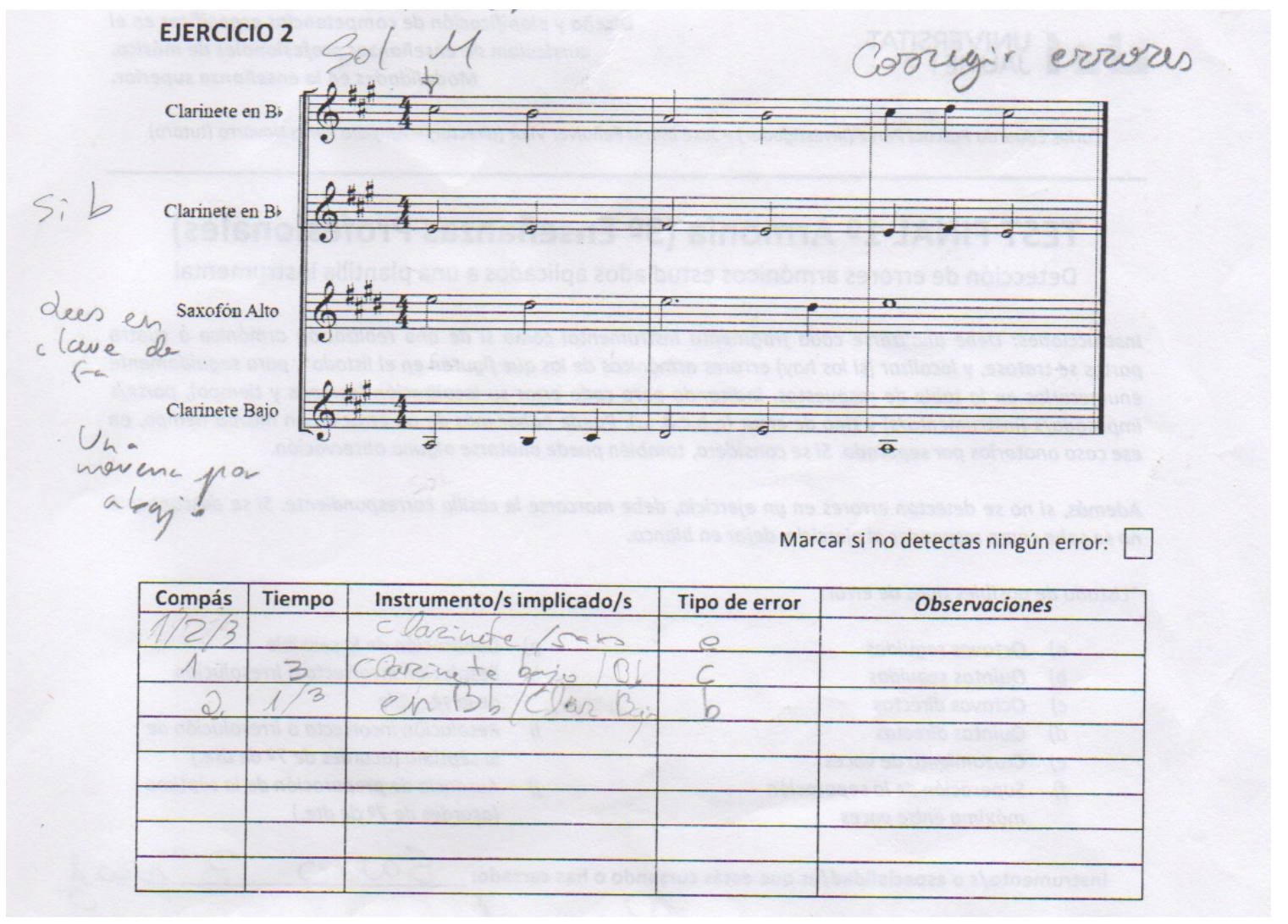

Figura 100. Detalle del ejercicio 2 del postest del sujeto $\mathrm{N}^{\circ} 15$. 
Diseño y planificación de competencias específicas en el currículum de enseñanzas profesionales de música: modalidades composición-dirección en la enseñanza superior.

Carlos Eduardo Pascual Pérez

El ejercicio 2 hallamos un $66 \%$ de aciertos con una respuesta incorrecta. Nuevamente hallamos anotaciones al margen respecto a la lectura por sustitución de clave y las octavaciones y transposiciones de los instrumentos implicados. Por último, en el ejercicio 3 encontramos un $20 \%$ de aciertos acompañado de otra respuesta incorrecta.

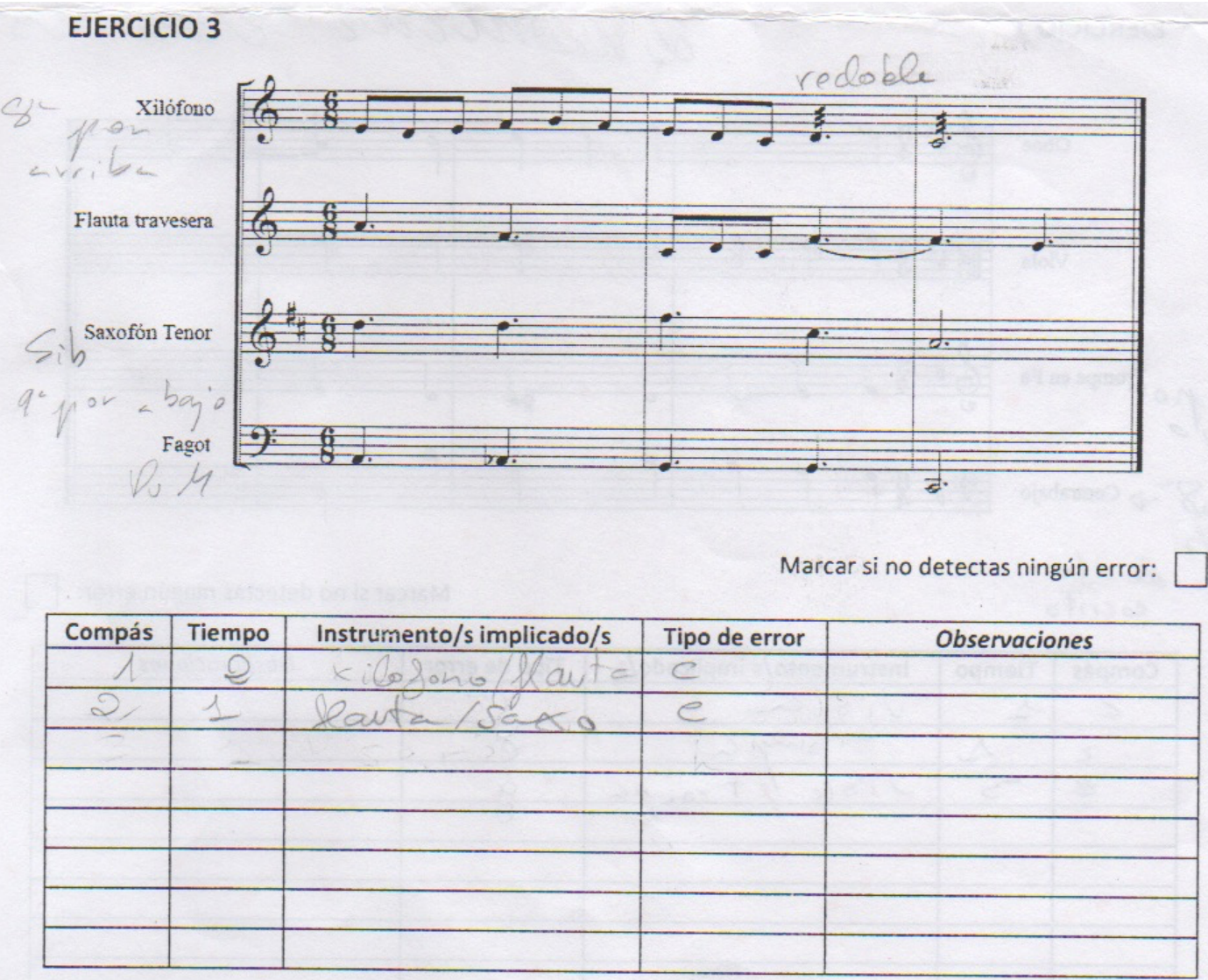

Figura 101. Detalle del ejercicio 3 del postest del sujeto $\mathrm{N}^{\mathrm{o}} 15$. 


\section{Carlos Eduardo Pascual Pérez}

A la vista de los resultados del postest podemos concluir que la competencia transversal de “Organología, instrumentación y orquestación en el ámbito de la orquesta sinfónica” está asumida en un muy alto grado. Denotamos una mejoría muy notable en todas las variables sin excepción, así como en la media aritmética de comparativa pretest-postest. Por último, observamos un grado error mínimo en lo curricular de la asignatura de armonía, el cual no consideramos determinante para no poder obtener un mejor resultado en la puntuación global del test.

\begin{tabular}{|c|c|c|c|c|c|c|c|c|c|c|c|c|}
\multicolumn{10}{|c|}{ PRETEST } & \multicolumn{10}{c|}{ POSTEST } \\
\hline ONT & OT & LENT & LET & ANTT & $M V$ & ONT & OT & LENT & LET & ANTT & $M V$ & MG \\
\hline 6,00 & 2,00 & 0,00 & 0,00 & 0,00 & 1,60 & 10,00 & 10,00 & 5,00 & 5,00 & 6,67 & 7,33 & $\mathbf{5 , 0 0}$ \\
\hline
\end{tabular}

Tabla 24. Resumen puntuaciones de variables, medias y global para el sujeto $\mathrm{N}^{\circ} 15$.

\subsubsection{Caso experimental $N^{o} 16$}

La valoración inicial del primer ejercicio del pretest nos sugiere una notable experiencia en la organología de los instrumentos sinfónicos del ámbito orquestal, con un $60 \%$ de aciertos completos y algunos aciertos parcialmente aceptados. 
Diseño y planificación de competencias específicas en el currículum de enseñanzas profesionales de música: modalidades composición-dirección en la enseñanza superior.

Carlos Eduardo Pascual Pérez

Respecto al segundo ejercicio de lecto-escritura y asociación entre instrumentos transpositores y no transpositores, podemos observar que no está resuelto el ejercicio, con únicamente una nota escrita en el pentagrama del fagot.

1. Identifica la afinación y octavación de los siguientes instrumentos:

\begin{tabular}{|c|c|c|c|c|c|}
\hline Instrumento & Afinación & Octavación & Instrumento & Afinación & Octavación \\
\hline Oboe & DOM & Octavanormal & Clarinete bajo & SibM & octavab \\
\hline Flautín & FM & una $8^{\circ} \uparrow$ & Saxofón alto & Mi bM & Octava \\
\hline Fagot & DOM & una. $8^{\circ} \downarrow$ & Saxofón tenor & SibM & octava $\downarrow$ \\
\hline Contrabajo & DOM & $\theta$ dos $8^{2} \downarrow$ & Lira & DOM & $18^{a} 1$ \\
\hline Trompa & FaM & $8^{\circ}$ normal & Flauta alto & DOM & octav a nound \\
\hline
\end{tabular}

2. Realiza los siguientes acordes:

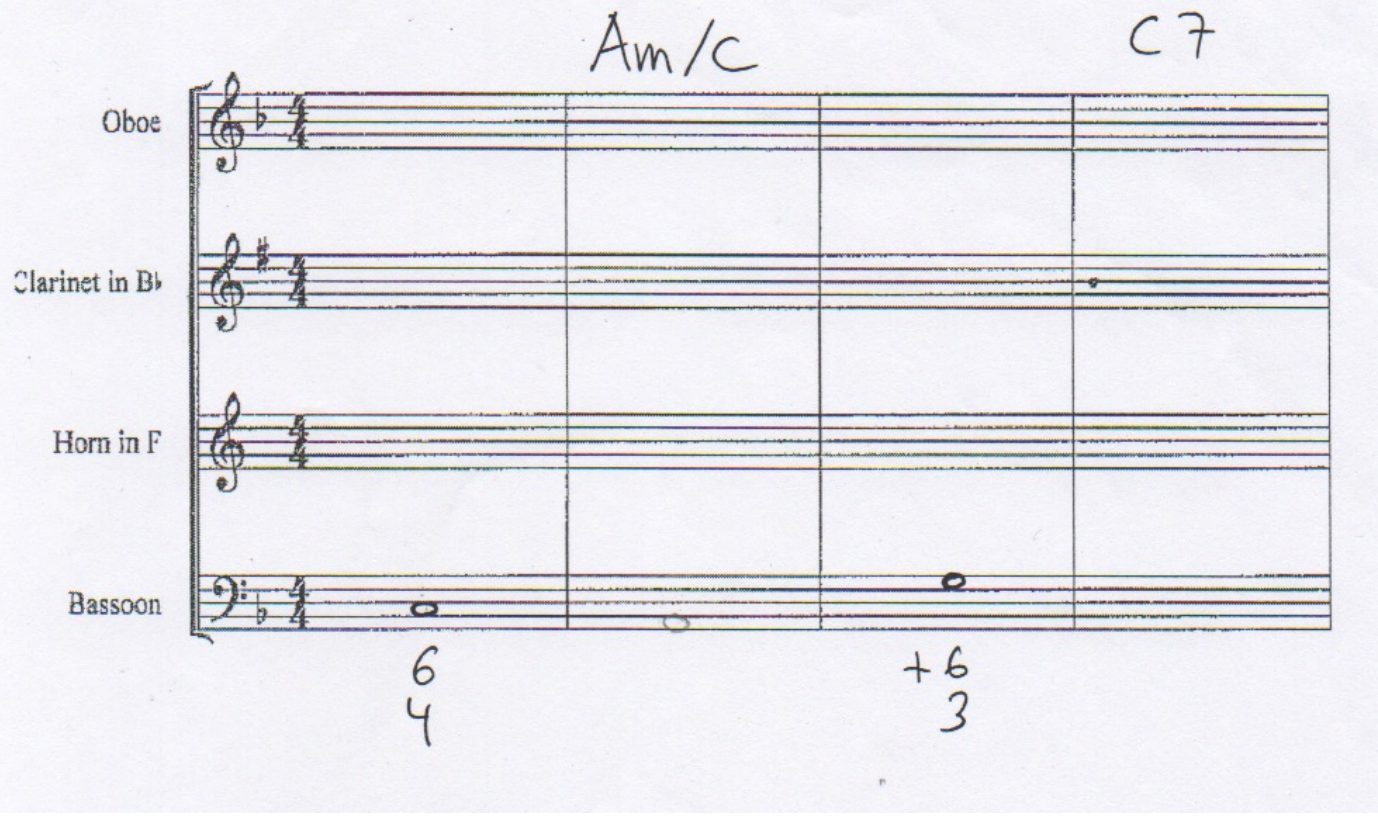

Figura 102. Pretest del caso experimental $\mathrm{N}^{\circ} 16$. 
Carlos Eduardo Pascual Pérez

A la vista de los resultados sugerimos una cierta experiencia a nivel teórico pero que no se ha visto aplicada en lo práctico, siendo determinante para la resolución del segundo ejercicio.

No disponemos de ninguna de las intervenciones ni del postest, dado que el sujeto abandonó la experiencia tras la el pretest. No obstante, a la vista de los resultados de la del mismo, podemos concluir que la competencia transversal "Organología, instrumentación y orquestación en el ámbito de la orquesta sinfónica” no está asumida.

\begin{tabular}{|c|c|c|c|c|c|c|c|c|c|c|c|c|}
\hline \multicolumn{10}{|c|}{ PRETEST } & \multicolumn{10}{c|}{ POSTEST } \\
\hline ONT & OT & LENT & LET & ANTT & $M V$ & ONT & OT & LENT & LET & ANTT & $M V$ & MG \\
\hline 6,00 & 6,00 & 0,00 & 0,00 & 0,00 & 2,40 & - & - & - & - & - & - & - \\
\hline
\end{tabular}

Tabla 25. Resumen puntuaciones de variables, medias y global para el sujeto $\mathrm{N}^{\mathrm{o}} 16$.

\subsubsection{Caso experimental $N^{o} 17$}


Diseño y planificación de competencias específicas en el currículum de enseñanzas profesionales de música: modalidades composición-dirección en la enseñanza superior.

Carlos Eduardo Pascual Pérez

La valoración inicial del primer ejercicio del pretest nos sugiere una cierta experiencia en la organología de los instrumentos sinfónicos del ámbito orquestal, con un $40 \%$ de aciertos completos y bastantes aciertos parcialmente aceptados.

Respecto al segundo ejercicio de lecto-escritura y asociación entre instrumentos transpositores y no transpositores, podemos observar que no está resuelto el ejercicio en su mayoría, con únicamente realizado el primer acorde, que además tiene incorrección en la parte de trompa. 
Diseño y planificación de competencias específicas en el currículum de enseñanzas profesionales de música: modalidades composición-dirección en la enseñanza superior.

Carlos Eduardo Pascual Pérez

1. Identifica la afinación y octavación de los siguientes instrumentos:

\begin{tabular}{|c|c|c|c|c|c|}
\hline Instrumento & Afinación & Octavación & Instrumento & Afinación & Octavación \\
\hline Oboe & DO M & & Clarinete bajo & si $b(4$ & octava t \\
\hline Flautín & DO M & octava & Saxofón alto & Mi b M & \\
\hline Fagot & DOM & & Saxofón tenor & Si bM & octava I \\
\hline Contrabajo & $D C M$ & 2 actaulas I & Lira & Do M & 6 octava \\
\hline Trompa & 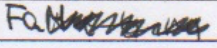 & & Flauta alto & DO M & \\
\hline
\end{tabular}

2. Realiza los siguientes acordes:

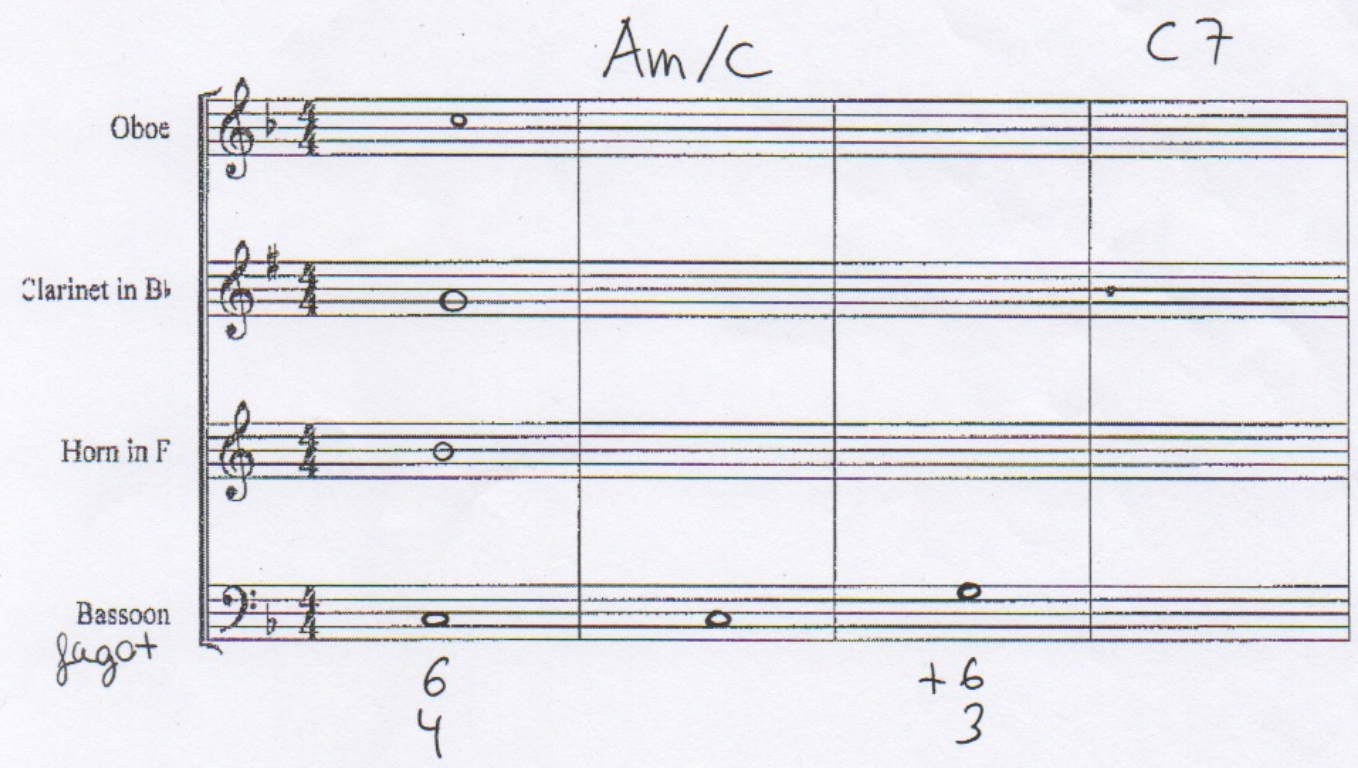

Figura 103. Pretest del caso experimental $\mathrm{N}^{\circ} 17$. 
No tenemos respuesta del primer ejercicio dado que el sujeto no lo presentó por motivos personales. No obstante, asistió a la sesión de la intervención y se le entregó el ejercicio para su realización. Desconocemos si pudo realizar parte del mismo a pesar de no presentarlo.

En el ejercicio de la segunda intervención observamos una mejora importante en el ámbito de la lecto-escritura y la organología, dado que cualquier mínimo acierto será significativo dados los precedentes de que disponemos. No obstante, hallamos cruce de voces entre el violín y el saxofón durante todo el ejercicio. No obstante, hallamos una indicación correcta de transposición en el saxofón, e incluso otra anotación expresa como recordatorio de evitar el cruce de voces entre ambos instrumentos. Encontramos también incorrecciones propiamente armónicas, como quintas seguidas entre la viola y el violoncello (compás 4) o entre la viola y el violón (compás 5). 
Diseño y planificación de competencias específicas en el currículum de enseñanzas profesionales de música: modalidades composición-dirección en la enseñanza superior.

Carlos Eduardo Pascual Pérez

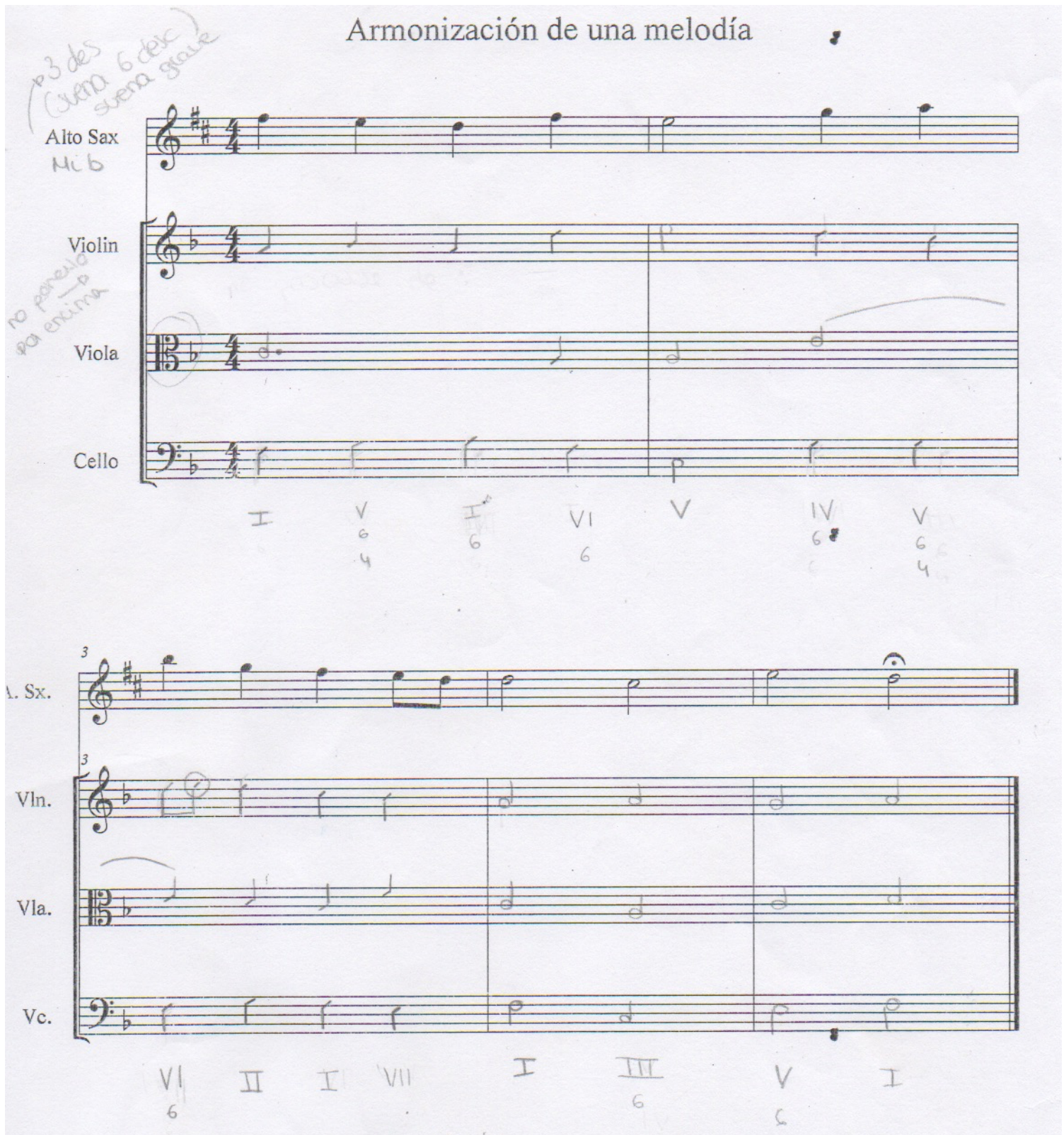

Figura 104. Detalle del ejercicio de la segunda intervención del sujeto $\mathrm{N}^{\circ} 17$. 
Diseño y planificación de competencias específicas en el currículum de enseñanzas profesionales de música: modalidades composición-dirección en la enseñanza superior.

Carlos Eduardo Pascual Pérez

En la evaluación final a través del postest observamos un grado bajo de acierto a nivel de organología tanto de instrumentos transpositores como no transpositores, así como de lectoescritura en instrumentos no transpositores. Hallamos anotaciones al margen sobre la transposición u octavación de los instrumentos, pero por su resolución entendemos que no están interiorizadas. Queda patente un alto grado de asimilación de los instrumentos trabajados a nivel teórico en la intervención, pero que no se ha visto reflejado a nivel práctico.

\section{EJERCICIO 1}

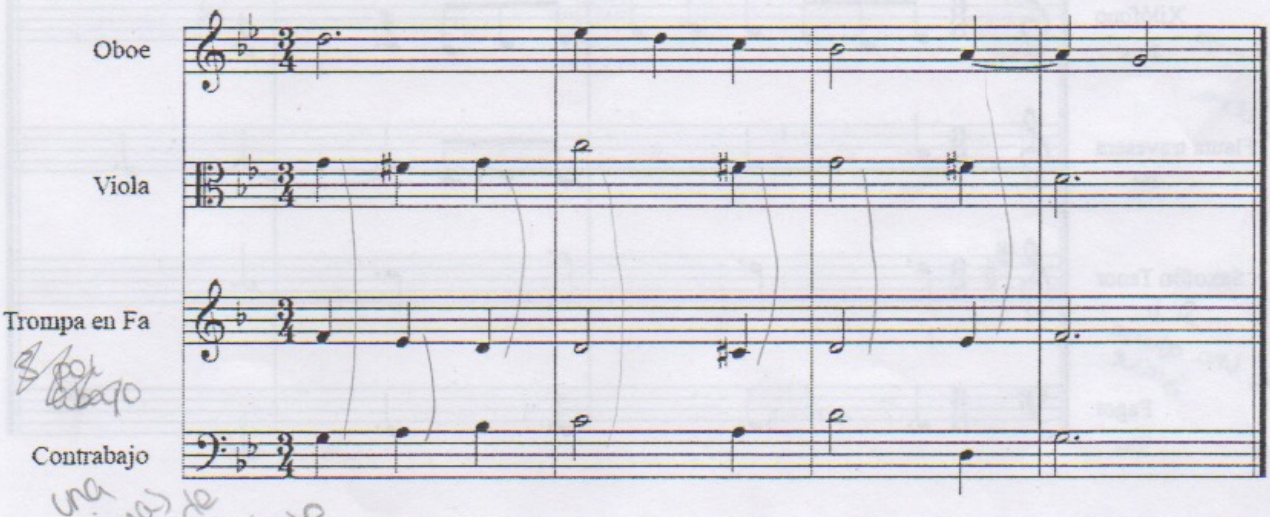

Marcar si no detectas ningún error:

\begin{tabular}{|c|c|c|c|c|}
\hline Compás & Tiempo & instrumento/s implicado/s & Tipo de error & Observaciones \\
\hline 2 & 3 & Vida y tiompa & $a$ & \\
\hline 3 & $1-2$ & vida y tiompa & a & \\
\hline 2 & $1-2$ & vida y contiabajo & $c$ & \\
\hline 2 & 3 & vida y tiompa & $c$ & \\
\hline 2 & 3 & contiobayo & $h$ & \\
\hline 3 & 3 & Tiompa & $h$ & \\
\hline & & & & \\
\hline & & & & \\
\hline
\end{tabular}


Diseño y planificación de competencias específicas en el currículum de enseñanzas profesionales de música: modalidades composición-dirección en la enseñanza superior.

Carlos Eduardo Pascual Pérez

Figura 105. Detalle del ejercicio 1 del postest del sujeto $\mathrm{N}^{\circ} 17$.

Respecto a la resolución del test (detección de errores armónicos) hallamos un $50 \%$ de aciertos para el ejercicio 1, acompañado de cinco respuestas incorrectas, las cuales se desprenden de aspectos curriculares propios de la asignatura y ajenos a la competencia transversal aplicada.

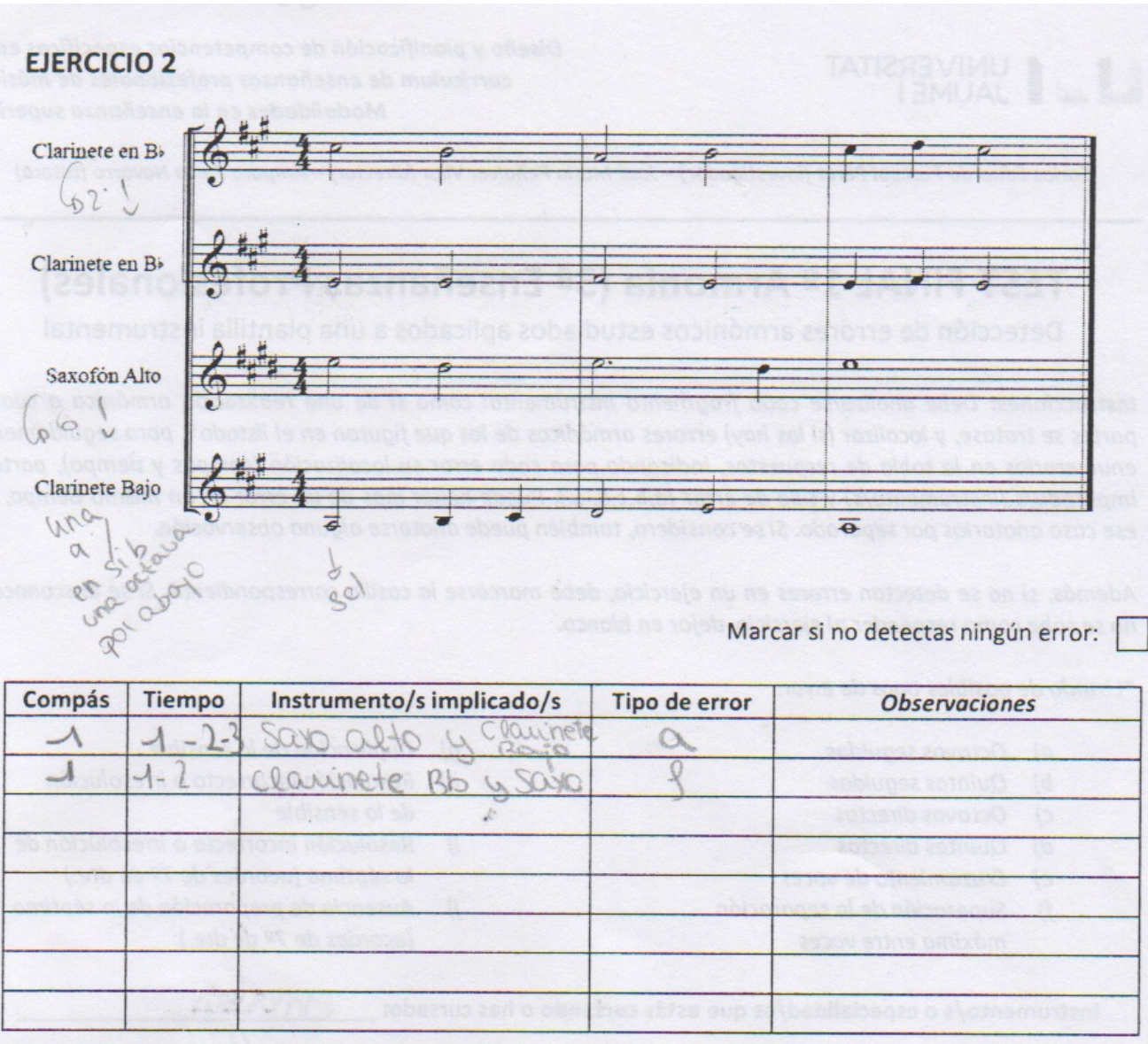

Figura 106. Detalle del ejercicio 2 del postest del sujeto $\mathrm{N}^{\circ} 17$. 
Diseño y planificación de competencias específicas en el currículum de enseñanzas profesionales de música: modalidades composición-dirección en la enseñanza superior.

Carlos Eduardo Pascual Pérez

El ejercicio 2 hallamos un $0 \%$ de aciertos con dos respuestas incorrectas. Nuevamente hallamos anotaciones al margen respecto a las transposiciones de los instrumentos implicados. Por último, en el ejercicio 3 encontramos un $40 \%$ de aciertos acompañado de otras dos respuestas incorrectas.

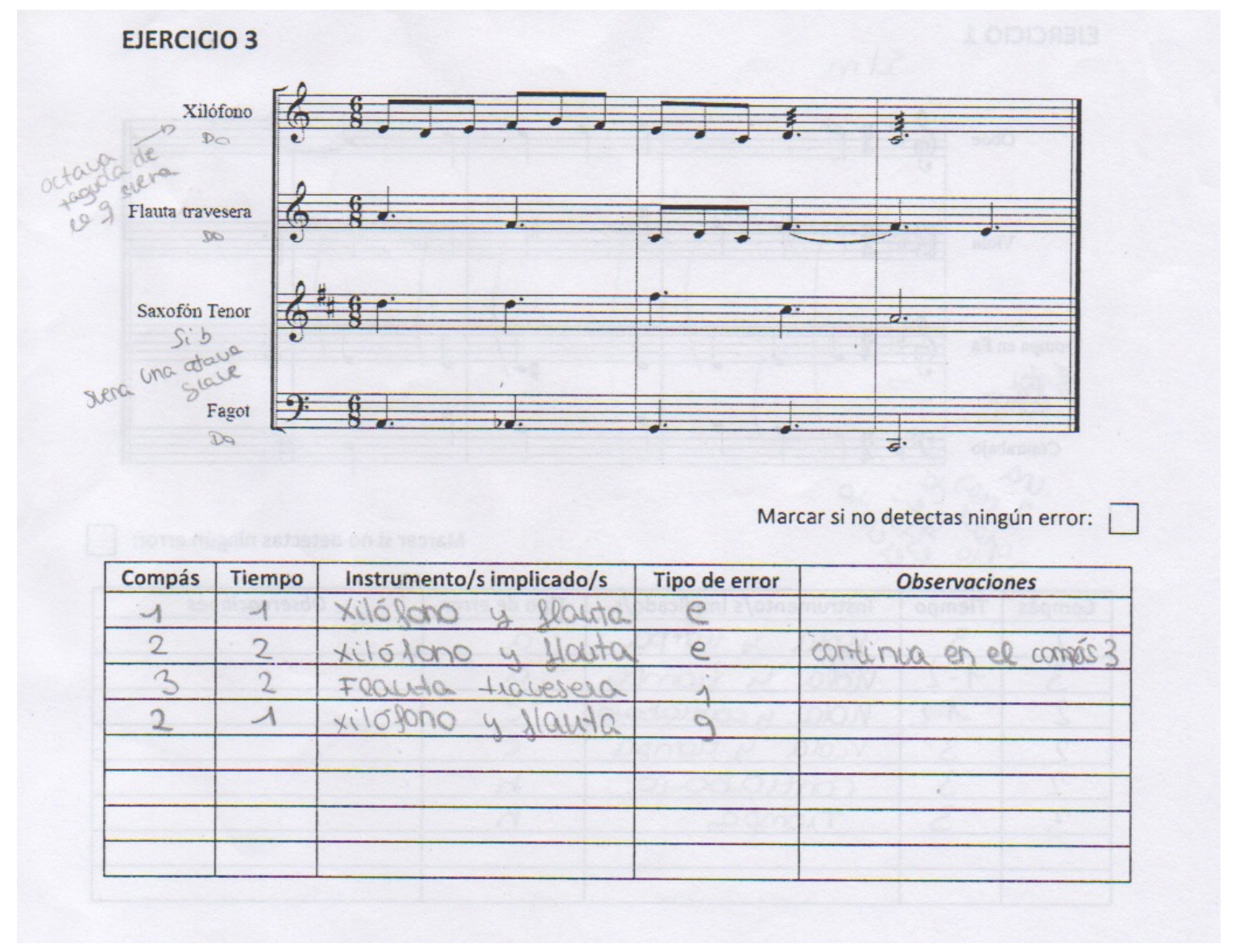

Figura 107. Detalle del ejercicio 3 del postest del sujeto $\mathrm{N}^{\circ} 17$. 
A la vista de los resultados del postest podemos concluir que la competencia transversal de “Organología, instrumentación y orquestación en el ámbito de la orquesta sinfónica” está asumida en un grado medio. Denotamos una mejoría muy notable en todas las variables excepto en la "lecto-escritura entre instrumentos transpositores", así como en la media aritmética de comparativa pretest-postest. Por último, observamos un cierto grado de error en lo curricular de la asignatura de armonía, el cual no consideramos determinante para no poder obtener un mejor resultado en la puntuación global del test.

\begin{tabular}{|c|c|c|c|c|c|c|c|c|c|c|c|c|}
\hline \multicolumn{1}{|c|}{ PRETEST } & \multicolumn{10}{c|}{ POSTEST } \\
\hline ONT & OT & LENT & LET & ANTT & $M V$ & ONT & OT & LENT & LET & ANTT & $M V$ & MG \\
\hline 4,00 & 4,00 & 3,80 & 1,60 & 0,00 & 2,60 & 8,00 & 10,00 & 5,00 & 0,00 & 3,33 & 5,27 & $\mathbf{3 , 0 0}$ \\
\hline
\end{tabular}

Tabla 26. Resumen puntuaciones de variables, medias y global para el sujeto №17.

\subsubsection{Caso experimental $N^{o} 18$}

La valoración inicial del primer ejercicio del pretest nos sugiere una cierta experiencia acerca de la organología de los instrumentos sinfónicos del ámbito orquestal. Hallamos tres aciertos 
Diseño y planificación de competencias específicas en el currículum de enseñanzas profesionales de música: modalidades composición-dirección en la enseñanza superior.

Carlos Eduardo Pascual Pérez

completos acompañados también de algún acierto parcial, como la afinación del clarinete bajo o la lira.

Respecto al segundo ejercicio de lecto-escritura y asociación entre instrumentos transpositores y no transpositores, podemos observar un error continuado en toda la transposición de la trompa en todos los acordes, así como la alteración accidental errónea del clarinete en el cuarto acorde. También encontramos nota errónea para el clarinete en el segundo compás. 
Diseño y planificación de competencias específicas en el currículum de enseñanzas profesionales de música: modalidades composición-dirección en la enseñanza superior.

Carlos Eduardo Pascual Pérez

1. Identifica la afinación y octavación de los siguientes instrumentos:

\begin{tabular}{|c|c|c|c|c|c|}
\hline Instrumento & Afinación & Octavación & Instrumento & Afinación & Octavación \\
\hline Oboe & DO & & Clarinete bajo & $3 i b$ & \\
\hline Flautín & 00 & $\Lambda \uparrow$ & Saxofón alto & Mib & \\
\hline Fagot & DO & 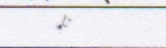 & Saxofón tenor & & \\
\hline Contrabajo & SOL & $\downarrow$ & Lira & DO & \\
\hline Trompa & $\mathrm{Fa}$ & & Flauta alto & 00 & \\
\hline
\end{tabular}

\section{Realiza los siguientes acordes:}

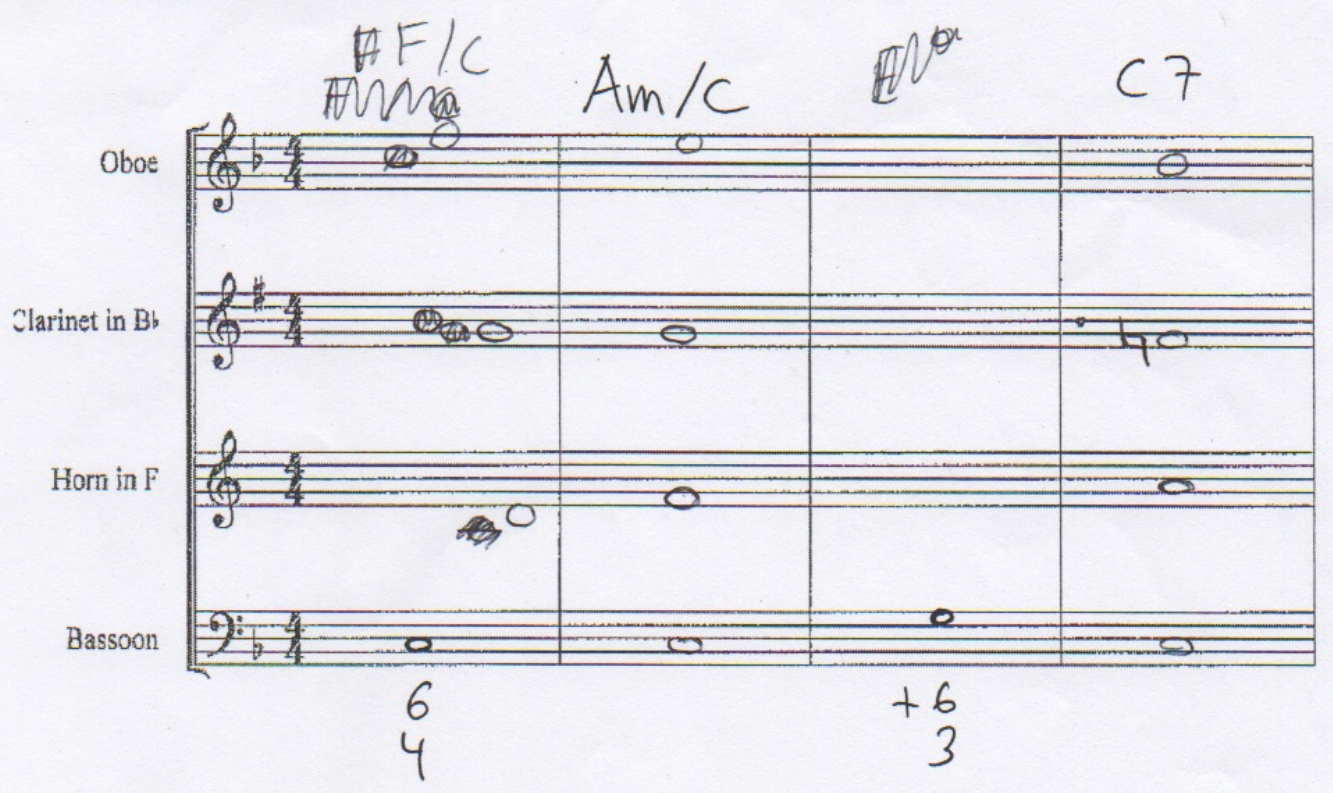

Figura 108. Pretest del caso experimental $\mathrm{N}^{\mathrm{o}} 18$. 
A la vista de los resultados creemos que existe un desconocimiento notable en el ámbito de la organología. Además, encontramos la ausencia de respuesta para el tercer acorde, entendiendo que se desprende de un desconocimiento del cifrado propuesto, que en todo caso es curricular de los contenidos de cursos anteriores.

Tras la primera intervención y la entrega del primer ejercicio observamos una mejora notable en el ámbito de la lecto-escritura y la organología, dado que desaparecen los errores de transposición. Tampoco hallamos errores nuevos como el cruce entre voces. También se evidencian errores conceptuales propios en lo curricular de la asignatura de armonía, no siendo estos aplicables al desarrollo de nuestra competencia transversal, como las quintas seguidas entre oboe y clarinete (compases 5,6 y 7). Hallamos también anotaciones al inicio de cada pentagrama con las indicaciones de registro de cada instrumento, así como una indicación de las tonalidades de transposición de cada instrumento. 
Diseño y planificación de competencias específicas en el currículum de enseñanzas profesionales de música: modalidades composición-dirección en la enseñanza superior.

Carlos Eduardo Pascual Pérez

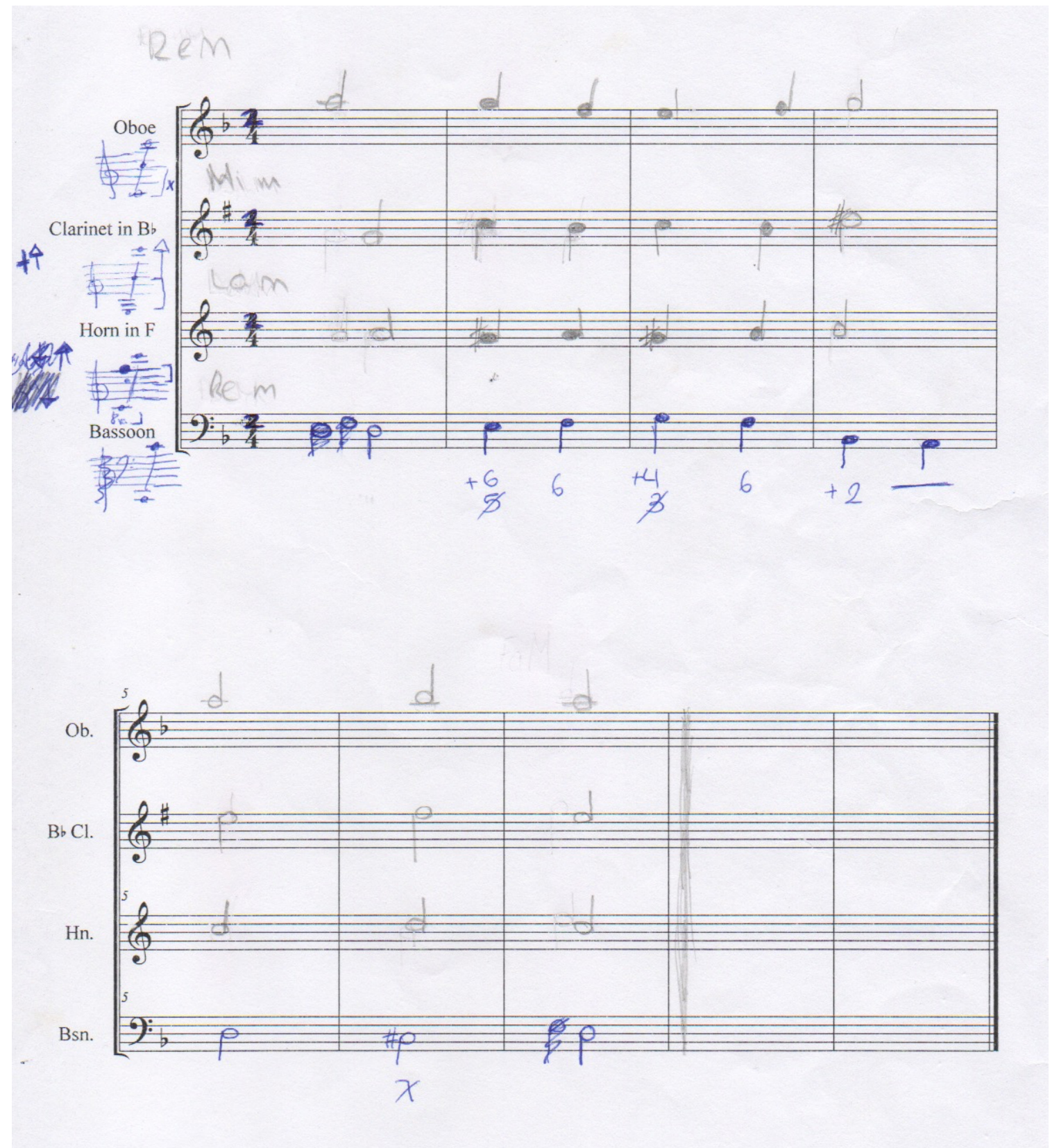

Figura 109. Detalle del ejercicio de la primera intervención del sujeto $\mathrm{N}^{\circ} 18$. 
En el ejercicio de la segunda intervención no hallamos una mejora en cuanto a la organología y la lecto-escritura, puesto que aparecen errores de superación de distancia entre voces (violín y viola), así como un error generalizado en la superación del registro de la viola en todo el ejercicio, acompañado de un cruce puntual entre el saxofón y el violín (compás 4). Respecto a la lectura del saxofón alto - único instrumento transpositor del ejercicio - encontramos una anotación al margen sobre la correcta transposición del instrumento. Además, encontramos una anotación del límite de registro en el violín. 
Diseño y planificación de competencias específicas en el currículum de enseñanzas profesionales de música: modalidades composición-dirección en la enseñanza superior.

Carlos Eduardo Pascual Pérez

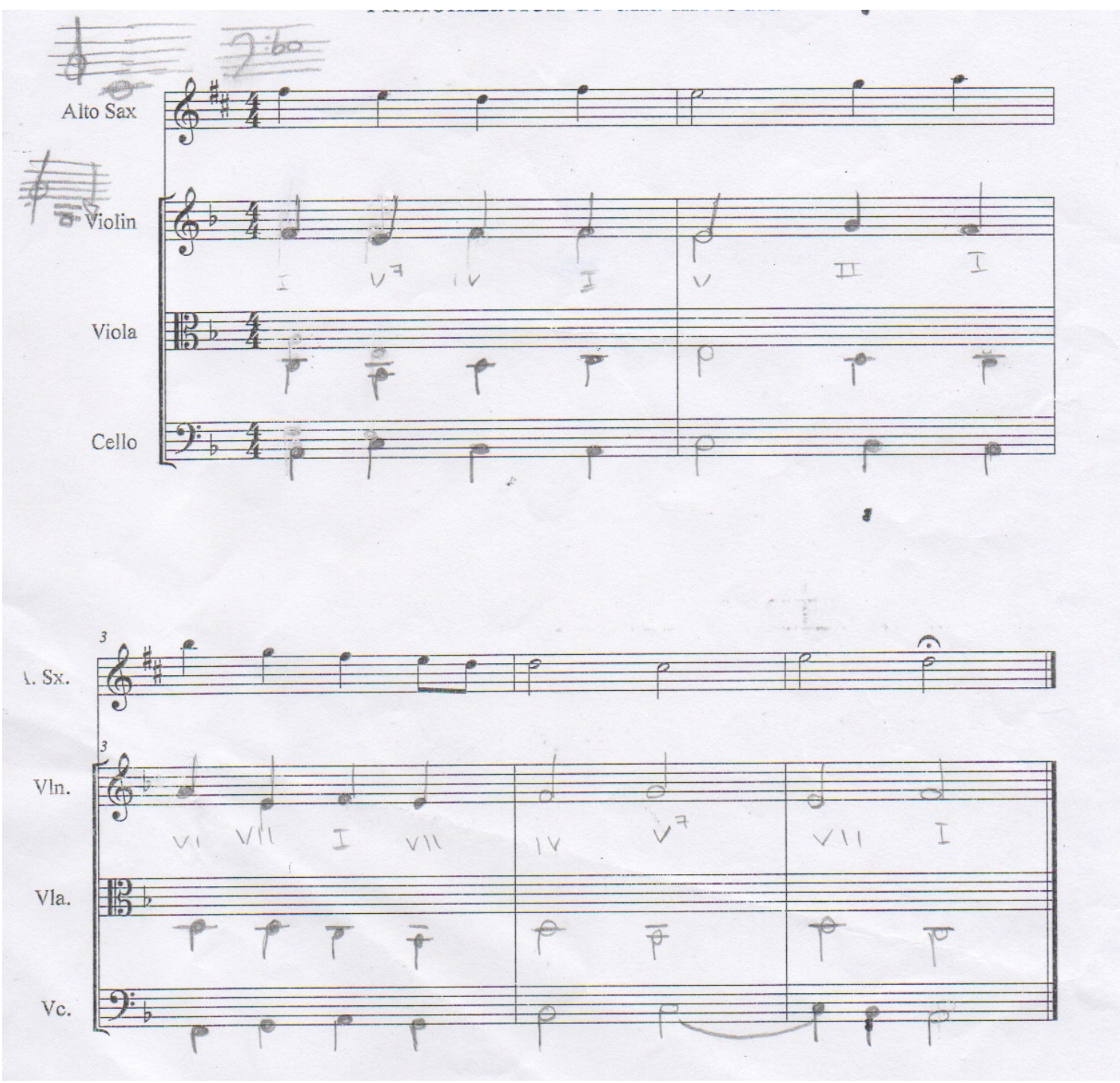

Figura 110. Detalle del ejercicio de la segunda intervención del sujeto $\mathrm{N}^{\mathrm{o}} 18$.

No obstante, detectamos errores propiamente curriculares - no significantes en la competencia transversal desarrollada - como el uso incorrecto de las notas extrañas (compás $3)$. 
No disponemos de resultados para el postest, dado que el sujeto abandonó la experiencia tras la segunda intervención y no se presentó a la realización de esta última prueba. No obstante, a la vista de los resultados de la intervención, podemos concluir que la competencia transversal “Organología, instrumentación y orquestación en el ámbito de la orquesta sinfónica” está asumida parcialmente. Aunque no podemos cuantificar los resultados, denotamos una mejoría en las experiencias respecto al pretest. Por último, observamos un bajo grado de error en lo curricular de la asignatura de armonía, el cual no podemos considerar determinante para no poder obtener un mejor resultado en la puntuación global del test al carecer de dichos resultados.

\begin{tabular}{|c|c|c|c|c|c|c|c|c|c|c|c|c|}
\multicolumn{10}{|c|}{ PRETEST } & \multicolumn{10}{c|}{ POSTEST } \\
\hline ONT & OT & LENT & LET & ANTT & $M V$ & ONT & OT & LENT & LET & ANTT & $M V$ & MG \\
\hline 2,00 & 0,00 & 7,50 & 3,10 & 0,00 & 2,40 & - & - & - & - & - & - & - \\
\hline
\end{tabular}

Tabla 27. Resumen puntuaciones de variables, medias y global para el sujeto $\mathrm{N}^{\circ} 18$.

\subsubsection{Caso experimental $N^{o} 19$}

Dado que el sujeto comenzó más tarde que el reto del grupo la experiencia, y dado que fue tras la primera intervención, no disponemos de su pretest de conocimientos iniciales. En caso 


\section{Carlos Eduardo Pascual Pérez}

que hubiésemos realizado el mismo, sus resultados no hubiesen sido significativos dado que ya se había realizado la primera sesión de la intervención y actualizado los conceptos y contenidos.

Tras la primera intervención y la entrega del primer ejercicio observamos una cierta experiencia en el ámbito de la lecto-escritura y organología de los instrumentos, dado que son correctas las transposiciones del clarinete y la trompa, así como su distribución de voces. Se evidencian no obstante errores conceptuales propios en lo curricular de la asignatura de armonía, no siendo estos aplicables al desarrollo de nuestra competencia transversal, como la duplicación de la sensible (clarinete, compás 6). Hallamos anotaciones al margen para cada instrumento respecto a su registro. 
Diseño y planificación de competencias específicas en el currículum de enseñanzas profesionales de música:

modalidades composición-dirección en la enseñanza superior.

\section{Carlos Eduardo Pascual Pérez}

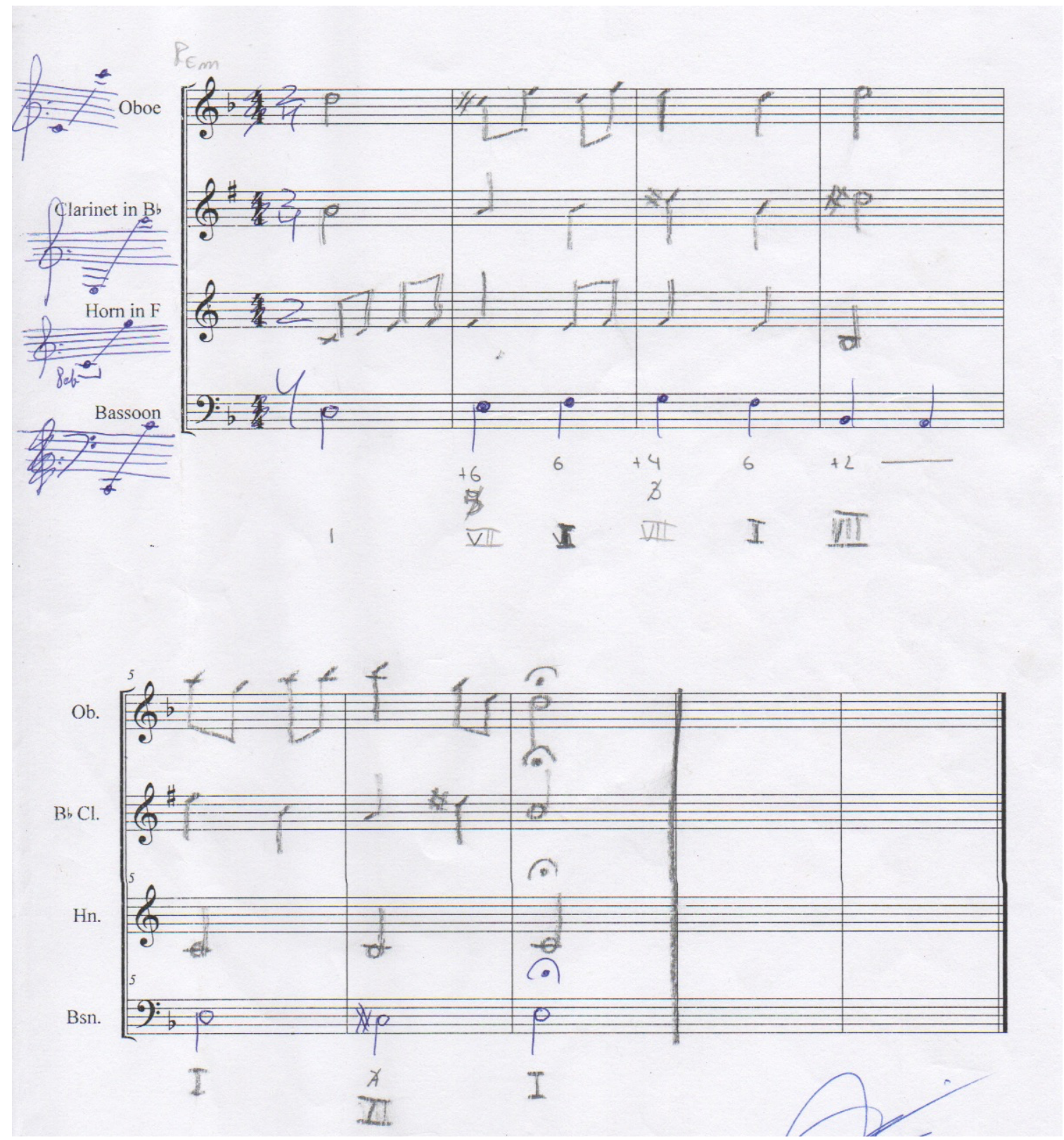

Figura 111. Detalle del ejercicio de la primera intervención del sujeto $\mathrm{N}^{\mathrm{o}} 19$. 
En el ejercicio de la segunda intervención hallamos una continuidad de acierto en cuanto a la organología y la lecto-escritura, dado que no hallamos nuevos errores. No encontramos anotaciones al margen o apuntes que indiquen ayudas a la realización, pero la misma es correcta, por lo que las entendemos como interiorizadas. 
Diseño y planificación de competencias específicas en el currículum de enseñanzas profesionales de música: modalidades composición-dirección en la enseñanza superior.

Carlos Eduardo Pascual Pérez

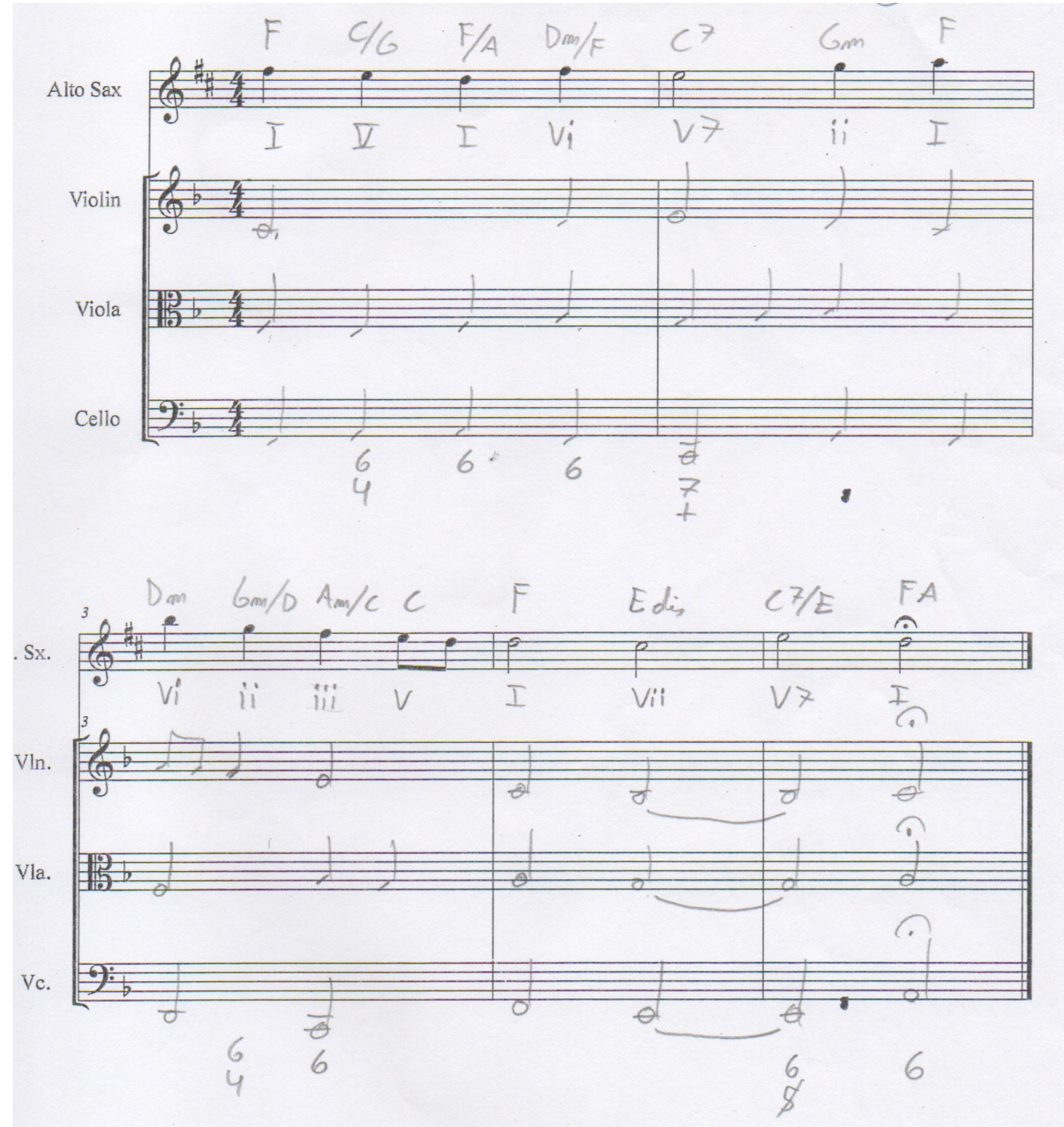

Figura 112. Detalle del ejercicio de la segunda intervención del sujeto $\mathrm{N}^{\circ} 19$. 
No detectamos errores melódicos a excepción de los propiamente curriculares - no significantes en la competencia transversal desarrollada - como las octavas seguidas entre violoncello y saxofón (compás 4).

En la evaluación final a través del postest observamos un alto grado de acierto a nivel de organología tanto de instrumentos transpositores como no transpositores, así como de lectoescritura en instrumentos no transpositores. No hallamos anotaciones al margen sobre la transposición u octavación de los instrumentos, pero por su resolución entendemos que están interiorizadas. Queda patente el alto grado de asimilación de los instrumentos trabajados a nivel práctico en la intervención, así como de los instrumentos únicamente revisados a nivel teórico. 
Diseño y planificación de competencias específicas en el currículum de enseñanzas profesionales de música: modalidades composición-dirección en la enseñanza superior.

Carlos Eduardo Pascual Pérez

\section{EJERCICIO 1}

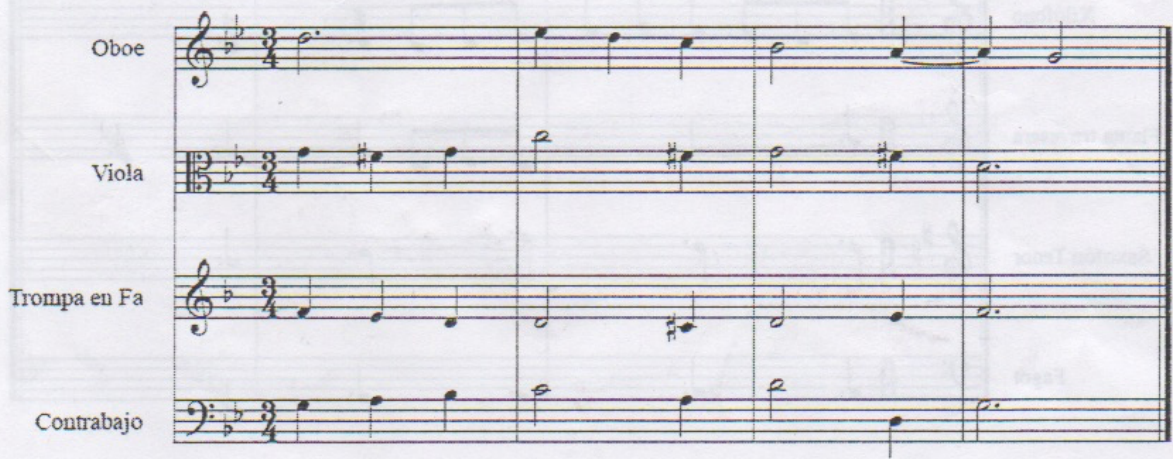

Marcar si no detectas ningún error:

\begin{tabular}{|c|c|c|c|c|}
\hline Compás & Tiempo & Instrumento/s implicado/s & Tipo de error & Observaciones \\
\hline j & 3 & TROMPA - CONYRABAJO & E) & \\
\hline 2 & 1 & TROMPA - CONTRABAJO & E) & \\
\hline 2 & 3 & TROMPG - CONTRARADO & E) & \\
\hline 3 & 1 & IROMPA - CONTRABAJO & E) & \\
\hline 2 & 1 & VIOLA - TROMPA & F) & \\
\hline 2 & $\frac{1}{3}$ & VIOLA - TROMPA & G) & \\
\hline $3-4$ & 3 & VIOLA - OBOE & & RESOLUGión DiferioA de LA \\
\hline 4 & $1-2$ & OBOE & & REYARDO $9-8$ \\
\hline
\end{tabular}

Figura 113. Detalle del ejercicio 1 del postest del sujeto $\mathrm{N}^{\circ} 19$.

Respecto a la resolución del test (detección de errores armónicos) hallamos el 100\% de aciertos para el ejercicio 1, acompañado de cuatro respuestas incorrectas, las cuales se desprende de incorrecciones propiamente que implican el uso de la competencia transversal, como la transposición errónea de la trompa junto a la octavación del contrabajo. 
Diseño y planificación de competencias específicas en el currículum de enseñanzas profesionales de música: modalidades composición-dirección en la enseñanza superior.

Carlos Eduardo Pascual Pérez

\section{EJERCICIO 2}

Clarinete en B;

Clarinete en B;

Saxofón Alto

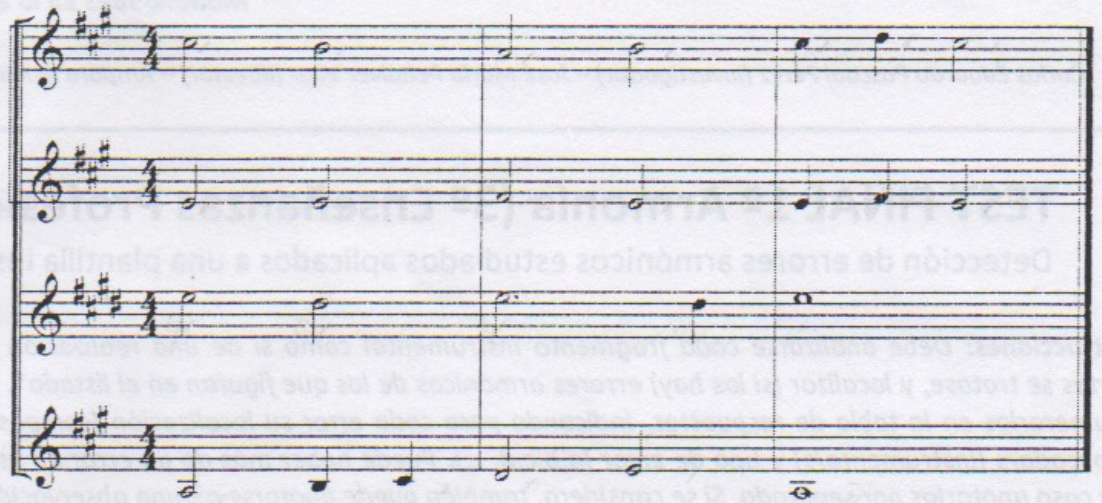

Clarinete Bajo

$\bar{a}$

Marcar si no detectas ningún error:

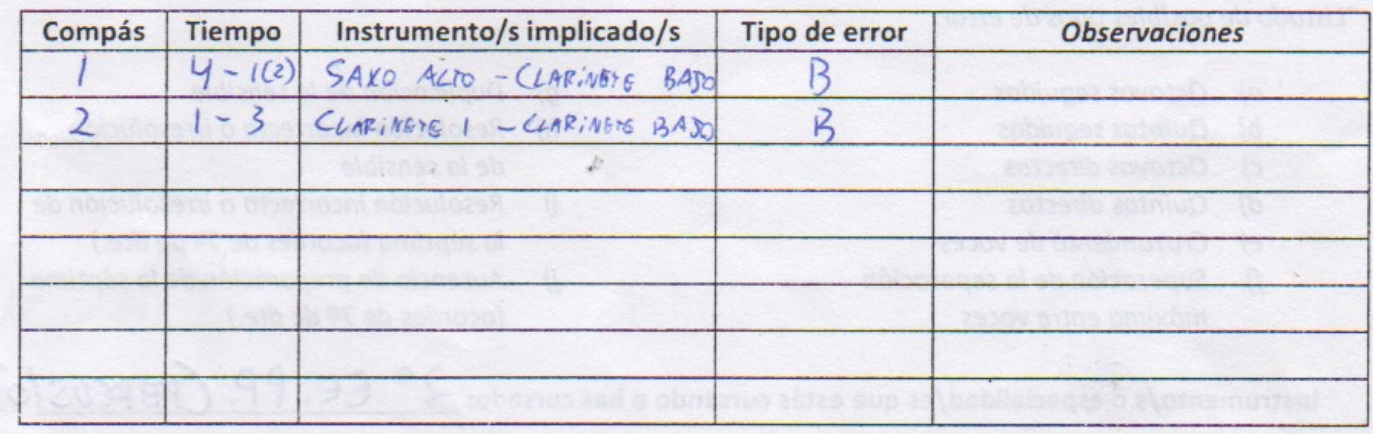

Figura 114. Detalle del ejercicio 2 del postest del sujeto $\mathrm{N}^{\circ} 19$.

El ejercicio 2 hallamos un $66 \%$ de aciertos con ninguna otra respuesta incorrecta.

Nuevamente no hallamos anotaciones al margen respecto a la escritura real de las transposiciones. Por último, en el ejercicio 3 encontramos un 20\% de aciertos, acompañado de una respuesta derivadas de una incorrección armónica de conceptos curriculares ajenos a 
Diseño y planificación de competencias específicas en el currículum de enseñanzas profesionales de música: modalidades composición-dirección en la enseñanza superior.

Carlos Eduardo Pascual Pérez

la competencia transversal. Hallamos también indicaciones de procesos (no de errores), las cuales no tomamos en consideración.

\section{EJERCICIO 3}

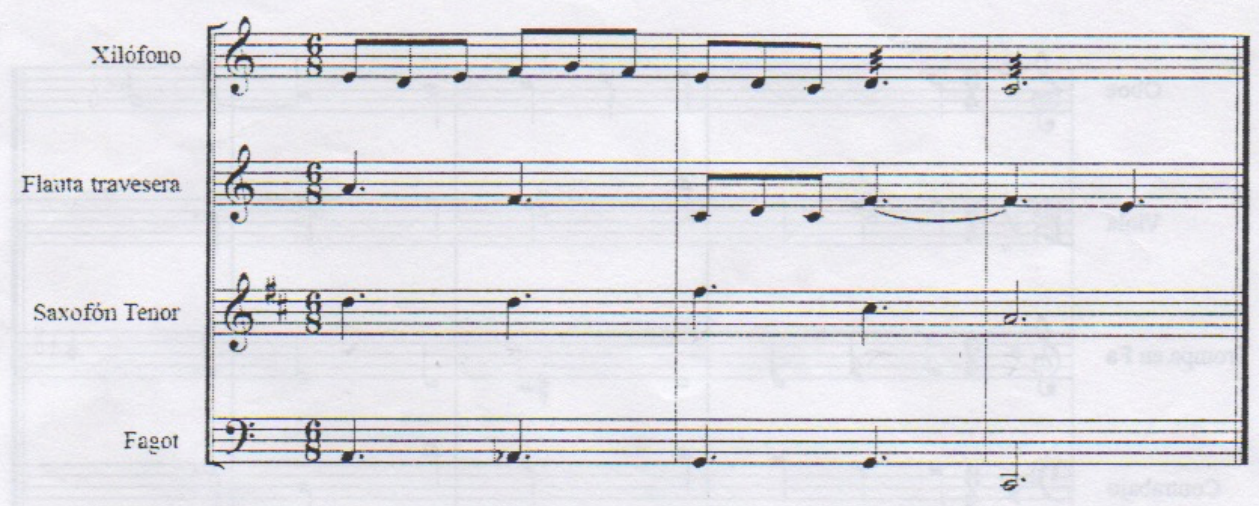

Marcar si no detectas ningún error:

\begin{tabular}{|c|c|c|c|c|c|}
\hline Compás & Tiempo & Instrume & ento/s implicado/s & Tipo de error & Observaciones \\
\hline 2 & 2 & FLAUT, & & $J$ & \\
\hline 3 & 1 & xक्षे- & RENOR - NAT & $H$ & \\
\hline & & & 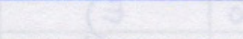 & & \\
\hline & & & 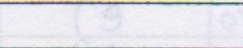 & & \\
\hline & & & - & & \\
\hline & & & 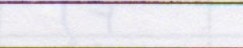 & & \\
\hline & & & +3 & & \\
\hline 3 & $1-2$ & FLAU & TA & & RETARDO $4-3$ \\
\hline
\end{tabular}

Figura 115. Detalle del ejercicio 3 del postest del sujeto $\mathrm{N}^{\circ} 19$.

A la vista de los resultados del postest podemos concluir que la competencia transversal de “Organología, instrumentación y orquestación en el ámbito de la orquesta sinfónica” está asumida en un muy alto grado. No podemos contrastar los resultados de mejora en las variables dado que carecemos del pretest, ni tampoco podemos comprar la media aritmética 
Diseño y planificación de competencias específicas en el currículum de enseñanzas profesionales de música: modalidades composición-dirección en la enseñanza superior.

\section{Carlos Eduardo Pascual Pérez}

de comparativa pretest-postest. No obstante, la puntuación final del postest y los valores de sus variables nos revelan un alto grado de asimilación. Por último, observamos un grado error mínimo en lo curricular de la asignatura de armonía, el cual no consideramos determinante para no poder obtener un mejor resultado en la puntuación global del test.

\begin{tabular}{|c|c|c|c|c|c|c|c|c|c|c|c|c|}
\hline \multicolumn{6}{|c|}{ PRETEST } & \multicolumn{7}{|c|}{ POSTEST } \\
\hline ONT & OT & LENT & LET & ANTT & $M V$ & ONT & OT & LENT & LET & ANTT & $M V$ & MG \\
\hline- & - & - & - & - & - & 6,00 & 6,00 & 10,00 & 10,00 & 3,33 & 7,07 & 5,00 \\
\hline
\end{tabular}

Tabla 28. Resumen puntuaciones de variables, medias y global para el sujeto $\mathrm{N}^{\mathrm{o}} 19$. 
Diseño y planificación de competencias específicas en el currículum de enseñanzas profesionales de música: modalidades composición-dirección en la enseñanza superior.

Carlos Eduardo Pascual Pérez

\subsubsection{Grupo control. Análisis individualizado de casos.}

Un análisis individualizado de los 36 test realizados en los grupos de control nos ha permitido clasificarlos globalmente - sin tener en cuneta su procedencia, ya que no es objetivo de la presente investigación evidenciar las diferencias observadas entre los diferentes centros educativos participantes - en tres categorías: resultado cero, acierto condicionado por la especialidad del alumno y grado de acierto considerable.

En primer lugar, observamos que prácticamente el $60 \%$ de los test no reportan un resultado cero, entre los que encontramos test con ausencia total de respuesta y test con totalidad de respuestas incorrectas, incluyendo la indicación expresa de "ausencia de error". Ejemplo de ello son los casos 20, 22 a 33, 38, 39 y 44 a 46 (referirse al Anexo III que relaciona los 36 postest de los grupos de control, numerados en su análisis estadístico como casos del 20 al 55). A continuación, hallamos unos casos singulares que tienen un bajo grado de acierto, entorno al 10\%, y que coincide propiamente con la especialidad del alumno, desprendiéndose de esta cualidad el acierto. 
Diseño y planificación de competencias específicas en el currículum de enseñanzas profesionales de música: modalidades composición-dirección en la enseñanza superior.

Carlos Eduardo Pascual Pérez

EJERCICIO 2

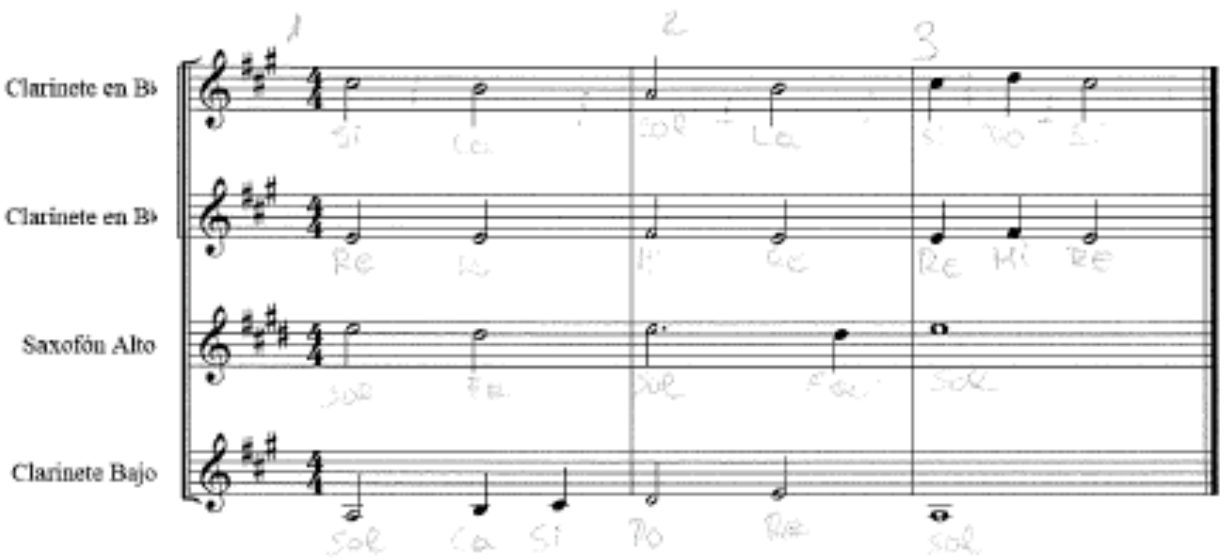

Marcar si no detectas ningún error

\begin{tabular}{|c|c|c|c|c|}
\hline Compás & Tiempo & Instrumento/s implicado/s & Tipo de error & Observaciones \\
\hline 1 & 4tifentin & Corinete Baio/Saxo & $b$ & \\
\hline 2 & d tienory & 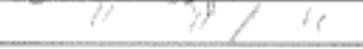 & $b$ & \\
\hline & & & & \\
\hline & & & & \\
\hline & & & & \\
\hline & & & & \\
\hline & & & & \\
\hline & & & & \\
\hline
\end{tabular}

Figura 116. Detalle del ejercicio 2 del postest del sujeto $\mathrm{N}^{\circ} 21$, en el que se refleja un acierto en un instrumento coincidente con la especialidad cursada por el sujeto (clarinete). 
Diseño y planificación de competencias específicas en el currículum de enseñanzas profesionales de música: modalidades composición-dirección en la enseñanza superior.

Carlos Eduardo Pascual Pérez

\section{EJERCICIO 1}

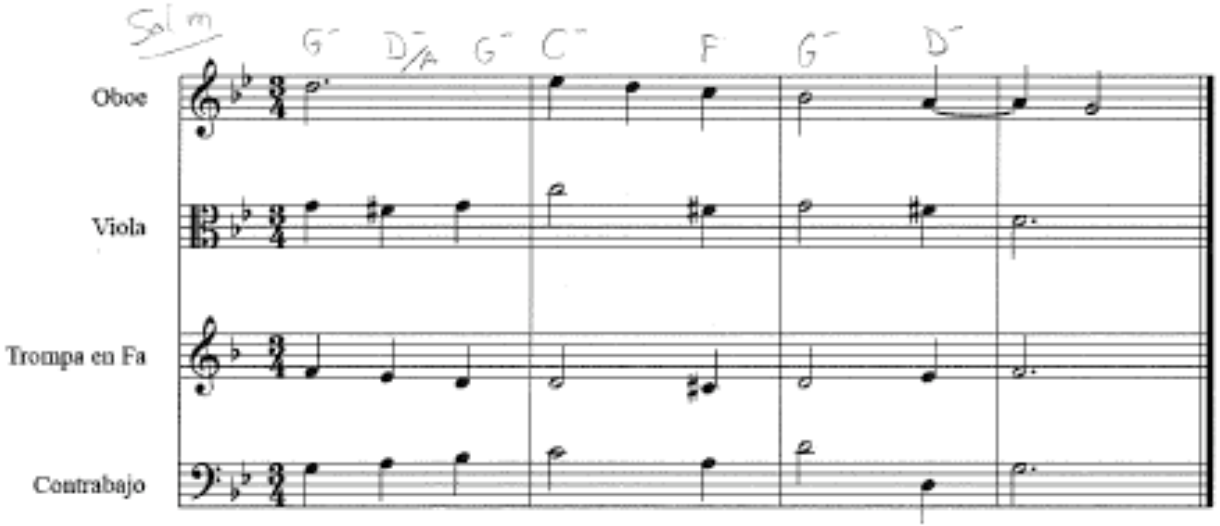

Marcar si no detectas ningún error:

\begin{tabular}{|c|c|c|c|c|}
\hline Compás & Tiempo & Instrumento/s implicado/s & Tipo de error & Observaciones \\
\hline 2 & $1 y 2$ & frumpa / Contrabaja & $e$ & \\
\hline 2 & 1 y 2 & Viola /Trompa & $f$ & \\
\hline 2 & 3 & Viala /Trom ta & 2 & \\
\hline 3 & 1 y 2 & Tromsa / Contrabaio & e & \\
\hline 3 & 3 & Vigla & $n$ & \\
\hline & & & & \\
\hline & & & & \\
\hline & & & & \\
\hline
\end{tabular}

Figura 117. Detalle del ejercicio 2 del postest del sujeto $\mathrm{N}^{0} 53$, en el que se refleja un acierto en un instrumento coincidente con la especialidad cursada por el sujeto (trompa).

Por último, hallamos un porcentaje inferior al $10 \%$ de casos con un leve grado de entorno al $25 \%$ de acierto global, siendo estos los mejores resultados obtenidos para los casos de control. En esta categoría, que es la más reducida de todas, también se agrava al ser sus puntuaciones tan reducidas. 
Diseño y planificación de competencias específicas en el currículum de enseñanzas profesionales de música: modalidades composición-dirección en la enseñanza superior.

Carlos Eduardo Pascual Pérez

\section{EJERCICIO 1}
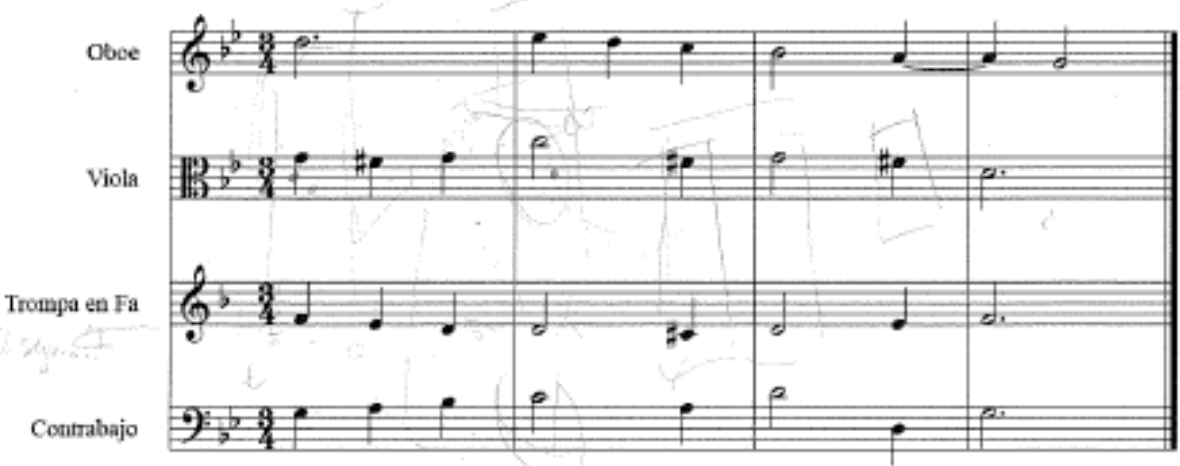

Marcar sỉ no detectas ningún error:

\begin{tabular}{|c|c|c|c|c|}
\hline Compás & Tiempo & Instrumento/s implicado/s & Tipo de error & Observaciones \\
\hline 2 & 3 & viole / trompen & g) & \\
\hline 1 & $\Lambda$ & Irampe I aboe & (4) & \\
\hline 2 & 3 & viole & 1 & \\
\hline 3 & 1 & wiula /taneria & a) & \\
\hline 3 & 3 & wiola & $n$ & \\
\hline 2 & 1 & tromga tobse & f) & \\
\hline & & & & \\
\hline & & & & \\
\hline
\end{tabular}

Figura 118. Detalle del ejercicio 1 del postest del sujeto $N^{0} 50$, en el que se refleja un acierto considerable sin que se condicione el mismo por la especialidad del sujeto (violín). 
Diseño y planificación de competencias específicas en el currículum de enseñanzas profesionales de música: modalidades composición-dirección en la enseñanza superior.

Carlos Eduardo Pascual Pérez

\section{EJERCICIO 2}

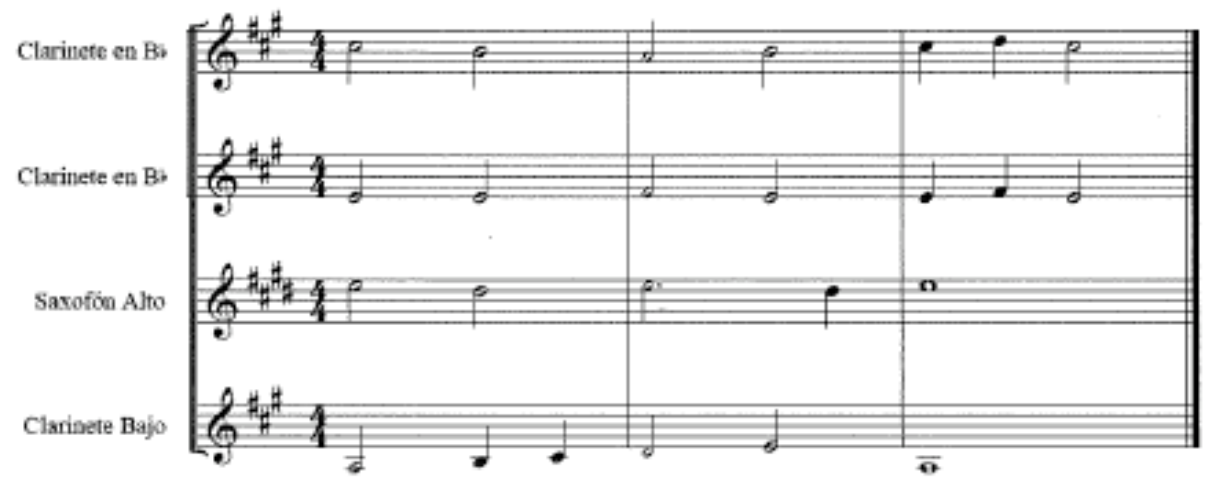

Marcar si no detectas ningún error:

\begin{tabular}{|c|c|c|c|c|}
\hline Compás & Tiempo & Instrumento/s implicado/s & Tipo de error & Observaciones \\
\hline $1,2,3,4$ & & 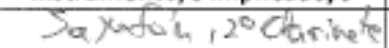 & (e) & \\
\hline$\frac{1}{2}$ & 1 & 1. Clives to Clarinet \& & bl & \\
\hline & & & & \\
\hline & & & & \\
\hline & & & & \\
\hline & & & & \\
\hline & & & & \\
\hline & & & & \\
\hline
\end{tabular}

Figura 119. Detalle del ejercicio 2 del postest del sujeto $\mathrm{N}^{\circ} 43$, en el que se refleja un acierto considerable sin que se condicione el mismo por la especialidad del sujeto (violoncello).

De este análisis se desprende una primera impresión de normalidad ante los resultados obtenidos, ya que coinciden con los esperados según nuestra hipótesis, en la que al carecer de metodologías específicas no se puede resolver favorablemente los ejercicios planteados, aunque curricularmente consecuentes, requieren de competencias específicas que no son adquiridas mediante el sistema actual curricular. 


\subsection{Resultados}

\subsubsection{Análisis preliminar}

La evaluación propuesta para analizar la respuesta de nuestra intervención será a través de una metodología pretest-postest en la que las que nuestras variables serán los criterios de evaluación curriculares, pero transversalmente aplicados a la competencia transversal implementada en nuestra intervención. Optamos de este modo por un diseño clásico de investigación empírico-analítica con un solo grupo pretest - postest y una comparación postest (test) entre dos grupos no relacionados. La búsqueda de resultados mediante este análisis radica en estos dos criterios:

- Comprobar si existe significancia después de nuestra intervención a partir de la utilización de procedimientos estadísticos aplicados al momento previo y al finalizar la intervención mediante un diseño pretest-postest del grupo único en el que se ha realizado la experiencia, mediante el contraste de indicadores de aprendizaje.

- Contrastar los resultados generales del postest realizado en otros grupos de control del mismo nivel curricular mediante el mismo test.

Los análisis precedentes son reducidos al perfil cuantitativo, dado que el objetivo del análisis es la comprobar significancia de la intervención. Al complementar este análisis con la utilización de técnicas afines al ámbito cualitativo -como lo será toda la valoración de la 
intervención - disponemos de una ayuda para comprender el alcance real de la experiencia con el grupo experimental.

Previo a todo el proceso necesitaremos determinar si los resultados de la intervención cumplen con una normalidad de la muestra para poder decidir si aplicábamos pruebas paramétricas o no paramétricas. Para ello utilizamos la prueba de bondad de ajuste ShapiroWilk (1965), al disponer de una muestra reducida $(\mathrm{N}<50)$ en el grupo experiencia. En ella observamos que nos encontramos ante una distribución no normal, lo cual ha determinado que usemos pruebas no paramétricas para los consiguientes análisis. (Anexo V)

\section{Pruebas de normalidad}

\begin{tabular}{l|c|c|c|c|c|c|} 
& \multicolumn{3}{c}{ Kolmogorov-Smirnov $^{\text {a }}$} & \multicolumn{3}{c}{ Shapiro-Wilk } \\
& Estadístico & gl & Sig. & Estadístico & gl & \multicolumn{1}{c}{ Sig. } \\
\hline LEInstNoTrans &, 212 & 18 &, 032 &, 870 & 18 &, 018 \\
\hline LEInstTrans &, 194 & 18 &, 073 &, 858 & 18 &, 012 \\
\hline OInstTrans &, 269 & 18 &, 001 &, 845 & 18 &, 007 \\
\hline OInstNoTrans &, 191 & 18 &, 080 &, 881 & 18 &, 027 \\
\hline ATransNoTrans &, 359 & 18 &, 000 &, 707 & 18 &, 000 \\
\hline
\end{tabular}

a. Corrección de significación de Lilliefors

Tabla 29. Resultados para las pruebas de normalidad aplicadas a las variables (elaboración propia).

La prueba se ha aplicado al pretest y al postest, y de ella se desprende que nuestra distribución no se ajusta a la ley normal. La muestra reducida $(\mathrm{N}=19)$ añadida al fundamento del muestreo aleatorio del sistema Shapiro-Wilk nos proporciona el grado de fiabilidad necesario. Asimismo, aplicamos la misma prueba de normalidad al conjunto de resultados de 
Diseño y planificación de competencias específicas en el currículum de enseñanzas profesionales de música: modalidades composición-dirección en la enseñanza superior.

Carlos Eduardo Pascual Pérez

los grupos de control, obteniendo la misma confirmación de no normalidad. Y, por último, al tener una muestra conjunta de todos los resultados de postest $(\mathrm{N}=55)$ que supera las 50 muestras, aplicamos en consecuencia el modelo Kolmogorov-Smirnov (1948) para determinar la bondad de ajuste en este caso, cuyo resultado nos reporta nuevamente una no normalidad.

De este modo, tras las pruebas de bondad de ajuste que rechazan la hipótesis nula de que los resultados ofrecen una distribución normal, determinamos el uso las siguientes pruebas no paramétricas para el contraste de resultados (Anexo V):

- Prueba T de Wilcoxon (1945) de comparación de medias para la realización de contrastes entre dos grupos relacionados.

- Prueba U de Mann-Withney (1947) de comparación de medias para realizar contrastes entre dos grupos independientes.

- Prueba H de Kruskall-Wallis (1952) de análisis de varianza para realizar contrastes entre más de dos grupos independientes.

No obstante, no obviamos una aplicación de pruebas paramétricas con objeto de cotejar si hay una equivalencia o simetría en los resultados obtenidos mediante aplicación de contrastes no paramétricos, y podemos afirmar que los siguientes contrastes corroboraron los resultados ya obtenidos (Anexo VI): 
Diseño y planificación de competencias específicas en el currículum de enseñanzas profesionales de música: modalidades composición-dirección en la enseñanza superior.

\section{Carlos Eduardo Pascual Pérez}

- Prueba T (Gosset, 1908) de muestras relacionadas para realizar contrastes entre dos grupos independientes.

- Prueba T (Gosset, 1908) de muestras independientes para realizar contrastes entre dos grupos independientes.

- Prueba F de análisis de la varianza ANOVA (Fisher, 1925) para realizar contrastes entre más de dos grupos independientes.

Por último, para lograr una comparativa fidedigna entre los resultados de forma global hemos procesado los resultados del pretest mediante las seis variables definidas y a su vez transformado los resultados a puntuaciones equivalentes. Es decir, aunque el número de ítems aplicados a cada variable sea distinto, el proceso final ha sido normalizado a decatipo (de 0 a 10 puntos) mediante la siguiente fórmula para cada variable:

Puntuación decatipo $=($ Puntuación obtenida x10) $/$ Número de ítems

De este modo podemos realizar contrastes entre las variables del pretest y el postest en el grupo de la experiencia. Respecto a la puntación global del postest - necesaria para el contraste entre los grupos de experiencia y los de control -, al ser la misma para todos los grupos y además estar en base 10 no requiere ajuste alguno para su análisis. 
Carlos Eduardo Pascual Pérez

\subsubsection{Eficacia y significación de la intervención}

La forma de contraste en el diseño pretest-postest mediante cinco variables que se fundamentan en cinco descriptores - descritos en los epígrafes de diseño - nos permite comprobar el resultado general mediante la prueba T de Wilcoxon (1945), obteniendo el siguiente resultado:

\section{Estadísticos de prueba ${ }^{a}$}

\begin{tabular}{l|r|r|r|r|r} 
& $\begin{array}{c}\text { POS_OInstNo } \\
\text { Trans - } \\
\text { PRE_OInstNo } \\
\text { Trans }\end{array}$ & $\begin{array}{c}\text { POS_OInstTra } \\
\text { ns - } \\
\text { PRE_OInstTra } \\
\text { ns }\end{array}$ & $\begin{array}{c}\text { POS_LEInstNo } \\
\text { Trans - } \\
\text { PRE_LEInstNo } \\
\text { Trans }\end{array}$ & $\begin{array}{c}\text { POS_LEInstTr } \\
\text { ans - } \\
\text { PRE_LEInstTr } \\
\text { ans }\end{array}$ & $\begin{array}{c}\text { POS_ATrans } \\
\text { NoTrans - } \\
\text { PRE_ATrans } \\
\text { NoTrans }\end{array}$ \\
\hline Z & $-2,970^{\mathrm{b}}$ & $-3,088^{\mathrm{b}}$ & $-2,162^{\mathrm{b}}$ &,$- 971^{\mathrm{c}}$ & $-2,203^{\mathrm{b}}$ \\
\hline Sig. asintótica(bilateral) &, 003 &, 002 &, 031 &, 331 &, 028 \\
\hline
\end{tabular}

a. Prueba de rangos con signo de Wilcoxon

b. Se basa en rangos negativos.

c. Se basa en rangos positivos.

Tabla 30. Resultados para la Prueba T de Wilcoxon (elaboración propia).

Los resultados de la prueba de rangos con signo de Wilcoxon (Anexo V) arrojan que:

- En 47 ítems de la suma de las variables la valoración del pretest es menor que la del postest.

- En 9 ítems de la suma de las variables la valoración del pretest es mayor que la del postest. 
Diseño y planificación de competencias específicas en el currículum de enseñanzas profesionales de música: modalidades composición-dirección en la enseñanza superior.

Carlos Eduardo Pascual Pérez

- En 11 ítems de la suma de las variables la valoración del pretest es igual que la del postest.

Estos resultados confirman que las diferencias entre el pretest y el postest son significativas en forma global, por lo que podemos afirmar que tras nuestra intervención los alumnos muestran un aprendizaje significativo - donde el $80 \%$ de las variables ofrecen una significación $\mathrm{p}<, 050$-, siendo este el valor de referencia. También evidenciamos que la intervención ha sido mayormente significativa para las variables de "Organología de los instrumentos no transpositores" y "Organología de los instrumentos transpositores", acercándose al máximo valor de significación $\mathrm{p}=, 000$. Del mismo modo, aunque el resultado es significativo para las variables "Lecto-escritura entre instrumentos no transpositores" y “Asociación de instrumentos transpositores y no transpositores", estas lo hacen con un menor grado, entorno a $\mathrm{p}=, 030$. Además, en los resultados individuales de cada variable podemos observar que una de ellas arroja un resultado opuesto. Concretamente, para la variable "Lecto-escritura de los instrumentos transpositores", los resultados muestras que la mejoría no es significativa $(\mathrm{p}=, 331)$, por lo que también concluimos que el aprendizaje de este descriptor y por tanto de los contenidos que conlleva no ha sido significativo. Por último, también se evidencia que, aunque en el $80 \%$ de los ítems se denota una mejoría, existe un $10 \%$ en el que se igualan los resultados y otro $10 \%$ en el que estos empeoran.

Además, la complementaria Prueba T (Gosset, 1909) paramétrica arroja el mismo resultado de significancia global y por variables: 
Diseño y planificación de competencias específicas en el currículum de enseñanzas profesionales de música: modalidades composición-dirección en la enseñanza superior.

Carlos Eduardo Pascual Pérez

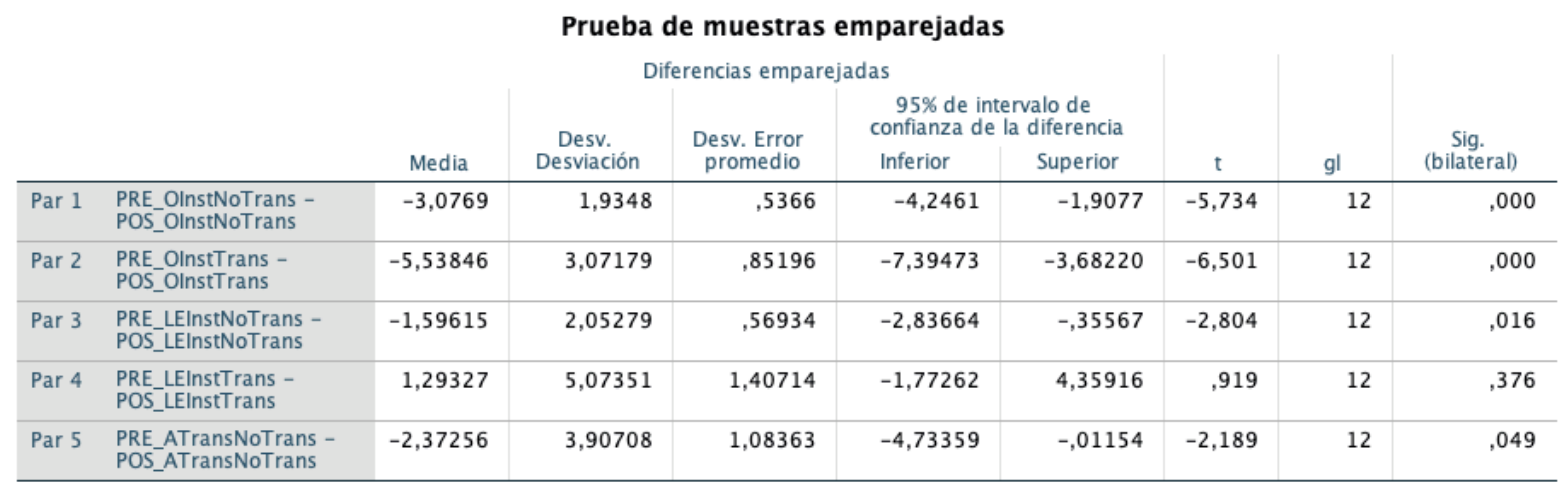

Tabla 31. Resultados paramétricos complementarios mediante Prueba T de Gosset (elaboración propia).

\subsubsection{Contraste único entre resultados del grupo experimental y el de control}

Con objeto de contrastar el aprendizaje significativo de nuestra intervención con grupos en los que no se ha intervenido, efectuamos la prueba U de Mann-Withney (1947) de comparación de medias en grupos independientes: 
Diseño y planificación de competencias específicas en el currículum de enseñanzas profesionales de música: modalidades composición-dirección en la enseñanza superior.

Carlos Eduardo Pascual Pérez

\section{Prueba de Mann-Whitney}

\begin{tabular}{ll|l|r|r} 
& \multicolumn{2}{c}{ Rangos } & \\
& Grupos & $\mathrm{N}$ & $\begin{array}{c}\text { Rango } \\
\text { promedio }\end{array}$ & $\begin{array}{c}\text { Suma de } \\
\text { rangos }\end{array}$ \\
\hline POSTEST_Puntuación & Experiencia & 14 & 39,68 & 555,50 \\
\cline { 2 - 6 } & Control & 36 & 19,99 & 719,50 \\
\cline { 2 - 5 } & Total & 50 & & \\
\hline
\end{tabular}

Estadísticos de prueba ${ }^{a}$

\begin{tabular}{lr} 
& $\begin{array}{c}\text { POSTEST_Pu } \\
\text { ntuación }\end{array}$ \\
\hline U de Mann-Whitney & 53,500 \\
\hline W de Wilcoxon & 719,500 \\
\hline Z & $-4,472$ \\
\hline Sig. asintótica(bilateral) &, 000 \\
\hline
\end{tabular}

a. Variable de agrupación: Grupos

Tabla 32. Resultados para la prueba U de Mann-Withney (elaboración propia).

Los resultados ofrecen un máximo grado de significación $(\mathrm{p}=, 000)$, de lo que se desprende que el grado de competencias adquirido por el grupo experiencia es significativamente superior al del grupo de control. La comparación de medias establece además una puntuación un $30 \%$ superior para el grupo experiencia: 
Diseño y planificación de competencias específicas en el currículum de enseñanzas profesionales de música: modalidades composición-dirección en la enseñanza superior.

Carlos Eduardo Pascual Pérez

\section{Medias}

\section{Resumen de procesamiento de casos}

\begin{tabular}{|c|c|c|c|c|c|c|}
\hline & \multicolumn{6}{|c|}{ Casos } \\
\hline & \multicolumn{2}{|c|}{ Incluido } & \multicolumn{2}{|c|}{ Excluido } & \multicolumn{2}{|c|}{ Total } \\
\hline & $\mathrm{N}$ & Porcentaje & $\mathrm{N}$ & Porcentaje & $\mathrm{N}$ & Porcentaje \\
\hline $\begin{array}{l}\text { POSTEST_Puntuación * } \\
\text { Grupos }\end{array}$ & 50 & $90,9 \%$ & 5 & $9,1 \%$ & 55 & $100,0 \%$ \\
\hline
\end{tabular}

\section{Informe}

POSTEST_Puntuación

\begin{tabular}{l|r|r|r} 
Grupos & Media & \multicolumn{1}{c}{ N } & $\begin{array}{c}\text { Desv. } \\
\text { Desviación }\end{array}$ \\
\hline Experiencia & 3,8571 & 14 & 2,17882 \\
\hline Control &, 8889 & 36 & 1,32617 \\
\hline Total & 1,7200 & 50 & 2,08042 \\
\hline
\end{tabular}

Tabla 33. Resultados para la comparación de medias entre grupos (elaboración propia).

También en este caso la complementaria Prueba T (Gosset, 1908) es coincidente y nos ofrece el mismo resultado de máxima significación:

\begin{tabular}{|c|c|c|c|c|c|c|c|c|c|c|}
\hline \multicolumn{11}{|c|}{ Prueba de muestras independientes } \\
\hline & & \multicolumn{2}{|c|}{$\begin{array}{l}\text { Prueba de Levene de } \\
\text { igualdad de varianzas }\end{array}$} & \multicolumn{7}{|c|}{ prueba t para la igualdad de medias } \\
\hline & & \multirow[b]{2}{*}{$\mathrm{F}$} & \multirow[b]{2}{*}{ Sig. } & \multirow[b]{2}{*}{$\mathrm{t}$} & \multirow[b]{2}{*}{ gl } & \multirow{2}{*}{$\begin{array}{c}\text { Sig. } \\
\text { (bilateral) }\end{array}$} & \multirow{2}{*}{$\begin{array}{l}\text { Diferencia de } \\
\text { medias }\end{array}$} & \multirow{2}{*}{$\begin{array}{l}\text { Diferencia de } \\
\text { error } \\
\text { estándar }\end{array}$} & \multicolumn{2}{|c|}{$\begin{array}{l}95 \% \text { de intervalo de } \\
\text { confianza de la diferencia }\end{array}$} \\
\hline & & & & & & & & & Inferior & Superior \\
\hline \multirow[t]{2}{*}{ POSTEST_Puntuación } & $\begin{array}{l}\text { Se asumen varianzas } \\
\text { iguales }\end{array}$ & 5,867 & 019 & 5,881 & 48 &, 000 & 2,96825 &, 50475 & 1,95338 & 3,98312 \\
\hline & $\begin{array}{l}\text { No se asumen varianzas } \\
\text { iguales }\end{array}$ & & & 4,766 & 16,886 &, 000 & 2,96825 & ,62285 & 1,65347 & 4,28303 \\
\hline
\end{tabular}

Tabla 34. Resultados para la Prueba T de Gosset (elaboración propia). 
Carlos Eduardo Pascual Pérez

\subsubsection{Contraste grupal entre resultados del grupo experimental y el de control}

Aunque no es el objeto del presente estudio contrastar los grupos no relacionados entre sí, queremos aprovechar la circunstancia para realizar un análisis de varianza y observar la trascendencia de su resultado mediante la Prueba H de Kruskall-Wallis (1952):

\section{Prueba de Kruskal-Wallis}

\begin{tabular}{rlr|r}
\multicolumn{2}{c}{ Rangos } & \multicolumn{2}{c}{} \\
& Grupos_Aula & N & \multicolumn{1}{c}{$\begin{array}{c}\text { Rango } \\
\text { promedio }\end{array}$} \\
\hline POSTEST_Puntuación & Experimental 1 & 6 & 39,67 \\
\cline { 2 - 4 } & Experimental 2 & 8 & 39,69 \\
\cline { 2 - 4 } & Control 1 & 19 & 14,71 \\
\cline { 2 - 4 } & Control 2 & 17 & 25,88 \\
\cline { 2 - 4 } & Total & 50 & \\
\hline
\end{tabular}

\begin{tabular}{lr}
\multicolumn{2}{|c}{ Estadísticos de } \\
& $\begin{array}{r}\text { prueba } \\
\text { POSTEST_bu } \\
\text { ntuación }\end{array}$ \\
\hline H de Kruskal-Wallis & 25,727 \\
\hline gl & 3 \\
\hline Sig. asintótica &, 000 \\
\hline
\end{tabular}

a. Prueba de Kruskal Wallis

b. Variable de agrupación: Grupos_Aula

Tabla 35. Resultados para la Prueba H de Krustal-Wallis (elaboración propia).

Obtenemos nuevamente una máxima significación para este contraste de los grupos-aula en los que se realizaron los postest. No obstante, podemos observar que el rango promedio para ambos grupos experimentales es muy similar, de lo que se desprende una similar efectividad 
Diseño y planificación de competencias específicas en el currículum de enseñanzas profesionales de música: modalidades composición-dirección en la enseñanza superior.

Carlos Eduardo Pascual Pérez

de la intervención en ambos. Por otro lado, se evidencian diferencias significativas de promedio entre los dos grupos de control.

El análisis paramétrico complementario mediante la Prueba $\mathrm{F}$ de análisis de la varianza ANOVA (Fisher, 1925) confirma nuevamente el resultado coincidiendo con el grado máximo de significación:

\section{ANOVA}

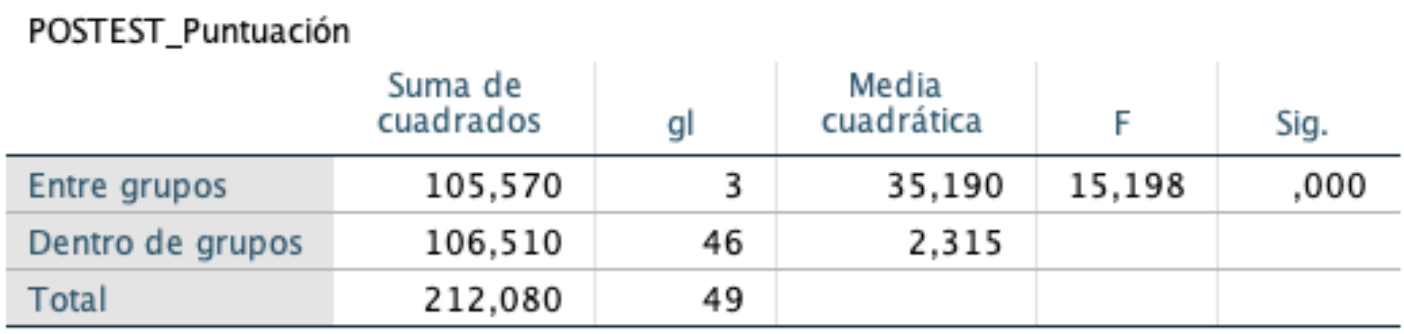

Tabla 36. Resultados paramétricos complementarios para la Prueba F de análisis de la varianza (elaboración propia). 


\section{Conclusiones}

Llegados a este último apartado, y dando por finalizada la investigación a la que se refiere la presente tesis doctoral, trataremos de dar respuesta a las incógnitas que desde la motivación de la misma hasta la interpretación de los resultados hemos ido versando. Si nos referimos a la hipótesis principal, y que consideramos en su planteamiento como objetivo último derivado de sus antecesores, y de la que esperábamos unos resultados que validasen positivamente la significancia de una aplicación metodológica en un contexto de diversificación en las Enseñanzas Profesionales, podemos afirmar que se ha cumplido.

Nuestro primer objetivo, nacido directamente desde la motivación de esta investigación, era evidenciar la falta de relación curricular existente entre las etapas oficiales de Enseñanzas Profesionales y Enseñanzas Superiores de música en España. Y en las conclusiones preliminares tras el análisis del estado de la cuestión (epígrafe 2.5, p. 44), ya desvelábamos que cumplíamos satisfactoriamente la hipótesis planteada en dicho objetivo. Lo que empezó siendo un conjunto de afirmaciones y experiencias recogidas durante años por muchos docentes y alumnos ha derivado en una constatación comparativa del marco legislativo y de ordenación académica del estado español. Además, buscábamos incidir en el requisito de competencias específicas precisadas por el alumnado para acceder a las Enseñanzas Superiores, es decir, poniendo el foco en la prueba de acceso. Y sin duda hemos evidenciado 
Diseño y planificación de competencias específicas en el currículum de enseñanzas profesionales de música: modalidades composición-dirección en la enseñanza superior.

también la gran casuística y desigualdad territorial que puede llegar a producirse, y que sitúa al alumno en un vacío competencial para el cual nuestro sistema educativo no tiene respuesta.

El siguiente objetivo lógico en la cadena lo formulamos como una creación, una primera respuesta ante el panorama que revelaba la hipótesis del primer objetivo; el diseño de una propuesta curricular de diversificación concreta que responda a nuestro perfil profesional y docente, y que pueda servir como guía para futuras líneas de investigación sobre otras especialidades. Incidimos en la necesidad de plantear una diversificación con unos itinerarios en las Enseñanzas Profesionales que respondan a las diferentes titulaciones superiores, y de las cuales, nuestra respuesta se limita a la que podemos dar respuesta con nuestro perfil profesional y docente. Consideramos este objetivo como cumplido, al haber diseñado un itinerario lógico, viable y definido mediante las competencias transversales que el alumnado requerirá en una hipotética prueba de acceso a los grados superiores de Composición y/o Dirección. No obstante, dado que su aplicación real - recogida en el último de los objetivos, y que además es el que cierra el continente de nuestra hipótesis general - la hemos llevado a cabo de forma parcial condicionados por la magnitud y desarrollo de la misma, no hemos podido obtener la respuesta de aplicabilidad completa para toda la propuesta.

Y de esta parte del diseño aplicado, que nos sitúa en el último de los objetivos, concluimos también como satisfactorio, al revelar sus resultados del análisis cuantitativo y cualitativo mediante un sistema pretest-postest la significancia global para dicha intervención. Sin embargo, dicho análisis nos ha revelado en el contexto de una variable - concretamente la 
Diseño y planificación de competencias específicas en el currículum de enseñanzas profesionales de música: modalidades composición-dirección en la enseñanza superior.

Carlos Eduardo Pascual Pérez

"Lecto-escritura entre instrumentos transpositores" - que su resultado no es lo satisfactorio que esperábamos, respuesta ante la que debemos responder que la experimentación es parcial, y que tanto la asignatura como sus metodologías deberían continuarse en un escenario futuro de un curso más, tras el cual un nuevo análisis confiamos en que revelara la subsanación de la competencia referida en dicha variable. Pero insistimos nuevamente en que a pesar de las propuestas de mejora que podemos recoger de los resultados, la significancia global y particular en más de un $80 \%$ de las competencias implementadas ha sido satisfactoria.

En su conjunto, la aplicación parcial y desarrollo de una diversificación enfocada a abordar con idoneidad una prueba de acceso específica superior, tiene también la consideración de especialización formativa, en tanto en cuanto que un alumno curse una especialización con competencias específicas en las Enseñanzas Profesionales, al margen de su acceso o continuidad de estudios, dispondrá de una titulación que le capacita para el ámbito laboral, con el valor añadido de disponer de dichas competencias, y la ventaja que ello puede suponer al optar a puestos de desempeño más específicos.

Desde aquí, consideramos que hemos establecido un punto de inicio para poder desarrollar, en primer lugar, la intervención completa de implementación de las competencias transversales al currículum dirigido a los grados superiores de Composición y Dirección. Esta iniciativa queda en manos de los centros, quienes actuando dentro de la legislación pueden tomar la iniciativa y establecer un itinerario como el que proponemos. Además, nuestra investigación también sugiere una metodología que se ha validado mediante sus resultados 
Diseño y planificación de competencias específicas en el currículum de enseñanzas profesionales de música: modalidades composición-dirección en la enseñanza superior.

para servir de homóloga ante el diseño del resto de itinerarios posibles, aquellos que hacen referencia a los estudios superiores que quedan sin referencia.

La búsqueda testimonial de los entes que configuran el entorno académico de las enseñanzas artísticas en nuestro país, y concretamente en el ámbito territorial que nos ocupa la intervención, nos ha reportado desde el principio un auspicio de apoyo y respaldo de nuestras ideas. No quedando únicamente en el plasmado de doctores, catedráticos, directores, compositores o profesores, sino que fuera del ámbito estrictamente académico, en el cerco del estudiantado que esta terminando las enseñanzas profesionales, o el que recientemente ha tenido que abordar una prueba de acceso, e incluso aquel que ha participado en nuestra experiencia, hemos comprobado que la vigencia de nuestra hipótesis - ahora confirmada es insuflada de realidad y veracidad.

Y, por último, consideramos un deseo de que la presente investigación llegue a servir como iniciativa ante una posible reforma profunda del sistema educativo estatal en sus aspectos curriculares de las Enseñanzas Profesionales. Quizá pueda plantearse por parte de los órganos de gobierno que, ante una respuesta transversal y metodológica para atajar un problema evidenciado durante años, pueda promoverse una respuesta legislativa que dejara sin efecto esta necesidad, al darla por intrínseca en un hipotético y utópico nuevo plan de estudios. 


\begin{abstract}
Anexos
I. Documentación y correspondencia sobre la intervención

II. Documentación: grupos experimentales

III. Documentación: grupos de control

IV. Tabla de datos para el cálculo estadístico

V. Estadísticos: pruebas no paramétricas

VI. Estadísticos: pruebas paramétricas complementarias

VII. Programaciones didácticas: Armonía, Análisis, Fundamentos de Composición, Fundamentos de Dirección

VIII. Propuesta de test: Análisis y Fundamentos de Composición
\end{abstract}


Diseño y planificación de competencias específicas en el currículum de enseñanzas profesionales de música: modalidades composición-dirección en la enseñanza superior.

$\boldsymbol{U}_{\text {NIVERSITAT }}$

JAUME+I

Carlos Eduardo Pascual Pérez

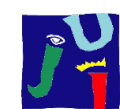

$\mathbf{U}_{\text {NIVERSITAT }}$ JAUME+1

\section{Anexo I}

\section{PROYECTO DE INVESTIGACIÓN EDUCATIVA}

Diseño y planificación de competencias especificas en el currículum de enseñanzas profesionales de música.

Carlos Eduardo Pascual Pérez, investigador

José María Peñalver Vilar, director de tesis

Departamento de educación, Universitat Jaume I de Castelló

Objetivos y ámbito del estudio:

Como docente en un Conservatorio Superior y jefe de estudios en un Centro Autorizado de Enseñanzas Profesionales en Música, vivo en lo cotidiano de la realidad de una parte del sistema artístico de nuestro estado. De ahí nace la motivación y preocupación por la investigación que deseo llevar a cabo, y que se puede resumir como una revisión, reestructuración y propuesta curricular para unas Enseñanzas Profesionales en concordancia y relación de especialización con las Enseñanzas Superiores. Es decir, que ante un espacio superior artístico que permite cursar con un instrumento diferentes ramas (interpretación, pedagogía, jazz, música antigua, etc...) en cuatro cursos, sólo disponemos de una línea (interpretación) en las enseñanzas profesionales previas en seis cursos. Por ello, planteo la necesidad de diversificar los itinerarios y currículum, partiendo de los precedentes semejantes que se desarrollan en otros sistemas educativos internacionales. Además, dispongo de la posibilidad de llevar a cabo un programa piloto en el Centro donde ejerzo, para generar unos resultados a medio plazo con un grupo experimental ante un grupo de control que cursa el currículum actual, siendo este último objeto de la presente solicitud. Asimismo, se adjunta el test propuesto para dicha prueba.

Objetivos:

1. Realizar una propuesta de mejora del currículum de Enseñanzas Profesionales de Música añadiendo competencias específicas en las materias comunes de Armonía y Análisis.

2. Llevar a la práctica en un grupo piloto de alumnos de la asignatura de Armonía (en un Centro Autorizado de Enseñanzas Profesionales de Música) la docencia de dicho currículum con las competencias específicas de la modalidad enfocada a la composición y dirección, durante dos cursos (la duración completa de dicha asignatura), con el fin de comprobar mediante test-evaluación de otros grupos de control (de otros Centros Autorizados y Conservatorios) el grado de adquisición de dichas competencias específicas transversales.

Centro docente y nivel educativo donde se pretende realizar el estudio:

Conservatorio Profesional de Música Mestre Tàrrega de Castelló (alumnado de 3o curso de Enseñanzas Profesionales, de la asignatura "Armonía")

Compromiso:

El director de tesis Dr. José María Peñalver Vilar, así como el investigador y solicitante Carlos Eduardo Pascual Pérez, se comprometen a la remisión de los resultados obtenidos a la Secretaría Autonómica de Educación e Investigación. 
Diseño y planificación de competencias específicas en el currículum de enseñanzas profesionales de música: modalidades composición-dirección en la enseñanza superior.

\section{Carlos Eduardo Pascual Pérez}

Av. de Campanar, 32 46015 - Valencia Tif: 961970114 Fax 961970001

\begin{tabular}{|c}
\hline Registre General \\
\hline Data $7 / 05 / 18$ \\
\hline Eixida $\frac{2018: 10235}{05 E D 012 / 2018 / 2 / 41^{5}}$ \\
\hline
\end{tabular}

Ref:SAEI/S/xg//pr/OF/NR/180507
Carlos Eduardo Pascual Pérez

Av/ Castelló $104^{\circ}$

12560 Benicàssim CASTELLÓ

Proyecto de Investigación: Resolución que autoriza el "Diseño y planificación de competencias especificas en el curriculum de enseñanzas profesionales de música".

En contestación a su solicitud de permiso de autorización de acceso centros educativos; le incluimos trascrita la resolución de 4 de mayo de 2018 del Secretario Autonómico de Educación e Investigación mediante la que se autoriza el acceso a los centros relacionados en el punto $1^{\circ}$ de la mencionada resolución para pasar los cuestionarios a cumplimentar por el alumnado aportados en su solicitud.

La resolución se trascribe a continuación:

«RESOLUCIÓ DE 4 DE MAIG DE 2018 DEL SECRETARI AUTONÓMIC DEDUCACIO I INVESTIGACIO DE LA CONSELLERIA D'EDUCACIO, INVESTIGACIOO, CULTURA I ESPORT PER LA QUAL S'AUTORITZA EL PROJECTE DINVESTIGACIÓ EDUCATIVA: "OISENO Y PLANIFICACION DE COMPETENCIAS ESPECIFICAS EN EL CURRICULUM DE ENSENANZAS PROFESIONALES DE MUSICA", DIRIGIT PER EN JOSE MARIA PENALVER,DIRECTOR DE LA TESI I PROFESSOR DEL DEPARTAMENT DEDUCACIO DE LA UNIVERSITAT JAUME I DE CASTELLOO

Vista la sol-hiclud, d'En Carlos Eduardo Pascual Perez, I segons les competéncies que em confereúx el Decret 186/2017 de 24 de novembre, del Consell, pel qual s'aprova el Reglament Orgánic de ta Conselleria d'Educacio, Imvestigació, Cultura i Esport

$$
\text { RESOLC }
$$

$f^{\circ}$ Autoritzar fompliment de qüestionaris per part de ralumnet eminarcists en el projecle dinvestigacio educativa antenoment citat als centre educatiu. Conservaton Professionel de Música Mestre Tárrega de Castello.

$2^{\circ}$ La Secretania Autonómica d'Educació i investigacio comunicara, aquesta autorizacio, untament amb ia cocumentacio del projecte. al Director Temitorial que corrospan als centres der projecte, a Director Tomitoriog que corespon als centes docents que participen on of projocle por a sor notificats. Una a Consell Espolar l"autontzecio perqu es puga emplenar totaf al Consell Escolar rautontzacio perque es puestionan per part de falumnat seleccionat.

$3^{0}$. Aquest projecte d'investigació haurà de comptar amb "autoritzacio previa dels pares de raluminat particjpant en el mateix; havent de garantir-se, en fot cas, fa confidencialital de les seves respostes, fanonimat respecte a la identificacio dels participants i als resultats de lestudi, aixi com la proteccio de dades segons la normativa aplicabie a aquest efecte.

$4^{\circ}$ La participació del professorat i de ralumnat en aques! projecte és aixi mateix voluntària i s'emmarca en rautonomis projecte es aixi maieix valuntaria i s'emmarca on fautonomio

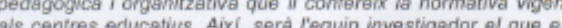
als centres educatics. Aixl, serd lequip invostigodor of que es aricicipacis en equest projecte, podent mostrar le present autoritzacib a te direcelo dels mateixos.

$5^{\circ}$ Qualsevol canvi en el o els questionaris, aixi cam deis contres.s on siguen aphicats, hawat de ser notricat a aquesta secretana.

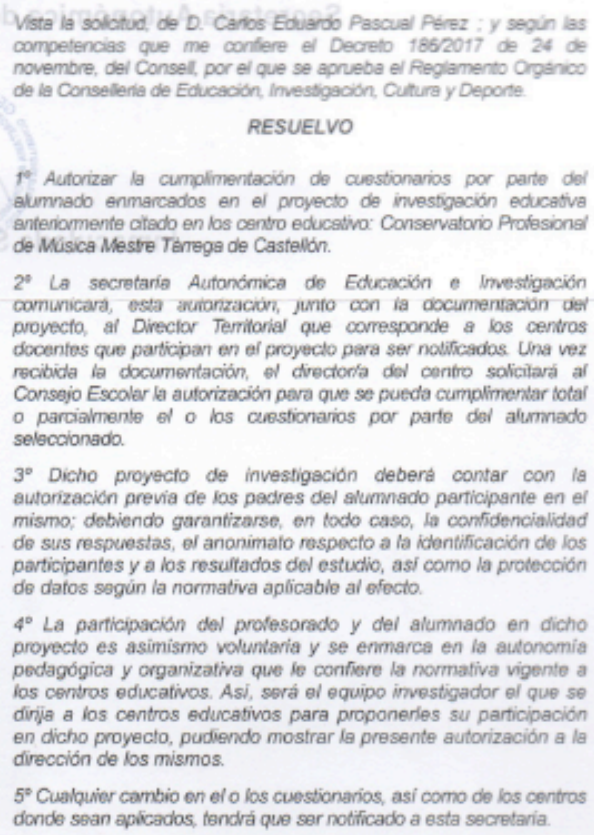

Vista la solichd, de D. Carlos Edvardo Pascual Perez; y segin las competencias que me confere el Decreto 186/2017 de 24 de novembre, del Consel, por el que se apnueba el Reglamento Orgénice de la Consellenta de Educación. imvestigación. Cutura y Deponte

RESUELVO

10. Autorizar la cumplimentación de cuestionarios por parte del aumnado enmarcados en el proyecto de investigación ectucativa

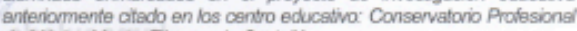
de Misica Mestre Tanega de Castellón.

$2^{\circ}$ La secretaria Autonómica de Educación e Investigación cominicara, esta autinzacion, junto con is documentación de cocentes gae patioinan en al propecto para ser nolificatios tha vez

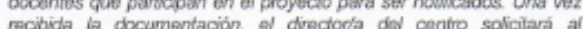
Cansajo Escoler la autorización pera gue se pueda cumplimentar totas c parcialmente el o las arestionarios por parto del alumrado seleccianado.

$3^{\circ}$ Dicho proyecto de investigación deberd contar con la aitumzacich previa de las padres del alummsdo panticipante en el mismo, doblendo garantizarse, on todo caso, ta conmodencialidad de sus resplestas, of ananimato rospecto a la identificación de los participantes y a los resuftados del estudio, así como la protección de datos según la normativa aplicabie al efecto

$4^{\circ}$ La participacion del provesarado y del alumnado en dicho proyecto es asimismo voluntaria y se enmarca en la autonomia pos conjos educativos. Asj, será ol equipo imvestigadar ol que se dirija a los centros educativos para proponerles su participeción dinja a los contos educasos para proponentes su participacion divección de los mismos.

$5^{\circ}$ Cualquiver cambio en el o los cuestionarios, asi como de los centros donde sean apuicados, tendrá que ser notificado a esta secretaria. 
Diseño y planificación de competencias específicas en el currículum de enseñanzas profesionales de música: modalidades composición-dirección en la enseñanza superior.

$6^{\circ}$ La Lei 39/2015, de 26 of doctubre, del procediment administratiu comé de les administracions puibliques (BOE nûm.

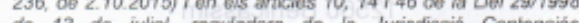
de 13 de juilol, reguladcra do la verisdiccio Cantencios. Administrativa (BOE nam. 167, do 14.07.98), ol prosent acte posa fi a la via edministrativa, padent ser roconeguit potestativament on reposicio o be caldre plantejar de rome directa of recurs stindiquen a continuagit. sindiquen a continuecis:

a) El recurs de reposició haurd dinterposar-se dovant el Secretari Autondmic d'Educació i Investigació de la Consellieria mes a comptar des de lendemed de la seua notificació.

b) El recurs contencids-administratiu haurd do plantejar-se davant el Tribunal Superior do Justicia de la Cormunitat Valenciana en ef termini de dos mesos a comptar des de rendema de la seus

E que pose en el seu coneixement i als efectes oportuns.

$6^{\circ}$ La Ley 39/2015, de 1 de octubre, del procedimiento administrativo camún de las administraciones püblicas (BOE núm 236, de 270.2015) y en las anticulas 10, 14 y 46 de la Ley 29/7998, de is de jullo, agriadara de ta jiriadicción Contenciaso-Administaciva (BOE nam, 167, do 14.07.98), El presente acto pano in a la via adininistrativa. pudiondo ser forma disota et rocurso ophtopiosicion o bion cabra plamear de y ante los dromos aus se indicon a continuación: tinuación:

a) El recurso de reposicion debera interponerse ante el Secretario Autonámico de Educacián e Investigación de la Conselleria de Educación. Investigación. Cuitura y Deporte, en el plazo de un mes a conter descle el dia siguiente al de su notificacion.

b) El recurso contencioso-administrativo deberá plantearse ante el Tribunal Superior de Justicis de la Comunitat sivienciana en al plazpde dos meses a contar desde el

Lo que pongo en su conocimiento $y$ a los efectos oportunos.

Lo que le comunico para su conocimiento y a los efectos oportunos

Valencia, a 4 de mayo de 2018

Asesora de Asuntos Generales

Secretaria Autonómica de Educación e Investigación 
Diseño y planificación de competencias específicas en el currículum de enseñanzas profesionales de música: modalidades composición-dirección en la enseñanza superior.

\section{Carlos Eduardo Pascual Pérez}

A/A D. Antonio Rodriguez Losada, director del Conservatorio Profesional de Música Mestre Tárrega de Castelló

D. Carlos Eduardo Pascual Pérez, con DNI 20484291P, y con domicilio en Av/Castellón 10, 4² de Benicassim (12560),

EXPONE

Que tras el contacto previamente realizado, hago constar esta solicitud para la intervención en su centro del proyecto de investigación educativa "Diseño y planificación de competencias especificas en el currículum de enseñanzas profesionales de música", consistente en la realización de un test anónimo en alumnado que finalice $3 \circ$ y 4 을 Armonía, solicitando dicha realización antes de la finalización del presente curso escolar y nuevamente a finales del curso 2018-19, en un grupo a determinar de 10-15 alumnos por nivel.

Adjunto con esta petición la Resolución por la que la Conselleria d'Educació autoriza nuestra intervención en su Centro, así como el proyecto en el que se describe dicha intervención y su investigación en forma de Tesis Doctoral por la Universitat Jaume I de Castelló.

Se adjunta también el modelo de solicitud y autorización a rellenar por su Centro para la realización de la intervención y modelo de conformidad del responsable legal para los casos de edad menor (modelos de la Comisión Deontológica de la UJ).

Quedo a la espera de su respuesta, muy agradecido de antemano,
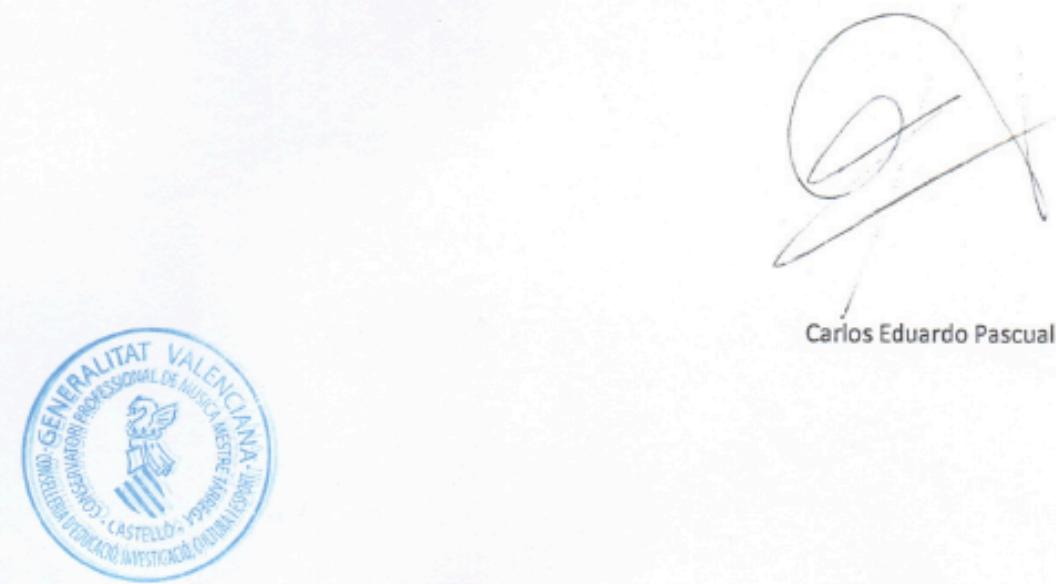

Carlos Eduardo Pascual Pérez

16 MAY 2018 
Diseño y planificación de competencias específicas en el currículum de enseñanzas profesionales de música: modalidades composición-dirección en la enseñanza superior.

Carlos Eduardo Pascual Pérez

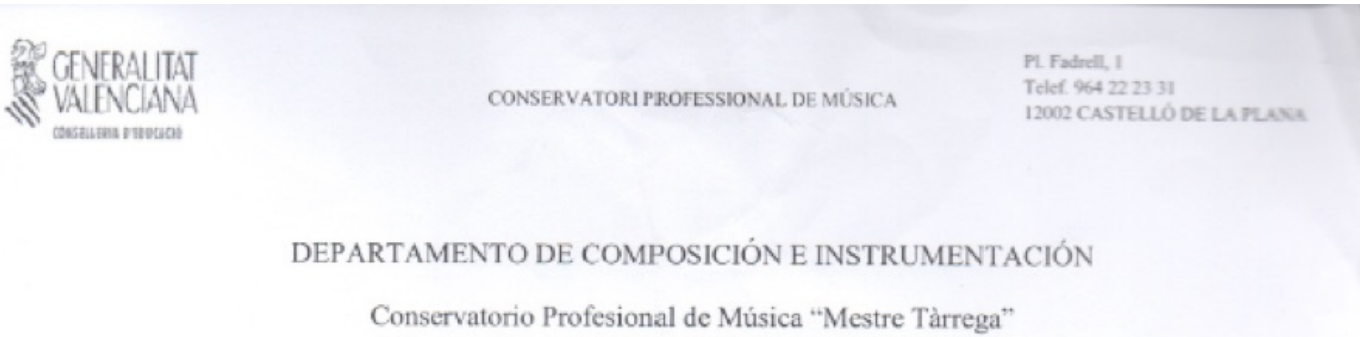

En relación a la autorización y test (que se adjuntan) solicitada por D. Carlos Eduardo Pascual Pérez, el Departamento de Composición e Instrumentación considera:

Que el interesado: D. Carlos Eduardo Pascual Pérez demuestra un desconocimiento tanto de la programación didáctica en vigor de nuestro centro, como del perfil del alumnado de $1^{\circ}$ de Armonía: se trata de alumnos que desconocen la escritura instrumental, las posibilidades de esta escritura y su transposición (sonido escrito/sonido real).

Por lo tanto, en ningún caso, ejercicios armonizados con instrumentos transpositores como el test propuesto.

Los contenidos de nuestra programación citan al respecto:

Acordes tríadas a cuatro partes:

a) Armonía vocal (4 voces humanas mixtas)

b) Tesituras del cuarteto vocal: soprano, contralto, tenor y bajo.

c) Diferentes sistemas para la escritura del cuarteto vocal: sistema tradicional a 4 claves, sistema actual a 2 claves y 4 pentagramas, y sistema abreviado con el empleo de 2 claves y 2 pentagramas.

Por lo cual, no tiene ningún sentido plantear un test (evaluación) sobre contenidos que no se contemplan.

En consecuencia, y ante la solicitud presentada, informamos tanto a la Dirección del Centro como al propio interesado con las observaciones aportadas.

Castellón, 21 de febrero de 2019
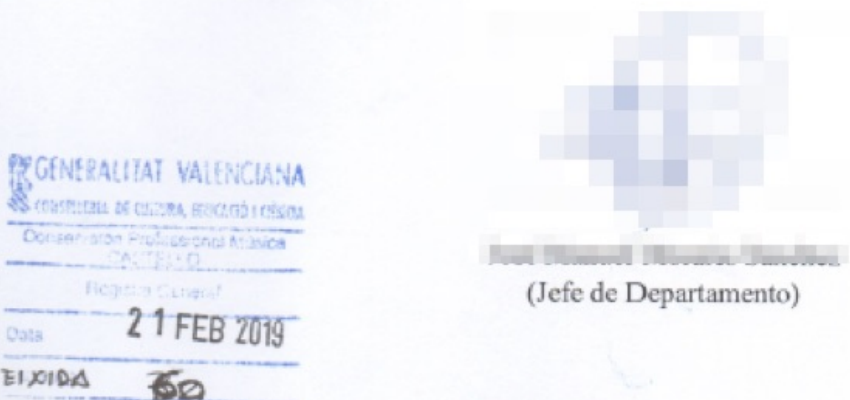

(Jefe de Departamento) 
Diseño y planificación de competencias específicas en el currículum de enseñanzas profesionales de música: modalidades composición-dirección en la enseñanza superior.

\section{A/A D. José Manuel Morales Sánchez y D. Antonio Rodriguez Losada}

En respuesta a la misiva con registro de salida 60 de 21 de febrero de 2019 , se atiende:

Que el TEST propuesto está aprobado por la Secretaría Autonómica de Educación e Investigación en la Resolución SAE1/1S/xg//pr/OF/NR/180507, cumpliendo con los únicos requisitos solicitados referidos al anonimato y confidencialidad de las pruebas.

Que en el TEST no se cuestionan materias o contenidos que el alumnado que ha finalizado $3^{\circ}$ curso de Enseñanzas Profesionales no debiera tener asumidos, si partimos de que la enseñanza es acumulativa desde 19 curso de dichas enseñanzas.

Que dichos contenidos y criterios de evaluación están reflejados tanto en la legislación (Decreto $158 / 20007$ ) como en las programaciones did.ácticas de su centro de las asignaturas de Lenguaje Musical (cursos precedentes) y Armonia.

- Que en ninguno de los contenidos, objetivos o criterios de evaluación que indica el Decreto $158 / 2007$ para la asignatura de Armonía se especifica o menciona que deben ser aplicados " a 4 partes" o "armonía vocal", tal y como presume la programación didáctica de su centro.

Que en base a estas consideraciones, el TEST se ha diseñado siguiendo las siguientes premisas:

- Objetivo Especifico "a" de las Enseñanzas Profesionales de Música: Superar con domino y capacidad critica los contenidos y objetivos planteados. (Decreto 158/2007)

- Objetivo Específico " $\mathrm{g}$ " de las Ensefianzas Profesionales de Música: Interrelacionar $\mathrm{y}$ aplicar los conocimientos adquiridos en todas las asignaturas que componen el curriculo junto con las vivencias y experiencias propias para conseguir una interpretación artistica de calidad. (Decreto 158/2007)

- Criterio de evaluación " 8 " de la asignatura de Armonía: Identificar mediante el análisis de obras los elementos morfológicos de la armonía tonal (Decreto 158/2007)

- Criterio de evaluación " 12 " de la asginatura de Armonía: Identificar mediante e análisis diversos errores en ejercicios preparados con esta finalidad y proponer soluciones. (Decreto 158/2007)

- Objetivo especifico " $\mathrm{d}$ " de la asignatura de Lenguaje Musical: Reconocer y representar gráficamente obras, fragmentos musicales a una o dos voces realizadas con diferentes instrumentos. (Decreto 158/2007)

- Contenidos especifico "Lecto-escritor" de la asignatura de Lenguaje Musical: Práctica de identificación y escritura de notas en su registro correcto. Conocimiento del ámbito sonoro de las claves. Lecturas de agrupaciones verticales de notas. (Decreto 158/2007)

- Criterio de evaluación " $12^{\prime \prime}$ de la asignatura de Lenguaje Musical: Reconocer y escribir fragmentos musicales realizados por dos instrumentos diferentes, excluyendo el piano. (Decreto 158/2007)

- Contenido de evaluación especifico para nivel de 22 de EEPP: Instrumentos musicales. Grupos orquestales y agrupaciones instrumentales. Claves empleadas en la escritura instrumental. Instrumentos transpositores. (Programación de Lenguaje Musical del Conservatorio Profesional de Música Mestre Tárrega de Castelló) 
Diseño y planificación de competencias específicas en el currículum de enseñanzas profesionales de música: modalidades composición-dirección en la enseñanza superior.

- Contenido de evaluación especifico para nivel de $3^{\circ}$ de EEPP :El transporte escrito, mental y de instrumentos transpositores. (Programación de Lenguaje Musical del Conservatorio Profesional de Música Mestre Tárrega de Castelló)

- Contenidos especificos de la asignatura de Armonía para el 3² curso: Normas sobre los movimientos armónicos sucesivos de 8 a y 5 a justas. Normas sobre los movimientos armónicos directos que desembocan en intervalos de 8 a o 5 a justas. Movimientos melódicos: intervalos melódicos dilrectos y prohibidos. El unisono: su tratamiento escolástico. Los cruzamientos. El rebase de tesitura. (Programación de Lenguaje Musical del Conservatorio Profesional de Música Mestre Tárrega de Castelló)

Que en vista a los argumentos aqui mostrados, la afirmación de D. José Manuel Morales Sánchez, indicando que "no tiene ningún sentido plantear un test sobre contenidos que no se contemplan" es errónea, puesto que tanto por Legislación como por Programación Didáctica todos los contenidos son contemplados. Asimismo, se evidencia juicio erróneo y la falta de criterio en la afirmación del profesor Morales acerca de mi "desconocimiento tanto de la programación didáctica en vigor de nuestro centro, como del perfil del alumnado de $1^{2}$ de Armonía".

Que incluso a pesar de todas estas observaciones en pro, hay parte del TEST que puede ser enfrentado con los conocimientos propios que sí que debe tener el alumnado según su Programación, es decir, contenidos propios de "armonía a 4 pentagramas sin transposición".

Que por todo lo aqui expuesto, se hace saber que la presente investigación tiene, entre otros de sus objetivos, la necesidad de conocer hasta que punto el estudiantado asume, mantiene y sabe aplicar los contenidos ya asumidos en cursos anteriores a los contenidos nuevos, para asi fusionarlos de forma critica y saber enfrentarse a nuevos retos.

Que el TEST en cuestión ha sido realizado en otros Centros Autorizados y Conservatorios, obteniendo resultados válidos para su análisis posterior, sin entrar a juzgar la superación o no de dicho test (que entre otras cosas, no tiene una puntuación numérica ni tampoco la búsqueda de la superación en si mismo)

Que en ningún caso el nombre del Centro o del alumnado en cuestión se verá desacreditado o afectado en tanto en cuanto los resultados que se puedan obtener, dado que serán para unirlos a los resultados del "grupo de control", teniendo ya recopilados otros resultados de alumnos que han cursado la asignatura de Armonía en un grupo piloto en el cual si se han implementado las competencias especificas que precisamente se ponen en evidencia en su misiva.

Con todo ello, les ruego tengan a bien reconsiderar la propuesta del test, que no tiene otro objetivo que la investigación acerca de la enseĥanza en los Conservatorios de nuestro territorio, y sin otro objetivo global que la mejora de la misma y aumento de su solvencia, calidad e interdisciplinariedad.

Por último, les solicito me sea devuelto el original de la autorización del proyecto de investigación, que se quedó por omisión el profesor Morales el dia de nuestra primera reunión.

Quedo agradecido, como no puede ser de otro modo, esperando su respuesta y abierto a cualquier aclaración al respecto.

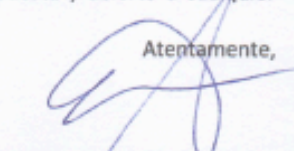

Carlos Eduardo Pascual Pérez Eduardi

Profesor de Armonia y Análisis en el CA Profesional de Música San José de Calasanz de Castellín (2013-2019) Funcionario interino Catedrático de Composición en el Conservatorio Superior de Música de Castelló (2015-2017) Profesor de Didáctica de la Expresión Musical en la Universitat Joume I de Castello (2017-2019) 
Diseño y planificación de competencias específicas en el currículum de enseñanzas profesionales de música: modalidades composición-dirección en la enseñanza superior.

Carlos Eduardo Pascual Pérez

SUBDIRECCIÓ GENERAL DE COORDINACIÓ I NORMALITZACIÓ DE PROCESSOS EN EDUCACIO

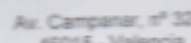
esors - Valenca Tel:-961970114 Fax 96197000

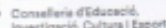

\begin{tabular}{|l|c|}
\hline \multicolumn{2}{|c}{ Registro General } \\
\hline Fecha $07 / 06 / 19$ \\
\hline \multirow{2}{*}{0 alida $\frac{7232}{\mathrm{CN} 00 \mathrm{~A} / 2019 / 163 / 5}$} \\
\hline
\end{tabular}

Carlos Eduardo Pascual Pérez Av/ Castelló $104^{\circ}$ 12560 Benicàssim CASTELLÓ

Ref: SDGCNPE/JM/xg/pr/RR/190606

Proyecto de Investigación: Recordatorio de compromiso con la Secretaria Autonómica de estudio realizado en centros educativos.

27 de marzo de 2018 tuvo entrada en la Secretaría Autonómica de Educación e Investigación

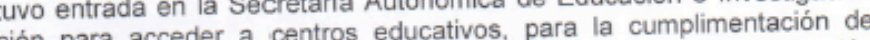
una solicitud de autorización para acceder a centros educativos, para la cumplimentación de cuestionarios por parte del alumnado, con la finalidad de llevar a cabo especificas en el curriculum do enseñanzas profesionales de música".

El Secretario Autonómico de Educación dictó Resolución de 4 de mayo de 2018 el la que se autorizaba su acceso.

Le recordamos que entre la documentación requerida, usted presentó firmado el compromiso de remitir a la Secretaría Autonòmica de Educación los resultados obtenidos o derivados de su estudio. Según nuestro archivo, usted aún tiene pendiente remitirnos dichos resultados.

En el caso de formar parte de una tesis doctoral, no es necesario que nos remita la tesis completa, sino únicamente el capitulo o apartado de la misma en que se reflejan los resultados y las conclusiones de los cuestionarios. Si el estudio o los resultados no están aún terminados nos lo expediente de la solicitud/autorización, indicándonos la fecha estimada de finalización. La Secretaría Autonómica de Educación remite los estudios a los órganos de la Conselleria de

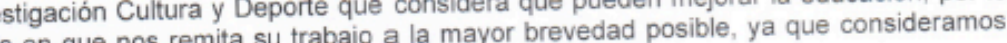
que le insistimos en que nos remita sue suficiente desde su autorización.

que ha transcurrido un tichas las anteriores puntualizaciones, puede remitir la documentación, si lo desea para su comodidad en formato digital, a saei@gva es (asunto: Resultados proyecto de investigación) o a la dirección postal que aparece en el encabezamiento de este recordatorio.

Valencia, 6 de junio de 2019

Subdirector General de Coordinació i Normalització de Processos en Educació

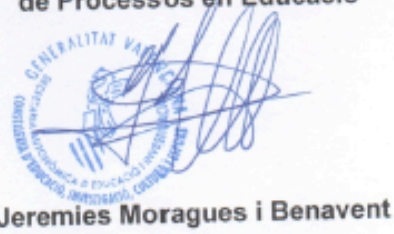


Diseño y planificación de competencias específicas en el currículum de enseñanzas profesionales de música: modalidades composición-dirección en la enseñanza superior.

De: Carlos Pascual cpascualperez igmail.com

Asunto: Resultados proyecto investigacion

Fecha: 12 de junio de 2019, 8:13

Para: saei@gva.es

\section{Buenos dlas,}

En respuesta a la carta recbida con registro de salida 7232 (CNOOAV2019/165/S), en la que se me solicitan los resultados de una investigacion autorizada en 2018, les comunico que dicha investigacion no se ha podido levar a cabo, dado que en el Centro para la que fue autorizada se negaron a llevarla a cabo, incluso estando aprobada por ell Consejo Escolar, y tampoco sirvio la mediacion de la Inspeccion Educativa. Adjunto respuesta del Centro con la negativa de realizar los test-cuestionarios que esta Conselleria autorizo. Y a pesar de esta negativa, se volvio a solicitar por escrito alegando otras propuestas para que fuera reconsiderado, y nunca obtuvimos ni tan siquiera respuesta.

Por ello, no tenemos resultados ni nada que poder comunicarles. La investigacion esta levandose a cabo en otros centros no dependientes de esta Conselleria. Es una verdadera lastima que los propios centros de esta Conselleria sean los que mas trabas $\theta$ impedimentos pongan a la innovacion educativa, y deban de ser los centros privados y municipales los que esten a servicio verdadero de la educacion.

Atentamente,

Carlos Pascual

De: Josquim Garcia Giménez garcia_joagim graves

Asunto: Re: Fwd: Resultados proyecto investigacion

Fecha: 12 de junio de 2019, 13.22

Para: cpascualperez@gmail.com

Buences diss Sr. Carbs

Le informamos que hemos carrado el expediante de su solictivi.

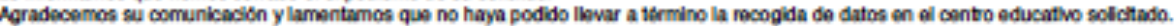

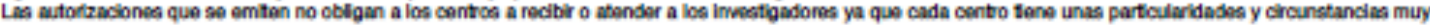
distintas y el paes de cuestonariba, por cualquier motivo puede no ser aportume. Recha un saludo y gracins por la reapuesta.

Asunto: Resultados proyecto imvestigacion

Fecha:Wed, 12 Jun $201909.1337+0200$

De:Carlos Pascual scpascualperez

Para:saeiggva.es

Buence dias.

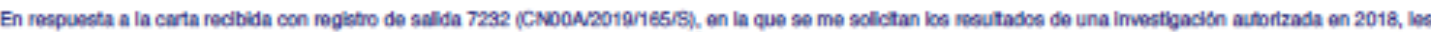

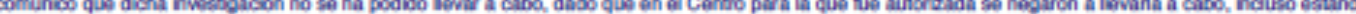

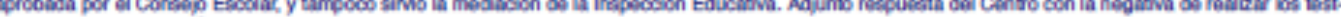

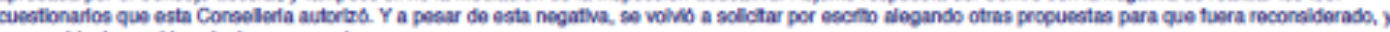
nunca cotuvimos ni tan siqulera reapuesta.

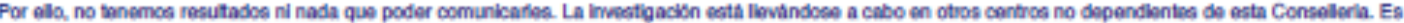

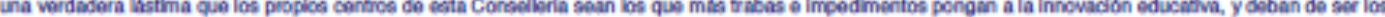
cantros privadca y municipales los que estion al servibio wardadero de la educacion.

Atantamenta.

Cartos Pascual

\section{GENERALITAT VALENCIANA}

Conselleria d'Educació, Investigació, Cultura i Esport
Josquim Gareia Giménez

Assessor Tecnie Docent

Axda. Cammanar, 32

961970822

garcia_joscimat graes 
Diseño y planificación de competencias específicas en el currículum de enseñanzas profesionales de música: modalidades composición-dirección en la enseñanza superior.

\section{Carlos Eduardo Pascual Pérez}

\section{Anexo II}

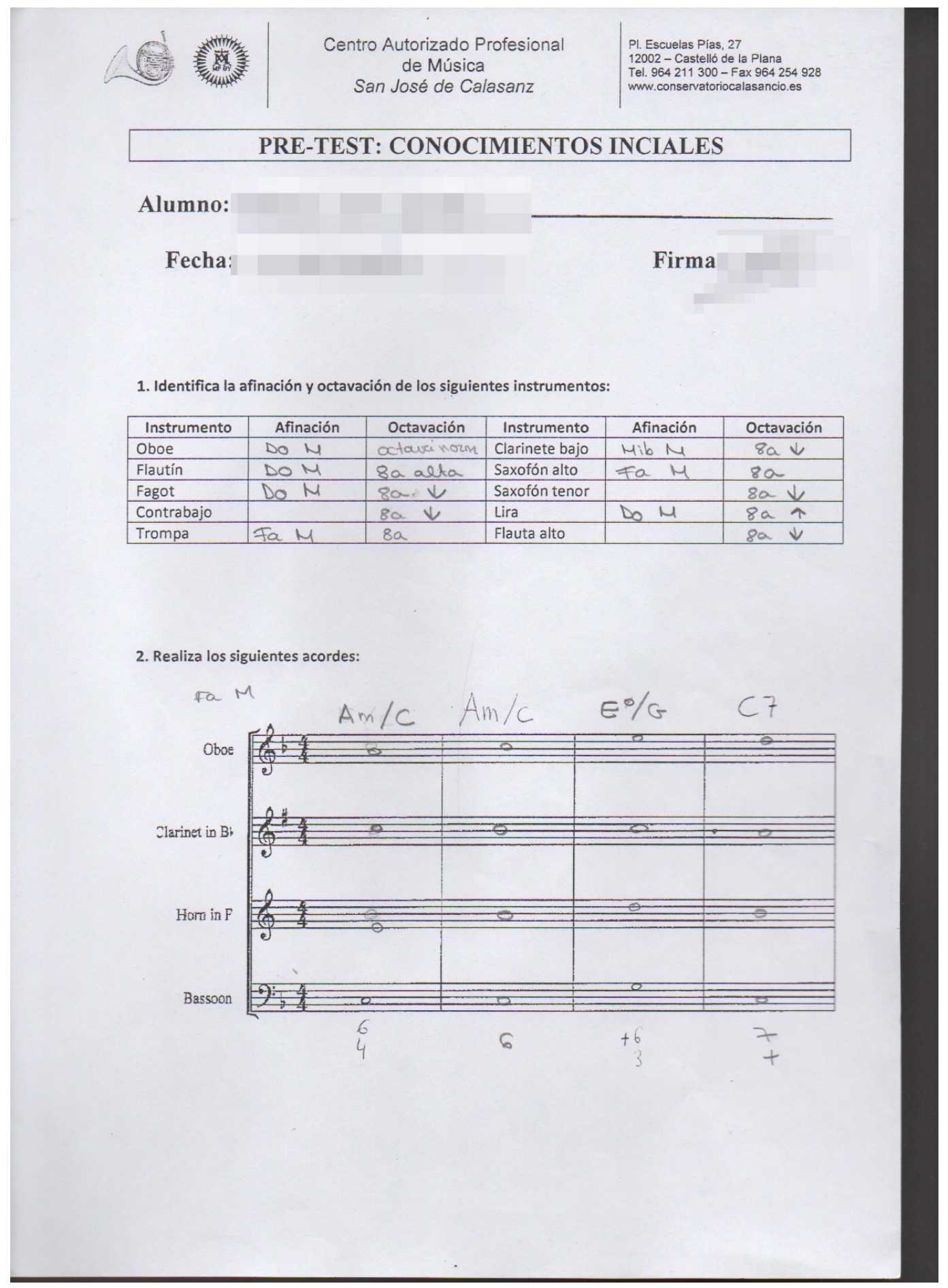


Diseño y planificación de competencias específicas en el currículum de enseñanzas profesionales de música: modalidades composición-dirección en la enseñanza superior.

Carlos Eduardo Pascual Pérez

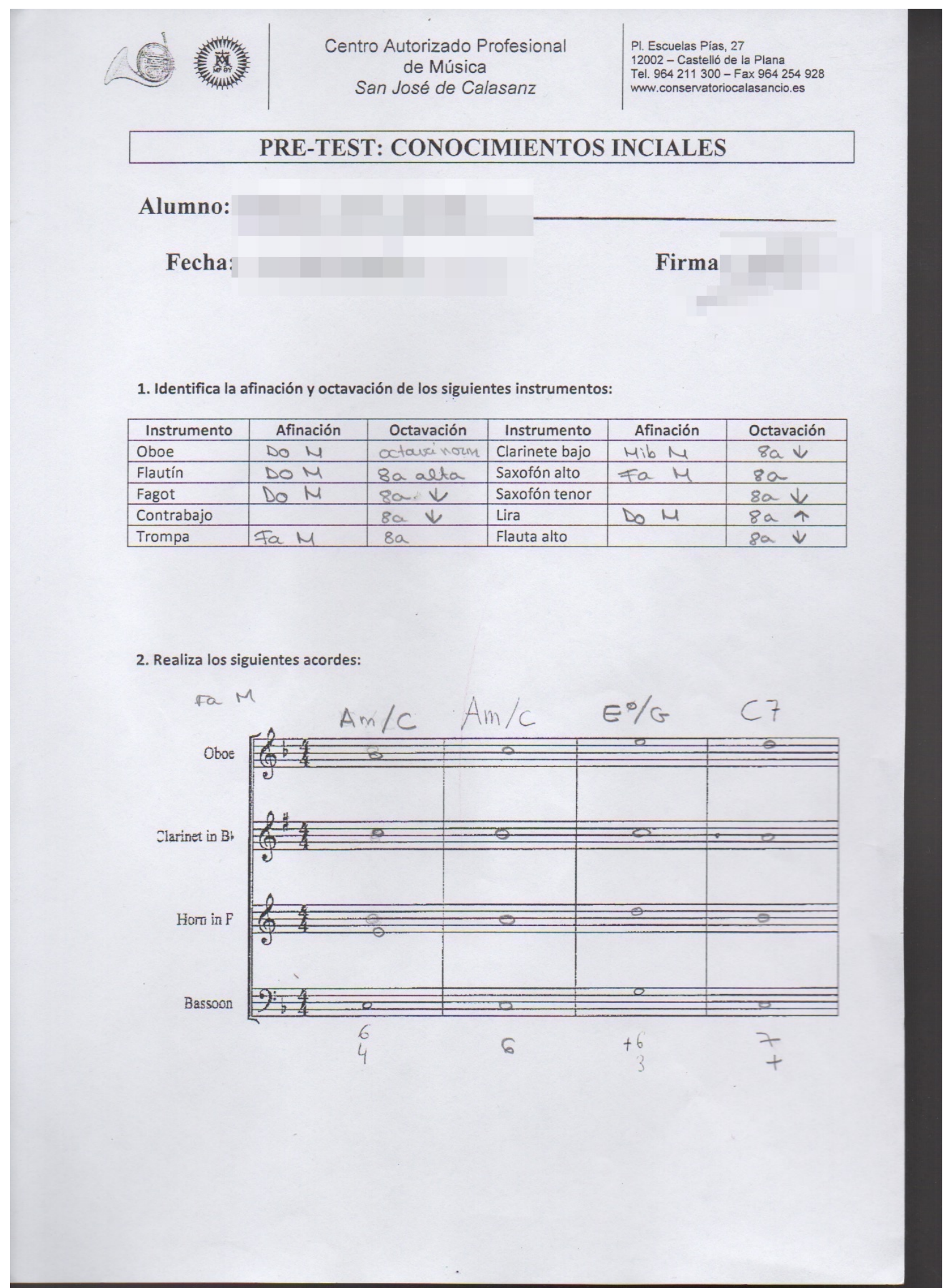


Diseño y planificación de competencias específicas en el currículum de enseñanzas profesionales de música: modalidades composición-dirección en la enseñanza superior

Carlos Eduardo Pascual Pérez
Centro Autorizado Profesional de Música
San José de Calasanz

PI. Escuelas Pias, 27

12002 - Castello de la Plana

Tel. 964211300 - Fax 96425492

unw.conservatoriocalasancio.es

\section{PRE-TEST: CONOCIMIENTOS INCIALES}

Alumno:

Fecha:

Firma:

1. Identifica la afinación y octavación de los siguientes instrumentos:

\begin{tabular}{|l|c|c|l|c|c|}
\hline \multicolumn{1}{|c|}{ Instrumento } & Afinación & Octavación & \multicolumn{1}{|c|}{ Instrumento } & Afinación & Octavación \\
\hline Oboe & & & Clarinete bajo & Bb & \\
\hline Flautín & & & Saxofón alto & & \\
\hline Fagot & & & Saxofón tenor & & \\
\hline Contrabajo & & Lira & & \\
\hline Trompa & $\mathrm{Fa}$ & $\mathrm{NO}$ & Flauta alto & & \\
\hline
\end{tabular}

2. Realiza los siguientes acordes:

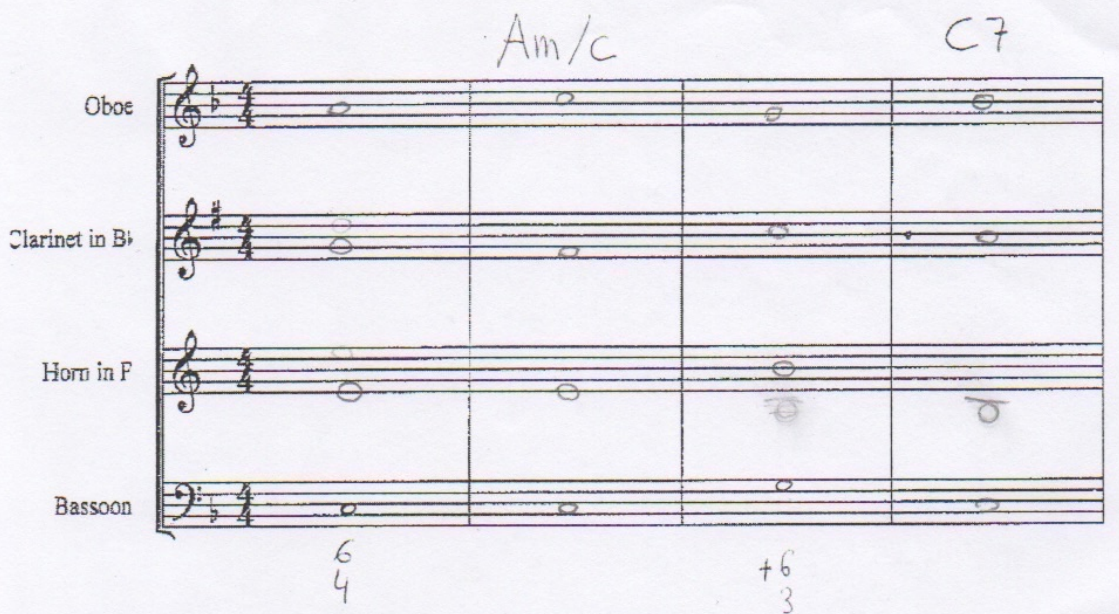


Diseño y planificación de competencias específicas en el currículum de enseñanzas profesionales de música: modalidades composición-dirección en la enseñanza superior

Carlos Eduardo Pascual Pérez

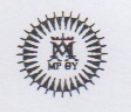

Centro Autorizado Profesional

de Música

San José de Calasanz

I. Escuelas Pias, 27

- Fax 96425492

unw.conservatoriocalasancio.es

\section{PRE-TEST: CONOCIMIENTOS INCIALES}

Alumno:

Fecha:

Firma:

1. Identifica la afinación y octavación de los siguientes instrumentos:

\begin{tabular}{|l|l|l|l|l|l|}
\hline Instrumento & Afinación & Octavación & Instrumento & Afinación & Octavación \\
\hline Oboe & & & Clarinete bajo & & \\
\hline Flautín & & & Saxofón alto & & \\
\hline Fagot & & & Saxofón tenor & & \\
\hline Contrabajo & & & Lira & & \\
\hline Trompa & F & & Flauta alto & & \\
\hline
\end{tabular}

2. Realiza los siguientes acordes:

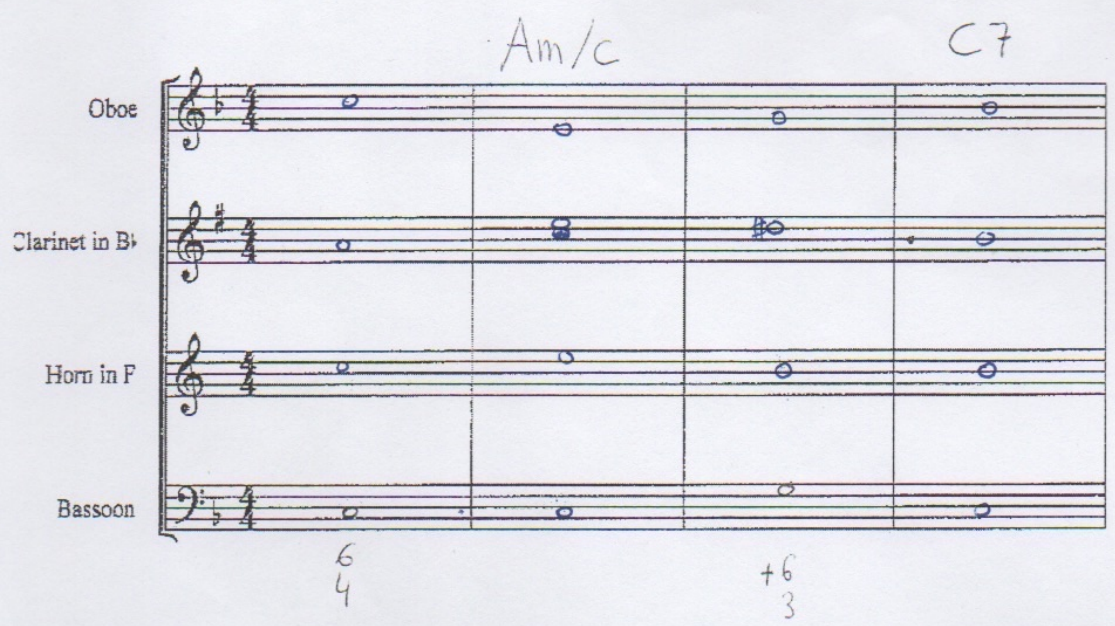


Diseño y planificación de competencias específicas en el currículum de enseñanzas profesionales de música: modalidades composición-dirección en la enseñanza superior.

Carlos Eduardo Pascual Pérez

\section{Centro Autorizado Profesiona de Música \\ San José de Calasanz}

PI. Escuelas Pias, 27

2002 - Castelló de la Plana

Tel. 964211300 - Fax 964254928

unw.conservatoriocalasancio.es

\section{PRE-TEST: CONOCIMIENTOS INCIALES}

Alumno:

Fecha:

Firma:

1. Identifica la afinación y octavación de los siguientes instrumentos:

\begin{tabular}{|l|c|c|l|c|c|}
\hline \multicolumn{1}{|c|}{ Instrumento } & Afinación & Octavación & \multicolumn{1}{|c|}{ Instrumento } & Afinación & Octavación \\
\hline Oboe & DO & - & Clarinete bajo & & \\
\hline Flautín & DO & $8 a$ alta & Saxofón alto & Mib & - \\
\hline Fagot & DO & - & Saxofón tenor & & \\
\hline Contrabajo & DO & $8 a b_{a j a}$ & Lira & & \\
\hline Trompa & FA & - & Flauta alto & DO & - \\
\hline
\end{tabular}

2. Realiza los siguientes acordes:

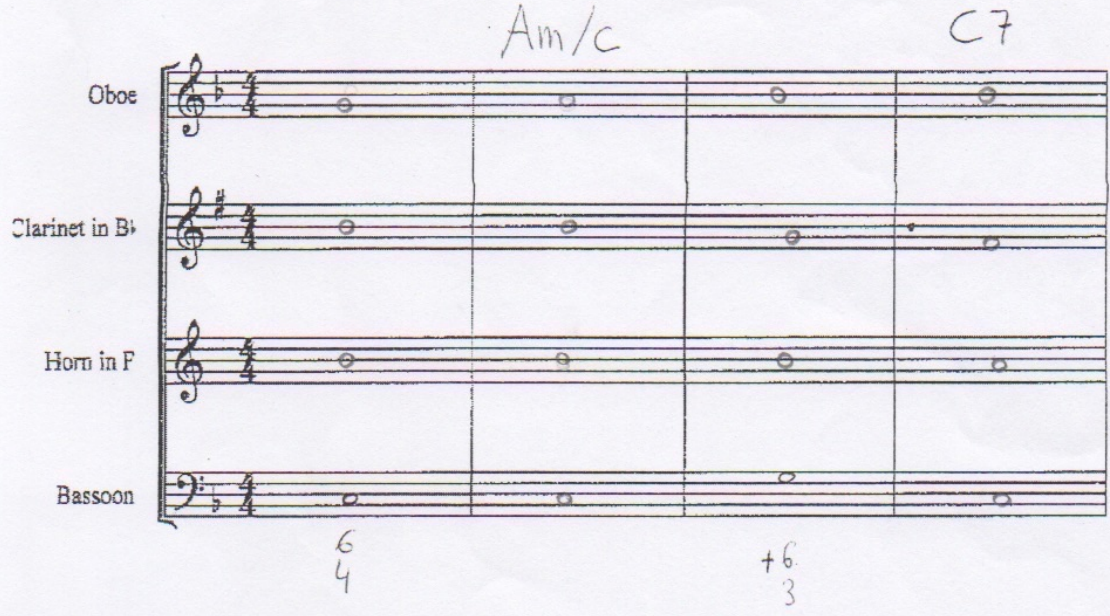


Diseño y planificación de competencias específicas en el currículum de enseñanzas profesionales de música: modalidades composición-dirección en la enseñanza superior

Carlos Eduardo Pascual Pérez

\section{Centro Autorizado Profesiona de Música \\ San José de Calasanz}

PI. Escuelas Pias, 27

2002 - Castelló de la Plana

Tel. 964211300 - Fax 96425492

unw. conservatoriocalasancio.es

\section{PRE-TEST: CONOCIMIENTOS INCIALES}

Alumno:

Fecha:

Firma:

1. Identifica la afinación y octavación de los siguientes instrumentos:

\begin{tabular}{|l|c|c|l|l|c|}
\hline \multicolumn{1}{|l|}{ Instrumento } & Afinación & Octavación & \multicolumn{1}{|l|}{ Instrumento } & Afinación & Octavación \\
\hline Oboe & DO & - & Clarinete bajo & & \\
\hline Flautín & PO & $8^{n}$ ACTA & Saxofón alto & & \\
\hline Fagot & DO & - & Saxofón tenor & & \\
\hline Contrabajo & DO & $8^{C}$ BAJA & Lira & DO & $8^{2}$ ACiA \\
\hline Trompa & FA & - & Flauta alto & DO & - \\
\hline
\end{tabular}

2. Realiza los siguientes acordes:

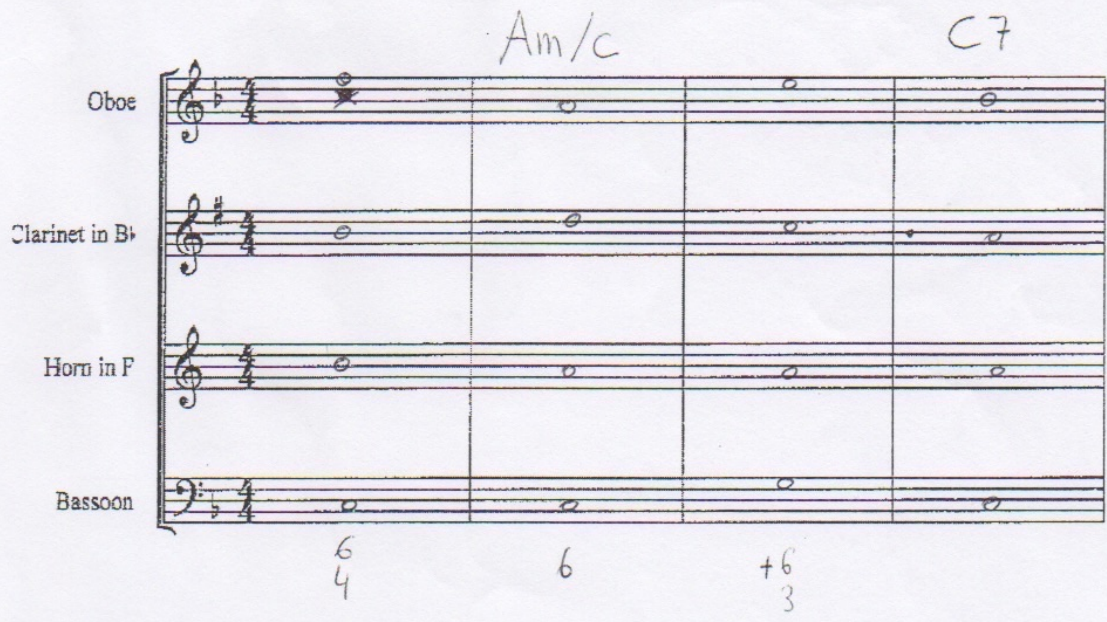


Diseño y planificación de competencias específicas en el currículum de enseñanzas profesionales de música: modalidades composición-dirección en la enseñanza superior.

Carlos Eduardo Pascual Pérez

\section{Centro Autorizado Profesional de Música \\ San José de Calasanz}

PI. Escuelas Pías, 27

12002 - Castelló de la Plana

Tel. 964211300 - Fax 964254928

www.conservatoriocalasancio.es

\section{PRE-TEST: CONOCIMIENTOS INCIALES}

Alumno:

Fecha:

Firma:

1. Identifica la afinación y octavación de los siguientes instrumentos:

\begin{tabular}{|c|c|c|c|c|c|}
\hline Instrumento & Afinación & Octavación & Instrumento & Afinación & Octavación \\
\hline Oboe & Sib & & Clarinete bajo & Si $b$ & \\
\hline Flautín & D $M$ & & Saxofón alto & $\mu_{i} b$ & \\
\hline Fagot & & 5 & Saxofón tenor & Si $b$ & \\
\hline Contrabajo & $D M$ & $18^{n} v$ & Lira & & $1-8^{a} \uparrow$ \\
\hline Trompa & Fa M & & Flauta alto & Sol $M$ & \\
\hline
\end{tabular}

2. Realiza los siguientes acordes:

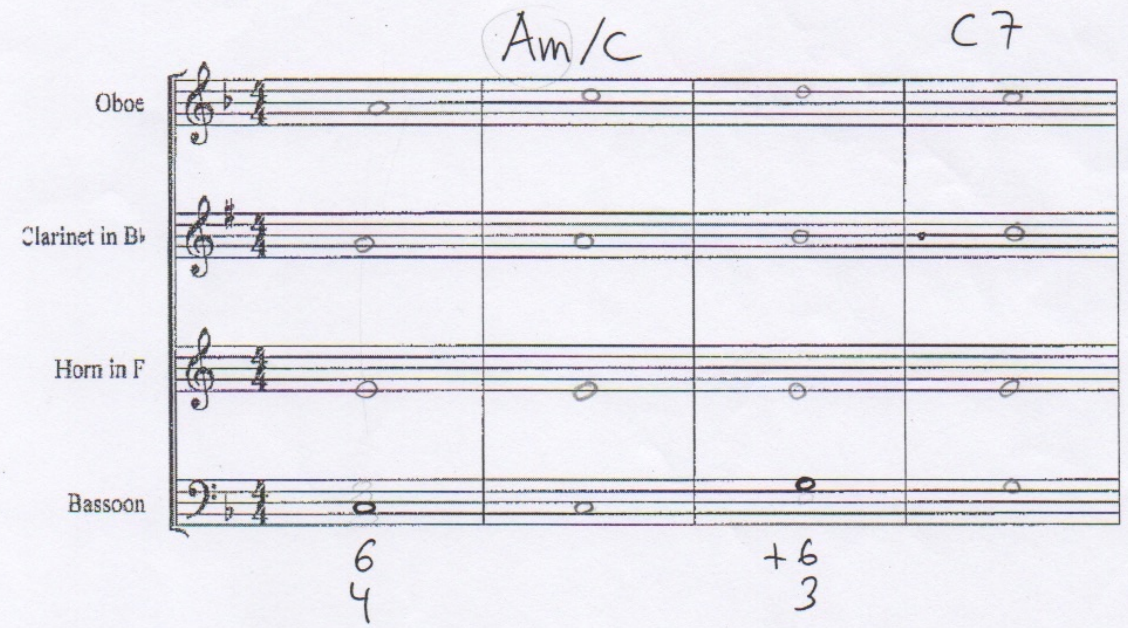


Diseño y planificación de competencias específicas en el currículum de enseñanzas profesionales de música: modalidades composición-dirección en la enseñanza superior.

Carlos Eduardo Pascual Pérez

\section{Centro Autorizado Profesional de Música \\ San José de Calasanz}

PI. Escuelas Pias, 27

12002 - Castelló de la Plana

Tel. 964211300 - Fax 964254928

www.conservatoriocalasancio.es

\section{PRE-TEST: CONOCIMIENTOS INCIALES}

Alumno:

Fecha:

Firma:

1. Identifica la afinación y octavación de los siguientes instrumentos:

\begin{tabular}{|c|c|c|c|c|c|}
\hline Instrumento & Afinación & Octavación & Instrumento & Afinación & Octavación \\
\hline Oboe & Mormal & ADD & Clarinete bajo & Es & si $8=$ fran \\
\hline Flautín & nnel & $\dot{r} \nabla=$ alfe & Saxofón alto & ES & No \\
\hline Fagot & & si 8 grave & Saxofón tenor & $B b$ & No \\
\hline Contrabajo & urkeal & 8. 8"que & Lira & nomal & li \\
\hline Trompa & & No & Flauta alto & movice & $8=a l$ \\
\hline
\end{tabular}

2. Realiza los siguientes acordes:

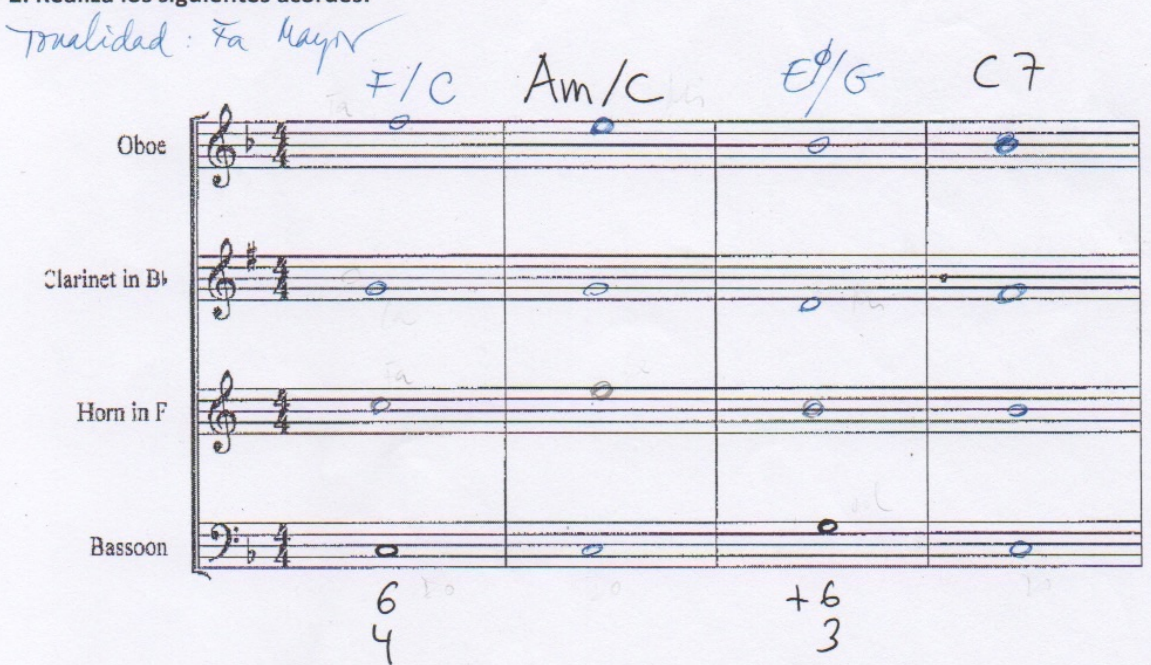


Diseño y planificación de competencias específicas en el currículum de enseñanzas profesionales de música: modalidades composición-dirección en la enseñanza superior.

Carlos Eduardo Pascual Pérez

\author{
Centro Autorizado Profesional \\ de Música \\ San José de Calasanz
}

P. Escuelas Pias, 27

12002 - Castelló de la Plana

Tel. $964211300-$ Fax 964254928

www.conservatoriocalasancio.es

\title{
PRE-TEST: CONOCIMIENTOS INCIALES
}

\section{Alumno:}

Fecha:

Firma:

1. Identifica la afinación y octavación de los siguientes instrumentos:

\begin{tabular}{|c|c|c|c|c|c|}
\hline Instrumento & Afinación & Octavación & Instrumento & Afinación & Octavación \\
\hline Oboe & $C_{a}$ & & Clarinete bajo & Si & \\
\hline Flautín & La & $\pi 8^{a}$ & Saxofón alto & mib & \\
\hline Fagot & & . & Saxofón tenor & uso do & \\
\hline Contrabajo & do & & Lira & La & \\
\hline Trompa & Sib & & Flauta alto & La & \\
\hline
\end{tabular}

2. Realiza los siguientes acordes:

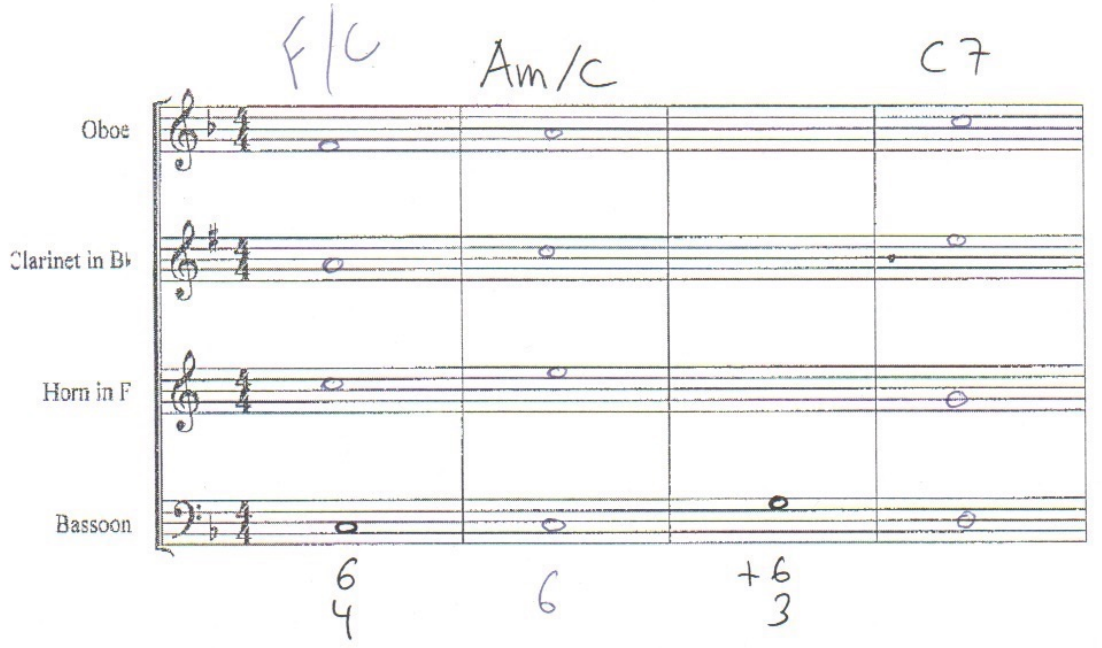


Diseño y planificación de competencias específicas en el currículum de enseñanzas profesionales de música: modalidades composición-dirección en la enseñanza superior.

\title{
Carlos Eduardo Pascual Pérez
}

\author{
Centro Autorizado Profesional \\ de Música \\ San José de Calasanz
}

PI. Escuelas Pías, 27

12002 - Castelló de la Plana

Tel. 964211300 - Fax 964254928

www.conservatoriocalasancio.es

\section{PRE-TEST: CONOCIMIENTOS INCIALES}

\section{Alumno:}

Fecha:

Firma:

1. Identifica la afinación y octavación de los siguientes instrumentos:

\begin{tabular}{|l|l|l|l|l|l|}
\hline \multicolumn{1}{|l|}{ Instrumento } & Afinación & Octavación & \multicolumn{1}{|l|}{ Instrumento } & Afinación & Octavación \\
\hline Oboe & Sib & & Clarinete bajo & Si & \\
\hline Flautín & Do & $18^{a} \uparrow$ & Saxofón alto & Mib & \\
\hline Fagot & Do & & Saxofón tenor & Fa & \\
\hline Contrabajo & Sol & 40 ctava $\downarrow$ & Lira & OO & \\
\hline Trompa & $\mathrm{Fa}$ & & Flauta alto & Do &
\end{tabular}

2. Realiza los siguientes acordes:

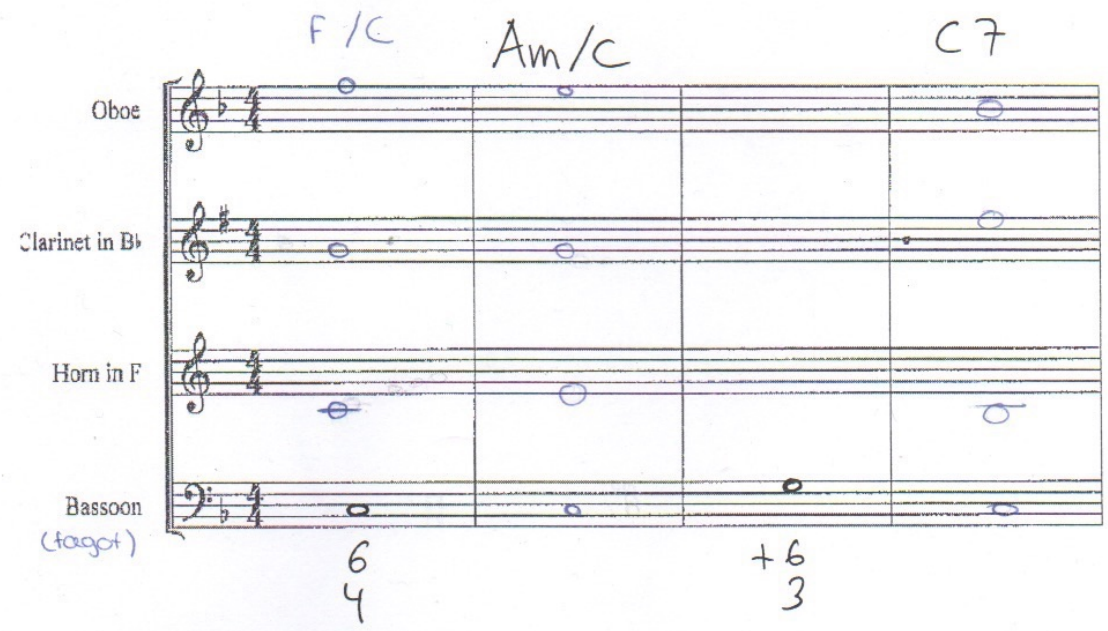


Diseño y planificación de competencias específicas en el currículum de enseñanzas profesionales de música: modalidades composición-dirección en la enseñanza superior

Carlos Eduardo Pascual Pérez

\section{Centro Autorizado Profesiona de Música}

San José de Calasanz
PI. Escuelas Pias, 27

12002 - Castello de la Plana

Tel. 964211300 - Fax 96425492

www.conservatoriocalasancio.es

\section{PRE-TEST: CONOCIMIENTOS INCIALES}

Alumno:

Fecha:

Firma:

1. Identifica la afinación y octavación de los siguientes instrumentos:

\begin{tabular}{|c|c|c|c|c|c|}
\hline Instrumento & Afinación & Octavación & Instrumento & Afinación & Octavación \\
\hline Oboe & sib & - & Clarinete bajo & sib & - \\
\hline Flautín & Do & $8 a T$ & Saxofón alto & sib & - \\
\hline Fagot & kess sib & - & Saxofón tenor & $M i b$ & - \\
\hline Contrabajo & Mib & $8 a \downarrow$ & Lira & Mib & $8 a T$ \\
\hline Trompa & $D \theta$ & - & Flauta alto & sib & S2a - \\
\hline
\end{tabular}

2. Realiza los siguientes acordes:

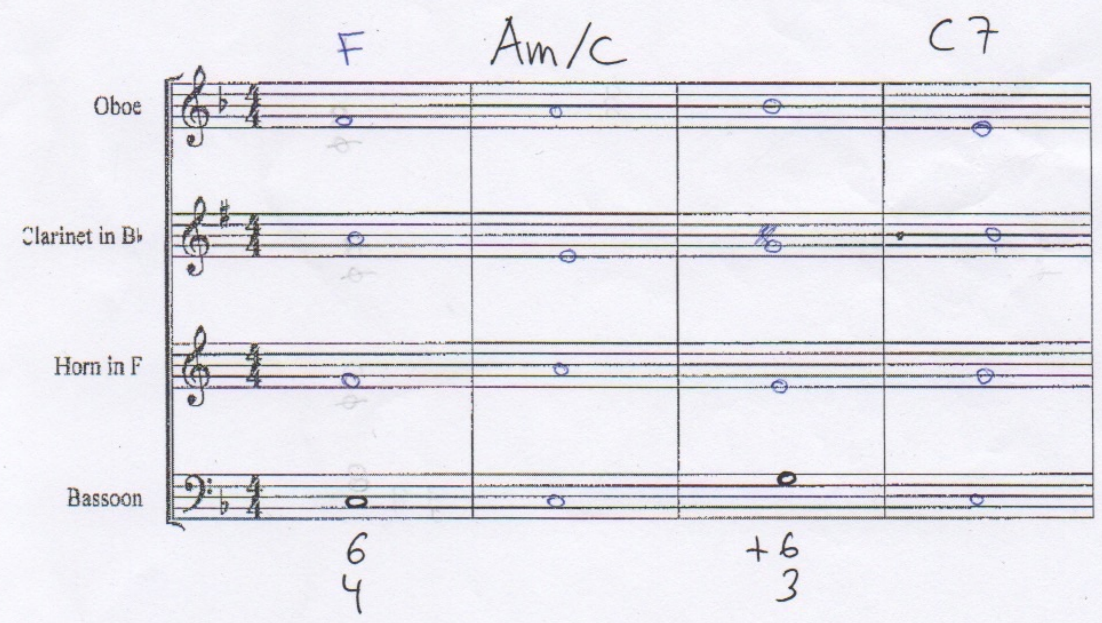


Diseño y planificación de competencias específicas en el currículum de enseñanzas profesionales de música: modalidades composición-dirección en la enseñanza superior.

Carlos Eduardo Pascual Pérez

\section{Centro Autorizado Profesional de Música}

San José de Calasanz
PI. Escuelas Pias, 27

2002 - Castelló de la Plana

Tel. 964211300 - Fax 964254928

www.conservatoriocalasancio.es

\section{PRE-TEST: CONOCIMIENTOS INCIALES}

Alumno:

Fecha:

Firma:

1. Identifica la afinación y octavación de los siguientes instrumentos:

\begin{tabular}{|l|l|l|l|c|c|}
\hline Instrumento & Afinación & Octavación & \multicolumn{1}{|c|}{ Instrumento } & Afinación & Octavación \\
\hline Oboe & & & Clarinete bajo & MibM & \\
\hline Flautín & & & Saxofón alto & & +2 \\
\hline Fagot & SibM & -2 & Saxofón tenor & SibM & \\
\hline Contrabajo & & & Lira & & \\
\hline Trompa & & & Flauta alto & & \\
\hline
\end{tabular}

2. Realiza los siguientes acordes:

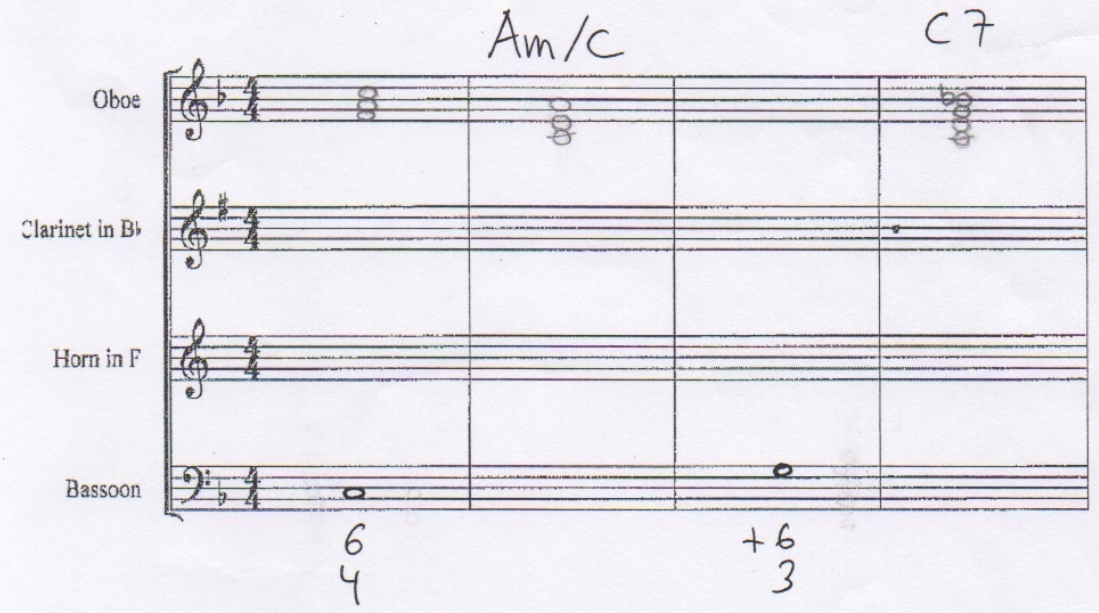


Diseño y planificación de competencias específicas en el currículum de enseñanzas profesionales de música: modalidades composición-dirección en la enseñanza superior.

Carlos Eduardo Pascual Pérez

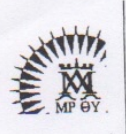
Centro Autorizado Profesional de Música

San José de Calasanz

\section{PRE-TEST: CONOCIMIENTOS INCIALES}

Alumno:

Fecha

Firma:

1. Identifica la afinación y octavación de los siguientes instrumentos:

\begin{tabular}{|l|c|c|l|c|c|}
\hline \multicolumn{1}{|c|}{ Instrumento } & Afinación & Octavación & Instrumento & Afinación & Octavación \\
\hline Oboe & SibM & +1 & Clarinete bajo & M,bM & 0 \\
\hline Flautín & MibM & +2 & Saxofón alto & SibM & +2 \\
\hline Fagot & SibM & 0 & Saxofón tenor & SibM & +1 \\
\hline Contrabajo & Do M & -2 & Lira & MibM & 0 \\
\hline Trompa & MibM & - & Flauta alto & SibM & +2 \\
\hline
\end{tabular}

2. Realiza los siguientes acordes:

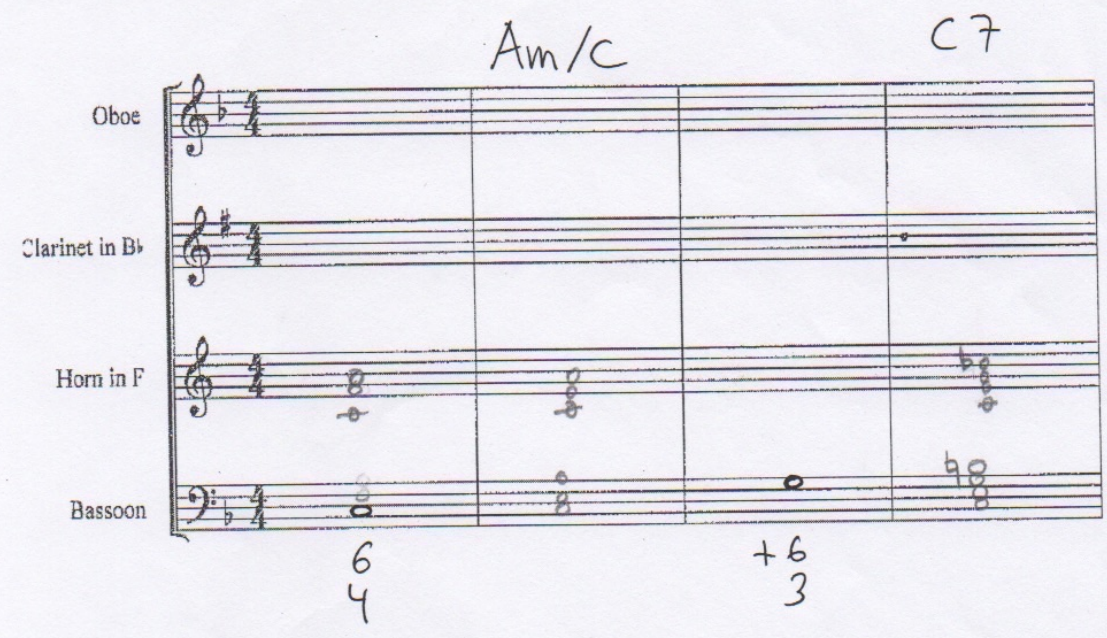


Diseño y planificación de competencias específicas en el currículum de enseñanzas profesionales de música: modalidades composición-dirección en la enseñanza superior.

\title{
Carlos Eduardo Pascual Pérez
}

\author{
Centro Autorizado Profesional \\ de Música
}

San José de Calasanz

12002 - Castelló de la Plana

Tel. 964211300 - Fax 964254928

www. conservatoriocalasancio.es

\section{PRE-TEST: CONOCIMIENTOS INCIALES}

Alumno:

Fecha:

Firma:

1. Identifica la afinación y octavación de los siguientes instrumentos:

\begin{tabular}{|l|l|l|l|l|c|}
\hline \multicolumn{1}{|c|}{ Instrumento } & \multicolumn{1}{|c|}{ Afinación } & Octavación & \multicolumn{1}{|c|}{ Instrumento } & \multicolumn{1}{c|}{ Afinación } & Octavación \\
\hline Oboe & Sib & & Clarinete bajo & Sib & \\
\hline Flautín & Do & $\uparrow$ & Saxofón alto & Mib & \\
\hline Fagot & Mib & & Saxofón tenor & Sib & \\
\hline Contrabajo & Mib & $\downarrow$ & Lira & Fa & $\uparrow$ \\
\hline Trompa & Fa & & Flauta alto & Do & \\
\hline
\end{tabular}

2. Realiza los siguientes acordes:

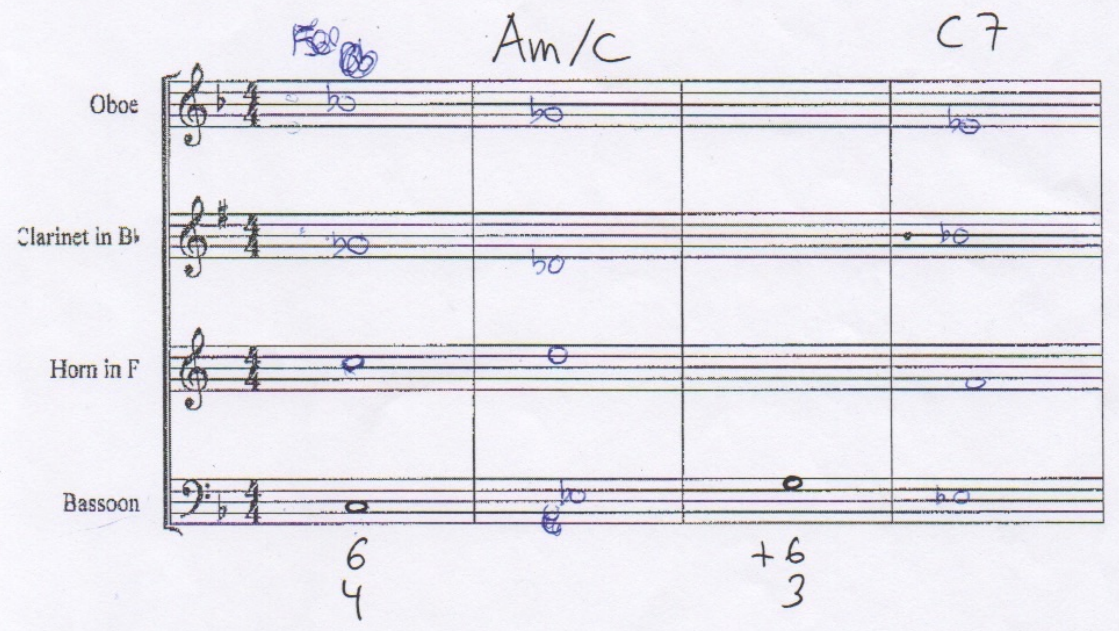


Diseño y planificación de competencias específicas en el currículum de enseñanzas profesionales de música: modalidades composición-dirección en la enseñanza superior.

Carlos Eduardo Pascual Pérez

\section{Centro Autorizado Profesional de Música \\ San José de Calasanz}

PI. Escuelas Pias, 27

12002 - Castelló de la Plana

Tel. 964211300 - Fax 964254928

www.conservatoriocalasancio.es

\section{PRE-TEST: CONOCIMIENTOS INCIALES}

\section{Alumno:}

Fecha

Firma:

1. Identifica la afinación y octavación de los siguientes instrumentos:

\begin{tabular}{|c|c|c|c|c|c|}
\hline Instrumento & Afinación & Octavación & Instrumento & Afinación & Octavación \\
\hline Oboe & Do & & Clarinete bajo & $M_{i b}$ & una $8^{a}$ por abeje \\
\hline Flautín & Do 8 & Uno $8^{\circ}$ arriba & Saxofón alto & Me & \\
\hline Fagot & 4 & 5 & Saxofón tenor & cib & Wha $8^{2}$ \\
\hline Contrabajo & Do & $18^{a}$ per abyo & Lira & RuM & Unc $8^{h} \mathrm{crribs}$ \\
\hline Trompa & & & Flauta alto & $D_{2} M$ & \\
\hline
\end{tabular}

2. Realiza los siguientes acordes:

$$
\text { C } 7
$$

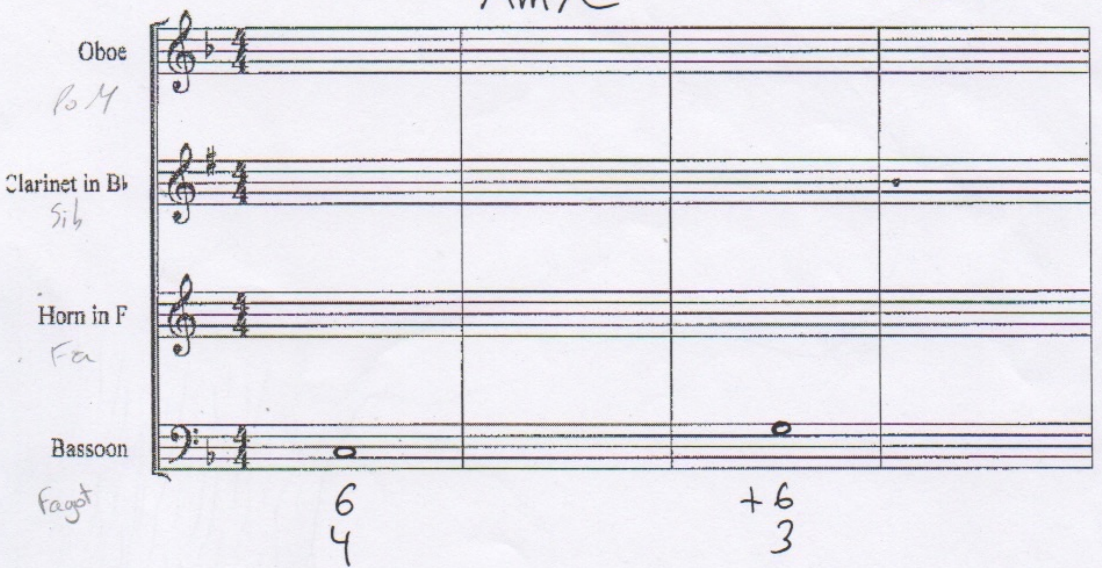


Diseño y planificación de competencias específicas en el currículum de enseñanzas profesionales de música: modalidades composición-dirección en la enseñanza superior.

Carlos Eduardo Pascual Pérez

Centro Autorizado Profesional de Música

San José de Calasanz
PI. Escuelas Pias, 27

Tel. 964211300 - Fax 964254928

www. conservatoriocalasancio.es

\section{PRE-TEST: CONOCIMIENTOS INCIALES}

Alumno:

Fecha:

Firma

1. Identifica la afinación y octavación de los siguientes instrumentos:

\begin{tabular}{|c|c|c|c|c|c|}
\hline Instrumento & Afinación & Octavación & Instrumento & Afinación & Octavación \\
\hline Oboe & DOM & detavavorma & Clarinete bajo & SibM & octavab \\
\hline Flautín & POM & una $8^{\circ} \uparrow$ & Saxofón alto & Mi bM & ertind \\
\hline Fagot & DOM & una. $8^{\circ} \downarrow$ & Saxofón tenor & SibM & octava $\downarrow$ \\
\hline Contrabajo & DOM & dos $8^{\circ} \downarrow$ & Lira & DOM & $18^{a} \uparrow$ \\
\hline Trompa & FaM & $8^{\text {a normal }}$ & Flauta alto & DOM & octava nound \\
\hline
\end{tabular}

2. Realiza los siguientes acordes:

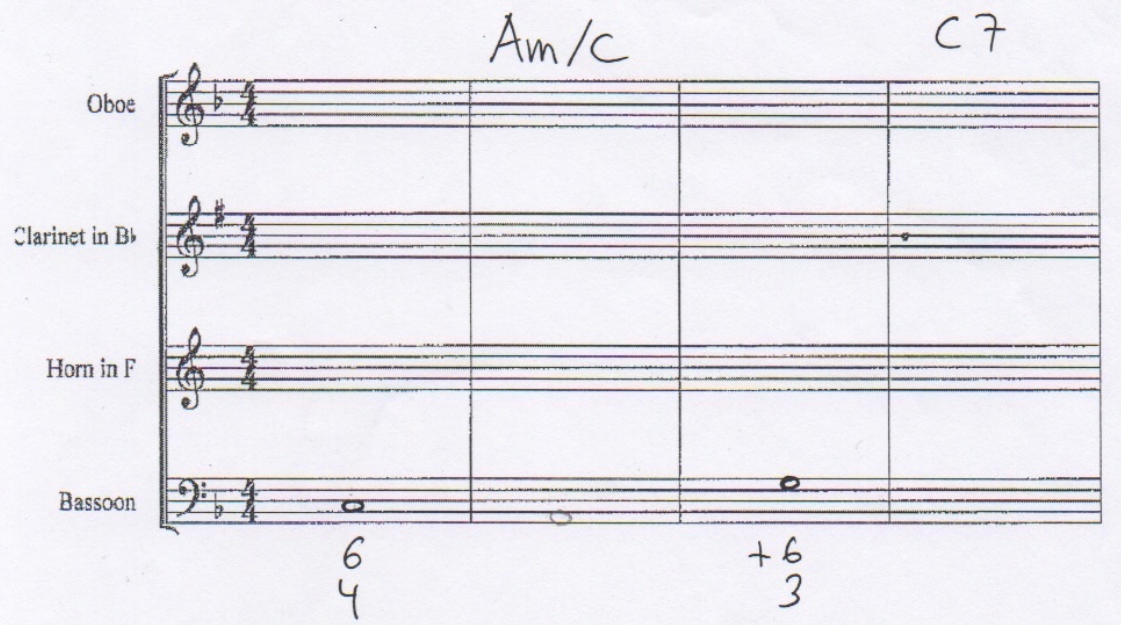


Diseño y planificación de competencias específicas en el currículum de enseñanzas profesionales de música: modalidades composición-dirección en la enseñanza superior.

Carlos Eduardo Pascual Pérez

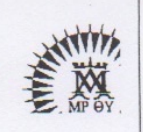
Centro Autorizado Profesional de Música

San José de Calasanz

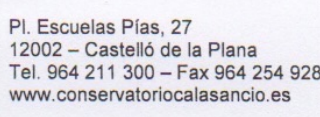

\section{PRE-TEST: CONOCIMIENTOS INCIALES}

Alumno:

Fecha:

Firm

1. Identifica la afinación y octavación de los siguientes instrumentos:

\begin{tabular}{|c|c|c|c|c|c|}
\hline Instrumento & Afinación & Octavación & Instrumento & Afinación & Octavación \\
\hline Oboe & DO M & & Clarinete bajo & sib $b$ & octava I \\
\hline Flautín & DO M & octava $\hat{\imath}$ & Saxofón alto & Mi b M & \\
\hline Fagot & $D N M$ & & Saxofón tenor & si bM & octava I \\
\hline Contrabajo & $D C M$ & 2 actaulas & Lira & Do M & octava 个 \\
\hline Trompa & Facturasents & & Flauta alto & DO M & \\
\hline
\end{tabular}

2. Realiza los siguientes acordes:

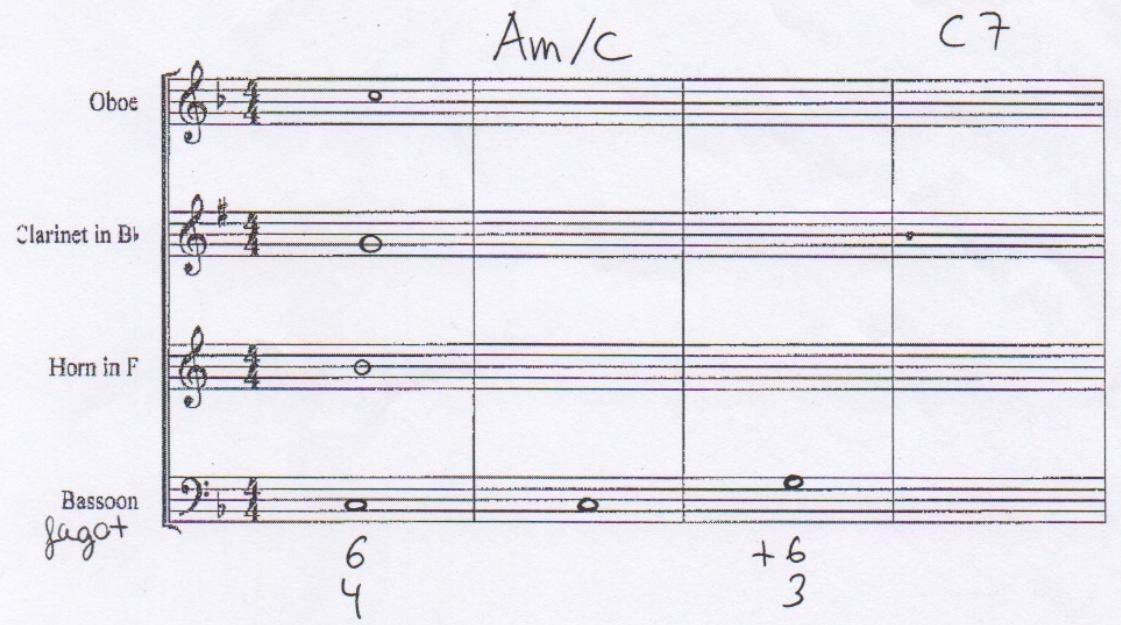


Diseño y planificación de competencias específicas en el currículum de enseñanzas profesionales de música: modalidades composición-dirección en la enseñanza superior.

Carlos Eduardo Pascual Pérez

Centro Autorizado Profesional de Música

San José de Calasanz
PI. Escuelas Pías, 27

12002 - Castelló de la Plana

Tel. $964211300-$ Fax 964254928

www.conservatoriocalasancio.es

\section{PRE-TEST: CONOCIMIENTOS INCIALES}

Alumno:

Fecha:

Firma:

1. Identifica la afinación y octavación de los siguientes instrumentos:

\begin{tabular}{|c|c|c|c|c|c|}
\hline Instrumento & Afinación & Octavación & Instrumento & Afinación & Octavación \\
\hline Oboe & DO & & Clarinete bajo & sib & \\
\hline Flautín & 00 & $\Lambda \uparrow$ & Saxofón alto & Mib & \\
\hline Fagot & DO & 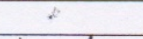 & Saxofón tenor & & \\
\hline Contrabajo & SOL & $b$ & Lira & DO & \\
\hline Trompa & $\mathrm{Fa}$ & & Flauta alto & DO & \\
\hline
\end{tabular}

2. Realiza los siguientes acordes:

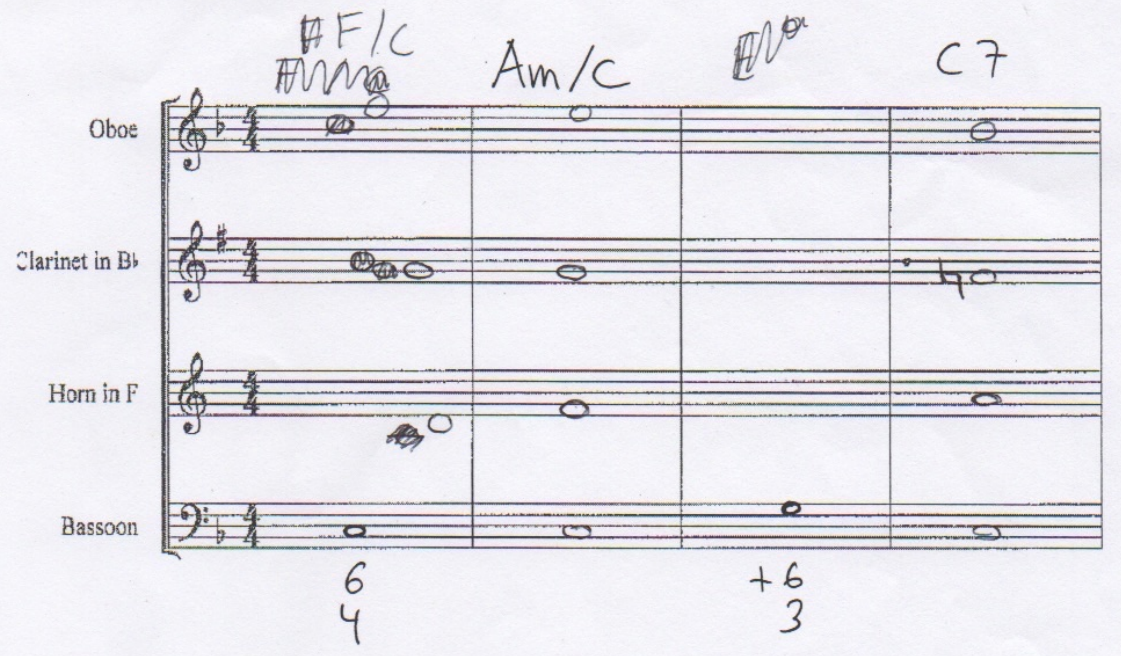


Diseño y planificación de competencias específicas en el currículum de enseñanzas profesionales de música: modalidades composición-dirección en la enseñanza superior.

Carlos Eduardo Pascual Pérez

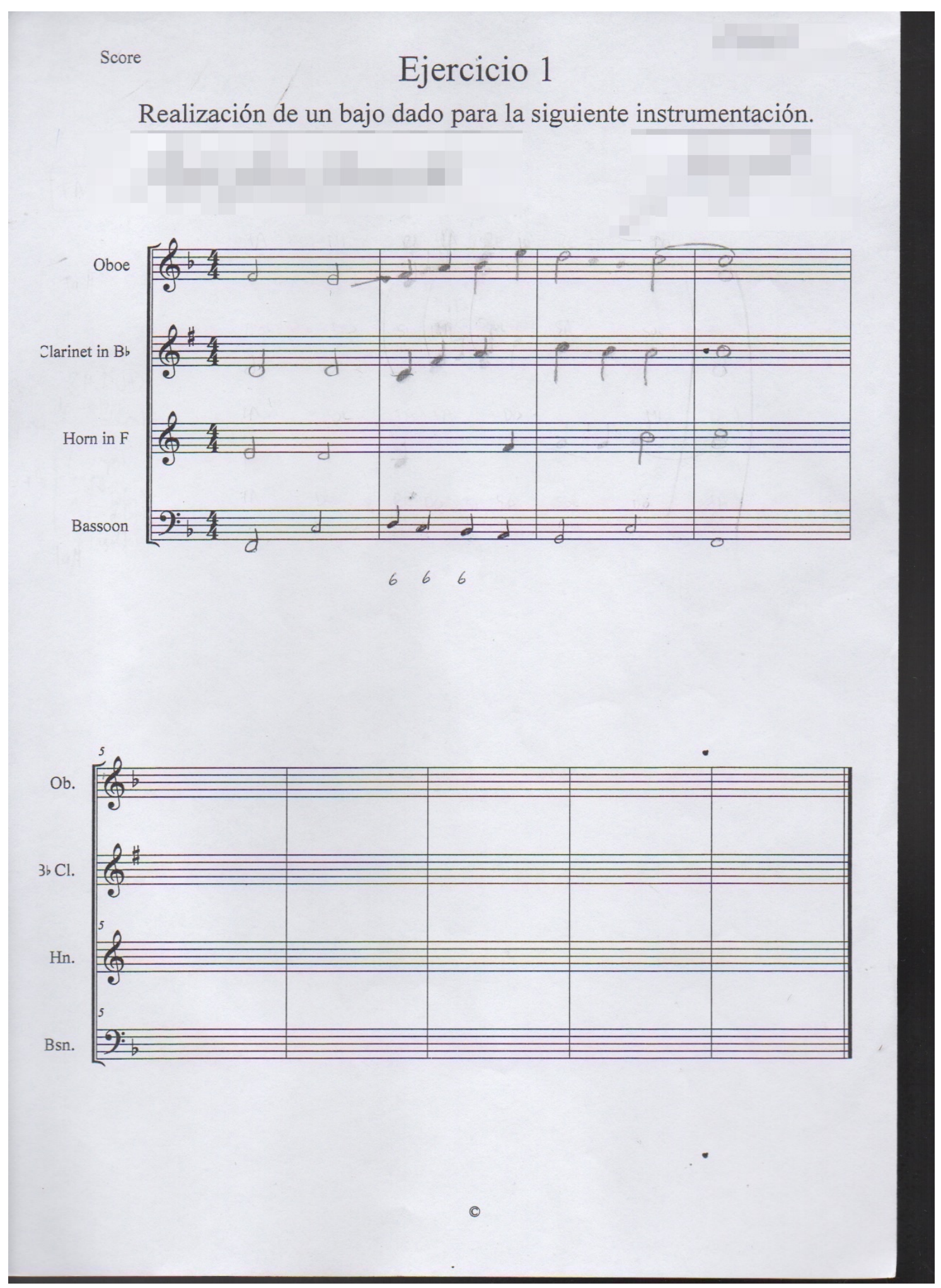


Diseño y planificación de competencias específicas en el currículum de enseñanzas profesionales de música: modalidades composición-dirección en la enseñanza superior.

\section{Carlos Eduardo Pascual Pérez}

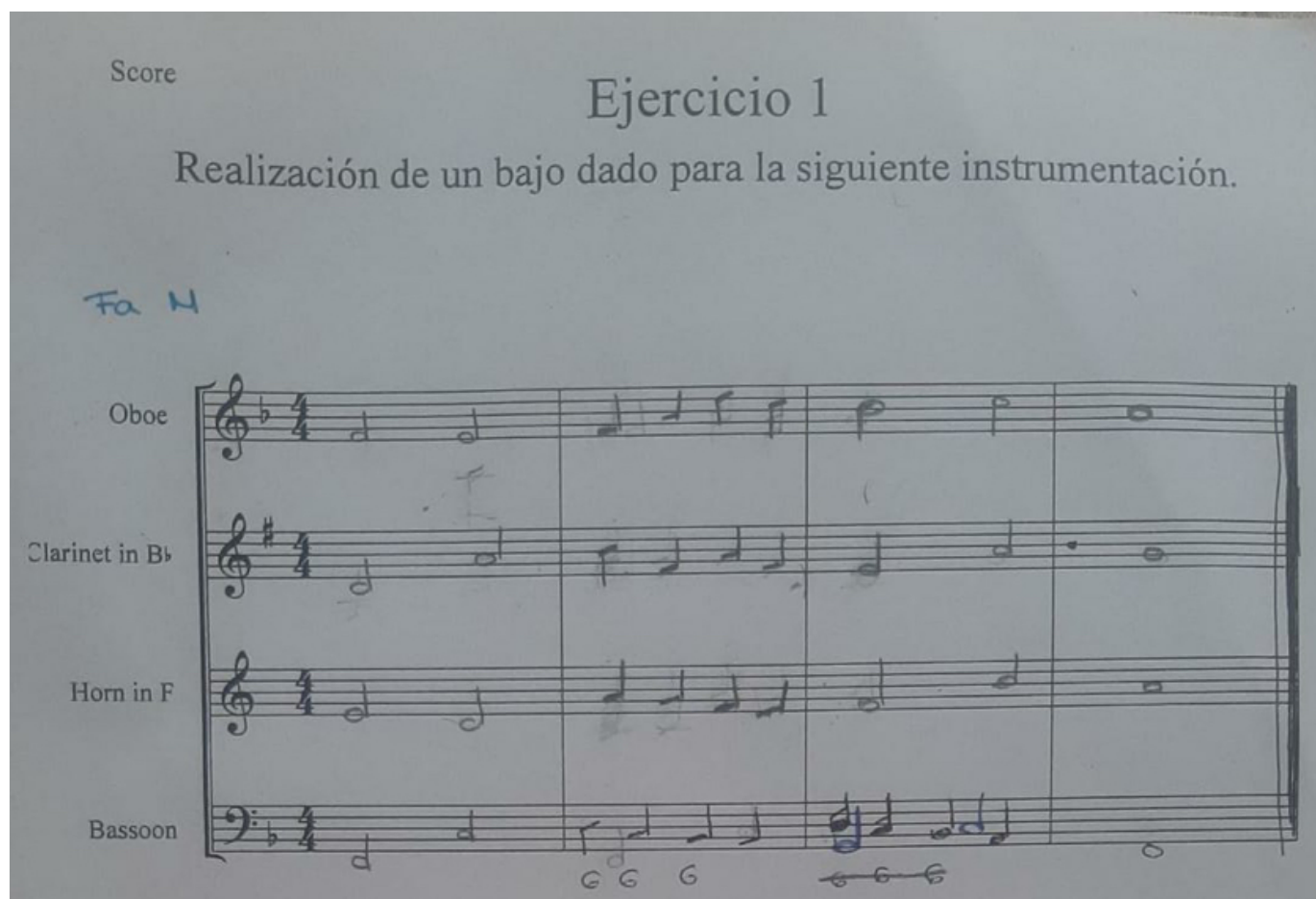

$\mathrm{Ob}$

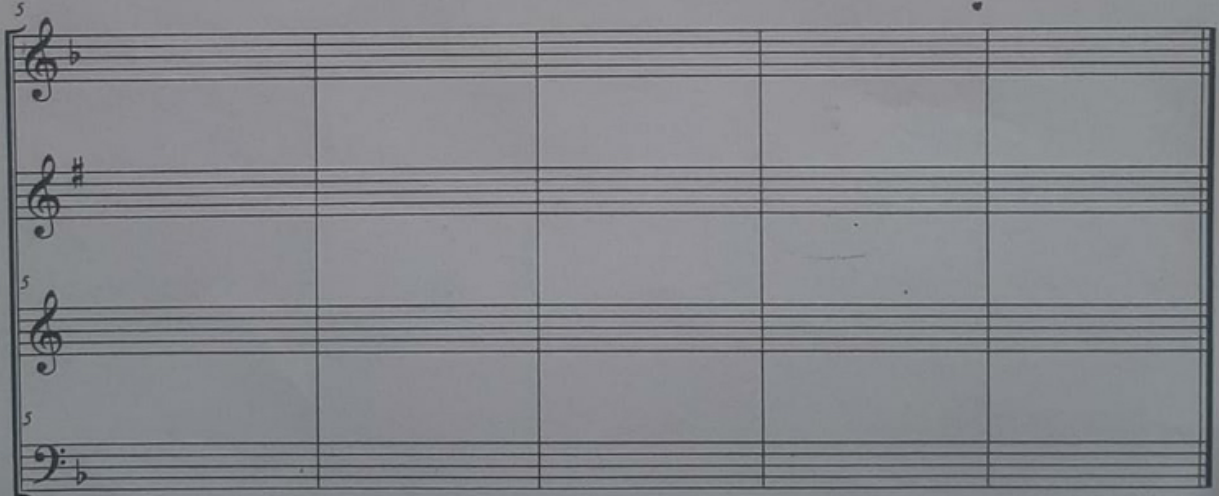


Diseño y planificación de competencias específicas en el currículum de enseñanzas profesionales de música: modalidades composición-dirección en la enseñanza superior.

Carlos Eduardo Pascual Pérez

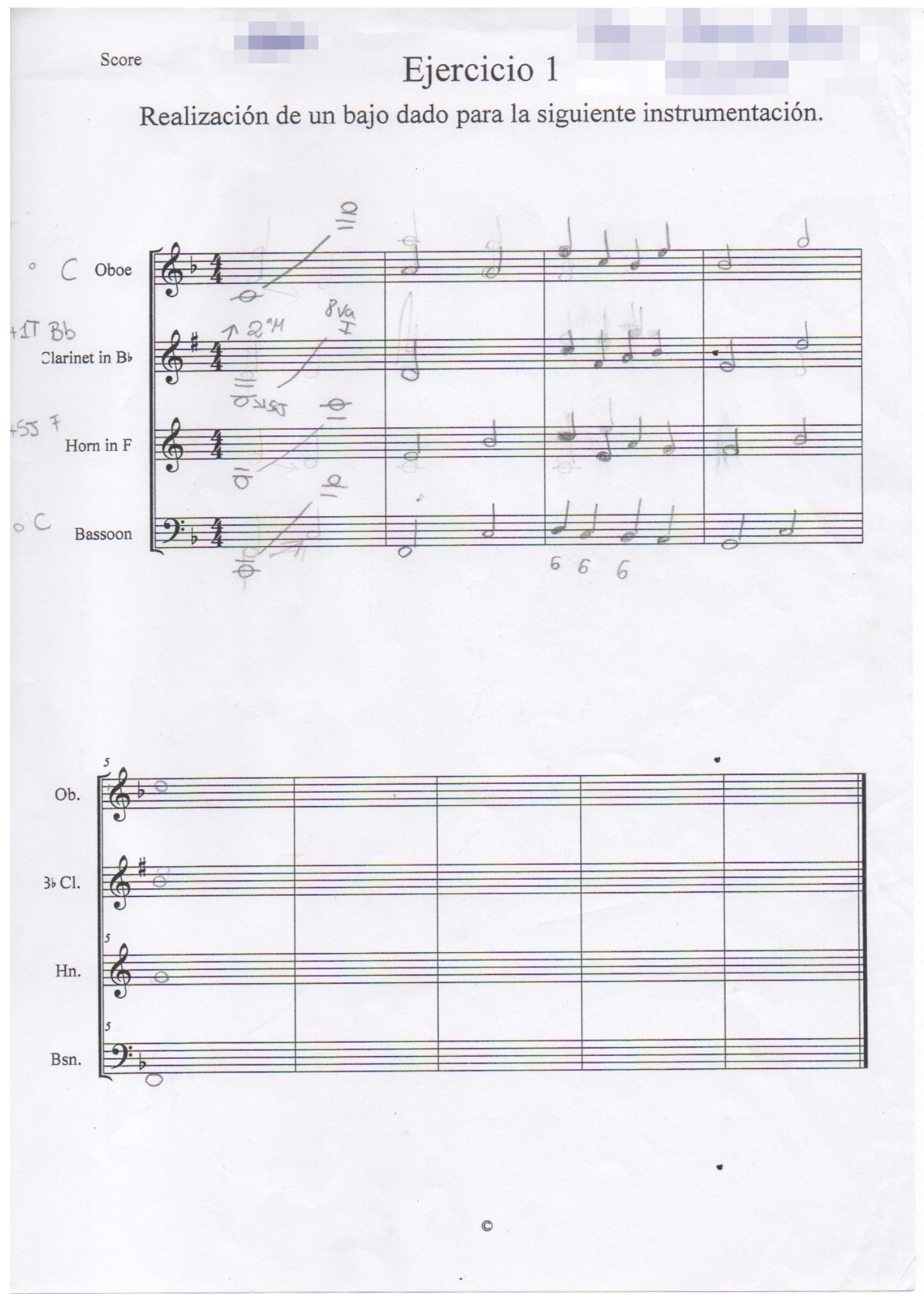


Diseño y planificación de competencias específicas en el currículum de enseñanzas profesionales de música: modalidades composición-dirección en la enseñanza superior.

Carlos Eduardo Pascual Pérez

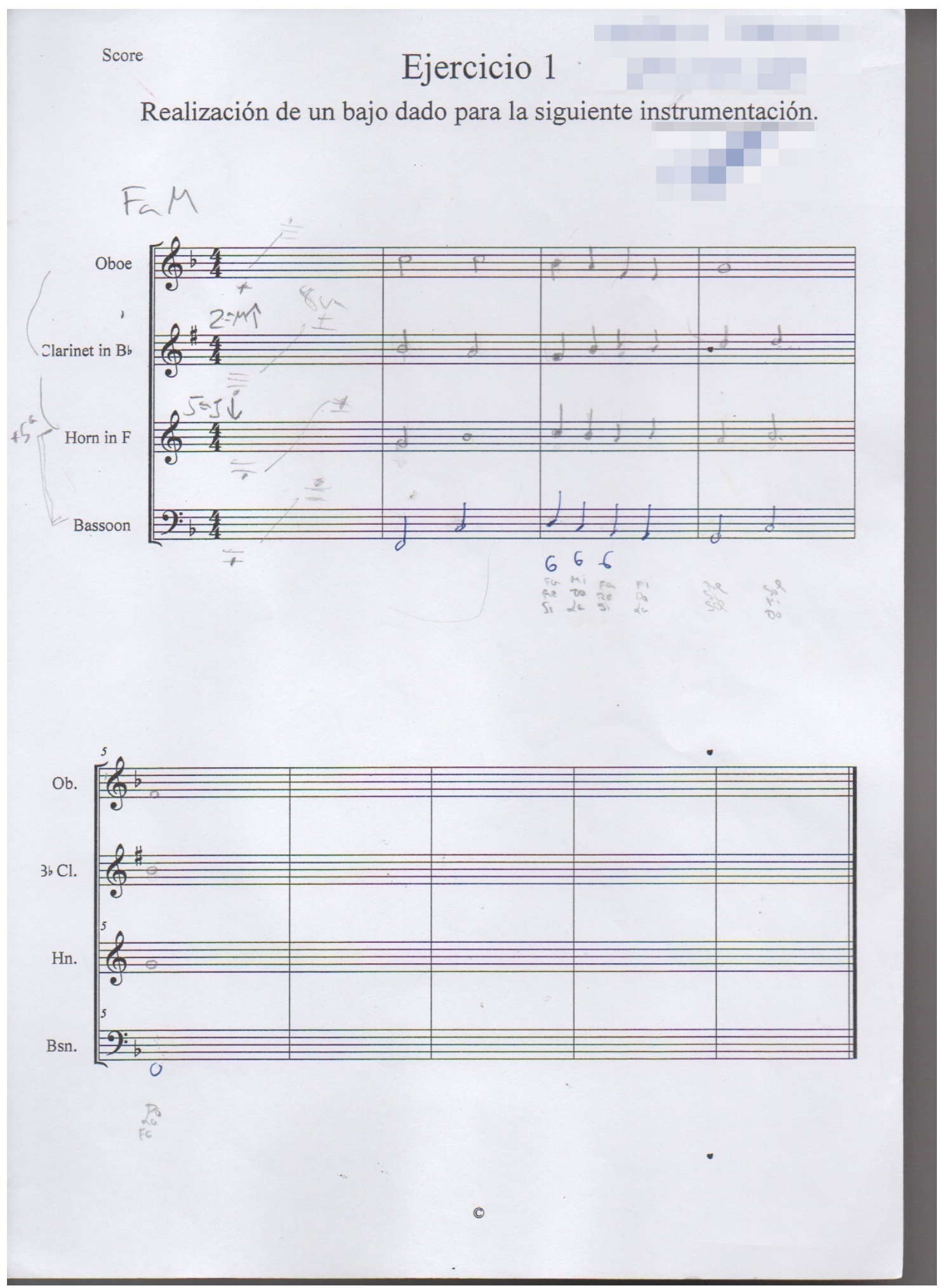


Diseño y planificación de competencias específicas en el currículum de enseñanzas profesionales de música: modalidades composición-dirección en la enseñanza superior.

\section{Carlos Eduardo Pascual Pérez}

Score

\section{Ejercicio 1}

Realización de un bajo dado para la siguiente instrumentación.

Clarinet in Bb

Oboe

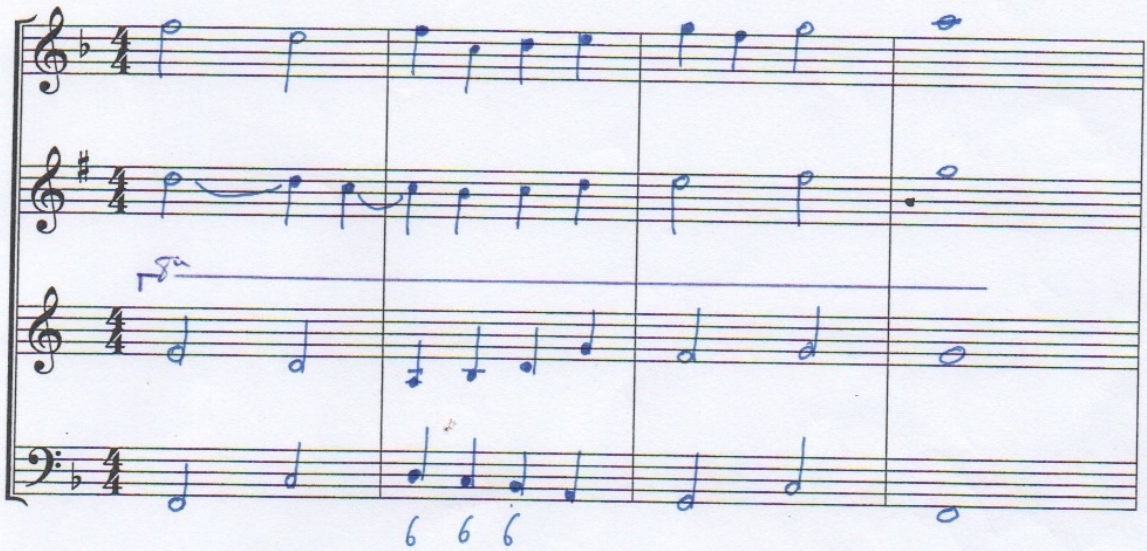

Ob.

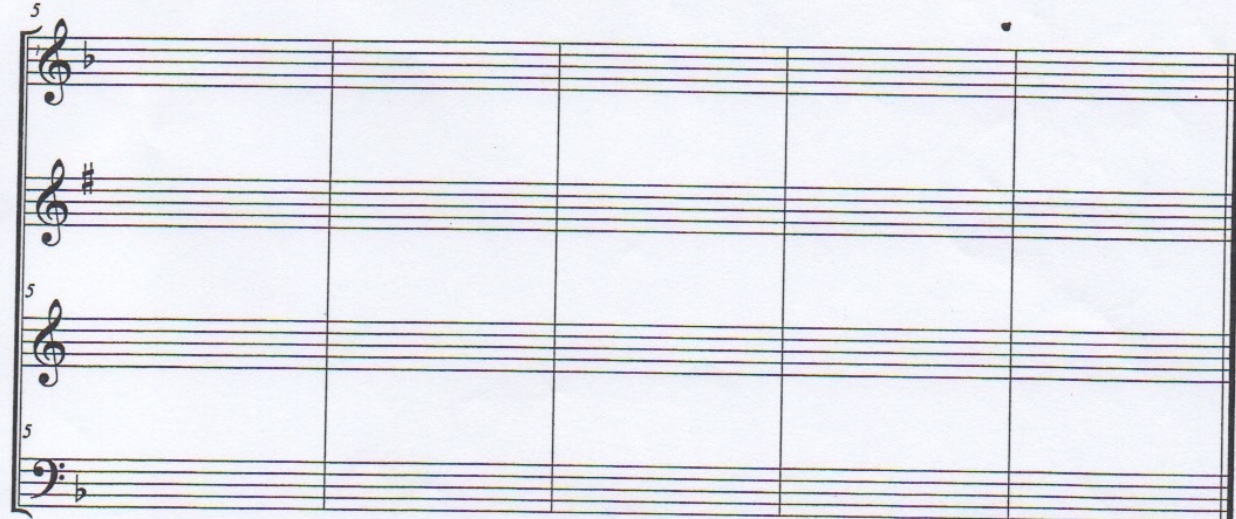


Diseño y planificación de competencias específicas en el currículum de enseñanzas profesionales de música: modalidades composición-dirección en la enseñanza superior.

Carlos Eduardo Pascual Pérez

Score

\section{Ejercicio 1}

Realización de un bajo dado para la siguiente instrumentación. (Bajo S)

Rew

Oboe

Clarinet in $\mathrm{B}$ b

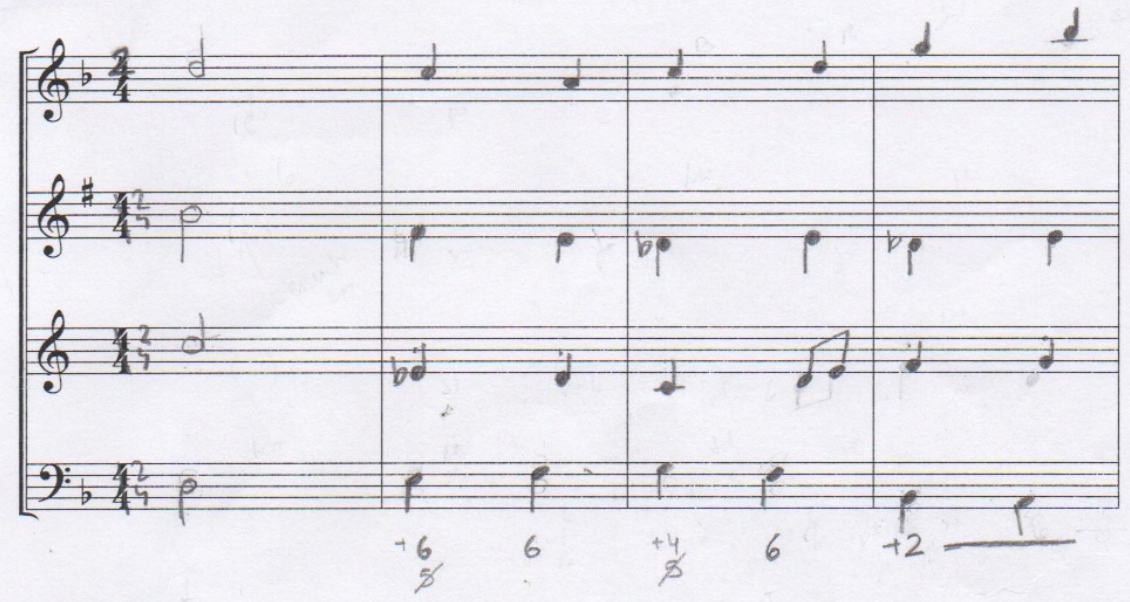

Ob.

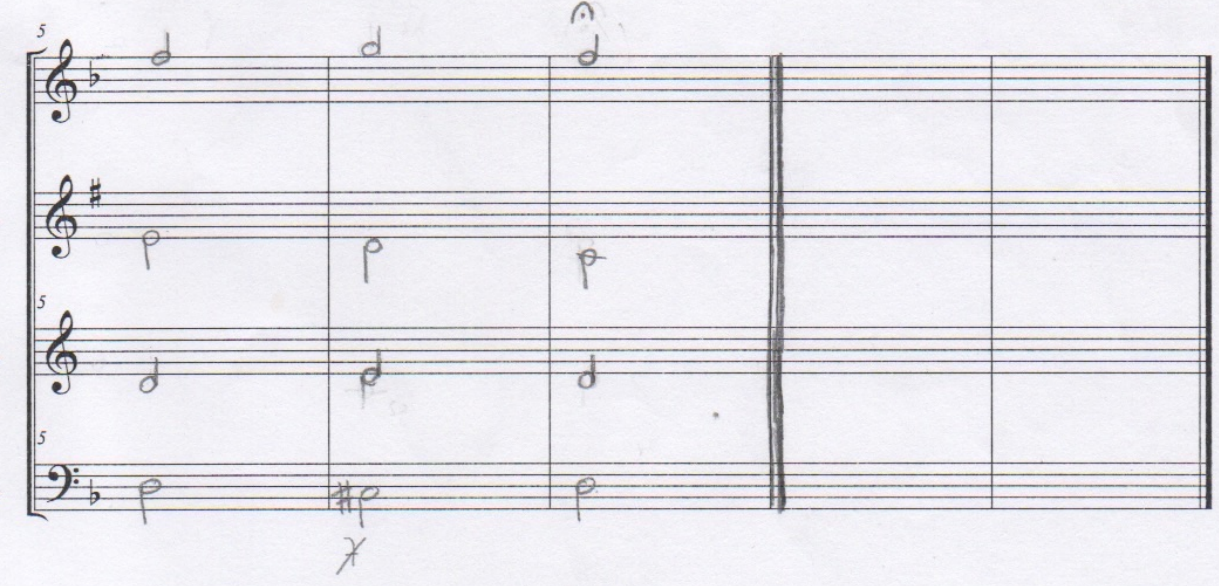


Diseño y planificación de competencias específicas en el currículum de enseñanzas profesionales de música: modalidades composición-dirección en la enseñanza superior.

Carlos Eduardo Pascual Pérez

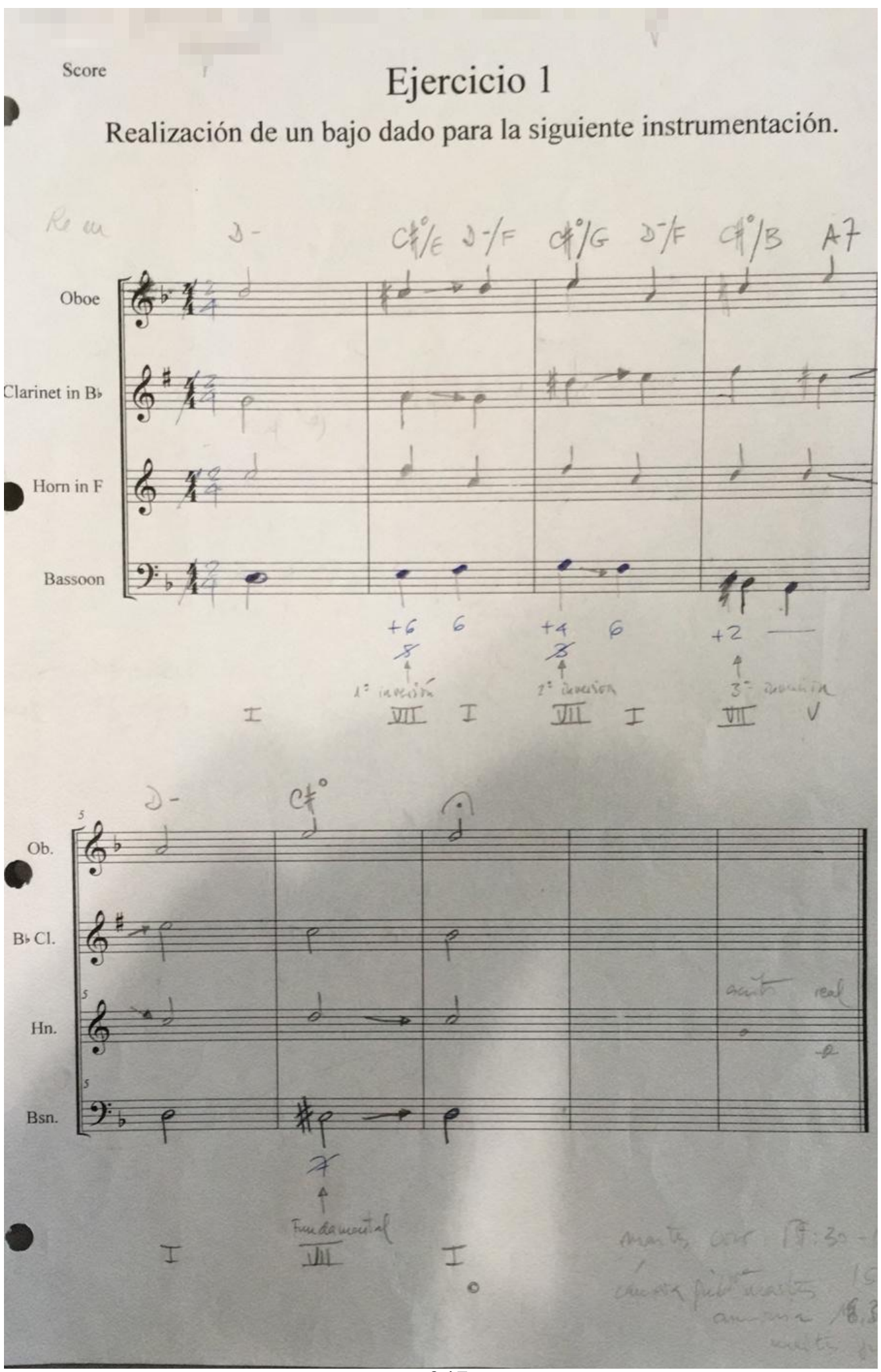


Diseño y planificación de competencias específicas en el currículum de enseñanzas profesionales de música: modalidades composición-dirección en la enseñanza superior.

\section{Carlos Eduardo Pascual Pérez}

Ejercicio 1

Realización de un bajo dado para la siguiente instrumentación.

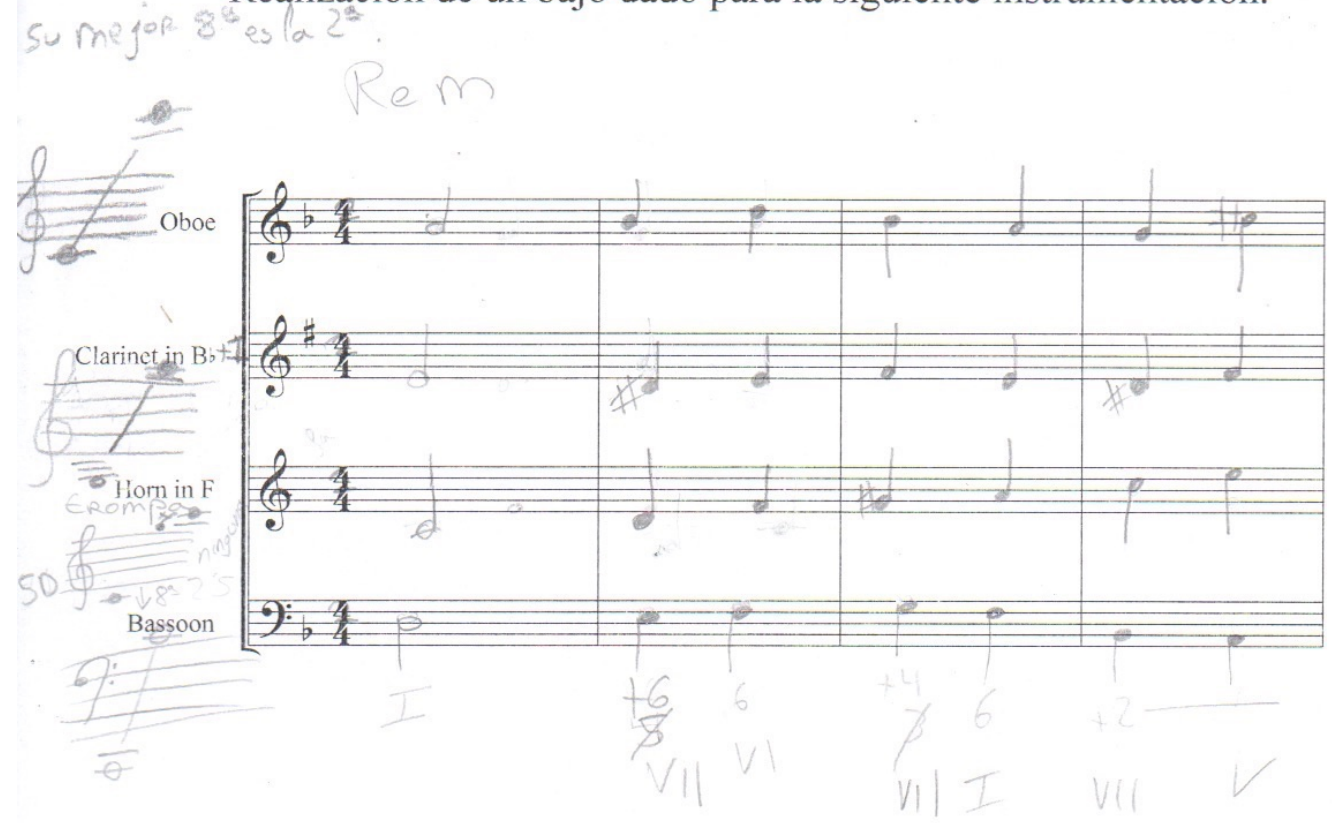

$\mathrm{Ob}$

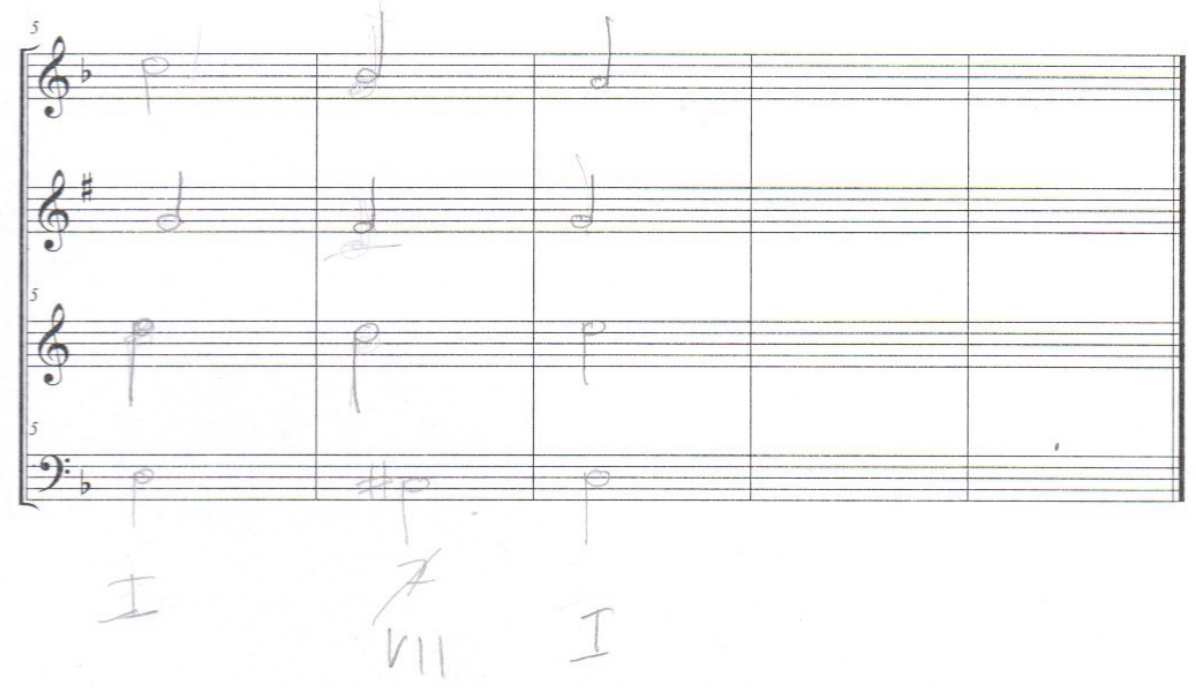


Diseño y planificación de competencias específicas en el currículum de enseñanzas profesionales de música: modalidades composición-dirección en la enseñanza superior.

\section{Carlos Eduardo Pascual Pérez}

Score

\section{Ejercicio 1}

Realización de un bajo dado para la siguiente instrumentación.

Rem

$x_{\text {Clarinet in } \mathrm{B} \text {, }}$

$\uparrow L$

Horn in $\mathrm{F}$

is

Bassoon

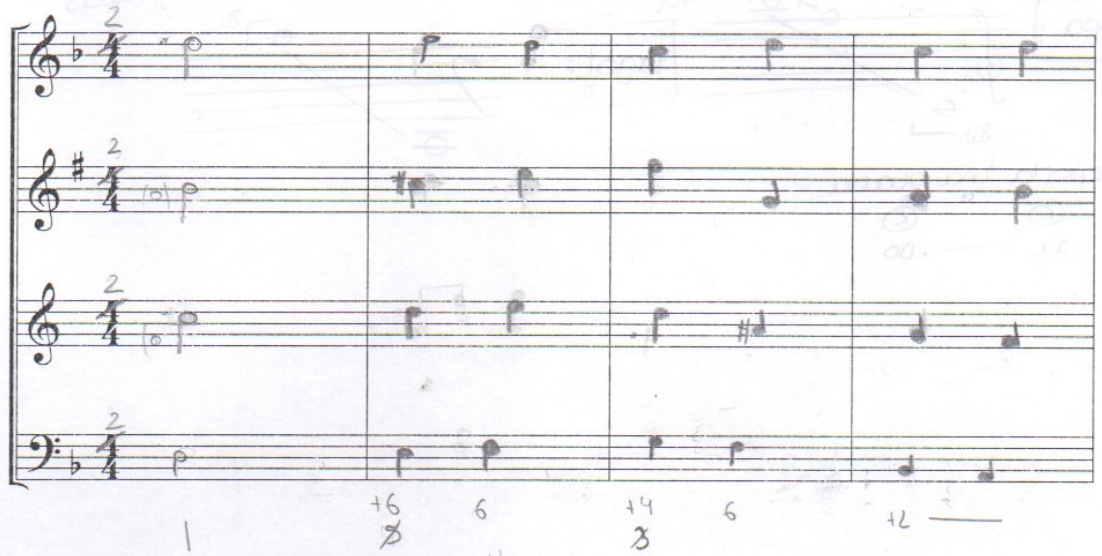

$\mathrm{Ob}$.

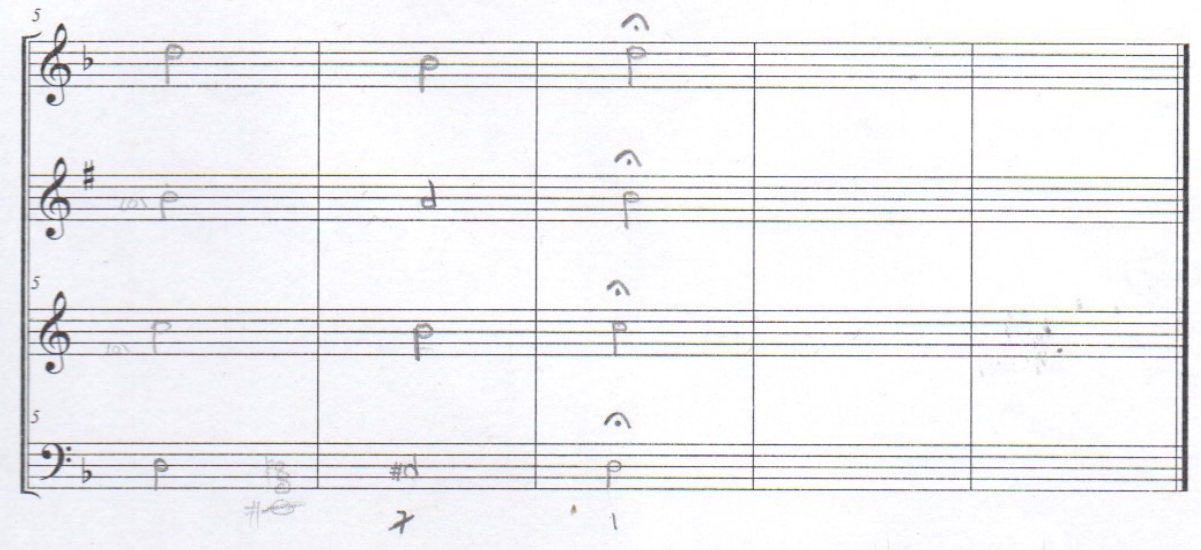


Diseño y planificación de competencias específicas en el currículum de enseñanzas profesionales de música: modalidades composición-dirección en la enseñanza superior.

\section{Carlos Eduardo Pascual Pérez}

Score

\section{Ejercicio 1}

Realización de un bajo dado para la siguiente instrumentación.

Clarinet in B,

Rem
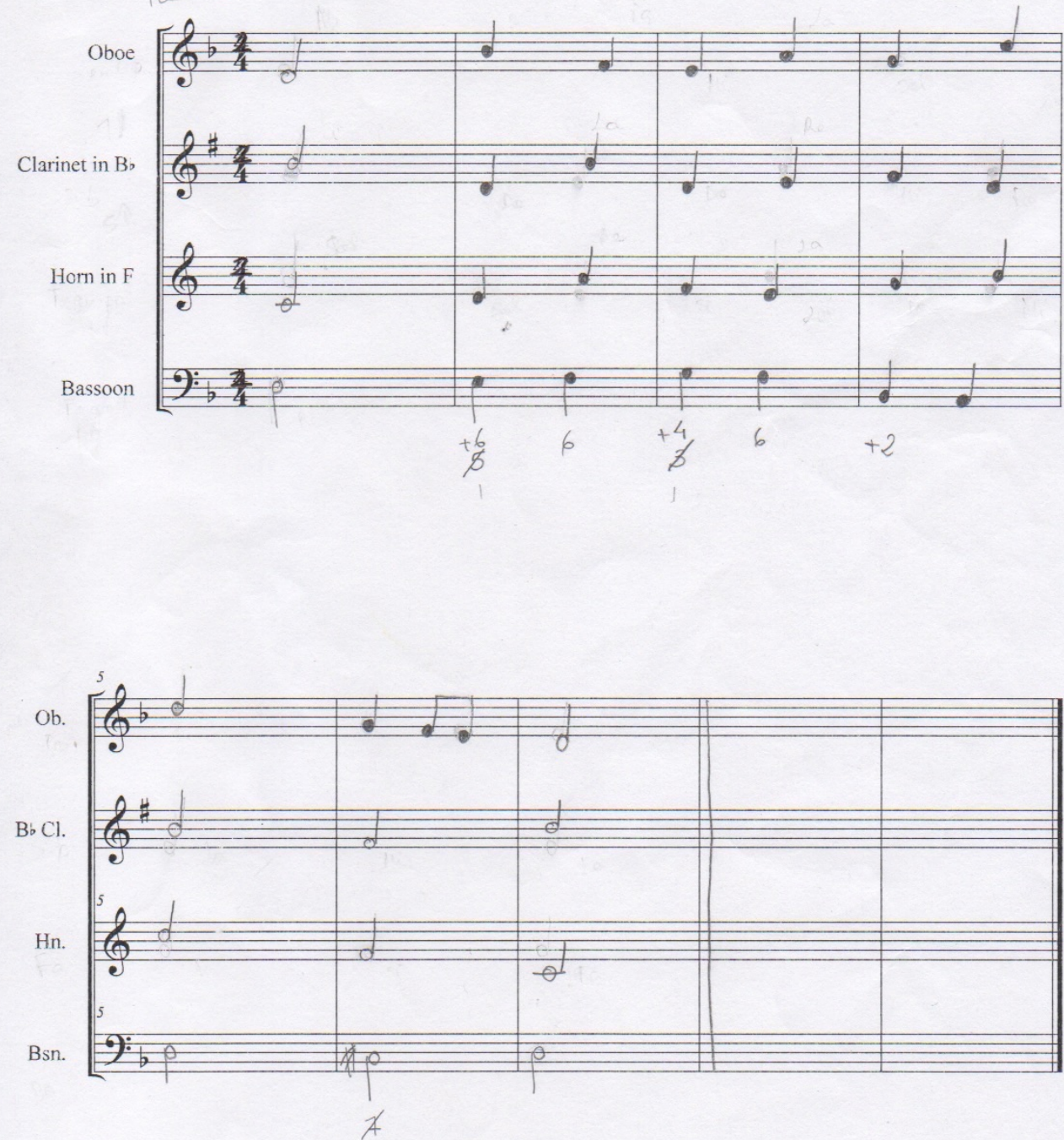
Diseño y planificación de competencias específicas en el currículum de enseñanzas profesionales de música: modalidades composición-dirección en la enseñanza superior.

\section{Carlos Eduardo Pascual Pérez}

Score

\section{Ejercicio 1}

Realización de un bajo dado para la siguiente instrumentación.

Oboe: está
Clarinete:
Trompa :
Fagst :

en Do

Fib

Do
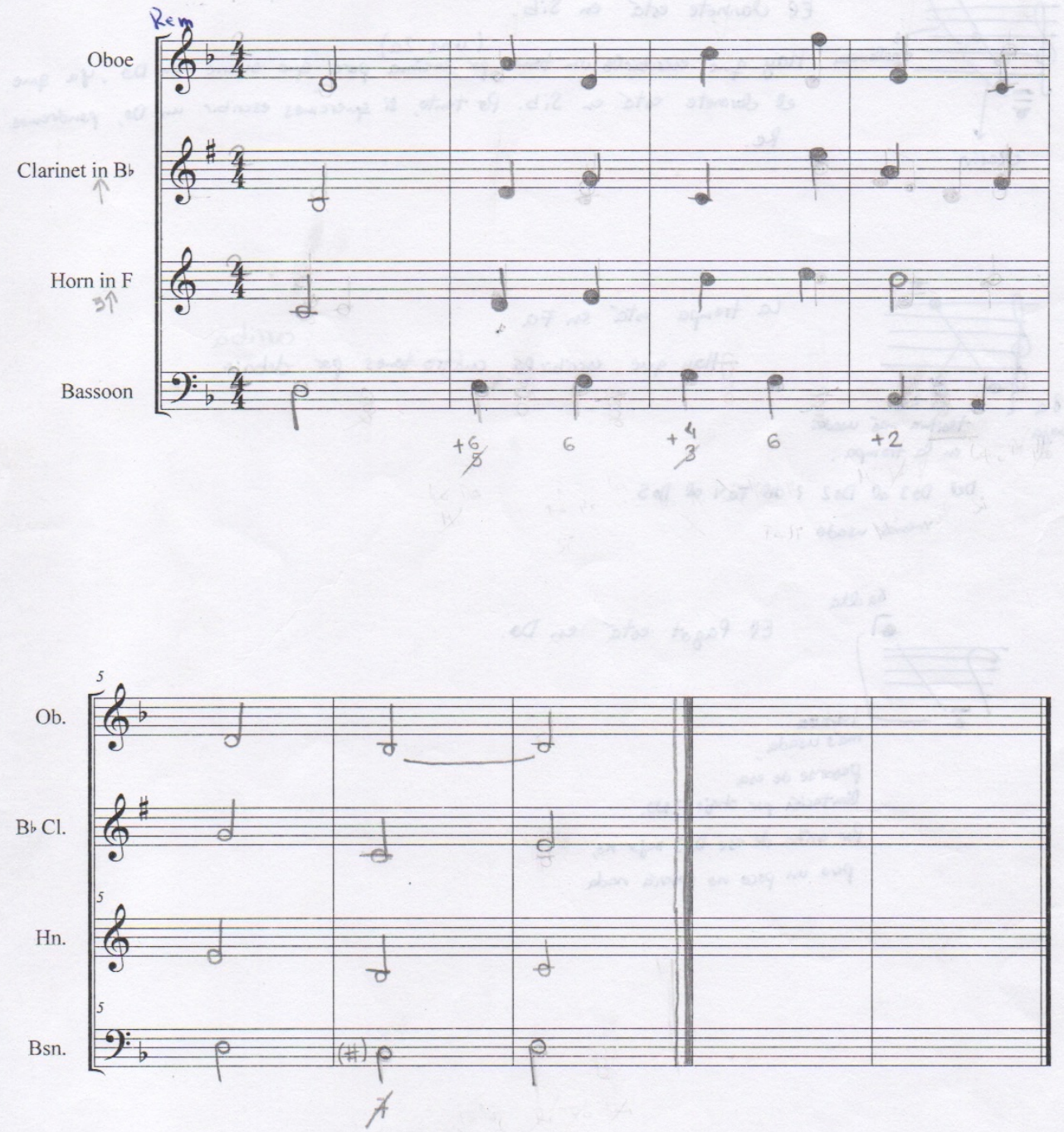
Diseño y planificación de competencias específicas en el currículum de enseñanzas profesionales de música: modalidades composición-dirección en la enseñanza superior.

\section{Carlos Eduardo Pascual Pérez}

Score

\section{Ejercicio 1}

Realización de un bajo dado para la siguiente instrumentación.

Clarinet in Bb

Bassoon

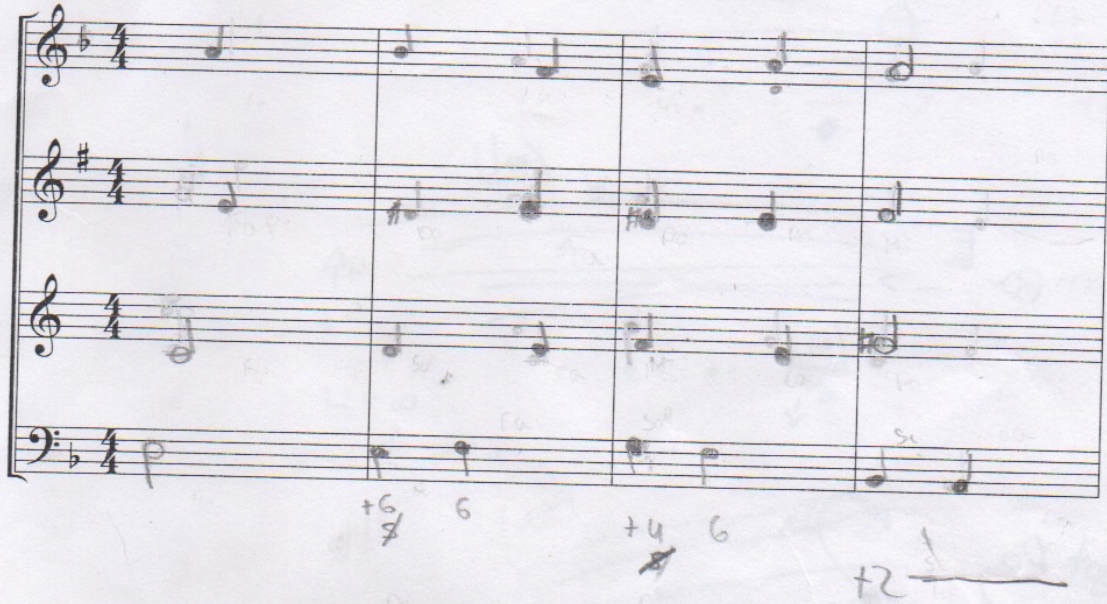

$\mathrm{Ob}$.

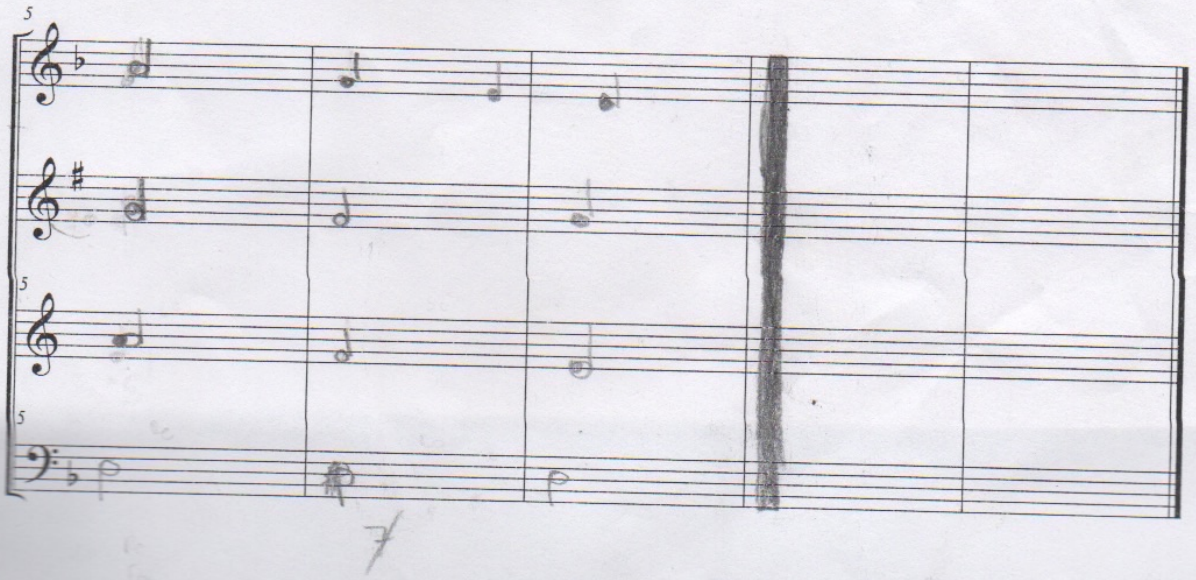

(c) 
Diseño y planificación de competencias específicas en el currículum de enseñanzas profesionales de música: modalidades composición-dirección en la enseñanza superior.

\section{Carlos Eduardo Pascual Pérez}

Score

\section{Ejercicio 1}

Realización de un bajo dado para la siguiente instrumentación.

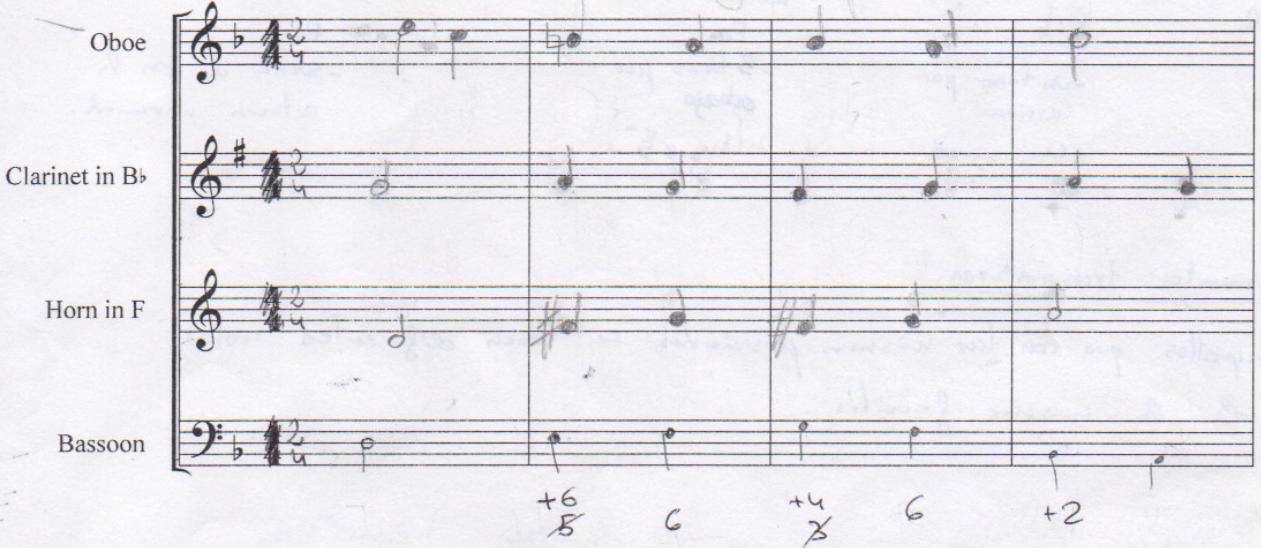

Ob.

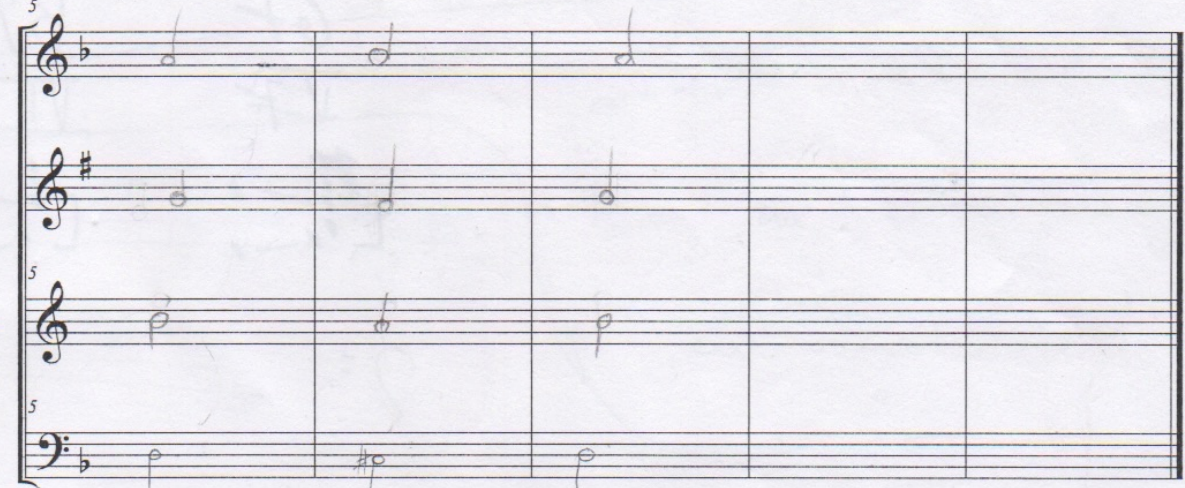

7 
Diseño y planificación de competencias específicas en el currículum de enseñanzas profesionales de música: modalidades composición-dirección en la enseñanza superior.

\section{Carlos Eduardo Pascual Pérez}

Score

\section{Ejercicio 1}

Realización de un bajo dado para la siguiente instrumentación.

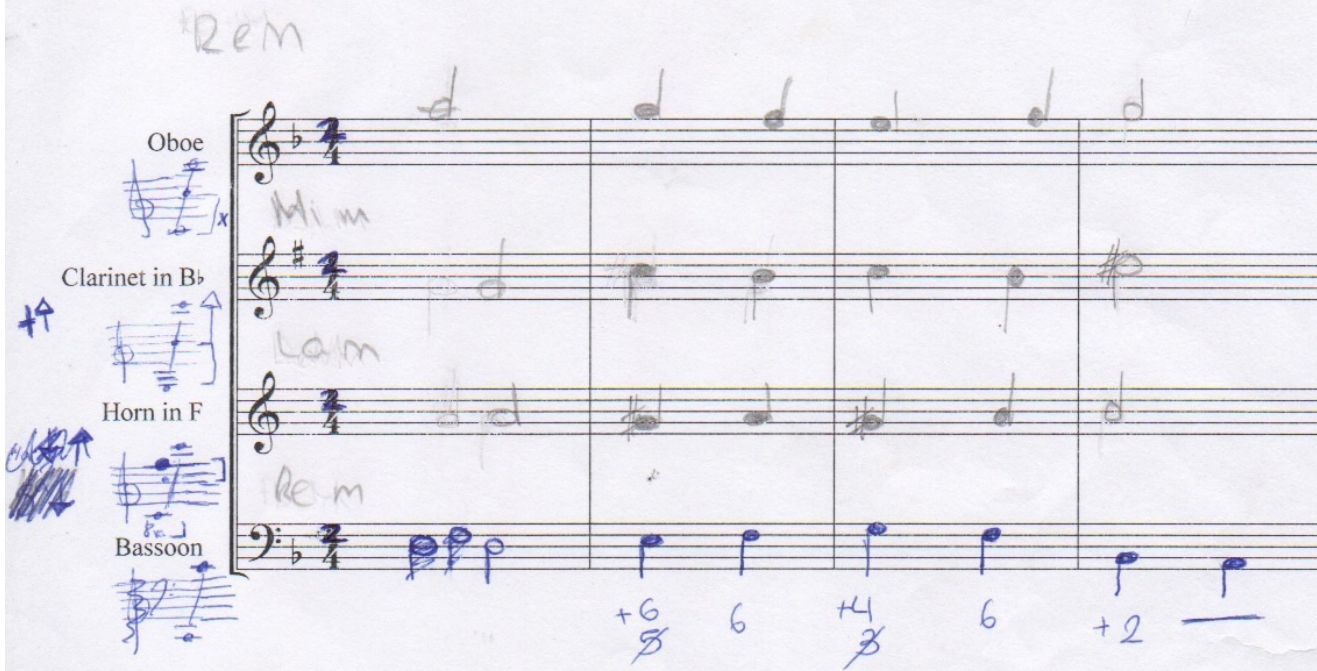

$\mathrm{Ob}$

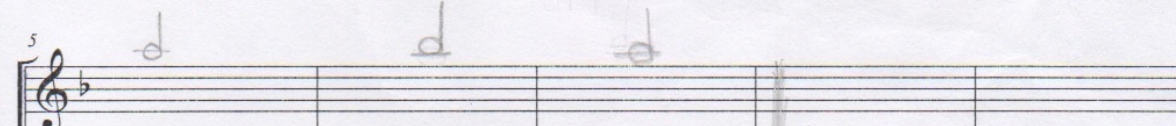

$\mathrm{Bb} \mathrm{Cl}$.

$\mathrm{Hn}$.

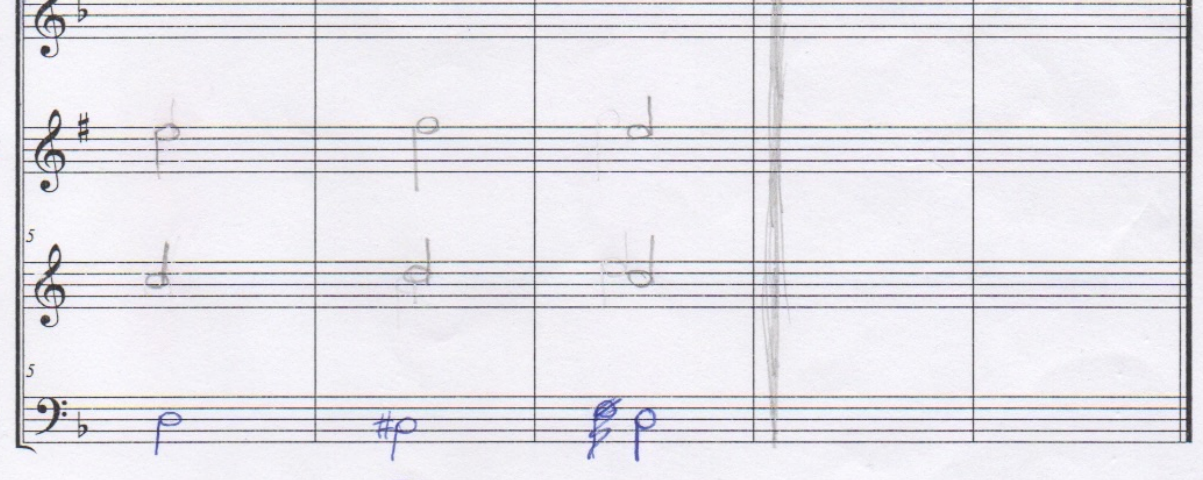

Bsn.

x 
Diseño y planificación de competencias específicas en el currículum de enseñanzas profesionales de música: modalidades composición-dirección en la enseñanza superior.

Carlos Eduardo Pascual Pérez

Score

\section{Ejercicio 1}

Realización de un bajo dado para la siguiente instrumentación.
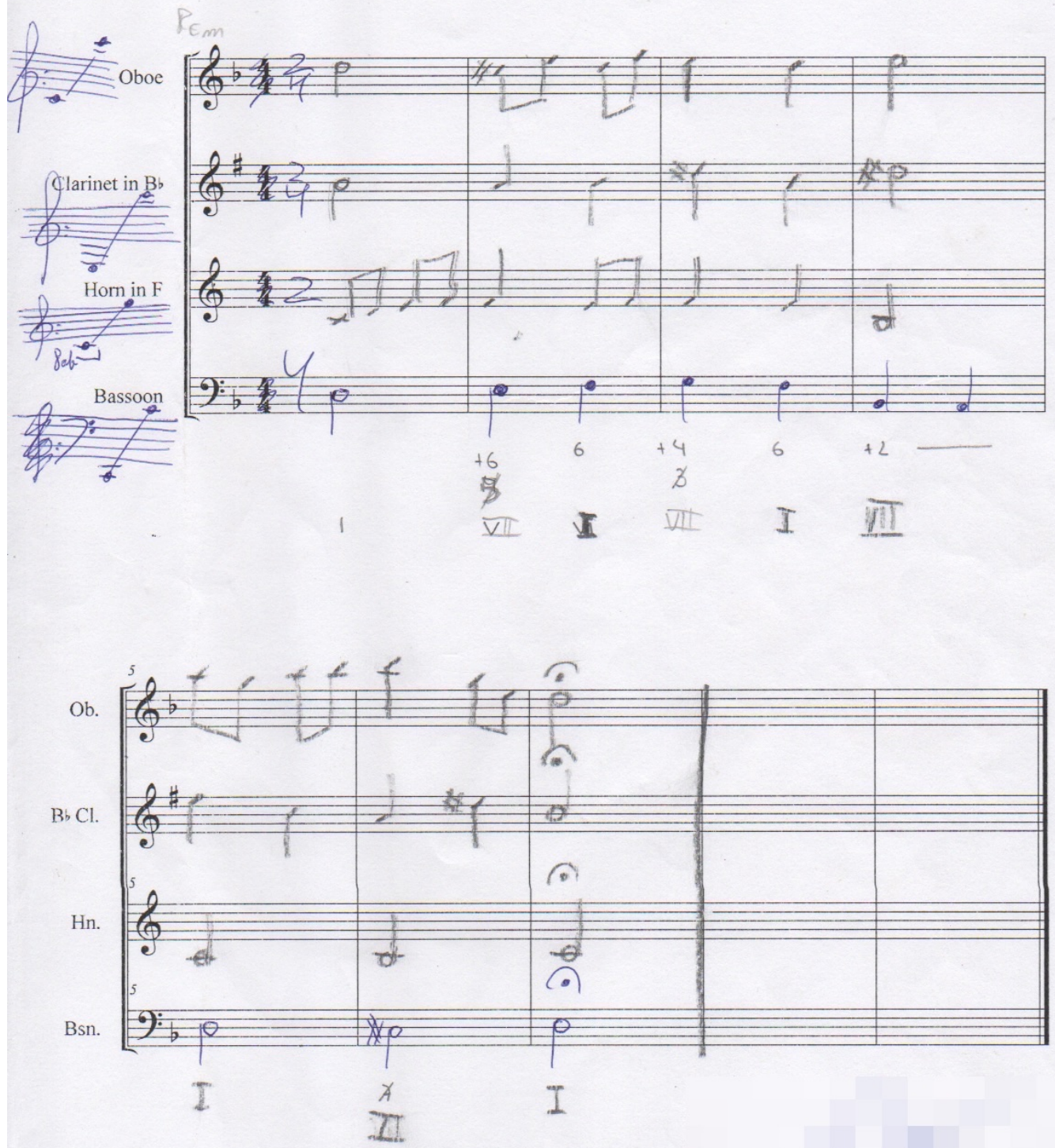
Diseño y planificación de competencias específicas en el currículum de enseñanzas profesionales de música: modalidades composición-dirección en la enseñanza superior.

Carlos Eduardo Pascual Pérez

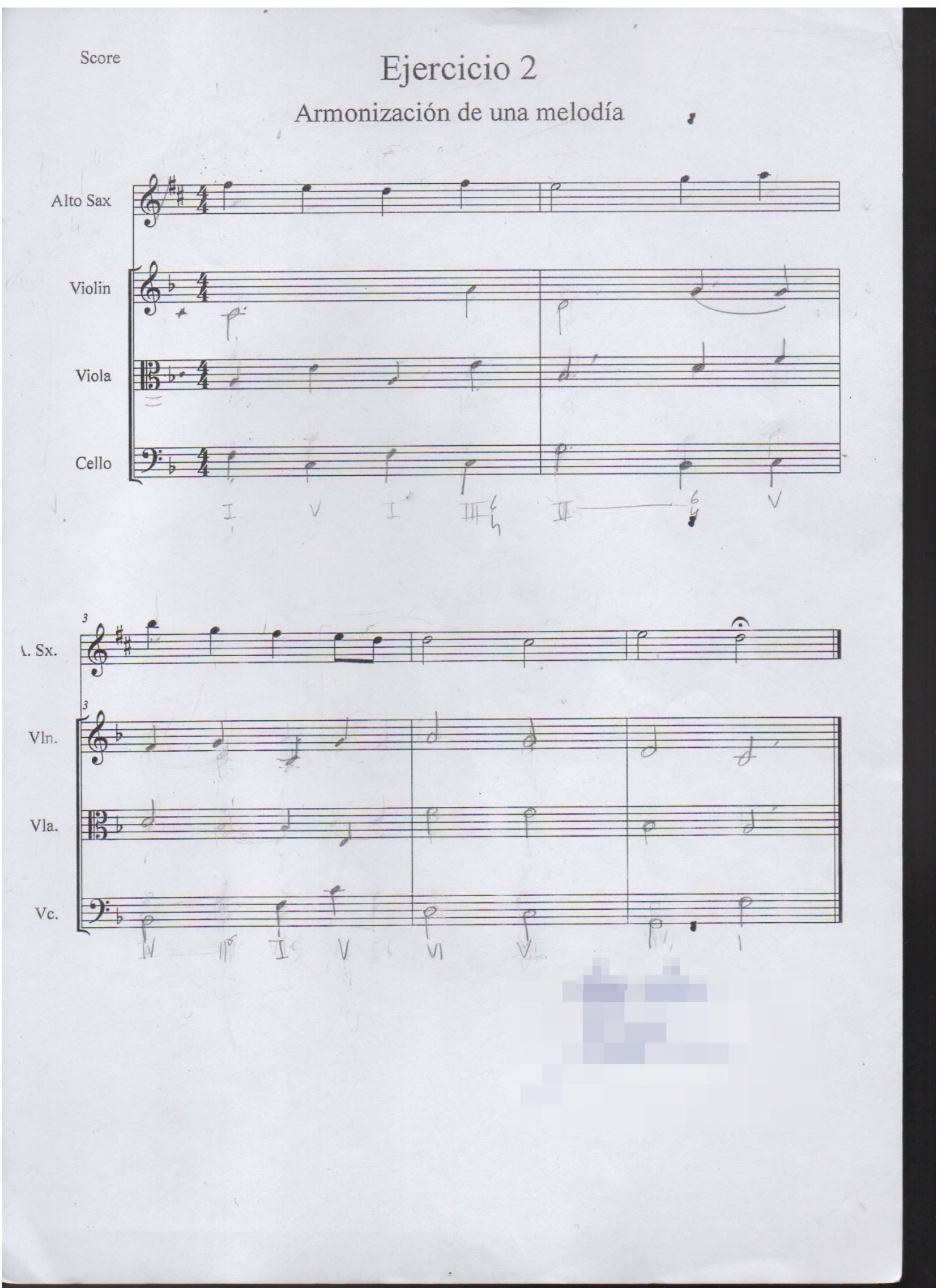


Diseño y planificación de competencias específicas en el currículum de enseñanzas profesionales de música: modalidades composición-dirección en la enseñanza superior.

Carlos Eduardo Pascual Pérez

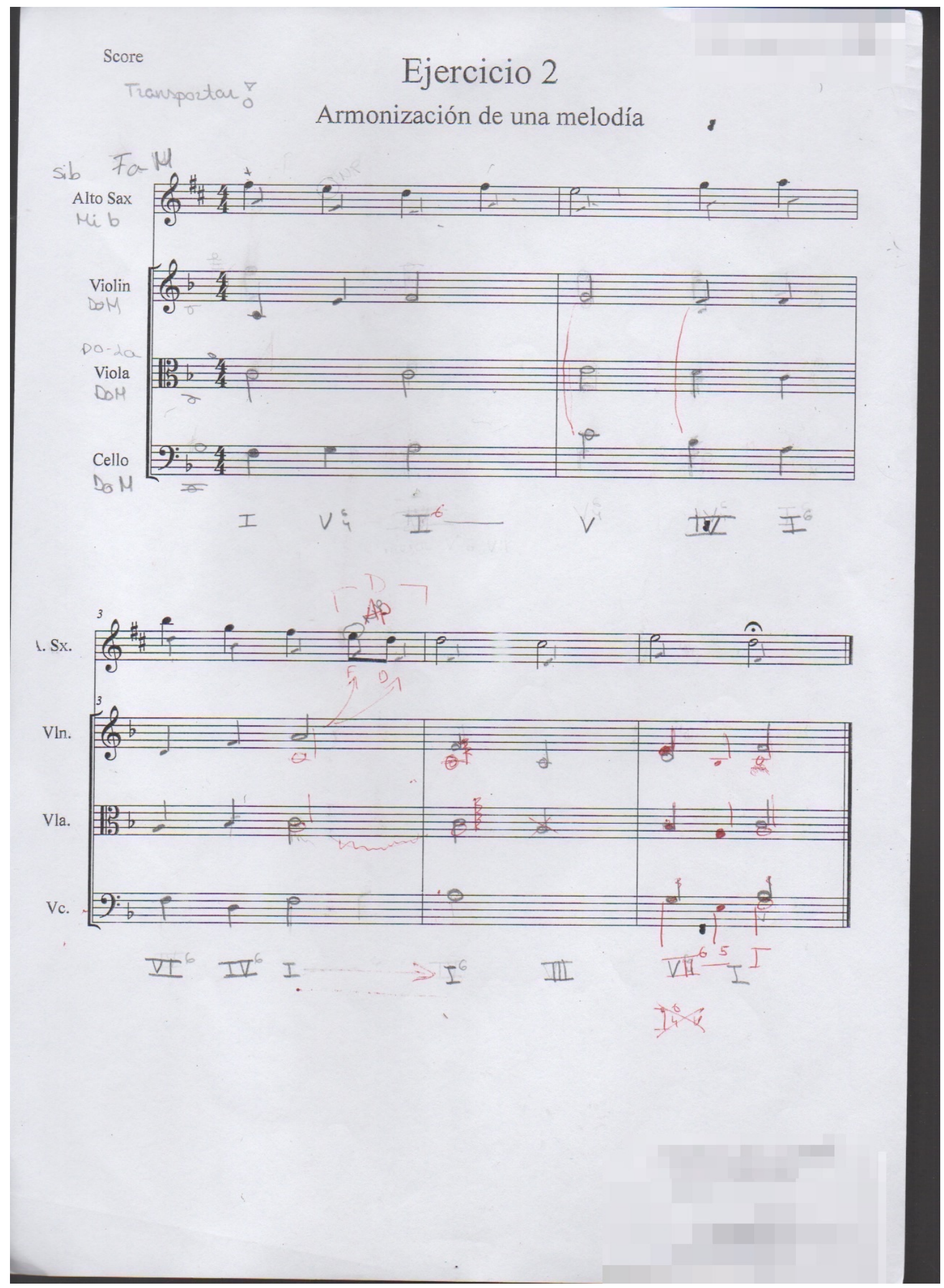


Diseño y planificación de competencias específicas en el currículum de enseñanzas profesionales de música: modalidades composición-dirección en la enseñanza superior.

\section{Carlos Eduardo Pascual Pérez}

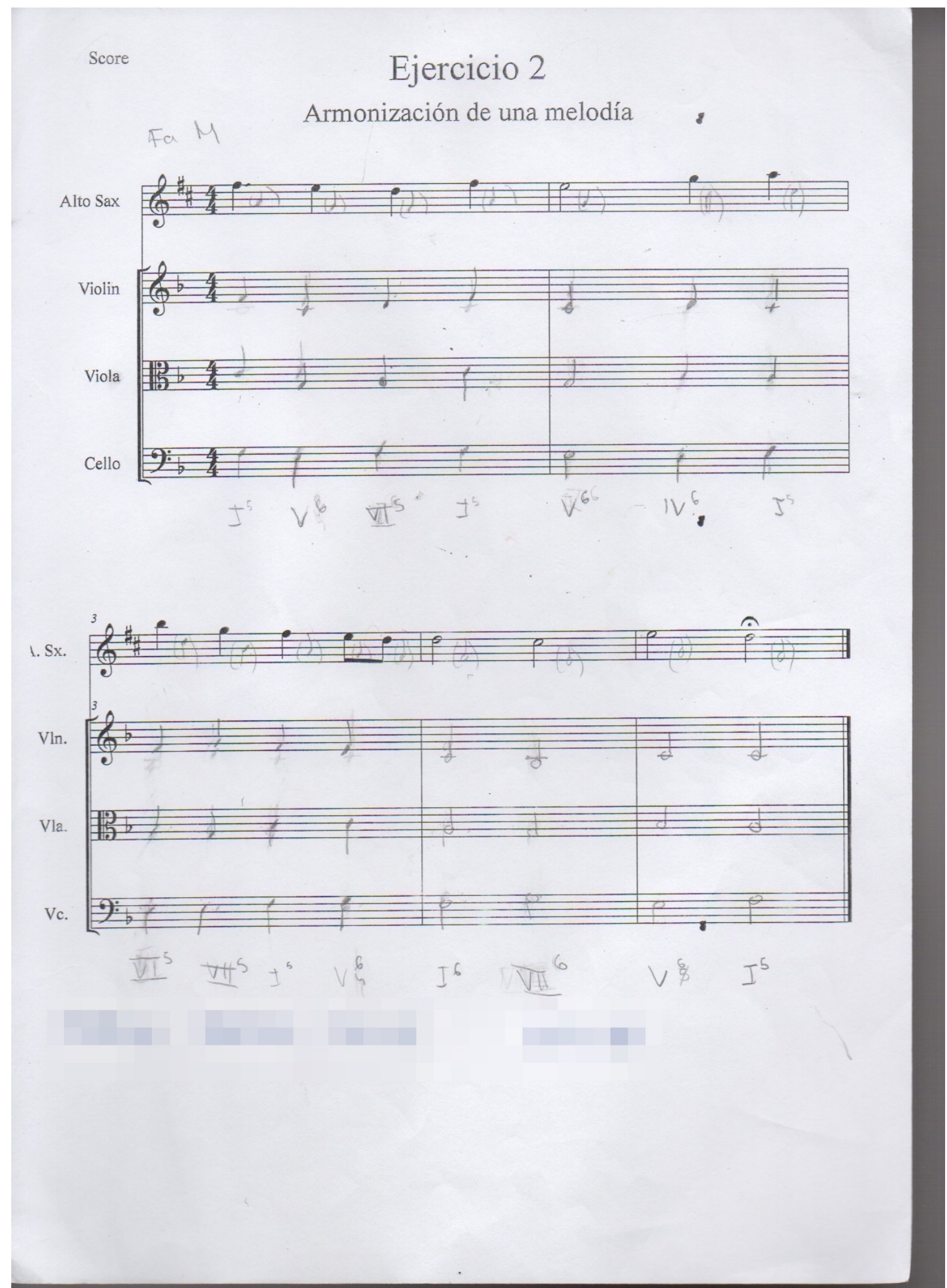


Diseño y planificación de competencias específicas en el currículum de enseñanzas profesionales de música: modalidades composición-dirección en la enseñanza superior.

Carlos Eduardo Pascual Pérez

Score

\section{Ejercicio 2}

Armonización de una melodía

Alto Sax

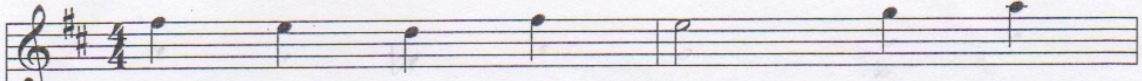

Violin

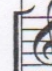

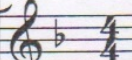

西

Cello

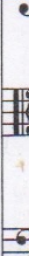

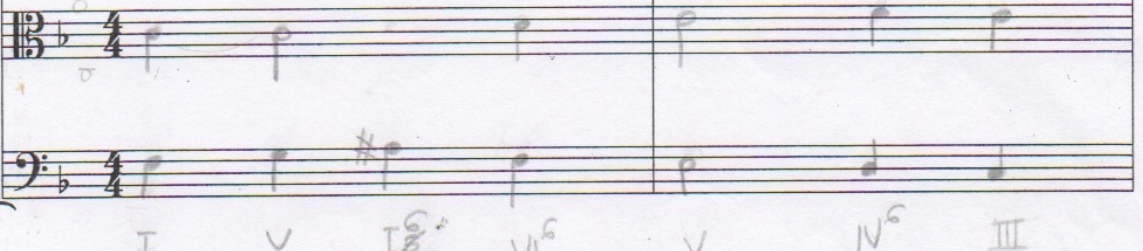

1. Sx.

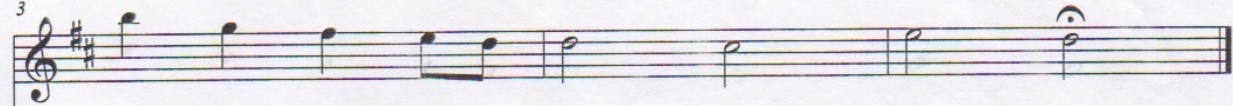

Vln.

8

Vla.

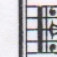

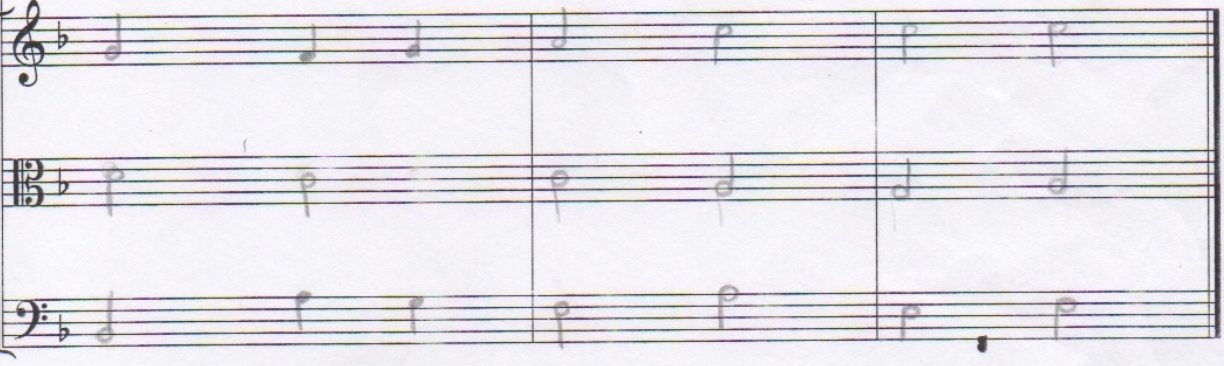

Vc.

II

$I^{5}$ III 
Diseño y planificación de competencias específicas en el currículum de enseñanzas profesionales de música: modalidades composición-dirección en la enseñanza superior.

Carlos Eduardo Pascual Pérez

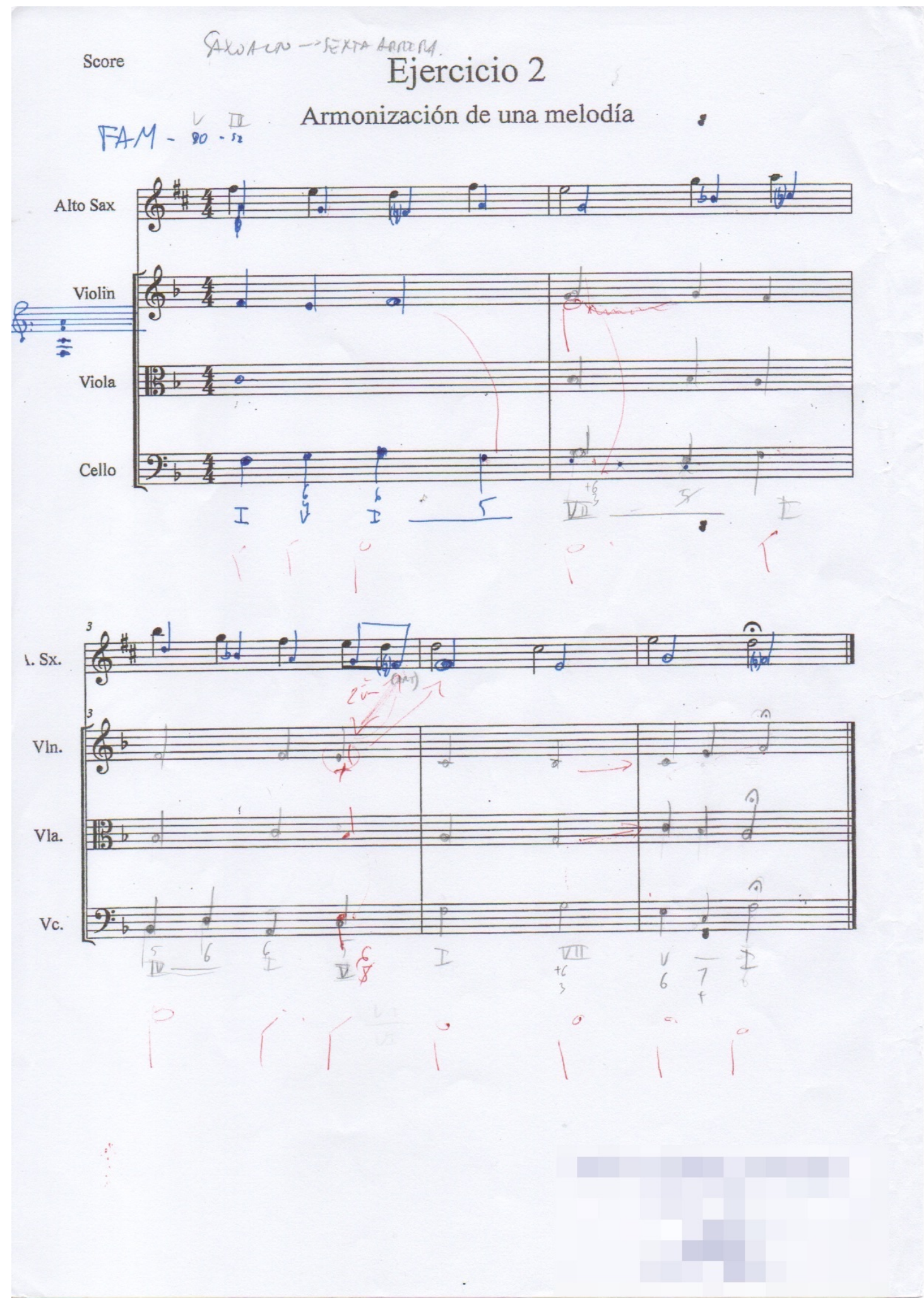


Diseño y planificación de competencias específicas en el currículum de enseñanzas profesionales de música: modalidades composición-dirección en la enseñanza superior.

Carlos Eduardo Pascual Pérez

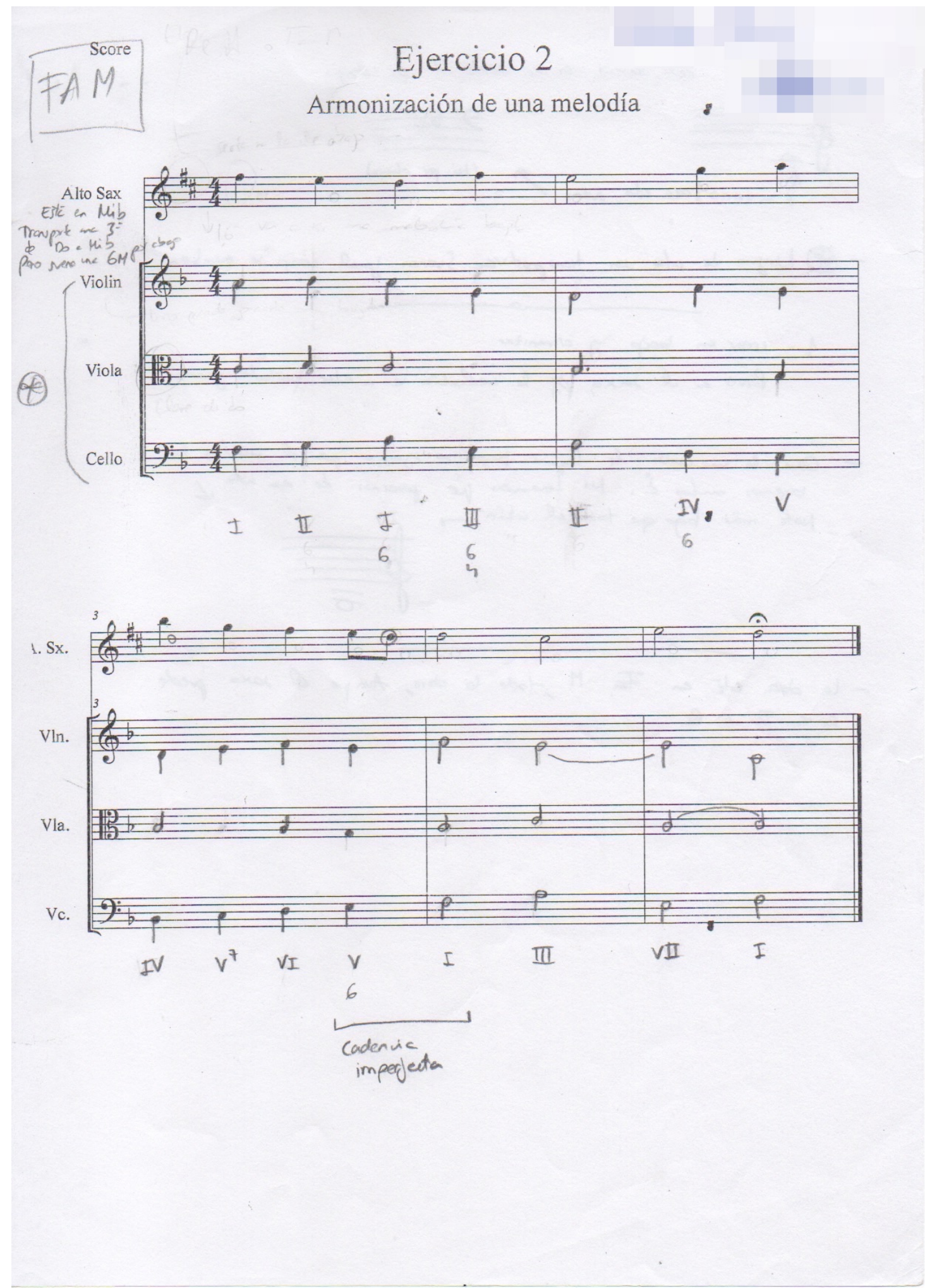


Diseño y planificación de competencias específicas en el currículum de enseñanzas profesionales de música: modalidades composición-dirección en la enseñanza superior.

\section{Carlos Eduardo Pascual Pérez}

Score

\section{Ejercicio 2}

Armonización de una melodía

A lio Sax

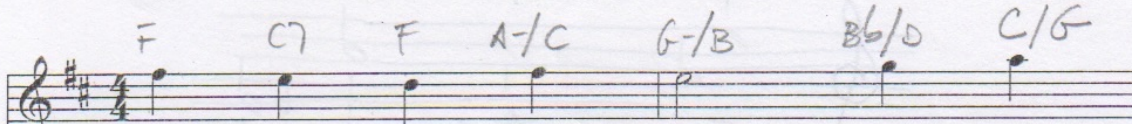

e

Violin

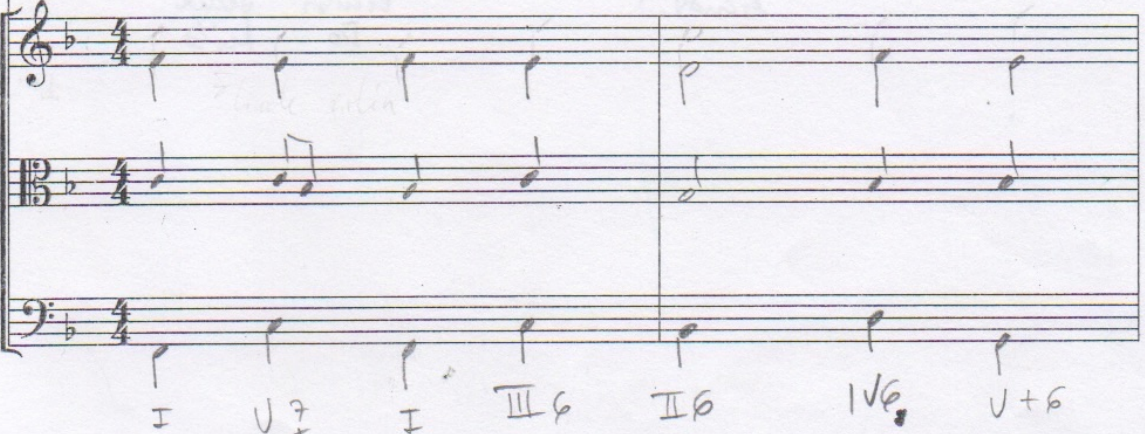

Sx

$D-F \quad B b \quad B-/ C \quad G-/ 3$

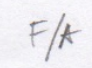

$E \varnothing$

$C 7 / E$

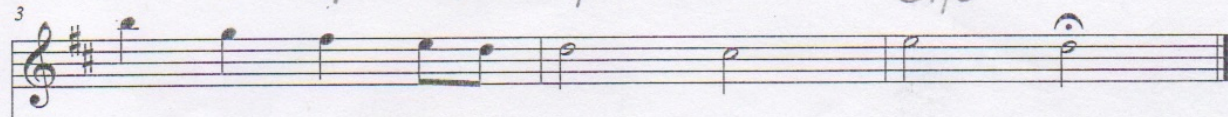

Vln.

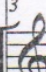

Vla.

Vc.

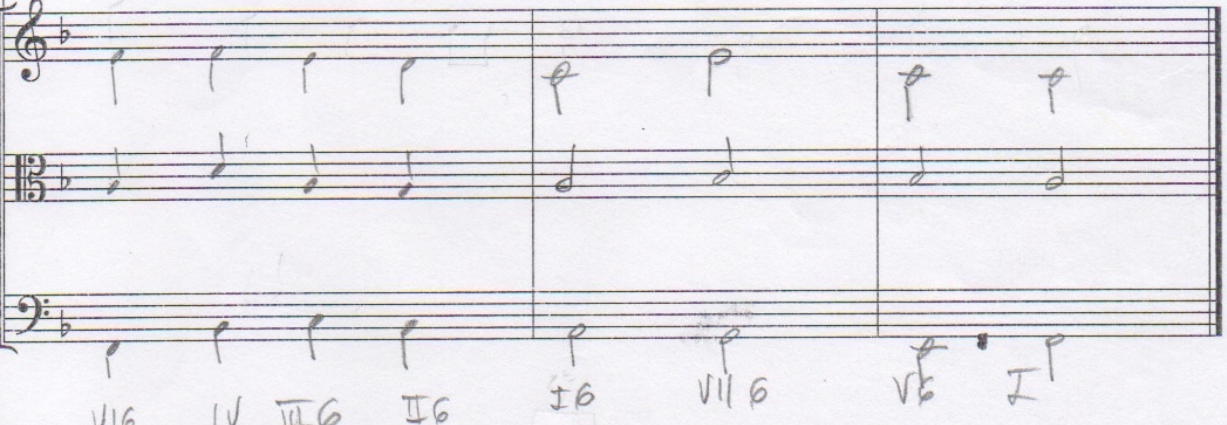


Diseño y planificación de competencias específicas en el currículum de enseñanzas profesionales de música: modalidades composición-dirección en la enseñanza superior.

Carlos Eduardo Pascual Pérez

Score

Ejercicio 2

Armonización de una melodía
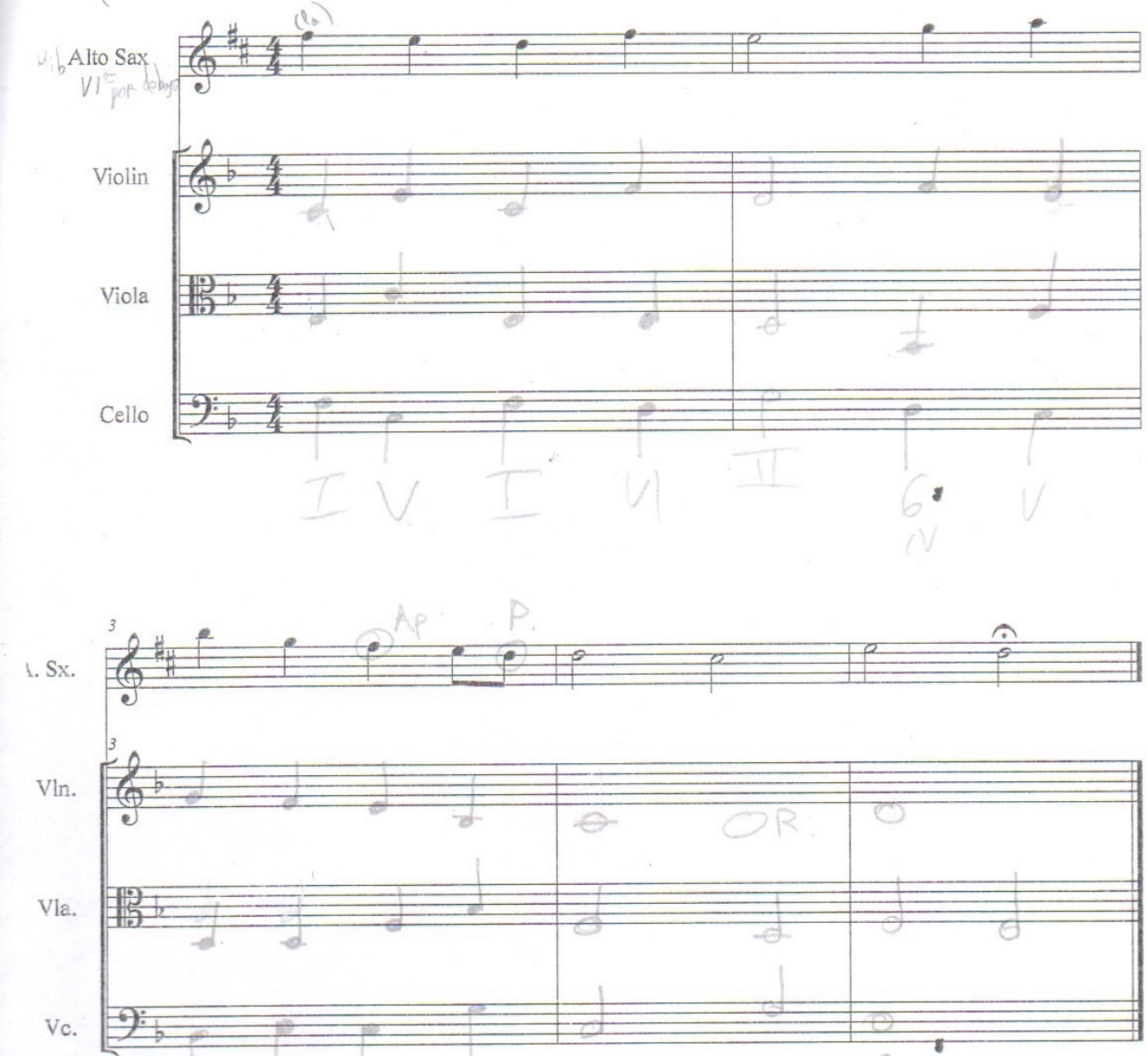
Diseño y planificación de competencias específicas en el currículum de enseñanzas profesionales de música: modalidades composición-dirección en la enseñanza superior.

\section{Carlos Eduardo Pascual Pérez}

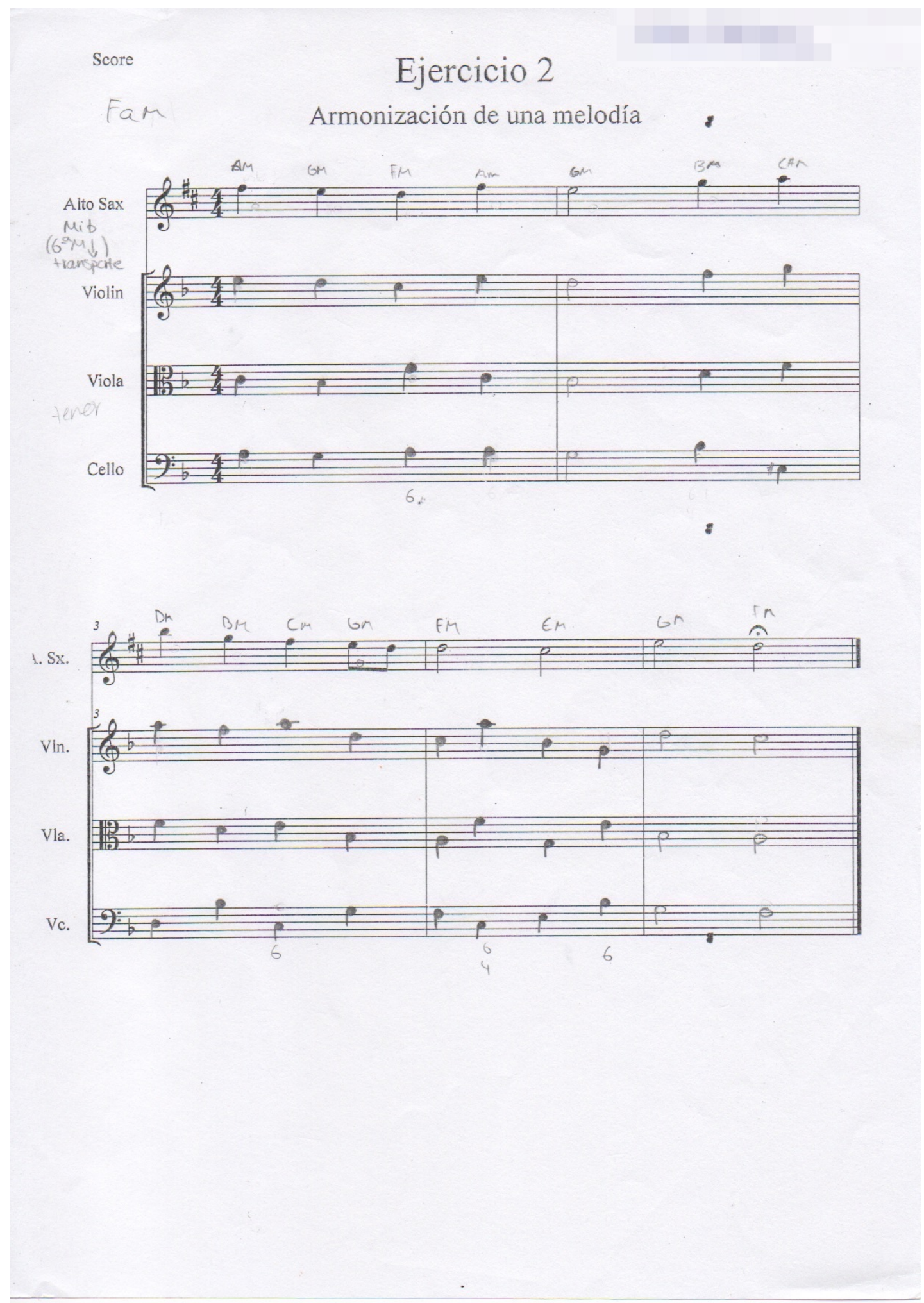


Diseño y planificación de competencias específicas en el currículum de enseñanzas profesionales de música: modalidades composición-dirección en la enseñanza superior.

\section{Carlos Eduardo Pascual Pérez}

\section{Ejercicio 2}

Armonización de una melodía

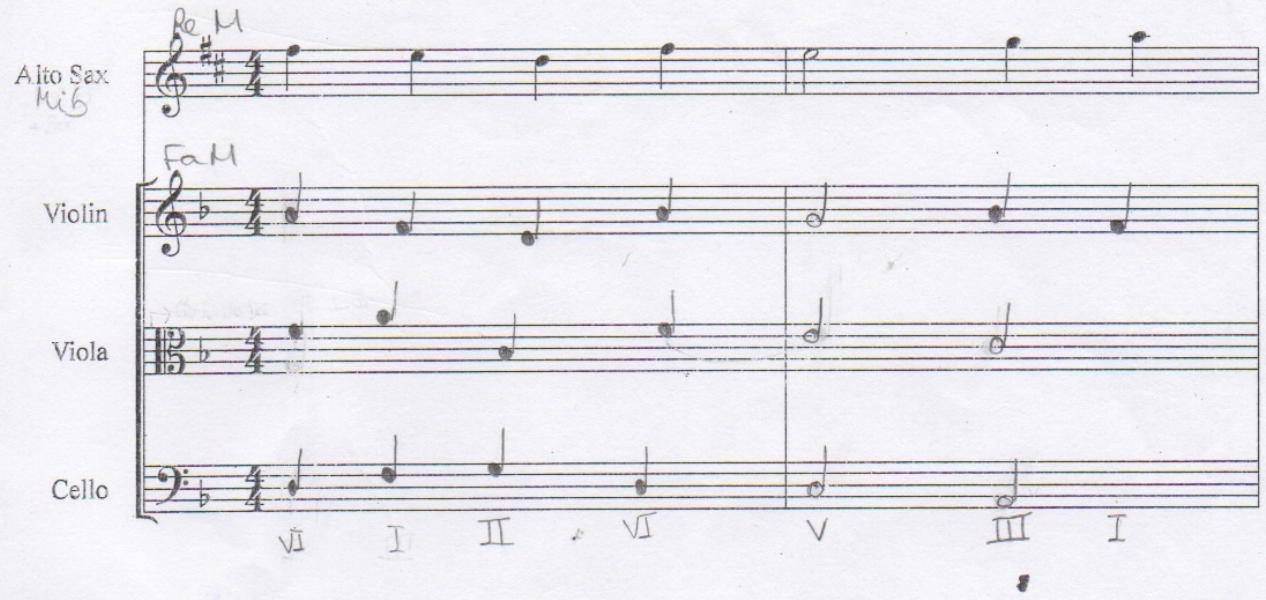

1. Sx.

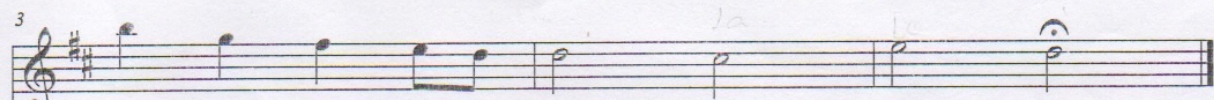

$\mathrm{V} \ln$.

3

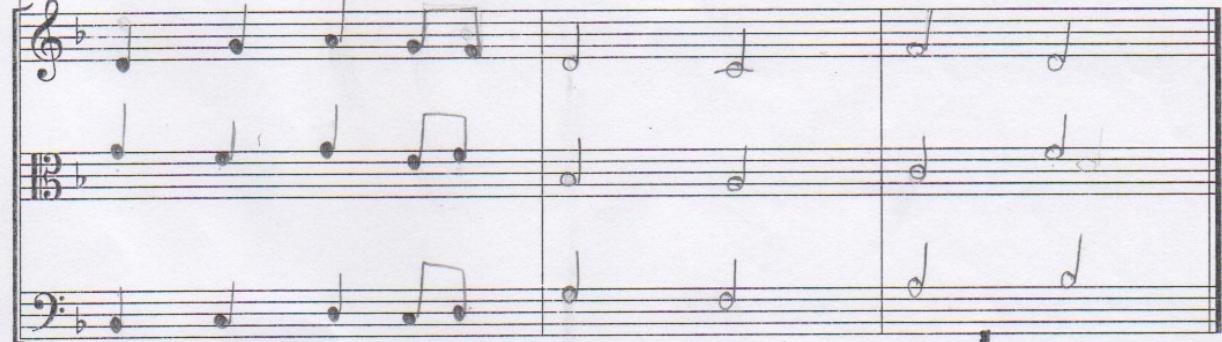

Vc.

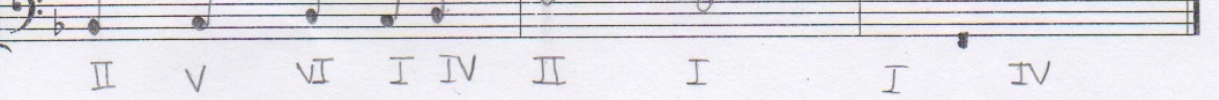


Diseño y planificación de competencias específicas en el currículum de enseñanzas profesionales de música: modalidades composición-dirección en la enseñanza superior.

Carlos Eduardo Pascual Pérez

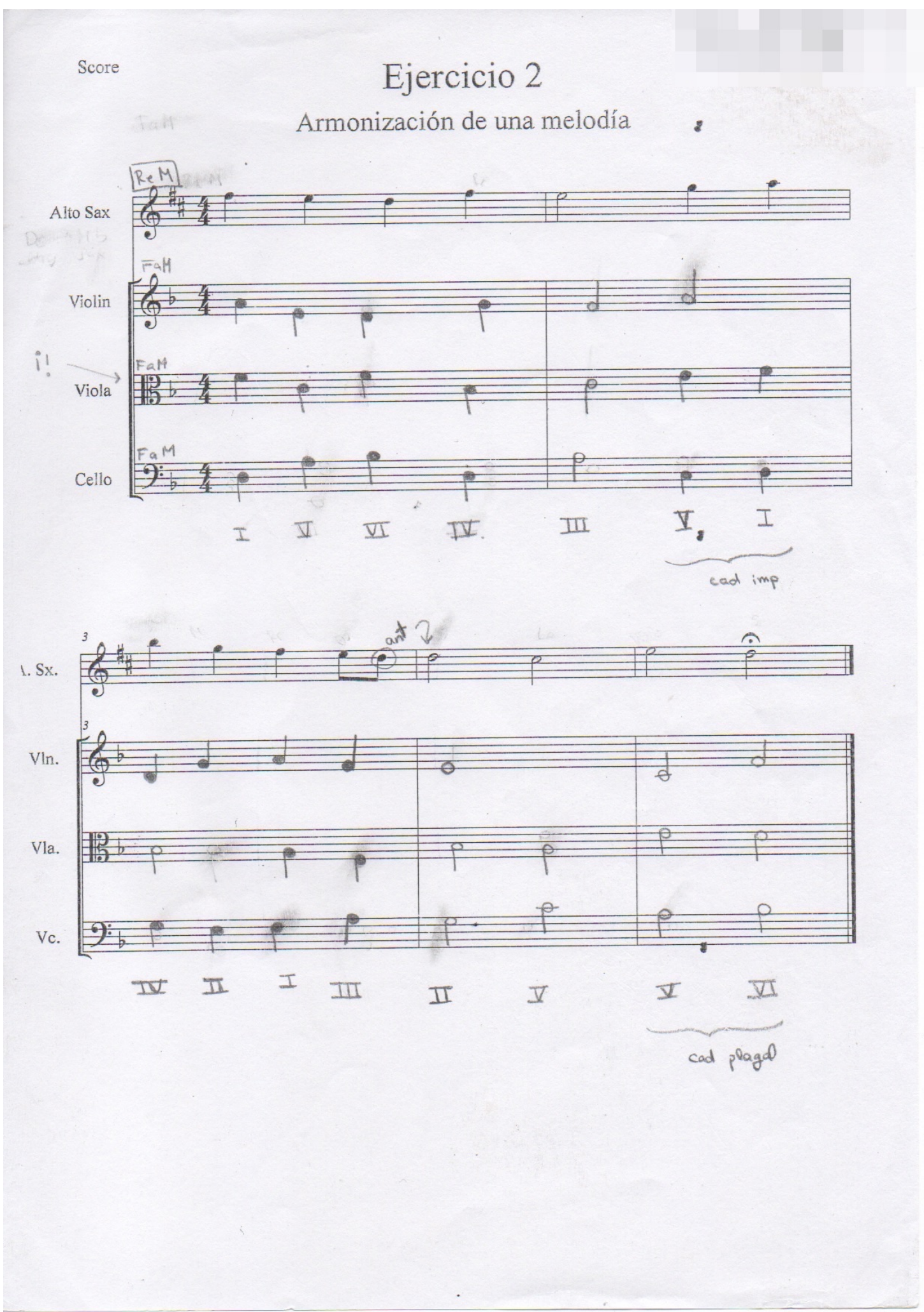


Diseño y planificación de competencias específicas en el currículum de enseñanzas profesionales de música: modalidades composición-dirección en la enseñanza superior.

\section{Carlos Eduardo Pascual Pérez}

Score

\section{Ejercicio 2}

Armonización de una melodía

Aito Sax

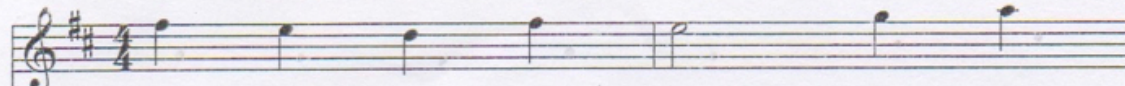

Violin
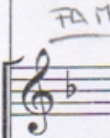

Viola

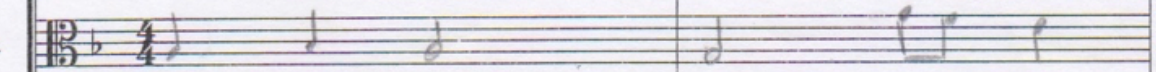

Cello

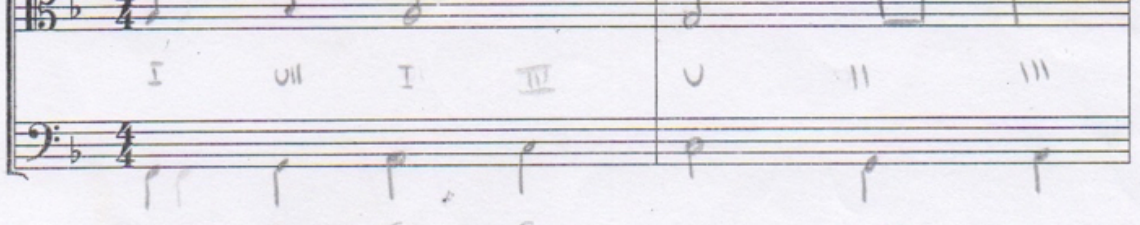

1. Sx.

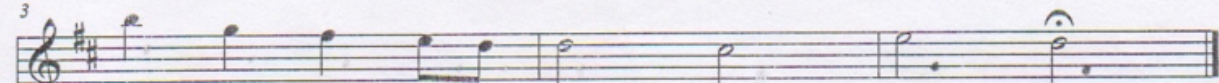

Vln.

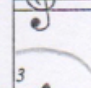

$\ln$.

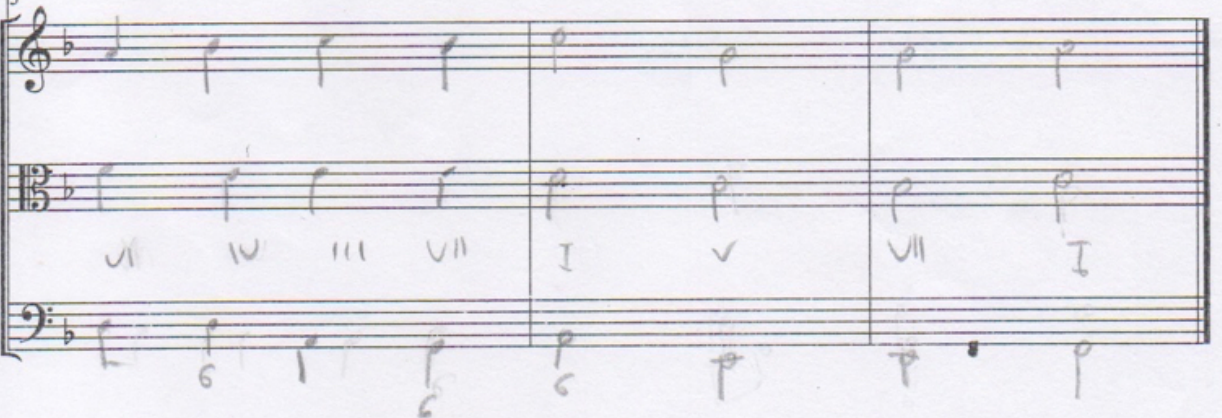

Vla. 
Diseño y planificación de competencias específicas en el currículum de enseñanzas profesionales de música: modalidades composición-dirección en la enseñanza superior.

Carlos Eduardo Pascual Pérez

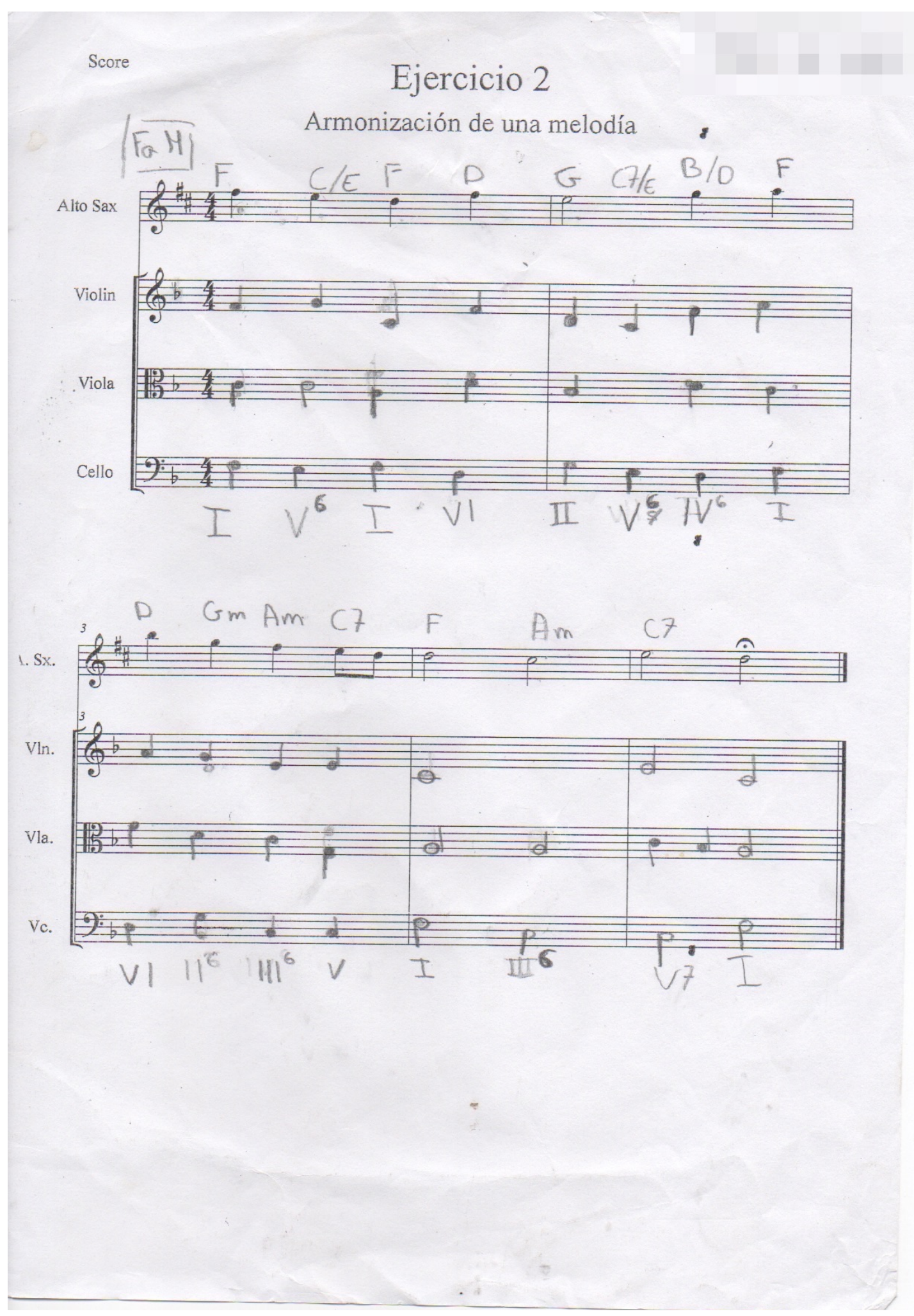


Diseño y planificación de competencias específicas en el currículum de enseñanzas profesionales de música: modalidades composición-dirección en la enseñanza superior.

\section{Carlos Eduardo Pascual Pérez}

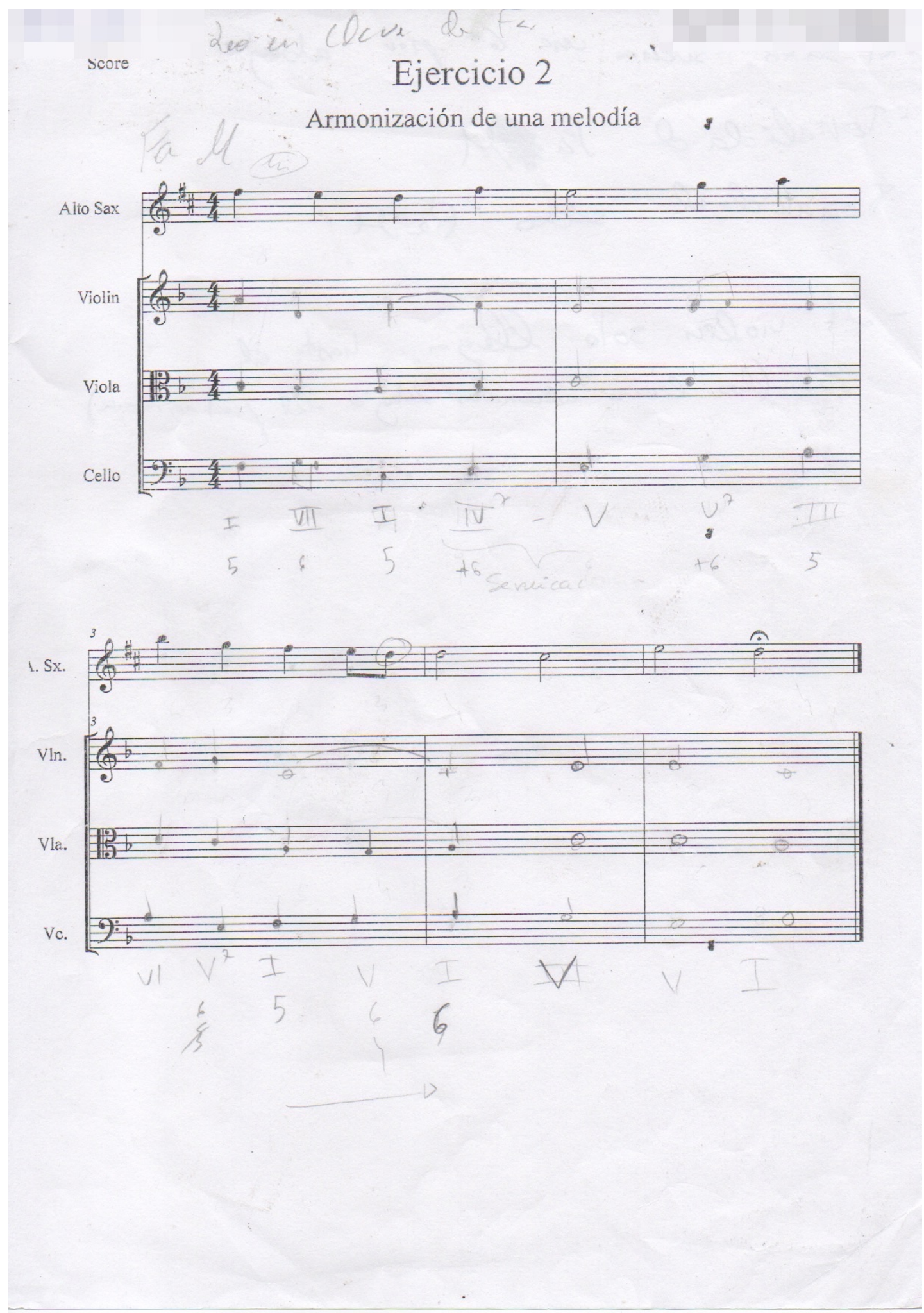


Diseño y planificación de competencias específicas en el currículum de enseñanzas profesionales de música: modalidades composición-dirección en la enseñanza superior.

\section{Carlos Eduardo Pascual Pérez}

\section{Ejercicio 2}

Armonización de una melodía ,

Alto Sax

Mib

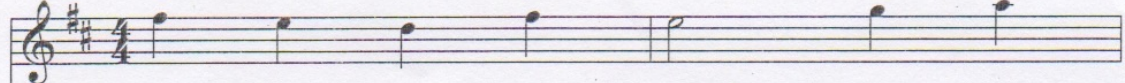

Violin

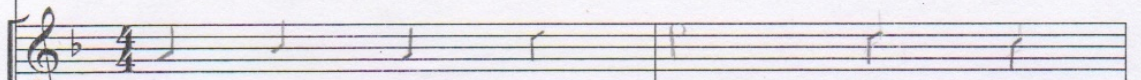

Viola

Cello

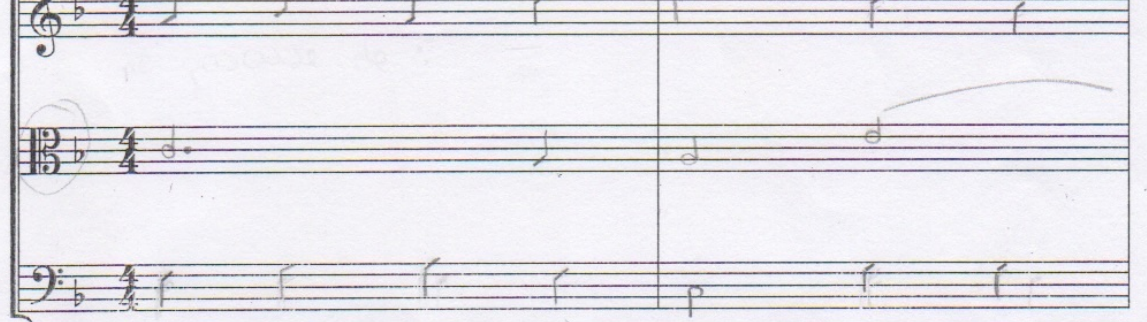

I

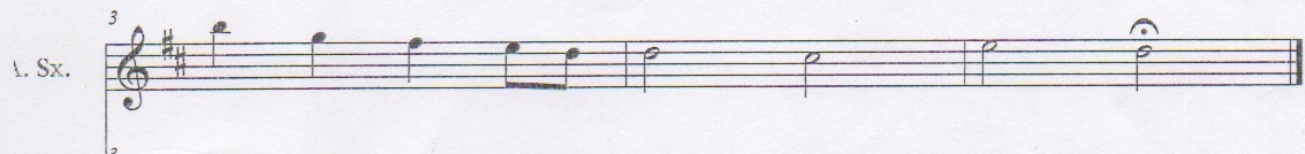

Vln.

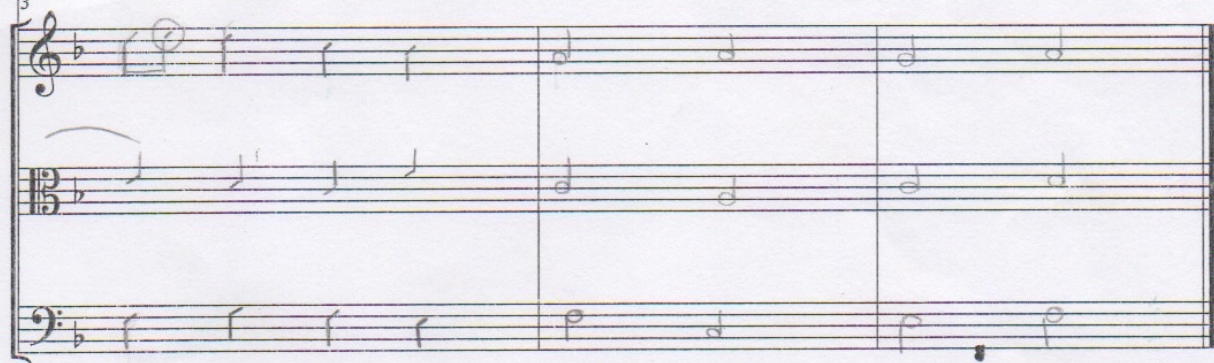

Ve.

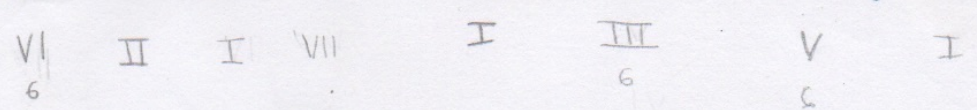


Diseño y planificación de competencias específicas en el currículum de enseñanzas profesionales de música: modalidades composición-dirección en la enseñanza superior.

\section{Carlos Eduardo Pascual Pérez}

Score

Ejercicio 2

Armonización de una melodía
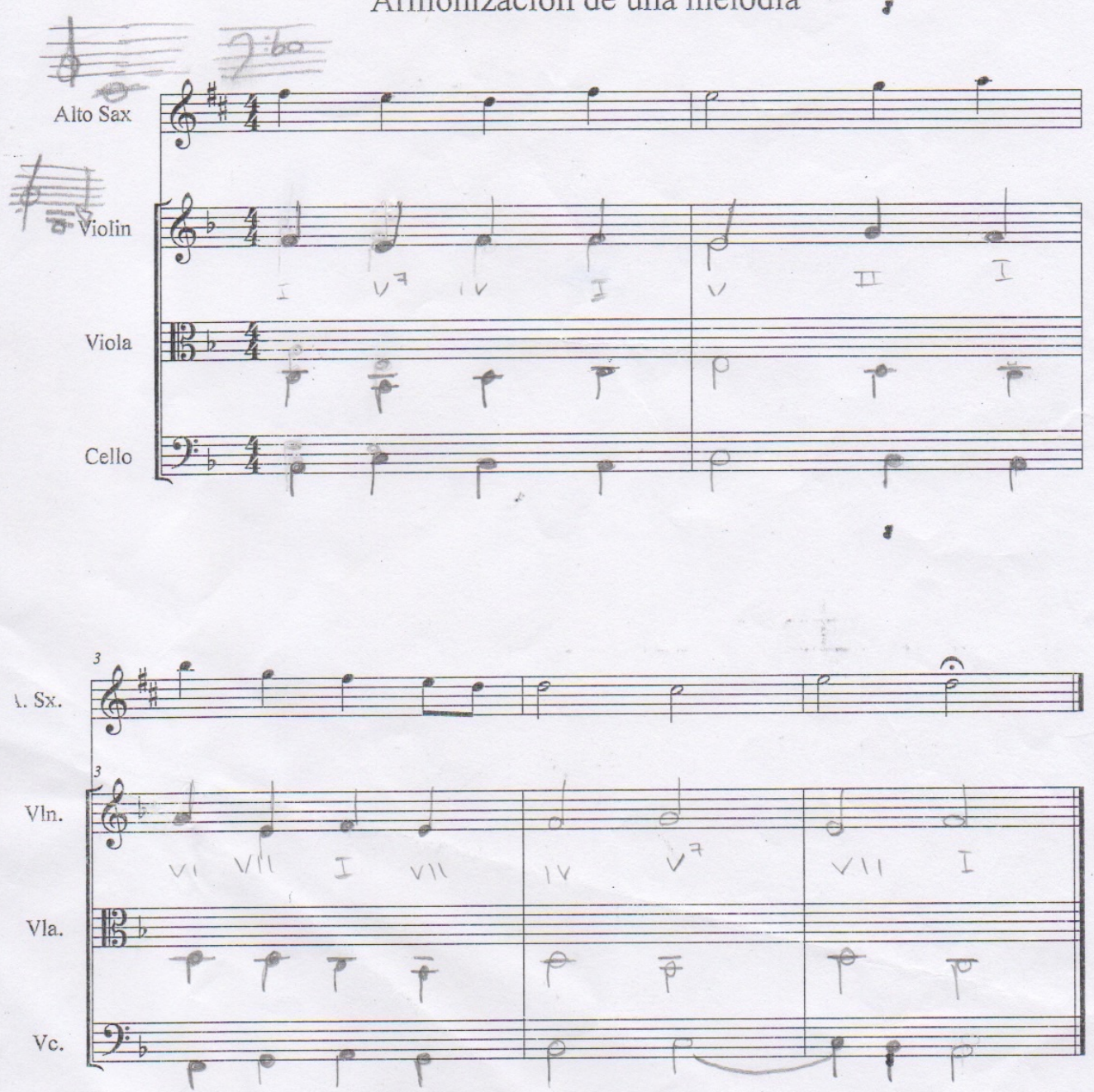
Diseño y planificación de competencias específicas en el currículum de enseñanzas profesionales de música: modalidades composición-dirección en la enseñanza superior.

\section{Carlos Eduardo Pascual Pérez}

Score

Ejercicio 2

Armonización de una melodía

Alto Sax

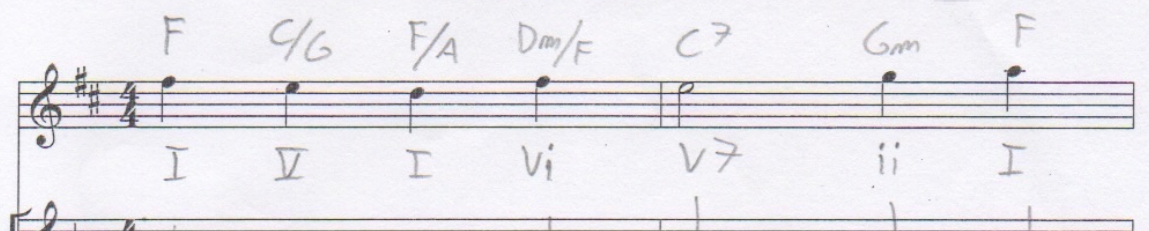

Violin

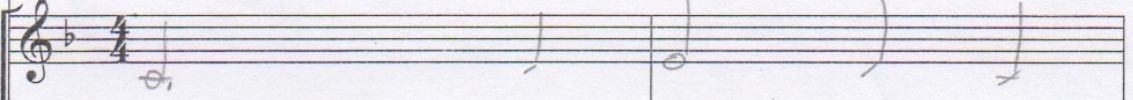

Viola

Cello

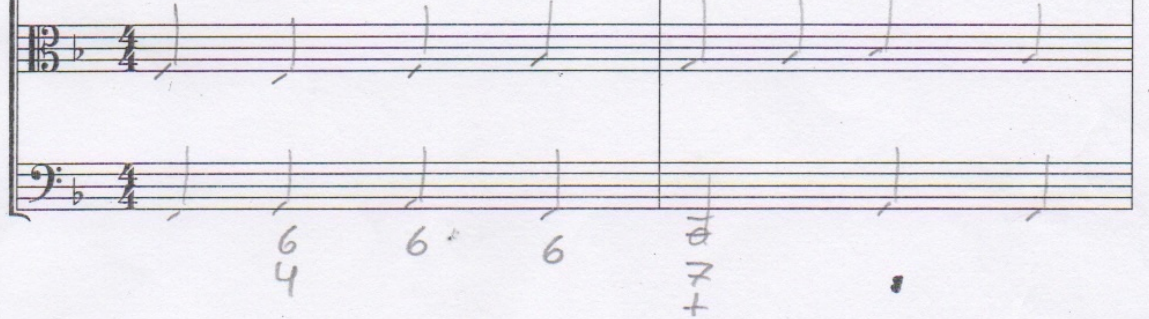

1. Sx.

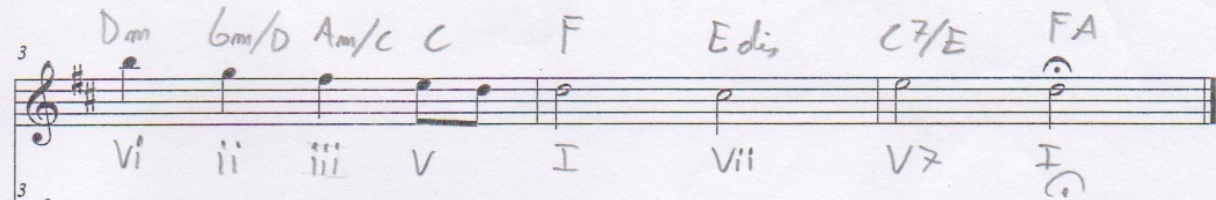

Vln.

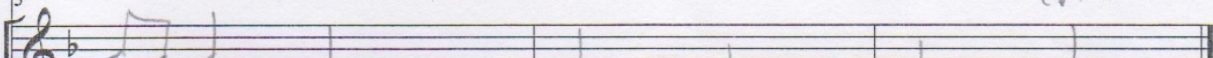

Vla.

Vc.

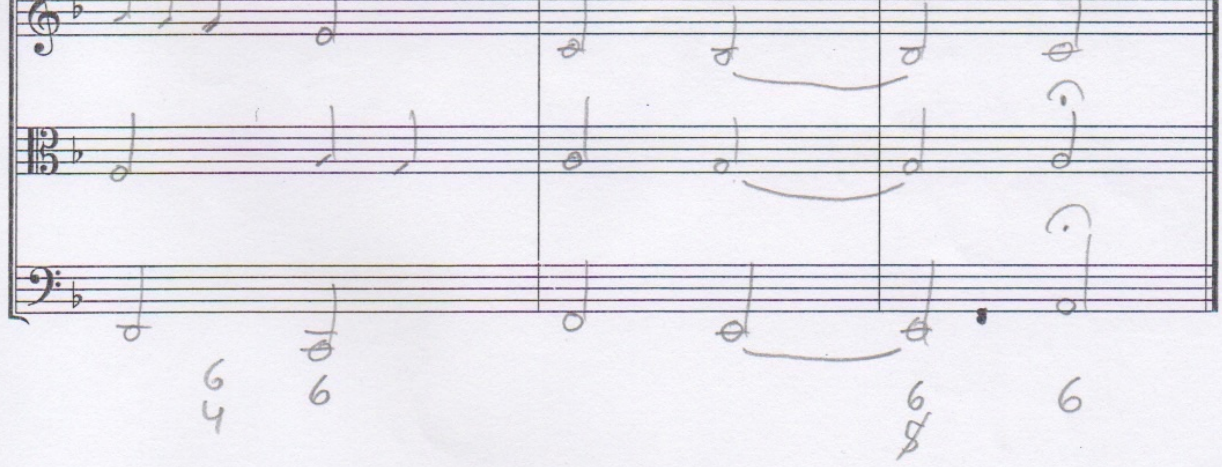


Diseño y planificación de competencias específicas en el currículum de enseñanzas profesionales de música: modalidades composición-dirección en la enseñanza superior.

Carlos Eduardo Pascual Pérez

\section{UNIVERSITAT}

Diseño y planificación de competencias especificas en el curriculum de enseñanzas profesionales de música. Modalidades en la enseñanza superior.

Carlos Eduardo Pascual Pérez (investigador) - José María Peñalver Vilar (director) - Amparo Porta Navarro (tutora)

\section{TEST FINAL 1 Armonía (3 Enseñanzas Profesionales)}

Detección de errores armónicos estudiados aplicados a una plantilla instrumental

Instrucciones: Debe analizarse cada fragmento instrumental como si de una realización armónica a cuatro partes se tratase, y localizar (si los hay) errores armónicos de los que figuran en el listado*, para seguidamente enumerarlos en la tabla de respuestas, indicando para cada error su localización (compás y tiempo), parte/s implicada/s (instrumento/s) y tipo de error $(a, b, c, d, \ldots)$. Puede haber más de un error en un mismo tiempo, en ese caso anotarlos por separado. Si se considera, también puede anotarse alguna observación.

Además, si no se detectan errores en un ejercicio, debe marcarse la casilla correspondiente. Si se desconoce o no se sabe como responder al ejercicio, dejar en blanco.

*Listado de posibles tipos de error:
a) Octavas seguidas
b) Quintas seguidas
c) Octavas directas
d) Quintas directas
e) Cruzamiento de voces
f) Superación de la separación máxima entre voces
g) Duplicación de la sensible
h) Resolución incorrecta o irresolución de la sensible
i) Resolución incorrecta o irresolución de la séptima (acordes de $7^{9}$ de dte.)
j) Ausencia de preparación de la séptima (acordes de $7 \underline{a}$ de dte.)

Instrumento/s o especialidad/es que estás cursando o has cursado:

\section{EJERCICIO 1}

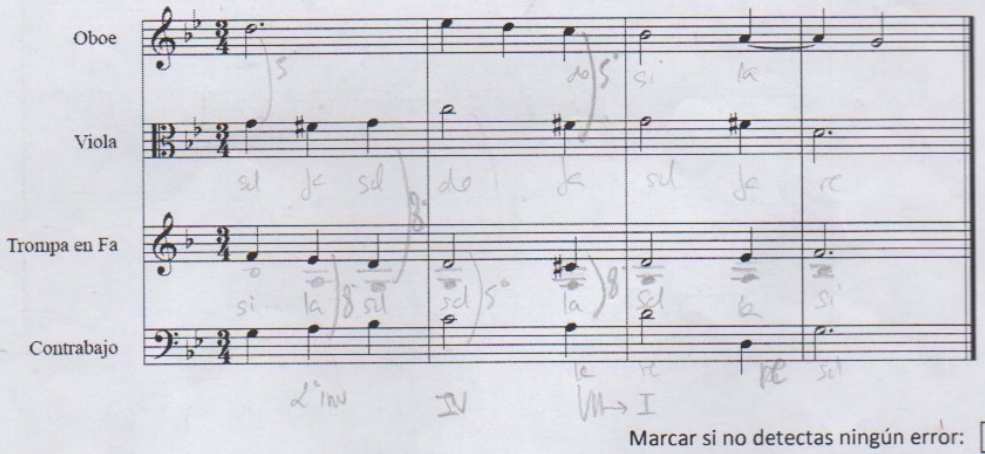

\begin{tabular}{|c|c|c|c|c|}
\hline Compás & Tiempo & Instrumento/s implicado/s & Tipo de error & Observaciones \\
\hline 1 & 3 & Vila a & a & \\
\hline 2 & 4 & Traripa en ta & & \\
\hline 2 & 1 & Vola & & \\
\hline 2 & 3 & Obol & 5 & \\
\hline & & & & \\
\hline & & & & \\
\hline & & & & \\
\hline & & & & \\
\hline
\end{tabular}


Diseño y planificación de competencias específicas en el currículum de enseñanzas profesionales de música: modalidades composición-dirección en la enseñanza superior.

Carlos Eduardo Pascual Pérez

EJERCICIO 2

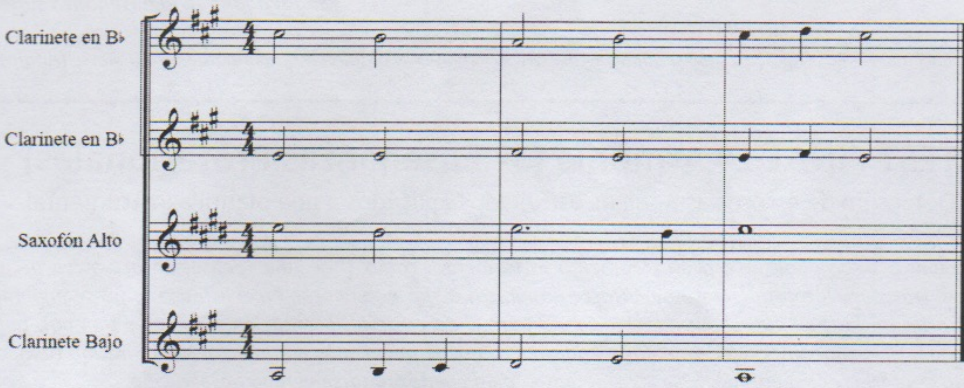

Marcar si no detectas ningún error:

\begin{tabular}{|l|l|l|l|l|}
\hline Compás & Tiempo & Instrumento/s implicado/s & Tipo de error & Observaciones \\
\hline & & & & \\
\hline & & & & \\
\hline & & & & \\
\hline & & & & \\
\hline & & & & \\
\hline & & & & \\
\hline & & & & \\
\hline & & & & \\
\hline
\end{tabular}

EJERCICIO 3

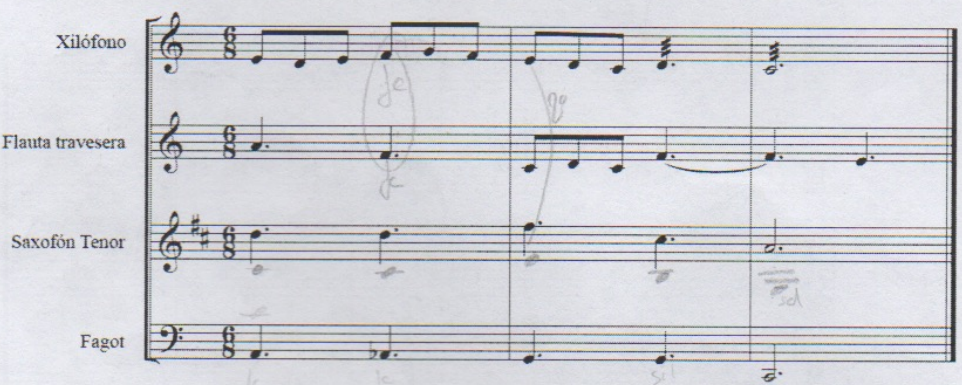

Marcar si no detectas ningún error:

\begin{tabular}{|c|c|c|c|c|}
\hline Compás & Tiempo & Instrumento/s implicado/s & Tipo de error & Observaciones \\
\hline 4 & 2 & Xilotono & $n$ & \\
\hline 2 & 1 & Souvelen end & $e$ & \\
\hline 2 & 2 & Laula hreveeca & e & \\
\hline & & $y$ & & \\
\hline & & & & \\
\hline & & & & \\
\hline & & & & \\
\hline & & & & \\
\hline
\end{tabular}


Diseño y planificación de competencias específicas en el currículum de enseñanzas profesionales de música: modalidades composición-dirección en la enseñanza superior.

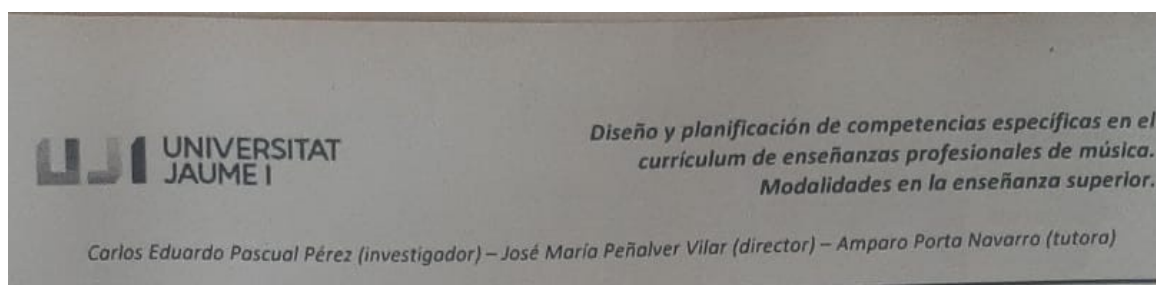

TEST FINAL 1 Armonía (3 Enseñanzas Profesionales)

Detección de errores armónicos estudiados aplicados a una plantilla instrumental

Instrucciones: Debe analizarse cada fragmento instrumental como si de una realización armónica a cuatro

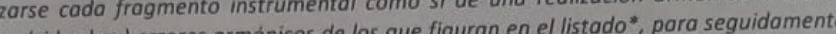
partes se tratase, y localizar (si los hay) errores armonicos de los que figuran en el listado", para seguidomente enumerarlos en la tabla de respuestos, indicando para cada error su localizacion (compas y tiempo), parte/s implicado/s (instrumento/s) y tipo de error $(a, b, c, d, \ldots)$. Puede haber más de un error en un mismo tiempo, en . Sise considera, también puede anotarse alguna observación. Además, si no se detecton errores en un ejercicio, debe marcarse la casilla correspondiente. Si se descono no se sabe como responder al ejercicio, dejar en blanco.

"Listado de posibles tipos de error:
a) Octavas seguida
b) Quintas seguidas
c) Octavas directos
d) Quintos directos
e) Cruzamiento de voces
f) Superación de la separación máxima entre voces

g) Duplicación de la sensible

h) Resolución incorrecta o irresolución de la sensible

Resolución incorrecta o irresolución de la séptima (acordes de 790 de dte.)

j) Ausencia de preparación de la séptimo (acordes de 79 de dte.)

Instrumento/s o especialidad/es que estás cursando o has cursado:

EERCICIO 1

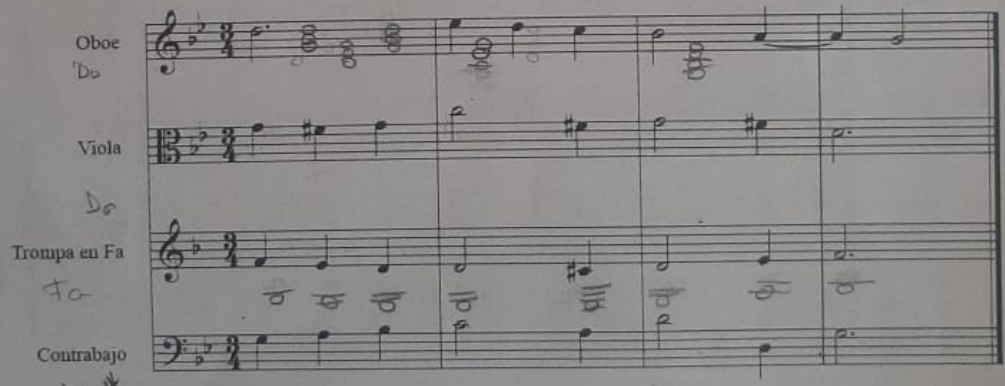

Marcar si no detectas ningún error:

\begin{tabular}{|c|c|c|c|c|}
\hline Compás & Tiempo & Instrumento/s implicado/s & Tipo de error & Observaciones \\
\hline 3 & Foodel & Trampa / contrabaje & e & \\
\hline 2 & $\Rightarrow 3$ & $11 / 1$ & e. & \\
\hline 1.1 & 3 & 111 & e & \\
\hline 2 & 1 & Vida / Tlampa & $\&$ & \\
\hline $2-3$ & $3-1$ & Viole - Fompa & $a$ & \\
\hline 1 & 2 & Trampa & h & \\
\hline 3 & 3 & Thomea / oboe & $g$ & \\
\hline & & & & \\
\hline
\end{tabular}


Diseño y planificación de competencias específicas en el currículum de enseñanzas profesionales de música: modalidades composición-dirección en la enseñanza superior.

Carlos Eduardo Pascual Pérez

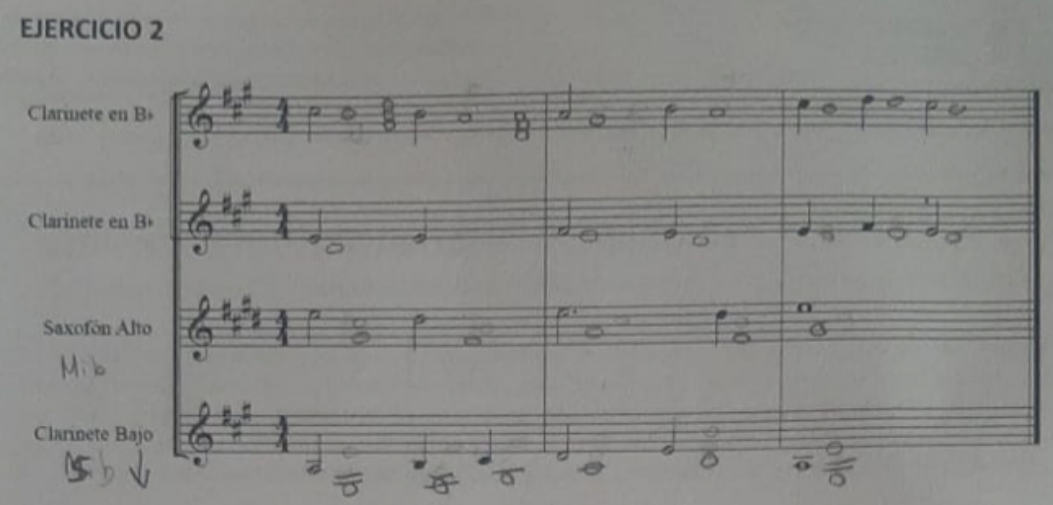

Marcar si no detectas ningún error:

\begin{tabular}{|l|l|l|l|l|}
\hline Compás & Tiempo & Instrumento/s implicado/s & Tipo de error & Observaciones \\
\hline & & & & \\
\hline & & & & \\
\hline & & & & \\
\hline & & & & \\
\hline & & & & \\
\hline & & & & \\
\hline & & & & \\
\hline & & & & \\
\hline
\end{tabular}

EJERCICIO 3

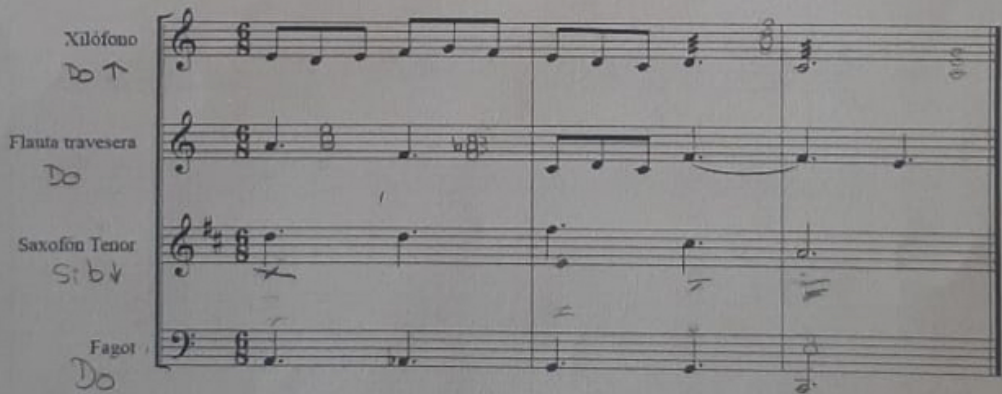

Marcar si no detectas ningún error:

\begin{tabular}{|c|c|c|c|c|}
\hline Compás & Tiempo & Instrumento/s implicado/s & Tipo de error & Observaciones \\
\hline 2 & Dibal & Savo tenor/Fasot & i & \\
\hline$\Lambda$ & Debe & Flanda/Saxo teuca & $a$ & \\
\hline & & & & \\
\hline & & & & \\
\hline & & & & \\
\hline & & & & \\
\hline & & & & \\
\hline & & & & \\
\hline
\end{tabular}


Diseño y planificación de competencias específicas en el currículum de enseñanzas profesionales de música: modalidades composición-dirección en la enseñanza superior.

TEST FINAL 1 Armonía (3 Enseñanzas Profesionales)

Detección de errores armónicos estudiados aplicados a una plantilla instrumental

Instrucciones: Debe analizarse cada fragmento instrumental como si de una realización armónica a cuatro partes se tratase, y localizar (si los hay) errores armónicos de los que figuran en el listado*, para seguidamente enumerarlos en la tabla de respuestas, indicando para cada error su localización (compás y tiempo), parte/s implicada/s (instrumento/s) y tipo de error $(a, b, c, d, \ldots)$. Puede haber más de un error en un mismo tiempo, en ese caso anotarlos por separado. Si se considera, también puede anotarse alguna observación.

Además, si no se detectan errores en un ejercicio, debe marcarse la casilla correspondiente. Si se desconoce o no se sabe como responder al ejercicio, dejar en blanco.

* Listado de posibles tipos de error:
a) Octavas seguidas
b) Quintas seguidas
c) Octavas directas
d) Quintas directas
e) Cruzamiento de voces
f) Superación de la separación máxima entre voces
g) Duplicación de la sensible
h) Resolución incorrecta o irresolución de la sensible
i) Resolución incorrecta o irresolución de la séptima (acordes de $7 \stackrel{9}{\text { de }}$ dte.)
j) Ausencia de preparación de la séptima (acordes de $7 \stackrel{9}{ }$ de dte.)

Instrumento/s o especialidad/es que estás cursando o has cursado:

\section{EJERCICIO 1}

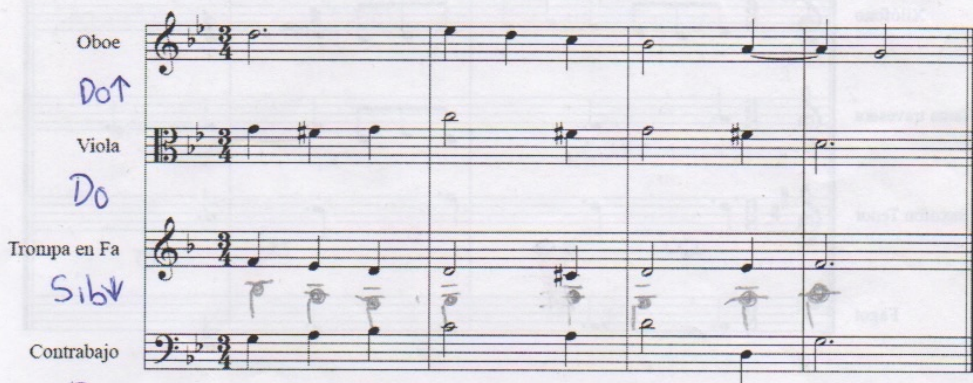

Do

Marcar si no detectas ningún error:

\begin{tabular}{|c|c|c|c|c|}
\hline Compás & Tiempo & Instrumento/s implicado/s & Tipo de error & Observaciones \\
\hline 7 & 1 & $C_{C} D D_{C}$ & $x$ & \\
\hline & & $\frac{10 \times 0}{111}$ & $x$ & \\
\hline$\infty$ & $\infty$ & $\sqrt{a t a n}$ & $\frac{x}{8}$ & \\
\hline 3 & 7 & Viola llanda & $c$ & \\
\hline G & 1 & Viola & h & \\
\hline & & $=$ & & \\
\hline & & & & \\
\hline & & & & \\
\hline
\end{tabular}


Diseño y planificación de competencias específicas en el currículum de enseñanzas profesionales de música: modalidades composición-dirección en la enseñanza superior.

Carlos Eduardo Pascual Pérez

EJERCICIO 2

$2 \mathrm{M}$ Clarinete en $\mathrm{B}$,

2 a M Clarinete en B,

64 desc Saxofón Alto

Sc Clarinete Bajo

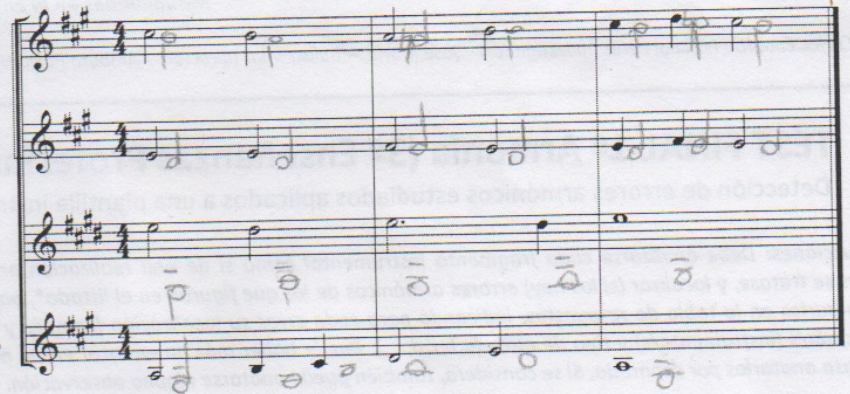

Ba desc

Marcar si no detectas ningún error:

\begin{tabular}{|l|l|l|l|l|}
\hline Compás & Tiempo & Instrumento/s implicado/s & Tipo de error & Observaciones \\
\hline & & & & \\
\hline & & & & \\
\hline & & & & \\
\hline & & & & \\
\hline & & & & \\
\hline & & & & \\
\hline & & & & \\
\hline
\end{tabular}

EJERCICIO 3

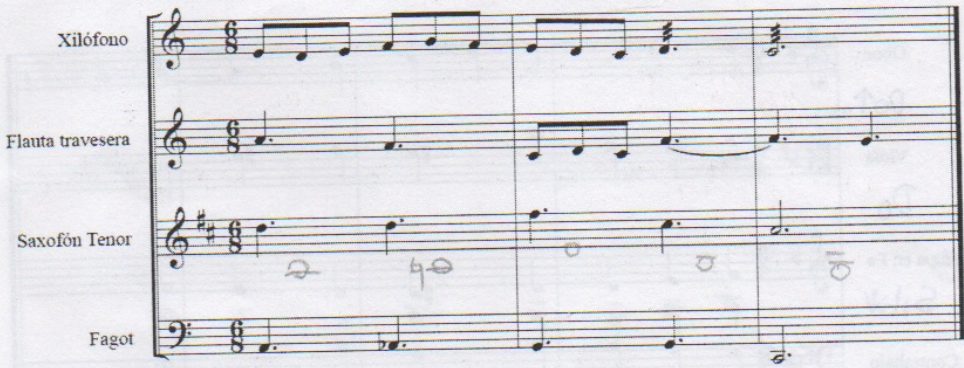

Marcar si no detectas ningún error:

\begin{tabular}{|c|c|c|c|c|}
\hline Compás & Tiempo & Instrumento/s implicado/s & Tipo de error & Observaciones \\
\hline 3 & 1 & Swo & $h$ & \\
\hline & & & & \\
\hline & & & & \\
\hline & & & & \\
\hline & & & & \\
\hline & & & & \\
\hline & & & & \\
\hline & & & & \\
\hline
\end{tabular}


Diseño y planificación de competencias específicas en el currículum de enseñanzas profesionales de música: modalidades composición-dirección en la enseñanza superior.

Carlos Eduardo Pascual Pérez 1. UNIVERSITAT
Diseño y planificación de competencias especificas en el curriculum de enseñanzas profesionales de música. Modalidades en la enseñanza superior.

Carlos Eduardo Pascual Pérez (investigador) - José María Peñalver Vilar (director) - Amparo Porta Navarro (tutora)

\section{TEST FINAL 10 Armonía (3 Enseñanzas Profesionales)}

Detección de errores armónicos estudiados aplicados a una plantilla instrumental

Instrucciones: Debe analizarse cada fragmento instrumental como si de una realización armónica a cuatro partes se tratase, y localizar (si los hay) errores armónicos de los que figuran en el listado*, para seguidamente enumerarlos en la tabla de respuestas, indicando para cada error su localización (compás y tiempo), parte/s implicada/s (instrumento/s) y tipo de error $(a, b, c, d, \ldots)$. Puede haber más de un error en un mismo tiempo, en ese caso anotarlos por separado. Si se considera, también puede anotarse alguna observación.

Además, si no se detectan errores en un ejercicio, debe marcarse la casilla correspondiente. Si se desconoce o no se sabe como responder al ejercicio, dejar en blanco.

* Listado de posibles tipos de error:
a) Octavas seguidas
b) Quintas seguidas
c) Octavas directas
d) Quintos directos
e) Cruzamiento de voces
f) Superación de la separación máxima entre voces

g) Duplicación de la sensible

h) Resolución incorrecta o irresolución de la sensible

i) Resolución incorrecta o irresolución de la séptima (acordes de 79 de dte.)

j) Ausencia de preparación de la séptima (acordes de 79 de dte.)

Instrumento/s o especialidad/es que estás cursando o has cursado:

Guitarra

EJERCICIO 1

Solm

Ren oboe

Viola

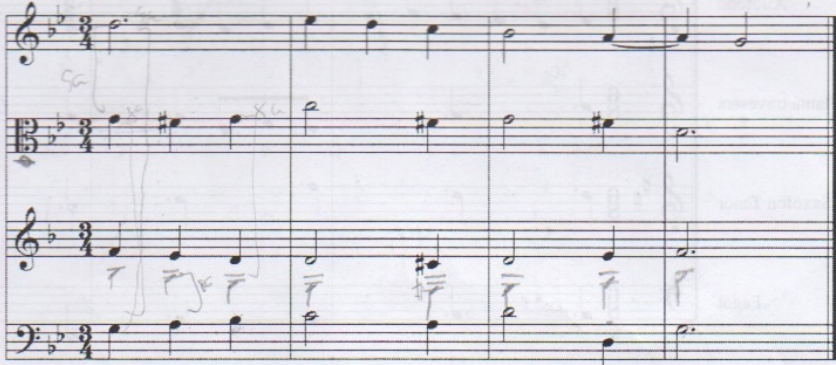

Marcar si no detectas ningún error:

\begin{tabular}{|c|c|c|c|c|}
\hline Compás & Tiempo & Instrumento/s implicado/s & Tipo de error & Observaciones \\
\hline - & & 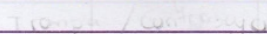 & - & \\
\hline$?$ & 1 & Vielu Grompa & 1 & \\
\hline 2 & 2 & 1111 & \& & \\
\hline 2 & 3 & vivea / Trumpa & a & \\
\hline 3 & 1 & Vivla /Trompk & c & \\
\hline 3 & 3 & Trompa / Conlicabyo & $f$ & \\
\hline 4 & 1 & viola & h & \\
\hline
\end{tabular}


Diseño y planificación de competencias específicas en el currículum de enseñanzas profesionales de música: modalidades composición-dirección en la enseñanza superior.

Carlos Eduardo Pascual Pérez

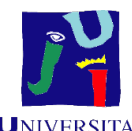

$\mathbf{U}_{\text {NIVERSITA }}$ JAUME+ I

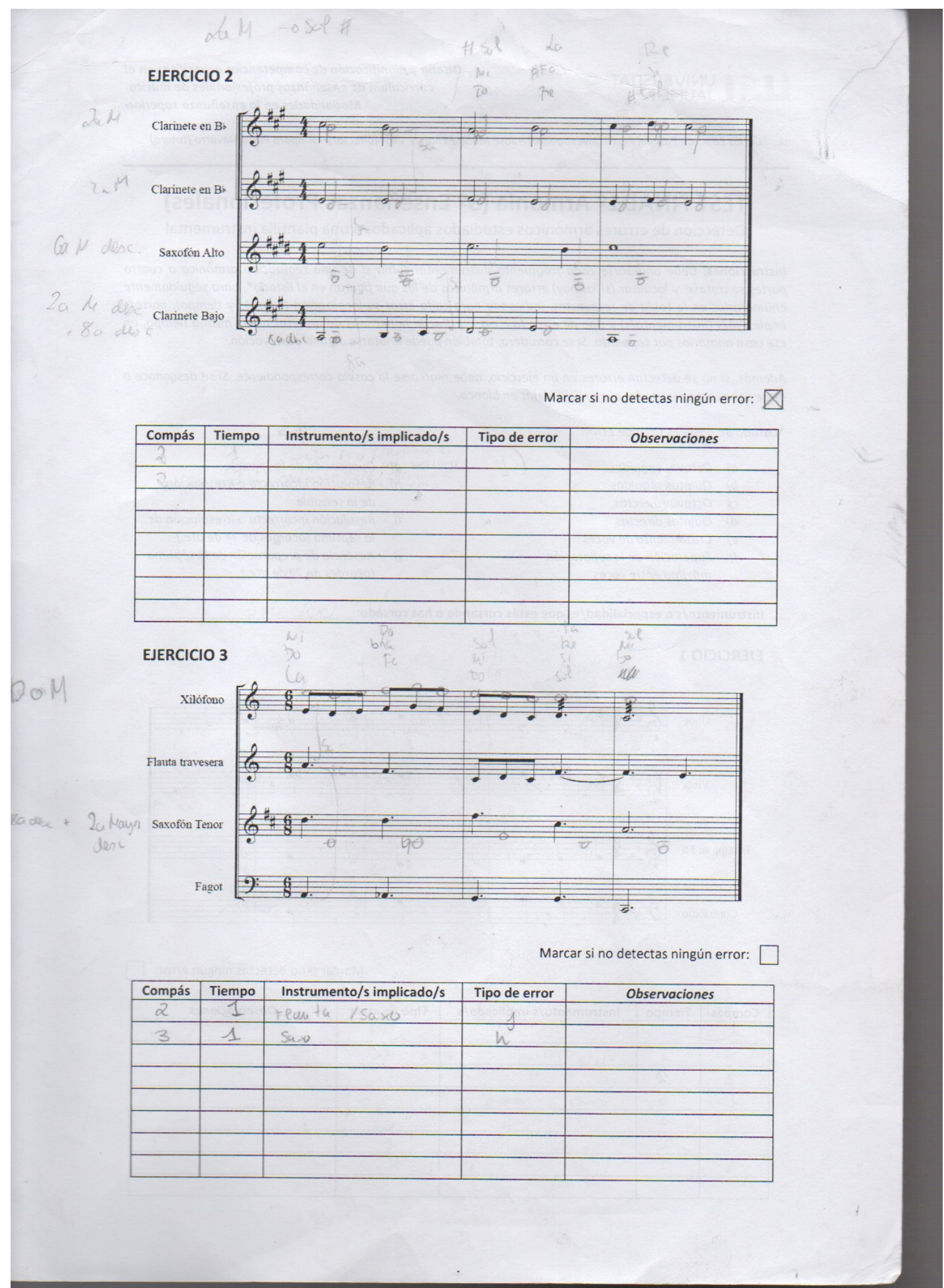


Diseño y planificación de competencias específicas en el currículum de enseñanzas profesionales de música: modalidades composición-dirección en la enseñanza superior.

\section{Carlos Eduardo Pascual Pérez}

\section{I UNIVERSITAT JAUME I}

Diseño y planificación de competencias especificas en el curriculum de enseñanzas profesionales de música. Modalidades en la enseñanza superior.

Carlos Eduardo Pascual Pérez (investigador) - José Maria Peñalver Vilar (director) - Amparo Porto Navarro (tutora)

TEST FINAL 1ㅇ Armonía (3 Enseñanzas Profesionales)

Detección de errores armónicos estudiados aplicados a una plantilla instrumental

Instrucciones: Debe analizarse cada fragmento instrumental como si de una realización armónica a cuatro partes se tratase, y localizar (si los hay) errores armónicos de los que figuran en el listado*, para seguidamente enumerarlos en la tabla de respuestas, indicando para cada error su localización (compás y tiempo), parte/s implicada/s (instrumento/s) y tipo de error $(a, b, c, d, \ldots)$. Puede haber más de un error en un mismo tiempo, en ese caso anotarlos por separado. Si se considera, también puede anotarse alguna observación.

Además, si no se detectan errores en un ejercicio, debe marcarse la casilla correspondiente. Si se desconoce o no se sabe como responder al ejercicio, dejar en blanco.

* Listado de posibles tipos de error:
a) Octavas seguidas
b) Quintas seguidas
c) Octavas directas
d) Quintas directas
e) Cruzamiento de voces
f) Superación de la separación máxima entre voces

g) Duplicación de la sensible

h) Resolución incorrecta o irresolución de la sensible

i) Resolución incorrecta o irresolución de la séptima lacordes de 7o de dte.

j) Ausencia de preparación de la séptimo (acordes de 79 de dte.)

Instrumento/s o especialidad/es que estás cursando o has cursado:

EJERCICIO 1

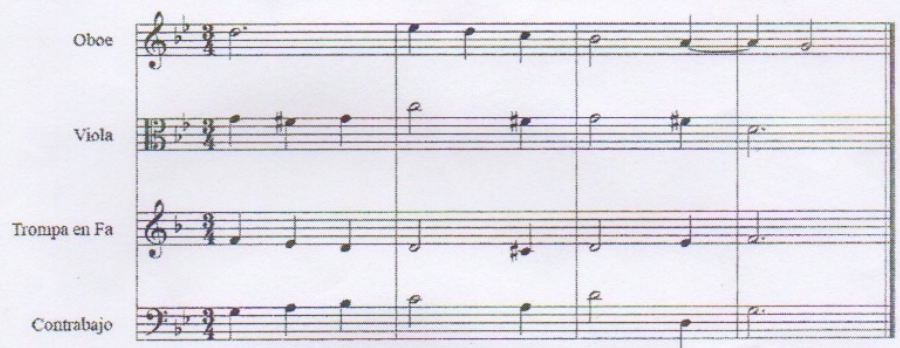

Marcar si no detectas ningún error:

\begin{tabular}{|c|c|c|c|c|}
\hline Compás & Tiempo & Instrumento/s implicado/s & Tipo de error & Observaciones \\
\hline 2 & 1 & Viala y trompa & 8 & \\
\hline 2 & 3 & Viala y trompa & 8 & \\
\hline 2 y 3 & 3 y & Viala y trompa & a & \\
\hline 2 y 3 & 3 ys & Viola y trompa & c & \\
\hline 3 & 3 & viola & $h$ & \\
\hline & & & & \\
\hline & & & & \\
\hline & & & & \\
\hline
\end{tabular}


Diseño y planificación de competencias específicas en el currículum de enseñanzas profesionales de música: modalidades composición-dirección en la enseñanza superior.

Carlos Eduardo Pascual Pérez

EJERCICIO 2

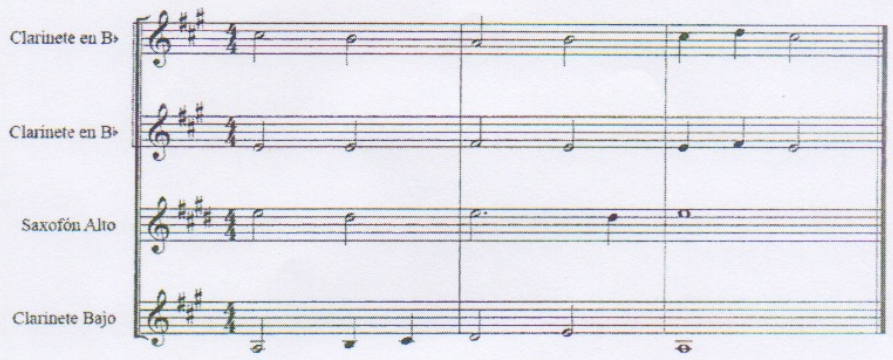

Marcar si no detectas ningún error:

\begin{tabular}{|c|c|c|c|c|}
\hline Compás & Tiempo & Instrumento/s implicado/s & Tipo de error & Observaciones \\
\hline $1 y^{2}$ & 3,4 ys & Saxabin y Clarinete Bap & e & \\
\hline$\Delta$ is 2 & $3,4, y \Delta$ & Sayolón y Clarinete Bap & $d$ & \\
\hline 2 & 283 & Clarinete en Bb y Claninete Baje & $b$ & \\
\hline 2 & $2 y 3$ & Qasinete an Bb y Clarisete Bajo & $d$ & \\
\hline & & & & \\
\hline & & & & \\
\hline & & & & \\
\hline
\end{tabular}

EJERCICIO 3

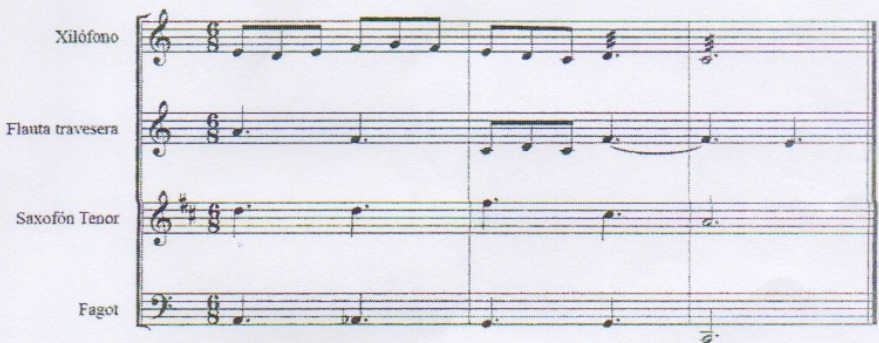

Marcar si no detectas ningún error:

\begin{tabular}{|c|c|c|c|c|}
\hline Compás & Tiempo & Instrumento/s implicado/s & Tipo de error & Observaciones \\
\hline 2 & 1 & Xilofano y flauta & a & \\
\hline 2 & $b$ & Xilofono y flauta & c & \\
\hline 2 & $\Delta-2$ & Flauta traveseta & i & \\
\hline 2 y 3 & $2-1$ & Saofón Tenor & L & \\
\hline & & & & \\
\hline & & & & \\
\hline & & & & \\
\hline & & & & \\
\hline
\end{tabular}


Diseño y planificación de competencias específicas en el currículum de enseñanzas profesionales de música: modalidades composición-dirección en la enseñanza superior.

Carlos Eduardo Pascual Pérez

\section{UNIVERSITAT JAUMEI}

Diseño y planificación de competencias específicas en el currículum de enseñanzas profesionales de música. Modalidades en la enseñanza superior.

Carlos Eduardo Pascual Pérez (investigador) - José Maria Peñalver Vilar (director) - Amparo Porta Navarro (tutora)

TEST FINAL 1ㅇ Armonía (3 Enseñanzas Profesionales)

Detección de errores armónicos estudiados aplicados a una plantilla instrumental

Instrucciones: Debe analizarse cada fragmento instrumental como si de una realización armónica a cuatro partes se tratase, y localizar (si los hay) errores armónicos de los que figuran en el listado*, para seguidamente enumerarlos en la tabla de respuestas, indicando para cada error su localización (compás y tiempo), parte/s implicada/s (instrumento/s) y tipo de error $(a, b, c, d, \ldots)$. Puede haber más de un error en un mismo tiempo, en ese caso anotarlos por separado. Si se considera, también puede anotarse alguna observación.

Además, si no se detectan errores en un ejercicio, debe marcarse la casilla correspondiente. Si se desconoce o no se sabe como responder al ejercicio, dejar en blanco.

*Listado de posibles tipos de error:
a) Octavas seguidas
b) Quintas seguidas
c) Octavas directas
d) Quintas directas
e) Cruzamiento de voces
f) Superación de la separación máxima entre voces

g) Duplicación de la sensible

h) Resolución incorrecta o irresolución de la sensible

i) Resolución incorrecta o irresolución de la séptima (acordes de $7 \underline{a}$ de dte.)

j) Ausencia de preparación de la séptima (acordes de $7 \stackrel{9}{ }$ de dte.)

Instrumento/s o especialidad/es que estás cursando o has cursado:

\section{EJERCICIO 1}

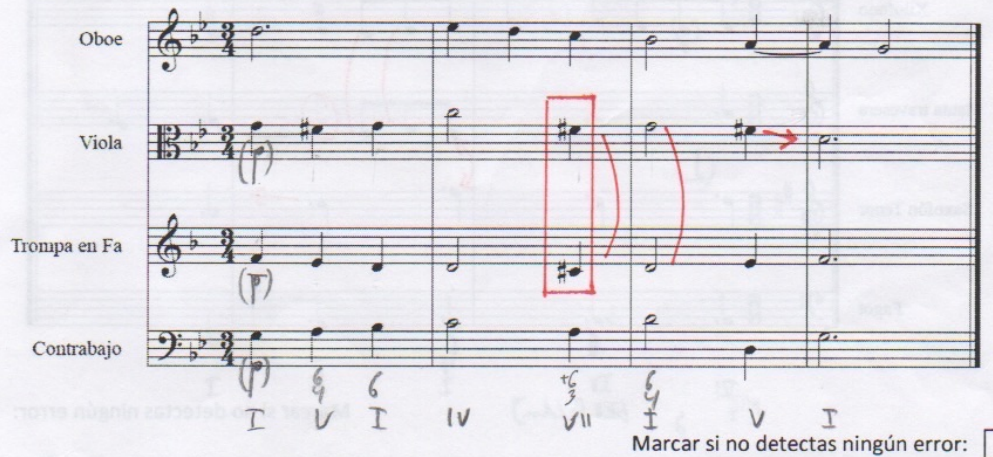

\begin{tabular}{|c|c|c|c|c|}
\hline Compás & Tiempo & Instrumento/s implicado/s & Tipo de error & Observaciones \\
\hline 2 & 3 & VIOLA / TROMPA & $G$ & DUPLICACIUUN SENSEBCE \\
\hline $2-3$ & $3-1$ & VIOLA /TROMPA & $A$ & OCTAVAS SEGUIDAS \\
\hline $3-4$ & $3-1$ & VIOLA & $\mathrm{H}$ & SENSTGLEMAL RESUELTA \\
\hline & & & & \\
\hline & & & & \\
\hline & & & & \\
\hline & & & & \\
\hline & & & & \\
\hline
\end{tabular}


Diseño y planificación de competencias específicas en el currículum de enseñanzas profesionales de música: modalidades composición-dirección en la enseñanza superior.

Carlos Eduardo Pascual Pérez

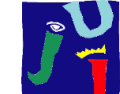

$\boldsymbol{U}_{\text {NIVERSITAT }}$ JAUME+ I

\section{EJERCICIO 2}

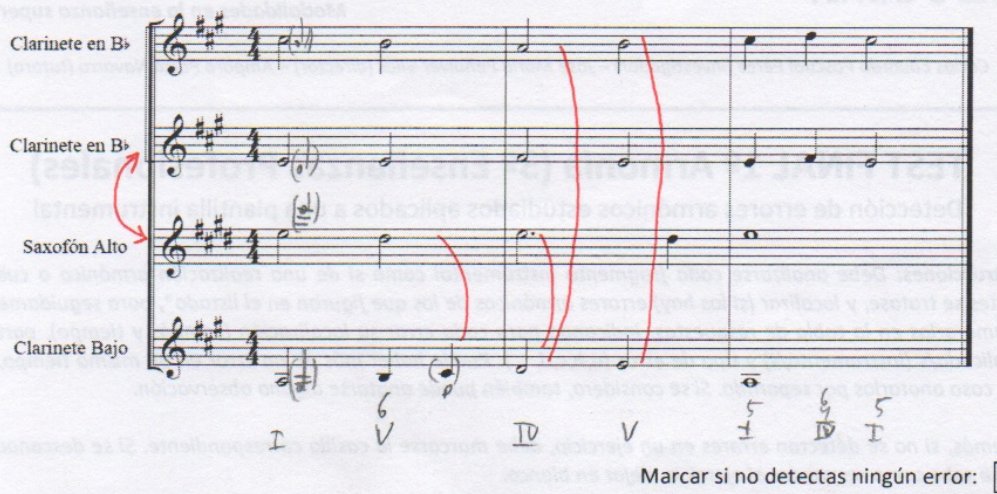

\begin{tabular}{|c|c|c|c|c|}
\hline Compás & Tiempo & Instrumento/s implicado/s & Tipo de error & Observaciones \\
\hline To90s & To90s & CLARINETE 2 - SAXNFON & $E$ & 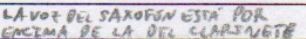 \\
\hline $1-2$ & $4-1$ & SAXOFIN / CLARTENETE BASO & $B$ & $\begin{array}{l}\text { AL SER DE OTSTSNTA ESPECTE } \\
\text { SE POPRAAN AQMITRR }\end{array}$ \\
\hline 2 & $1-2$ & CLARINETE $1^{\circ} / \angle L A R Z N E R E B O D O$ & $B$ & QLINTAS SEGUIDAS \\
\hline 3 & 4 & 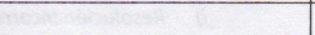 & & 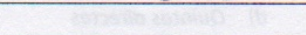 \\
\hline & & & & \\
\hline & & & & \\
\hline & & & & \\
\hline & & 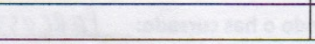 & - & 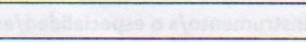 \\
\hline
\end{tabular}

\section{EJERCICIO 3}

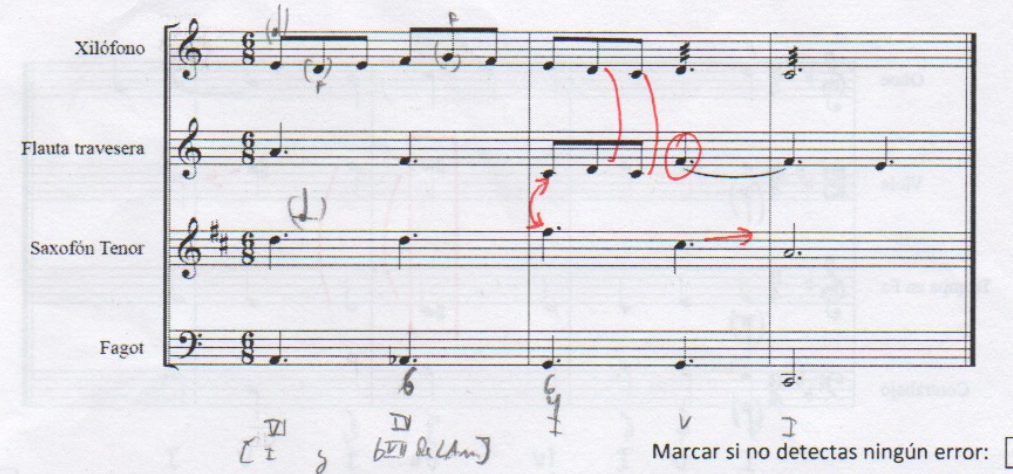

\begin{tabular}{|c|c|c|c|c|}
\hline Compás & Tiempo & Instrumento/s implicado/s & Tipo de error & Observaciones \\
\hline 2 & 1 & FLAUTA / SAXOFO'N & $E$ & 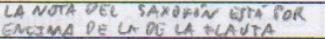 \\
\hline 2 & 1 & XILÓFONO / FLAUTA & $A y C$ & OCTAUES SEGUTOAS Y DERECIAS \\
\hline 2 & 2 & FLAUTA & J & $7^{\circ}$ NO PREPARAQA \\
\hline 2 & 2 & SAXOFON & $I$ & SENSIBLE MAC RESVELTA \\
\hline & & & & \\
\hline & & & & \\
\hline & & & & \\
\hline & & & & \\
\hline
\end{tabular}


Diseño y planificación de competencias específicas en el currículum de enseñanzas profesionales de música: modalidades composición-dirección en la enseñanza superior.

\section{Carlos Eduardo Pascual Pérez}

\section{UnNIVERSITAT
JAUMEI}

Diseño y planificación de competencias especificas en el currículum de enseñanzas profesionales de música. Modalidades en la enseñanza superior.

Carlos Eduardo Pascual Pérez (investigador) - José Maria Peñalver Vilar (director) - Amparo Porta Navarro (tutora)

\section{TEST FINAL 1ㅇ Armonía (3 Enseñanzas Profesionales)}

Detección de errores armónicos estudiados aplicados a una plantilla instrumental

Instrucciones: Debe analizarse cada fragmento instrumental como si de una realización armónica a cuatro partes se tratase, y localizar (si los hay) errores armónicos de los que figuran en el listado*, para seguidamente enumerarlos en la tabla de respuestas, indicando para cada error su localización (compás y tiempo), parte/s implicada/s (instrumento/s) y tipo de error $(a, b, c, d, \ldots$ ). Puede haber más de un error en un mismo tiempo, en ese caso anotarlos por separado. Si se considera, también puede anotarse alguna observación.

Además, si no se detectan errores en un ejercicio, debe marcarse la casilla correspondiente. Si se desconoce o no se sabe como responder al ejercicio, dejar en blanco.

* Listado de posibles tipos de error:
a) Octavas seguidas
b) Quintas seguidas
c) Octavas directos
d) Quintas directas
e) Cruzamiento de voces
f) Superación de la separación máxima entre voces

g) Duplicación de la sensible

h) Resolución incorrecta o irresolución de la sensible

i) Resolución incorrecta o irresolución de la séptima (acordes de 79 de dte.)

j) Ausencia de preparación de la séptime (acordes de $7 \underline{a}$ de dte.)

Instrumento/s o especialidad/es que estás cursando o has cursado:

EJERCICIO 1

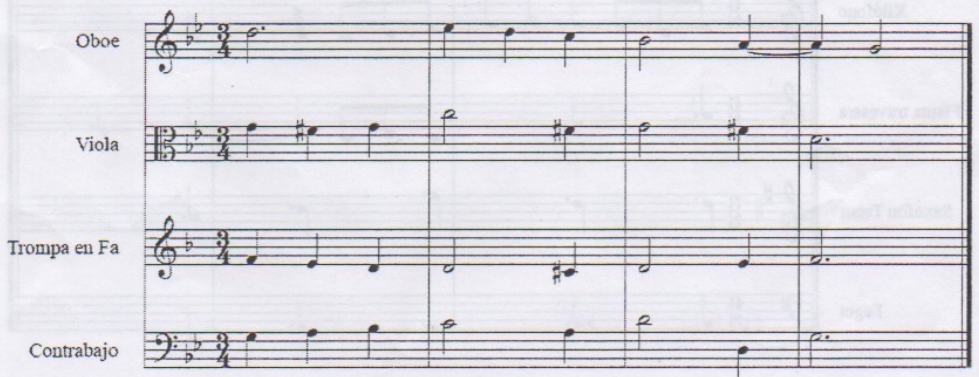

Marcar si no detectas ningún error:

\begin{tabular}{|c|c|c|c|c|c|}
\hline Compás & Tiempo & Instrumento/s implicado/s & Tipo de error & \multicolumn{2}{|r|}{ Observaciones } \\
\hline 1 & 3 & throwa & e & 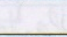 & \\
\hline 2 & 1 & vires & f & & \\
\hline 2 & 1 & tarneysa & e & & \\
\hline 2 & 3 & tromen & e & way & was oruces \\
\hline 2 & 3 & nita Thrulpe & 5 & t & \\
\hline 3 & 3 & illh & $h$ & & \\
\hline & & & & & \\
\hline & & & & & \\
\hline
\end{tabular}


Diseño y planificación de competencias específicas en el currículum de enseñanzas profesionales de música: modalidades composición-dirección en la enseñanza superior.

Carlos Eduardo Pascual Pérez

EJERCICIO 2

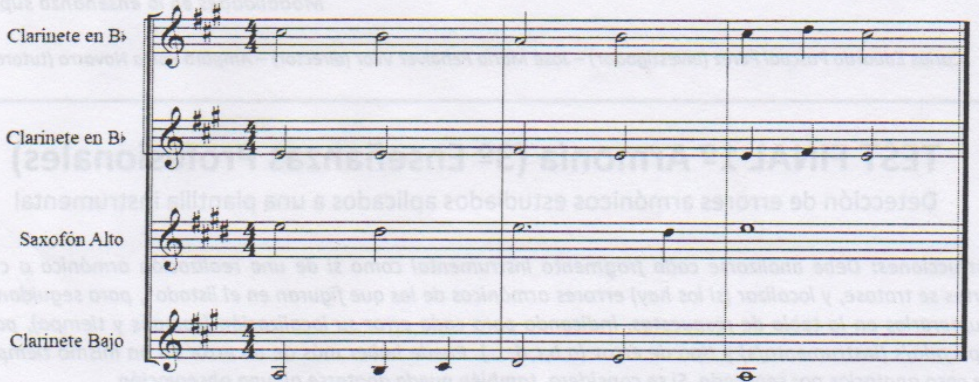

Marcar si no detectas ningún error:

\begin{tabular}{|c|c|c|c|c|}
\hline Compás & Tiempo & Instrumento $/ \mathrm{s} \mathrm{implicado/s}$ & Tipo de error & Observaciones \\
\hline $1 / 2 / 3$ & & claniete saso & $e$ & \\
\hline 2 & $1 / 3$ & 4 en Bb/Clar. bas & $b$ & \\
\hline 1 & 3 & denieh on bb/ " I & C & 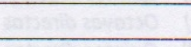 \\
\hline ( & & 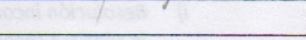 & & 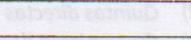 \\
\hline & & & & \\
\hline & & & & \\
\hline 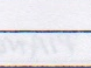 & & 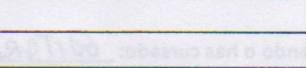 & 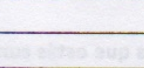 & \\
\hline
\end{tabular}

\section{EJERCICIO 3}

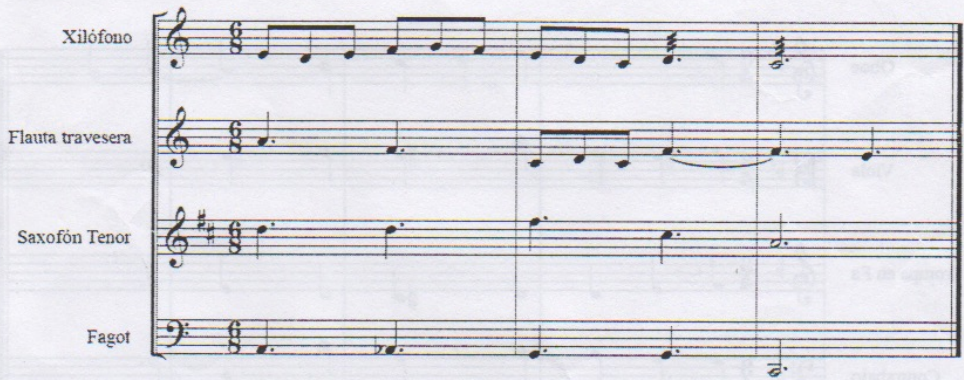

Marcar si no detectas ningún error:

\begin{tabular}{|c|c|c|c|c|}
\hline Compás & Tiempo & Instrumento/s implicado/s & Tipo de error & Observaciones \\
\hline 1 & 2 & xiking lack & $c$ & \\
\hline 2 & 1 & lanta / saxitrin & e & \\
\hline 2 & 2 & $\operatorname{sax} 0$ & j & \\
\hline 3 & 1 & $5 a \times 0$ & $h$ & \\
\hline 2 & 2 & $\operatorname{lan} k$ & j & \\
\hline & & 7 & d & \\
\hline & & & & \\
\hline & & & & \\
\hline
\end{tabular}


Diseño y planificación de competencias específicas en el currículum de enseñanzas profesionales de música: modalidades composición-dirección en la enseñanza superior.

\section{Carlos Eduardo Pascual Pérez}

\section{UNIVERSITAT}

Diseño y planificación de competencias especificas en el currículum de enseñanzas profesionales de música. Modalidades en la enseñanza superior.

Carlos Eduardo Pascual Pérez (investigador) - José Maria Peñalver Vilar (director) - Amparo Porta Navarro (tutora)

\section{TEST FINAL 1ำ Armonía (3ำ Enseñanzas Profesionales)}

Detección de errores armónicos estudiados aplicados a una plantilla instrumental

Instrucciones: Debe analizarse cada fragmento instrumental como si de una realización armónica a cuatro partes se tratase, y localizar (si los hay) errores armónicos de los que figuran en el listado*, para seguidamente enumerarlos en la tabla de respuestas, indicando para cada error su localización (compás y tiempo), parte/s implicada/s (instrumento/s) y tipo de error $(a, b, c, d, \ldots)$. Puede haber más de un error en un mismo tiempo, en ese caso anotarlos por separado. Si se considera, también puede anotarse alguna observación.

Además, si no se detectan errores en un ejercicio, debe marcarse la casilla correspondiente. Si se desconoce o no se sabe como responder al ejercicio, dejar en blanco.

*Listado de posibles tipos de error:
a) Octavas seguidas
b) Quintas seguidas
c) Octavas directas
d) Quintas directas
e) Cruzamiento de voces
f) Superación de la separación máxima entre voces

g) Duplicación de la sensible

h) Resolución incorrecta o irresolución de la sensible

i) Resolución incorrecta o irresolución de la séptima (acordes de $7 \underline{\underline{O}}$ de dte.)

j) Ausencia de preparación de la séptima (acordes de 79 de dte.)

Instrumento/s o especialidad/es que estás cursando o has cursado:

\section{EJERCICIO 1}

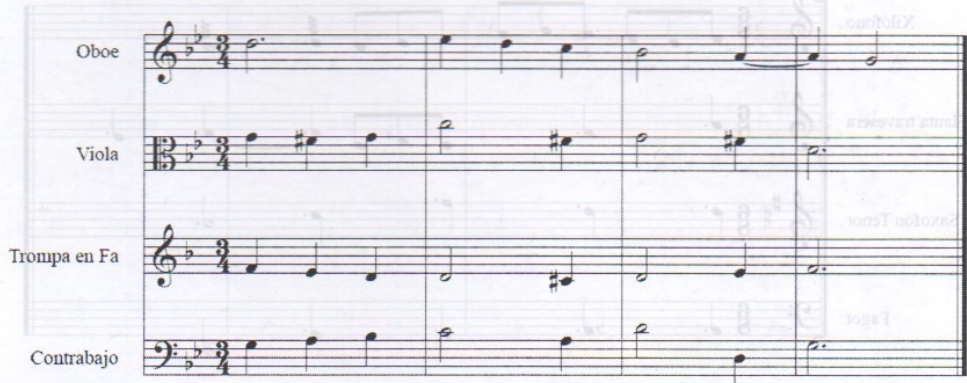

Marcar si no detectas ningún error:

\begin{tabular}{|c|c|c|c|c|}
\hline Compás & Tiempo & Instrumento/s implicado/s & Tipo de error & Observaciones \\
\hline 1 & 3 & trompa & $e$ & \\
\hline 2 & 7 & Nioea & $\rho$ & \\
\hline 2 & 3 & trompa & $e$ & \\
\hline 2 & 3 & vioba & 9 & \\
\hline 2 & 3 & trompa & 9 & \\
\hline 3 & 3 & Loea & $h$ & \\
\hline & & & & \\
\hline & & & & \\
\hline
\end{tabular}


Diseño y planificación de competencias específicas en el currículum de enseñanzas profesionales de música: modalidades composición-dirección en la enseñanza superior.

\section{Carlos Eduardo Pascual Pérez}

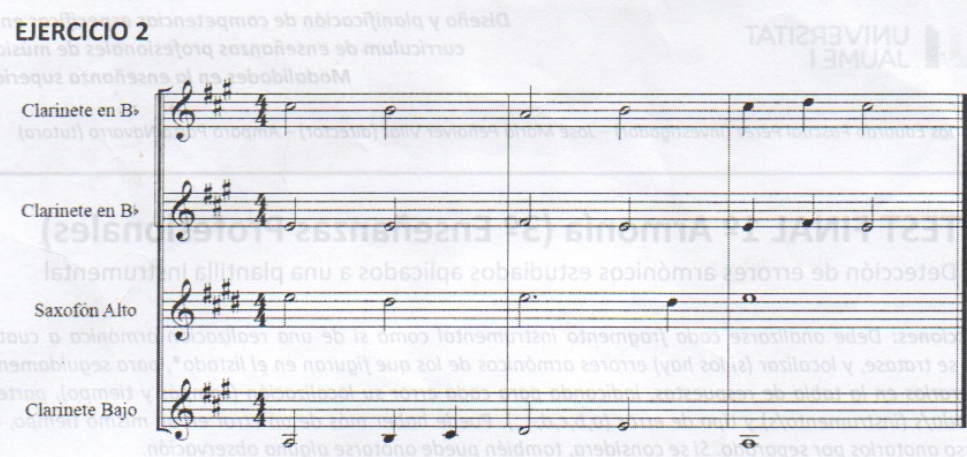

Marcar si no detectas ningún error:

\begin{tabular}{|c|c|c|c|c|}
\hline Compás & Tiempo & Instrumento/s implicado/s & Tipo de error & Observaciones \\
\hline 1 & todo & cearinete & $e$ & \\
\hline 2 & 1 & cearchede b-/Dajo & $b$ & \\
\hline 2 & 3 & Garinete os / Pajo & $b$ & \\
\hline & & & & \\
\hline & & & & \\
\hline & & & & \\
\hline & & & & \\
\hline & & & & \\
\hline
\end{tabular}

EJERCICIO 3

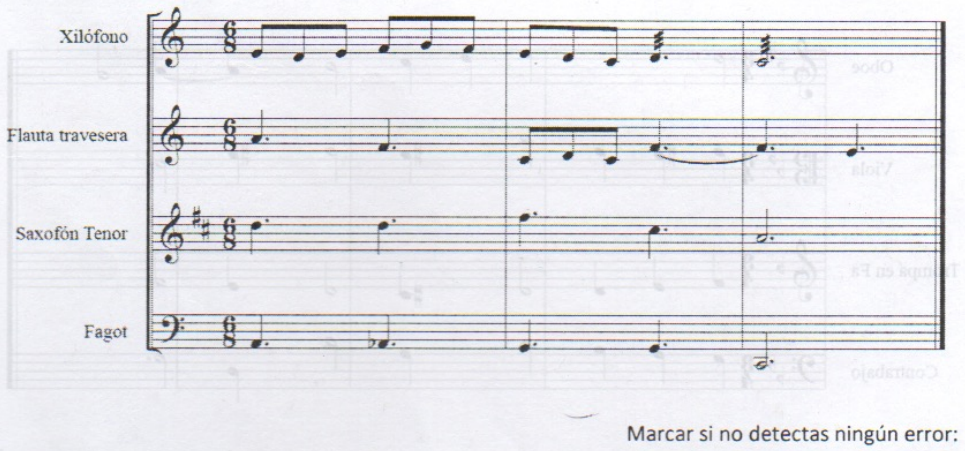

\begin{tabular}{|c|c|c|c|c|c|}
\hline Compás & Tiempo & Instrumento/s implicado/s & Tipo de error & \multicolumn{2}{|c|}{ Observaciones } \\
\hline 1 & 2 & xilós ono & obsemialos & mentant & $259 m 03$ \\
\hline 1 & 2 & rearta & c & 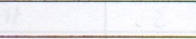 & \\
\hline 2 & 7 & reauta & $e$ & & \\
\hline 2 & 7 & saxalán & e & & \\
\hline 3 & 1 & saxojón & $h$ & & \\
\hline & & & & & \\
\hline & & & & & \\
\hline & & & & & \\
\hline
\end{tabular}


Diseño y planificación de competencias específicas en el currículum de enseñanzas profesionales de música: modalidades composición-dirección en la enseñanza superior.

\section{Carlos Eduardo Pascual Pérez

\section{UNIVERSITAT
JAUMEI}

Diseño y planificación de competencias especificas en el currículum de enseñanzas profesionales de músico. Modalidades en la enseñanza superior.

Carlos Eduardo Pascual Pérez (investigador) - José María Peñalver Vilar (director) - Amparo Porta Navarro (tutora)

TEST FINAL 10 Armonía (3 Enseñanzas Profesionales)

Detección de errores armónicos estudiados aplicados a una plantilla instrumental

Instrucciones: Debe analizarse cada fragmento instrumental como si de una realización armónica a cuatro partes se tratase, y localizar (si los hay) errores armónicos de los que figuran en el listado*, para seguidamente enumerarlos en la tabla de respuestas, indicando para cada error su localización (compás y tiempo), parte/s implicada/s (instrumento/s) y tipo de error $(a, b, c, d, \ldots)$. Puede haber más de un error en un mismo tiempo, en ese caso anotarlos por separado. Si se considera, también puede anotarse alguna observación.

Además, si no se detectan errores en un ejercicio, debe marcarse la casilla correspondiente. Si se desconoce o no se sabe como responder al ejercicio, dejar en blanco.

*Listado de posibles tipos de error:
a) Octavas seguidas
b) Quintas seguidas
c) Octavas directos
d) Quintas directas
e) Cruzamiento de voces
f) Superación de la separación máxima entre voces
g) Duplicación de la sensible
h) Resolución incorrecta o irresolución de la sensible
i) Resolución incorrecta o irresolución de la séptima (acordes de $7 \underline{g}$ de dte.)
j) Ausencia de preparación de la séptima (acordes de 7음 de dte.

Instrumento/s o especialidad/es que estás cursando o has cursado:

EJERCICIO 1

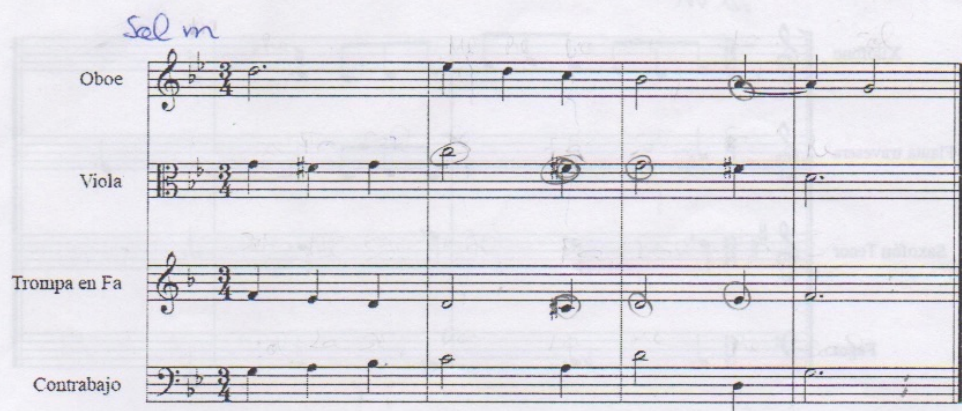

Marcar si no detectas ningún error:

\begin{tabular}{|c|c|c|c|c|}
\hline Compás & Tiempo & Instrumento/s implicado/s & Tipo de error & Observaciones \\
\hline 2 & 3 & Viala y trompa & $\mathrm{g}$ & \\
\hline 3 & 1 & Viola y Arompa & a & \\
\hline 3 & 3 & Trompa y obae & $a$ & \\
\hline 2 & 3 & Viala & $h$ & \\
\hline & & & & \\
\hline & & & & \\
\hline & & & & \\
\hline & & & & \\
\hline
\end{tabular}


Diseño y planificación de competencias específicas en el currículum de enseñanzas profesionales de música: modalidades composición-dirección en la enseñanza superior.

\section{Carlos Eduardo Pascual Pérez}

\section{EJERCICIO 2}

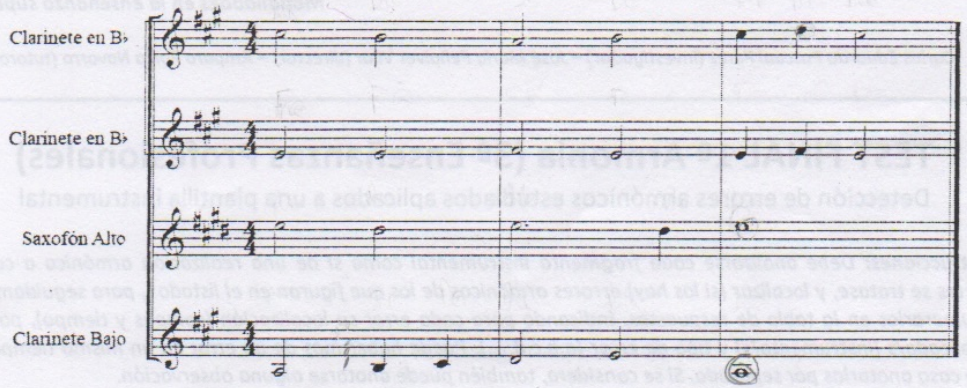

Marcar si no detectas ningún error:

\begin{tabular}{|c|c|c|c|c|}
\hline Compás & Tiempo & Instrumento/s implicado/s & Tipo de error & Observaciones \\
\hline 3 & $1 y^{2}$ & Savón y Clarinete & g & \\
\hline 3 & 1 & Savofón y Clarinete & f & \\
\hline & & & & \\
\hline & & & & \\
\hline & & & & \\
\hline & & & & \\
\hline & & & & \\
\hline
\end{tabular}

\section{EJERCICIO 3}

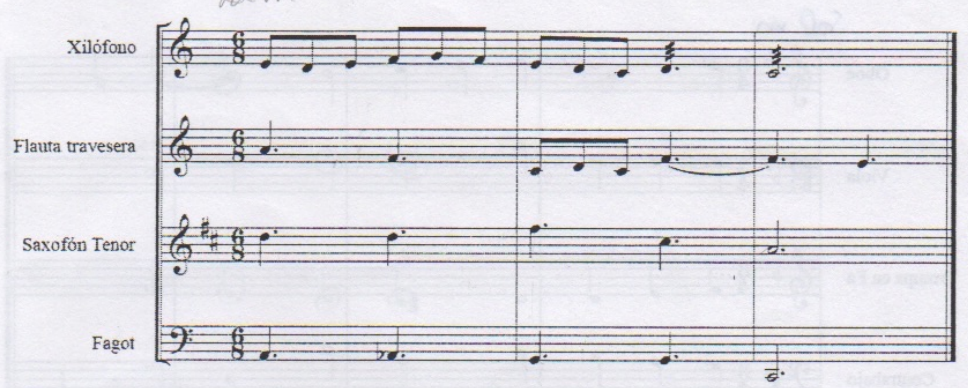

Marcar si no detectas ningún error:

\begin{tabular}{|l|l|l|l|l|}
\hline Compás & Tiempo & Instrumento/s implicado/s & Tipo de error & Observaciones \\
\hline & & & & \\
\hline & & & & \\
\hline & & & & \\
\hline & & & & \\
\hline & & & & \\
\hline & & & & \\
\hline & & & & \\
\hline & & & & \\
\hline
\end{tabular}


Diseño y planificación de competencias específicas en el currículum de enseñanzas profesionales de música: modalidades composición-dirección en la enseñanza superior.

\section{Carlos Eduardo Pascual Pérez}

UNIVERSITAT
JAUMEI
Diseño y planificación de competencias especificas en el

currículum de enseñanzas profesionales de música.

Modalidades en la enseñanza superior.

Carlos Eduardo Pascual Pérez (investigador) - José María Peñalver Vilar (director) - Amparo Porta Navarro (tutora)

\section{TEST FINAL 1 Armonía (3 Enseñanzas Profesionales)}

Detección de errores armónicos estudiados aplicados a una plantilla instrumental

Instrucciones: Debe analizarse cada fragmento instrumental como si de una realización armónica a cuatro partes se tratase, y localizar (si los hay) errores armónicos de los que figuran en el listado*, para seguidamente enumerarlos en la tabla de respuestas, indicando para cada error su localización (compás y tiempo), parte/s implicada/s (instrumento/s) y tipo de error $(a, b, c, d, \ldots)$. Puede haber más de un error en un mismo tiempo, en ese caso anotarlos por separado. Si se considera, también puede anotarse alguna observación.

Además, si no se detectan errores en un ejercicio, debe marcarse la casilla correspondiente. Si se desconoce o no se sabe como responder al ejercicio, dejar en blanco.

* Listado de posibles tipos de error:
a) Octavas seguidas
b) Quintas seguidas
c) Octavas directas
d) Quintas directas
e) Cruzamiento de voces
f) Superación de la separación máxima entre voces

g) Duplicación de la sensible

h) Resolución incorrecta o irresolución de la sensible

i) Resolución incorrecta o irresolución de la séptima (acordes de 7ọ de dte.)

j) Ausencia de preparación de la séptime (acordes de $7 \underline{9}$ de dte.)

Instrumento/s o especialidad/es que estás cursando o has cursado:

EJERCICIO 1

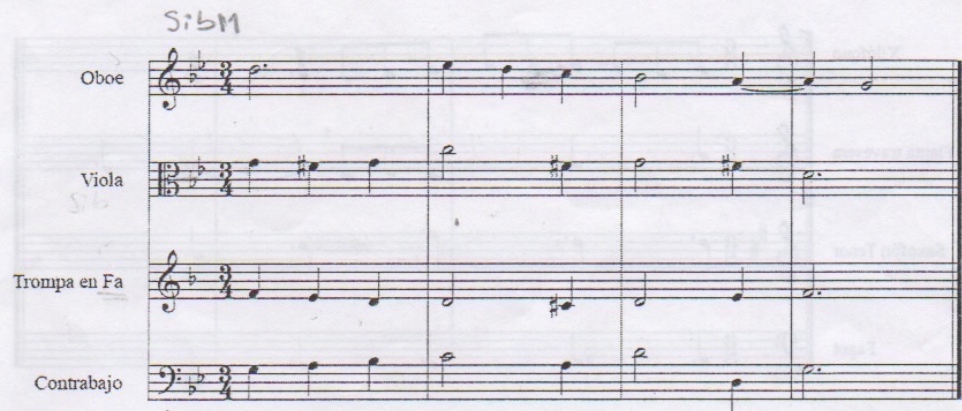

Marcar si no detectas ningún error:

\begin{tabular}{|c|c|c|c|c|}
\hline Compás & Tiempo & Instrumento/s implicado/s & Tipo de error & Observaciones \\
\hline 1 & 1 & & $a$ & \\
\hline 2 & 2 & & $g$ & \\
\hline 4 & 1 & & $f$ & \\
\hline & & & & \\
\hline & & & & \\
\hline & & & & \\
\hline & & & & \\
\hline & & & & \\
\hline
\end{tabular}


Diseño y planificación de competencias específicas en el currículum de enseñanzas profesionales de música: modalidades composición-dirección en la enseñanza superior.

Carlos Eduardo Pascual Pérez

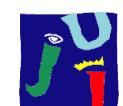

UNIVERSITA JAUME+ $\mathbf{I}$

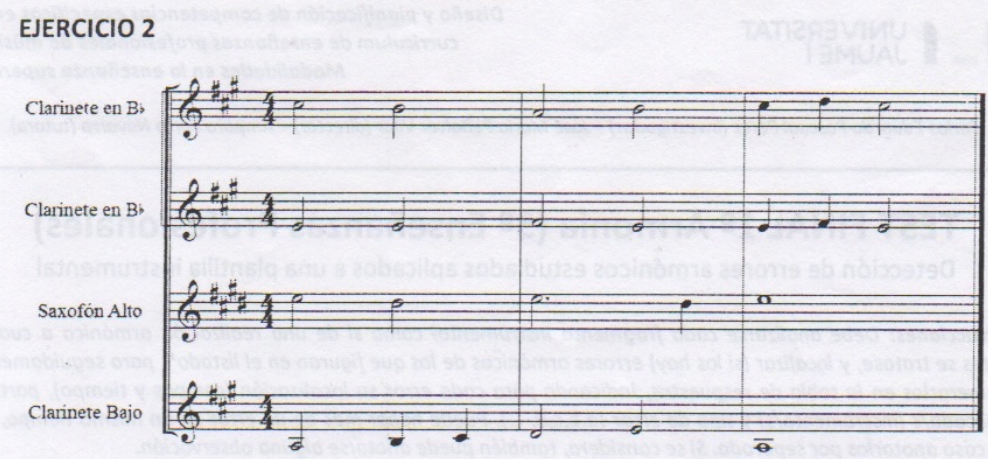

Marcar si no detectas ningún error: $\mathbb{X}$

\begin{tabular}{|l|l|l|l|l|}
\hline Compás & Tiempo & Instrumento/s implicado/s & Tipo de error & Observaciones \\
\hline & & & & \\
\hline & & & & \\
\hline & & & & \\
\hline & & & & \\
\hline & & & & \\
\hline & & & & \\
\hline & & & & \\
\hline
\end{tabular}

EJERCICIO 3

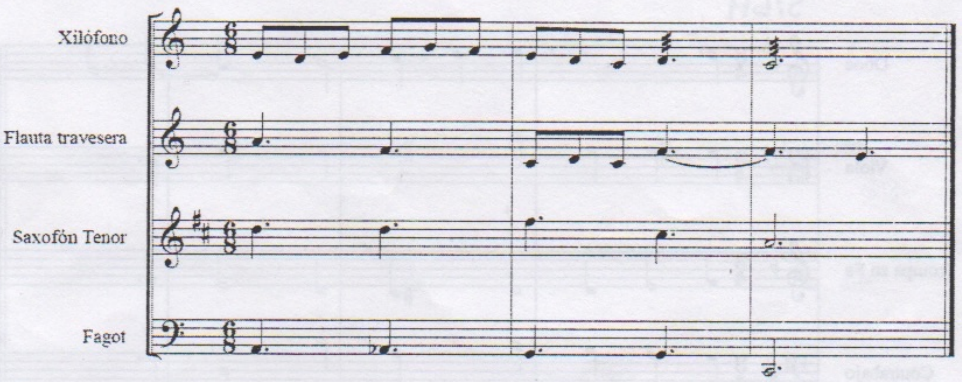

Marcar si no detectas ningún error:

\begin{tabular}{|c|c|c|c|c|}
\hline Compás & Tiempo & Instrumento/s implicado/s & Tipo de error & Observaciones \\
\hline 1 & 2 & & $b$ & \\
\hline 2 & 1 & & $c$ & \\
\hline & & & & \\
\hline & & & & \\
\hline & & & & \\
\hline & & & & \\
\hline & & & & \\
\hline & & & & \\
\hline
\end{tabular}


Diseño y planificación de competencias específicas en el currículum de enseñanzas profesionales de música: modalidades composición-dirección en la enseñanza superior.

\section{Carlos Eduardo Pascual Pérez}

1. UNIVERSITAT ieño y planificación de competencias especificas en el currículum de enseñanzas profesionales de música. Modalidades en la enseñanza superior.

Carlos Eduardo Pascual Pérez (investigador) - José María Peñalver Vilar (director) - Amparo Porta Navarro (tutora)

TEST FINAL 1을 Armonía (3 Enseñanzas Profesionales)

Detección de errores armónicos estudiados aplicados a una plantilla instrumental

Instrucciones: Debe analizarse cada fragmento instrumental como si de una realización armónica a cuatro partes se tratase, y localizar (si los hay) errores armónicos de los que figuran en el listado*, para seguidamente enumerarlos en la tabla de respuestas, indicando para cada error su localización (compás y tiempo), parte/s implicada/s (instrumento/s) y tipo de error $(a, b, c, d, \ldots)$. Puede haber más de un error en un mismo tiempo, en ese caso anotarlos por separado. Si se considera, también puede anotarse alguna observación.

Además, si no se detectan errores en un ejercicio, debe marcarse la casilla correspondiente. Si se desconoce o no se sabe como responder al ejercicio, dejar en blanco.

* Listado de posibles tipos de error:
a) Octavas seguidas
b) Quintas seguidas
c) Octavas directas
d) Quintas directas
e) Cruzamiento de voces
f) Superación de la separación máxima entre voces

g) Duplicación de la sensible

h) Resolución incorrecta o irresolución de la sensible

i) Resolución incorrecta o irresolución de la séptima (acordes de 7므 de dte.)

j) Ausencia de preparación de la séptima (acordes de 79 de dte.

Instrumento/s o especialidad/es que estás cursando o has cursado:

\section{EJERCICIO 1}

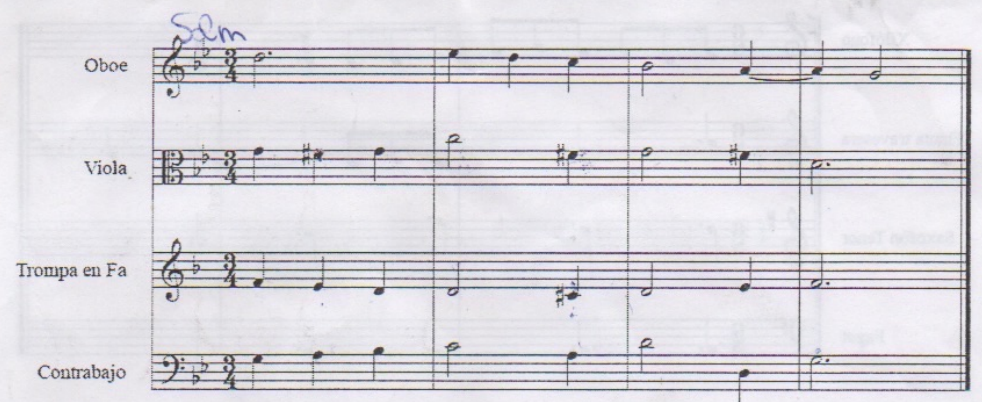

Marcar si no detectas ningún error:

\begin{tabular}{|c|c|c|c|c|}
\hline Compás & Tiempo & Instrumento/s implicado/s & Tipo de error & Observaciones \\
\hline 2 & 1 & Trompa en Fa Vide & l & \\
\hline & -3 & Afrompesde & है? & \\
\hline 3 & 1 & Trompa, ore & $a$ & \\
\hline 1 & 2 & Voln & i & \\
\hline 42 & 3 & Viola & t & \\
\hline & & & & \\
\hline & & & & \\
\hline & & & & \\
\hline
\end{tabular}


Diseño y planificación de competencias específicas en el currículum de enseñanzas profesionales de música: modalidades composición-dirección en la enseñanza superior.

\section{Carlos Eduardo Pascual Pérez}

EJERCICIO 2

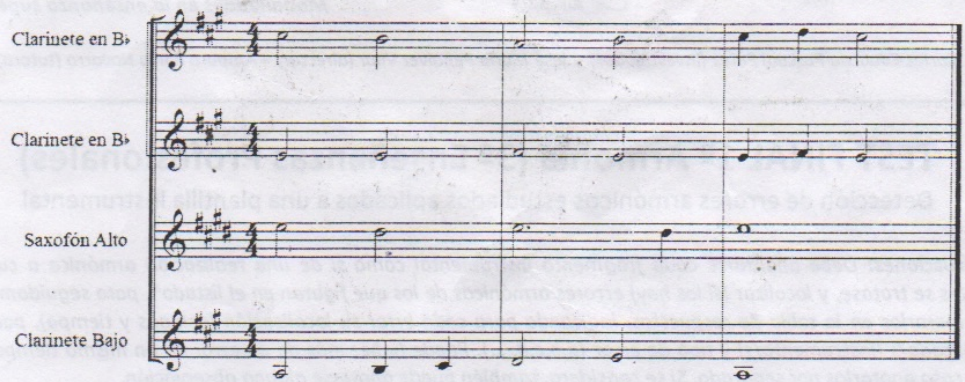

Marcar si no detectas ningún error:

\begin{tabular}{|c|c|c|c|c|}
\hline Compás & Tiempo & Instrumento/s implicado/s & Tipo de error & Observaciones \\
\hline 1 & 1 & Q earinedc/Soxo & $e$ & \\
\hline 2 & 3 & Qarinete/Saxo & $e$ & \\
\hline 1 & 2 & Qarinete Sojo & 2 & \\
\hline & & & & \\
\hline & & & & \\
\hline & & & & \\
\hline & & & & \\
\hline & & & & \\
\hline
\end{tabular}

EJERCICIO 3

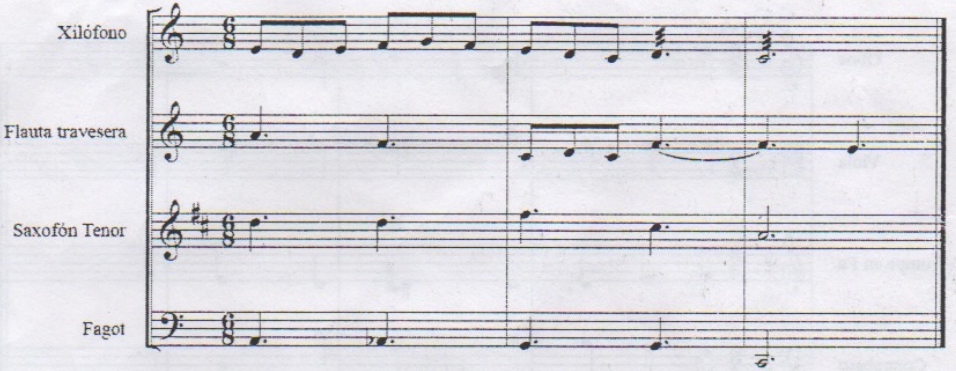

Marcar si no detectas ningún error:

\begin{tabular}{|c|c|c|c|c|}
\hline Compás & Tiamno & Instrumento/s implicado/s & Tipo de error & Observaciones \\
\hline & 4 & Flauta Xilofono & S & \\
\hline 3 & 1 & Savo, fagot & $a$ & \\
\hline & & & & \\
\hline & & & & \\
\hline & & & & \\
\hline & & & & \\
\hline & & & & \\
\hline
\end{tabular}


Diseño y planificación de competencias específicas en el currículum de enseñanzas profesionales de música: modalidades composición-dirección en la enseñanza superior.

\section{Carlos Eduardo Pascual Pérez}

\section{UNIVERSITAT}

Diseño y planificación de competencias específicas en el currículum de enseñanzas profesionales de música. Modalidades en la enseñanza superior.

Carlos Eduardo Pascual Pérez (investigador) - José María Peñalver Vilar (director) - Amparo Porta Navarro (tutora)

TEST FINAL 1․ Armonía (3 Enseñanzas Profesionales)

Detección de errores armónicos estudiados aplicados a una plantilla instrumental

Instrucciones: Debe analizarse cada fragmento instrumental como si de una realización armónica a cuatro partes se tratase, y localizar (si los hay) errores armónicos de los que figuran en el listado*, para seguidamente enumerarlos en la tabla de respuestas, indicando para cada error su localización (compás y tiempo), parte/s implicada/s (instrumento/s) y tipo de error $(a, b, c, d, \ldots)$. Puede haber más de un error en un mismo tiempo, en ese caso anotarlos por separado. Si se considera, también puede anotarse alguna observación.

Además, si no se detectan errores en un ejercicio, debe marcarse la casilla correspondiente. Si se desconoce o no se sabe como responder al ejercicio, dejar en blanco.

*Listado de posibles tipos de error
a) Octavas seguidas
b) Quintas seguidas
c) Octavas directas
d) Quintas directas
e) Cruzamiento de voces
f) Superación de la separación máxima entre voces

g) Duplicación de la sensible

h) Resolución incorrecta o irresolución de la sensible

i) Resolución incorrecta o irresolución de la séptima (acordes de 790 de dte.)

j) Ausencia de preparación de la séptima (acordes de $7 \stackrel{a}{a}$ de dte.)

Instrumento/s o especialidad/es que estás cursando o has cursado:

EJERCICIO 1

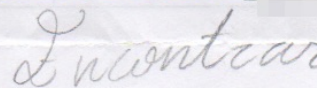

erader
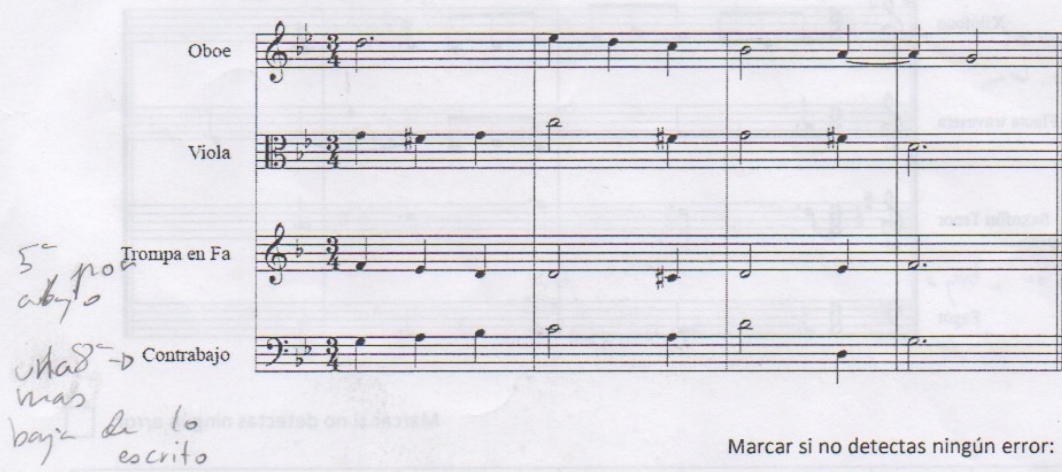

escrito

Marcar si no detectas ningún error:

\begin{tabular}{|c|c|c|c|c|}
\hline Compás & Tiempo & Instrumento/s implicado/s & Tipo de error & Observaciones \\
\hline 2 & 1 & viola & Q & \\
\hline 2 & 1 & Trompa & 8 & \\
\hline 2 & 3 & Uiok I t rompa & 9 & \\
\hline & & 4 & 0 & \\
\hline & & & & \\
\hline & & & & \\
\hline & & & & \\
\hline & & & & \\
\hline
\end{tabular}


Diseño y planificación de competencias específicas en el currículum de enseñanzas profesionales de música: modalidades composición-dirección en la enseñanza superior.

Carlos Eduardo Pascual Pérez

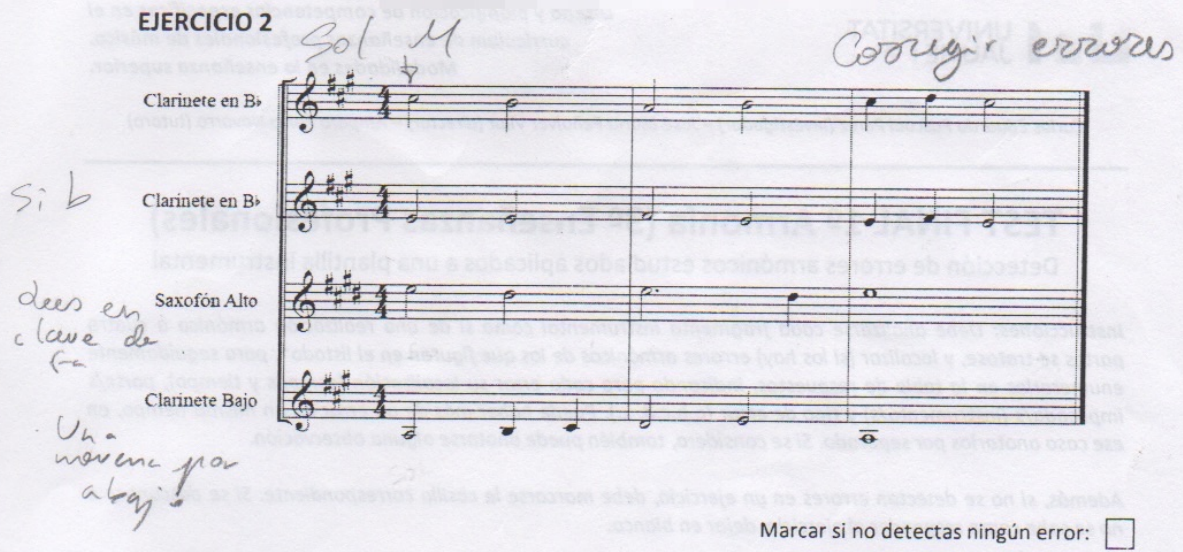

\begin{tabular}{|c|c|c|c|c|}
\hline Compás & Tiempo & Instrumento/s implicado/s & Tipo de error & Observaciones \\
\hline $1 / 2 / 3$ & & clarinde / Sars & 은 & \\
\hline 1 & 3 & Clareing te brjo OL & C & \\
\hline 2 & $1 / 3$ & $\operatorname{en~} B_{b} / C \operatorname{sen} B_{0}$ & b & +2 \\
\hline & & 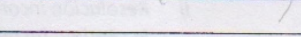 & & \\
\hline & & & & \\
\hline & & & & \\
\hline & & & & \\
\hline & & 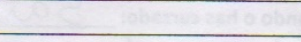 & +2 & +2 \\
\hline
\end{tabular}

EJERCICIO 3

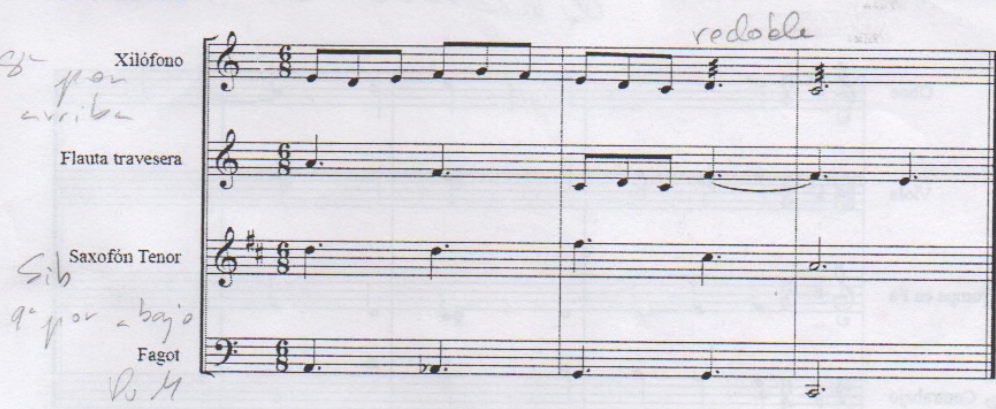

Marcar si no detectas ningún error:

\begin{tabular}{|c|c|c|c|c|}
\hline Compás & Tiempo & Instrumento/s implicado/s & Tipo de error & Observaciones \\
\hline 1 & 2 & kilofono llavte & c & \\
\hline 2 & 1 & Lauta/saera & e & \\
\hline & & & + & \\
\hline & & & 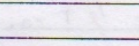 & \\
\hline & & & & \\
\hline & & & & \\
\hline & & & & \\
\hline
\end{tabular}


Diseño y planificación de competencias específicas en el currículum de enseñanzas profesionales de música: modalidades composición-dirección en la enseñanza superior.

\section{Carlos Eduardo Pascual Pérez}

UNIVERSITAT
JAUMEI
Diseño y planificación de competencias específicas en el currículum de enseñanzas profesionales de música. Modalidades en la enseñanza superior.

Carlos Eduardo Pascual Pérez (investigador) - José María Peñalver Vilar (director) - Amparo Porta Navarro (tutora)

TEST FINAL 1 Armonía (3 Enseñanzas Profesionales)

Detección de errores armónicos estudiados aplicados a una plantilla instrumental

Instrucciones: Debe analizarse cada fragmento instrumental como si de una realización armónica a cuatro partes se tratase, y localizar (si los hay) errores armónicos de los que figuran en el listado*, para seguidamente enumerarlos en la tabla de respuestas, indicando para cada error su localización (compás y tiempo) parte/s implicada/s (instrumento/s) y tipo de error $(a, b, c, d, \ldots)$. Puede haber más de un error en un mismo tiempo, en ese caso anotarlos por separado. Si se considera, también puede anotarse alguna observación.

Además, si no se detectan errores en un ejercicio, debe marcarse la casilla correspondiente. Si se desconoce o no se sabe como responder al ejercicio, dejar en blanco.

* Listado de posibles tipos de error:
a) Octavas seguidas
b) Quintas seguidas
c) Octavas directas
d) Quintas directas
e) Cruzamiento de voces
f) Superación de la separación máxima entre voces

g) Duplicación de la sensible

h) Resolución incorrecta o irresolución de la sensible

i) Resolución incorrecta o irresolución de la séptima (acordes de $7 \underline{0}$ de dte.)

j) Ausencia de preparación de la séptima (acordes de $7 \underline{a}$ de dte.)

Instrumento/s o especialidad/es que estás cursando o has cursado:

EJERCICIO 1

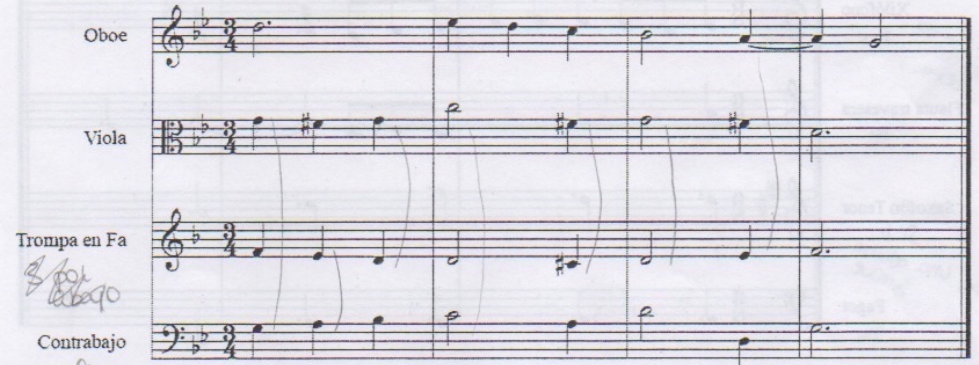

und

$8 \mathrm{ng}^{2}, \mathrm{C}^{2}, \mathrm{x}^{2}$

o

Marcar si no detectas ningún error:

\begin{tabular}{|c|c|c|c|c|}
\hline Compás & Tiempo & instrumento/s implicado/s & Tipo de error & Observaciones \\
\hline 2 & 3 & Vida y tiompa & $a$ & \\
\hline 3 & $1-2$ & Vida y tiompa & $a$ & \\
\hline 2 & $1-2$ & vida y contiabajo & $c$ & \\
\hline 2 & 3 & Vida y tiompa & $c$ & \\
\hline 2 & 3 & contiaboyo & $h$ & \\
\hline 3 & 3 & Trompa & $h$ & \\
\hline & & & & \\
\hline & & & & \\
\hline
\end{tabular}


Diseño y planificación de competencias específicas en el currículum de enseñanzas profesionales de música: modalidades composición-dirección en la enseñanza superior.

\section{Carlos Eduardo Pascual Pérez}

\section{EJERCICIO 2}

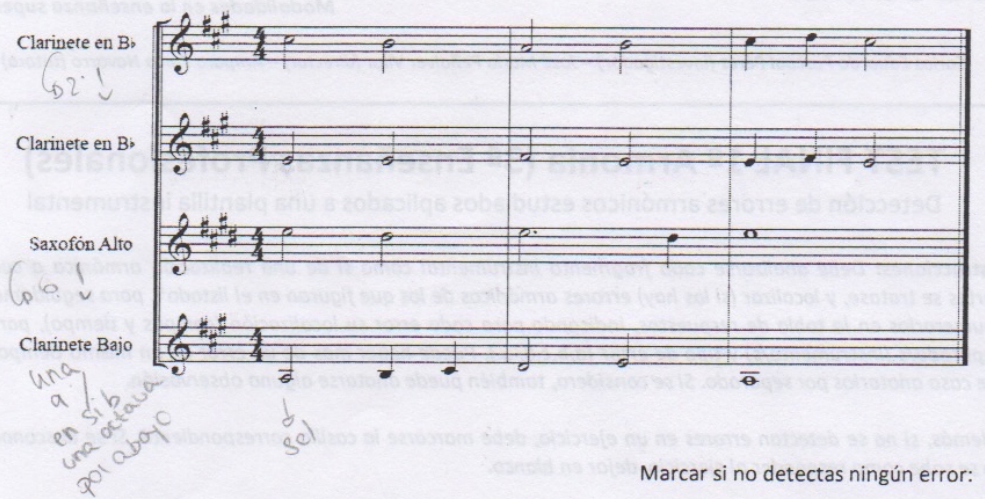

\begin{tabular}{|c|c|c|c|c|}
\hline Compás & Tiempo & Instrumento/s implicado/s & Tipo de error & Observaciones \\
\hline 1 & $1-2-3$ & Savo alto y Coavinete & a & \\
\hline 1 & $1-2$ & Clawinete Bb y Sava & $f$ & \\
\hline & & & & \\
\hline & & & & \\
\hline & & & & \\
\hline & & & & \\
\hline & & & & \\
\hline & & & & \\
\hline
\end{tabular}

EJERCICIO 3

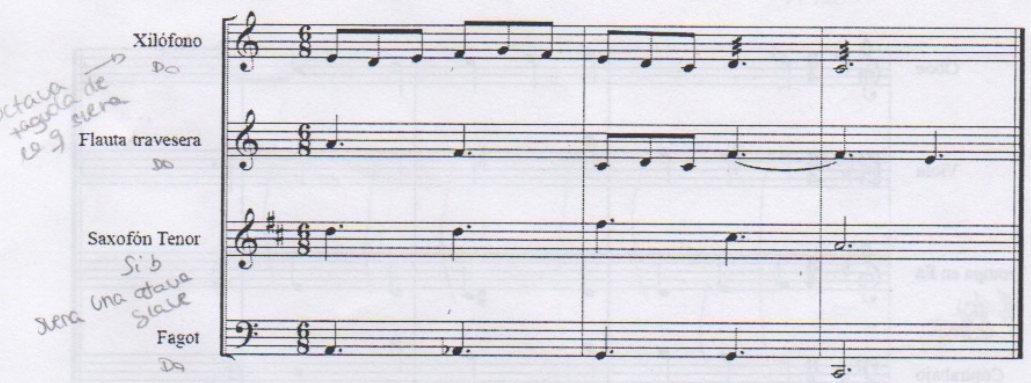

Marcar si no detectas ningún error:

\begin{tabular}{|c|c|c|c|c|}
\hline Compás & Tiempo & instrumento/s implicado/s & Tipo de error & Observaciones \\
\hline 1 & 1 & Xilófono y flauta & $e$ & \\
\hline 2 & 2 & xiló fono y Houta & $e$ & continua en el comṕs 3 \\
\hline 3 & 2 & Frouta tiauesera & $j$ & \\
\hline 2 & 1 & xilofono y flauta & 9 & \\
\hline & & & & \\
\hline & & & & \\
\hline & & & & \\
\hline & & & & \\
\hline
\end{tabular}


Diseño y planificación de competencias específicas en el currículum de enseñanzas profesionales de música: modalidades composición-dirección en la enseñanza superior.

\section{Carlos Eduardo Pascual Pérez}

\section{W UNIVERSITAT}

Diseño y planificación de competencias específicas en el currículum de enseñanzas profesionales de música. Modalidades en la enseñanza superior.

\section{TEST FINAL 1ㅇ Armonía (3 Enseñanzas Profesionales)}

Detección de errores armónicos estudiados aplicados a una plantilla instrumental

Instrucciones: Debe analizarse cada fragmento instrumental como si de una realización armónica a cuatro partes se tratase, y localizar (si los hay) errores armónicos de los que figuran en el listado*, para seguidamente enumerarlos en la tabla de respuestas, indicando para cada error su localización (compás y tiempo), parte/s implicada/s (instrumento/s) y tipo de error $(a, b, c, d, \ldots)$. Puede haber más de un error en un mismo tiempo, en ese caso anotarlos por separado. Si se considera, también puede anotarse alguna observación.

Además, si no se detectan errores en un ejercicio, debe marcarse la casilla correspondiente. Si se desconoce o no se sabe como responder al ejercicio, dejar en blanco.

* Listado de posibles tipos de error:
a) Octavas seguidas
b) Quintas seguidas
c) Octavas directas
d) Quintas directos
e) Cruzamiento de voces
f) Superación de la separación máxima entre voces
g) Duplicación de la sensible
h) Resolución incorrecta o irresolución de la sensible
i) Resolución incorrecta o irresolución de la séptima (acordes de $7 \stackrel{9}{\text { de de }}$ dte)
j) Ausencia de preparación de la séptima lacordes de 79 de dte.

Instrumento/s o especialidad/es que estás cursando o has cursado:

\section{EJERCICIO 1}

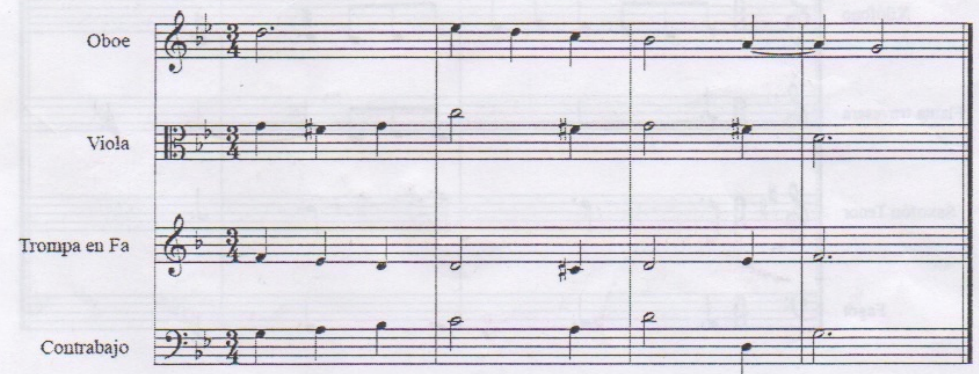

Marcar si no detectas ningún error:

\begin{tabular}{|c|c|c|c|c|}
\hline Compás & Tiempo & Instrumento/s implicado/s & Tipo de error & Observaciones \\
\hline 1 & 3 & TRQMPA - CONYRABAJO & E) & \\
\hline 2 & 1 & TROMPA - CONTRABAJO & E) & \\
\hline 2 & 3 & TROMPG - CONTRARAOO & E) & \\
\hline 3 & 1 & IROMPA - CONTRABAJO & E) & \\
\hline 2 & 1 & VIOLA - TROMPA & F) & \\
\hline 2 & 3 & VIOLA - TROMPA & G) & \\
\hline $3-2 / 4$ & 3 & V.OLA - OBOE & & Resolución direrion de LA \\
\hline 4 & $1-2$ & OBOE & & REYARDO $9-8$ \\
\hline
\end{tabular}


Diseño y planificación de competencias específicas en el currículum de enseñanzas profesionales de música: modalidades composición-dirección en la enseñanza superior.

\section{Carlos Eduardo Pascual Pérez}

\section{EJERCICIO 2}

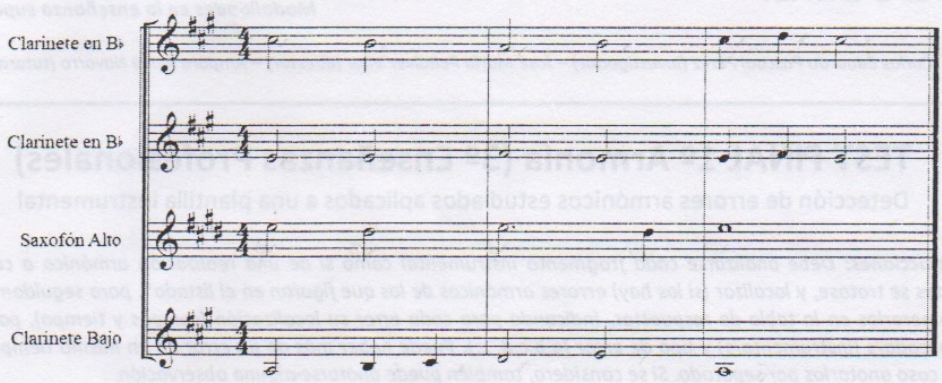

Marcar si no detectas ningún error:

\begin{tabular}{|c|c|c|c|c|}
\hline Compás & Tiempo & Instrumento/s implicado/s & Tipo de error & Observaciones \\
\hline 1 & $4-1(2)$ & SAXO ALTO - CLARINGYG BASO & B & \\
\hline 2 & $1-3$ & CLARIRGES 1 - CLARINETS BASOO & $B$ & \\
\hline & & 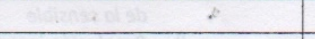 & & 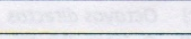 \\
\hline & & 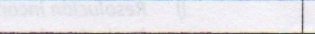 & & 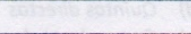 \\
\hline & & & & \\
\hline & & & & \\
\hline & & & & \\
\hline & & 2 & & \\
\hline
\end{tabular}

\section{EJERCICIO 3}

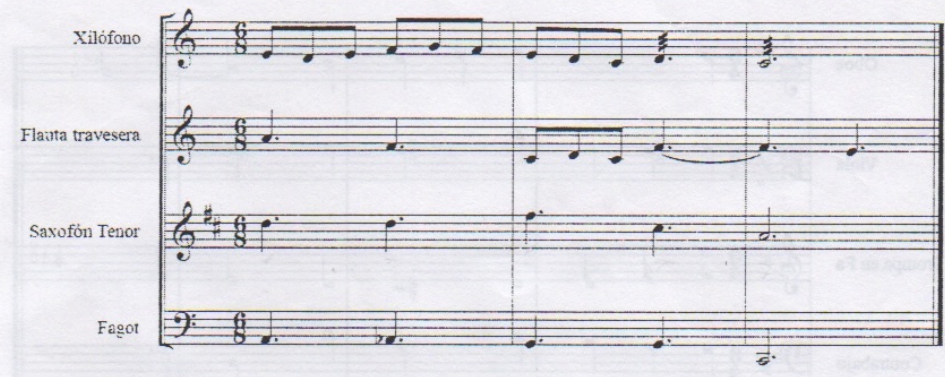

Marcar si no detectas ningún error:

\begin{tabular}{|c|c|c|c|c|}
\hline Compás & Tiempo & Instrumento/s implicado/s & Tipo de error & Observaciones \\
\hline 2 & 2 & FLAUYA & $J$ & \\
\hline 3 & 1 & & $H$ & \\
\hline & & & & \\
\hline & & & & \\
\hline & & & & \\
\hline & & & & \\
\hline & & & & \\
\hline 3 & $1-2$ & FLAUTA & & RETARDO \\
\hline
\end{tabular}


Diseño y planificación de competencias específicas en el currículum de enseñanzas profesionales de música: modalidades composición-dirección en la enseñanza superior.

Carlos Eduardo Pascual Pérez

\title{
Anexo III
}

\section{U. UNIVERSITAT}

Diseño y planificación de competencias especifficas en el curriculum de enseñanzas profesionales de música. Modalidades en la enseñanza superior.

Corlos Eduardo Pascual Pérez (investigador) - José Maria Peñolver Vilar (director) - Amparo Porta Nevarro (tutora)

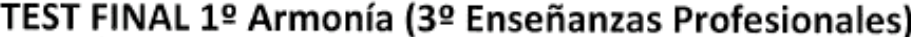

Detección de errores armónicos estudiados aplicados a una plantilla instrumental

\begin{abstract}
Instrucciones: Debe analizarse cada fragmento instrumentol como si de una realización armónica a cuatro partes se tratase, y localizar (si los hay) ecrores armónicos de los que flguran en el listado*, para seguidamente enumerarlos en la tabla de respuestas, indicando para cado error su localización (compás y tiempo), parte/s implicada/s (instrumento/s) y tipo de error $(a, b, c, d, \ldots)$. Puede haber más de un error en un mismo tiempo, en ese caso anotarlos por separado. Si se considera, también puede onotarse alquna observación.
\end{abstract}

Además, si no se detectan errores en un ejercicio, debe marcarse la casilla correspondiente. Si se desconoce o no se sabe como responder al ejercicio, dejar en blanco.

"Listado de posibles tipos de error:
a) Octovas seguidas
b) Quintas seguida.
c) Octovas directos
d) Quintas directos
e) Cruzamiento de vaces
f) Superación de la separación
máxima entre voces

g) Duplicación de la sensible

h) Resolución incorrecto o irresolución

de la sensible

i) Resolución incorrecto a irresolución de la séptima (acordes de 79 de dte.)

j) Ausencia de preparación de la septima (acordes de 79 de dte.

Instrumento/s o especialidad/es que estás cursando o has cursado:

\section{CLARINET}

\section{EJERCICIO 1}

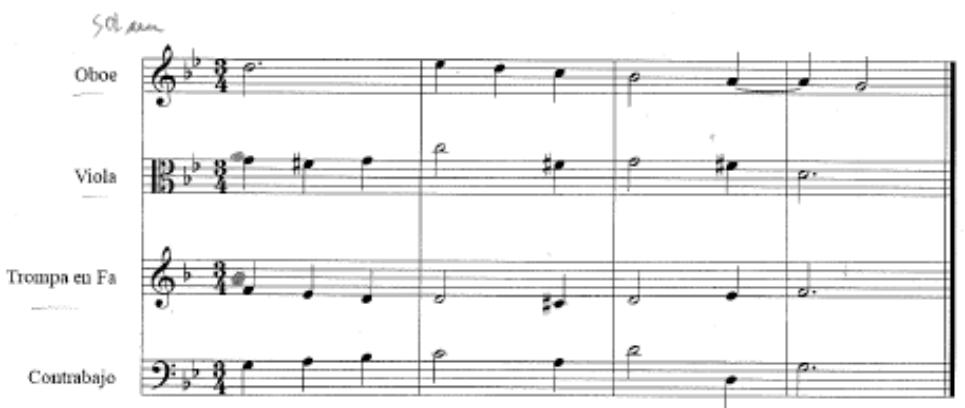

Marcar si no detectas ningún error:

\begin{tabular}{|l|l|l|l|l|}
\hline Compás & Tiempo & Instrumento/s implicado/s & Tipo de error & Observaciones \\
\hline & & & & \\
\hline & & & & \\
\hline & & & & \\
\hline & & & & \\
\hline & & & & \\
\hline & & & & \\
\hline & & & & \\
\hline
\end{tabular}


Diseño y planificación de competencias específicas en el currículum de enseñanzas profesionales de música: modalidades composición-dirección en la enseñanza superior.

Carlos Eduardo Pascual Pérez

\section{EJERCICIO 2}

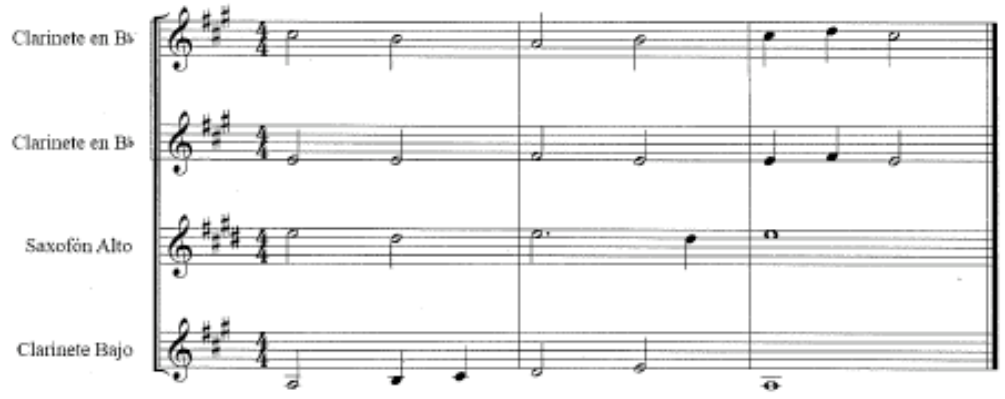

Marcar si no detectas ningún error:

\begin{tabular}{|l|l|l|l|l|}
\hline Compás & Tiempo & Instrumento/s implicado/s & Tipo de error & Observaciones \\
\hline & & & & \\
\hline & & & & \\
\hline & & & & \\
\hline & & & & \\
\hline & & & & \\
\hline & & & & \\
\hline & & & & \\
\hline & & & & \\
\hline
\end{tabular}

EJERCICIO 3

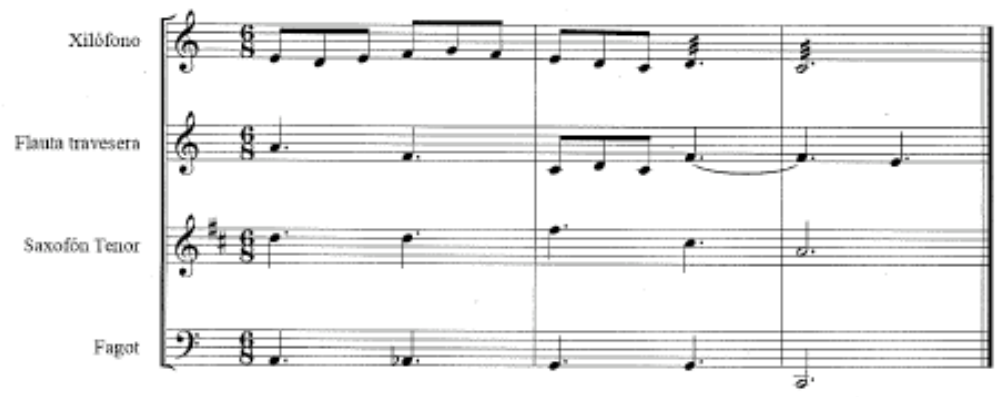

Marcar si no detectas ningún error:

\begin{tabular}{|l|l|l|l|l|}
\hline Compás & Tiempo & Instrumento/s implicado/s & Tipo de error & Observaciones \\
\hline & & & & \\
\hline & & & & \\
\hline & & & & \\
\hline & & & & \\
\hline & & & & \\
\hline & & & & \\
\hline & & & & \\
\hline
\end{tabular}


Diseño y planificación de competencias específicas en el currículum de enseñanzas profesionales de música: modalidades composición-dirección en la enseñanza superior.

Carlos Eduardo Pascual Pérez

TEST FINAL 1ำ Armonía (3ำ Enseñanzas Profesionales)

Detección de errores armónicos estudiados aplicados a una plantilla instrumental

Instrucciones: Debe analizarse cada fragmento instrumental como si de una realización armónica a cuatro partes se tratase, y localizar (si los hay) errores armónicos de los que figuran en el listodo*, para seguidamente enumerarlos en la tabla de respuestas, indicando para cada error su focalización (compós y tiempo), parte/s implicada/s (instrumento/s) y tipo de error $(a, b, c, d, \ldots)$, Puede haber más de un error en un mismo tiempo, en ese caso anotorlos por separado. Si se considera, también puede onotorse alguna observación.

Ademós, si no se detecton errores en un ejercicio, debe marcarse la casilla correspondiente. Si se desconoce o no se sabe camo responder al ejercicio, dejar en blanco.

* Listado de posibles tipos de error:
a) Octavos seguidas
b) Quintos seguidas
c) Octavas directas
g) Duplicación de la sensible
Quintos directos
h) Resolución incorrecta o irresolución de la sensible
e) Cruzamiento de voces
Resolución incorrecta o irresolución de
Superación de la separación la séptima (acordes de $7^{g}$ de dte.)
máxima entre voces
j) Ausencia de preparación de la séptimo (acordes de $7^{g}$ de dite.

Instrumento/s o especialidad/es que estás cursando o has cursado:

EJERCICIO 1

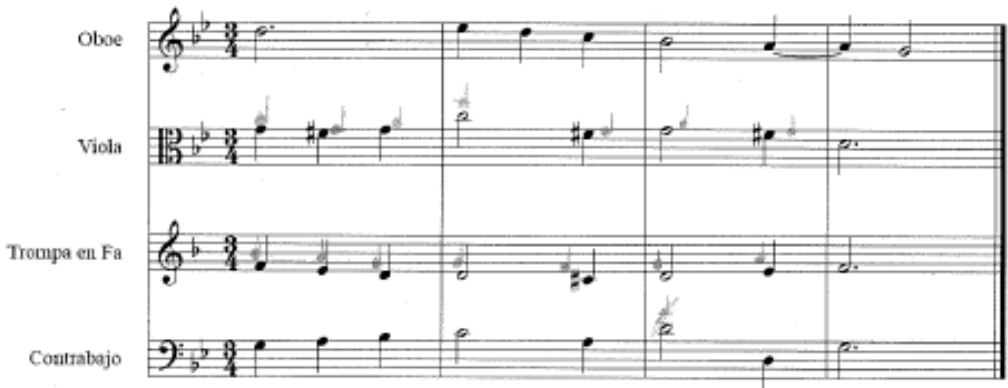

Marcar si no detectas ningún error:

\begin{tabular}{|c|c|c|c|c|}
\hline Compás & Tiempo & Instrumento/s implicado/s & Tipo de error & Observaciones \\
\hline 2 & 3 & Viola trompa & $8)$ & \\
\hline & & & & \\
\hline & & & & \\
\hline & & & & \\
\hline & & & & \\
\hline & & & & \\
\hline & & & & \\
\hline & & & & \\
\hline
\end{tabular}


Diseño y planificación de competencias específicas en el currículum de enseñanzas profesionales de música: modalidades composición-dirección en la enseñanza superior.

Carlos Eduardo Pascual Pérez

EJERCICIO 2

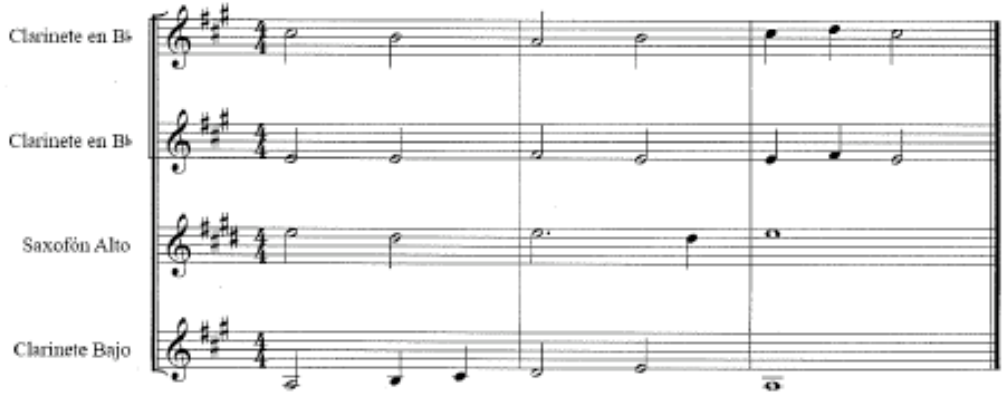

Marcar si no detectas ningún error:

\begin{tabular}{|l|l|l|l|l|}
\hline Compás & Tiempo & Instrumento/s implicado/s & Tipo de error & Observaciones \\
\hline & & & & \\
\hline & & & & \\
\hline & & & & \\
\hline & & & & \\
\hline & & & & \\
\hline & & & & \\
\hline & & & & \\
\hline & & & & \\
\hline
\end{tabular}

EJERCICIO 3

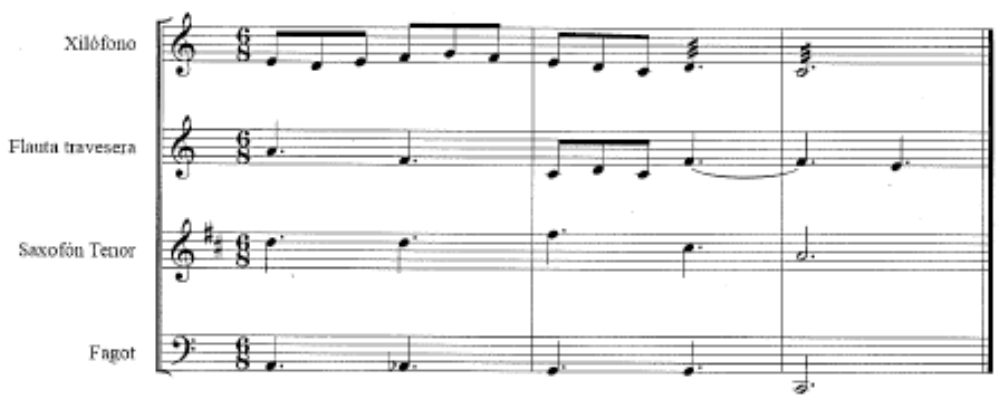

Marcar si no detectas ningún error:

\begin{tabular}{|l|l|l|l|l|}
\hline Compás & Tiempo & Instrumento/s implicado/s & Tipo de error & Observaciones \\
\hline & & & & \\
\hline & & & & \\
\hline & & & & \\
\hline & & & & \\
\hline & & & & \\
\hline & & & & \\
\hline & & & & \\
\hline & & & & \\
\hline
\end{tabular}


Diseño y planificación de competencias específicas en el currículum de enseñanzas profesionales de música: modalidades composición-dirección en la enseñanza superior.

Carlos Eduardo Pascual Pérez

I I UNINERSTAT

JAUME I

Diseño y planificación de competencias especificas en el

curriculum de enseñanzas profesionales de música. Modalidades en la enseñanza superior.

Carlos Eduardo Pascual Pérez (investigador) - José Maria Peñalver Vilar (director) - Amparo Porta Navarro (tutara)

TEST FINAL 1 Armonía (3ำ Enseñanzas Profesionales)

Detección de errores armónicos estudiados aplicados a una plantilla instrumental

Instrucciones: Debe analizarse cada fragmento instrumental como si de una realización armónica a cuatro partes se trotase, y localizar (si los hay) errores armónicos de los que figuran en el listado*, para seguidamente enumerarlos en la tabla de respuestas, indicando para cado error su localización (compós y tiempo), parte/s implicada/s (instrumento/s) y tipo de error $(a, b, c, d, \ldots)$. Puede haber más de un error en un mismo tiempo, en ese caso anotarlos por separado. Si se considera, también puede anotorse alguna observación.

Además, si no se detectan errores en un ejercicio, debe marcarse la casilla correspondiente. Si se desconoce o no se sabe como responder al ejercicio, dejar en blanco.

* Listado de posibles tipos de error:
a) Octovas seguidas
b) Quintas seguidas
c) Octovas directos
d) Quintas directos
e) Cruzamiento de voces
f) Superación de la separación máxima entre voces

g) Duplicación de la sensible

h) Resolución incorrecta o irresolución de la sensible

i) Resolución incorrecta o irresolución de la séptima (acordes de $7^{9}$ de dte.)

i) Ausencia de preporación de la séptima (acordes de $7^{\circ}$ de dte.)

Instrumento/s o especialidad/es que estás cursando o has cursado:

Clarinete

\section{EJERCICIO 1}

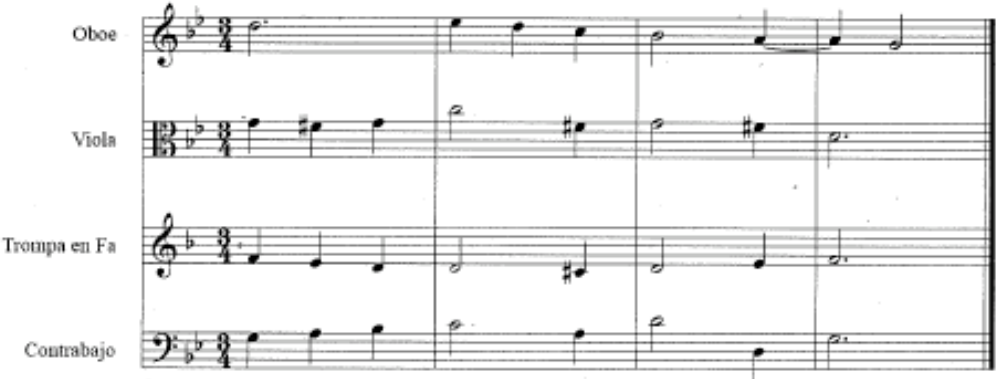

Marcar si no detectas ningún error: $\bar{X}$

\begin{tabular}{|c|c|c|c|c|}
\hline Compás & Tiempo & Instrumento/s implicado/s & Tipo de error & Observaciones \\
\hline \multicolumn{1}{|l}{} & 2 & & & \\
\hline & & & & \\
\hline & & & & \\
\hline & & & & \\
\hline & & & & \\
\hline & & & & \\
\hline & & & & \\
\hline
\end{tabular}


Diseño y planificación de competencias específicas en el currículum de enseñanzas profesionales de música: modalidades composición-dirección en la enseñanza superior.

Carlos Eduardo Pascual Pérez

\section{EJERCICIO 2}

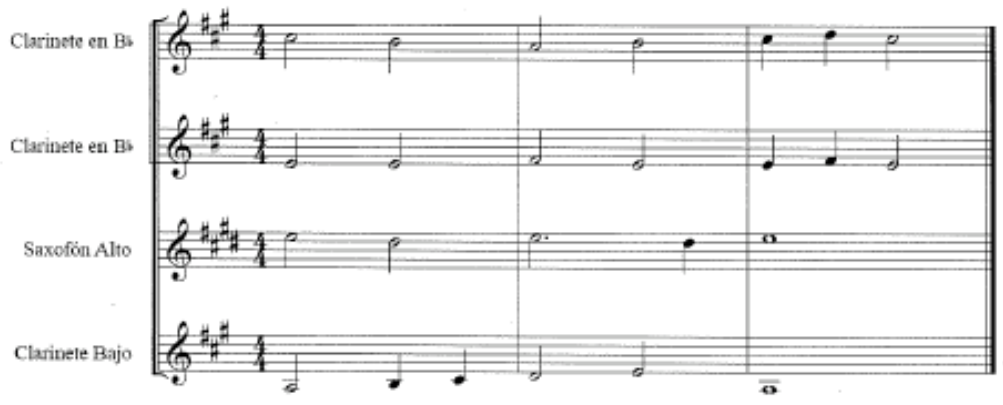

Marcar si no detectas ningún error:

\begin{tabular}{|l|l|l|l|l|}
\hline Compás & Tiempo & Instrumento/s implicado/s & Tipo de error & Observaciones \\
\hline & & & & \\
\hline & & & & \\
\hline & & & & \\
\hline & & & & \\
\hline & & & & \\
\hline & & & & \\
\hline & & & & \\
\hline
\end{tabular}

EJERCICIO 3

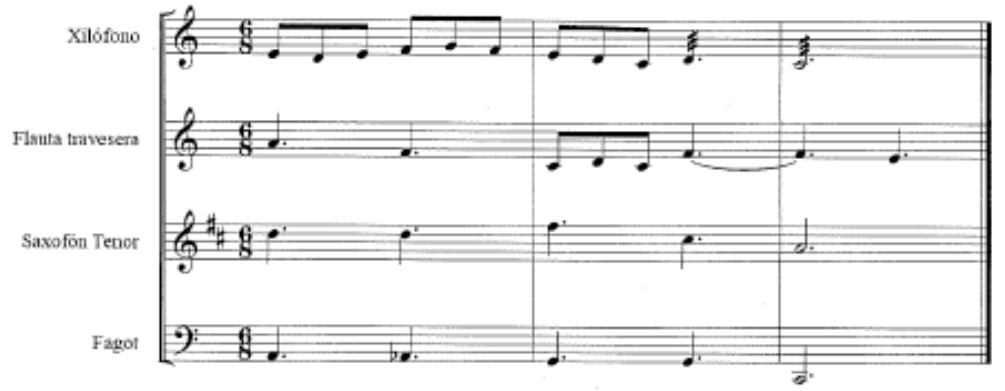

Marcar si no detectas ningún error: $\mathrm{X}$

\begin{tabular}{|l|l|l|l|l|}
\hline Compás & Tiempo & Instrumento/s implicado/s & Tipo de error & Observaciones \\
\hline & & & & \\
\hline & & & & \\
\hline & & & & \\
\hline & & & & \\
\hline & & & & \\
\hline & & & & \\
\hline & & & & \\
\hline
\end{tabular}


Diseño y planificación de competencias específicas en el currículum de enseñanzas profesionales de música: modalidades composición-dirección en la enseñanza superior.

Carlos Eduardo Pascual Pérez

\section{TEST FINAL 1ㅇ Armonía (3ำEnseñanzas Profesionales)}

Detección de errores armónicos estudiados aplicados a una plantilla instrumental

Instrucciones: Debe analizarse cada fragmento instrumental como si de una realización armónica a cuatro partes se tratase, y localizar (si los hay) errores armónicos de los que figuran en el listodo*, para seguidamente enumerarlos en la tabla de respuestas, indicando para cado error su focalización (compás y tiempo), parte/s implicado/s (instrumento/s) y tipo de error $(a, b, c, d, \ldots)$. Puede haber más de un error en un mismo tiempo, en ese caso anotorlos por seporado. Si se considera, también puede anotarse alguna observación.

Además, si no se detecton errores en un ejercicio, debe marcarse la casilla correspondiente. Si se desconoce o no se sabe como responder al ejercicio, dejar en blanco.

"Listado de posibles tipos de error:
a) Octovas seguidas
b) Quintas seguidas
c) Octovas directos
d) Quintas directos
e) Cruzamiento de voces
f) Superación de la separación
máximo entre voces

g) Duplicación de la sensible

h) Resolución incorrecto o irresolución de la sensible

i) Resolución incorrecta o irresolución de la séptima (acordes de $7^{g}$ de dite.)

j) Ausencia de preparación de la séptima (acordes de 79 de dte.)

Instrumento/s o especialidad/es que estás cursando o has cursado:

Flauta

\section{EJERCICIO 1}
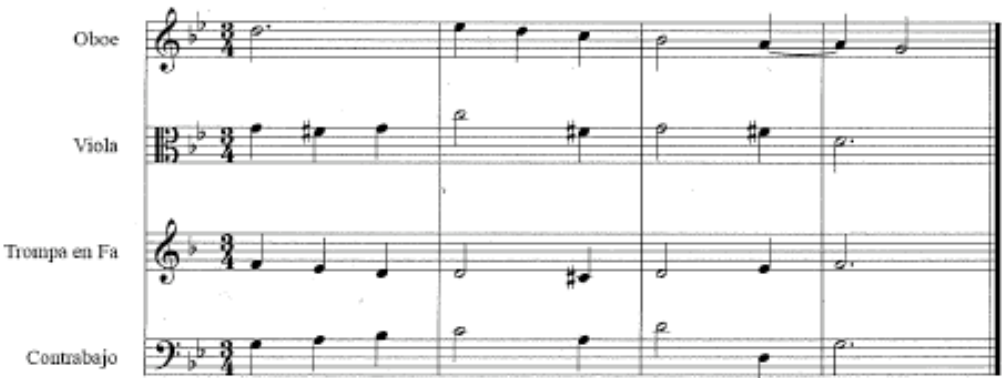

Marcar si no detectas ningún error:

\begin{tabular}{|l|l|l|l|l|}
\hline Compás & Tiempo & Instrumento/s implicado/s & Tipo de error & Observaciones \\
\hline & & & & \\
\hline & & & & \\
\hline & & & & \\
\hline & & & & \\
\hline & & & & \\
\hline & & & & \\
\hline & & & & \\
\hline & & & & \\
\hline
\end{tabular}


Diseño y planificación de competencias específicas en el currículum de enseñanzas profesionales de música: modalidades composición-dirección en la enseñanza superior.

Carlos Eduardo Pascual Pérez

EJERCICIO 2

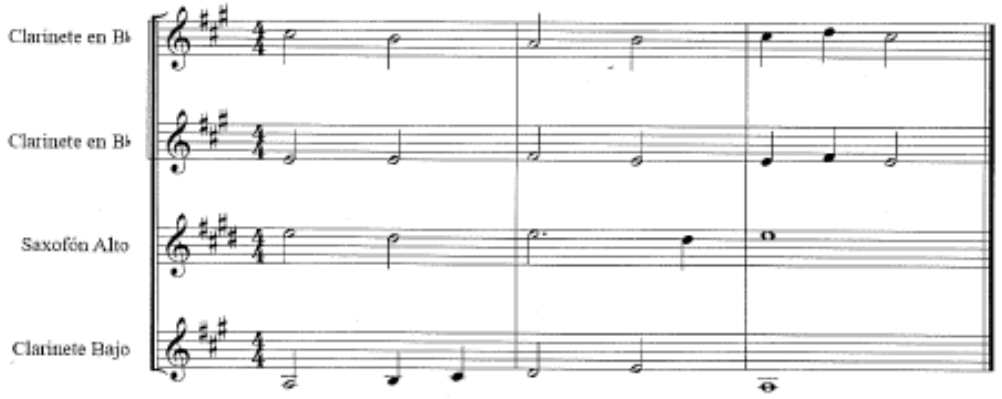

Marcar si no detectas ningún error: $\mathbb{X}$

\begin{tabular}{|l|l|l|l|l|}
\hline Compás & Tlempo & Instrumento/s implicado/s & Tipo de error & Observaciones \\
\hline & & & & \\
\hline & & & & \\
\hline & & & & \\
\hline & & & & \\
\hline & & & & \\
\hline & & & & \\
\hline & & & & \\
\hline
\end{tabular}

EJERCICIO 3

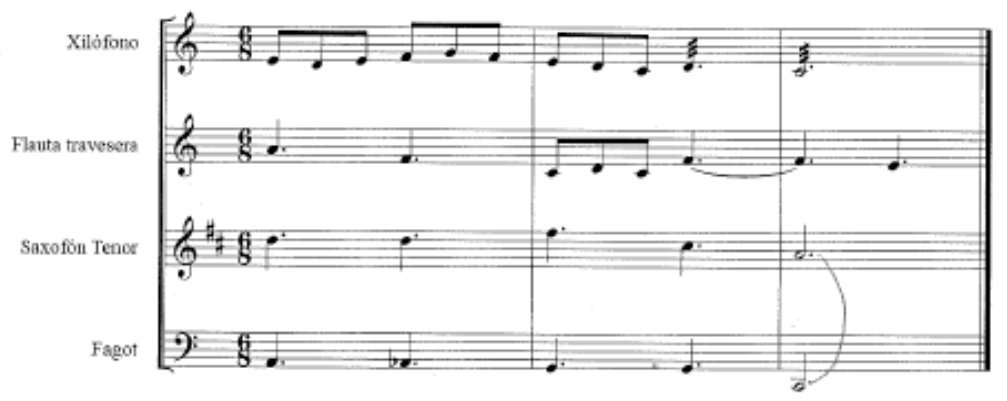

Marcar si no detectas ningún error:

\begin{tabular}{|c|c|c|c|c|}
\hline Compás & Tiempo & Instrumento/s implicado/s & Tipo de error & Observaciones \\
\hline 3 & 1 & Son $\times 0-$ agot & $f$ & \\
\hline & & & & \\
\hline & & & & \\
\hline & & & & \\
\hline & & & & \\
\hline & & & & \\
\hline & & & & \\
\hline
\end{tabular}


Diseño y planificación de competencias específicas en el currículum de enseñanzas profesionales de música: modalidades composición-dirección en la enseñanza superior.

Carlos Eduardo Pascual Pérez

1 UNIVERSITAT
Diseño y planificación de competencias especificas en el curriculum de enserianzas profesionales de música. Modalidades en la enseñanza superior.

Corlos Eduardo Pascual Pérez (investigador) - fosé Maria Peñalver Vilar (director) - Amparo Porta Navorro (tutora)

TEST FINAL 1 Armonía (3 Enseñanzas Profesionales)

Detección de errores armónicos estudiados aplicados a una plantilla instrumental

Instrucciones: Debe analizarse cada fragmento instrumental como si de una realización armónica a cuatro partes se tratase, y localizar (si los hay) errores armónicos de los que figuran en el listado*, para seguidamente enumerarlos en la tabla de respuestas, indicando para cada error su focalización (compás y tiempo), parte/s implicada/s (instrumento/s) y tipo de error $(a, b, c, d, \ldots)$. Puede haber más de un error en un mismo tiempo, en ese caso anotarlos por separado. Si se considera, también puede anotorse alguna observación.

Además, si no se detecton errores en un ejercicio, debe marcarse la casilla correspondiente. Si se desconoce o no se sobe como responder al ejercicio, dejar en blanco.

* Listado de posibles tipos de error:
a) Octovas seguidas
b) Quintas seguidas
c) Octavas directos
d) Quintos directos
e) Cruzamiento de voces
f) Superación de la separación
moxima entre voces

g) Duplicación de la sensible

h) Resolución incorrecto o irresolución de la sensible

i) Resolución incorrecta a irresolución de la séptima (acordes de $7^{9}$ de dte.)

j) Ausencia de preparación de la séptima (acordes de $7^{g}$ de dte.)

Instrumento/s o especialidad/es que estás cursando o has cursado: Gur taw a

\section{EJERCICIO 1}

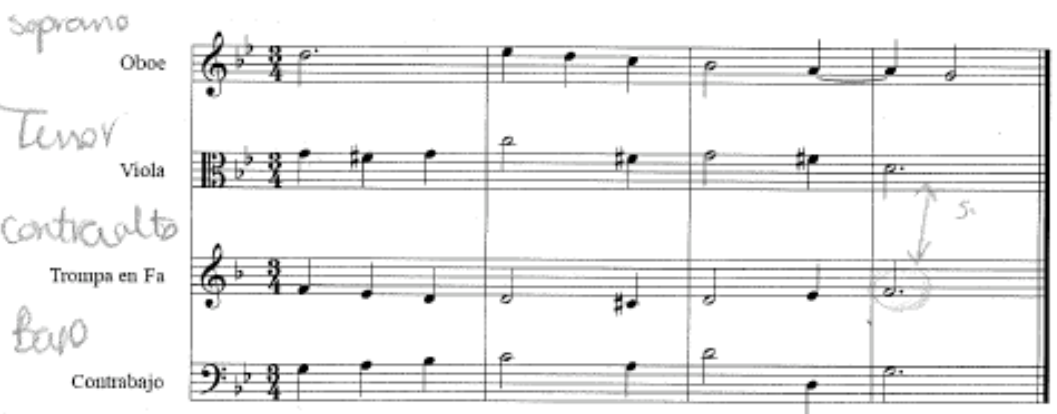

Marcar si no detectas ningún error:

\begin{tabular}{|c|c|c|c|c|}
\hline Compás & Tiempo & Instrumento/s implicado/s & Tipo de error & Observaciones \\
\hline 4 & 10 & viola Tromper & $e$ & \\
\hline $3-4$ & $9-10$ & viola & $h$ & \\
\hline & & & & \\
\hline & & & & \\
\hline & & & & \\
\hline & & & & \\
\hline & & & & \\
\hline & & & & \\
\hline
\end{tabular}


Diseño y planificación de competencias específicas en el currículum de enseñanzas profesionales de música: modalidades composición-dirección en la enseñanza superior.

Carlos Eduardo Pascual Pérez

EJERCICIO 2

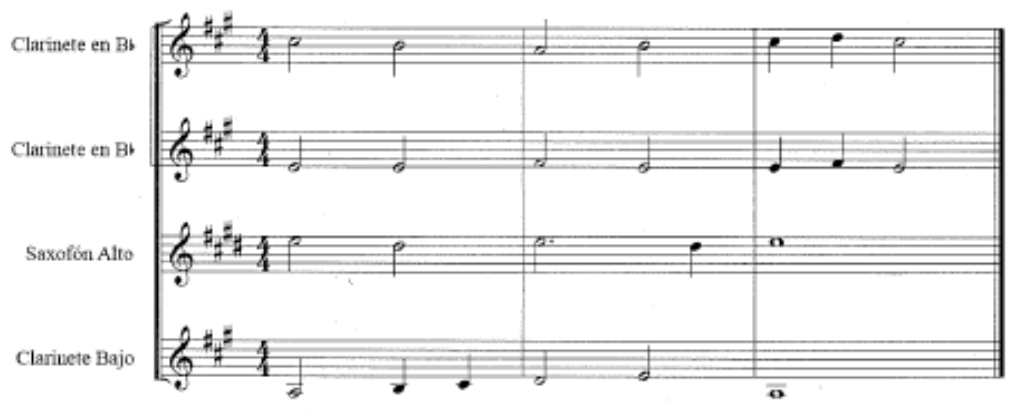

Marcar si no detectas ningún error: cremeamiente de roces

\begin{tabular}{|c|c|c|c|c|}
\hline Compás & Tiempo & Instrumento/s implicado/s & Tipo de error & Observaciones \\
\hline- & - & Souxo jon /tto & Supetsule & \\
\hline & & & & \\
\hline & & & & \\
\hline & & & & \\
\hline & & & & \\
\hline & & & & \\
\hline & & & & \\
\hline
\end{tabular}

EJERCICIO 3

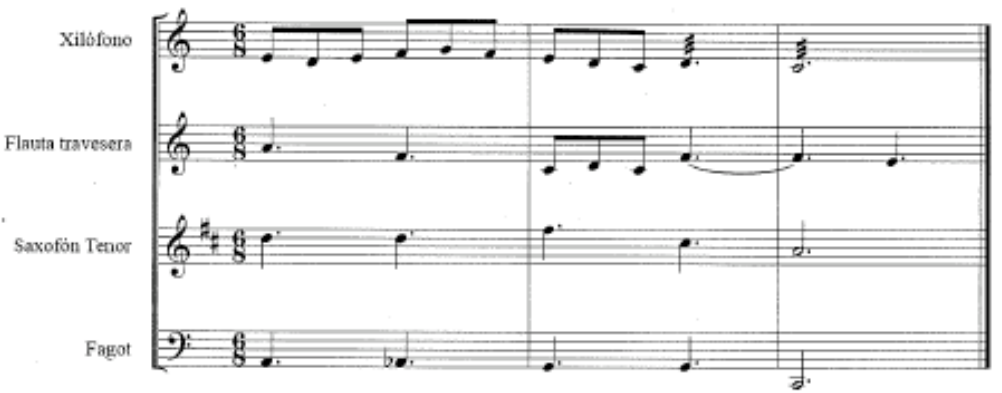

Marcar si no detectas ningún error:

\begin{tabular}{|c|c|c|c|c|}
\hline Compás & Tiempo & Instrumento/s implicado/s & Tipo de error & Observaciones \\
\hline- & - & Scaxposh & C & \\
\hline & & & & \\
\hline & & & & \\
\hline & & & & \\
\hline & & & & \\
\hline & & & & \\
\hline & & & & \\
\hline & & & & \\
\hline
\end{tabular}


Diseño y planificación de competencias específicas en el currículum de enseñanzas profesionales de música: modalidades composición-dirección en la enseñanza superior.

Carlos Eduardo Pascual Pérez

TEST FINAL 1 Armonía (3 Enseñanzas Profesionales)

Detección de errores armónicos estudiados aplicados a una plantilla instrumental

Instrucciones: Debe analizarse cada fragmento instrumental como si de una realización armónica a cuatro partes se tratase, $y$ locafizar (si los hay) errores armónicos de los que figuran en el listado*, para seguidamente enumerarlos en la tabla de respuestas, indicando para cada error su focalización (compás y tiempo), parte/s implicada/s (instrumento/s) y tipo de error $(a, b, c, d, \ldots)$. Puede haber más de un error en un mismo tiempo, en ese caso anotarfos por separado. Si se considera, tombién puede anotorse alguna observación.

Además, si no se detectan errores en un ejercicio, debe marcarse fa casilla correspondiente. Si se desconoce o no se sabe como responder al ejercicio, dejar en blanco.

*Listado de posibles tipos de error:
a) Octovas seguidas
b) Quintas seguidas
c) Octavas directas
a) Duplicación de la sensible
d) Quintos directos
h) Resolución incorrecto o irresolución de la sensible
e) Cruzamiento de voces
i) Resolución incorrecta o irresolución de
máxima entre voces
la séptima lacordes de $7^{q}$ de dte.)
j) Ausencia de preparación de la séptima (acordes de 79 de dte.)

Instrumento/s o especialidad/es que estás cursando o has cursado:

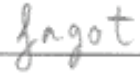

\section{EJERCICIO 1}

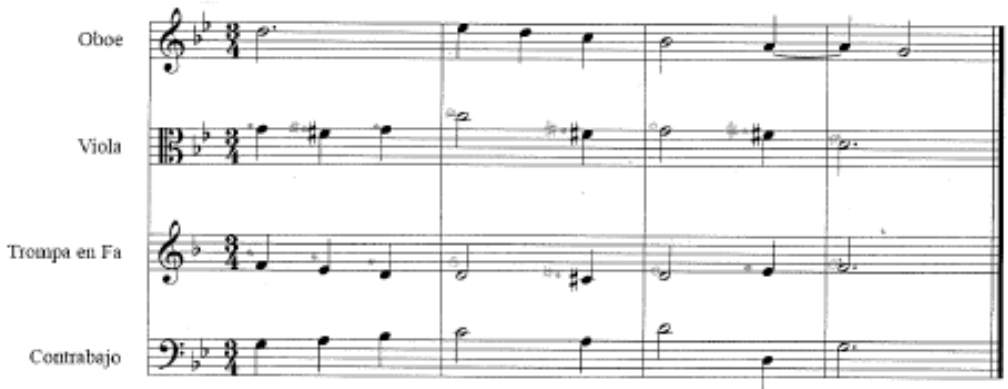

Marcar si no detectas ningún error:

\begin{tabular}{|c|c|c|c|c|}
\hline Compás & Tiempo & Instrumento $/ \mathrm{s}$ implicado/s & Tipo de error & Observaciones \\
\hline$\frac{3}{4}$ & d & 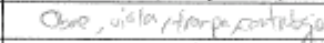 & $S^{2 / 3}$ serguide & \\
\hline$z_{1}^{2}$ & $d$ & 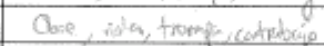 & 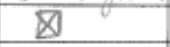 & \\
\hline 4 & $\sqrt{3}$ & Oboe, vide, fromper, sentrobsio & 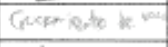 & - \\
\hline$y$ & J & Ohee, vida, trempa, cidrobegio & & \\
\hline$\frac{5}{4}$ & $J$ & Oove, vids it merpa, cotoboji & 8 & \\
\hline$\frac{15}{4}$ & J & Oose, vida, troris, chebo & & \\
\hline 7 & $d$ & Oboc, ido, tronapos cantribuje & $\vec{e}$ & \\
\hline 8 & J & 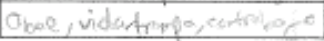 & (8) & \\
\hline
\end{tabular}


Diseño y planificación de competencias específicas en el currículum de enseñanzas profesionales de música: modalidades composición-dirección en la enseñanza superior.

Carlos Eduardo Pascual Pérez

EJERCICIO 2

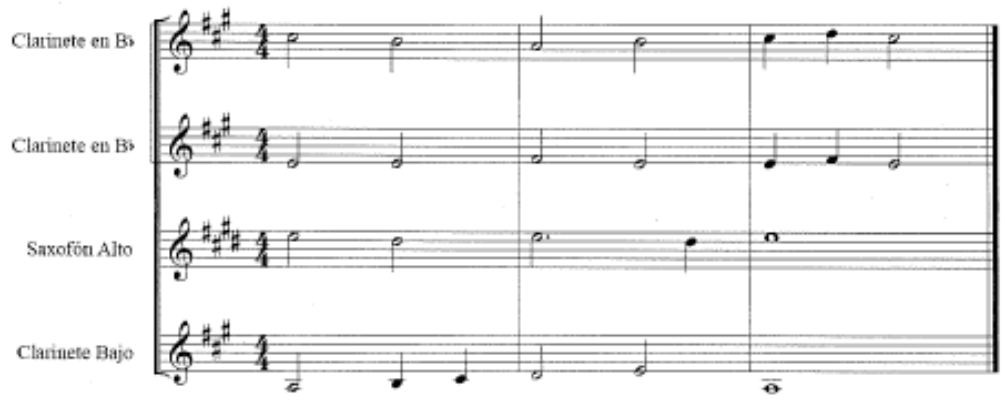

Marcar si no detectas ningún error:

\begin{tabular}{|c|c|c|c|c|}
\hline Compás & Tiempo & Instrumento/s implicado/s & Tipo de error & Observaciones \\
\hline 4 & $J$ & 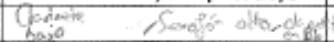 & ie & \\
\hline$?$ & $d$ & 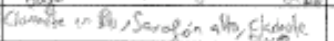 & $C$ & \\
\hline 3 & I & 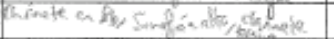 & $x$ & \\
\hline 4 & J & Cherete en Bb, fongeg/n alturabere & $b$ & \\
\hline$\frac{4}{5}$ & d & 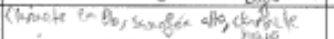 & $y$ & \\
\hline$\&$ & $d$ & 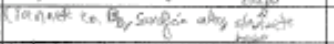 & 3 & \\
\hline से & $d$ & 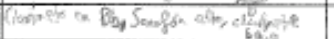 & $d$ & \\
\hline 4 & $d$ & 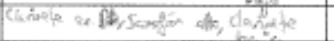 & $a$ & \\
\hline
\end{tabular}

EJERCICIO 3

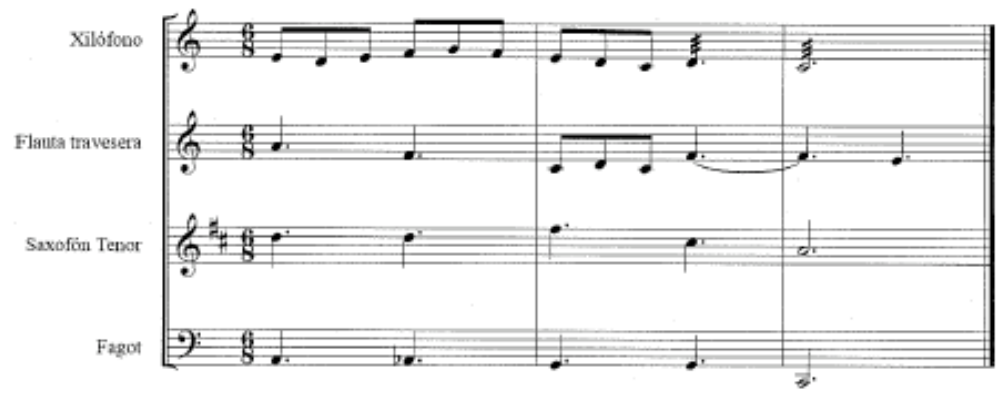

Marcar si no detectas ningún error:

\begin{tabular}{|c|c|c|c|c|}
\hline Compas & Tiempo & Instrumento/s implicado/s & Tipo de error & Observaciones \\
\hline$\frac{1}{4}$ & d & 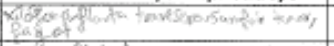 & $\frac{1}{8}$ & \\
\hline$\frac{2}{4}$ & J & 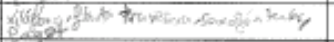 & $x$ & \\
\hline$\frac{3}{4}$ & J & 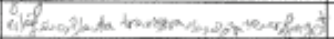 & & \\
\hline$\frac{5}{4}$ & 2 & 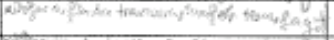 & $a$ & \\
\hline$\xi$ & d & 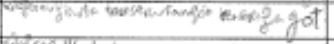 & x & \\
\hline$\frac{5}{4}$ & d & 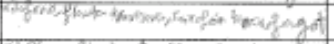 & C & \\
\hline बे & d & 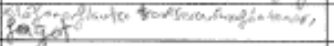 & h & \\
\hline 4 & 2 & 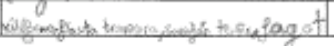 & $x$ & \\
\hline
\end{tabular}


Diseño y planificación de competencias específicas en el currículum de enseñanzas profesionales de música: modalidades composición-dirección en la enseñanza superior.

Carlos Eduardo Pascual Pérez

\section{TEST FINAL 1ㅇ Armonía (3ํㅡㄹeñanzas Profesionales)}

Detección de errores armónicos estudiados aplicados a una plantilla instrumental

Instrucciones: Debe anafizarse coda fragmento instrumental como si de una realización armónica a cuatro partes se tratase, y localizor (si los hay) errores armónicos de los que figuran en el listodo*, para seguidomente enumerarlos en la tabia de respuestas, indicando para cada error su focalización (compós y tiempo), porte/s implicada/s (instrumento/s) y tipo de error $(a, b, c, d, \ldots)$. Puede haber más de un error en un mismo tiempo, en ese caso anotorlos por seporado. Si se considera, también puede anotorse alguna observación.

Además, si no se detectan errores en un ejercicio, debe marcarse fa casilla correspondiente. Si se desconoce o no se sabe como responder al ejercicio, dejar en blanco.

"Listodo de posibles tipos de error:
a) Octovas seguidas
b) Quintas seguidas
c) Octavas directos
g) Duplicación de la sensible
Quintos directos
h) Resolución incorrecta o irresolución de la sensible
e) Cruzamiento de voces
Resolución incorrecta o irresolución de
Superación de la separación la séptima locordes de $7^{g}$ de dte.)
máxima entre voces
i) Ausencia de preparación de la séptima (acordes de 79 de dite.

Instrumento/s o especialidad/es que estás cursando o has cursado: Percusión

\section{EJERCICIO 1}

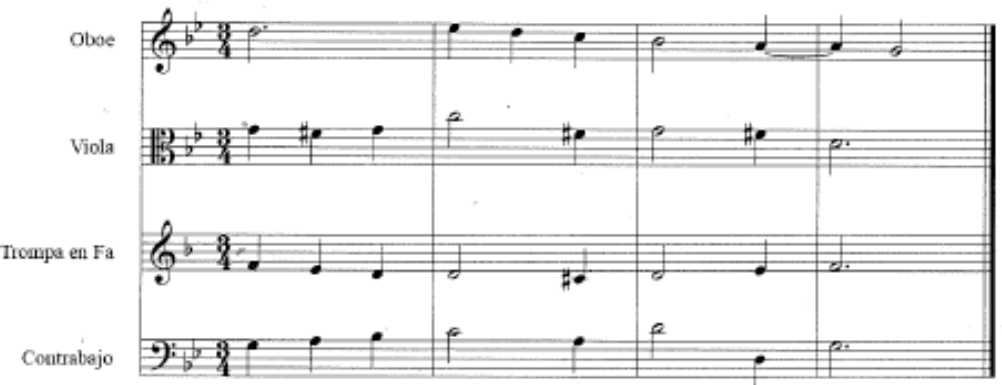

Marcar si no detectas ningún error:

\begin{tabular}{|l|l|l|l|l|}
\hline Compás & Tiempo & Instrumento/s implicado/s & Tipo de error & Observaciones \\
\hline & & & & \\
\hline & & & & \\
\hline & & & & \\
\hline & & & & \\
\hline & & & & \\
\hline & & & & \\
\hline & & & & \\
\hline
\end{tabular}


Diseño y planificación de competencias específicas en el currículum de enseñanzas profesionales de música: modalidades composición-dirección en la enseñanza superior.

Carlos Eduardo Pascual Pérez

\section{EJERCICIO 2}

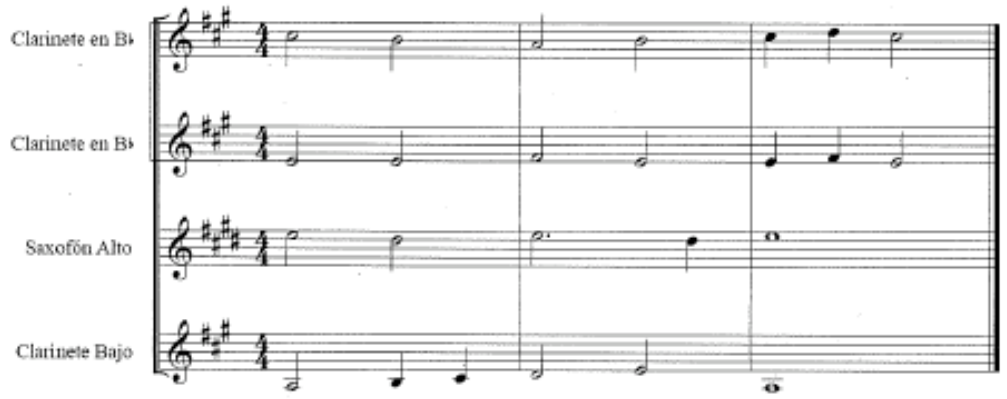

Marcar si no detectas ningún error: $\square$

\begin{tabular}{|l|l|l|l|l|}
\hline Compás & Tiempo & Instrumento/s implicado/s & Tipo de error & Observaciones \\
\hline & & & & \\
\hline & & & & \\
\hline & & & & \\
\hline & & & & \\
\hline & & & & \\
\hline & & & & \\
\hline & & & & \\
\hline & & & & \\
\hline
\end{tabular}

\section{EJERCICIO 3}

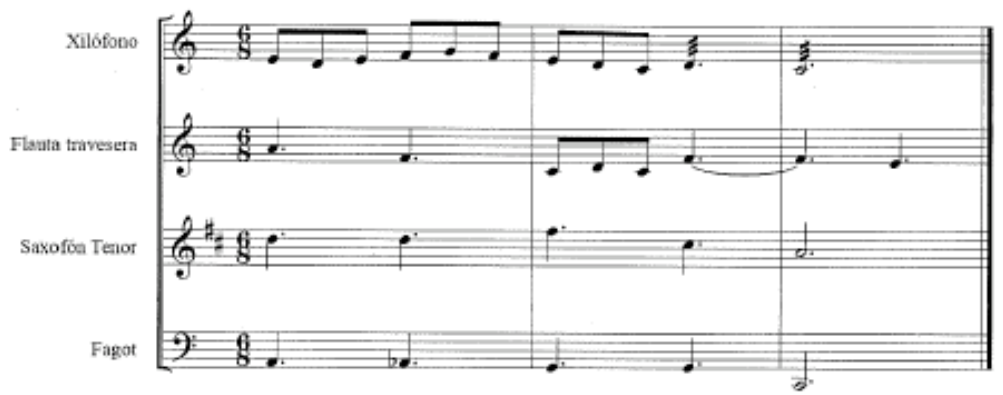

Marcar si no detectas ningún error:

\begin{tabular}{|l|l|l|l|l|}
\hline Compás & Tiempo & Instrumento/s implicado/s & Tipo de error & Observaciones \\
\hline & & & & \\
\hline & & & & \\
\hline & & & & \\
\hline & & & & \\
\hline & & & & \\
\hline & & & & \\
\hline & & & & \\
\hline & & & & \\
\hline
\end{tabular}


Diseño y planificación de competencias específicas en el currículum de enseñanzas profesionales de música: modalidades composición-dirección en la enseñanza superior.

Carlos Eduardo Pascual Pérez

U. UNIVERSITAT
Diseño y planificación de competencias específicas en el curriculum de enseñanzas profesionales de música. Modalidades en la enseñanza superior.

Corlos Eduardo Pascual Pérez (investigador) - José Maria Peñalver Vilar (director) - Amparo Porta Novorro (tutora)

\section{TEST FINAL 1 Armonía (3ำ Enseñanzas Profesionales)}

Detección de errores armónicos estudiados aplicados a una plantilla instrumental

Instrucciones: Debe analizarse cada fragmento instrumentaf como si de una reaflización armónica o cuatro partes se tratase, y localizar (si los hay) errores armónicos de los que figuran en el listado*, para seguidamente enumerarios en la tabla de respuestas, indicando para cada error su localización (compás y tiempo), parte/s implicada/s (instrumento/s) y tipo de error $(a, b, c, d, \ldots)$. Puede haber mós de un error en un mismo tiempo, en ese caso anotarlos por separado. Si se considera, también puede anotarse alguna observación.

Además, si no se detectan errores en un ejercicio, debe marcarse la casilla correspondiente. Si se desconoce o no se sabe como responder al ejercicio, dejar en blanco.

* Listado de posibles tipos de error:
a) Octavas seguidas
b) Quintas seguidas
c) Octavas directos
d) Quintas directos
e) Cruzamiento de voces
f) Superación de la separación máxima entre voces

g) Duplicación de lo sensible

h) Resolución incorrecto o irresolución de la sensible

i) Resolución incorrecta o irresolución de la séptima (acordes de $7^{\circ}$ de dte.)

j) Ausencia de preparación de la séptima (acordes de 79 de dte.)

Instrumento/s o especialidad/es que estás cursando o has cursado: Percus ión

\section{EJERCICIO 1}

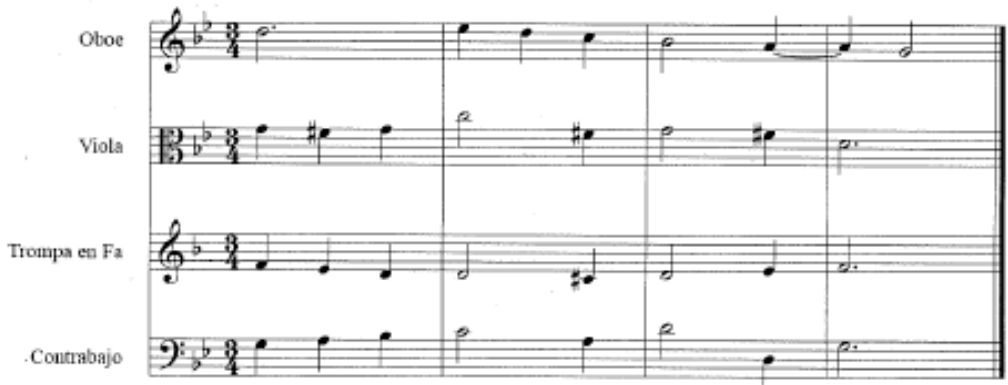

Marcar si no detectas ningún error: $\not$

\begin{tabular}{|l|l|l|l|l|}
\hline Compás & Tiempo & Instrumento/s implicado/s & Tipo de error & Observaciones \\
\hline & & & & \\
\hline & & & & \\
\hline & & & & \\
\hline & & & & \\
\hline & & & & \\
\hline & & & & \\
\hline & & & & \\
\hline
\end{tabular}


Diseño y planificación de competencias específicas en el currículum de enseñanzas profesionales de música: modalidades composición-dirección en la enseñanza superior.

Carlos Eduardo Pascual Pérez

\section{EJERCICIO 2}

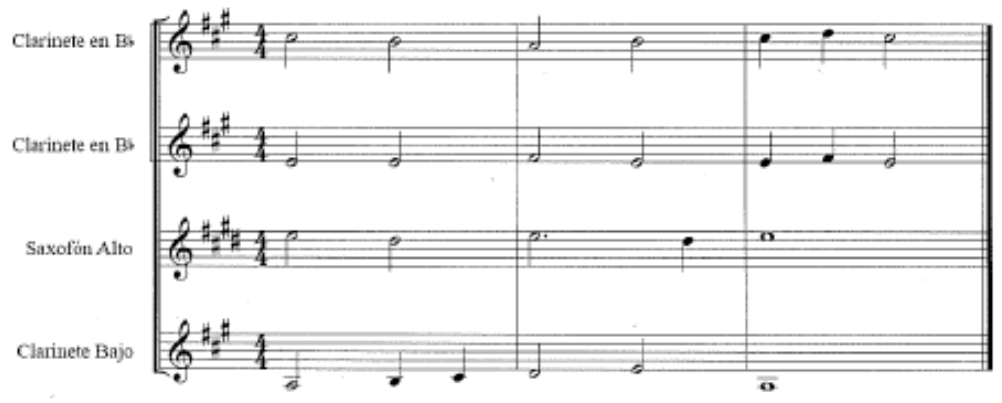

Marcar si no detectas ningún error: Х

\begin{tabular}{|l|l|l|l|l|}
\hline Compás & Tiempo & Instrumento/s implicado/s & Tipo de error & Observaciones \\
\hline & & & & \\
\hline & & & & \\
\hline & & & & \\
\hline & & & & \\
\hline & & & & \\
\hline & & & & \\
\hline & & & & \\
\hline & & & & \\
\hline
\end{tabular}

\section{EJERCICIO 3}

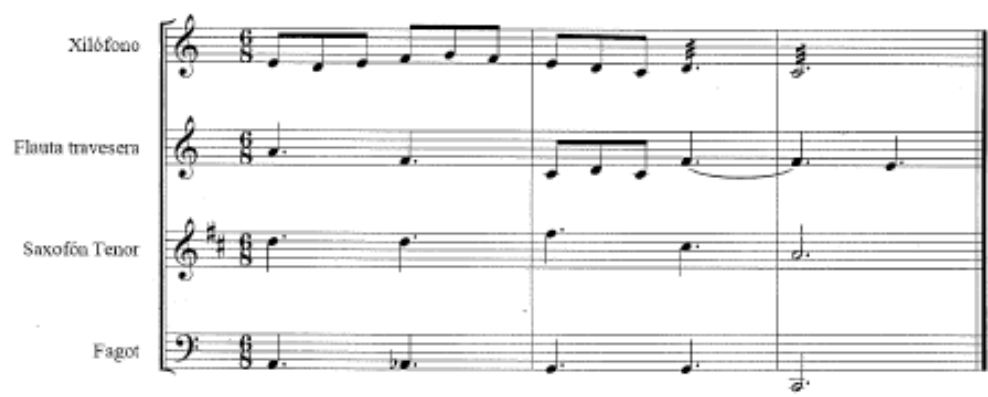

Marcar si no detectas ningún error:

\begin{tabular}{|c|c|c|c|c|}
\hline Compás & Tiempo & Instrumento/s implicado/s & Tipo de error & Observaciones \\
\hline 1 & 1 & Xilofono / Pauta & $e$ & \\
\hline a3 & $1: 2$ & Xilotono/Flauta & $e$ & \\
\hline & & & & \\
\hline & & & & \\
\hline & & & & \\
\hline & & & & \\
\hline & & & & \\
\hline & & & & \\
\hline
\end{tabular}


Diseño y planificación de competencias específicas en el currículum de enseñanzas profesionales de música: modalidades composición-dirección en la enseñanza superior.

Carlos Eduardo Pascual Pérez

\section{TEST FINAL 1 Armonía (3 Enseñanzas Profesionales)}

Detección de errores armónicos estudiados aplicados a una plantilla instrumental

Instrucciones: Debe anafizarse cada fragmento instrumental como si de uno realización armónica a cuatro partes se tratase, y localizar (si los hay) errores armónicos de los que figuran en el listado*, para seguidamente enumerarios en la tabla de respuestas, indicando para cada error su localización (compós y tiempo), porte/s implicada/s (instrumento/s) y tipo de error $(a, b, c, d, \ldots)$. Puede haber más de un error en un mismo tiempo, en ese caso anotarios por separado. Si se considera, también puede anotarse alguna observación.

Además, si no se detectan errores en un ejercicio, debe marcarse la casilla correspondiente. Si se desconoce o no se sabe como responder al ejercicio, dejar en blanco.

*Listado de posibles tipos de error:
a) Octovas seguidas
b) Quintas seguidas
c) Octovas directas
d) Quintos directas
e) Cruzamiento de voces
f) Superación de la separación
máxima entre voces

g) Duplicación de la sensible

h) Resolución incorrecto o irresolución de la sensible

i) Resolución incorrecto o irresolución de la séptima (acordes de $7^{9}$ de dte.)

j) Ausencia de preparación de lo séptima (acordes de $7^{9}$ de dte.)

Instrumento/s o especialidad/es que estás cursando o has cursado:

\section{EJERCICIO 1}

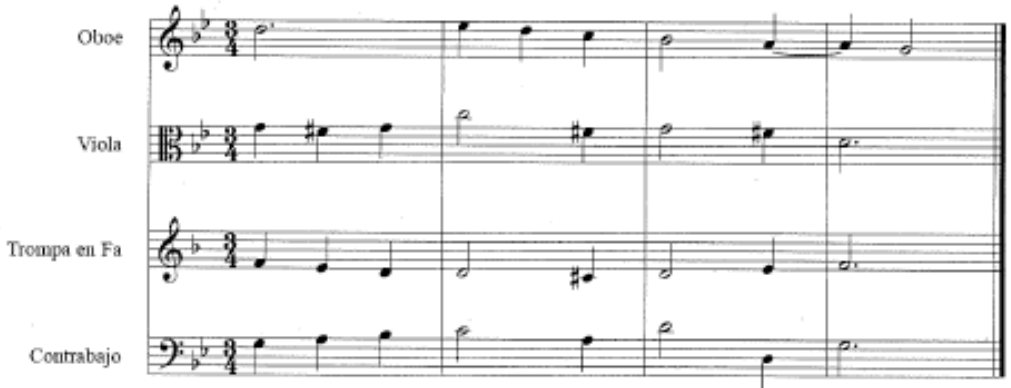

Marcar si no detectas ningún error: $Q$

\begin{tabular}{|l|l|l|l|l|}
\hline Compás & Tiempo & Instrumento/s implicado/s & Tipo de error & Observaciones \\
\hline & & & & \\
\hline & & & & \\
\hline & & & & \\
\hline & & & & \\
\hline & & & & \\
\hline & & & & \\
\hline & & & & \\
\hline & & & & \\
\hline
\end{tabular}


Diseño y planificación de competencias específicas en el currículum de enseñanzas profesionales de música: modalidades composición-dirección en la enseñanza superior.

Carlos Eduardo Pascual Pérez

\section{EJERCICIO 2}

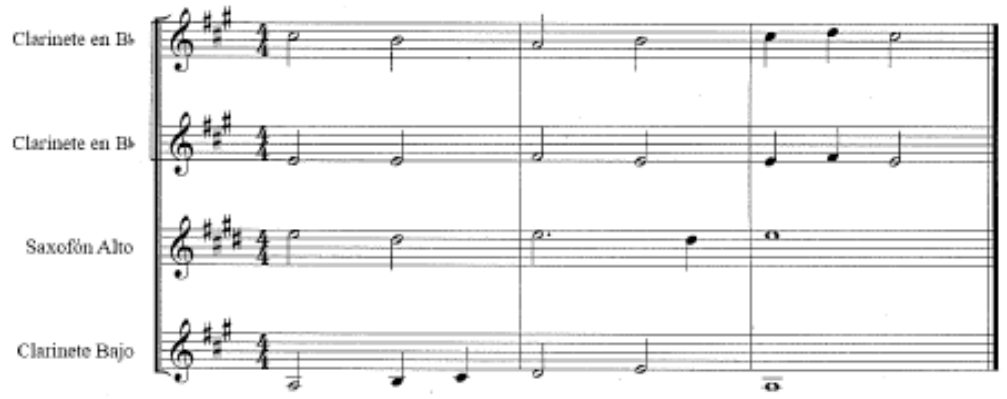

Marcar si no detectas ningún error:

$\square$

\begin{tabular}{|l|l|l|l|l|}
\hline Compás & Tiempo & Instrumento/s implicado/s & Tipo de error & Observaciones \\
\hline & & & & \\
\hline & & & & \\
\hline & & & & \\
\hline & & & & \\
\hline & & & & \\
\hline & & & & \\
\hline & & & & \\
\hline & & & & \\
\hline
\end{tabular}

EJERCICIO 3

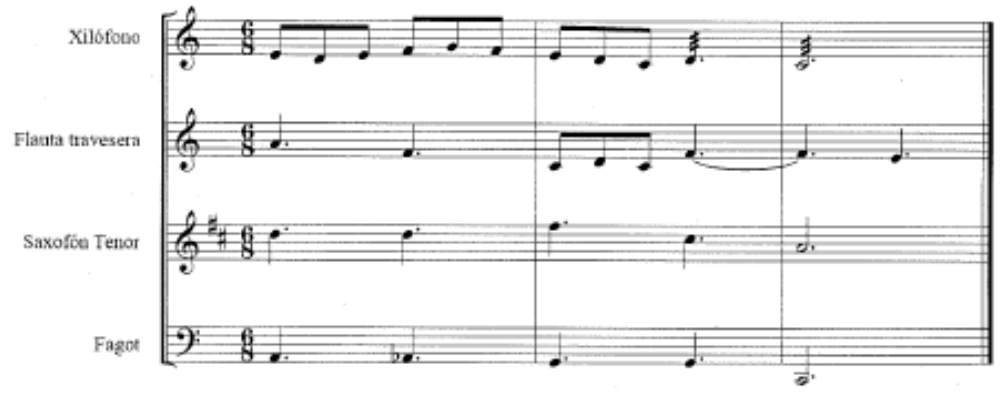

Marcar si no detectas ningún error:

\begin{tabular}{|l|l|l|l|l|}
\hline Compás & Tiempo & Instrumento/s implicado/s & Tipo de error & Observaciones \\
\hline & & & & \\
\hline & & & & \\
\hline & & & & \\
\hline & & & & \\
\hline & & & & \\
\hline & & & & \\
\hline & & & & \\
\hline & & & & \\
\hline
\end{tabular}


Diseño y planificación de competencias específicas en el currículum de enseñanzas profesionales de música: modalidades composición-dirección en la enseñanza superior.

Carlos Eduardo Pascual Pérez

1. UNIVERSITAT JAUME I
Diseño y planificación de competencias especificas en el curriculum de enseñanzas profesionales de música. Modalidades en la enseñanza superior.

Corlos Eduardo Pascual Pérez (investigodor) - José Maria Peñalver Vilar (director) - Amparo Parta Novarro (tutora)

\section{TEST FINAL 1 Armonía (3 Enseñanzas Profesionales)}

Detección de errores armónicos estudiados aplicados a una plantilla instrumental

Instrucciones: Debe analizarse cado fragmento instrumental como si de una realización armónica a cuotro partes se tratase, y locolizar (si los hay) errores armónicos de los que figuran en el listado*, para seguidomente enumerarlos en la tabla de respuestas, indicando para cada error su localización (compós y tiempo), parte/s implicoda/s (instrumento/s) y tipo de error $(a, b, c, d, \ldots)$. Puede haber más de un error en un mismo tiempo, en ese caso anotarlos por separado. Si se considera, también puede anotorse alguna observación.

Además, si no se detectan errores en un ejercicio, debe marcarse la casilla correspondiente. Si se desconoce o no se sabe como responder al ejercicio, dejar en blanco.

* Listodo de posibles tipos de error:
a) Octavas seguidas
b) Quintos seguidas
c) Octovas directas
d) Quintos directas
e) Cruzamiento de voces
f) Superación de la separación
máxima entre voces

g) Duplicación de fa sensible

h) Resolución incorrecta o irresolución de la sensible

i) Resolución incorrecta o irresolución de fa séptima (acordes de 79 de dte.)

j) Ausencia de preparación de la séptima (acordes de $7^{g}$ de dite.)

Instrumento/s o especialidad/es que estás cursando o has cursado: thoino

\section{EJERCICIO 1}
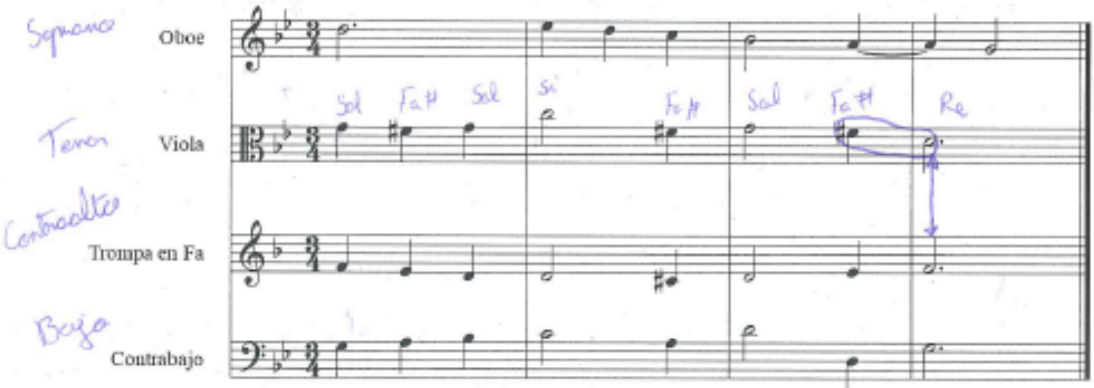

Marcar si no detectas ningún error:

\begin{tabular}{|c|c|c|c|c|}
\hline Compás & Tiempo & Instrumento/s implicado/s & Tipo de error & Observaciones \\
\hline $3-4$ & $9-10$ & Vuda & h) & \\
\hline 4 & 10 & Vida y Trompo & e) & \\
\hline & & & & \\
\hline & & & & \\
\hline & & & & \\
\hline & & & & \\
\hline & & & & \\
\hline & & & & \\
\hline
\end{tabular}


Diseño y planificación de competencias específicas en el currículum de enseñanzas profesionales de música: modalidades composición-dirección en la enseñanza superior.

\section{Carlos Eduardo Pascual Pérez}

\section{EJERCICIO 2}

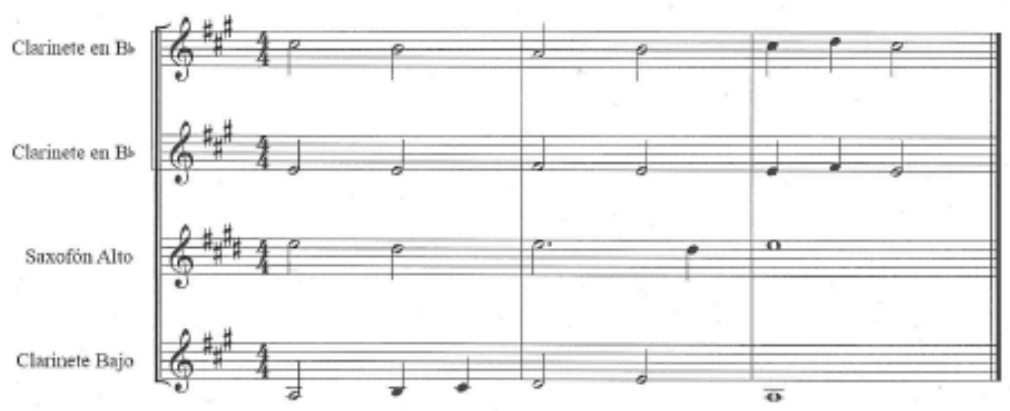

Marcar si no detectas ningún error:

\begin{tabular}{|l|l|c|c|c|}
\hline Compás & Tiempo & Instrumento/s implicado/s & Tipo de error & Observaciones \\
\hline tedos & tedos & Cós Tos & e) & \\
\hline & & & & \\
\hline & & & & \\
\hline & & & & \\
\hline & & & & \\
\hline & & & & \\
\hline & & & & \\
\hline
\end{tabular}

EJERCICIO 3

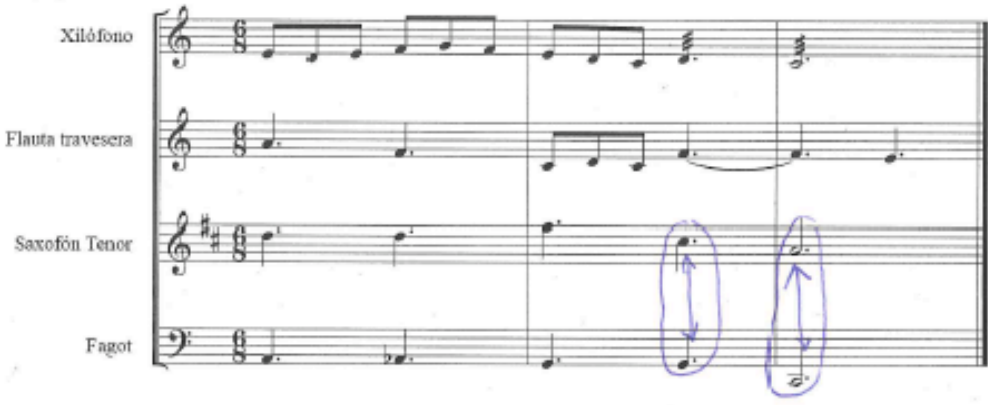

Marcar si no detectas ningún error:

\begin{tabular}{|l|r|r|r|l|}
\hline Compás & Tiempo & Instrumento/s implicado/s & Tipo de error & Observaciones \\
\hline $2-3$ & $10-11$ & Srugón Tesos toged & a) & \\
\hline & & & & \\
\hline & & & & \\
\hline & & & & \\
\hline & & & & \\
\hline & & & & \\
\hline & & & & \\
\hline
\end{tabular}


Diseño y planificación de competencias específicas en el currículum de enseñanzas profesionales de música: modalidades composición-dirección en la enseñanza superior.

Carlos Eduardo Pascual Pérez

\section{TEST FINAL 1 Armonía (3 Enseñanzas Profesionales)}

Detección de errores armónicos estudiados aplicados a una plantilla instrumental

Instrucciones: Debe analizarse cada fragmento instrumental como si de una realización armónica a cuatro partes se tratase, y localizar (si los hay) errores armónicos de los que figuran en el listado*, para seguidamente enumerarios en la tabla de respuestas, indicando para cado error su focalización (compás y tiempol, parte/s implicada/s (instrumento/s) y tipo de error $(a, b, c, d, \ldots)$. Puede haber más de un error en un mismo tiempo, en ese caso anotarlos por separado. Si se considera, también puede onotarse alguna observación.

Además, si no se detecton errores en un ejercicio, debe marcarse la casilla correspondiente. Si se desconoce o no se sabe como responder al ejercicio, dejar en bianco.

- Listado de pasibles tipos de error:
a) Octavas seguidas
b) Quintas seguidas
c) Octavas directas
d) Quintas directas
e) Cruzamiento de voces
f) Superoción de la separación máximo entre voces
g) Duplicación de la sensible
h) Resolución incorrecta o irresolución de la sensible
11) Resolución incorrecta o irresolución de la séptima (acordes de $7^{g}$ de dite.)
i) Ausencia de oreparación de la séptima (acordes de 79 de ote.)

Instrumento/s o especialidad/es que estás cursando o has cursado:

\section{EJERCICIO 1}

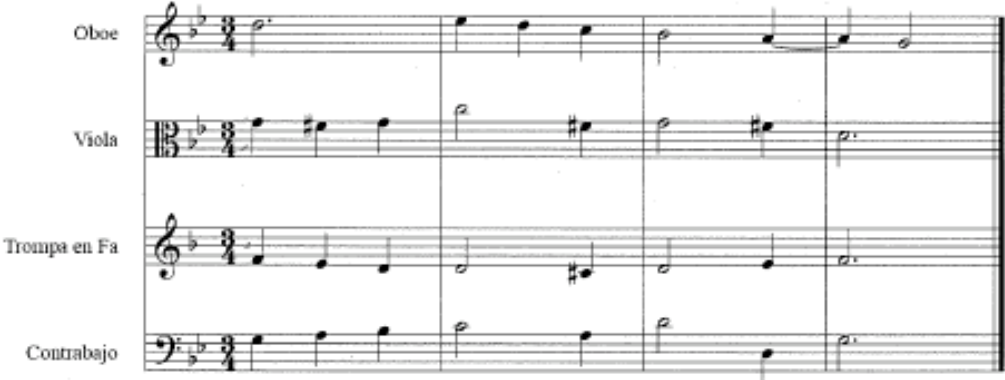

Marcar si no detectas ningún error:

\begin{tabular}{|l|l|l|l|l|}
\hline Compás & Tiempo & Instrumento/s implicado/s & Tipo de error & Observaciones \\
\hline & & & & \\
\hline & & & & \\
\hline & & & & \\
\hline & & & & \\
\hline & & & & \\
\hline & & & & \\
\hline & & & & \\
\hline & & & & \\
\hline
\end{tabular}


Diseño y planificación de competencias específicas en el currículum de enseñanzas profesionales de música: modalidades composición-dirección en la enseñanza superior.

Carlos Eduardo Pascual Pérez

\section{EJERCICIO 2}

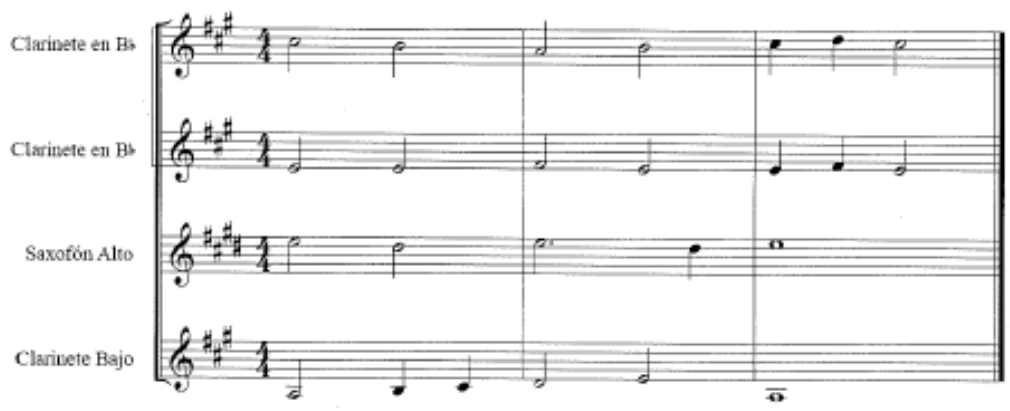

Marcar si no detectas ningún error:

\begin{tabular}{|l|l|l|l|l|}
\hline Compás & Tiempo & Instrumento/s implicado/s & Tipo de error & Observaciones \\
\hline & & & & \\
\hline & & & & \\
\hline & & & & \\
\hline & & & & \\
\hline & & & & \\
\hline & & & & \\
\hline & & & & \\
\hline & & & & \\
\hline
\end{tabular}

EJERCICIO 3

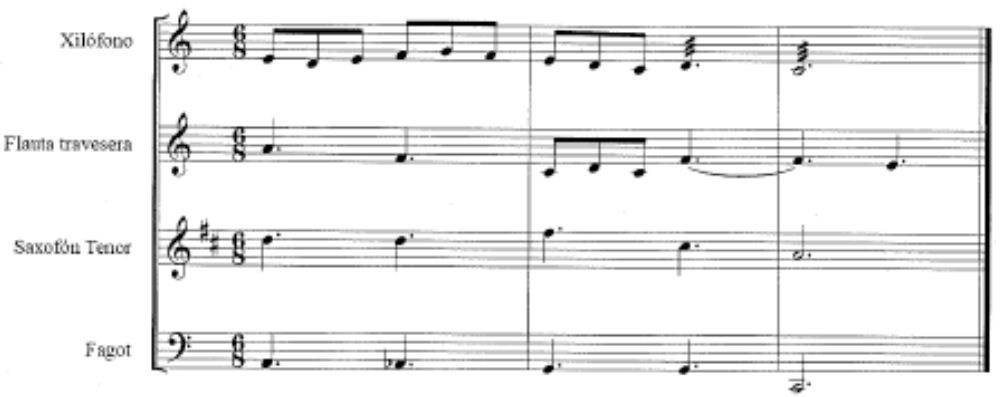

Marcar si no detectas ningún error: $\varnothing$

\begin{tabular}{|l|l|l|l|l|}
\hline Compás & Tiempo & Instrumento/s implicado/s & Tipo de error & Observaciones \\
\hline & & & & \\
\hline & & & & \\
\hline & & & & \\
\hline & & & & \\
\hline & & & & \\
\hline & & & & \\
\hline & & & & \\
\hline & & & & \\
\hline
\end{tabular}


Diseño y planificación de competencias específicas en el currículum de enseñanzas profesionales de música: modalidades composición-dirección en la enseñanza superior.

Carlos Eduardo Pascual Pérez

TEST FINAL 10 Armonía (3ำ Enseñanzas Profesionales)

Detección de errores armónicos estudiados aplicados a una plantilla instrumental

Instrucciones: Debe analizarse cada fragmento instrumental como si de una realización armónica a cuatro partes se tratase, y localizar (si los hay) errores armónicos de los que figuran en el listado*, para seguidamente enumerarios en la tabla de respuestas, indicando para cada error su localizoción (compás y tiempo), parte/s implicada/s (instrumento/s) y tipo de error $(a, b, c, d, \ldots)$. Puede hober más de un error en un mismo tiempo, en ese caso anotarlos por separado. Si se considera, también puede anotarse alguna observación.

Además, si no se detecton errores en un ejerciclo, debe marcarse la casilla correspondiente. Si se desconoce o no se sabe como responder al ejercicio, dejar en blanco.

*istado de posibles tipos de error:
a) Octavas seguidas
b) Quintas seguidas
c) Octavas directas
g) Duplicación de la sensible
d) Quintas directos
h) Resolución incorrecto o irresolución de la sensible
e) Cruzamiento de voces
f) Superación de la separación
i) Resolución incorrecto o irresoluclón de la séptima (acordes de 79 de dte.)
máxima entre voces
j) Ausencia de preparación de la séptimo (acordes de 79 de dte.

Instrumento/s o especialidad/es que estás cursando o has cursado:

savogarin

\section{EJERCICIO 1}

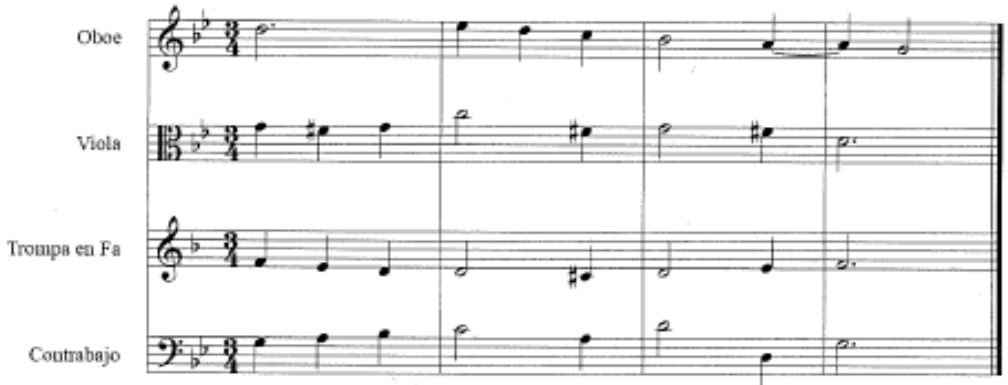

Marcar si no detectas ningún error: $>$

\begin{tabular}{|l|l|l|l|l|}
\hline Compás & Tiempo & Instrumento/s implicado/s & Tipo de error & Observaciones \\
\hline & & & & \\
\hline & & & & \\
\hline & & & & \\
\hline & & & & \\
\hline & & & & \\
\hline & & & & \\
\hline & & & & \\
\hline
\end{tabular}


Diseño y planificación de competencias específicas en el currículum de enseñanzas profesionales de música: modalidades composición-dirección en la enseñanza superior.

Carlos Eduardo Pascual Pérez

EJERCICIO 2

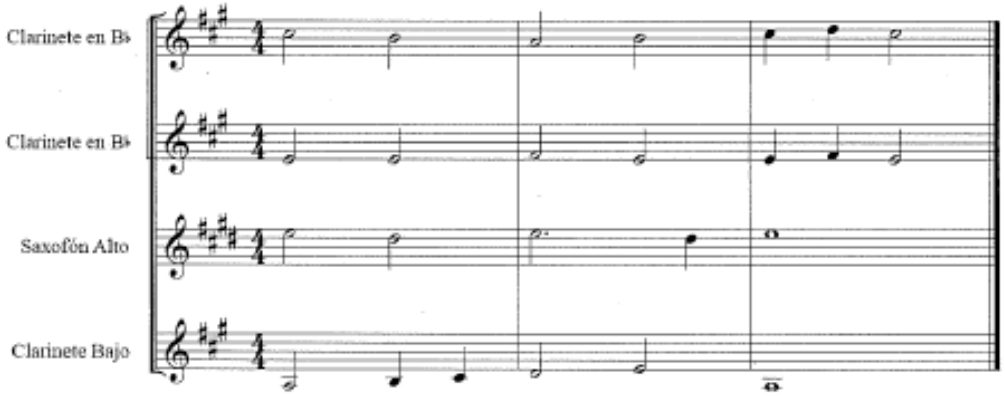

Marcar si no detectas ningủn error:

\begin{tabular}{|l|l|l|l|l|}
\hline Compás & Tiempo & Instrumento/s implicado/s & Tipo de error & Observaciones \\
\hline & & & & \\
\hline & & & & \\
\hline & & & & \\
\hline & & & & \\
\hline & & & & \\
\hline & & & & \\
\hline & & & & \\
\hline & & & & \\
\hline
\end{tabular}

EJERCICIO 3

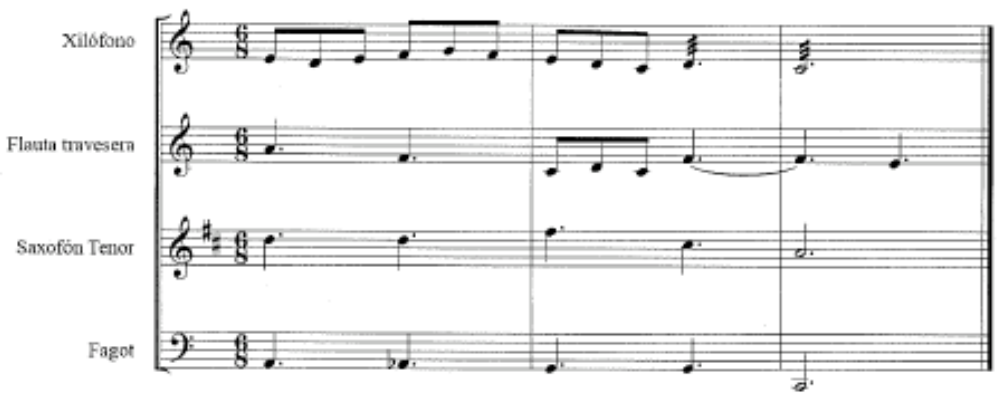

Marcar si no detectas ningún error:

\begin{tabular}{|c|c|c|c|c|}
\hline Compás & Tiempo & Instrumento/s implicado/s & Tipo de error & Observaciones \\
\hline $1: 2$ & $6 \times 1$ & 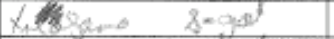 & a) & \\
\hline 2 & $2 \times 3$ & 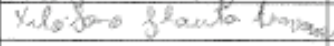 & a) & \\
\hline & & & & \\
\hline & & & & \\
\hline & & & & \\
\hline & & & & \\
\hline & & & & \\
\hline 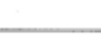 & 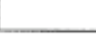 & 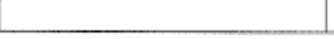 & 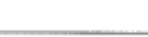 & . \\
\hline
\end{tabular}


Diseño y planificación de competencias específicas en el currículum de enseñanzas profesionales de música: modalidades composición-dirección en la enseñanza superior.

Carlos Eduardo Pascual Pérez

Diseño y planificación de competencias especificas en el curriculum de enseñanzas profesionales de música. Modalidades en la enseñanza superior.

\section{TEST FINAL 1 Armonía (3ํㅡㄹ Enseñanzas Profesionales)}

Detección de errores armónicos estudiados aplicados a una plantilla instrumental

Instrucciones: Debe analizarse cada fragmento instrumental como si de una realización armónica a cuatro partes se tratase, y localizar (si los hay) errores armónicos de los que figuran en el listado*, para seguidamente enumerarlos en la tabla de respuestas, indicando para cada error su localización (compós y tiempo), parte/s implicada/s (instrumento/s) y tipo de error $(a, b, c, d, \ldots)$. Puede haber más de un error en un mismo tiempo, en ese caso anotarlos por separado. Si se considera, tambièn puede anotorse alguna observación.

Además, si no se detecton errores en un ejercicio, debe marcarse la casilla correspondiente. Si se desconoce o no se sabe como responder al ejercicio, dejar en blanco.

* Listado de posibles tipos de error:
a) Octavas seguidas
b) Quintas seguidas
c) Octovas directos
d) Quintas directos
e) Cruzamiento de voces
f) Superación de la separación
móxima entre voces

g) Duplicación de la sensible

h) Resolución incorrecta o irresolución de la sensible

i) Resolución incorrecta o irresolución de la séptima (acordes de $7^{\circ}$ de dte.)

j) Ausencia de preparación de lo séptimo (acordes de 7g de dte.)

Instrumento/s o especialidad/es que estás cursando o has cursado:

\section{EJERCICIO 1}

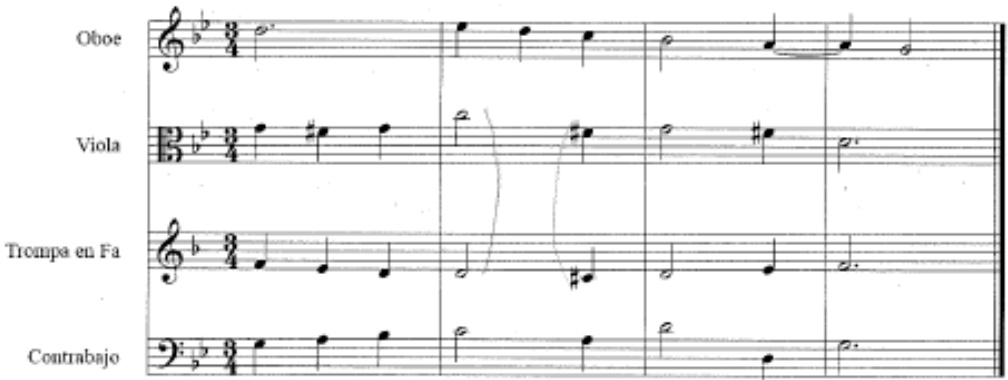

Marcar si no detectas ningún error:

\begin{tabular}{|l|l|l|l|l|}
\hline Compás & Tiempo & Instrumento/s implicado/s & Tipo de error & Observaciones \\
\hline & & & & \\
\hline & & & & \\
\hline & & & & $\vdots$ \\
\hline & & & & \\
\hline & & & & \\
\hline & & & & \\
\hline & & & & \\
\hline & & & & \\
\hline
\end{tabular}


Diseño y planificación de competencias específicas en el currículum de enseñanzas profesionales de música: modalidades composición-dirección en la enseñanza superior.

Carlos Eduardo Pascual Pérez

\section{EJERCICIO 2}

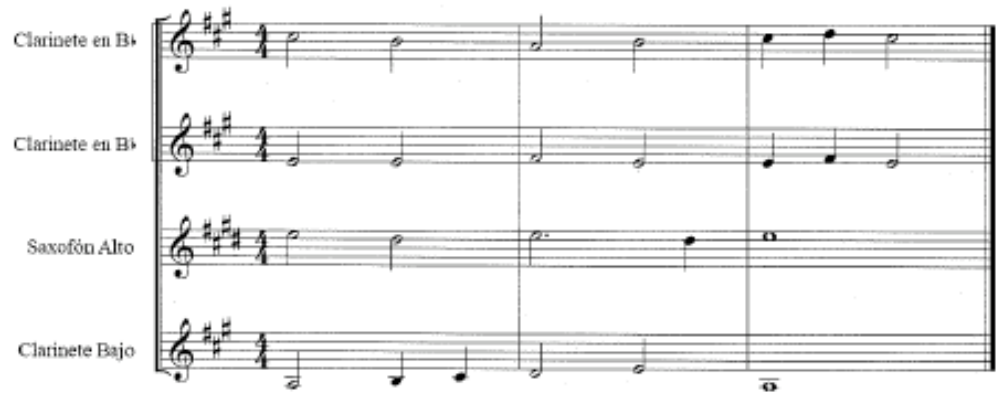

Marcar si no detectas ningún error:

\begin{tabular}{|l|l|l|l|l|}
\hline Compás & Tiempo & Instrumento/s implicado/s & Tipo de error & Observaciones \\
\hline & & & & \\
\hline & & & & \\
\hline & & & & \\
\hline & & & & \\
\hline & & & & \\
\hline & & & & \\
\hline & & & & \\
\hline
\end{tabular}

EJERCICIO 3

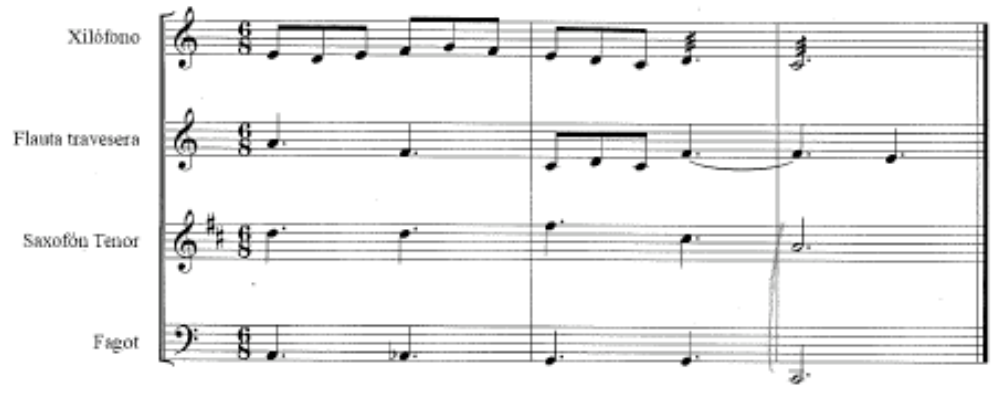

Marcar si no detectas ningún error:

\begin{tabular}{|c|c|c|c|c|}
\hline Compás & Tiempo & Instrumento/s implicado/s & Tipo de error & Observaciones \\
\hline$B$ & $\wedge$ & & & \\
\hline & & & & \\
\hline & & & & \\
\hline & & & & \\
\hline & & & & \\
\hline & & & & \\
\hline & & & & \\
\hline & & & & \\
\hline
\end{tabular}


Diseño y planificación de competencias específicas en el currículum de enseñanzas profesionales de música: modalidades composición-dirección en la enseñanza superior.

Carlos Eduardo Pascual Pérez 1 UNIVERSITAT
Diseño y planificación de competencias especificas en el curriculum de enseñanzas profesionales de música. Modalidades en la enseñanza superior.

Carios Eduardo Pascual Pérez (innestigador) - Josè Maria Peñafver Vilar (director) - Amporo Porto Novorro (tutora)

\section{TEST FINAL 1 Armonía (3 Enseñanzas Profesionales)}

Detección de errores armónicos estudiados aplicados a una plantilla instrumental

Instrucciones: Debe analizarse cada fragmento instrumental como si de una realización armónico a cuatro partes se tratase, y localizar (si los hay) errores armónicos de los que figuran en el fistado*, para seguidamente enumerarlos en la tobla de respuestas, indicando para cada error su focalización (compós y tiempo), parte/s implicado/s (instrumento/s) y tipo de error $(a, b, c, d, \ldots)$. Puede haber más de un error en un mismo tiempo, en ese caso anotarlos por separado. Si se considera, tambièn puede anotarse alguna observación.

Además, si no se detectan errores en un ejercicio, debe marcarse la casilla correspondiente. Si se desconoce o no se sabe como responder al ejercicio, dejar en blanco.

- Listado de posibles tipos de error:
a). Octovas seguidas
b) Quintas seguidas
c) Octovas directos
d) Quintas directas
e) Cruzamiento de voces
f) Superación de la separación móxima entre voces
g) Duplicación de la sensible
h) Resolución incorrecta o irresolución de la sensible
i) Resolución incorrecta o irresolución de la séptima (acordes de $7^{g}$ de dite.)
i) Ausencia de preparación de la séptima (acordes de $7^{9}$ de dte.)

Instrumento/s o especialidad/es que estás cursando o has cursado:

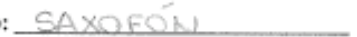

\section{EJERCICIO 1}

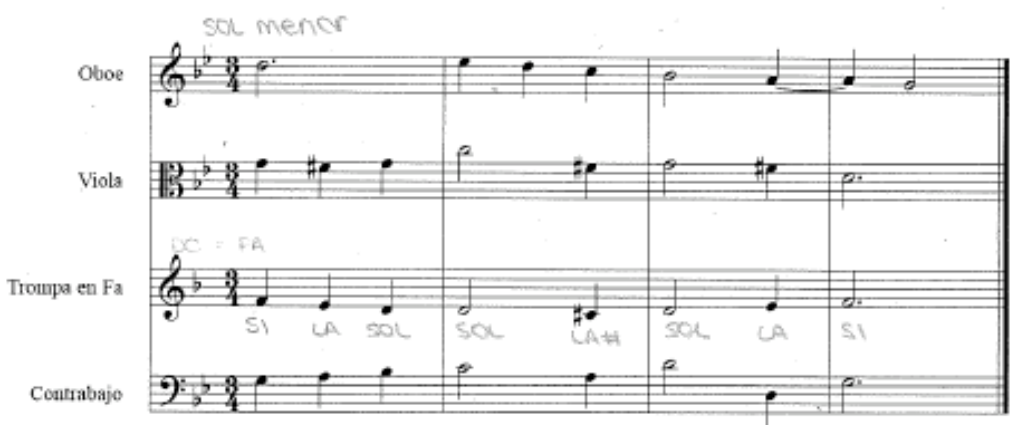

Marcar si no detectas ningún error:

\begin{tabular}{|l|l|l|l|l|}
\hline Compás & Tiempo & Instrumento/s implicado/s & Tipo de error & Observaciones \\
\hline & & & & \\
\hline & & & & \\
\hline & & & & \\
\hline & & & & \\
\hline & & & & \\
\hline & & & & \\
\hline & & & & \\
\hline & & & & \\
\hline
\end{tabular}


Diseño y planificación de competencias específicas en el currículum de enseñanzas profesionales de música: modalidades composición-dirección en la enseñanza superior.

Carlos Eduardo Pascual Pérez

\section{EJERCICIO 2}

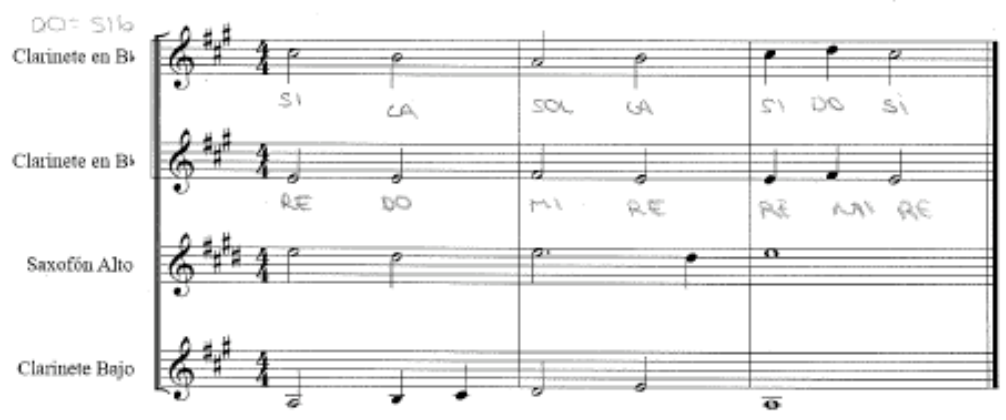

Marcar si no detectas ningún error: $\triangle$

\begin{tabular}{|l|l|l|l|l|}
\hline Compás & Tiempo & Instrumento/s implicado/s & Tipo de error & Observaciones \\
\hline & & & & \\
\hline & & & & \\
\hline & & & & \\
\hline & & & & \\
\hline & & & & \\
\hline & & & & \\
\hline & & & & \\
\hline & & & & \\
\hline
\end{tabular}

\section{EJERCICIO 3}

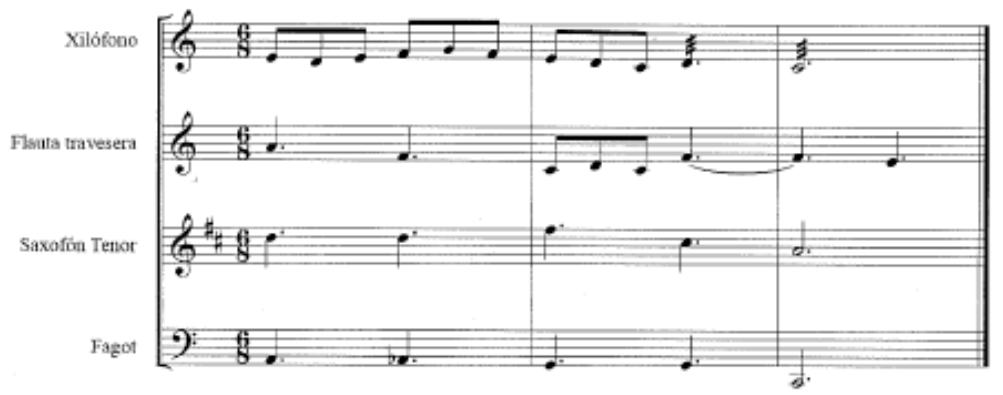

Marcar si no detectas ningún error: $X$

\begin{tabular}{|l|l|l|l|l|}
\hline Compas & Tiempo & Instrumento/s implicado/s & Tipo de error & Observaciones \\
\hline & & & & \\
\hline & & & & \\
\hline & & & & \\
\hline & & & & \\
\hline & & & & \\
\hline & & & & \\
\hline & & & & \\
\hline & & & & \\
\hline
\end{tabular}


Diseño y planificación de competencias específicas en el currículum de enseñanzas profesionales de música: modalidades composición-dirección en la enseñanza superior.

Carlos Eduardo Pascual Pérez

\section{UNIVERSITAT JAUME I}

Diseño y planificación de competencias especificas en el curriculum de enseñanzas profesionales de música. Modalidades en la enseñanza superior.

\section{TEST FINAL 1 Armonía (3 Enseñanzas Profesionales)}

Detección de errores armónicos estudiados aplicados a una plantilla instrumental

Instrucciones: Debe onolizarse cada fragmento instrumental como si de una realización armónica a cuatro partes se tratase, y localizar (si los hay) errores armónicos de las que figuran en el fistado*, para seguidamente enumerarlos en la tabla de respuestas, indicando para cada error su focalizoción (compós y tiempo), parte/s implicada $/ s$ (instrumento/s) y tipo de error $(a, b, c, d, \ldots)$. Puede haber más de un error en un mismo tiempo, en ese caso anotarlos por separado. Si se considera, tamblén puede onotorse alguna observación.

Además, si no se detectan errores en un ejercicio, debe marcarse fa casilla correspondiente. Si se desconoce o no se sabe como responder al ejercicio, dejor en blonco.

*listado de pasibles tipos de error:
a) Octavas seguidas
b) Quintas seguidos
c) Octavas directas
d) Quintas directas
e) Cruzamiento de voces
f) Superación de la separación
móxima entre voces

g) Duplicación de fa sensible

h) Resolución incorrecta o irresolución de la sensible

i) Resolución incorrecta o irresolución de la séptima (acordes de $7^{g}$ de dte.)

j) Ausencia de preparación de la séptima (acordes de $7^{9}$ de dte.)

Instrumento/s o especialidad/es que estás cursando o has cursado:

\section{EJERCICIO 1}

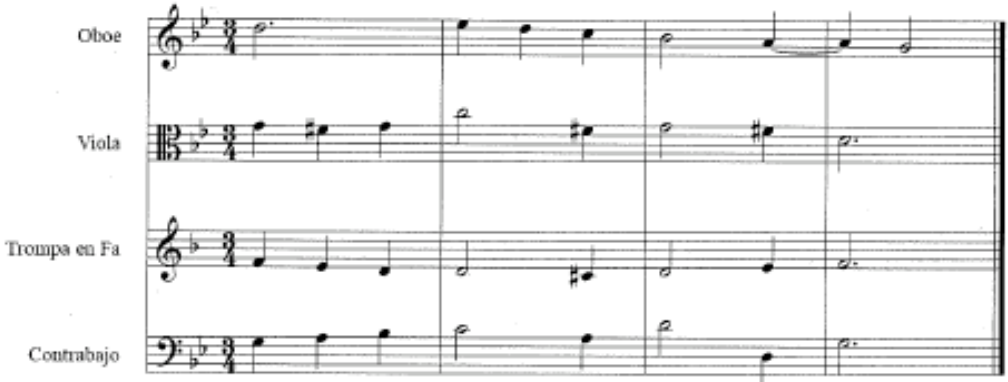

Marcar si no detectas ningún error: $\mathbb{X}$

\begin{tabular}{|l|l|l|l|l|}
\hline Compás & Tiempo & Instrumento/s implicado/s & Tipo de error & Observaciones \\
\hline & & & & \\
\hline & & & & \\
\hline & & & & \\
\hline & & & & \\
\hline & & & & \\
\hline & & & & \\
\hline & & & & \\
\hline & & & & \\
\hline
\end{tabular}


Diseño y planificación de competencias específicas en el currículum de enseñanzas profesionales de música: modalidades composición-dirección en la enseñanza superior.

Carlos Eduardo Pascual Pérez

EJERCICIO 2

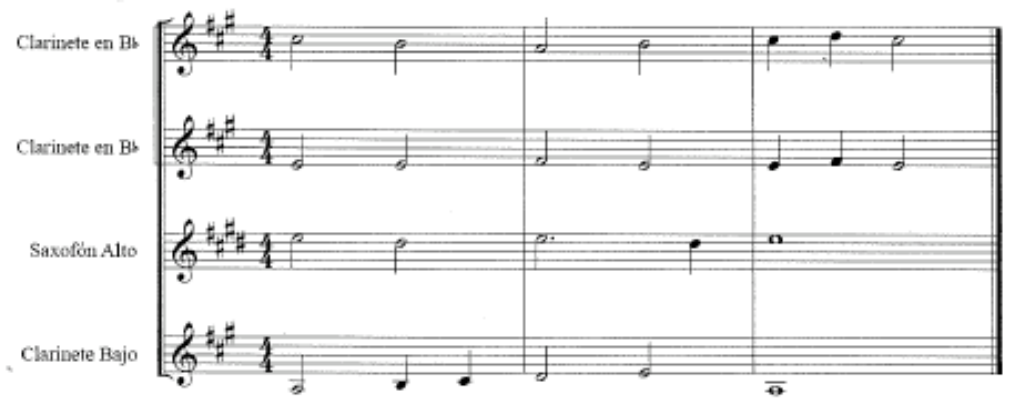

Marcar si no detectas ningún error:

\begin{tabular}{|c|c|c|c|c|}
\hline Compás & Tiempo & Instrumento/s implicado/s & Tipo de error & Observaciones \\
\hline 1 & $2-3$ & Cleriato bojo & $h$ & \\
\hline & & & & \\
\hline & & & & \\
\hline & & & & \\
\hline & & & & \\
\hline & & & & \\
\hline & & & & \\
\hline & & & & \\
\hline
\end{tabular}

\section{EJERCICIO 3}

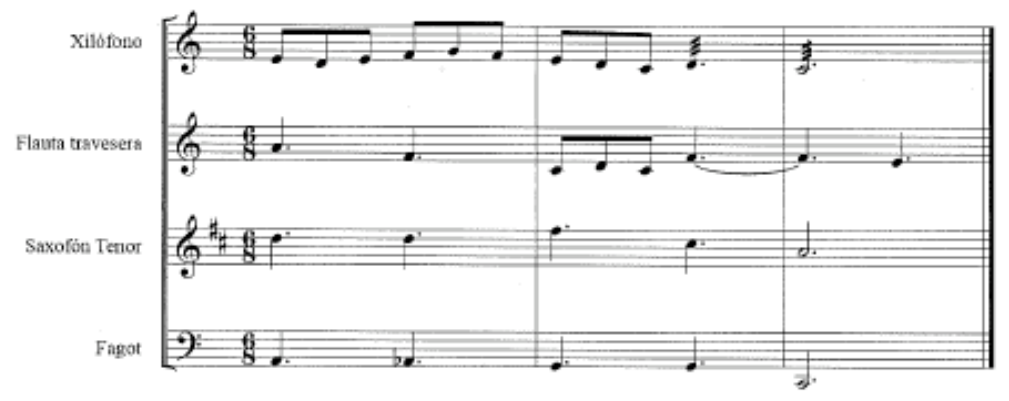

Marcar si no detectas ningún error:

\begin{tabular}{|c|c|c|c|c|}
\hline Compás & Tiempo & Instrumento/s implicado/s & Tipo de error & Observaciones \\
\hline 1 & 2 & & & \\
\hline & & & & \\
\hline & & & & \\
\hline & & & & \\
\hline & & & & \\
\hline & & & & \\
\hline & & & & \\
\hline & & & & \\
\hline
\end{tabular}


Diseño y planificación de competencias específicas en el currículum de enseñanzas profesionales de música: modalidades composición-dirección en la enseñanza superior.

Carlos Eduardo Pascual Pérez

\section{UNIVERSITAT}

Diseño y planificación de competencias especificas en el curriculum de enseñanzas profesionales de música. Modalidades en la enseñanza superior.

Carlos Eduardo Pascual Pérez (investigador) - José María Peñafver Vilar (director) - Amparo Porta Navarro (tutora)

TEST FINAL 1 Armonía (3ำ Enseñanzas Profesionales)

Detección de errores armónicos estudiados aplicados a una plantilla instrumental

Instrucciones: Debe analizarse cada fragmento instrumental como si de una realización armónica a cuatro partes se tratase, y localizar (si los hay) errores armónicos de los que figuran en el listado*, para seguidamente enumerarlos en la tabla de respuestas, indicando para cada error su localización (compós y tiempo), parte/s implicado/s (instrumento/s) y tipo de error $(a, b, c, d, \ldots)$. Puede haber mós de un error en un mismo tiempo, en ese caso anotarlos por separado. Si se considera, también puede anotarse alguna observación.

Además, si no se detectan errores en un ejercicio, debe marcarse la casilla correspondiente. Si se desconoce o no se sabe como responder al ejercicio, dejar en blanco.

*Listado de posibles tipos de error:
a) Octavas seguidas
b) Quintos seguidas
c) Octavas directas
d) Quintos directas
e) Cruzamiento de voces
f) Superación de la separación máxima entre voces

g) Duplicación de la sensible

h) Resofución incorrecta o irresolución de la sensible

i) Resolución incorrecta o irresolución de la séptima (acordes de $7^{g}$ de dte.)

j) Ausencia de preparación de la séptima (acordes de 79 de dte.)

Instrumento/s o especialidad/es que estás cursando o has cursado:

\section{EJERCICIO 1}

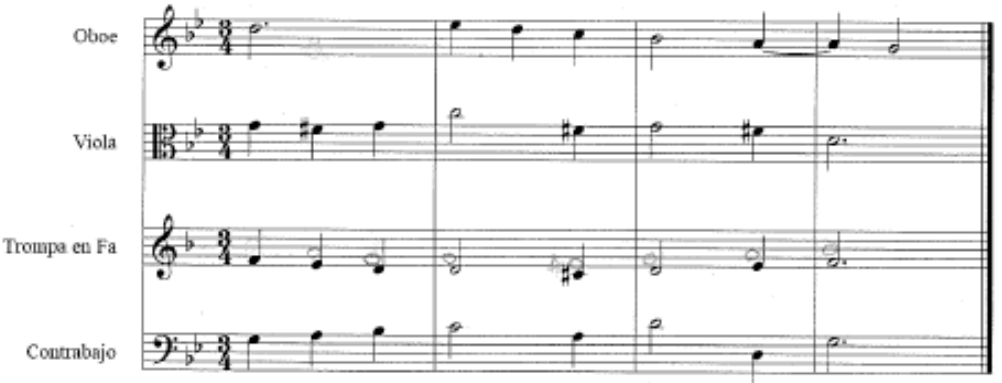

Marcar si no detectas ningún error:

\begin{tabular}{|c|c|c|c|c|}
\hline Compás & Tiempo & Instrumento/s implicado/s & Tipo de error & Observaciones \\
\hline 1 & 2 & Trompori & & Dehearie' de ' 5 \\
\hline 2 & 3 & Viola thom po & g & \\
\hline & & & & \\
\hline & & & & \\
\hline & & & & \\
\hline & & & & \\
\hline & & & & \\
\hline & 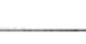 & 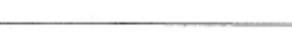 & 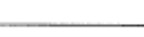 & ( \\
\hline
\end{tabular}


Diseño y planificación de competencias específicas en el currículum de enseñanzas profesionales de música: modalidades composición-dirección en la enseñanza superior.

Carlos Eduardo Pascual Pérez

\section{EJERCICIO 2}

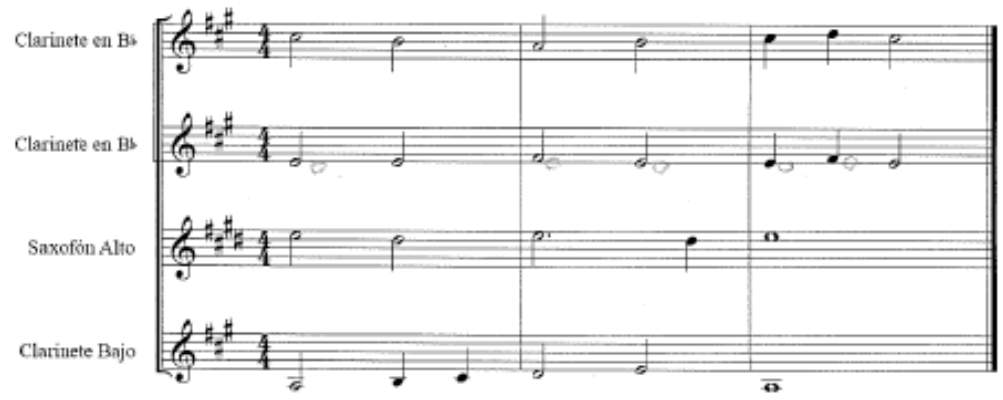

Marcar si no detectas ningún error:

\begin{tabular}{|l|l|l|l|l|}
\hline Compás & Tiempo & Instrumento/s implicado/s & Tipo de error & Observaciones \\
\hline & & & & \\
\hline & & & & \\
\hline & & & & \\
\hline & & & & \\
\hline & & & & \\
\hline & & & & \\
\hline & & & & \\
\hline
\end{tabular}

EJERCICIO 3

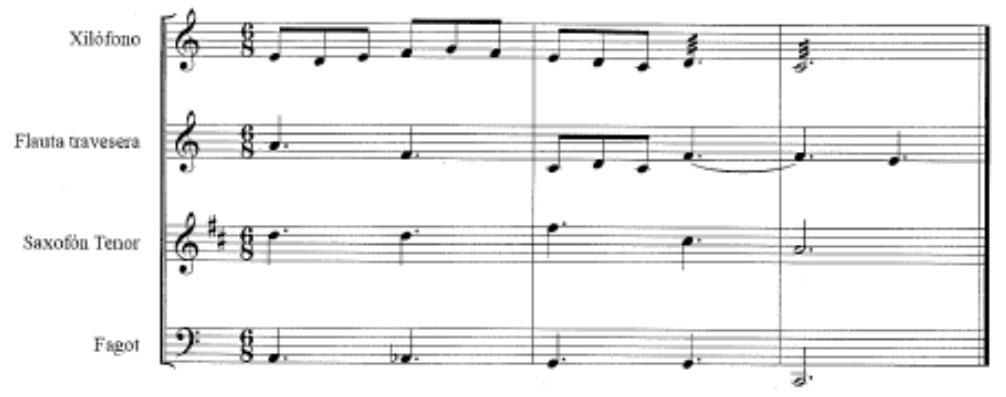

Marcar si no detectas ningún error:

\begin{tabular}{|l|l|l|l|l|}
\hline Compás & Tiempo & Instrumento/s implicado/s & Tipo de error & Observaciones \\
\hline & & & & \\
\hline & & & & \\
\hline & & & & \\
\hline & & & & \\
\hline & & & & \\
\hline & & & & \\
\hline & & & & \\
\hline & & & & \\
\hline
\end{tabular}


Diseño y planificación de competencias específicas en el currículum de enseñanzas profesionales de música: modalidades composición-dirección en la enseñanza superior.

\section{Carlos Eduardo Pascual Pérez}

U.1. UNIVERSITAT
Diseño y planificación de competencias especificas en el curriculum de enseñanzas profesionales de música. Modalidades en la enseñanza superior.

\section{TEST FINAL 1 Armonía (3 Enseñanzas Profesionales)}

Detección de errores armónicos estudiados aplicados a una plantilla instrumental

Instrucciones: Debe analizarse cada fragmento instrumental como si de una realización armónica a cuatro partes se tratase, y localizar (si las hay) errores armónicos de los que figuron en el listado*, para seguidamente enumerorios en la tabla de respuestas, indicando para cado error su locolización (compás y tiempo), parte/s implicada/s (instrumento/s) y tipo de error $(a, b, c, d, \ldots)$. Puede haber más de un error en un mismo tiempo, en ese caso anotarios por separado. Si se considera, tombién puede anotarse alguna observación.

Ademós, si no se detectan errores en un ejercicio, debe marcarse la casilla correspondiente. Si se desconoce o no se sobe como responder al ejercicio, dejar en blanco.

*Listado de posibles tipos de error:
a) Octavas seguidas
b) Quintas seguidos
c) Octavas directos
d) Quintas directas
e) Cruzamiento de voces
f) Superación de la separación máxima entre voces
g) Duplicación de lo sensible
h) Resolución incorrecta o irresolución de la sensible
i) Resolución incorrecta o irresolución de la séptima (acordes de $7^{\underline{a}}$ de dte.)
j) Ausencia de preparación de la séptima (acordes de $7^{\circ}$ de dte.)

Instrumento/s o especialidad/es que estás cursando o has cursado: $V$ boloncel

\section{EJERCICIO 1}

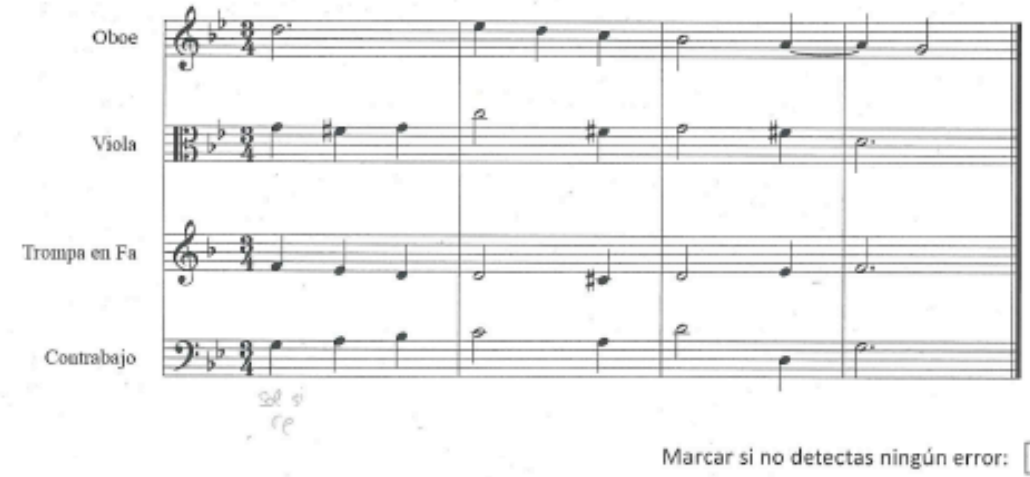

\begin{tabular}{|c|c|l|c|l|}
\hline Compás & Tiempo & Instrumento/s implicado/s & Tipo de error & Observaciones \\
\hline 1 & 1 & Trompa en Fa & $e$ & \\
\hline 1 & 2 & Trompa en Fa & $e$ & \\
\hline 2 & 1 & Trompa en Fa & $e$ & \\
\hline 2 & 2 & Trompa en Fa & $e$ & \\
\hline 3 & 1 & Trompa en Fa & $e$ & \\
\hline 3 & 2 & Trompa en Fa & $e$ & \\
\hline 4 & 1 & Trompa en Fa & $e$ & \\
\hline 4 & 2 & Trompa en Fa & $e$ & \\
\hline
\end{tabular}


Diseño y planificación de competencias específicas en el currículum de enseñanzas profesionales de música: modalidades composición-dirección en la enseñanza superior.

Carlos Eduardo Pascual Pérez

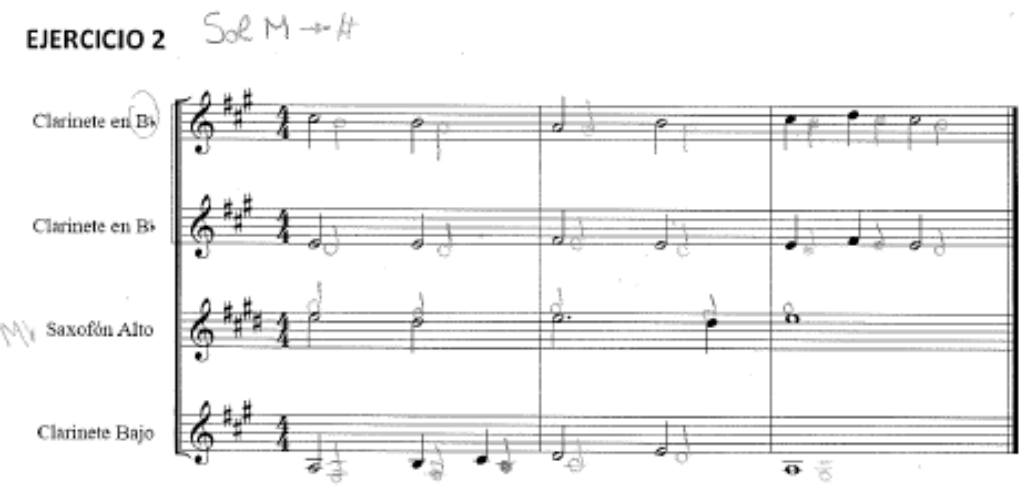

Marcar si no detectas ningún error:

\begin{tabular}{|c|c|c|c|c|}
\hline Compás & Tiempo & Instrumento/s implicado/s & Tipo de error & Observaciones \\
\hline 1 & 1 & Qoninete en $\mathrm{Bb}$ & e & \\
\hline 1 & 2 & Carinete n Bb & e & \\
\hline 2 & 1 & Cearinele en $B b$ & $e$ & \\
\hline 2 & 2 & Coarinete en Bb & e & \\
\hline 3 & $\lambda$ & contingte ex Bb & $e$ & \\
\hline 3 & 2 & Conincte en Bb & e & \\
\hline & & & & \\
\hline & & & & \\
\hline
\end{tabular}

\section{EJERCICIO 3}

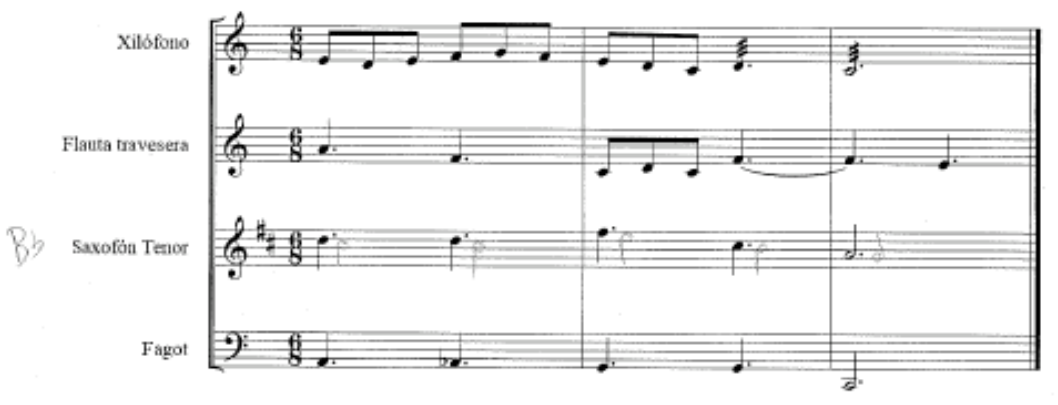

Marcar si no detectas ningún error:

\begin{tabular}{|c|c|c|c|c|}
\hline Compás & Tiempo & Instrumento/s implicado/s & Tipo de error & Observaciones \\
\hline 1 & 1 & Saxofón Tenor & $e$ & \\
\hline 1 & 2 & Sarofón Tenor & $e$ & \\
\hline 2 & 1 & Saxofón Tenor & $e$ & \\
\hline 2 & 2 & Saxofón Tenor & $e$ & \\
\hline 3 & 1 & Saxofón Tenor & $e$ & \\
\hline 3 & 2 & Saxofón Tenor & $e$ & \\
\hline & & & & \\
\hline & & & & \\
\hline
\end{tabular}


Diseño y planificación de competencias específicas en el currículum de enseñanzas profesionales de música: modalidades composición-dirección en la enseñanza superior.

Carlos Eduardo Pascual Pérez

\section{TEST FINAL 1 Armonía (3 Enseñanzas Profesionales)}

Detección de errores armónicos estudiados aplicados a una plantilla instrumental

Instrucciones: Debe analizarse cada fragmento instrumental como si de una realización armónica a cuatro partes se tratase, y localizar (si los hay) errores armónicos de las que figuran en el listado*, para seguidamente enumerarlos en la tabla de respuestas, indicando para cada error su localización (compós y tiempo), parte/s implicada/s (instrumento/s) y tipo de error $(a, b, c, d, \ldots)$. Puede haber más de un error en un mismo tiempo, en ese caso anotorlos por separado. Si se considera, también puede anotorse alguna observación

Ademós, si no se detectan errores en un ejercicio, debe marcarse la casilla correspondiente. Si se desconoce o no se sabe como responder al ejercicio, dejar en blanco.

-Listado de posibles tipos de error:
a) Octavas seguidas
b) Quintas seguidas
c) Octavas directas
d) Quintas directos
e) Cruzamiento de voces
f) Superación de la separación máxima entre voces
g) Duplicación de la sensible
h) Resolución incorrecto o irresolución de la sensible
i) Resolución incorrecto o irresolución de la séptima (acordes de $7^{2}$ de dte.)
j) Ausencia de preparación de la séptima (acordes de 79 de ate.)

Instrumento/s o especialidad/es que estás cursando o has cursado:

\section{EJERCICIO 1}

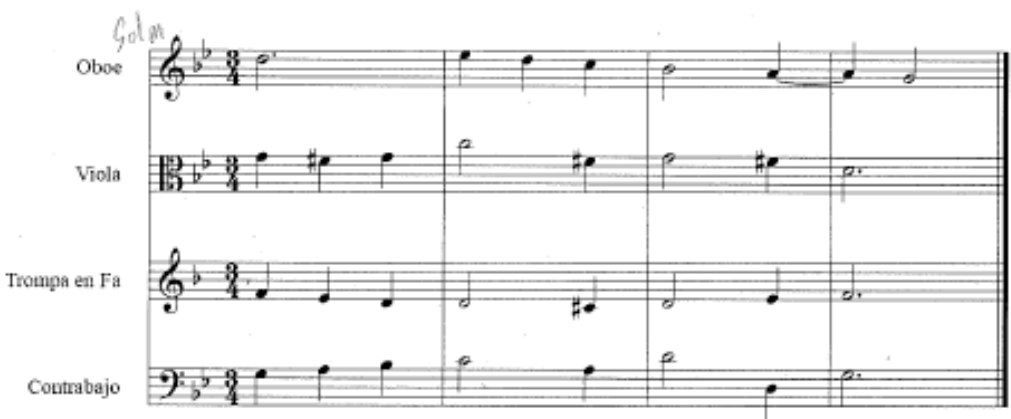

Marcar si no detectas ningún error:

\begin{tabular}{|c|c|c|c|c|}
\hline Compás & Tiempo & Instrumento/s implicado/s & Tipo de error & Observaciones \\
\hline 1 & 3 & 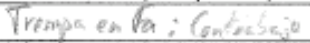 & b) & \\
\hline 2 & 3 & Viola; Trampa en Fa & g) & \\
\hline 2 & 2 & Viola: Contraboir & a) & \\
\hline 3 & 1 & Oboe & $i^{2}$ & \\
\hline & & & & \\
\hline & & & & \\
\hline & & & & \\
\hline
\end{tabular}


Diseño y planificación de competencias específicas en el currículum de enseñanzas profesionales de música: modalidades composición-dirección en la enseñanza superior.

Carlos Eduardo Pascual Pérez

\section{EJERCICIO 2}

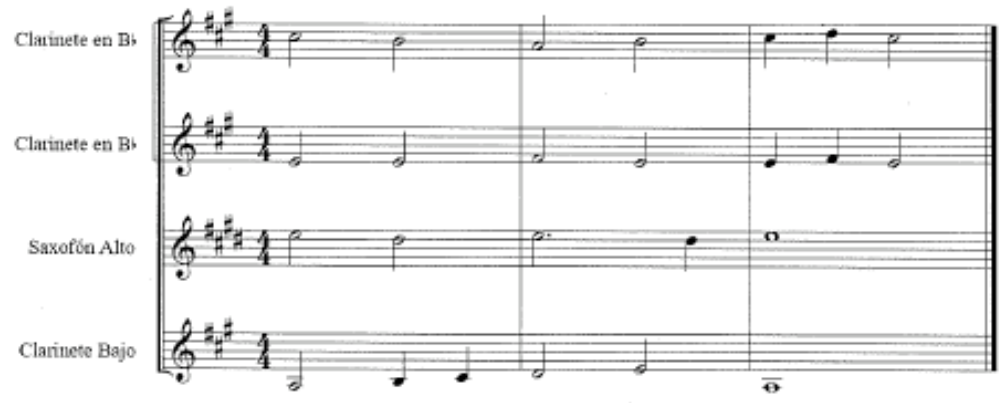

Marcar si no detectas ningún error:

\begin{tabular}{|l|l|l|l|l|}
\hline Compás & Tiempo & Instrumento/s implicado/s & Tipo de error & Observaciones \\
\hline & & & & \\
\hline & & & & \\
\hline & & & & \\
\hline & & & & \\
\hline & & & & \\
\hline & & & & \\
\hline & & & & \\
\hline & & & & \\
\hline
\end{tabular}

EJERCICIO 3

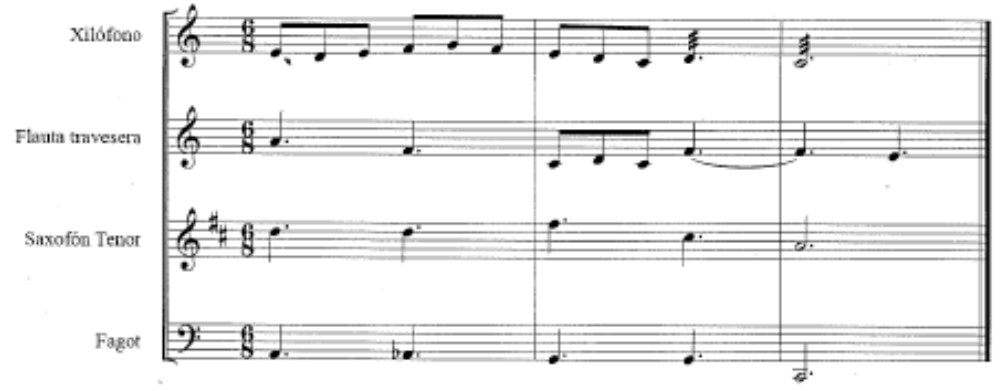

Marcar si no detectas ningún error:

\begin{tabular}{|l|l|l|l|l|}
\hline Compás & Tiempo & Instrumento/s implicado/s & Tipo de error & Observaciones \\
\hline & & & & \\
\hline & & & & \\
\hline & & & & \\
\hline & & & & \\
\hline & & & & \\
\hline & & & & \\
\hline & & & & \\
\hline
\end{tabular}


Diseño y planificación de competencias específicas en el currículum de enseñanzas profesionales de música: modalidades composición-dirección en la enseñanza superior.

Carlos Eduardo Pascual Pérez

Diseño y planificación de competencias especificas en el currículum de enseñanzas profesionales de música. Modalidades en la enseñanza superior.

Carlos Eduardo Pascual Pérez (investigador) - José Maria Peñalver Vilar (director) - Amparo Porta Navarro (tutora)

\section{TEST FINAL 1ㅇ Armonía (3ำ Enseñanzas Profesionales)}

Detección de errores armónicos estudiados aplicados a una plantilla instrumental

Instrucciones: Debe anolizarse cada fragmento instrumental como si de una realización armónica a cuatro partes se tratase, y localizar (si los hay) errores armónicos de los que figuran en el listado*, para seguidamente enumerarlos en fa tabla de respuestas, indicando para coda error su localización (compós y tiempol, parte/s implicada/s (instrumento/s) y tipo de error $(a, b, c, d, \ldots)$. Puede haber más de un error en un mismo tiempo, en ese caso anotorlos por separado. Si se considera, también puede anotarse alguna observación.

Además, si no se detectan errores en un ejercicio, debe marcarse la cosilla correspondiente. Si se desconoce o no se sabe como responder al ejercicio, dejar en blanco.

* Listado de posibles tipos de error:
a) Octavas seguidas
b) Quintas seguidas
c) Octavos directos
d) Quintos directas
e) Cruzamiento de voces
f) Superación de la separación móxima entre voces
g) Duplicación de lo sensible
h) Resolución incorrecta o irresolución de la sensible
i) Resolución incorrecto o irresofución de la séptima (acordes de $7^{\mathrm{g}}$ de dte.)
i) Ausencia de preparación de la séptima (ocordes de $7^{\text {g }}$ de dte.)

Instrumento/s o especialidad/es que estás cursando o has cursado:

\section{EJERCICIO 1}

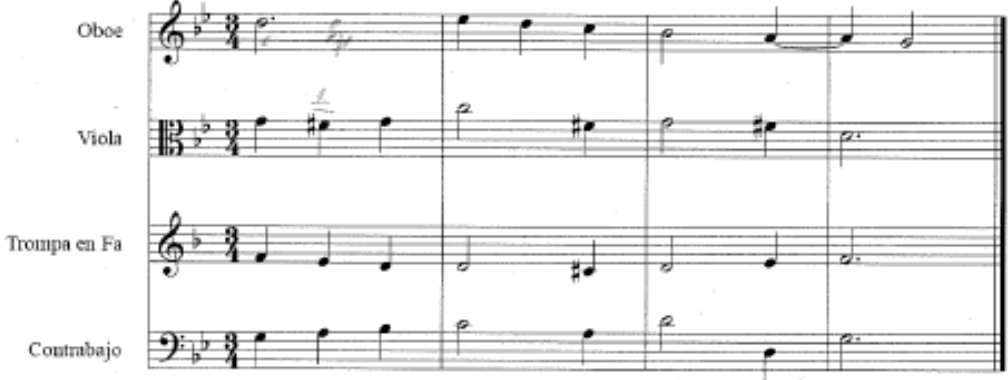

Marcar si no detectas ningún error:

\begin{tabular}{|c|c|c|c|c|}
\hline Compás & Tiempo & Instrumento/s implicado/s & Tipo de error & Observaciones \\
\hline 1 & tots & VOLA - TRUMPA & $E$ & - \\
\hline 2 & tols & VIOLA-TRonlen & $E$ & - \\
\hline 3 & To7s & VYOA - TROHPA & E & - \\
\hline 4 & 7515 & VIULA - TROMAA & E & - \\
\hline & & & & \\
\hline & & & & \\
\hline & & & & \\
\hline
\end{tabular}


Diseño y planificación de competencias específicas en el currículum de enseñanzas profesionales de música: modalidades composición-dirección en la enseñanza superior.

Carlos Eduardo Pascual Pérez

\section{EJERCICIO 2}

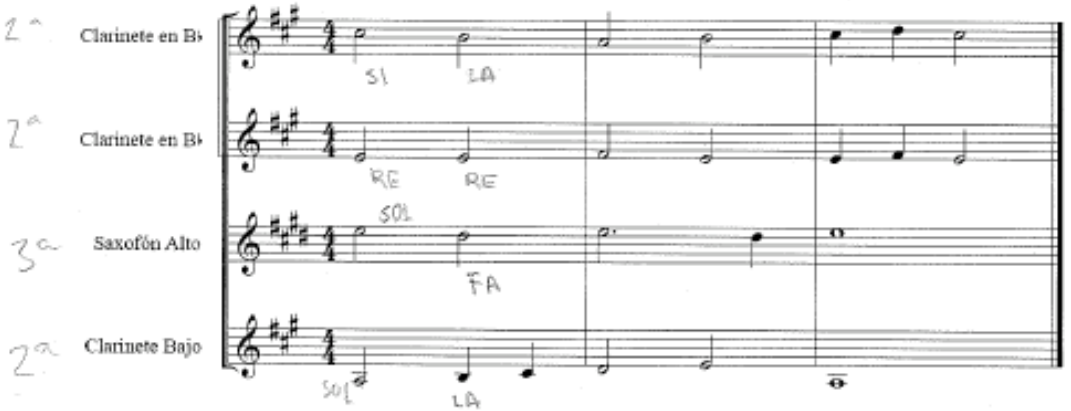

Marcar si no detectas ningún error:

\begin{tabular}{|c|c|c|c|c|}
\hline Compás & Tiempo & Instrumento/s implicado/s & Tipo de error & Observaciones \\
\hline 1 & 1 & SAX ALT - CLAR B b & $E$ & \\
\hline 1 & 2 & SAX BLT CLARBb & $E$ & \\
\hline 2 & & TOT & $E$ & \\
\hline 3 & & TOT & & \\
\hline & & & & \\
\hline & & & & \\
\hline & & & & \\
\hline
\end{tabular}

EJERCICIO 3

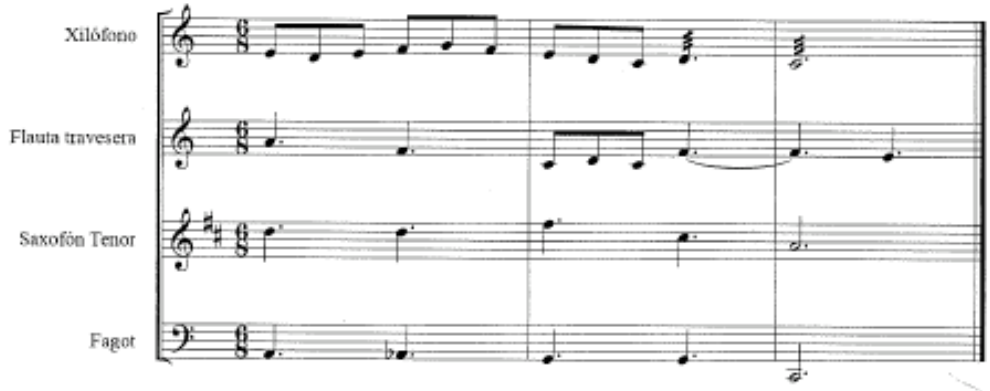

Marcar si no detectas ningún error:

\begin{tabular}{|c|c|c|c|c|}
\hline Compás & Tiempo & Instrumento/s implicado/s & Tipo de error & Observaciones \\
\hline 1 & & SAX T - FLAU & $E$ & \\
\hline 2 & & 1 & $E$ & \\
\hline 3 & & 1 & $E$ & \\
\hline & & & & \\
\hline & & & & \\
\hline & & & & \\
\hline & & & & \\
\hline & & & & \\
\hline
\end{tabular}


Diseño y planificación de competencias específicas en el currículum de enseñanzas profesionales de música: modalidades composición-dirección en la enseñanza superior.

Carlos Eduardo Pascual Pérez

\section{UNIVERSITAT}

Diseño y planificación de competencias especificas en el curriculum de enseñanzas profesionales de música. Modalidades en la enseñanza superior.

Corios Eduardo Pascual Pérez (îmestigadar) - José Maria Peñaiver Vilar (divector) - Amparo Parto Navarro (tutora)

TEST FINAL 1을 Armonía (3ำ Enseñanzas Profesionales)

Detección de errores armónicos estudiados aplicados a una plantilla instrumental

Instrucciones: Debe analizarse cada frogmento instrumental como si de una reafización armónica a cuatro partes se tratase, y localizar (si los hay) errores armónicos de los que figuran en el listado*, para seguidamente enumerarios en la tabla de respuestas, indicando para cada error su locolización (compás y tiempo), parte/s implicada/s (instrumento/s) y tipo de error $(a, b, c, d, \ldots)$. Puede haber más de un error en un mismo tiempo, en ese caso anotarlos por separodo. Si se considera, también puede onotorse alguna observación.

Además, si no se detectan errores en un ejercicio, debe marcarse la casilila correspondiente. Si se desconoce o no se sabe como respander of ejercicio, dejar en blanco.

* Listado de posibles tipos de error:
a) Octavas seguidas
b) Quintos seguidas
c) Octavos directas
d) Quintos directos
e) Cruzamiento de voces
f) Superación de la separación móxima entre voces
g) Duplicación de la sensible
Resolución incorrecto o irresolución de ia sensible
1) Resolución incorrecto o irresalución de la séptima (acordes de 79 de dé.)
j) Ausencia de preporación de la séptima (acordes de 79 de dte.)

Instrumento/s o especialidad/es que estás cursando o has cursado: piono

\section{EJERCICIO 1}

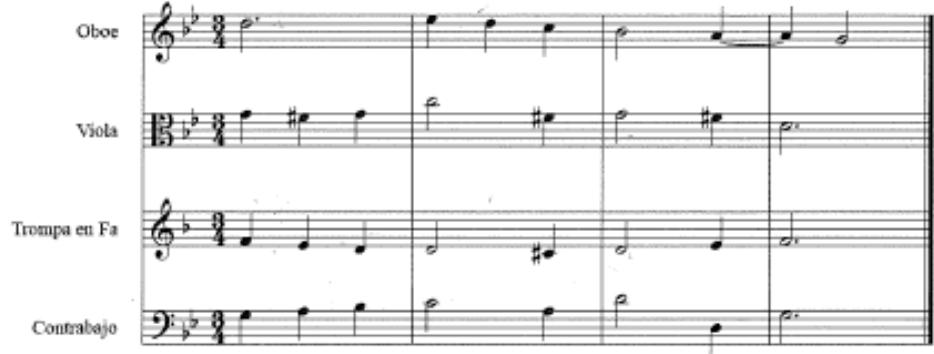

Marcar si no detectas ningún error:

\begin{tabular}{|c|c|c|c|c|}
\hline Compás & Tiempo & Instrumento/s implicado/s & Tipo de error & Observaciones \\
\hline 1 & $\Delta$ & Contraboj & $e$ & \\
\hline 3 & 3 & Violc & $i$ & \\
\hline & & & & \\
\hline & & & & \\
\hline & & & & \\
\hline & & & & \\
\hline & & & & \\
\hline & & & & \\
\hline
\end{tabular}


Diseño y planificación de competencias específicas en el currículum de enseñanzas profesionales de música: modalidades composición-dirección en la enseñanza superior.

Carlos Eduardo Pascual Pérez

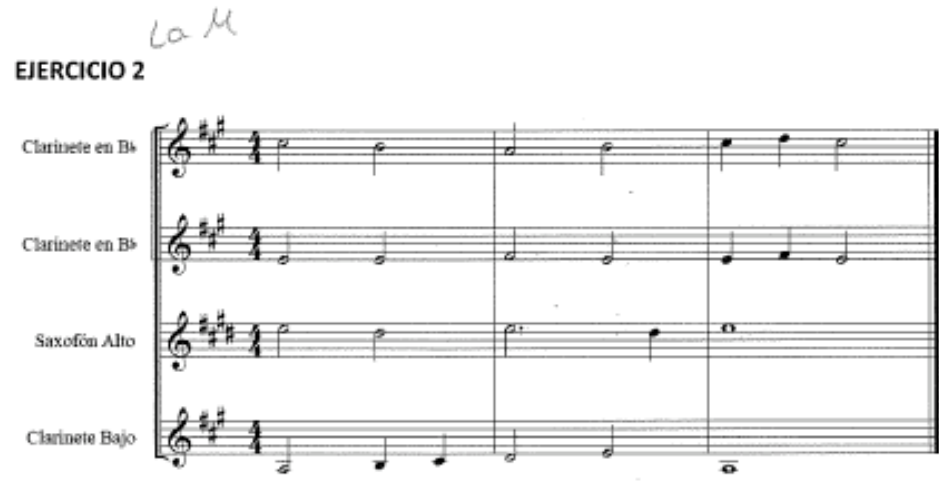

Marcar si no detectas ningún error: $\bigotimes$

\begin{tabular}{|l|l|l|l|l|}
\hline Compás & Tiempo & Instrumento/s implicado/s & Tipo de error & Observaciones \\
\hline & & & & \\
\hline & & & & \\
\hline & & & & \\
\hline & & & & \\
\hline & & & & \\
\hline & & & & \\
\hline & & & & \\
\hline & & & & \\
\hline
\end{tabular}

EJERCICIO 3

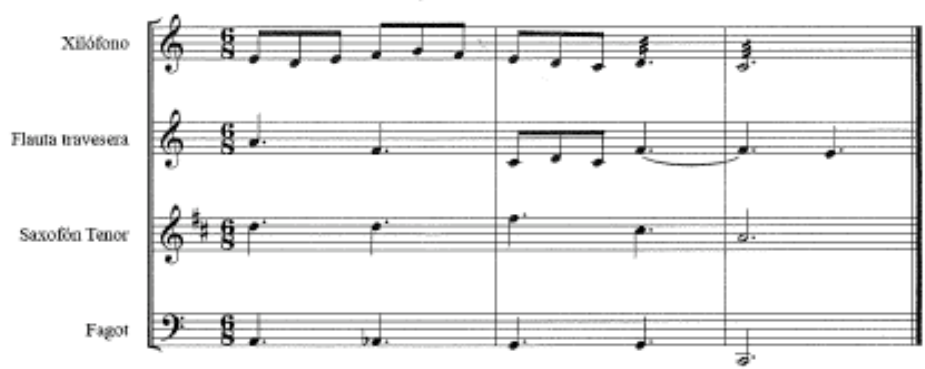

Marcar si no detectas ningún error:

\begin{tabular}{|c|c|c|c|c|}
\hline Compás & Tiempo & Instrumento/s implicado/s & Tipo de error & Observaciones \\
\hline 2 & 1 & sazopan Feafle $4 y_{i}$ & $b$ & \\
\hline 2 & 1 & xib/ono/ FT & $c$ & \\
\hline & & & & \\
\hline & & & & \\
\hline & & & & \\
\hline & & & & \\
\hline & & & & \\
\hline & & & & \\
\hline
\end{tabular}


Diseño y planificación de competencias específicas en el currículum de enseñanzas profesionales de música: modalidades composición-dirección en la enseñanza superior.

Carlos Eduardo Pascual Pérez Modalidodes en la ensefianza superior.

Carios Eduardo Pascual Pérez (investigador) - José Maria Peñalver Villar (director) - Amparo Porto Navarro (tutoro)

\section{TEST FINAL 1 Armonía (3ำ Enseñanzas Profesionales)}

Detección de errores armónicos estudiados aplicados a una plantilla instrumental

Instrucciones: Debe analizarse cada fragmento instrumental como si de una realización armónico a cuatro portes se tratase, y localizar (si Ios hay) errores armónicos de los que figuran en el listado*, pora seguidamente enumerarios en la tabia de respuestas, indicando para cada error su localización (compás y tiempo), parte/s implicada/s (instrumento/s) y tipo de error $(a, b, c, d, \ldots)$. Puede haber más de un error en un mismo tiempo, en ese coso anotarios por separado. Si se considero, también puede anotarse alguno observación.

Ademós, si no se detectan errores en un ejercicio, debe marcarse la casilla correspandiente. Si se desconoce o no se sabe como responder al ejercicio, dejar en blanco.

*Listodo de posibles tipos de error:
a) Octavas seguidas
b) Quintas seguidos
c) Octavas directos
d) Quintas directos
e) Cruzamiento de voces
f) Superación de la separación múxima entre voces

g) Duplicación de la sensible

b) Resolución incarrecta o irresolución

de la sensible

i) Resolución incorrecta o irresolución de la séptima (ocordes de 7 ㅁ de dte.)

i) Ausencia de preparoción de la séptima (ocordes de $7^{9}$ de dite.)

Instrumento/s o especialidad/es que estás cursando o has cursado:

\section{EJERCICIO 1}

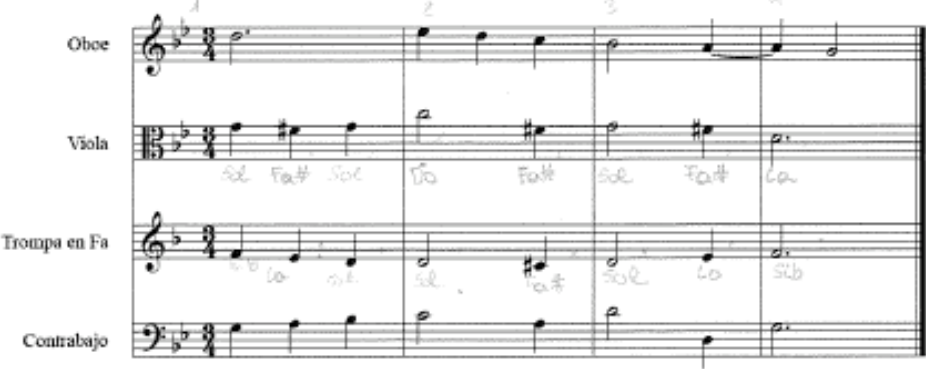

Marcar si no detectas ningún error:

\begin{tabular}{|c|c|c|c|c|}
\hline Compás & Tiempo & Instrumento/s implicado/s & Tipo de error & Observaciones \\
\hline 4 & codo & Oboe / Vino & $e$ & \\
\hline 2 & 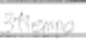 & Wiolo / iromace & $a_{2}$ & \\
\hline 3 & $1 / 245$ & Volo Tromien & $a_{m}$ & \\
\hline 2 & 3 kences & vion /Obne & $b$ & \\
\hline 3 & $679+40$ & Dboe yicpa & 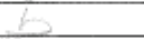 & \\
\hline & & & & \\
\hline & & & & \\
\hline & & & & \\
\hline
\end{tabular}


Diseño y planificación de competencias específicas en el currículum de enseñanzas profesionales de música: modalidades composición-dirección en la enseñanza superior.

Carlos Eduardo Pascual Pérez

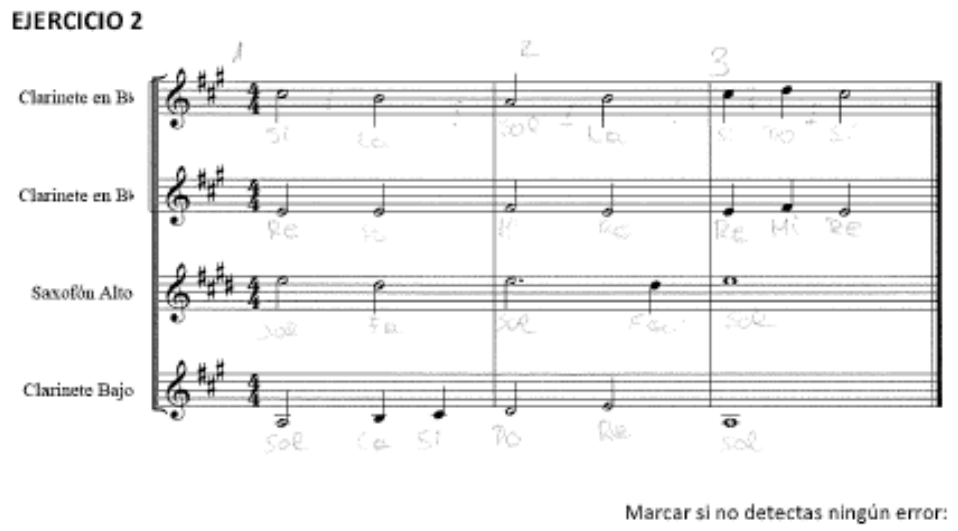

\begin{tabular}{|c|c|c|c|c|}
\hline Compás & Tiempo & Instrumento/s implicado/s & Tipo de error & Observaciones \\
\hline 1 & 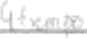 & harinete Baio/Saxo & $b$ & \\
\hline 2 & Shiens & $1 / \geqslant / 1$ & $b$ & \\
\hline & & & & \\
\hline & & & & \\
\hline & & & & \\
\hline & & & & \\
\hline & & & & \\
\hline & & & & \\
\hline
\end{tabular}

\section{EJERCICIO 3}

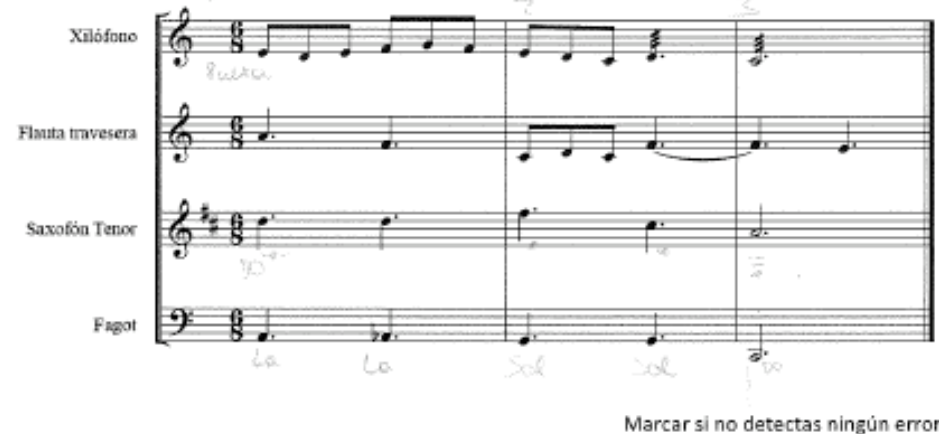

\begin{tabular}{|c|c|c|c|c|}
\hline Compás & Tiempo & Instrumento/s implicado/s & Tipo de error & Observaciones \\
\hline 2 & 2 thind & Soxo/foont & $b$ & \\
\hline 3 & $T_{W A O}$ & $x<y$ & $b$ & \\
\hline 3 & Ifienter & tondo $/ x_{10}$ & $a$ & \\
\hline 2 & $f+a_{20}$ & 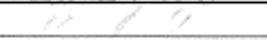 & $a_{2}$ & \\
\hline & & & & \\
\hline & & & & \\
\hline & & & & \\
\hline & & & & \\
\hline
\end{tabular}


Diseño y planificación de competencias específicas en el currículum de enseñanzas profesionales de música: modalidades composición-dirección en la enseñanza superior.

Carlos Eduardo Pascual Pérez

\section{UNIVERSITAT}

Diseño y planificación de competencias especificas en el curriculum de enseñanzas profesionales de música. Modolidades en la enseñanza superior.

Corios Eduordo Poscual Pérez (investigodar) - jasé Moríg Peñolver Vilor (diliector) - Amparo Parto Navarro (tutoro)

\section{TEST FINAL 1 Armonía (3 Enseñanzas Profesionales)}

Detección de errores armónicos estudiados aplicados a una plantilla instrumental

Instrucciones: Debe anafizarse cada fragmento instrumental como si de una realizoción armónica a cuatro partes se tratase, y locolizar (si los hay) errores amónicas de los que figuran en el listado*, para seguildamente enumerarios en la tabla de respuestas, indicando para cada error su lacalización (compás y tiempo), parte/s implicada/s (instrumento/s) y tipo de error $(a, b, c, d, \ldots)$. Puede haber más de un error en un mismo tiempo, en ese caso anotarios por separado. Si se considera, también puede anotarse alguna observación.

Además, si no se detecton errores en un efercicio, debe marcarse fo casillla correspandiente. Si se desconoce o no se sabe como responder al ejercicio, dejar en bianco.

"Listado de posibles tipos de errar:
a) Octavas seguidas
b) Quintos seguidas
c) Octavas directas
d) Quintas directas
e) Cruzamiento de vaces
f Superoción de la separación máximo entre vaces

g) Duplicación de la sensible

h) Resolución incorrecto o irresolución de la sensible

i) Resolución incorrecta o irresolución de la séptima lacordes de $7^{9}$ de dte.

i) Ausencia de preparoción de la séptima (acordes de $7^{g}$ de dte.)

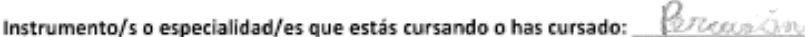

\section{EJERCICIO 1}

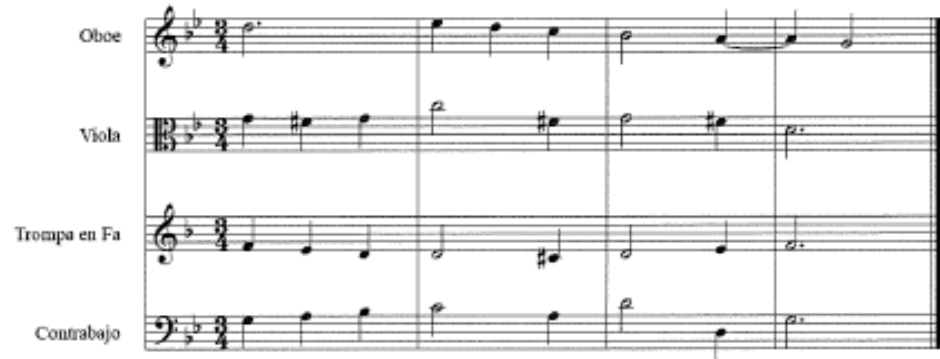

Marcar si no detectas ningún error:

\begin{tabular}{|c|c|c|c|c|}
\hline Compás & Tiempo & Instrumento/s implicado/s & Tipo de error & Observaciones \\
\hline 3 & 1 & Villa / Tampe & a & \\
\hline & & & & \\
\hline & & & & \\
\hline & & & & \\
\hline & & & & \\
\hline & & & & \\
\hline & & & & \\
\hline & & & & \\
\hline
\end{tabular}


Diseño y planificación de competencias específicas en el currículum de enseñanzas profesionales de música: modalidades composición-dirección en la enseñanza superior.

Carlos Eduardo Pascual Pérez

EJERCICIO 2

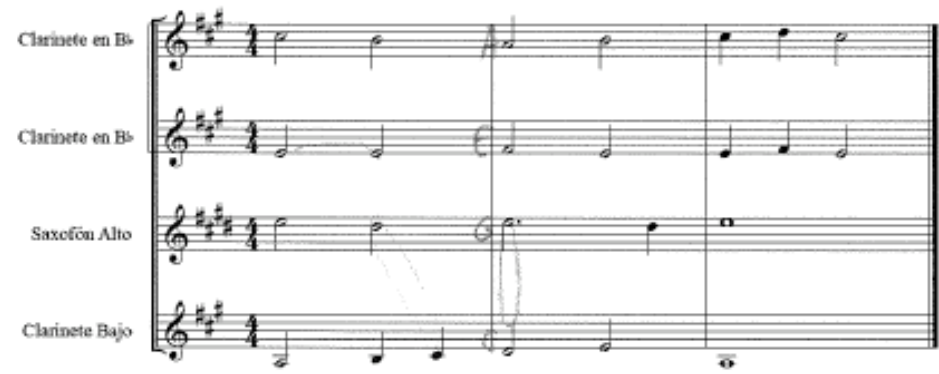

Marcar si no detectas ningún erro:

\begin{tabular}{|c|c|c|c|c|}
\hline Compás & Tiempo & Instrumento/s implicado/s & Tipo de error & Observaciones \\
\hline & 1 & & 6 & \\
\hline & & & & \\
\hline & & & & \\
\hline & & & & \\
\hline & & & & \\
\hline & & & & \\
\hline & & & & \\
\hline & & & & \\
\hline
\end{tabular}

EJERCICIO 3

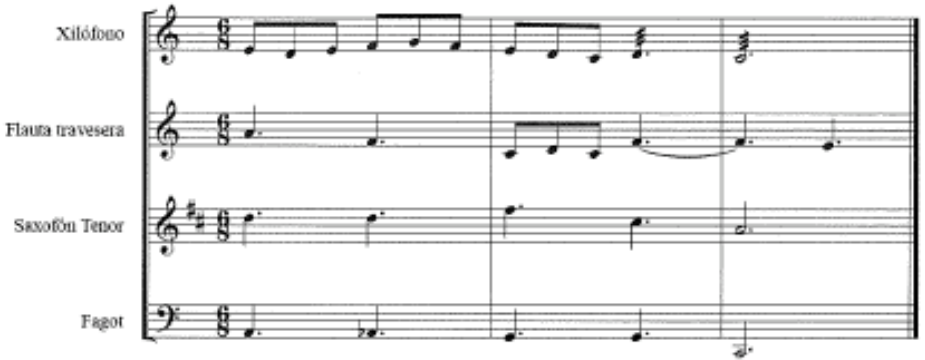

Marcar si no detectas ningún error:

\begin{tabular}{|c|c|c|c|c|}
\hline Compás & Tiempo & Instrumento/s implicado/s & Tipo de error & Observaciones \\
\hline 2 & 4 & Xeater / Pinda & $a$ & \\
\hline & & & & \\
\hline & & & & \\
\hline & & & & \\
\hline & & & & \\
\hline & & & & \\
\hline & & & & \\
\hline & & & & \\
\hline
\end{tabular}


Diseño y planificación de competencias específicas en el currículum de enseñanzas profesionales de música: modalidades composición-dirección en la enseñanza superior.

Carlos Eduardo Pascual Pérez

\section{UNIVERSITAT}

Diseño y planificación de competencias especificas en el currículum de enseñanzas profesionales de música. Modalidades en la enseñanzo superior.

Carlas Eduardo Pascual) Pérez (inwestigador) - José Maria Pefíaiver Vilar (director) - Amparo Porta Navarro (tutora)

TEST FINAL 1 Armonía (3 Enseñanzas Profesionales)

Detección de errores armónicos estudiados aplicados a una plantilla instrumenta

Instrucciones: Debe analizarse cada fragmento instrumental como si de una realización armónica a cuatro portes se tratase, y focalizar (si los hay) errares armónicos de los que figuran en el listodo*, para sequidamente enumerarlos en la tabla de respuestas, indicondo para cada error su lacalización (compás y tiempo), parte/s implicada/s (instrumento/s) y tipo de error $(a, b, c, d, \ldots)$. Puede haber más de un error en un mismo tiempo, en ese caso anotarios por separado. Si se considera, también puede anotarse alguna observación.

Además, sij no se detecton errores en un ejercicio, debe marcarse la cosilla correspondiente. Si se desconoce o no se sabe como responder al ejercicio, dejar en blanco.

*Listado de posibles tipos de error:
a) Octavas seguidas
b) Quintas seguidas
c) Octavas directos
d) Quintas directos
e) Cruzamiento de voces
f) Superación de la separación móximg entre voces

g) Duplicación de la sensible

h) Resolución incorrecta o irresolución

de la sensible

i) Resolución incorrecta o irresolución de la séptima lacordes de $7^{\prime}$ de dite.)

1) Ausencia de preparación de la séptima (acordes de 79 de dite.)

Instrumento/s o especialidad/es que estás cursando o has cursado:

\section{EJERCICIO 1}

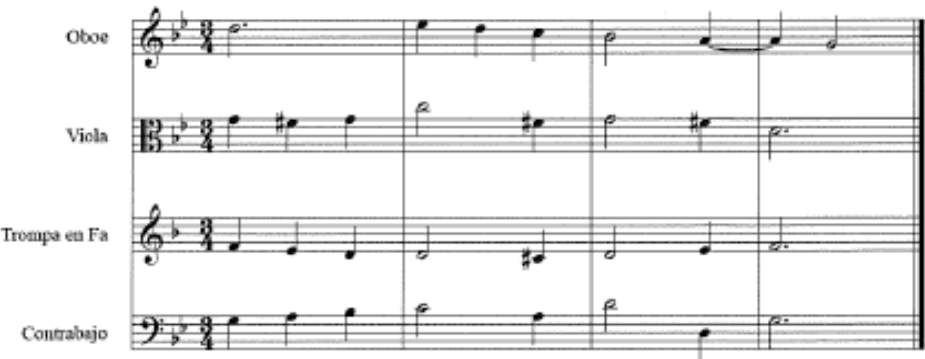

Marcar si no detectas ningún error:

\begin{tabular}{|l|l|l|l|l|}
\hline Compás & Tiempo & Instrumento/s implicado/s & Tipo de error & Observaciones \\
\hline & & & & \\
\hline & & & & \\
\hline & & & & \\
\hline & & & & \\
\hline & & & & \\
\hline & & & & \\
\hline & & & & \\
\hline & & & & \\
\hline
\end{tabular}


Diseño y planificación de competencias específicas en el currículum de enseñanzas profesionales de música: modalidades composición-dirección en la enseñanza superior.

Carlos Eduardo Pascual Pérez

EJERCICIO 2

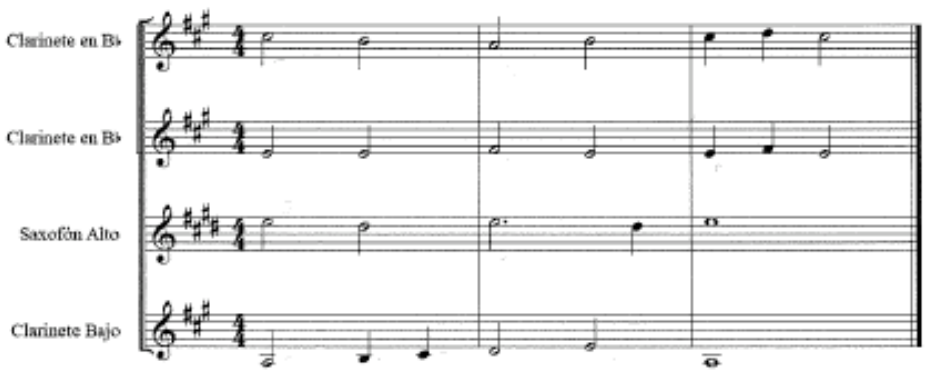

Marcar si no detectas ningún error:

\begin{tabular}{|l|l|l|l|l|}
\hline Compás & Tiempo & Instrumento/s implicado/s & Tipo de error & Observaciones \\
\hline & & & & \\
\hline & & & & \\
\hline & & & & \\
\hline & & & & \\
\hline & & & & \\
\hline & & & & \\
\hline & & & & \\
\hline & & & & \\
\hline
\end{tabular}

\section{EERCICIO 3}

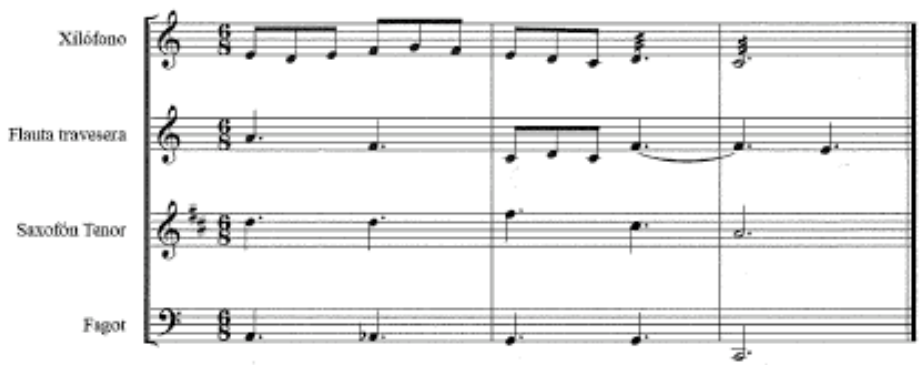

Marcar si no detectas ningún error:

\begin{tabular}{|l|c|c|l|l|}
\hline Compás & Tiempo & Instrumento/s implicado/s & Tipo de error & Observaciones \\
\hline 2 & 2 & $y$ & & \\
\hline & & & & \\
\hline & & & & \\
\hline & & & & \\
\hline & & & & \\
\hline & & & & \\
\hline & & & & \\
\hline & & & & \\
\hline
\end{tabular}


Diseño y planificación de competencias específicas en el currículum de enseñanzas profesionales de música: modalidades composición-dirección en la enseñanza superior.

Carlos Eduardo Pascual Pérez

\section{U. UNIVERSITAT}

Diseño y planificación de competencias especificas en el curriculum de enseñanzos profesionales de músico. Modalidades en la enseñonza superior.

Carlos Eduardo Pascual Pérez (investigador) - José Maria Pefialver Vilar (director) - Amparo Parta Novarro (tutara)

\section{TEST FINAL 10 Armonía (3 Enseñanzas Profesionales)}

Detección de errores armónicos estudiados aplicados a una plantilla instrumental

Instrucciones: Debe analizarse cada fragmento instrumental camo sij de una realización armónica a cuatro partes se tratose, y focalizar (si fos hay) errores armónicos de los que figuran en el listado*, para seguidamente enumerarlos en fa tobla de respuestas, indicando para cada error su focalización (compás y tiempo), parte/s implicada/s (instrumento/s) y tipo de error $(a, b, c, d, \ldots)$. Puede haber mós de un error en un mismo tiempo, en ese caso anotorlas por separado. Si se considera, también puede anotarse alquna observación.

Ademós, si no se detectan errores en un ejercicio, debe marcarse la cosilla correspondiente. Si se desconoce o no se sabe como responder al ejercício, dejar en blanco.

*Listado de posibles tipos de error:
a) Octavas seguides
b) Quintos seguidas
c) Octavas directos
d) Quintos directos
e) Cruzamiento de vaces
f) Superacidin de la separación
máxima entre voces

g) Duplicación de la sensibie

h) Resolución incorrecta o irresolución de la sensible

i) Resolución incorrecto o irresolución de

la séptima (acordes de 72 de dte.)

j) Ausencia de preparación de la séptima focordes de $7^{a}$ de dite.

Instrumento/s o especialidad/es que estás cursando o has cursado: Vio boh che ho

\section{EJERCICIO 1}

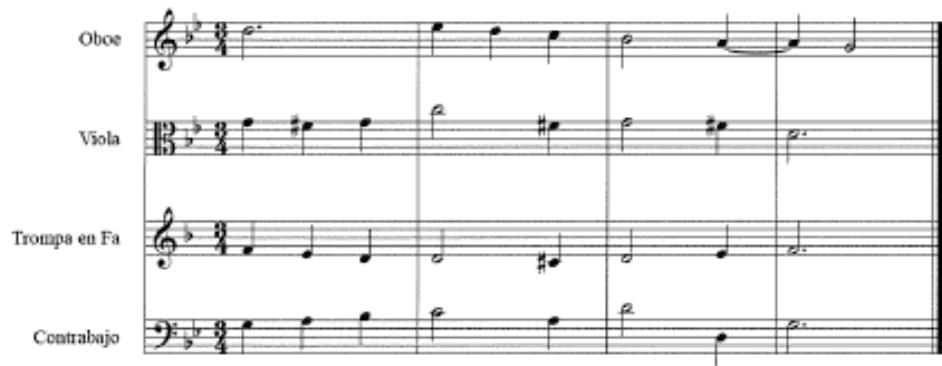

Marcar si no detectas ningún error:

\begin{tabular}{|c|c|c|c|c|}
\hline Compás & Tiempo & Instrumento/s implicado/s & Tipo de error & Observaciones \\
\hline 3 & 1 & Viofo, Trompa & aj & \\
\hline 3 & 2 & Tods & $j$ & \\
\hline 1 & 1 & oboe, Vioto & e) & \\
\hline & & & & \\
\hline & & & & \\
\hline & & & & \\
\hline & & & & \\
\hline & & & & \\
\hline
\end{tabular}


Diseño y planificación de competencias específicas en el currículum de enseñanzas profesionales de música: modalidades composición-dirección en la enseñanza superior.

Carlos Eduardo Pascual Pérez

EJERCICIO 2

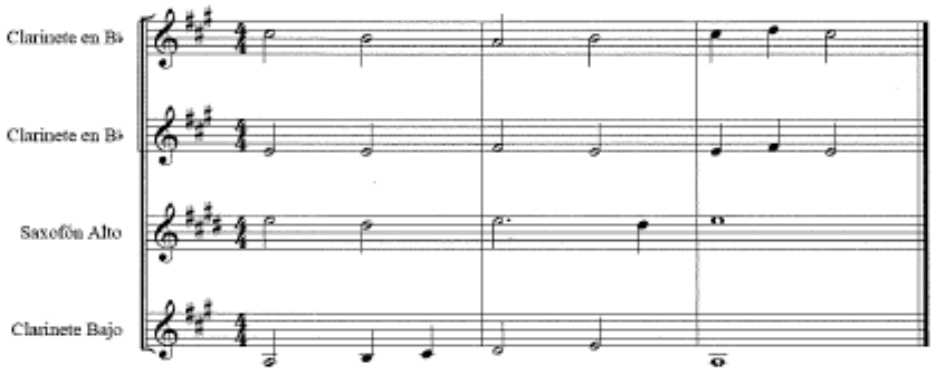

Marcar si no detectas ningún error:

\begin{tabular}{|c|c|c|c|c|}
\hline Compás & Tiempo & Instrumento/s implicado/s & Tipo de error & Observaciones \\
\hline $8,2,3,4$ & & Saxacain, $2^{\circ}$ Caribete & e) & \\
\hline 2. & 1 & Archarive tea, Chrimede $Q$. & b) & \\
\hline & & & & \\
\hline & & & & \\
\hline & & & & \\
\hline & & & & \\
\hline & & & & \\
\hline & & & & \\
\hline
\end{tabular}

EJERCICIO 3

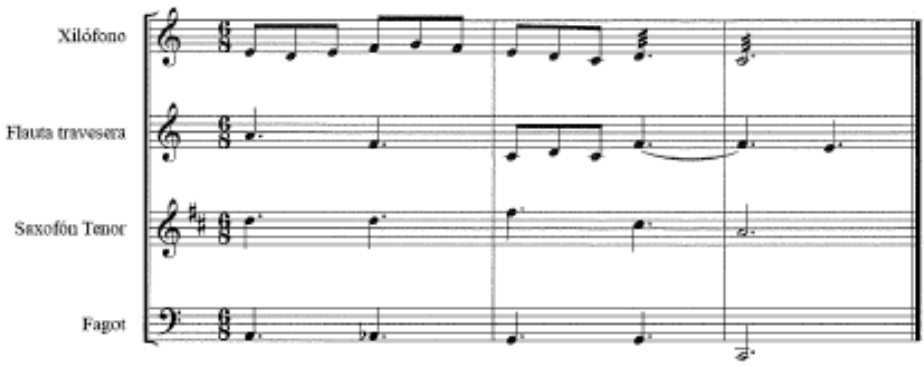

Marcar si no detectas ningún error:

\begin{tabular}{|c|c|c|c|c|}
\hline Compás & Tiempo & Instrumento/s implicado/s & Tipo de error & Observaciones \\
\hline 2 & 1 & Fea ta, Sexs & d) & \\
\hline 3 & & Tods s & $j$ & \\
\hline & & & & \\
\hline & & & & \\
\hline & & & & \\
\hline & & & & \\
\hline & & & & \\
\hline & & & & \\
\hline
\end{tabular}


Diseño y planificación de competencias específicas en el currículum de enseñanzas profesionales de música: modalidades composición-dirección en la enseñanza superior.

Carlos Eduardo Pascual Pérez

\section{UNIVERSITAT}

Diseño y planificación de competencias especificas en el curriculum de enseñanzas profesionales de música. Modalidades en la enseñanza superior.

Carios Eduardo Pascual Pérez (investigador) - Jasé Maria Peñalver Vilar (director) - Amparo Porto Novorro (tutoro)

TEST FINAL 1ㅇ Armonía (3ำEnseñanzas Profesionales)

Detección de errores armónicos estudiados aplicados a una plantilla instrumental

Instrucciones: Debe analizarse cada fragmento instrumental como si de una realización armónica a cuatro partes se tratose, y locolizar (sil los hoy) errores armónicas de los que figuran en el listado*, para seguidamente enumerarios en la tabia de respuestas, indicando para cada error su localización (compós y tiempo), parte/s implicada/s (instrumento/s) y tipo de error $(a, b, c, d, \ldots)$. Puede haber más de un error en un mismo tiempo, en ese caso anotarlos por separado. Si se considero, también puede anotorse alguna observación.

Además, si no se detectan errores en un ejercicio, debe marcarse ia casilla correspondiente. Si se desconoce o no se sabe como responder al ejercicio, dejar en blanco.

*Listado de posibles tipos de error:
a) Octavas seguidas
b) Quintas seguidas
c) Octavas directos
d) Quintas directos
e) Cruzamiento de voces
f) Superación de la separación móxima entre voces

g) Duplicación de la sensible

h) Resolución incorrecto o itresolución de la sensible

1) Resolución incorrecta o irresolución de fa séptima (ocordes de 7 ge de dte.)

i) Ausencia de preparación de fo séptime (acordes de 79 de dte.)

Instrumento/s o especialidad/es que estás cursando o has cursade:

EJERCICIO 1

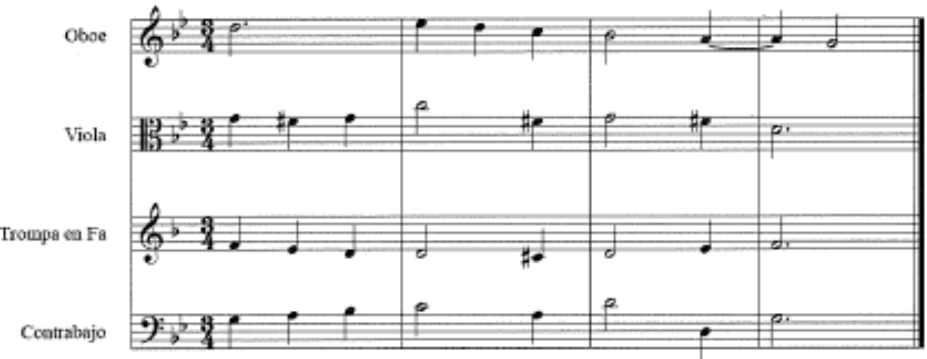

Marcar si no detectas ningún error:

\begin{tabular}{|c|c|c|l|l|}
\hline Compás & Tiempo & Instrumento/s implicado/s & Tipo de error & Observaciones \\
\hline 2 & & Movibuicuto dinecto & & \\
\hline & & & & \\
\hline & & & & \\
\hline & & & & \\
\hline & & & & \\
\hline & & & & \\
\hline & & & & \\
\hline & & & & \\
\hline
\end{tabular}


Diseño y planificación de competencias específicas en el currículum de enseñanzas profesionales de música: modalidades composición-dirección en la enseñanza superior.

Carlos Eduardo Pascual Pérez

EJERCICIO 2

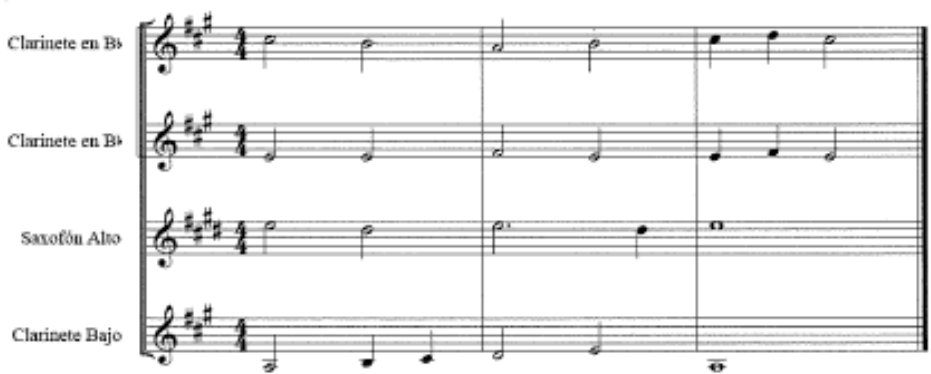

Marcar si no detectas ningún error: $\mathrm{X}$

\begin{tabular}{|l|l|l|l|l|}
\hline Compás & Tiempo & Instrumento/s implicado/s & Tipo de error & Observaciones \\
\hline & & & & \\
\hline & & & & \\
\hline & & & & \\
\hline & & & & \\
\hline & & & & \\
\hline & & & & \\
\hline & & & & \\
\hline & & & & \\
\hline
\end{tabular}

EJERCICIO 3

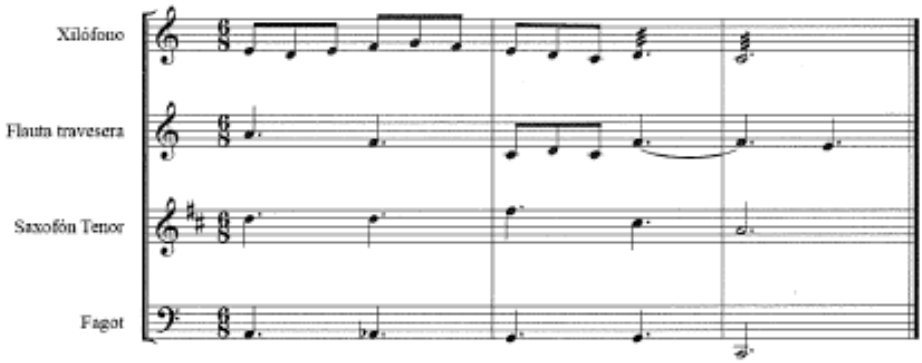

Marcar si no detectas ningún error:

\begin{tabular}{|l|l|l|l|l|}
\hline Compás & Tiempo & Instrumento/s implicado/s & Tipo de error & Observaciones \\
\hline & & & & \\
\hline & & & & \\
\hline & & & & \\
\hline & & & & \\
\hline & & & & \\
\hline & & & & \\
\hline & & & & \\
\hline & & & & \\
\hline
\end{tabular}


Diseño y planificación de competencias específicas en el currículum de enseñanzas profesionales de música: modalidades composición-dirección en la enseñanza superior.

Carlos Eduardo Pascual Pérez

\section{UNIVERSITAT}

Diseño y plonificaclón de competencias especificos en el currículum de enseñanzas profesionales de músico.

Modalidades en la enseñanza superior.

Corios Eduardo Poscual Pérez (investigador) - Jasé María Peñolver Vilar (director) - Amparo Porta Navarro (tutero)

TEST FINAL 1 Armonía (3 Enseñanzas Profesionales)

Detección de errores armónicos estudiados aplicados a una plantilla instrumental

Instrucciones: Debe analizarse cada fragmento instrumental como si de una realización armónica a cuatro partes se trotase, y localizar (si los hay) errores armónicos de los que figuran en el listodo*, para seguidamente enumerarlos en fa tabla de respuestos, indicando para cada error su lacalización (compás y tiempo), parte/s implicado/s (instrumento/s) y tipo de error $(a, b, c, d, \ldots)$. Puede haber mós de un error en un mismo tiempo, en ese caso anotarlas par separado. Si se considera, también puede anotarse alguna abservación.

Además, si no se detectan errores en un ejercicio, debe marcarse la casilla correspondiente. Si se desconace o no se sabe como responder al ejercicio, dejar en blanco.

* Listado de posibles típos de error:
a) Octovas seguidas
b) Quintos seguidas
c) Octovas directos
d) Quintos directos
e) Cruzamiento de voces
f) Superación de la separación móxima entre voces

g) Duplicación de la sensible

h) Resolución incorrecta o irresalución de la sensible

i) Resolución incorrecta o irresolución de la séptima (acordes de $7^{2}$ de dte)

j) Ausencia de preparación de lo séptimo (acordes de $7^{a}$ de dte.)

Instrumento/s o especialidad/es que estás cursando o has cursado:

\section{EJERCICIO 1}
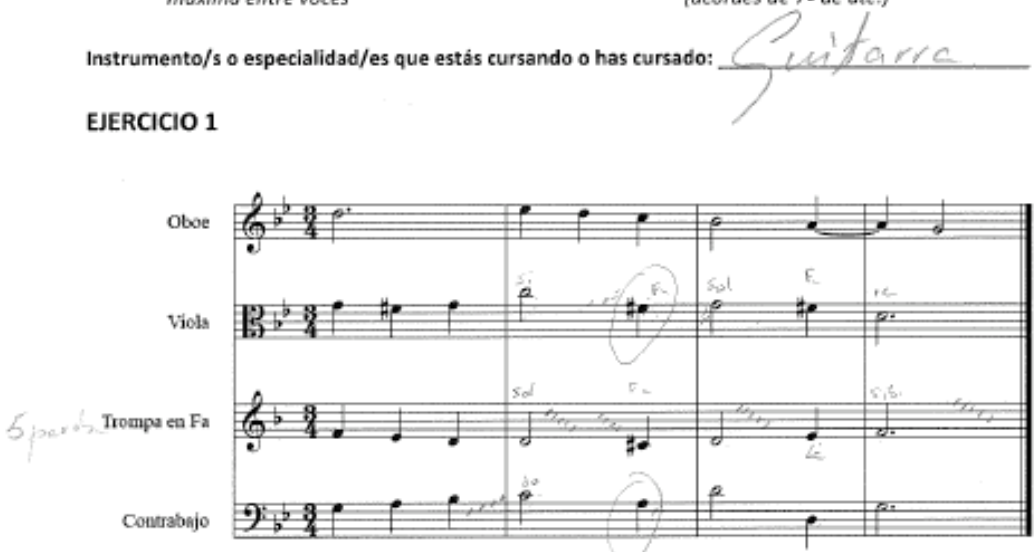

Marcar si no detectas ningún error:

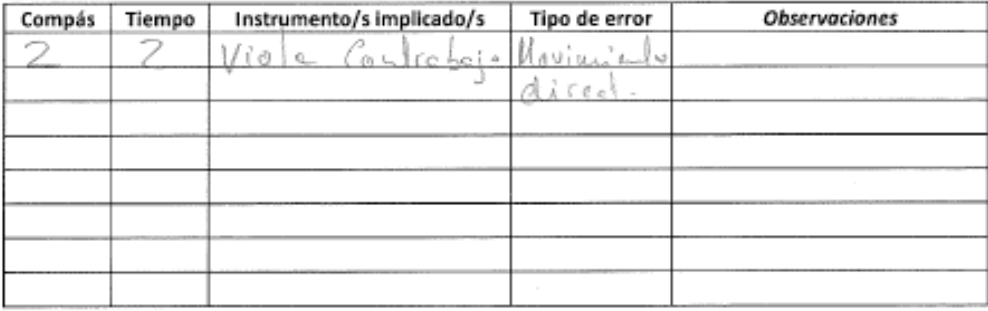


Diseño y planificación de competencias específicas en el currículum de enseñanzas profesionales de música: modalidades composición-dirección en la enseñanza superior.

Carlos Eduardo Pascual Pérez

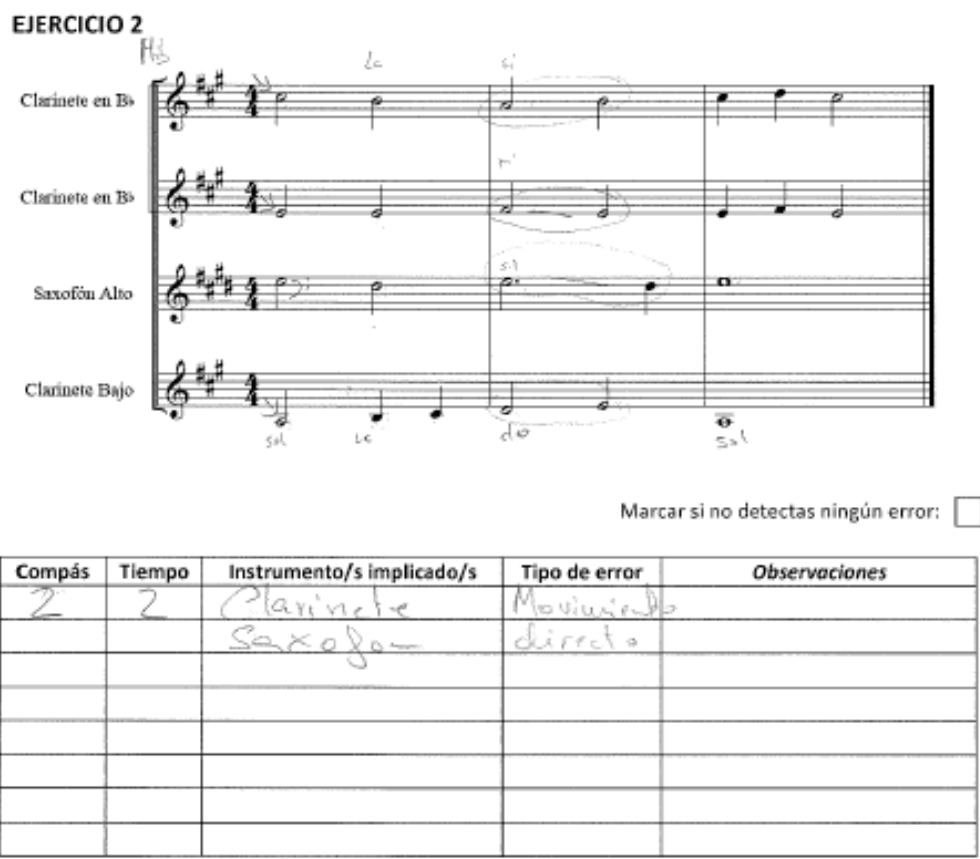

EJERCICIO 3

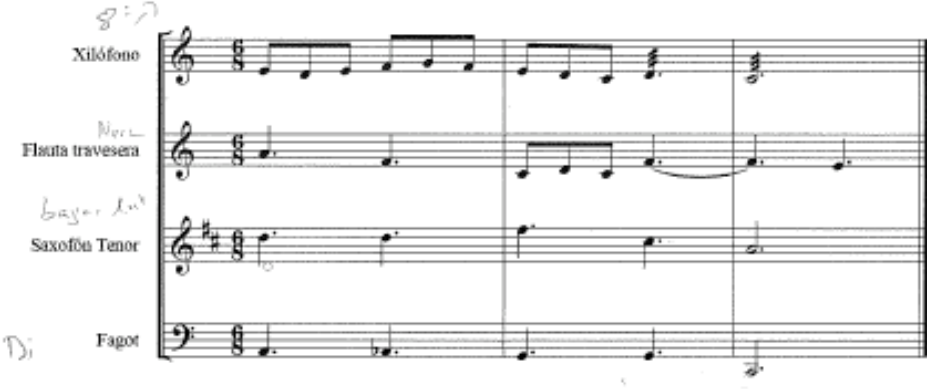

Marcar si no detectas ningún error:

\begin{tabular}{|c|c|c|c|c|}
\hline Compás & Tiempo & Instrumento/s implicado/s & Tipo de error & Observaciones \\
\hline 2 & 2 & Sareteng. & Movimidal, & \\
\hline 3 & $1^{2}$ & & diresto & \\
\hline 4 & 2 & Flaut t rav Xilol. & t dewnes & ctare \\
\hline & & & & \\
\hline & & & & \\
\hline & & & & \\
\hline & & & & \\
\hline & & & & \\
\hline
\end{tabular}


Diseño y planificación de competencias específicas en el currículum de enseñanzas profesionales de música: modalidades composición-dirección en la enseñanza superior.

Carlos Eduardo Pascual Pérez

\section{U. UNIVERSITAT}

Diseño y planificación de competencias especificas en el curriculum de enseñanzas profesionales de música. Modalidades en la enseñanza superior.

Corios Eduardo Poscual) Pérez (Inwestigodar) - José Maria Peñaiver Vilar (director) - Amparo Porto Navarro (tutara)

TEST FINAL 1 Armonía (3ำEseñanzas Profesionales)

Detección de errores armónicos estudiados aplicados a una plantilla instrumental

Instrucciones: Debe analizarse cada frogmento instrumental como si de una reafización armónica a cuatro partes se trotase, y localizar (si los hay) errores armónicos de los que figuran en el listado*, para seguidomente enumerarios en la tabla de respuestas, indicando para cada error su lacalización (compás y tiempo), parte/s implicada/s (instrumento/s) y tipo de error $(a, b, c, d, \ldots)$. Puede haber mós de un error en un mismo tiempo, en ese caso anotarlos por separado. Si se considera, tambien puede anotorse alquna observación.

Además, si no se detectan errores en un ejercicio, debe marcarse fo casilla correspandiente. Si se desconoce o no se sabe como responder al ejercicio, dejar en blanco.

*Listodo de posibles tipos de error:
a) Octovas seguidas
b) Quintas seguidas
c) Octovos directos
d) Quintos directos
e) Cruzamiento de vaces
f) Superación de la separación móxima entre voces

g) Dupficación de la sensible

h) Resolución incorrecta o irresolución de la sensible

i) Resolución incorrecta o irresolución de la séptima (acordes de 79 de dte.)

j) Ausencla de preparación de la séptima (acordes de 79 de dte.)

Instrumento/s o especialidad/es que estás cursando o has cursado: Pencuvión y Dulzaina

EJERCICIO 1

5

Viola

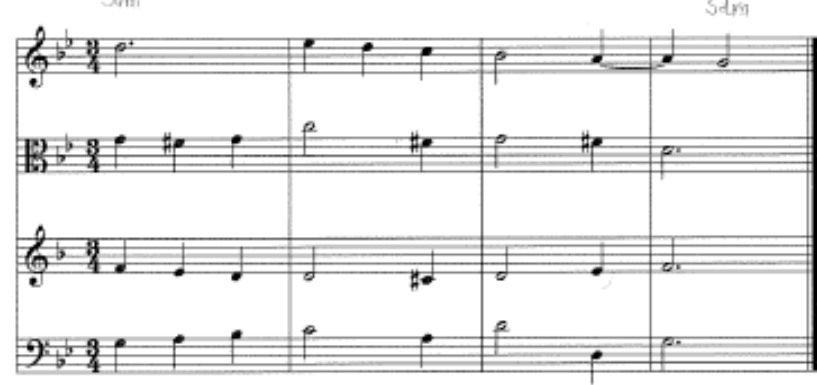

Marcar si no detectas ningún error:

\begin{tabular}{|c|c|c|c|c|}
\hline Compás & Tiempo & Instrumento $/ \mathrm{s}$ implicado $/ \mathrm{s}$ & Tipo de error & Observaciones \\
\hline $3 ; 4$ & $3 r$ & Vida & h) & E) Foll va a Sol, b tonic \\
\hline 3 & $I_{r}$ & Trampa & f) & - \\
\hline & & & & \\
\hline & & & & \\
\hline & & & & \\
\hline & & & & \\
\hline & & & & \\
\hline & & & & \\
\hline
\end{tabular}


Diseño y planificación de competencias específicas en el currículum de enseñanzas profesionales de música: modalidades composición-dirección en la enseñanza superior.

Carlos Eduardo Pascual Pérez

EJERCICIO 2

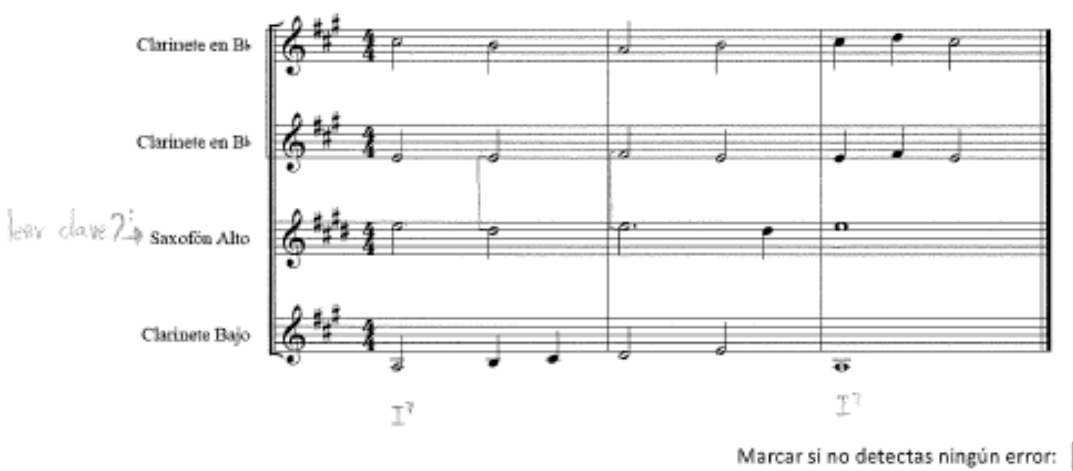

\begin{tabular}{|c|c|c|c|c|}
\hline Compás & Tiempo & Instrumento/s implicado/s & Tipo de error & Observaciones \\
\hline $1 / 2$ & $3 r$ & Clarinete en Bb/Sardor $A$ b & a) & \\
\hline & & & & \\
\hline & & & & \\
\hline & & & & \\
\hline & & & & \\
\hline & & & & \\
\hline & & & & \\
\hline & & & & \\
\hline
\end{tabular}

EJERCICIO 3

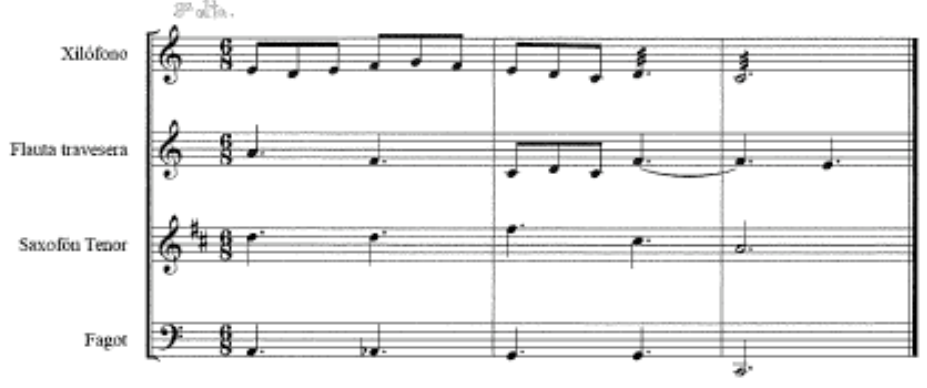

Marcar si no detectas ningún error: $D$

\begin{tabular}{|l|l|l|l|l|}
\hline Compás & Tlempo & Instrumento/s implicado/s & Tipo de error & Observaciones \\
\hline & & & & \\
\hline & & & & \\
\hline & & & & \\
\hline & & & & \\
\hline & & & & \\
\hline & & & & \\
\hline & & & & \\
\hline
\end{tabular}


Diseño y planificación de competencias específicas en el currículum de enseñanzas profesionales de música: modalidades composición-dirección en la enseñanza superior.

Carlos Eduardo Pascual Pérez

\section{I UNIVERSITAT}

Diseño y planificación de competencias especificas en el curriculum de enseñanzas profesionales de música. Modalidades en la enseñanza superior.

Carias Eduordo Pascual Pérez (investigador) - Jose Moria Peñolver Vilar (director) - Amporo Porto Navarro (tutora)

\section{TEST FINAL 1 Armonía (3 Enseñanzas Profesionales)}

Detección de errores armónicos estudiados aplicados a una plantilla instrumental

Instrucciones: Debe analizarse coda frogmento instrumental como si de una realización armónica a cuatro partes se tratase, y localizar (si los hay) errores armónicas de los que figuran en el listado*, para seguidamente enumerarios en la tabla de respuestas, indicando para cada error su localizoción (compós y tiempo), parte/s implicada/s (instrumento/s) y tipo de error $(a, b, c, d, \ldots)$. Puede haber mós de un error en un mismo tiempo, en ese coso anotarlos por separado. Si se cansidera, tambien puede anotarse aiguna observoción.

Además, si no se detecton errores en un ejercicio, debe marcarse la casilla correspandiente. Si se descanoce o no se sabe como responder al ejercicio, dejar en blanco.

*Listado de posibles tipos de error:
a) Octavas seguidos
b) Quintas seguidos
c) Octavas directos
d) Quintas directo
e) Cruzamiento de voces
f) Superación de la separación máxima entre vaces

g) Duplicación de la sensible

h) Resolución incorrecto o irresolución de la sensible

i) Resolución incorrecto o irresolución de la séptima (acordes de 79 de dte.)

i) Ausencia de preparación de fa séptima (acordes de $7^{9}$ de dte.)

Instrumento/s o especialidad/es que estás cursando o has cursado

\section{EJERCICIO 1}

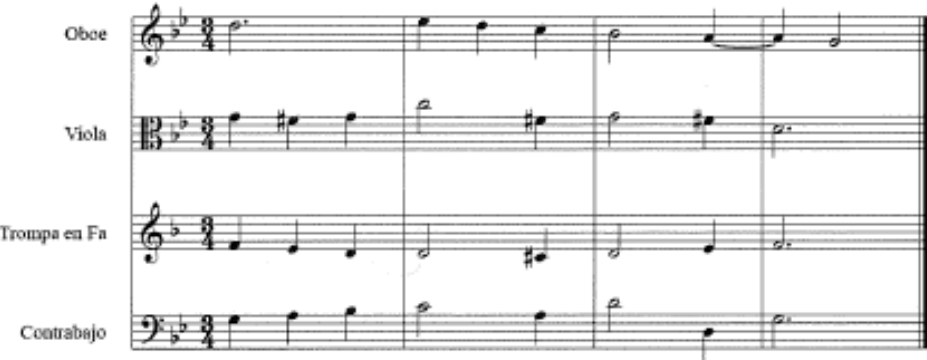

Marcar si no detectas ningún error:

\begin{tabular}{|l|l|l|l|l|}
\hline Compás & Tiempo & Instrumento/s implicado/s & Tipo de error & Observaciones \\
\hline 2 & & & & \\
\hline & & & & \\
\hline & & & & \\
\hline & & & & \\
\hline & & & & \\
\hline & & & & \\
\hline & & & & \\
\hline & & & & \\
\hline
\end{tabular}


Diseño y planificación de competencias específicas en el currículum de enseñanzas profesionales de música: modalidades composición-dirección en la enseñanza superior.

Carlos Eduardo Pascual Pérez

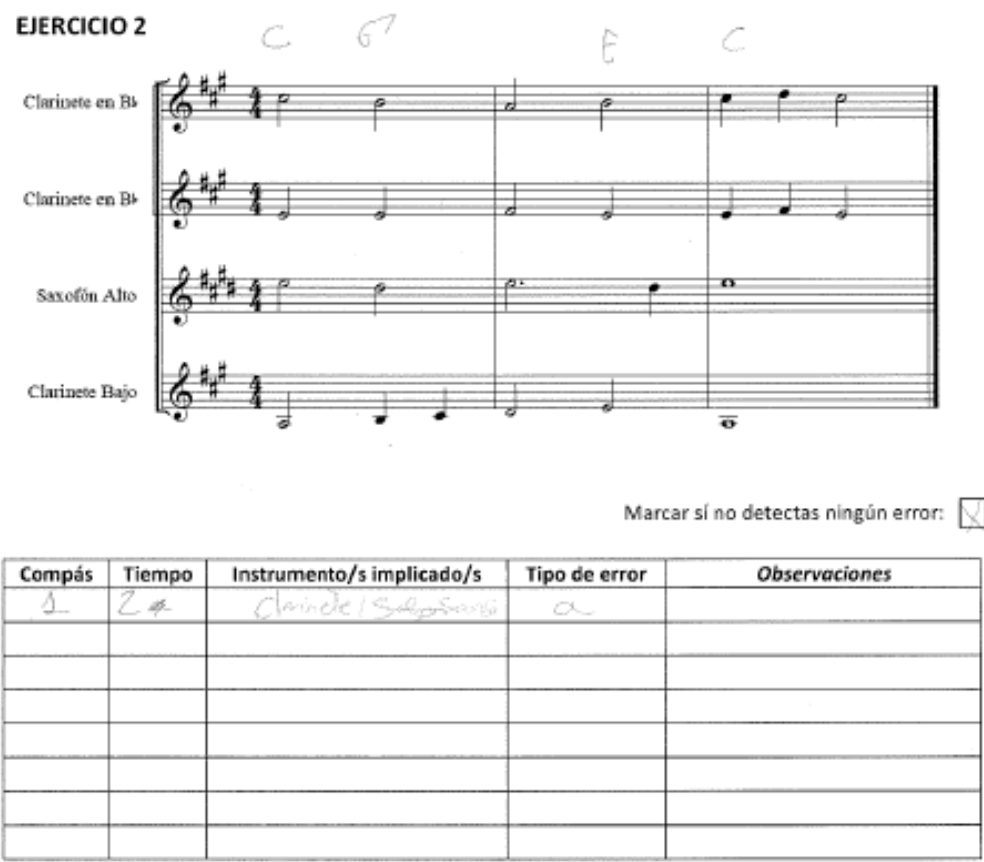

EJERCICIO 3

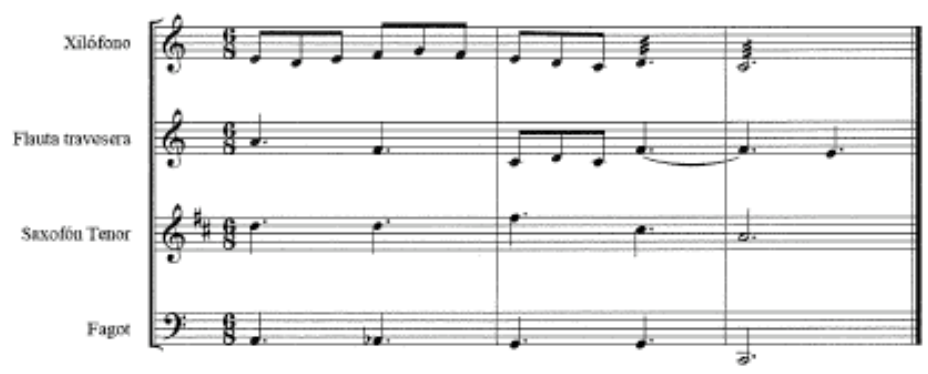

Marcar si no detectas ningún error

\begin{tabular}{|c|c|c|c|c|}
\hline Compás & Tiempo & Instrumento/s implicado/s & Tipo de error & Observaciones \\
\hline 1 & & & 5 & \\
\hline 2 & & & & \\
\hline 2 & & & & \\
\hline & & & & \\
\hline & & & & \\
\hline & & & & \\
\hline & & & & \\
\hline & & & & \\
\hline
\end{tabular}


Diseño y planificación de competencias específicas en el currículum de enseñanzas profesionales de música: modalidades composición-dirección en la enseñanza superior.

Carlos Eduardo Pascual Pérez Modallidades en la enseñanzo superior.

Carlos Eduardo Poscual Pérez (investigador) - José Mario Peñalver Vijor (directar) - Amparo Parto Novarro (tutaro)

\section{TEST FINAL 1 Armonía (3ำ Enseñanzas Profesionales)}

Detección de errores armónicos estudiados aplicados a una plantilla instrumental

Instrucciones: Debe analizarse cada fragmento instrumental como si de una realización armónica a cuatro partes se tratase, y localizar (si fas hoy) errores armónicos de los que figuran en el listado*, para seguidamente enumerarlos en la tabla de respuestas, indicondo para cada error su localización (compós y tjempol, porte/s implicada/s (instrumento/s) y tipo de error $(a, b, c, d, . .$.$) . Puede haber más de un error en un mismo tiempo, en$ ese caso anotarios por separado. Si se considera, también puede anotarse alguna observación.

Además, si no se detectan errores en un ejercicio, debe marcarse ia casilla correspondiente. Si se desconoce o no se sabe como responder al ejercicio, dejar en blanco.

*istodo de posibles tipos de error:
a) Octavos seguidas
b) Quintos seguidas
c) Octavas directa:
d) Quintos directos
Cruzamiento de voces
f) Superación de la separación
máxima entre voces
g) Duplicación de la sensible
h) Resolución incorrecto o irresolución
de la sensible
1) Resolución incarrecto o irresolución de
la séptima (acordes de 79 de dte.)
i) Ausencia de preparación de la septima
(acordes de 72 de dte.)

Instrumento/s o especialidad/es que estás cursando o has cursado:

\section{EERCICIO 1}

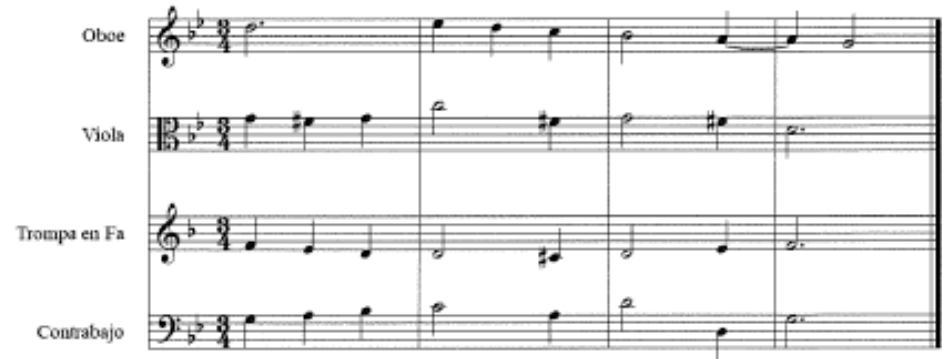

Marcar si no detectas ningún error:

\begin{tabular}{|c|c|c|c|c|}
\hline Compás & Tiempo & Instrumento/s implicado/s & Tipo de error & Observaciones \\
\hline 2 & 3 & & 6 & \\
\hline 3 & 3 & & $H$ & \\
\hline & & & & \\
\hline & & & & \\
\hline & & & & \\
\hline & & & & \\
\hline & & & & \\
\hline & & & & \\
\hline
\end{tabular}


Diseño y planificación de competencias específicas en el currículum de enseñanzas profesionales de música: modalidades composición-dirección en la enseñanza superior.

Carlos Eduardo Pascual Pérez

EJERCICIO 2

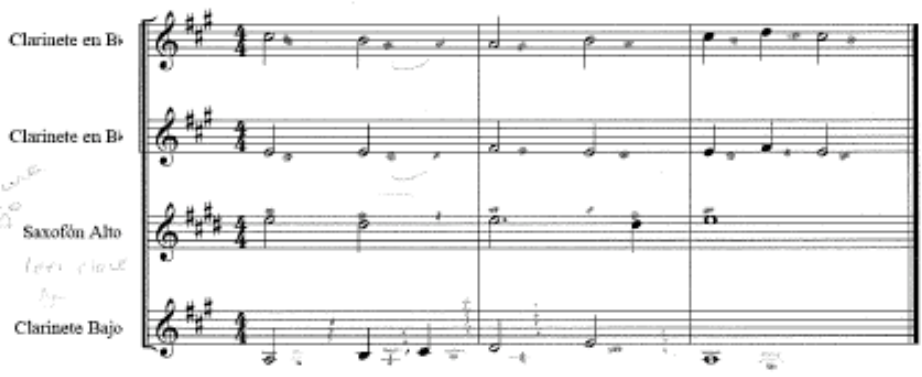

Marcar si no detectas ningún error:

\begin{tabular}{|l|l|l|l|l|}
\hline Compás & Tiempo & Instrumento/s implicado/s & Tipo de error & Observaciones \\
\hline & & & & \\
\hline & & & & \\
\hline & & & & \\
\hline & & & & \\
\hline & & & & \\
\hline & & & & \\
\hline & & & & \\
\hline & & & & \\
\hline
\end{tabular}

EJERCICIO 3

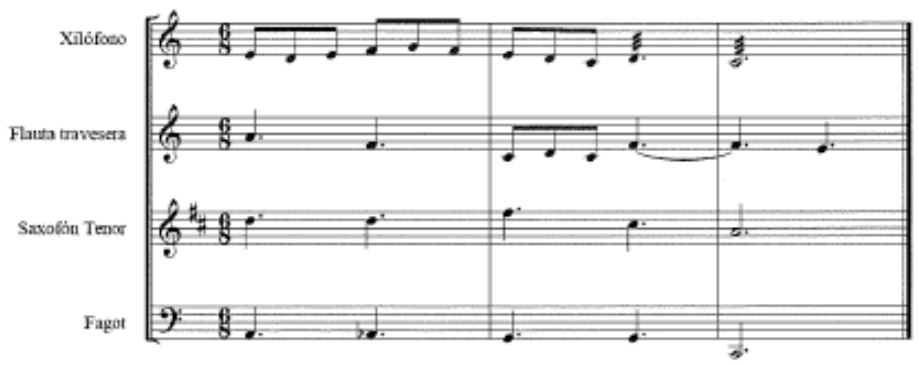

Marcar si no detectas ningún error:

\begin{tabular}{|l|l|l|l|l|}
\hline Compás & Tiempo & Instrumento/s implicado/s & Tipo de error & Observaciones \\
\hline & & & & \\
\hline & & & & \\
\hline & & & & \\
\hline & & & & \\
\hline & & & & \\
\hline & & & & \\
\hline & & & & \\
\hline & & & & \\
\hline
\end{tabular}


Diseño y planificación de competencias específicas en el currículum de enseñanzas profesionales de música: modalidades composición-dirección en la enseñanza superior.

Carlos Eduardo Pascual Pérez Modalidades en la enseñanza superior.

Carlos Eduardo Pascual Pérez (irnestigador) - Jasé Maria Peñalver Vilar (director) - Amparo Parta Navorro (tutora)

\section{TEST FINAL 1 Armonía (3ํㅡseñanzas Profesionales)}

Detección de errores armónicos estudiados aplicados a una plantilla instrumental

Instrucciones: Debe analizarse cada fragmento instrumental como si de una realización armónica a cuatro partes se trotase, y lacolizar (si los hay) errores armónicos de los que figuran en el fistado*, para seguidamente enumerarlos en la tabla de respuestas, indicando para cada error su localización (compás y tiempo), parte/s implicado/s (instrumento/s) y tipo de errar $(a, b, c, d, \ldots)$. Puede hober más de un error en un mismo tiempo, en ese caso anotarlos por separado. Si se considera, también puede anotorse alguna observación.

Además, si no se defectan errores en un ejercicio, debe marcarse fo casilila correspandiente. Si se desconoce o no se sabe como responder of ejercicio, dejar en blanco.

*Listodo de posibles tipos de error:
a) Octavas seguidas
b) Quintas seguidas
c) Octavas directas
d) Quintos directos
e) Cruzamiento de voces
f) Superación de lo separación móximo entre voces

g) Duplicación de la sensible

h) Resolución incorrecta o irresolución de lo sensible

i) Resolución incorrecta o irresolución de la séptima (acordes de $7^{\mathrm{a}}$ de dte.)

1) Ausencia de preparación de la séptima (acordes de 79 de dte.)

Instrumento/s o especialidad/es que estás cursando o has cursado:

CLARTNETE

\section{EJERCICIO 1}

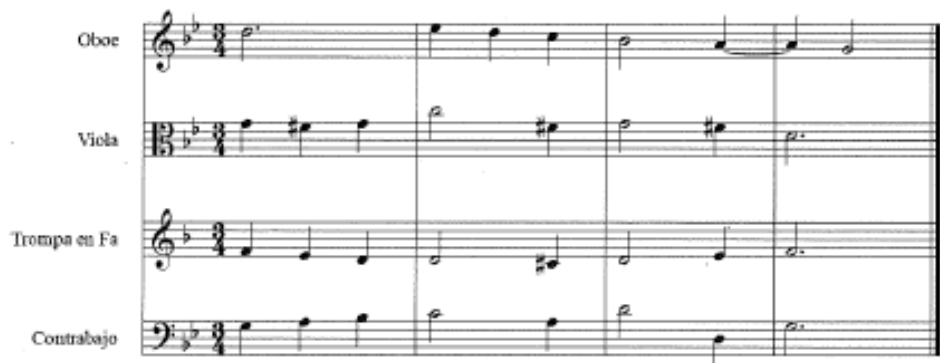

Marcar si no detectas ningún error:

\begin{tabular}{|c|c|c|c|c|}
\hline Compás & Tiempo & Instrumento/s implicado/s & Tipo de error & Observaciones \\
\hline 2 & 3 & Trompa en fa/vicia & G & \\
\hline 3 & 3 & Viota & H & \\
\hline 3 & 1 & vio lo I trompo & F & \\
\hline & & & & \\
\hline & & & & \\
\hline & & & & \\
\hline & & & & \\
\hline & & & & \\
\hline
\end{tabular}


Diseño y planificación de competencias específicas en el currículum de enseñanzas profesionales de música: modalidades composición-dirección en la enseñanza superior.

Carlos Eduardo Pascual Pérez

\section{EJERCICIO 2}

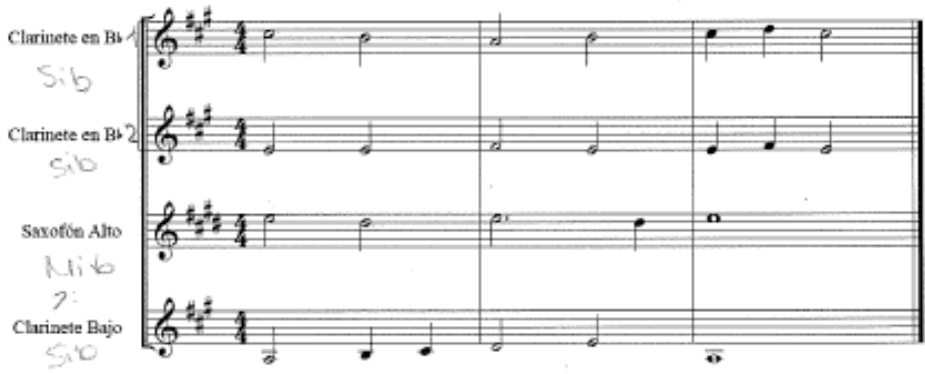

Marcar si no detectas ningún error:

\begin{tabular}{|c|c|c|c|c|}
\hline Compás & Tiempo & Instrumento/s implicado/s & Tipo de error & Observaciones \\
\hline 1 & 1,3 & Clorincte 1 Saxo & A & \\
\hline & & & & \\
\hline & & & & \\
\hline & & & & \\
\hline & & & & \\
\hline & & & & \\
\hline & & & & \\
\hline & & & & \\
\hline
\end{tabular}

\section{EJERCICIO 3}

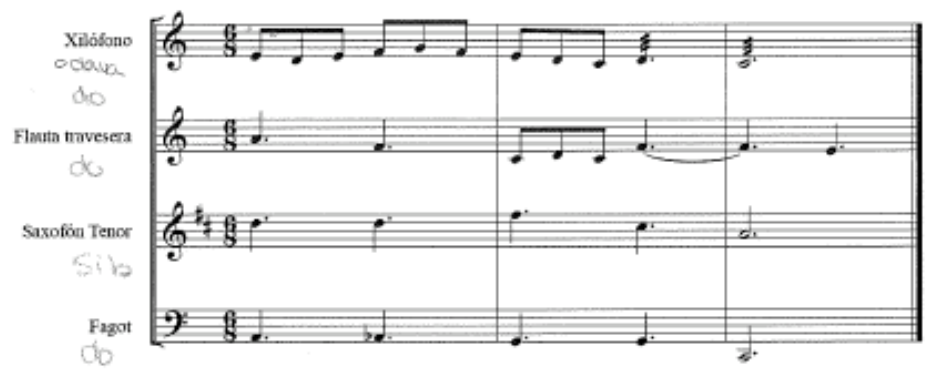

Marcar si no detectas ningún error:

\begin{tabular}{|l|l|l|l|l|}
\hline Compás & Tiempo & Instrumento/s implicado/s & Tipo de error & Observociones \\
\hline & & & & \\
\hline & & & & \\
\hline & & & & \\
\hline & & & & \\
\hline & & & & \\
\hline & & & & \\
\hline & & & & \\
\hline & & & & \\
\hline
\end{tabular}


Diseño y planificación de competencias específicas en el currículum de enseñanzas profesionales de música: modalidades composición-dirección en la enseñanza superior.

Carlos Eduardo Pascual Pérez

\section{UNIVERSITAT \\ JAUME I}

Diseño y planificación de competencias especificas en el curriculum de enseñanzos profesionales de música. Modalidades en la enseñanzo superior.

Carlas Eduardo Pascual Pérez (investigador) - José Maria Peñalver Vilar (director) - Amparo Parta Navarro (tutora)

TEST FINAL 1 Armonía (3ำ Enseñanzas Profesionales)

Detección de errores armónicos estudiados aplicados a una plantilla instrumental

Instrucciones: Debe analizorse cada fragmento instrumental como si de una realización armónico a cuatro partes se tratase, y localizar (si los hay) errores armónicos de los que figuran en el listado*, para seguidamente enumerarlos en la tabla de respuestas, indicando para cada error su localización (compós y tiempol, parte/s implicada/s (instrumento/s) y tipo de error $(a, b, c, d, \ldots)$. Puede haber mós de un error en un mismo tiempo, en ese caso anotorlos por seporado. Si se considera, también puede anotarse alguna observación.

Ademós, si no se detectan errores en un ejercicio, debe marcarse la cosillo correspondiente. Si se desconoce o no se sabe como responder al ejercicio, dejar en blanco.

*ustado de posibles tipos de error:
a) Octavas seguidas
b) Quintas seguidas
c) Octovas directos
d) Quintas directos
e) Cruzamiento de voces
f) Superoción de la seporación
múxima entre voces
g) Duplicación de la sensible
h) Resolución incorrecto o irresolución de la sensible
i) Resolución incorrecta o irresolución de la séptima (acordes de $7^{2}$ de dte.)
i) Ausencio de preparación de lo séptima (acordes de $7^{9}$ de dte.)

Instrumento/s o especialidad/es que estás cursando o has cursado:

\section{EJERCICIO 1}

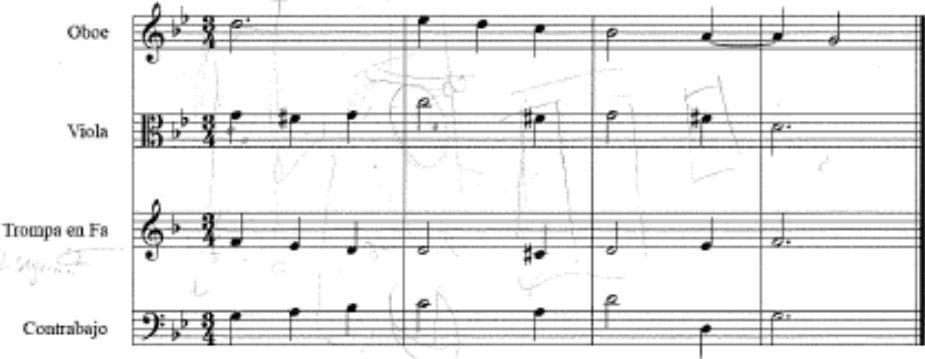

Marcar si no detectas ningún error:

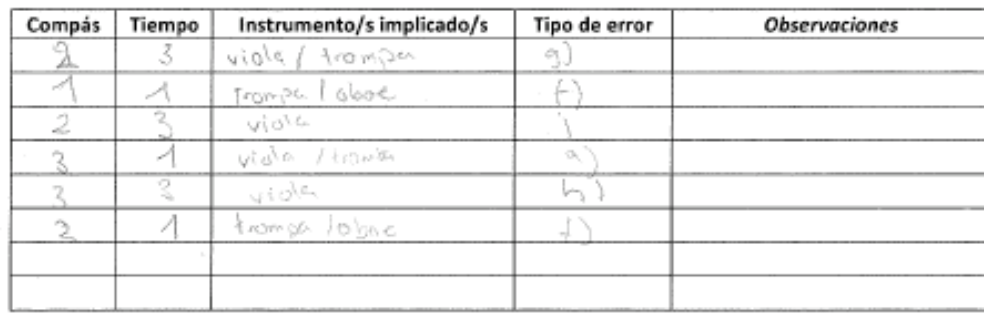


Diseño y planificación de competencias específicas en el currículum de enseñanzas profesionales de música: modalidades composición-dirección en la enseñanza superior.

Carlos Eduardo Pascual Pérez

EJERCICIO 2

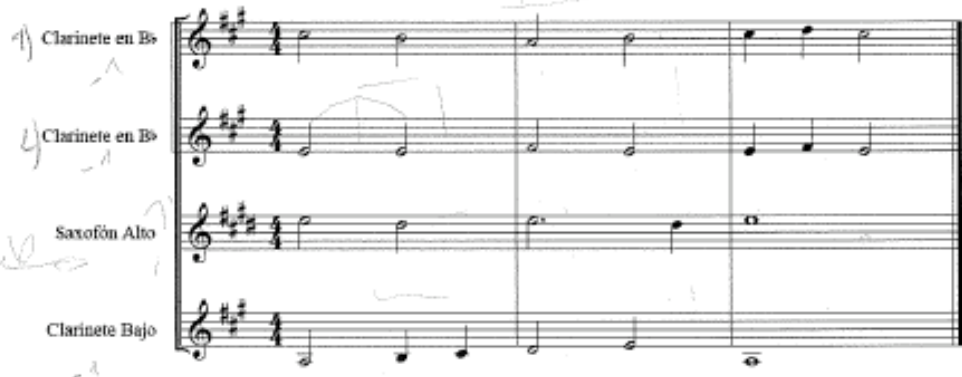

Marcar si no detectas ningủn error:

\begin{tabular}{|c|c|c|c|c|}
\hline Compás & Tiempo & Instrumento/s implicado/s & Tipo de error & Observociones \\
\hline 1 & 3 & 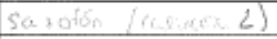 & $e$ & \\
\hline 2 & 1 & saxu/cluarin bu & $b$ & \\
\hline 2 & 1 & 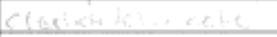 & $b$ & \\
\hline & & & & \\
\hline & & & & \\
\hline & & & & \\
\hline & & & & \\
\hline & & & & \\
\hline
\end{tabular}

EJERCICIO 3

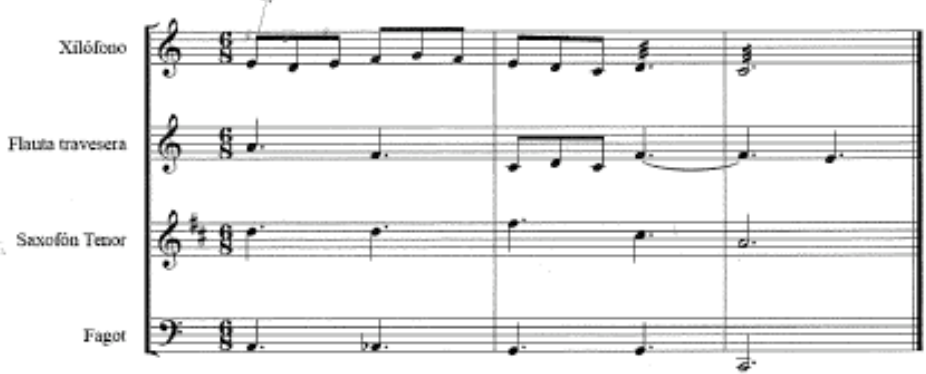

Marcar si no detectas ningún error:

\begin{tabular}{|c|c|c|c|c|}
\hline Compás & Tiempo & Instrumento/s implicado/s & Tipo de error & Observaciones \\
\hline 7000 & & Say & & \\
\hline 3 & 2 & fasot & $7)$ & \\
\hline 2 & 3 & Soyb & $h$ & \\
\hline & & & & \\
\hline & & & & \\
\hline & & & & \\
\hline & & & & \\
\hline & & & & \\
\hline
\end{tabular}


Diseño y planificación de competencias específicas en el currículum de enseñanzas profesionales de música: modalidades composición-dirección en la enseñanza superior.

Carlos Eduardo Pascual Pérez

\section{UNIVERSITAT}

Diseño y planificoción de competencias especificas en el curriculum de enseñanzos profesionales de música. Modalidades en la enseñanzo superior.

Carlas Eduardo Pascual Pérez (investigador) - José Maria Peñalver Vilar (director) - Amparo Porta Navarro (tutora)

\section{TEST FINAL 1ㅇ Armonía (3ํㅡㄹeñanzas Profesionales)}

Detección de errores armónicos estudiados aplicados a una plantilla instrumenta

Instrucciones: Debe analizarse cada fragmento instrumental como si de una realización armónica a cuotro partes se tratase, y localizar (si fos hoy) errores armónicos de los que figuran en el listado*, para seguidamente enumerarios en la tabla de respuestas, indicando para cada error su localización (compás y tiempo), parte/s implicada/s (instrumento/s) y tipo de error $(a, b, c, d, \ldots)$. Puede haber más de un error en un mismo tiempo, en ese caso anotarios por separado. Si se considero, también puede onotarse alguna observación.

Además, sij no se detectan errores en un ejercicio, debe marcarse fo casilla carrespandiente. Si se desconoce o no se sabe como responder al ejercicio, dejar en blanco.

*Listado de pasibles tipos de error:
a) Octovos seguidas
b) Quintos seguidos
c) Octavas directas
d) Quintos directos
e) Cruzamiento de voces
f) Superación de la separación móxima entre voces

g) Duplicación de la sensible

h) Resalución incorrecta o irresolución

de la sensible

1) Resolución incorrecta o irresolución de la séptima (acordes de $7^{79}$ de dte.)

i) Ausencia de preparación de la séptima (acordes de $7 q$ de dite.)

Instrumento/s o especialidad/es que estás cursando o has cursado:

\section{EJERCICIO 1}

Trompn en F

Othe

Viol

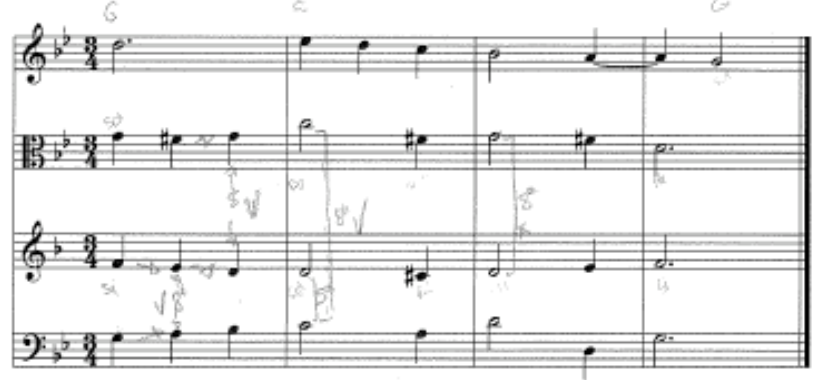

Marcar si no detectas ningún error:

\begin{tabular}{|c|c|c|c|c|}
\hline Compás & Tiempo & Instrumento/s implicado/s & Tipo de error & Observaciones \\
\hline 3 & $1^{\circ}$ & Vista it itromp & f) & \\
\hline 3 & $3^{\circ}$ & Vida & n) & \\
\hline 2 & $3^{\circ}$ & Trompa vede & a) & \\
\hline & & & & \\
\hline & & & & \\
\hline & & & & \\
\hline & & & & \\
\hline & & & & \\
\hline
\end{tabular}


Diseño y planificación de competencias específicas en el currículum de enseñanzas profesionales de música: modalidades composición-dirección en la enseñanza superior.

Carlos Eduardo Pascual Pérez

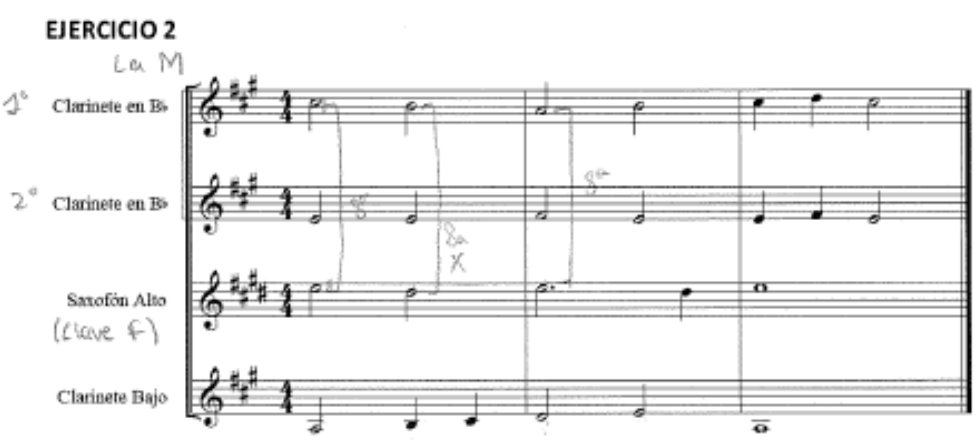

Marcar si no detectas ningún error:

\begin{tabular}{|c|c|c|c|c|}
\hline Compás & Tiempo & Instrumento/s implicado/s & Tipo de error & Observociones \\
\hline 1 & 10,3 & Clownete 10 y & & \\
\hline 2 & $2^{\circ}$ & Clarmete jo Saco & & \\
\hline & & & & \\
\hline & & & & \\
\hline & & & & \\
\hline & & & & \\
\hline & & & & \\
\hline & & & & \\
\hline
\end{tabular}

\section{EJERCICIO 3}

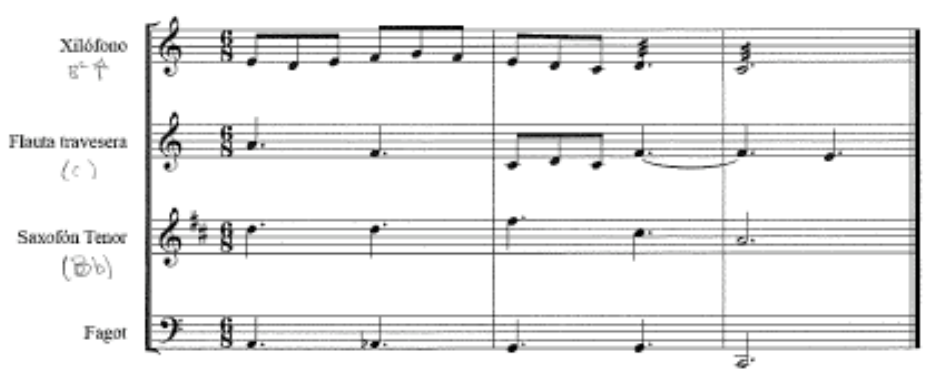

Marcar si no detectas ningún error:

\begin{tabular}{|l|l|l|l|l|}
\hline Compás & Tiempo & Instrumento/s implicado/s & Tipo de error & Observociones \\
\hline $1,2,3$ & todos & Xilofono & $f$ & \\
\hline & & & & \\
\hline & & & & \\
\hline & & & & \\
\hline & & & & \\
\hline & & & & \\
\hline & & & & \\
\hline & & & & \\
\hline
\end{tabular}


Diseño y planificación de competencias específicas en el currículum de enseñanzas profesionales de música: modalidades composición-dirección en la enseñanza superior.

Carlos Eduardo Pascual Pérez

TEST FINAL 1 Armonía (3ำ Enseñanzas Profesionales)

Detección de errores armónicos estudiados aplicados a una plantilla instrumental

Instrucciones: Debe analizarse cada fragmento instrumental como si de una realización armónica a cuatro partes se tratase, y localizar (si los hay) errores armónicas de los que figuran en el listado*, para seguidamente enumerarios en lo tobla de respuestos, indicando para cada error su localización (compás y tiempol, parte/s imolicada/s (instrumento/s) y tipo de error $(a, b, c, d, \ldots)$. Puede haber más de un error en un mismo tiempo, en ese caso anotarios por separado. Si se considera, también puede anotarse alguna observación.

Ademós, si no se detectan errores en un ejercicio, debe marcarse la casilla correspondiente. Si se desconoce o no se sabe como responder al ejercicio, dejar en blanco.

* Listado de posibles tipos de error:
a) Octavas seguidas
b) Quintas seguidas
actavas directos
Octavas directos
e) Cruzamiento de voces
f) Superación de la separación
móxima entre voces

g) Duplicación de la sensible

h) Resolución incorrecta o irresolución

de la sensible

1) Resolución incorrecta o irresolución de

la séptima (acordes de 79 de dte.)

j) Ausencia de preparación de la séptimo (ocordes de 70 de dite.)

Instrumento/s o especialidad/es que estás cursando o has cursado:

\section{EJERCICIO 1}

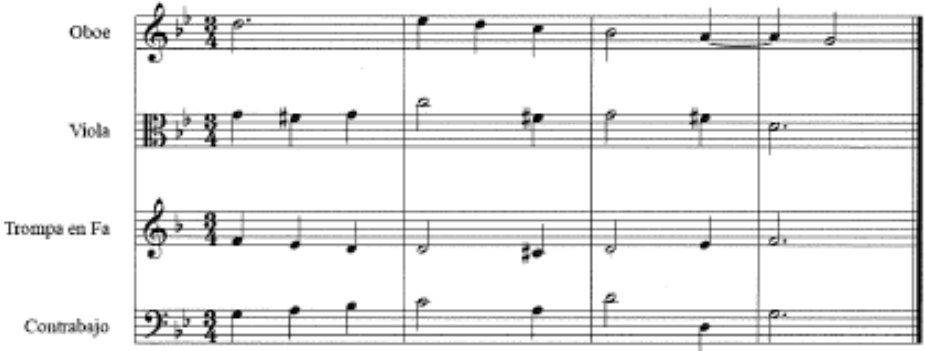

Marcar si no detectas ningún error:

\begin{tabular}{|c|c|c|c|c|}
\hline Compás & Tlempo & Instrumento/s implicado/s & Tipo de error & Observaciones \\
\hline 2 & 1 & Trameo/vion & F & \\
\hline & $f$ & 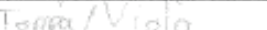 & F & \\
\hline 7 & 3 & Franer / $/$ iola & 9 & \\
\hline 274 & $3 / 1$ & Viola & bis & \\
\hline & & & & \\
\hline & & & & \\
\hline & & & & \\
\hline & & & & \\
\hline
\end{tabular}


Diseño y planificación de competencias específicas en el currículum de enseñanzas profesionales de música: modalidades composición-dirección en la enseñanza superior.

Carlos Eduardo Pascual Pérez

\section{EJERCICIO 2}

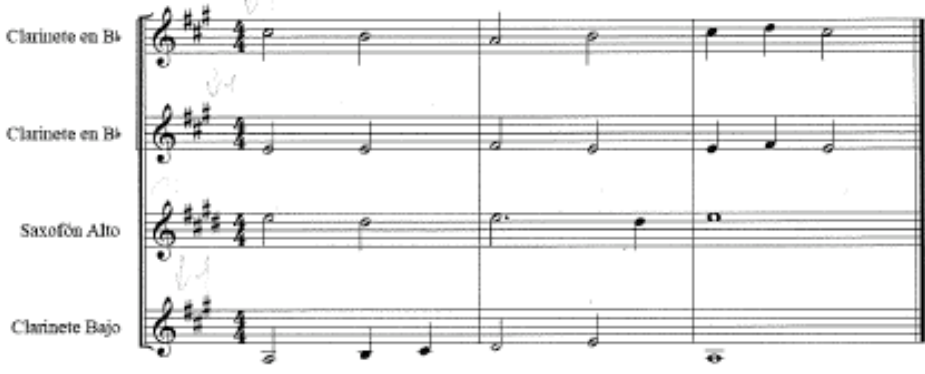

Marcar si no detectas ningún error:

\begin{tabular}{|c|c|c|c|c|}
\hline Compás & Tiempo & Instrumento/s implicado/s & Tipo de error & Observaciones \\
\hline 2 & 43 & $(j, 3 a / C+8 b$ & & \\
\hline & & & & \\
\hline & & & & \\
\hline & & & & \\
\hline & & & & \\
\hline & & & & \\
\hline & & & & \\
\hline & & & & \\
\hline
\end{tabular}

\section{EJERCICIO 3}

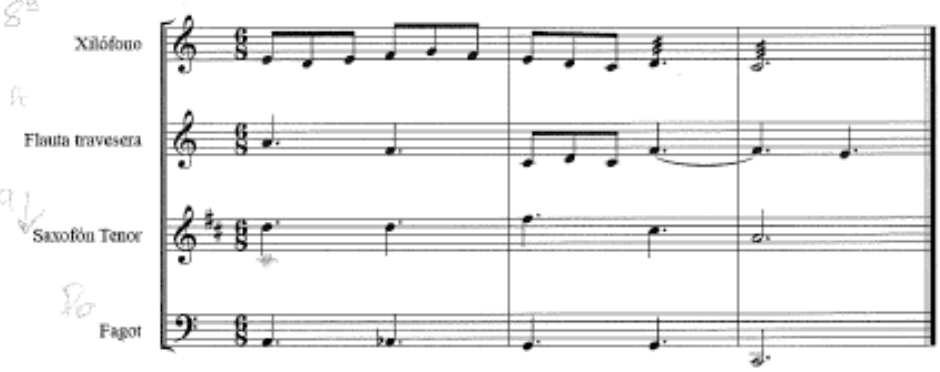

Marcar si no detectas ningún error:

\begin{tabular}{|l|l|l|l|l|}
\hline Compás & Tiempo & Instrumento/s implicado/s & Tipo de error & Observaciones \\
\hline & & & & \\
\hline & & & & \\
\hline & & & & \\
\hline & & & & \\
\hline & & & & \\
\hline & & & & \\
\hline & & & & \\
\hline & & & & \\
\hline
\end{tabular}


Diseño y planificación de competencias específicas en el currículum de enseñanzas profesionales de música: modalidades composición-dirección en la enseñanza superior.

Carlos Eduardo Pascual Pérez

\section{UNIVERSITAT} Diseño y planificación de competencios especificas en el
curriculum de enseñanzas profesionales de música. Modalidades en la enseñanza superior.

Carlos Eduardo Pascuol Pérez (investigador) - Jasé Moría Peñolver Vilar (directar) - Amparo Porta Novarro (tutoro)

\section{TEST FINAL 1ํ Armonía (3ำ Enseñanzas Profesionales)}

Detección de errores armónicos estudiados aplicados a una plantilla instrumental

Instrucciones: Debe analizarse cada fragmento instrumental como si de una reafización armónica a cuatro partes se trotose, y localizar (si los hay) errares armónicos de los que figuran en el listado*, para seguidamente enumerarlos en la tobla de respuestas, indicando para cada error su localización (compás y tiempo), parte/s implicada/s (instrumento/s) y tipo de error $(a, b, c, d, \ldots)$. Puede haber mós de un error en un mismo tiempo, en ese caso anotarlas por separado. Si se cansidera, también puede anotarse alguno observación.

Además, si no se detectan errores en un ejercicio, debe marcarse fa cosilla correspondiente. Si se desconoce o no se sabe como responder al ejercicio, dejar en blanco

*Listado de posibles típos de error:
a) Octovas seguidas
b) Quintos seguidas
c) Octavas directos
d) Quintos directos
e) Cruzamiento de voces
f) Superación de la separación
móxima entre voces

g) Duplicación de la sensible

h) Resolución incorrecto o irresolución de la sensible

i) Resolución incorrecto o irresolución de Ja septima (acordes de 79 de dte.)

i) Ausencia de preparación de la séptima (acordes de $7^{9}$ de dte.)

Instrumento/s o especialidad/es que estás cursando o has cursado:

\section{EJERCICIO 1}

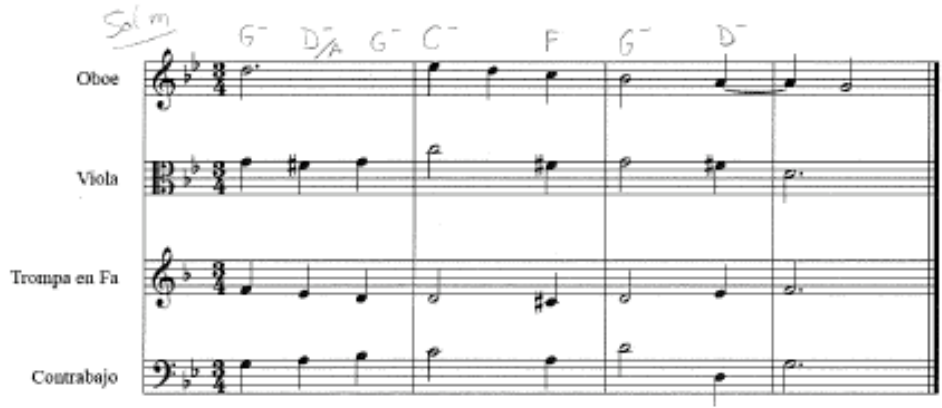

Marcar si no detectas ningún error:

\begin{tabular}{|c|c|c|c|c|}
\hline Compás & Tiempo & Instrumento $/ \mathrm{s}$ implicado/s & Tipo de error & Observociones \\
\hline 2 & $1 \quad y^{2}$ & Tramsa / Contractajo & e & \\
\hline 2 & 1 y 2 & Viola/Trompo. & $f$ & \\
\hline 2 & 3 & Viala /Trom sa & 2 & \\
\hline 3 & $1=2$ & Tesmog/Contrabaio & e & \\
\hline 3 & 3 & Visla & $n$ & \\
\hline & & & & \\
\hline & & & & \\
\hline & & & & \\
\hline
\end{tabular}


Diseño y planificación de competencias específicas en el currículum de enseñanzas profesionales de música: modalidades composición-dirección en la enseñanza superior.

Carlos Eduardo Pascual Pérez

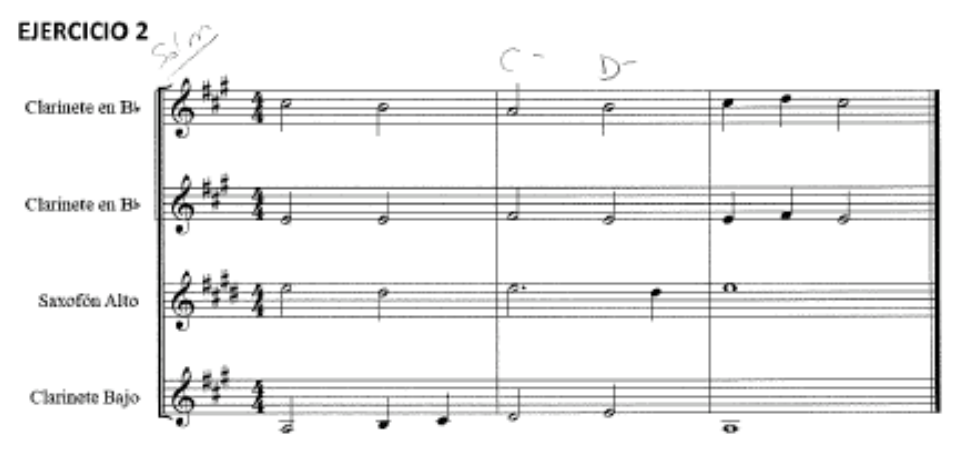

Marcar si no detectas ningún error:

\begin{tabular}{|c|c|c|c|c|}
\hline Compás & Tiempo & Instrumento/s implicado/s & Tipo de error & Observaciones \\
\hline $1 y^{2}$ & $3 y^{4} y^{2}$ & 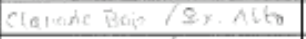 & $b$ & \\
\hline 2 & $2 \backsim 3$ & Clannete en Bb/Clanneste Bais & $b$ & \\
\hline & & & & \\
\hline & & & & \\
\hline & & & & \\
\hline & & & & \\
\hline & & & & \\
\hline & & & & \\
\hline
\end{tabular}

EJERCICIO 3

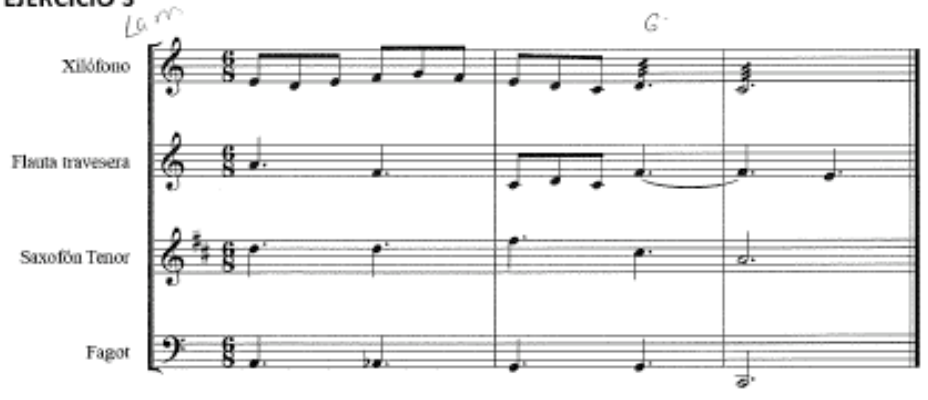

Marcar sì no detectas ningún error

\begin{tabular}{|c|c|c|c|c|}
\hline Compás & Tiempo & Instrumento/s implicado/s & Tipo de error & Observociones \\
\hline 1 & 2 & Xithofors / Flanto Trav. & $f$ & \\
\hline 2 & $\lambda$ & Xilotana/Flout a Trav. & $f$ & \\
\hline 3 & 2 & Flautha Travesera & $h$ & \\
\hline & & & & \\
\hline & & & & \\
\hline & & & & \\
\hline & & & & \\
\hline & & & & \\
\hline
\end{tabular}


Diseño y planificación de competencias específicas en el currículum de enseñanzas profesionales de música: modalidades composición-dirección en la enseñanza superior.

Carlos Eduardo Pascual Pérez

1. UNIVERSITAT
Diseño y planificación de competencias especificas en el curriculum de enseñanzas profesionales de música. Modalidades en la enseñanzo superior.

Carlos Eduardo Poscual Pérez (investigador) - José María Peflitiver Whar (director) - Amparo Parto Novarro (tutara)

TEST FINAL 1 Armonía (3ำ Enseñanzas Profesionales)

Detección de errores armónicos estudiados aplicados a una plantilla instrumental

Instrucciones: Debe analizarse cada fragmento instrumental como si de una realización armónica a cuatro partes se tratase, y localizar (si los hay) errares armónicos de los que figuran en el listodo*, para seguidamente enumerarlas en la tabla de respuestas, indicando para cada error su focalización (compás y tiempo), parte/s implicada/s (instrumento/s) y tipo de error $(a, b, c, d, \ldots)$. Puede haber mós de un error en un mismo tiempo, en ese caso anotarios por separado. Si se considera, también puede anotarse alguna observación.

Ademós, si no se detecton errores en un ejerciclo, debe marcarse la cosilla correspondiente. Si se desconoce o no se sabe como responder al ejercicio, dejar en blanco.

*Listodo de posibles tipos de error:
a) Octavas seguidas
b) Quintos sequidas
c) Octovos directos
d) Quintos directos
e) Cruzomiento de voces
f) Superación de la separación
móxima entre vaces

g) Duplicaclón de la sensible

h) Resolución incorrecto o irresolución de la sensible

i) Resolución incorrecto o irresolución de la séptimo (acordes de 79 de dte.)

j) Ausencia de preparación de la séptima (acordes de $7^{9}$ de dte.)

Instrumento/s o especialidad/es que estás cursando o has cursado:

\section{EJERCICIO 1}

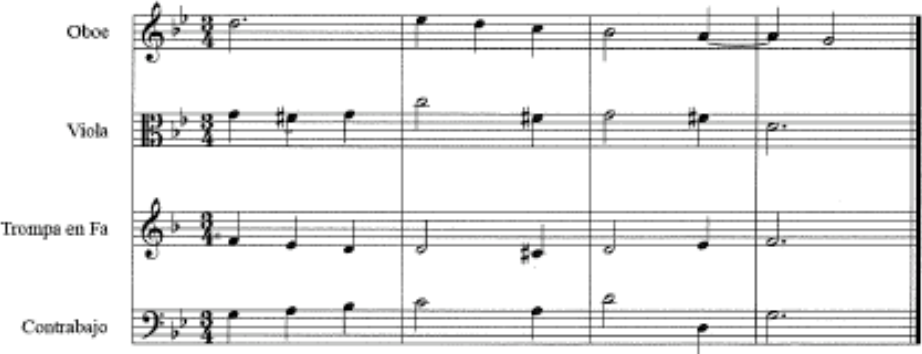

Marcar si no detectas ningún error:

\begin{tabular}{|c|c|c|c|c|}
\hline Compás & Tiempo & Instrumento/s implicado/s & Tipo de error & Observociones \\
\hline & & & & \\
\hline 3 & 1 & Tror & $f$ & \\
\hline 3 & 3 & Viala & 9 & \\
\hline & & & & \\
\hline & & & & \\
\hline & & & & \\
\hline & & & & \\
\hline & & & & \\
\hline
\end{tabular}


Diseño y planificación de competencias específicas en el currículum de enseñanzas profesionales de música: modalidades composición-dirección en la enseñanza superior.

Carlos Eduardo Pascual Pérez

EJERCICIO 2

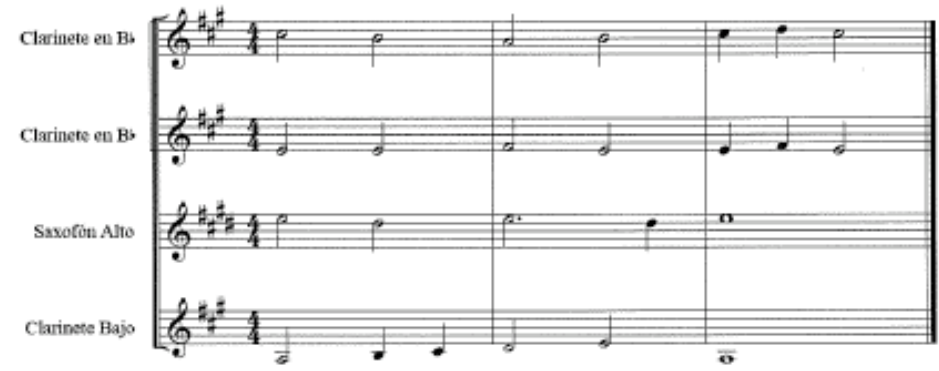

Marcar si no detectas ningún error:

\begin{tabular}{|l|l|l|l|l|}
\hline Compás & Tiempo & Instrumento/s implicado/s & Tipo de error & Observaciones \\
\hline 2 & $3 / 4$ & dwi Bojo/sacten $1 / 6$ & $2 / 6$ & \\
\hline & & & & \\
\hline & & & & \\
\hline & & & & \\
\hline & & & & \\
\hline & & & & \\
\hline & & & & \\
\hline & & & & \\
\hline
\end{tabular}

EJERCICIO 3

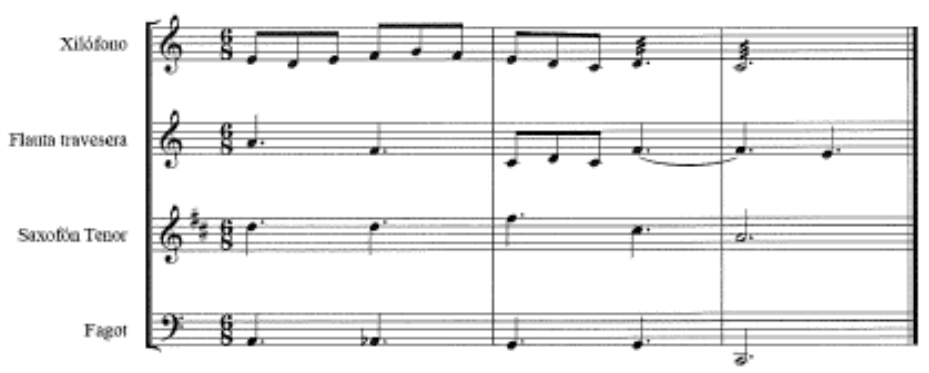

Marcar si no detectas ningún error

\begin{tabular}{|c|c|c|c|c|}
\hline Compás & Tiempo & Instrumento/s implicado/s & Tipo de error & Observaciones \\
\hline 1 & 2 & 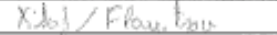 & $\mathcal{1}$ & \\
\hline 2 & 1 & 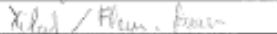 & 8 & \\
\hline & & & & \\
\hline & & & & \\
\hline & & & & \\
\hline & & & & \\
\hline & & & & \\
\hline & & & & \\
\hline
\end{tabular}


Diseño y planificación de competencias específicas en el currículum de enseñanzas profesionales de música: modalidades composición-dirección en la enseñanza superior.

Carlos Eduardo Pascual Pérez

\section{UNIVERSITAT}

Disefio y planificoción de competencias especificos en el curriculum de ensefianzas profesionales de músico. Modalidades en la enseñanzo superior.

Carlos Eduardo Pascual Pérez (învestigador) - Josè Maria Peñalver Vilar (director) - Amparo Porta Navorro (tutora)

TEST FINAL 1 Armonía (3 Enseñanzas Profesionales)

Detección de errores armónicos estudiados aplicados a una plantilla instrumenta

Instrucciones: Debe analizarse cada fragmento instrumental como sji de una realización armónica a cuatro partes se trotose, y localizor (si las hay) errores armónicos de los que figuran en el listado*, para seguidamente enumerarios en la tabla de respuestas, indicando para coda error su localización (compós y tjempo), porte/s implicada/s (instrumento/s) y tipo de error $(a, b, c, d, \ldots)$. Puede haber mós de un error en un mismo tiempo, en. ese caso anotarias por seporado. Si se considera, también puede anotarse alquna observación.

Además, si no se detecton errores en un ejercicio, debe marcarse fo casilla correspondiente. Si se desconace o no se sabe como responder al ejercicio, dejor en blanco.

Listado de pasibles tipos de error:
a) Octavas seguidas
b) Quintas seguidas
c) Octavas directas
d) Quintas directas
e) Cruzamiento de voces
f) Superación de la separación máxima entre vaces

g) Duplicación de la sensible

h) Resofución incorrecto o irresolución de lo sensibie

i) Resolución incorrecta o irresolución oe lo séptima (acordes de 79 de dte.)

1) Ausencia de preparación de la séptime (acordes de $7 g$ de dte.)

Instrumento/s o especialidad/es que estás cursando o has cursado:

\section{EJERCICIO 1}

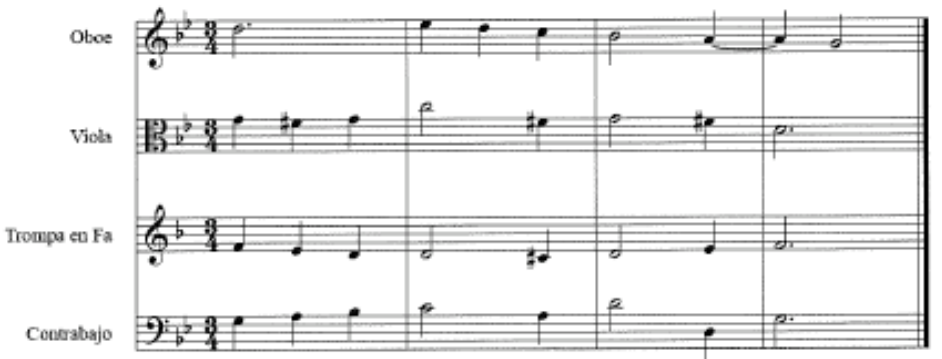

Marcar si no detectas ningún error:

\begin{tabular}{|l|l|l|l|l|}
\hline Compás & Tiempo & Instrumento/s implicado/s & Tipo de error & Observaciones \\
\hline & & & & \\
\hline & & & & \\
\hline & & & & \\
\hline & & & & \\
\hline & & & & \\
\hline & & & & \\
\hline & & & & \\
\hline & & & & \\
\hline
\end{tabular}


Diseño y planificación de competencias específicas en el currículum de enseñanzas profesionales de música: modalidades composición-dirección en la enseñanza superior.

Carlos Eduardo Pascual Pérez

\section{EJERCICIO 2}

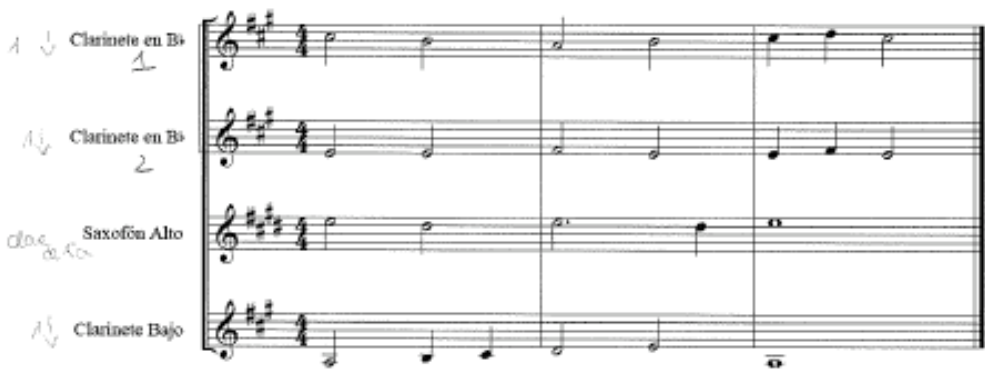

Marcar si no detectas ningún error:

\begin{tabular}{|c|c|c|c|c|}
\hline Compás & Tiempo & Instrumento/s implicado/s & Tipo de error & Observociones \\
\hline 2 & $1 \times 2$ & clainete 1 y bcio & $b$ & \\
\hline & & & & \\
\hline & & & & \\
\hline & & & & \\
\hline & & & & \\
\hline & & & & \\
\hline & & & & \\
\hline & & & & \\
\hline
\end{tabular}

EJERCICIO 3

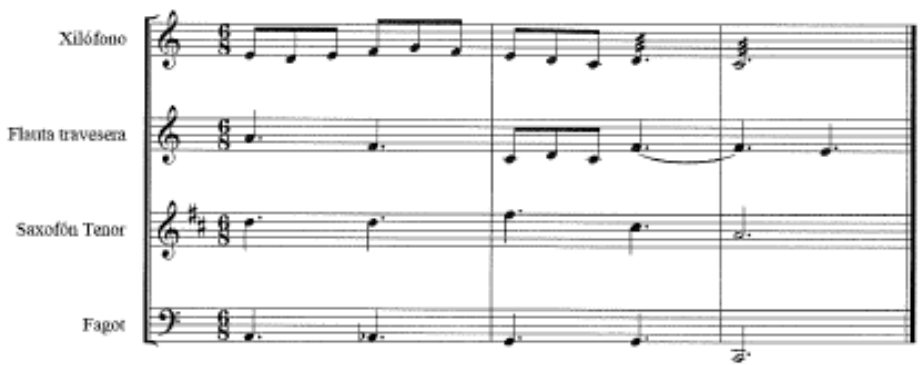

Marcar si no detectas ningún error: $\square$

\begin{tabular}{|l|l|l|l|l|}
\hline Compás & Tiempo & Instrumento/s implicado/s & Tipo de error & Observaciones \\
\hline & & & & \\
\hline & & & & \\
\hline & & & & \\
\hline & & & & \\
\hline & & & & \\
\hline & & & & \\
\hline & & & & \\
\hline & & & & \\
\hline
\end{tabular}


Diseño y planificación de competencias específicas en el currículum de enseñanzas profesionales de música: modalidades composición-dirección en la enseñanza superior.

Carlos Eduardo Pascual Pérez

\section{Anexo IV}

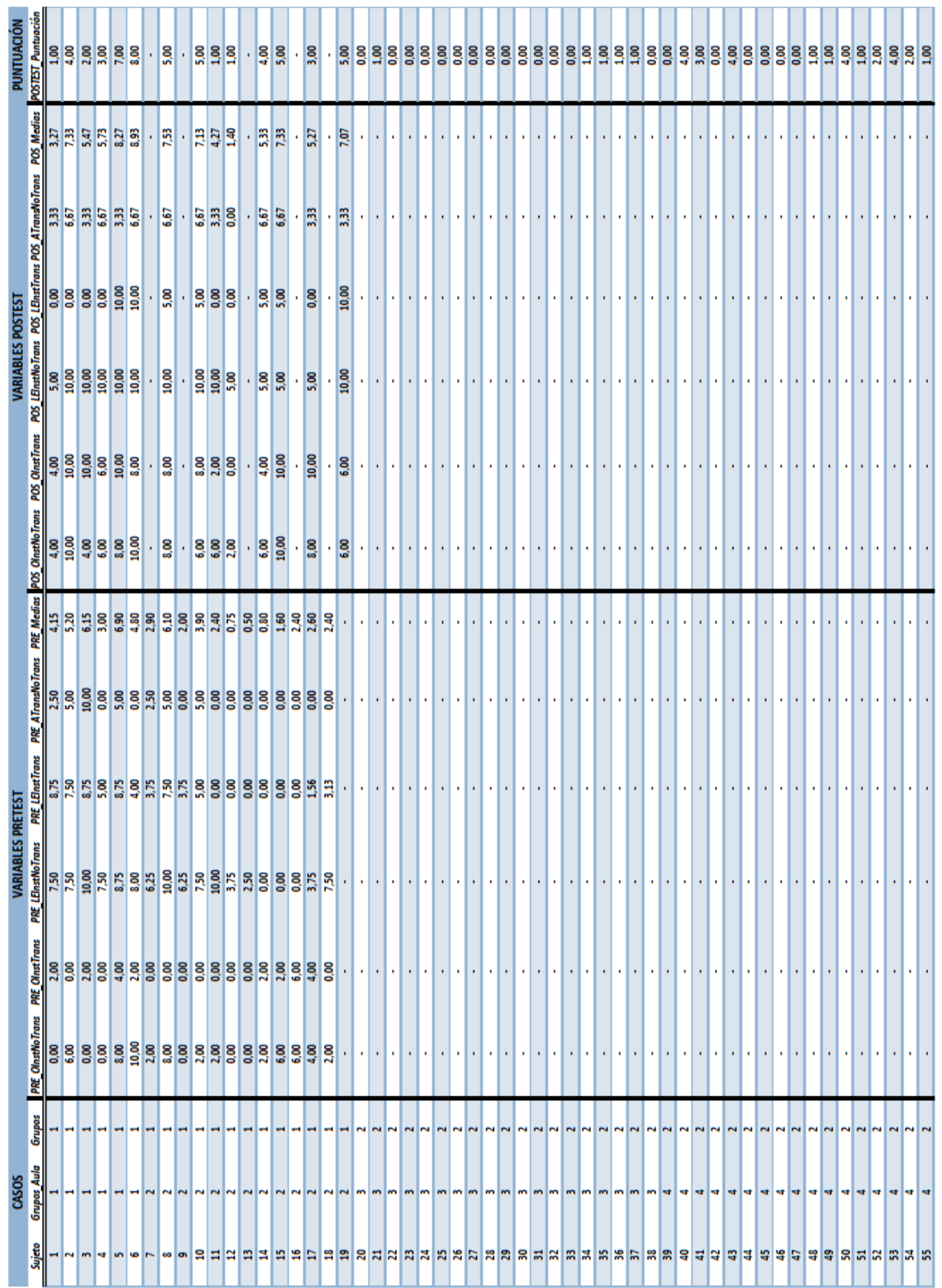


Diseño y planificación de competencias específicas en el currículum de enseñanzas profesionales de música: modalidades composición-dirección en la enseñanza superior.

Carlos Eduardo Pascual Pérez

\section{Anexo V}

\section{Estadísticos de prueba ${ }^{a}$}

\begin{tabular}{l|r|r|r|r|r} 
& $\begin{array}{c}\text { POS_OInstNo } \\
\text { Trans - } \\
\text { PRE_OInstNo } \\
\text { Trans }\end{array}$ & $\begin{array}{c}\text { POS_OInstTra } \\
\text { ns - } \\
\text { PRE_OInstTra } \\
\text { ns }\end{array}$ & $\begin{array}{c}\text { POS_LEInstNo } \\
\text { Trans - } \\
\text { PRE_LEInstNo } \\
\text { Trans }\end{array}$ & $\begin{array}{c}\text { POS_LEInstTr } \\
\text { ans - } \\
\text { PRE_LEInstTr } \\
\text { ans }\end{array}$ & $\begin{array}{c}\text { POS_ATrans } \\
\text { NoTrans - } \\
\text { PRE_ATrans } \\
\text { NoTrans }\end{array}$ \\
\hline Z & $-2,970^{\mathrm{b}}$ & $-3,088^{\mathrm{b}}$ & $-2,162^{\mathrm{b}}$ &,$- 971^{\mathrm{c}}$ & $-2,203^{\mathrm{b}}$ \\
\hline Sig. asintótica(bilateral) &, 003 &, 002 &, 031 &, 331 &, 028 \\
\hline
\end{tabular}

a. Prueba de rangos con signo de Wilcoxon

b. Se basa en rangos negativos.

c. Se basa en rangos positivos.

\section{Prueba de Mann-Whitney}

\begin{tabular}{ll|l|r|r} 
& \multicolumn{2}{c}{ Rangos } & & \\
& Grupos & N & $\begin{array}{c}\text { Rango } \\
\text { promedio }\end{array}$ & $\begin{array}{c}\text { Suma de } \\
\text { rangos }\end{array}$ \\
\hline POSTEST_Puntuación & Experiencia & 14 & 39,68 & 555,50 \\
\cline { 2 - 5 } & Control & 36 & 19,99 & 719,50 \\
\cline { 2 - 5 } & Total & 50 & & \\
\hline
\end{tabular}

Estadísticos de prueba ${ }^{a}$

\begin{tabular}{lr} 
& $\begin{array}{c}\text { POSTEST_Pu } \\
\text { ntuación }\end{array}$ \\
\hline U de Mann-Whitney & 53,500 \\
\hline W de Wilcoxon & 719,500 \\
\hline Z & $-4,472$ \\
\hline Sig. asintótica(bilateral) &, 000 \\
\hline
\end{tabular}

a. Variable de agrupación: Grupos 
Diseño y planificación de competencias específicas en el currículum de enseñanzas profesionales de música: modalidades composición-dirección en la enseñanza superior.

Carlos Eduardo Pascual Pérez

\section{Prueba de Kruskal-Wallis}

\section{Rangos}

\begin{tabular}{ll|r|r} 
& Grupos_Aula & N & \multicolumn{1}{c}{$\begin{array}{c}\text { Rango } \\
\text { promedio }\end{array}$} \\
\hline POSTEST_Puntuación & Experimental 1 & 6 & 39,67 \\
\cline { 2 - 4 } & Experimental 2 & 8 & 39,69 \\
\cline { 2 - 4 } & Control 1 & 19 & 14,71 \\
\cline { 2 - 4 } & Control 2 & 17 & 25,88 \\
\cline { 2 - 4 } & Total & 50 & \\
\hline
\end{tabular}

\section{Estadísticos de prueba ${ }^{a, b}$}

\begin{tabular}{lr} 
& $\begin{array}{c}\text { POSTEST_Pu } \\
\text { ntuación }\end{array}$ \\
\hline H de Kruskal-Wallis & 25,727 \\
\hline gl & 3 \\
\hline Sig. asintótica &, 000 \\
\hline
\end{tabular}
a. Prueba de Kruskal Wallis
b. Variable de agrupación: Grupos_Aula


Diseño y planificación de competencias específicas en el currículum de enseñanzas profesionales de música: modalidades composición-dirección en la enseñanza superior.

Carlos Eduardo Pascual Pérez

\section{Anexo VI}

Estadísticas de muestras emparejadas

\begin{tabular}{|c|c|c|c|c|c|}
\hline & & Media & $\mathrm{N}$ & $\begin{array}{l}\text { Desv. } \\
\text { Desviación }\end{array}$ & $\begin{array}{c}\text { Desv. Error } \\
\text { promedio }\end{array}$ \\
\hline \multirow[t]{2}{*}{ Par 1} & PRE_OInstNoTrans & 3,692 & 13 & 3,5446 & 9831 \\
\hline & POS_OInstNoTrans & 6,769 & 13 & 2,5217 & ,6994 \\
\hline \multirow[t]{2}{*}{ Par 2} & PRE_OlnstTrans & 1,38 & 13 & 1,502 & ,417 \\
\hline & POS_OlnstTrans & 6,9231 & 13 & 3,42689 & ,95045 \\
\hline \multirow[t]{2}{*}{ Par 3} & PRE_LEInstNoTrans & 6,481 & 13 & 3,5081 & ,9730 \\
\hline & POS_LEInstNoTrans & 8,0769 & 13 & 2,53185 & ,70221 \\
\hline \multirow[t]{2}{*}{ Par 4} & PRE_LEInstTrans & 4,370 & 13 & 3,6782 & 1,0201 \\
\hline & POS_LEInstTrans & 3,0769 & 13 & 3,83974 & 1,06495 \\
\hline \multirow[t]{2}{*}{ Par 5} & PRE_ATransNoTrans & 2,500 & 13 & 3,2275 & ,8951 \\
\hline & POS_ATransNoTrans & 4,8726 & 13 & 2,20227 & ,61080 \\
\hline
\end{tabular}

Correlaciones de muestras emparejadas

\begin{tabular}{|c|c|c|c|c|}
\hline & & $\mathrm{N}$ & Correlación & Sig. \\
\hline Par 1 & $\begin{array}{l}\text { PRE_OlnstNoTrans \& } \\
\text { POS_OInstNoTrans }\end{array}$ & 13 & 849 & ,000 \\
\hline Par 2 & $\begin{array}{l}\text { PRE_OInstTrans \& } \\
\text { POS_OlnstTrans }\end{array}$ & 13 & ,443 & 129 \\
\hline Par 3 & $\begin{array}{l}\text { PRE_LEInstNoTrans \& } \\
\text { POS_LEInstNoTrans }\end{array}$ & 13 & ,816 & ,001 \\
\hline Par 4 & $\begin{array}{l}\text { PRE_LEInstTrans \& } \\
\text { POS_LEInstTrans }\end{array}$ & 13 & ,090 & 771 \\
\hline Par 5 & $\begin{array}{l}\text { PRE_ATransNoTrans \& } \\
\text { POS_ATransNoTrans }\end{array}$ & 13 & ,000 & 1,000 \\
\hline
\end{tabular}

Prueba de muestras emparejadas

Diferencias emparejadas

\begin{tabular}{|c|c|c|c|c|c|c|c|c|c|}
\hline \multicolumn{7}{|c|}{ Diferencias emparejadas } & \multirow[b]{3}{*}{$t$} & \multirow[b]{3}{*}{ gl } & \multirow{3}{*}{$\begin{array}{c}\text { Sig. } \\
\text { (bilateral) }\end{array}$} \\
\hline & & \multirow[b]{2}{*}{ Media } & \multirow{2}{*}{$\begin{array}{c}\text { Desv. } \\
\text { Desviación }\end{array}$} & \multirow{2}{*}{$\begin{array}{c}\text { Desv. Error } \\
\text { promedio }\end{array}$} & \multicolumn{2}{|c|}{$\begin{array}{l}95 \% \text { de intervalo de } \\
\text { confianza de la diferencia }\end{array}$} & & & \\
\hline & & & & & Inferior & Superior & & & \\
\hline Par 1 & $\begin{array}{l}\text { PRE_OInstNoTrans - } \\
\text { POS_OInstNoTrans }\end{array}$ & $-3,0769$ & 1,9348 &, 5366 & $-4,2461$ & $-1,9077$ & $-5,734$ & 12 &, 000 \\
\hline Par 2 & $\begin{array}{l}\text { PRE_OInstTrans - } \\
\text { POS_OInstTrans }\end{array}$ & $-5,53846$ & 3,07179 & ,85196 & $-7,39473$ & $-3,68220$ & $-6,501$ & 12 &, 000 \\
\hline Par 3 & $\begin{array}{l}\text { PRE_LEInstNoTrans - } \\
\text { POS_LEInstNoTrans }\end{array}$ & $-1,59615$ & 2,05279 & ,56934 & $-2,83664$ &,- 35567 & $-2,804$ & 12 & 016 \\
\hline Par 4 & $\begin{array}{l}\text { PRE_LEInstTrans - } \\
\text { POS_LEInstTrans }\end{array}$ & 1,29327 & 5,07351 & 1,40714 & $-1,77262$ & 4,35916 & ,919 & 12 & ,376 \\
\hline Par 5 & $\begin{array}{l}\text { PRE_ATransNoTrans - } \\
\text { POS_ATransNoTrans }\end{array}$ & $-2,37256$ & 3,90708 & 1,08363 & $-4,73359$ &,- 01154 & $-2,189$ & 12 &, 049 \\
\hline
\end{tabular}


Diseño y planificación de competencias específicas en el currículum de enseñanzas profesionales de música: modalidades composición-dirección en la enseñanza superior.

Carlos Eduardo Pascual Pérez

\section{Prueba T}

\begin{tabular}{ll|r|r|r|r}
\multicolumn{7}{c}{ Estadísticas de grupo } \\
& Grupos & N & Media & $\begin{array}{c}\text { Desv. } \\
\text { Desviación }\end{array}$ & $\begin{array}{c}\text { Desv. Error } \\
\text { promedio }\end{array}$ \\
\hline POSTEST_Puntuación & Experiencia & 14 & 3,8571 & 2,17882 &, 58231 \\
\cline { 2 - 7 } & Control & 36 &, 8889 & 1,32617 &, 22103 \\
\hline
\end{tabular}

\begin{tabular}{|c|c|c|c|c|c|c|c|c|c|c|}
\hline \multicolumn{11}{|c|}{ Prueba de muestras independientes } \\
\hline & & \multicolumn{2}{|c|}{$\begin{array}{l}\text { Prueba de Levene de } \\
\text { igualdad de varianzas }\end{array}$} & \multicolumn{7}{|c|}{ prueba t para la igualdad de medias } \\
\hline & & \multirow[b]{2}{*}{$\mathrm{F}$} & \multirow[b]{2}{*}{ Sig. } & \multirow[b]{2}{*}{$\mathrm{t}$} & \multirow[b]{2}{*}{ gl } & \multirow{2}{*}{$\begin{array}{c}\text { Sig. } \\
\text { (bilateral) }\end{array}$} & \multirow{2}{*}{$\begin{array}{l}\text { Diferencia de } \\
\text { medias }\end{array}$} & \multirow{2}{*}{$\begin{array}{l}\text { Diferencia de } \\
\text { error } \\
\text { estándar }\end{array}$} & \multicolumn{2}{|c|}{$\begin{array}{l}95 \% \text { de intervalo de } \\
\text { confianza de la diferencia }\end{array}$} \\
\hline & & & & & & & & & Inferior & Superior \\
\hline \multirow[t]{2}{*}{ POSTEST_Puntuación } & $\begin{array}{l}\text { Se asumen varianzas } \\
\text { iguales }\end{array}$ & 5,867 & ,019 & 5,881 & 48 &, 000 & 2,96825 & ,50475 & 1,95338 & 3,98312 \\
\hline & $\begin{array}{l}\text { No se asumen varianzas } \\
\text { iguales }\end{array}$ & & & 4,766 & 16,886 &, 000 & 2,96825 & 62285 & 1,65347 & 4,28303 \\
\hline
\end{tabular}

ANOVA

\begin{tabular}{l|r|r|r|r|r} 
POSTEST_Puntuación & $\begin{array}{c}\text { Suma de } \\
\text { cuadrados }\end{array}$ & gl & \multicolumn{1}{c}{$\begin{array}{c}\text { Media } \\
\text { cuadrática }\end{array}$} & \multicolumn{1}{c}{ F } & \multicolumn{1}{c}{ Sig. } \\
\hline Entre grupos & 105,570 & 3 & 35,190 & 15,198 &, 000 \\
\hline Dentro de grupos & 106,510 & 46 & 2,315 & & \\
\hline Total & 212,080 & 49 & & & \\
\hline
\end{tabular}




\section{PROGRAMACIÓN DIDÁCTICA}

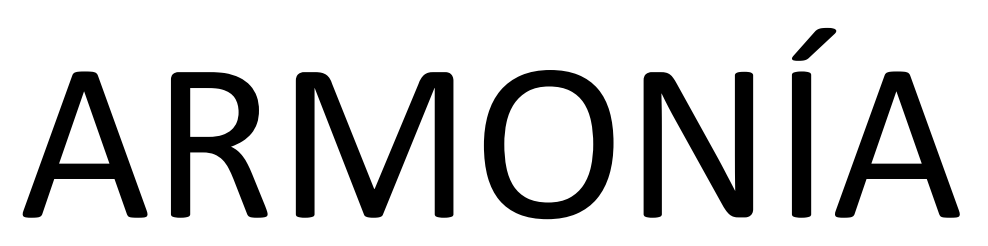

\section{ENSEÑANZAS PROFESIONALES} COMPETENCIAS CLAVE 
Diseño y planificación de competencias específicas en el currículum de enseñanzas profesionales de música: modalidades composición-dirección en la enseñanza superior.

Las competencias que se recogen en esta programación se han establecido de conformidad con los resultados de la investigación educativa y con las tendencias europeas recogidas en la Recomendación 2006/962/EC, del Parlamento Europeo y del Consejo, de 18 de diciembre de 2006, sobre las competencias clave para el aprendizaje permanente. Dichas competencias se describen, se indica su finalidad y aspectos distintivos, y se pone de manifiesto, en cada una de ellas, las claves de desarrollo que debe alcanzar todo el alumnado referidas al final de la enseñanza profesional de música, pero cuyo desarrollo debe iniciarse desde el comienzo de la escolarización, de manera que su adquisición se realice de forma progresiva y coherente a lo largo de las distintas etapas educativas.

Las competencias clave deberán estar estrechamente vinculadas a los objetivos definidos para la enseñanza artística de Música. Esta vinculación favorece que la consecución de dichos objetivos a lo largo de la vida académica lleve implícito el desarrollo de las competencias clave, para que todas las personas puedan alcanzar su desarrollo personal y lograr una correcta incorporación en la sociedad.

Un enfoque metodológico basado en las competencias clave y en los resultados de aprendizaje conlleva importantes cambios en la concepción del proceso de enseñanza-aprendizaje, cambios en la organización y en la cultura escolar; requiere la estrecha colaboración entre los docentes en el desarrollo curricular y en la transmisión de información sobre el aprendizaje de los alumnos y alumnas, así como cambios en las prácticas de trabajo y en los métodos de enseñanza. De este hecho se desprenden las competencias clave del currículo en el sistema educativo español.

\section{Comunicación lingüística.}

Es el resultado de la acción comunicativa dentro de prácticas musicales y sociales determinadas, en las cuales el individuo actúa con otros interlocutores y a través de textos en múltiples modalidades, formatos y soportes. Estas situaciones y prácticas pueden implicar el uso de distintos lenguajes musicales, en diversos ámbitos y de manera individual o colectiva. Para ello el individuo dispone de su repertorio musical, pero ajustado a las experiencias comunicativas que experimenta a lo largo de la vida. Los distintos lenguajes musicales que utiliza pueden haber tenido vías y tiempos distintos de adquisición y constituir, por tanto, experiencias de aprendizaje musicales, tanto populares como de otra índole. Esta visión de la competencia en comunicación lingüística vinculada con prácticas musicales determinadas ofrece una imagen del individuo como agente comunicativo que produce, y no sólo recibe, mensajes a través de las diferentes manifestaciones musicales con distintas finalidades. Valorar la relevancia de esta afirmación en la toma de decisiones educativas supone optar por metodologías activas de aprendizaje (aprendizaje basado en tareas y proyectos, en problemas, en retos, etcétera), ya sean estas en lenguajes musicales vanguardistas y actuales, frente a opciones metodológicas más tradicionales. Además, la competencia en comunicación lingüística musical, representa una vía de conocimiento y contacto con la diversidad cultural que implica un factor de enriquecimiento para la propia competencia y que adquiere una particular relevancia en el caso de las músicas de otras culturas. Por tanto, un enfoque intercultural en la enseñanza y el 
Diseño y planificación de competencias específicas en el currículum de enseñanzas profesionales de música: modalidades composición-dirección en la enseñanza superior.

Carlos Eduardo Pascual Pérez

aprendizaje de las diferentes músicas implica una importante contribución al desarrollo de la competencia en comunicación lingüística musical del alumnado.

Esta competencia es, por definición, siempre parcial y constituye un objetivo de aprendizaje permanente a lo largo de toda la vida. Por ello, para que se produzca un aprendizaje satisfactorio de las diferentes músicas, es determinante que se promuevan unos contextos de uso de lenguajes musicales ricos y variados, en relación con las tareas que se han de realizar y sus posibles interlocutores, textos e intercambios comunicativos.

La competencia en comunicación lingüística musical es extremadamente compleja. Se basa, en primer lugar, en el conocimiento del componente lingüístico musical. Pero además, como se produce y desarrolla en situaciones comunicativas concretas y contextualizadas, el individuo necesita activar su conocimiento del componente pragmático-discursivo y socio-cultural.

Esta competencia precisa de la interacción de distintas destrezas, ya que se produce en múltiples modalidades de comunicación y en diferentes soportes. Desde la oralidad y la escritura hasta las formas más sofisticadas de comunicación audiovisual o mediada por la tecnología, el individuo participa de un complejo entramado de posibilidades comunicativas gracias a las cuales expande su competencia y su capacidad de interacción con otros individuos. Por ello, esta diversidad de modalidades y soportes requiere de una alfabetización musical más compleja, recogida en el concepto de alfabetizaciones múltiples, que permita al individuo su participación como ciudadano activo.

La competencia en comunicación lingüística musical es también un instrumento fundamental para la socialización y el aprovechamiento de la experiencia educativa, por ser una vía privilegiada de acceso al conocimiento dentro y fuera de la escuela. De su desarrollo depende, en buena medida, que se produzcan distintos tipos de aprendizaje en distintos contextos, formales, informales y no formales. En este sentido, es especialmente relevante en el contexto escolar la consideración de la lectura como destreza básica para la ampliación de la competencia en comunicación lingüística musical y el aprendizaje. Así, el lenguaje musical es la principal vía de acceso a todas las áreas, por lo que el contacto con una diversidad de textos resulta fundamental para acceder a las fuentes originales del saber. Por ello, donde manifiesta su importancia, de forma más patente, es en el desarrollo de las destrezas que conducen al conocimiento de los textos musicales, no solo en su consideración como canon artístico o en su valoración como parte del patrimonio cultural, sino, sobre todo, y principalmente, como fuente de disfrute y aprendizaje a lo largo de la vida.

Desde esta perspectiva, es recomendable que el centro educativo sea la unidad de acción para el desarrollo de la competencia en comunicación lingüística musical. En este sentido, actuaciones como el diseño de un Proyecto Artístico Musical de Centro que forme parte del propio Proyecto Educativo de Centro, un Plan Lector o unas estrategias para el uso de la Biblioteca y Fonoteca Escolar como espacio de aprendizaje y disfrute permiten un tratamiento 
Diseño y planificación de competencias específicas en el currículum de enseñanzas profesionales de música: modalidades composición-dirección en la enseñanza superior.

Carlos Eduardo Pascual Pérez

más global y eficaz de la competencia en comunicación lingüística musical en los términos aquí expresados.

La competencia en comunicación lingüística musical se inscribe en un marco de actitudes y valores que el individuo pone en funcionamiento: el respeto a las normas de convivencia; el ejercicio activo de la ciudadanía; el desarrollo de un espíritu crítico; el respeto a los derechos humanos y el pluralismo; la concepción del diálogo como herramienta primordial para la convivencia, la resolución de conflictos y el desarrollo de las capacidades afectivas en todos los ámbitos; una actitud de curiosidad, interés y creatividad hacia el aprendizaje y el reconocimiento de las destrezas inherentes a esta competencia (lectura, conversación, escritura, etcétera) como fuentes de placer relacionada con el disfrute personal y cuya promoción y práctica son tareas esenciales en el refuerzo de la motivación hacia el aprendizaje.

En resumen, para el adecuado desarrollo de esta competencia resulta necesario abordar el análisis y la consideración de los distintos aspectos que intervienen en ella, debido a su complejidad. Para ello, se debe atender a los cinco componentes que la constituyen y a las dimensiones en las que se concretan:

- El componente lingüístico musical que comprende diversas dimensiones: la léxica, la gramatical, la semántica, la fonológica, la ortográfica y la ortoépica, entendida esta como la articulación correcta del sonido a partir de la representación gráfica de la música.

- El componente pragmático-discursivo contempla tres dimensiones: la socio-musical (vinculada con la adecuada producción y recepción de mensajes en diferentes contextos sociales); la pragmática (que incluye las microfunciones comunicativas y los esquemas de interacción); y la discursiva (que incluye las macrofunciones textuales y las cuestiones relacionadas con los géneros discursivos).

- El componente socio-cultural incluye dos dimensiones: la que se refiere al conocimiento del mundo y la dimensión intercultural.

- El componente estratégico permite al individuo superar las dificultades y resolver los problemas que surgen en el acto comunicativo. Incluye tanto destrezas y estrategias comunicativas para la lectura, la escritura, la interpretación musical, la escucha, como destrezas vinculadas con el tratamiento de la información, la lectura multimodal y la producción de textos electrónicos en diferentes formatos; asimismo, también forman parte de este componente las estrategias generales de carácter cognitivo, metacognitivo y socioafectivas que el individuo utiliza para comunicarse eficazmente, aspectos fundamentales en el aprendizaje de las otras culturas musicales extranjeras. 
Diseño y planificación de competencias específicas en el currículum de enseñanzas profesionales de música: modalidades composición-dirección en la enseñanza superior.

Carlos Eduardo Pascual Pérez

- Por último, la competencia en comunicación lingüística musical incluye un componente personal que interviene en la interacción comunicativa en tres dimensiones: la actitud, la motivación y los rasgos de personalidad.

\section{Competencia matemática y competencias básicas en ciencia y tecnología.}

La competencia matemática y las competencias básicas en ciencia y tecnología inducen y fortalecen algunos aspectos esenciales de la formación de las personas que resultan fundamentales para la vida. En una sociedad donde el impacto de las matemáticas, las ciencias y las tecnologías es determinante, la consecución y sostenibilidad del bienestar social exige conductas y toma de decisiones personales estrechamente vinculadas a la capacidad crítica y visión razonada y razonable de las personas. A ello contribuyen la competencia matemática y competencias básicas en ciencia y tecnología, las cuales están incluidas en la enseñanza musical a través de sus distintas asignaturas.

La competencia matemática implica la capacidad de aplicar el razonamiento matemático y sus herramientas para describir, interpretar y predecir distintos fenómenos en su contexto, al igual que ocurre en las estructuras musicales. La competencia matemática musical requiere de conocimientos sobre las medidas y las estructuras que componen las obras musicales, así como de las operaciones y las representaciones armónicas, y la comprensión de los términos que conllevan estas representaciones.

El uso de herramientas matemáticas, dentro de la enseñanza musical, implica una serie de destrezas que requieren la aplicación de los principios y procesos matemáticos en distintos contextos, ya sean personales, sociales, profesionales o científicos, así como para emitir juicios fundados y seguir cadenas argumentales en la realización de cálculos, el análisis de gráficos y representaciones armónicas y la manipulación de expresiones musicales, incorporando los medios digitales cuando sea oportuno. Forma parte de esta destreza la creación de descripciones y explicaciones musicales que llevan implícitas la interpretación de resultados compositivos y la reflexión sobre su adecuación al contexto, al igual que la determinación de si las soluciones son adecuadas y tienen sentido en la situación en que se presentan. Se trata, por tanto, de reconocer el papel que desempeñan las estructuras matemático-musicales en el mundo y utilizar los conceptos, procedimientos y herramientas para aplicarlos en la resolución de los problemas que puedan surgir en una situación determinada a lo largo de la vida. La activación de la competencia matemática supone que el aprendiz es capaz de establecer una relación profunda entre el conocimiento conceptual y el conocimiento procedimental, implicados en la resolución de una tarea matemático-musical determinada.

La competencia matemática incluye una serie de actitudes y valores que se basan en el rigor, el respeto a los datos y la veracidad. Así pues, para el adecuado desarrollo de la competencia 
Diseño y planificación de competencias específicas en el currículum de enseñanzas profesionales de música: modalidades composición-dirección en la enseñanza superior.

Carlos Eduardo Pascual Pérez

matemática resulta necesario abordar cuatro áreas relativas a los signos musicales, la armonía, la geometría musical, interrelacionadas de formas diversas:

- El espacio y la forma: incluyen una amplia gama de fenómenos que se encuentran en nuestro mundo musical, visual y físico: patrones, propiedades de los objetos, posiciones, direcciones y representaciones de ellos; descodificación y codificación de información visual y musical, así como navegación e interacción dinámica con formas reales, o con representaciones. La competencia matemático-musical en este sentido incluye una serie de actividades como la comprensión de la perspectiva, la elaboración y lectura de partituras, la transformación de las formas con y sin tecnología, la interpretación de vistas de escenas tridimensionales desde distintas perspectivas y la construcción de representaciones de formas musicales.

- El cambio y las relaciones: el mundo despliega multitud de relaciones temporales y permanentes entre los objetos y las circunstancias, donde los cambios se producen dentro de sistemas de objetos interrelacionados. Tener más conocimientos sobre el cambio y las relaciones supone comprender los tipos fundamentales de cambio y cuándo tienen lugar, con el fin de utilizar modelos músico-estructurales adecuados para describirlo y predecirlo.

- La incertidumbre y los datos: son un fenómeno central del análisis estructural de la música en el presente en distintos momentos del proceso de resolución de problemas en el que resulta clave la presentación e interpretación de dichas estructuras. Esta categoría incluye el reconocimiento del lugar de la variación en los procesos, la posesión de un sentido de cuantificación de esa variación, la admisión de incertidumbre y error en las mediciones y los conocimientos sobre el azar. Asimismo, comprende la elaboración, interpretación y valoración de las conclusiones extraídas en situaciones donde la incertidumbre y los datos son fundamentales.

Las competencias básicas en ciencia y tecnología son aquellas que proporcionan un acercamiento al mundo físico y a la interacción responsable con él desde acciones, tanto individuales como colectivas, orientadas a la conservación y mejora del medio natural, decisivas para la protección y mantenimiento de la calidad de vida y el progreso de los pueblos. Estas competencias contribuyen al desarrollo del pensamiento científico, pues incluyen la aplicación de los métodos propios de la racionalidad científica y las destrezas tecnológicas, que conducen a la adquisición de conocimientos, al contraste de ideas y la aplicación de los descubrimientos al bienestar social.

Las competencias en ciencia y tecnología capacitan a ciudadanos responsables y respetuosos que desarrollan juicios críticos sobre los hechos científicos y tecnológicos que se suceden a lo largo de los tiempos, pasados y actuales. Estas competencias han de capacitar, básicamente, para identificar, plantear y resolver situaciones de la vida cotidiana -personal y socialanálogamente a como se actúa frente a los retos y problemas propios de la actividades científicas y tecnológicas. 
Diseño y planificación de competencias específicas en el currículum de enseñanzas profesionales de música: modalidades composición-dirección en la enseñanza superior.

Para el adecuado desarrollo de las competencias en ciencia y tecnología resulta necesario abordar los saberes o conocimientos científicos relativos a la física, la química, la biología, la geología, las matemáticas y la tecnología, los cuales se derivan de conceptos, procesos y situaciones interconectadas. Estos saberes el alumnado los adquirirá en la enseñanza general (ESO, Bachillerato). Se requiere igualmente el fomento de destrezas que permitan utilizar y manipular herramientas y máquinas tecnológicas, así como utilizar datos y procesos científicos para alcanzar un objetivo; es decir, identificar preguntas, resolver problemas, llegar a una conclusión o tomar decisiones basadas en pruebas y argumentos.

Asimismo, estas competencias incluyen actitudes y valores relacionados con la asunción de criterios éticos asociados a la ciencia y a la tecnología, el interés por la ciencia, el apoyo a la investigación científica y la valoración del conocimiento científico; así como el sentido de la responsabilidad en relación a la conservación de los recursos naturales y a las cuestiones medioambientales y a la adopción de una actitud adecuada para lograr una vida física y mental saludable en un entorno natural y social.

\section{Competencia digital.}

La competencia digital es aquella que implica el uso creativo, crítico y seguro de las tecnologías de la información y la comunicación para alcanzar los objetivos relacionados con el trabajo, la empleabilidad, el aprendizaje, el uso del tiempo libre, la inclusión y participación en la sociedad.

Esta competencia supone, además de la adecuación a los cambios que introducen las nuevas tecnologías en la alfabetización, la lectura y la escritura de la música, un conjunto nuevo de conocimientos, habilidades y actitudes necesarias hoy en día para ser competente en un entorno digital.

Requiere de conocimientos relacionados con el lenguaje específico básico: textual, numérico, icónico, visual, gráfico y sonoro, así como sus pautas de decodificación y transferencia. Esto conlleva el conocimiento de las principales aplicaciones informáticas. Supone también el acceso a las fuentes y el procesamiento de la información; y el conocimiento de los derechos y las libertades que asisten a las personas en el mundo digital. Igualmente precisa del desarrollo de diversas destrezas relacionadas con el acceso a la información, el procesamiento y uso para la comunicación, la creación de contenidos, la seguridad y la resolución de problemas, tanto en contextos formales como no formales e informales. La persona ha de ser capaz de hacer un uso habitual de los recursos tecnológicos disponibles con el fin de resolver los problemas reales de un modo eficiente, así como evaluar y seleccionar nuevas fuentes de información e innovaciones tecnológicas, a medida que van apareciendo, en función de su utilidad para acometer tareas u objetivos específicos.

La adquisición de esta competencia requiere además actitudes y valores que permitan al usuario adaptarse a las nuevas necesidades establecidas por las tecnologías, su apropiación y adaptación a los propios fines y la capacidad de interaccionar socialmente en torno a ellas. Se 
Diseño y planificación de competencias específicas en el currículum de enseñanzas profesionales de música: modalidades composición-dirección en la enseñanza superior.

trata de desarrollar una actitud activa, crítica y realista hacia las tecnologías y los medios tecnológicos, valorando sus fortalezas y debilidades y respetando principios éticos en su uso. Por otra parte, la competencia digital implica la participación y el trabajo colaborativo, así como la motivación y la curiosidad por el aprendizaje y la mejora en el uso de las tecnologías.

Por tanto, para el adecuado desarrollo de la competencia digital resulta necesario abordar:

- La información: esto conlleva la comprensión de cómo se gestiona la información y de cómo se pone a disposición de los usuarios, así como el conocimiento y manejo de diferentes motores de búsqueda y bases de datos, sabiendo elegir aquellos que responden mejor a las propias necesidades de información.

- Igualmente, supone saber analizar e interpretar la información que se obtiene, cotejar y evaluar el contenido de los medios de comunicación en función de su validez, fiabilidad y adecuación entre las fuentes, tanto online como offline. Y por último, la competencia digital supone saber transformar la información en conocimiento a través de la selección apropiada de diferentes opciones de almacenamiento.

- La comunicación: supone tomar conciencia de los diferentes medios de comunicación digital y de varios paquetes de software de comunicación y de su funcionamiento así como sus beneficios y carencias en función del contexto y de los destinatarios. Al mismo tiempo, implica saber qué recursos pueden compartirse públicamente y el valor que tienen, es decir, conocer de qué manera las tecnologías y los medios de comunicación pueden permitir diferentes formas de participación y colaboración para la creación de contenidos que produzcan un beneficio común. Ello supone el conocimiento de cuestiones éticas como la identidad digital y las normas de interacción digital.

- La creación de contenidos: implica saber cómo los contenidos digitales pueden realizarse en diversos formatos (texto, audio, vídeo, imágenes) así como identificar los programas/aplicaciones que mejor se adaptan al tipo de contenido que se quiere crear. Supone también la contribución al conocimiento de dominio público (wikis, foros públicos, revistas), teniendo en cuenta las normativas sobre los derechos de autor y las licencias de uso y publicación de la información.

- La seguridad: implica conocer los distintos riesgos asociados al uso de las tecnologías y de recursos online y las estrategias actuales para evitarlos, lo que supone identificar los comportamientos adecuados en el ámbito digital para proteger la información, propia y de otras personas, así como conocer los aspectos adictivos de las tecnologías.

- La resolución de problemas: esta dimensión supone conocer la composición de los dispositivos digitales, sus potenciales y limitaciones en relación a la consecución de metas personales, así como saber dónde buscar ayuda para la resolución de problemas teóricos y técnicos, lo que implica una combinación heterogénea y bien equilibrada de las tecnologías digitales y no digitales más importantes en esta área de conocimiento.

\section{Aprender a aprender.}

La competencia de aprender a aprender es fundamental para el aprendizaje permanente que se produce a lo largo de la vida y que tiene lugar en distintos contextos formales, no formales e informales. 
Diseño y planificación de competencias específicas en el currículum de enseñanzas profesionales de música: modalidades composición-dirección en la enseñanza superior.

Carlos Eduardo Pascual Pérez

Esta competencia se caracteriza por la habilidad para iniciar, organizar y persistir en el aprendizaje. Esto exige, en primer lugar, la capacidad para motivarse por aprender. Esta motivación depende de que se genere la curiosidad y la necesidad de aprender, de que el estudiante se sienta protagonista del proceso y del resultado de su aprendizaje $y$, finalmente, de que llegue a alcanzar las metas de aprendizaje propuestas y, con ello, que se produzca en él una percepción de auto-eficacia. Todo lo anterior contribuye a motivarle para abordar futuras tareas de aprendizaje. En segundo lugar, en cuanto a la organización y gestión del aprendizaje, la competencia de aprender a aprender requiere conocer y controlar los propios procesos de aprendizaje para ajustarlos a los tiempos y las demandas de las tareas y actividades que conducen al aprendizaje. La competencia de aprender a aprender desemboca en un aprendizaje cada vez más eficaz y autónomo.

Esta competencia incluye una serie de conocimientos y destrezas que requieren la reflexión y la toma de conciencia de los propios procesos de aprendizaje. Así, los procesos de conocimiento se convierten en objeto del conocimiento $y$, además, hay que aprender a ejecutarlos adecuadamente.

Aprender a aprender incluye conocimientos sobre los procesos mentales implicados en el aprendizaje (cómo se aprende). Además, esta competencia incorpora el conocimiento que posee el estudiante sobre su propio proceso de aprendizaje que se desarrolla en tres dimensiones:

- el conocimiento que tiene acerca de lo que sabe y desconoce, de lo que es capaz de aprender, de lo que le interesa, etcétera;

- el conocimiento de la disciplina en la que se localiza la tarea de aprendizaje y el conocimiento del contenido concreto y de las demandas de la tarea misma

- el conocimiento sobre las distintas estrategias posibles para afrontar la tarea.

Todo este conocimiento se vuelca en destrezas de autorregulación y control inherentes a la competencia de aprender a aprender, que se concretan en estrategias de planificación en las que se refleja la meta de aprendizaje que se persigue, así como el plan de acción que se tiene previsto aplicar para alcanzarla; estrategias de supervisión desde las que el estudiante va examinando la adecuación de las acciones que está desarrollando y la aproximación a la meta; y estrategias de evaluación desde las que se analiza tanto el resultado como del proceso que se ha llevado a cabo. La planificación, supervisión y evaluación son esenciales para desarrollar aprendizajes cada vez más eficaces. Todas ellas incluyen un proceso reflexivo que permite pensar antes de actuar (planificación), analizar el curso y el ajuste del proceso (supervisión) y consolidar la aplicación de buenos planes o modificar los que resultan incorrectos (evaluación del resultado y del proceso). Estas tres estrategias deberían potenciarse en los procesos de aprendizaje y de resolución de problemas en los que participan los estudiantes.

Aprender a aprender se manifiesta tanto individualmente como en grupo. En ambos casos el dominio de esta competencia se inicia con una reflexión consciente acerca de los procesos de 
Diseño y planificación de competencias específicas en el currículum de enseñanzas profesionales de música: modalidades composición-dirección en la enseñanza superior.

aprendizaje a los que se entrega uno mismo o el grupo. No solo son los propios procesos de conocimiento, sino que, también, el modo en que los demás aprenden se convierte en objeto de escrutinio. De ahí que la competencia de aprender a aprender se adquiera también en el contexto del trabajo en equipo. Los profesores han de procurar que los estudiantes sean conscientes de lo que hacen para aprender y busquen alternativas. Muchas veces estas alternativas se ponen de manifiesto cuando se trata de averiguar qué es lo que hacen los demás en situaciones de trabajo cooperativo.

Respecto a las actitudes y valores, la motivación y la confianza son cruciales para la adquisición de esta competencia. Ambas se potencian desde el planteamiento de metas realistas a corto, medio y largo plazo. Al alcanzarse las metas aumenta la percepción de auto-eficacia y la confianza, y con ello se elevan los objetivos de aprendizaje de forma progresiva. Las personas deben ser capaces de apoyarse en experiencias vitales y de aprendizaje previas con el fin de utilizar y aplicar los nuevos conocimientos y capacidades en otros contextos, como los de la vida privada y profesional, la educación y la formación.

Saber aprender en un determinado ámbito implica ser capaz de adquirir y asimilar nuevos conocimientos y llegar a dominar capacidades y destrezas propias de dicho ámbito. En la competencia de aprender a aprender puede haber una cierta trasferencia de conocimiento de un campo a otro, aunque saber aprender en un ámbito no significa necesariamente que se sepa aprender en otro. Por ello, su adquisición debe llevarse a cabo en el marco de la enseñanza de las distintas áreas y materias del ámbito formal, y también de los ámbitos no formal e informal.

Podría concluirse que para el adecuado desarrollo de la competencia de aprender a aprender se requiere de una reflexión que favorezca un conocimiento de los procesos mentales a los que se entregan las personas cuando aprenden, un conocimiento sobre los propios procesos de aprendizaje, así como el desarrollo de la destreza de regular y controlar el propio aprendizaje que se lleva a cabo.

\section{Competencias sociales y cívicas.}

Las competencias sociales y cívicas implican la habilidad y capacidad para utilizar los conocimientos y actitudes sobre la sociedad, entendida desde las diferentes perspectivas, en su concepción dinámica, cambiante y compleja, para interpretar fenómenos y problemas sociales en contextos cada vez más diversificados; para elaborar respuestas, tomar decisiones y resolver conflictos, así como para interactuar con otras personas y grupos conforme a normas basadas en el respeto mutuo y en convicciones democráticas. Además de incluir acciones a un nivel más cercano y mediato al individuo como parte de una implicación cívica y social.

Se trata, por lo tanto, de aunar el interés por profundizar y garantizar la participación en el funcionamiento democrático de la sociedad, tanto en el ámbito público como privado, y preparar a las personas para ejercer la ciudadanía democrática y participar plenamente en la 
Diseño y planificación de competencias específicas en el currículum de enseñanzas profesionales de música: modalidades composición-dirección en la enseñanza superior.

Carlos Eduardo Pascual Pérez

vida cívica y social gracias al conocimiento de conceptos y estructuras sociales y políticas y al compromiso de participación activa y democrática.

La competencia social se relaciona con el bienestar personal y colectivo. Exige entender el modo en que las personas pueden procurarse un estado de salud física y mental óptimo, tanto para ellas mismas como para sus familias y para su entorno social próximo, y saber cómo un estilo de vida saludable puede contribuir a ello.

Para poder participar plenamente en los ámbitos social e interpersonal es fundamental adquirir los conocimientos que permitan comprender y analizar de manera crítica los códigos de conducta y los usos generalmente aceptados en las distintas sociedades y entornos, así como sus tensiones y procesos de cambio. La misma importancia tiene conocer los conceptos básicos relativos al individuo, al grupo, a la organización del trabajo, la igualdad y la no discriminación entre hombres y mujeres y entre diferentes grupos étnicos o culturales, la sociedad y la cultura. Asimismo, es esencial comprender las dimensiones intercultural y socioeconómica de las sociedades europeas y percibir las identidades culturales y nacionales como un proceso sociocultural dinámico y cambiante en interacción con la europea, en un contexto de creciente globalización.

Los elementos fundamentales de esta competencia incluyen el desarrollo de ciertas destrezas como la capacidad de comunicarse de una manera constructiva en distintos entornos sociales y culturales, mostrar tolerancia, expresar y comprender puntos de vista diferentes, negociar sabiendo inspirar confianza y sentir empatía. Las personas deben ser capaces de gestionar un comportamiento de respeto a las diferencias expresado de manera constructiva.

Asimismo, esta competencia incluye actitudes y valores como una forma de colaboración, la seguridad en uno mismo y la integridad y honestidad. Las personas deben interesarse por el desarrollo socioeconómico y por su contribución a un mayor bienestar social de toda la población, así como la comunicación intercultural, la diversidad de valores y el respeto a las diferencias, además de estar dispuestas a superar los prejuicios y a comprometerse en este sentido.

La competencia cívica se basa en el conocimiento crítico de los conceptos de democracia, justicia, igualdad, ciudadanía y derechos humanos y civiles, así como de su formulación en la Constitución española, la Carta de los Derechos Fundamentales de la Unión Europea y en declaraciones internacionales, y de su aplicación por parte de diversas instituciones a escala local, regional, nacional, europea e internacional. Esto incluye el conocimiento de los acontecimientos contemporáneos, así como de los acontecimientos más destacados y de las principales tendencias en las historias nacional, europea y mundial, así como la comprensión de los procesos sociales y culturales de carácter migratorio que implican la existencia de sociedades multiculturales en el mundo globalizado. 
Diseño y planificación de competencias específicas en el currículum de enseñanzas profesionales de música: modalidades composición-dirección en la enseñanza superior.

Las destrezas de esta competencia están relacionadas con la habilidad para interactuar eficazmente en el ámbito público y para manifestar solidaridad e interés por resolver los problemas que afecten al entorno escolar y a la comunidad, ya sea local o más amplia. Conlleva la reflexión crítica y creativa y la participación constructiva en las actividades de la comunidad o del ámbito mediato e inmediato, así como la toma de decisiones en los contextos local, nacional o europeo y, en particular, mediante el ejercicio del voto y de la actividad social y cívica.

Las actitudes y valores inherentes a esta competencia son aquellos que se dirigen al pleno respeto de los derechos humanos y a la voluntad de participar en la toma de decisiones democráticas a todos los niveles, sea cual sea el sistema de valores adoptado. También incluye manifestar el sentido de la responsabilidad y mostrar comprensión y respeto de los valores compartidos que son necesarios para garantizar la cohesión de la comunidad, basándose en el respeto de los principios democráticos. La participación constructiva incluye también las actividades cívicas y el apoyo a la diversidad y la cohesión sociales y al desarrollo sostenible, así como la voluntad de respetar los valores y la intimidad de los demás y la recepción reflexiva y crítica de la información procedente de los medios de comunicación.

Por tanto, para el adecuado desarrollo de estas competencias es necesario comprender y entender las experiencias colectivas y la organización y funcionamiento del pasado y presente de las sociedades, la realidad social del mundo en el que se vive, sus conflictos y las motivaciones de los mismos, los elementos que son comunes y los que son diferentes, así como los espacios y territorios en que se desarrolla la vida de los grupos humanos, y sus logros y problemas, para comprometerse personal y colectivamente en su mejora, participando así de manera activa, eficaz y constructiva en la vida social y profesional.

Asimismo, estas competencias incorporan formas de comportamiento individual que capacitan a las personas para convivir en una sociedad cada vez más plural, dinámica, cambiante y compleja para relacionarse con los demás; cooperar, comprometerse y afrontar los conflictos y proponer activamente perspectivas de afrontamiento, así como tomar perspectiva, desarrollar la percepción del individuo en relación a su capacidad para influir en lo social y elaborar argumentaciones basadas en evidencias.

Adquirir estas competencias supone ser capaz de ponerse en el lugar del otro, aceptar las diferencias, ser tolerante y respetar los valores, las creencias, las culturas y la historia personal y colectiva de los otros.

\section{Sentido de iniciativa y espíritu emprendedor.}

La competencia sentido de iniciativa y espíritu emprendedor implica la capacidad de transformar las ideas en actos. Ello significa adquirir conciencia de la situación a intervenir o resolver, y saber elegir, planificar y gestionar los conocimientos, destrezas o habilidades y actitudes necesarios con criterio propio, con el fin de alcanzar el objetivo previsto. 
Diseño y planificación de competencias específicas en el currículum de enseñanzas profesionales de música: modalidades composición-dirección en la enseñanza superior.

Carlos Eduardo Pascual Pérez

Esta competencia está presente en los ámbitos personal, social, escolar y laboral en los que se desenvuelven las personas, permitiéndoles el desarrollo de sus actividades y el aprovechamiento de nuevas oportunidades. Constituye igualmente el cimiento de otras capacidades y conocimientos más específicos, e incluye la conciencia de los valores éticos relacionados. La adquisición de esta competencia es determinante en la formación de futuros ciudadanos emprendedores, contribuyendo así a la cultura del emprendimiento. En este sentido, su formación debe incluir conocimientos y destrezas relacionados con las oportunidades de carrera y el mundo del trabajo, la educación económica y financiera o el conocimiento de la organización y los procesos empresariales, así como el desarrollo de actitudes que conlleven un cambio de mentalidad que favorezca la iniciativa emprendedora, la capacidad de pensar de forma creativa, de gestionar el riesgo y de manejar la incertidumbre. Estas habilidades resultan muy importantes para favorecer el nacimiento de emprendedores sociales, como los denominados intraemprendedores (emprendedores que trabajan dentro de empresas u organizaciones que no son suyas), así como de futuros empresarios.

Entre los conocimientos que requiere la competencia sentido de iniciativa y espíritu emprendedor se incluye la capacidad de reconocer las oportunidades existentes para las actividades personales, profesionales y comerciales. También incluye aspectos de mayor amplitud que proporcionan el contexto en el que las personas viven y trabajan, tales como la comprensión de las líneas generales que rigen el funcionamiento de las sociedades y las organizaciones sindicales y empresariales, así como las económicas y financieras; la organización y los procesos empresariales; el diseño y la implementación de un plan (la gestión de recursos humanos y/o financieros); así como la postura ética de las organizaciones y el conocimiento de cómo estas pueden ser un impulso positivo, por ejemplo, mediante el comercio justo y las empresas sociales.

Asimismo, esta competencia requiere de las siguientes destrezas o habilidades esenciales: capacidad de análisis; capacidades de planificación, organización, gestión y toma de decisiones; capacidad de adaptación al cambio y resolución de problemas; comunicación, presentación, representación y negociación efectivas; habilidad para trabajar, tanto individualmente como dentro de un equipo; participación, capacidad de liderazgo y delegación; pensamiento crítico y sentido de la responsabilidad; autoconfianza, evaluación y auto-evaluación, ya que es esencial determinar los puntos fuertes y débiles de uno mismo y de un proyecto, así como evaluar y asumir riesgos cuando esté justificado (manejo de la incertidumbre y asunción y gestión del riesgo).

Finalmente, requiere el desarrollo de actitudes y valores como: la predisposición a actuar de una forma creadora e imaginativa; el autoconocimiento y la autoestima; la autonomía o independencia, el interés y esfuerzo y el espíritu emprendedor. Se caracteriza por la iniciativa, la pro-actividad y la innovación, tanto en la vida privada y social como en la profesional. También está relacionada con la motivación y la determinación a la hora de cumplir los objetivos, ya sean personales o establecidos en común con otros, incluido el ámbito laboral. Así 
Diseño y planificación de competencias específicas en el currículum de enseñanzas profesionales de música: modalidades composición-dirección en la enseñanza superior.

Carlos Eduardo Pascual Pérez

pues, para el adecuado desarrollo de la competencia sentido de la iniciativa y espíritu emprendedor resulta necesario abordar:

- La capacidad creadora y de innovación: creatividad e imaginación; autoconocimiento y autoestima; autonomía e independencia; interés y esfuerzo; espíritu emprendedor; iniciativa e innovación.

- La capacidad pro-activa para gestionar proyectos: capacidad de análisis; planificación, organización, gestión y toma de decisiones; resolución de problemas; habilidad para trabajar tanto individualmente como de manera colaborativa dentro de un equipo; sentido de la responsabilidad; evaluación y auto-evaluación.

- La capacidad de asunción y gestión de riesgos y manejo de la incertidumbre: comprensión y asunción de riesgos; capacidad para gestionar el riesgo y manejar la incertidumbre.

- Las cualidades de liderazgo y trabajo individual y en equipo: capacidad de liderazgo y delegación; capacidad para trabajar individualmente y en equipo; capacidad de representación y negociación.

- Sentido crítico y de la responsabilidad: sentido y pensamiento crítico; sentido de la responsabilidad.

\section{Conciencia y expresiones culturales.}

La competencia en conciencia y expresión cultural implica conocer, comprender, apreciar y valorar con espíritu crítico, con una actitud abierta y respetuosa, las diferentes manifestaciones culturales y artísticas, utilizarlas como fuente de enriquecimiento y disfrute personal y considerarlas como parte de la riqueza y patrimonio de los pueblos.

Esta competencia incorpora también un componente expresivo referido a la propia capacidad estética y creadora y al dominio de aquellas capacidades relacionadas con los diferentes códigos artísticos y culturales, para poder utilizarlas como medio de comunicación y expresión personal. Implica igualmente manifestar interés por la participación en la vida cultural y por contribuir a la conservación del patrimonio cultural y artístico, tanto de la propia comunidad como de otras comunidades.

Así pues, la competencia para la conciencia y expresión cultural requiere de conocimientos que permitan acceder a las distintas manifestaciones sobre la herencia cultural (patrimonio cultural, histórico-artístico, literario, filosófico, tecnológico, medioambiental, etcétera) a escala local, nacional y europea y su lugar en el mundo. Comprende la concreción de la cultura en diferentes autores y obras, así como en diferentes géneros y estilos, tanto de las bellas artes (música, pintura, escultura, arquitectura, cine, literatura, fotografía, teatro y danza) como de otras manifestaciones artístico-culturales de la vida cotidiana (vivienda, vestido, gastronomía, artes aplicadas, folclore, fiestas....). Incorpora asimismo el conocimiento básico de las principales técnicas, recursos y convenciones de los diferentes lenguajes artísticos y la identificación de las 
Diseño y planificación de competencias específicas en el currículum de enseñanzas profesionales de música: modalidades composición-dirección en la enseñanza superior.

relaciones existentes entre esas manifestaciones y la sociedad, lo cual supone también tener conciencia de la evolución del pensamiento, las corrientes estéticas, las modas y los gustos, así como de la importancia representativa, expresiva y comunicativa de los factores estéticos en la vida cotidiana.

Dichos conocimientos son necesarios para poner en funcionamiento destrezas como la aplicación de diferentes habilidades de pensamiento, perceptivas, comunicativas, de sensibilidad y sentido estético para poder comprenderlas, valorarlas, emocionarse y disfrutarlas. La expresión cultural y artística exige también desarrollar la iniciativa, la imaginación y la creatividad expresada a través de códigos artísticos, así como la capacidad de emplear distintos materiales y técnicas en el diseño de proyectos.

Además, en la medida en que las actividades culturales y artísticas suponen con frecuencia un trabajo colectivo, es preciso disponer de habilidades de cooperación y tener conciencia de la importancia de apoyar y apreciar las contribuciones ajenas.

El desarrollo de esta competencia supone actitudes y valores personales de interés, reconocimiento y respeto por las diferentes manifestaciones artísticas y culturales, y por la conservación del patrimonio. Exige asimismo valorar la libertad de expresión, el derecho a la diversidad cultural, el diálogo entre culturas y sociedades y la realización de experiencias artísticas compartidas. A su vez, conlleva un interés por participar en la vida cultural y, por tanto, por comunicar y compartir conocimientos, emociones y sentimientos a partir de expresiones artísticas. Así pues, para el adecuado desarrollo de la competencia para la conciencia y expresión cultural resulta necesario abordar:

- El conocimiento, estudio y comprensión tanto de los distintos estilos y géneros artísticos como de las principales obras y producciones del patrimonio cultural y artístico en distintos periodos históricos, sus características y sus relaciones con la sociedad en la que se crean, así como las características de las obras de arte producidas, todo ello mediante el contacto con las obras de arte. Está relacionada, igualmente, con la creación de la identidad cultural como ciudadano de un país o miembro de un grupo.

- El aprendizaje de las técnicas y recursos de los diferentes lenguajes artísticos y formas de expresión cultural, así como de la integración de distintos lenguajes.

- El desarrollo de la capacidad e intención de expresarse y comunicar ideas, experiencias y emociones propias, partiendo de la identificación del potencial artístico personal (aptitud/talento). Se refiere también a la capacidad de percibir, comprender y enriquecerse con las producciones del mundo del arte y de la cultura.

- La potenciación de la iniciativa, la creatividad y la imaginación propias de cada individuo de cara a la expresión de las propias ideas y sentimientos. Es decir, la capacidad de imaginar y realizar producciones que supongan recreación, innovación y transformación. Implica el fomento de habilidades que permitan reelaborar ideas y sentimientos propios y ajenos y exige desarrollar el autoconocimiento y la autoestima, así como la capacidad de resolución de problemas y asunción de riesgos. 
Diseño y planificación de competencias específicas en el currículum de enseñanzas profesionales de música: modalidades composición-dirección en la enseñanza superior.

Carlos Eduardo Pascual Pérez

- El interés, aprecio, respeto, disfrute y valoración crítica de las obras artísticas y culturales que se producen en la sociedad, con un espíritu abierto, positivo y solidario.

- La promoción de la participación en la vida y la actividad cultural de la sociedad en que se vive, a lo largo de toda la vida. Esto lleva implícitos comportamientos que favorecen la convivencia social.

- El desarrollo de la capacidad de esfuerzo, constancia y disciplina como requisitos necesarios para la creación de cualquier producción artística de calidad, así como habilidades de cooperación que permitan la realización de trabajos colectivos.

\section{LAS COMPETENCIAS CLAVE Y LOS OBJETIVOS}

1. Las competencias clave deberán estar estrechamente vinculadas a los objetivos definidos para la Enseñanzas Elementales y Profesionales de Música

2. La relación de las competencias clave con los objetivos de las distintas asignaturas del currículo hace necesario diseñar estrategias para promover y evaluar las competencias desde las etapas educativas iniciales e intermedias hasta su posterior consolidación en etapas superiores, que llevarán a los alumnos y alumnas a desarrollar actitudes y valores, así como un conocimiento de base conceptual y un uso de técnicas y estrategias que favorecerán su incorporación a la vida adulta y que servirán de cimiento para su aprendizaje a lo largo de su vida.

3. La adquisición eficaz de las competencias clave por parte del alumnado y su contribución al logro de los objetivos de las diferentes asignaturas, desde un carácter interdisciplinar y transversal, requiere del diseño de actividades de aprendizaje integradas que permitan avanzar hacia los resultados de aprendizaje de más de una competencia al mismo tiempo.

\section{LAS COMPETENCIAS CLAVE EN EL CURRÍCULO}

1. Las competencias clave deben estar integradas en las áreas o materias de las propuestas curriculares, y en ellas definirse, explicitarse y desarrollarse suficientemente los resultados de aprendizaje que los alumnos y alumnas deben conseguir.

2. Las competencias deben desarrollarse en los ámbitos de la educación formal, no formal e informal a lo largo de la Educación Primaria, la Educación Secundaria Obligatoria y el Bachillerato, y en la educación permanente a lo largo de toda la vida.

3. Todas las áreas o materias del currículo deben participar, desde su ámbito correspondiente, en el desarrollo de las distintas competencias del alumnado.

4. La selección de los contenidos y las metodologías debe asegurar el desarrollo de las competencias clave a lo largo de la vida académica.

5. Los criterios de evaluación deben servir de referencia para valorar lo que el alumnado sabe y sabe hacer en cada área o materia. Estos criterios de evaluación se desglosan en estándares de aprendizaje evaluables. Para valorar el desarrollo competencial del alumnado, serán estos 
Diseño y planificación de competencias específicas en el currículum de enseñanzas profesionales de música: modalidades composición-dirección en la enseñanza superior.

Carlos Eduardo Pascual Pérez

estándares de aprendizaje evaluables, como elementos de mayor concreción, observables y medibles, los que, al ponerse en relación con las competencias clave, permitirán graduar el rendimiento o desempeño alcanzado en cada una de ellas.

6. El conjunto de estándares de aprendizaje evaluables de un área o materia determinada dará lugar a su perfil de área o materia. Dado que los estándares de aprendizaje evaluables se ponen en relación con las competencias, este perfil permitirá identificar aquellas competencias que se desarrollan a través de esa área o materia.

7. Todas las áreas y materias deben contribuir al desarrollo competencial. El conjunto de estándares de aprendizaje evaluables de las diferentes áreas o materias que se relacionan con una misma competencia da lugar al perfil de esa competencia (perfil de competencia). La elaboración de este perfil facilitará la evaluación competencial del alumnado.

\section{ESTRATEGIAS METODOLÓGICAS PARA EL TRABAJO POR COMPETENCIAS}

Todo proceso de enseñanza-aprendizaje debe partir de una planificación rigurosa de lo que se pretende conseguir, teniendo claro cuáles son los objetivos o metas, qué recursos son necesarios, qué métodos didácticos son los más adecuados y cómo se evalúa el aprendizaje y se retroalimenta el proceso. Los métodos didácticos han de elegirse en función de lo que se sabe que es óptimo para alcanzar las metas propuestas y en función de los condicionantes en los que tiene lugar la enseñanza.

La naturaleza de la materia, las condiciones socioculturales, la disponibilidad de recursos y las características de los alumnos y alumnas condicionan el proceso de enseñanza-aprendizaje, por lo que será necesario que el método seguido por el profesor se ajuste a estos condicionantes con el fin de propiciar un aprendizaje competencial en el alumnado.

Los métodos deben partir de la perspectiva del docente como orientador, promotor y facilitador del desarrollo competencial en el alumnado; además, deben enfocarse a la realización de tareas o situaciones-problema, planteadas con un objetivo concreto, que el alumnado debe resolver haciendo un uso adecuado de los distintos tipos de conocimientos, destrezas, actitudes y valores; asimismo, deben tener en cuenta la atención a la diversidad y el respeto por los distintos ritmos y estilos de aprendizaje mediante prácticas de trabajo individual y cooperativo.

En el actual proceso de inclusión de las competencias como elemento esencial del currículo, es preciso señalar que cualquiera de las metodologías seleccionadas por los docentes para favorecer el desarrollo competencial de los alumnos y alumnas debe ajustarse al nivel competencial inicial de estos. Además, es necesario secuenciar la enseñanza de tal modo que se parta de aprendizajes más simples para avanzar gradualmente hacia otros más complejos.

Uno de los elementos clave en la enseñanza por competencias es despertar y mantener la motivación hacia el aprendizaje en el alumnado, lo que implica un nuevo planteamiento del papel del alumno, activo y autónomo, consciente de ser el responsable de su aprendizaje. Los 
Diseño y planificación de competencias específicas en el currículum de enseñanzas profesionales de música: modalidades composición-dirección en la enseñanza superior.

métodos docentes deberán favorecer la motivación por aprender en los alumnos y alumnas y, a tal fin, los profesores han de ser capaces de generar en ellos la curiosidad y la necesidad por adquirir los conocimientos, las destrezas y las actitudes y valores presentes en las competencias. Asimismo, con el propósito de mantener la motivación por aprender es necesario que los profesores procuren todo tipo de ayudas para que los estudiantes comprendan lo que aprenden, sepan para qué lo aprenden y sean capaces de usar lo aprendido en distintos contextos dentro y fuera del aula. Para potenciar la motivación por el aprendizaje de competencias se requieren, además, metodologías activas y contextualizadas. Aquellas que faciliten la participación e implicación del alumnado y la adquisición y uso de conocimientos en situaciones reales, serán las que generen aprendizajes más transferibles y duraderos.

Las metodologías activas han de apoyarse en estructuras de aprendizaje cooperativo, de forma que, a través de la resolución conjunta de las tareas, los miembros del grupo conozcan las estrategias utilizadas por sus compañeros y puedan aplicarlas a situaciones similares. Para un proceso de enseñanza-aprendizaje competencial las estrategias interactivas son las más adecuadas, al permitir compartir y construir el conocimiento y dinamizar la sesión de clase mediante el intercambio verbal y colectivo de ideas. Las metodologías que contextualizan el aprendizaje y permiten el aprendizaje por proyectos, los centros de interés, el estudio de casos o el aprendizaje basado en problemas favorecen la participación activa, la experimentación y un aprendizaje funcional que va a facilitar el desarrollo de las competencias, así como la motivación de los alumnos y alumnas al contribuir decisivamente a la transferibilidad de los aprendizajes.

El trabajo por proyectos, especialmente relevante para el aprendizaje por competencias, se basa en la propuesta de un plan de acción con el que se busca conseguir un determinado resultado práctico. Esta metodología pretende ayudar al alumnado a organizar su pensamiento favoreciendo en ellos la reflexión, la crítica, la elaboración de hipótesis y la tarea investigadora a través de un proceso en el que cada uno asume la responsabilidad de su aprendizaje, aplicando sus conocimientos y habilidades a proyectos reales. Se favorece, por tanto, un aprendizaje orientado a la acción en el que se integran varias áreas o materias: los estudiantes ponen en juego un conjunto amplio de conocimientos, habilidades o destrezas y actitudes personales, es decir, los elementos que integran las distintas competencias.

Asimismo, resulta recomendable el uso del portfolio, que aporta información extensa sobre el aprendizaje del alumnado, refuerza la evaluación continua y permite compartir resultados de aprendizaje. El portfolio es una herramienta motivadora para el alumnado que potencia su autonomía y desarrolla su pensamiento crítico y reflexivo. La selección y uso de materiales y recursos didácticos constituye un aspecto esencial de la metodología. El profesorado debe implicarse en la elaboración y diseño de diferentes tipos de materiales, adaptados a los distintos niveles y a los diferentes estilos y ritmos de aprendizaje de los alumnos y alumnas, con el objeto de atender a la diversidad en el aula y personalizar los procesos de construcción de los aprendizajes. Se debe potenciar el uso de una variedad de materiales y recursos, considerando 
Diseño y planificación de competencias específicas en el currículum de enseñanzas profesionales de música: modalidades composición-dirección en la enseñanza superior.

Carlos Eduardo Pascual Pérez

especialmente la integración de las Tecnologías de la Información y la Comunicación en el proceso de enseñanza-aprendizaje que permiten el acceso a recursos virtuales.

Finalmente, es necesaria una adecuada coordinación entre los docentes sobre las estrategias metodológicas y didácticas que se utilicen. Los equipos educativos deben plantearse una reflexión común y compartida sobre la eficacia de las diferentes propuestas metodológicas con criterios comunes y consensuados. Esta coordinación y la existencia de estrategias conexionadas permiten abordar con rigor el tratamiento integrado de las competencias $y$ progresar hacia una construcción colaborativa del conocimiento. Las enseñanzas especializadas de música contribuirán a desarrollar en los alumnos las competencias clave así como los valores cívicos propios del sistema educativo a través de los objetivos establecidos en la programación de la asignatura.

\section{Objetivos y Contenidos}

\section{Objetivos generales de las Enseñanzas Profesionales}

Según establece el Artículo 4 del DECRETO 158/2007, de 21 de septiembre, del Consell, por el que se establece el currículo de las enseñanzas profesionales de música y se regula el acceso a estas enseñanzas, las enseñanzas elementales de música tienen como objetivo contribuir a desarrollar en los alumnos y alumnas capacidades generales y los valores cívicos propios del sistema educativo y, además, las capacidades siguientes:

a) Fomentar la audición de la música y establecer conceptos estéticos propios que permitan fundamentar y desarrollar criterios interpretativos individuales.

b) Desarrollar la sensibilidad artística y el criterio estético como fuente de formación y enriquecimiento personal.

c) Analizar y valorar críticamente las diferentes manifestaciones y estilos musicales.

d) Conocer las aportaciones de la música al desarrollo personal del individuo y al desarrollo colectivo de las sociedades.

e) Participar en actividades de difusión cultural musical que permitan experimentar con la música y disfrutar de la música.

f) Conocer y emplear con precisión el vocabulario específico relativo a los conceptos científicos y artísticos de la música. 
Diseño y planificación de competencias específicas en el currículum de enseñanzas profesionales de música: modalidades composición-dirección en la enseñanza superior.

g) Conocer y valorar el patrimonio musical como parte integrante del patrimonio histórico y cultural de la Humanidad.

h) Conocer y valorar la importancia de la música propia de la Comunidad Valenciana, así como sus características y manifestaciones más importantes.

\section{Contenidos comunes de las Enseñanzas Profesionales}

Del mismo modo, en el Anexo I de dicho DECRETO se establecen los contenidos comunes de la práctica instrumental:

a) Superar con dominio y capacidad crítica los objetivos y contenidos planteados.

b) Conocer los elementos básicos de los lenguajes musicales, sus características, funciones y evoluciones en los diferentes contextos históricos.

c) Utilizar el «oído interno» como base de la afinación, de la audición armónica y de la interpretación musical.

d) Formar una imagen ajustada de las posibilidades y características musicales tanto a nivel individual como en la relación con el grupo, con la disposición necesaria para saber integrarse como un miembro más del mismo o como responsable del conjunto.

e) Compartir vivencias musicales de grupo en el aula y fuera de ella que permitan enriquecer la relación afectiva con la música a través del canto y de participación instrumental en grupo.

f) Utilizar el cuerpo y la mente para adquirir la técnica necesaria y así, concentrarse en la audición e interpretación musical.

g) Interrelacionar y aplicar los conocimientos adquiridos en todas las asignaturas que componen el currículo junto con las vivencias y experiencias propias para conseguir una interpretación artística de calidad.

h) Adquirir y aplicar las destrezas necesarias para resolver las dificultades que surjan en la interpretación de la música.

i) Practicar la improvisación y la transposición como elementos inherentes a la creatividad musical. 
Diseño y planificación de competencias específicas en el currículum de enseñanzas profesionales de música: modalidades composición-dirección en la enseñanza superior.

j) Interpretar, individualmente o dentro de la agrupación correspondiente, obas escritas en todos los lenguajes musicales, profundizando en el conocimiento de los diferentes estilos y épocas, así como en los recursos interpretativos de cada uno de ellos.

k) Actuar en público con autocontrol, dominio de la memoria musical y capacidad comunicativa.

I) Adquirir autonomía personal en la comunicación musical.

m) Consolidar hábitos de estudio adecuados y continuados en función de la dificultad de los contenidos de las asignaturas de los diferentes cursos y niveles.

n) Conocer y aplicar las técnicas del instrumento o de la voz de acuerdo con las exigencias de las obras.

\section{Objetivos propios de la especialidad}

Por concreción curricular, a enseñanza de Armonía en el grado profesional tendrá como objetivo contribuir a des arrollar en los alumnos las capacidades siguientes:

a) Conocer los elementos básicos de la armonía tonal y sus carac- terísticas, funciones y transformaciones en los distintos contextos históricos.

b) Utilizar en trabajos escritos los elementos y procedimientos básicos de la armonía tonal

c) Desarrollar el oído interno tanto en el análisis como en la reali- zación de ejercicios escritos.

d) Identificar a través de la audición los acordes y procedimientos más comunes de la armonía tonal.

e) Identificar a través del análisis de obras los acordes, los procedimientos más comunes de la armonía tonal y las transformaciones temáticas.

f) Comprender la interrelación de los procesos armónicos con la forma musical.

g) Aprender a valorar la calidad de la música.

\section{Contenidos propios de la especialidad}


El acorde.

Consonancia y disonancia.

Estado fundamental e inversiones de los acordes triadas y de séptima sobre todos los grados de la escala y de los acordes de novena dominante.

Enlace de acordes.

Tonalidad y funciones tonales.

Elementos y procedimientos de origen modal presentes en el Sistema Tonal.

El ritmo armónico.

Cadencias Perfecta, Imperfecta, Plagal, Rota.

Procesos cadenciales.

Modulación: Diatónica y cromática, por cambio de función tonal, cambios de tono y modo, etc.

Flexiones introtonales.

Progresiones unitonales y modulantes.

Series de sextas y de séptimas.

Utilización de los elementos y procedimientos anteriores en la realización de trabajos escritos.

Practica auditiva e instrumental que conduzca a la interiorización de los elementos y procedimientos aprendidos.

Análisis de obras para relacionar dichos elementos y procedimientos, así como las transforma- ciones temáticas de los materiales utilizados con su contexto estilístico y la forma musical.

\section{Evaluación}


Carlos Eduardo Pascual Pérez

\section{Criterios generales}

1. Interpretar obras con el suficiente nivel de calidad en correspondencia con los objetivos y su maduración psicoevolutiva.

2. El aspecto anterior supone, además, un hábito de expresión musical da cara al público, actividad que se distribuirá en frecuentes audiciones a lo largo del curso. El carácter diferenciador, en cuanto a la aplicación de los conceptos, viene determinado por las correspondientes obras, piezas y ejercicios del programa de cada curso.

3. Coordinación con el equipo docente para analizar la consecución y profundidad de los objetivos generales del grado.

4. Participar en audiciones del curso a nivel de aula y de centro. Los profesores podrán coordinar y supervisar audiciones trimestrales a nivel de aula, en las cuales participarán todos los alumnos de cada profesor e interpretarán un repertorio común según cada curso propuesto por el profesorado. Las audiciones servirán para evaluar al alumno y el porcentaje de calificación de dichas audiciones será determinado por cada profesor, según el trabajo desarrollado por el alumno en las clases lectivas.

5. El alumno deberá desarrollar una conciencia de grupo y de su propio nivel a partir de las audiciones conjuntas desarrolladas durante el curso, lo cual contribuirá en buen grado a la unificación de niveles.

6. Coordinación con el equipo docente para analizar la consecución y profundidad de los objetivos generales del grado.

7. Analizar los criterios de evaluación, identificación en cada uno las capacidades, los contenidos que incluye y los indicadores de los objetivos de la asignatura.

8. La Regularidad en el estudio y la trayectoria en el mismo.

\section{Criterios específicos}

1. Realizar ejercicios a partir de un bajo cifrado dado.

2. Realizar ejercicios de armonización a partir de tiples dados.

3. Realizar ejercicios de armonización a partir de bajos sin cifrar dados. 
Diseño y planificación de competencias específicas en el currículum de enseñanzas profesionales de música: modalidades composición-dirección en la enseñanza superior.

Carlos Eduardo Pascual Pérez

4. Componer ejercicios breves a partir de un esquema armónico dado o propio.

5. Identificar auditivamente los principales elementos morfológicos de la armonía tonal.

6. Identificar auditivamente los principales procedimientos sintácticos de la armonía tonal.

7. Identificar auditivamente estructuras formales concretas.

8. Identificar mediante el análisis de obras los elementos morfológicos de la armonía tonal.

9. Identificar mediante el análisis de obras los procedimientos sintácticos y formales de la armonía tonal.

10. Identificar mediante el análisis de obras los procedimientos de transformación temática.

11. Identificar auditivamente diversos errores en ejercicios preparados con esta finalidad y proponer soluciones.

12. Identificar mediante el análisis diversos errores en ejercicios preparados con esta finalidad y proponer soluciones.

\section{Procedimientos e instrumentos de evaluación}

La evaluación será continua y establecida según el tipo y grado de aprendizaje que se espera hayan alcanzado los alumnos en un momento determinado, respeto a las capacidades indicadas en los objetivos generales y específicos de la especialidad. También será flexible, teniendo en cuenta el contexto del alumno, es decir, el ciclo educativo en el que se encuentra, así como sus propias características y posibilidades. Además, los instrumentos de evaluación a utilizar serán los siguientes:

1. Evaluación competencial de cada sesión.

2. Fiel seguimiento individual del alumno mediante el "Cuaderno del profesor"

3. Boletines trimestrales informativos

4. Temporalización del repertorio por cursos y trimestres

5. Evaluación actitudinal mensual

Por norma general, para el cálculo de la nota media las tareas prácticas se valorarán con un $50 \%$, la evaluación actitudinal con un $20 \%$ y las pruebas trimestrales con un $30 \%$.

\section{Mínimos exigibles}


Diseño y planificación de competencias específicas en el currículum de enseñanzas profesionales de música: modalidades composición-dirección en la enseñanza superior.

Carlos Eduardo Pascual Pérez

3o Curso

- Conocer, clasificar y utilizar correctamente los acordes tríadas.

- Utilizar de forma correcta las diferentes inversiones.

- Conocer y utilizar el cifrado de los acordes.

- Conocer, clasificar y distinguir los principales tipos de cadencias.

- Utilizar de forma correcta los distintos procesos cadenciales.

- Reconocer y armonizar correctamente las series de sextas.

- Reconocer y realizar progresiones armónicas, unitónicas o modulantes.

- Conocer los diferentes tipos de modulación (diatónica y cromática).

- Saber utilizar correctamente el recurso de la modulación.

- Analizar ejercicios escolásticos a cuatro voces.

- Analizar corales de J. S. Bach adecuados a este nivel.

- Conocer, clasificar y utilizar correctamente el acorde de séptima de dominante.

4o Curso

- Conocer, clasificar y utilizar correctamente los acordes cuatríadas.

- Utilizar de forma correcta sus diferentes inversiones.

- Conocer y utilizar el cifrado de los acordes cuatríadas.

- Conocer, clasificar y distinguir los principales tipos de cadencias.

- Utilizar de forma correcta los distintos procesos cadenciales.

- Reconocer y realizar progresiones armónicas, unitónicas o modulantes.

- Conocer los diferentes tipos de modulación (diatónica, cromática).

- Saber utilizar correctamente el recurso de la modulación.

- Reconocer las notas extrañas de carácter melódico.

- Reconocer las notas extrañas de carácter armónico.

- Utilizar de forma correcta los diferentes tipos de notas extrañas.

- Armonizar y analizar corales de J. S. Bach.

- Analizar obras pianísticas o de cámara del sistema tonal tradicional.

\section{Promoción}

1. Los alumnos promocionarán de curso cuando hayan superado la totalidad de las asignaturas de cada curso o tengan evaluación negativa como máximo en dos asignaturas. En el supuesto de asignaturas pendientes referidas a práctica instrumental o canto, la recuperación deberá realizarse en la clase del curso siguiente si forma parte del mismo. 
Diseño y planificación de competencias específicas en el currículum de enseñanzas profesionales de música: modalidades composición-dirección en la enseñanza superior.

Carlos Eduardo Pascual Pérez

2. La calificación negativa en tres o más asignaturas de uno o varios cursos impedirá la promoción de un alumno al curso siguiente.

3. Los alumnos que al término del 6 curso tuvieran pendientes de evaluación positiva tres asignaturas o más deberán repetir el curso en su totalidad. Cuando la calificación negativa se produzca en una o dos asignaturas, solo será preceptivo cursar las asignaturas pendiente

\section{Aspectos de la evaluación continua}

Se considerará que un alumno ha perdido el derecho a la evaluación continua cuando acumule ocho o más faltas de asistencia durante todo el curso. Podrá ser evaluado en junio, mediante un equipo de profesores del departamento. Deberá presentar un programa acorde a los mínimos exigibles y acorde con el nivel del curso del cual ha perdido el derecho a la evaluación continua.

Los alumnos y alumnas de enseñanzas profesionales que no superen el curso en el mes de junio podrán recuperar la asignatura mediante la realización de una prueba extraordinaria al finalizar el curso; de acuerdo con el DECRETO 157/2007. El examen extraordinario será diseñado por el profesor que haya impartido la especialidad, teniendo en cuenta los mínimos exigidos en cada curso contemplados en esta programación.

El límite de permanencia en las enseñanzas profesionales de música será de ocho años. El alumno no podrá permanecer más de dos años en el mismo curso, excepto en 60 curso, hasta completar el límite de permanencia.

\section{Metodología}

\section{Principios metodológicos}

a) Adecuar los contenidos y su secuenciación al momento y situación del desarrollo evolutivo del alumno, de forma que el aprendizaje sea constructivo, progresivo y motivador.

b) Motivar al alumno para el estudio de la música mediante su actividad y participación en el progreso, dándole el protagonismo.

c) Respetar las peculiaridades de los alumnos, individual y colectivamente, facilitando así la convivencia en el seno del grupo y la colaboración, de forma que se eviten las discriminaciones de todo tipo. 
Diseño y planificación de competencias específicas en el currículum de enseñanzas profesionales de música: modalidades composición-dirección en la enseñanza superior.

d) Utilizar procedimientos y recursos variados que estimulen la capacidad crítica y creativa del alumno mediante la aceptación del dialogo y las argumentaciones razonadas

e) Procurar que la asimilación de los contenidos conceptuales por parte del alumno se completa con la adquisición de contenidos procedimentales y actitudinales que propicien su autonomía en el trabajo tato para el momento presente como para el futuro.

f) Facilitar a los alumnos el conocimiento y empleo del código convencional de expresión a la vez que la corrección y la exactitud en el uso del lenguaje, con el fin de que el aprendizaje y la comunicación sean efectivos.

g) Ejercitar la creatividad del alumno, de modo que adquiera estrategias propias de estudio y de realizaciones musicales con el fin de que pueda superar las dificultades que se les presenten.

\section{Otros aspectos metodológicos}

Se implementarán competencias transversales desarrolladas específicamente para una completa preparación en las pruebas de acceso a enseñanzas superiores en composición y/o dirección. Estas son:

- Organología, instrumentación y orquestación en el ámbito de la orquesta sinfónica

\section{Concreción curricular del Primer Curso}

\section{INTRODUCCIÓN}

1. Concepto de Armonía.

2. La Armonía en el análisis y en la composición musical.

3. Importancia del análisis armónico en el análisis musical y su valor estético.

\section{LOS INTERVALOS (repaso)}

1. Mayores, menores, justos, aumentados y disminuidos.

2. Armónicos y melódicos. Conjuntos y disjuntos.

3. Consonantes y disonantes. (relatividad de estos conceptos)

II. LA TONALIDAD Y LA MODALIDAD (repaso) 
Diseño y planificación de competencias específicas en el currículum de enseñanzas profesionales de música: modalidades composición-dirección en la enseñanza superior.

1. Concepto y características diferenciales.

2. Formación de los tonos mayor y menor. Sus escalas diatónicas (armónica y melódica).

3. Denominación de los grados de la tonalidad.

\section{EL ACORDE}

1. El fenómeno físico-armónico de la resonancia superior.

2. Formación de acordes por la serie de armónicos o por el sistema tradicional de terceras superpuestas.

\section{ACORDES TRÍADAS O DE QUINTA}

1. El acorde de tres sonidos:

a) El acorde tríada natural (serie de armónicos)

b) Clasificación por su constitución: perfectos mayor y menor, disminuidos y aumentados.

c) Formación de acordes sobre cada uno de os grados de las escalas mayor y menores (armónica y melódica): su constitución.

d) Clasificación por su función tonal: acordes tonales o principales y acordes complementarios.

e) Estado fundamental o directo, y de inversión.

2. Acordes tríadas a cuatro partes:

a) Armonía vocal (4 voces humanas mixtas)

b) Tesituras del cuarteto vocal: soprano, contralto, tenor y bajo.

c) Diferentes sistemas para la escritura del cuarteto vocal: sistema tradicional a 4 claves, sistema actual a 2 claves y 4 pentagramas, y sistema abreviado con el empleo de 2 claves y 2 pentagramas.

d) Duplicaciones (fundamental, $3 a$ o 5 a) y supresiones.

e) Disposiciones: unidas, separadas, mixtas.

3. Cifrado de los acordes:

a) Información sobre los diferentes sistemas de cifrado.

b) Sistema tradicional.

c) Cifrado de los acordes tríadas en estado fundamental. (a partir de ahora, con la presentación de las inversiones y nuevos acordes, se darán a conocer los cifrados correspondiente). 
Diseño y planificación de competencias específicas en el currículum de enseñanzas profesionales de música: modalidades composición-dirección en la enseñanza superior.

Carlos Eduardo Pascual Pérez

4. Estudio del acorde de 5a sobre sensible en los modos mayor y menor y llo grado del modo menor, del acorde de 5a aumentada del Illo del modo menor, (acordes de sonoridad y funcionamiento especial).

\section{MOVIMIENTOS MELÓDICOS}

a) Movimientos armónicos: paralelo, directo, oblicuo y contrario

b) Enlaces básicos de acordes tríadas en estado fundamental con duplicación del bajo.

c) Normas sobre los movimientos armónicos sucesivos de 8a y 5a justas.

d) Normas sobre los movimientos armónicos directos que desembocan en intervalos de 8 a o 5 a justas.

e) Movimientos melódicos: intervalos melódicos directos y prohibidos.

f) El unísono: su tratamiento escolástico.

g) Los cruzamientos.

h) El rebase de tesitura.

VI. INVERSIÓN DE LOS ACORDES TRÍADAS

1. 1a Inversión del acorde tríada (acorde de 6a)

a) Formación sobre cada uno de los grados de las escalas mayor y menores (armónica y melódica).

b) La 1a inversión de los acorde de 5 a de sensible del modo mayor y menor y llo grado del modo menor, y del acorde de $5 a$ aumentada del Illo del modo menor.

c) Duplicaciones.

d) Enlaces: con acordes tríadas directos y con otros de $6 a$.

e) Series de 6a.

f) Los acordes de 6a como resultado del empleo de notas extrañas de carácter consonante. (introducción a la ornamentación de la armonía básica).

2. 2a Inversión del acorde tríada (acordes de cuarta y sexta)

a) Formación sobre cada uno de los grados de las escalas mayor y menores (armónica y melódica).

b) La 2a inversión de los acordes de 5 a de sensible del modo mayor y menor y llo grado del modo menor, y del acorde de $5 a$ aumentada del Illo del modo menor.

c) Duplicaciones.

d) Enlaces con todos los acordes estudiados.

e) Los acordes de cuarta y sexta como resultado del empleo de notas extrañas de 
Diseño y planificación de competencias específicas en el currículum de enseñanzas profesionales de música: modalidades composición-dirección en la enseñanza superior.

Carlos Eduardo Pascual Pérez

carácter consonante.

f) Los acordes de cuarta y sexta de uso común. El cuarta y sexta cadencial.

VII. CADENCIAS

1. Concepto y finalidad.

2. Diferentes tipos: perfecta, imperfecta, plagal, rota, semicadencia.

VIII. PROGRESIONES ARMÓNICAS O MARCHAS PROGRESIVAS

1. Progresiones unitónicas.

2. Progresiones modulantes.

IX. LA MODULACIÓN

1. Concepto y finalidad.

2. Clases de modulación.

3. Tonos relativos, vecinos y lejanos.

4. Acordes comunes entre tonalidades vecinas.

5. Las notas características.

6. Modulación diatónica. Procedimientos básicos.

7. Modulación cromática. Procedimientos básicos. Falsas relaciones cromáticas.

8. Acordes Préstamo. Dominante de la Dominante. Sexta Napolitana (sólo a nivel de análisis).

\section{EL ACORDE DE SÉPTIMA DE DOMINANTE}

1. Su constitución en estado fundamental e inversiones.

2. Cifrado.

3. Duplicaciones y supresiones.

4. Enlaces con los acordes conocidos. Tratamiento escolástico de la disonancia (resoluciones naturales).

5. El acorde de 7a de dominante en la modulación.

\section{Concreción curricular del Segundo Curso}

I. ACORDES CUATRIADAS O DE SÉPTIMA 1. El acorde de cuatro sonidos:

a) El acorde cuatríada natural (serie de armónicos).

b) Clasificación por su constitución interválica. Especies de 7a. 
Diseño y planificación de competencias específicas en el currículum de enseñanzas profesionales de música: modalidades composición-dirección en la enseñanza superior.

Carlos Eduardo Pascual Pérez

c) Formación de acordes de 7a sobre cada uno de los grados de las escalas mayor y menor (armónica y melódica).

d) Clasificación por su función tonal.

2. El acorde de 7a de Dominante (repaso y continuación):

a) b) c) d)

3. Los acorde de 7a de Sensible de los modos mayor y menor:

a) Su constitución en estado fundamental e inversión.

b) Cifrado.

c) Duplicaciones y supresiones.

d) Enlaces con los acordes conocidos. Tratamiento escolástico de la disonancia (resoluciones naturales y excepciones).

4. Acordes de 7a sobre los grados IV, II, VI, III y I (acordes de 7a diatónicos o de especie)
a) Su constitución en estado fundamental e inversión.
b) Cifrado.
c) Duplicaciones y supresiones.
d) Enlaces con los acordes conocidos. Tratamiento escolástico (resoluciones naturales y excepcionales).
e) Series de 7a unitónica.

5. El acorde de 7a como préstamo: Dominante Secundaria. Dominante de la Dominante. Sexta Napolitana

II. LOS CORALES

1. Estructura y armonización: análisis de corales.

III. EL ACORDE DE 9a MAYOR Y MENOR DE DOMINANTE:

a) Su constitución en estado fundamental e inversión.

b) Cifrado.

c) Supresiones.

d) Enlaces naturales y excepcionales. Tratamiento escolástico de las disonancias. 
Diseño y planificación de competencias específicas en el currículum de enseñanzas profesionales de música: modalidades composición-dirección en la enseñanza superior.

Carlos Eduardo Pascual Pérez

e) Series con acordes de 9a de dominante (a 5 voces). Series de 9a de dominante combinados con acordes tríada y de séptima.

\section{ACORDES DE LA FAMILIA DE LA DOMINANTE SOBRE TÓNICA}

1. Constitución y cifrado.

2. Empleo y resoluciones.

V. NOTAS EXTRAÑAS A LA ARMONÍA BÁSICA (continuación de su estudio en el aspecto práctico).

1. Notas de adorno de carácter melódico:

a) La nota de paso. Normas para su buen uso.

b) El floreo o bordadura. Normas para el buen uso.

c) La anticipación y la escapada. Normas para el buen uso.

d) La apoyatura melódica. Normas para su buen uso.

2. Notas extrañas o de adorno con incidencia armónica:

a) El retardo. Normas para el buen uso.

b) La pedal armónica: definición, tipos, cifrado y normas.

VI. LA IMITACIÓN

1. El estilo imitativo en la armonía.

VII. LA MELODÍA INSTRUMENTAL

1. Análisis de la armonización para piano u otros instrumentos.

2. Análisis de la armonización para orquesta.

VIII. AMPLIACIÓN DE LA TONALIDAD (sólo a nivel de análisis)

1. Armonía alterada.

2. Acordes de la familia de la dominante con la quinta alterada en más y en menos.

Disposiciones tradicionales.

3. Acordes de 6a aumentada clásicos. Su función.

4. Cifrado de los acordes alterados. 


\section{PROGRAMACIÓN DIDÁCTICA}

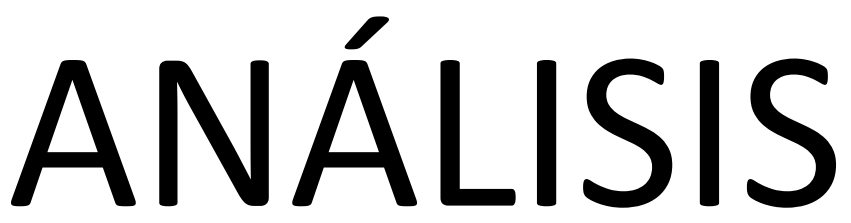

ENSEÑANZAS PROFESIONALES 
Diseño y planificación de competencias específicas en el currículum de enseñanzas profesionales de música: modalidades composición-dirección en la enseñanza superior.

Carlos Eduardo Pascual Pérez

\section{COMPETENCIAS CLAVE}

Las competencias que se recogen en esta programación se han establecido de conformidad con los resultados de la investigación educativa y con las tendencias europeas recogidas en la Recomendación 2006/962/EC, del Parlamento Europeo y del Consejo, de 18 de diciembre de 2006, sobre las competencias clave para el aprendizaje permanente. Dichas competencias se describen, se indica su finalidad y aspectos distintivos, y se pone de manifiesto, en cada una de ellas, las claves de desarrollo que debe alcanzar todo el alumnado referidas al final de la enseñanza profesional de música, pero cuyo desarrollo debe iniciarse desde el comienzo de la escolarización, de manera que su adquisición se realice de forma progresiva y coherente a lo largo de las distintas etapas educativas.

Las competencias clave deberán estar estrechamente vinculadas a los objetivos definidos para la enseñanza artística de Música. Esta vinculación favorece que la consecución de dichos objetivos a lo largo de la vida académica lleve implícito el desarrollo de las competencias clave, para que todas las personas puedan alcanzar su desarrollo personal y lograr una correcta incorporación en la sociedad.

Un enfoque metodológico basado en las competencias clave y en los resultados de aprendizaje conlleva importantes cambios en la concepción del proceso de enseñanza-aprendizaje, cambios en la organización y en la cultura escolar; requiere la estrecha colaboración entre los docentes en el desarrollo curricular y en la transmisión de información sobre el aprendizaje de los alumnos y alumnas, así como cambios en las prácticas de trabajo y en los métodos de enseñanza. De este hecho se desprenden las competencias clave del currículo en el sistema educativo español.

1. Comunicación lingüística.

Es el resultado de la acción comunicativa dentro de prácticas musicales y sociales determinadas, en las cuales el individuo actúa con otros interlocutores y a través de textos en múltiples modalidades, formatos y soportes. Estas situaciones y prácticas pueden implicar el uso de distintos lenguajes musicales, en diversos ámbitos y de manera individual o colectiva. Para ello el individuo dispone de su repertorio musical, pero ajustado a las experiencias comunicativas que experimenta a lo largo de la vida. Los distintos lenguajes musicales que utiliza pueden haber tenido vías y tiempos distintos de adquisición y constituir, por tanto, experiencias de aprendizaje musicales, tanto populares como de otra índole. Esta visión de la competencia en comunicación lingüística vinculada con prácticas musicales determinadas ofrece una imagen del individuo como agente comunicativo que produce, y no sólo recibe, mensajes a través de las diferentes manifestaciones musicales con distintas finalidades. Valorar la relevancia de esta afirmación en la toma de decisiones educativas supone optar por metodologías activas de aprendizaje (aprendizaje basado en tareas y proyectos, en problemas, en retos, etcétera), ya sean estas en lenguajes musicales vanguardistas y actuales, frente a opciones metodológicas más tradicionales. Además, la competencia en comunicación lingüística musical, representa una vía de conocimiento y contacto con la diversidad cultural que implica un factor de 
Diseño y planificación de competencias específicas en el currículum de enseñanzas profesionales de música: modalidades composición-dirección en la enseñanza superior.

Carlos Eduardo Pascual Pérez

enriquecimiento para la propia competencia y que adquiere una particular relevancia en el caso de las músicas de otras culturas. Por tanto, un enfoque intercultural en la enseñanza y el aprendizaje de las diferentes músicas implica una importante contribución al desarrollo de la competencia en comunicación lingüística musical del alumnado.

Esta competencia es, por definición, siempre parcial y constituye un objetivo de aprendizaje permanente a lo largo de toda la vida. Por ello, para que se produzca un aprendizaje satisfactorio de las diferentes músicas, es determinante que se promuevan unos contextos de uso de lenguajes musicales ricos y variados, en relación con las tareas que se han de realizar y sus posibles interlocutores, textos e intercambios comunicativos.

La competencia en comunicación lingüística musical es extremadamente compleja. Se basa, en primer lugar, en el conocimiento del componente lingüístico musical. Pero además, como se produce y desarrolla en situaciones comunicativas concretas y contextualizadas, el individuo necesita activar su conocimiento del componente pragmático-discursivo y socio-cultural.

Esta competencia precisa de la interacción de distintas destrezas, ya que se produce en múltiples modalidades de comunicación y en diferentes soportes. Desde la oralidad y la escritura hasta las formas más sofisticadas de comunicación audiovisual o mediada por la tecnología, el individuo participa de un complejo entramado de posibilidades comunicativas gracias a las cuales expande su competencia y su capacidad de interacción con otros individuos. Por ello, esta diversidad de modalidades y soportes requiere de una alfabetización musical más compleja, recogida en el concepto de alfabetizaciones múltiples, que permita al individuo su participación como ciudadano activo.

La competencia en comunicación lingüística musical es también un instrumento fundamental para la socialización y el aprovechamiento de la experiencia educativa, por ser una vía privilegiada de acceso al conocimiento dentro y fuera de la escuela. De su desarrollo depende, en buena medida, que se produzcan distintos tipos de aprendizaje en distintos contextos, formales, informales y no formales. En este sentido, es especialmente relevante en el contexto escolar la consideración de la lectura como destreza básica para la ampliación de la competencia en comunicación lingüística musical y el aprendizaje. Así, el lenguaje musical es la principal vía de acceso a todas las áreas, por lo que el contacto con una diversidad de textos resulta fundamental para acceder a las fuentes originales del saber. Por ello, donde manifiesta su importancia, de forma más patente, es en el desarrollo de las destrezas que conducen al conocimiento de los textos musicales, no solo en su consideración como canon artístico o en su valoración como parte del patrimonio cultural, sino sobre todo, y principalmente, como fuente de disfrute y aprendizaje a lo largo de la vida.

Desde esta perspectiva, es recomendable que el centro educativo sea la unidad de acción para el desarrollo de la competencia en comunicación lingüística musical. En este sentido, actuaciones como el diseño de un Proyecto Artístico Musical de Centro que forme parte del propio Proyecto Educativo de Centro, un Plan Lector o unas estrategias para el uso de la 
Diseño y planificación de competencias específicas en el currículum de enseñanzas profesionales de música: modalidades composición-dirección en la enseñanza superior.

Biblioteca y Fonoteca Escolar como espacio de aprendizaje y disfrute permiten un tratamiento más global y eficaz de la competencia en comunicación lingüística musical en los términos aquí expresados.

La competencia en comunicación lingüística musical se inscribe en un marco de actitudes y valores que el individuo pone en funcionamiento: el respeto a las normas de convivencia; el ejercicio activo de la ciudadanía; el desarrollo de un espíritu crítico; el respeto a los derechos humanos y el pluralismo; la concepción del diálogo como herramienta primordial para la convivencia, la resolución de conflictos y el desarrollo de las capacidades afectivas en todos los ámbitos; una actitud de curiosidad, interés y creatividad hacia el aprendizaje y el reconocimiento de las destrezas inherentes a esta competencia (lectura, conversación, escritura, etcétera) como fuentes de placer relacionada con el disfrute personal y cuya promoción y práctica son tareas esenciales en el refuerzo de la motivación hacia el aprendizaje.

En resumen, para el adecuado desarrollo de esta competencia resulta necesario abordar el análisis y la consideración de los distintos aspectos que intervienen en ella, debido a su complejidad. Para ello, se debe atender a los cinco componentes que la constituyen y a las dimensiones en las que se concretan:

- El componente lingüístico musical que comprende diversas dimensiones: la léxica, la gramatical, la semántica, la fonológica, la ortográfica y la ortoépica, entendida esta como la articulación correcta del sonido a partir de la representación gráfica de la música.

- El componente pragmático-discursivo contempla tres dimensiones: la socio-musical (vinculada con la adecuada producción y recepción de mensajes en diferentes contextos sociales); la pragmática (que incluye las microfunciones comunicativas y los esquemas de interacción); y la discursiva (que incluye las macrofunciones textuales y las cuestiones relacionadas con los géneros discursivos).

- El componente socio-cultural incluye dos dimensiones: la que se refiere al conocimiento del mundo y la dimensión intercultural.

- El componente estratégico permite al individuo superar las dificultades y resolver los problemas que surgen en el acto comunicativo. Incluye tanto destrezas y estrategias comunicativas para la lectura, la escritura, la interpretación musical, la escucha, como destrezas vinculadas con el tratamiento de la información, la lectura multimodal y la producción de textos electrónicos en diferentes formatos; asimismo, también forman parte de este componente las estrategias generales de carácter cognitivo, metacognitivo y socioafectivas que el individuo utiliza para comunicarse eficazmente, aspectos fundamentales en el aprendizaje de las otras culturas musicales extranjeras. 
Diseño y planificación de competencias específicas en el currículum de enseñanzas profesionales de música: modalidades composición-dirección en la enseñanza superior.

Carlos Eduardo Pascual Pérez

- Por último, la competencia en comunicación lingüística musical incluye un componente personal que interviene en la interacción comunicativa en tres dimensiones: la actitud, la motivación y los rasgos de personalidad.

\section{Competencia matemática y competencias básicas en ciencia y tecnología.}

La competencia matemática y las competencias básicas en ciencia y tecnología inducen y fortalecen algunos aspectos esenciales de la formación de las personas que resultan fundamentales para la vida. En una sociedad donde el impacto de las matemáticas, las ciencias y las tecnologías es determinante, la consecución y sostenibilidad del bienestar social exige conductas y toma de decisiones personales estrechamente vinculadas a la capacidad crítica y visión razonada y razonable de las personas. A ello contribuyen la competencia matemática y competencias básicas en ciencia y tecnología, las cuales están incluidas en la enseñanza musical a través de sus distintas asignaturas.

La competencia matemática implica la capacidad de aplicar el razonamiento matemático y sus herramientas para describir, interpretar y predecir distintos fenómenos en su contexto, al igual que ocurre en las estructuras musicales. La competencia matemática musical requiere de conocimientos sobre las medidas y las estructuras que componen las obras musicales, así como de las operaciones y las representaciones armónicas, y la comprensión de los términos que conllevan estas representaciones.

El uso de herramientas matemáticas, dentro de la enseñanza musical, implica una serie de destrezas que requieren la aplicación de los principios y procesos matemáticos en distintos contextos, ya sean personales, sociales, profesionales o científicos, así como para emitir juicios fundados y seguir cadenas argumentales en la realización de cálculos, el análisis de gráficos y representaciones armónicas y la manipulación de expresiones musicales, incorporando los medios digitales cuando sea oportuno. Forma parte de esta destreza la creación de descripciones y explicaciones musicales que llevan implícitas la interpretación de resultados compositivos y la reflexión sobre su adecuación al contexto, al igual que la determinación de si las soluciones son adecuadas y tienen sentido en la situación en que se presentan. Se trata, por tanto, de reconocer el papel que desempeñan las estructuras matemático-musicales en el mundo y utilizar los conceptos, procedimientos y herramientas para aplicarlos en la resolución de los problemas que puedan surgir en una situación determinada a lo largo de la vida. La activación de la competencia matemática supone que el aprendiz es capaz de establecer una relación profunda entre el conocimiento conceptual y el conocimiento procedimental, implicados en la resolución de una tarea matemático-musical determinada.

La competencia matemática incluye una serie de actitudes y valores que se basan en el rigor, el respeto a los datos y la veracidad. Así pues, para el adecuado desarrollo de la competencia 
Diseño y planificación de competencias específicas en el currículum de enseñanzas profesionales de música: modalidades composición-dirección en la enseñanza superior.

Carlos Eduardo Pascual Pérez

matemática resulta necesario abordar cuatro áreas relativas a los signos musicales, la armonía, la geometría musical, interrelacionadas de formas diversas:

- El espacio y la forma: incluyen una amplia gama de fenómenos que se encuentran en nuestro mundo musical, visual y físico: patrones, propiedades de los objetos, posiciones, direcciones y representaciones de ellos; descodificación y codificación de información visual y musical, así como navegación e interacción dinámica con formas reales, o con representaciones. La competencia matemático-musical en este sentido incluye una serie de actividades como la comprensión de la perspectiva, la elaboración y lectura de partituras, la transformación de las formas con y sin tecnología, la interpretación de vistas de escenas tridimensionales desde distintas perspectivas y la construcción de representaciones de formas musicales.

- El cambio y las relaciones: el mundo despliega multitud de relaciones temporales y permanentes entre los objetos y las circunstancias, donde los cambios se producen dentro de sistemas de objetos interrelacionados. Tener más conocimientos sobre el cambio y las relaciones supone comprender los tipos fundamentales de cambio y cuándo tienen lugar, con el fin de utilizar modelos músico-estructurales adecuados para describirlo y predecirlo.

- La incertidumbre y los datos: son un fenómeno central del análisis estructural de la música en el presente en distintos momentos del proceso de resolución de problemas en el que resulta clave la presentación e interpretación de dichas estructuras. Esta categoría incluye el reconocimiento del lugar de la variación en los procesos, la posesión de un sentido de cuantificación de esa variación, la admisión de incertidumbre y error en las mediciones y los conocimientos sobre el azar. Asimismo, comprende la elaboración, interpretación y valoración de las conclusiones extraídas en situaciones donde la incertidumbre y los datos son fundamentales.

Las competencias básicas en ciencia y tecnología son aquellas que proporcionan un acercamiento al mundo físico y a la interacción responsable con él desde acciones, tanto individuales como colectivas, orientadas a la conservación y mejora del medio natural, decisivas para la protección y mantenimiento de la calidad de vida y el progreso de los pueblos. Estas competencias contribuyen al desarrollo del pensamiento científico, pues incluyen la aplicación de los métodos propios de la racionalidad científica y las destrezas tecnológicas, que conducen a la adquisición de conocimientos, al contraste de ideas y la aplicación de los descubrimientos al bienestar social.

Las competencias en ciencia y tecnología capacitan a ciudadanos responsables y respetuosos que desarrollan juicios críticos sobre los hechos científicos y tecnológicos que se suceden a lo largo de los tiempos, pasados y actuales. Estas competencias han de capacitar, básicamente, para identificar, plantear y resolver situaciones de la vida cotidiana -personal y socialanálogamente a como se actúa frente a los retos y problemas propios de la actividades científicas y tecnológicas. 
Diseño y planificación de competencias específicas en el currículum de enseñanzas profesionales de música: modalidades composición-dirección en la enseñanza superior.

Para el adecuado desarrollo de las competencias en ciencia y tecnología resulta necesario abordar los saberes o conocimientos científicos relativos a la física, la química, la biología, la geología, las matemáticas y la tecnología, los cuales se derivan de conceptos, procesos y situaciones interconectadas. Estos saberes el alumnado los adquirirá en la enseñanza general (ESO, Bachillerato). Se requiere igualmente el fomento de destrezas que permitan utilizar y manipular herramientas y máquinas tecnológicas, así como utilizar datos y procesos científicos para alcanzar un objetivo; es decir, identificar preguntas, resolver problemas, llegar a una conclusión o tomar decisiones basadas en pruebas y argumentos.

Asimismo, estas competencias incluyen actitudes y valores relacionados con la asunción de criterios éticos asociados a la ciencia y a la tecnología, el interés por la ciencia, el apoyo a la investigación científica y la valoración del conocimiento científico; así como el sentido de la responsabilidad en relación a la conservación de los recursos naturales y a las cuestiones medioambientales y a la adopción de una actitud adecuada para lograr una vida física y mental saludable en un entorno natural y social.

\section{Competencia digital.}

La competencia digital es aquella que implica el uso creativo, crítico y seguro de las tecnologías de la información y la comunicación para alcanzar los objetivos relacionados con el trabajo, la empleabilidad, el aprendizaje, el uso del tiempo libre, la inclusión y participación en la sociedad.

Esta competencia supone, además de la adecuación a los cambios que introducen las nuevas tecnologías en la alfabetización, la lectura y la escritura de la música, un conjunto nuevo de conocimientos, habilidades y actitudes necesarias hoy en día para ser competente en un entorno digital.

Requiere de conocimientos relacionados con el lenguaje específico básico: textual, numérico, icónico, visual, gráfico y sonoro, así como sus pautas de decodificación y transferencia. Esto conlleva el conocimiento de las principales aplicaciones informáticas. Supone también el acceso a las fuentes y el procesamiento de la información; y el conocimiento de los derechos y las libertades que asisten a las personas en el mundo digital. Igualmente precisa del desarrollo de diversas destrezas relacionadas con el acceso a la información, el procesamiento y uso para la comunicación, la creación de contenidos, la seguridad y la resolución de problemas, tanto en contextos formales como no formales e informales. La persona ha de ser capaz de hacer un uso habitual de los recursos tecnológicos disponibles con el fin de resolver los problemas reales de un modo eficiente, así como evaluar y seleccionar nuevas fuentes de información e innovaciones tecnológicas, a medida que van apareciendo, en función de su utilidad para acometer tareas u objetivos específicos.

La adquisición de esta competencia requiere además actitudes y valores que permitan al usuario adaptarse a las nuevas necesidades establecidas por las tecnologías, su apropiación y adaptación a los propios fines y la capacidad de interaccionar socialmente en torno a ellas. Se 
Diseño y planificación de competencias específicas en el currículum de enseñanzas profesionales de música: modalidades composición-dirección en la enseñanza superior.

trata de desarrollar una actitud activa, crítica y realista hacia las tecnologías y los medios tecnológicos, valorando sus fortalezas y debilidades y respetando principios éticos en su uso. Por otra parte, la competencia digital implica la participación y el trabajo colaborativo, así como la motivación y la curiosidad por el aprendizaje y la mejora en el uso de las tecnologías.

Por tanto, para el adecuado desarrollo de la competencia digital resulta necesario abordar:

- La información: esto conlleva la comprensión de cómo se gestiona la información y de cómo se pone a disposición de los usuarios, así como el conocimiento y manejo de diferentes motores de búsqueda y bases de datos, sabiendo elegir aquellos que responden mejor a las propias necesidades de información.

- Igualmente, supone saber analizar e interpretar la información que se obtiene, cotejar y evaluar el contenido de los medios de comunicación en función de su validez, fiabilidad y adecuación entre las fuentes, tanto online como offline. Y por último, la competencia digital supone saber transformar la información en conocimiento a través de la selección apropiada de diferentes opciones de almacenamiento.

- La comunicación: supone tomar conciencia de los diferentes medios de comunicación digital y de varios paquetes de software de comunicación y de su funcionamiento así como sus beneficios y carencias en función del contexto y de los destinatarios. Al mismo tiempo, implica saber qué recursos pueden compartirse públicamente y el valor que tienen, es decir, conocer de qué manera las tecnologías y los medios de comunicación pueden permitir diferentes formas de participación y colaboración para la creación de contenidos que produzcan un beneficio común. Ello supone el conocimiento de cuestiones éticas como la identidad digital y las normas de interacción digital.

- La creación de contenidos: implica saber cómo los contenidos digitales pueden realizarse en diversos formatos (texto, audio, vídeo, imágenes) así como identificar los programas/aplicaciones que mejor se adaptan al tipo de contenido que se quiere crear. Supone también la contribución al conocimiento de dominio público (wikis, foros públicos, revistas), teniendo en cuenta las normativas sobre los derechos de autor y las licencias de uso y publicación de la información.

- La seguridad: implica conocer los distintos riesgos asociados al uso de las tecnologías y de recursos online y las estrategias actuales para evitarlos, lo que supone identificar los comportamientos adecuados en el ámbito digital para proteger la información, propia y de otras personas, así como conocer los aspectos adictivos de las tecnologías.

- La resolución de problemas: esta dimensión supone conocer la composición de los dispositivos digitales, sus potenciales y limitaciones en relación a la consecución de metas personales, así como saber dónde buscar ayuda para la resolución de problemas teóricos y técnicos, lo que implica una combinación heterogénea y bien equilibrada de las tecnologías digitales y no digitales más importantes en esta área de conocimiento.

\section{Aprender a aprender.}

La competencia de aprender a aprender es fundamental para el aprendizaje permanente que se produce a lo largo de la vida y que tiene lugar en distintos contextos formales, no formales e informales. 
Diseño y planificación de competencias específicas en el currículum de enseñanzas profesionales de música: modalidades composición-dirección en la enseñanza superior.

Carlos Eduardo Pascual Pérez

Esta competencia se caracteriza por la habilidad para iniciar, organizar y persistir en el aprendizaje. Esto exige, en primer lugar, la capacidad para motivarse por aprender. Esta motivación depende de que se genere la curiosidad y la necesidad de aprender, de que el estudiante se sienta protagonista del proceso y del resultado de su aprendizaje $y$, finalmente, de que llegue a alcanzar las metas de aprendizaje propuestas y, con ello, que se produzca en él una percepción de auto-eficacia. Todo lo anterior contribuye a motivarle para abordar futuras tareas de aprendizaje. En segundo lugar, en cuanto a la organización y gestión del aprendizaje, la competencia de aprender a aprender requiere conocer y controlar los propios procesos de aprendizaje para ajustarlos a los tiempos y las demandas de las tareas y actividades que conducen al aprendizaje. La competencia de aprender a aprender desemboca en un aprendizaje cada vez más eficaz y autónomo.

Esta competencia incluye una serie de conocimientos y destrezas que requieren la reflexión y la toma de conciencia de los propios procesos de aprendizaje. Así, los procesos de conocimiento se convierten en objeto del conocimiento $y$, además, hay que aprender a ejecutarlos adecuadamente.

Aprender a aprender incluye conocimientos sobre los procesos mentales implicados en el aprendizaje (cómo se aprende). Además, esta competencia incorpora el conocimiento que posee el estudiante sobre su propio proceso de aprendizaje que se desarrolla en tres dimensiones:

- el conocimiento que tiene acerca de lo que sabe y desconoce, de lo que es capaz de aprender, de lo que le interesa, etcétera;

- el conocimiento de la disciplina en la que se localiza la tarea de aprendizaje y el conocimiento del contenido concreto y de las demandas de la tarea misma

- el conocimiento sobre las distintas estrategias posibles para afrontar la tarea.

Todo este conocimiento se vuelca en destrezas de autorregulación y control inherentes a la competencia de aprender a aprender, que se concretan en estrategias de planificación en las que se refleja la meta de aprendizaje que se persigue, así como el plan de acción que se tiene previsto aplicar para alcanzarla; estrategias de supervisión desde las que el estudiante va examinando la adecuación de las acciones que está desarrollando y la aproximación a la meta; y estrategias de evaluación desde las que se analiza tanto el resultado como del proceso que se ha llevado a cabo. La planificación, supervisión y evaluación son esenciales para desarrollar aprendizajes cada vez más eficaces. Todas ellas incluyen un proceso reflexivo que permite pensar antes de actuar (planificación), analizar el curso y el ajuste del proceso (supervisión) y consolidar la aplicación de buenos planes o modificar los que resultan incorrectos (evaluación del resultado y del proceso). Estas tres estrategias deberían potenciarse en los procesos de aprendizaje y de resolución de problemas en los que participan los estudiantes.

Aprender a aprender se manifiesta tanto individualmente como en grupo. En ambos casos el dominio de esta competencia se inicia con una reflexión consciente acerca de los procesos de 
Diseño y planificación de competencias específicas en el currículum de enseñanzas profesionales de música: modalidades composición-dirección en la enseñanza superior.

aprendizaje a los que se entrega uno mismo o el grupo. No solo son los propios procesos de conocimiento, sino que, también, el modo en que los demás aprenden se convierte en objeto de escrutinio. De ahí que la competencia de aprender a aprender se adquiera también en el contexto del trabajo en equipo. Los profesores han de procurar que los estudiantes sean conscientes de lo que hacen para aprender y busquen alternativas. Muchas veces estas alternativas se ponen de manifiesto cuando se trata de averiguar qué es lo que hacen los demás en situaciones de trabajo cooperativo.

Respecto a las actitudes y valores, la motivación y la confianza son cruciales para la adquisición de esta competencia. Ambas se potencian desde el planteamiento de metas realistas a corto, medio y largo plazo. Al alcanzarse las metas aumenta la percepción de auto-eficacia y la confianza, y con ello se elevan los objetivos de aprendizaje de forma progresiva. Las personas deben ser capaces de apoyarse en experiencias vitales y de aprendizaje previas con el fin de utilizar y aplicar los nuevos conocimientos y capacidades en otros contextos, como los de la vida privada y profesional, la educación y la formación.

Saber aprender en un determinado ámbito implica ser capaz de adquirir y asimilar nuevos conocimientos y llegar a dominar capacidades y destrezas propias de dicho ámbito. En la competencia de aprender a aprender puede haber una cierta trasferencia de conocimiento de un campo a otro, aunque saber aprender en un ámbito no significa necesariamente que se sepa aprender en otro. Por ello, su adquisición debe llevarse a cabo en el marco de la enseñanza de las distintas áreas y materias del ámbito formal, y también de los ámbitos no formal e informal.

Podría concluirse que para el adecuado desarrollo de la competencia de aprender a aprender se requiere de una reflexión que favorezca un conocimiento de los procesos mentales a los que se entregan las personas cuando aprenden, un conocimiento sobre los propios procesos de aprendizaje, así como el desarrollo de la destreza de regular y controlar el propio aprendizaje que se lleva a cabo.

\section{Competencias sociales y cívicas.}

Las competencias sociales y cívicas implican la habilidad y capacidad para utilizar los conocimientos y actitudes sobre la sociedad, entendida desde las diferentes perspectivas, en su concepción dinámica, cambiante y compleja, para interpretar fenómenos y problemas sociales en contextos cada vez más diversificados; para elaborar respuestas, tomar decisiones y resolver conflictos, así como para interactuar con otras personas y grupos conforme a normas basadas en el respeto mutuo y en convicciones democráticas. Además de incluir acciones a un nivel más cercano y mediato al individuo como parte de una implicación cívica y social.

Se trata, por lo tanto, de aunar el interés por profundizar y garantizar la participación en el funcionamiento democrático de la sociedad, tanto en el ámbito público como privado, y preparar a las personas para ejercer la ciudadanía democrática y participar plenamente en la 
Diseño y planificación de competencias específicas en el currículum de enseñanzas profesionales de música: modalidades composición-dirección en la enseñanza superior.

Carlos Eduardo Pascual Pérez

vida cívica y social gracias al conocimiento de conceptos y estructuras sociales y políticas y al compromiso de participación activa y democrática.

La competencia social se relaciona con el bienestar personal y colectivo. Exige entender el modo en que las personas pueden procurarse un estado de salud física y mental óptimo, tanto para ellas mismas como para sus familias y para su entorno social próximo, y saber cómo un estilo de vida saludable puede contribuir a ello.

Para poder participar plenamente en los ámbitos social e interpersonal es fundamental adquirir los conocimientos que permitan comprender y analizar de manera crítica los códigos de conducta y los usos generalmente aceptados en las distintas sociedades y entornos, así como sus tensiones y procesos de cambio. La misma importancia tiene conocer los conceptos básicos relativos al individuo, al grupo, a la organización del trabajo, la igualdad y la no discriminación entre hombres y mujeres y entre diferentes grupos étnicos o culturales, la sociedad y la cultura. Asimismo, es esencial comprender las dimensiones intercultural y socioeconómica de las sociedades europeas y percibir las identidades culturales y nacionales como un proceso sociocultural dinámico y cambiante en interacción con la europea, en un contexto de creciente globalización.

Los elementos fundamentales de esta competencia incluyen el desarrollo de ciertas destrezas como la capacidad de comunicarse de una manera constructiva en distintos entornos sociales y culturales, mostrar tolerancia, expresar y comprender puntos de vista diferentes, negociar sabiendo inspirar confianza y sentir empatía. Las personas deben ser capaces de gestionar un comportamiento de respeto a las diferencias expresado de manera constructiva.

Asimismo, esta competencia incluye actitudes y valores como una forma de colaboración, la seguridad en uno mismo y la integridad y honestidad. Las personas deben interesarse por el desarrollo socioeconómico y por su contribución a un mayor bienestar social de toda la población, así como la comunicación intercultural, la diversidad de valores y el respeto a las diferencias, además de estar dispuestas a superar los prejuicios y a comprometerse en este sentido.

La competencia cívica se basa en el conocimiento crítico de los conceptos de democracia, justicia, igualdad, ciudadanía y derechos humanos y civiles, así como de su formulación en la Constitución española, la Carta de los Derechos Fundamentales de la Unión Europea y en declaraciones internacionales, y de su aplicación por parte de diversas instituciones a escala local, regional, nacional, europea e internacional. Esto incluye el conocimiento de los acontecimientos contemporáneos, así como de los acontecimientos más destacados y de las principales tendencias en las historias nacional, europea y mundial, así como la comprensión de los procesos sociales y culturales de carácter migratorio que implican la existencia de sociedades multiculturales en el mundo globalizado. 
Diseño y planificación de competencias específicas en el currículum de enseñanzas profesionales de música: modalidades composición-dirección en la enseñanza superior.

Las destrezas de esta competencia están relacionadas con la habilidad para interactuar eficazmente en el ámbito público y para manifestar solidaridad e interés por resolver los problemas que afecten al entorno escolar y a la comunidad, ya sea local o más amplia. Conlleva la reflexión crítica y creativa y la participación constructiva en las actividades de la comunidad o del ámbito mediato e inmediato, así como la toma de decisiones en los contextos local, nacional o europeo y, en particular, mediante el ejercicio del voto y de la actividad social y cívica.

Las actitudes y valores inherentes a esta competencia son aquellos que se dirigen al pleno respeto de los derechos humanos y a la voluntad de participar en la toma de decisiones democráticas a todos los niveles, sea cual sea el sistema de valores adoptado. También incluye manifestar el sentido de la responsabilidad y mostrar comprensión y respeto de los valores compartidos que son necesarios para garantizar la cohesión de la comunidad, basándose en el respeto de los principios democráticos. La participación constructiva incluye también las actividades cívicas y el apoyo a la diversidad y la cohesión sociales y al desarrollo sostenible, así como la voluntad de respetar los valores y la intimidad de los demás y la recepción reflexiva y crítica de la información procedente de los medios de comunicación.

Por tanto, para el adecuado desarrollo de estas competencias es necesario comprender y entender las experiencias colectivas y la organización y funcionamiento del pasado y presente de las sociedades, la realidad social del mundo en el que se vive, sus conflictos y las motivaciones de los mismos, los elementos que son comunes y los que son diferentes, así como los espacios y territorios en que se desarrolla la vida de los grupos humanos, y sus logros y problemas, para comprometerse personal y colectivamente en su mejora, participando así de manera activa, eficaz y constructiva en la vida social y profesional.

Asimismo, estas competencias incorporan formas de comportamiento individual que capacitan a las personas para convivir en una sociedad cada vez más plural, dinámica, cambiante y compleja para relacionarse con los demás; cooperar, comprometerse y afrontar los conflictos y proponer activamente perspectivas de afrontamiento, así como tomar perspectiva, desarrollar la percepción del individuo en relación a su capacidad para influir en lo social y elaborar argumentaciones basadas en evidencias.

Adquirir estas competencias supone ser capaz de ponerse en el lugar del otro, aceptar las diferencias, ser tolerante y respetar los valores, las creencias, las culturas y la historia personal y colectiva de los otros.

\section{Sentido de iniciativa y espíritu emprendedor.}

La competencia sentido de iniciativa y espíritu emprendedor implica la capacidad de transformar las ideas en actos. Ello significa adquirir conciencia de la situación a intervenir o resolver, y saber elegir, planificar y gestionar los conocimientos, destrezas o habilidades y actitudes necesarios con criterio propio, con el fin de alcanzar el objetivo previsto. 
Diseño y planificación de competencias específicas en el currículum de enseñanzas profesionales de música: modalidades composición-dirección en la enseñanza superior.

Carlos Eduardo Pascual Pérez

Esta competencia está presente en los ámbitos personal, social, escolar y laboral en los que se desenvuelven las personas, permitiéndoles el desarrollo de sus actividades y el aprovechamiento de nuevas oportunidades. Constituye igualmente el cimiento de otras capacidades y conocimientos más específicos, e incluye la conciencia de los valores éticos relacionados. La adquisición de esta competencia es determinante en la formación de futuros ciudadanos emprendedores, contribuyendo así a la cultura del emprendimiento. En este sentido, su formación debe incluir conocimientos y destrezas relacionados con las oportunidades de carrera y el mundo del trabajo, la educación económica y financiera o el conocimiento de la organización y los procesos empresariales, así como el desarrollo de actitudes que conlleven un cambio de mentalidad que favorezca la iniciativa emprendedora, la capacidad de pensar de forma creativa, de gestionar el riesgo y de manejar la incertidumbre. Estas habilidades resultan muy importantes para favorecer el nacimiento de emprendedores sociales, como los denominados intraemprendedores (emprendedores que trabajan dentro de empresas u organizaciones que no son suyas), así como de futuros empresarios.

Entre los conocimientos que requiere la competencia sentido de iniciativa y espíritu emprendedor se incluye la capacidad de reconocer las oportunidades existentes para las actividades personales, profesionales y comerciales. También incluye aspectos de mayor amplitud que proporcionan el contexto en el que las personas viven y trabajan, tales como la comprensión de las líneas generales que rigen el funcionamiento de las sociedades y las organizaciones sindicales y empresariales, así como las económicas y financieras; la organización y los procesos empresariales; el diseño y la implementación de un plan (la gestión de recursos humanos y/o financieros); así como la postura ética de las organizaciones y el conocimiento de cómo estas pueden ser un impulso positivo, por ejemplo, mediante el comercio justo y las empresas sociales.

Asimismo, esta competencia requiere de las siguientes destrezas o habilidades esenciales: capacidad de análisis; capacidades de planificación, organización, gestión y toma de decisiones; capacidad de adaptación al cambio y resolución de problemas; comunicación, presentación, representación y negociación efectivas; habilidad para trabajar, tanto individualmente como dentro de un equipo; participación, capacidad de liderazgo y delegación; pensamiento crítico y sentido de la responsabilidad; autoconfianza, evaluación y auto-evaluación, ya que es esencial determinar los puntos fuertes y débiles de uno mismo y de un proyecto, así como evaluar y asumir riesgos cuando esté justificado (manejo de la incertidumbre y asunción y gestión del riesgo).

Finalmente, requiere el desarrollo de actitudes y valores como: la predisposición a actuar de una forma creadora e imaginativa; el autoconocimiento y la autoestima; la autonomía o independencia, el interés y esfuerzo y el espíritu emprendedor. Se caracteriza por la iniciativa, la pro-actividad y la innovación, tanto en la vida privada y social como en la profesional. También está relacionada con la motivación y la determinación a la hora de cumplir los objetivos, ya sean personales o establecidos en común con otros, incluido el ámbito laboral. Así 
Diseño y planificación de competencias específicas en el currículum de enseñanzas profesionales de música: modalidades composición-dirección en la enseñanza superior.

Carlos Eduardo Pascual Pérez

pues, para el adecuado desarrollo de la competencia sentido de la iniciativa y espíritu emprendedor resulta necesario abordar:

- La capacidad creadora y de innovación: creatividad e imaginación; autoconocimiento y autoestima; autonomía e independencia; interés y esfuerzo; espíritu emprendedor; iniciativa e innovación.

- La capacidad pro-activa para gestionar proyectos: capacidad de análisis; planificación, organización, gestión y toma de decisiones; resolución de problemas; habilidad para trabajar tanto individualmente como de manera colaborativa dentro de un equipo; sentido de la responsabilidad; evaluación y auto-evaluación.

- La capacidad de asunción y gestión de riesgos y manejo de la incertidumbre: comprensión y asunción de riesgos; capacidad para gestionar el riesgo y manejar la incertidumbre.

- Las cualidades de liderazgo y trabajo individual y en equipo: capacidad de liderazgo y delegación; capacidad para trabajar individualmente y en equipo; capacidad de representación y negociación.

- Sentido crítico y de la responsabilidad: sentido y pensamiento crítico; sentido de la responsabilidad.

\section{Conciencia y expresiones culturales.}

La competencia en conciencia y expresión cultural implica conocer, comprender, apreciar y valorar con espíritu crítico, con una actitud abierta y respetuosa, las diferentes manifestaciones culturales y artísticas, utilizarlas como fuente de enriquecimiento y disfrute personal y considerarlas como parte de la riqueza y patrimonio de los pueblos.

Esta competencia incorpora también un componente expresivo referido a la propia capacidad estética y creadora y al dominio de aquellas capacidades relacionadas con los diferentes códigos artísticos y culturales, para poder utilizarlas como medio de comunicación y expresión personal. Implica igualmente manifestar interés por la participación en la vida cultural y por contribuir a la conservación del patrimonio cultural y artístico, tanto de la propia comunidad como de otras comunidades.

Así pues, la competencia para la conciencia y expresión cultural requiere de conocimientos que permitan acceder a las distintas manifestaciones sobre la herencia cultural (patrimonio cultural, histórico-artístico, literario, filosófico, tecnológico, medioambiental, etcétera) a escala local, nacional y europea y su lugar en el mundo. Comprende la concreción de la cultura en diferentes autores y obras, así como en diferentes géneros y estilos, tanto de las bellas artes (música, pintura, escultura, arquitectura, cine, literatura, fotografía, teatro y danza) como de otras manifestaciones artístico-culturales de la vida cotidiana (vivienda, vestido, gastronomía, artes aplicadas, folclore, fiestas....). Incorpora asimismo el conocimiento básico de las principales técnicas, recursos y convenciones de los diferentes lenguajes artísticos y la identificación de las 
Diseño y planificación de competencias específicas en el currículum de enseñanzas profesionales de música: modalidades composición-dirección en la enseñanza superior.

relaciones existentes entre esas manifestaciones y la sociedad, lo cual supone también tener conciencia de la evolución del pensamiento, las corrientes estéticas, las modas y los gustos, así como de la importancia representativa, expresiva y comunicativa de los factores estéticos en la vida cotidiana.

Dichos conocimientos son necesarios para poner en funcionamiento destrezas como la aplicación de diferentes habilidades de pensamiento, perceptivas, comunicativas, de sensibilidad y sentido estético para poder comprenderlas, valorarlas, emocionarse y disfrutarlas. La expresión cultural y artística exige también desarrollar la iniciativa, la imaginación y la creatividad expresada a través de códigos artísticos, así como la capacidad de emplear distintos materiales y técnicas en el diseño de proyectos.

Además, en la medida en que las actividades culturales y artísticas suponen con frecuencia un trabajo colectivo, es preciso disponer de habilidades de cooperación y tener conciencia de la importancia de apoyar y apreciar las contribuciones ajenas.

El desarrollo de esta competencia supone actitudes y valores personales de interés, reconocimiento y respeto por las diferentes manifestaciones artísticas y culturales, y por la conservación del patrimonio. Exige asimismo valorar la libertad de expresión, el derecho a la diversidad cultural, el diálogo entre culturas y sociedades y la realización de experiencias artísticas compartidas. A su vez, conlleva un interés por participar en la vida cultural y, por tanto, por comunicar y compartir conocimientos, emociones y sentimientos a partir de expresiones artísticas. Así pues, para el adecuado desarrollo de la competencia para la conciencia y expresión cultural resulta necesario abordar:

- El conocimiento, estudio y comprensión tanto de los distintos estilos y géneros artísticos como de las principales obras y producciones del patrimonio cultural y artístico en distintos periodos históricos, sus características y sus relaciones con la sociedad en la que se crean, así como las características de las obras de arte producidas, todo ello mediante el contacto con las obras de arte. Está relacionada, igualmente, con la creación de la identidad cultural como ciudadano de un país o miembro de un grupo.

- El aprendizaje de las técnicas y recursos de los diferentes lenguajes artísticos y formas de expresión cultural, así como de la integración de distintos lenguajes.

- El desarrollo de la capacidad e intención de expresarse y comunicar ideas, experiencias y emociones propias, partiendo de la identificación del potencial artístico personal (aptitud/talento). Se refiere también a la capacidad de percibir, comprender y enriquecerse con las producciones del mundo del arte y de la cultura.

- La potenciación de la iniciativa, la creatividad y la imaginación propias de cada individuo de cara a la expresión de las propias ideas y sentimientos. Es decir, la capacidad de imaginar y realizar producciones que supongan recreación, innovación y transformación. Implica el fomento de habilidades que permitan reelaborar ideas y sentimientos propios y ajenos y exige desarrollar el autoconocimiento y la autoestima, así como la capacidad de resolución de problemas y asunción de riesgos. 
Diseño y planificación de competencias específicas en el currículum de enseñanzas profesionales de música: modalidades composición-dirección en la enseñanza superior.

Carlos Eduardo Pascual Pérez

- El interés, aprecio, respeto, disfrute y valoración crítica de las obras artísticas y culturales que se producen en la sociedad, con un espíritu abierto, positivo y solidario.

- La promoción de la participación en la vida y la actividad cultural de la sociedad en que se vive, a lo largo de toda la vida. Esto lleva implícitos comportamientos que favorecen la convivencia social.

- El desarrollo de la capacidad de esfuerzo, constancia y disciplina como requisitos necesarios para la creación de cualquier producción artística de calidad, así como habilidades de cooperación que permitan la realización de trabajos colectivos.

\section{LAS COMPETENCIAS CLAVE Y LOS OBJETIVOS}

1. Las competencias clave deberán estar estrechamente vinculadas a los objetivos definidos para la Enseñanzas Elementales y Profesionales de Música

2. La relación de las competencias clave con los objetivos de las distintas asignaturas del currículo hace necesario diseñar estrategias para promover y evaluar las competencias desde las etapas educativas iniciales e intermedias hasta su posterior consolidación en etapas superiores, que llevarán a los alumnos y alumnas a desarrollar actitudes y valores, así como un conocimiento de base conceptual y un uso de técnicas y estrategias que favorecerán su incorporación a la vida adulta y que servirán de cimiento para su aprendizaje a lo largo de su vida.

3. La adquisición eficaz de las competencias clave por parte del alumnado y su contribución al logro de los objetivos de las diferentes asignaturas, desde un carácter interdisciplinar y transversal, requiere del diseño de actividades de aprendizaje integradas que permitan avanzar hacia los resultados de aprendizaje de más de una competencia al mismo tiempo.

\section{LAS COMPETENCIAS CLAVE EN EL CURRÍCULO}

1. Las competencias clave deben estar integradas en las áreas o materias de las propuestas curriculares, y en ellas definirse, explicitarse y desarrollarse suficientemente los resultados de aprendizaje que los alumnos y alumnas deben conseguir.

2. Las competencias deben desarrollarse en los ámbitos de la educación formal, no formal e informal a lo largo de la Educación Primaria, la Educación Secundaria Obligatoria y el Bachillerato, y en la educación permanente a lo largo de toda la vida.

3. Todas las áreas o materias del currículo deben participar, desde su ámbito correspondiente, en el desarrollo de las distintas competencias del alumnado.

4. La selección de los contenidos y las metodologías debe asegurar el desarrollo de las competencias clave a lo largo de la vida académica.

5. Los criterios de evaluación deben servir de referencia para valorar lo que el alumnado sabe y sabe hacer en cada área o materia. Estos criterios de evaluación se desglosan en estándares de aprendizaje evaluables. Para valorar el desarrollo competencial del alumnado, serán estos 
Diseño y planificación de competencias específicas en el currículum de enseñanzas profesionales de música: modalidades composición-dirección en la enseñanza superior.

Carlos Eduardo Pascual Pérez

estándares de aprendizaje evaluables, como elementos de mayor concreción, observables y medibles, los que, al ponerse en relación con las competencias clave, permitirán graduar el rendimiento o desempeño alcanzado en cada una de ellas.

6. El conjunto de estándares de aprendizaje evaluables de un área o materia determinada dará lugar a su perfil de área o materia. Dado que los estándares de aprendizaje evaluables se ponen en relación con las competencias, este perfil permitirá identificar aquellas competencias que se desarrollan a través de esa área o materia.

7. Todas las áreas y materias deben contribuir al desarrollo competencial. El conjunto de estándares de aprendizaje evaluables de las diferentes áreas o materias que se relacionan con una misma competencia da lugar al perfil de esa competencia (perfil de competencia). La elaboración de este perfil facilitará la evaluación competencial del alumnado.

\section{ESTRATEGIAS METODOLÓGICAS PARA EL TRABAJO POR COMPETENCIAS}

Todo proceso de enseñanza-aprendizaje debe partir de una planificación rigurosa de lo que se pretende conseguir, teniendo claro cuáles son los objetivos o metas, qué recursos son necesarios, qué métodos didácticos son los más adecuados y cómo se evalúa el aprendizaje y se retroalimenta el proceso. Los métodos didácticos han de elegirse en función de lo que se sabe que es óptimo para alcanzar las metas propuestas y en función de los condicionantes en los que tiene lugar la enseñanza.

La naturaleza de la materia, las condiciones socioculturales, la disponibilidad de recursos y las características de los alumnos y alumnas condicionan el proceso de enseñanza-aprendizaje, por lo que será necesario que el método seguido por el profesor se ajuste a estos condicionantes con el fin de propiciar un aprendizaje competencial en el alumnado.

Los métodos deben partir de la perspectiva del docente como orientador, promotor y facilitador del desarrollo competencial en el alumnado; además, deben enfocarse a la realización de tareas o situaciones-problema, planteadas con un objetivo concreto, que el alumnado debe resolver haciendo un uso adecuado de los distintos tipos de conocimientos, destrezas, actitudes y valores; asimismo, deben tener en cuenta la atención a la diversidad y el respeto por los distintos ritmos y estilos de aprendizaje mediante prácticas de trabajo individual y cooperativo.

En el actual proceso de inclusión de las competencias como elemento esencial del currículo, es preciso señalar que cualquiera de las metodologías seleccionadas por los docentes para favorecer el desarrollo competencial de los alumnos y alumnas debe ajustarse al nivel competencial inicial de estos. Además, es necesario secuenciar la enseñanza de tal modo que se parta de aprendizajes más simples para avanzar gradualmente hacia otros más complejos.

Uno de los elementos clave en la enseñanza por competencias es despertar y mantener la motivación hacia el aprendizaje en el alumnado, lo que implica un nuevo planteamiento del papel del alumno, activo y autónomo, consciente de ser el responsable de su aprendizaje. Los 
Diseño y planificación de competencias específicas en el currículum de enseñanzas profesionales de música: modalidades composición-dirección en la enseñanza superior.

métodos docentes deberán favorecer la motivación por aprender en los alumnos y alumnas y, a tal fin, los profesores han de ser capaces de generar en ellos la curiosidad y la necesidad por adquirir los conocimientos, las destrezas y las actitudes y valores presentes en las competencias. Asimismo, con el propósito de mantener la motivación por aprender es necesario que los profesores procuren todo tipo de ayudas para que los estudiantes comprendan lo que aprenden, sepan para qué lo aprenden y sean capaces de usar lo aprendido en distintos contextos dentro y fuera del aula. Para potenciar la motivación por el aprendizaje de competencias se requieren, además, metodologías activas y contextualizadas. Aquellas que faciliten la participación e implicación del alumnado y la adquisición y uso de conocimientos en situaciones reales, serán las que generen aprendizajes más transferibles y duraderos.

Las metodologías activas han de apoyarse en estructuras de aprendizaje cooperativo, de forma que, a través de la resolución conjunta de las tareas, los miembros del grupo conozcan las estrategias utilizadas por sus compañeros y puedan aplicarlas a situaciones similares. Para un proceso de enseñanza-aprendizaje competencial las estrategias interactivas son las más adecuadas, al permitir compartir y construir el conocimiento y dinamizar la sesión de clase mediante el intercambio verbal y colectivo de ideas. Las metodologías que contextualizan el aprendizaje y permiten el aprendizaje por proyectos, los centros de interés, el estudio de casos o el aprendizaje basado en problemas favorecen la participación activa, la experimentación y un aprendizaje funcional que va a facilitar el desarrollo de las competencias, así como la motivación de los alumnos y alumnas al contribuir decisivamente a la transferibilidad de los aprendizajes.

El trabajo por proyectos, especialmente relevante para el aprendizaje por competencias, se basa en la propuesta de un plan de acción con el que se busca conseguir un determinado resultado práctico. Esta metodología pretende ayudar al alumnado a organizar su pensamiento favoreciendo en ellos la reflexión, la crítica, la elaboración de hipótesis y la tarea investigadora a través de un proceso en el que cada uno asume la responsabilidad de su aprendizaje, aplicando sus conocimientos y habilidades a proyectos reales. Se favorece, por tanto, un aprendizaje orientado a la acción en el que se integran varias áreas o materias: los estudiantes ponen en juego un conjunto amplio de conocimientos, habilidades o destrezas y actitudes personales, es decir, los elementos que integran las distintas competencias.

Asimismo, resulta recomendable el uso del portfolio, que aporta información extensa sobre el aprendizaje del alumnado, refuerza la evaluación continua y permite compartir resultados de aprendizaje. El portfolio es una herramienta motivadora para el alumnado que potencia su autonomía y desarrolla su pensamiento crítico y reflexivo. La selección y uso de materiales y recursos didácticos constituye un aspecto esencial de la metodología. El profesorado debe implicarse en la elaboración y diseño de diferentes tipos de materiales, adaptados a los distintos niveles y a los diferentes estilos y ritmos de aprendizaje de los alumnos y alumnas, con el objeto de atender a la diversidad en el aula y personalizar los procesos de construcción de los aprendizajes. Se debe potenciar el uso de una variedad de materiales y recursos, considerando 
Diseño y planificación de competencias específicas en el currículum de enseñanzas profesionales de música: modalidades composición-dirección en la enseñanza superior.

Carlos Eduardo Pascual Pérez

especialmente la integración de las Tecnologías de la Información y la Comunicación en el proceso de enseñanza-aprendizaje que permiten el acceso a recursos virtuales.

Finalmente, es necesaria una adecuada coordinación entre los docentes sobre las estrategias metodológicas y didácticas que se utilicen. Los equipos educativos deben plantearse una reflexión común y compartida sobre la eficacia de las diferentes propuestas metodológicas con criterios comunes y consensuados. Esta coordinación y la existencia de estrategias conexionadas permiten abordar con rigor el tratamiento integrado de las competencias y progresar hacia una construcción colaborativa del conocimiento. Las enseñanzas especializadas de música contribuirán a desarrollar en los alumnos las competencias clave así como los valores cívicos propios del sistema educativo a través de los objetivos establecidos en la programación de la asignatura.

\section{Objetivos y Contenidos}

\section{Objetivos generales de las Enseñanzas Profesionales}

Según establece el Artículo 4 del DECRETO 158/2007, de 21 de septiembre, del Consell, por el que se establece el currículo de las enseñanzas profesionales de música y se regula el acceso a estas enseñanzas, las enseñanzas elementales de música tienen como objetivo contribuir a desarrollar en los alumnos y alumnas capacidades generales y los valores cívicos propios del sistema educativo y, además, las capacidades siguientes:

a) Fomentar la audición de la música y establecer conceptos estéticos propios que permitan fundamentar y desarrollar criterios interpretativos individuales.

b) Desarrollar la sensibilidad artística y el criterio estético como fuente de formación y enriquecimiento personal.

c) Analizar y valorar críticamente las diferentes manifestaciones y estilos musicales.

d) Conocer las aportaciones de la música al desarrollo personal del individuo y al desarrollo colectivo de las sociedades.

e) Participar en actividades de difusión cultural musical que permitan experimentar con la música y disfrutar de la música.

f) Conocer y emplear con precisión el vocabulario específico relativo a los conceptos científicos y artísticos de la música. 
Diseño y planificación de competencias específicas en el currículum de enseñanzas profesionales de música: modalidades composición-dirección en la enseñanza superior.

g) Conocer y valorar el patrimonio musical como parte integrante del patrimonio histórico y cultural de la Humanidad.

h) Conocer y valorar la importancia de la música propia de la Comunidad Valenciana, así como sus características y manifestaciones más importantes.

\section{Contenidos comunes de las Enseñanzas Profesionales}

Del mismo modo, en el Anexo I de dicho DECRETO se establecen los contenidos comunes de la práctica instrumental:

a) Superar con dominio y capacidad crítica los objetivos y contenidos planteados.

b) Conocer los elementos básicos de los lenguajes musicales, sus características, funciones y evoluciones en los diferentes contextos históricos.

c) Utilizar el «oído interno» como base de la afinación, de la audición armónica y de la interpretación musical.

d) Formar una imagen ajustada de las posibilidades y características musicales tanto a nivel individual como en la relación con el grupo, con la disposición necesaria para saber integrarse como un miembro más del mismo o como responsable del conjunto.

e) Compartir vivencias musicales de grupo en el aula y fuera de ella que permitan enriquecer la relación afectiva con la música a través del canto y de participación instrumental en grupo.

f) Utilizar el cuerpo y la mente para adquirir la técnica necesaria y así, concentrarse en la audición e interpretación musical.

g) Interrelacionar y aplicar los conocimientos adquiridos en todas las asignaturas que componen el currículo junto con las vivencias y experiencias propias para conseguir una interpretación artística de calidad.

h) Adquirir y aplicar las destrezas necesarias para resolver las dificultades que surjan en la interpretación de la música.

i) Practicar la improvisación y la transposición como elementos inherentes a la creatividad musical. 
Diseño y planificación de competencias específicas en el currículum de enseñanzas profesionales de música: modalidades composición-dirección en la enseñanza superior.

j) Interpretar, individualmente o dentro de la agrupación correspondiente, obas escritas en todos los lenguajes musicales, profundizando en el conocimiento de los diferentes estilos y épocas, así como en los recursos interpretativos de cada uno de ellos.

k) Actuar en público con autocontrol, dominio de la memoria musical y capacidad comunicativa.

I) Adquirir autonomía personal en la comunicación musical.

m) Consolidar hábitos de estudio adecuados y continuados en función de la dificultad de los contenidos de las asignaturas de los diferentes cursos y niveles.

n) Conocer y aplicar las técnicas del instrumento o de la voz de acuerdo con las exigencias de las obras.

\section{Objetivos propios de la especialidad}

Por concreción curricular, a enseñanza de Armonía en el grado profesional tendrá como objetivo contribuir a des arrollar en los alumnos las capacidades siguientes:

a) Conocer los elementos básicos de la armonía tonal y sus carac- terísticas, funciones y transformaciones en los distintos contextos históricos.

b) Utilizar en trabajos escritos los elementos y procedimientos básicos de la armonía tonal

c) Desarrollar el oído interno tanto en el análisis como en la reali- zación de ejercicios escritos.

d) Identificar a través de la audición los acordes y procedimientos más comunes de la armonía tonal.

e) Identificar a través del análisis de obras los acordes, los procedimientos más comunes de la armonía tonal y las transformaciones temáticas.

f) Comprender la interrelación de los procesos armónicos con la forma musical.

g) Aprender a valorar la calidad de la música.

\section{Contenidos propios de la especialidad}


El acorde.

Consonancia y disonancia.

Estado fundamental e inversiones de los acordes triadas y de séptima sobre todos los grados de la escala y de los acordes de novena dominante.

Enlace de acordes.

Tonalidad y funciones tonales.

Elementos y procedimientos de origen modal presentes en el Sistema Tonal.

El ritmo armónico.

Cadencias Perfecta, Imperfecta, Plagal, Rota.

Procesos cadenciales.

Modulación: Diatónica y cromática, por cambio de función tonal, cambios de tono y modo, etc.

Flexiones introtonales.

Progresiones unitonales y modulantes.

Series de sextas y de séptimas.

Utilización de los elementos y procedimientos anteriores en la realización de trabajos escritos.

Practica auditiva e instrumental que conduzca a la interiorización de los elementos y procedimientos aprendidos.

Análisis de obras para relacionar dichos elementos y procedimientos, así como las transforma- ciones temáticas de los materiales utilizados con su contexto estilístico y la forma musical.

Evaluación 
Carlos Eduardo Pascual Pérez

\section{Criterios generales}

1. Interpretar obras con el suficiente nivel de calidad en correspondencia con los objetivos y su maduración psicoevolutiva.

2. El aspecto anterior supone, además, un hábito de expresión musical da cara al público, actividad que se distribuirá en frecuentes audiciones a lo largo del curso. El carácter diferenciador, en cuanto a la aplicación de los conceptos, viene determinado por las correspondientes obras, piezas y ejercicios del programa de cada curso.

3. Coordinación con el equipo docente para analizar la consecución y profundidad de los objetivos generales del grado.

4. Participar en audiciones del curso a nivel de aula y de centro. Los profesores podrán coordinar y supervisar audiciones trimestrales a nivel de aula, en las cuales participarán todos los alumnos de cada profesor e interpretarán un repertorio común según cada curso propuesto por el profesorado. Las audiciones servirán para evaluar al alumno y el porcentaje de calificación de dichas audiciones será determinado por cada profesor, según el trabajo desarrollado por el alumno en las clases lectivas.

5. El alumno deberá desarrollar una conciencia de grupo y de su propio nivel a partir de las audiciones conjuntas desarrolladas durante el curso, lo cual contribuirá en buen grado a la unificación de niveles.

6. Coordinación con el equipo docente para analizar la consecución y profundidad de los objetivos generales del grado.

7. Analizar los criterios de evaluación, identificación en cada uno las capacidades, los contenidos que incluye y los indicadores de los objetivos de la asignatura.

8. La Regularidad en el estudio y la trayectoria en el mismo.

\section{Criterios específicos}

1. Realizar ejercicios a partir de un bajo cifrado dado.

2. Realizar ejercicios de armonización a partir de tiples dados.

3. Realizar ejercicios de armonización a partir de bajos sin cifrar dados. 
Diseño y planificación de competencias específicas en el currículum de enseñanzas profesionales de música: modalidades composición-dirección en la enseñanza superior.

Carlos Eduardo Pascual Pérez

4. Componer ejercicios breves a partir de un esquema armónico dado o propio.

5. Identificar auditivamente los principales elementos morfológicos de la armonía tonal.

6. Identificar auditivamente los principales procedimientos sintácticos de la armonía tonal.

7. Identificar auditivamente estructuras formales concretas.

8. Identificar mediante el análisis de obras los elementos morfológicos de la armonía tonal.

9. Identificar mediante el análisis de obras los procedimientos sintácticos y formales de la armonía tonal.

10. Identificar mediante el análisis de obras los procedimientos de transformación temática.

11. Identificar auditivamente diversos errores en ejercicios preparados con esta finalidad y proponer soluciones.

12. Identificar mediante el análisis diversos errores en ejercicios preparados con esta finalidad y proponer soluciones.

\section{Procedimientos e instrumentos de evaluación}

La evaluación será continua y establecida según el tipo y grado de aprendizaje que se espera hayan alcanzado los alumnos en un momento determinado, respeto a las capacidades indicadas en los objetivos generales y específicos de la especialidad. También será flexible, teniendo en cuenta el contexto del alumno, es decir, el ciclo educativo en el que se encuentra, así como sus propias características y posibilidades. Además, los instrumentos de evaluación a utilizar serán los siguientes:

1. Evaluación competencial de cada sesión.

2. Fiel seguimiento individual del alumno mediante el "Cuaderno del profesor"

3. Boletines trimestrales informativos

4. Temporalización del repertorio por cursos y trimestres

5. Evaluación actitudinal mensual

Por norma general, para el cálculo de la nota media las tareas prácticas se valorarán con un $50 \%$, la evaluación actitudinal con un $20 \%$ y las pruebas trimestrales con un $30 \%$. 
Carlos Eduardo Pascual Pérez

\section{Mínimos exigibles}

- Identificar, a través del análisis, sucesiones que se estructuran a partir de la repetición, variación y contraste.

- Identificar, a través del análisis, sucesiones combinadas de valores de duración y alturas de sonidos que se estructuran a partir de la repetición, variación y contraste.

- Identificar, a través del análisis, la estructura armónico y formal de una obra.

- Análisis armónico, estructural y formal de obras correspondientes a cada curso.

- Identificar, a través de la audición, la estructura formal de una obra.

- Identificar, a través de la audición, el estilo y los posibles autores.

\section{Promoción}

1. Los alumnos promocionarán de curso cuando hayan superado la totalidad de las asignaturas de cada curso o tengan evaluación negativa como máximo en dos asignaturas. En el supuesto de asignaturas pendientes referidas a práctica instrumental o canto, la recuperación deberá realizarse en la clase del curso siguiente si forma parte del mismo.

2. La calificación negativa en tres o más asignaturas de uno o varios cursos impedirá la promoción de un alumno al curso siguiente.

3. Los alumnos que al término del 60 curso tuvieran pendientes de evaluación positiva tres asignaturas o más deberán repetir el curso en su totalidad. Cuando la calificación negativa se produzca en una o dos asignaturas, solo será preceptivo cursar las asignaturas pendiente

\section{Aspectos de la evaluación continua}

Se considerará que un alumno ha perdido el derecho a la evaluación continua cuando acumule ocho o más faltas de asistencia durante todo el curso. Podrá ser evaluado en junio, mediante un equipo de profesores del departamento. Deberá presentar un programa acorde a los mínimos exigibles y acorde con el nivel del curso del cual ha perdido el derecho a la evaluación continua. 
Diseño y planificación de competencias específicas en el currículum de enseñanzas profesionales de música: modalidades composición-dirección en la enseñanza superior.

Los alumnos y alumnas de enseñanzas profesionales que no superen el curso en el mes de junio podrán recuperar la asignatura mediante la realización de una prueba extraordinaria al finalizar el curso; de acuerdo con el DECRETO 157/2007. El examen extraordinario será diseñado por el profesor que haya impartido la especialidad, teniendo en cuenta los mínimos exigidos en cada curso contemplados en esta programación.

El límite de permanencia en las enseñanzas profesionales de música será de ocho años. El alumno no podrá permanecer más de dos años en el mismo curso, excepto en 60 curso, hasta completar el límite de permanencia.

\section{Metodología}

\section{Principios metodológicos}

a) Adecuar los contenidos y su secuenciación al momento y situación del desarrollo evolutivo del alumno, de forma que el aprendizaje sea constructivo, progresivo y motivador.

b) Motivar al alumno para el estudio de la música mediante su actividad y participación en el progreso, dándole el protagonismo.

c) Respetar las peculiaridades de los alumnos, individual y colectivamente, facilitando así la convivencia en el seno del grupo y la colaboración, de forma que se eviten las discriminaciones de todo tipo.

d) Utilizar procedimientos y recursos variados que estimulen la capacidad crítica y creativa del alumno mediante la aceptación del dialogo y las argumentaciones razonadas

e) Procurar que la asimilación de los contenidos conceptuales por parte del alumno se completa con la adquisición de contenidos procedimentales y actitudinales que propicien su autonomía en el trabajo tato para el momento presente como para el futuro.

f) Facilitar a los alumnos el conocimiento y empleo del código convencional de expresión a la vez que la corrección y la exactitud en el uso del lenguaje, con el fin de que el aprendizaje y la comunicación sean efectivos.

g) Ejercitar la creatividad del alumno, de modo que adquiera estrategias propias de estudio y de realizaciones musicales con el fin de que pueda superar las dificultades que se les presenten.

\section{Otros aspectos metodológicos}


Carlos Eduardo Pascual Pérez

Se implementarán competencias transversales desarrolladas específicamente para una completa preparación en las pruebas de acceso a enseñanzas superiores en composición y/o dirección. Estas son:

- Reproducción escrita de fragmentos melódicos y polifónicos de hasta cuatro voces a partir de una escucha orquestal

- Organología, instrumentación y orquestación en el ámbito de la orquesta sinfónica

\section{Concreción curricular del Primer Curso}

\section{ELEMENTOS PRIMARIOS DE LA ESTRUCTURA MUSICAL}

1. Fenómenos estructurales: tonalidad, cadencias, ritmo, melodía, textura, movimiento, timbre.

2. Terminología y conceptos tradicionales de la sintaxis musical: tema, motivo, inciso, semifrase, frase, periodo, etc.

3. Unidades estructurales: sección, períodos (modulantes, simétricos-asimétricos, paralelos-contrastantes, simples-dobles), enlaces, puentes, extensiones cadenciales, etc.

4. Recursos generadores de estructura: repetición, variante, contraste.

5. Funciones estructurales: expositiva, de transición, de desarrollo y conclusiva.

\section{PROCEDIMIENTOS TÉCNICOS DE TRANSFORMACIÓN}

1. Dilatación y contracción rítmica.

2. Apéndices (coda), aumentación y disminución.

3. Variación ornamental, variación decorativa por elaboración.

4. Imitaciones, progresiones.

\section{TIPOS FORMALES DE MENOR LONGITUD}

1. Pequeño tipo formal primario.

2. Pequeño tipo formal binario. Lied binario.

3. Pequeño tipo formal ternario. Lied ternario.

\section{LA MONODIA}

1. Características principales.

2. Estilos: silábico, neumático y melismático. 
Diseño y planificación de competencias específicas en el currículum de enseñanzas profesionales de música: modalidades composición-dirección en la enseñanza superior.

Carlos Eduardo Pascual Pérez

3. Formas básicas: Salmo, Secuencia, Responsorio, Antífona, Himno.

4. Características de la música profana.

V. LA POLIFONÍA

1. Organum, Discantus y Conductus.

2. Modalidad: reglas para conocer el modo de una pieza polifónica.

3. La semitonía.

4. Formas musicales más representativas del Renacimiento:

a) El motete.

b) La misa: Kyrie, Gloria, Credo, Benedictus, Sanctus y Agnus Dei.

c) Madrigal, Villancico y Canción polifónica. d) El Coral.

VI. LA IMITACIÓN

1. Generalidades. Principios básicos a seguir en el análisis estructural de un fragmento escrito en estilo imitativo.

2. Procedimientos imitativos:

a) Imitación por movimiento directo.

b) Imitación por movimiento contrario.

c) Imitación por movimiento retrógrado.

d) Imitación por movimiento contrario retrógrado.

e) Imitación por aumentación.

f) Imitación por disminución.

3. Imitación en forma de canon.

4. Imitación en forma de fuga.

VII. EL BARROCO. PRINCIPALES FORMAS

1. La Suite: Allemanda, Corranda, Zarabanda y Giga.

2. Otras danzas: Minué, Gavota, Bourrée, Pasapié, Les Doubles, etc.

3. La fuga.

4. Forma Rondó simple.

5. Variaciones.

6. Concierto y Concierto Grosso.

7. La Sonata barroca: Sonata de cámara (sonata da camera) y Sonata de iglesia (sonata da 
chiesa).

8. Introducción a la forma ternaria: La Sonata bitemática.

VIII. EL CLASICISMO 1. La Sonata clásica:
a) Forma Sonata.
b) Forma Rondó-Sonata.

\section{Concreción curricular del Segundo Curso}

\section{ELEMENTOS PRIMARIOS DE LA ESTRUCTURA MUSICAL (Repaso)}

1. Fenómenos estructurales: tonalidad, cadencias, ritmo, melodía, textura, movimiento, timbre.

2. Terminología y conceptos tradicionales de la sintaxis musical: tema, motivo, inciso, semifrase, frase, periodo, etc.

3. Unidades estructurales: sección, períodos (modulantes, simétricos- asimétricos, paralelos-contrastantes, simples-dobles), enlaces, puentes, extensiones cadenciales, etc.

4. Recursos generadores de estructura: repetición, variante, contraste.

5. Funciones estructurales: expositiva, de transición, de desarrollo y conclusiva. II.

\section{PROCEDIMIENTOS TÉCNICOS DE TRANSFORMACIÓN (Repaso)}

1. Dilatación y contracción rítmica.

2. Apéndices (coda), aumentación y disminución.

3. Variación ornamental, variación decorativa por elaboración. 4. Imitaciones, progresiones.

III. TIPOS FORMALES DE MENOR LONGITUD (Repaso)

1. Pequeño tipo formal primario.

2. Pequeño tipo formal binario.

3. Pequeño tipo formal ternario.

IV. EL CLASICISMO. PRINCIPALES FORMAS

1. La Sonata clásica: 
Diseño y planificación de competencias específicas en el currículum de enseñanzas profesionales de música: modalidades composición-dirección en la enseñanza superior.

\section{Carlos Eduardo Pascual Pérez}

a) Primer tiempo: esquema de la "Forma Sonata".

b) Segundo tiempo: Lied, Tema con Variaciones, etc. c) Tercer tiempo: Minué o scherzo.

d) Cuarto tiempo: Rondó-Sonata.

2. La Sonata cíclica y la forma Rondó-Sonata.

3. El Cuarteto.

4. La Sinfonía.

5. El Concierto.

V. EL ROMANTICISMO

1. La Sonata romántica.

2. Pequeñas formas románticas: Preludio, Estudio, Capricho, Rapsodia, Nocturno, Impromptu, Romanza, Polonesa, Vals, etc.

3. Formas extensas: Poema Sinfónico, Obertura, Fantasía, etc.

4. Música vocal: Lied, Ópera, Oratorio, Cantata y Pasión.

5. Géneros afines: Opereta, Singspiel, Ópera bufa, Zarzuela, etc. 6. El drama lírico: Wagner. La técnica del leit-motiv.

\section{APROXIMACIÓN A LA ESTRUCTURA Y AL ANÁLISIS EN LA MÚSICA DEL S. XX}

1. Alternativas al sistema tonal: el Impresionismo

2. Nuevos sistemas de organización de los sonidos:

a) Escala de tonos enteros. Escala pentáfona.

b) Modos sistemáticos de $\mathrm{O}$. Messiaen.

c) Armonía por cuartas, armonía por quintas, cuartos de tono, etc.

3. Otros métodos compositivos del siglo XX:

a) El lenguaje dodecafónico.

b) El serialismo.

c) Atonalidad.

d) Politonalidad y bitonalidad.

e) Música aleatoria, concreta y electrónica. f) Minimalismo.

4. La "adaptación" de algunas formas clásicas a estructuras del siglo XX: 
Diseño y planificación de competencias específicas en el currículum de enseñanzas profesionales de música: modalidades composición-dirección en la enseñanza superior.

\section{Carlos Eduardo Pascual Pérez}

a) Ejemplos de imitación en forma de canon del repertorio musical del siglo XX.

b) Ejemplos de imitación en forma de fuga del repertorio musical del siglo XX.

5. El jazz, el rock y la música de consumo.

6. Las nuevas tecnologías aplicadas a la música. 


\section{PROGRAMACIÓN DIDÁCTICA}

\section{FUNDAMENTOS}

DE

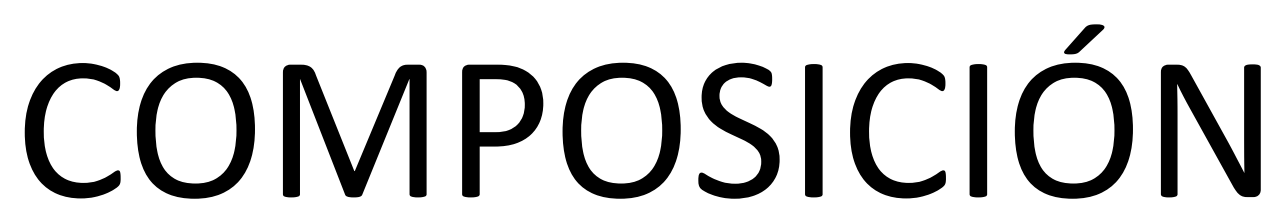

\section{ENSEÑANZAS PROFESIONALES}


Diseño y planificación de competencias específicas en el currículum de enseñanzas profesionales de música: modalidades composición-dirección en la enseñanza superior.

Carlos Eduardo Pascual Pérez

\section{COMPETENCIAS CLAVE}

Las competencias que se recogen en esta programación se han establecido de conformidad con los resultados de la investigación educativa y con las tendencias europeas recogidas en la Recomendación 2006/962/EC, del Parlamento Europeo y del Consejo, de 18 de diciembre de 2006, sobre las competencias clave para el aprendizaje permanente. Dichas competencias se describen, se indica su finalidad y aspectos distintivos, y se pone de manifiesto, en cada una de ellas, las claves de desarrollo que debe alcanzar todo el alumnado referidas al final de la enseñanza profesional de música, pero cuyo desarrollo debe iniciarse desde el comienzo de la escolarización, de manera que su adquisición se realice de forma progresiva y coherente a lo largo de las distintas etapas educativas.

Las competencias clave deberán estar estrechamente vinculadas a los objetivos definidos para la enseñanza artística de Música. Esta vinculación favorece que la consecución de dichos objetivos a lo largo de la vida académica lleve implícito el desarrollo de las competencias clave, para que todas las personas puedan alcanzar su desarrollo personal y lograr una correcta incorporación en la sociedad.

Un enfoque metodológico basado en las competencias clave y en los resultados de aprendizaje conlleva importantes cambios en la concepción del proceso de enseñanza-aprendizaje, cambios en la organización y en la cultura escolar; requiere la estrecha colaboración entre los docentes en el desarrollo curricular y en la transmisión de información sobre el aprendizaje de los alumnos y alumnas, así como cambios en las prácticas de trabajo y en los métodos de enseñanza. De este hecho se desprenden las competencias clave del currículo en el sistema educativo español.

1. Comunicación lingüística.

Es el resultado de la acción comunicativa dentro de prácticas musicales y sociales determinadas, en las cuales el individuo actúa con otros interlocutores y a través de textos en múltiples modalidades, formatos y soportes. Estas situaciones y prácticas pueden implicar el uso de distintos lenguajes musicales, en diversos ámbitos y de manera individual o colectiva. Para ello el individuo dispone de su repertorio musical, pero ajustado a las experiencias comunicativas que experimenta a lo largo de la vida. Los distintos lenguajes musicales que utiliza pueden haber tenido vías y tiempos distintos de adquisición y constituir, por tanto, experiencias de aprendizaje musicales, tanto populares como de otra índole. Esta visión de la competencia en comunicación lingüística vinculada con prácticas musicales determinadas ofrece una imagen del individuo como agente comunicativo que produce, y no sólo recibe, mensajes a través de las diferentes manifestaciones musicales con distintas finalidades. Valorar la relevancia de esta afirmación en la toma de decisiones educativas supone optar por metodologías activas de aprendizaje (aprendizaje basado en tareas y proyectos, en problemas, en retos, etcétera), ya sean estas en lenguajes musicales vanguardistas y actuales, frente a opciones metodológicas más tradicionales. Además, la competencia en comunicación lingüística musical, representa una vía de conocimiento y contacto con la diversidad cultural que implica un factor de 
Diseño y planificación de competencias específicas en el currículum de enseñanzas profesionales de música: modalidades composición-dirección en la enseñanza superior.

Carlos Eduardo Pascual Pérez

enriquecimiento para la propia competencia y que adquiere una particular relevancia en el caso de las músicas de otras culturas. Por tanto, un enfoque intercultural en la enseñanza y el aprendizaje de las diferentes músicas implica una importante contribución al desarrollo de la competencia en comunicación lingüística musical del alumnado.

Esta competencia es, por definición, siempre parcial y constituye un objetivo de aprendizaje permanente a lo largo de toda la vida. Por ello, para que se produzca un aprendizaje satisfactorio de las diferentes músicas, es determinante que se promuevan unos contextos de uso de lenguajes musicales ricos y variados, en relación con las tareas que se han de realizar y sus posibles interlocutores, textos e intercambios comunicativos.

La competencia en comunicación lingüística musical es extremadamente compleja. Se basa, en primer lugar, en el conocimiento del componente lingüístico musical. Pero además, como se produce y desarrolla en situaciones comunicativas concretas y contextualizadas, el individuo necesita activar su conocimiento del componente pragmático-discursivo y socio-cultural.

Esta competencia precisa de la interacción de distintas destrezas, ya que se produce en múltiples modalidades de comunicación y en diferentes soportes. Desde la oralidad y la escritura hasta las formas más sofisticadas de comunicación audiovisual o mediada por la tecnología, el individuo participa de un complejo entramado de posibilidades comunicativas gracias a las cuales expande su competencia y su capacidad de interacción con otros individuos. Por ello, esta diversidad de modalidades y soportes requiere de una alfabetización musical más compleja, recogida en el concepto de alfabetizaciones múltiples, que permita al individuo su participación como ciudadano activo.

La competencia en comunicación lingüística musical es también un instrumento fundamental para la socialización y el aprovechamiento de la experiencia educativa, por ser una vía privilegiada de acceso al conocimiento dentro y fuera de la escuela. De su desarrollo depende, en buena medida, que se produzcan distintos tipos de aprendizaje en distintos contextos, formales, informales y no formales. En este sentido, es especialmente relevante en el contexto escolar la consideración de la lectura como destreza básica para la ampliación de la competencia en comunicación lingüística musical y el aprendizaje. Así, el lenguaje musical es la principal vía de acceso a todas las áreas, por lo que el contacto con una diversidad de textos resulta fundamental para acceder a las fuentes originales del saber. Por ello, donde manifiesta su importancia, de forma más patente, es en el desarrollo de las destrezas que conducen al conocimiento de los textos musicales, no solo en su consideración como canon artístico o en su valoración como parte del patrimonio cultural, sino sobre todo, y principalmente, como fuente de disfrute y aprendizaje a lo largo de la vida.

Desde esta perspectiva, es recomendable que el centro educativo sea la unidad de acción para el desarrollo de la competencia en comunicación lingüística musical. En este sentido, actuaciones como el diseño de un Proyecto Artístico Musical de Centro que forme parte del propio Proyecto Educativo de Centro, un Plan Lector o unas estrategias para el uso de la 
Diseño y planificación de competencias específicas en el currículum de enseñanzas profesionales de música: modalidades composición-dirección en la enseñanza superior.

Biblioteca y Fonoteca Escolar como espacio de aprendizaje y disfrute permiten un tratamiento más global y eficaz de la competencia en comunicación lingüística musical en los términos aquí expresados.

La competencia en comunicación lingüística musical se inscribe en un marco de actitudes y valores que el individuo pone en funcionamiento: el respeto a las normas de convivencia; el ejercicio activo de la ciudadanía; el desarrollo de un espíritu crítico; el respeto a los derechos humanos y el pluralismo; la concepción del diálogo como herramienta primordial para la convivencia, la resolución de conflictos y el desarrollo de las capacidades afectivas en todos los ámbitos; una actitud de curiosidad, interés y creatividad hacia el aprendizaje y el reconocimiento de las destrezas inherentes a esta competencia (lectura, conversación, escritura, etcétera) como fuentes de placer relacionada con el disfrute personal y cuya promoción y práctica son tareas esenciales en el refuerzo de la motivación hacia el aprendizaje.

En resumen, para el adecuado desarrollo de esta competencia resulta necesario abordar el análisis y la consideración de los distintos aspectos que intervienen en ella, debido a su complejidad. Para ello, se debe atender a los cinco componentes que la constituyen y a las dimensiones en las que se concretan:

- El componente lingüístico musical que comprende diversas dimensiones: la léxica, la gramatical, la semántica, la fonológica, la ortográfica y la ortoépica, entendida esta como la articulación correcta del sonido a partir de la representación gráfica de la música.

- El componente pragmático-discursivo contempla tres dimensiones: la socio-musical (vinculada con la adecuada producción y recepción de mensajes en diferentes contextos sociales); la pragmática (que incluye las microfunciones comunicativas y los esquemas de interacción); y la discursiva (que incluye las macrofunciones textuales y las cuestiones relacionadas con los géneros discursivos).

- El componente socio-cultural incluye dos dimensiones: la que se refiere al conocimiento del mundo y la dimensión intercultural.

- El componente estratégico permite al individuo superar las dificultades y resolver los problemas que surgen en el acto comunicativo. Incluye tanto destrezas y estrategias comunicativas para la lectura, la escritura, la interpretación musical, la escucha, como destrezas vinculadas con el tratamiento de la información, la lectura multimodal y la producción de textos electrónicos en diferentes formatos; asimismo, también forman parte de este componente las estrategias generales de carácter cognitivo, metacognitivo y socioafectivas que el individuo utiliza para comunicarse eficazmente, aspectos fundamentales en el aprendizaje de las otras culturas musicales extranjeras. 
Diseño y planificación de competencias específicas en el currículum de enseñanzas profesionales de música: modalidades composición-dirección en la enseñanza superior.

Carlos Eduardo Pascual Pérez

- Por último, la competencia en comunicación lingüística musical incluye un componente personal que interviene en la interacción comunicativa en tres dimensiones: la actitud, la motivación y los rasgos de personalidad.

\section{Competencia matemática y competencias básicas en ciencia y tecnología.}

La competencia matemática y las competencias básicas en ciencia y tecnología inducen y fortalecen algunos aspectos esenciales de la formación de las personas que resultan fundamentales para la vida. En una sociedad donde el impacto de las matemáticas, las ciencias y las tecnologías es determinante, la consecución y sostenibilidad del bienestar social exige conductas y toma de decisiones personales estrechamente vinculadas a la capacidad crítica y visión razonada y razonable de las personas. A ello contribuyen la competencia matemática y competencias básicas en ciencia y tecnología, las cuales están incluidas en la enseñanza musical a través de sus distintas asignaturas.

La competencia matemática implica la capacidad de aplicar el razonamiento matemático y sus herramientas para describir, interpretar y predecir distintos fenómenos en su contexto, al igual que ocurre en las estructuras musicales. La competencia matemática musical requiere de conocimientos sobre las medidas y las estructuras que componen las obras musicales, así como de las operaciones y las representaciones armónicas, y la comprensión de los términos que conllevan estas representaciones.

El uso de herramientas matemáticas, dentro de la enseñanza musical, implica una serie de destrezas que requieren la aplicación de los principios y procesos matemáticos en distintos contextos, ya sean personales, sociales, profesionales o científicos, así como para emitir juicios fundados y seguir cadenas argumentales en la realización de cálculos, el análisis de gráficos y representaciones armónicas y la manipulación de expresiones musicales, incorporando los medios digitales cuando sea oportuno. Forma parte de esta destreza la creación de descripciones y explicaciones musicales que llevan implícitas la interpretación de resultados compositivos y la reflexión sobre su adecuación al contexto, al igual que la determinación de si las soluciones son adecuadas y tienen sentido en la situación en que se presentan. Se trata, por tanto, de reconocer el papel que desempeñan las estructuras matemático-musicales en el mundo y utilizar los conceptos, procedimientos y herramientas para aplicarlos en la resolución de los problemas que puedan surgir en una situación determinada a lo largo de la vida. La activación de la competencia matemática supone que el aprendiz es capaz de establecer una relación profunda entre el conocimiento conceptual y el conocimiento procedimental, implicados en la resolución de una tarea matemático-musical determinada.

La competencia matemática incluye una serie de actitudes y valores que se basan en el rigor, el respeto a los datos y la veracidad. Así pues, para el adecuado desarrollo de la competencia 
Diseño y planificación de competencias específicas en el currículum de enseñanzas profesionales de música: modalidades composición-dirección en la enseñanza superior.

Carlos Eduardo Pascual Pérez

matemática resulta necesario abordar cuatro áreas relativas a los signos musicales, la armonía, la geometría musical, interrelacionadas de formas diversas:

- El espacio y la forma: incluyen una amplia gama de fenómenos que se encuentran en nuestro mundo musical, visual y físico: patrones, propiedades de los objetos, posiciones, direcciones y representaciones de ellos; descodificación y codificación de información visual y musical, así como navegación e interacción dinámica con formas reales, o con representaciones. La competencia matemático-musical en este sentido incluye una serie de actividades como la comprensión de la perspectiva, la elaboración y lectura de partituras, la transformación de las formas con y sin tecnología, la interpretación de vistas de escenas tridimensionales desde distintas perspectivas y la construcción de representaciones de formas musicales.

- El cambio y las relaciones: el mundo despliega multitud de relaciones temporales y permanentes entre los objetos y las circunstancias, donde los cambios se producen dentro de sistemas de objetos interrelacionados. Tener más conocimientos sobre el cambio y las relaciones supone comprender los tipos fundamentales de cambio y cuándo tienen lugar, con el fin de utilizar modelos músico-estructurales adecuados para describirlo y predecirlo.

- La incertidumbre y los datos: son un fenómeno central del análisis estructural de la música en el presente en distintos momentos del proceso de resolución de problemas en el que resulta clave la presentación e interpretación de dichas estructuras. Esta categoría incluye el reconocimiento del lugar de la variación en los procesos, la posesión de un sentido de cuantificación de esa variación, la admisión de incertidumbre y error en las mediciones y los conocimientos sobre el azar. Asimismo, comprende la elaboración, interpretación y valoración de las conclusiones extraídas en situaciones donde la incertidumbre y los datos son fundamentales.

Las competencias básicas en ciencia y tecnología son aquellas que proporcionan un acercamiento al mundo físico y a la interacción responsable con él desde acciones, tanto individuales como colectivas, orientadas a la conservación y mejora del medio natural, decisivas para la protección y mantenimiento de la calidad de vida y el progreso de los pueblos. Estas competencias contribuyen al desarrollo del pensamiento científico, pues incluyen la aplicación de los métodos propios de la racionalidad científica y las destrezas tecnológicas, que conducen a la adquisición de conocimientos, al contraste de ideas y la aplicación de los descubrimientos al bienestar social.

Las competencias en ciencia y tecnología capacitan a ciudadanos responsables y respetuosos que desarrollan juicios críticos sobre los hechos científicos y tecnológicos que se suceden a lo largo de los tiempos, pasados y actuales. Estas competencias han de capacitar, básicamente, para identificar, plantear y resolver situaciones de la vida cotidiana -personal y socialanálogamente a como se actúa frente a los retos y problemas propios de la actividades científicas y tecnológicas. 
Diseño y planificación de competencias específicas en el currículum de enseñanzas profesionales de música: modalidades composición-dirección en la enseñanza superior.

Para el adecuado desarrollo de las competencias en ciencia y tecnología resulta necesario abordar los saberes o conocimientos científicos relativos a la física, la química, la biología, la geología, las matemáticas y la tecnología, los cuales se derivan de conceptos, procesos y situaciones interconectadas. Estos saberes el alumnado los adquirirá en la enseñanza general (ESO, Bachillerato). Se requiere igualmente el fomento de destrezas que permitan utilizar y manipular herramientas y máquinas tecnológicas, así como utilizar datos y procesos científicos para alcanzar un objetivo; es decir, identificar preguntas, resolver problemas, llegar a una conclusión o tomar decisiones basadas en pruebas y argumentos.

Asimismo, estas competencias incluyen actitudes y valores relacionados con la asunción de criterios éticos asociados a la ciencia y a la tecnología, el interés por la ciencia, el apoyo a la investigación científica y la valoración del conocimiento científico; así como el sentido de la responsabilidad en relación a la conservación de los recursos naturales y a las cuestiones medioambientales y a la adopción de una actitud adecuada para lograr una vida física y mental saludable en un entorno natural y social.

\section{Competencia digital.}

La competencia digital es aquella que implica el uso creativo, crítico y seguro de las tecnologías de la información y la comunicación para alcanzar los objetivos relacionados con el trabajo, la empleabilidad, el aprendizaje, el uso del tiempo libre, la inclusión y participación en la sociedad.

Esta competencia supone, además de la adecuación a los cambios que introducen las nuevas tecnologías en la alfabetización, la lectura y la escritura de la música, un conjunto nuevo de conocimientos, habilidades y actitudes necesarias hoy en día para ser competente en un entorno digital.

Requiere de conocimientos relacionados con el lenguaje específico básico: textual, numérico, icónico, visual, gráfico y sonoro, así como sus pautas de decodificación y transferencia. Esto conlleva el conocimiento de las principales aplicaciones informáticas. Supone también el acceso a las fuentes y el procesamiento de la información; y el conocimiento de los derechos y las libertades que asisten a las personas en el mundo digital. Igualmente precisa del desarrollo de diversas destrezas relacionadas con el acceso a la información, el procesamiento y uso para la comunicación, la creación de contenidos, la seguridad y la resolución de problemas, tanto en contextos formales como no formales e informales. La persona ha de ser capaz de hacer un uso habitual de los recursos tecnológicos disponibles con el fin de resolver los problemas reales de un modo eficiente, así como evaluar y seleccionar nuevas fuentes de información e innovaciones tecnológicas, a medida que van apareciendo, en función de su utilidad para acometer tareas u objetivos específicos.

La adquisición de esta competencia requiere además actitudes y valores que permitan al usuario adaptarse a las nuevas necesidades establecidas por las tecnologías, su apropiación y adaptación a los propios fines y la capacidad de interaccionar socialmente en torno a ellas. Se 
Diseño y planificación de competencias específicas en el currículum de enseñanzas profesionales de música: modalidades composición-dirección en la enseñanza superior.

trata de desarrollar una actitud activa, crítica y realista hacia las tecnologías y los medios tecnológicos, valorando sus fortalezas y debilidades y respetando principios éticos en su uso. Por otra parte, la competencia digital implica la participación y el trabajo colaborativo, así como la motivación y la curiosidad por el aprendizaje y la mejora en el uso de las tecnologías.

Por tanto, para el adecuado desarrollo de la competencia digital resulta necesario abordar:

- La información: esto conlleva la comprensión de cómo se gestiona la información y de cómo se pone a disposición de los usuarios, así como el conocimiento y manejo de diferentes motores de búsqueda y bases de datos, sabiendo elegir aquellos que responden mejor a las propias necesidades de información.

- Igualmente, supone saber analizar e interpretar la información que se obtiene, cotejar y evaluar el contenido de los medios de comunicación en función de su validez, fiabilidad y adecuación entre las fuentes, tanto online como offline. Y por último, la competencia digital supone saber transformar la información en conocimiento a través de la selección apropiada de diferentes opciones de almacenamiento.

- La comunicación: supone tomar conciencia de los diferentes medios de comunicación digital y de varios paquetes de software de comunicación y de su funcionamiento así como sus beneficios y carencias en función del contexto y de los destinatarios. Al mismo tiempo, implica saber qué recursos pueden compartirse públicamente y el valor que tienen, es decir, conocer de qué manera las tecnologías y los medios de comunicación pueden permitir diferentes formas de participación y colaboración para la creación de contenidos que produzcan un beneficio común. Ello supone el conocimiento de cuestiones éticas como la identidad digital y las normas de interacción digital.

- La creación de contenidos: implica saber cómo los contenidos digitales pueden realizarse en diversos formatos (texto, audio, vídeo, imágenes) así como identificar los programas/aplicaciones que mejor se adaptan al tipo de contenido que se quiere crear. Supone también la contribución al conocimiento de dominio público (wikis, foros públicos, revistas), teniendo en cuenta las normativas sobre los derechos de autor y las licencias de uso y publicación de la información.

- La seguridad: implica conocer los distintos riesgos asociados al uso de las tecnologías y de recursos online y las estrategias actuales para evitarlos, lo que supone identificar los comportamientos adecuados en el ámbito digital para proteger la información, propia y de otras personas, así como conocer los aspectos adictivos de las tecnologías.

- La resolución de problemas: esta dimensión supone conocer la composición de los dispositivos digitales, sus potenciales y limitaciones en relación a la consecución de metas personales, así como saber dónde buscar ayuda para la resolución de problemas teóricos y técnicos, lo que implica una combinación heterogénea y bien equilibrada de las tecnologías digitales y no digitales más importantes en esta área de conocimiento.

\section{Aprender a aprender.}

La competencia de aprender a aprender es fundamental para el aprendizaje permanente que se produce a lo largo de la vida y que tiene lugar en distintos contextos formales, no formales e informales. 
Diseño y planificación de competencias específicas en el currículum de enseñanzas profesionales de música: modalidades composición-dirección en la enseñanza superior.

Carlos Eduardo Pascual Pérez

Esta competencia se caracteriza por la habilidad para iniciar, organizar y persistir en el aprendizaje. Esto exige, en primer lugar, la capacidad para motivarse por aprender. Esta motivación depende de que se genere la curiosidad y la necesidad de aprender, de que el estudiante se sienta protagonista del proceso y del resultado de su aprendizaje $y$, finalmente, de que llegue a alcanzar las metas de aprendizaje propuestas y, con ello, que se produzca en él una percepción de auto-eficacia. Todo lo anterior contribuye a motivarle para abordar futuras tareas de aprendizaje. En segundo lugar, en cuanto a la organización y gestión del aprendizaje, la competencia de aprender a aprender requiere conocer y controlar los propios procesos de aprendizaje para ajustarlos a los tiempos y las demandas de las tareas y actividades que conducen al aprendizaje. La competencia de aprender a aprender desemboca en un aprendizaje cada vez más eficaz y autónomo.

Esta competencia incluye una serie de conocimientos y destrezas que requieren la reflexión y la toma de conciencia de los propios procesos de aprendizaje. Así, los procesos de conocimiento se convierten en objeto del conocimiento $y$, además, hay que aprender a ejecutarlos adecuadamente.

Aprender a aprender incluye conocimientos sobre los procesos mentales implicados en el aprendizaje (cómo se aprende). Además, esta competencia incorpora el conocimiento que posee el estudiante sobre su propio proceso de aprendizaje que se desarrolla en tres dimensiones:

- el conocimiento que tiene acerca de lo que sabe y desconoce, de lo que es capaz de aprender, de lo que le interesa, etcétera;

- el conocimiento de la disciplina en la que se localiza la tarea de aprendizaje y el conocimiento del contenido concreto y de las demandas de la tarea misma

- el conocimiento sobre las distintas estrategias posibles para afrontar la tarea.

Todo este conocimiento se vuelca en destrezas de autorregulación y control inherentes a la competencia de aprender a aprender, que se concretan en estrategias de planificación en las que se refleja la meta de aprendizaje que se persigue, así como el plan de acción que se tiene previsto aplicar para alcanzarla; estrategias de supervisión desde las que el estudiante va examinando la adecuación de las acciones que está desarrollando y la aproximación a la meta; y estrategias de evaluación desde las que se analiza tanto el resultado como del proceso que se ha llevado a cabo. La planificación, supervisión y evaluación son esenciales para desarrollar aprendizajes cada vez más eficaces. Todas ellas incluyen un proceso reflexivo que permite pensar antes de actuar (planificación), analizar el curso y el ajuste del proceso (supervisión) y consolidar la aplicación de buenos planes o modificar los que resultan incorrectos (evaluación del resultado y del proceso). Estas tres estrategias deberían potenciarse en los procesos de aprendizaje y de resolución de problemas en los que participan los estudiantes.

Aprender a aprender se manifiesta tanto individualmente como en grupo. En ambos casos el dominio de esta competencia se inicia con una reflexión consciente acerca de los procesos de 
Diseño y planificación de competencias específicas en el currículum de enseñanzas profesionales de música: modalidades composición-dirección en la enseñanza superior.

aprendizaje a los que se entrega uno mismo o el grupo. No solo son los propios procesos de conocimiento, sino que, también, el modo en que los demás aprenden se convierte en objeto de escrutinio. De ahí que la competencia de aprender a aprender se adquiera también en el contexto del trabajo en equipo. Los profesores han de procurar que los estudiantes sean conscientes de lo que hacen para aprender y busquen alternativas. Muchas veces estas alternativas se ponen de manifiesto cuando se trata de averiguar qué es lo que hacen los demás en situaciones de trabajo cooperativo.

Respecto a las actitudes y valores, la motivación y la confianza son cruciales para la adquisición de esta competencia. Ambas se potencian desde el planteamiento de metas realistas a corto, medio y largo plazo. Al alcanzarse las metas aumenta la percepción de auto-eficacia y la confianza, y con ello se elevan los objetivos de aprendizaje de forma progresiva. Las personas deben ser capaces de apoyarse en experiencias vitales y de aprendizaje previas con el fin de utilizar y aplicar los nuevos conocimientos y capacidades en otros contextos, como los de la vida privada y profesional, la educación y la formación.

Saber aprender en un determinado ámbito implica ser capaz de adquirir y asimilar nuevos conocimientos y llegar a dominar capacidades y destrezas propias de dicho ámbito. En la competencia de aprender a aprender puede haber una cierta trasferencia de conocimiento de un campo a otro, aunque saber aprender en un ámbito no significa necesariamente que se sepa aprender en otro. Por ello, su adquisición debe llevarse a cabo en el marco de la enseñanza de las distintas áreas y materias del ámbito formal, y también de los ámbitos no formal e informal.

Podría concluirse que para el adecuado desarrollo de la competencia de aprender a aprender se requiere de una reflexión que favorezca un conocimiento de los procesos mentales a los que se entregan las personas cuando aprenden, un conocimiento sobre los propios procesos de aprendizaje, así como el desarrollo de la destreza de regular y controlar el propio aprendizaje que se lleva a cabo.

\section{Competencias sociales y cívicas.}

Las competencias sociales y cívicas implican la habilidad y capacidad para utilizar los conocimientos y actitudes sobre la sociedad, entendida desde las diferentes perspectivas, en su concepción dinámica, cambiante y compleja, para interpretar fenómenos y problemas sociales en contextos cada vez más diversificados; para elaborar respuestas, tomar decisiones y resolver conflictos, así como para interactuar con otras personas y grupos conforme a normas basadas en el respeto mutuo y en convicciones democráticas. Además de incluir acciones a un nivel más cercano y mediato al individuo como parte de una implicación cívica y social.

Se trata, por lo tanto, de aunar el interés por profundizar y garantizar la participación en el funcionamiento democrático de la sociedad, tanto en el ámbito público como privado, y preparar a las personas para ejercer la ciudadanía democrática y participar plenamente en la 
Diseño y planificación de competencias específicas en el currículum de enseñanzas profesionales de música: modalidades composición-dirección en la enseñanza superior.

Carlos Eduardo Pascual Pérez

vida cívica y social gracias al conocimiento de conceptos y estructuras sociales y políticas y al compromiso de participación activa y democrática.

La competencia social se relaciona con el bienestar personal y colectivo. Exige entender el modo en que las personas pueden procurarse un estado de salud física y mental óptimo, tanto para ellas mismas como para sus familias y para su entorno social próximo, y saber cómo un estilo de vida saludable puede contribuir a ello.

Para poder participar plenamente en los ámbitos social e interpersonal es fundamental adquirir los conocimientos que permitan comprender y analizar de manera crítica los códigos de conducta y los usos generalmente aceptados en las distintas sociedades y entornos, así como sus tensiones y procesos de cambio. La misma importancia tiene conocer los conceptos básicos relativos al individuo, al grupo, a la organización del trabajo, la igualdad y la no discriminación entre hombres y mujeres y entre diferentes grupos étnicos o culturales, la sociedad y la cultura. Asimismo, es esencial comprender las dimensiones intercultural y socioeconómica de las sociedades europeas y percibir las identidades culturales y nacionales como un proceso sociocultural dinámico y cambiante en interacción con la europea, en un contexto de creciente globalización.

Los elementos fundamentales de esta competencia incluyen el desarrollo de ciertas destrezas como la capacidad de comunicarse de una manera constructiva en distintos entornos sociales y culturales, mostrar tolerancia, expresar y comprender puntos de vista diferentes, negociar sabiendo inspirar confianza y sentir empatía. Las personas deben ser capaces de gestionar un comportamiento de respeto a las diferencias expresado de manera constructiva.

Asimismo, esta competencia incluye actitudes y valores como una forma de colaboración, la seguridad en uno mismo y la integridad y honestidad. Las personas deben interesarse por el desarrollo socioeconómico y por su contribución a un mayor bienestar social de toda la población, así como la comunicación intercultural, la diversidad de valores y el respeto a las diferencias, además de estar dispuestas a superar los prejuicios y a comprometerse en este sentido.

La competencia cívica se basa en el conocimiento crítico de los conceptos de democracia, justicia, igualdad, ciudadanía y derechos humanos y civiles, así como de su formulación en la Constitución española, la Carta de los Derechos Fundamentales de la Unión Europea y en declaraciones internacionales, y de su aplicación por parte de diversas instituciones a escala local, regional, nacional, europea e internacional. Esto incluye el conocimiento de los acontecimientos contemporáneos, así como de los acontecimientos más destacados y de las principales tendencias en las historias nacional, europea y mundial, así como la comprensión de los procesos sociales y culturales de carácter migratorio que implican la existencia de sociedades multiculturales en el mundo globalizado. 
Diseño y planificación de competencias específicas en el currículum de enseñanzas profesionales de música: modalidades composición-dirección en la enseñanza superior.

Las destrezas de esta competencia están relacionadas con la habilidad para interactuar eficazmente en el ámbito público y para manifestar solidaridad e interés por resolver los problemas que afecten al entorno escolar y a la comunidad, ya sea local o más amplia. Conlleva la reflexión crítica y creativa y la participación constructiva en las actividades de la comunidad o del ámbito mediato e inmediato, así como la toma de decisiones en los contextos local, nacional o europeo y, en particular, mediante el ejercicio del voto y de la actividad social y cívica.

Las actitudes y valores inherentes a esta competencia son aquellos que se dirigen al pleno respeto de los derechos humanos y a la voluntad de participar en la toma de decisiones democráticas a todos los niveles, sea cual sea el sistema de valores adoptado. También incluye manifestar el sentido de la responsabilidad y mostrar comprensión y respeto de los valores compartidos que son necesarios para garantizar la cohesión de la comunidad, basándose en el respeto de los principios democráticos. La participación constructiva incluye también las actividades cívicas y el apoyo a la diversidad y la cohesión sociales y al desarrollo sostenible, así como la voluntad de respetar los valores y la intimidad de los demás y la recepción reflexiva y crítica de la información procedente de los medios de comunicación.

Por tanto, para el adecuado desarrollo de estas competencias es necesario comprender y entender las experiencias colectivas y la organización y funcionamiento del pasado y presente de las sociedades, la realidad social del mundo en el que se vive, sus conflictos y las motivaciones de los mismos, los elementos que son comunes y los que son diferentes, así como los espacios y territorios en que se desarrolla la vida de los grupos humanos, y sus logros y problemas, para comprometerse personal y colectivamente en su mejora, participando así de manera activa, eficaz y constructiva en la vida social y profesional.

Asimismo, estas competencias incorporan formas de comportamiento individual que capacitan a las personas para convivir en una sociedad cada vez más plural, dinámica, cambiante y compleja para relacionarse con los demás; cooperar, comprometerse y afrontar los conflictos y proponer activamente perspectivas de afrontamiento, así como tomar perspectiva, desarrollar la percepción del individuo en relación a su capacidad para influir en lo social y elaborar argumentaciones basadas en evidencias.

Adquirir estas competencias supone ser capaz de ponerse en el lugar del otro, aceptar las diferencias, ser tolerante y respetar los valores, las creencias, las culturas y la historia personal y colectiva de los otros.

\section{Sentido de iniciativa y espíritu emprendedor.}

La competencia sentido de iniciativa y espíritu emprendedor implica la capacidad de transformar las ideas en actos. Ello significa adquirir conciencia de la situación a intervenir o resolver, y saber elegir, planificar y gestionar los conocimientos, destrezas o habilidades y actitudes necesarios con criterio propio, con el fin de alcanzar el objetivo previsto. 
Diseño y planificación de competencias específicas en el currículum de enseñanzas profesionales de música: modalidades composición-dirección en la enseñanza superior.

Carlos Eduardo Pascual Pérez

Esta competencia está presente en los ámbitos personal, social, escolar y laboral en los que se desenvuelven las personas, permitiéndoles el desarrollo de sus actividades y el aprovechamiento de nuevas oportunidades. Constituye igualmente el cimiento de otras capacidades y conocimientos más específicos, e incluye la conciencia de los valores éticos relacionados. La adquisición de esta competencia es determinante en la formación de futuros ciudadanos emprendedores, contribuyendo así a la cultura del emprendimiento. En este sentido, su formación debe incluir conocimientos y destrezas relacionados con las oportunidades de carrera y el mundo del trabajo, la educación económica y financiera o el conocimiento de la organización y los procesos empresariales, así como el desarrollo de actitudes que conlleven un cambio de mentalidad que favorezca la iniciativa emprendedora, la capacidad de pensar de forma creativa, de gestionar el riesgo y de manejar la incertidumbre. Estas habilidades resultan muy importantes para favorecer el nacimiento de emprendedores sociales, como los denominados intraemprendedores (emprendedores que trabajan dentro de empresas u organizaciones que no son suyas), así como de futuros empresarios.

Entre los conocimientos que requiere la competencia sentido de iniciativa y espíritu emprendedor se incluye la capacidad de reconocer las oportunidades existentes para las actividades personales, profesionales y comerciales. También incluye aspectos de mayor amplitud que proporcionan el contexto en el que las personas viven y trabajan, tales como la comprensión de las líneas generales que rigen el funcionamiento de las sociedades y las organizaciones sindicales y empresariales, así como las económicas y financieras; la organización y los procesos empresariales; el diseño y la implementación de un plan (la gestión de recursos humanos y/o financieros); así como la postura ética de las organizaciones y el conocimiento de cómo estas pueden ser un impulso positivo, por ejemplo, mediante el comercio justo y las empresas sociales.

Asimismo, esta competencia requiere de las siguientes destrezas o habilidades esenciales: capacidad de análisis; capacidades de planificación, organización, gestión y toma de decisiones; capacidad de adaptación al cambio y resolución de problemas; comunicación, presentación, representación y negociación efectivas; habilidad para trabajar, tanto individualmente como dentro de un equipo; participación, capacidad de liderazgo y delegación; pensamiento crítico y sentido de la responsabilidad; autoconfianza, evaluación y auto-evaluación, ya que es esencial determinar los puntos fuertes y débiles de uno mismo y de un proyecto, así como evaluar y asumir riesgos cuando esté justificado (manejo de la incertidumbre y asunción y gestión del riesgo).

Finalmente, requiere el desarrollo de actitudes y valores como: la predisposición a actuar de una forma creadora e imaginativa; el autoconocimiento y la autoestima; la autonomía o independencia, el interés y esfuerzo y el espíritu emprendedor. Se caracteriza por la iniciativa, la pro-actividad y la innovación, tanto en la vida privada y social como en la profesional. También está relacionada con la motivación y la determinación a la hora de cumplir los objetivos, ya sean personales o establecidos en común con otros, incluido el ámbito laboral. Así 
Diseño y planificación de competencias específicas en el currículum de enseñanzas profesionales de música: modalidades composición-dirección en la enseñanza superior.

Carlos Eduardo Pascual Pérez

pues, para el adecuado desarrollo de la competencia sentido de la iniciativa y espíritu emprendedor resulta necesario abordar:

- La capacidad creadora y de innovación: creatividad e imaginación; autoconocimiento y autoestima; autonomía e independencia; interés y esfuerzo; espíritu emprendedor; iniciativa e innovación.

- La capacidad pro-activa para gestionar proyectos: capacidad de análisis; planificación, organización, gestión y toma de decisiones; resolución de problemas; habilidad para trabajar tanto individualmente como de manera colaborativa dentro de un equipo; sentido de la responsabilidad; evaluación y auto-evaluación.

- La capacidad de asunción y gestión de riesgos y manejo de la incertidumbre: comprensión y asunción de riesgos; capacidad para gestionar el riesgo y manejar la incertidumbre.

- Las cualidades de liderazgo y trabajo individual y en equipo: capacidad de liderazgo y delegación; capacidad para trabajar individualmente y en equipo; capacidad de representación y negociación.

- Sentido crítico y de la responsabilidad: sentido y pensamiento crítico; sentido de la responsabilidad.

\section{Conciencia y expresiones culturales.}

La competencia en conciencia y expresión cultural implica conocer, comprender, apreciar y valorar con espíritu crítico, con una actitud abierta y respetuosa, las diferentes manifestaciones culturales y artísticas, utilizarlas como fuente de enriquecimiento y disfrute personal y considerarlas como parte de la riqueza y patrimonio de los pueblos.

Esta competencia incorpora también un componente expresivo referido a la propia capacidad estética y creadora y al dominio de aquellas capacidades relacionadas con los diferentes códigos artísticos y culturales, para poder utilizarlas como medio de comunicación y expresión personal. Implica igualmente manifestar interés por la participación en la vida cultural y por contribuir a la conservación del patrimonio cultural y artístico, tanto de la propia comunidad como de otras comunidades.

Así pues, la competencia para la conciencia y expresión cultural requiere de conocimientos que permitan acceder a las distintas manifestaciones sobre la herencia cultural (patrimonio cultural, histórico-artístico, literario, filosófico, tecnológico, medioambiental, etcétera) a escala local, nacional y europea y su lugar en el mundo. Comprende la concreción de la cultura en diferentes autores y obras, así como en diferentes géneros y estilos, tanto de las bellas artes (música, pintura, escultura, arquitectura, cine, literatura, fotografía, teatro y danza) como de otras manifestaciones artístico-culturales de la vida cotidiana (vivienda, vestido, gastronomía, artes aplicadas, folclore, fiestas....). Incorpora asimismo el conocimiento básico de las principales técnicas, recursos y convenciones de los diferentes lenguajes artísticos y la identificación de las 
Diseño y planificación de competencias específicas en el currículum de enseñanzas profesionales de música: modalidades composición-dirección en la enseñanza superior.

relaciones existentes entre esas manifestaciones y la sociedad, lo cual supone también tener conciencia de la evolución del pensamiento, las corrientes estéticas, las modas y los gustos, así como de la importancia representativa, expresiva y comunicativa de los factores estéticos en la vida cotidiana.

Dichos conocimientos son necesarios para poner en funcionamiento destrezas como la aplicación de diferentes habilidades de pensamiento, perceptivas, comunicativas, de sensibilidad y sentido estético para poder comprenderlas, valorarlas, emocionarse y disfrutarlas. La expresión cultural y artística exige también desarrollar la iniciativa, la imaginación y la creatividad expresada a través de códigos artísticos, así como la capacidad de emplear distintos materiales y técnicas en el diseño de proyectos.

Además, en la medida en que las actividades culturales y artísticas suponen con frecuencia un trabajo colectivo, es preciso disponer de habilidades de cooperación y tener conciencia de la importancia de apoyar y apreciar las contribuciones ajenas.

El desarrollo de esta competencia supone actitudes y valores personales de interés, reconocimiento y respeto por las diferentes manifestaciones artísticas y culturales, y por la conservación del patrimonio. Exige asimismo valorar la libertad de expresión, el derecho a la diversidad cultural, el diálogo entre culturas y sociedades y la realización de experiencias artísticas compartidas. A su vez, conlleva un interés por participar en la vida cultural y, por tanto, por comunicar y compartir conocimientos, emociones y sentimientos a partir de expresiones artísticas. Así pues, para el adecuado desarrollo de la competencia para la conciencia y expresión cultural resulta necesario abordar:

- El conocimiento, estudio y comprensión tanto de los distintos estilos y géneros artísticos como de las principales obras y producciones del patrimonio cultural y artístico en distintos periodos históricos, sus características y sus relaciones con la sociedad en la que se crean, así como las características de las obras de arte producidas, todo ello mediante el contacto con las obras de arte. Está relacionada, igualmente, con la creación de la identidad cultural como ciudadano de un país o miembro de un grupo.

- El aprendizaje de las técnicas y recursos de los diferentes lenguajes artísticos y formas de expresión cultural, así como de la integración de distintos lenguajes.

- El desarrollo de la capacidad e intención de expresarse y comunicar ideas, experiencias y emociones propias, partiendo de la identificación del potencial artístico personal (aptitud/talento). Se refiere también a la capacidad de percibir, comprender y enriquecerse con las producciones del mundo del arte y de la cultura.

- La potenciación de la iniciativa, la creatividad y la imaginación propias de cada individuo de cara a la expresión de las propias ideas y sentimientos. Es decir, la capacidad de imaginar y realizar producciones que supongan recreación, innovación y transformación. Implica el fomento de habilidades que permitan reelaborar ideas y sentimientos propios y ajenos y exige desarrollar el autoconocimiento y la autoestima, así como la capacidad de resolución de problemas y asunción de riesgos. 
Diseño y planificación de competencias específicas en el currículum de enseñanzas profesionales de música: modalidades composición-dirección en la enseñanza superior.

Carlos Eduardo Pascual Pérez

- El interés, aprecio, respeto, disfrute y valoración crítica de las obras artísticas y culturales que se producen en la sociedad, con un espíritu abierto, positivo y solidario.

- La promoción de la participación en la vida y la actividad cultural de la sociedad en que se vive, a lo largo de toda la vida. Esto lleva implícitos comportamientos que favorecen la convivencia social.

- El desarrollo de la capacidad de esfuerzo, constancia y disciplina como requisitos necesarios para la creación de cualquier producción artística de calidad, así como habilidades de cooperación que permitan la realización de trabajos colectivos.

\section{LAS COMPETENCIAS CLAVE Y LOS OBJETIVOS}

1. Las competencias clave deberán estar estrechamente vinculadas a los objetivos definidos para la Enseñanzas Elementales y Profesionales de Música

2. La relación de las competencias clave con los objetivos de las distintas asignaturas del currículo hace necesario diseñar estrategias para promover y evaluar las competencias desde las etapas educativas iniciales e intermedias hasta su posterior consolidación en etapas superiores, que llevarán a los alumnos y alumnas a desarrollar actitudes y valores, así como un conocimiento de base conceptual y un uso de técnicas y estrategias que favorecerán su incorporación a la vida adulta y que servirán de cimiento para su aprendizaje a lo largo de su vida.

3. La adquisición eficaz de las competencias clave por parte del alumnado y su contribución al logro de los objetivos de las diferentes asignaturas, desde un carácter interdisciplinar y transversal, requiere del diseño de actividades de aprendizaje integradas que permitan avanzar hacia los resultados de aprendizaje de más de una competencia al mismo tiempo.

\section{LAS COMPETENCIAS CLAVE EN EL CURRÍCULO}

1. Las competencias clave deben estar integradas en las áreas o materias de las propuestas curriculares, y en ellas definirse, explicitarse y desarrollarse suficientemente los resultados de aprendizaje que los alumnos y alumnas deben conseguir.

2. Las competencias deben desarrollarse en los ámbitos de la educación formal, no formal e informal a lo largo de la Educación Primaria, la Educación Secundaria Obligatoria y el Bachillerato, y en la educación permanente a lo largo de toda la vida.

3. Todas las áreas o materias del currículo deben participar, desde su ámbito correspondiente, en el desarrollo de las distintas competencias del alumnado.

4. La selección de los contenidos y las metodologías debe asegurar el desarrollo de las competencias clave a lo largo de la vida académica.

5. Los criterios de evaluación deben servir de referencia para valorar lo que el alumnado sabe y sabe hacer en cada área o materia. Estos criterios de evaluación se desglosan en estándares de aprendizaje evaluables. Para valorar el desarrollo competencial del alumnado, serán estos 
Diseño y planificación de competencias específicas en el currículum de enseñanzas profesionales de música: modalidades composición-dirección en la enseñanza superior.

Carlos Eduardo Pascual Pérez

estándares de aprendizaje evaluables, como elementos de mayor concreción, observables y medibles, los que, al ponerse en relación con las competencias clave, permitirán graduar el rendimiento o desempeño alcanzado en cada una de ellas.

6. El conjunto de estándares de aprendizaje evaluables de un área o materia determinada dará lugar a su perfil de área o materia. Dado que los estándares de aprendizaje evaluables se ponen en relación con las competencias, este perfil permitirá identificar aquellas competencias que se desarrollan a través de esa área o materia.

7. Todas las áreas y materias deben contribuir al desarrollo competencial. El conjunto de estándares de aprendizaje evaluables de las diferentes áreas o materias que se relacionan con una misma competencia da lugar al perfil de esa competencia (perfil de competencia). La elaboración de este perfil facilitará la evaluación competencial del alumnado.

\section{ESTRATEGIAS METODOLÓGICAS PARA EL TRABAJO POR COMPETENCIAS}

Todo proceso de enseñanza-aprendizaje debe partir de una planificación rigurosa de lo que se pretende conseguir, teniendo claro cuáles son los objetivos o metas, qué recursos son necesarios, qué métodos didácticos son los más adecuados y cómo se evalúa el aprendizaje y se retroalimenta el proceso. Los métodos didácticos han de elegirse en función de lo que se sabe que es óptimo para alcanzar las metas propuestas y en función de los condicionantes en los que tiene lugar la enseñanza.

La naturaleza de la materia, las condiciones socioculturales, la disponibilidad de recursos y las características de los alumnos y alumnas condicionan el proceso de enseñanza-aprendizaje, por lo que será necesario que el método seguido por el profesor se ajuste a estos condicionantes con el fin de propiciar un aprendizaje competencial en el alumnado.

Los métodos deben partir de la perspectiva del docente como orientador, promotor y facilitador del desarrollo competencial en el alumnado; además, deben enfocarse a la realización de tareas o situaciones-problema, planteadas con un objetivo concreto, que el alumnado debe resolver haciendo un uso adecuado de los distintos tipos de conocimientos, destrezas, actitudes y valores; asimismo, deben tener en cuenta la atención a la diversidad y el respeto por los distintos ritmos y estilos de aprendizaje mediante prácticas de trabajo individual y cooperativo.

En el actual proceso de inclusión de las competencias como elemento esencial del currículo, es preciso señalar que cualquiera de las metodologías seleccionadas por los docentes para favorecer el desarrollo competencial de los alumnos y alumnas debe ajustarse al nivel competencial inicial de estos. Además, es necesario secuenciar la enseñanza de tal modo que se parta de aprendizajes más simples para avanzar gradualmente hacia otros más complejos.

Uno de los elementos clave en la enseñanza por competencias es despertar y mantener la motivación hacia el aprendizaje en el alumnado, lo que implica un nuevo planteamiento del papel del alumno, activo y autónomo, consciente de ser el responsable de su aprendizaje. Los 
Diseño y planificación de competencias específicas en el currículum de enseñanzas profesionales de música: modalidades composición-dirección en la enseñanza superior.

métodos docentes deberán favorecer la motivación por aprender en los alumnos y alumnas y, a tal fin, los profesores han de ser capaces de generar en ellos la curiosidad y la necesidad por adquirir los conocimientos, las destrezas y las actitudes y valores presentes en las competencias. Asimismo, con el propósito de mantener la motivación por aprender es necesario que los profesores procuren todo tipo de ayudas para que los estudiantes comprendan lo que aprenden, sepan para qué lo aprenden y sean capaces de usar lo aprendido en distintos contextos dentro y fuera del aula. Para potenciar la motivación por el aprendizaje de competencias se requieren, además, metodologías activas y contextualizadas. Aquellas que faciliten la participación e implicación del alumnado y la adquisición y uso de conocimientos en situaciones reales, serán las que generen aprendizajes más transferibles y duraderos.

Las metodologías activas han de apoyarse en estructuras de aprendizaje cooperativo, de forma que, a través de la resolución conjunta de las tareas, los miembros del grupo conozcan las estrategias utilizadas por sus compañeros y puedan aplicarlas a situaciones similares. Para un proceso de enseñanza-aprendizaje competencial las estrategias interactivas son las más adecuadas, al permitir compartir y construir el conocimiento y dinamizar la sesión de clase mediante el intercambio verbal y colectivo de ideas. Las metodologías que contextualizan el aprendizaje y permiten el aprendizaje por proyectos, los centros de interés, el estudio de casos o el aprendizaje basado en problemas favorecen la participación activa, la experimentación y un aprendizaje funcional que va a facilitar el desarrollo de las competencias, así como la motivación de los alumnos y alumnas al contribuir decisivamente a la transferibilidad de los aprendizajes.

El trabajo por proyectos, especialmente relevante para el aprendizaje por competencias, se basa en la propuesta de un plan de acción con el que se busca conseguir un determinado resultado práctico. Esta metodología pretende ayudar al alumnado a organizar su pensamiento favoreciendo en ellos la reflexión, la crítica, la elaboración de hipótesis y la tarea investigadora a través de un proceso en el que cada uno asume la responsabilidad de su aprendizaje, aplicando sus conocimientos y habilidades a proyectos reales. Se favorece, por tanto, un aprendizaje orientado a la acción en el que se integran varias áreas o materias: los estudiantes ponen en juego un conjunto amplio de conocimientos, habilidades o destrezas y actitudes personales, es decir, los elementos que integran las distintas competencias.

Asimismo, resulta recomendable el uso del portfolio, que aporta información extensa sobre el aprendizaje del alumnado, refuerza la evaluación continua y permite compartir resultados de aprendizaje. El portfolio es una herramienta motivadora para el alumnado que potencia su autonomía y desarrolla su pensamiento crítico y reflexivo. La selección y uso de materiales y recursos didácticos constituye un aspecto esencial de la metodología. El profesorado debe implicarse en la elaboración y diseño de diferentes tipos de materiales, adaptados a los distintos niveles y a los diferentes estilos y ritmos de aprendizaje de los alumnos y alumnas, con el objeto de atender a la diversidad en el aula y personalizar los procesos de construcción de los aprendizajes. Se debe potenciar el uso de una variedad de materiales y recursos, considerando 
Diseño y planificación de competencias específicas en el currículum de enseñanzas profesionales de música: modalidades composición-dirección en la enseñanza superior.

Carlos Eduardo Pascual Pérez

especialmente la integración de las Tecnologías de la Información y la Comunicación en el proceso de enseñanza-aprendizaje que permiten el acceso a recursos virtuales.

Finalmente, es necesaria una adecuada coordinación entre los docentes sobre las estrategias metodológicas y didácticas que se utilicen. Los equipos educativos deben plantearse una reflexión común y compartida sobre la eficacia de las diferentes propuestas metodológicas con criterios comunes y consensuados. Esta coordinación y la existencia de estrategias conexionadas permiten abordar con rigor el tratamiento integrado de las competencias y progresar hacia una construcción colaborativa del conocimiento. Las enseñanzas especializadas de música contribuirán a desarrollar en los alumnos las competencias clave así como los valores cívicos propios del sistema educativo a través de los objetivos establecidos en la programación de la asignatura.

\section{Objetivos y Contenidos}

\section{Objetivos generales de las Enseñanzas Profesionales}

Según establece el Artículo 4 del DECRETO 158/2007, de 21 de septiembre, del Consell, por el que se establece el currículo de las enseñanzas profesionales de música y se regula el acceso a estas enseñanzas, las enseñanzas elementales de música tienen como objetivo contribuir a desarrollar en los alumnos y alumnas capacidades generales y los valores cívicos propios del sistema educativo y, además, las capacidades siguientes:

a) Fomentar la audición de la música y establecer conceptos estéticos propios que permitan fundamentar y desarrollar criterios interpretativos individuales.

b) Desarrollar la sensibilidad artística y el criterio estético como fuente de formación y enriquecimiento personal.

c) Analizar y valorar críticamente las diferentes manifestaciones y estilos musicales.

d) Conocer las aportaciones de la música al desarrollo personal del individuo y al desarrollo colectivo de las sociedades.

e) Participar en actividades de difusión cultural musical que permitan experimentar con la música y disfrutar de la música.

f) Conocer y emplear con precisión el vocabulario específico relativo a los conceptos científicos y artísticos de la música. 
Diseño y planificación de competencias específicas en el currículum de enseñanzas profesionales de música: modalidades composición-dirección en la enseñanza superior.

g) Conocer y valorar el patrimonio musical como parte integrante del patrimonio histórico y cultural de la Humanidad.

h) Conocer y valorar la importancia de la música propia de la Comunidad Valenciana, así como sus características y manifestaciones más importantes.

\section{Contenidos comunes de las Enseñanzas Profesionales}

Del mismo modo, en el Anexo I de dicho DECRETO se establecen los contenidos comunes de la práctica instrumental:

a) Superar con dominio y capacidad crítica los objetivos y contenidos planteados.

b) Conocer los elementos básicos de los lenguajes musicales, sus características, funciones y evoluciones en los diferentes contextos históricos.

c) Utilizar el «oído interno» como base de la afinación, de la audición armónica y de la interpretación musical.

d) Formar una imagen ajustada de las posibilidades y características musicales tanto a nivel individual como en la relación con el grupo, con la disposición necesaria para saber integrarse como un miembro más del mismo o como responsable del conjunto.

e) Compartir vivencias musicales de grupo en el aula y fuera de ella que permitan enriquecer la relación afectiva con la música a través del canto y de participación instrumental en grupo.

f) Utilizar el cuerpo y la mente para adquirir la técnica necesaria y así, concentrarse en la audición e interpretación musical.

g) Interrelacionar y aplicar los conocimientos adquiridos en todas las asignaturas que componen el currículo junto con las vivencias y experiencias propias para conseguir una interpretación artística de calidad.

h) Adquirir y aplicar las destrezas necesarias para resolver las dificultades que surjan en la interpretación de la música.

i) Practicar la improvisación y la transposición como elementos inherentes a la creatividad musical. 
Diseño y planificación de competencias específicas en el currículum de enseñanzas profesionales de música: modalidades composición-dirección en la enseñanza superior.

j) Interpretar, individualmente o dentro de la agrupación correspondiente, obas escritas en todos los lenguajes musicales, profundizando en el conocimiento de los diferentes estilos y épocas, así como en los recursos interpretativos de cada uno de ellos.

k) Actuar en público con autocontrol, dominio de la memoria musical y capacidad comunicativa.

I) Adquirir autonomía personal en la comunicación musical.

m) Consolidar hábitos de estudio adecuados y continuados en función de la dificultad de los contenidos de las asignaturas de los diferentes cursos y niveles.

n) Conocer y aplicar las técnicas del instrumento o de la voz de acuerdo con las exigencias de las obras.

\section{Objetivos propios de la especialidad}

Por concreción curricular, la enseñanza de Fundamentos de composición en el grado profesional tendrá como objetivo contribuir a des arrollar en los alumnos las capacidades siguientes:

1. Conocer los principales elementos y procedimientos compositivos de las distintas épocas y autores desde el canto gregoriano hasta la actualidad.

2. Utilizar los principales elementos y procesos compositivos de las épocas barroca, clásica y romántica.

3. Realizar pequeñas obras libres con el fin de desarrollar la espontaneidad creativa.

4. Tocar en un instrumento polifónico de forma esquemática los procedimientos compositivos básicos estudiados.

5. Tocar en un instrumento polifónico los trabajos realizados.

\section{Contenidos propios de la especialidad}


Diseño y planificación de competencias específicas en el currículum de enseñanzas profesionales de música: modalidades composición-dirección en la enseñanza superior.

Carlos Eduardo Pascual Pérez

Practica escrita de los elementos y procedimientos compositivos que intervienen en

el sistema tonal, tanto de carácter armónico como contrapuntístico.

Conocimiento básico de las características y posibilidades de los diferentes instrumentos.

Realización de trabajos y composición de pequeñas obras vocales o instrumentales

(o fragmentos) en los estilos barroco, clásico o romántico.

Realización de pequeñas obras libres.

\section{Evaluación}

\section{Criterios generales}

1. Interpretar obras con el suficiente nivel de calidad en correspondencia con los objetivos y su maduración psicoevolutiva.

2. El aspecto anterior supone, además, un hábito de expresión musical da cara al público, actividad que se distribuirá en frecuentes audiciones a lo largo del curso. El carácter diferenciador, en cuanto a la aplicación de los conceptos, viene determinado por las correspondientes obras, piezas y ejercicios del programa de cada curso.

3. Coordinación con el equipo docente para analizar la consecución y profundidad de los objetivos generales del grado.

4. Participar en audiciones del curso a nivel de aula y de centro. Los profesores podrán coordinar y supervisar audiciones trimestrales a nivel de aula, en las cuales participarán todos los alumnos de cada profesor e interpretarán un repertorio común según cada curso propuesto por el profesorado. Las audiciones servirán para evaluar al alumno y el porcentaje de calificación de dichas audiciones será determinado por cada profesor, según el trabajo desarrollado por el alumno en las clases lectivas.

5. El alumno deberá desarrollar una conciencia de grupo y de su propio nivel a partir de las audiciones conjuntas desarrolladas durante el curso, lo cual contribuirá en buen grado a la unificación de niveles. 
Diseño y planificación de competencias específicas en el currículum de enseñanzas profesionales de música: modalidades composición-dirección en la enseñanza superior.

6. Coordinación con el equipo docente para analizar la consecución y profundidad de los objetivos generales del grado.

7. Analizar los criterios de evaluación, identificación en cada uno las capacidades, los contenidos que incluye y los indicadores de los objetivos de la asignatura.

8. La Regularidad en el estudio y la trayectoria en el mismo.

\section{Criterios específicos}

1. Realizar ejercicios a partir de bajos cifrados, bajos sin cifrar y tiples dados.

2. Componer ejercicios breves a partir de un esquema armónico o procedimiento, dado o propio, pensando en un medio instrumental o vocal concreto.

\section{Armonizar corales.}

4. Escribir líneas melódicas en contrapunto a dos, tres y cuatro voces a una voz dada.

5. Dado un fragmento, de carácter predominantemente armónico, completarlo en el mismo estilo, siguiendo un esquema formal predeterminado o libre.

6. Dado un fragmento, de carácter predominantemente contrapuntístico, completarlo en el mismo estilo, siguiendo un esquema formal predeterminado o libre.

7. Realizar ejercicios de contrapunto invertible a distintos intervalos.

8. Realizar cánones por movimiento directo, contrario, retrógrado, aumentación y disminución a dos o más voces. 
9. Componer pequeñas obras vocales o instrumentales (o fragmentos) en los estilos barroco, clásico o romántico.

\section{Procedimientos e instrumentos de evaluación}

La evaluación será continua y establecida según el tipo y grado de aprendizaje que se espera hayan alcanzado los alumnos en un momento determinado, respeto a las capacidades indicadas en los objetivos generales y específicos de la especialidad. También será flexible, teniendo en cuenta el contexto del alumno, es decir, el ciclo educativo en el que se encuentra, así como sus propias características y posibilidades. Además, los instrumentos de evaluación a utilizar serán los siguientes:

1. Evaluación competencial de cada sesión.

2. Fiel seguimiento individual del alumno mediante el "Cuaderno del profesor"

3. Boletines trimestrales informativos

4. Temporalización del repertorio por trimestres

5. Evaluación actitudinal mensual

Por norma general, para el cálculo de la nota media las tareas prácticas se valorarán con un $50 \%$, la evaluación actitudinal con un $20 \%$ y las pruebas trimestrales con un $30 \%$.

\section{Mínimos exigibles}

- Componer ejercicios breves a partir de un esquema armónico o procedimiento, dado o propio, pensando en un medio instrumental o vocal concreto.

- Dado un fragmento, de carácter predominantemente contrapuntístico, completarlo en el mismo estilo, siguiendo un esquema formal libre o predeterminado.

- Componer pequeñas obras libres.

\section{Promoción}

1. Los alumnos promocionarán de curso cuando hayan superado la totalidad de las asignaturas de cada curso o tengan evaluación negativa como máximo en dos asignaturas. 
Diseño y planificación de competencias específicas en el currículum de enseñanzas profesionales de música: modalidades composición-dirección en la enseñanza superior.

Carlos Eduardo Pascual Pérez

En el supuesto de asignaturas pendientes referidas a práctica instrumental o canto, la recuperación deberá realizarse en la clase del curso siguiente si forma parte del mismo.

2. La calificación negativa en tres o más asignaturas de uno o varios cursos impedirá la promoción de un alumno al curso siguiente.

3. Los alumnos que al término del 60 curso tuvieran pendientes de evaluación positiva tres asignaturas o más deberán repetir el curso en su totalidad. Cuando la calificación negativa se produzca en una o dos asignaturas, solo será preceptivo cursar las asignaturas pendiente

\section{Aspectos de la evaluación continua}

Se considerará que un alumno ha perdido el derecho a la evaluación continua cuando acumule ocho o más faltas de asistencia durante todo el curso. Podrá ser evaluado en junio, mediante un equipo de profesores del departamento. Deberá presentar un programa acorde a los mínimos exigibles y acorde con el nivel del curso del cual ha perdido el derecho a la evaluación continua.

Los alumnos y alumnas de enseñanzas profesionales que no superen el curso en el mes de junio podrán recuperar la asignatura mediante la realización de una prueba extraordinaria al finalizar el curso; de acuerdo con el DECRETO 157/2007. El examen extraordinario será diseñado por el profesor que haya impartido la especialidad, teniendo en cuenta los mínimos exigidos en cada curso contemplados en esta programación.

El límite de permanencia en las enseñanzas profesionales de música será de ocho años. El alumno no podrá permanecer más de dos años en el mismo curso, excepto en 60 curso, hasta completar el límite de permanencia.

\section{Metodología}

\section{Principios metodológicos}

a) Adecuar los contenidos y su secuenciación al momento y situación del desarrollo evolutivo del alumno, de forma que el aprendizaje sea constructivo, progresivo y motivador.

b) Motivar al alumno para el estudio de la música mediante su actividad y participación en el progreso, dándole el protagonismo. 
Diseño y planificación de competencias específicas en el currículum de enseñanzas profesionales de música: modalidades composición-dirección en la enseñanza superior.

c) Respetar las peculiaridades de los alumnos, individual y colectivamente, facilitando así la convivencia en el seno del grupo y la colaboración, de forma que se eviten las discriminaciones de todo tipo.

d) Utilizar procedimientos y recursos variados que estimulen la capacidad crítica y creativa del alumno mediante la aceptación del dialogo y las argumentaciones razonadas

e) Procurar que la asimilación de los contenidos conceptuales por parte del alumno se completa con la adquisición de contenidos procedimentales y actitudinales que propicien su autonomía en el trabajo tato para el momento presente como para el futuro.

f) Facilitar a los alumnos el conocimiento y empleo del código convencional de expresión a la vez que la corrección y la exactitud en el uso del lenguaje, con el fin de que el aprendizaje y la comunicación sean efectivos.

g) Ejercitar la creatividad del alumno, de modo que adquiera estrategias propias de estudio y de realizaciones musicales con el fin de que pueda superar las dificultades que se les presenten.

\section{Otros aspectos metodológicos}

Se implementarán competencias transversales desarrolladas específicamente para una completa preparación en las pruebas de acceso a enseñanzas superiores en composición y/o dirección. Estas son:

- Organología, instrumentación y orquestación en el ámbito de la orquesta sinfónica

\section{Concreción curricular del Curso}

\section{CONTRAPUNTO IMITATIVO}

1. Tipos o especies de imitación: regular, irregular y rítmica.

2. Procedimientos imitativos:

3. Práctica de importantes citados: imitación por movimiento directo. Imitación por movimiento contrario. Imitación por movimiento retrógrado. Imitación por movimiento 
Carlos Eduardo Pascual Pérez

contrario retrógrado. Imitación por aumentación. Imitación por disminución. Imitación a contratiempo. Imitación interrumpida. Imitación periódica.

V. EL CANON (como forma musical)

1. Concepto.

2. Canon abierto. Canon cerrado. (sólo a 2 voces)

3. Formas canónicas:

1. a) Canon simple por movimiento directo.

2. b) Canon por movimiento contrario.

3. c) Canon por movimiento retrógrado.

4. d) Canon por movimiento contrario retrógrado.

5. e) Canon por aumentación.

6. f) Canon por disminución.

7. g) Práctica del canon a dos partes con los procedimientos citados

\section{EL CORAL}

1. Elementos de la armonización de corales.

2. Realización de una sola frase.

3. Realización de dos o más frases.

4. El coral completo.

\section{ARMONIZACIONES A CUATRO VOCES}

1. Ejercicios vocales o instrumentales con esquemas armónicos o contrapuntísticos dados.

2. Ejercicios con esquemas formales predeterminados o libres.

\section{CONTRAPUNTO INVERTIBLE}

1. Contrapunto doble a la $8 a, 10 a$ y 120.

2. Contrapunto doble a otros intervalos.

\section{LA INVENCIÓN}

1. Estudio del plan tonal de la invención.

2. Estudio de los elementos temáticos y expositivos.

3. Estudio y práctica de la elaboración de los diversos divertimentos y posibles pedales.

4. Composición de invenciones a dos y tres voces. 
Carlos Eduardo Pascual Pérez

VII. OTRAS FORMAS BARROCAS

1. El Preludio Coral

2. Los distintos tipos de Preludios de Fuga.

XIII. LA VARIACIÓN (estudio analítico-práctico)

1. Preliminares:

a) Variación ornamental.

b) Variación elaborada (armónico-contrapuntística).

c) Variación amplificativa.

2. La Variación preclásica:

1. a) Variación sobre un modelo melódico (cantus firmus): El Coral Variado.

2. b) La Variación sobre un modelo de bajo. La Chacona. La Passacaglia.

3. La Variación clásica y posclásica:

a) Tema con variaciones.

IX. LA SUITE

1. Estudio analítico-práctico de las principales características de las piezas más frecuentes de la Suite barroca.

\section{LA SONATA}

1. Estudio analítico-práctico de la evolución histórica de la forma Sonata.

XI. EL CUARTETO INSTRUMENTAL

1. Posibilidad técnica.

2. Práctica de la escritura para cuartetos de cuerda.

3. Escritura para otras formaciones de cuarteto.

XII. LA MELODÍA ACOMPAÑADA

1. Acompañamiento pianístico.

2. Recursos técnicos: acordes compactos, acordes disueltos, baterías, redoblamientos, la 


\section{Carlos Eduardo Pascual Pérez}

nota pedal pianística, etc.

3. El bajo de Alberti.

XIII. LA INSTRUMENTACIÓN

1. Los instrumentos de cuerda. Extensión y posibilidades técnicas.

2. Los instrumentos de viento. Extensión y posibilidades técnicas.

3. Los instrumentos de percusión:

a) De sonidos determinados.

b) De sonidos indeterminados.

4. La orquesta: su origen y evolución. 


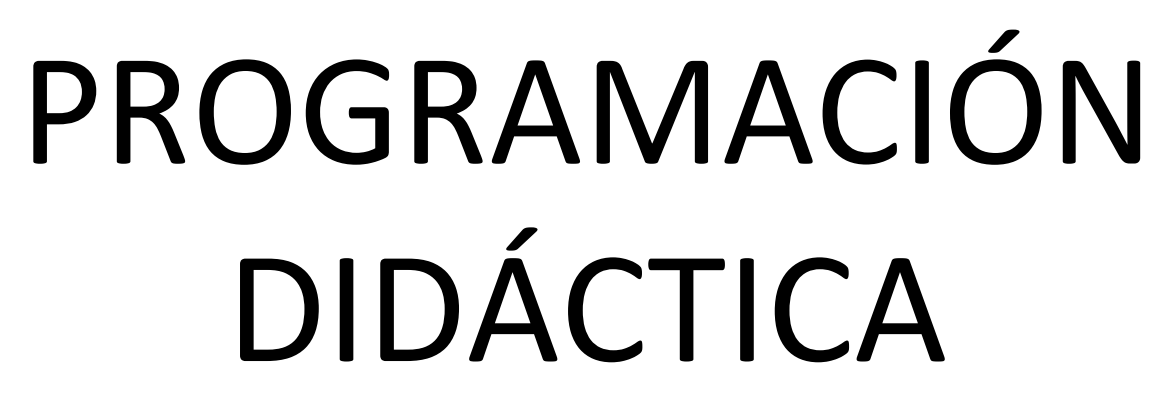

FUNDAMENTOS DE DIRECCIÓN 
Diseño y planificación de competencias específicas en el currículum de enseñanzas profesionales de música: modalidades composición-dirección en la enseñanza superior.

Carlos Eduardo Pascual Pérez

\section{COMPETENCIAS CLAVE}

Las competencias que se recogen en esta programación se han establecido de conformidad con los resultados de la investigación educativa y con las tendencias europeas recogidas en la Recomendación 2006/962/EC, del Parlamento Europeo y del Consejo, de 18 de diciembre de 2006, sobre las competencias clave para el aprendizaje permanente. Dichas competencias se describen, se indica su finalidad y aspectos distintivos, y se pone de manifiesto, en cada una de ellas, las claves de desarrollo que debe alcanzar todo el alumnado referidas al final de la enseñanza profesional de música, pero cuyo desarrollo debe iniciarse desde el comienzo de la escolarización, de manera que su adquisición se realice de forma progresiva y coherente a lo largo de las distintas etapas educativas.

Las competencias clave deberán estar estrechamente vinculadas a los objetivos definidos para la enseñanza artística de Música. Esta vinculación favorece que la consecución de dichos objetivos a lo largo de la vida académica lleve implícito el desarrollo de las competencias clave, para que todas las personas puedan alcanzar su desarrollo personal y lograr una correcta incorporación en la sociedad.

Un enfoque metodológico basado en las competencias clave y en los resultados de aprendizaje conlleva importantes cambios en la concepción del proceso de enseñanza-aprendizaje, cambios en la organización y en la cultura escolar; requiere la estrecha colaboración entre los docentes en el desarrollo curricular y en la transmisión de información sobre el aprendizaje de los alumnos y alumnas, así como cambios en las prácticas de trabajo y en los métodos de enseñanza. De este hecho se desprenden las competencias clave del currículo en el sistema educativo español.

1. Comunicación lingüística.

Es el resultado de la acción comunicativa dentro de prácticas musicales y sociales determinadas, en las cuales el individuo actúa con otros interlocutores y a través de textos en múltiples modalidades, formatos y soportes. Estas situaciones y prácticas pueden implicar el uso de distintos lenguajes musicales, en diversos ámbitos y de manera individual o colectiva. Para ello el individuo dispone de su repertorio musical, pero ajustado a las experiencias comunicativas que experimenta a lo largo de la vida. Los distintos lenguajes musicales que utiliza pueden haber tenido vías y tiempos distintos de adquisición y constituir, por tanto, experiencias de aprendizaje musicales, tanto populares como de otra índole. Esta visión de la competencia en comunicación lingüística vinculada con prácticas musicales determinadas ofrece una imagen del individuo como agente comunicativo que produce, y no sólo recibe, mensajes a través de las diferentes manifestaciones musicales con distintas finalidades. Valorar la relevancia de esta afirmación en la toma de decisiones educativas supone optar por metodologías activas de aprendizaje (aprendizaje basado en tareas y proyectos, en problemas, en retos, etcétera), ya sean estas en lenguajes musicales vanguardistas y actuales, frente a opciones metodológicas más tradicionales. Además, la competencia en comunicación lingüística musical, representa una vía de conocimiento y contacto con la diversidad cultural que implica un factor de 
Diseño y planificación de competencias específicas en el currículum de enseñanzas profesionales de música: modalidades composición-dirección en la enseñanza superior.

Carlos Eduardo Pascual Pérez

enriquecimiento para la propia competencia y que adquiere una particular relevancia en el caso de las músicas de otras culturas. Por tanto, un enfoque intercultural en la enseñanza y el aprendizaje de las diferentes músicas implica una importante contribución al desarrollo de la competencia en comunicación lingüística musical del alumnado.

Esta competencia es, por definición, siempre parcial y constituye un objetivo de aprendizaje permanente a lo largo de toda la vida. Por ello, para que se produzca un aprendizaje satisfactorio de las diferentes músicas, es determinante que se promuevan unos contextos de uso de lenguajes musicales ricos y variados, en relación con las tareas que se han de realizar y sus posibles interlocutores, textos e intercambios comunicativos.

La competencia en comunicación lingüística musical es extremadamente compleja. Se basa, en primer lugar, en el conocimiento del componente lingüístico musical. Pero además, como se produce y desarrolla en situaciones comunicativas concretas y contextualizadas, el individuo necesita activar su conocimiento del componente pragmático-discursivo y socio-cultural.

Esta competencia precisa de la interacción de distintas destrezas, ya que se produce en múltiples modalidades de comunicación y en diferentes soportes. Desde la oralidad y la escritura hasta las formas más sofisticadas de comunicación audiovisual o mediada por la tecnología, el individuo participa de un complejo entramado de posibilidades comunicativas gracias a las cuales expande su competencia y su capacidad de interacción con otros individuos. Por ello, esta diversidad de modalidades y soportes requiere de una alfabetización musical más compleja, recogida en el concepto de alfabetizaciones múltiples, que permita al individuo su participación como ciudadano activo.

La competencia en comunicación lingüística musical es también un instrumento fundamental para la socialización y el aprovechamiento de la experiencia educativa, por ser una vía privilegiada de acceso al conocimiento dentro y fuera de la escuela. De su desarrollo depende, en buena medida, que se produzcan distintos tipos de aprendizaje en distintos contextos, formales, informales y no formales. En este sentido, es especialmente relevante en el contexto escolar la consideración de la lectura como destreza básica para la ampliación de la competencia en comunicación lingüística musical y el aprendizaje. Así, el lenguaje musical es la principal vía de acceso a todas las áreas, por lo que el contacto con una diversidad de textos resulta fundamental para acceder a las fuentes originales del saber. Por ello, donde manifiesta su importancia, de forma más patente, es en el desarrollo de las destrezas que conducen al conocimiento de los textos musicales, no solo en su consideración como canon artístico o en su valoración como parte del patrimonio cultural, sino sobre todo, y principalmente, como fuente de disfrute y aprendizaje a lo largo de la vida.

Desde esta perspectiva, es recomendable que el centro educativo sea la unidad de acción para el desarrollo de la competencia en comunicación lingüística musical. En este sentido, actuaciones como el diseño de un Proyecto Artístico Musical de Centro que forme parte del propio Proyecto Educativo de Centro, un Plan Lector o unas estrategias para el uso de la 
Diseño y planificación de competencias específicas en el currículum de enseñanzas profesionales de música: modalidades composición-dirección en la enseñanza superior.

Biblioteca y Fonoteca Escolar como espacio de aprendizaje y disfrute permiten un tratamiento más global y eficaz de la competencia en comunicación lingüística musical en los términos aquí expresados.

La competencia en comunicación lingüística musical se inscribe en un marco de actitudes y valores que el individuo pone en funcionamiento: el respeto a las normas de convivencia; el ejercicio activo de la ciudadanía; el desarrollo de un espíritu crítico; el respeto a los derechos humanos y el pluralismo; la concepción del diálogo como herramienta primordial para la convivencia, la resolución de conflictos y el desarrollo de las capacidades afectivas en todos los ámbitos; una actitud de curiosidad, interés y creatividad hacia el aprendizaje y el reconocimiento de las destrezas inherentes a esta competencia (lectura, conversación, escritura, etcétera) como fuentes de placer relacionada con el disfrute personal y cuya promoción y práctica son tareas esenciales en el refuerzo de la motivación hacia el aprendizaje.

En resumen, para el adecuado desarrollo de esta competencia resulta necesario abordar el análisis y la consideración de los distintos aspectos que intervienen en ella, debido a su complejidad. Para ello, se debe atender a los cinco componentes que la constituyen y a las dimensiones en las que se concretan:

- El componente lingüístico musical que comprende diversas dimensiones: la léxica, la gramatical, la semántica, la fonológica, la ortográfica y la ortoépica, entendida esta como la articulación correcta del sonido a partir de la representación gráfica de la música.

- El componente pragmático-discursivo contempla tres dimensiones: la socio-musical (vinculada con la adecuada producción y recepción de mensajes en diferentes contextos sociales); la pragmática (que incluye las microfunciones comunicativas y los esquemas de interacción); y la discursiva (que incluye las macrofunciones textuales y las cuestiones relacionadas con los géneros discursivos).

- El componente socio-cultural incluye dos dimensiones: la que se refiere al conocimiento del mundo y la dimensión intercultural.

- El componente estratégico permite al individuo superar las dificultades y resolver los problemas que surgen en el acto comunicativo. Incluye tanto destrezas y estrategias comunicativas para la lectura, la escritura, la interpretación musical, la escucha, como destrezas vinculadas con el tratamiento de la información, la lectura multimodal y la producción de textos electrónicos en diferentes formatos; asimismo, también forman parte de este componente las estrategias generales de carácter cognitivo, metacognitivo y socioafectivas que el individuo utiliza para comunicarse eficazmente, aspectos fundamentales en el aprendizaje de las otras culturas musicales extranjeras. 
Diseño y planificación de competencias específicas en el currículum de enseñanzas profesionales de música: modalidades composición-dirección en la enseñanza superior.

Carlos Eduardo Pascual Pérez

- Por último, la competencia en comunicación lingüística musical incluye un componente personal que interviene en la interacción comunicativa en tres dimensiones: la actitud, la motivación y los rasgos de personalidad.

\section{Competencia matemática y competencias básicas en ciencia y tecnología.}

La competencia matemática y las competencias básicas en ciencia y tecnología inducen y fortalecen algunos aspectos esenciales de la formación de las personas que resultan fundamentales para la vida. En una sociedad donde el impacto de las matemáticas, las ciencias y las tecnologías es determinante, la consecución y sostenibilidad del bienestar social exige conductas y toma de decisiones personales estrechamente vinculadas a la capacidad crítica y visión razonada y razonable de las personas. A ello contribuyen la competencia matemática y competencias básicas en ciencia y tecnología, las cuales están incluidas en la enseñanza musical a través de sus distintas asignaturas.

La competencia matemática implica la capacidad de aplicar el razonamiento matemático y sus herramientas para describir, interpretar y predecir distintos fenómenos en su contexto, al igual que ocurre en las estructuras musicales. La competencia matemática musical requiere de conocimientos sobre las medidas y las estructuras que componen las obras musicales, así como de las operaciones y las representaciones armónicas, y la comprensión de los términos que conllevan estas representaciones.

El uso de herramientas matemáticas, dentro de la enseñanza musical, implica una serie de destrezas que requieren la aplicación de los principios y procesos matemáticos en distintos contextos, ya sean personales, sociales, profesionales o científicos, así como para emitir juicios fundados y seguir cadenas argumentales en la realización de cálculos, el análisis de gráficos y representaciones armónicas y la manipulación de expresiones musicales, incorporando los medios digitales cuando sea oportuno. Forma parte de esta destreza la creación de descripciones y explicaciones musicales que llevan implícitas la interpretación de resultados compositivos y la reflexión sobre su adecuación al contexto, al igual que la determinación de si las soluciones son adecuadas y tienen sentido en la situación en que se presentan. Se trata, por tanto, de reconocer el papel que desempeñan las estructuras matemático-musicales en el mundo y utilizar los conceptos, procedimientos y herramientas para aplicarlos en la resolución de los problemas que puedan surgir en una situación determinada a lo largo de la vida. La activación de la competencia matemática supone que el aprendiz es capaz de establecer una relación profunda entre el conocimiento conceptual y el conocimiento procedimental, implicados en la resolución de una tarea matemático-musical determinada.

La competencia matemática incluye una serie de actitudes y valores que se basan en el rigor, el respeto a los datos y la veracidad. Así pues, para el adecuado desarrollo de la competencia 
Diseño y planificación de competencias específicas en el currículum de enseñanzas profesionales de música: modalidades composición-dirección en la enseñanza superior.

Carlos Eduardo Pascual Pérez

matemática resulta necesario abordar cuatro áreas relativas a los signos musicales, la armonía, la geometría musical, interrelacionadas de formas diversas:

- El espacio y la forma: incluyen una amplia gama de fenómenos que se encuentran en nuestro mundo musical, visual y físico: patrones, propiedades de los objetos, posiciones, direcciones y representaciones de ellos; descodificación y codificación de información visual y musical, así como navegación e interacción dinámica con formas reales, o con representaciones. La competencia matemático-musical en este sentido incluye una serie de actividades como la comprensión de la perspectiva, la elaboración y lectura de partituras, la transformación de las formas con y sin tecnología, la interpretación de vistas de escenas tridimensionales desde distintas perspectivas y la construcción de representaciones de formas musicales.

- El cambio y las relaciones: el mundo despliega multitud de relaciones temporales y permanentes entre los objetos y las circunstancias, donde los cambios se producen dentro de sistemas de objetos interrelacionados. Tener más conocimientos sobre el cambio y las relaciones supone comprender los tipos fundamentales de cambio y cuándo tienen lugar, con el fin de utilizar modelos músico-estructurales adecuados para describirlo y predecirlo.

- La incertidumbre y los datos: son un fenómeno central del análisis estructural de la música en el presente en distintos momentos del proceso de resolución de problemas en el que resulta clave la presentación e interpretación de dichas estructuras. Esta categoría incluye el reconocimiento del lugar de la variación en los procesos, la posesión de un sentido de cuantificación de esa variación, la admisión de incertidumbre y error en las mediciones y los conocimientos sobre el azar. Asimismo, comprende la elaboración, interpretación y valoración de las conclusiones extraídas en situaciones donde la incertidumbre y los datos son fundamentales.

Las competencias básicas en ciencia y tecnología son aquellas que proporcionan un acercamiento al mundo físico y a la interacción responsable con él desde acciones, tanto individuales como colectivas, orientadas a la conservación y mejora del medio natural, decisivas para la protección y mantenimiento de la calidad de vida y el progreso de los pueblos. Estas competencias contribuyen al desarrollo del pensamiento científico, pues incluyen la aplicación de los métodos propios de la racionalidad científica y las destrezas tecnológicas, que conducen a la adquisición de conocimientos, al contraste de ideas y la aplicación de los descubrimientos al bienestar social.

Las competencias en ciencia y tecnología capacitan a ciudadanos responsables y respetuosos que desarrollan juicios críticos sobre los hechos científicos y tecnológicos que se suceden a lo largo de los tiempos, pasados y actuales. Estas competencias han de capacitar, básicamente, para identificar, plantear y resolver situaciones de la vida cotidiana -personal y socialanálogamente a como se actúa frente a los retos y problemas propios de la actividades científicas y tecnológicas. 
Diseño y planificación de competencias específicas en el currículum de enseñanzas profesionales de música: modalidades composición-dirección en la enseñanza superior.

Para el adecuado desarrollo de las competencias en ciencia y tecnología resulta necesario abordar los saberes o conocimientos científicos relativos a la física, la química, la biología, la geología, las matemáticas y la tecnología, los cuales se derivan de conceptos, procesos y situaciones interconectadas. Estos saberes el alumnado los adquirirá en la enseñanza general (ESO, Bachillerato). Se requiere igualmente el fomento de destrezas que permitan utilizar y manipular herramientas y máquinas tecnológicas, así como utilizar datos y procesos científicos para alcanzar un objetivo; es decir, identificar preguntas, resolver problemas, llegar a una conclusión o tomar decisiones basadas en pruebas y argumentos.

Asimismo, estas competencias incluyen actitudes y valores relacionados con la asunción de criterios éticos asociados a la ciencia y a la tecnología, el interés por la ciencia, el apoyo a la investigación científica y la valoración del conocimiento científico; así como el sentido de la responsabilidad en relación a la conservación de los recursos naturales y a las cuestiones medioambientales y a la adopción de una actitud adecuada para lograr una vida física y mental saludable en un entorno natural y social.

\section{Competencia digital.}

La competencia digital es aquella que implica el uso creativo, crítico y seguro de las tecnologías de la información y la comunicación para alcanzar los objetivos relacionados con el trabajo, la empleabilidad, el aprendizaje, el uso del tiempo libre, la inclusión y participación en la sociedad.

Esta competencia supone, además de la adecuación a los cambios que introducen las nuevas tecnologías en la alfabetización, la lectura y la escritura de la música, un conjunto nuevo de conocimientos, habilidades y actitudes necesarias hoy en día para ser competente en un entorno digital.

Requiere de conocimientos relacionados con el lenguaje específico básico: textual, numérico, icónico, visual, gráfico y sonoro, así como sus pautas de decodificación y transferencia. Esto conlleva el conocimiento de las principales aplicaciones informáticas. Supone también el acceso a las fuentes y el procesamiento de la información; y el conocimiento de los derechos y las libertades que asisten a las personas en el mundo digital. Igualmente precisa del desarrollo de diversas destrezas relacionadas con el acceso a la información, el procesamiento y uso para la comunicación, la creación de contenidos, la seguridad y la resolución de problemas, tanto en contextos formales como no formales e informales. La persona ha de ser capaz de hacer un uso habitual de los recursos tecnológicos disponibles con el fin de resolver los problemas reales de un modo eficiente, así como evaluar y seleccionar nuevas fuentes de información e innovaciones tecnológicas, a medida que van apareciendo, en función de su utilidad para acometer tareas u objetivos específicos.

La adquisición de esta competencia requiere además actitudes y valores que permitan al usuario adaptarse a las nuevas necesidades establecidas por las tecnologías, su apropiación y adaptación a los propios fines y la capacidad de interaccionar socialmente en torno a ellas. Se 
Diseño y planificación de competencias específicas en el currículum de enseñanzas profesionales de música: modalidades composición-dirección en la enseñanza superior.

trata de desarrollar una actitud activa, crítica y realista hacia las tecnologías y los medios tecnológicos, valorando sus fortalezas y debilidades y respetando principios éticos en su uso. Por otra parte, la competencia digital implica la participación y el trabajo colaborativo, así como la motivación y la curiosidad por el aprendizaje y la mejora en el uso de las tecnologías.

Por tanto, para el adecuado desarrollo de la competencia digital resulta necesario abordar:

- La información: esto conlleva la comprensión de cómo se gestiona la información y de cómo se pone a disposición de los usuarios, así como el conocimiento y manejo de diferentes motores de búsqueda y bases de datos, sabiendo elegir aquellos que responden mejor a las propias necesidades de información.

- Igualmente, supone saber analizar e interpretar la información que se obtiene, cotejar y evaluar el contenido de los medios de comunicación en función de su validez, fiabilidad y adecuación entre las fuentes, tanto online como offline. Y por último, la competencia digital supone saber transformar la información en conocimiento a través de la selección apropiada de diferentes opciones de almacenamiento.

- La comunicación: supone tomar conciencia de los diferentes medios de comunicación digital y de varios paquetes de software de comunicación y de su funcionamiento así como sus beneficios y carencias en función del contexto y de los destinatarios. Al mismo tiempo, implica saber qué recursos pueden compartirse públicamente y el valor que tienen, es decir, conocer de qué manera las tecnologías y los medios de comunicación pueden permitir diferentes formas de participación y colaboración para la creación de contenidos que produzcan un beneficio común. Ello supone el conocimiento de cuestiones éticas como la identidad digital y las normas de interacción digital.

- La creación de contenidos: implica saber cómo los contenidos digitales pueden realizarse en diversos formatos (texto, audio, vídeo, imágenes) así como identificar los programas/aplicaciones que mejor se adaptan al tipo de contenido que se quiere crear. Supone también la contribución al conocimiento de dominio público (wikis, foros públicos, revistas), teniendo en cuenta las normativas sobre los derechos de autor y las licencias de uso y publicación de la información.

- La seguridad: implica conocer los distintos riesgos asociados al uso de las tecnologías y de recursos online y las estrategias actuales para evitarlos, lo que supone identificar los comportamientos adecuados en el ámbito digital para proteger la información, propia y de otras personas, así como conocer los aspectos adictivos de las tecnologías.

- La resolución de problemas: esta dimensión supone conocer la composición de los dispositivos digitales, sus potenciales y limitaciones en relación a la consecución de metas personales, así como saber dónde buscar ayuda para la resolución de problemas teóricos y técnicos, lo que implica una combinación heterogénea y bien equilibrada de las tecnologías digitales y no digitales más importantes en esta área de conocimiento.

\section{Aprender a aprender.}

La competencia de aprender a aprender es fundamental para el aprendizaje permanente que se produce a lo largo de la vida y que tiene lugar en distintos contextos formales, no formales e informales. 
Diseño y planificación de competencias específicas en el currículum de enseñanzas profesionales de música: modalidades composición-dirección en la enseñanza superior.

Carlos Eduardo Pascual Pérez

Esta competencia se caracteriza por la habilidad para iniciar, organizar y persistir en el aprendizaje. Esto exige, en primer lugar, la capacidad para motivarse por aprender. Esta motivación depende de que se genere la curiosidad y la necesidad de aprender, de que el estudiante se sienta protagonista del proceso y del resultado de su aprendizaje $y$, finalmente, de que llegue a alcanzar las metas de aprendizaje propuestas y, con ello, que se produzca en él una percepción de auto-eficacia. Todo lo anterior contribuye a motivarle para abordar futuras tareas de aprendizaje. En segundo lugar, en cuanto a la organización y gestión del aprendizaje, la competencia de aprender a aprender requiere conocer y controlar los propios procesos de aprendizaje para ajustarlos a los tiempos y las demandas de las tareas y actividades que conducen al aprendizaje. La competencia de aprender a aprender desemboca en un aprendizaje cada vez más eficaz y autónomo.

Esta competencia incluye una serie de conocimientos y destrezas que requieren la reflexión y la toma de conciencia de los propios procesos de aprendizaje. Así, los procesos de conocimiento se convierten en objeto del conocimiento $y$, además, hay que aprender a ejecutarlos adecuadamente.

Aprender a aprender incluye conocimientos sobre los procesos mentales implicados en el aprendizaje (cómo se aprende). Además, esta competencia incorpora el conocimiento que posee el estudiante sobre su propio proceso de aprendizaje que se desarrolla en tres dimensiones:

- el conocimiento que tiene acerca de lo que sabe y desconoce, de lo que es capaz de aprender, de lo que le interesa, etcétera;

- el conocimiento de la disciplina en la que se localiza la tarea de aprendizaje y el conocimiento del contenido concreto y de las demandas de la tarea misma

- el conocimiento sobre las distintas estrategias posibles para afrontar la tarea.

Todo este conocimiento se vuelca en destrezas de autorregulación y control inherentes a la competencia de aprender a aprender, que se concretan en estrategias de planificación en las que se refleja la meta de aprendizaje que se persigue, así como el plan de acción que se tiene previsto aplicar para alcanzarla; estrategias de supervisión desde las que el estudiante va examinando la adecuación de las acciones que está desarrollando y la aproximación a la meta; y estrategias de evaluación desde las que se analiza tanto el resultado como del proceso que se ha llevado a cabo. La planificación, supervisión y evaluación son esenciales para desarrollar aprendizajes cada vez más eficaces. Todas ellas incluyen un proceso reflexivo que permite pensar antes de actuar (planificación), analizar el curso y el ajuste del proceso (supervisión) y consolidar la aplicación de buenos planes o modificar los que resultan incorrectos (evaluación del resultado y del proceso). Estas tres estrategias deberían potenciarse en los procesos de aprendizaje y de resolución de problemas en los que participan los estudiantes.

Aprender a aprender se manifiesta tanto individualmente como en grupo. En ambos casos el dominio de esta competencia se inicia con una reflexión consciente acerca de los procesos de 
Diseño y planificación de competencias específicas en el currículum de enseñanzas profesionales de música: modalidades composición-dirección en la enseñanza superior.

aprendizaje a los que se entrega uno mismo o el grupo. No solo son los propios procesos de conocimiento, sino que, también, el modo en que los demás aprenden se convierte en objeto de escrutinio. De ahí que la competencia de aprender a aprender se adquiera también en el contexto del trabajo en equipo. Los profesores han de procurar que los estudiantes sean conscientes de lo que hacen para aprender y busquen alternativas. Muchas veces estas alternativas se ponen de manifiesto cuando se trata de averiguar qué es lo que hacen los demás en situaciones de trabajo cooperativo.

Respecto a las actitudes y valores, la motivación y la confianza son cruciales para la adquisición de esta competencia. Ambas se potencian desde el planteamiento de metas realistas a corto, medio y largo plazo. Al alcanzarse las metas aumenta la percepción de auto-eficacia y la confianza, y con ello se elevan los objetivos de aprendizaje de forma progresiva. Las personas deben ser capaces de apoyarse en experiencias vitales y de aprendizaje previas con el fin de utilizar y aplicar los nuevos conocimientos y capacidades en otros contextos, como los de la vida privada y profesional, la educación y la formación.

Saber aprender en un determinado ámbito implica ser capaz de adquirir y asimilar nuevos conocimientos y llegar a dominar capacidades y destrezas propias de dicho ámbito. En la competencia de aprender a aprender puede haber una cierta trasferencia de conocimiento de un campo a otro, aunque saber aprender en un ámbito no significa necesariamente que se sepa aprender en otro. Por ello, su adquisición debe llevarse a cabo en el marco de la enseñanza de las distintas áreas y materias del ámbito formal, y también de los ámbitos no formal e informal.

Podría concluirse que para el adecuado desarrollo de la competencia de aprender a aprender se requiere de una reflexión que favorezca un conocimiento de los procesos mentales a los que se entregan las personas cuando aprenden, un conocimiento sobre los propios procesos de aprendizaje, así como el desarrollo de la destreza de regular y controlar el propio aprendizaje que se lleva a cabo.

\section{Competencias sociales y cívicas.}

Las competencias sociales y cívicas implican la habilidad y capacidad para utilizar los conocimientos y actitudes sobre la sociedad, entendida desde las diferentes perspectivas, en su concepción dinámica, cambiante y compleja, para interpretar fenómenos y problemas sociales en contextos cada vez más diversificados; para elaborar respuestas, tomar decisiones y resolver conflictos, así como para interactuar con otras personas y grupos conforme a normas basadas en el respeto mutuo y en convicciones democráticas. Además de incluir acciones a un nivel más cercano y mediato al individuo como parte de una implicación cívica y social.

Se trata, por lo tanto, de aunar el interés por profundizar y garantizar la participación en el funcionamiento democrático de la sociedad, tanto en el ámbito público como privado, y preparar a las personas para ejercer la ciudadanía democrática y participar plenamente en la 
Diseño y planificación de competencias específicas en el currículum de enseñanzas profesionales de música: modalidades composición-dirección en la enseñanza superior.

Carlos Eduardo Pascual Pérez

vida cívica y social gracias al conocimiento de conceptos y estructuras sociales y políticas y al compromiso de participación activa y democrática.

La competencia social se relaciona con el bienestar personal y colectivo. Exige entender el modo en que las personas pueden procurarse un estado de salud física y mental óptimo, tanto para ellas mismas como para sus familias y para su entorno social próximo, y saber cómo un estilo de vida saludable puede contribuir a ello.

Para poder participar plenamente en los ámbitos social e interpersonal es fundamental adquirir los conocimientos que permitan comprender y analizar de manera crítica los códigos de conducta y los usos generalmente aceptados en las distintas sociedades y entornos, así como sus tensiones y procesos de cambio. La misma importancia tiene conocer los conceptos básicos relativos al individuo, al grupo, a la organización del trabajo, la igualdad y la no discriminación entre hombres y mujeres y entre diferentes grupos étnicos o culturales, la sociedad y la cultura. Asimismo, es esencial comprender las dimensiones intercultural y socioeconómica de las sociedades europeas y percibir las identidades culturales y nacionales como un proceso sociocultural dinámico y cambiante en interacción con la europea, en un contexto de creciente globalización.

Los elementos fundamentales de esta competencia incluyen el desarrollo de ciertas destrezas como la capacidad de comunicarse de una manera constructiva en distintos entornos sociales y culturales, mostrar tolerancia, expresar y comprender puntos de vista diferentes, negociar sabiendo inspirar confianza y sentir empatía. Las personas deben ser capaces de gestionar un comportamiento de respeto a las diferencias expresado de manera constructiva.

Asimismo, esta competencia incluye actitudes y valores como una forma de colaboración, la seguridad en uno mismo y la integridad y honestidad. Las personas deben interesarse por el desarrollo socioeconómico y por su contribución a un mayor bienestar social de toda la población, así como la comunicación intercultural, la diversidad de valores y el respeto a las diferencias, además de estar dispuestas a superar los prejuicios y a comprometerse en este sentido.

La competencia cívica se basa en el conocimiento crítico de los conceptos de democracia, justicia, igualdad, ciudadanía y derechos humanos y civiles, así como de su formulación en la Constitución española, la Carta de los Derechos Fundamentales de la Unión Europea y en declaraciones internacionales, y de su aplicación por parte de diversas instituciones a escala local, regional, nacional, europea e internacional. Esto incluye el conocimiento de los acontecimientos contemporáneos, así como de los acontecimientos más destacados y de las principales tendencias en las historias nacional, europea y mundial, así como la comprensión de los procesos sociales y culturales de carácter migratorio que implican la existencia de sociedades multiculturales en el mundo globalizado. 
Diseño y planificación de competencias específicas en el currículum de enseñanzas profesionales de música: modalidades composición-dirección en la enseñanza superior.

Las destrezas de esta competencia están relacionadas con la habilidad para interactuar eficazmente en el ámbito público y para manifestar solidaridad e interés por resolver los problemas que afecten al entorno escolar y a la comunidad, ya sea local o más amplia. Conlleva la reflexión crítica y creativa y la participación constructiva en las actividades de la comunidad o del ámbito mediato e inmediato, así como la toma de decisiones en los contextos local, nacional o europeo y, en particular, mediante el ejercicio del voto y de la actividad social y cívica.

Las actitudes y valores inherentes a esta competencia son aquellos que se dirigen al pleno respeto de los derechos humanos y a la voluntad de participar en la toma de decisiones democráticas a todos los niveles, sea cual sea el sistema de valores adoptado. También incluye manifestar el sentido de la responsabilidad y mostrar comprensión y respeto de los valores compartidos que son necesarios para garantizar la cohesión de la comunidad, basándose en el respeto de los principios democráticos. La participación constructiva incluye también las actividades cívicas y el apoyo a la diversidad y la cohesión sociales y al desarrollo sostenible, así como la voluntad de respetar los valores y la intimidad de los demás y la recepción reflexiva y crítica de la información procedente de los medios de comunicación.

Por tanto, para el adecuado desarrollo de estas competencias es necesario comprender y entender las experiencias colectivas y la organización y funcionamiento del pasado y presente de las sociedades, la realidad social del mundo en el que se vive, sus conflictos y las motivaciones de los mismos, los elementos que son comunes y los que son diferentes, así como los espacios y territorios en que se desarrolla la vida de los grupos humanos, y sus logros y problemas, para comprometerse personal y colectivamente en su mejora, participando así de manera activa, eficaz y constructiva en la vida social y profesional.

Asimismo, estas competencias incorporan formas de comportamiento individual que capacitan a las personas para convivir en una sociedad cada vez más plural, dinámica, cambiante y compleja para relacionarse con los demás; cooperar, comprometerse y afrontar los conflictos y proponer activamente perspectivas de afrontamiento, así como tomar perspectiva, desarrollar la percepción del individuo en relación a su capacidad para influir en lo social y elaborar argumentaciones basadas en evidencias.

Adquirir estas competencias supone ser capaz de ponerse en el lugar del otro, aceptar las diferencias, ser tolerante y respetar los valores, las creencias, las culturas y la historia personal y colectiva de los otros.

\section{Sentido de iniciativa y espíritu emprendedor.}

La competencia sentido de iniciativa y espíritu emprendedor implica la capacidad de transformar las ideas en actos. Ello significa adquirir conciencia de la situación a intervenir o resolver, y saber elegir, planificar y gestionar los conocimientos, destrezas o habilidades y actitudes necesarios con criterio propio, con el fin de alcanzar el objetivo previsto. 
Diseño y planificación de competencias específicas en el currículum de enseñanzas profesionales de música: modalidades composición-dirección en la enseñanza superior.

Carlos Eduardo Pascual Pérez

Esta competencia está presente en los ámbitos personal, social, escolar y laboral en los que se desenvuelven las personas, permitiéndoles el desarrollo de sus actividades y el aprovechamiento de nuevas oportunidades. Constituye igualmente el cimiento de otras capacidades y conocimientos más específicos, e incluye la conciencia de los valores éticos relacionados. La adquisición de esta competencia es determinante en la formación de futuros ciudadanos emprendedores, contribuyendo así a la cultura del emprendimiento. En este sentido, su formación debe incluir conocimientos y destrezas relacionados con las oportunidades de carrera y el mundo del trabajo, la educación económica y financiera o el conocimiento de la organización y los procesos empresariales, así como el desarrollo de actitudes que conlleven un cambio de mentalidad que favorezca la iniciativa emprendedora, la capacidad de pensar de forma creativa, de gestionar el riesgo y de manejar la incertidumbre. Estas habilidades resultan muy importantes para favorecer el nacimiento de emprendedores sociales, como los denominados intraemprendedores (emprendedores que trabajan dentro de empresas u organizaciones que no son suyas), así como de futuros empresarios.

Entre los conocimientos que requiere la competencia sentido de iniciativa y espíritu emprendedor se incluye la capacidad de reconocer las oportunidades existentes para las actividades personales, profesionales y comerciales. También incluye aspectos de mayor amplitud que proporcionan el contexto en el que las personas viven y trabajan, tales como la comprensión de las líneas generales que rigen el funcionamiento de las sociedades y las organizaciones sindicales y empresariales, así como las económicas y financieras; la organización y los procesos empresariales; el diseño y la implementación de un plan (la gestión de recursos humanos y/o financieros); así como la postura ética de las organizaciones y el conocimiento de cómo estas pueden ser un impulso positivo, por ejemplo, mediante el comercio justo y las empresas sociales.

Asimismo, esta competencia requiere de las siguientes destrezas o habilidades esenciales: capacidad de análisis; capacidades de planificación, organización, gestión y toma de decisiones; capacidad de adaptación al cambio y resolución de problemas; comunicación, presentación, representación y negociación efectivas; habilidad para trabajar, tanto individualmente como dentro de un equipo; participación, capacidad de liderazgo y delegación; pensamiento crítico y sentido de la responsabilidad; autoconfianza, evaluación y auto-evaluación, ya que es esencial determinar los puntos fuertes y débiles de uno mismo y de un proyecto, así como evaluar y asumir riesgos cuando esté justificado (manejo de la incertidumbre y asunción y gestión del riesgo).

Finalmente, requiere el desarrollo de actitudes y valores como: la predisposición a actuar de una forma creadora e imaginativa; el autoconocimiento y la autoestima; la autonomía o independencia, el interés y esfuerzo y el espíritu emprendedor. Se caracteriza por la iniciativa, la pro-actividad y la innovación, tanto en la vida privada y social como en la profesional. También está relacionada con la motivación y la determinación a la hora de cumplir los objetivos, ya sean personales o establecidos en común con otros, incluido el ámbito laboral. Así 
Diseño y planificación de competencias específicas en el currículum de enseñanzas profesionales de música: modalidades composición-dirección en la enseñanza superior.

Carlos Eduardo Pascual Pérez

pues, para el adecuado desarrollo de la competencia sentido de la iniciativa y espíritu emprendedor resulta necesario abordar:

- La capacidad creadora y de innovación: creatividad e imaginación; autoconocimiento y autoestima; autonomía e independencia; interés y esfuerzo; espíritu emprendedor; iniciativa e innovación.

- La capacidad pro-activa para gestionar proyectos: capacidad de análisis; planificación, organización, gestión y toma de decisiones; resolución de problemas; habilidad para trabajar tanto individualmente como de manera colaborativa dentro de un equipo; sentido de la responsabilidad; evaluación y auto-evaluación.

- La capacidad de asunción y gestión de riesgos y manejo de la incertidumbre: comprensión y asunción de riesgos; capacidad para gestionar el riesgo y manejar la incertidumbre.

- Las cualidades de liderazgo y trabajo individual y en equipo: capacidad de liderazgo y delegación; capacidad para trabajar individualmente y en equipo; capacidad de representación y negociación.

- Sentido crítico y de la responsabilidad: sentido y pensamiento crítico; sentido de la responsabilidad.

\section{Conciencia y expresiones culturales.}

La competencia en conciencia y expresión cultural implica conocer, comprender, apreciar y valorar con espíritu crítico, con una actitud abierta y respetuosa, las diferentes manifestaciones culturales y artísticas, utilizarlas como fuente de enriquecimiento y disfrute personal y considerarlas como parte de la riqueza y patrimonio de los pueblos.

Esta competencia incorpora también un componente expresivo referido a la propia capacidad estética y creadora y al dominio de aquellas capacidades relacionadas con los diferentes códigos artísticos y culturales, para poder utilizarlas como medio de comunicación y expresión personal. Implica igualmente manifestar interés por la participación en la vida cultural y por contribuir a la conservación del patrimonio cultural y artístico, tanto de la propia comunidad como de otras comunidades.

Así pues, la competencia para la conciencia y expresión cultural requiere de conocimientos que permitan acceder a las distintas manifestaciones sobre la herencia cultural (patrimonio cultural, histórico-artístico, literario, filosófico, tecnológico, medioambiental, etcétera) a escala local, nacional y europea y su lugar en el mundo. Comprende la concreción de la cultura en diferentes autores y obras, así como en diferentes géneros y estilos, tanto de las bellas artes (música, pintura, escultura, arquitectura, cine, literatura, fotografía, teatro y danza) como de otras manifestaciones artístico-culturales de la vida cotidiana (vivienda, vestido, gastronomía, artes aplicadas, folclore, fiestas....). Incorpora asimismo el conocimiento básico de las principales técnicas, recursos y convenciones de los diferentes lenguajes artísticos y la identificación de las 
Diseño y planificación de competencias específicas en el currículum de enseñanzas profesionales de música: modalidades composición-dirección en la enseñanza superior.

relaciones existentes entre esas manifestaciones y la sociedad, lo cual supone también tener conciencia de la evolución del pensamiento, las corrientes estéticas, las modas y los gustos, así como de la importancia representativa, expresiva y comunicativa de los factores estéticos en la vida cotidiana.

Dichos conocimientos son necesarios para poner en funcionamiento destrezas como la aplicación de diferentes habilidades de pensamiento, perceptivas, comunicativas, de sensibilidad y sentido estético para poder comprenderlas, valorarlas, emocionarse y disfrutarlas. La expresión cultural y artística exige también desarrollar la iniciativa, la imaginación y la creatividad expresada a través de códigos artísticos, así como la capacidad de emplear distintos materiales y técnicas en el diseño de proyectos.

Además, en la medida en que las actividades culturales y artísticas suponen con frecuencia un trabajo colectivo, es preciso disponer de habilidades de cooperación y tener conciencia de la importancia de apoyar y apreciar las contribuciones ajenas.

El desarrollo de esta competencia supone actitudes y valores personales de interés, reconocimiento y respeto por las diferentes manifestaciones artísticas y culturales, y por la conservación del patrimonio. Exige asimismo valorar la libertad de expresión, el derecho a la diversidad cultural, el diálogo entre culturas y sociedades y la realización de experiencias artísticas compartidas. A su vez, conlleva un interés por participar en la vida cultural y, por tanto, por comunicar y compartir conocimientos, emociones y sentimientos a partir de expresiones artísticas. Así pues, para el adecuado desarrollo de la competencia para la conciencia y expresión cultural resulta necesario abordar:

- El conocimiento, estudio y comprensión tanto de los distintos estilos y géneros artísticos como de las principales obras y producciones del patrimonio cultural y artístico en distintos periodos históricos, sus características y sus relaciones con la sociedad en la que se crean, así como las características de las obras de arte producidas, todo ello mediante el contacto con las obras de arte. Está relacionada, igualmente, con la creación de la identidad cultural como ciudadano de un país o miembro de un grupo.

- El aprendizaje de las técnicas y recursos de los diferentes lenguajes artísticos y formas de expresión cultural, así como de la integración de distintos lenguajes.

- El desarrollo de la capacidad e intención de expresarse y comunicar ideas, experiencias y emociones propias, partiendo de la identificación del potencial artístico personal (aptitud/talento). Se refiere también a la capacidad de percibir, comprender y enriquecerse con las producciones del mundo del arte y de la cultura.

- La potenciación de la iniciativa, la creatividad y la imaginación propias de cada individuo de cara a la expresión de las propias ideas y sentimientos. Es decir, la capacidad de imaginar y realizar producciones que supongan recreación, innovación y transformación. Implica el fomento de habilidades que permitan reelaborar ideas y sentimientos propios y ajenos y exige desarrollar el autoconocimiento y la autoestima, así como la capacidad de resolución de problemas y asunción de riesgos. 
Diseño y planificación de competencias específicas en el currículum de enseñanzas profesionales de música: modalidades composición-dirección en la enseñanza superior.

Carlos Eduardo Pascual Pérez

- El interés, aprecio, respeto, disfrute y valoración crítica de las obras artísticas y culturales que se producen en la sociedad, con un espíritu abierto, positivo y solidario.

- La promoción de la participación en la vida y la actividad cultural de la sociedad en que se vive, a lo largo de toda la vida. Esto lleva implícitos comportamientos que favorecen la convivencia social.

- El desarrollo de la capacidad de esfuerzo, constancia y disciplina como requisitos necesarios para la creación de cualquier producción artística de calidad, así como habilidades de cooperación que permitan la realización de trabajos colectivos.

\section{LAS COMPETENCIAS CLAVE Y LOS OBJETIVOS}

1. Las competencias clave deberán estar estrechamente vinculadas a los objetivos definidos para la Enseñanzas Elementales y Profesionales de Música

2. La relación de las competencias clave con los objetivos de las distintas asignaturas del currículo hace necesario diseñar estrategias para promover y evaluar las competencias desde las etapas educativas iniciales e intermedias hasta su posterior consolidación en etapas superiores, que llevarán a los alumnos y alumnas a desarrollar actitudes y valores, así como un conocimiento de base conceptual y un uso de técnicas y estrategias que favorecerán su incorporación a la vida adulta y que servirán de cimiento para su aprendizaje a lo largo de su vida.

3. La adquisición eficaz de las competencias clave por parte del alumnado y su contribución al logro de los objetivos de las diferentes asignaturas, desde un carácter interdisciplinar y transversal, requiere del diseño de actividades de aprendizaje integradas que permitan avanzar hacia los resultados de aprendizaje de más de una competencia al mismo tiempo.

\section{LAS COMPETENCIAS CLAVE EN EL CURRÍCULO}

1. Las competencias clave deben estar integradas en las áreas o materias de las propuestas curriculares, y en ellas definirse, explicitarse y desarrollarse suficientemente los resultados de aprendizaje que los alumnos y alumnas deben conseguir.

2. Las competencias deben desarrollarse en los ámbitos de la educación formal, no formal e informal a lo largo de la Educación Primaria, la Educación Secundaria Obligatoria y el Bachillerato, y en la educación permanente a lo largo de toda la vida.

3. Todas las áreas o materias del currículo deben participar, desde su ámbito correspondiente, en el desarrollo de las distintas competencias del alumnado.

4. La selección de los contenidos y las metodologías debe asegurar el desarrollo de las competencias clave a lo largo de la vida académica.

5. Los criterios de evaluación deben servir de referencia para valorar lo que el alumnado sabe y sabe hacer en cada área o materia. Estos criterios de evaluación se desglosan en estándares de aprendizaje evaluables. Para valorar el desarrollo competencial del alumnado, serán estos 
Diseño y planificación de competencias específicas en el currículum de enseñanzas profesionales de música: modalidades composición-dirección en la enseñanza superior.

Carlos Eduardo Pascual Pérez

estándares de aprendizaje evaluables, como elementos de mayor concreción, observables y medibles, los que, al ponerse en relación con las competencias clave, permitirán graduar el rendimiento o desempeño alcanzado en cada una de ellas.

6. El conjunto de estándares de aprendizaje evaluables de un área o materia determinada dará lugar a su perfil de área o materia. Dado que los estándares de aprendizaje evaluables se ponen en relación con las competencias, este perfil permitirá identificar aquellas competencias que se desarrollan a través de esa área o materia.

7. Todas las áreas y materias deben contribuir al desarrollo competencial. El conjunto de estándares de aprendizaje evaluables de las diferentes áreas o materias que se relacionan con una misma competencia da lugar al perfil de esa competencia (perfil de competencia). La elaboración de este perfil facilitará la evaluación competencial del alumnado.

\section{ESTRATEGIAS METODOLÓGICAS PARA EL TRABAJO POR COMPETENCIAS}

Todo proceso de enseñanza-aprendizaje debe partir de una planificación rigurosa de lo que se pretende conseguir, teniendo claro cuáles son los objetivos o metas, qué recursos son necesarios, qué métodos didácticos son los más adecuados y cómo se evalúa el aprendizaje y se retroalimenta el proceso. Los métodos didácticos han de elegirse en función de lo que se sabe que es óptimo para alcanzar las metas propuestas y en función de los condicionantes en los que tiene lugar la enseñanza.

La naturaleza de la materia, las condiciones socioculturales, la disponibilidad de recursos y las características de los alumnos y alumnas condicionan el proceso de enseñanza-aprendizaje, por lo que será necesario que el método seguido por el profesor se ajuste a estos condicionantes con el fin de propiciar un aprendizaje competencial en el alumnado.

Los métodos deben partir de la perspectiva del docente como orientador, promotor y facilitador del desarrollo competencial en el alumnado; además, deben enfocarse a la realización de tareas o situaciones-problema, planteadas con un objetivo concreto, que el alumnado debe resolver haciendo un uso adecuado de los distintos tipos de conocimientos, destrezas, actitudes y valores; asimismo, deben tener en cuenta la atención a la diversidad y el respeto por los distintos ritmos y estilos de aprendizaje mediante prácticas de trabajo individual y cooperativo.

En el actual proceso de inclusión de las competencias como elemento esencial del currículo, es preciso señalar que cualquiera de las metodologías seleccionadas por los docentes para favorecer el desarrollo competencial de los alumnos y alumnas debe ajustarse al nivel competencial inicial de estos. Además, es necesario secuenciar la enseñanza de tal modo que se parta de aprendizajes más simples para avanzar gradualmente hacia otros más complejos.

Uno de los elementos clave en la enseñanza por competencias es despertar y mantener la motivación hacia el aprendizaje en el alumnado, lo que implica un nuevo planteamiento del papel del alumno, activo y autónomo, consciente de ser el responsable de su aprendizaje. Los 
Diseño y planificación de competencias específicas en el currículum de enseñanzas profesionales de música: modalidades composición-dirección en la enseñanza superior.

métodos docentes deberán favorecer la motivación por aprender en los alumnos y alumnas y, a tal fin, los profesores han de ser capaces de generar en ellos la curiosidad y la necesidad por adquirir los conocimientos, las destrezas y las actitudes y valores presentes en las competencias. Asimismo, con el propósito de mantener la motivación por aprender es necesario que los profesores procuren todo tipo de ayudas para que los estudiantes comprendan lo que aprenden, sepan para qué lo aprenden y sean capaces de usar lo aprendido en distintos contextos dentro y fuera del aula. Para potenciar la motivación por el aprendizaje de competencias se requieren, además, metodologías activas y contextualizadas. Aquellas que faciliten la participación e implicación del alumnado y la adquisición y uso de conocimientos en situaciones reales, serán las que generen aprendizajes más transferibles y duraderos.

Las metodologías activas han de apoyarse en estructuras de aprendizaje cooperativo, de forma que, a través de la resolución conjunta de las tareas, los miembros del grupo conozcan las estrategias utilizadas por sus compañeros y puedan aplicarlas a situaciones similares. Para un proceso de enseñanza-aprendizaje competencial las estrategias interactivas son las más adecuadas, al permitir compartir y construir el conocimiento y dinamizar la sesión de clase mediante el intercambio verbal y colectivo de ideas. Las metodologías que contextualizan el aprendizaje y permiten el aprendizaje por proyectos, los centros de interés, el estudio de casos o el aprendizaje basado en problemas favorecen la participación activa, la experimentación y un aprendizaje funcional que va a facilitar el desarrollo de las competencias, así como la motivación de los alumnos y alumnas al contribuir decisivamente a la transferibilidad de los aprendizajes.

El trabajo por proyectos, especialmente relevante para el aprendizaje por competencias, se basa en la propuesta de un plan de acción con el que se busca conseguir un determinado resultado práctico. Esta metodología pretende ayudar al alumnado a organizar su pensamiento favoreciendo en ellos la reflexión, la crítica, la elaboración de hipótesis y la tarea investigadora a través de un proceso en el que cada uno asume la responsabilidad de su aprendizaje, aplicando sus conocimientos y habilidades a proyectos reales. Se favorece, por tanto, un aprendizaje orientado a la acción en el que se integran varias áreas o materias: los estudiantes ponen en juego un conjunto amplio de conocimientos, habilidades o destrezas y actitudes personales, es decir, los elementos que integran las distintas competencias.

Asimismo, resulta recomendable el uso del portfolio, que aporta información extensa sobre el aprendizaje del alumnado, refuerza la evaluación continua y permite compartir resultados de aprendizaje. El portfolio es una herramienta motivadora para el alumnado que potencia su autonomía y desarrolla su pensamiento crítico y reflexivo. La selección y uso de materiales y recursos didácticos constituye un aspecto esencial de la metodología. El profesorado debe implicarse en la elaboración y diseño de diferentes tipos de materiales, adaptados a los distintos niveles y a los diferentes estilos y ritmos de aprendizaje de los alumnos y alumnas, con el objeto de atender a la diversidad en el aula y personalizar los procesos de construcción de los aprendizajes. Se debe potenciar el uso de una variedad de materiales y recursos, considerando 
Diseño y planificación de competencias específicas en el currículum de enseñanzas profesionales de música: modalidades composición-dirección en la enseñanza superior.

Carlos Eduardo Pascual Pérez

especialmente la integración de las Tecnologías de la Información y la Comunicación en el proceso de enseñanza-aprendizaje que permiten el acceso a recursos virtuales.

Finalmente, es necesaria una adecuada coordinación entre los docentes sobre las estrategias metodológicas y didácticas que se utilicen. Los equipos educativos deben plantearse una reflexión común y compartida sobre la eficacia de las diferentes propuestas metodológicas con criterios comunes y consensuados. Esta coordinación y la existencia de estrategias conexionadas permiten abordar con rigor el tratamiento integrado de las competencias y progresar hacia una construcción colaborativa del conocimiento. Las enseñanzas especializadas de música contribuirán a desarrollar en los alumnos las competencias clave así como los valores cívicos propios del sistema educativo a través de los objetivos establecidos en la programación de la asignatura.

\section{Objetivos y Contenidos}

\section{Objetivos generales de las Enseñanzas Profesionales}

Según establece el Artículo 4 del DECRETO 158/2007, de 21 de septiembre, del Consell, por el que se establece el currículo de las enseñanzas profesionales de música y se regula el acceso a estas enseñanzas, las enseñanzas elementales de música tienen como objetivo contribuir a desarrollar en los alumnos y alumnas capacidades generales y los valores cívicos propios del sistema educativo y, además, las capacidades siguientes:

a) Fomentar la audición de la música y establecer conceptos estéticos propios que permitan fundamentar y desarrollar criterios interpretativos individuales.

b) Desarrollar la sensibilidad artística y el criterio estético como fuente de formación y enriquecimiento personal.

c) Analizar y valorar críticamente las diferentes manifestaciones y estilos musicales.

d) Conocer las aportaciones de la música al desarrollo personal del individuo y al desarrollo colectivo de las sociedades.

e) Participar en actividades de difusión cultural musical que permitan experimentar con la música y disfrutar de la música.

f) Conocer y emplear con precisión el vocabulario específico relativo a los conceptos científicos y artísticos de la música. 
Diseño y planificación de competencias específicas en el currículum de enseñanzas profesionales de música: modalidades composición-dirección en la enseñanza superior.

g) Conocer y valorar el patrimonio musical como parte integrante del patrimonio histórico y cultural de la Humanidad.

h) Conocer y valorar la importancia de la música propia de la Comunidad Valenciana, así como sus características y manifestaciones más importantes.

\section{Contenidos comunes de las Enseñanzas Profesionales}

Del mismo modo, en el Anexo I de dicho DECRETO se establecen los contenidos comunes de la práctica instrumental:

a) Superar con dominio y capacidad crítica los objetivos y contenidos planteados.

b) Conocer los elementos básicos de los lenguajes musicales, sus características, funciones y evoluciones en los diferentes contextos históricos.

c) Utilizar el «oído interno» como base de la afinación, de la audición armónica y de la interpretación musical.

d) Formar una imagen ajustada de las posibilidades y características musicales tanto a nivel individual como en la relación con el grupo, con la disposición necesaria para saber integrarse como un miembro más del mismo o como responsable del conjunto.

e) Compartir vivencias musicales de grupo en el aula y fuera de ella que permitan enriquecer la relación afectiva con la música a través del canto y de participación instrumental en grupo.

f) Utilizar el cuerpo y la mente para adquirir la técnica necesaria y así, concentrarse en la audición e interpretación musical.

g) Interrelacionar y aplicar los conocimientos adquiridos en todas las asignaturas que componen el currículo junto con las vivencias y experiencias propias para conseguir una interpretación artística de calidad.

h) Adquirir y aplicar las destrezas necesarias para resolver las dificultades que surjan en la interpretación de la música.

i) Practicar la improvisación y la transposición como elementos inherentes a la creatividad musical. 
Carlos Eduardo Pascual Pérez

j) Interpretar, individualmente o dentro de la agrupación correspondiente, obas escritas en todos los lenguajes musicales, profundizando en el conocimiento de los diferentes estilos y épocas, así como en los recursos interpretativos de cada uno de ellos.

k) Actuar en público con autocontrol, dominio de la memoria musical y capacidad comunicativa.

I) Adquirir autonomía personal en la comunicación musical.

m) Consolidar hábitos de estudio adecuados y continuados en función de la dificultad de los contenidos de las asignaturas de los diferentes cursos y niveles.

n) Conocer y aplicar las técnicas del instrumento o de la voz de acuerdo con las exigencias de las obras.

\section{Objetivos propios de la especialidad}

Por concreción curricular, la enseñanza de Fundamentos de dirección en el grado profesional tendrá como objetivo contribuir a des arrollar en los alumnos las capacidades siguientes:

1. Conocer los principales elementos de la técnica de dirección y desprender su uso del adecuado análisis musical.

2. Realizar análisis del repertorio propio y afín y llevar a cabo una gestualización efectiva en la dirección.

3. Dirigir pequeñas obras o fragmentos mediante la interpretación real o reproducida con el fin de dotar de fluidez al proceso.

4. Ser capaz de proponer los recursos técnicos a emplear para una efectiva dirección tras el análisis de una partitura.

\section{Contenidos propios de la especialidad}


Diseño y planificación de competencias específicas en el currículum de enseñanzas profesionales de música: modalidades composición-dirección en la enseñanza superior.

Carlos Eduardo Pascual Pérez

Análisis y estudio de repertorio asequible dentro del lenguaje tonal y armónicocontrapuntístico conocido, para la preparación de una dirección efectiva.

Conocimiento básico de los recursos técnicos y gestuales de la dirección.

Práctica de la dirección del repertorio trabajado en un conjunto vocal o instrumental determinado, de reducción pianística o en un sistema de reproducción.

\section{Evaluación}

\section{Criterios generales}

1. Interpretar obras con el suficiente nivel de calidad en correspondencia con los objetivos y su maduración psicoevolutiva.

2. El aspecto anterior supone, además, un hábito de expresión musical da cara al público, actividad que se distribuirá en frecuentes audiciones a lo largo del curso. El carácter diferenciador, en cuanto a la aplicación de los conceptos, viene determinado por las correspondientes obras, piezas y ejercicios del programa de cada curso.

3. Coordinación con el equipo docente para analizar la consecución y profundidad de los objetivos generales del grado.

4. Participar en audiciones del curso a nivel de aula y de centro. Los profesores podrán coordinar y supervisar audiciones trimestrales a nivel de aula, en las cuales participarán todos los alumnos de cada profesor e interpretarán un repertorio común según cada curso propuesto por el profesorado. Las audiciones servirán para evaluar al alumno y el porcentaje de calificación de dichas audiciones será determinado por cada profesor, según el trabajo desarrollado por el alumno en las clases lectivas.

5. El alumno deberá desarrollar una conciencia de grupo y de su propio nivel a partir de las audiciones conjuntas desarrolladas durante el curso, lo cual contribuirá en buen grado a la unificación de niveles.

6. Coordinación con el equipo docente para analizar la consecución y profundidad de los objetivos generales del grado.

7. Analizar los criterios de evaluación, identificación en cada uno las capacidades, los contenidos que incluye y los indicadores de los objetivos de la asignatura. 
Diseño y planificación de competencias específicas en el currículum de enseñanzas profesionales de música: modalidades composición-dirección en la enseñanza superior.

8. La Regularidad en el estudio y la trayectoria en el mismo.

\section{Criterios específicos}

1. Realizar análisis técnicos escritos sobre partitura que acompañen además una revisión de su contexto histórico e interpretativo: con este criterio se evalúa el dominio del alumno en lo referente a la mecánica de los elementos estudiados, así como su capacidad para emplear con sentido musical los procedimientos técnicos.

2. Realizar ejercicios técnicos gestuales: con este criterio se pretende evaluar la capacidad de abstracción del alumno de los contenidos individualizados, como las indicaciones agógicas, dinámicas, de tempo y orquestales.

\section{Procedimientos e instrumentos de evaluación}

La evaluación será continua y establecida según el tipo y grado de aprendizaje que se espera hayan alcanzado los alumnos en un momento determinado, respeto a las capacidades indicadas en los objetivos generales y específicos de la especialidad. También será flexible, teniendo en cuenta el contexto del alumno, es decir, el ciclo educativo en el que se encuentra, así como sus propias características y posibilidades. Además, los instrumentos de evaluación a utilizar serán los siguientes:

1. Evaluación competencial de cada sesión.

2. Fiel seguimiento individual del alumno mediante el "Cuaderno del profesor"

3. Boletines trimestrales informativos

4. Temporalización del repertorio por trimestres

5. Evaluación actitudinal mensual

Por norma general, para el cálculo de la nota media las tareas prácticas se valorarán con un $50 \%$, la evaluación actitudinal con un $20 \%$ y las pruebas trimestrales con un $30 \%$.

\section{Mínimos exigibles}


Diseño y planificación de competencias específicas en el currículum de enseñanzas profesionales de música: modalidades composición-dirección en la enseñanza superior.

Carlos Eduardo Pascual Pérez

- Ser capaz de gestualizar una obra tras su estudio y llevar a cabo su dirección ante un grupo instrumental o vocal o una reproducción mecánica de forma completa.

- Identificar, a través del análisis, los elementos estructurales, armónicos, melódicos y organizativos en una partitura para conjunto vocal o instrumental con objeto de conseguir su clara dirección.

\section{Promoción}

1. Los alumnos promocionarán de curso cuando hayan superado la totalidad de las asignaturas de cada curso o tengan evaluación negativa como máximo en dos asignaturas. En el supuesto de asignaturas pendientes referidas a práctica instrumental o canto, la recuperación deberá realizarse en la clase del curso siguiente si forma parte del mismo.

2. La calificación negativa en tres o más asignaturas de uno o varios cursos impedirá la promoción de un alumno al curso siguiente.

3. Los alumnos que al término del 60 curso tuvieran pendientes de evaluación positiva tres asignaturas o más deberán repetir el curso en su totalidad. Cuando la calificación negativa se produzca en una o dos asignaturas, solo será preceptivo cursar las asignaturas pendiente

\section{Aspectos de la evaluación continua}

Se considerará que un alumno ha perdido el derecho a la evaluación continua cuando acumule ocho o más faltas de asistencia durante todo el curso. Podrá ser evaluado en junio, mediante un equipo de profesores del departamento. Deberá presentar un programa acorde a los mínimos exigibles y acorde con el nivel del curso del cual ha perdido el derecho a la evaluación continua.

Los alumnos y alumnas de enseñanzas profesionales que no superen el curso en el mes de junio podrán recuperar la asignatura mediante la realización de una prueba extraordinaria al finalizar el curso; de acuerdo con el DECRETO 157/2007. El examen extraordinario será diseñado por el profesor que haya impartido la especialidad, teniendo en cuenta los mínimos exigidos en cada curso contemplados en esta programación.

El límite de permanencia en las enseñanzas profesionales de música será de ocho años. El alumno no podrá permanecer más de dos años en el mismo curso, excepto en 60 curso, hasta completar el límite de permanencia. 
Carlos Eduardo Pascual Pérez

\section{Metodología}

\section{Principios metodológicos}

a) Adecuar los contenidos y su secuenciación al momento y situación del desarrollo evolutivo del alumno, de forma que el aprendizaje sea constructivo, progresivo y motivador.

b) Motivar al alumno para el estudio de la música mediante su actividad y participación en el progreso, dándole el protagonismo.

c) Respetar las peculiaridades de los alumnos, individual y colectivamente, facilitando así la convivencia en el seno del grupo y la colaboración, de forma que se eviten las discriminaciones de todo tipo.

d) Utilizar procedimientos y recursos variados que estimulen la capacidad crítica y creativa del alumno mediante la aceptación del dialogo y las argumentaciones razonadas

e) Procurar que la asimilación de los contenidos conceptuales por parte del alumno se completa con la adquisición de contenidos procedimentales y actitudinales que propicien su autonomía en el trabajo tato para el momento presente como para el futuro.

f) Facilitar a los alumnos el conocimiento y empleo del código convencional de expresión a la vez que la corrección y la exactitud en el uso del lenguaje, con el fin de que el aprendizaje y la comunicación sean efectivos.

g) Ejercitar la creatividad del alumno, de modo que adquiera estrategias propias de estudio y de realizaciones musicales con el fin de que pueda superar las dificultades que se les presenten.

\section{Otros aspectos metodológicos}

Se implementarán competencias transversales desarrolladas específicamente para una completa preparación en las pruebas de acceso a enseñanzas superiores en composición y/o dirección. Estas son:

- Aspectos básicos de la técnica de dirección

- Organología, instrumentación y orquestación en el ámbito de la orquesta sinfónica 
Carlos Eduardo Pascual Pérez

\section{Concreción curricular del Curso}

\section{EL ESTUDIO ANALÍTICO DE LA PARTITURA PARA SU DIRECCIÓN}

1. Contextualización histórica y estilística.

2. Lectura y comprensión global de la partitura.

3. Búsqueda y asimilación de referencias externas en formato audiovisual.

\section{LA GESTUALIZACIÓN}

1. Técnica base del gesto en la dirección.

2. Conceptos clave: tempo, agógica y dinámica.

3. El fraseo.

4. La coordinación y ayuda en organizativa en la formación.

III. PRÁCTICA

1. La dinámica del ensayo. Organización previa y adaptativa.

2. Búsqueda de solución a los problemas surgidos en la etapa de preparación.

3. La repentización en la dirección.

3. La interpretación completa (final) de una obra/programa. 
Diseño y planificación de competencias específicas en el currículum de enseñanzas profesionales de música: modalidades composición-dirección en la enseñanza superior.

Carlos Eduardo Pascual Pérez

\section{Anexo VIII}

\section{UNIVERSITAT JAUME I} Diseño y planificación de competencias específicas en el
currículum de enseñanzas profesionales de música:
modalidad Composición-Dirección en la enseñanza superior.

Carlos Eduardo Pascual Pérez (investigador) - José María Peñalver Vilar (director) - Amparo Porta Navarro (tutora)

\section{TEST FINAL 2ㅇ Análisis (6ㅇ Enseñanzas Profesionales)}

EJERCICIO 1: Dado el fragmento a reproducir, coincidente con la sección de exposición de un movimiento de sinfonía orquestal de entre 1750 y 1850, determina los siguientes aspectos. Además, siguiendo el cronómetro que se muestra, indica en cada casilla la marca temporal (minutos y segundos).

Tipo de movimiento $(I, I I, I I I, I V)$ :

Tempo/Tempi:

Estilo/Compositor/Otros:

Plantilla instrumental:

- Cuerdas: SI /NO ¿Orquestal o solistas?

- Maderas: SI / NO ¿Ausencias?:

- Metal: SI /NO ¿Ausencias?:

- Percusión: SI /NO ¿̇lnstrumentos?:

- Otros: SI / NO ¿instrumentos?

INTRODUCCIÓN SI / NO

TEMA A (Mayor/menor)

- Motivo principa:

- Instrumento/Sección del motivo:

PUENTE SI/NO

- Modulación : SI / NO ¿Tipo?

TEMA B (Mayor/menor): ___ Relación tonal con el Tema A:

- Motivo principal

- Instrumento/Sección del motivo:

- Material nuevo (a parte del motívico B): SI / NO

- Material del Tema A: SI / NO

CLOSING THEMES SI/NO

- Material nuevo SI / NO

- Material motívico SI / NO ¿De A o de B?

CODA/CODETA SI / NO

- Material nuevo SI / NO

- Material motívico SI / NO ¿De A o de B? 
Diseño y planificación de competencias específicas en el currículum de enseñanzas profesionales de música: modalidades composición-dirección en la enseñanza superior.

Carlos Eduardo Pascual Pérez

EJERCICIO 2: Para el fragmento orquestal propuesto, responder:

- Época/Estilo/Compositor:

- Tipo de obra y tipo (no) de movimiento si procede:

- ¿Qué presenta/interpreta el clarinete 10 en el compás 19?:

- Define las notas ajenas al acorde que interpretan los violines I y II en el compás 20:

- ¿De dónde proviene el diseño tutti empleado en el compás 35 ?

- Define y justifica la textura entre los compases 44 y 48?:

- ¿Qué acorde y grado se está produciendo en los compases 53-54?:

- ¿Qué está precediendo el compás 56?:

- ¿Cómo definirías el fragmento comprendido entre los compases 131 y 142?:

- Explica y justifica las diferencias tonal y de instrumentación de los fragmentos análogos entre compás $57-70$ y 178-190?:

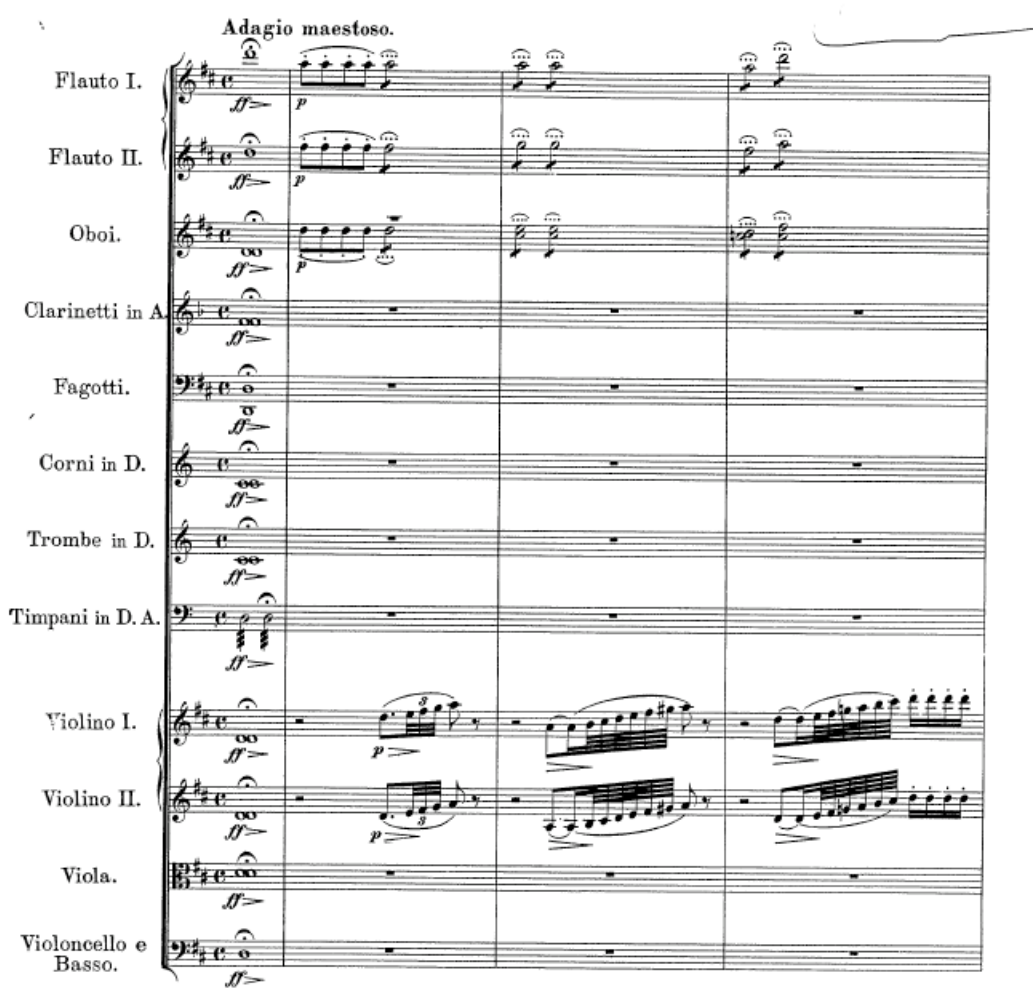




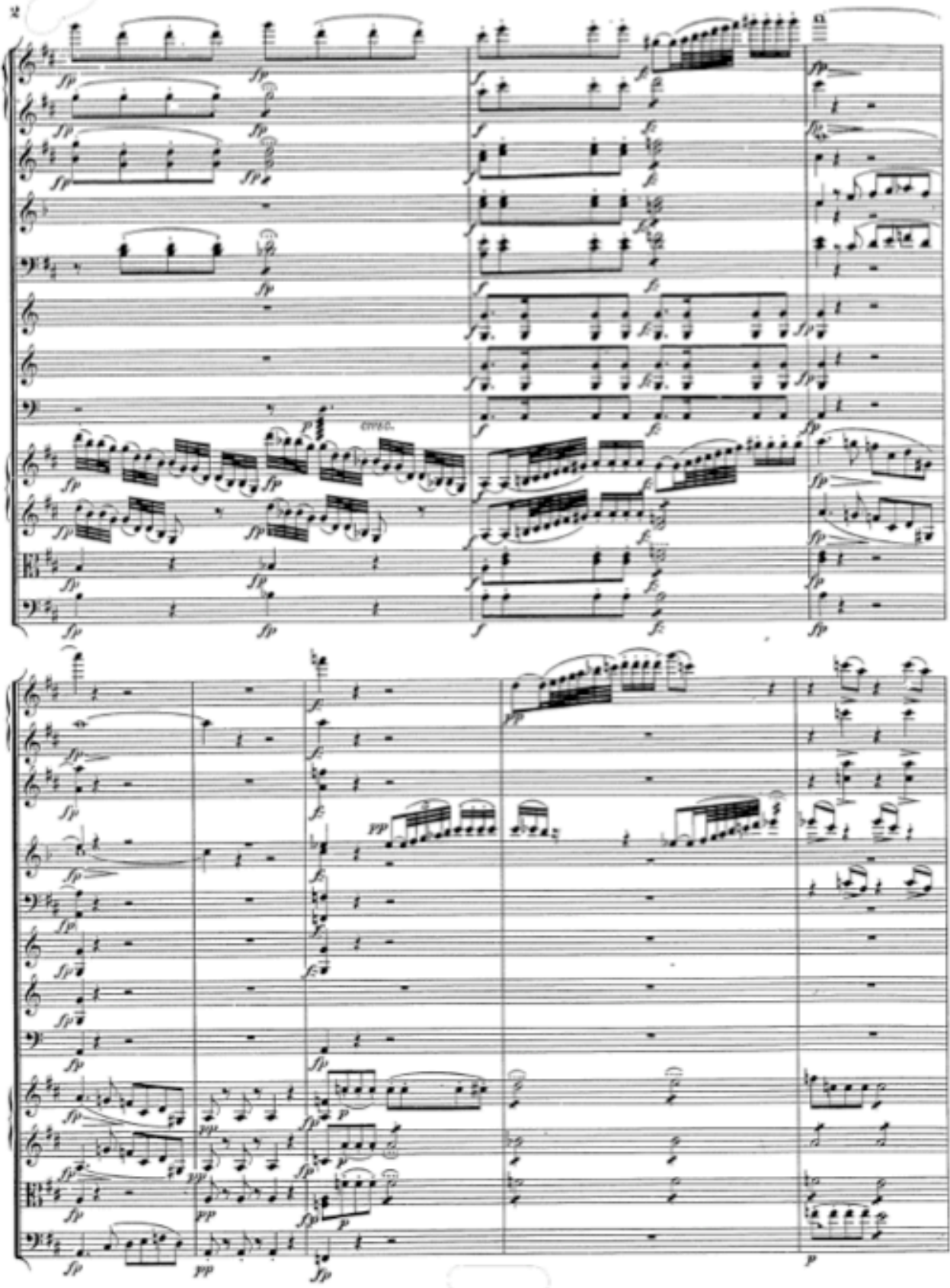



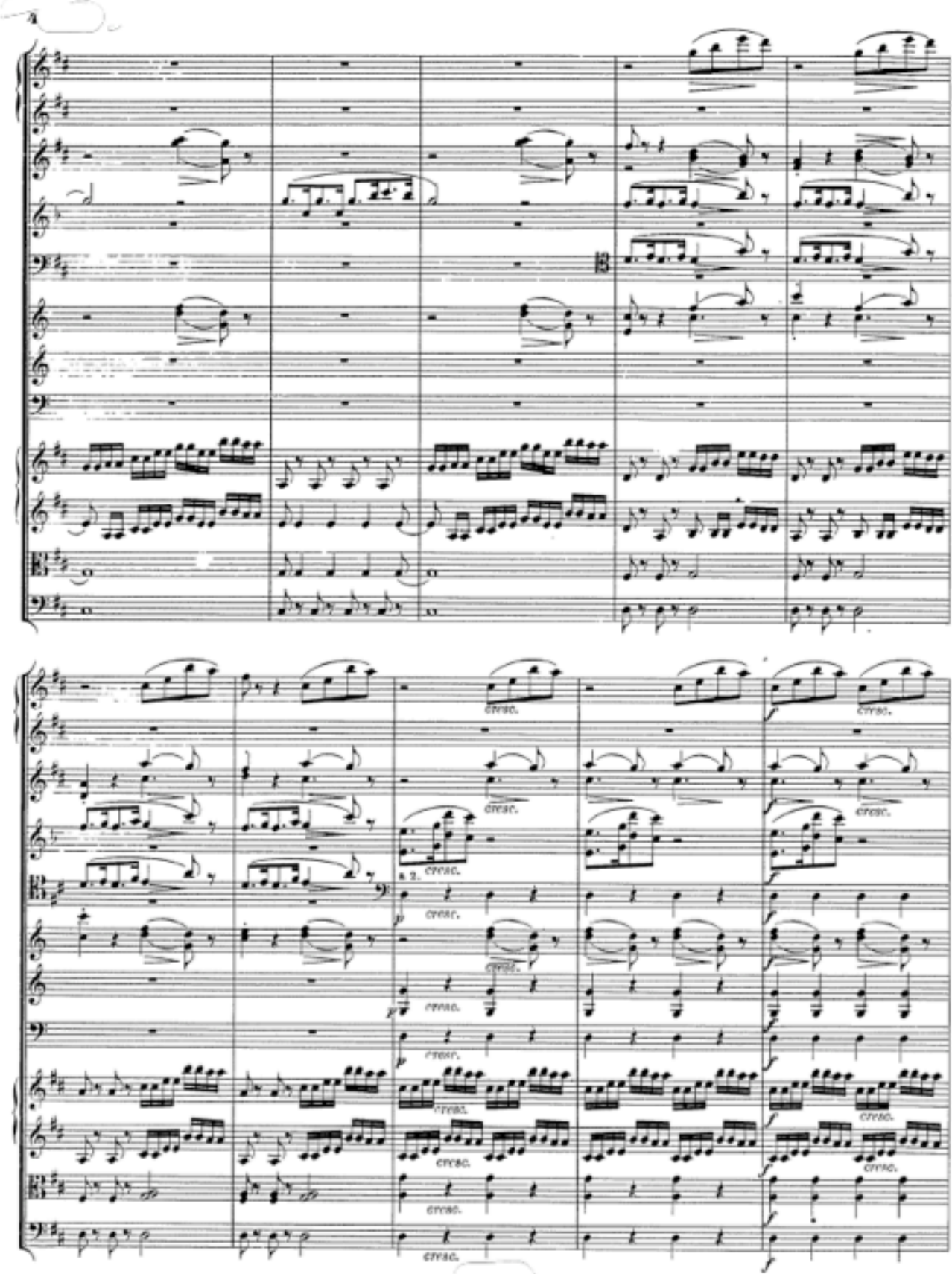

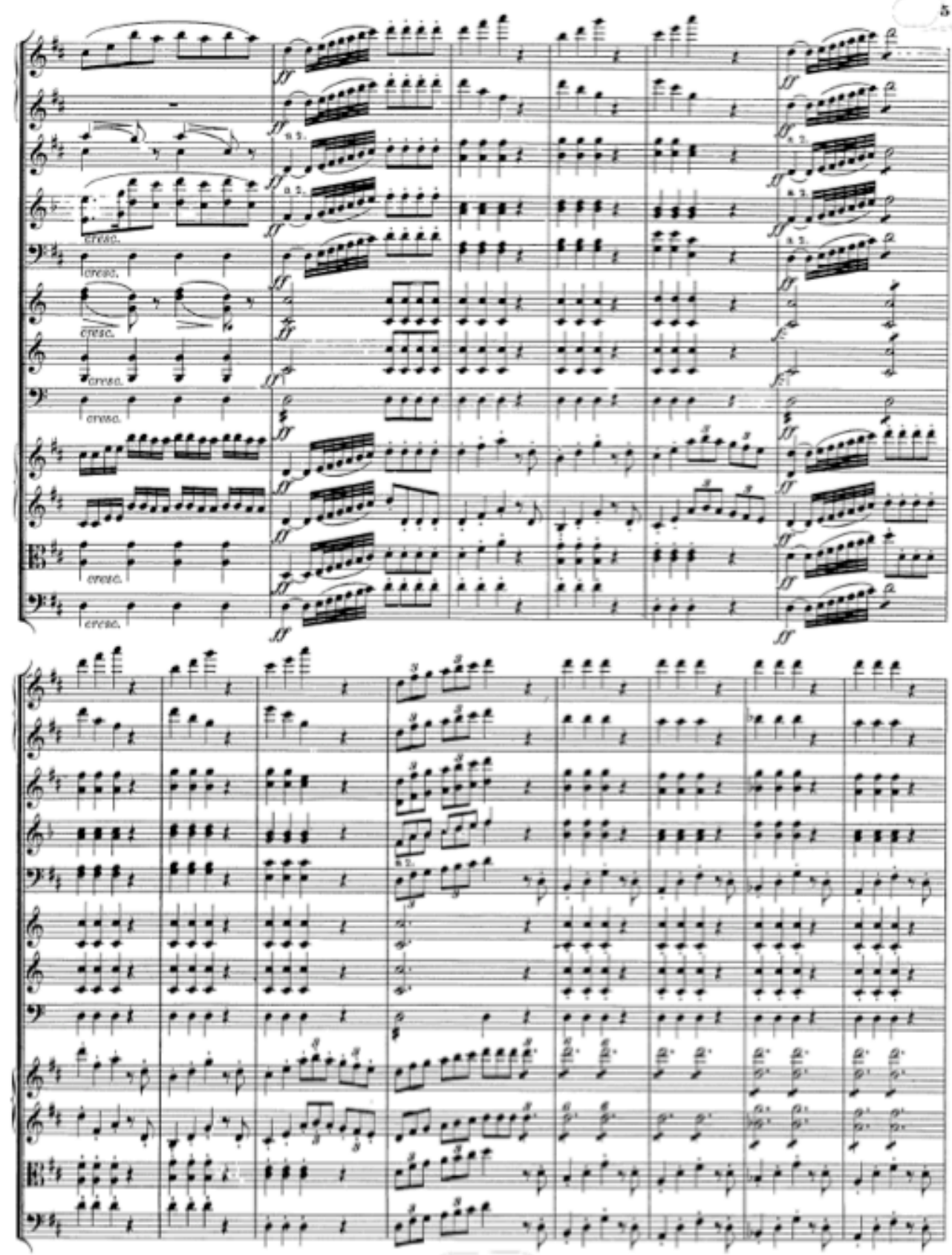

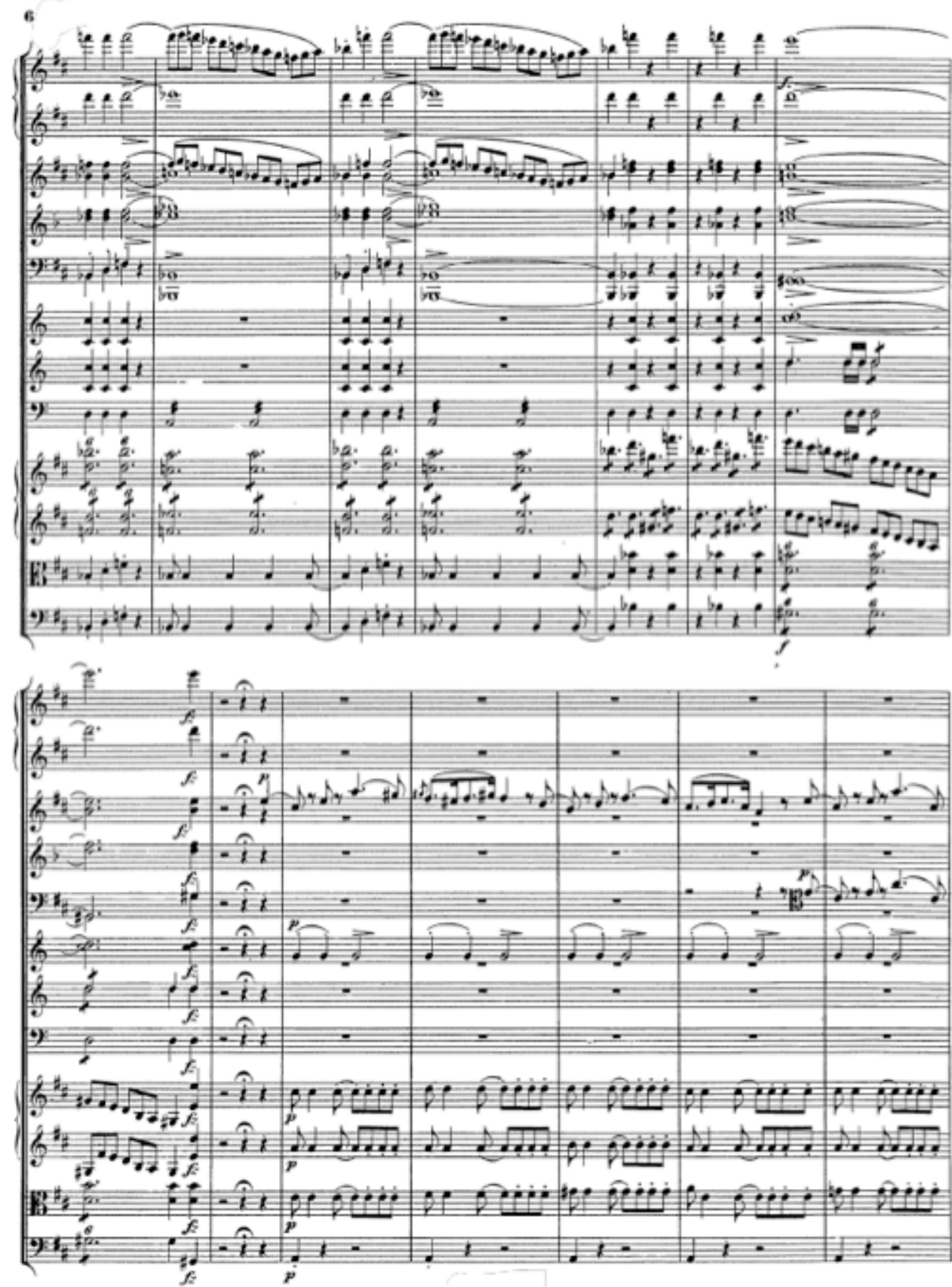

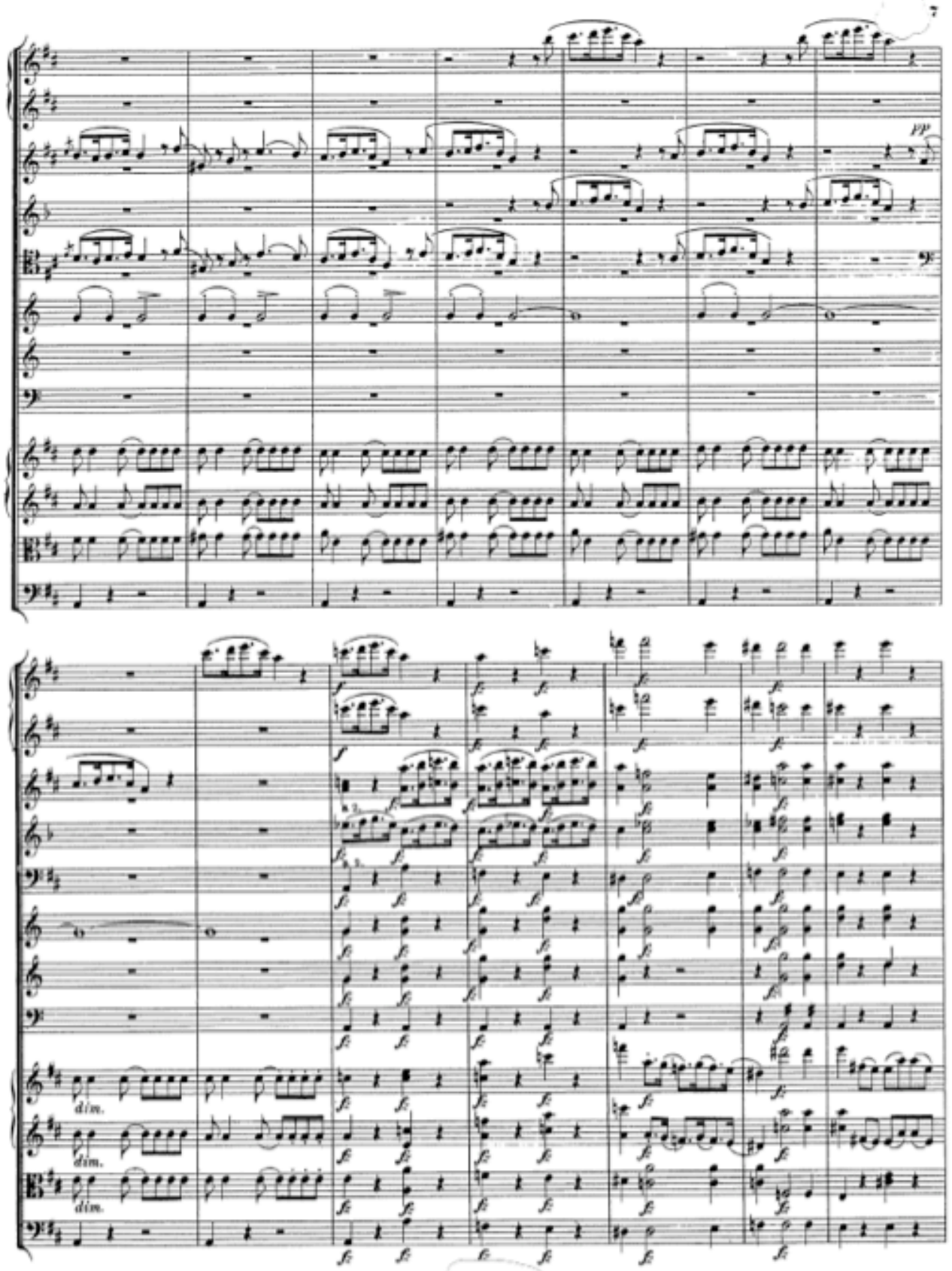
Carlos Eduardo Pascual Pérez

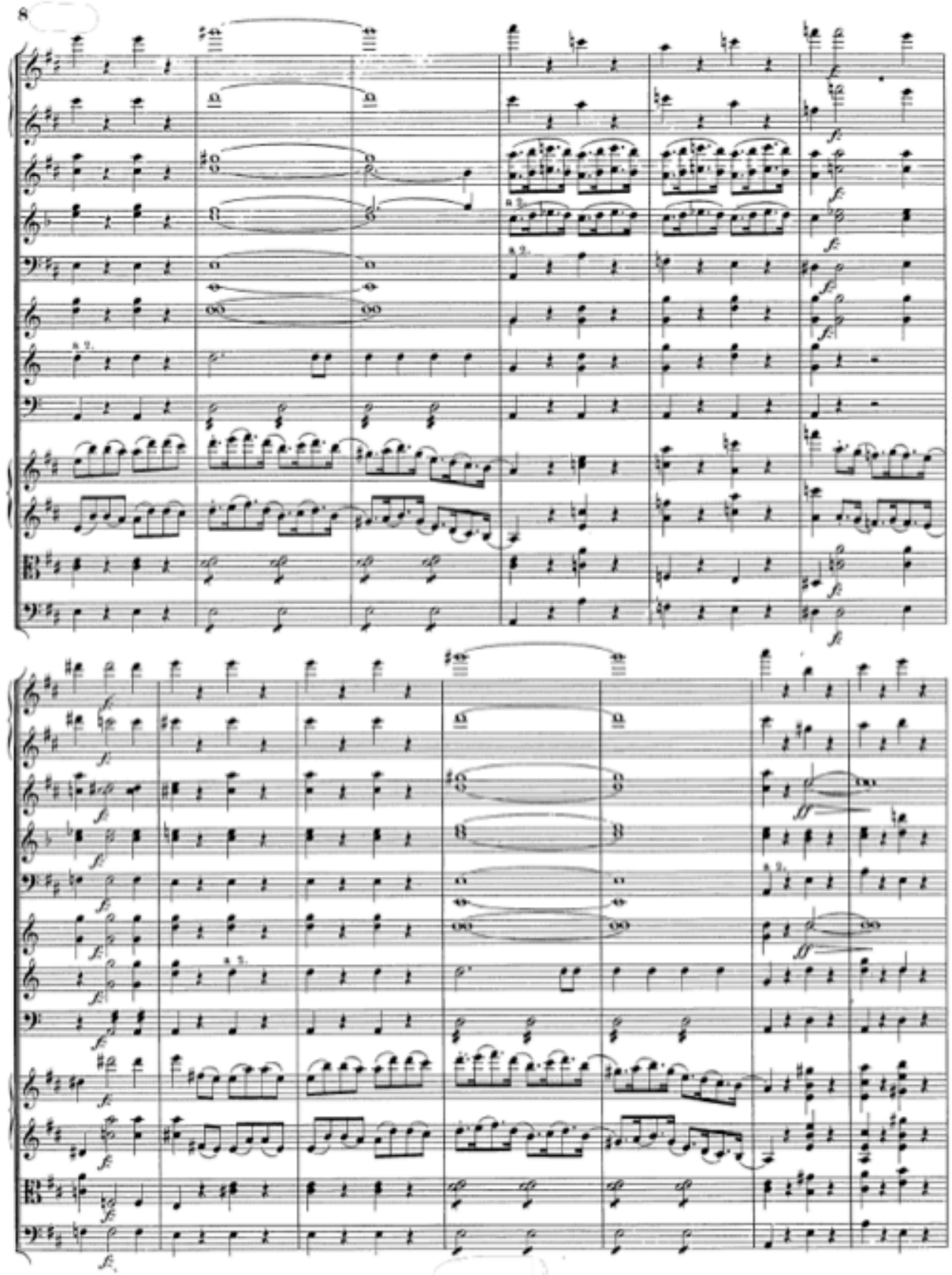


Diseño y planificación de competencias específicas en el currículum de enseñanzas profesionales de música: modalidades composición-dirección en la enseñanza superior.
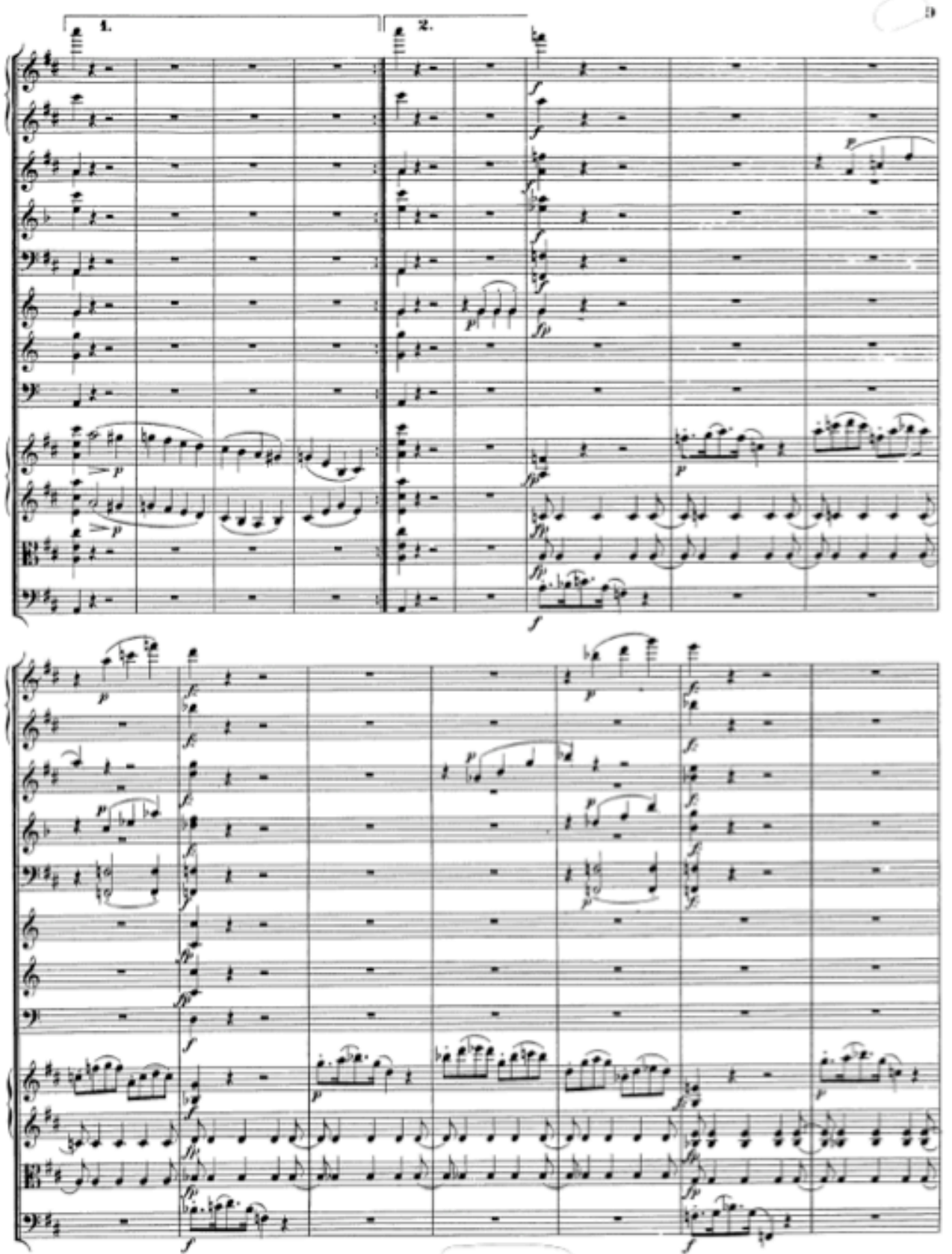


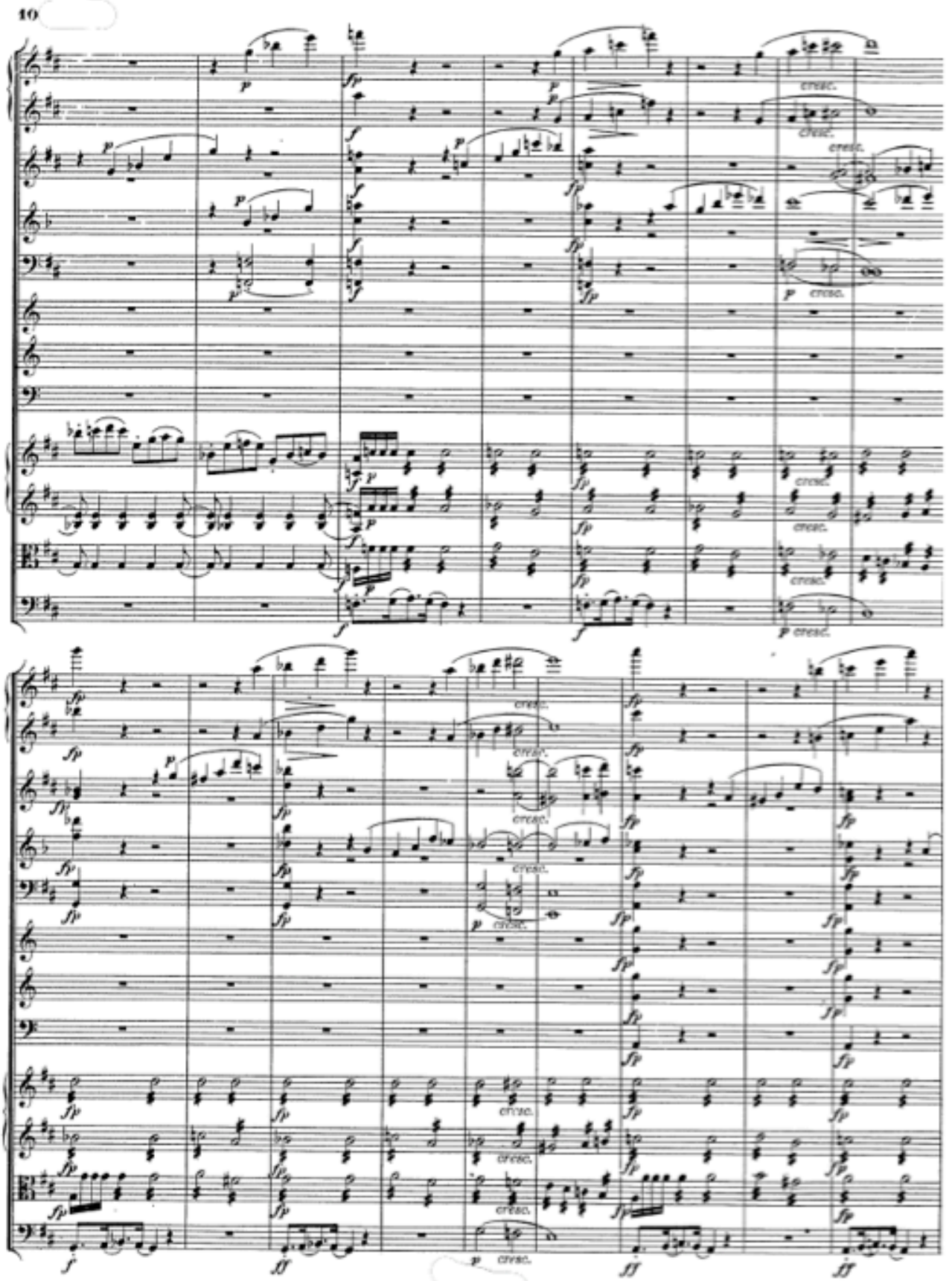


Diseño y planificación de competencias específicas en el currículum de enseñanzas profesionales de música: modalidades composición-dirección en la enseñanza superior.

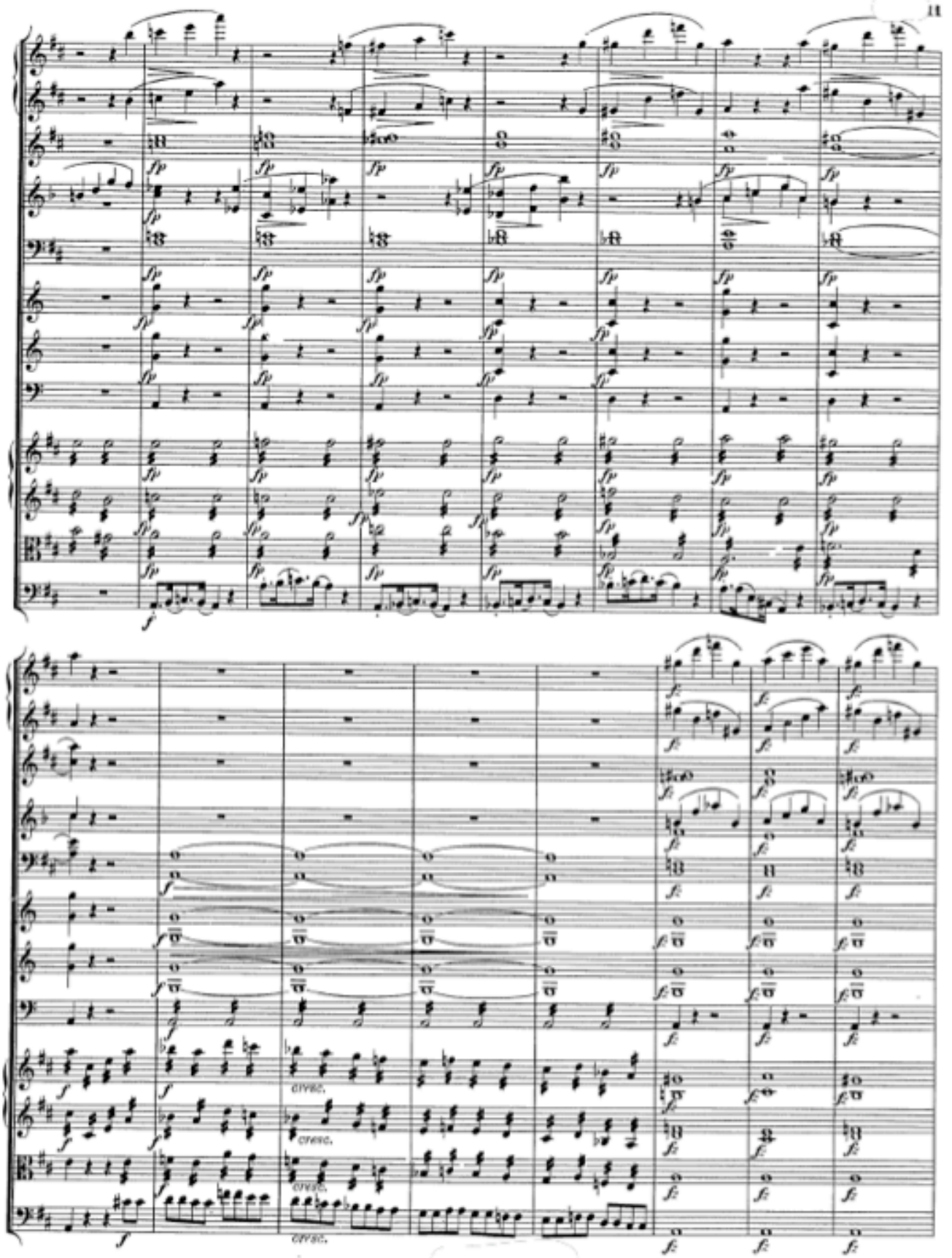


Diseño y planificación de competencias específicas en el currículum de enseñanzas profesionales de música: modalidades composición-dirección en la enseñanza superior.

Carlos Eduardo Pascual Pérez
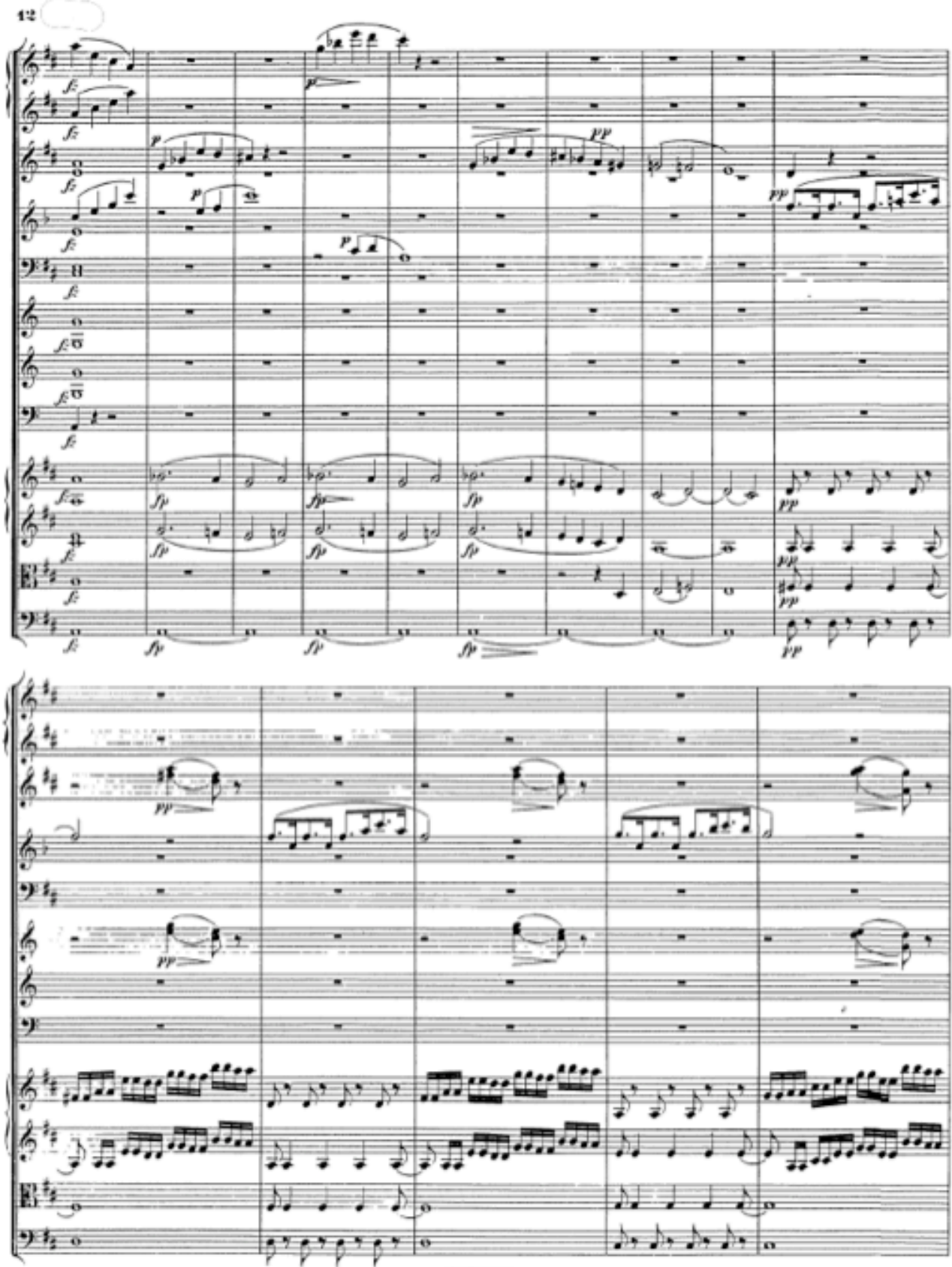

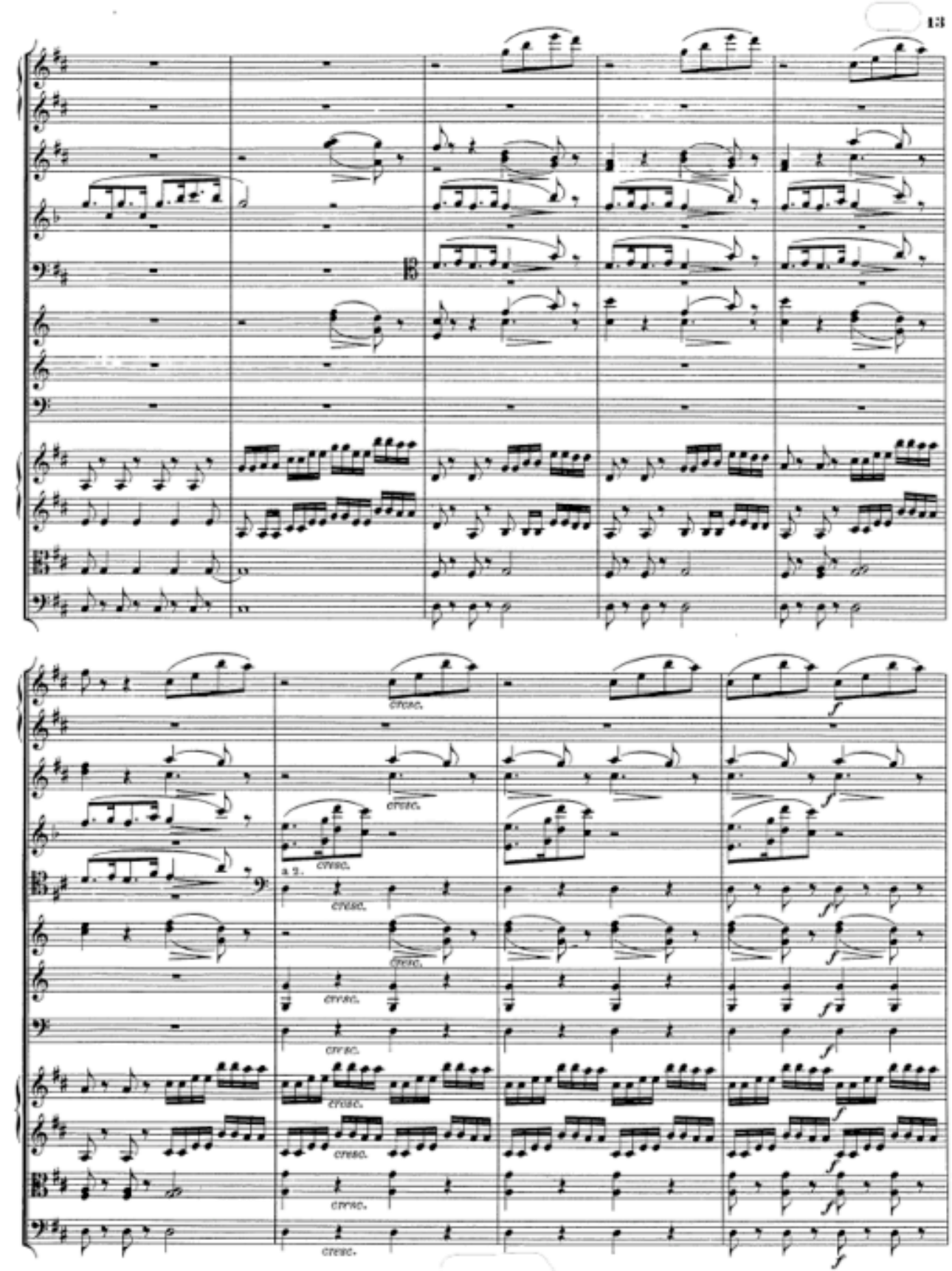

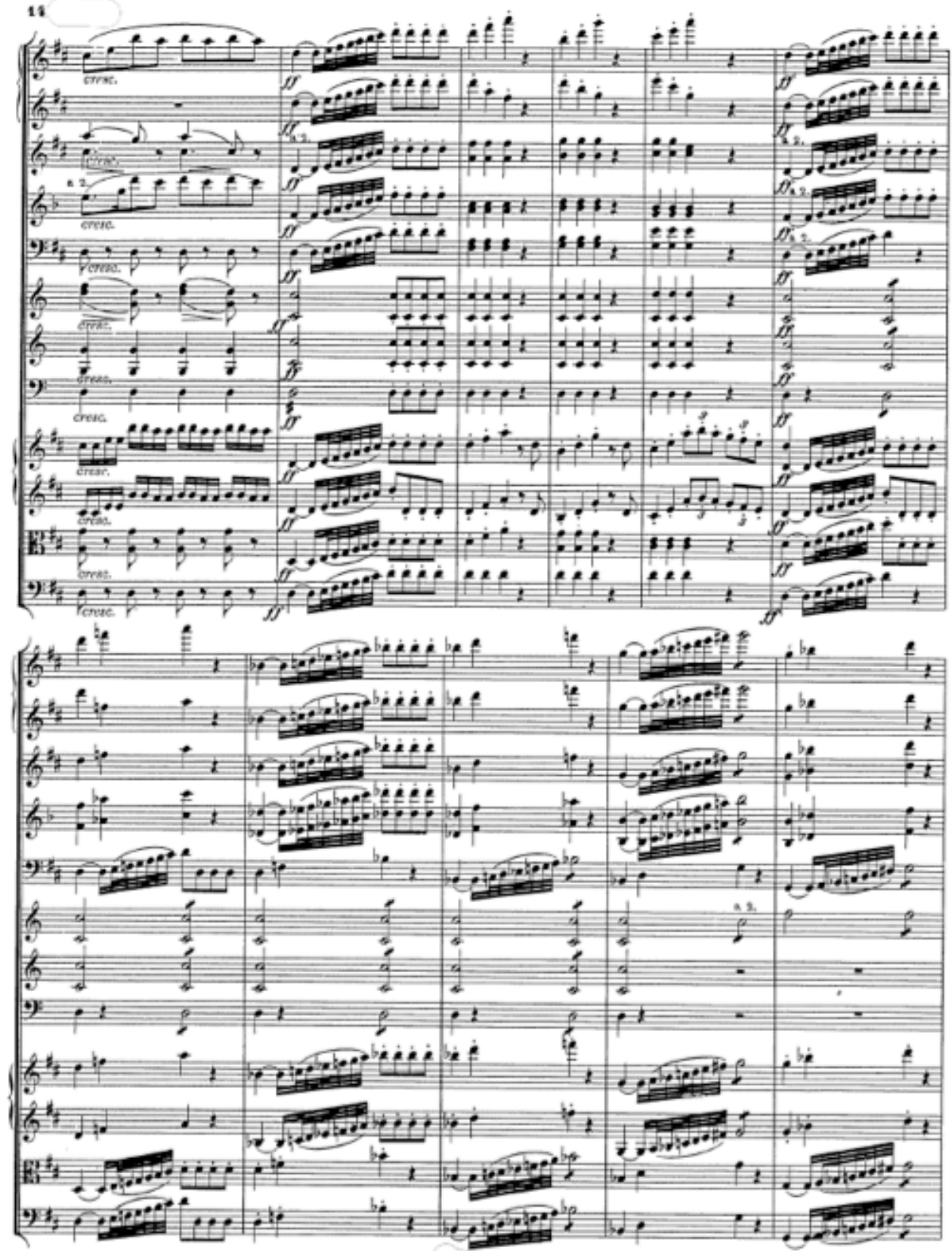

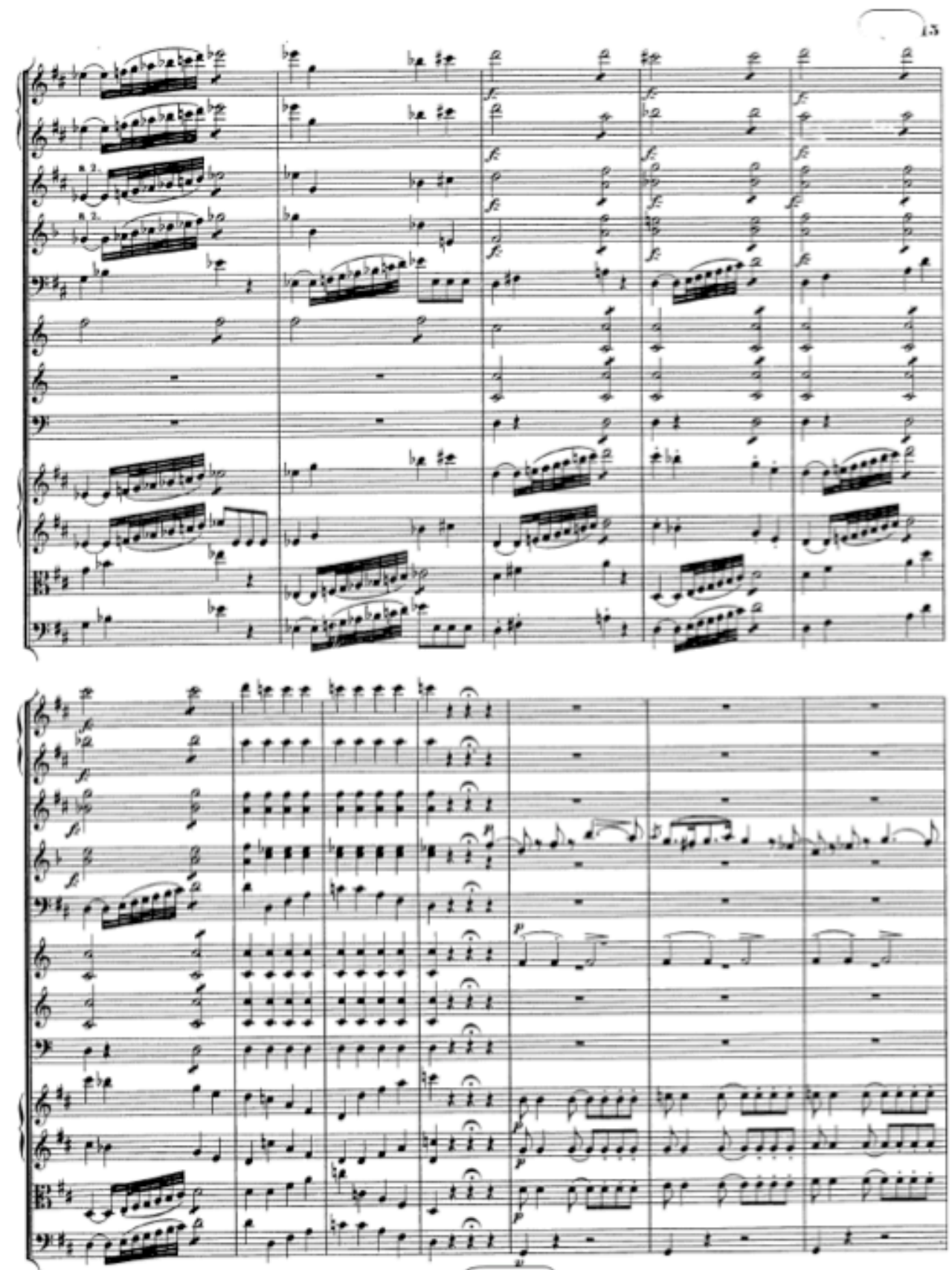

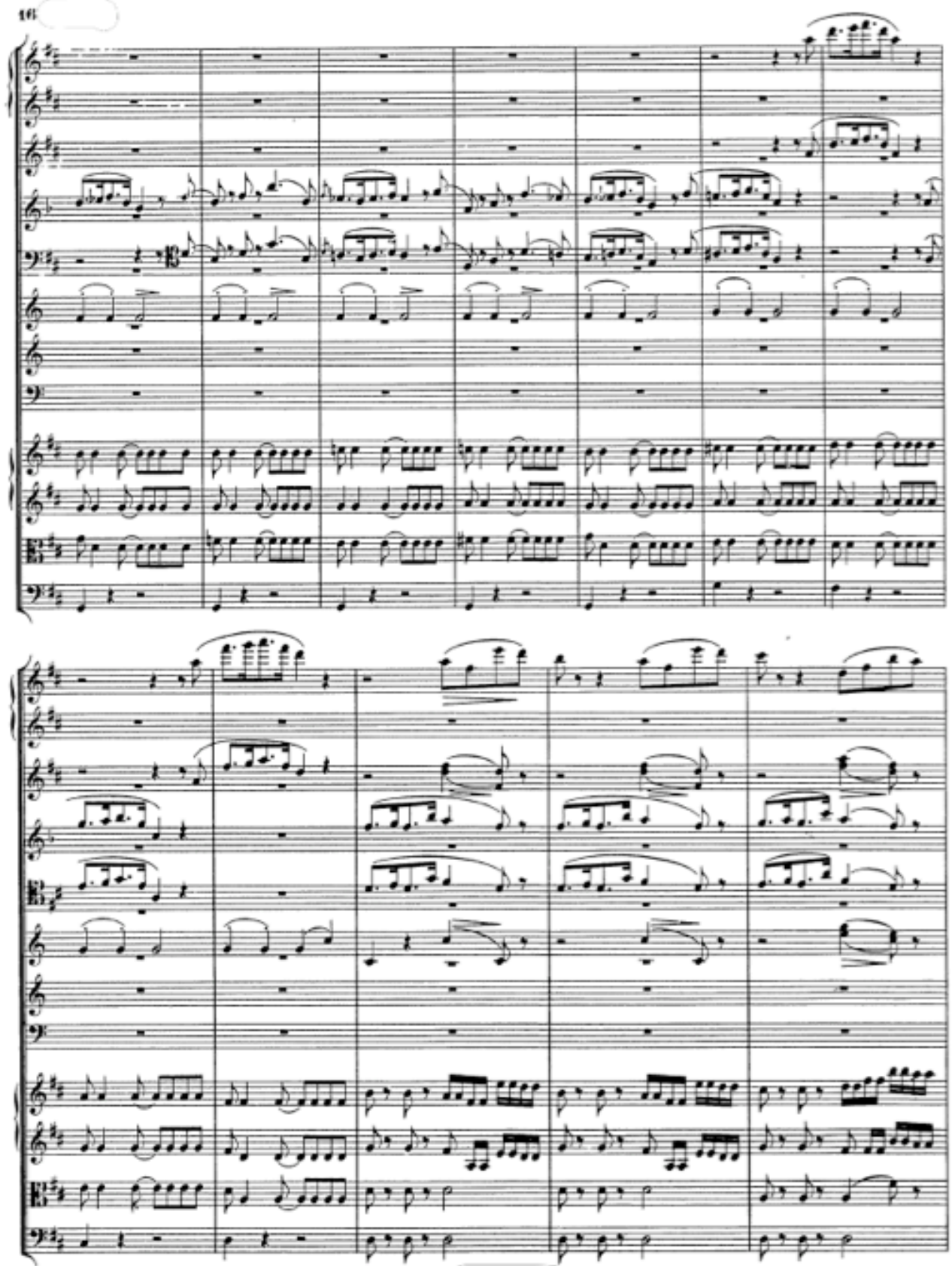

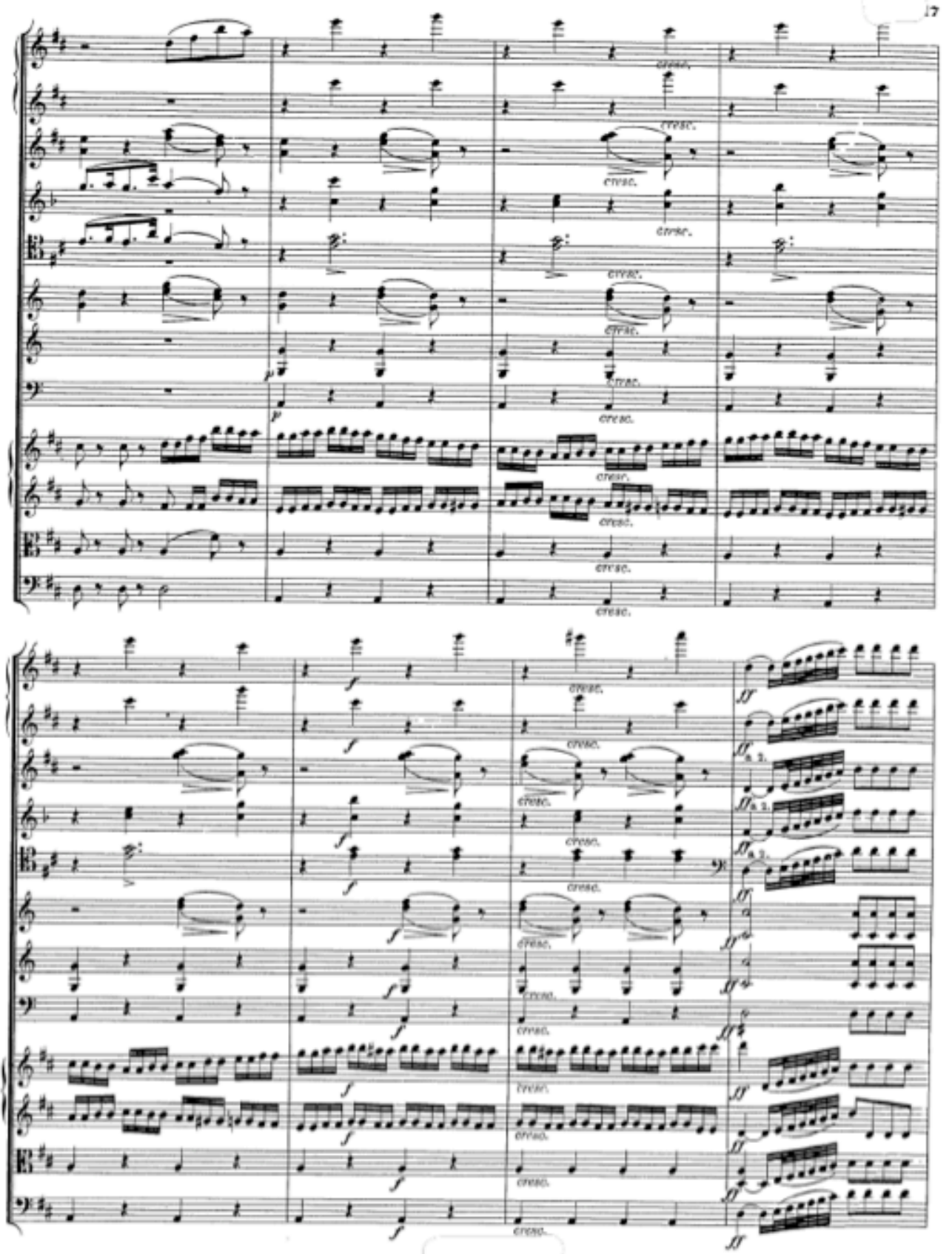

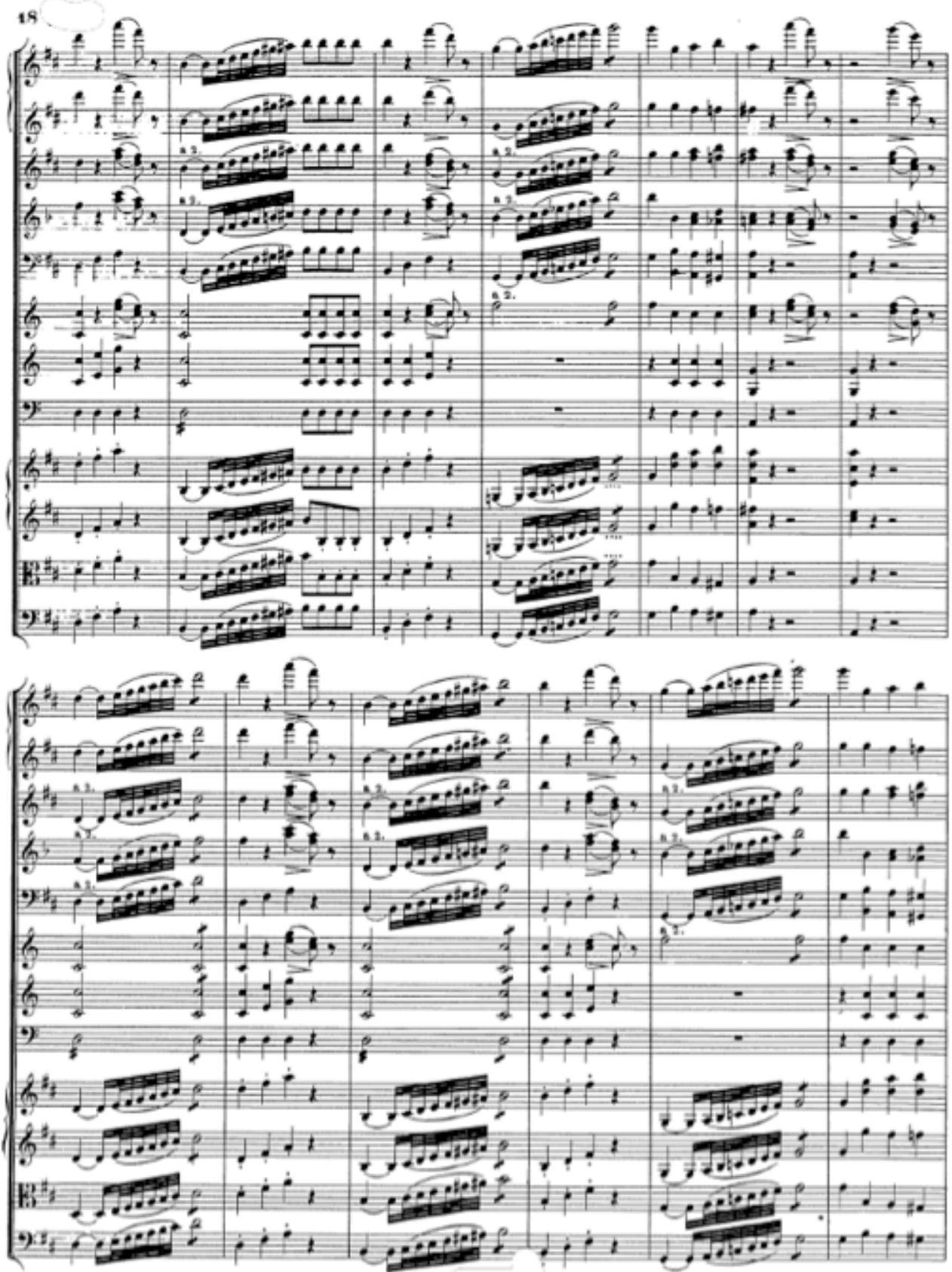


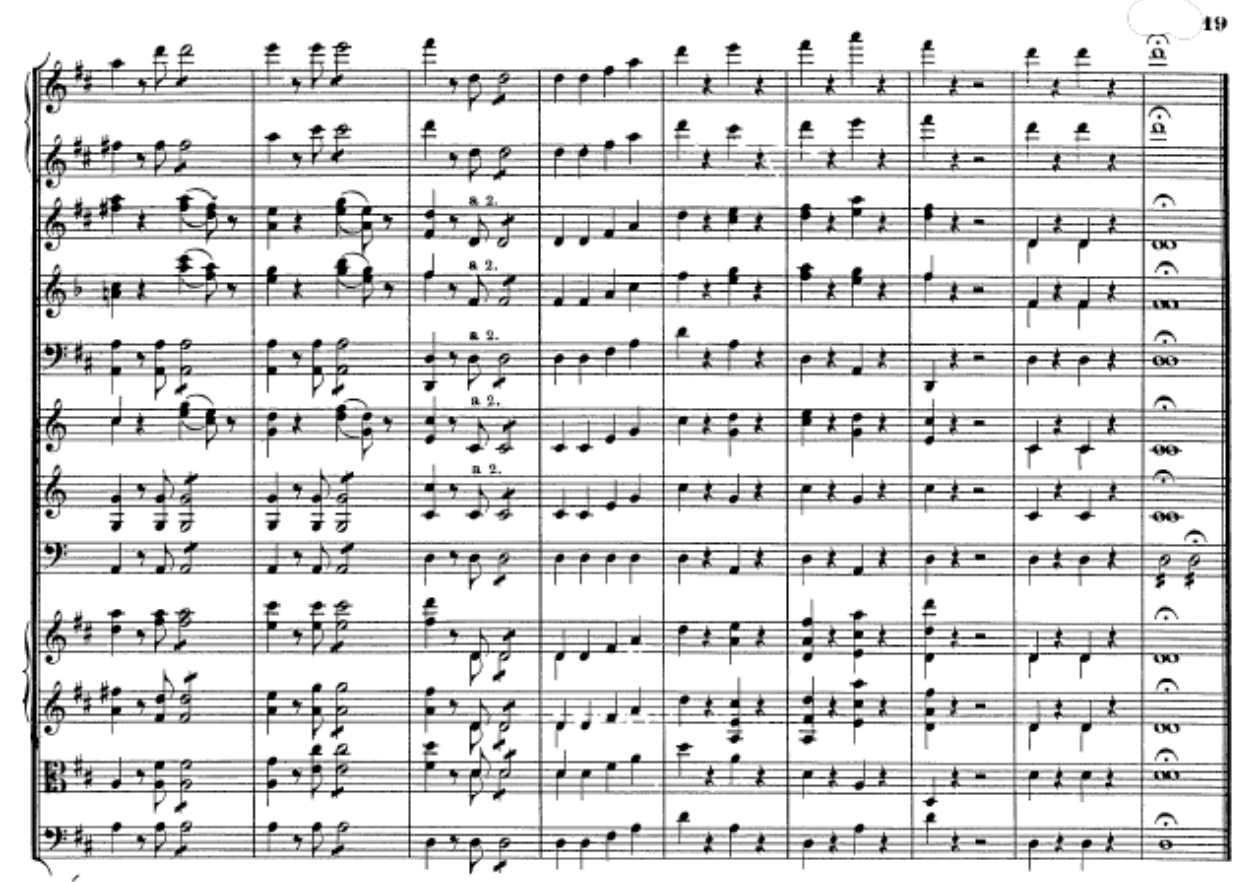


Diseño y planificación de competencias específicas en el currículum de enseñanzas profesionales de música: modalidades composición-dirección en la enseñanza superior.

Carlos Eduardo Pascual Pérez

\section{TEST FINAL Fundamentos de Composición (5 Enseñanzas Profesionales)}

EJERCICIO 1: Dado este fragmento perteneciente a un tercer movimiento de sinfonía clásica (1788), orquestar para la plantilla dada con la máxima corrección en el estilo e instrumentación.

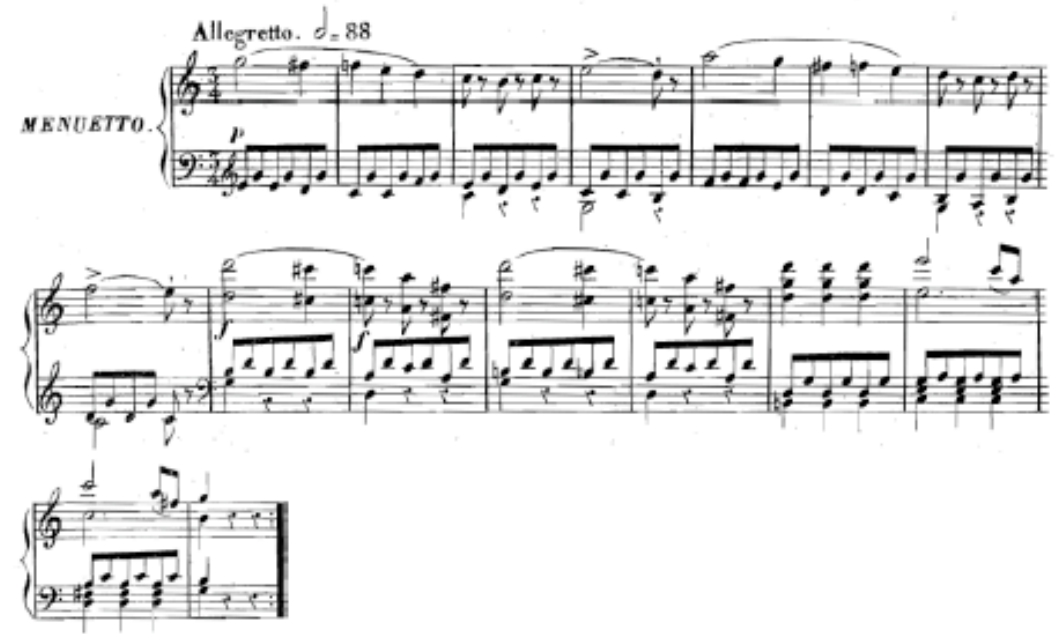

EJERCICIO 2: Dado este antecedente melódico (con dinámica y articulación libres), terminar y armonizar una frase de entre 12 compases, además de orquestar libremente en textura de melodía acompañada para la plantilla propuesta. Recuerda ajustar correctamente los instrumentos transpositores (mediante armadura o alteraciones accidentales).

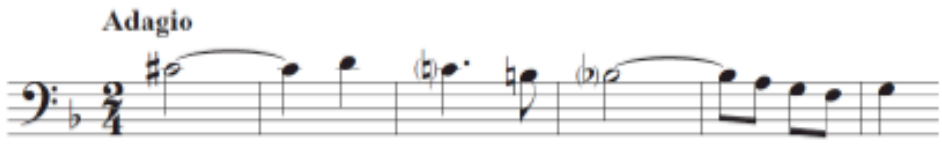


Diseño y planificación de competencias específicas en el currículum de enseñanzas profesionales de música: modalidades composición-dirección en la enseñanza superior.

\section{Carlos Eduardo Pascual Pérez}

EJERCICIO 1 (respuesta):
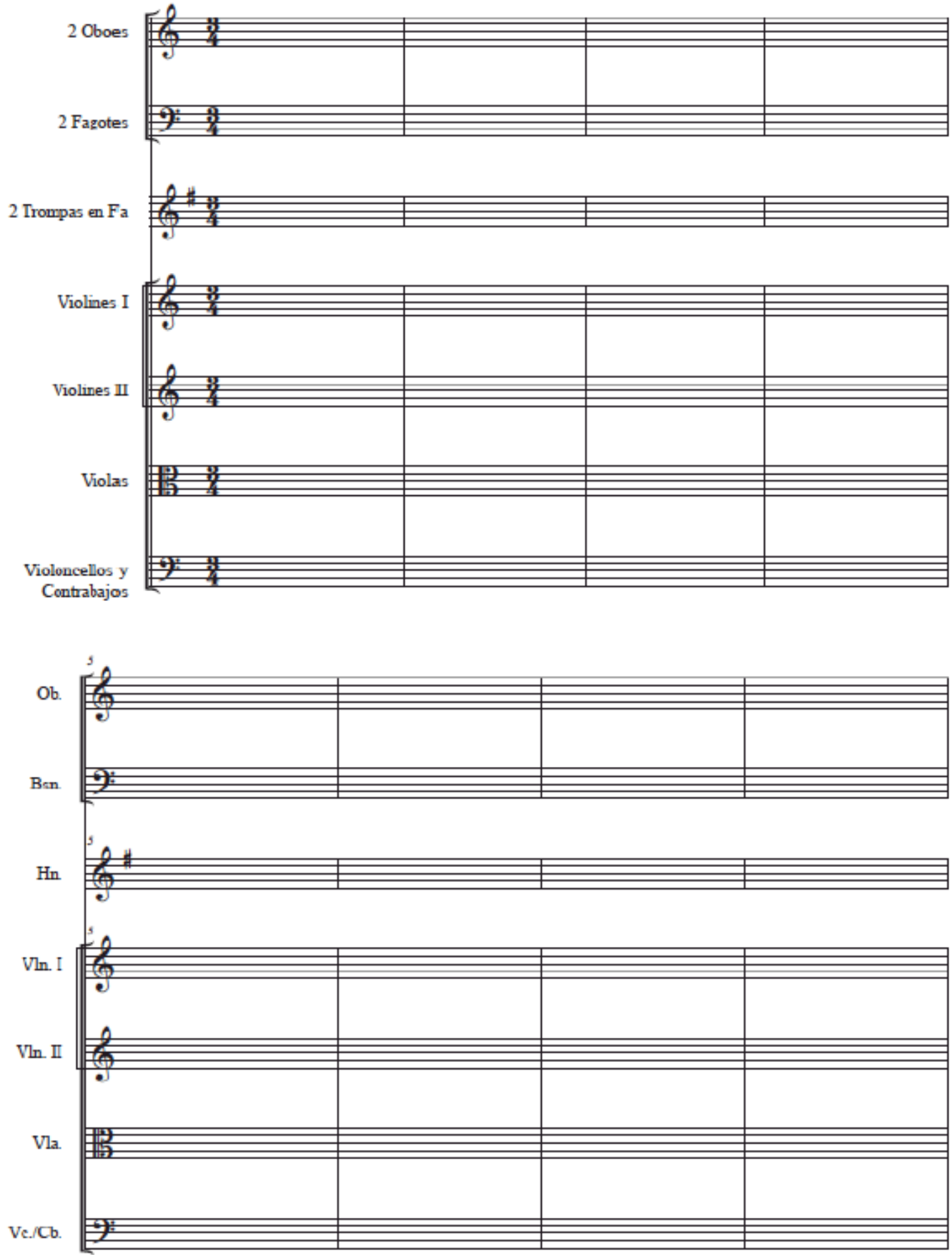
Diseño y planificación de competencias específicas en el currículum de enseñanzas profesionales de música: modalidades composición-dirección en la enseñanza superior.
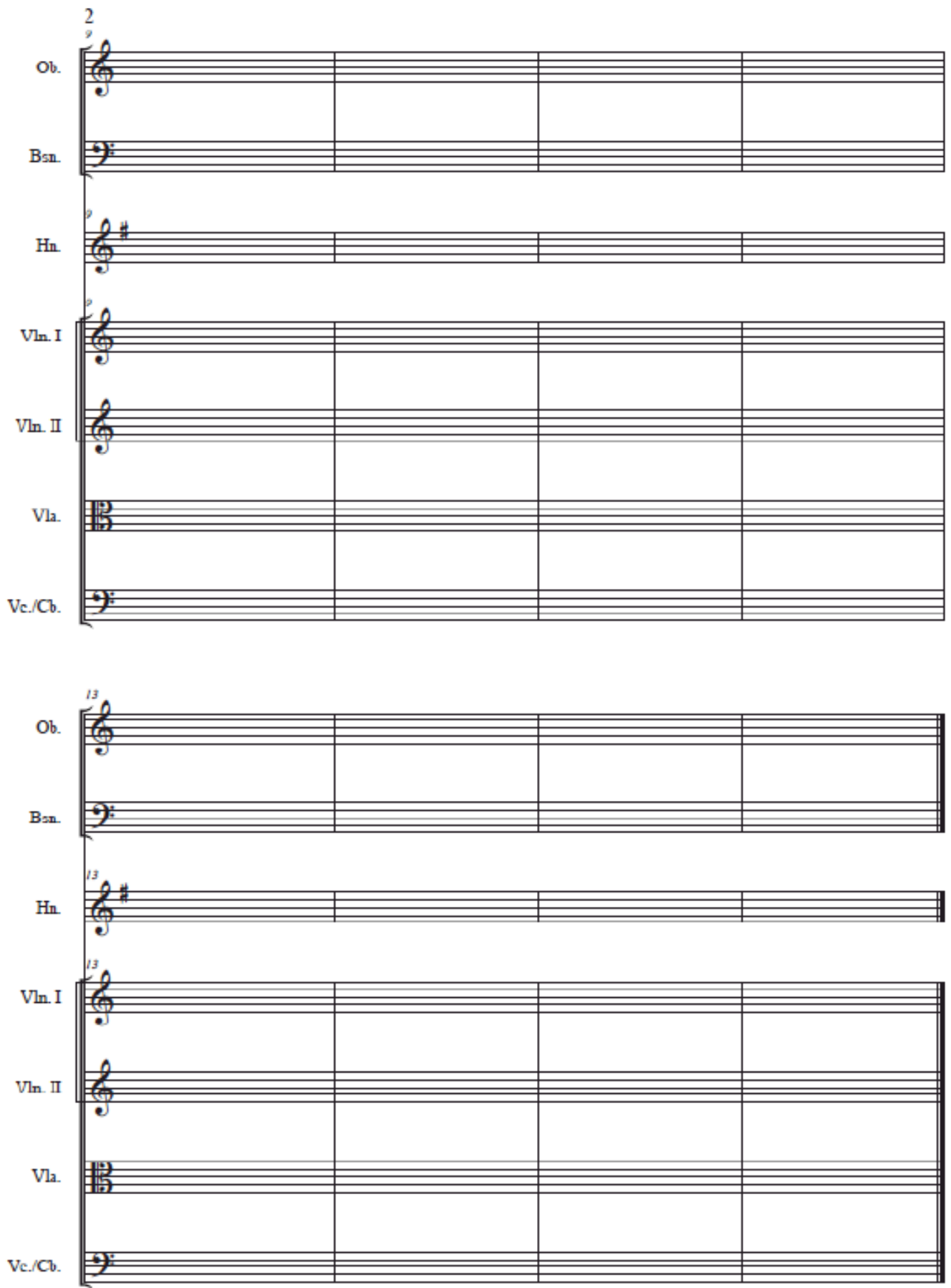
Diseño y planificación de competencias específicas en el currículum de enseñanzas profesionales de música: modalidades composición-dirección en la enseñanza superior.

\section{Carlos Eduardo Pascual Pérez}

EJERCICIO 2 (respuesta):
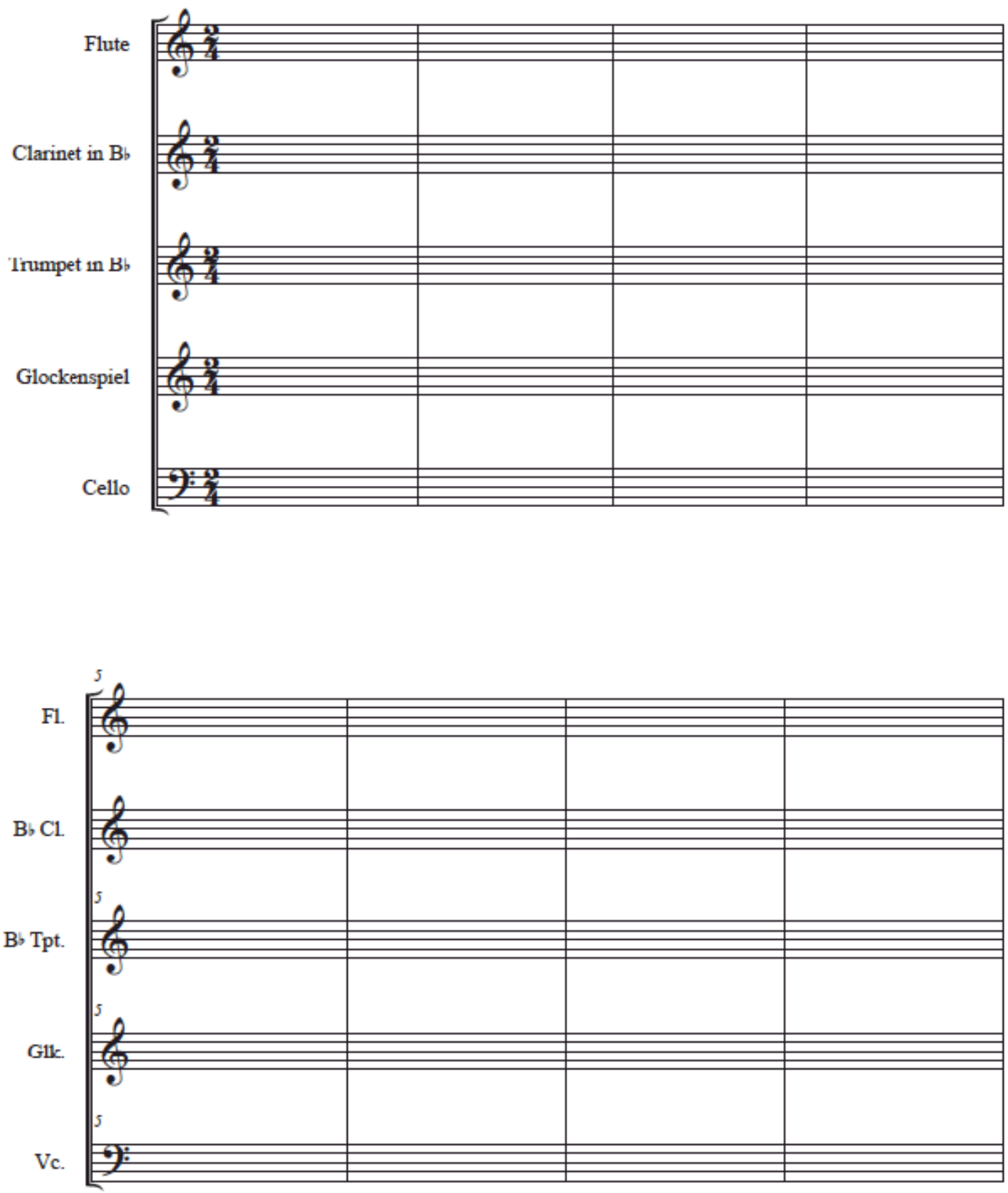
Diseño y planificación de competencias específicas en el currículum de enseñanzas profesionales de música: modalidades composición-dirección en la enseñanza superior.

\section{Carlos Eduardo Pascual Pérez}

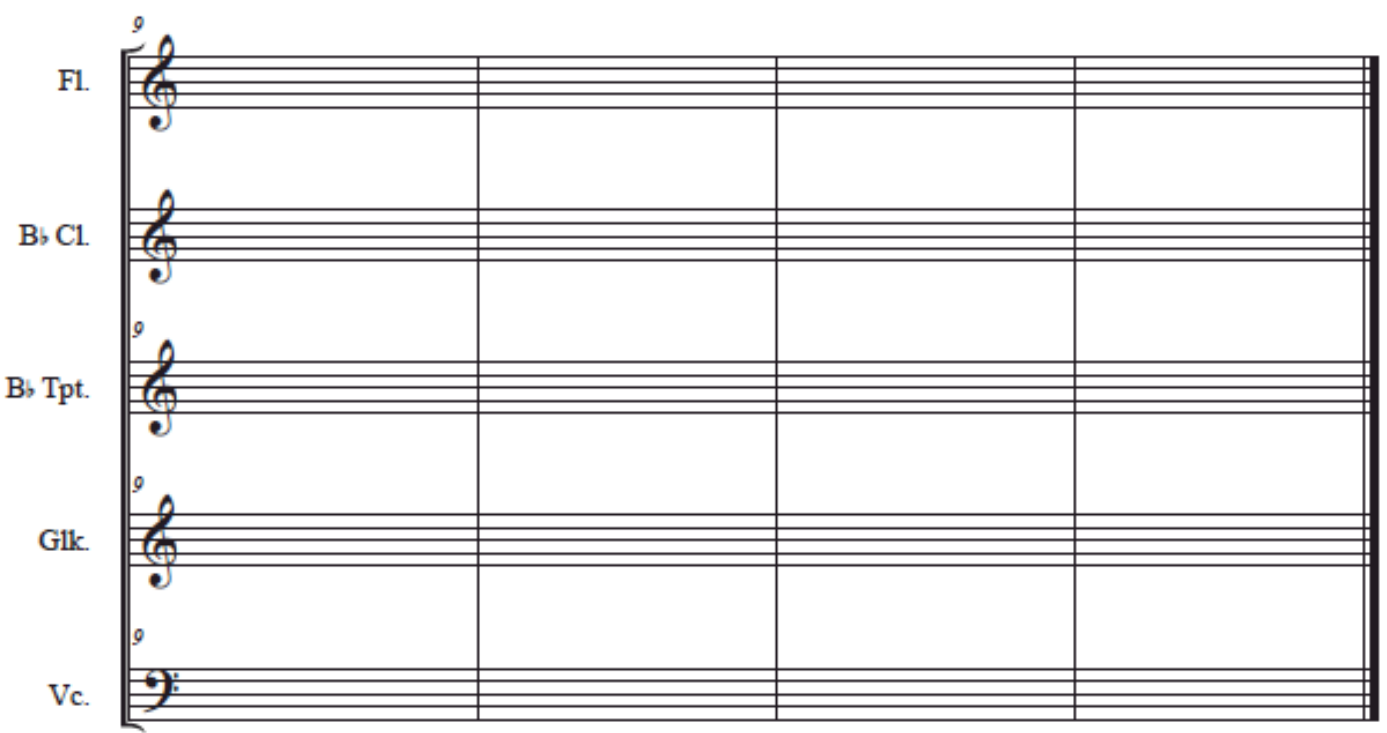


Diseño y planificación de competencias específicas en el currículum de enseñanzas profesionales de música: modalidades composición-dirección en la enseñanza superior.

Carlos Eduardo Pascual Pérez 


\section{Bibliografía}

\section{Documentación oficial citada}

Commission/EACEA/Eurydice, E. (2015). The Structure of the European Education Systems 2015/16: Schematic Diagrams (Eurydice F). Luxembourg: publications Office of the European Union.

Conservatorio Profesional de Música de Valencia (2020). Optativas 2020-21 [Archivo PDF]. Recuperado de https://docs.google.com/document/d/1O4H_dJME61MWhdMEwHY9u8ZZ0W1Me Msuaf6b7BII5Bg/edit

Conservatorio Superior de Castilla y León. (2018). Contenido detallado de las pruebas de específicas de acceso y pruebas de nivel para el curso 2018-2019 [Archivo PDF]. Recuperado de http://coscyl.com/wp-content/uploads/2018/04/Especificacionescontenidos-pruebas-de-acceso-superior.pdf

Conservatorio Superior de Castilla-La Mancha. (2018). Pruebas de acceso 2018-2019: criterios de evaluación y calificación [Archivo PDF). Recuperado de http://www.csmclm.com/documentos/contenidos/587.pdf 
Diseño y planificación de competencias específicas en el currículum de enseñanzas profesionales de música: modalidades composición-dirección en la enseñanza superior.

Carlos Eduardo Pascual Pérez

Conservatorio Superior de Música de Aragón. (2018). Pruebas de Acceso, especialidad dirección [archivo PDF]. Recuperado de https://csma.es/wpcontent/uploads/2018/09/PRUEBA-DIRECCION.pdf

Decreto $111 / 2007$, de 22 de mayo, por el que se establece el currículo de las enseñanzas profesionales de música de régimen especial reguladas por la Ley Orgánica 2/2006, de 3 de mayo, de Educación. Diario oficial de Extremadura, núm. 61, de 29 de mayo de 2007, páginas 9584 a 9638.

Decreto 126/2007 de 20 de septiembre por el que se establece el currículo de las enseñanzas profesionales de Música y se regula su acceso en la Comunidad Autónoma de Cantabria. Boletín oficial de Cantabria, núm. 191, de 1 de octubre de 2007, páginas 13263 a 13293.

Decreto 158/2007, de 21 de septiembre, del Consell, por el que se establece el currículo de as enseñanzas profesionales de música y se regula el acceso a estas enseñanzas. Diario oficial de la Comunidad Valenciana, núm. 5606, de 25 de septiembre de 2007, páginas 37005 a 37088.

Decreto 203/2007, de 27 de septiembre, por el que se establece el currículo de las enseñanzas profesionales de régimen especial de música. Diario oficial de Galicia, núm. 211, de 31 de octubre de 2007, páginas 17467 a 17514. 
Decreto 229/2007 de 11 de diciembre por el que se establece el currículo de las enseñanzas profesionales de música y el acceso a dichas enseñanzas. Boletín oficial del País Vasco, núm. 52, de 13 de marzo de 2008, páginas 5698 a 5803.

Decreto 241/2007, de 4 de septiembre, por el que se establece la ordenación y el currículo de las enseñanzas profesionales en Andalucía. Boletín oficial de la Junta de Andalucía, núm. 182, de 14 de septiembre de 2007, páginas 15 a 20.

Decreto 25/2008, de 29 de enero, por el que se establece la ordenación curricular de las enseñanzas de música de grado profesional y se regula la prueba de acceso. Diario oficial de la Generalitat de Catalunya, núm. 5060, de 31 de enero de 2008.

Decreto 29/2008, de 18 de mayo, por el que se establece el currículo de las enseñanzas profesionales de música impartidas en los centros de la Comunidad Autónoma de La Rioja. Boletín oficial de la Rioja, núm. 69, de 22 de mayo de 2007, página 3737 a 3792.

Decreto 30/2007 de 14 de junio, del Consejo de Gobierno por el que se establece para la Comunidad de Madrid el currículo de las enseñanzas profesionales de música. Boletín oficial de la Comunidad de Madrid, núm. 167, de 25 de junio de 2007, páginas 7 a 167. 
Decreto 364/2007, de 2 de diciembre, por el que se establece la ordenación y el currículo de las enseñanzas profesionales de música en la Comunidad Autónoma de Canarias. Boletín oficial de Canarias, núm. 206, de 16 de octubre de 2007, páginas 23602 a 23809.

Decreto 53/2011, de 20 de mayo, del currículum de las enseñanzas profesionales de música. Boletín oficial de les Illes Balears, núm. 81, de 2 de junio de 2011, páginas 13 a 30.

Decreto 58/2007, de 24 de mayo, por el que se establece la ordenación y el currículo de las enseñanzas profesionales de música en el Principado de Asturias. Boletín oficial del Principado de Asturias, núm. 141, de 18 de junio de 2007, páginas 11983 a 12045.

Decreto 60/2007, de 7 de junio, por el que se establece el currículo de las enseñanzas elementales y profesionales de música en la Comunidad de Castilla y León. Boletín oficial de Castilla y León, núm. 114, de 13 de junio de 2007, páginas 290 a 339.

Decreto 75/2008 de 2 de mayo por el que se establece la ordenación y el currículo de las enseñanzas profesionales de música para la Región de Murcia. Boletín oficial de la Región de Murcia, núm. 105, de 7 de mayo de 2008, páginas 14347 a 14398. 
Diseño y planificación de competencias específicas en el currículum de enseñanzas profesionales de música: modalidades composición-dirección en la enseñanza superior.

Carlos Eduardo Pascual Pérez

Decreto 76/2007 de 19 de junio de 2007 por el que se regula el currículo de las enseñanzas profesionales de música en la Comunidad Autónoma de Castilla-La Mancha. Diario oficial de Castilla La Mancha, núm. 131, de 22 de junio de 2007, páginas 16974 a 17011.

Decreto Foral 21/2007, de 19 de marzo, por el que se establece el currículo de las enseñanzas profesionales de música reguladas por la Ley Orgánica 2/2006, de 3 de mayo, de Educación, en el ámbito de la Comunidad Foral de Navarra. Boletín oficial de Navarra, núm. 56, de 4 de mayo de 2007, páginas 3448 a 3512.

Escola Superior de Música de Catalunya. (2018). Ejercicios Parte B - Composición [URL). Recuperado de http://www.esmuc.cat/spa/Titulo-superior-de-musica/Acceso-yadmision/Estructura-y-contenidos-de-las-pruebas-de-acceso/Ejercicios-Parte-BComposicion

Escola Superior de Música de Catalunya. (2018). Ejercicios Parte B - Dirección [URL]. Recuperado de http://www.esmuc.cat/spa/Titulo-superior-de-musica/Acceso-yadmision/Estructura-y-contenidos-de-las-pruebas-de-acceso/Ejercicios-Parte-BDireccion

Musikene. (2017). Resolución 3-2017, de 23 de febrero, de la Directora General y Académica de Musikene, que establece la estructura de las Pruebas de Acceso al curso 2017-2018 
Diseño y planificación de competencias específicas en el currículum de enseñanzas profesionales de música: modalidades composición-dirección en la enseñanza superior.

Carlos Eduardo Pascual Pérez

[Archivo PDF]. Recuperado de http://musikene.eus/wpcontent/uploads/2017_PA_Estructura.pdf

Orden 31/2016, de 4 de julio, de la Conselleria de Educación, Cultura y Deporte, por la que se aprueban las bases reguladoras de las subvenciones y asignaciones económicas para la realización de proyectos de investigación e innovación educativa en centros educativos no universitarios sostenidos con fondos públicos de la Comunitat Valenciana. Diario oficial de la Comunidad Valenciana, núm. 7823, de 7 de julio de 2016, páginas 18756 a 18765 .

Orden 49/2015, de 14 de mayo, de la Conselleria de Eduación, Cultura y Deporte, por la que se modifican aspectos de la Orden 28/2011, de 10 de mayo, por la que se regula la admisión, en acceso y matrícula, así como los aspectos de ordenación general, para el alunado que curse las enseñanzas elementales y profesionales de música y danza en la Comunidad Valenciana. Diario oficial de la Comunidad Valenciana, núm. 7526, de 15 de mayo de 2015, páginas 14250 a 14266.

Orden 2369/2011, de 10 de junio, por la que se regula, para la Comunidad de Madrid, la prueba específica de acceso a las Enseñanzas Artísticas Superiores de Grado reguladas por la Ley Orgánica 2/2006, de 3 de mayo, de Educación. Boletín Oficial de la Comunidad de Madrid, núm. 145, de 21 de junio de 2011, páginas 42 a 145. 
Diseño y planificación de competencias específicas en el currículum de enseñanzas profesionales de música: modalidades composición-dirección en la enseñanza superior.

Carlos Eduardo Pascual Pérez

Orden de 15 de abril de 2013, de la Consejera de Educación, Universidad, Cultura y Deporte, por la que se regula la admisión, y acceso a las enseñanzas artísticas superiores y se establecen criterios complementarios de matriculación. Boletín oficial de Aragón, núm. 79, de 24 de abril de 2013, páginas 9111 a 9132.

Orden de 18 de abril de 2012, por la que se regulan las pruebas de acceso a las enseñanzas artísticas superiores y la admisión del alumnado en los centros públicos que imparten estas enseñanzas. Boletín oficial de la Junta de Andalucía, núm. 83, de 30 de abril de 2012.

Orden de 21 de noviembre de 2016 por la que se regula la ordenación de las enseñanzas artísticas superiores de Música en desarrollo del Decreto 163/2015, de 29 de octubre, por el que se establece el plan de estudios de las enseñanzas artísticas superiores de Música, en las especialidades de Composición, Interpretación, Musicología y Pedagogía en la Comunidad Autónoma de Galicia. Diario Oficial de Galicia, núm. 230, de 1 de diciembre de 2016, páginas 53229 a 53264.

Orden de 3 de mayo de 2007, del Departamento de Educación, Cultura y Deporte, por la que se establece el currículo de las enseñanzas profesionales de música reguladas por la Ley Orgánica 2/2006, de 3 de mayo, de Educación, que se imparten en la Comunidad Autónoma de Aragón. Boletín oficial de Aragón, núm. 65, de 1 de junio de 2007, páginas de 8739 a 8780 . 
Diseño y planificación de competencias específicas en el currículum de enseñanzas profesionales de música: modalidades composición-dirección en la enseñanza superior.

Orden ECI/1890/2007 de 19 de junio, por la que se establece el currículo de las enseñanzas profesionales de música y se regula su acceso en los conservatorios profesionales de música de Ceuta y Melilla. Boletín oficial del estado, núm. 240, de 6 de octubre de 2007, páginas 40677 a 40677.

Real Decreto 303/2010, de 15 de marzo, por el que se establecen los requisitos mínimos de los centros que impartan enseñanzas artísticas reguladas en la Ley Orgánica 2/2006, de 3 de mayo, de Educación. Boletín oficial del estado, núm. 86, de 9 de abril de 2010, páginas 32100 a 32114.

Real Decreto 1577/2006, de 22 de diciembre, por el que se fijan los aspectos básicos del currículo de las enseñanzas profesionales de música reguladas por la Ley Orgánica 2/2006, de 3 de mayo, de Educación. Boletín oficial del estado, núm. 18, de 20 de enero de 2007, páginas 2853 a 2900.

Real Decreto 1614/2009, de 26 de octubre, por el que se establece la ordenación de las enseñanzas artísticas superiores reguladas por la Ley Orgánica 2/2006, de 3 de mayo, de Educación. Boletín oficial del estado, núm. 259, de 27 de octubre de 2009, páginas 89743 a 89752. 
Diseño y planificación de competencias específicas en el currículum de enseñanzas profesionales de música: modalidades composición-dirección en la enseñanza superior.

Real Decreto 756/1992, de 26 de junio, por el que se establecen los aspectos básicos del currículo de los grados elemental y medio de las enseñanzas de música. Boletín oficial del Estado, núm. 206, de 27 de agosto de 1992, páginas 29781 a 29800.

Resolución de 16 de marzo de 2017 de la Consejería de Educación y Cultura, de segunda modificación de la Resolución de 16 de mayo de 2011 de la Consejería de Educación y Ciencia, por la que se regulan aspectos de la ordenación académica de las enseñanzas artísticas superiores. Boletín oficial del Principado de Asturias, núm. 63, de 23 de marzo de 2017, páginas 1 a 6.

Resolución de 30 de abril de 2019, del director general de Política Educativa, por la que se convocan subvenciones y asignaciones económicas para desarrollar proyectos de investigación e innovación educativa en centros educativos sostenidos con fondos públicos en la Comunitat Valenciana, durante el curso académico 2019-2020. Diario Oficial de la Comunidad Valenciana, núm. 8542, de 7 de mayo de 2019, páginas 21361 a 21370.

Resolución de 25 de julio de 2013, de la Dirección General de Formación Profesional y Educación de Personas Adultas, por la que se establece para la Comunidad Autónoma de la Región de Murcia el plan de estudios y la ordenación de los estudios superiores de Música, se completan los planes de estudios iniciados en los años académicos 
Diseño y planificación de competencias específicas en el currículum de enseñanzas profesionales de música: modalidades composición-dirección en la enseñanza superior.

Carlos Eduardo Pascual Pérez

2010-2011 y 2011-2012 y se regula la prueba específica de acceso. Boletín oficial de la Región de Murcia, núm. 189, de 16 de agosto de 2013, páginas 33079 a 33249.

Resolución de 8 de mayo de 2012, de la dirección del Instituto Superior de Enseñanzas Artísticas de la Comunitat Valenciana, por la que se dictan instrucciones y convoca la prueba de acceso a las enseñanzas artísticas superiores. Diario Oficial de la Comunidad Valenciana, núm. 6775, de 16 de mayo de 2012, páginas 13858 a 13870.

Resolución, de 25 mayo 2011, de la Dirección General de Formación Profesional y Educación de Adultos de la Consejería de Educación, Universidades, Cultura y Deportes, por la que se dictan instrucciones sobre organización y desarrollo de las pruebas de acceso a las enseñanzas artísticas superiores de Grado en Música, Arte Dramático y Diseño en la Comunidad Autónoma de Canarias. Boletín Oficial de Canarias, núm. 106, de 31 de mayo de 2011, páginas 13938 a 14025. 
Diseño y planificación de competencias específicas en el currículum de enseñanzas profesionales de música: modalidades composición-dirección en la enseñanza superior.

\section{Fuentes específicas citadas}

Abeling, K. (2006). 36 Bach Chorales in set for Brass quintet, Clarinet quartet, Saxophone quartet \& quintet, String quartet and Woodwind quartet \& quintet. Kansas: Lincoln Music Publications.

Adler, S. (2006). El estudio de la orquestación. Barcelona: Idea Books.

Aranda, R., \& González, A. (2010). Mejora metodológica de las enseñanzas en el EEES en el caso de las materias pedagógicas. Tendencias Pedagógicas, 15(1), 29-56.

Asensio, V. (2008). La guía docente: punto de partida para la concreción de un nuevo grado superior de música adaptado al Espacio Europeo de Educación Superior. Revista Electrónica de LEEME. Recuperado de http://dialnet.unirioja.es/servlet/articulo?codigo $=2662014$

Asensio, V. G. (2008). La guía docente: punto de partida para la concreción de un nuevo grado superior de música adaptado al Espacio Europeo de Educación Superior. Revista Electrónica de LEEME. Recuperado de http://search.ebscohost.com/login.aspx?direct=true \&profile=ehost\&scope=site\&authty $\mathrm{pe}=$ crawler $\& \mathrm{jrnl}=15759563 \& \mathrm{AN}=64162577 \& \mathrm{~h}=\mathrm{wkXG} 7 \mathrm{yx} 1$ gygiah3ZMA879HECd 2 2ETmwtK9FhujsGHGanofYBv3bqaq1Q61 gnFBBmtwvc0kFEq\%2FM0Q333HXTp\% $2 \mathrm{Fg} \% 3 \mathrm{D} \% 3 \mathrm{D} \& \mathrm{crl}=\mathrm{c}$

Bach, J.S. (1871). 371 Vierstimmige Choralgesägnge. Leipzig: Breitkopf und Härtel. 
Diseño y planificación de competencias específicas en el currículum de enseñanzas profesionales de música: modalidades composición-dirección en la enseñanza superior.

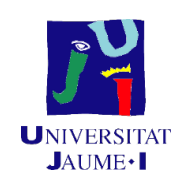

Carlos Eduardo Pascual Pérez

Beethoven, L. von. (1864). Trio für Blasinstrumente, Nr.63. Leipzig: Breitkopf und Härtel.

Blanes, L. (2002). Armonía tonal. Madrid: Real Musical.

Casella, A. (1950). La técnica de la orquesta contemporánea. Buenos Aires: Ricordi Americana S.A.E.C.

Casellas, M. L.-P. (2013). Una Propuesta de Investigación en Torno a la Música en Educación Superior. Revista Música Hodie. Recuperado de http://search.ebscohost.com/login.aspx?direct=true\&profile=ehost\&scope=site\&authty

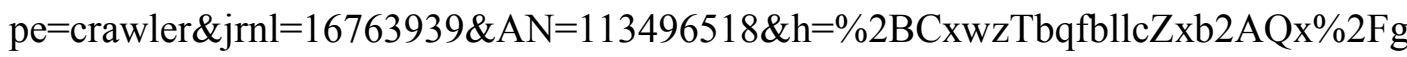
QM\%2FO\%2BxtaDaFKi0LAQhg\%2BXbUzPFQAzMSxsycd3yRy1htfZGJ\%2BU1Tn 2p5xY9VgFSvQ\%3D $\% 3 D \& c r l=c$

Chuliá, S. (2002). Apuntes de armonía. Valencia: Piles editorial de música S.A.

de la Motte, D. (1998). Harmonielehre. Kassel: Bärenreiter-Verlag.

Eslava, H. (1856). Conservatorio de música y declamación, Gaceta Musical de Madrid, año II, núm. 28, 13-VII-1856, pp. 215-217.

Gilabert, T. (2020). MusicNetMaterials: ejercicios de armonía con soluciones [URL]. Recuperado de https://musicnetmaterials.wordpress.com/2020/07/03/ejercicios-dearmonia-con-soluciones-nivel-medio/

Gosset, W.S. (1908). The Probable Error of a Mean. Biometrika, 6, 1-26. 
Diseño y planificación de competencias específicas en el currículum de enseñanzas profesionales de música: modalidades composición-dirección en la enseñanza superior.

Carlos Eduardo Pascual Pérez

Garres, F. (2011). La prueba de acceso a grado superior de clarinete como eje vertebrador de la docencia en el último ciclo de Enseñanzas Profesionales: propuesta metodológica. Universidad Católica, Murcia.

Hummel, J. N. (1825). Symphonien für Pianoforte. Mainz: B. Schott's Söhne.

Kolmogorov, A.N. (1933). Sulla determinazione empirica di una legge di distribuzione. Giornale dell'Instituto Italiano degli Attuari 4, 83-91.

Korsakov, R. (1946). Principios de orquestación. Buenos Aires: Ricordi Americana S.A.E.C.

Mateu, M. A. (2004). Armonía práctica. Vol. 1. Valencia: AB Música.

Mozart, W. A. (1881). Serie XIV: Quartette für Streichinstrumente, Bd.1, No.4. Leipzig: Breitkopf \& Härtel.

Mozart, W. A. (1957). Neue Mozart-Ausgabe, Serie IV, Werkgruppe 11, Sinofnien, Band 9. Kassel: Bärenreiter-Verlag.

Pascual Pérez, C. E., \& Peñalver Vilar, J. M. (2019). Conservatorios de música en España. Epistemus. Revista De Estudios En Música, Cognición Y Cultura, 7(1), 004. https://doi.org/10.24215/18530494e004 
Pascual Pérez, C. E.; Peñalver Vilar, J. M. (2017). Diseño y planificación de competencias específicas en el currículum de enseñanzas profesionales de música: Modalidades en la enseñanza superior. VI Jornada Nacional sobre estudios universitarios. II Taller de innovación educativa. Competencias: formación y evaluación. Universitat Jaume I. Ed. Universitat Jaume I. ISBN 9788416546800.

Piston, W. (1941). Harmony. Nueva York: W. W. Norton \& Co.

Piston, W. (1955). Orchestation. Nueva York: W. W. Norton \& Co.

Shapiro, S. S.; Wilk, M. B. (1965). An analysis of variance test for normality (complete samples). Biometrika. 52 (3-4): 591-611.

Smirnov, N.V. (1948) Table for estimating the goodness of fit of empirical distributions. Ann. Math. Stat. 19, 279-281.

Tchaikovsky, P. I. (1881). Roméo et Juliette, ouverture-fantasie. Berlin: Ed. Bote \& G. Bock.

Vicario, A. V. (2012). Evaluación curricular de los estudios superiores de música: percepción del estudiante. Recuperado de 
Diseño y planificación de competencias específicas en el currículum de enseñanzas profesionales de música: modalidades composición-dirección en la enseñanza superior.

Carlos Eduardo Pascual Pérez

https://scholar.google.es/scholar?start=20\&q=estudios + superiores $+\mathrm{m} \% \mathrm{C} 3 \%$ BAsica + eees\&hl=es\&as_sdt $=0,5 \# 7$

Wason, R. W. (2002). Musica practica: music as pedagogy. The Cambridge History of Western Music Theory.

Wilcoxon, F. (1945). "Individual comparisons by ranking methods". Biometrics Bulletin. 1 (6): 80-83.

Mann, H. B.; Whitney, D.R. (1947). On a Test of Whether one of Two Random Variables is Stochastically Larger than the Other. Annals of Mathematical Statistics. 18 (1): 50 60.

Kruskal; W. (1952). Use of ranks in one-criterion variance analysis. Journal of the American Statistical Association. 47 (260): 583-621. 
Diseño y planificación de competencias específicas en el currículum de enseñanzas profesionales de música: modalidades composición-dirección en la enseñanza superior.

\section{Fuentes específicas consultadas}

Amador, M. \& Jariot, M. (1995). Manual pràctic per al processament de dades d'investigació en ciències socials amb el suport informàtic del paquet SPSS. Barcelona: Cícero.

Bou i Bauzà, G. \& Amador, M. (1993). Curs d'estadística descriptiva aplicada a l'educació. Barcelona: Printer Men.

Burland, K., \& Pitts, S. (2007). Becoming a Music Student Investigating the skills and attitudes of students beginning a music degree. Arts and Humanities in Higher Education, (6), 289. http://doi.org/10.1177/147402220708

Checa, R. (2003). Cambio de modelo en la formación del profesorado de las enseñanzas de Música. Eufonia N. 29, 14, 96.

Delgado, F. (2006). La construcción del sistema nacional de conservatorios en España (18921942). Cuadernos de música iberoamericana, volumen 12.

Domínguez, D. C. (2010). El EEES en España: una reforma más allá de la Universidad. Sapiens. Revista Universitaria de .... Recuperado de http://www.redalyc.org/html/410/41028422004/

Fisher, R. A. (1925). Statistical methods for research workers. Edinburgh: Oliver and Boyd. 
Diseño y planificación de competencias específicas en el currículum de enseñanzas profesionales de música: modalidades composición-dirección en la enseñanza superior.

Carlos Eduardo Pascual Pérez

García, V. (2014). El proceso de adaptación de los Estudios Superiores de música en España al espacio europeo de Educación Superior. Artseduca. Recuperado de http://dialnet.unirioja.es/servlet/articulo? codigo $=4734009$

García, V. (2016). Estudio y análisis de los posibles modelos de gestión y organización de las Enseñanzas Artísticas Superiores en España. Págs. 46-71. ARTSEDUCA. Recuperado de http://www.erevistes.uji.es/index.php/artseduca/article/download/2022/1703

Georgii-Hemming, E., \& Westvall, M. (2010). Teaching music in our time: student music teachers' reflections on music education, teacher education and becoming a teacher. Music Education Research, $\quad$ 353-367. http://doi.org/10.1080/14613808.2010.519380

Jorgensen, E. R. (2008). Questions for music education research. Music Education Research, 10(3), 331-346. http://doi.org/10.1080/14613800802280050

Muñoz, S. T. (2009). Calidad de vida de los estudiantes de música del Conservatorio de Música de Aragón. (Spanish). Quality of Life of Music Students at the Conservatory of Music of Aragón. (English), (24), 77-85. Recuperado de http://search.ebscohost.com/login.aspx?direct=true\&db=fua\&AN=55507145\&lang $=$ es\&site $=$ ehost-live 
Diseño y planificación de competencias específicas en el currículum de enseñanzas profesionales de música: modalidades composición-dirección en la enseñanza superior.

Las titulaciones de música en el EEES: Adaptación de los nuevos planes de estudios al nuevo $\begin{array}{llll}\text { panorama } & \text { (n.d.). } & \text { Recuperado }\end{array}$ http://revista.musicrearte.com/musicrearte_digital_numero02_2013_files/musicrearte_ digital_02_2013_art02.pdf

López, M., Martínez, J., \& Crevillén, E. (2010). Las enseñanzas artísticas superiores en el Espacio Europeo de Educación Superior. Recuperado de https://books.google.es/books?hl=es\&lr=\&id=RxJ33LckceUC\&oi=fnd\&pg=PA3\&d $\mathrm{q}=$ estudios + superiores $+\mathrm{m} \% \mathrm{C} 3 \% \mathrm{BAsica}+$ eees \&ots $=8 \mathrm{UPjRg} 1 \mathrm{w} 4 \mathrm{~L} \&$ sig $=17 \mathrm{rUaag} 3 \mathrm{ni}$ OUPMcZVdcqsyFKs8s

Peñalver Vilar, J.M. (2013): Análisis de la práctica de la improvisación musical en las distintas metodologías: características y criterios de clasificación. En revista Artseduca, n. 4 , p. $74-$ 85. http://repositori.uji.es/xmlui/bitstream/handle/10234/87211/56490.pdf?sequence $=1 \&$ isAllowed $=\mathrm{y}$

Pliego, V. (2014). Oportunidad y conveniencia de integrar las enseñanzas artísticas en la universidad. Revista Danzaratte, 8, 104-119. Recuperado de http://www.fe.ccoo.es/comunes/recursos/25/1860742articulo_de_Victor_Pliego_en_Revista_Danzaratte.pdf

Rafael Polanco, O. (2013). La orientación académica y profesional en los conservatorios de música. Artseduca, $58-69$. Recuperado de 
Diseño y planificación de competencias específicas en el currículum de enseñanzas profesionales de música: modalidades composición-dirección en la enseñanza superior.

\section{Carlos Eduardo Pascual Pérez}

http://dialnet.unirioja.es/descarga/articulo/4339753.pdflnhttp://dialnet.unirioja.es/ser vlet/extart?codigo $=4339753$

Real Decreto Legislativo 1/1996, de 12 de abril, por el que se aprueba el texto refundido de la Ley de Propiedad Intelectual. Boletín Oficial del Estado, n.97, de 22 de abril de 1996.

Serra, J. (2013). Ser o no ser universidad, ¿ es esa la cuestión? Scherzo: Revista de Música. Recuperado de http://www.ekamusica.com/images/Scherzo_282_JA_Serra_02.2013.pdf 
UNIVERSITAT

JAUME - I 